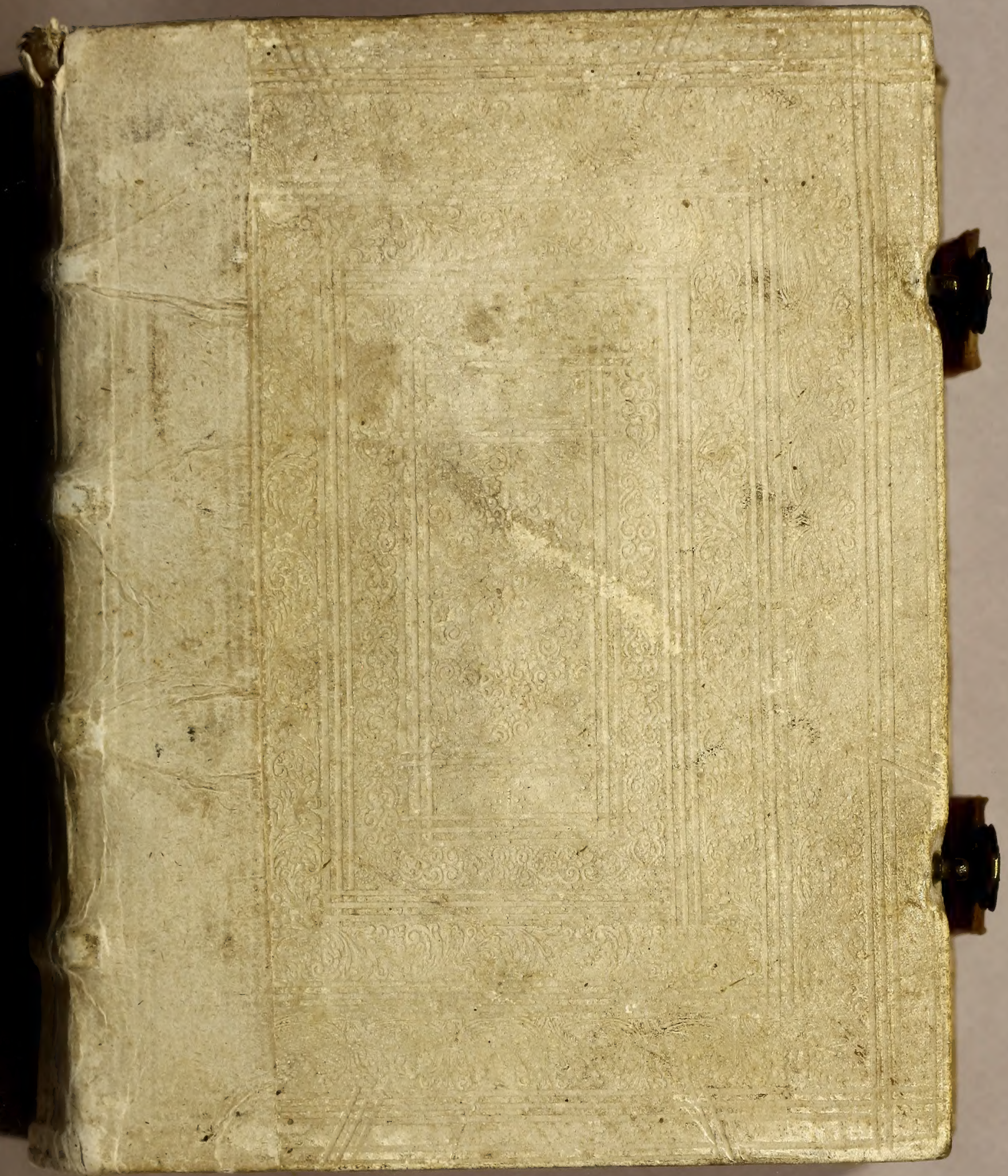




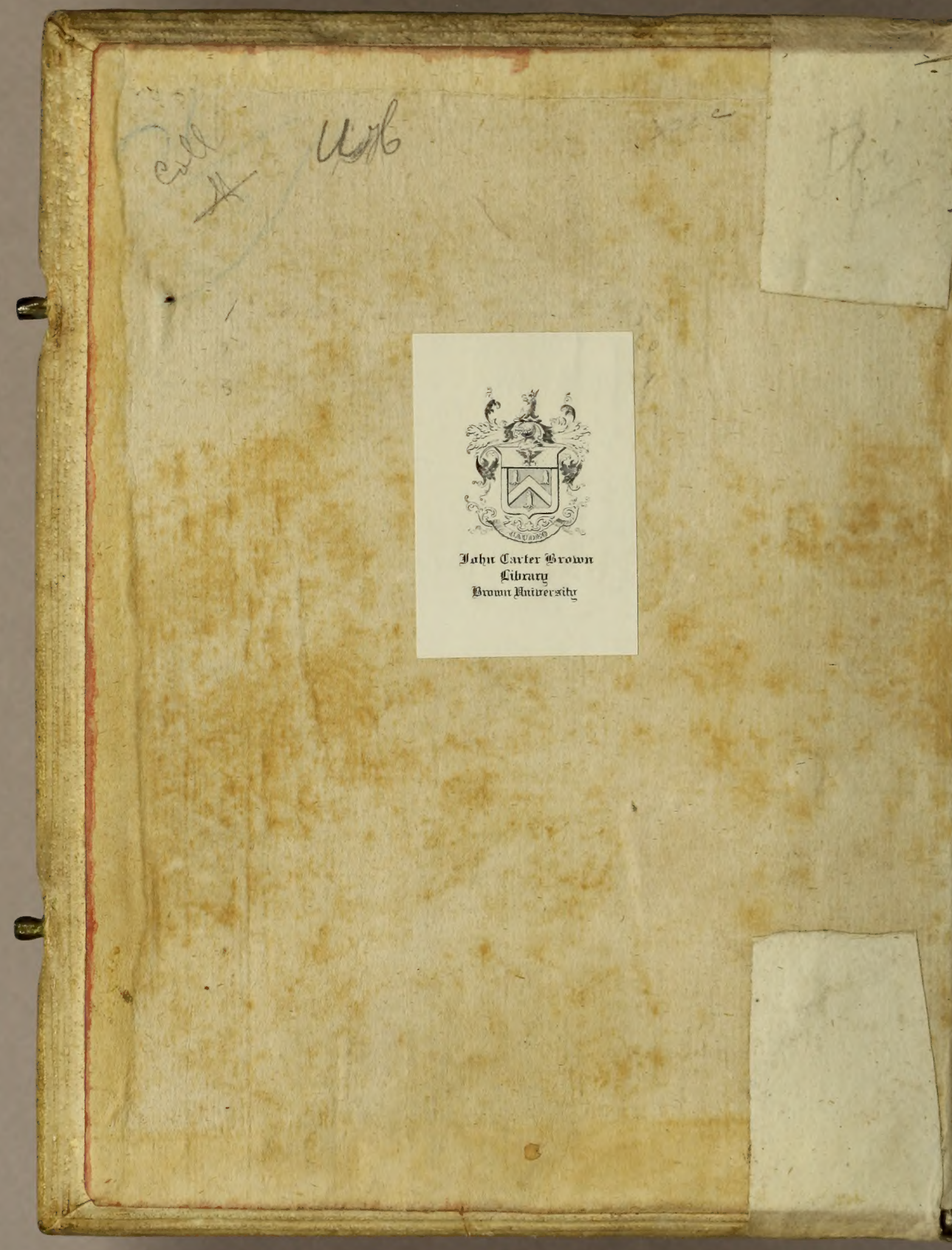





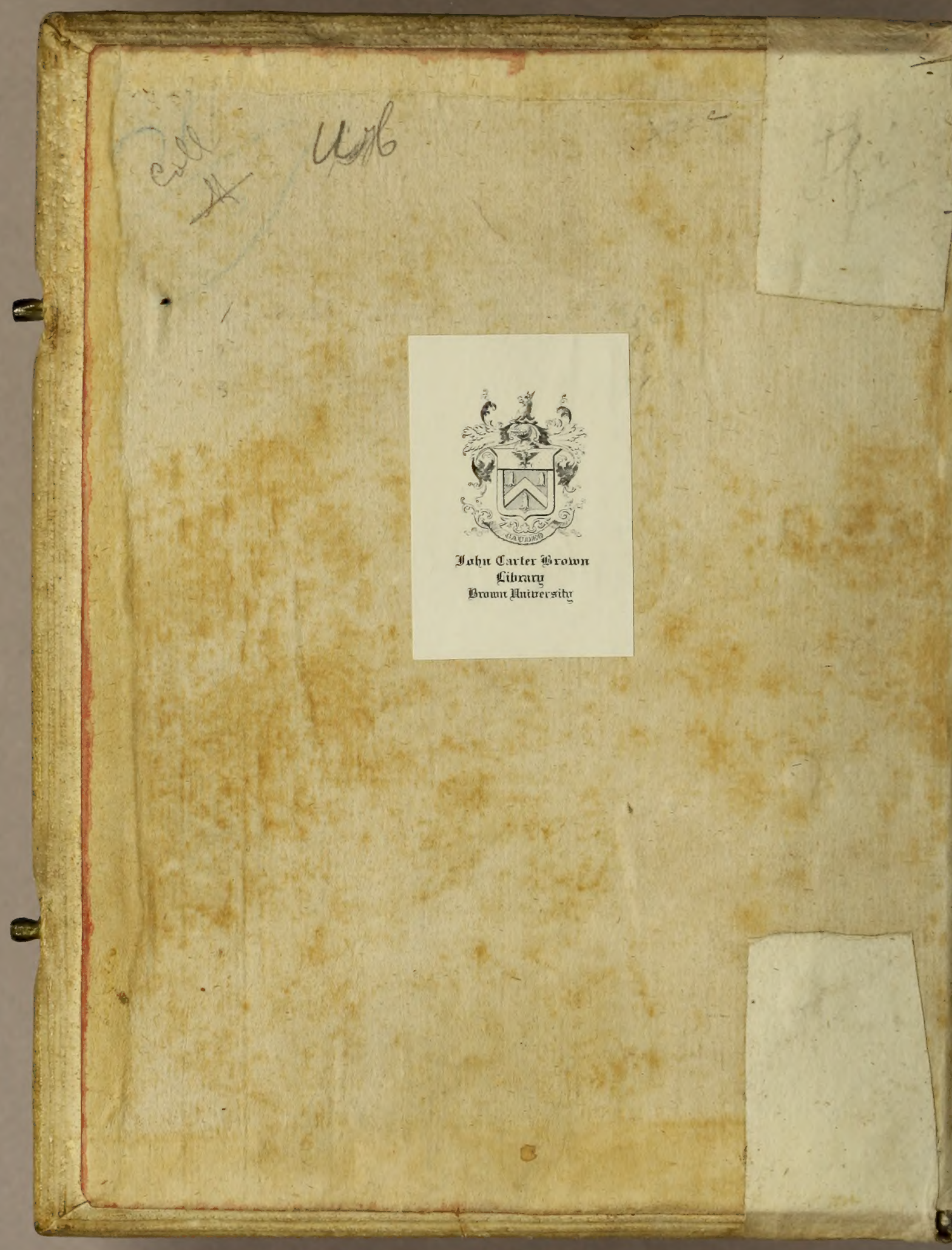





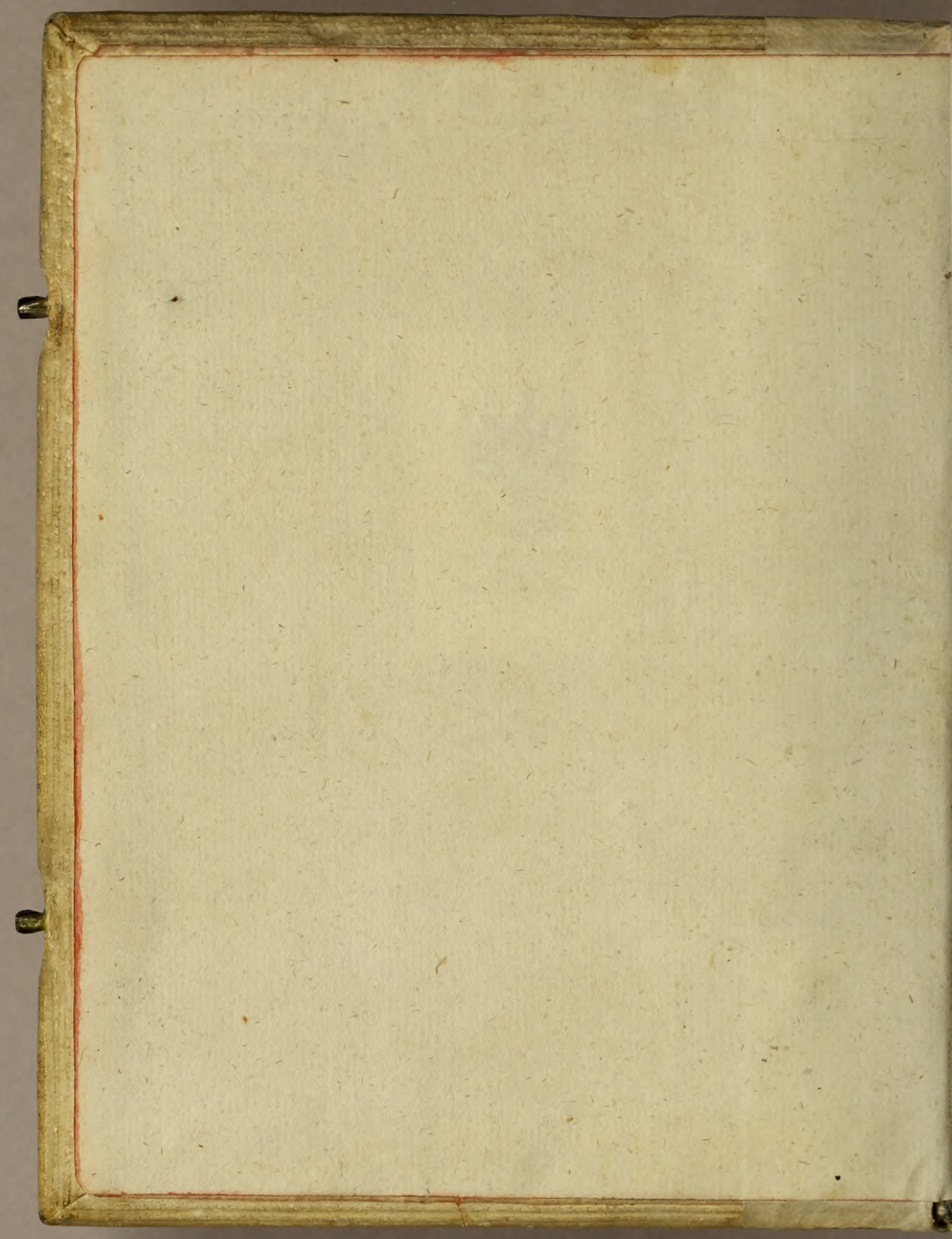





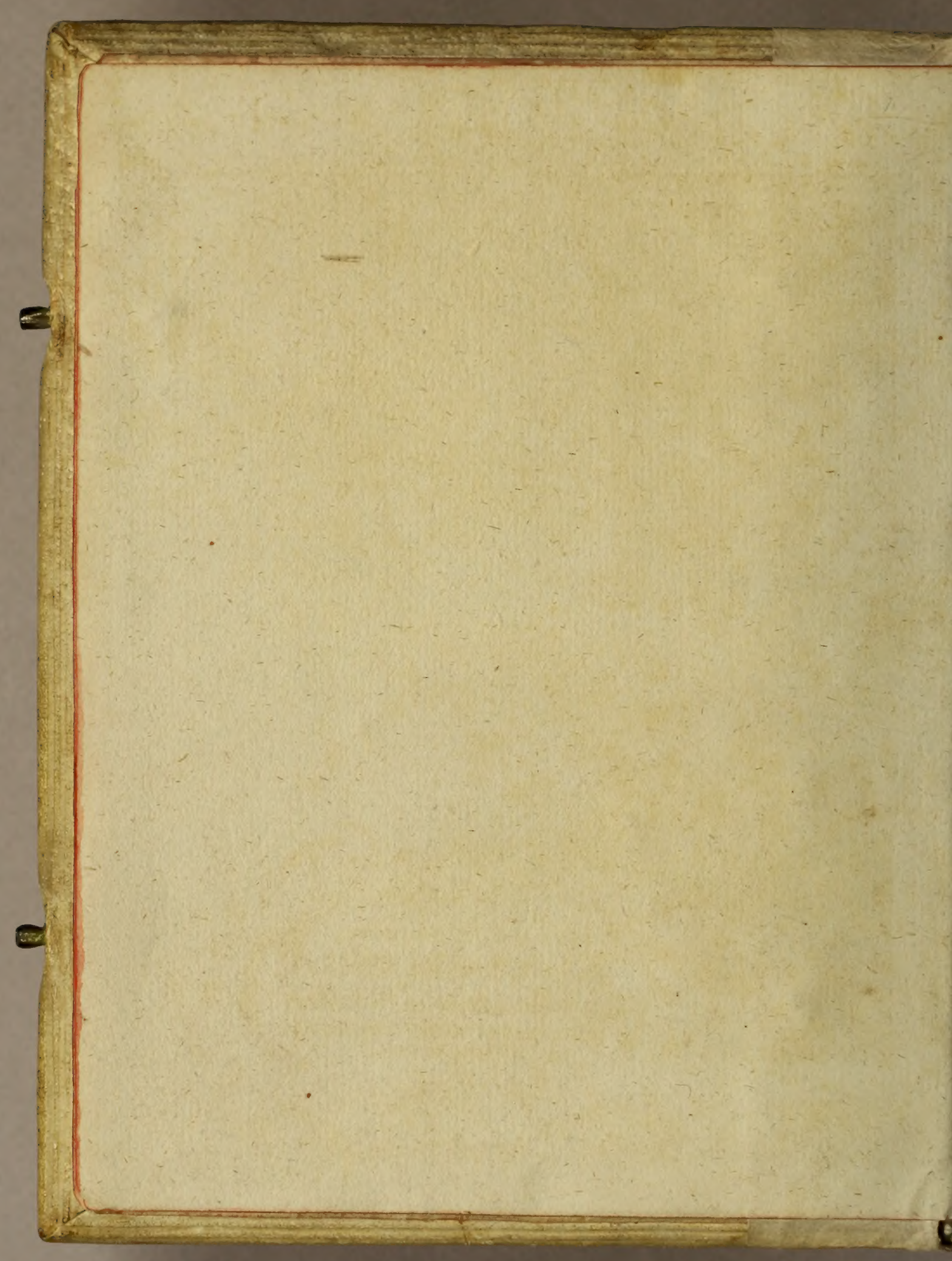




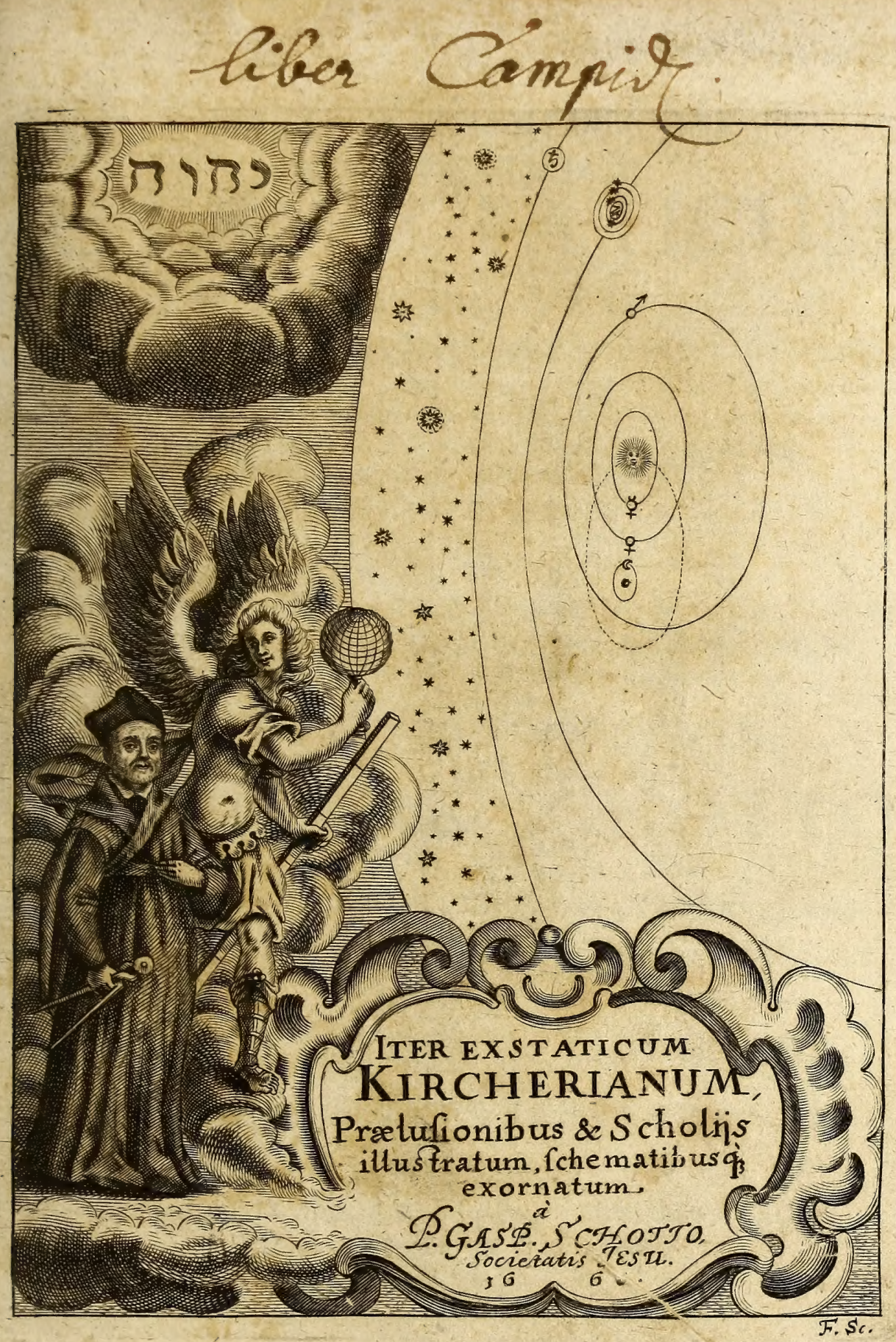




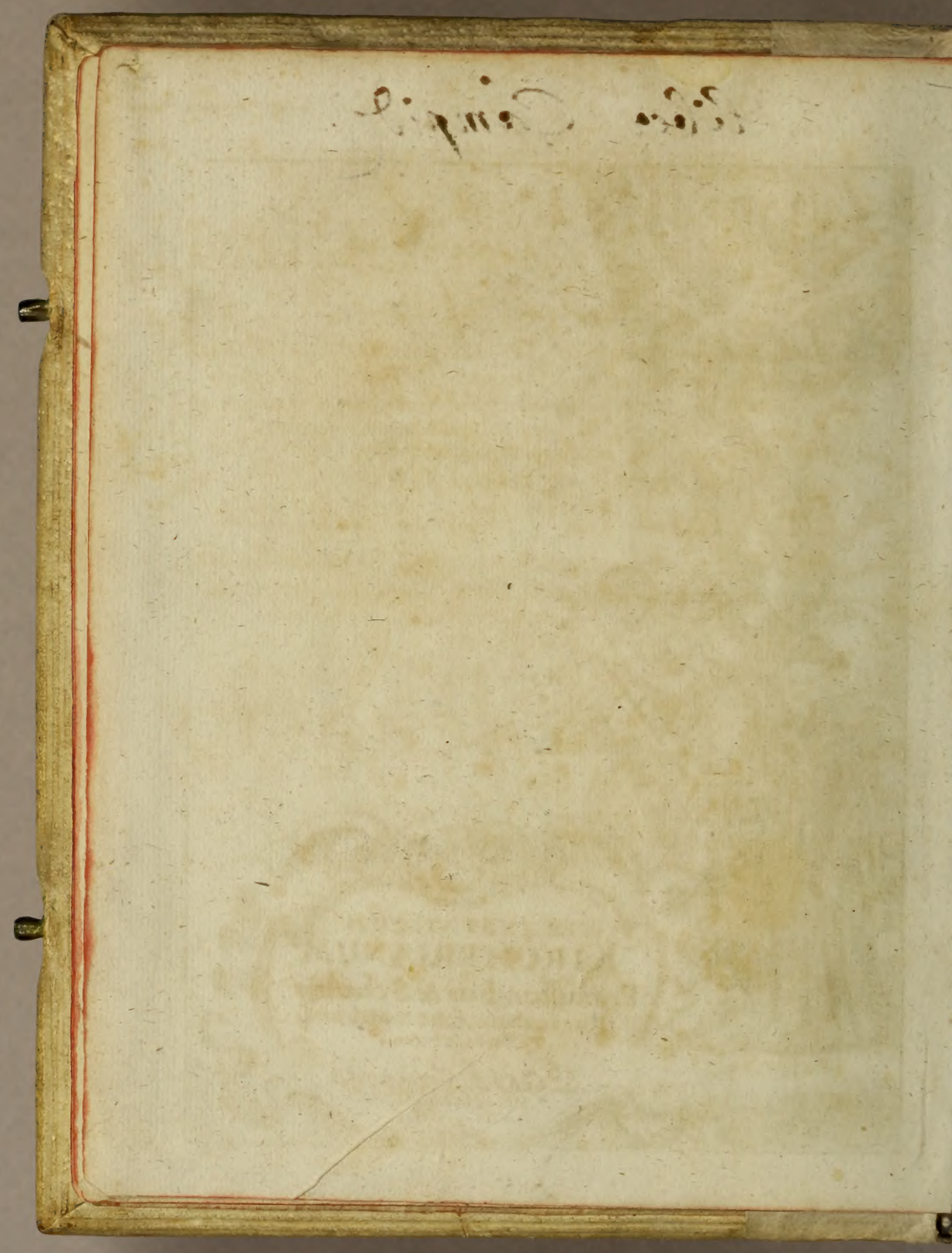




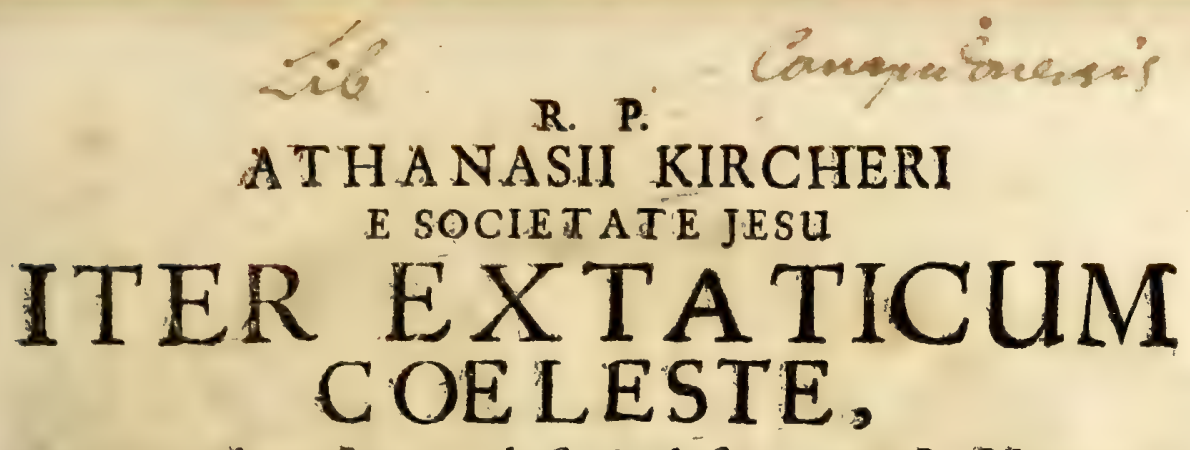

QuoMundi-opificium, id eft, Cøeleftis Expanf, fiderumq; sam er rantium, quàm fixorum natura,vires, propriecates, fingulerumq; conipoficio \& f ftructura,ab infimo Telluris globo, usq; ad ulcima Mundi confinia, per fieti raptus integumentum explerata novâ hypothefiexponitur ad veritatem, INTERLOCVTORIBUS

COSMIELE ET THEODID ACTO:

Hac fecundâ editione Pralúfionibus \& Scholiis illuftrasum; ac fchemaxismis neceflarris, qui deerant, exornacum; nec non à mendis, qux in primam Romanam editionem irre. plerant,expurgatum, IPSO AUCTORE ANNUENTE, P. GASPARE SCHOTTO Olim in Panormita no Sicilix, nunc in Herbipolitano Franconix Gymnafio ejusdem Socte TA TIS Jesu Matheleos Profeffore.

Acceffit ejusdem Auctoris

ITER EXSTATICUM TERRESTRE, B

SYNOPSIS MUNDI SUBTERRANEI.

HERBIPOZI

Sumptibus Joh. Andr. \& Wolffg. Jun. Endterorum hxredibus, Proftat Norimberga apud cosderes. ANNO M. DC. LX. 


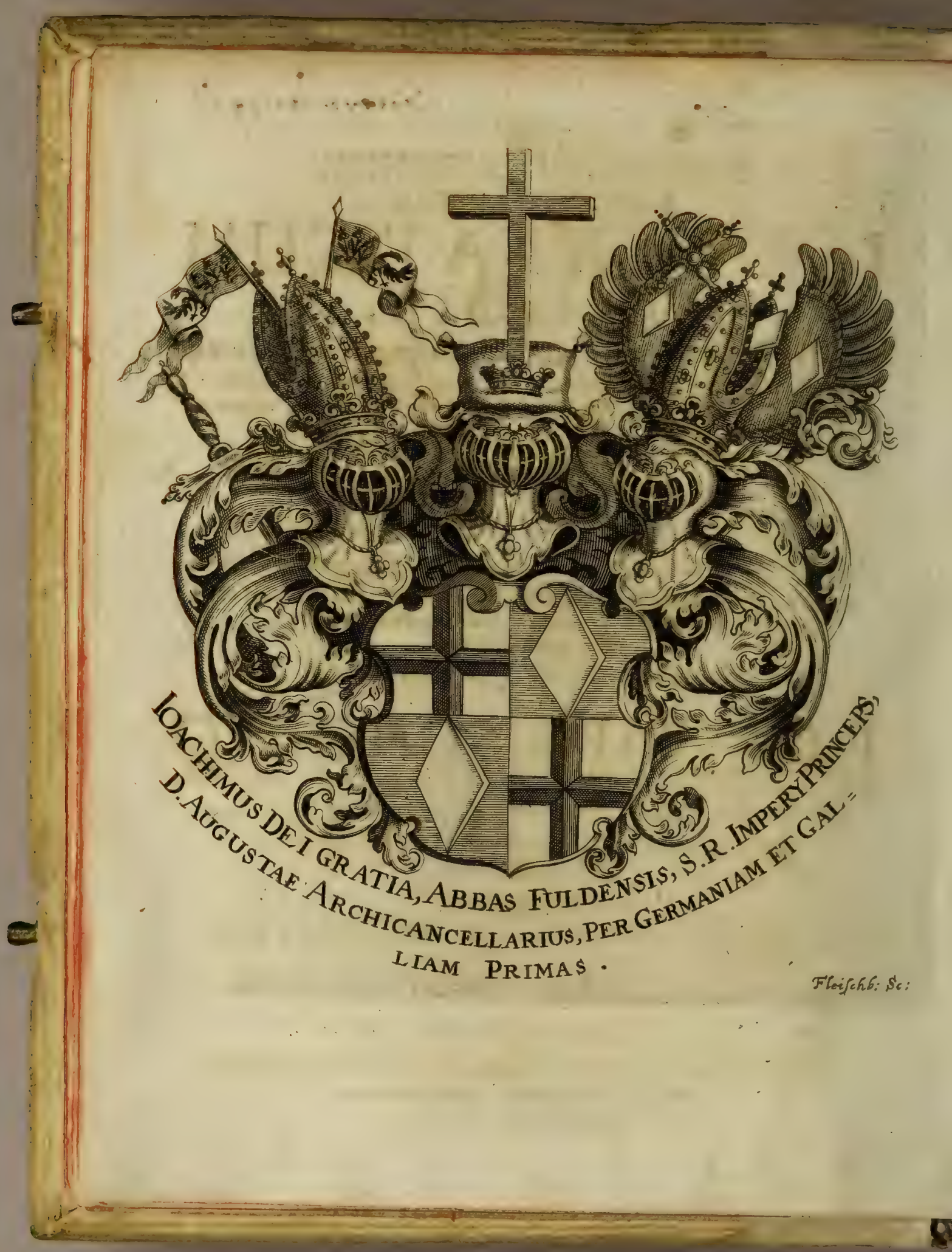




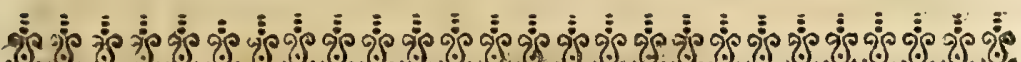

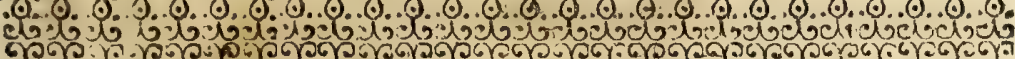

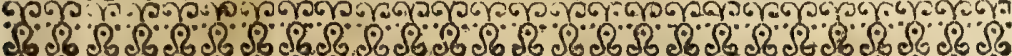

Reverendisfimo at $g_{s}$ Illuftrisfimo Principi ac Domino,

\section{I O A CH I M O} E PERILLUSTRI FAMILIA LIBERORUM IMPERII B A R ONUM A GRAVENEGG, ECCLESIÆ FULDENSIS A B B A T F,

S. R. Imperii Principi, D. Auguftæ Archicancellario, per: Germaniam \& Galliam.

PRIMATI,

Domino meoClementisfimo.

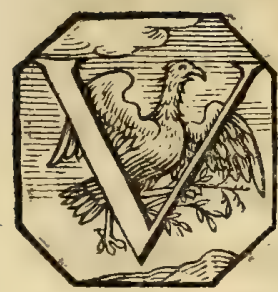

Enio quờ me munus meum, \& mea proniffima ducit voluntas; ad Te inquam, P RINCEPS ILLUSTRISSIME Colum offero; Non quod Syracufius olim è vitro fabricavit Ar$x^{2} \quad$ chi- 


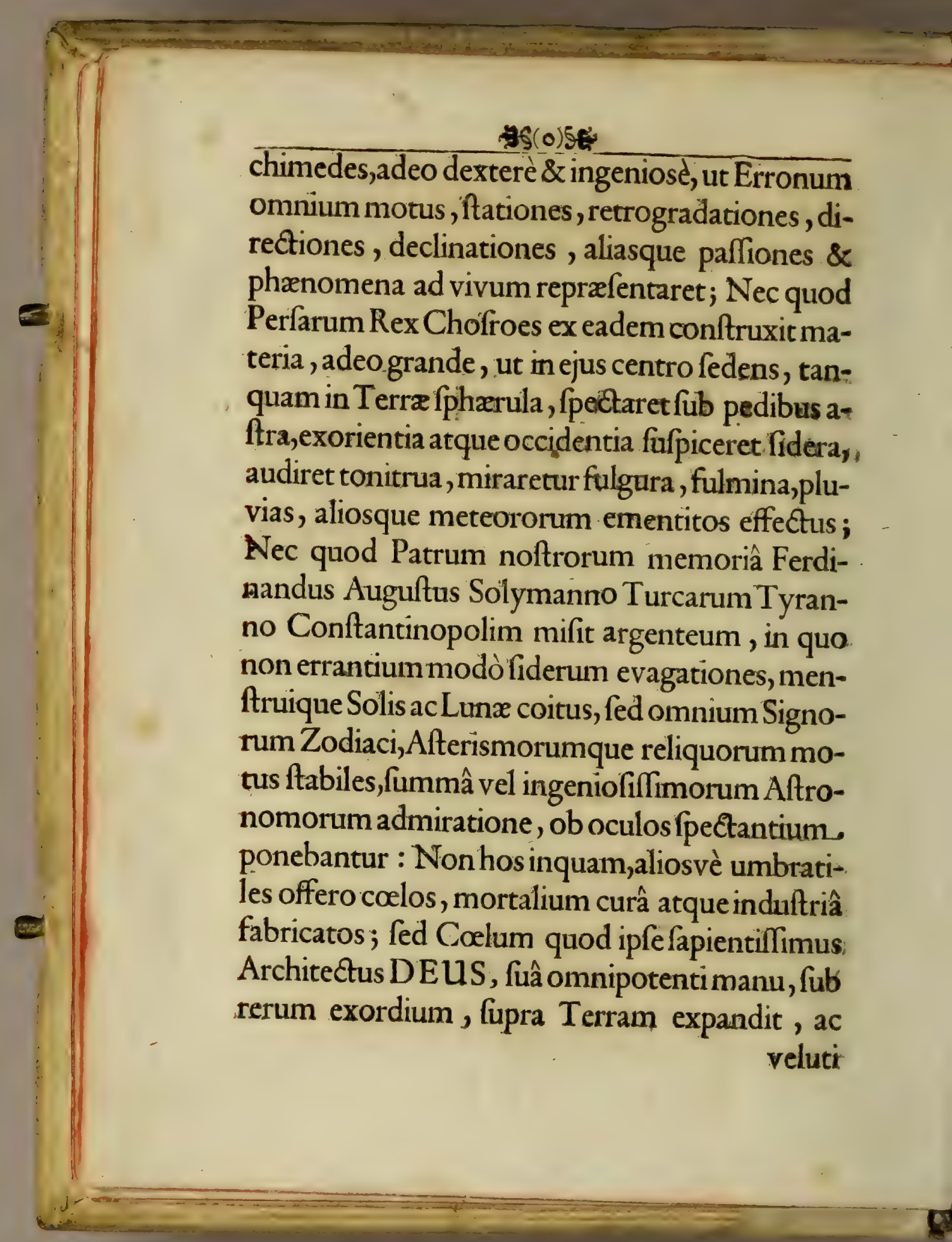




\section{As(o) 5}

vefuti patentem librum, fulgidiffimis aftris ceu aureis exaratum characteribus, hominum. oculis atque animis legendum affiduè explicavit, eontemplandumque perpetuò propofuit : Cœlum dico, quod non ita pridem immortalis memorix Vir Athanafius Kircherus fublimiffimo ingenio fuo cæteris altiùs ingreffus, perluftravit intimè, novisque atque exoticis ratiociniis, è Combinatoria \& Analogica arte depromptis, velutivivis coloribus depinxit, \& omnibus coeleftis Philofophix percupidis propofuit, meisque nunc PrxIufionibus,Scholiis, acSchematismis auctum, in . fcenam demuò producit. Etcuilllud potiori jure, quàm Tibi, PrinCEPS Illus T RISSIME, offeram? Colum enim non Ipfe tantùm, ut doctum. Principem, \& Præfulem decet religiofiffimum, animo volvis affiduè, fed aliis quoque curæ Tuæ concreditis,ac præcipuè Buchonicæ Juventuti,intuendum nuper, \&mente volvendum propofuifti,dum pro ornamento patrix, pro fubditorum . falute, pro Ecclefix incremento, pro gloria demum Perilluftris Familiz. Tuæ Baronum à Gravenegg, inter difficillima tempora, inter perftrepentia 


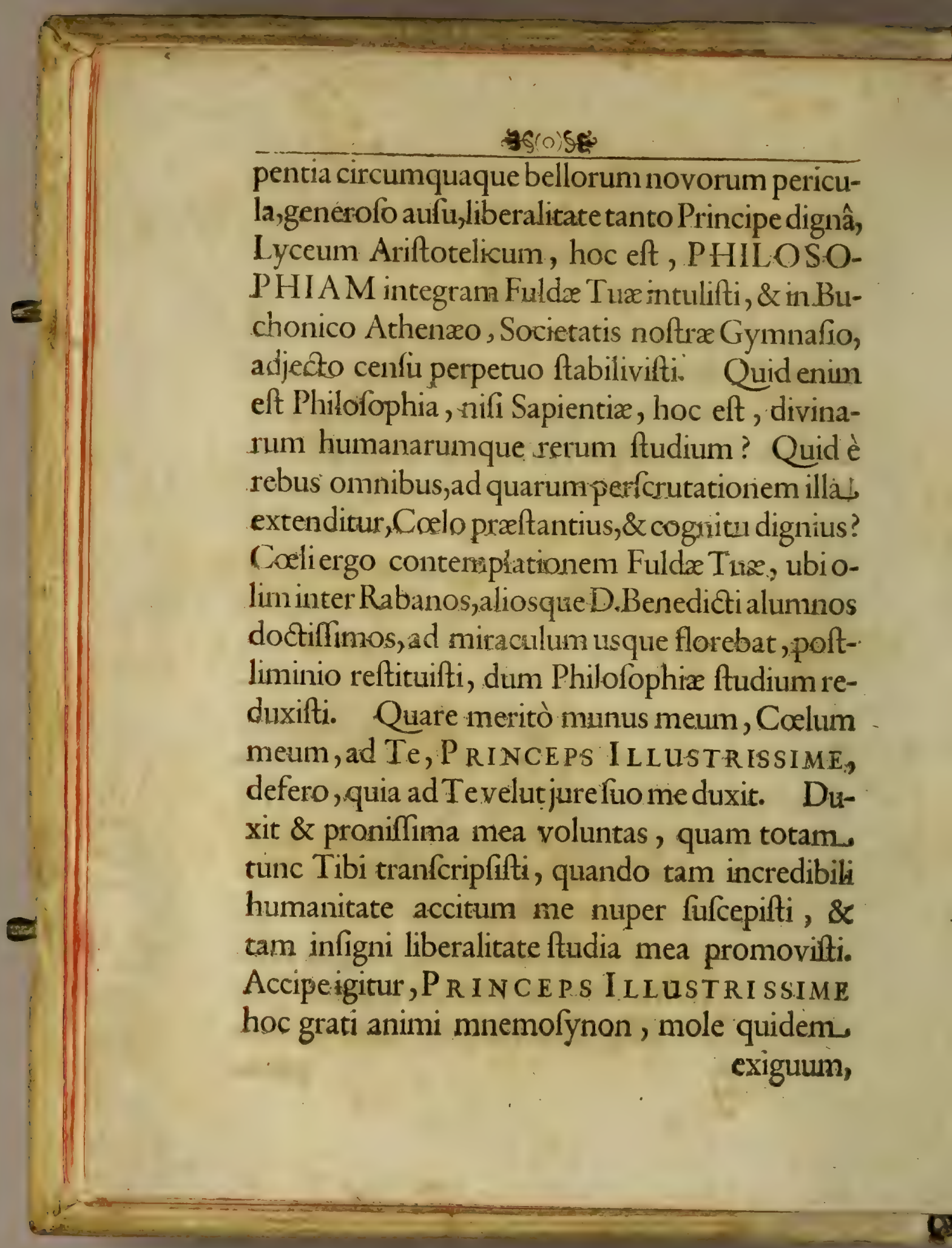




\section{क्षे}

exiguum, at argumenti pondere ingens, affectu verò maximum. Vive, PRINCEPS, diu acfeliciter DEO, Ecclefiæ, Imperio,Patriæ, ac Tibi; \&poftannos Neftorios Coelum revife. Ita animitùs voveo Herbipali, Die VIII. Septembris Anni M. DC. LX.

\section{Celfitudinis Veftræ}

Humidimus Cliens

GASPARU's SCHOTt,

S. J.

)$(x$ FACUL- 


\section{FACULTAS}

- R.P.Provincialis Societatis JESU per Rheni fuperioris Provinciam, Auctorifacta.

\section{RICQVINUS GÖLTGENS}

Provincialis Societatis JESU Rheni fuperioris.

QUm Prodromum in Mundum Mirabilem, compofotum JP. Gapparo Scbott noftre Societ atis Sacerdote, tres ejusdem, Societatis Sacerdotes, quibus id commifJum fuit, recognoverint, $G^{2}$ in lucem edi poffe probaverint; facultate nobis ád Admodumo Reverendo Patre Golvvino Nickel Prapofito Generalicommunicatá concedinuse, ut idem typis mandetur. In cujus reifidem, has: Litteras manu noft râ Jibbforiptas, \&u figillo noftro munt as: dedimus. Herbipoli 27. Junii 266 a.

$$
\text { L.S. }
$$

Ricquinus Gôltgens.

$$
F A C \cup L T A S
$$

\section{R. P. Provincialis Societatis JES U per Rheni} fuperioris Provinciam, Bibliopolx facta.

\section{R.ICQVINUS GÖLTGENS}

Provincialis Societatis J ESU Rheni fuperioris.

E Go Ricquinus Goltgens Societ at is J ESU per Rhenifuperiori. Provinciam Propafitus Provincialis, poteft ate mihi ab Admodum Reverendo P. N. Gofvino Nickel, Prapofito Generali conce ßà, facult atem do foanni Andrex, है. Wolffgangi Endteri 7 unioris Heredibus, suis Jumptibus excudendi P. Gapari Schot é Sacietate Noftra.Prodromum in Mundum Mirabilem. In cujus rei fidem boc ei teftimonium manu noft râ fubfcriptum, E̋ figillo nof ro munitum dedimus. Herbipoli 27. Junii. Anno 1660 .

L.S.

Ricquinus Gôltgens.

Biblio- 
c. w क०

Bibliopola

\section{Monitio ad Lectorem.}

PRodromus in Mundum Mirabilem, cujus bicmentio fit, est ipfummet Iter Exftaticum Kircherianum Colefte, Pralufionibus, Scholiis, G Schematismis a R.P. Gappare Schot to exornatum, E auctum: verfat enim animo dictus Auctor Opus non mediocre, quod Mundum. Mir abilem appellabit; in quo prater alia, plerabue qua boc in Opufculo traduntur, fufus explicabuntur, \& rationibus pluribus ftabilientur. Quod, te, Lector,latere nolui. Vale. 


\section{In R. P. Athanafii Kircheri ITINERARIUM EXSTATICUM.

\author{
AD LECTOREM:
}

Fabulà eft Icaram volatu obiiffe Coelos:

Fabula tamen non eflet, nomen eum dediffe aquis,

Si non effet fabula cereis eum alis volaffe.

Sed fabula non eft Ingenio fúo luftrafie Coelos

A T HANASIUM KI RCHERUM.

Imò fabula effet, fupra humanum captum eum non evolaffe;

Nifi eflet:fabulä,Ingenium ejus non excedere

Prope Captum humanum

Quantò feliciùs autem! caro volaverit KIR CHE R US, In utriusquevid̈e Ićinerario.

Içarus Itineris:füi Nomenclaturam fignavit aquis:

Sed ad eo fluidè,ut præeter nomen nihil leggas

$$
\text { In aquis; }
$$

Cærera enim omnia jam dudum cum aquis diffluxere:

Nam quò'quáve volârit, nec ipłra aqua nôrunt.

Sicfcilicet fabulofum iter fignari meruit.

KIRCHE RUS verò Itineris fui rationem \& viam

Signavit in Libro

Ubi \& nomen fuum \& Iter reliquit.

Nec malè,quòd in Libro;

Quando tota ejus Peregrinatio fiebat

In Libro \& per Librum,

Cujus,ut ipfe ait, folia.

Interdiu fint candida vel carula,noctu nigra ;

Characteres aurei, fcilicet ipfa fidera ;

Libri Typotheta DEUS TRI UNUS;

Officina, è qua prodiit,Mens DEI Archetypa.

Cujus Index \& fummarium Homo;

Cenfor Is, qui qua fecerat, vidit efle bona, 


\section{$25(0) 54$}

Et approbavit nemine hucusque improbance,

Nifi vel Amente, vel Acheo.

Per iftum Librum complicatum, iter hucusque reconditum,

Quod invenit:ATHANAS IUS KIRCHERUS,

Videbis, fi hunc explicabis;

Et leges,fi intelliges:

Nè autem in primo ingreflu offendas,

Noli purare fabulofum effe, quia legis efle

ITINERARIUM EXSTATICUM,

It quidem à Mathematico fomniante natum.

Sic.Vulgus indoctum judicac.

Nequeillico fabulofum eft, quod Mathematicum audic,

Si vera Philofophia fit Còmes::

Quando nec veruseftMathematicus; qui non eft Philofophus;

$\mathrm{Nec}$ verus Philofophus, quinon eft Mathematicus.

Undetioc differt inter Ingenium

Vulgo-Mathematici \& Philoföpho-Mathematici:

Illud vento, hoc ratione fertur:

Illius fomniafunt deliria,

Hujus funt dogmat a, quia ratiocinia.

Et illius deliria cum fornno, E. Sape ant e. fornnumeranefount,

Hujus Dogmat a poft fornum ơ annos छ'atatem ferunt, Quiamatura:

PHILOSOPHIA ET MATHEMATICA

Binæ Ala funt quib. volavit ATHANASIUS KIRCHERUS,

Et à Lunausque ad ultima MundiConfinia

Penetravit, viditque omnia

Qux Architectatus eft Mundi Opifex

DEUS TRIUNUS:

Inde reduxiisdem le libiavit in terram

Ad ipfum usq; Centrum,

Et maria men fus \& Abyflos.

Pulchro tamen ordine, Philofopho verè digno:

Luftravit nimirum Terram;quam deferere deberet, ) $x_{3}$ 


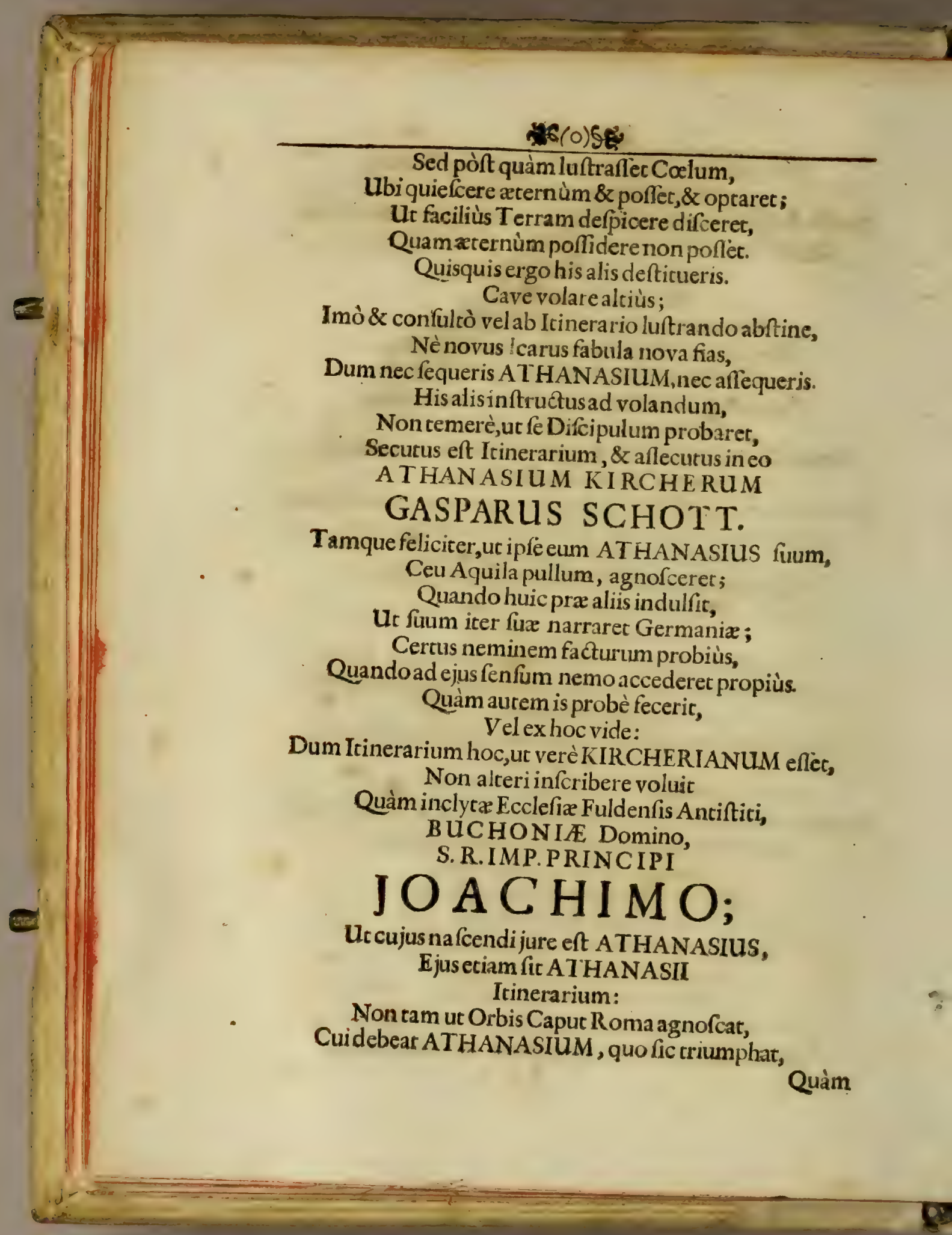


Quàm ur Buchonia Orbis angulus videar,

Talem fuo è finu educi potuifle Virum ,

Quem Orbis fufpiciat univerfus,

Doctus \& Indoctus,

Si modò Lividum excipias.

I nunc, \& Itinerarium hoc fcrutare;

Et precare

Utc Rei-publicæ Litterarix

Diu vivant incolumes

KIRCHERUS ET SCHOTTUS;

Quibus ex animo precatur

Incolumitatem ærernam.

P. Nicolaus Mohr

Societatis Je su. 


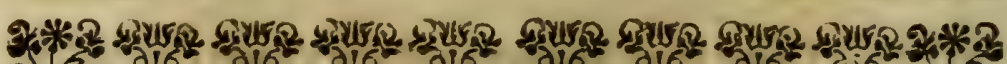

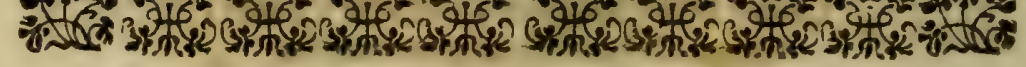
ELENCHUS TITULORUM TOTIUS OPERIS.

3. ITER EXSTATICUM I.

Prafatio Scholiafte ad Benevolum Lectorem.

Prafatio Auctoris ad ftudiofum coeleftis Philofophix pas.I rem.

Pralufio Catholica Scholiaft a, five Ifagoge Afronomica pro Tyronibus; quâ Mundi conftitutio, mundanorumque corporums difpofitio, ordo, natura, proprietates, fummatim exponuntur, variaque. Mundi Syftemata explicantur.

I.I. De ordine partium Mundi; deque ejus figura, centro, diametris, axe, \& polis.

20

5. II. De ftellis califiderei, earumque numero, $\sigma^{\circ}$ differentiis. 22 I.III. De.Comet is, E'ftellis novis.

S.IV. De motibus ftellarum, mot unmque varietate.

S.V. Denatur a celiferereiguoad fuiditatemacfoliditatem. 20 5.V. De natura coli fiàereiquoadfluiditatem acfoliditatem. 28 S.VI. De numero \&' mot uccelorum.

f.VII. Decali compofitione, fo corruptibilitate. I.VIII. De aftrorum natura, E' proprietatibus quibusdam,motuque ab Oriente in Occidentem, \& vici]/sm.

I.IX. Devariis Mundisyftematibus.

Prælufio Paranecica AuetorisKircher. fculum fulum hoc nihil peregrinum habere, quod non facrarum. Litterarum, Sanctorumq; Ecclefix Doctorum auctoritatibus, \& irrefragabilibus obfervationum experimentis confentiat.

Scholium 1. Decentro fingulis aftris proprio.

scholium II. An aftra moveantur ab Intelligentiis. 


\section{DIALOGUS I.}

De cœleftis Expanfi fiderumque narura,acproprietatibus.

CAPUT I. De caufa \& origine hujus Opufculi.

PRÆLUSIO IN LUNAM.

S.I. De diver fis Lune phafibus, ejusque maculis tàm novis, quàm antiquis.

S.II. Quid fint macule antique or nova in Luna.

ibid.

5.III. De Luna atmoßphara, \& maximo ejusdem dominio in. hurnidafublunaria. 69

f.IV. De Lune natura, atque ft ructura.

CAPU T II. De Itinere in Lunam. Habet Scholia XVI. in quibus agitur de annulari eclipfs solis vifa ab elevato Jupra Terrams de totali eclipfi ejusdem vifa à conftituto in. Terra; de parte Terre vifa ab oculo in variis diftantiis fupra eam pofito; de facie Terre ex alto regionis aïrex loco vif $a$; de paradifo terreftri, num adbucextet; an fint homines, animalia,plante, in Luna, aut in aliis planet is 8 aftris ; an fupras. aërem, or infra Luna concavum, $\sqrt{3} t$ ignis; de phafibus Terra $e ̀$ Luna ßpectata; de diebus E? noctibus exiftentium in Luna; de centro Lune, aliorumque planetarum, bc. $\quad 72.6 \mathrm{Jeqq}$.

PRELUSIO IN VENEREM.

6.I. Dephanomenis antiquis Veneris.

f.II. De novo Veneris phanomeno, ejusque in colo liquido inter planetas loco, $\sigma^{2}$ motu. $\quad$ I3I

I.1II. De variis Aftronomorum obfervationibus circa Venerem.

133

5.IV. Alia obfervationes, phanomena, Z oftenta Veneris. 136 f.V. Deftructura E' nat ura globi Veneris. ... 138

CAP U T III. De Itinere ex Luna in globum Veneris". Ha" $x)(x$ 


\section{$35(0) 5$}

bet Scholia $1 V$. in quibus agitur de Veneris vertigine circa fuum axem \& centrum, of de magnitudine ejusdem; de Jeptem. Intelligentiis quifeptem planet us praeffe creduntur, E?. 339. $6.5 \mathrm{eqq}$.

PRÆLUSIO IN MERCURIUM.

I. I. De loco, motu, \& figura Mercurii.

S.II. Deftructura \& natura Mercurii.

ibid. Is6

CAP U T. IV. De Itinere ex globo Veneris in globum Mercurii. Habet Scholia II. 156. E'jegq.

PRALUSIO IN SOLEM.

5. I. Ansolfit igneus, G formaliter calidus.

f. IL. Solvuntur argument a contra igneam Solis naturam. 176 f. III. De maculis ó faculis solis.

1.85

f.IV. De motu vertiginis Solis circa funn centrum of axem.

5.V. Deftructura \&ँ natura Solis; \& de macularum acf facularum Solarium jubftantia.

$x 86$

CAPUT V. De Icinere ex globo Mercurii in Solem; \& de mirabili Solis ftructura. Habet Scholia VIJL in quibus agttur de Solis magnitudine collata cum Terra; de vorticibus globorum coeleftium; de velocitate motus Solaris diurni, छ'c. so. o.jeqq.

\section{PRALUSIO IN MARTEM.}

5. I. De Martis figura ex obfervationibus.

5. II De Martis influentios \&o effectibus in wablunaria 243

5. III. Deftructura o' natura globi Martus.

CAPUT VI. DeItinere in globum|Martis; \& de mira ejus conftructione. Habet Scholia V. in quibus agitur de diffanstia Martis ì Terra, Luna, Venere, Mercurio, Sole, Fove, Saturnosftellis fixis, do 
PRELUSIO IN JOVEM.

f.I. De Zonis feu falciis Jovis.

262

f.I1. De vertigine fovis, aut libratione circa funm centrum.

f. III. De Jovis atmoßhera, Eo a peritate.

267 S.IV. De quatuor ftellis circa fovem, quas ejus Satellites $\int e u C o$ mites vocant, earumque fitu, mot $w, \xi 5 c$.

5.V. An dentur plures Satellites fovis quàm quatuor. 273

S.VI. Deftructura or natura fovis. 278

CAPUT. VII. De Itinere ad globum Jovis, ejusque admirando in natura rerum opificio. Habet Scholia VIII, in quibus agitur de Jovis influxu in hacinferiora; de diffantia fovialium comitum à Fove, छ' a je invicem, $\xi^{2}$ de eorum moti. bus, ¿oc.

278.05 eqg.

\section{PRALUSIO IN SATURNUM.}

f.1. Deobfervationibus Saturni E Comitum ejus, ope telefcopit.

5.II. De aliis Saturni E Comitun ejus phenomenis, variisque circa ipfa Auctorum opinionibus. $\quad 302$

5.111. Deftruct ura Saturni o Comitum ejus. 305

CAPUT VIII. DeItinere in globum Saturni. Habet Scholia $X$. in quibus agitur de Saturni natura of effectibus; cur Comites ejus tam diver as figuras cum ipfo efficiant; de magnitudine Saturni, \& diftantia ejus à Terra; de mot uvertiginis Saturni, of ejus Connitum; de phanomeno anfularum Saturni; de dift antia ejus ab aliis planet is of Terra, in femidiametris Terre, of milliaribus, or c. 206. E' Seqg.

PRALUSIO IN FIRMAMENTUM.

5.I. Denumeroftellarum fixarum, \& deftellis recenter ope telefcopii detect is.

S.II. Dediftantia fixarum à Terra. 


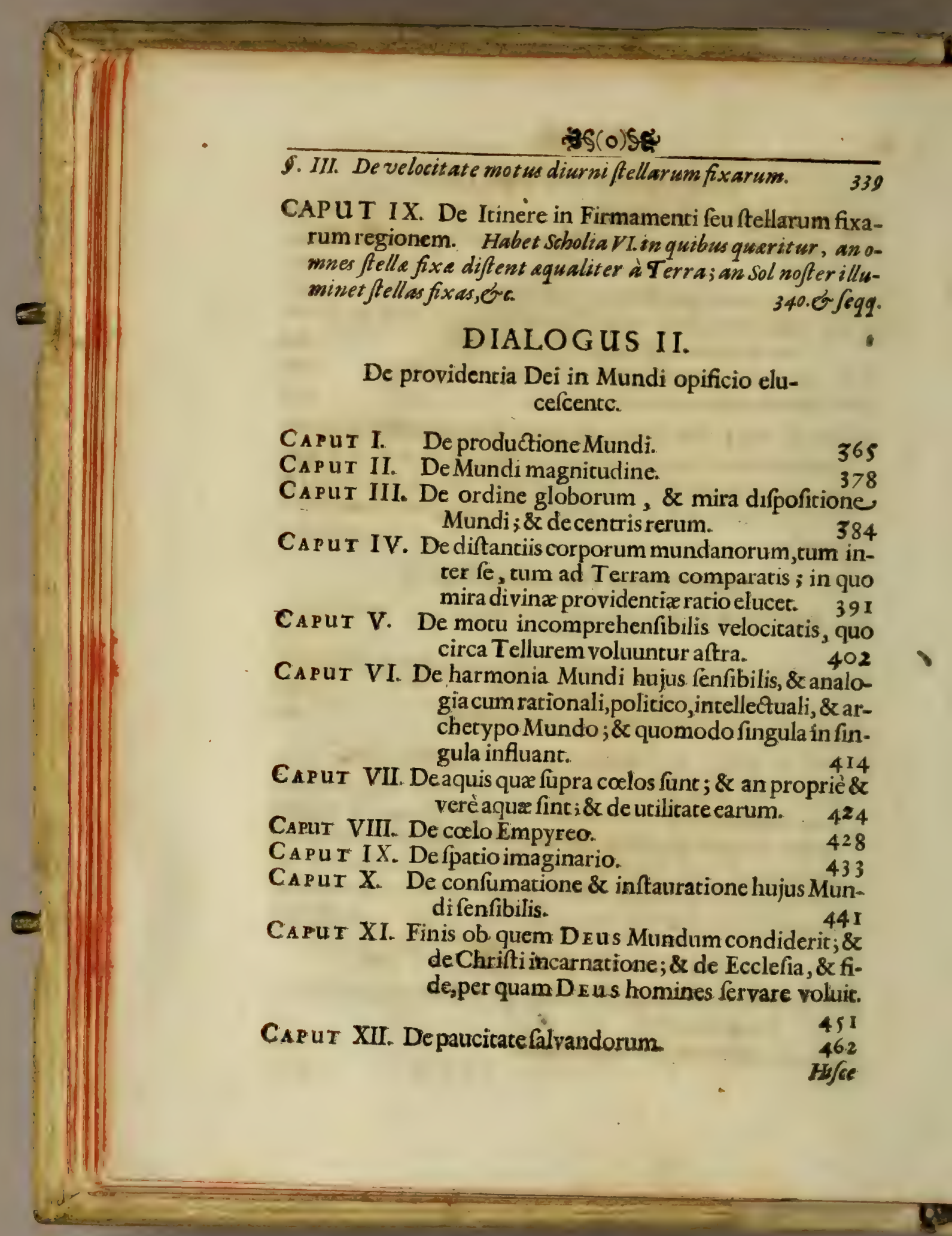




\section{$36(0) 5$}

Hifce plerisque Capitibus interferuntur hincinde nonnulla scholix.

EPILOGUS.

CONCLUSIO OPERIS.

AUCTORITATES quibus Mundi hypothefis in hoc Ope. re explanata confirmatur.

473

$\triangle P O L O G E T I C O N$ contracenfuramnonnullarum Propofitionom, ex Itinerario Exftatico Kircheriano excerptarum.

Apologeticon R.P.Melchioris Cornai.

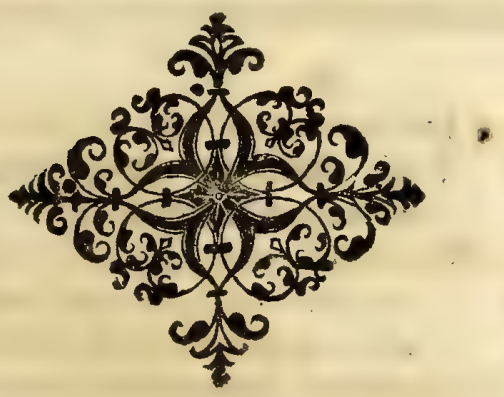




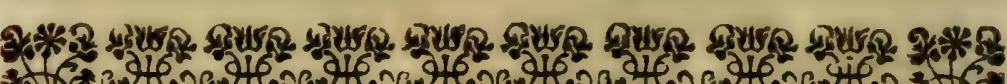

ITER EXSTATICUM II.

Præfatio ad Lectorem, de cœepti exftatici Itineris fcopo, deque caufa \& origine hujus Opufculi. pag. 514

\section{DIALOGUS I.}

De elemento Aqux, \& univerfalirerum principio.

Ca pu T I. De Aquei elementi in natura rerumneceflitace, \& urilitate.

\section{DIALOGUS II.}

Deadmirandis Geocofmi five Terreftris Mundi arcanis.

Caput I. Deexterioris Geocofmi facie.

Caput II. Varia dubia folvuntur circa externam Geocofmiconftitutionem.

Ca pux III. Quomodo ex interioribus Naturæ reconditoriis fpermaricis plantæ \& animalia vivant; \& unde originem fuam trahant.

Ca pu T IV. Quomodouniverfale femen Mundiconcurrat ad mixtorum compofitionem. Et primò quidem de ortu, natura, viribus vegerabilium.

CapUT V. Deortu \& viribus fenfitive Natura.

DIALOGUS III.

Iter exftaticum in Mundum Subterraneum. 
CAPUT I. Exploratur maris tum extrinfeca, tum intrinfeca conftitutio, animaliumque in eo multitudo \& varietas def cribitur.

614

Caput II. Exploratur marisfundus, \& communicatio Marium cum Oceano.

632

CA PU T III. Subterranei Mundi arcana explorantur. 642

CA Pu I IV. Introductio intra ignea Subterranei Mundi conceptacula. 618

Caput V. EpilogusAfceticus,in quo de variisæternæbeatritudinis confequenda mediisagitur. 669

SY NOPSIS Mundi Subrerranei,five earum rerum, de quibus in Opere Mundi Subterraneĩ per decem libros fusè difceptatwrà R.P.AT HANASIO KIRCHERO. 684

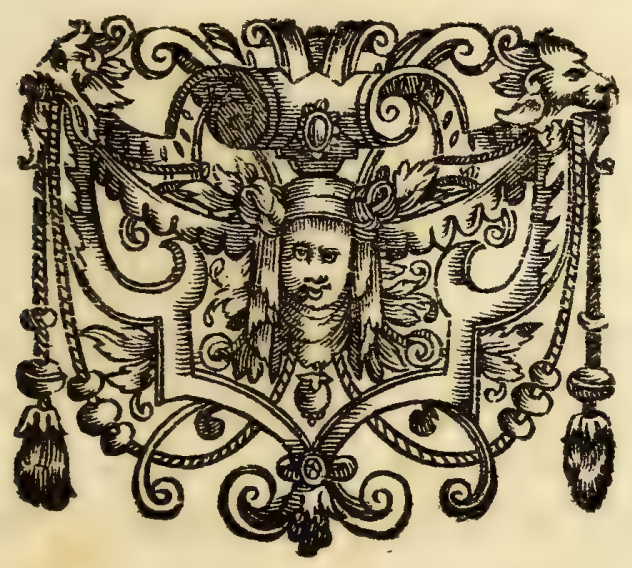

PREFA- 


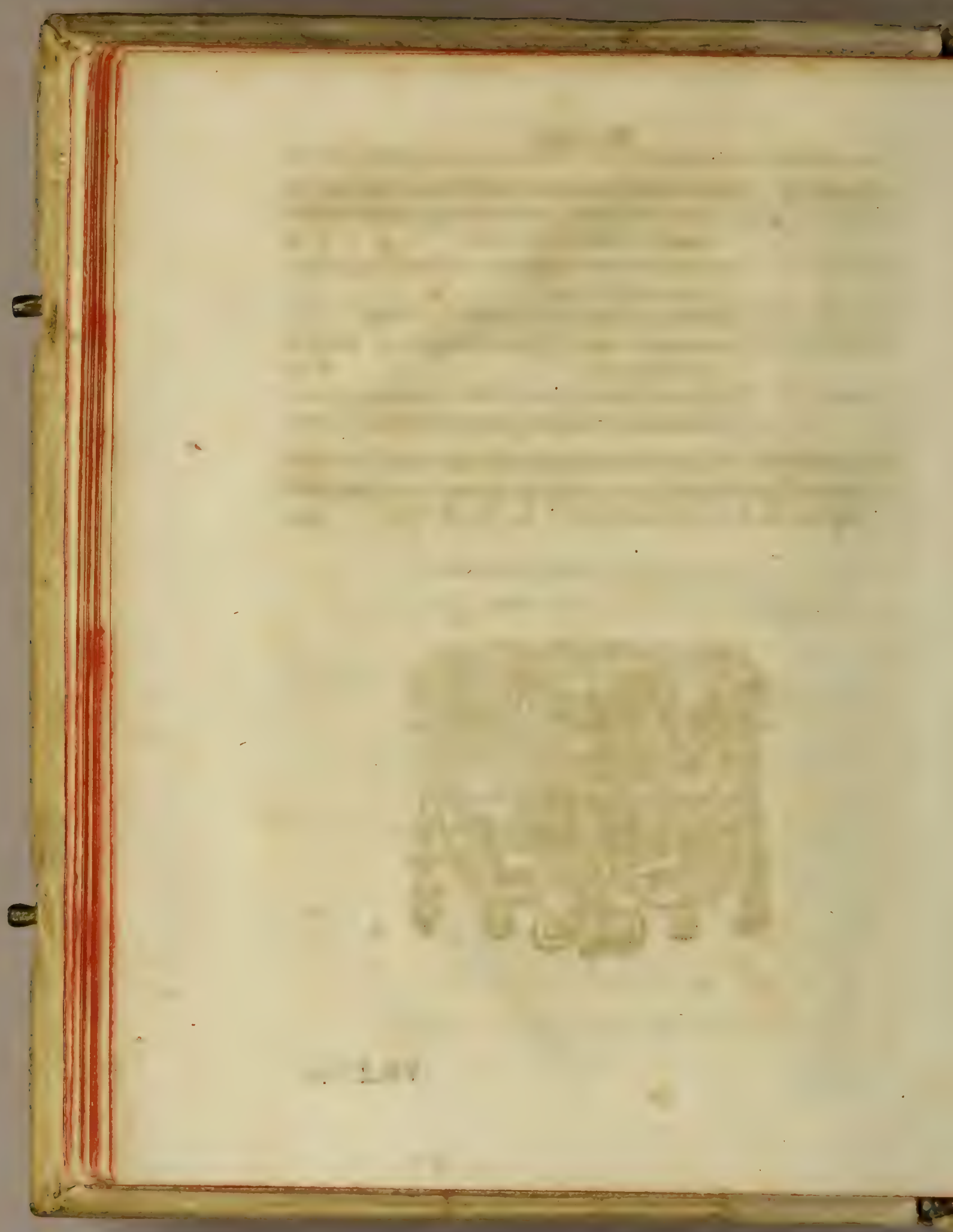




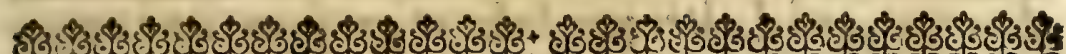
ต.

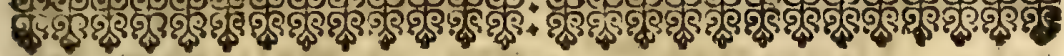

$P R A F A T I O$

\section{SCHOLIAST $Æ$}

\section{AD BENEVOLUM LECTOREM.}

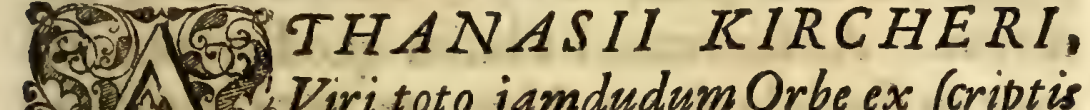

libris noti, Itinerarium Exftaticum Colefte Pralufionibus EO Scholiis illuAratum, fchemat ismis neceffariis antea defideratis exornatum, mendisque omnibus, qua in $\mathrm{Rot}_{+}$ manam editionem irrep ferant, expurgatum, ip/o annuente Auctore, bac fecundâ editione tibi, $L E G T O R$ BENEVOLE, fifto. It inerarium dico tam raris, exoticis, $\mathcal{E}^{2}$ ante hac inauditis refertum opinionibus, ut cum primum ejus fama percrebuit in It alia, anteguam pralum eluctaretur Romanum, omnia ponè exemplaria fuerint divendita $;$, ut vero allatum in Galliam E Germaniam, ac perlectum à doctis E rerum intelligentibus, adeo rapuit omnes in admirationem, ut me cum diginisfimum jus anmat A dica- 
dicarint, quod alterum (ubiret pralum, quo omnibus coleft is Pbilofophice Andiofis ejus copia fieret. Meumergo Ef commune multorum defiderium Auctori per litteras expolui, rogavique permitteret, ut prelo denuo fubjiceretur. Annuit is, fuafut que, ut neceffaria fchemat a (qua, ut fum-

Kirsberi consenfuss, at Isinere ris reims. primaneur. ptibus parceret, omi(erat) $\sigma$ commentaria adderem. Ad Itineraria Exftatica quod attinet, inquit in Epiftola die 22. Nov. An.1685. Romá ad me dat $\hat{a}$, opera Reverentiæ Veftræ, quâ ea recudenda judicat, peraccepta mihi fuit; quod tamen antequam fiat, non abs re foret, fi Reverentia $\mathrm{Ve}$ ftrabrevia Commentaria in ea ederet, unà cum figuris obfervationum, quas de Luna, Venere, Mercurio, Sole, Marte, Jove, Saturno, ac Stellis fixis $\mathrm{P}$. Ricciolus in fuo Almagelto novo pulchre exhibet ; hoc pacto Opus majorem \& fplendorem, \& admirationem adquireret: mea enim intentio fuit, hujus Operis exhibitione novum Mundo exhibereSyftema phyficum colefte, ex obfervationibus aftronomicis conflatum, quo omnes huc usque difficultates circa naturam coli in Scholis occurrentes facillimé folvi poffent ; jamque adeò placuit, ut plures habeam ubique locorum mex do-

ctrinx 
Itinerarium I: Prafatio Scholiafte.

Atrinæ fectatores. Reverentia Veltra maturè rem expendat, \& de omnibus dubiis occurrentibus propediem me certiorem faciat: ingentem enim campum commentandi reperiet in eo, five phyficas, five aftronomicas fpeculationes attendat; magnumque apud Rempub. Litterariam \& meritum, \& nomen fuâ operâ fe adquifituram fciat. Vale,Pater mi dulciflime, eumque, qui te medullitùs diligit, redama; quod fiet, fi mei in fanctiflimis Sacrificiis \& orationibus memor fueris.

$E_{\dot{O}}$ autem libentius laborem hunc $\int u \int c e p i$, Kircherum guod Opus ipfum me non impigro hortatore pri- is calorum mam lucem jpect afje videri queat. Res geft a it a nuisurboje habet. Trium annorum patio, quibus Romano in collegio Societatis noftre Auctori cobabitavi, E5 meam qualem qualem opellam in edendo Oedipo Egyptiaco impendi, quoties defatigati Audiis ad campos $\sigma$ hortos Romanos liberioris cure captande ergo concedebamus, aut Tu/culum, aliáve vicuna loca revijebamus; de rebus coleftibus, de fiderum natura, compofitione, $E$ conftitutione, de Mundi fyfematibus, de aliorum circa bac opinationibus, aliisque firrilipus de rebus colloquia infituebamus. Quibus in col-

$$
A 2 \text { loquiis }
$$




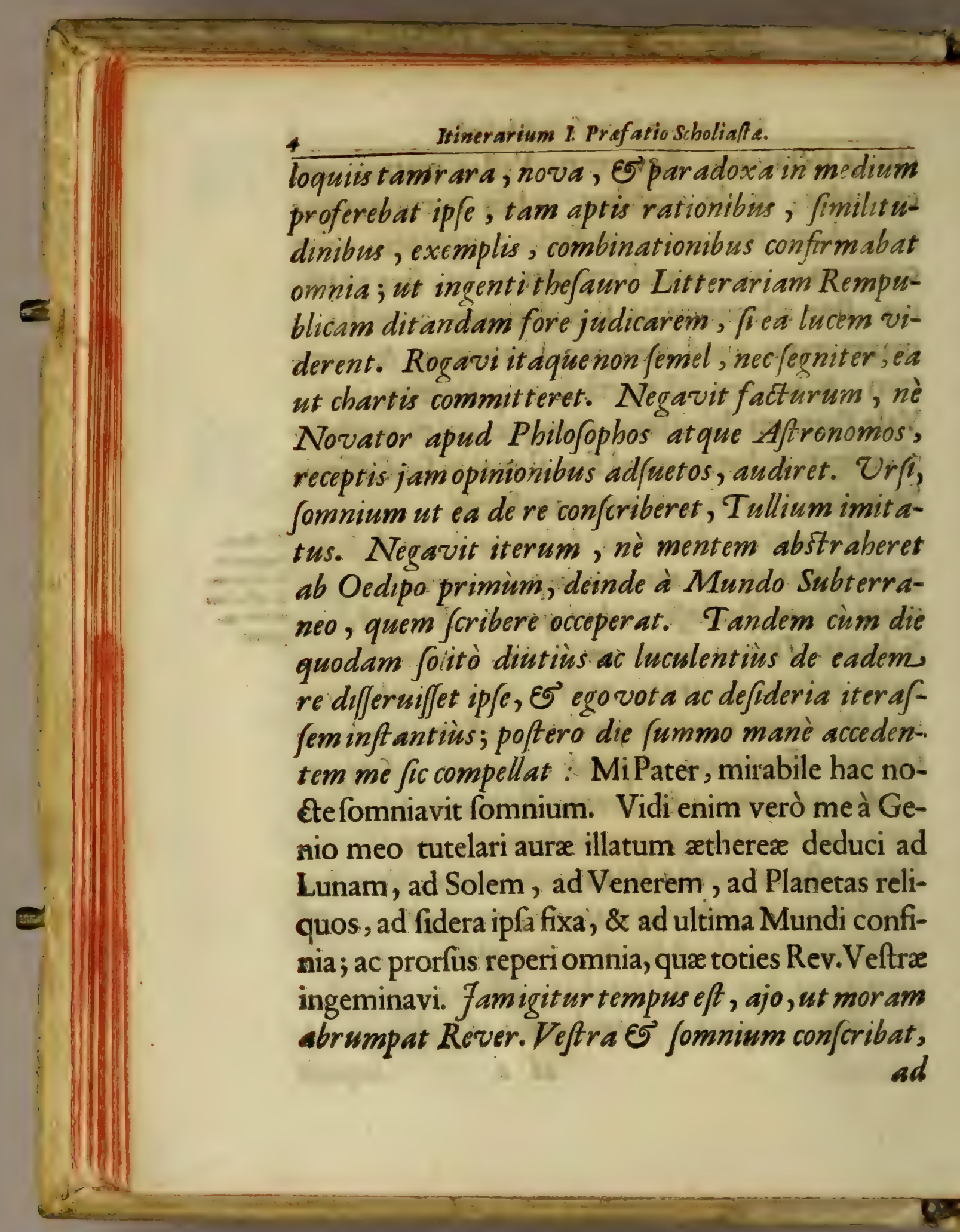


Itinerarium 1. Prefatio Scholiafte.

ad quod me toties fuaforem babuit, Eo infigatorem. Conmunicat a deinde re cum Viro doct is $\sqrt{l}$ mo, Eearundem rerum ftudio is imo, non defiti unà cum iplo urgere denuò Auctorem, ut fepofit á paulisper cogit atione de Mundo Subterraneo, Itiner arium conforiberet Exf aticum, de quo prafens est fermo. Quo poft meum Romà disceffum abfoluto, cum Romanis Societ at is noftra Cenforibus (qui quatuor funt Viri doct is fmi, ex It alia, Hipania, Gallia, E Germania (electi) oblatum ad cenfendum effet; tantum abfuit, ut ( quod timebatur, ob novas opiniones, $\mathcal{F}^{2}$ exoticas enarrationes ) rejiceretur, aut ulla in parte corrigi juberetur, ut faterentur unanimi confen/upalam omnes, nullum ab Auctore mirabitius ac luce publicâ dignius Opre confcriptum, uti nonnemo ad me Româ datis teftatur litteris.

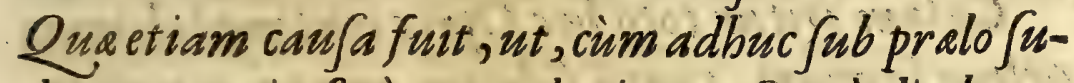
daret, omnia ferè exemplaria, ut fuprà dicebam, fuerint divendita, vix ut paucula pro Germa-

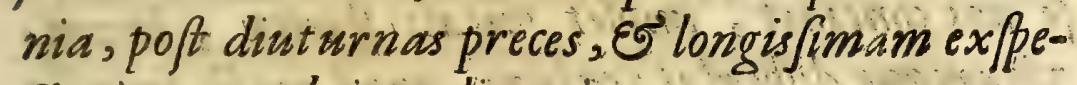
etationem, obtinerelicuerit.

Ne igitur tali ac tanto the auro Germania noltra defraudaretur, fecundam banc editionem

$$
\text { A } 3 \text { curavi, }
$$




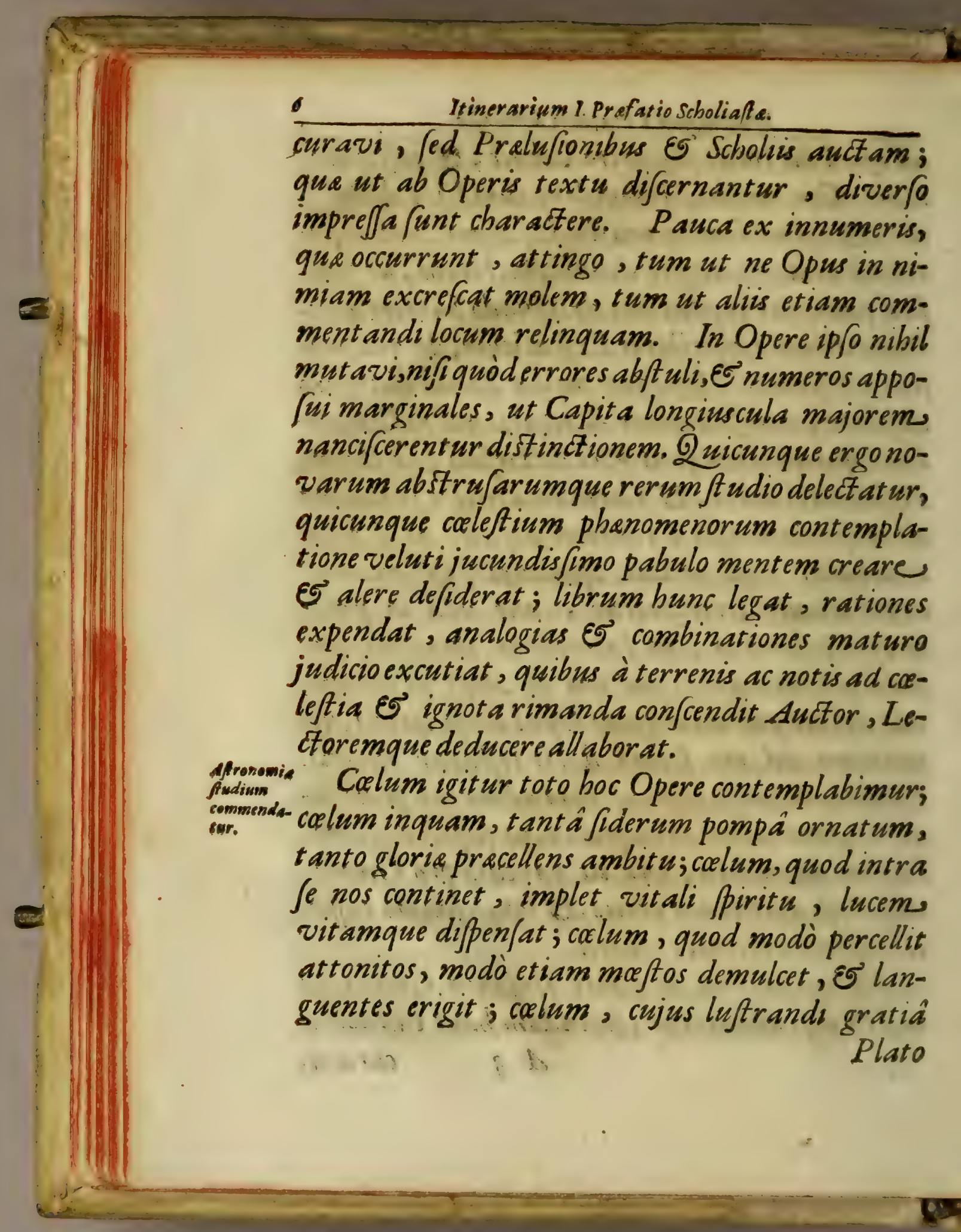


ac Mercurius nepos. Eidem ftudio dediti inter Graces er ant Lacedomoniorum Reges, qui, \& $A$ fronomi non effent, Regum nomine E infignibus jpoliabantur; inter Romanos primus ac potentisfimus Monarch $C_{a}$ far, qui media inter pralia femper ftellarum colique plagis, fuperisque vacabat; inter Egyptios Ptolemaus Rex, qui Aftronomorum Phanix jamdudum audit; inter Hipanos Alphonfus Caftella Rex, qui Aftronomize refiauranda ergò non dubitavit aurearum quadringenta millia profundere; inter $O_{c}$ cident is Imperatores ter Auguftus Carolus. cognomento Magnus, inter alios populos alii Reges ac Principes. Nunc poftquam Orbem Terrarum dirus babendi ac dominandi ardor infecit penè univerfum; poftquam alii ambitionis oftu per Syrtes abrepti, Er ceca vite pericula; alii libidinum facibus ambufti, ES in brutorum vitam ablegati, in praceps ruunt, E barathrum vitiorum; divina bac ftudia negliguntur, $\mathcal{E}$ paucos admodum coleftium rerum cura exercet. Quin mentem igitur reerigimus, Eे novâ hac atque jucundâ philofophandi ratione, quam Auctor doctisfimus in pralenti Opusculo omnibus propo- 
ninesarium 1. Pricfatio Scholiafte.

nut, excitati penetramus in Coll adyta? Hoc ut non doct is tant ium, $\sigma^{2}$ in aftronomica feudio exercit at is fas fit, lod coleftium rerum amatoribus omnibus; Pralufiones \& Soboticinoft ra facem praferent; $\sigma^{\prime}$ lucem, ut pero, impertientur non con ternnendam.

A Colo deinde ad Terram delabimur, â pa tria loco ad ftationem exilii, à Divorum curia ad Dit is ac Proferpina regna: Volo dicere, Itiner riexfatico Golefti addimus ejusdem Auctoris Kircheri Iter Exftaticum Terreftre, quo Geoco/mi opificium, five Terreftris Globi ftruEtura, unà cum abditis in conftioutis arcanioris Nature reconditoriis, per ficti fimiliter raptus integumentum exponitur ad veritatem, non minus quàm in Calefti factum, variè, doctie, ac folidè. Nullas tamen Pralugiones, Scholia nulla adjicimus, fed Opus integrum, prout ab Auctore fuo con/criptum fuit ac editum, damus, nifi quiod typographicos nevos, qui in primam Romanam editionem irrepferunt; fuftulerimus. Addimus Opufculum boc priori Operi, ut integram Mundi fabricam, ab infimo Terre Clobo ad juprema eius confinia, ob appectum Lectori exponamus; $B \quad$ nibil 
20

trinerinitum 1. Profatio Scholiafic.

nibit de noftro addimus, quoniam Subterraneum Auctoris Mundum, in quo plenius omnia explicabuntur, propediem expect amus.

Ne tamen lateat Curiofum Lectorem, quod dicti Operis fit argumentum, adeò dignum, ut tanto tempore à tanto viro elaboretur; adeo multis ac magnis refertum rebus, wt mundi nomen mereatur; pretium opera, E Lectori gratumme facturum cenfui, fi earum rerum, de, quibus per decem Libros fuse in illo disceptat, Synopfin, Rome otim apud Auctorem le-: - Ifam, ac tandem transmiffam, in finefubjungexem.

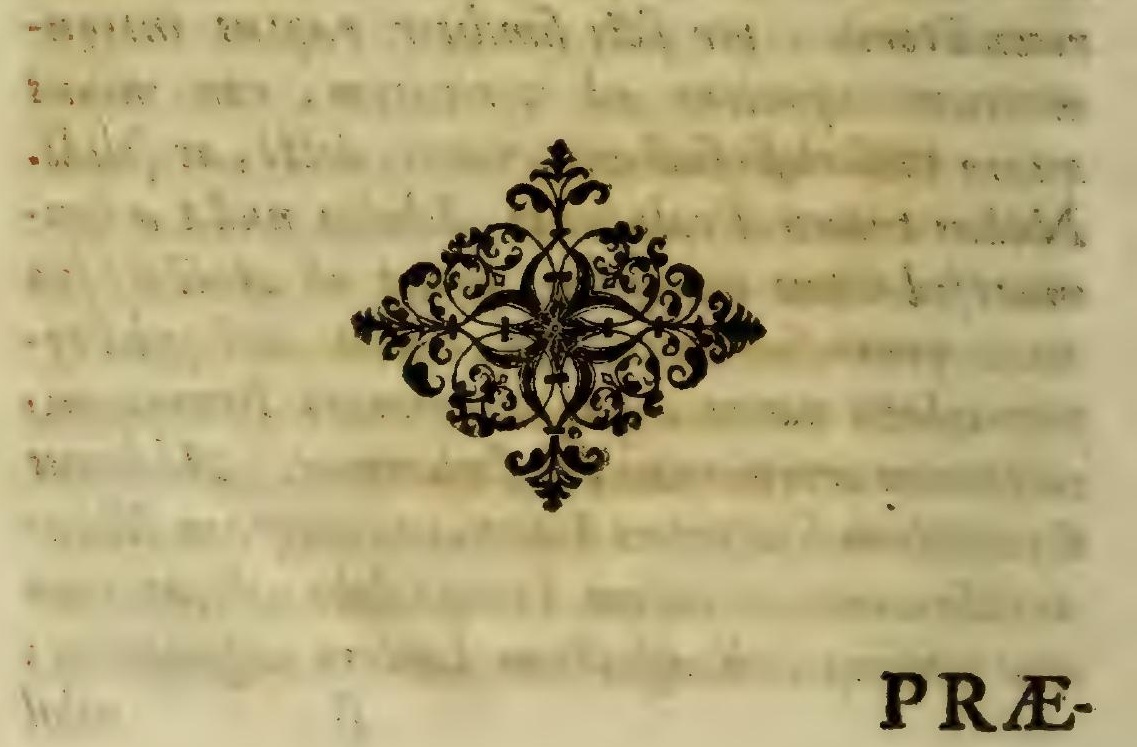




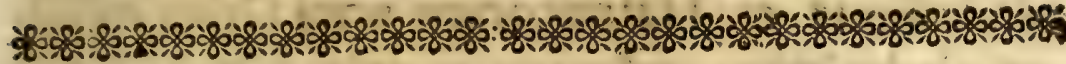

PRÆFATIO AUCTORIS adftudiofum Cacleftis Philofophia LECT ORE M.

TA eft, Lector; ita fuaviter ludit in Orbe terrarum aterna Dei fapientia, ut vix feculum aded rude \& impolitum extiterit, quo non Mundum ad antiqua veluti naufeabundum novis divinæ potentiæ fux fpectaculis exhilarârit, novis magnæ fcenæ præludiis erudiêrit; ut vel hoc pacto homines in amorem atque admirationem fui raperet, \&, fi quandoque à via mandatorum divinorum declinaffent, formidandis prodigiorum monftris prevaricatores ad cor reduceret. Quod uti olim, ita \& hifce ultimis potiffmùm feculis, magno mortalium fupore evenit. Nihil unquam venerabilis antiquitas de novi Orbis in rerum natura exiftentia norât; nihil de vafta Dceani circa terrarum Orbem diffulione; nihil de Antichtonum ftatu compererat; cùm ecces DEUS Opt. Max. poft expleta infcrutabilis confilii fui tempora novum nobis Mundi theatrum, tantâ exoticarum rerum varietate, quantam cum

B 2 admi- 
admiratione ex Hiltoricorum navi Orbis monimentis legimus, refertum aperuit : quas fi veteribus quispiam enarraffet, eas non dicam inter hiftorias verofimiles, fed puras putas inter fabulas \& anilia deliramenta haud dubiè cenfuiffent. Non ftetit hîc divinæe benignitatisis lufus', dum non ita. longo annorum intervallo poft novi Orbis detectionem , novum nobis Coeleftium ipectaculorum theatrum expandic, inaudita omnibus retrò feculis coeleftis tubi beneficio revelavit. Mundanæ machinæ fabrica ab immemorabili hucusque tempore externum tantùm faciei fuse decorem hominibus oftenderat; modò verò aperto corțice s nucleam detexit, apertisque clauftris interiorem, rerum ftatum, rotarum fitum, dispofitionem, proportionemque; globorum quoque compofitionem, centrorum officia, materiæ \& formæ, quibus fingula componuntur, oftendit, occultas motuum femitas pandit, nidos lucis ac caloris explicuit, tanto Philofophorum ftupore, ut nemo ferè effet, qui ad infolentia Naturæ monftra fummo conatu contemplanda armatis oculis non accurrerit. Hîc in coeli fcenam prodierunt preter antit qua, fed olim indiftincta, in nebulofis fideribus, \& 
in toto Galaxix ambicu numeroforum fiderum. agmina; novarum ftellarum in Cafliopea, Serpentario, \& Cygno, naturâ, proprietate, figurâ, colorumque diverfitate mirum in modum difcrepantium genefes; ut interim Cometarum varietatem, dira mortalibus omina, omittam. Hîc Sol, quo nihil hucusque mundus lucidius nitidiusque credidit, mirâ quadam macularum, umbrarumque varietate transformatus, ac veluti ingentes rftuum ebullitiones moliens, conftantiflmum Mundi fidus, perpetuæ alterationum vicisfitudini obnoxium comparuit Híc Luna montibus, lacubus, maribus, infulis aggravata in fcenam fe dedit; quam Venus fecuta corniculatâ fronte, partium afperitate non ita venuftam fefe, ac Veteres crediderunt, oftendit. Mercurius lucidus, fcaber, ac in varias divifus facies mirum prabuit fpectaculum; tum Mars gibbo ac retufo quodam, nec planè rotundo unbone, at ferrugineâ maculâ trux, ignisque eructatione formidabilis; tum Jovis fidus quaternis, non tam fatellitum, quàm Regulorum circumdatum fplendoribus, rarò unico, frepius gemino, rarius tergemino balteo transverfim cinctum. Agmen tandem claudit Sa-

B 3 turnus, $2+\operatorname{sig} x$

B 3 turnus,


turnus, Planetarum Geryon, tricorporis ftellæz monftro ac ftupore admirabilis, fefe horrendá vifui formâ exhibuit. Hic itaque novus Mundi apparatus, ac inaudita lafcivientis Naturæ feracitas, tametfi omnium in fefe Aftronomorum oculos attraxerit, dicitamen vix poteft, quantum tam infolentium effectuum caufæ nullius non ingenium torferint. Et uti rerum infolitarum rumores omnium aures mirum in modum vellicant, ita non Mathematicos tantùm \& Philofophos, fed \& Principum curiofitatem anxiè exftimulavic. Inter hos merîtồ connumerari potelt Auguftiflimus $\mathrm{C}$ far , Ferdinandus III. Mecænas munificentiflimus, quipro laudabili curiofitatis fux inftinctu, dum: Mundi fubterranei à me jamdudum incepti arcana mylteria urget, coleftium quoque hujusmodi portentorum, quæ hujus feculi fagacitas peperit, rationes \& caufas unà exponi juffit. Cujus quidem imperio non obfecundare nefas ratus, novum hoc Opufculum, non tam fpontaneo conatu, quàm armatâ tanti Principis aliorumque deprecatione extortum condidi. Quod quidem ut jucundiùs amoniusque in legentium animos infueret, in dialogi formam concinnare vifum fuit, 
Itinerarium 1. Prafatio Auctoris. 1) Exftatuci It ineraru nomine indigitatum ; in que obfervationum hucusque factarum congeriem. ad incudem revocans, hoc unicum intentâ mentis contemplatione, pertinaci fudio, \& varize combinationis rerum indagine, nec non multiplici rerum apparatu intendi, ut latentes tantorum paradoxorum caufas, exinacceffa, quâ in hæc usque tempora involvebantur, caligine evolverem, rationibusque aflignatis Mundi fabricam multò reconditioribus principiis, quàm fibi aut præteritorum feculorum fimplicitas, aut vulgares hujus temporis Philofophi perfuadere polfint, conftitutam effe demontrarem; multòque majora in abditis illis altioris Naturæ finibus \& reconditoriis, quàm hucusque creditum fuit, fuis quandoque in mortalium folatium revelanda temporibus, latere docerem. Quod antequam faciam, hifee, ea qua par eft animi ingenuitate \& candore, proteftari volui, me nihil hoc in Opusculo, nifiSanctis Patribus, Sacræ Scripturæ, \& experimentis ab obfervationibus deductis, undequaque congruum adducturum. Llbi verò Lector audaciores forfan Theodidacti cum Cofmiele fermocinationes evolverit, ubi raptus, extafes exoticasque operationes, 
tiones, fimilesque contemplantium affectus effectusque tacitus expenderit; hoc obnixè ab éodem efflagitem, ne de me finiftræ nefcio cujus fufpicionis umbram animo fuo infidere patiatur, meque ideo non nullius temeritatis arguat, quafi ultra. humanum quid altius mihi arrogem, aut revelationum coelitus mihi infpiratarum oraculum, novus propheta novam apocalyṕrin Mundo confidentius obtrudere attentem, aut arcano Numinis confilio interfuiffe plus xquo mihi arrogare voluerim : abfit ; hujusmodi enim maleferiatorum hominum ambitio, quantum $a b$ animo meo abhorreat, ii norunt, quí me meaque omnia norunt. opusculum Finis itaque \& unica fufcepti Operis intentio fuit, boc cur ad modum Dialogifori Dialogi eam in hoc libello fectare methodum, quam jam. olim ex veteribus Trismegiftus, Plato, Lucianus, \& ex fuccedentibus feculis complures tum Poëtæ, tum Oratores, laudabili fanè confuetudine tenuerunt; methodum, inquam, quam jucundum, amœnum, \& ad Lectoris guftum accommodatum dicendi genus ornaret, allegorica vero enarrationum involucra veluti lucem, coloremque, umbratiles linearum ductus fuaviter contemperarent, Thaumaturgicæ quoque ftylo poëtico de(C)

fcriptx 
fcriptæ operationes, Lectoris animum pruritu quodam follicitatum ad propofitarum rerum ponderationem fuaviori impetu raperent. Nullum itaque hîc myfterium, nullum raptum, aut divini $\mathrm{Nu}$ minis revelationem, nullam epiphaniam angeli$\mathrm{cam}$, nullum Oraculi Delphici afflatum fubeffe velim ; fed ut omnia luculenter demonftrarentur, ratiociniaque de rebus adeo incognitis fuaviùs Lectoris animo ingererentur, fub ingeniofi figmenti velamine, feu ficti raptus integumento exhibita effe Lector fibi perfuadeat velim. Ne verò folus intellectus mirandorum operum magnitudine captus, fine ulla ad tanti Conditoris fapientiam, bonitatem , \& amorem facta reflexione, voluntatem debitis laudis, honoris, amorisque affectibus, intentis unicè in hoc Opufculo pafcuis, deftitueret; hinc Afcetarum more Theodidactus poft maxima Sapientiffimi Conditoris opera vi divini amoris actus, atque in admirationis affectus raptus, nihil aliud intendit, quàm ut Lectorem ad fimiles DEO debitas gratiarum actiones, ad fimiles animi DEO pleni affectus concitet; ut hoc pacto per vifibilia hujus mundanæ machinæ prodigia, ad inC vifi- 


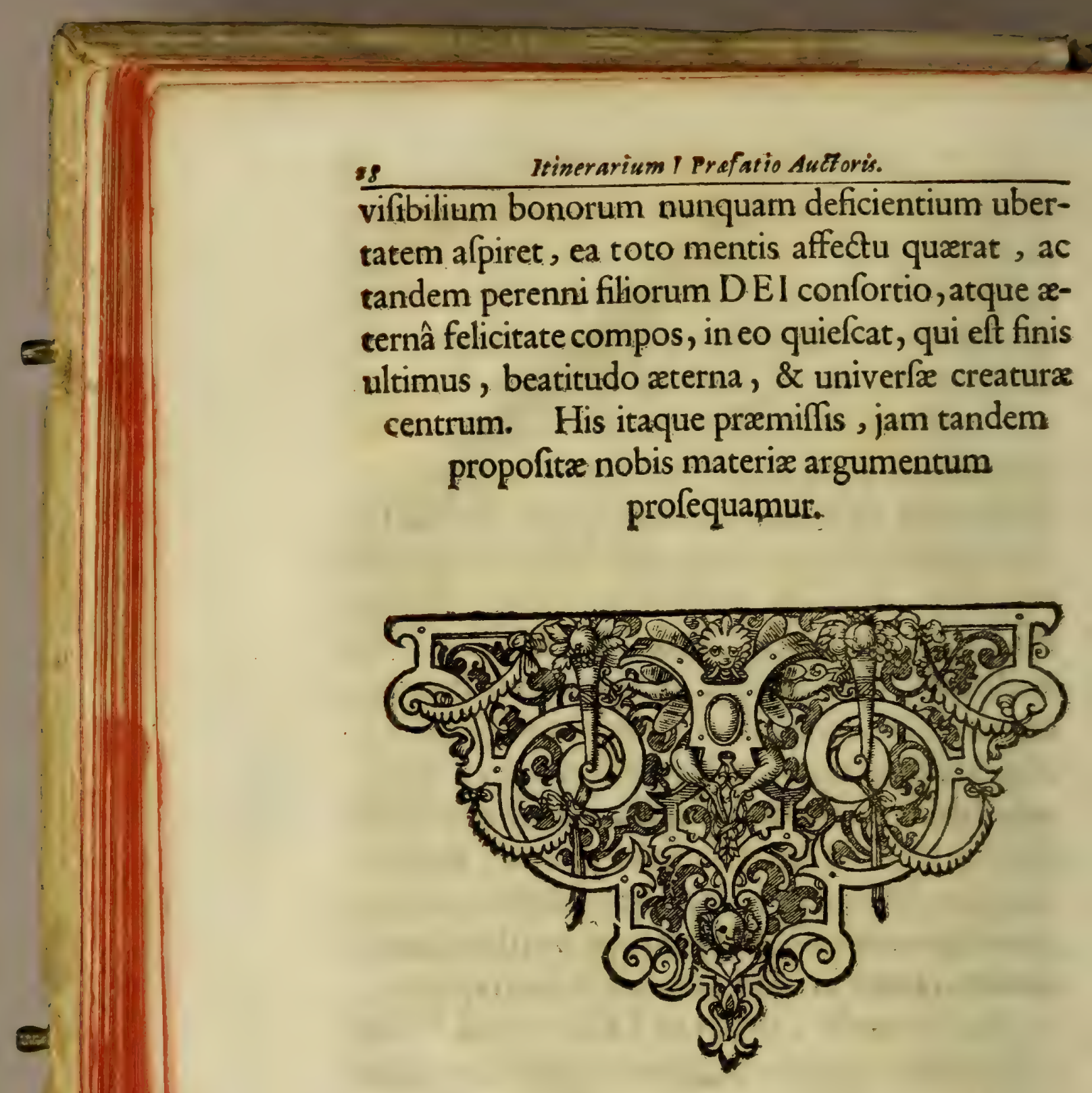

PRI- 


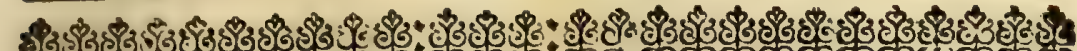

\section{PR ELUS IO C A- THOLICA SCHO-

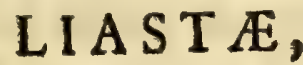

Sive

Jjagoge Aftronomica proTyronibus, Es in fudio Affronomicomixus provect is;

Qua Mundi conftitutio, mundanorumque corporum difpofitio, ordo, natura, proprietates, fummatim exponuntur, variaque Mundi fyftemaca explicantur. Undum, quem ob eximium ornatum
Craci ко́ rus, ob rerum omnium com(1) lexum E copiam Ziniver um Latini appellant, in Colum ac Terram Mundid: acer ejus Hiftoricus Moyjes, in $\mathrm{Ca}_{0}{ }^{\text {siffos. }}$ leftem ac Element arem Spharam Co/mographi atque Afronomi dipelcunt. Hujus univerfipartes, partium dipofitionem, ordinem, naturam, proprietates, aliaque accidentia explicare, variaque Mundi Syftemata proponere in Operis bujus veftibulo, opera preting duxi, cumut Mundi $C 2$ opi 

opificium fummatim ob oculos ftudiofi Lectoris in aftronomico ft udio novitii (provecti enim bis fubfidis non indigent) ponatur, tum ut facilius ac jucundius, que toto boc Opere dicentur, ejus animo influant. Perftringam quàm potero brevisfimè omnia, fufius de iisdem acturus, DEO dante, in Mundo Mirabili,quem mente agito. Nil agode circulis, quos Aftronomi in Calo ac Mundo concipiunt, ES per Spheram Armillarem reprefent ant, cujusmodi funt Horizon, Meridianus, Equator, Zodiacus, duo Coluri, duo Tropici, E5 duo Polares circuli; quoniam corum rudis ac fuperficialis cognitio fufficit inftituto noftro; que tamen cognitio facilius ac brevius Armillaris Sphere inpectione, Ev viva vocis explicatione hauritur, quaim mult is verbis libro commisfis. Tranfcripfimus pler aque, qua in banc Prelufionem conjecimus, ex libro 7. Cur/us noftri Matbematici, quem propediem luci publica, Divino Numine favente, committemus.

S.I. De ordine partium Mundi ; deque ejus figura, centro, diametris, axe, \& polis.

Murali 


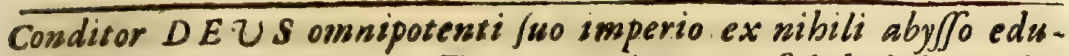
$x u t s^{2}$ creavit Colum \& Terram, aliter res fele babebat) dispofuno or ordo, wt in medio Elementaris Spherefit Terra, utpote elementorum omnium gravisfima: Terra partim infufa, partim circumf u/a est Ajua, Oceano, maribus, Auminibus, lacubus, fontibus difcreta, unumg' cum Terra globum conftituens, qui ob id Terraquens globus, Jeus Terraqua appellari poteft : Circa Terraguam expan/us est Aer, in tres diftunctus regiones, infimam, mediam, El Jummam: Circa Aërem putatur efJe Ignis; quem alit melius defecatum aërem, alii verò at hera appellant, cùm ignis careat propriet at ibus, ut qui nec lucere, nec surere, nec pabulo indigere à lus Affertoribus dicatur: Circa putatum Ignem छ Calum fidereum, fic dictum, quod fidera continet, tam errantia, quàm fixa: Huic/upereminent Aque fuperceleftes, of bis calum Empyresum, quod Scriptura lacre est tertium calum, reppectu siderei, quod fecundum, \& Aëri, quod primum eft, exaëre छे putato igne conflatum.

Figuram Mundi phericè rotuindam effe cenfent Philofophi Mundi fic. Aftronomi penè omwes (de adgregato ex Celo fidereo $\sigma^{2}$ Ele-gura Shen mentis est /ormo, Empyreum enim cum Aquis fuperceleftibus ad rick. Theologos \& Scripture Interpretes $\beta$ pect at ) colligunt ǵ probabili.

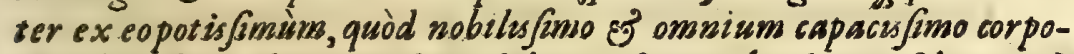
ri nobilisfima of capacisfima debetur figura ( $t$ alis est pherica;) guod coelum ferenis diebus ac noctibus appareat concameratum; quod fiderum motus ab Oriente in Occidentem circularis est. Alias rationes vide apud alios; qus, uti $\sigma^{2}$ allata, tametfi rem non evincant, fatis tamen probabilem reddunt, prefertim propter doEtorsmetiam bonsinum, ne dum vulgi, ea in re confenfum. Meritò ergò Sphera nomen obtimuit Mundus.

Centrum Mundi est punctum in ejus medio conceptum, dे quso Mundicenomnes line a rect a ad/upremam E extimam Cele fiderei juperficiem trum. duct a, funt inter fe equales. Hoc centrum an idem fit cum Terragua centro, poftea difcutietur.

Diametri Mundi Junt qualibet linee recta imaginaria,

$$
C_{3} \text { trans- }
$$


22

Mundi dis transeunces percentrum ejus, $\xi$ utrimque ad ulcimam Cali foderei metri.

Mundi

exis. fuperficiem definextes.

Axis Mundi est illa ejes diameter, tirss quam Calsom cum fideribus volvitur, aut volvi concepitur (poflea rem hancexaminabimus) ab Oriente in Octdentem, ßpatio 24. horarum, motu concitat isfimo, regulari, ó continuo. Huius axis unuse extremum repicit Sepientrionem, alierum Auftrum.

Merdipoli. Poli Mundi fient duo excrema hujus axis: quorum polorum ille, qui est verfus Septentrionem, appellatur sepientronalis, of arcticus, id est, urfines, iconftellatione quadam ipf vicunâ, quee grecè apxi@, latinè urfa dicitur : alter verò, qui est ver/us Axfrum, vocatur auftralis, \& antariticus, idest, arctico oppojitus, ei quod diametraliter ipfo opposeasur.

Mundity-

En typum dictorum, in quo interior of minimus circulas re-

pula. prafentast Terraquam, quam circumdat Aêr, putatus Ignis, Celum fidereum, Aqua fupercelefter, of Empyrewan, quod rotundum effe, ac Colum fidereum cum Aguis /uperceleft ibes circumdare, nunc fupponitur. A est centrum Mundi; linea $B C$ axis Mundi; eadem, $\dot{O} D E$, diametri; $B$ polus arctucus; $C$ polus antarcticus. vide Tce. Exbibet ergo fchema tot um Univer/um plano per centrum $\sigma$ axem nifmi $L$ feEtum.

Fig. I.

Vide Iconifmi $L$.

Circulos precipuos Phere Mundi, quos initio enumeravi, reEig. IL. prefesztat utcunque Jequens Jchema, fimul cum axe, polis, of alis anteaciplicatis.

\section{§.II. De ftellis coli fiderei, earumque nume- ro \& differentiis.}

Y Eli foderei wat uram, proprietates, of conditiones, num кnicum fot, an multsplex; durum, an liquidum; mobile, an ins: mobile; corruptibile, an fecus (fine quorum intelligentia intelligi non polfunt, que Auctor Itinerarii toto in Opere aut Jupponit, aut adfrutt) indagaturi, ab aftris inchoamus, corumque dift inctione, numero, ordine, motu; horum enin cognitione, ó non aliâ via, in cell cognitionem deducimur.

Stellarum igitur Celifiderci dus funt claffes, Fixa five Inerrantes, 


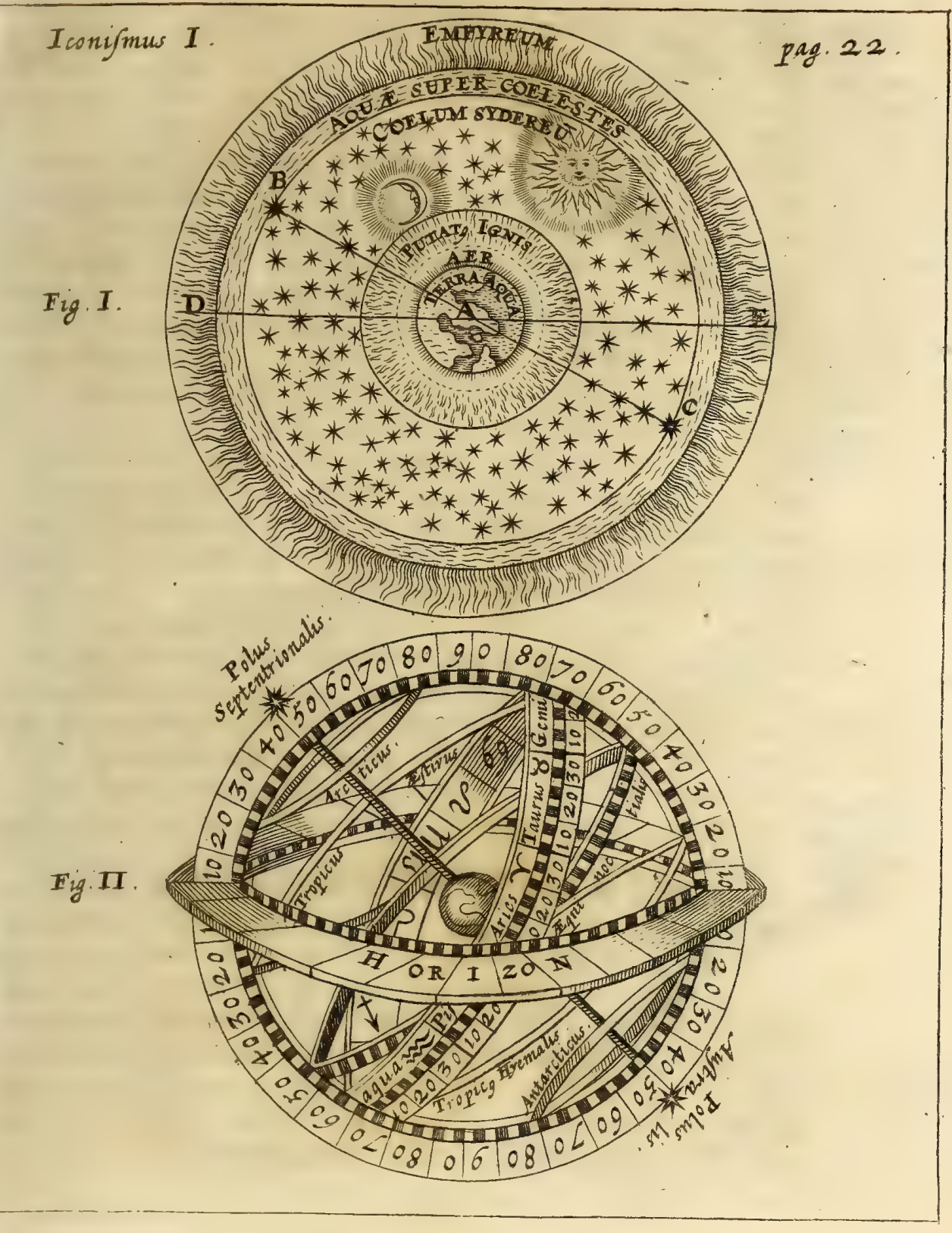




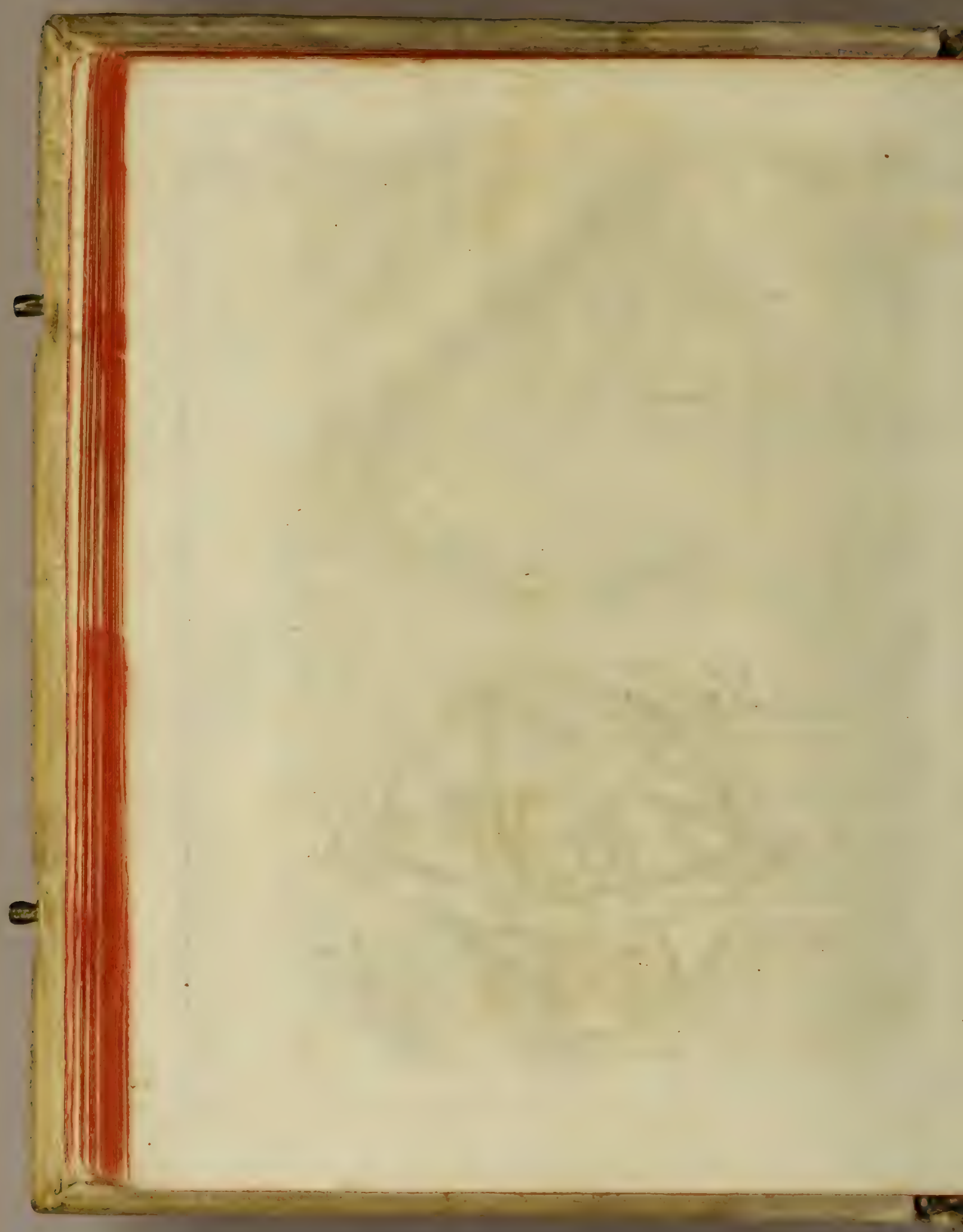


rantes, \& Planeta five Eirrantes. Fixd funt ills, que licet quo. Stekarum sidie moveantur ab Oriente in Occidentem circa Spbaram Ele- dua funt ment arem, non apparenter ob fenfunm ludibrium, ut volumt non- claffes, fixes nulli, fed verè ac realitè, at poftea probabitur; fervant tamen oundem femper fium, candemque diftantiam inter le, perinde ac fo tanguam clavi aurei, aut pyropi lucivomi, colo infix a effent, do cum calo circumvoluta moverentur: unde pars illa cali, in qua funt ejusmodiftelli, nempe fuprema fiderei cali, quam Spharam, octavam, \& Firmamentum Aftronomi appellunt, dicitur Gracis d $\pi \lambda \lambda_{\text {ayn; }}$ h. e. inerrans, (ew ab errore immunis, è quìd flellas continet inerrantes.

Planeta funt ftella ill $\alpha$, que infrafix as quotidiano quidem \& Planete cum fixis communi motu moventur circa Terram, mut ant tamen quanam alio contrario in peciem motu continuo fitum, ordinem, ac diftanti- Feke. ans inter $\int e, \xi$ aे fixis, at que ab Ecliptica buc illucque in caelo vagantur E errant, non quidem incerto os vago, fed mult ùm tamen va-

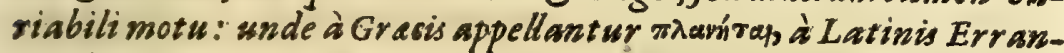
tes, feu Errones, E' Erraticeftella. Horum ab Antiquis obfervati fuêre Jeptem tantìm, nempe Luna, Mercurius, Venus, Sol, Mars, Fupiter, Saturnus. Hifce Neoterici Aftronomi addint quatuor comites govis, of duos Saturni laterones (ita vocant) fubfidio telefcopii, quo carwit ant iquitas, deprehenfos, ut fuo loco dicemus. Tres priores è feptem enumeratis dicuntur Planet a fuperiores; sol medius, religui inferiores. Sol ó Luna vocantur in Sicris Lit teris lumina- Plinete ria magna, non quòd buna reliquas felles mole cor poris, ut Sol fupe-quomodod ret,oum omnium minim a fat, excep to Nercurio; fed quia ob vicinit a. Atellis fixic, tem reliquis major Es clarior apparet. Iidem dwo ab Aftronomis vo diffinguans caniur ma ores, reliqui quinque verò minores. Sol \& Lunamanife-tur.

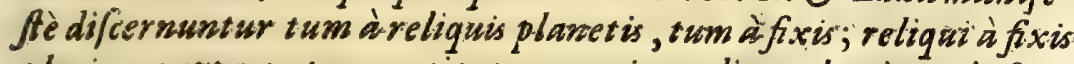
plerisque apparente quantitate corporis, qualitate luminis, \& fitu: zam lunt ad wifum ferè grandiores ftellis fixis; clariùs छे conftanvius lucent, or minus. Jcintillant; $\sigma^{2}$ funt omnibus inferiores. Ihter fe veróplaneta etiam difting unntur is dern notss. Nam Venus poft solem of Lunam apparet onnium inaxima, cui proximus oft Iupiter, Jovealiquanto minor Mars, Marti aqualis Satur- 
nus. Mininisus onnium Mercurins: Leness eft plendidisfma, aureo colore in csu durem diffulo; Gupiter est Veneri fimilis, fed minus plendesis, colore inter aureum \&u argenteum medio; Mars ruti-

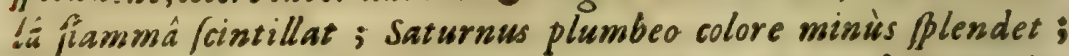
Vernis Pla- Mercurius lucidus est, jed parum candidus. Venus of Mercurius seta, ejus $z_{z}$ nomina.

Solem aliquando precedunt, aliquando Jubjequnotur; $\sigma^{2}$ Verus guidem non recedit ab eo ultra gradus 48. Mercurius autem non uliva 28. Venus precedens manè Solem vocatur Pbofphorus, feu Lucifer; vepperi verò eundem lequens dicitur Heperus, (eu Veßperugo. Thercurius aut /ub Solis nimio plendore latet ferè femper abfconditus; aut fi paululim inde difcedit, tyronibus ob exilitatem. vix obfervabilis est.

Stellarum

fxxarum

Stellarum fixarum numerus videtur effe innumerabilis prinsenerive. mo apect $u$, finudos oculos, E multo mag is fi tubo optico munitos intendas in calum ferenum noct $v$. Qua commodé nudis oculis videri poffunt, ante novum Orbem det ect um, numerat a fueruat folium 1022. Eं diftributa ab Af ronomis premiom in qô. deinde in so. figuras, quas conftellationes, E afterifmos, E? figna coleftia appellant. Easdem diftribuerunt in fex magnitudinum claffes, quarum waximas appellant prima magnitudinis, proximie minores fecunde magnitudinis, dein tertie, quarta, quinte, Eे fexte. confells- Item alias appellant claras, alias obfcuras, alias nebulofas. Post sionum now novum vero detect um Orbem, in parte Cali Auftrali plures alice ordo. nunc vifuntur ftella, antiquis ignot a, quas recentiores Aftronomi ad 12. novas conftellationes reduxerunt, adeo ut conftellationes nunc in univerfum fint 62 .

Harum conftellationum alia funt in Zodiaco, alia extra; $\tilde{O}^{3}$ ba vel recedunt in Septentrionem, $\xi$ Boreales appellantur; vel in Meridiem, $\xi$ dicuntur Auftrales. In Zodiaco funt 12. nempe Aries, Taurses, Gemini, Cancer, Leo, Virgo, Libra, Scorpiws, Sagittarius, Capricornus, Aquarius, Pifces. Primafex in Boream ab Equatore declinant, releque fex in Auftrum. Boreales funt 23. nempe Urfa minor, Urfamajor, Draco, Cephess, Bootes, Corosa Borea, Hercules, Lyra, Cygnus, Ca/2opeia, Perfeus, Auriga, Serpes. tarius, Serpens, Sagitta, Aquila, Antinous, Delphinus, Equicu- 
lus, Pegafus, Andromeda, Triangulum boreale, Coma Berenices: Aufrales funt 27 . quarum 15 . priores /unt antique, relique 12. nove à Recentioribus addite. Nomina priorum /unt, Cete, Orion, Eridanus, Lepus, Canis major, Canis minor, Argonavis, Centaurus, Lupus, Hydra, Crater, Corvus, Thuribulum, Corona Auftralis, Pifcis Notius. Nomina pofteriorum funt, Grus, Phanix; Indus, Pa: vo, Avis Indica, Musca Indica, Triangulum auftrale, Chameleon, Pifcis volasus, Dorado, Toucan avis, Hydrus.

Its antiquis conftellationibus numer ant ur ftelle 1022, ut fuprà Stellarum dixi; in bis $\xi$ norvis aliqui numerant 1225 , alii 1302 , alii 1709 . In in confellater has font 1s. prima magnitudinis, nimirum Arcturus, Lyr Co tiones dispella, Oculus Tari Cor Leonis Cauda Leonis, Spicas, Lyra, Ca tributarum pella, Oculus Tauri, Cor Leonis, Cauda Leowis, Spica Virginis, Os numerus. Pifcis Notii, Cor Hydra, Cor Scorpii, Pes finifter Orionis, Eridani ex. Stella pritrema, Canis major, Canopus, Pes dexter Centauri.

Preter enumeratas, innumerabiles alia telefcopio detect a Stella infunt. Nam Galileus in nebulofa Orionis numeravit 12 , in nebu- wumerabilofa Prajepii 36, in Pleiadibses plures quàm 40, intra cingulum or enfem Orionis ad minimum so, intra patium unius aut alterius gradus Orionis pliss quism soo. Idem obfervavit, Galaxiam feu Vian lacteam nibil aliud effe quàm innumerarum ftellarsm concervationem. Idem fentit de alies areolis cali Galaxia finilibus, $\sigma$ deftellis nebulofis, putatque in univer/um effe ultra 10000. fiellas. Plures adbuc notarunt alii, ut fuo loco dicemus. Certè Sacra Scripiura innuit, ftellas effe innumerabiles, Gen.12, \& 22. Ferem. 33*

\section{§. III. De Cometis; \& ftellis novis.}

$\mathrm{P}$ Rater fixas of erraticas ftellas, hactenus enumeratas, nova fubinde exoriuntur in calo phenomena, $\xi^{2}$ intereunt, \& mnium feculorum, \& noftri maxımè, ac proximè prateriti, teftantur biforia. Horum phenomenorum alia Cometas appellant, aliaftellas novas. Comet as hact enus vifos non fuiffe omnes comete. fublunares, fed mulios jupralunares, irrefragabilibus argumentis, maximè ex Parallax defumptis, probant plurimi ac doatifini Matbematici, quibus denegare fidem temerarium foret. 
Et hiprater motum ab oriente in occidentem mirabiles alios motus \& grros in Caelo fidereo exhibuerunt, modo in confequentia, mod'̀ in antecedentia prog rediendo, \& nunc afcendendo, nunc defcendendo, nunc tarde, mox velociter progrediendo.

stella note

Apparuerunt quoque diverfis temporibus ftelle nove, ite-

Earia. romque dipparuerunt, differentes à Comet is, prorfosque finniles antiquis ftellis Firmamenti. Nam Anno 1572, ad s Idus Nov. apparuit in Calfiopeia novum fidus aguale V'eneri quoad quantitasem vifibilem; per Decembrem autem Fovis fidus emulabarur; Januario autem Anwi 5573 , ftellis prime magnitudinis paulò majus; fed Februario of Martio aquale; $E^{2}$ ftellis fecunde magnitu. dinis Aprili \& Majo; Junio \& $\sigma^{2}$ ulio ftellis tertie magnitudinis; in fine anni vix excedebat quint am magnitudinem; tandem. Anno 1574 , in Martio evanuit. Iterum Anno 1604, Die 9. Octob. apparuit novum fidus mirè rutilans in Serpentario, magnitudine apparente adaquans Venerem ; o evanuit Anno 1606, initio Februarii. Et antea Anno 1600, apparuit in pettore Cygni novaftella tertic magnitudinis, duravitque usque ad Annum 1621. Et tamet $\sqrt{2}$ evidenter demonftratum nondum fit, quanta barum novarum flellarum diftantia ì Terra fuerit, probabilius tamen ac ferè evidense st, illas fuiffe non folium fupra Lunam, Jed fupra omnes Planet as, or inter iplas ftellas fixas, ut infrà fuo locoiterum dicetur.

\section{§.IV. De motibusftellarum, motuumque varietate.}

Uplex pracipuè ab Aftronomis notatus est motus in fiellis; 1 unus communis omnibus, quern \& Primum; alter propriws, quem E' Secundum appellant.

Matmofet- Larum exercitus movetur quotidie ab Oriente per meridiem in

Primus of communis omnibses ftellis motus est, quo totsus felmus 8 com-Occidentem, indeque rurfus per mediam noct em in Orientem.; sunnis. unde or motus Diurnus Jes 2 uotidianus appellatur. Hic morus eft veress ac realis, non apparens ex eo, quod Terra moveatur ab Occidente in Orientem, us nonnulli volunt, guos poltea refutabimus. 
mow. Non est perfecti circularis \& in fe rediens, fed piralis phericus, quia ftelle son egrediuntur quotidie ex eodem puscto Horizont is, nec in codem occidunt, nec femper babent edndem altitudinem meridianam; fed hac omnia quotidie mut ant ur, valde lenfibiliter in planetis inferioribus E' sole, minùs fenfibiliter infuperioribus, infenfibiliter in ftellis fixis. Patent hacpartim Jenfu manifeftè, partim obfervationibus Aftronomorum.

Secundus É proprius ftellarum motus est ab Occa/u per me-Mosus falridiem in Ortum, indeque rurfus per mediam noctem in Occa- Larumfsfom. Notarunt enim Aftronomi, non tantùm Solem Eे Lunam proprim. (quod omnibus patet) fed reliquos etiam Planet as non babere femper eundem inter fe fitum or diftantiam, Jed Lunam uno die effe conjundt am cum Sole, alio ab co rece Jiffe verfus partes orientales eandem Lunam, caterosque Planetas omnes elfe uno die cum tali ftella fixa conjunctos, aut in tali gradu alicujus figni Zodiaci exiftere, alio verò die difceffj]e ab illa ftella, aut gradu, verfus partes orientales. Notarunt praterea iidem Aftronomi, diftantias ftellarum fixarum ì punctis solftitialibus of Aquinoctialibus Coeli ftellati non manere easdem femper, fed crefcere \& angeri fecundìm fucceffionem fignorum Zodiaci ejusdem Cali fellati, boc est, ver/us Orientales partes progrediendo, ita ut plurime ftelle, que aliquo tempore fuerunt ante puncta folftitialsa $\delta^{3}$ aquinodtialia, nunc reperiantur post ip/a; alia verò. qua ab ippis verfus occidentales partes remota erant, propius ad illa acce/Jerint. Hic motus, qui tardisfimus est, vocatur motus in longitudinem, $\xi^{\xi}$ in con/equentia fignorum Zodiaci, nixiorums ab Ariete in Taurum, à Tauro in Geminos, $\xi^{\circ} c$. Et propter bunc zodiaci motum Aftronomi ftat uunt duos Zodiacos in coelo ftellato, unum duo isceintelligibilem duodecim signorum inchoatum à puncto equino-lo. Cii verni, alterum vifibilem duodecim Afteri/morum incboarum à prima ftella afterifmi Arietis. Pradict us motus ftellarum ab Occidente in Orientem non est realis, Jed apparens tantùm, propter retardationem, è quìd non omnes ftelle motu fuo ab Motus reOriente in Occidentem fimul integrum circulum leu fpiram per. tardationis ficiant, fed guando Sol v. g. fuam jam perfecit, Luna nondum, fellarum. $D: \quad$ per- 
perfecit fuum, led retrò manet, ideo retrogredi nobis apparet ab Occtente in Orientem. It a bunc motum explicant plurimi antiqui ac recentiores, quos in Mundo Mirabili citabo; \& vix potest aliter commodè explicari, ft ante Cali fluiditate, quanı §y. Fequenti cum Auctore nof roftabiliemus. De aliis planetarum notibes fermoerit in Cur/u Matbem.lib. 8 .

Hunc retardationis motum $P$. Kircherus, cujus fententiam, per litteras exquifiveram, Jwo etiam calculo comprobat : nam in litteris ad me Româ datis boc Anno 1660, die g. Apr. ita foribit: Jam verò ad ea, qua R.a V.a fcire defiderat, progredior. Et primò quidem quod ad motes Mercurii, Veneris, Martis, \&c. circa Solem attinet; rectè tenet, \& fummopere approbo fentenriam eam, quâ eos unico motu fimplici, at fpirali, in profundo atherei moveri exiftimar; cùm, ut rectè dicic, proprius ille fiderum motus, ab Occafu in Ortum contra fignorum ordinem, aliud dici non poffit, nec debeat, quàm retardatio quadam, quâ ex tarditate \& lentitudine motus non præcisè locum, unde evoluta fuerant, atcingere poffunt fpacio 24. horarum; \& confequenter retrò multiplicatis intervallis fingulis diebus, vel aliquot minutis, ac gradibus, prout terra viciniora funt, manere coguncur. Hac Kircherus; qua in Mundo Mirabili meliùs explicabimus.

\section{V. De natura Coli fiderei quoad fluidi-} tatem ac foliditatem.

Calum an fit fluidum ac permeabile. Solidum apud Matbematicos idem est ac corpus trinam habens tem; apud Phyficos verò fignificat corpus durum ac impenetrabile, guale est marmor, es, cryft allus, \&o fimilia. Fluidum vocamos, quod pervium acpermeabile est, ut aër, aqua, ơ alis. 2uafio est antiquifima inter Philofophos of Aftronomos, num fidereum $\mathrm{Ce}_{\boldsymbol{B}}$ lum durum fit in acceptione fecund a, an fluidunn ac permeabile; nec adhuc, ex toto faltem, dirempta lis est.

Prima opinio vudt, totum Crelum fidereum, à Lune concavo, $v^{\circ}$ infimo Elementaris Sphara confinio, mogue ad convexam. 
\& fupremam ejus fuperficiem, Aqwis fupercaleftibus contiguam, effe folidum, $\sigma^{3}$ inft ar cryft alli durum, impervium, \&' impermeabiLe: ftellasque ipfi in fixas elle ut nodos tabule, aut gernmas annulo. Ita fentit Arift. lib. 2. de Caelo à tex. 43. ad sz. \& Anaximander apud Plutarchum lib. 2, de placidis Philof. cap.16. quos lequuntur plurimi ex Theolog is \& Philolophes apud Ricciolum tib. g. Almag. Novi cap. 7. num. It

Secunda opinio vult, totum effe fluidum, pervium, ac permeabile aftellis, velut aër abavibus, \&ु aqua à pifcibus. It a Priforum aliqui apud Ariftot. loc.cit. Ev innumerabiles antiqui ac neoterici Theologi, PhiloJophi; ac Mathematici apud eundem Ricciolum loc.cit.13.2. Eandem docent quàm plurimi Sancti Patres, \& Sacre Scripture Interpretes apud eundem, $\Xi^{2}$ apud scheinerum in Rofa Urfana; quorum nonnullos adducit Auctor in /e guenti Pralsafione Parenetica, qui in eadem bac fecund a fententia est.

Tertia opinio wult, durum effe coelum quoad partem fuperiorem Aquis fupercoeleftibus contiguam, of ftellis fixis confpicuam; fluidum verò guoad inferiorem religuam, cont insentem planet as. It a fertit Ricciolus locicit, nusw. I3. cum nonweslis antiquis E' recentioribus, quos cit averiat rums. 2.

Prime opinionis ratio fumitur Primơ ex Sacra Scriptura: Calum foliINam $306.32 . v+18$. Caelum dicitur folidiffimum quaff are fufum. dum effe,qui Et IJa. sI. v.6. dicitur, quòd tanquam fumus liquefcet. Et Hebra. Gr quomodo 4. dicitur, Chriftum penetrafle colos. siquafi are eft fu fum CaIum, fliquefcet tanguam fumus, fi penet ratum ac pervium est; ergo durum est. Secundò ex nomine; quod Calo inditur ì Sacra Scriptuara. Nawi Gera, 1. v. G. appellatur latinè Firmamentum, grace 5epírus feu folidum, bebraice Rachiah, quod expanfionem fev expan/un cum aliqua firmitate ouconfolidatione fignificat. Tertiơ ex officio, quod babet finftentandi Aquas fsopercaiteftes, ne defiuani, $\sigma^{3}$ deferendi Sc ellas fixas uniformit er $\xi^{2}$ cum eadem femper diftanria inter fe. Quartò ex abfurdis, qua fequerentur, ff folidum non

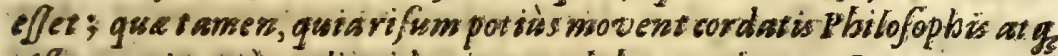
Afronomis, griàm aliguidewincant, labens aritto. Iegat ex, gni volet, apied Riccialmen loc cit. 
Celum fide. Tertia opinio utitur tertio pracedente argumento delumpto ex officio Celi, ut probet durum effe quoad partem (speriorem; 3 ? rarionibus fecunde fententia, que /equuntur, ut probet fluidum effe. quoad partem inferiorem.

reuns effe reum effe inter ip fa fixa fider vife funt nove ftelle, que poft aliquod tem-
fuidum,
qui 8 quomodo pre- genite, five de novo cò adduct $x$, cali fluiditatem fupponunt; nebont. que enim celum folidum penetrare potuiffent. 2 wòd verò Pbilocepea nimis prafidentes, dicant fuifJe miraculosè a $D E O$ product as atque deftructas, mag is pertinaciam, quàn folidam fapit Philofophiam. Secundò, quia plurimi Cometa /upra Lunam fuerunt vifi, ut diximus ibidem, \& fatentur tam Veterum, quàm Recentiorum plurimi : ibi ergo vel orta corum materia, vel aliunde è delata, ibique interierunt; quod iterum fine Cali liquiditate fieri nequit. Terciò, qui hujusmodi nova ftella of Comese interdum valde extraordinariis motionibus per Calum discurrerunt, modò afcendendo, modò defcendendo, nunc in Auftrum, munc in septextrionem progrediendo. Quartò, quia Venus छs Tercurius moventur motibus propris circa Solem tanquam centrum, $\sigma^{3}$ aliquando Supra, aliquando infra Solem exiftunt ; o Mcercurius quidem piras valde implicatas ac tortuolas circa eum defcribit. Hec fufius explicabuntur in Itineve in Venerem, of Mercurium. Quintò, quia Mars etiam, cujus intricatis fimses, E' mirabiliter perplexses est motus, interdum infra solem defcendit, $\varepsilon^{0}$ Patium ipfo deputatum profunde interfecat, ut ex incremento magnitudinis apparentis, ex parallaxi, $\sigma^{2}$ ex aliis fignis ac obfervationibus evidentisfimè colligitur, ut melius explicabi. tur in Itinere in Martem. Sexcò, quia Saturni laterones, of jovis comites mirabilibus motibus prope aut circa illos Planetas moventur, ut videbimus in ltinere in Jovem of Saturmum. Septimò, quia praftantisfimi Matbematici recentiores omnes, pavecis exceptis, qui tertiam fententian defendunt, cum multis antiquis Patribus, OKathemsaticis, Philofophis, geli liquidutatem propugrant. 
pugnant, folidiratem oppugnant ac rident; quos fuse citabo in. Mundo Mirabili. Octavò, quin, admißà sali fluiditate, omne afrorsm motus, novarum fiellarum Eo Cometarum fupralunarium altitudines gyri, $\vartheta^{2}$ agitationes facillimè explicantur; admißà verò loliditate vix, aut ne vix quidem, quoscunque affirges circulos excentricos, epicyclos, excentrepicyclos, bomocentrepsigyclos, aliague fimilia monfira. Nonò, quia numeras \&s motus calorum, admißâ coeli duritie, introduct us ad falvanda caleftia phenomern, est omnino incredibilis, Es imperceptibilis, introdu-Cati folidiCtus olim, \& in populares Pbilolophos ac Matbematicos $\beta$ arfus ab tatem quiEudoxo, Calippo, on Ariftotele, ac poftea à femiprifcis ac femibar-duxerint. baris Tractatusun Sphare Scriptoribus; qui ut Mundo res miras vendirarent, tales celorum confructiones, exientricis $छ$ epicyclis veris ac realibus refertas propalarunt; $\xi^{2}$ quas Veteres appellavêre Hypothefes, illi tanquam Thefes few affertiones abfolutas, fine neceffitate, fone previa ob/ervatione, fine ulla evidenti, imò ne probabili quidem ratione affump ferunt. Decimò, $f \mathbf{f}$ Celum

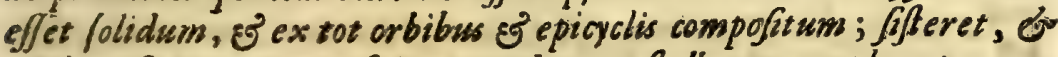
mirè reflecteret as refringeret lumen fellarum ac planetarum. ut ex Opticis conftat, ratione. Cujus refiexionis ac refractionis mirabiles colores ac veluti irides continui in celo apparerent. Preterea fogure ac magnitudines fiderum, mutusque eorum difantic poffim ac notabiliter variarentur, ideoque felle non apparent ea in loco, in quo revera effent, bs in quo ab Aftronomis predicerentur addatum tempus apparituras. Undecimò, quia Califinidi-

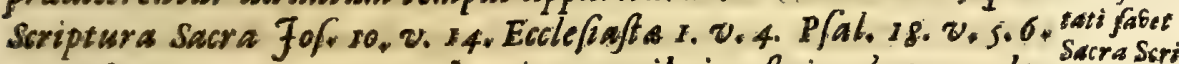
7. Habac. 3. $v$. J. motum Es quietem tribsit aftris, of non calo sacra Scrio guod evian faciunt multi ss. Patres apud Schsinerum lib. 4. Rofe. Urfans par. 2. cap. 26. quorum aliquos citat Luctor nofter in Praluf. Paranet. Es plurimi citabuntur is nobis in Mundo Mirabilit.

His, aliesque rationibus adductus amplector aum Auctore cali folsdiseftrobane fecusdam fententiam.

iateris ad.

Ad Primam racionem in contrarium Repondeo, verba illa fruentium apud Iob zon effe spiritus Sarkiti, Sed garruli Eliu, amici Job, qui huntur. 
etiam cap. Jequenti reprehenditur a $D E O$ ut involvens fentencias fermonibus imperitis. Verba Jaia fignificant, quòd colum. potius liquefcet tanquam fumus, \& evane cet, quàm deficiant promiffiones DEI. Chriftus penetravit oclum, ut fagitta E? avis aërem, qui fluidus est. Ad fecundam racionem Reppondea cum SS. Patribus, quorum nonnullos citat AuCtor nofter infrì is Praluf. Paran. Calum dici Firmament wm, septope, Kacbiah, quia expan/um eft cen terminus of limes intransgre]jibilis, à $D E O$ confitutus inter aquas fuperiores $\sigma^{3}$ inferiores; $\sigma^{2}$ quia trinam dimenfoonem babet.

Ad Tertiam rationem Dico cum iisdem SS. Patribus, etiam caelum liquidum fuftent are poffe aquas, ut ä̈r fuftent at nubes. StelLe autem ita ordinate movent ur fecundùm leges à Deo prafcriptas, idque vel à propries formis, vel ab Intelligentiis, vel immediate ab ipfo DEO, st poftea examinabimus.

\section{§. V I. De numero \& motu Colorum.} Calum fiunicum.

$\mathrm{E}$ $X$ bis conftat $I$. anicum offe Calum fidereum, non multiplex, ut contraria fingunt fententia AuCFores. Mente tamen dividitur in tot coslos, quot funt regiones feu fpatia, in quibus planete Ev ftells exiftunt, of fuos gyros exercent. Sic Colum Luns, solis, Joves, Saturni, ftellarum fixarum vocamus patium, in quo est ac movetur Luma, Sol, E'c. Colum ftell arum fixarsu, tametfo innumerabiles font, necomnes in eadem fuperficie, fed alie alis altiores ac profundius immer $\sqrt{2}$, unicum facimus; $\sigma^{2}$ Firmamentum, Oct avum Colum, acprimum Mobile appellamus: Planetarum verò caelos dicimus fecunda Mobilia.

Colum li-

Conftat II. Calum ipfum liquidum non moveri ab Oriente quidumnon in Occidentem, nifi quatenus fcinditur, fecundim partes protrumpisturab ditur, trabitur a fellis in illo motis ab Oriente in Occidentem., Orzente in Occidensem. co modo, quo Aëreum Calum ab avibus in illo volantibus fcindi. tur, propellitur, \& ponè trabitur fecundium partes. Sola igitur fidera, non Colum totum, moventur quotidie ab Oriente in Occidentem circa Terram; $\sigma^{2}$ alia quidem atiùs, alia tardius circulum integrum few Jptram perficisnt, ideogue hac ab illis retroce- 
scholiafte.

dere ver fus Orientem putastur. Prater bunc fiderum motum, qui Primus vocatsur, aligue nibilominìs ftella alios peculiares motus, fed cum Primo insplicatos babent; cujusmodi eft Mercurii ac Veneris circa Solem, Jovis comitum circa ipfum, Lateronum Saturni prope ip fum, de quibus /uis locis infra.

Tamet fi vero calum non moveatur modo dicto, nibilominùs calum lidoctrine causâ concipimus ip um unà cum/tellis inharentibus move-quidun ri quotidiè $\sigma^{2}$ continuè ab Oriente in Occidentem, eodemque tempore moberi conftellas proprits $\sigma^{3}$ oppofit is motibus moveri ab Occidente in Orientem, Oriente in aut aliter, prout phonomena motuum exigunt. Lege, qua dicimus Occidentew. in Curfus Matbem. Lib. 7.part. 3. cap. II.

\section{§. VII. De coeli compofitione, \& corru- ptibilitate.}

YOElum corpus effe fimplex, id est, non compofitum ex materia Catum of Go forma realiter distinct is, multi cenfuerunt antiquorum porpus con
philofophorum : aliitamen antiquorum, of recentiores communiter affirmant, materiâ छ' formê inter fe reipsâ distinct is conflare; o. meritò, quoniam boc con formius est auctoritati pluriumP at rum, Doctorum Ecclefie, Scripture Sacre Interpretum, ipfaque divine scripture, ut probabitur in Mundo Mirabili.

Mat eriam porrò cali ejusdem rationis effe cum fublunarium Maserie rerum materia, non folum probabile, fed ferè certumn eft ac in- cjus cadem dubitatum, quia mixt um quoddam est, \& corruptioni fubject um, noribus. ut poftea probabitur. Cujus tamen nature fit, aut ex quo feus guibus element is mixtum, non convenit inter omnes. Nam aliqui putant, calum effe igneum, imò ipfum illud elementum, quod vocamus ignem, purum tamen, $\sigma^{2}$ ob raritatem fue fubftantie non idoneum ad comburendum. Alii verò cenfent elfe aqueum, alii ä̈reum. Auctores ac rationes afferentur in Mundo Mira-colum ef bili. Ego interim exiftimo, totum colum fidereum usque ad atbereum, Aquas fupercaleftes nibil aliud effe quàm puriffmum ac liquidis- tialiter aiofimum atherem, qui revera \& effextialiter est aër purisfimus ac reum. defecati[fimus, quem proinde eodem jure ignem vocaveris, quo jure ignem vocant multi aёrem purum, qui inter Lune conca- 


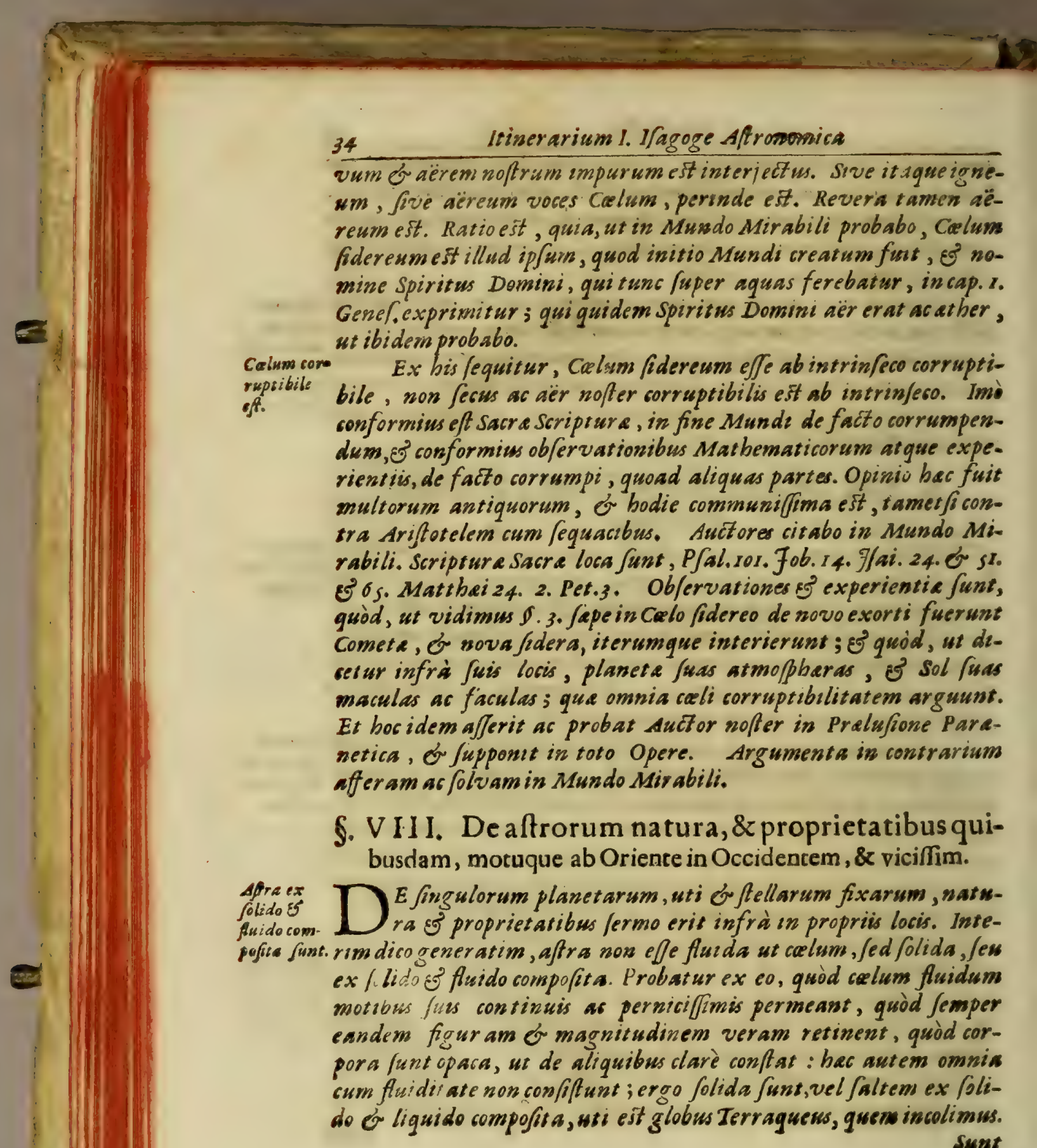


Scholiafte.

Suni etiam corpora corruptibilia, quia ex eadem materia. Afracm quá calun, conft ant; ex ea enien prajacente format a /unt die Mun ruptibilie di quario, ut probabimss in Mundo Mirabili. Eadem corruptibi. lisas probatur ex folaribus maculis, ex planetarum atmopharis, excometarum fuperlonarium ac novarnom fellarum ortu G'inieritu, alisque fimilibus fignis.

sunt praterea diverfis qualitatibus fecundis, fo mixtorum Afra quaticorporum propries predita, nempe sol calore, Luna bumiditate, catibus leMars ficcitate, alia aliis qualitatibus; quas cum in his inferioribus dita. producant, necefe est, cas inter fe contineans. Sed boc meliùs pate. bit ex fequentibus.

Afra moventur ab Oriente in Occidentem in calo liquido Atra moper fe, tdeft, mon raptata à motu cali, fue deinde à propries move- Gentur in ant ur formis, five ab Intelligentis; quod infrà examixabimus. Et culo liquis. quamvis videantur moveri preterea codem etiam tempore ab Oc- in Occidencidente inOrientem, motus tamen ille, ut fuprà diximus, non est tem. realis, fed folim eft retardatio quadam. Hanc itaexplico.

Fingamus calum totum, aut Equinoctialem circulum, mo. Afrorum verivealiter ab Oriente in Occidentem patio-24. borarum aquino matus ab ctialium, Afrum verò quodlibet moveri fmiliter ab Oriente in $0 \mathrm{c}$ in Orien. cidentem, fed lentiùs quàm celum; tumc punctum coli, in quo bodie tem eft foaltrum exiftic, in fine 24 . hore abjolvet integrum circulum, aftrum dim retarveró miximè, fed aliquantulicm retrò manebit; ad cum modum, trarismequo fo rota aliqua circumrotaretur patio 24 . hor arum, mu/ca verò tw. circa rote peripberiam per eandem viam ambulans lentuis moveretur quaim punct um rote, in quo initio extiterat, tardius abfolveret istegrum circulum quàm punctum illud rota, Éidè retrò manerer. Quoniam igitur aftra lentius moventur circa terram mots reali, quaim puncta cali, in quibus exifebant in principio motus, motu inaginario ; retardantur aftra, $\sigma^{2}$ propter retardationems reptare credunt ur ab allertoribus foliditat is sali.

Alia, que ad aftrorum naturam, proprietater, on qualitates pectant, maximè verò ad propria ip forum centra, explicabuntur in fequentibus. 


\section{§. IX. De variis Mundi Syftematibus.}

$\mathrm{Q}$

Va de Syftematibus Mundi hoc loco dicemus, motibusque planet arum circa Solem; intelligenda funt de motibus fecundis ab Occalu in Ortum, non de primo ab Ortuin Occa/um : bi enim ßpiral (unt, ut fapè diximus, or omnes funt circa Terram, modo la. xiori, modo arctiori circuitu; quo fit, ut nunc Terre propiores fint planeta \& perigai, nunc remotiores \& apogai. Interim tamen Mercurius, Venus, \& Mars, per varias alternas retardationes as incitationes motuum ficorum piralium Solem ambiunt. Matbematica igitur Jeu Aftronomica Syftemat a dabimus, non Pby/icum; hoc enim guale fit, patet $6 x$ dict is, or melivis ex dicendis conft abit.

SyftemaMüdi quid fit.

Syftema Mundi boc loco appellamus coordinationem feu compofitionem magnarum Mundi partium, boc est, Elementorum, ftellarum, ac Calorum, quoad ordinem ac fitum eorum inter fe 6 repect u centri Univerfi. Qwa in re dua funt extreme fententia. Aliqui enim Terram cum elementis collocant in medio Univer $\beta_{2}, \beta_{1}-$ ve mobilem, five immobilem, circaque eam rotant planet as \& ftellas fixas in circulis five concentricis, five excentricis. Aliiveró Solem in Mundi centro collocant immobilem, E' circa eum Terram cum element is \& planet is mobilem, ftellas verò fix as immobiles. Viramque breviter explicemus.

Syperme ax-

Primum igitur ac vetuftifinum Mundi Syftemaest, in quo siquum. Terragueus globus in centro Musdi immot us quiefcit, circaque eum Element a $S^{2}$ Coeli co ordine collocantur, quem characteres planetarum indecant in Syftemate Ptolemaico, nimirum ut primo ac infimo

vide Ico- Loco fit Luna, dein Mercurius, Venus, Sol, Mars, Jupiter, Saturnus,

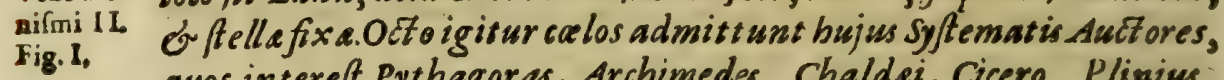
quos intereft Pythagoras, Archimedes, Chaldei, Cicero, Plinius; Prolomeus, plurimi Arabes, Alphonfini, Purbachiani, E' communiter alii usque ad Maginum Eे Clavium; quorum tamen aliqui

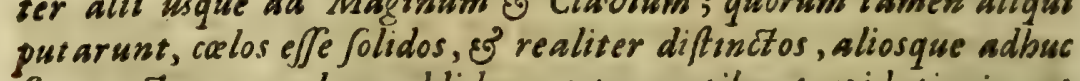
fupra octavum colum addiderunt pro motibus trepidationis, ut diximus in Carfu Matbem. lib. 7. part. 3.

securdum Syftema ponit fomiliter Terraguan cum Elemen- 


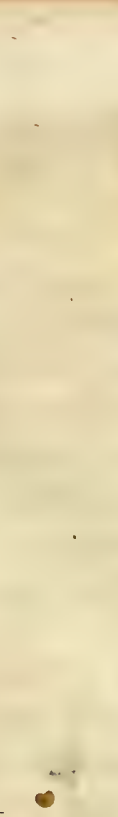

\section{$s$}




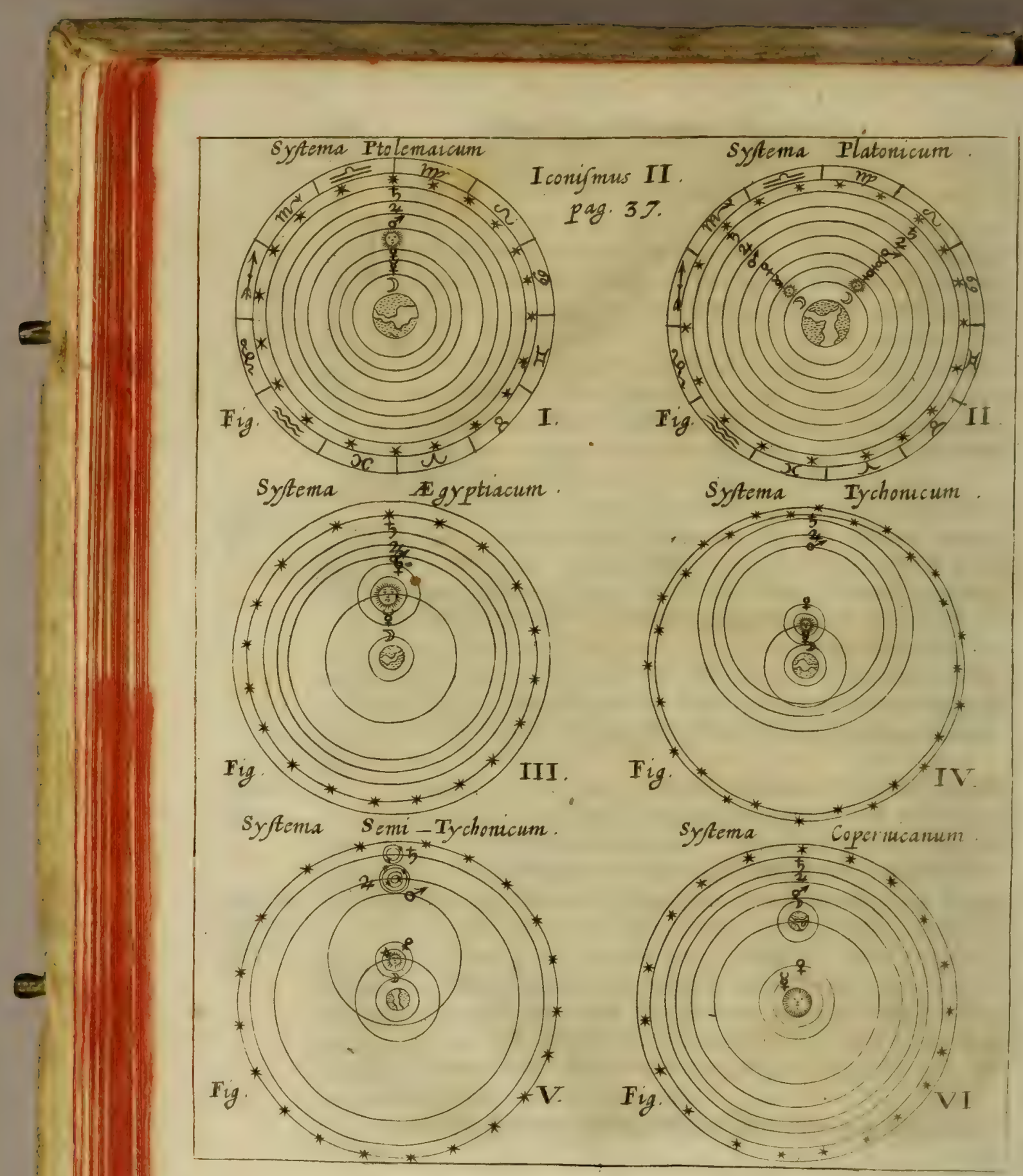



tis in centro Mundi immobilem, circaque Element arem Bheram, syfemapla planet as ac ftell as fixas, fed diverfoor dine aे predecto quoad aliquos, ut apparet in Syfemate Platonico. Nam Plato cum Ariftotele, Eu-Vide Icodoxo, Calippo, Theone, Gebro, ponunt immediatè Solem fupra Lu- nifmi II. nam, deinde Mercurium, Venerem, Martem, Jovem, Saturnum, E' Stellas fixas; alii verò, ut Porphyrius, Apulejus, Marfilius Ficinus, Auctor libelli de Mundo ad Alexandrum, \& quidam Plat onici, poft Lunam ac Solem collocant Venerem, deinde Mercurium, reliquis priore ordine retent is. Utramque feriem Syftema Platonicum exhibet. Virumque quoque Syftema orbes totales planet arum concentricos Mundo facit; qua lequentur (Copernicano excepto) partim concentricos, partim excentricos faciunt.

Tertium Syftema ponit Tellurem in medio Mundi cum elementis, ut duo priora. छ' circa hac ponit primum Calum Luna, fecundum Solis, tertium Martis, quartum Fovis, quintum Saturni, fextum Syfems stellarum fixarum : circa Solem verò, velut circa centrum, collocat Isgptiact. Mercurii \& Veneris Epicyclos, fed ita, ut Mercurius illum circum- Vide Icoeat arcziore, Venus laxiore gyro, at que adè modo infra Solem fe-nifmi II. rantur, modo Jupra; ex qso fit, ut juxt a boc Syftema Mercurius fit Fig. III. aliquando Terre vicinior aut remotior quàm Venus, alidss verò Venus quàm Mercurius, ut confideranti predictum Syftema pater. Fuit boc Syftema Egyptiorum; cui Jub/cripsêre Vitruvius, Martianus Capella, Macrobius, Beda, \& Argolus; quorum ultimus tamen vult, Terram moveri circa proprium centrum ab Occidente in Orientem.

Quartum Syftema babet Terram cum elementis in medio Mundi immobilem, Es circa eam primò Luna, deinde Sol, demum Syfema $T$ y. Sphara fixarum gyratur, atque adeo Terra centrum est etiam chonicum. centrum curfus Lunaris, Solaris, E\$ Sphere fixarum: At reliquorum quinque planet arum centrum est ipfe sol, ut apparet in Syfte- Vide Icomate Tychonico. Et Mars quidem it a Solem ambit, ut in oppofi- Fig. IV. tione cum sole perigeus fact us infrasolem defcendat, ejusque orbem profundè ingrediatur atque interfecet, ac propior Terre fiat quàm ipfe Sol. Excogitavit hoc Syftema Tycho Brabe, nobilis Aftronomus bujus of prateriti feculi, guem fequitur Longomon- 
tanus, ( Sed addito Telluris motu diurno circa centrum Jumm ab $\mathrm{O}_{6}$ cidente in Orientem ) Scheinerm, Blancanus, o plenique ex noftro Societate.

Sypema Semi-Tychonicuen.

Vide Ico. nifmi II. Fig. V.

Quintum Syftema habet omria cum Tychonico communia, exceptis Orbibus Saturni, \& Fovis, quorum centrum non ponit Solem, fed Terram, ut apparet in Syftemate Semi-Tychonico, quod indicat P. Joan. Bapt. Ricciolus in silmag. Novolib. 3. cap. 6. EJ lib. 9. Sect.3. indeque probabile cenfet, quia Sat wrnus duobus Lateronibus, of $\mathcal{J} u$ piter quatwor Comitibus up/um ambientibus, fripati, vidensur effe Planete primarii, of Monarchiam fuam in Jwo Murdo ac Calo exercentis, non minus ac Sol Mercurio, Fenere, ac Marte tanquan fat ellitibus fipatus in fuso Calo.

Syferma Co pernicanw. Sext um Syftema ponit in centro Mundi Solem immobilem, fal. Vide Icoifmi II. Fig. VI.

diebus quod motum translationis; of circa esm proxime Mercurium diebus 80. fuam revolutionem abfolventem; deinde Venerem noniin Orbe annuo (us vocant) annuam dierum $365_{2}^{\frac{1}{2}}$ revolutionem ab Occaf $\mathrm{O}$ Oriestem verfus peragentem, (bocest, in fimili Orbe, ant circulo, quali Syftema Ptolemascum, \& Egyptiacum, E' Tychonicum ponunt Solem annuâ periodo revolut um ) fimulque motum diurnum circa funs centrum etiam ab Occidente in Orientem |patio 24. horarum: Luna verò ambit Terram ó Element a menftruâ revolutione: deinde iterume Mars circa Solem tanguam centrum Univerfi revobutionem fuam bimam; deinde fupiter duodennem ; of tandem Saturnus tricennem peragunt; Fixarum verò Sphar a ultima prorfus immobilis eft; $\xi$ adeo vafto intervallo à Saturni sphera distans, ut Terre Orbis annums fit puncti inft ar ad illam. Hoc Syftema dicitur Copernicasum, à Nicolao Copernico Borufjo, qui illud olime ex parte excogitatum à Philolao Pythagorico, of Ariftarcho Samio, ac deinde relufcitatum a Nicolao Cu/ano, tandem perfecit, ac pluribus argumentis, ingeniofisque byporbefibus fulcivit; quem deinde fecwti funt penc̀ omner Matbematici Acatbolici, ङ nonnulli ex Catbolicis, quibu nimirnm ingenium of calames prurit ad sovs vendit anda.

Hac funt pracipus Syfemata. Nos ex amnibus cligimes cum Ando 
Axctore noftro Tychonicum, Atatsimusque Terram omnino immo- Cherianum,

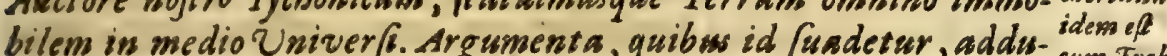
bilem in medio Univer dib ximus in Curfu Mathern. lib.7. part. 2. Copernicanum igitur 0- nica. mnino rejicimus, tum ob alias rationes ibidem infinuat as, tum quia Sacre Scriptura adverfari videtur, que Terre quietem, Soli É afrris motum attribust. Meritò ergo probibitum est à Congregatione Rituum Roma Anno 1616. die s. Martii, de mandato Pauli V. Summi Pontif. Eु iterum Anno 16 33. die 22. Funii, de mandato Urbani VI II. itidem Summi Pontificis , fi abfolute, E' non wt bypothefis affumatur.

Hec Iufficiant pro Introductione; qui plara defiderat, adeas Spher e Scriptores, ob citatum lib.7. Curfus noftri Mathematici.Nunc ad Auctorem noft rum revertanur.

\section{PRELUSIO PARANETICA ALCTO-}

\section{RIS KIRCHERI;}

In qua luculenter docetur, Opufculum boc nibil peregrinum habere, quod non Sacrarum Litteraram, Jancitorues Ecclefis Dofitorum auctoritatibus, of irrefraga-

bilibus obfervationum experimentis

$$
\text { confentiat. }
$$

I. TINER A R I U M exftaticum adornaturus, Lectori

Q 1 curiofo meam priùs mentem circa noñulla fitu pror6. Ator aperiendum à nobis coeleftium regionum iter cum fperato Dogrinat fructu, abditasque Nature alcior is femitas inoffenfo pede percur- bujus opusreret. Multa, fateor, in eo occurrunt, qux haud immeritò Natu-na nacree r $x$ inexperto nova penitùs, paradoxa, \& inaudita hucusque vide- Scriptwre, ri poffint; qua tamen, tantum abeft, uc ralia fint, potiùs nihil adeò ex experimbus inufitatum, \& in toto hoc noftro ratiocinio mirabile occurrat, sis, E ratioquod non vel ipfis facris coeleft is Oraculifoncibus, Sanctorum $\mathrm{Pa}-\boldsymbol{n i}$. trum doctrinx, \& unanimi propè Aftronomicorum hujus temporis Philofophorum opinioni magna ex parte confentiat.

II. Quod ut demonftretur, quatuor mihi hoc in Itinera- 2ustwor 
In Itiners.

rio probanda funt; quafi, uti fpero, rectè, \& absque omni fu-

co \& finiftri affectus perturbatione fincerè xftimentur, certè integram me fidem veritatis in Mundi opificio, corporumque ftructura coleftium elucefcentis, obtenturum confido. Primum eft, in coelefti Mundo, fi fiderum corpora excipias, nullam præterea foliditatem admitci aut poffe, aut debere, atque adeò coelum totum ab aëris regione fuprema usque ad coelum empyreum, liquidum, \& athereum efle, Secundum eft, nullum effe corpusin natura rerum, quod alcerationibus \& corruptionibus quoad partem non fit obnoxium, atque adeò omnia fiderum globofa corpora ex Naturz quadam neceffitate hifce alterarionis legibus, utpote fine quibus confiftere non poffint, fubjeAta effe, coelumque adeò cum univerfis corporibus fuis corruptibile effe. Tertium, omnia fiderea Mundi corpora ex quatuor clementorum mixtura modo ipfis congruo, non fecus ac terram, compofita effe, diverfistantùm proprietatibus qualitatibusque; uti etiam fingula fuis propriis centris à fupremo Mundi Opifice inftructa fuiffe. 2uartum, fecundùm analogiam quan. damomnia Mundi corpora eâdem fe ratione ad invicem habere, quâ Sol, Venus, Mercurius, Luna, Terra ad fe invicem habenu.

II I. Eadem hæe quatuor fusè , \& ferè integris Voluminibus infignes Viri, P. Jobannes Baptifta Ricciolus in Almagefto novo, \& P. Chriftophoras Scheinerus in Rofa Urfina, à folio 591. usque ad 784. probant ; ubi fummà \& incredibili diligentiâ non facras tantùm ex divinorum oraculorum fontibus depromptas auctoritates pro liquida coli natura, pro ignea \& aquea Aftrorum fubftantia , contra colorum aftrorumque $\dot{\alpha} \Phi$ sagsia feu incorruptibilitatem congefferunt; fed \& copiosè adductis omnium pæenè SS. Patrum ceftimoniis \& genuinis interpretationibus ita roborarunt, tam folidè, doctè, \& fcitè, ratione, experientiaque omnium ductrice ac Magiftrâ, nec non unanimi omnium Aftronomorum confpiran. tium confenfu expofuerunt, ut de tantarum auctoritatum. veritate, de rationum adductarum pondere, obfervationum- 
Auctoris.

que toto terrarum orbe $a b$ Aftronomis peractarum irrefragabili certitudine amplius importerum dubitari non poftit. Qux qui leget, apertè comperiet, nihil me toto hoc Itinerario, quod illi non priùs ex innumeris Auctoribus comprobatum afleruerint, adducere. Inveniet quoque in dicto Scheineri Opere, prater igneam \& aqueam aftrorum naturam, colique liquiditatem, omnia mundi corpora, uti ex quatuor elementis compofita, ita generationibus \& corruptionibus obnoxia, uti is, ubi de cometarum novarumque ftellarum. exortu agit, fusè docet, exiftere. Hîc fingulos aftralium corporum globos fuas exfpirare atmofphæras, fingulos fuis infructos centris, fingulos differentes influxuum rationes polfidere difcet. Hîc cum admiracione folaris corporis, xtu \& ebullitione ad ignei cujusdam Oceani perpecuò agitati rationem; Lunam verò contrà humiditate offufam; aftrorumque circa proprium centrum circumvolucionem deprehender. Secuti hunc Rheite đo Wendelinus, qui propriâ experientiâ, \& cœleftis oculi fubfidio fulti, ille in oculo fuo Enoch \& Elix, hic in variis tractatibus Aftronomicis, ita id comprobarune, ut non dicam ingenio præpotens, fed durioris animi, qui contrariam opinionem fuftinere voluerit, philofophus exiftimandus fic. Si itaque Sancti Patres folo rationis lumine ex facris fontibus hautto, liquidam corruptibilemque cœli naturam, tanto argumentorum pondere comprobarunt, tantâ contentione aliis perfuadere conati funt; quid, fi hujus temporis obfervationibus inftructi fuillent; cos non præftitife putabimus ? Certè folum Ariftotelem primum inter omnes præteritorum feculorum philofophos fuiffe, qui coli foliditatem adftruxeric, mundum intricatis orbium involueris confuderic, quintam eflentiam nullo intellectu concepribilem introduxerir, Scheinerus, Merfennus,aliique fusè pro'ant; cui proinde Echnico Sophiftæ plus credere, ejus auctoritafm pluris æitimare, quàm Sauctorum Pacrum, fi non iniquum, falcem temerarium efle putant.

.. Examinatis iraque tum Sacræ Scriptura circa coeleftems F : difci-

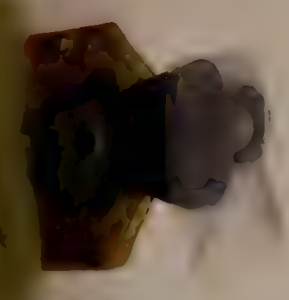




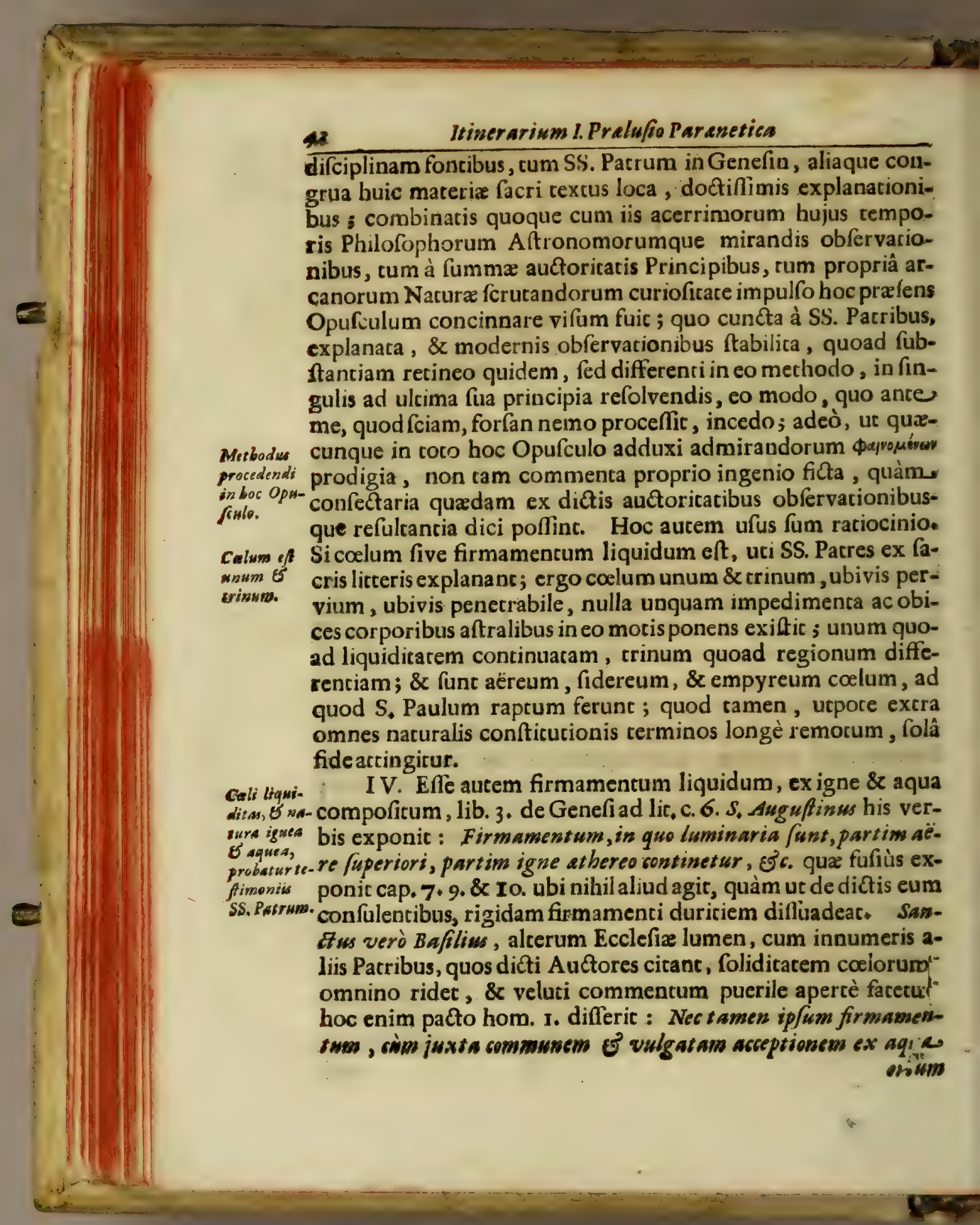


ortum (uum habuiffe videatur, aut aquse in glaciem concrete, aut materia cusiquam tali, qua lui principium ortûs ex bumore percolato fomit. Jonile cen/endum est effe, qualem cryft alli lapidis naturam effe conftat. Et paulò pònt: Ex bis it aque nulli fimile firmoment un effe cenfemun; est enim puexilis fimplicisque profectò mentis, tales de corporibus caleftibis opiniones babere: neque tamen, quoniam omni in omnibus infunt, ignis in aëre, ä̈r in aqua, $6 \dot{0}-$ terorsonque aliud ixest in alio, of nullum onnino corum, qua fub (en/um cadunt, elementum fincerum est, mixtioneque caret, ut non fit aut medii, aut oppofiti particeps; firmamentum ob id it fume aut ex unb elementorum, aut ex omnibus mixtum effe afferere no: bis placet, que jam aे divina foriptura ita inftituti fumus, ofe. Que cum it a fant, infatratâ illâ (apientiâ (Philofophorum) aquas fuperceleftes, of ab ignis ceeleftis ardore abfumi folitas ne-

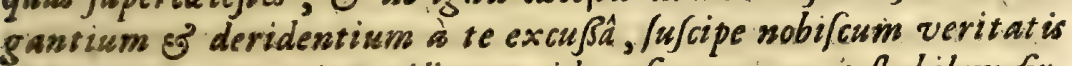
doctrinam, imperitam illam quidem fermone, at fabilem firwanque cognitione, quid in Scriptur a fognificati habeat firmianenti nowen, nimirum naturam infonuat, neutiquam reluct an-tum quid tem aut folidam, quavè fuo pondere gravis fit aut renitens; non filio, S. Bi... ejusmodi dicit effe firmamentum, alioquin fific gravem mole ejus intelligis naturans, proprius aut juftius banc labi vendicaffet Terra nomenclaturam firmamenti; fed quod nat ura rerum nobis fupereminentium ac fublimium tenuis adwodum fit of rara, nec ullo Jenfu percipi polfit, hoc appellavit Moyjes firmamentum, corporum comparatione, qua tenuiffima funt, or qua fen/u facilè comprebenduntur. Et paulò pòlt: Quidas bacopinione (quòd coelum ex quatuor elementis confter) veluti son probabili pof habitâ repulsâque, quintam quandam effentiam corporis ad calum conftituendum jwopte ingenio atque feipfis commentitiam, É protempore excogitatam introduxerunt; ob hasitague rationum neceffitates majorum fuorum rationibus rejectes, illis opus fuit, ut opinionem Juam privatá quadam \& peculiari fuppofitione finfulcirent, qui quintam quandam corporis effentiam ad cali fiderumque confituendam generationem fuppofuerunt. Et paulò pòlt: Hifce de rebu nunc faggredimur dicere, in mugas perinde ac ipfa incide- 


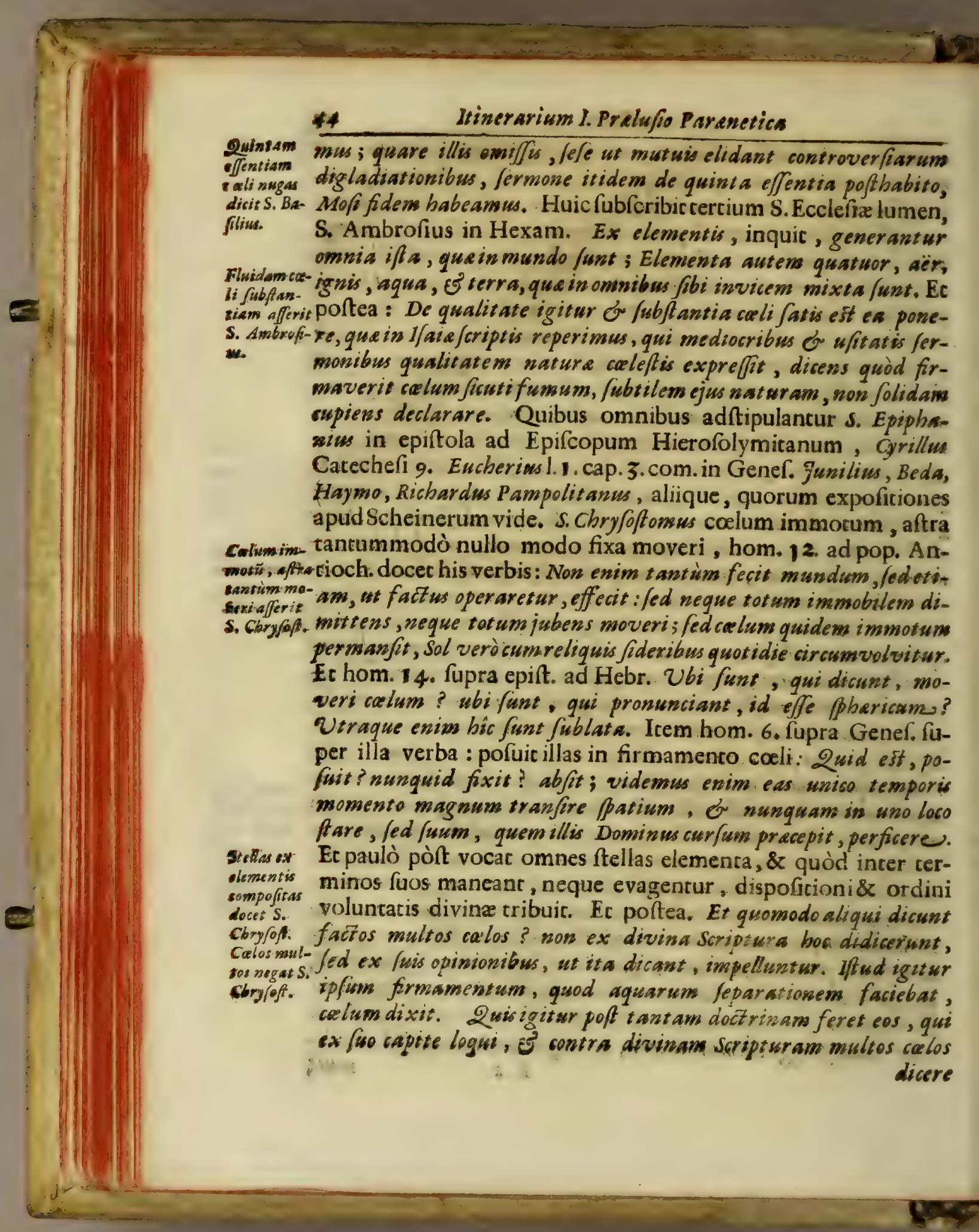


dicere audent? Ec deinde folvic objectiones corum, qui ex ilto, laudent eum cali calorum, pluralitatem colorum inferunt, \& fitè hebraicam illam dicendi formulam, qua duali numero coelum exprimunt, videlicet שמי Schamaim , effe dicit. Cui fubfribit Diodorus Gazenfos his verbis : Nemo cùm audierit ( \& pofuit ea in firmamento coeli, ) exiftimet Solem, Luram, ftellas in calo fixas, gentile dogma in Ecolefan inducens. 2uemadmodum itaque homines in terra, ita luminarta in culo pofita fupernum fuum iter peragunt. Eufebius Emiffenus cœlum firmum atque immobile elle, Solem verò, Lunam, ftellasque in colo moveri, ac curfum fuum peragere dicic. Nam cinm a $\mathrm{J}$ o/ue dictum est; Sol \& Lun a ftet; non ait, coelum movens solem \& Lunam ftet : item cuin ab Ezechia dictum est ; Sol rerrocedat; non ait, calsm movens Solem retrocedat: cacus eft, qui ex his aftra in liquido moveri non videt. Ifid. 1.13. Ethber locus eft, in quo fidera funt, E' fignificat ignem, qui à toto mundo in alterum leparatus est; (ane et ber est ipfum elementum, atbera veròplendor etheris. Et fusè in fequentibus omnia profequitur. Richardus de S.Victore Exercitation. cap. 7. fupra hæc verba: In Ricbardus principio creavit, \&c. Calum, inquic, tria funt elementa, ignis, de S. Victer, iër, aqua, que erant in unum confufione permixta, fove in una permixrione confufa, circa quartum, quod est terra, fluctuantia; creavit itaque $D E \cup S$ in principio quatuor Elementa, fimplicem rerum omnium fecundam materiam. Theodoretus in Gen.quaft. 1. Sutne unum celum, an dwo?. fic refpondic: Qui non credit fecundum effe crelsm, femitam rectam transgreditur; qui veró plures numerare conatur, adheret fabulis, poftpofot à divini Spi-

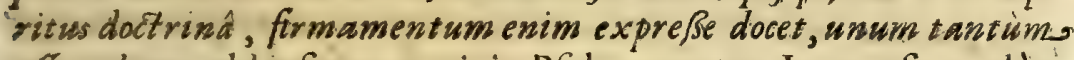
effe calum. Id ipfum repetit in Pfalmum 148. Iraque fecundü Affraex 4 . ipfum oportet planetas \& fellas in eo liberè moveri, \& fic fir-compofite mamentum permeabile efle. Lege, fi placet, D, Bonaventurame effe, docent lib. 2. Fent p. 2. ubi fuifo ratiocinio unum tantúm concinutum Ss. Patres. colum docer effe, non nifi mobilibus antris distinctum. Ignem ponit S. Bam praterea \& aquam fingulis ftellis dispertitam, Theodoretus afentura.

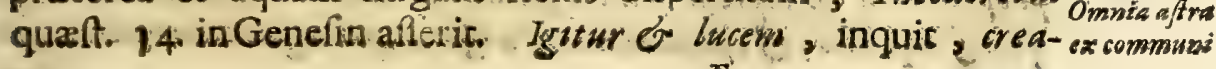

$$
F_{3} \text { vit, }
$$


elemertorum maffe effe compru ats, docet Theodoretus.

Idem fertit S. Atbanafirs.

vit.quemadnodum ei libuit: ficuti vero formamento diftinxit aquarum naturam, \& quasdam (urfum collocavit, reliquas deorJam reliquit : foc locem illam pro arbitrio fuo diffinguens, luminaria magna os parva condidit. Qux diftinctius refert S. Athanafius quxit. 83 . in Gen. Et dixit Deus, fiat lux E' fact a est. lux : Hec lux magna os plendidifima cùm effet, divifit eam, DEUS in lumisaria, Solem, Lunam, of reliqua. Qua \& Procopius commencario in Genefin eodem ferè verborum tenore referc. Dess, inquit, puriffimam partem primigenie lucis accipiens, transtulit in Solem, reliquam partem diftribuit inter Lunam, $\sigma^{2}$ roliqua aftra; quemadmodun $D E U$ S univer lam aquam, qua prius inundabat terram, in unum quafe receptaculum, viempe in varia flumina put eosque conjecit, foc lucem in omnia diff u fam ubertim in unum contraxit, \&s Solem, Lunam, ckteraque aftra inde illuftravit. Unde Funilius, Epifcopus Africanus, cenfebac, ignem noftrum elementarem portiunculam effe luminarium coleftium, ejusdem naturæ cum eo, eo quòd per vitra concava, convexaque Solis radii excepti ignem fimilem noftro paomnia a- riant. Porrò S. Gregorius Nyfenus in Hex. non tantùm omnia fraex 4. Mundi corpora elementis conftare, fed \& fingula qualicaciconftruta, bus elementis propriis inftructa fuife, his verbis afleric: Non docet S.Gre-opinor veftram opinionem abeo, quod probabile atque confentagor. Nylen. neum est, aberraturam effe, fl boc Moyjen intellexiffe exiftimamus, quèd ab initio quidem omnium illuminatrix vis apud feiplam coacervata atque collect a fact a fit lux, Jed quoniam magra guadam in illa lubtili $\sigma^{2}$ agili ratione majoris of mineris differentia in univerfa rerum natura effecernebatur, triduum temporis pacium fat is fuit, ut horum unumquodque per piceretur, छs absque confufione alterum ab altero diduceretur, difcernereturque; ut id quidem, quod exignea suaturafubtile os leve, infummo loco fub fenfum cadentis natura verfaretur; quidquid autem do tardum of ignarum effet, intra complexum tenuis illius of levis circa lefe coiret; atque boc rurfus pro differentia infite fibi proprietatis in feptem partes fecaretur ommibus particulis lucio; que o equales, É ejusdem natura effent, pro cognatione inter fele cos- 
coalefentibus, \& ab iis, que alterius generis effent, feparat is atque diremptis. Sic igitur quidquid folaris nature illuminatricis inperfum erat, cum omnes he particule alie ad alias concurrifent, unum magnum lumen factum est; itidem etiam in Luwa, $\sigma^{\circ}$ in unaquaque caterarum, tum errantium, tum inerrantium of fixarum ftellarum uniuscujusque particularum ad fui generis ejus concurfus, unum quoddam ex iis, que in celo apparent, efficit, atque it a univerfa fact a Junt. Hoc fanè magni Doctoris teftimonium tantum eft, ut eorum, qua in Itinerario noftro vulgò paradoxa recenfuimus, quadam veluci anacephalaofis eflequear.

V. Atque ha funt de fluida, ignea, atque aquea cœli fubftantia SS, Patrum auctoritates, ex innumeris paucæ, pracipuorum tamen Ecclefix Doctorum; quas primò proponendas du$x i$, ne novam peregrinæ doctrinæ fabricam Mundo obcrudere velle viderer. Nihil porrò reftat, nifi ut hifce fuppofitis ad ipfa nos experimenta conferamus, quibus ea candem oculari demonftratione comperta afferamus, qua rectè quidem \& verè SS. Patres, fed fub a mbiguo tamen fenfu non fine perplexitate quadam diverfimodè fpeculati funt.

VI. Hujus temporis Mathematici minimè fcholafticis obferbatio. iftis concertationibus contenti, altius \& fublimius quid mo-nes caleftes lientes oculi coeleftis fubfidio, ad ipfa coleftia corpora audaci Aftronofanè confilio afcendentes, litem tandem omnium ferè Philo- tabapisicilfophorum in fcholis pendentem ita diremerunt, ut Philofophus anciqua pratericorum temporum de colefti doctrina. dogmata defendere minùs poffit, cùm ocularem fenfatamque experientiam proprio judicio fuo negare, non fit Philolophi; prafertim cùm non unus tantùm ea obfervafte cenferi debeat Aftronomus, quin innumeri in hunc usque diem iftiusmodi novis coeleftium apparitionum miraculis intenti, quantò plura vident, tantò majora rarioraque deregunt. Quis au- Calum non tem, dum Venerem \& Mercurium circa Solem verfari videt, eft folidum, folidum colum credac ? quis Martem, Solaris Spharæ inco-dum. 


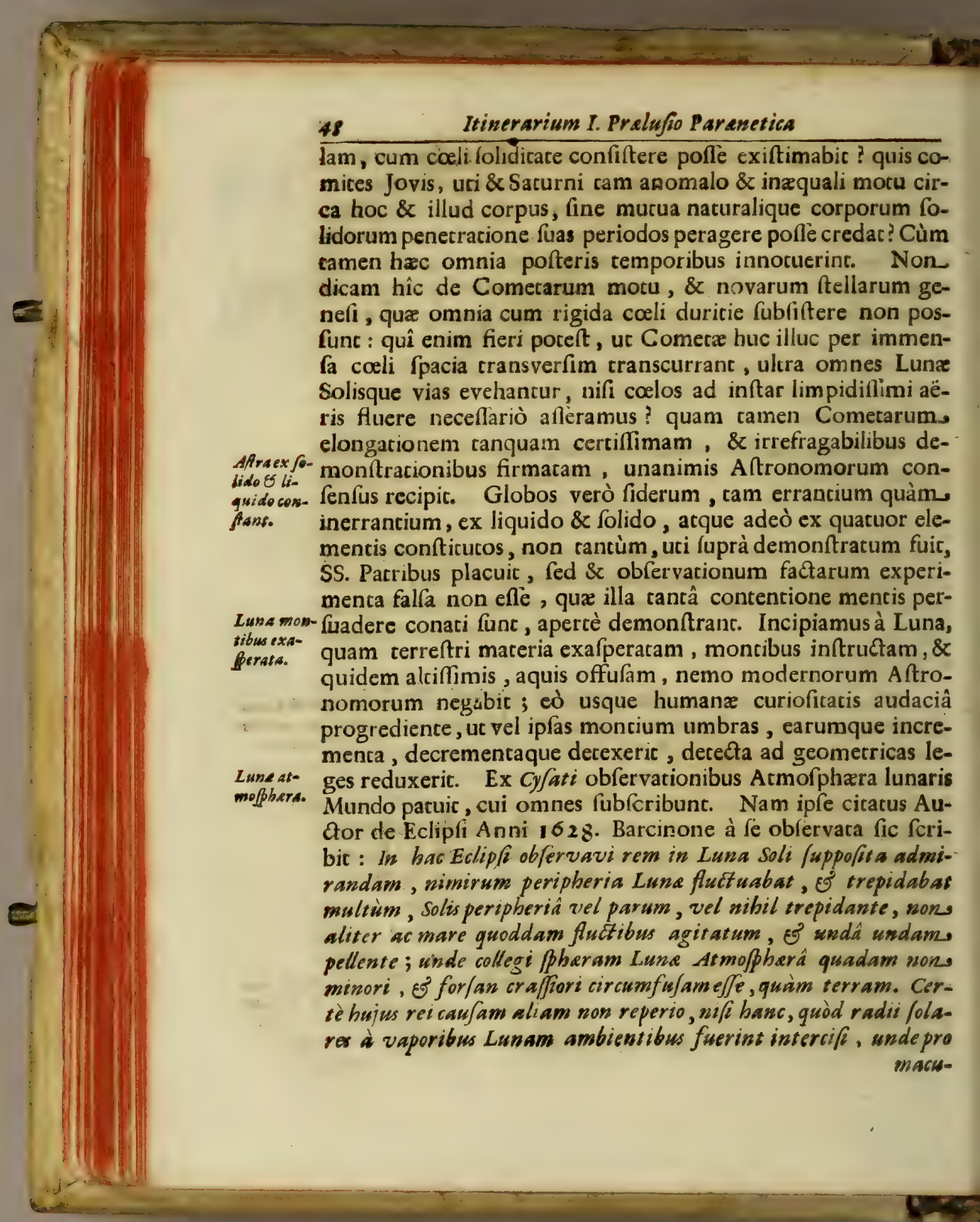


maculis folaribus \& Cometes major lux videtur oriri. Sicut è Terra, Lunaque globo, ita è reliquorum planetarum globis vapores expirant. Hæc erudicus ille Mathematicus, Joannes Bapcifta Cylarus nofter, cujus acuto difcurfui reliqui fubfequentes ob. fervatores fubferiplerunt, \& Scheinerus fummè approbavic his verbis : Refricat mibi hujus experientic enarratio in memoriam finile quoddam experimentum in sole ab initio inventi d me Solaris phonomeni bucusque femper animadverfum, fo est boc, quod sol preter tremorem marginalem, quem tamen non femper pectandum prebet, proter exaßperationem frequenter exbibitam, de quibus alibi fape, etiam quajä quadam repentinà solis af us fulguratsone toto /no patente hemispherio quaquaverfus ex equo 8 ebullitio. corulcat, hawà aliter ac fi intus conceptâ intumefcess luce rumperetur, $\xi$ in fulguris morem effulgeret ac jubare momenta. veo fubfult aret. Hoc idem portentum củm fæpe fxpius Scheinerus hic Roma mihi oftendiflet, \& Sol non fecus ac mare ingentes aftus volverer ; certê aliud concludere non potui, quàm illud ipfum effe, quod revera erar, videlicer æituancifimam Solaris Oceani fluctuationem ; quam \& simons Marius in Mundo fuo Joviali nihil aliud, quám quafi quandam fulminationem, \& materix Solaris ebullitionem exiftimat: Hac enim, inquit, ratione vidi fuperficiem solis commoveri, non aliter ac aurum à Jummo calore liquef act um, in quo Auxu fimilis commotio $\sigma^{2}$ quaf fulminatio exiftit in juperficie auri. Cui fubfcribunc, quotquot hucusque portenta hujusmodi Solaria accuratè obfervarunt. Sed ut ad Lunam rever-Atmophses ramur, teftatur \& hanc Lunz agitationem Hevelises in fua ra omnium Selenographia; \& doctifimus Ricciolus id non negat Rbeit $^{\text {jaderum. }}$ quoque in Oculo fuo Enoch \& Elia, in omnibus paffim planetis, nec non ftellis fixis, mirifico fuo tubo colefti id fe obfervafle affeverat; unde omnes Mundi globos fingulos fingulis fuis atmofphæris veftiri dicit. Optimofanè jure ; cùm enim fuprà è SS. Pacribus oftenfün fit, omnia Mundì corpora ex quatuor elementis compofita efle, \& ignem aquamque fingulis pro rata portione ex primigenia primi diei Mundi luce di- 
Atributam; quid aliud inde concludicur, quàm fingula eodem. modo facta effe, id eft, globos ex liquido \& folido conftitutos? Cùm itaque unum elementum fine alcero effe non poffit, \& omnia omnibus commixta fint; certum eft, calidum \& humidum, five liquorem \& terreftrem materiam, ex quibus globi conftituuntur, neceffariò non fecus ac in terra fefe habere, ubi calidum in humidum agens illud refolvit, humor corporibus inficus calore rarefactus in tenuem fubftanciam, abit, quam Aftronomi atmofphæram vocant; five globus ille ex igne liquido, five aqua fluida conftituatur. Nam ut rectè S. Ambrofius I. 1. Hexam. c. 6. Satis est, inquit, ad prafentem affertionem, quod in principio calum fecerit, unde generationis caufa; of terram, in qua generationis effet fubftantia: In his enim elementa creata Junt, ex quibus geserentur omnia ifta, que Mundifunt: Element autem quatwor, Aër, Ignis, Aqua, Terra, que in ommibus fibi invicem mixt a funt. Ex quibus

Afracom ruptibilis fwst.

Calefin corporatejusdem natwra cum inferiorihats luculenter parex, in omnibus Mundi globis, uti fpecie à fublunari materia elementari non differunt, ita generationis \& corruptionis legibus paricer effe fubjecta, ubi in fingulis gravia ad uniuscujusque centrum, à centro verò levia per refolutionem humidi à calido exfpirata, effluvium illud, quod Aftronomi atmolphæram dicunt, efficiuns. Cùm enim fenfaca experientia omnia Mundi corpora opaca repererit, certum. eft, Solarium corporum radios in ea, qua inæqualitate partium mirificè exafperantur, impactos, calorem, non fecus ac in terrena Solaris lucis reflexione contingit, fummè intende. re ; extintentione verò caloris, humidi intra terreftrem fubftantiam exiftentis fit refolutio, ex refolutione rarefactio, ex rarefactione in remotiori Atmofphæra termino ob frigidi $x-$ theris vicini auram iterum condenfacio, ex condenfacione tandem in id, quod erat, fit reditus. Si enim folus ignis in hujusmodi coeleftibus corporibus conftitutus fuiffer, is utique otiofus foret, cùm non haberer, in quod ageret; neque humidum effe folum debuic, cùm non haberet, cui fubjiceretur, aut à quo paterecur; Si verò corpora coeleftia àfublunaribus ditferen- 
Autroris.

ferentes naturas à DF O conlecuca funfent, illx haud dubiè in inferiora elementa, à quibus eflentialiter differrent, agere nun potuiffent, neque ullo modo per fympachicas antipachicasque operaciones ad invicem comparatas ullum influxibus fuis effectum proportionatum, neque in inferioribus, neque in circumfitis corporıbus praftare potuillent ; atque adeò 0 mnis unı, concordia, \& harmonra Mundi periiflec, qux in eo confiftic potiffimùm, quòd unum Mundi corpus alcerum. naturali appecicu fovere, \& connacuralibus facultacibus movereac promovere, \& promotum confervare inclinet; quod minimè fieret, fi coleftis materia aut quinta quadam eflèntia.. aut effentialicer differre à fublunaribus cogicaretur. Atque, hæc unica fuic ratio, quam \& S. Bafilius fcitè innuit, cur Sancti Patres Mundum, \& omnia,qua in Mundo funt ( qua uri ex quatuor elementis compofita fuerunt, ita communes omnibus corruptionis leges (equuntur) minimè incorruptibilem. quoad naturam, fed corruptibilem ex facris literis copiosè demonftrârint.

VII. Manet itaque, omnia Mundi corpora ad eandem. divinx artis amuffim codem modoefle condita, neque quoad materiam elementarem ullâ racione inter fe differre, fed formarum tantummodò proprietatumq́ue diverficate à fe invicem diffidere; non fecus ac in terreftri globo, in quo etiamfi innumeræ rerum fpecies formis proprietacibusque differre comperiantur, omnia tamen quoad materiam elementarem. eadem efle mveniuntur, uti ex refolutione chymica patet. Sed hoc fufius in Itinerario noftro. Nemo itaque miretur, fi nos globos cœleftes folaris nacuræ, ex igne liquido \& cerreftriportione ; Lunarıs verò naturæ , ex aqua terreftri fubitantia concrecos afferamus : hæc enim naturali confequentia ex præfuppofitis deducuntur. Quod enim in terreftri globo fieri cenfendum eft, illud fecundum analogiam quandam in cœleftibus pariter corporibus fieri putemus, ita ut quxcunque, elementorum conjunctionem confequuncur actiones, eàsdem in coleltibus glubis, in uno tamen plùs, in altero minùs, G 2 repe: 


\section{caleftium corporum qualisates jecundsa.}

$s^{2}$

reperiri,certò inferri poflic. Dantur itaque prater primas qualitates in globis coleftibus \& fecunda, levitas, gravitas, molhries, durities, rarefactio, condenfatio confurmes meteorologica impreffiones neceflariò confequuntur. Omniaigicur, qua in terreftri globo fpectantur, in. coeleftibus quoque, fi vegetabilem \& fenfitivam naturam, quas aterux fapientia ratio inde exclufit ${ }_{2}$ excipias, fpectari neceffe: elt.

VIII. Unde quemadmodum in Terra fingulæ rerum: Angelice- fpecies, D. Dionyfio tefte, prafidem Angelum habent, ita \& porum pre-coleftium globorum fingula elementa, qui ea in fines fuos a fides. Nacura Dei miniftra intentos dirigant, habent; unde colligimus, plures Angelos unicuique globo, pro rerum in eo adminiftrandarum varietace præfectos; quos facra Scriptura Exer. citus coleftis militix, feu militias cœlorum JJaie 40: vocat; unde ftellas quoque ftantes, contra Sifaram pugnafle Jud. s. non nifi de Angelis ftellarum prafidibus: commentatores in hune locum intelligunt; Et illud Jobi : Cum me laudarent aftra. matutine, E jubilarent omnes flii $D E I$; non de materialibus: Af ris fin- aftris, fed de globorum prafidibus intelligitur. Meminit quoAngeli pre- que Angelicarum cuftodiarum, \& minifterii eorundem , BAfides attri- ruch. Propheta, $c_{\text {: }} 3$, Sunt itaque in fingulis aftris veluti in choknti funt. ros quosdam diftribura Angelica cuftodia, quarum minifterio globorum: vis in bonum Univerfi adminitratur. Sed hæc: ita clara func, ut expoficione non indigeant : fola innumerabilis ftellarum multitudo, univerfique vaftiras incomprehenfibilis, nonnulli dubium movere poflet; fed noverit, Scripturam facram exprefsè dicere, , parum nos operum divinorum. noffe; oculi fiquidem cœleftis fubfidio, quantò plùs quæris, tantò plùs ufque ad innumerabilem multitudinem te invenire deprehendes, apertèque fateberis nullum ftellarum finem. \& numerum fpectari ; ut proinde non incongrué arenæe mastekeinnw.ris, \& Abrahie propagini comparentur numern fiellas, f merabiks. potes? Solus itaque Deus conditor omnium ftellarum mulcisudinem numerar, \& omnibus eis nomina vocat; qua haud 
dubiè non in eadem frmamenti fuperficie; fed in intimis cjusdem \& immenfis, imfenerrabilibusque receffibus, inexplicabili diftantiâ diftant ; ue proinde minùs probandi fint nonnulli hujus temporis Philofophi, qui ab experimentis \& obfervationibus non folùm abftinere, , fed ea plurimùm ab. horrere folent, ne ab antiquis Peripatio opinionibus tantillùm difcedere fenfu \& ratione ducti, aut praferiptis fuis fententiis aliquid adjungere, auc in iis quidquam immutare cogantur. Cxerùm gui novam hujus temporis circa coeleftium phrnomenorum doctrinam fcire defiderat, is confulat primò scheinerum cir. lib: deinde doctiflimi \& eruditifimi P. Foanwis Baptiffe Riccioli Almagefti novi librum 8, \& 9, ubi, quidquid circa hanc doctrinam concipi poteft, acri curâ, , nec non incredibili diligentiâ tractavit ; ubi \& omnium Auctorum, quỉ aur nova in coelo detexerunt, aut ex detectis novam Philofophiam condere conati funt, nomina reperiet. Verè totius Aftronomica difciplinæx promus condus uberrimus eft dicti $\mathrm{Au}-$ Atoris Öpus.

IX. Er quoniam mira circa coeleftium portentorum rationes \& caufas opinionum diverfitas eft, quid nos ex prafuppofitis fundamentis fentiamus, \& quomodo omnia etiam paradoxa paffim facillimo negotio defendi queant, mediam quandam viam fectati, in hoc Itinerario Exftarico demonftrandum duximus. Qux fi æquus Lector, fepofito omni finiftro affectu, aquá veritatis lance ponderaverit, rationesque allatas ricè difcufferic; is haud dubiè prater facillimam. omnium difficultatum, qua in hoc usque tempus fcholas prnè omnes torferunt, folutionem, fingulis juxta combinatoria artis regulas ritè exploratis, aliter Mundi opificium fefe habere non poffe, quàm diximus, fatebitur. Si verò̀ quispiam aliquid noftris racionibus meliüs adduxerit, ei non invitos nos: fubfcripturos pollicemur. Ne verò̀ quidquam Sacræ Roma$n æ$ Ecclefiæ decretis \& inftitucis contrarium afteramus; id unicum contendimus, ut coeleftium globorum incolas unà cum mobilitate terra perpetuò profcriberemus. Si verò nonG 3 nihil nihil . 
nihil vel incogıtanti, auc non advertenci lufpectum contra. mentem eruperic, id revocatum recractatumque hilce yolui. Quò autem fingula majori cum delectatione Lectorum animis influerent; Opufculum in Dialngi formam, incerlocutorsbus Colmiele \& Theodidacto digeflimus ; in quo fub exftafis feu raptûs figmento ultrò cirròque varia dubiorum, circa coleftium globorum raciones occurrentum, difficultates, per reciprocas interrogationes \& refponfiones juxca obiervationum, factarum nociciam refolvuncur, \& hoc ad majorem legentium voluptatem, Principumq́ue, qui hoc ipfum inftanter à me eftlagicarunt, mentis rerum policicarum curis feflæx relaxacionem. Ut veròaliqua inde Deo devoris mencibus fpiricus urılicas afferretur, phyficas contemplationes plerumque ardentes in Deum tantarum rerum Conditorem , admirationis amorisque affectus excipiunc. Er ne quidquam Opufculo circa Mundi conftrutionem deeflec, in fecunda parte de divina providentia agere vılum fuic, in qua præterquàm quòd ea, quæ in præcedenti fusè dicta funt, luculentiùs exponuntur, complura quoque de Colo Empyreo, de fpatio imaginario, de Mundi confummatione; de abditis divinorum judiciorum aby $\Pi$ is, de fidei Cacholic $x$ excellencia, adnexuimus; Omnia ad majorem De1, Marrisque gloriam \& honorem,\& ad proximifalutem. Vale Lector, \& fave,

\section{SCHOLILM I.}

\section{De centro fingulis aftris proprio.}

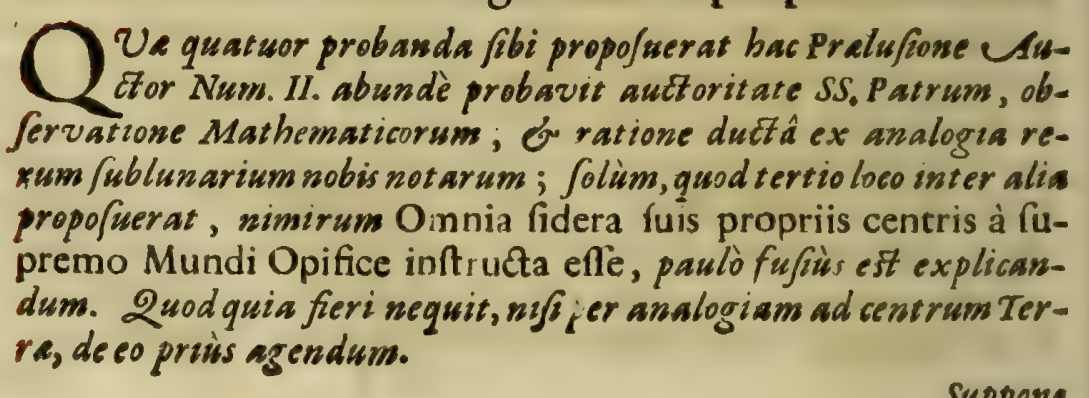

Suppores 


\section{Auctoris.}

Suppono itague 1.idguod fusè explicavi 3. p. Mag. Naturalis Centrum

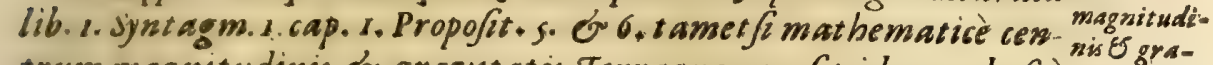
trum magnitudinis \& gravitat is Terraque non fit idem, phyfice Gistatis Tertannen of ad (enfum idem cen/eri poffe, propter exiguam unius ab re quoad altero in tanta mole diftantiam. II. Terraquam effe in medio denfum i- funt: Mundi, non folim quoad fenfum, ut Copernicani etiam concedunt, Terra eft de quibus in Preluf. Catbolica S. g. in fexto Sy/temate Mundi egi; Gerè in meFed ferè mathematicè, it a ut medium Terraque congruat mediou- $f_{i .}$ niverfi, fi non revera femper Eं precisè, faltem parum admodum ab eo diftet; illsed dico medium Terraqua, quod initio Mundi $D E \cup S$ congruere voluit medio Univerfi. III. Omnia gravia Grafia fubfublunaria appetere medium Terraqua, còque ferri, $\sqrt{2}$ liber aditus lunaria opateat. Et quoniam medium Terraque congruit medio. Univer- mnia appes $f_{1}, u t$ Jupponitur; recte dicitur, omnia gravia fublunaria appete- ${ }_{\text {trum }}^{\text {tun }}$ Terre centrum Univerfi. His fuppofit is,

2uaftio est, an Terraqua tota, \& fingula ejus partes, appe-quenter $u$. tant naturaliter centrum Univerf, conenturque centra fua in niberfi. umiverfic centro collocare; \& utrum fis tota Terraqua dimoveretur à dicfo centro Univerf, aut quavis ejus pars haberet liberum adillud acceffum, è naturaliter moveretur. Affirmativam ferstentiam fupponunt, quotguot probant ex eo Ierram effe in medio Mundi, quod onnium fublunarium gravifima est, ideoque infunum Mundi locum; qui Mundi mealium est, petit. Quod autem de tota Terva dicitur, intelligi etiam debet de partibus ipfius, propter paritatem rationis. Negativam fententiam Jupponun omnes, qui Copernici fyftema Mundi amplectuntur; qusi lanè plurimi (unt, Ej graviffimi Pbilolophi ac Matbematici, inter quos est Galilæus \& Keplerus.

2uaftionem banc fufius exagitabo in Mundo Mirabili. In-Grasiafus terim dico, probabilius videri, nec totam Terram, nec partes lunaria ejus, nec ulla gravi fublunaria, peters naturaliter $\xi^{\circ}$ ab in- non appeixinfeco effe in centro Mundiperfe, adeoguse centrum gravium medium $u_{0}$ fublunarium non effeper fe centrum Mundi, fed centrum Terra: nibirfi Quod gitur nuno defacto partes Tirre, El catera gravia is tota Terradifincta, ferantur adcenirum Uwiverfi, per accidens. 
est, quatenus boc congruit cum centro Terre, ad quod gravia feruntur. It aque fo tota Terra alio transferretur, omnia gravia fublonaria eams comitarentur naturali inclinatione, nec ulla ad Univerfo centrum confluevent naturaliter $E$ ab intrinfeco, Jed violenter è traberentur ad locum à Terra derelictum replendum, ne vacuum in rerum Natura daretur. Et fiextra Munedi centrum tot Terra collocaretur, \& pars Terre avulfa alibi exifleret: fublato impedimento non tenderet ad centrum Mundi, Terra cur fed ad Terram. Imò fi, pofî́â Terrâ extra Mundi centrum, ins unibers bocexifteret pars Terre, aliudve grave fublunare; moveretur collocata é fublato impedimento ad Ierram. It aque Terra nuncexiftit in, DEO. medio Mundi, non quz naturâ fuá locum illum petit, féd DEI ordinatione, qui ideo volut eam ibi exiftere, st aqualiter undique diftaret aे calo of aftris, ad excipiendos corsm influxus. Mo. veor ad boc afjerendum, quia omnia aft ralia corpor a gravia funt, uspote elementata, of funt in ethere purifimo ac levifimo, nec tamen defcerdunt verfus Mundi centrum per liquidum colum; ergo gravia ex natura fua of ab intrinfeco non petunt effe ins. Mundimedio. Necest unajor ratio, cur Terra petat allud medium, guàm alia corpora gravia.

Dices: gravis fublunaria petunt ex watura /us effe infra levior a fe, nec quiefcunt, fublat is impediment is, donec infr a illa fint, ut patet experientià, dum terra $\xi^{3}$ aqua in aëre pofita feruntur deor/um, donec fint infra aêrem; $\Xi^{2}$ dum terra in aqua. pofit a non quiefcit, donec fit infra aquam: Sed dum Terra feu to-

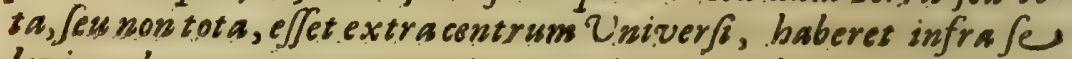
levius slementum, nempe aërem, qui tunc medium Mundi occuparet; ergo illuc tenderet fublat is obftaculis. Refpondeo, gravia fublunaria petere effe infra levia, of de facto infra catendere, quia petunt effe infimo loco Syftemat is gravium fublunarium; hic autem locus est medium Terre, non medium Muridi: alioquin etiam aftra defcenderent, guia non folium gravia fublunaria, fed onnia omnino gravia petunt efje infra leviora/e. Dices iterum : Terra est omnium gravium grave fima, ideogue in infimo lo60, qui est Mundi centrum, petit effe. Relpondeo, id 
non conffare; \& probabilius videri, aftra, que funt majora, quàns Ierra, effe etiam graviora. Hec non mea folum, fed omnium Copernicanorum est fententia, quam fufius explicabo, ut dixi, in Mundo Mirabili. Interim vide Ricciolum lib.g. Almag. Novi Sect. 4. cap. 2 s. ubi late de ea re tradtat. $2 u e$ quidem fententia fi veraest, jam apparet fruftra laborare, qui probant, Terram ex mutatione quacunque centri gravitatis nutare. 2uam fententiam examinavimus 3. p. Magie Naturalis lib. I. Syntagm. I cap. 2. pofito quod centrum Vniverfigit centrum gravium per $\int e$; quod Affrmant is Sententic Auct ores fupponere debent.

His prernifis, difcutiendum, num fingula aftra babeant fua Aftra fingupropria centra. Quaftio procedit tam de partibus aftrorum, la babent quàm de totis aftris.Ad primum quod attinet, facilis est ex. Auctoris centra ruaG noftra fextentia folutio. Sicut enim partes Terre quin graves rum parti, quis graves umintr. funt, centrum babent, ad quod tendunt, fi à tota Terrafe. divellantur; ita partes corporum aftralium, quis graves funt, centrum habere debent, ad quod tendunt, $\sqrt{2}$ a tot is aftris divellantur. 2uodquidem centrum aliud elle non poteft qudm mediun afralis corporis; ficut centrum partium Terre est medium Terre. Eadem prorfus poft hacforipta, inveni apud P.Ignatium DerKennis in opere fex dierum, Die Mundi Jecundo, cap.2. Num.r7.

Major difficult as est de centro totius corporis aftralis, an nimirum Lun habeat centrum fuum in colo Lune, Sol in calo Solis, Sat urnus in coelo Sarturni, orc. id est, an Luna, Sol, or reliqua Atrapetant naturâ fuâ, \& ab intrinfeco efje in illis cali liquidi regionibus, in quibus de fatto exiftunt; or an, finde dimoverentur, naturaliter cò reverterentur; $\xi^{2}$ univer faliter, quanam virtus retineant aftra gravia in illis coli liquidi regionibus, in quibus reuse Junt, हैं Mundi exordio fuerunt.

In Magia Natur. par. 3. lib.5. Syntagm.3. Erotem. 13. retuli- Opinio aumus, quendam apud Merfennum in Phanomenis Hydraulicis jusdam de Propofit. 48. in Corollario, quod est de natatu minorum Mundi frorum in Syftematum in majori, credere liquidam totius Mundi mate-calo liquiriam effe diver $\int_{e}$ denfitatis, atque adeo diver $\sqrt{2}$ ponderis of in do. ejus medio, juxta Copernicanorum opinionem, solem conflitu- 
tum partes maceria, jobi viciniores ita calefacere, E r rarefacere, Ist Tellus, Es planete, juxta proportionem Juarum denfitatsm, magis aut minus ad Solem accedant, co modo, quo varii giobuli, in phialan diverfis liquoribus diverfo denfitatis as raritatis plenam inclufi, varia loca pro globulorum gravitatibus ac levitatibus, Es pro liquorum dexpitatibus of raritatibus occuparent. si enim quirgace v.g. liquores fumerentur ejus generis, ut unw effet gravior cateris, Ef reliqus fe invicem ordine fequerentur, femper leviores (prout diximus lib. cit. Syntagm.2. Pragm.18.ubi de quatuor liquoribus quatuor elementorum amulis phiala inclu/is ) \& quinque globuli pararentur, atque ita temperarentur corum pondera, wt fingulis liquoribus finguli innatarent; quantumvis illos liquores turbares, of globulos vi ad fundum detruderes, aut adduceres ad fuperiorem liguorum fuperfictem, ftatim ad priftina loca foopte nutureftituerentur. Eodem modo pbilofopharinos poffe, judicat ille apud Merfenmum de Mundi materialiquida, \& planet arum corporibus intra illam merfis, redituranimirsm omnic ad cundem ordinem, in groo nunc funt, etiamfi fusque deque ommia verterentur. At que banc natatus cogisationem ait Merfennus it a placuiffe magno Viro, ut non folum in. de concluferit planetarum circa solem loca, of mot ves, fed etians ( in fententia (ua of Copernicanorum) majorem of minoren Telluris $\&$ corundem planetarum ad solem acceffum or receffum, of ram perigea, quàm apogea commode fatis per bunc modum explicari poffe putarit. Cuim exim, inquit, Sol patio 28 . dierum fuam circa proprium axens periodum abfolvat (de qua re infrà fuo loco) o' reliquam circa fe Mundi materiam liquidam ufque ad Saturnum celerius aut tardius moveat, juxta diverlas diftantias; planetas in illis d:ftantis occurrentes circa fe movet codern motw, quo materiam ibidem occurrentem; boc est, Mercuriam tribses menfibus, Venerem novem, Tellurem anno, Martem biennio, govem duodecim annis, o Sarurnum annis triginta. Stellas vero fix as ab iftius materie motibss eximit, quippe que forfitan nova fyftemat efficiant. Hacille apud Merfennum. Mirabiles /anè of audax philofophandi ratio, quam ideo refutandam non cen/eo, 
Auctoris. se

quoniam nulli hacteurs perfuafam, nec perfuadendam pofthac csoiquam credo. Vide, que circa finilem opinionem dico infrà Scholio s.ltiweris in Lunam.

Egoexiftimo Primò, ut Terra centro fuo inftruct a est, ad quod, centra fon etiamfi extra Mundi medium collocaretur, omnes of fingulapropriata. ejus partes graviores naturali appetitu inclinant, of $f i$ avel- bent aftra. lantur, ad illud feruntur, of à quo leviores expirate ad circumferentiam fer untwr;ita omnia of fingula Mundi corpora, ex folido E' liquido conflata, (cujusmodi aftra (unt, fi SS, Patribus, Aftronomorum obfervationibus, \& rationibus, in Auctoris $\mathcal{G}^{2}$ noftra Pralufione adduct is credimus) (wis pradita effe centris, in qua omses \& fingule corum partes graviores naturali inclinant appetitu, ob totorum confervationem; $\sigma^{5}$ ad que, fi avellerentur dtot is , densio ferrentur; or à quibus leviores portiones ab bumido ex/pirate ad circumferentiam or liquidum circumnfifens ferustur.

Exiftimo Secundò, fout Terra, etfif ftabilem in Mundi medio Aftro non Locum ì DEO nact afit, ills tamen tanquam centro affixa nonest petunt cernuturâfut, fed folium ex DEI voluntate, ob finem fuprà expli-ex nature catum; it a multo minus aftra in calo liquido certum locum, aus fua. certan regionem, ex naturafua petunt, fed DEIordinatione illis addict a funt regionibus, in quibus de facto funt; $छ$ 'sinde dimoverentur, pon redirent è intrinfecà virtute. Ejusdem ment is fuiffe videtur S. Chryfoftomus loso cit. Juprà in PraluS. Paranet. Auctoris Num. 4 .

Her itaque differentiaest inter Terram ơ aftra, quod Terra babet centrum fixum in corpore immobili, aftra centrum fixcim in corpore mobili: Terra locum fixum in Univerfo, in quo quiefcat, ut aftroram influxus fufcipiat; aftra regionem fixam, ix qua moventur circa Terram,ut in illam influxus fuos transfundant. sed de bac re iterum infrà cum Auctore noftro Dialogo $2_{+}$cap. 3 . ubi agit de centro Telluris छs aftrorum, छ' eadem ferc babet, qua de aftrorum centris hio diximus.

H 2

Scho- 


\section{SCHOLIUM II.}

\section{An aftra moveanturab Intelligentiis?}

Afrean mobeaniur ab Intelligentivis.
Veleberrima est jam inde àprimis Pbilofophic \& Afronomic. ac, forta]fis, etiam Mundi post cataclyjmum reparati incunabulis, de colorum aut aftrorum caula motrice, controverfia. Alii enim exiftimant, moveri a propria forma, feu ab intrinfeco, noforma illa fit otiofa, E' inferior form is elementorum. Alii moveri quidem i propria forma dicunt, fed que eflet anima intellectiva, aut fenfitiva, aut vegetativa, aut ab bis omnibus diffincta. Alii immediatè à DEO moveri a/ferunt. Alii denique olim EJ nune com: muniter exiftimant, Jeu colum cum fideribus, fi folidum est caelum, feu fola fine colo fidera, Sifuidum est, moveri ab Intelligentiis leu Angelis, tanquam a ffiftentibus, or immediatis caufis effectivis, non autem tanquam ab animabus informantibus colum, at que adeo moveri ab extrinfeco principio, fed creato. In bac opinione est. Auctor nofter, ut vidimus in Pralufione precedenti Num, ult. proqua Ricciolus lib. 9. Almag. Novi Sect. $2+$ cap. 1 , tot. adducit Auctores antiguos ac modernos, Ev tot Scriptura facre teftimonia, ut concludere audeat, Licet nec metaphyficè, nec mathemaricè , led ad fummum phyficè aut moraliter demonftrari poffit, colum aut fidera moveri ab Intelligentiis ; fpectatâ tamen auctoricace tum facrâ, tum prophanâ, dicendum ç, moveri ab Intelligentiis. Auctores referam in Mundo Mirabili. Teftimoniafacra Scripture bacfunt: Sub quo curvantur, qui portant orbem, 706. 9. Columna coli contremifcunt, 706.26. Cùm me laudarent aftra matutina, \& jubilarent omnes filii DEI, 706.38. Virtuces colorum movebuntur, Matib. 24. 2ue teftimonia multi Sancti Patres de Angelis exponunt, uti o alia loca Ifaia 40. Jud. s. Baruch. 3. ut ibidem videbimus; ubi etiam contraria argumenta Jolvemus, of rationes Jevicongruentiax pro hac lententia afferemus. 


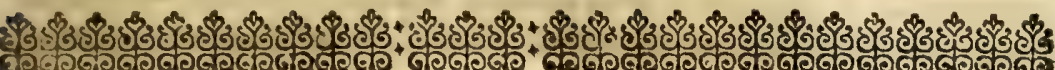
ITINERARII EXSTATICI DIALOGUS I.

De coleftis Expanfi fiderumque natura, ac proprietatibus.

Interlocutoribus Cofmiele E Theodidacto. CAPUT I. De canfa E origine bujus Opufculi. (a)

Ti mihi nullo non tempore ardentifimum rerum; qua hucusque latuerunt, cognofeendarum defiderium fuic, fic vel maximè in admiranda hujus mundanæ machina penetranda, \& eximiarum rerum, quas Deus Opr. Max. cujus fapientia non eft numerus, nec finis, in fupremo illo colorum domiciho repofuit, inveftigandarum ftudio mihi xeftuans cor fuic; potifimùm hifce temporibus, quo fumma \& infinita DE I bonitas theatrum fuum aliquò ufque viris Aftronomize ftudiodedicis, tubi aftronomici fubfidio, aperuit rerum fanè admirandarum, \& prio- tia multa ribus feculis inaudicarum, quas vel ipfe nunquam credidiffem, dosers. nifi propriis eas oculis fummo animi mei gaudio exploraffem, \& omnium meliorum hujus avi Aftronomorum continuo commercio didiciffem, Quidnam verò illud in Luna montuofum, \& veluti lacubus quibusdam transfufum? Quidnam illud in Sole Oceani inftar ignei æftuans, \& maculis facibusque refplendens ? Quidnam in Lunæ morem falcatis Venere \& Mercurio? Quid in Marte nefcio quid fumofx materix exhalans effet, penetrare non licuic, Admiratus fum fplendorem \& fummam Jovis Majeftatem tam infolito fatelltio circumdatam,; confideravi Sacurni fphæram, ejusque admirandam confti-

$$
\text { H } 3 \text { tutio: }
$$




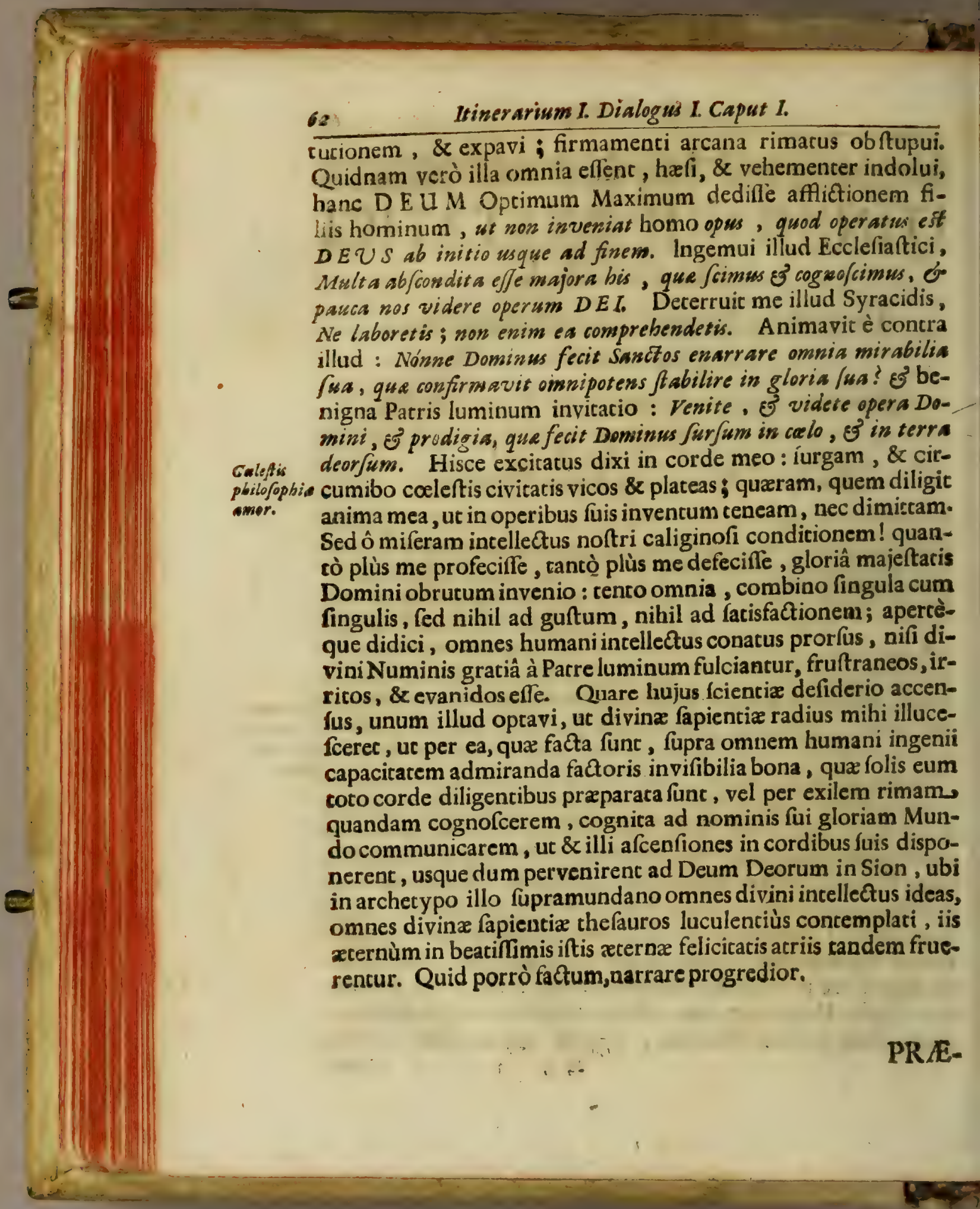




\section{PRELUSIO IN LUNAM.}

A Luna, amico Terra fidere, E Elementari A sphera vicinisfimo, fuam aupicatur exfaticam enarrationem Auctor, quoniam illa Jublunaris Mundi confinia transgreffo, et hereasque ingreffo regiones, prima occurrit. Mult ac mira de ejus natura, compofitione conftitutioneque enarrat, multa breviter infinuat, mult a fupponit, deducta precipuè ex modernorum Afronomorum obfervationibus, E irrefragabilibus experimentis, tele/copii Jubfidio captis. Opera ergo pretium fuerit, in corum gratiam, qui dictas obfervationes ignorant, cas in medium afferre aliague nonnulle ad Luns naturam, fructuram, ac conditionem pect antia explanare, at que ex. bis deinde Lune naturam rimari.

\section{\$. I. De diverfis Lunæ phafibus, ejusque maculis} tàm novis, quàmantiquis.

T Unam menfibus fingulis diverfas exhibere phajes feu appa- Lnnaphis: 1 vitiones, not um est oranibus: apparet enim modò plena, mo-feso dô femiplena, modò gibba ac pratumida, modó falcata jeu in cormua curvata, E' quidens cornibas nanc converfis in Orientem. sunc in Occidentem, \& nuns erectis, nunc inclinatis. Varios hos vultus induit pro vario ad Solewn appectu. Nam Soli diametraliter oppofit apparet plenè ac integro difco illuminata; eidemo conjunct a, penitus ob/cures est ; in aliis a/pectibus partern foliums 


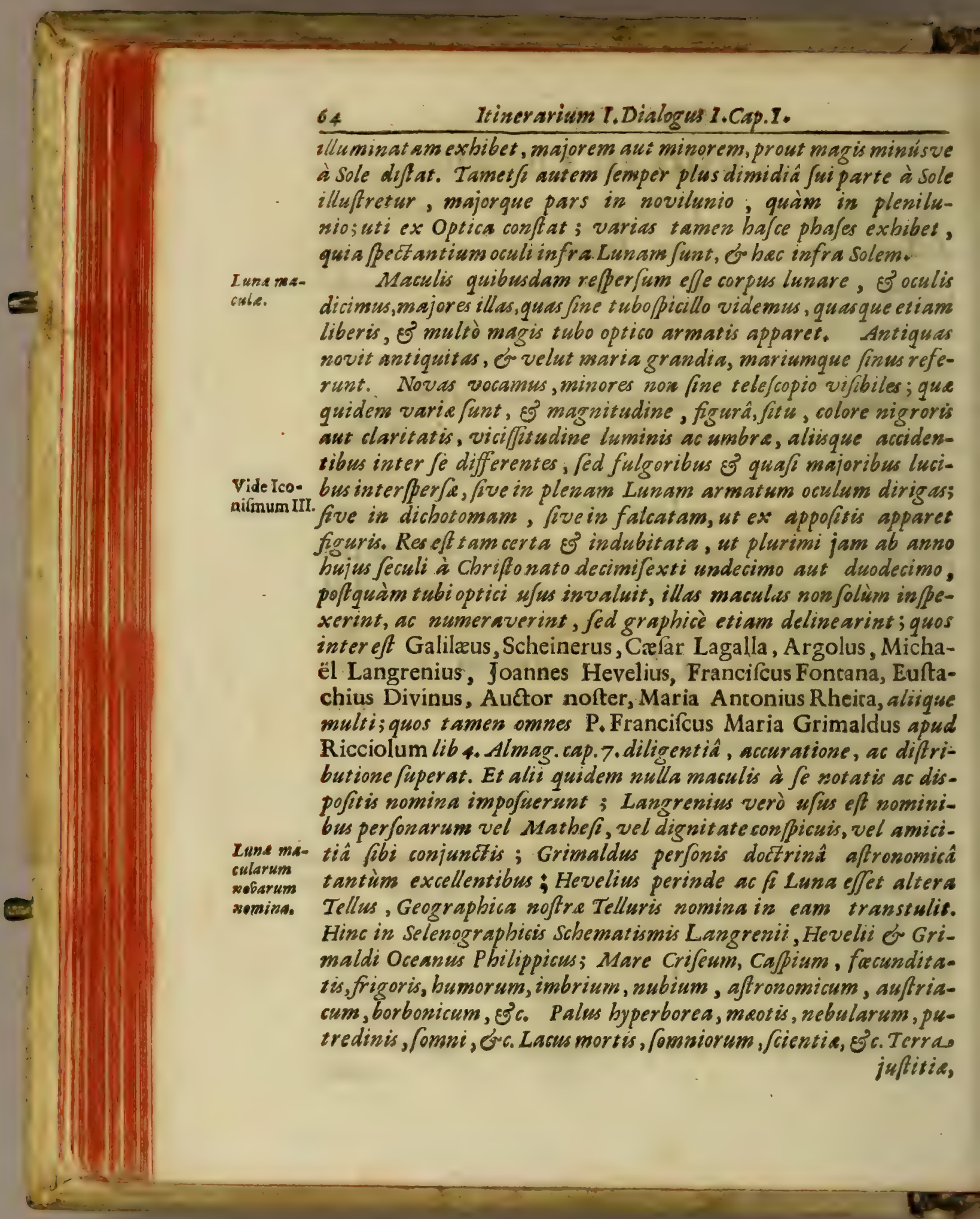




\section{Iconifmus III. \\ pag. 64.}

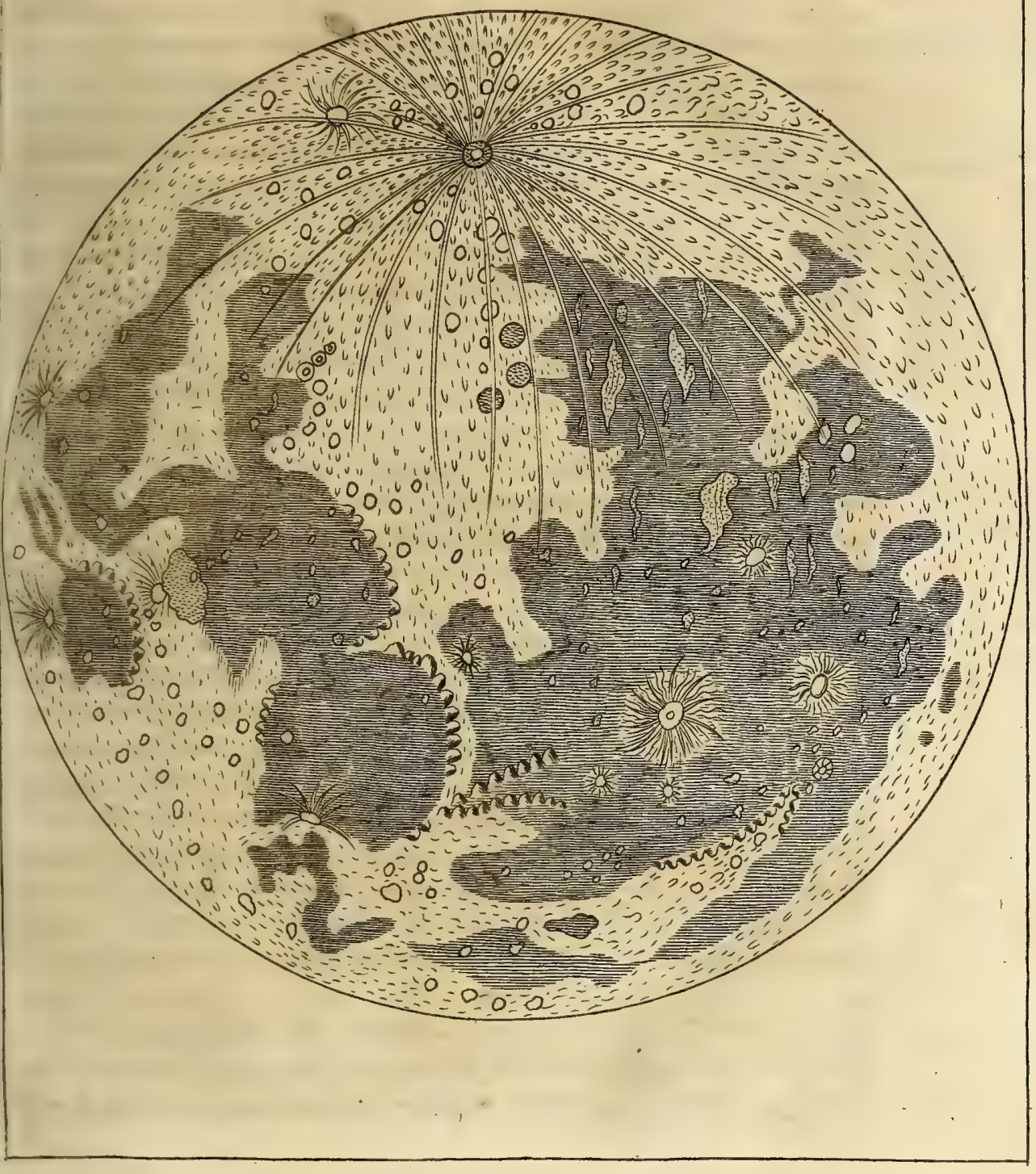





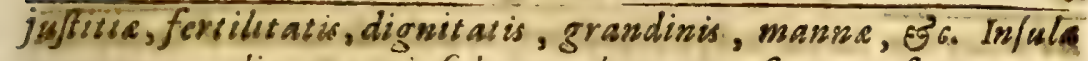
ventorum, aliaque peninfularwm, lutorum, finum, ftagnorum, montium nomira, prout ex parte apparet in pradict is diagram matis.

Numerus macularum novarum in fohemate Langreniana Nomenu. Iuna plene afcendit ad 270 is Heveliano ad sso. in Grimaldico ad 000. non griod plures now not a verint, (ed quia plures commit tere libris non placuit, feu propter earum exilutatem, (eu propter nimiam earum ferè copiam, adeo ui tota Lun superficies in plesilunio nabis. con/picua, bis velutiglobis ac lapidibus fit confper]a:prater majores, guemaria, (inusve marium, vel lacus, vel paludes, vel/yrtes, (copulósve, aut rivos E' flumina, aut in/ulas E' peninfulas, aut magnas. denique Telluris noftre continentes pre le ferunt. In tanto macularuno numero Ricciolus cum Grimaldoquatuor valde notanda obJervavit. Primum eft, quod minims quadam macule confertim in oblongo guodam tractu sta fibi proxinie fuccedunt, ut vel imperfeaf iori telefcopio, vel longè à termino univerfalis illuminationis peif at a videantur velut radiorum quorundam fulci; at fi inconfinio illumixatrowis pectentur perfectionibus tubis, videntur wsacula invicem distincta, non fecus acin Via lactea ftellarum congeries: Secundum $e f t$, quòd maculis quibstsdam alia minores fic adharent, vel innexe funt, wt gemme ansulis; vel fic inferte, ut portio unius portionem alter ius jibi ferè equalis obtegat ; vel fic circum obfe $\iint_{a}$, guafe coronat e monticulis, ut juxt a vici[fitudinem illuminationum aliquando veluti rofam, aliquando lacum pra fe ferant. Tercium est, quiod maculis quibusdam velut in uteris aut finibus infunt una vel plures minores, que umbrulam fuam verfus eandem partem projiciunt, ad quam vergit umbra macularum eas includentiü. Quartum eft, quòd alique in majoribus item ficincluduntur, ut umbram fuam in partem oppofitam umbre includentium projiciant.

Figuraantiquarum macularum pra fe fert maria, aut mari- Figura. mus fonus, continentes, infulas, or peninfulas, ut jam dixi. Figura novarum plerumque rol unditatem aut ellipfin affect at, fed in eadem macula non raro apparenter mutatur; five boc fiat ob librationem globi Lunaris circa fusm axem, ob quam accedendo

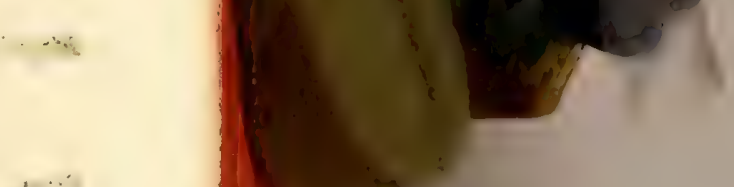




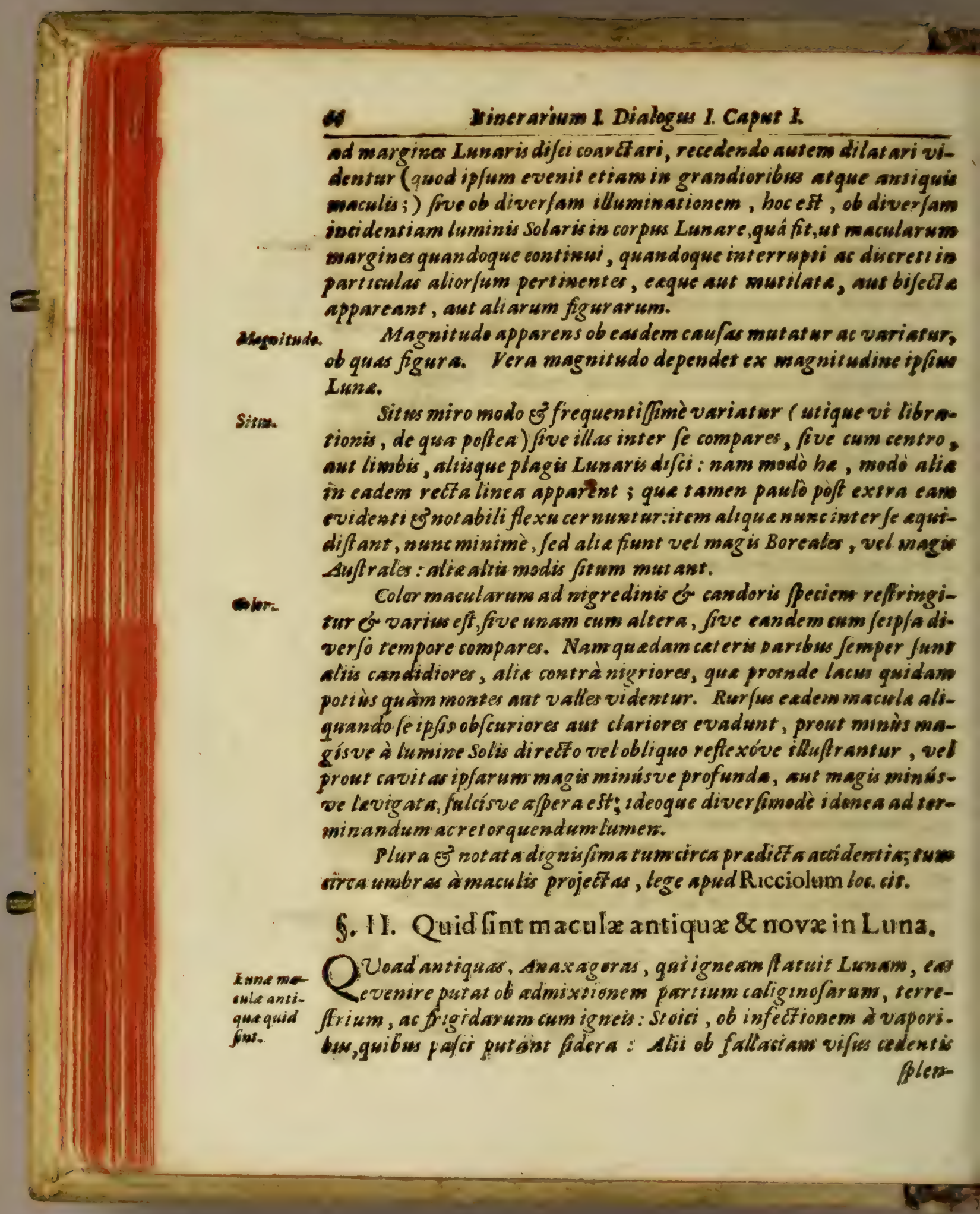


Auttoris.

Sendori pre imbecilluate. Sed conftantia illarum macularum in cadem femper figura, Iymmetria, $b^{2}$ fits, fat is refutat bas opinationes. Alivenfent, eas effe funclacra Oceani of marium, nofratium in Luma tanquam in peculo apparentium. Sed priwo magnes eft diffinuilitudo inter lunares maculas og maria terreftria, fout of inter clares Lune plagas or Terre noftre continewer, in fors, in figura, in magnitudine, st confideranti pacet. Deinde fi Luna peculum effei Terraquei bemi/pherii, macuLe viderentur in alio atque alio fot u Jeu loco Lunaris di/ci,pro diverfitate ftasionums oculorum, Go non omnes partes Telluris ad omrinm oculos diverfis in locis reflecterentur, ut ex Catoptricis confat. Alii multi exiftimant, difcrimen inter clares E' ob/curas Luse partes orivi ex diverfa rartiate $\sigma$ denfitate, diverfague diaphaneitate of opasitate: \& alii quidam putant, maculas effe in partibus rarioribus ac con picuis, co quìd lumen solis non fiftant in juperficie, nec totum ftatimque reflect ant, fed introrfuen penetrans abforbeant, nec nifor refractione admixtá modicam partem ejus reflect ant; alii vero exiftimant, easdem effe in partubus denfroribus so opacioribus, ut pote quibus parum luminis sol commusicare poffit. Prius tamen probabiliss videtur, ut poftea dicemus. Irague cum bac fententinfentio.

2uoad novas maculas, putunt nownulli eas fimiliter oriri Lane ma. ex mera raritatis $\varepsilon^{2}$ opacitatis differesatia. Alii communiter cule nube

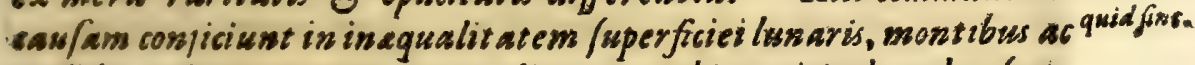
vallibur a/perate, quan inequalitatem, iubis opticis depreben/an, probant bifce argumentis. Primò. Lun non folim dichotoma jeus bs/ect a, fed etiam anse do poft dichotomiam, si twebo/prcillo pect at wr, lineam dividentem plendidum ipfius à tenebrofo habet tortuofans or laciniatam, $\sigma^{2}$ confinium illud manifefte anfrattuofumeft, ne Luns aber dum dentatum aut ferratom. Signum ergo eft, effe in ea partes a- rita bineliguas bumiler, aliquas elatiores : neque enim dici poteft ob/curas qu los fus parres,que anfractibus illis fe ineterferunt, ob Jum denfitatem aut opacitatem impervias efje lumini, cum pofte ca crefcente Lun e illunisatione clarefcant, \& è contrario illa, qua ant es lucebant, decrefceñ-

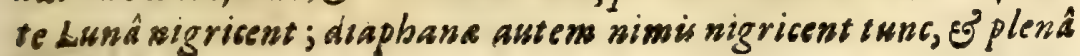

I a Luna




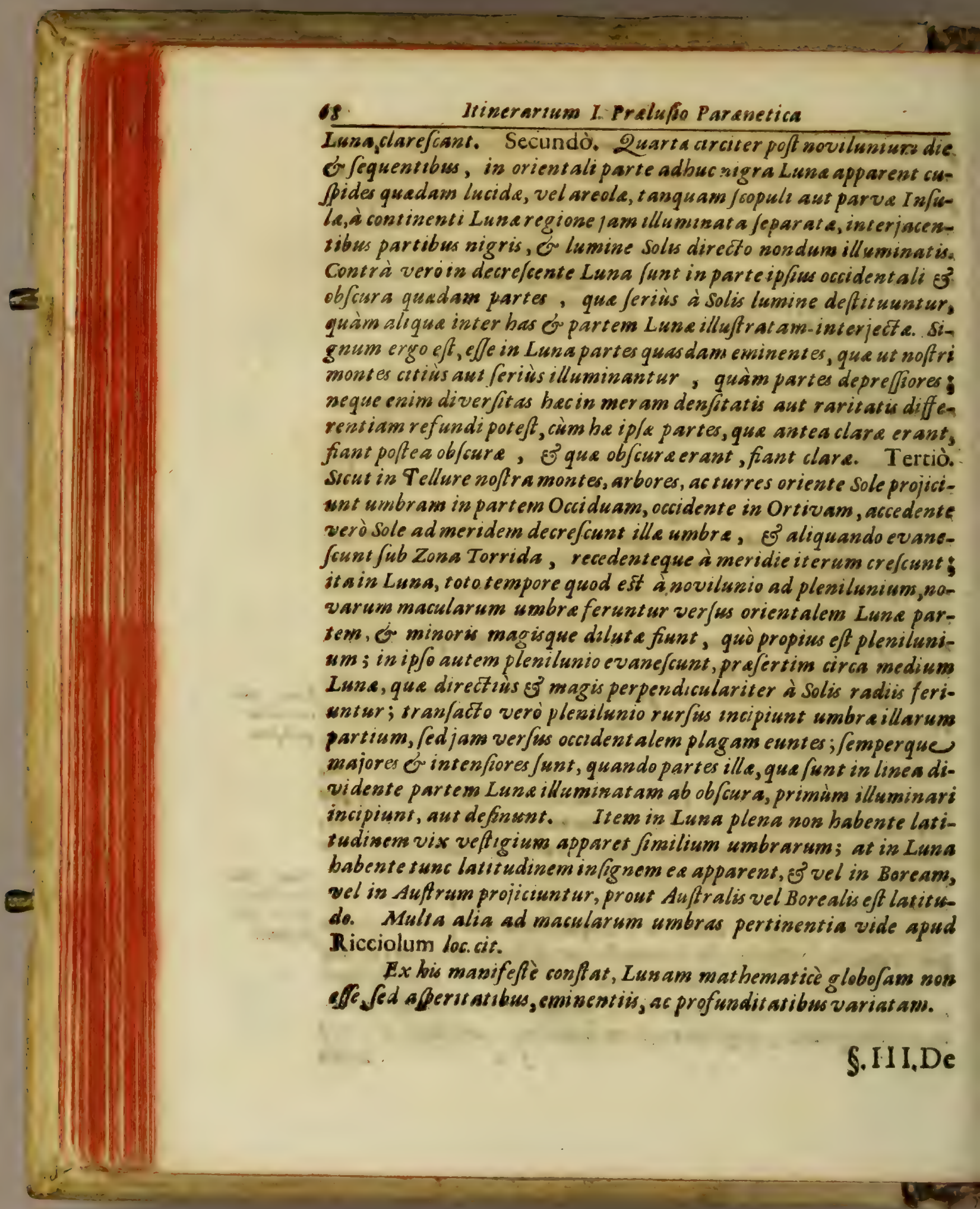


§.111. De Lunz atmofphra, \& maximo ejusdem dominio in humida fublunaria.

PEr at mo/pharam intelligo hî́ aërem vapidum, vel alivd Lune atmo1 quid aëri vapsdo E cra/susculo fimile, iircumfufusm Luna. Bhera. 2u.eritur igitur, an Luna fuam circa fe babeat atmolpharams ficut Tellus noftra fusm habet? Plurimi enim recentiorum post tubi optici ufum agnofcunt circa iplam aërem, aut denfiorem atherem, ut funt Keplerus, Mæetlinus, Galilxus, Longomontanus, Jordanus Brunus, David Fabricius, Antonius Maria de Rheira, Marius Betrinus, Langrenius, Wendelinus, Joannes Baptifta Cyfatus, \& Scheinerus, quorum duos ultimos sitavit, adduct is eorum verbis, Auctor nofter lupra in Pralufione Pararetica, quibus iple adbaret, forem explicat ac stabilit analogia defumpiâ ex noftra Tellure. Idem repetit in feguenti cap.2. ofeft $^{2}$ valde probabile, confirmaturgue ex proximè fequentibus de Lame sominio is bumida.

Maximum enim dominium Luna effe in bumida fublunaria, Lune do. $\sigma^{\prime}$ eam in bac inferior bumiditatem influere, patet quotidia. minium in nâ experientiâ, छo omnes fatentur. Hinc bumorer crefcente Lunầ humida. crefcunt, decrefcente decre/cunt. Et veriffrmè lib.z. cap. og. Jcribit Plinius, Lunam fidus effe, quod terras faturet, accedensque corpora impleac, abfcedens inaniat ; ideo cum incremento ejus augeri conchylia, \& maximè fpiritum fentire,quibus fanguis non fir ; fed \& fanguine hominem etiam cum lumine ejus augeri ac minui. Et cap. 101. Lumam fidus feemineum appellat ac molle, è quod bumorem folvat, glaciem refundat, ferarum occifas corpor a in iabem redigat, cunctaque bumifico piritu laxet. Notum eft omnibus, cancrorum \& concharum corpors Lune incremento augeri, decremento minui ; capillos छo ungues sre/cente Lunâ abjciffas citius cre/cere, quàm eádem defciente: Hinc regula of canones Columellie Es aliorum de re ruftica. Scriptorum, grotempore go qua at ate Lune cadende, plantande, eradicands arbores, $\sigma^{2} \%$ Galenus caufam morbormm pituito- 


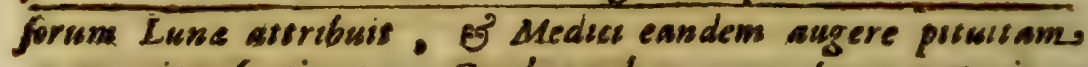
commusiter fenticust. Cevebrum basmanum Lien mutationes perfentifcit, \& Lumatici, quos vocant, certis Lunse cum Sole cossfigurationebus, ob cerebri tunc temporis nimiam huwiditateme. - L Luna aubzam affiguntur. Omitto ismumeres alian experientias.

\section{§. IV. De Lunx natura, atque Atructura.}

F $x$ dictis battenus, circe Lune naturam at que fruduram, quam precipue indag are volebam, hecft atuo.

Lane eft I. Luna eft corpeis denfum atque opacum, aptum ad solis corpus opa- lumess foftendums ac reflecterdum. Patet ex dict is $\delta$. I. de phafe-

bus Lune, ex quibus manifeftè patet, Lanans mut uari lumers à Sole, Gnullam babere infocam locem. Idem pater ex eclipfobus Lune, quasdoea nmbram Terreingreffa obfcuratur vel ex parte, vel totaliter. Secundarium antem lumen, quod in parte nobis adver/a non illuft rata is sole apparet, quando plena non eft, of aliquando etiam in novrlunies, eft lumen reflexun à Terra: fout enim bacilluminatur i Luna, reflectente lumen receptum à Sole; foc viciflem Luna iो Terra, reflectente idem folare lumen. 2uod ausem Luna ecliplas a adbuc obfcuram aliquam lucem referat, videt ur oriri is radic Solis refract is ad atmo/pheram terreftrem ver/us axem coni, quem Luna ecliplata eft ingrefJa.

Lusa eft
Sharica,

II. Luna eft pbarica. Patet ex dicf is eodem 9. I. de Lune non tamen phafsbus: nam ex ÿs colligitur, Lunam illuminari pherice, id eft, ce

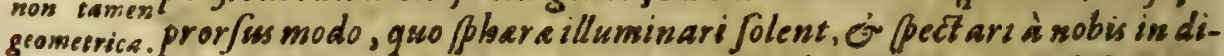
verfis fitibus; quem quidem modum quilibet experin poteft. fo atcessdai ad fucce [jo am illuminationem globorum inauratorum apicibus turrium impofitorum; aut fi pheram aliquam opacam in obficuro cubiculo Jupendat, E' alius lumen à longè circa ipjum Ef pher ans circumferat, it a ut is modo fit inter Jpharam \&ै lumen, nodò Sphere ixter lumen é ipfum, modioin alio fitu.

1II. Luiza non ef geometrice (pharica, id eft equa politag.

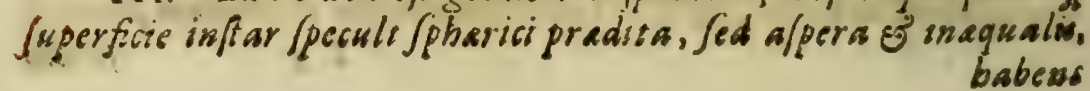


babeos parres alias eminentiores of extanter, alias depreffiores

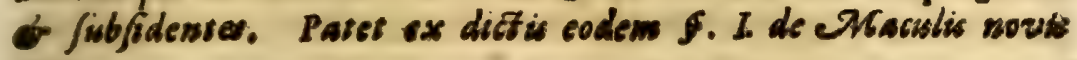
Iwre.

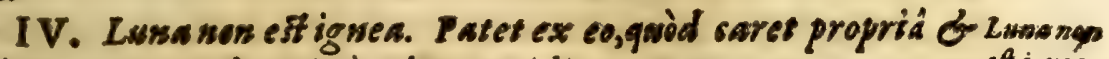
infícíluce, eamque baurit à Sole, ut vidimus. of ignea.

V. Luna conftat partibus folidis of fluidis. Patet ex dictis Luna coo6.2. \& 3. Nam macule ejus antiguse of nove grandiores, feupar. Pas partites ejus minus lumsne perfufe, optine explicantur, fo dicantur es fimidio. sfe fluida, que lumen salis receptum magis imbibant, of minis reflectant ; partes vero ma is illuftrats dicantur effe folide es confiftentes, of magis apti ad idem solis lumen reflectendsm. Certe fonvile quid pect amus in Terraqua noftra, quando ex alt isfrmu montibus eam contemplanur: licèt enim maria remota magio Plendeant quaim proxima terre, hec tamen plendidior apposet quim mare proximum è mostibus deßpectum, guod nigrorem guendam pre fe fere, wti non femel vidi in sicilia in altiffrno monte Erct a prope Panormom, of in altiore monte Veneris prope Drepanum, \&- in Sichtanis montibus è regione Melite, of è Netenfs arbe monti altiffmo prope mare lonism impofita, of alibi. Susdentur etiam partics ficce ac conffftentes Lune ex inequalitate ejus,

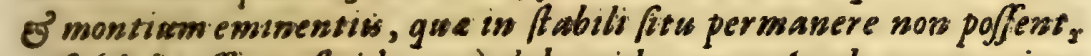
wifo fohdie effent: fluida verò br humida partes jwadent wr ex ejusdem Lunc influentios bumidis, que fortem effe bumidum argunt. Eidem compolstio ex partibus confiftentibus ac fusidis confirmatur ex Lons atmo/phorn, quam Auctores /upriscicati circaiplam agnofownt.

VI. Probabile eft, Lunam effe terragueam, noftrogue Ter. Luna eft raqueo globo fimilem, adeogne ex terra \& agsa compofit am. It terraguess. fenvisunt quamplurini suctores apud Ricciolum lib. 4. Almag. cap. 2. nimirum Pytbagorai , Thales Milefius, Heraclides?, Democricus, Zeno Ciricus, Macrobius, Longomontanus: Keplerus, Maeflinus, du alii, quibus adheret P. Der-Kennis in Opere fex dierum Die Mundi 4. cap. 2 . E Auctor nofter cap. Fegrenti, $\sigma^{2}$ lib: I. Artis Magne Luces $\sigma^{2}$ Umbre capp: 4. Certe fhuidas Luna parter aguam effe, fatis probat dominium ejus ino bumida 


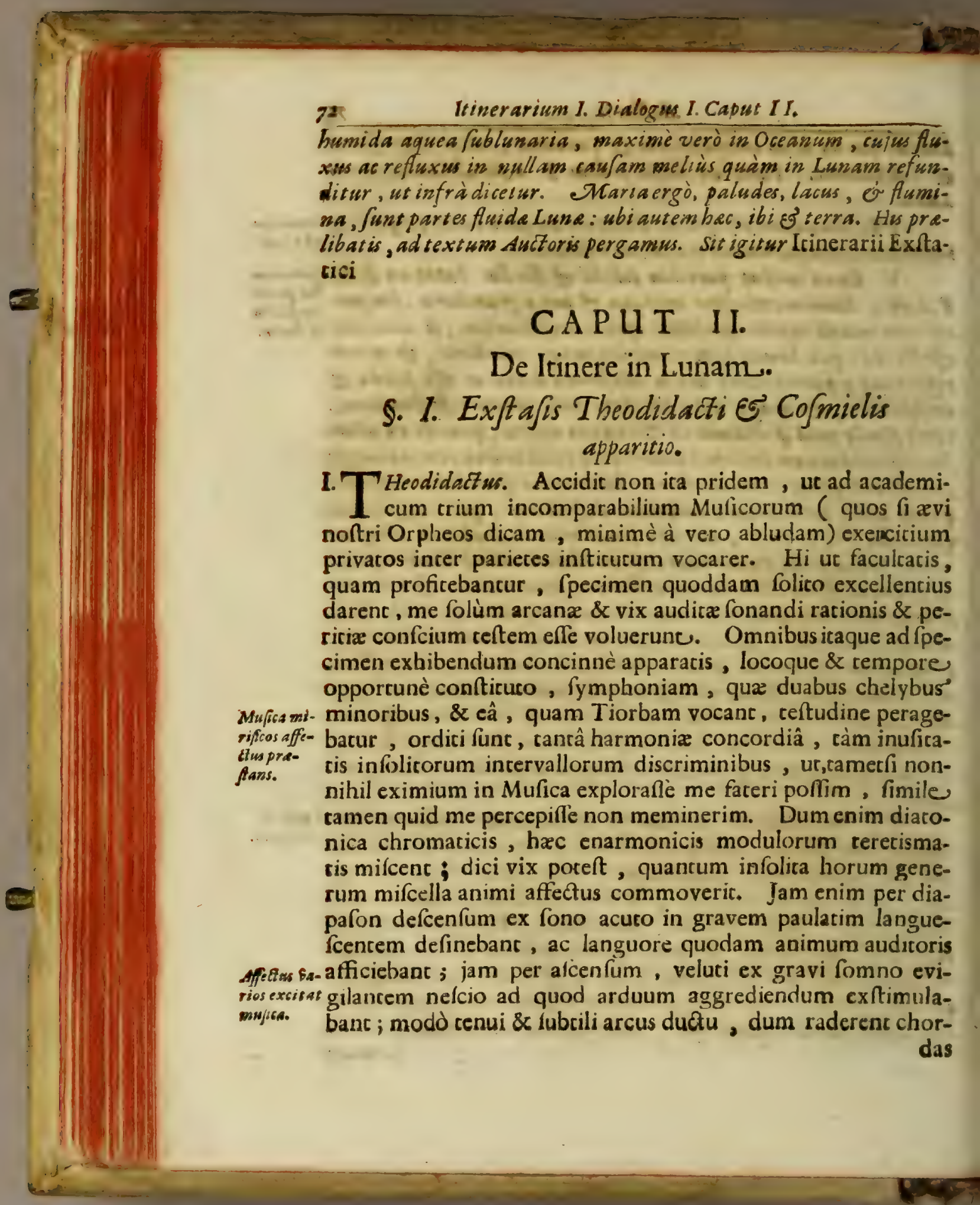


das, unà lecum cordis fubfulcantis f piricus follicitare vi!ebantur ; nonnunquam fubtrifti murmuris indignatione affectum ad nefcio quid mœetum luctuofumque conirabant , tragica fcena te interefle diceres : mox ex fubtrifti modulatione paulatim ex remiffis in f́pillos, incenfos, \& plenos gaudii ac cripudii chromatifmos tanto impetu rapiebant, ut parum ab. fuerit, quin lymphatico quodam me furore obruerent; fubinde in nefcio quid tumultuarium \& vehementis ferocia plenum exurgentes alternis infecutionibus, animum ad pralia, \& pugnas incitabant, remifloque denique imperu, in nefcio quid dulcioris affectionis proprium, ad compafionem, divinum amorem, feculique contem ptum ciebant, tancấ graciâ \& venuftatis majeftace, ut veteres illos Heroës Orpheum, Terpandrum, carerosque famà nominis apud pofteros celeberrimos Muficos ad fimile artificium nunquam pertigifle planè mihì perfuadeam.

II. Hac iraque incomparabili fane fymphoniâ delibu. tus animus, exotico quodam affectu in mirificam coeleftium, globorum harmoniam rapiebacur. Hîc omnium \& fingulorum hujus mundi corporum confenfuum diflenfuumque leges contemplabar ita ordinatas, ut dum fingula confona diffonis abundent, omnia tamen in omnibus ad confervationem Univerfi intentam harmoniam confpirare reperirem. Cùm itaque prædicta fymphonia fpecies in varias phantafinatum imagines animum jam harmonicis modulis pra. gnantem agitarent; factum eft, ur,dum quodam die Dei ter Opt. Max, unicè fefe in admiranda \& incomprehenfa Mundana fabrica conftitutione exerentis fapientiam folito ferventiủs contemplarer ; ecce derepente veluri gravi quodam fopore perculfum in vaftiffima quadam prati planitie me confticutum putabam : Et protinus mihi infolitæ conftitutionis vir adftitit : caput ejus faciesque miro quodam fulgebar jubare, oculi carburculorum inftar corufcabane, habitus torius comielws corporis exotico\& invilo hucusque veftimento conftituebatur, fiquidem admirandâ quadam in formam alarum complica- 
carum exturâ ica adornabatur, ut nullum fetè colorum genus, quod penna'cjus non exprimerent, concipi aut animo fingi poffic; manus pedesque omnem lapidum pretioforum. nitorem fuperabant, dextrâ fpharam geftabat, in qua quoc vagantium fiderum orbes, tot ex lapidibus pretiofis diverfi coloris fpharula eidem inferta fpectabantur; mirum vifu opus ; finiftrâ menforium baculum gemmeo artificio apprimè elaboratum, \& mirâ arte diltributum gerebat, Ego ad inufitatam \& prorfus humano oculo in hunc usque diem invifam fpeciem penè exanimatus, affixusque humi, obftupui, fteteruntque coma, \& vox faucibus hafic. Corde itaque palpitante, \& medullis omnibus obrigefcentibus, cùm fpiritum. vix traherem, nec tantum mihi virium fupereflet, quantum ad verba formanda fufficeret; audivi vocem, fuprà quàm dici poteft, blandam, fuavem, \& amabilem, hoc verborum contextu refonantem: Co/micl. Surge, nè timeas Theodidacte; ecce exaudita funt defideria tua ; $\hat{x}$ ego ad te millus fum, ut tibi fummam Dei Optimi Maximi Majeftatem, quantum humano oculo in hac mortali carne conftituto permiflum eft, in operibus fuis mundanis elucefcentem monftrarem. Ego verò infolitâ illâ coleftis viri voce exciratus, viribusque priftinis in momento recuperatis, refpondi : quis es tu,Domine mi के \& quinam eft infolitus ille, quo adornaris, habitus ? Is refpondic, ego fum Cofmiel,minifter Dei altifimi, \& Mundi - Cupefis Genius. Capitis jubar, quo me radiare confpicis, Cherubifrmb be'um ca intelligentia fplendorem indicat; oculi carbunculorum inquibus $2 x-$ ftar corufci , funt illuminationes divina, quibus indeficienti frsebatur Cospoisob. fupremi Numinis confpectu illuftramur ; pennatus innumerâ colorum varietate decorus habitus, fublimitatem intelleAus innuit, quo rerum omnium à fupremo Opifice in hac Mundi machina conditarum innumeras virtuces , \& arcana Natura facramenta penetramus, \& adminiftramus; fphxra, quam vides, fiderei Mundi prafidium fignat; baculus gemmeus, quo juxta leges à Deo prafcriptas omnia menfuramus, \& in concianifimam harmoniam difponimus. Tu verò fi- 
li ni, quaxcunque à me impolterum didiceris, ea alco pectore conde, divinamque milericordism erga te roti mundo propalaco. Ego verò Theodidactus profundâ quadam admiratione attonicus, in haec verba veluci Numinis aftlacu corre; cus prorupi.

III. Theodidactus. Er quisnam ego candem, cinis \& Apofrrophe pulvis? quis ego vilis terra lumbricus, in peccatorum volu r-eodidadt Deum Creacorens meum loquiaufim ? Egóne cacuciens nycticorax in ignorantia mex tenebris natus \& educatus, oculos meos immundos, torpidos, debiles, \& impotentes ad lumen illud, quod in profundo divinitatis receflu abdicum, onnem humana incelligentia fublimitatem longè excedic, inveftigandum dirigam ? Sub ce curvari video qui portanc Orbem; Seraphicos fpiritus alatis vultuum velamentis obvolutos incomprehenfam Majeltatis glorix tua magnitudinem cum cimore \& tremore teftari confpicio. Ergóne coram Summa Majeftare rua ego luceo habitaculo circumdatus, os meum aperiam., ad cujus confpectum vel ipfa mundi fundamenta contremifeunt, columnæ Orbis terrarum labefcunt, montium magnitudines liquefcunt, colles uti cera defluunt : fatur ad non ens", \& producitur ; alloquitur ens, \& in nihilum redigitur ; ad mundum clamat, \& expanditur, minimoque digito colorum meticur expanfa, \& manus ejus fphærarum tentoria complectitur; qui pracipic Soli, \& non oritur , \& ftellas claudit veluti fub fignaculo; qui facit magna , \& incomprehenfibilia , \& mirabilia, quorum non eft numerus. Quis ego fum purredo fuperba, qui involvam fentencias meas fermonibus imperitis": An non mecuendum mihi facrum eloquium cuum; qai fru. tacor est majeffatis, opprimetur à gloxia? Sed tu lux lucium,. vita vitarum, fpes \& dulcedo cordis mei , mex condonabis temericati ; fiquidem tu ex vena lucis intellectum hominis eduxift; tu eum lumine ex veftimentis glorix tux defumpro induifti, non alia de caufa, nifi ut te cognoferet, cognofcendo quareret, quaficum aternum amaret. Tubumanæ menti cuK 2 riofitacis

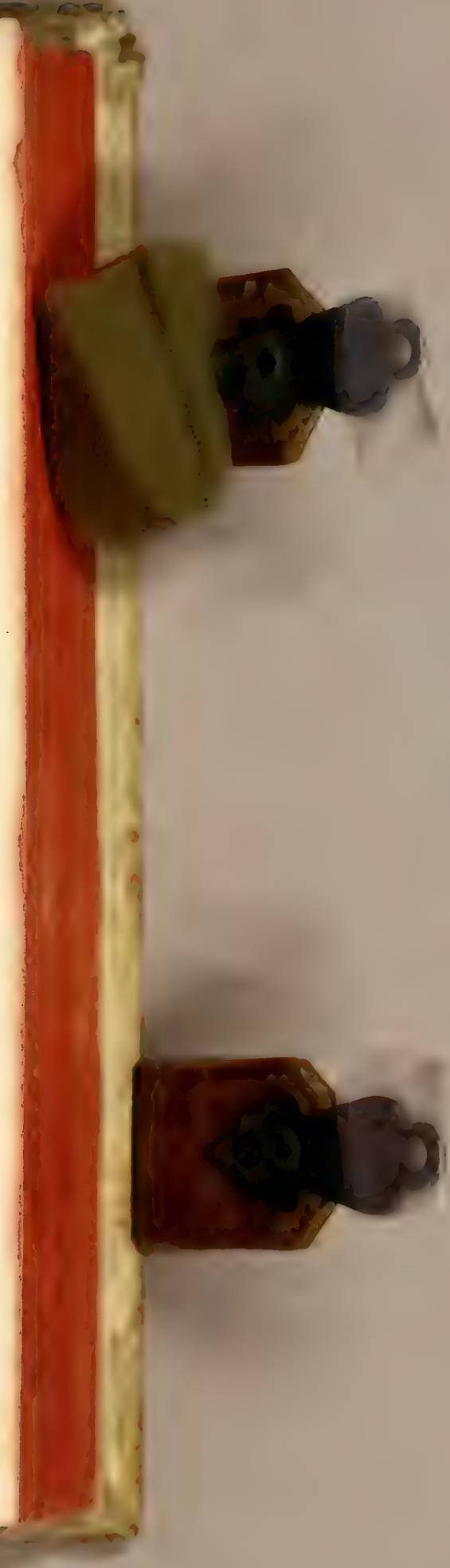




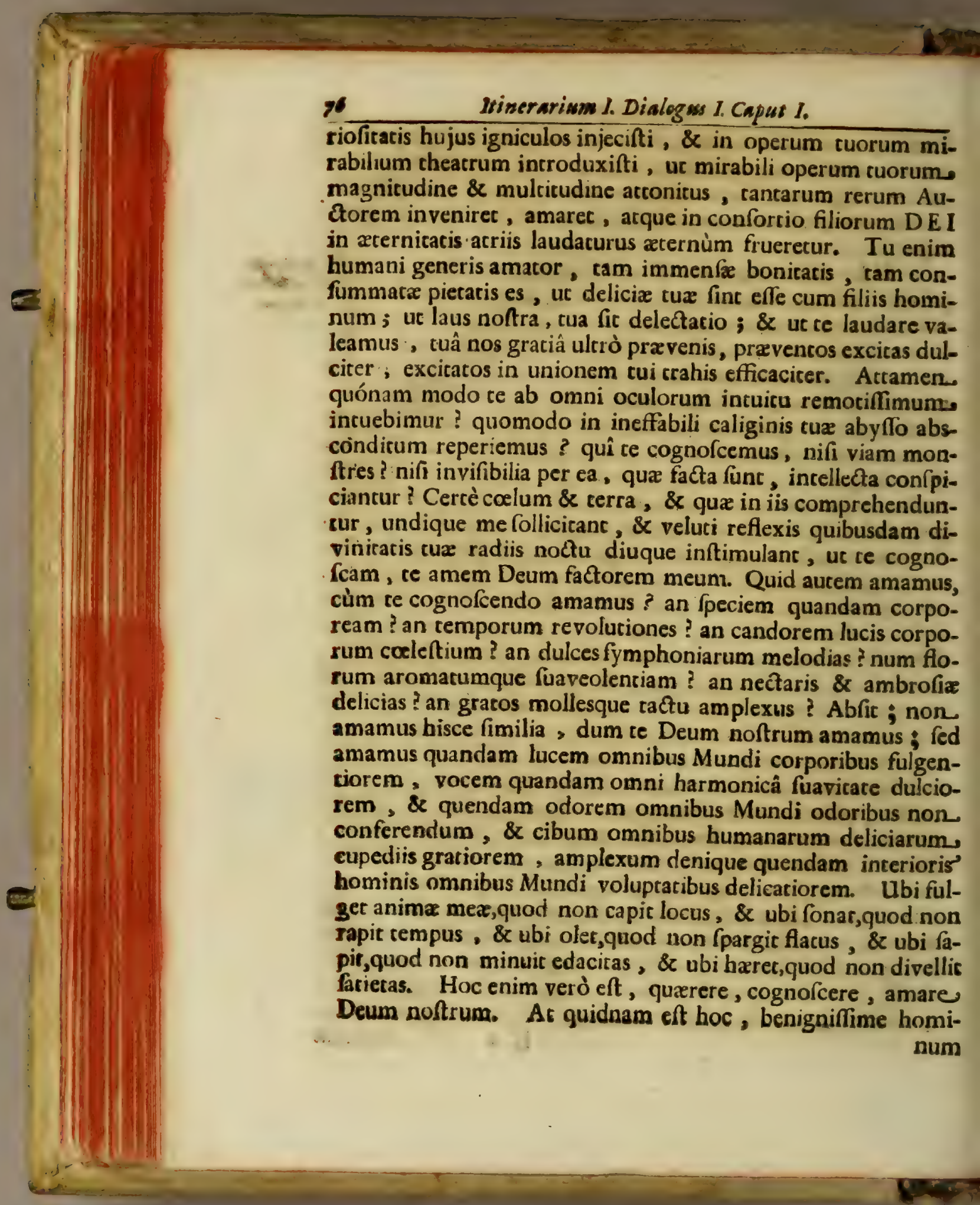


num amator ? interrogavi cerram, \& omnium animantium œconomiam; audivi abyflos, \& reptilia vivencium , quorum non eft numerus ; \& refponderunt, non fumus Deus tuus, quare fupra nos : interrogavi dulces auræ flabilis fufurros, \& dixe. runc,non : circumivi fphararum coeleftium cencoria, vaftiffima coelorum habicacula perambulavi, anxiè quafivi, ánne vos eftis quem diligic anima mea ; ar dixerunt, non fumus, fed iple,qui fecic nos; qui enim fecic adeò magna, major eft nobis; qui produxic adeò pulchra, pulchrior eft ; \& qui fecir adeò bona, infinitis parafangis melior eft nobis. His itaque incitatus, confifusque in immenfa bonicatis tua clementia, confideravi opera tua admiranda, \& expavi, \& ex colorum gloriam tuam enarrantium affiduâ expenfione , omnipotentis virtutis cua dexteram obftupui, bonitatem immenfam in omnibus elucefcentem cognovi, infinitum tuum erga genus humanum amorem, \& incomprebenfas prudenria tua femicas luculenter confpexi. Ac quid eft, quòd tantâ filios hominum afflictione involveris, ut non cognofceremus opera, qua operatus es, DEUS nofter , ab initio usque ad finem?

\section{SCHOLIUM I.}

NOn figmentum, fed biftoria est, qwam initio capitis recitat Andfor de trium Mufficorum concertatione, oui interfuit. No-

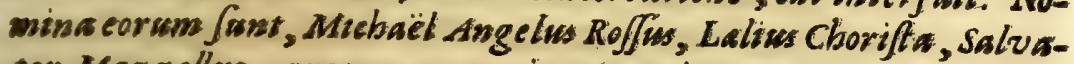
cor Mazzellus, quos omres novi. Somnium Auctoris, de quo in Prafatsone fuprà mentionem feci, contigit, ni fallor, nocte proxiwá à dicta concertatione.

\section{II. Exftaticum iter in Lunam.}

VI.T Heodidactus. Vix hac accenfe mentis aftu effudeI ram, cùm ecce Cofmiel fuis me complicarum, qua ex larere emergebant, alarum remigiis, duarum verò.qua ex humeris emergere videbancur, extenfione, fupra omnia ter- 


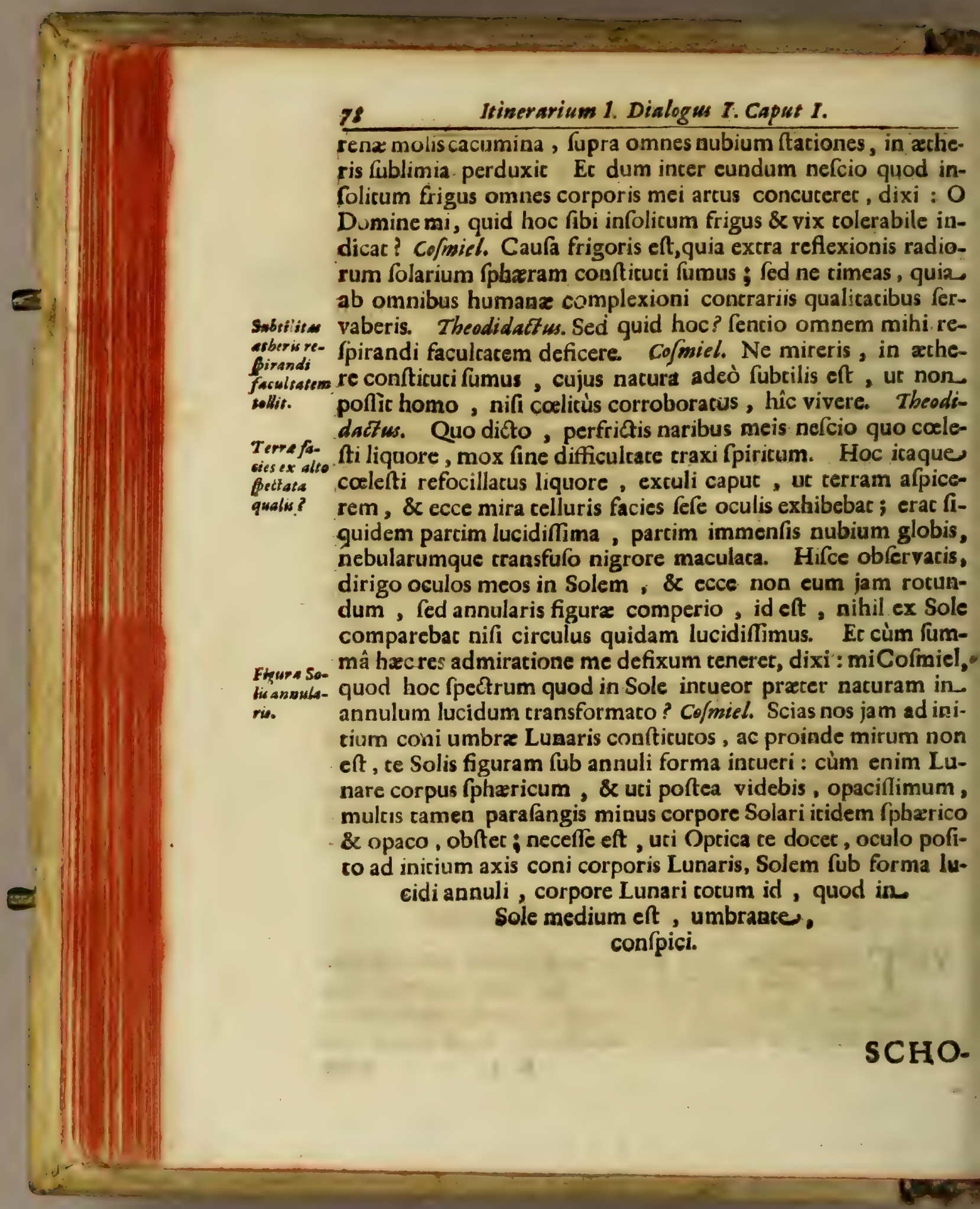




\section{SCHOLIUM II.}

\section{De annulari eclipfi Solis vifa ab elevato fupra Terram.}

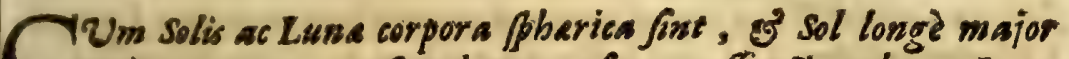

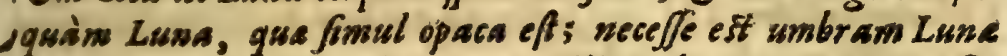
soli object conicam elle, of in conjunctione luminarium verfus Terram projici. Tantò autem brevior eft conus feu axis umbre lunaris, quantò sol Terre vicinior, Linna verò remotior eft, ut umbre loex Opticn patet. It aque Sole exiftente perigao, É Lunê apo- naris corpoced, brevior eft umbra predicta, quàm sole apogeo of Luná peri- da. geá, du quàm velutroque planetầ apogeo, vel utroque perizeo. 2 santa astem fit, ex variorum Aftronomorum fententia, dicte umbre longitudo, docet Ricciolus lib+4. Almag. cap. 17. Probl.6. ex guo loco colligitur, apicem umbra lunaris confiftere aliquassdo ciera', aliquando wltra Terra fuperficiem, Ev aliquando pracisè ferè in finperficie Terre , in noviluniis eclipticis ; $\theta^{2}$ conequenter Solis eclipfin polfe aliguando efje totalem fine moras, aliquando totalem cum mora, aliguando annularem., relibto filicet circa Solem esliplatum arnulo lucido immuni ab eclipf. Et in boc ultimo cafu diameter apparens solis eft major guàm diameter apparens Lunc. Fieri igitur poteft, ut quis Exlippss sols non folum in Terra exiftens, fed etiam ì Terra elevatus, in aëre annularis conftitutus, fot citra apicem coni umbre lanaris, in conjunctione luminarium, atque adeo tunc ßpectet Solem transformatum in annulsom lucisdum; quod Auct or nofter innuit, ac meritò, cùm iple lib. 9. De Lum, do Umb. par. 2. pag. 739. attribuat diffantice Lane apogea aे Terra femidiametros Terra 67, axi verò feu longitudini umbra Lune apogea multi att ribuant folum femidiamebres Terra 57, E Ricciolus tant iom 53. Vide que dicimus in fequenti scholio.

Scio multos, qui negant, diametrum apparentem Lune effe usaquam minorens diamerro apparente solis, Jaluare ecliples ansulares è Terra pectatas per refractionem luminis vel in folari, 


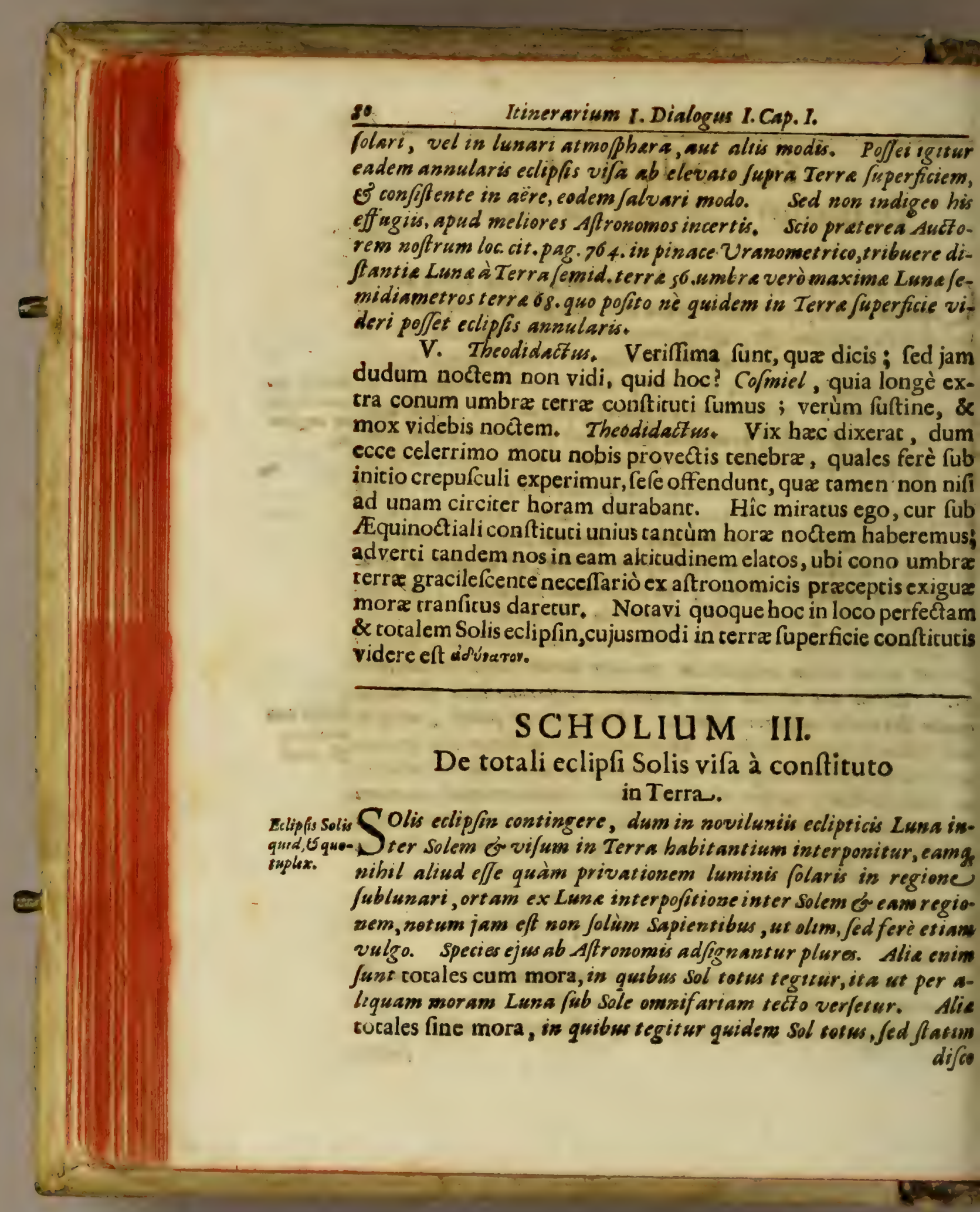


difco operiri ex parte incipit. Alie parcuales centrales, quias dnnulares appellavimus scbolio precedenti, in quibus it a tegleur of it Luna, ut iamen lucidus adbuc circa Solem annulus; feu veluti lucids corona circa Lunam appareat. Et bas tres feccies aiunt contingere Aftronomi, quando \& quibus latitudo Luns apparens f bujus enim, bon ver e ratio haberidebet in eclipsibus) aut nulla, aur penè nulla est; feu cuin rett a linea ex ocules pect antum per centra luminarium duci potést. Alie denique funt partiales corniculares, in quibus pars solistect a Luna apparet lunata, feu inflar Lesna finuate in cornua.

- Vt centralis feu axnularis eclipfis fiat, umbra mera Lune non debet pertingere ad Terram fuo mucrone; ut totalis fine mo. ra, pertingere pracisè ad' ipfam debet; ut denique totalis cum mora, ultra Terre fuperficiem verfos centrum ejus dictus umbra musro fen apex pertingere debet. 'Dari pofje eclipjes Solis totales, in quibus tot us Sot iे Lunategatur, negat Tycho Brahe tom. I. Eclippes. So. Progymnaf. pag. 134. quem lequitur Mulerius in Tabulis Frifi lis totales cis pag. 4.26. Longomoncanus in Aftronomia Danica lib. 1. daripofTheoricor.cap. g. Rationem adfgnant, quoniam in luminarism conjunctione ecliptica dianseter apparens Lune femper minor reperitur, quàm diameter apparens Solis. Contrarium fentiunt ownes Aftronomi antiqui os recentiores, quos magno numero citat of lequitur Ricciolus lib. s. cap.20. isbi affert 22. ecliples totales ex biftoriss collectas. Rationem adfiguant, quia major potest ac folet effe in eclipticis copulis apparens diameter Lunx, aut non minor, quàn apparens diameter solis. Auctor nofter híc lequitur priorem/ententiam; quod merito mireris, quoniam is lib. 0 . de Luce $\sigma^{3}$ Vmb. pag. 739. diametro apparenti Solis apogei tribuit grad. $30 \cdot 20^{\top}$. mediigr. $30.54^{1} \cdot$ perigei, gr. $3 r_{0} 28^{\mathrm{T}}$. at diametro apparenti Lans apogax in copulis tribuit grad. 20. $22^{\mathrm{1}}$. perigea verò gr.34.40'. Nifs dicere velis, eum folum velle, in Terra fuperficie conftitutos non poffe videre talem eclipfin Solis totalem, qualis in aëre conftitut is apparet, nim. tam perfecta, $\mathcal{G}^{3}$ cum tantamora, quoniam ibi Lune diameter longè major apparet, propter vicinitatem oculi.

VI.Theo- 


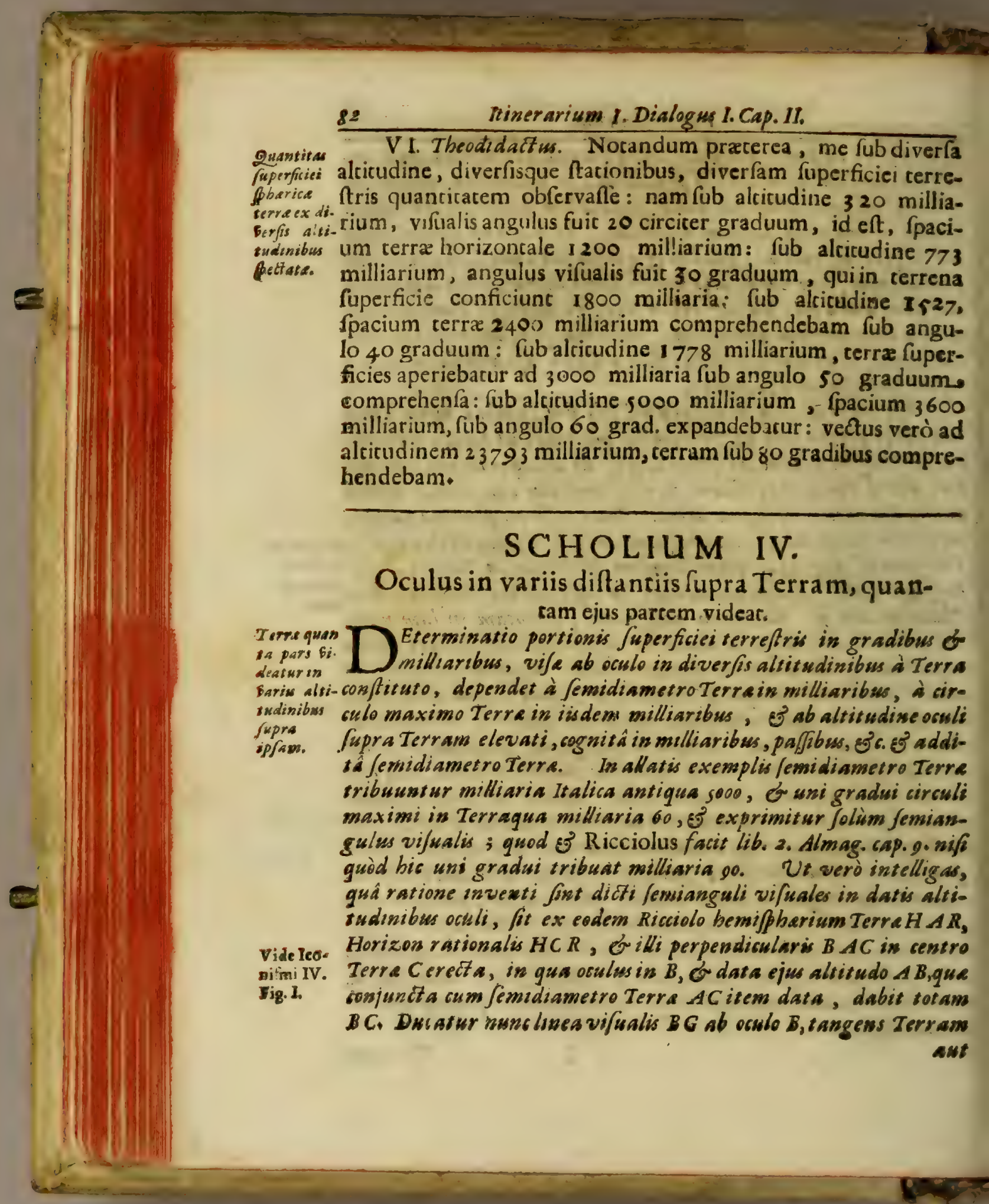


mata

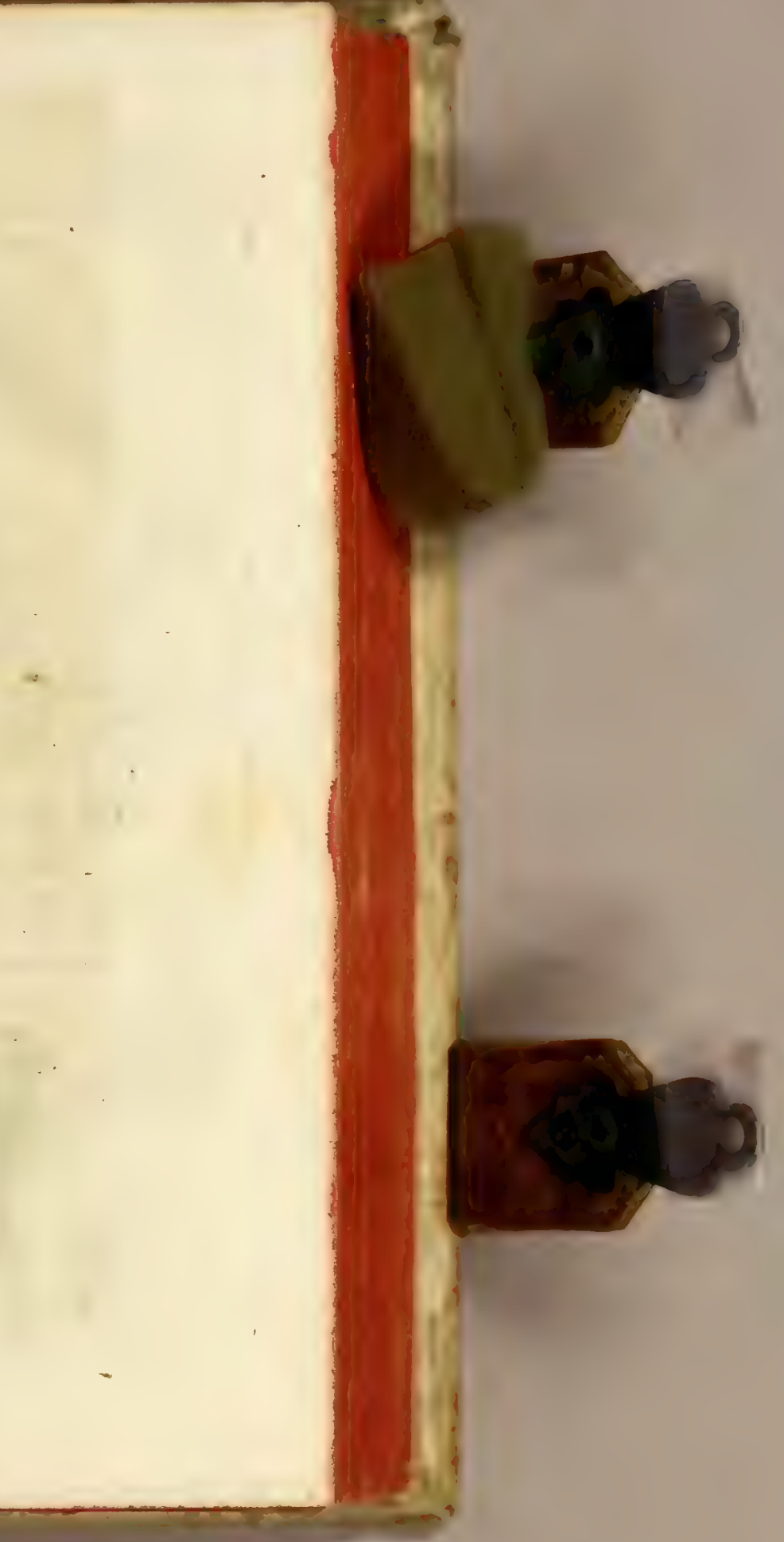




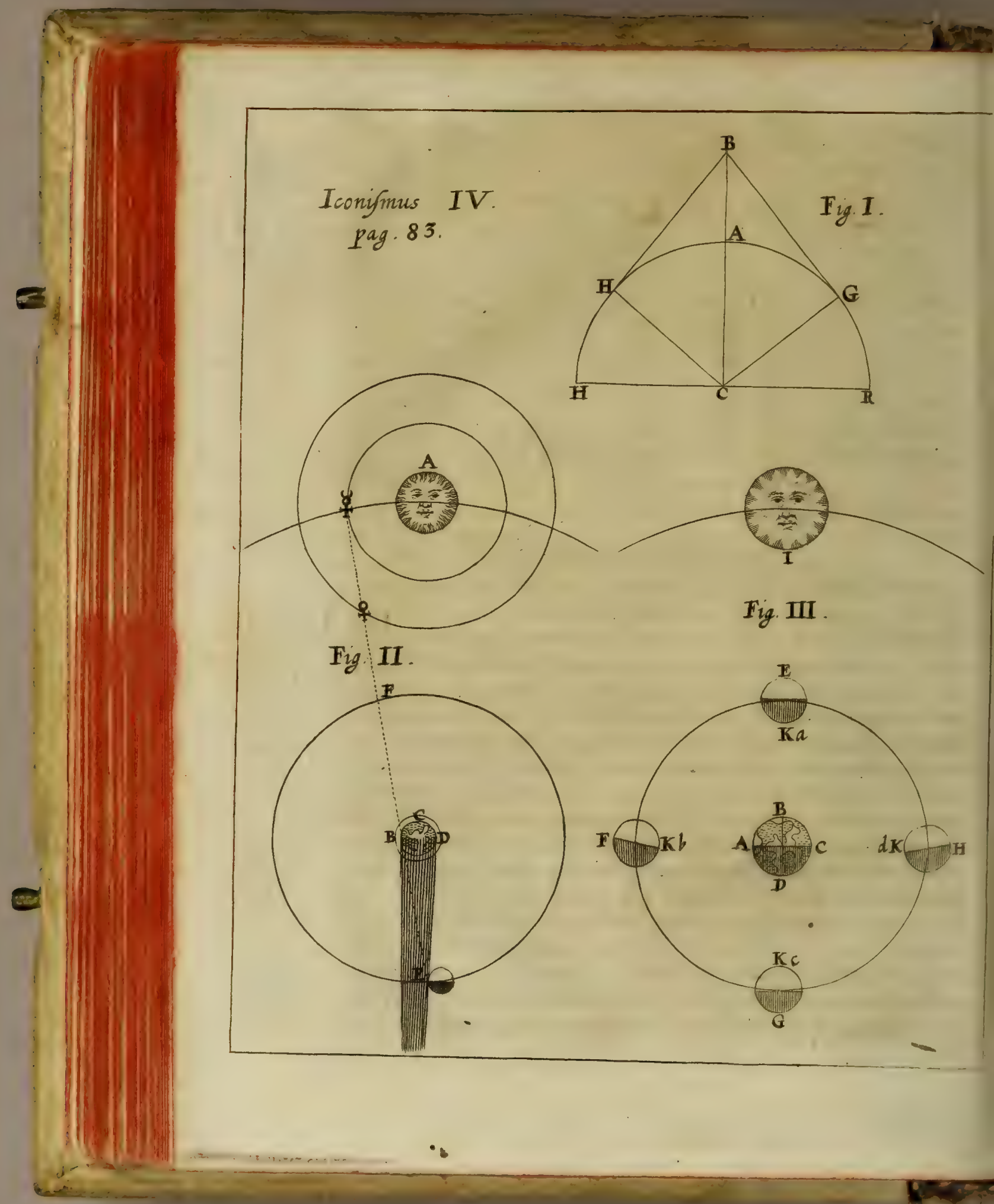


ant Mare in $G$, Ed ad punctum contactus $G$ ducatur ex centro $C$ rect a $C G$ : faciet ea, per 18 Terii F.uclid. angulum redium cum, tangente in pundto $G$, \& triangulum $C G$ B erit rect angulum ad $G$. In quo triangulo cùm data fit bafis $B C$, El latus $C G$, dabitur per Trigonomet. pract. angulus $C B G$, i fiat ut bafis $B C$ ad finum totum, it a latus datum $C G$, feu ferwidiameter Terre, ad finum anguli $C B G$. Hicfofubtrabatur à go, habebitur angulus $B C G$ quimetitur arcum $A G$; o bic in milliaria converfus oftendet diftantiam, ad quam fe oculus in $B$ conftitutus ext endit ver $\int u s$. Hunc arcums $A G$ f duplices, habes totum arcuir $G A H$, quem comprebendit vifus in Bconftitutus.

VII. Multa hoc loco admiranda fanè fpectacula fefe ob-Terra qud tulerunt. Primum fuic T erræalcerum Lunæ. Terra fiquidem formá exe inftar immenfe fphæricæ figura montisque apparuit; quam alto comdum diligentiùs infpicio, ecce totam maculis innumeris offufam, \& fupra Luna lucem corufcam reperi. Macula in diverfa difci terreftris facie jam fubitò crefcebant, modò decrefcebant, paulò pòft in varias figurarum fyftales dilatabantur, jam conftringebantur, nunc hanc, modó illam partem terreftris difci offufcabane; nonnulla fubinde umbarum inftar, interdum ad inftar lucium feu corufcantium nubium fpectabantur, nonnunquam tota facies terræ, fuprà quàm dici poteft, illuftris fpectabatur non undequaque, fed obfcuriufculâ quâdam diverfarum figurarum luce interfufa. Hæc dum oppidò mirarer , Cofmiel advertens defiderium meum dixit, Cofmiel. Macula, quas vides, \& miraris tantoperè, nihil aliud Maru'arums funt, quàm nubes per cerrenam fuperficiem divagantes; qua- $i t \mathrm{rra}^{6} \mathrm{bi}$ rum inconftans natura \& qualitas eft, crefcere fubitò, \& mox alto barieubi creverint, aliis identidem in diverfis terræ partibus fuc-tas. crefcentibus, interire. Quòd verò nonnullas fufcas, alias lucidas videas, id Solis lumen eft, qui lucem ipfis pro ratione denfitatis auc raricatis confert. Varias quas induune figuras non eft quòd mireris, cùm tibi experientiâ notum fic, quàm inftabilis fic nubium natura, quàmque ea è terra confpecta in varias abeant figuras : plura fimilia hujusmodi fpectacula.

$$
\text { I } 2 \text { in }
$$




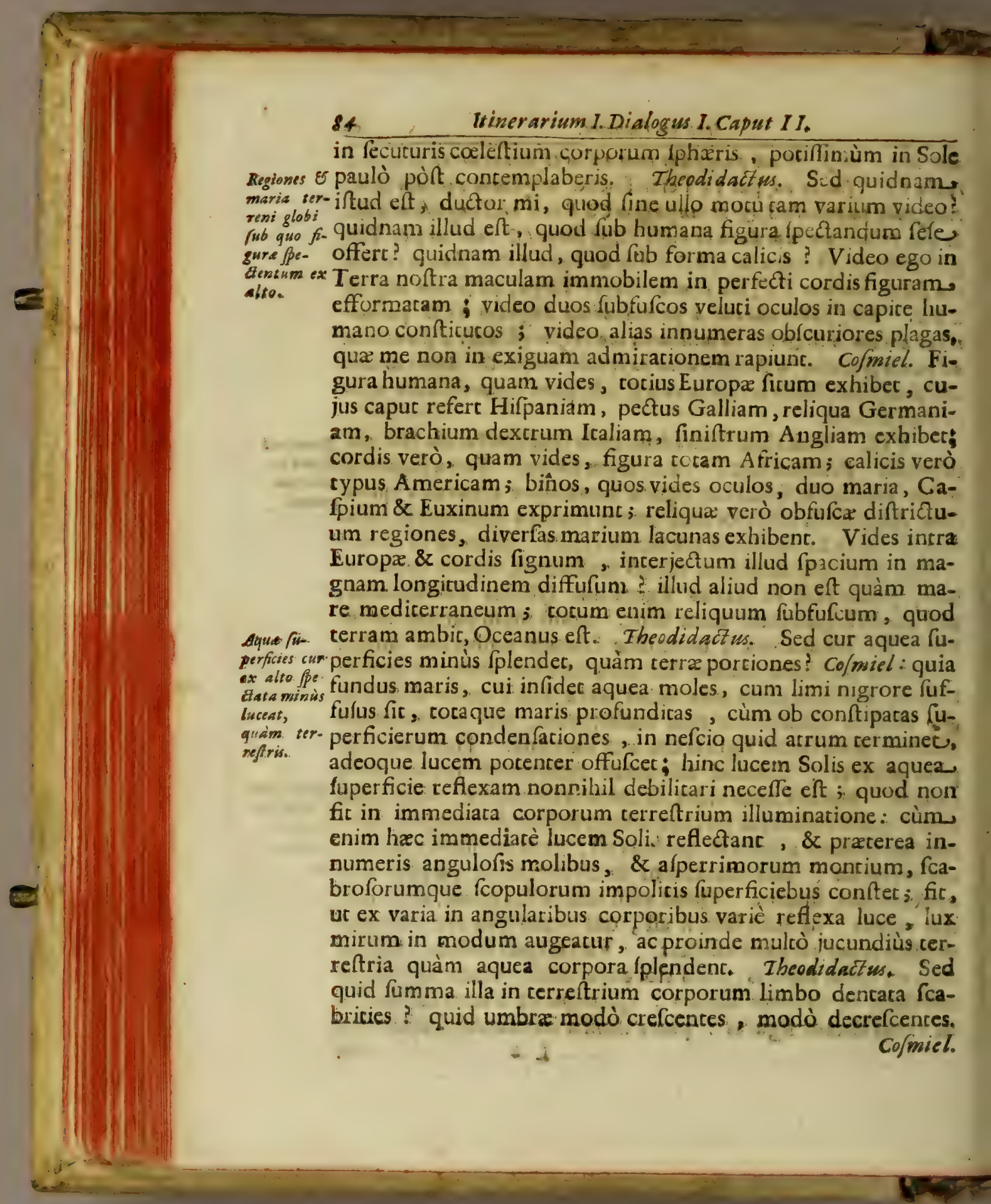


Co/miel. Scabrities, quam in limbo cerreltris globi vıdes, ex una parte Caucafi juga concatenato montium ordine protenfa ex alcera montium A merica, quos Andas vocanc, concatenaci vercices funt. Theodidactius. Sed quid quafo illud intenfum lumen eft, quod oculi mei vix fuftinere poffunt, \& circa partes tam Aufralis, quam Borealis cerra oculos meos tam potenter ftringit? \& quid immenfus ille tractus circa Aufrinum terrapolum fufciori colore dilutus ?. Cofmiel. Lumina illa relu- Glaciales (5) nibofe centia, quibus partes cerra tam Boreales quàm Auftiales collu- rerra partes cere vides, nihil aliud funt, quàm maria glacie conftricta, mon-ex alto $\beta_{e-}$ tiumque juga perperuò nive candentia; qua cùm lucis folaris ate incapaciflima fint, quin \& ipfa lucem exfefpargant, hine fit, ut $t^{t}$ receptis folaribus radiis vehementi intenfione lucem augeant : tractus verò ille circa Auftrum longâ, intercapedine procenfus, rerra Aufralis, Europais adhuc incognica regio eft. Theodidactus. Rogo director dulcilime, éfne tam ingens f ber por ab hominibus habicatum? quoniam video, id una ex parte fe-tio. rè terra polum atcingere. Cofmiel. Omninò, non fecus ac: catera Orbis terra partes, tameti infcrutabili Dei judicio nec-: dum detectum, fuo tamen quandoque freculo, quando divina providentize vifum fuerit, detegendum; de quibus pluribus in ulcimo tecum colloquio agam, Vidésne lucidiffimam illam, cux immediatè polo Auftrali fubjacet, regionem? TheodidaVideo. Cofmiel. Ea vaftiffima infula eft, alriffimis: montium fcopulis perperuum ignem vomentibus circumdata, quibus tamen Regio cancum abert uc inhabicata maneat, ut porius is abomni fterilicate \& frigor is vehementia, quam fibi quispiam fub hac plaga imaginari poller, vindicetur. Idem.

ensel lucene fubdica.

\section{fieri cenfere debes fub plaga Borex}




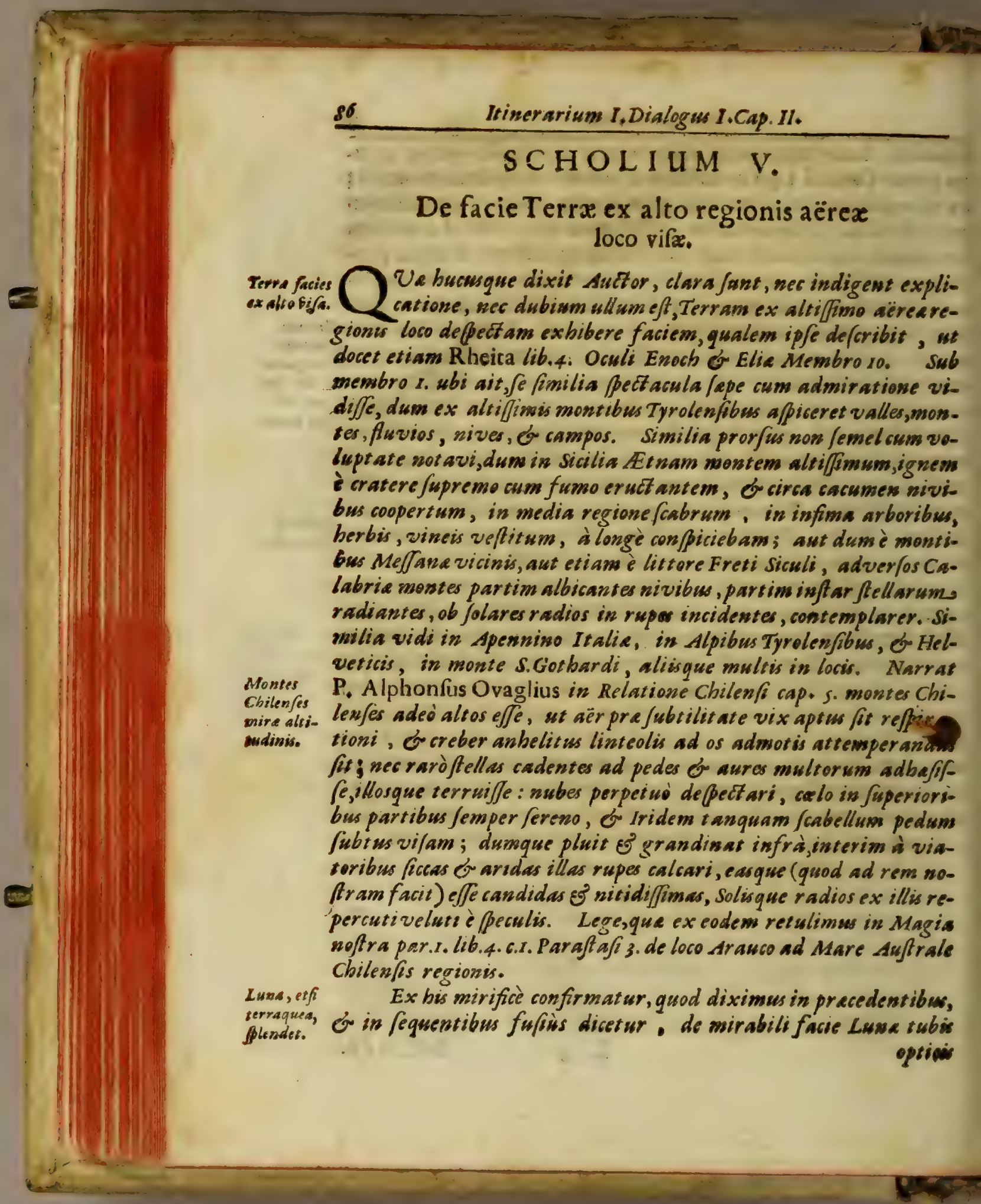


Iter in Lurams.

opricis infpecta: fi exim Terraquem globos suofter, licet herbis, arboribresque mult is in locis veftitus, eminus conpectus tans miram exhibet facien; wirum won eft, fimilem, El longè plendidiorem. exhibere Lunam, $f$, wt probabilifinum eft, nullis veftita herbis es plantis, fed ex folis aguis of feabris montibus compofita exifat.

Europan noftram referre figuram mulieris fedent is ; aut draconis volantis, Af ricsm cordis, Americam calicis, conft at ex inDpectione chartarum geographicarum, $\Xi$ affirmatur à Geographis communiter.

VIII. Theodidactus. Sed unum adhuc te rogo, Magifter, ut explices, quid fibi velic plaga illa juxta mare Cafpium, quax tam inufitatâ luce radiar? Co/miel. Miram rem quaris, filî mi, fed nefcio,urrum tibi talem ac tantam rem revelare debeam; fiquidem nemo adhuc morcalium eam plagam, ob inacceffa fcopul forum montium pracipitia in coronam quafi coordinata, penerravir, neque voluntas Dei eft,ut is locus, nifi temporibus noviffimis, reveletur. Hunc, fub inicium Mundi Paredifints conditi, Protoplafti omni felicitate beati incoluerunt, à quo demum per peccatum expulfi , locum mortalibus inacceflum reliquerunt ; in hunc pofteris temporibus Henoch \& Elias translati, beatam \& ab omnibus caducitatis humanx miferiis liberam vitam, rerum divinarum contemplatione usque ad conftitutum ipfis à Deo tempus tranfigunt. Vides ibi binos veluti fubfufcos quosdam cirros? Theodidactus. Video. Cofmiel. Hi funt duo flumina, qua ex memorato paradifo per occultos terræ mæandros emanant, \& dicuntur, uti nofti, Tigris \& Euphraces ; reliqua verò bina flumina Philon \& Gehon, poft diluvium alveis mutatis, per alıos abditos fubterraneos canales in remotioribus regionum montibus exitum fibi aperuerunt, 


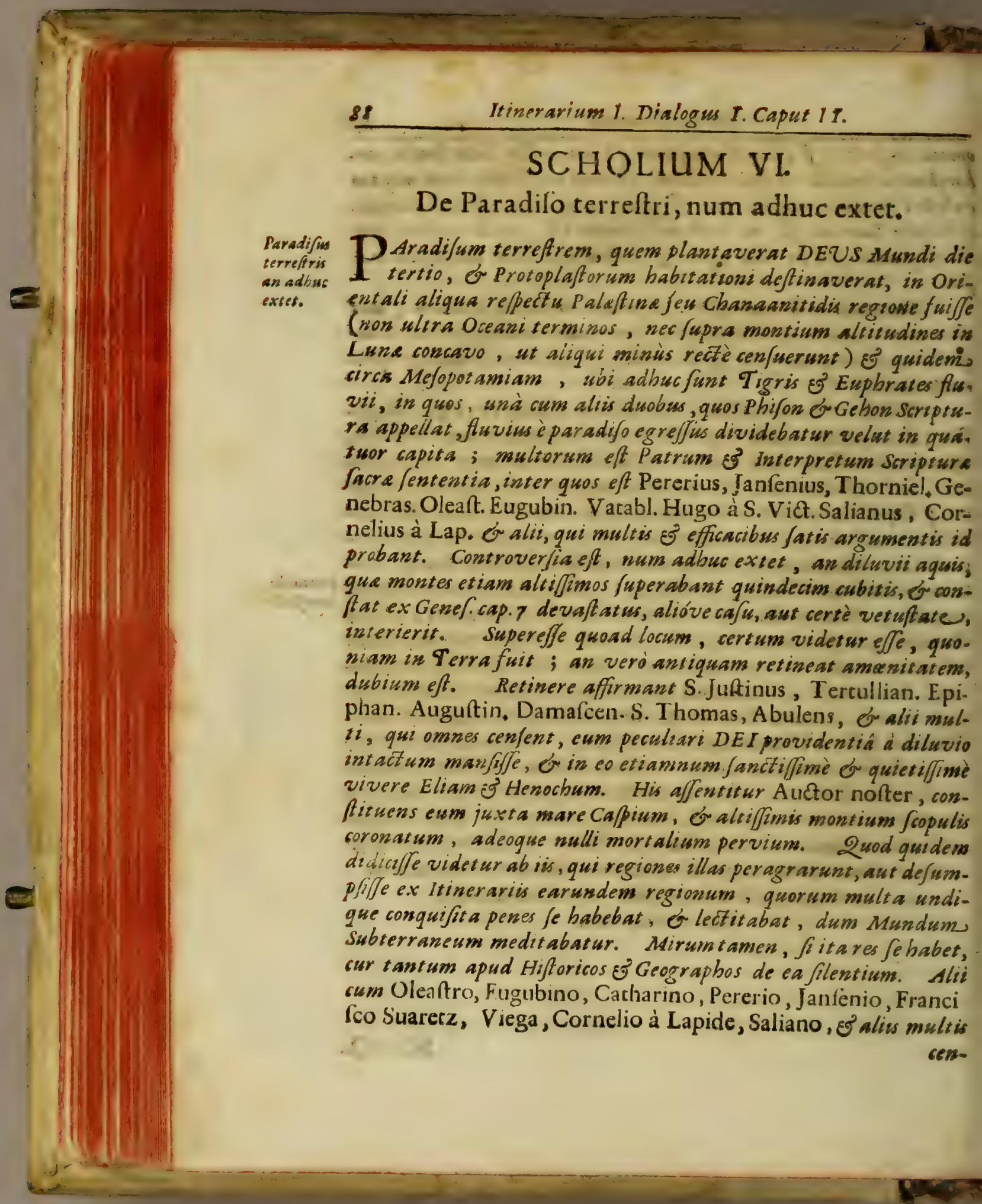


cenfent, \& forte probabilions, usque ad diluvium retinuiffe paradifum primevam /uam amaenitatem, quia conflat, cim DEUS expulit ex co Adamum, pofuife ante eum Cberubinum pro cuftodia ; wtique ut probiberet introitum hominibus; nulla autems neceffit as fulfet cuftodice, fi propter foopuloforum montium coronam in asceefsus foret. Verum in diluvio cenfent iidem, perdidiffo amenitatem illam fuan, quoniam aqua per annum integrume rocam terram occuparunt, asque adeò ơ locum paradifi. Credo equidem facile, effe alicubi in orientalibus regionibus inaccef/a quedam fcopuloforum montium pracipitia; at intra illa paradifon fuiffe, ant, ff fuit, adbus in amanitate (us perfeverare, minimè credo: quis enim id vidit, fo inacceffa funt loca ? 2 uod Henoch translatns dicatur in paradifum, Ecclefiaftici 44.v. 16. wit \& $^{2}$ Elias, interpretantur plerique de loco quodam amano, fed mortalibue incognito, nt egregié difputat Pererius $\mho^{2}$ Saliasus.

\section{\$.111. Introductio in ipfam Lunam.}

IX. Cofmiel. Sed jam tempus eft, ucterrâ derelictã , oculos furfum collamus , \& coeleftium corporum apparatum. quantum humano oculo conceflum fuerit, contemplemur. Theodid. Quafo, fiat. Cofmiel. Refpice in oppofitam terra plagam. Theodidactuss. Er ecce conversâ facie vidi Lunz cor-Lana fú pus paulò fub minori, quàm quo terram priùs videram, angu-qua fgure lo: ac multò diftinctiùs quàm priùs videram globum terre-pedetafíc. ftrem : fiquidem afpectus ejus inftar vafti montis blandifimo lumine illuftrati, \& innumeratâ macularum varietate confperfi comparebat. Hîc altiflimorum montium juga, præfercim in Lune circumferentia; hîc valles, lacus, flumina, maria, oculis undique ingerebantur. Hîc ego infinitã admiracione defixus, humiliter efflagicavi ducem meum, ut fingulorum objectorum rationes exponeret; qui hoc verborum. concexru me affatus eft. Cofmiel. Fili mi, non ea tantùm tibi oftendam eminus, fed, ut omnia \& fingula cominus confpicias, te in ipfum globum introducam. Theodid. Vix effarus. M cùm 


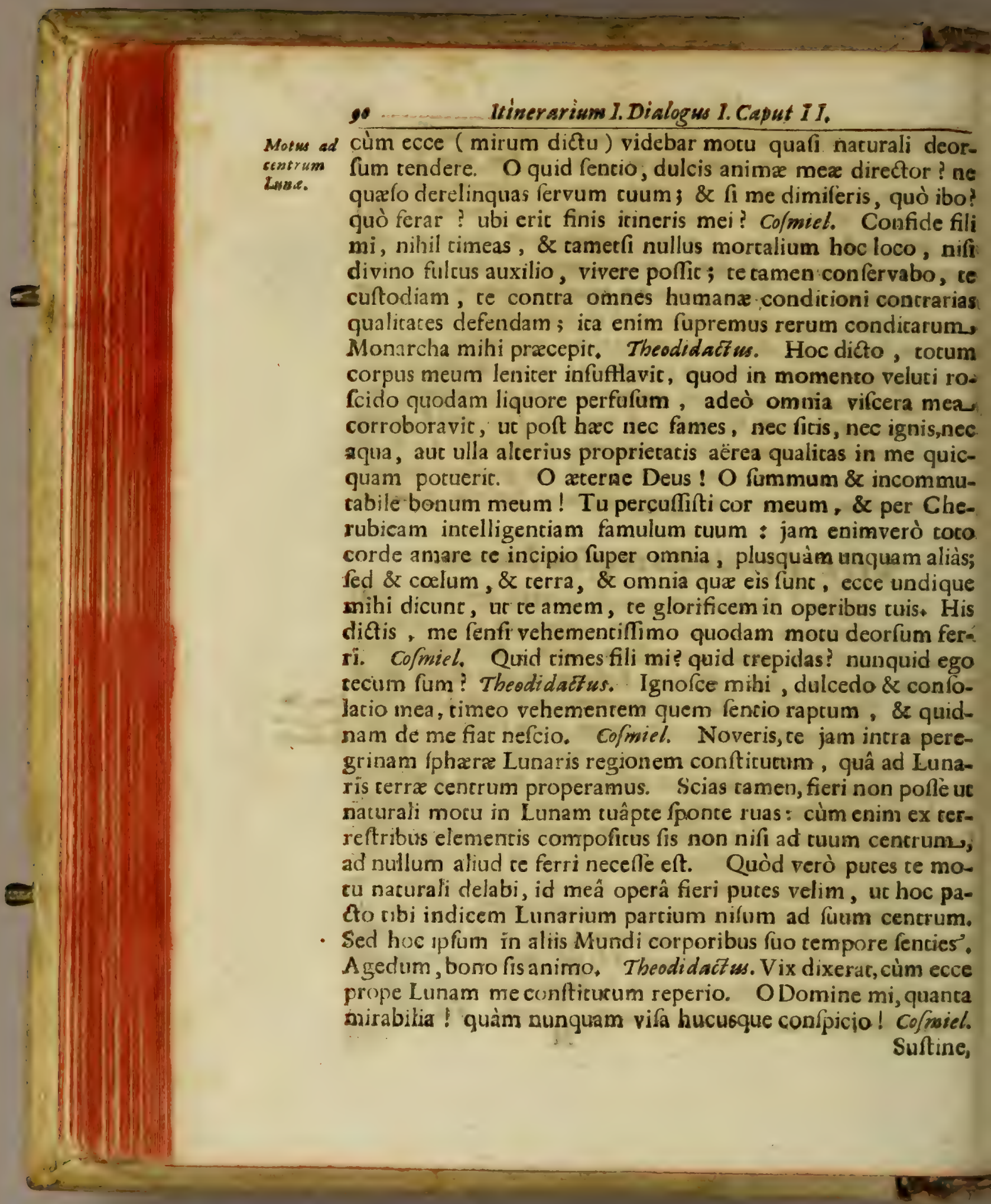


Suftine, properemus, ut cominus onnia luculentrùs pateant. Theodidactus. Hoc dicto, fupra alunimum mont is Lunaris apicem me dimiflum conftituit; \& ecce, nova \& inuficaca rerum facies oculis occurrit meis ; hîcomnia nova. \& inaudita, $\&$ multum à nacura terra in omnibus differens clieatrum aperitur ; hic valles profundiflina, hic moncium convacenari ordines, hic immenfus Oceani, marium, lacuum que procractus; bîc Infula Occano infertx; \& -montibus altiffimis circumdatx; Lune globîc flumina ex montibus erumpentia, per varios gyros fele bus qualis in maria exonerabant; fed omnia camen alterius nacurx, quoad colorem, vires, \& proprietates, quàm quibus terrefrem noftrim Mundum confticui videmus. Saxum montis erat è candido variegatum, \& veluti duritie quadam indomitâ incorruptibile, variis ftriis diverfi coloribus adornatum.. O Domine mi, explica mihi fingula in admiranda hac rerum facie, ut inde in ineffabilia Conditoris fapiencifimi myfteria pleno animo ferar. Co/miel. Fiat. Theodidactus. Et ecce,mirâ velocitace in vaftiffimo quodam campo ad lictus maris me conficurum invenio. Campus non erat herbis conficus, fed invisâ lapidum formâ Atracus, qui omnes nelcio quid oleaceum fudabanc. Tunc exploravi aquas Lunares, quas adeò Aqua lanalimpidas, adeò fubtiles \& diaphanas reperi, ut nihil fimile me res qui.les limpidas, adeo fubtiles \& diaphanas reperi, ut nihil limile me fint.
vidille meminerim in terreftris Mundi facie ; adeò mobiles, ${ }^{2}$ vel minimo flacu commoveri potuerint. Theodidactus. Colmiel, dic amabo, licétne fruftum ex hujusmodi lapidibus, aut lagenam aqux hujus coeleftis in terram deferre, ur inde terricolis admiranda Dei myfteria pateant? Cofmiel. Minimè; neque enim in cerreftri Mundo hujusmodi lapis confiftere pol Luxaricorfer, led mox ac eum dimiferis, fuam propediem fpharam el pore interfec repeciturus tanquam proprium \& naturale centrum fu ram portaum, ad quod tanquam pars ad totum fuum, adeò inviola- n m redibilem fympachiam habet, ut in nullo alio Mundi loco, nifi in ret. hoc eidem connaturali, hoc eft, in Lunari fuo globo confiftere poflit ; tanta eft tenacitas juris, quod fingula mundana corpora in fux fidei commillas partes inviolabili quaram. $\therefore$ M 2 con- 


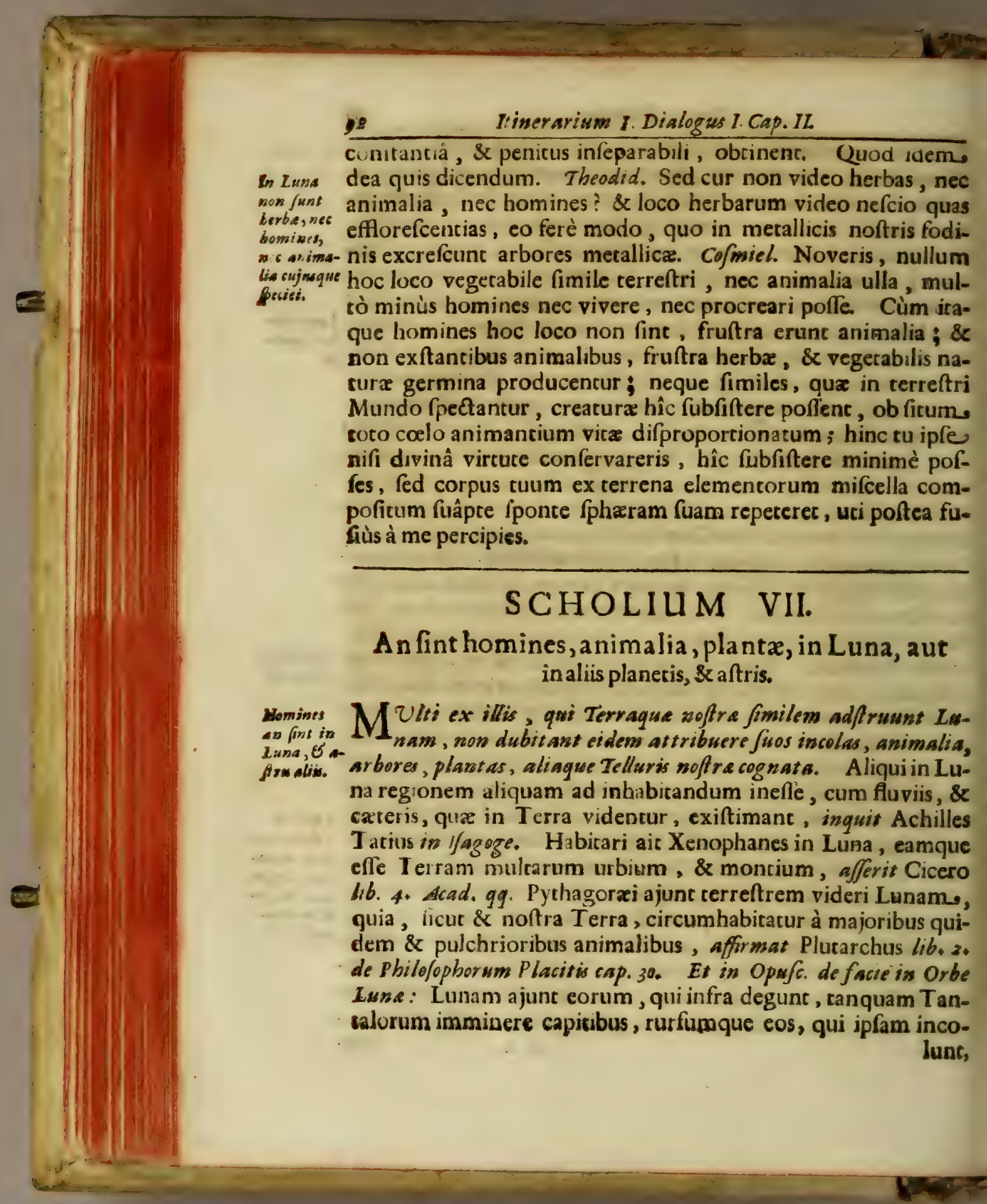


lunc, Ixionum inftar alligatos tanto impecu volvi ac revolvi, uc mirum non fit, fi impetu agitationis Leo in Peloponnefum deciderit. Subdit, cavernas effe in Luna, $\theta^{2}$ cavernarum maxiwam vocari Penetralia Hecates, ibique animas corum, que egerust, aut paffa funt, rationem reddere, ac panas dare; $\delta$ partos Liene celo obverfas appellari Campum Elyfanm. Macrobius b6. I. in Somnimm Scipio. 6. 13. Iunares populos, \& purgatoriom animarum posit in Luna. Hanc candem fextensiam de animabus of Genis in Luna velut in Terra atberes dogentibus, tribuir Beda Libre de Murdi conftitut, tit. de Atbere, quibusdam Phyficis.t In hare de Lunse incolis fententiam inclinant onnes, quos mox cirabo.

2uod de Iuna citati Auctores affernat, ad reliquos planes sas, \& affines planet is fellar extewdunt Heraclides, Pychagorai, \& fectatores Orphei, tefte Nicolao Caufine lib. x. de Domo Dei cap. 14. \& expreßse Nicolaus Cufanus Cardinalis lib. 2. de Dodta ignorantia cap. 11. \& in eandem propendet, loguendo de Jove o 'Luna, Joannes Keplerus in Aftronomia Optica pag 250. ${ }^{2}$ in Difertatione cum Nuncio fidereo pag. 10. dicens: veri non abfimile effe non tantum in Luna, fed eriam in Jove ipfo incolas efle. Cufani verba affert $\mathrm{R}$ heida lib. 4. Oculi Enoch do Elie cap. I. memb. 3. poft qua addit, nos poft detectos circa Saturnum of fovem novos errones, babere majorem caufam Ju/picandi de aftrorum incolis, quaim Veteres \& Calanus; nec contra rationem put at efle illius conject ationem, qui id fuppicaretur. Addit tanen, tutius elfe fentire cum communi, of ablinexe di novis fententivis.

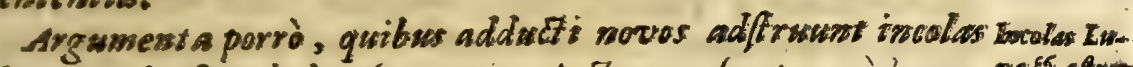
in plansetis $\varepsilon^{2}$ aftris bujus fententice Awctores, funt, quod non ne af afrom videatur credibile, tot es tam inmen/a ac pectofa corpora effe admitiquit, bominabus vacua, quibus plenus est Orbis nofter luteus, ET pre alit melitis ffris exilis; quid non ideo tantion videantur condita, ut Ter- negantram illwwoment in woft rum conmodum, cime nullus paterfamilias facem accendat in domefticosnom ulum ipsâ domo majorem: guod DEI benefieentia now fis ad pauculas bomines Terramo $M_{3}$ nofram 


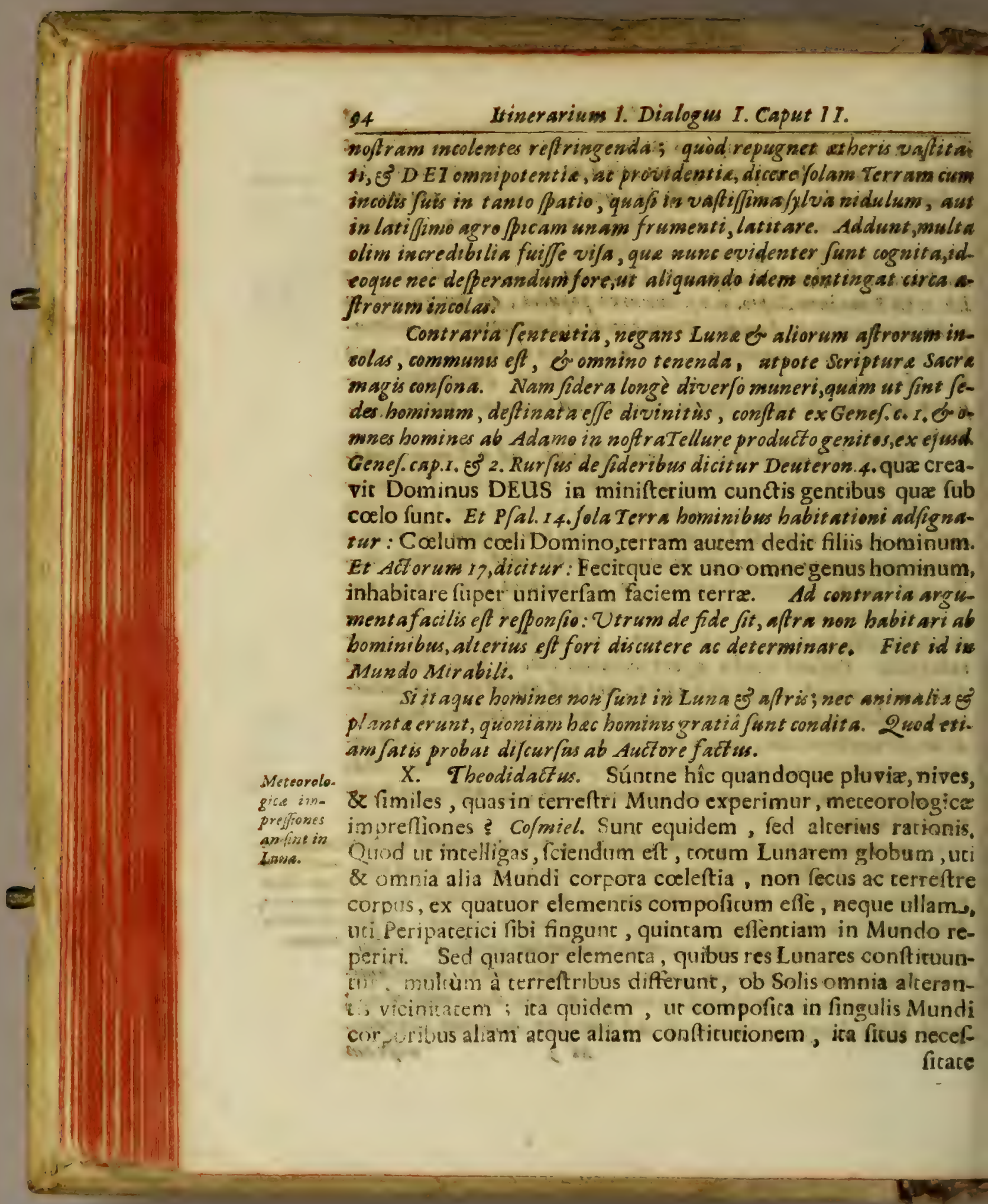


fitace poftulante; fortiancur, quenadmodum poftea videbis, corpu L*Et tametfi prima quatuor qualicates omnibus infint corpori-nedquats bus mundialibus, quia tamen aliam pofitionem refpectui mentiscomMundi, aliosque admodum differences influxus aliter \& ali-pofitum. ter participant, non quidem effentiali quoad materiam, fed accidentali differentiâ eas incer fe differre' neceftè eft '; quod bîc in Luna maximè apparet. Vides aquam lunarem verè elfe humidam, fed camen adeò fubcilem, ut in vapores exaltari nifi fubtilifimos non queat; hinc nebula, pluvix, nubes hîc non reperiuntur, fed correfpondens tamen is fimile, quiddam, videlicet fubtilifimus ros :, inftar vaporis, quem, humidum Lunare emitrit, fuamque armofpharam conficit, qui camen mox à Sole vehemenciori abfumpcus, in auras renues evanefcir, vel fi frigidiorem aërem incurrac, non pluvia adinftar., fed ranquam fubrilifimum defluvium Lunarem, fuperficiem irrorat; quod potiffrmùm circa novilunii rempus accidic, uri poftea videbitur. Si enim crafle, freculenta; Nubes cur \& variâ materialis mifcellæ impuritate foetæ nubes in Luna o- reant in rirentur, illa haud dubiè ex terra fpectari pollent, uti nos in reant Luna confticuti, eas per cerræ fuperficiem divagantes difparium inftar macularum intuemur : fed cùm nihil in terra. confticuris fimile nobis appareac, uci jam propriis oculis in Luna confticucus comperis; fruftra hic quaras fimiles noftris meteorologicas impreffiones. Habene etiam aquæ hæ Lunares, uti \& tota Lunæ compages, reconditam quandam. virtucen \& proprietatem, à Deo Optimo Maximo ei fingulari fua providentia difpofitione inditam; qua ubi fefe in cor-Virtus Lune pora humido pollentia diffuderit, mox vehementi quadam. influxína vi illa inflet, dılater, \& mirificè agiter ; quam quidem virtutem rotum Lunare corpus poffider fibi peculiarem; hinc radii ejus in fuperficiem cerræ diffufi, omnia inferiora terra, qura ex humore pradominante conftant, mirificè dilatany; maria agitantur, lacus \& flumina inflantur, Oceanus fluxum $\&$ refluxum paticur, humores in corporibus augentur \& dilatantur, \& tantò quidem violentrìs, quantò rectiori radio 


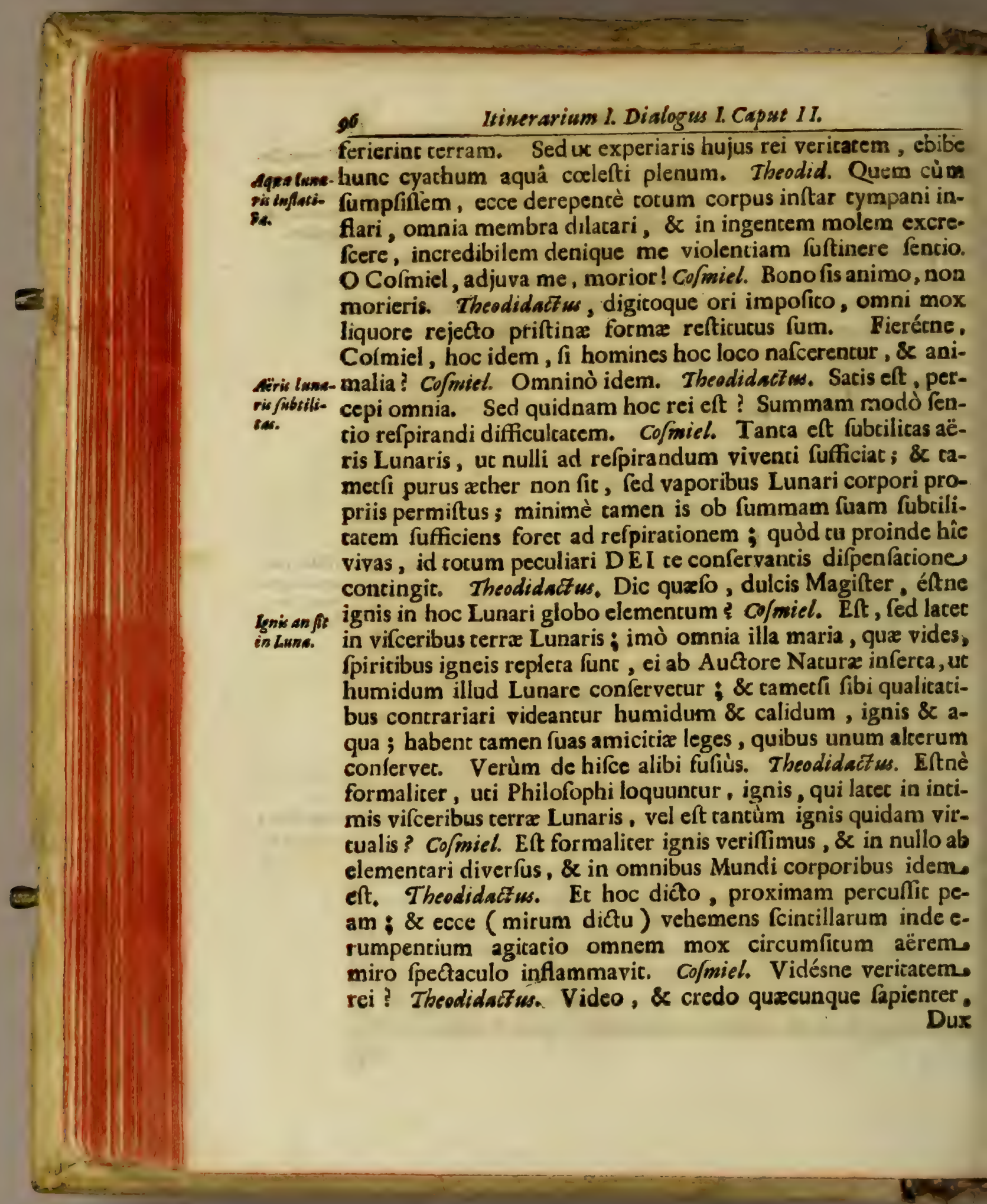


Dux cordis mei, exponis. Sed unum eft quod in principio itineris noftri te interrogare mihi conftitutum erat, quod ut mihi exponas, eriam atque eciam abs re efflagito. Cofmiel. Ec-Igtisnon eft quodnam illud? Theodidactus. Scias, Domine mi, me à pue- in concafo ro mulca in peripaterica Schola de fphæra ignis inaudivifle, Luma. quam tamen nec fupra, nec infra Lunam vidi, nec etiam expercus fum; fi enim alicubi ignea fphæra lateret, utique illam fummo meo cruciatu in itineris noftri decurfu fenfiflem. colmiel. Erras fanè fummoperè , fi Ariftotelem de iis rebus, qux ad fupremorum corporum naturam pertinent, omnia vera locutum effe tibi perfuadeas ; fiquidem uti nihil eorum, qua tibi poftea monftracurus fum, intellectu fuo penetravir, isa mirum non eft, fi etiam circa fphæram ignis hallucinatus fit. Rectè dicis, fphram ignis, quam is fub Luna concavo difpofuic, nec vidifle te oculis, nec tactu fenfifle; unde ibidem proprius effe ejus locus non poteft, cum nec Lunæ concavum videris, nec virtutem \& efficaciam caloris ignis proprii fenCeris; expaofum enim illud, per quod te deduxi, vicinum Lunx, non ignis eft, fed limpidiffimus ather, ut hîc, ita per univerfam Mundi machinam diffufus, fibimet femper fimilis \& idem eft. Quanam verò propria ignis fphæra fic, poftea oftendam, cùm globum Solis examinaveris. Theodidactus. Omnia qua dicis, mi dulciffime Cofmiel, veriffima funt, \& jam video quantum plerique Philofophi à veritace olim aberrarint, dum poft fphram ignis intra Lunæ concavum pofitam. omnes fupra cam difpofitas ordine fpharas coleftes, veluci ex criftallina quadam foliditate conftitucas efle affirmarunt, omnia corpora coleftia materiâ \& formâ elemencari privaverunt, qualitates omnes abftulerunt, prater lucem rihil 2liud ibidem efle fibi perfuaferune; his enim omaia contraria deprebendunt hodie Aftronomi, qui miro älo tubi optici organo, corporum coleftium adyta penetrarunt, \& quantum licuit, arcanam corundem conftitutionem prope verum derexerunt. Co/miel. Sic eft, fili mi; fieri enim non poteft, uc Philofophi,folis fuis cogitatis infiftentes, repudiatisque experienN tiis, 
tiis, quidpiam folidi circa naturalem Mundi confticutionem concludere poffint ; conceptus enim hominum, nifi experimentis fulciantur , tanto fæpe numero à vero aberranc longiùs, quanto hune globum Lunarem à terreno longiùs diftare videmus. Sed hæc fuo tempore \& loco luculenciùs difcucientur.

$\operatorname{Igniw} 4 \mathrm{~s}$ fit in coxeabo Lune.

\section{SCHOLIUM VIII.}

\section{An fupra aërem, \& infra Lunæ concavum,}

fit ignis.

A Ffrmativa fententia à multis jam feculis inter PeripateA ticos viguit, è quòd Ariftoteles id afferat lib. 2. de Coeloc. 3 . it tex. 18. quem plerique funt fecuti. Noftro tamen feculo labef act a ita fuit, ut exulare cogatur à Lyceo. Eam oppugnant Scheinerus in Rofa Urfina, Borrus in Aftronomia, Auctor nofter bic, of in Arte magna Luc. E' Umb. Lib.s.p.r. fol oss. Cabeus lib.r. Meteor. tex. 4.q. 5. Gu palfim toto illo libro, Arriaga $\mathrm{D}$ ipput. 4 de Generat. mum. 67. C in Opere fex dierum di/fut. 30. num. 22. Suaretz Lufic.

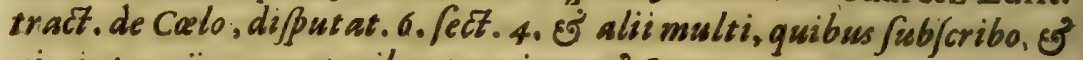
aio, inter aërem vaporibus pervium, \& Lune concavum, nullum. effe verum ac realemignem, fed folum putatum, qui nibil aliud eft quàm defacatus aër, (quem alii atberem vocant, alii autem propter confuetudinem. \& ex defectw alterius vocubuli; ignem) nec diffinguitur fubftantialiter aust à colofidereo, aut à noftro Arifoteles impuro seiere. Probo 1. ex Ariftotele, qui, qua docuerat de igne negaram in in loc. sit. de coelo, explacat lib.1. Meteor. tex. I4. his verbis: In medio crumia concabe Lune. igitur, \& circa medium, eft graviffimum \& frigidiffimum fegregatum, terra, \& aqua ; circa hæc autem, \& attigua his, eft aër , \& quod pl uprer confuetudinem vocamus ignem, non eft autem ignis ; excerfus enim calidi, \& veluti fervor, eft ignis. Sed oportet intelligere, dicti à nobis aëris id, quod eft circa terram, velut humidum \& calidum effe, propterea quòd vapores \& exhalationem habeat terrx; quod autcm fuper hoc,calidum jam \& ficeum; eft enim vaporis nacura humidum \& calidum; exhalacionis au-

tem, 
tem, calidum \& ficcum : \& eft vapor quidem potentiâ veluc aqua, exhalatio autem potentiâ velut ignis. Vides qualem ignem conftituat Ariftoteles in concavo Lund, corpus videlicet exhalationibus plenuw, quod propter sonfuetudinem vocamusignem, verè antem ignis non eft, quia ignis verus eft exceffur quidam caloris, छ? velutifervor; corpus autem, quod ibi eft, non habet exceffum caloris, nec eft fervor quidam, of eft folim potentiâ ignis, quia aptum fieri ignis, propter admift as exbalationes calidas Ef ficcas. Probo 11. argumento ad hominem. Corpus infra Lune concavum, quod adverfarii ignems appellant, non luset, neque urit, neque pabulo indiget, we ipfimet fatentur; ergo proprietatibus ignis caret; ergoignis non of , qui naturaliter fine propriet atibus fubfftere nequit.

Probant contraria jententia Auctores opinionem fuam or Argumenta communem ex co, quod ignis nofter fublunaris furfum tendat ;eorum, qai utique ut evolet in fuam Spheram : quòd in fuprema regione ignom ad.

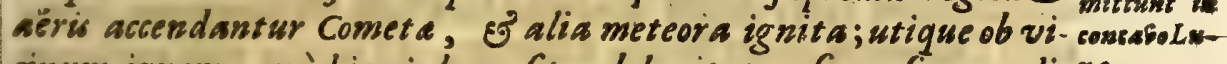
cinum igrem: quòd ignis locus fot, ob levitatem fuam fupra reli-na. qua element a ; quibus ciom DEUSdederit locum fuum, utique non denegaverit funm igni. Addunt, mirum non effe, quid fine pabu.

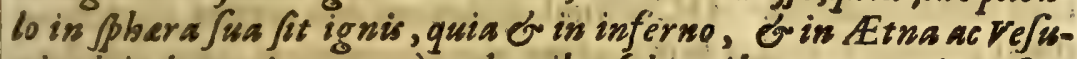
vio, \& in lucernis perpetuo ardentibus (de quibus 3.p. Magie noftre. lib.2.) Fre pabulo eft.

At nibil evincunt. Surfum tendit ignis, id eft, flamma Refutantur. ignis; quia levior eft aïre circurinfiante vapido $\hat{\theta}^{3}$ craffo; nunquam tamen furfum evolat, donec ad Luna concavim pertingat, fed vel in aëre humido ac frigido occurrente extinguitur, vel deficiente pabulo deficit in via. Comete $\sigma$ alia meteora accenduntur in fuprema sëris rezione, ino ó Jupra fupremam in ipso loco, quem igni deputant adverfarii, non propter vicinum ignem, led propter candem caulam, propiter quaxn of in media., of in infina regione fape accenduntur fimilia meteora ignita, filicet propter exhalationes conftipatas, E per antiperiftafin. aut aliầ ratione fefe inflarmmantes. DEU s denegavit ignilocum fupremum, quia propter voracitatem fuam pabulo indiget, guod ibi non inveniret. Vel dic, $D E \cup M$ nequaquam fupre$\mathrm{N}_{2}$ тим 
mum locum igni denegafe, cum illum ad usque Solis Calum evexerit; soletenim formaliter ignis eft, ut dicetur. Inferni ignic fine pabulo perdurat miraculosè : ignis Etne or Veluvii depa/cttur aêrem of vaporem undique per craterem, latera, fubterraneos cunisulos attractum: Lucerne perpetua modico pabulo funt contente. Vide, qua dicimus in Magia loc. cit.

Macuba Lu

O intelledtus mei illuminator Cofmares qua- miel, quxfo ignofce curiofitati mex; unum à te contendo, ut mihi jam exponas, quænam illæ fint macula, quas ego in terra confticutus fæpè tancoperè admiracus fum; quænam finc illæluces, quanam umbrx, qux fubinde nobis in cerra confticuris, \& admiratione defixis, Optici inftrumenti fubfidio comparenc; hisce enim cognitis, majorem hujus coleft is globi notiriam acquiram. Cofmicl. Faciam quod periifti. Theodrdactus. Ec mox rapidà vertigine agitatum in vaftiffimo Lunæ Uceano me conftitutum vidi, quem quidam Oceanum Philippicum, nonnulli Oceanum procellarum dixerune, ubi tancos vidi aquarum curbines, tor ferventium aquarum in morem ebullitiones, tanram Oceani agitationem comperi, ut nihil fimile me expercum teftari poffim. OCofmicl, quantam hîc rerum cataftrophen incueor? quàm horrendam cumulcuantium aquarum feenam apertam contemplor? Sed ô amantıffime inftructor, quid eft formidabilis ifta fragoris vehementia quam auribus excipio? quid infulæ illa, montesque, fcopulique fine numero per ingentem hunc Oceanum difpertici? Cofmicl. Intende auribus \& corde aperco fingula qux tibi exponam percipe. Oceanus quem vides, totius Lunaris globi circumferentiam ambic,unàoreawi ln que cum Lunæ vercigine in circulum perpecuo curfu fluxuque saris mira irgitatur; qui tum vel maximè fiunt, cúm Solarium radiorum normali influxu, quod plenilunii aut novilunit tempore contingic, percuflis fueric. Nam cùm, ut fuprà audifti, aqua $\mathrm{Lu}$ naris mirum in modum mobilis fit, fic ut finul ac eam Sol normali radiorum diffufione ferierit, ea mox in fummam raritatem redacta, vehementer illas agitaciones tam tempore Luna plenx in couverfa facie, quàm tempore novx in averfa facie, 
efficiat. Hinc dum aqua Lunaris Oceani agitata, tum ad obvios fcopuloforum, tum ad vaftos montium, quorum, uti vides, non eft numerus, parietes vehementiùs illiditur; horrendam inde ex contrariis motibus agitationem caufari necefle eft. Accedit ad inftabilis elementi Lunaris fummam mobilicatem motus Luna diurnus, quo impulfum mare lunare tantò majores vires acquirit , quantò ficus ipfius ad Solem fueric normalior. Hinc quoque provenic formidabilis ille fonus: illifio fiquidem undarum, tum ad fcopulos obvios, tum ad feiplas facta, miram quandam Lunaris aëris, feu quod idem eft, Lunaris effluvii agicationem caufat, ex quo peregrinus ille $\&$ infolitus fonus efficitur; novifti enim ex terrenarum rerum fimilitudine, aquam turbatam cum aëris quiete confiftere minimè poffe. Theodidactus. Sed rogote fodes, in quem finem fupremus Mundi Opifex tantas in Luna aquarum agicariones dis- Finis motus pofuic ? Co/miel. Finis potiflimus tantre agitationum vehemen-Lunaris 0 tix eft, ut influxus Lunaris validiùs terreno globo communica- ceani exporecur: quod fieri non pofler, $f(i$ auc globus Lunaris fine aqueo elemento compątus eflet, aut aquz quietr manerent; ex agitatione fiquidem illa, Lunaris virtutis influxus mirâ quadam. difpofitione in terreftris globi fuperficiem derivatus, fimili motûs analogiâ fubjecta fibi corpora ad confervationem totius afficit, atque in fines fuos inftimular; atque adeò idem hic accidere tibi perfuadeas velim, quod in quoliber liquore nos experientia docet, quem fi vehementiủs commoveris, tantò inde pro ratione qualitatis liquoris, aut fuaviorem, aut tetriorem odorem efflari deprehendes; Aromaticx fpecies, uti \& plantæ odoriferæ, tunc vel maximè vim fuam exerunt, cùm perfrictione præviâ incaluerint, aut cum humido miltæx, fummo odoris fó. nore, caloris vi exhalantur. Cìm igitur Lunare corpus perpetuo virturis fur profluvio terrenum globum feriat , illud vel maximè hac agitatione promoveri tibi perfuadeas velim. Accedic quòd humidum iftiusmodi profluvium mirificè quoq; æftuantes Solis radios infringendo ad temperiem reducat, temperatosq; unà vircute fuâ rarefactivâ \& humectativâ imbuat, unde Solis impra- 
porcionaci caloris aftusque radius, cerreno globo oppidò nocivus, terrenarum rerum generationibus vel maximè ex hac opportuna radiorum mifcella, aptus redditur * Quoniam verò, fi Luna femper hoc eodem virtutis profluvio terram feritet, terra nimio humore fuffocata non exiguum detrimentum incurreret; hine divina providencia difpofitione factum eft, ut Luna non nifi circa conjunctionis \& oppofitionis puncta, ubi influxus ejus normalis eft, quàm maximè vim fuam exerat, non item in quadraturis, aut punctis ejus vicinis, quia tunc temporis radius influrivus non niff obliquè terram noftram ferit.

\section{SCHOLIUM IX.}

\section{De vertigine Lunx circa fuum centrum} \& axem.

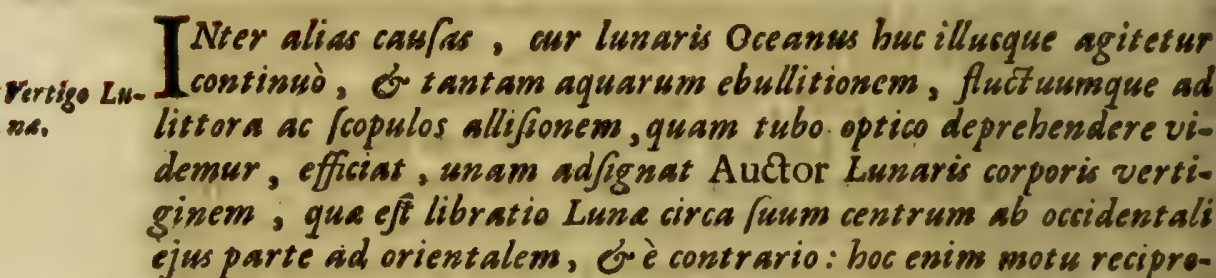
ejus parte ad orientalem, or è contrario: boc enim motu recipro-
$c$ dum agitatur totius Luna globus, \& confequenter totus Lunar is Oceanus; fieri non poteft, quis vebementer commotus, $\sigma^{2}$ nusc verfus orientalem, nunc ver/us occidentalems partem impul/us, in littora, in fcopulos, in infulas medio Oceano diper/as illidatur, $\varepsilon$ ? immanes fluctus jactet. Beprehendit bunc motum primu, quod fciamns, Galilaus tele/copio, dum notavit maculam, quam Grimaldi vocat Ricciolus, of eft orientali Lune limbo vicina, modò accedere ad orientalem ferè limbum, modò ab eo recedere; aliam verò, quam mare Ca/pium idem Ricciolus appellat, $\delta$ eft priori ferè dismetraliter oppofita verfus livbum oscidentalem, aicedere ad occidentalem limbum, alternatimque ab co recedere, it a ut und accedente ad/sum linsbum, altera recedat aे fuo. Eass- 
dem libraionem accurate of per multos annos obfervavit Langremus, deinde Petrus Gaflendus, Bullialdus, Hevelius, Patres noftre Socieinis Nicolaus Zucchius, Daniel Barcolus, Francifcus Grimaldus, E' Joan. Bapc. Ricciolus, mibi omnes notifjemi, quorum duo ultimi non folum deprehenderust acceffum acre-.

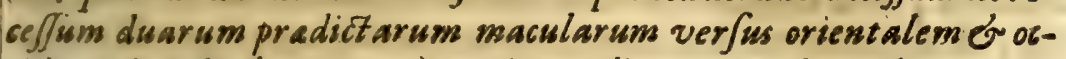
cidenialem limbum, verùm etiam aliarum, of quidem etiam ver/sus Boream of Auftrum. Inso ei usque proce/(Jit Riccioli diligentia, ut detorminare fit anfus, prinso, quant a fit predict a libratio, fes quantam Lunc partem vi illius ultra antiquorum opintonem videamus: Jecundo, que fint maculd, que ob librationem lunarem non femper apparent : tertio, quis fit modus obfervandi, ver/us quas Mundi Lunavè plagas fiat libratio lunaris globi, so verfus quas dirigatur axis bujus librationis: quartò, quanra fic periodus cujusvis librationis fingulat im fumpta: quinto, quesam fot caufa talis librationis, Jew qua motuum bypotbefs explicari polfit. Onitto alia qua idem determinant. Nullo ergo pacto de Lune vertigine dubitari poteft, nec quin mot us lunaris Oceanieam. mitetur.

XII. Theodidactus. Si vapores funt in globo boc Lunari, quemadmodum fenfibili experientiâ convictus negare non poflum, quæfo, explica mihi, cur nubes non compareant; has enim necdum mihi videre licuic; \& quanam ea vis eft rarefactiva \& humectaciva, qua tantos in cerra noftra effectus. parit? \& quodnam ejus fubjectum? Cofmiel. Quod ad primum, Nubes cur uti propriis oculis intueris, funt aqua Lunares ita renuis fub- non fint ftantia, ur nihil in is fupernatare poffic, nec hic ulla naviga- nam. tio inftitui poffet; pra vimia aquarum exilitate. Hinc vapo- Vapares rem quoque emirtic adeò exilem, \& ab omni terreftri frece adeò depurgacum, ut in nubes congelarinon poffic, nec fenfibiles meteorologicas impreffiones caufare valeat. Hinc vides luculentè aquas Lunares terreftribus limpidiores; quia tamen in vafto illo athereo fpacio fuperficierum agglomeracione condenfantur, hinc ex terra deprehenfa eft nonnulla atmofphara ; fed stmophishorum fufius ribi \& ufum \& modum in fine hujus capituli narra- ra Lunis.

bo. 


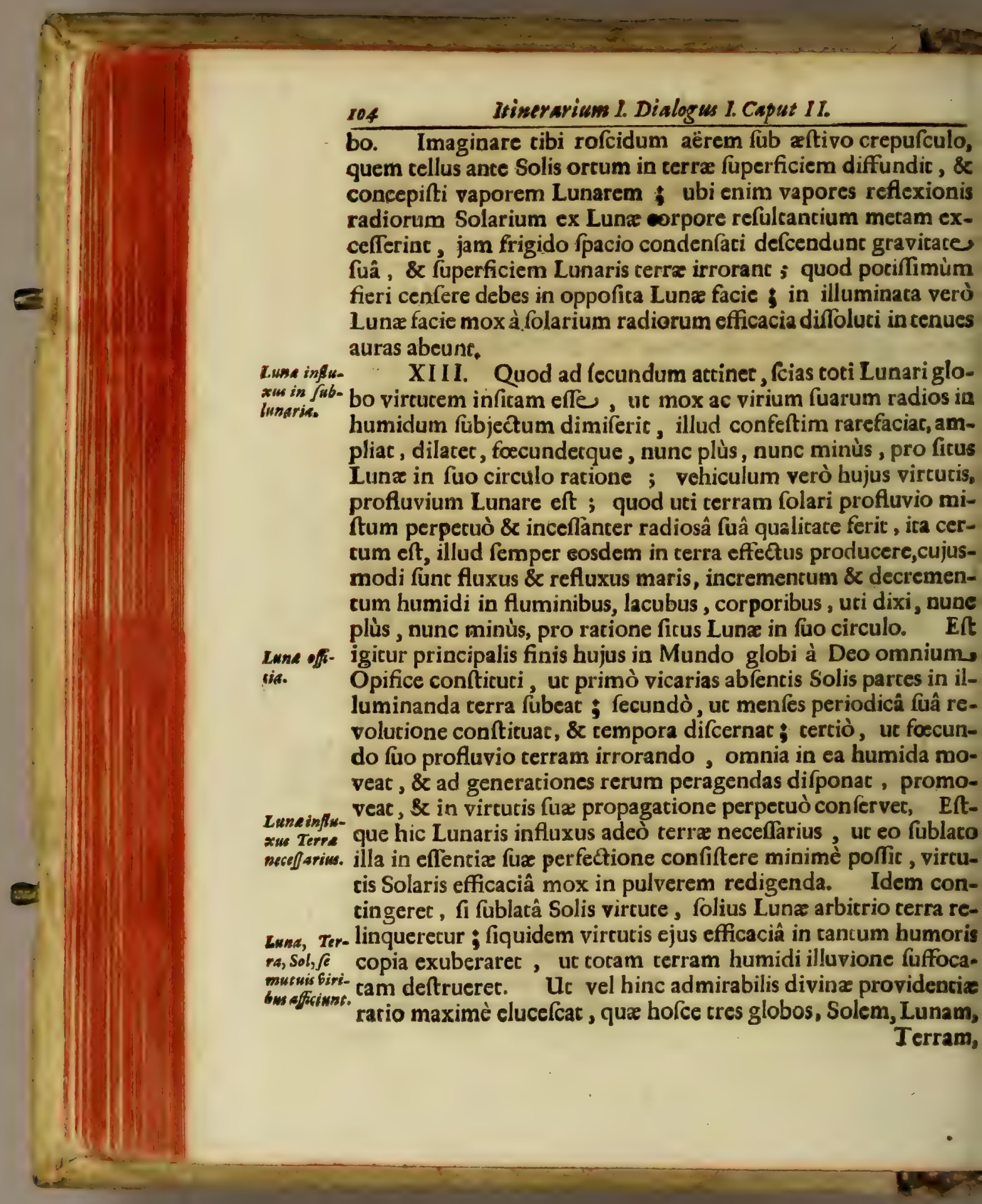


Terram, eo artificio difpoluit, ut uno horum trium deficiente, reliqua interire neceffe fit, Eo enim Natura fine conftituti fune, ut mutuò fefe ex reciproco influxu foveant, Sol Lunam. \& Terram, Terra Solem \& Lunam, Luna Solem \& Terram. Quod \& de reliquis corporibus mundanis dictum fit, ut in fequentibus prolixiùsà me defcribecur. Theodidactus. Cepi omnia,\& fummâ animi mei voluptate didici admirabilem divinæ providentia difpofitionem in magno hujus mundani globi apparatu.

XIV. Sed,ô dulciffime Co/miel, exponaś quáo modò, quid fibi velint illæ maculæ, quas tantoperè femper ex terræ fuperficie cubi coeleft is fubfidio intuitus obftupui? Cofmiel. Faciam, quod petis , \& quidem eo ordine, quo variorum Aftronomorum felenographia eas affabrè in charta defignavic. Theodidactus. Bt ecce derepentè translatus fui in montium altiffimis jugis coronatam congeriem. Montes ex faxo candido \& Macularaus fplendenti videbantur à natura difpofiti, \& in varias plicas ra- lunariusu diorum ad inftar difpertiti, infulam quandam ingentem confti- explicatio. cuebant, Oceano Lunari innatantem. Cofmiel. Viden'mirandam hanc rerum faciem ? Theodidact us. Video, \& vix fpi- ${ }_{\text {Fons lucis }}$ ritum pra admiratione traho. Cofmiel. Hic eft locus ille in Lu-in Lunn nari Oceano , quem Aftronomi fontem lucis appellant; fiqui- quid fist. dem radii Solares, dum in fcabrorum hunc montium ordinem incidunt, lucem in candenti faxo vehementer intendunt, unde ex terra afpicientibus mirum non eft, veluti quandam radiofam coronam comparere. Vidiftíne montes altiflimos nive perperuâ coopertos, \& Sole illuftratos, veluti lucem quandam. candidifimam à fe eminus confpicientibus exhibere ? Theodidactus. Vidi, \& in itinere noftro æthereo, dum terrenum. globum ex alto contemplarer, in Caucafeis montibus fimile quid, quod modò in Luna mel obfervaffe recordor ; \& proinde omnia optimè concipio ; video enim corporis Lunaris compagem ferè totam 'ex hujusmodi candenti faxo conftitutam.; unde non miror \& infulas innumeras in hoc Oceano Lunari infi- 


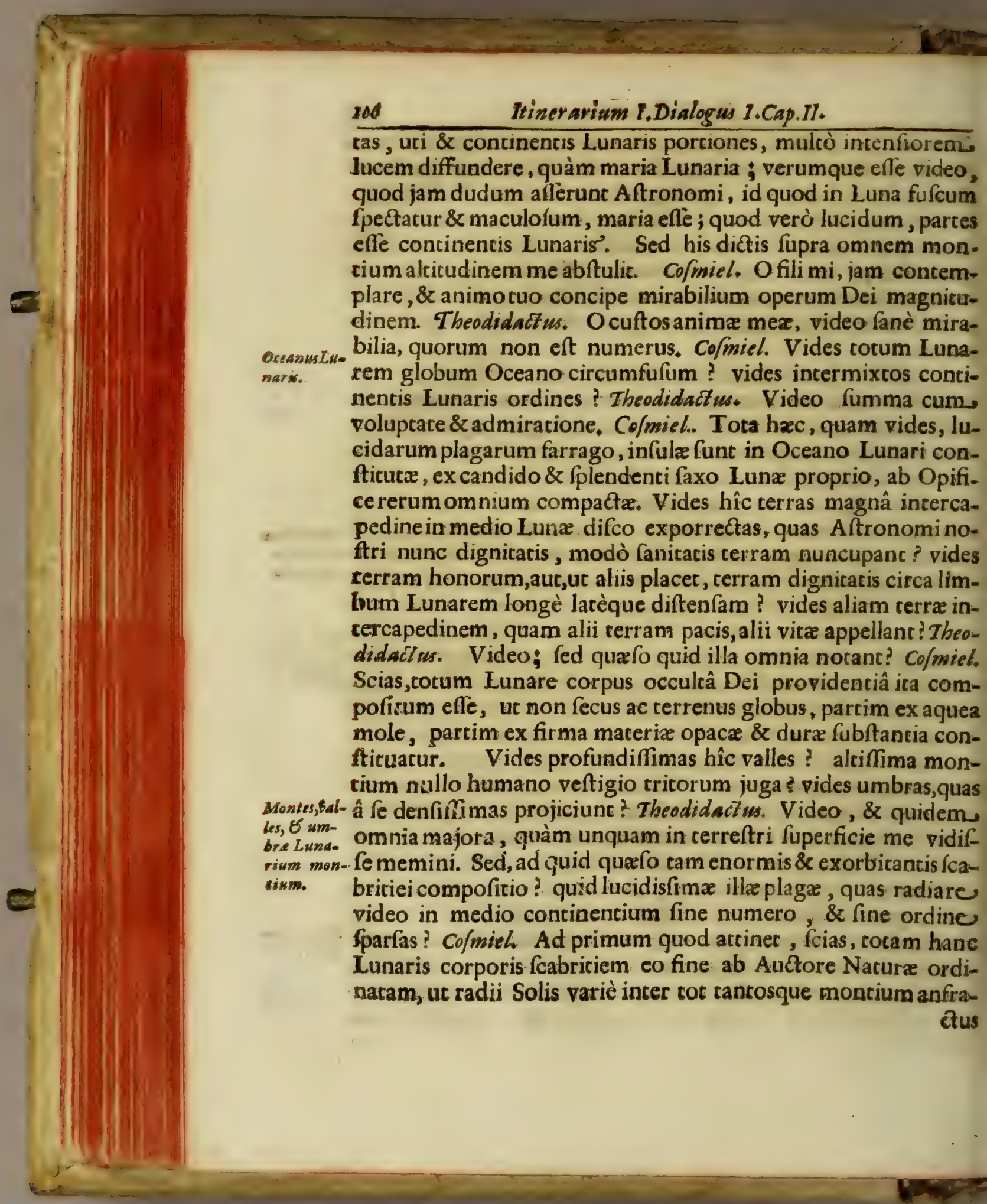


atus reflexi, aëris Lunaris calorem intenderent; aëris verò ca- Lunaris lor mari Lunari communicaretur, atque adeo hujus caloris vi globms cur efficaciâ cocius Lunaris globi profluvium feu vis influxiva tam ine\& efficaciâ cotius Lunaris globi profuvium feu vis influxiva qualis 8 in globi terreftris emolumentum perpettò excitarecur; quod fcabritie nullâ racione fieret, fi globus Lunaris totus politus \& levis, fine plenus. ulla parrium eminentinm ftructura forer. Ob eandem quoque caưam terrenum globum cantâ inæqualitate parrium confticutum videmus. Alcera caufa eft lucis incenfio ad terram illuminandam inftruta, qua ex varia illa radiorum in afperis \& feabrofis fuperficiebus incidentium reflexione mirificè incendicur. Unde vehementer illi Philofophi hallucinati func, qui Lunam fpecularis nacura corpus afleruerunt:fi enim politi inftar convexi cujusdam fpeculi foret, quis nelcit, figu- Luna ß ram Solis in eo expreflam, reflexamque, non minus intolerabi- pus efferon lilucis fulgore apparicuram, quàm ipfum Solem ? \& experien- potefef. cia quocidiana id docet in fpeculis noftris, Solis fpeciem in oculos nottros non ferendâ lucis affúfione reverberantibus. Accedit, fpeculum hoc non femper exhibicurum nobis Solis faciem, nifi ubi angulus inoidentium radiorum fuerit æqualis angulo reflexionis eorundem, uti tu copiolè demonftrafti in cuis Operibus. Nè igitur nox in apertum diem validâ fpeculi Lunaris in terram reflexione facta mutarecur, hinc fummo Nacurx confilio factum eft, urfux Solis in fcabrofam Lunx compagem illapfa, calorem quidem incenderet, lucem camen illuminand $x$ terræ proportionatam fuppeditaret. Si confideres, cur murus auc mons quispiam Sole illuminatus, Solis camen faciem non reddat, vitreum autem maris fpeculum exhibeat, rem concepifti. Theodidactus. Sed rogo, doctor mi, Aque Lun cur, cùm magna difci Lunaris fuperficies maris alluvione affu- cur fufea, fa fic, Solis tamen fpeciem non reddit? Cofmiel. Caufa eft fun- twcide fous. dus Oceani Lunaris, qui cùm ucplurimùm fúcus fic , \& aqua multò aquâ terrenâ tenuior, uti vidifti; mirum non eft , fubobfcurius reddi lumen maris ad nos transmiflum , cùm radii Solares non nifi in fundo ejus reflexi ad nos ferantur. Alterum, quod nolle cupiebas, funt lucida illa plagx, quarum innume-

$$
02 \text { rabilis }
$$




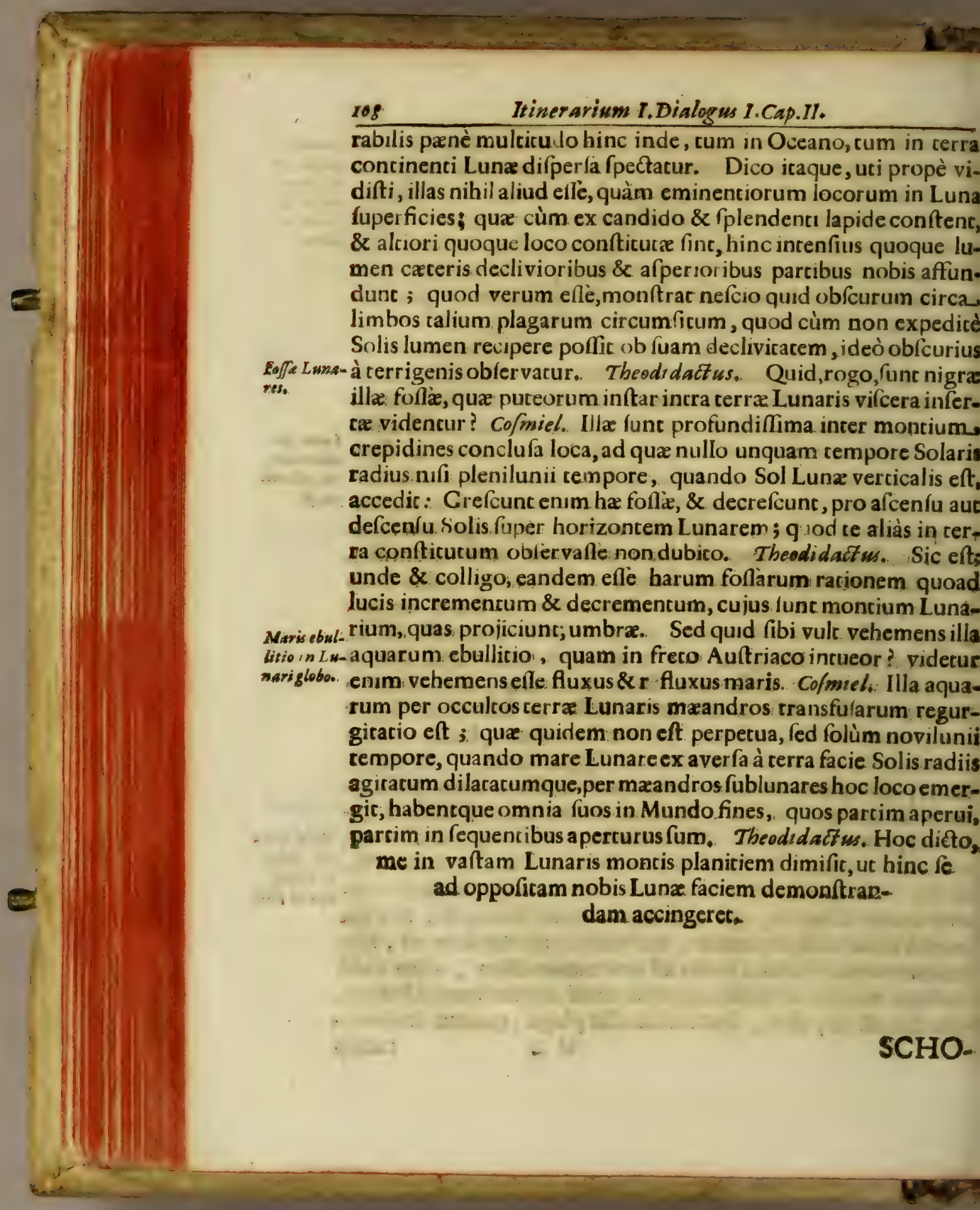




\section{SCHOLILM X.}

Ve à Num. XI. bucusque docuit Auctor de Lune fructurn. macules, /cabritie, ó fimilibus, clara funt, đo nullâindigersi explicatione. planeque explicant lunaria pbenomena per. ielefcopinw deprebenja, $\sigma^{g}$ à variis Anctoribus in Selenographic expojican.

\section{S. IV. De vifis in averfa à Sole facie \\ Luna.}

X V. Theodidactus, Sed,ố Cofmiel,divine Magifter, quid, rogo, fibi vulc diuturnus ille dies Lunæ, quo jam ferè quatuordecim dierum itinere neque noctem, neque ftellas ullas vidimus? certè luculenter apparet, nos in altero Mundo conítitutos effe; omnia enimalia \& alia ac in Mundo terreftri experior. Cofmiel. Scire debes, nos irer juxta: zquinoctialis Lunaris femitam femper contınuaffe; \& quoniam Lunaris fphara femper corporisfui medictatem Soli obverfam haber, nos veró motum Lunæ 2 uatuorin fuo circulo fecuti fimus: mirum non eft, Solis præfentia decim diefemper nos fivile expoficos, \& intenfisfimus prorfusque incole ${ }_{i n}^{r u m}$ dies rabilis aftus, quem expertus, \& de quo tantopere conqueftus es, id luculenter reftacur, ubi enim Sol prafens eft, ibi dominante xftu diuturno nox effe non poteft; \& ubi nulla nox eft; ibi ftellarum fplendores, urpore lumine majori minus nimiâ. fuâ in enfione obfufcante, fpectari non poffunc. Sed ut defiderio tuo facisfiat, jam \& noctem tibi oftendam, \& totam ftellarum congeriem, juxta eum fitum \& difpofitionem, quam illa in hoc Lunariglobo conftitutis exhibent.

\section{SCHOLILM XI.}

A 2 uinoctinlis lunaris femitan vocat Auctor Orbitam Les$\mathcal{L}_{n e}$, quam conficit motw on longutudinem, dum à sole elon-

$$
0_{3} \text { gatur. }
$$


gatur. Initioltineris, adhuc infra Lunam conftitutus, /pectavit Solem annularem, ac proirde Lunam Soli conjunct ams deinde in converfam ì sole faciem translatus, Bpectavit Lune maculas, ou umbrarum à montibus Lune project arum incremsent a ac decremerta, omniaque phanomera, qua in ea à noviturnio usque ad plenilunium telefcopio deprebenduntur, conffitur us interim fempes in facie illiminata à Sole. Semiorbutamergo Luna, ab ipfa Luna vectus, confecit. Nunc in partem averjam à Sole transfer. tur.

Lune facies i Sole afer- vercigine fublatum, in oppofita illultris terræ lunaris facie conSa qualis fir. At ticuic, Mox obfcurum iter ingreflus tenebras comperi, quaoceanus $L$ m- les apud nos fub crepufculorum initium fenciuntur. Hoc iticomfinme glebe. nere comperi Oceanum Lunarem globo toci circumfufum,cum Oceano illuftris faciei Lunæe alicubi quidem longè latèque diffufis undis, alicubi quoque per modum freti latiusculi continuari ; terreftres verò Lunx partes immensâ incercapedine in cerjectas, adeò alperas vidi, uc omnem humano veatigio adiLane affe-tum prorfus intercluderent. Si hiftricis aculeis horridam, hiparte is Sele fpidamque pellem videris, tunc terreftres hujus hemifphæri aberfa. portiones, rimis, fifluris, \& prominentibus undique fínofo rum lapidum aculeis oppletas rectè conceperis. Circa con. finia verò lucis \& umbra latitudinem montium quis meria. tur ? certè faftigiatarum turrium in morem Oceani Lunari veluti repagula quædam eminus concatenati fpectabancur Erigus in fa- Frigus præcterea tam intenfum erat; aẻrque, prafertim pleniSole aberfa lunii tempore, tam gelidus, ut frigus fubtilius \& penetrantiv. Sole aberfá nunquam me fenfifle meminerim : imồ nifí divinâ vircure munito, ob aëris, nefcio quâ vi fuffocativå pollentis, aëri terreno nimis improportionatam habitudinem \& proprietarem. vitam nè ad momentum quidem hoc loco trahere licuifleu

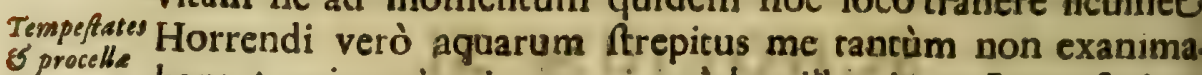
¿ procelle bant ; cujus rei ratio erat ; quôd ex ifluminata Lunæ facie aunde orian-quæ Oceani Lunaris concinuâ Solarium radiorum percuffione cur. rarefactre dilatacaque, dum effugium nifi in obfcuro Lunæ he. 
mitphario non reperiunt, ibidem coacervata, $\$$ in moles moncrum inftar conglobata, favifimas procellarum, rurbinum, vorsrcumque luctas \& pralia movebanc; qua omnia abditos in nacura fines admirabili divina fapientia difpoficione, uti in fequentibus fufiùs docebitur, habent.

X VII. Sed ô fumme Deus, quid hoc? O amanciffime Cofmiel, quàm inaudita, quàm infolita terrigenis in æthereo Mando incueor? Ofi Aftronomi hîc mecum effent, quàm luculentius, quàm diftinctiùs omnia, quàm illi cœlefti cubo armatr, afpicerent? Cofmiel. Quid vides fili mi ? Theodidactus. Globos igneos ad inftar montium ego video; fed rogo, explica mihicam inaudica coli portenta. Cofmiel. Globus ille lucidomaculofus, quem in medio coli incueris, ille globus terrenus eft. Theodida67 ws. Mihi id equidem mirum videtur. Cofmiel. Ita eft ; afpice, \& Gbbi terre omnia diligenti indagine explora. Theodidactus. Quid infolita il- fris ex Lula terreni globi magnicudo \& quid lucidus ille circulus, quem ${ }^{\text {na }}$ apectuo. globum ambıre video, diametro fuâ ferè integrum gradum cum dimidio occupans ? quid infolitx faculx \& macula? quid obfcuritates illa derepentè oborientes, \& mox definentes ?: Cofmiel. Cùm terrenus globus hoc Lunari longè fit major, optica ratio fuader, eum multò, ac terrigenis in globo fuo conftitutis Luna videcur, fpectari majorem. Circulus ille lucidus, quem terreftrem Atmo/pheglobum ambire confpicis,reflexio lucis eff ex atmofphara terre- men Solis ftri ad nos delaca; cum enim ea denfrffimis vaporibus conftipe. refringis. tur, Solares radii in ea mulcifariam refracti, hanc, quam vides, lu. cidam coronam exhibent.

\section{SCHOLILM XII.}

R Adii Solis $A$ e culo liquido in atmolpharam bCD Terre cirR cumfufam, id eft, è medio rdriori in denfuss, delati, refrin-viae Yco. gentur ad perpendicularem, ew verf w hemi/pherium Terra à sole Fig.11. aver/um; sivide conftitutus in Luna ad prinatum E v'. g. nimirum prope confinium partis illuminate of obfcure Lune, fed extra umbram Terra, neceffario pectat Terram circulo lucido circumda- 
cumdatam. Et quoniam aver fa is Sole facies Terra illuminatur a Luna plena, 5 ex parte à radiis ex at mo (phera Terre in ip/am Terram reflexis; videt etiam or deftinguit oceanum of maria, velut partes maculofas or obfcuriores, à continente jeu terre tractibus velut a magis lucedis, ob carfam in precedentibus explicat am. 2ue fequuntur de Terre variis regionibus, de nubibus circa Tellur em, of non circa Lunam comparentibus, slara funt. Que num.XIX. ba bet de Venere $\mathcal{O}^{\circ}$ Mercurio, intelligentur ex dicendis in ltinere in illos planetas. Interim in (pice precedens diagramma. Neceffe tamen eft, ut dicti duo planet e habeant maximam vicinitatem ad Lunam, banc non in oppofitione prope $E$, fed in conjunctione, aut non proculab ea, in F exiftere.

X V III. Cofmiel. Maculolæ verò, quas intueris, partes, uti maria, ita lucidiores fune immenfi terrarum tractus. Theodidactus. Bene dicis,jam enim paulatim cognitos mihi in Geographico globo fingulorum ficus diftinguo; jam Europam in figuram nefcio cui humanæ figuræ fimilem contorram video, ac capire quidem Hifpaniam, pectore Galliam , dextrâ Icaliam. noftram , finiftrâ Angliam exhiberi confpicio. Video Africam fub cordis figura, cognofco \& mediterraneum pelagus inter Europam \& Africam pulchrè intercepcum. Poncum Euxinum \& Cafpium mare, ad inftar duorum oculorum obfurcata contueor. Ecce Afiam Indo \& Gange, Africam Nilo \& Nigro fluminibus, Europam Danubio, Rhenoque, veluti argenteis quibusdam filis exornatam. Video \& agnofco magnum Sinarum regnum ; Indiam infar lingua cujusdam inNubes ter - tra Oceanum protenfam video. Sed,ô Cofmiel, quid fibi voram perba- lunt fumi illi, quos per univerfam telluris faciem ad inftar magantes. cularum hinc inde jam in nigredinem vergentium, modò in lucidiffimos faces degenerantium, perpetuâ viciflicudine nullo .. loco ftabiles, intueor ? Cofmiel. Hæ funt nubes, qua pervagantur terræ fuperficiem, jamque in uno loco nafcentes, jam in altero in pluvias refolutæ mox origini fua reftituuntur; \& nigrore quodam fuffufa, funt nubes magnâ aquarum mole prægnan. tes; illuftrioris verò conftitutionis illa funt, qua ob tenuita- 
tem fuam lucem, uti facilè imbibunt, ita nullo negotio illam ad nos reflectunt. Theodidaczus. Sed cur fimilia in terra con-Nubes cur ficuti non confpicimus in Luna? Co/miel. Audifti fuprà, fili mi, non co $\beta \beta^{i-}$ aquas Lunares ob earum exilitatem non effe fufficientes ad Luns. nubes, pluvias, grandines efformandas, fed abundare vaporibus, uti hîc coràm vides, illuftribus, qui,tamerfi per Luna faciem divagencur, non tamen eam, utpore opacitatis incapaces, obfuicare pollune; terreftrıs verò globi nubes ex aqueo elemento terrenæ mifcella copiâ referto confticuuncur, ideoque facilè quoque in alcum fublatæ à frıgidiori aëris circumfiftencia, provida Natura confilio, vel in nubes denfantur opacas, vel in grandines glaciantur, aut in pluvias colliquefcunt neceffarias, fine quibus terreftris Mundi machina confiftere non pofSer.

XIX. Theodidactus. Capio omnia. Sed quid, rogo, ignei illi globi funt, quos circa Lunæ horızontem jam bicornes, modò dichotomos, jam plenos video ?' Cofmiel. Ille, quem remotiorem ab Horizonte vides, globus Veneris eft, alter Mercurii globus. Theodidact w. Sed cur tam inufitata ma. Venus 8 gnıcudinis videntur? jurarem fanè binas effe. Cofmiel. Ratio Mercurius eft, quòd uterque ad Lunam hoc tempore vicinitatem maxi- les compismam in fuo circulo adeptus fir, aphelius uterque , hoc enim, reans. pacto fit, ut quantò à Sole plùs removencur, tantò Luna viciniùs fe fiftant ex ea parte, quâ aphelia Veneris \& Mercurii cum Luna aphelio concurrunt, \& confequenter uc fub majori forma videantur, ratio optica docet . Caterùm cùm illa duo globofa corpora fint, qua ex fe nullam nifi à Sole lucem recipiant, hinc quoque eadem phanomena, quæ in terreftri \& Lunari globo occurrunt, confequi neceffe eft. Sed quoniam hæc omnia paulò pòt ex ipforum dictorum corporum luftratione luculentiùs comperies, de iis longior effe nolo. Theodidactus. Sed Stellarum \&,ô quam miram ftellarum faciem comperio ! hîc innumerx appect us. ftella fefe meo objiciunt obtutui, quas in terra conftitutus ne per fomnium quidem imaginabar. Quàm difpar earum fitus! quanta diftantiarum ab invicem difcrepantia! quanta magni- 


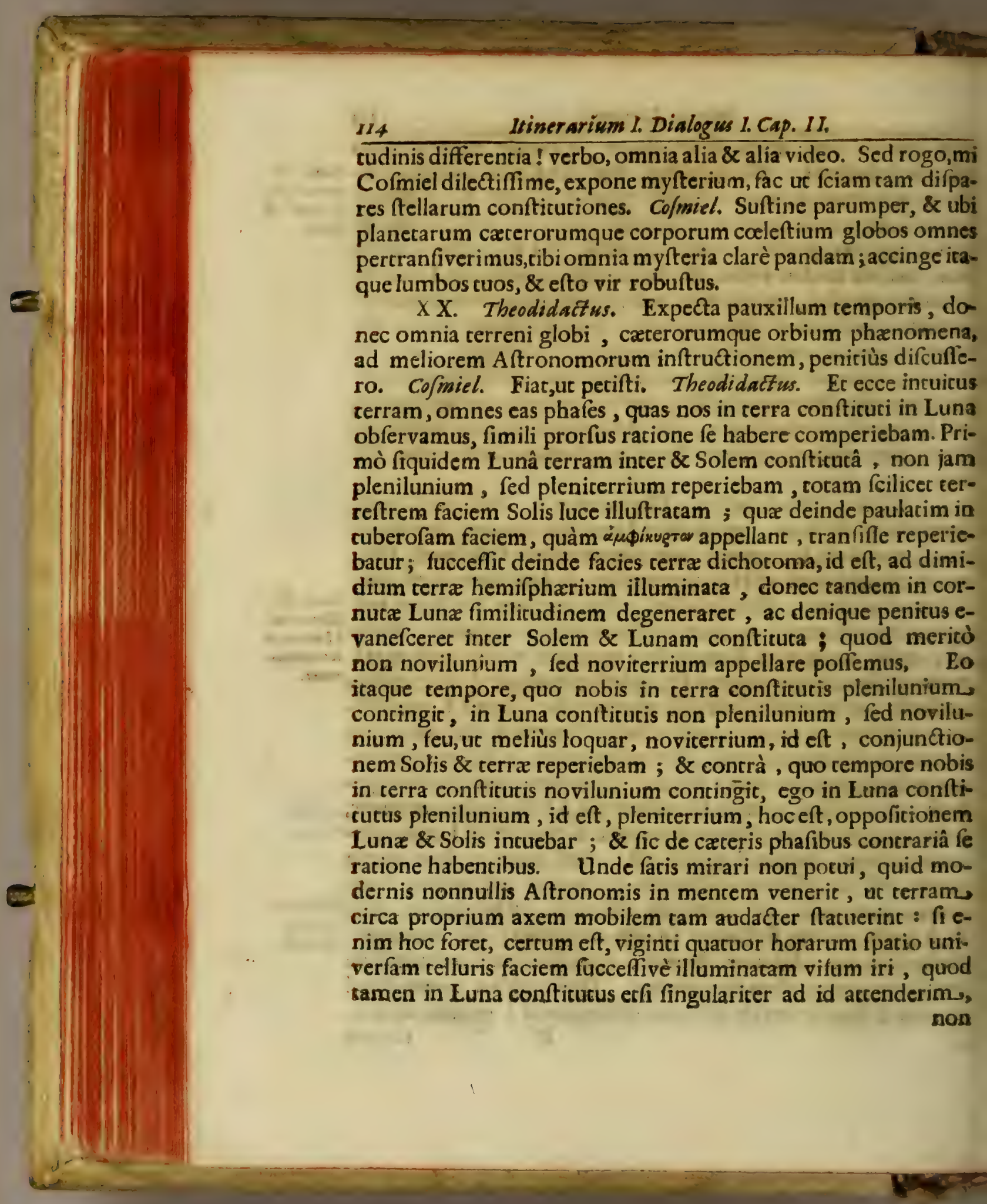


non comperi. Iterum Lunæ morum, in qua Tabfintebam, nullum Cur in Lusprorfus adverti, fed cerram moveri putabam juxca eas leges, qui- na confitubus nos in cerra confticuti Lunam moveri confpicimus. Eclipfin nen fentina. quoque terræ eo ipfo cempore in Luna conftiturus adverti,quando Terrigen eodem tempore eclipfin obfervabant Solarem; \& contra egoSolarem, quando illi Lunarem. Et quoniam Lunare hemifpharium femper ex aliqua parte refpicic cerram, \& terra, fertur circe uci dixi, non fertur circa proprium axem, ficuti Luna fercur cir-propriwm ca terram; ideò cantùm in ea hemilpharii parte, qua terra ob- axem. vertebacur, videbam rellurem, fed miro quodam modo, \& folico majorem, ob fummam in vaporibus terreftribus, quibus perperuò circumdacur, refractionem. Præcerea tellus ex ea parte, qua à Sole avercitur, (pectata, lecundariâ quadam \& fuboblcurâ luce, non fecus ac nos in Eclipfibus notamus, fplendere videbacur : qua quidem lux aliud non erat, quàm lux terra in averfam à Sole parcem reflexa.

\section{SCHOLIUM XIII.}

\section{De phafibus Terrx è Luna lpectatx.}

Via Terra quiefcit in medio Univerfo, $\xi^{2}$ Luna mot $u$ men- Pbafes Ten Aruo movetur circa iplann, Es femper candem ipfi faciem rapetiste feu bemißharium obvertit; habitantes in hemi/Pherio illo Lun i Lusw. viderens fingulis menfobses phales easdem in Terra, quas nos videmes è Terra in Luna, fed ordine contrario. 2 uod ut intelligatur, fot Sol in $I$, Luna in Orbe. fwo EF G H moveatur ab $E$ in $F$, Vide Ico. Terram $A B C D$. Exiftente Lunâ in $E$, /cilicet Fig.11. cet is prima 2 wadratura, quando incole A Terra apparet Lura femiplena, incole Kb Luna apparebit Terra femiplena. Exifente Lunn̂ in $G$, quando incole $D$ Terra apparet plenilunium,

$$
P_{2} \text { inco- }
$$




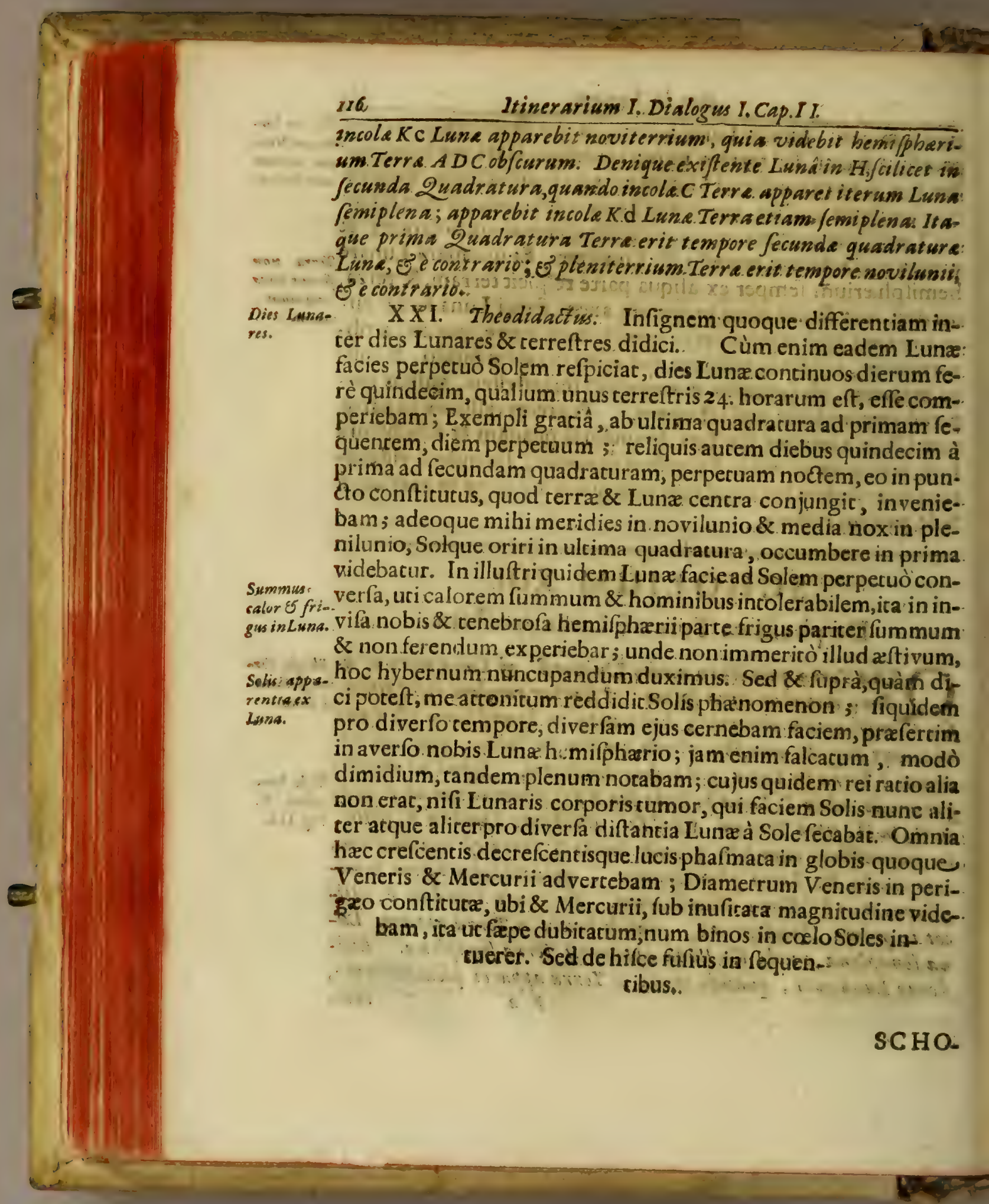




\section{SCHOLIUM XIV.}

\section{De diebus \& noctibus exiltentium in}

\section{Luna..}

\section{$\mathrm{Q}^{2}$}

Ve de die exiftentis in Luna', continuato per dies quindecim Dies Es noColares, of de nocte per totidem noctes continuata, uti $\sigma^{2}$ de ites exiftenmeridie, ortu, \& occalu Solis, afferit Auctor Nums. XXI. intelli-ns. genda funt repectu: incole Lunaris exiftent is femper in punct. iuna connect ente centra Lune ó Terre, hoc est, in puncto, à quo ducta linea rect a tranfit peridicta centra. Itaque exiftenti in puncto H precedent is schemat is, abi est in itium Jecunde quadra-vide Iconiture Luna , oritur Sol $I$; exiftenti in $E$ eft in meridie, exiftenti frni IV. Fig.$F$ occidit; toto autem tempore, quo. Luna ab $H$ per $E$ in F movetur, III. grood est dierum quindecim, dicto incole eft dies: At exiftenti in $F$ est initium noctis, in $G$ medium, in $H$ finis noct is, or toto intenmedio tempore est noxicontinua dierum quindecim, pide Rheitam in Oculo Enoch \&. Elve lib. 4. cap. 2.menb. 10. Jubmemb. 3. ubi rem banc: aliten explicat. sed preferenda eft Auctoris noftri: explicatio:.

XX I Theodidactus Hisce peractis, ita Cofmielem affabar. O fideliffime:Dux, ô fapienciflime inftrtictor, vidi jam opera Domini incomprebenfibilia, quorum non eft numerus ; illumina quæfo infirmum incellectum meum, ut quæ non capio , ce omnifcio Magiftro addifcam. cofmiel: Quære liberè, tuoque defiderio fatisfaciam, ad hoc enim tibi adjunctus" fum. Theodidact us Unum eft, quod non capio', quomiodo Iuna in hoc æthereo fpacio fúbfiftat; ad quid tantus in Luna montium, vallium, lacuum, mariumque apparatus ; cur nullum motum Lunæe fentiam, cùm tamen nos in terra conftitùti illam quotidie nafci \& occumbere, \& fub magna Zodiaci femita nunc in Auftum, modo in Boream declinare videamùs. Cofmiel. Ordine, uti petifti tibi fingula exponam. Er primùm quidem quaris, quomodo in immenlo illo acherej ex-non cadat 


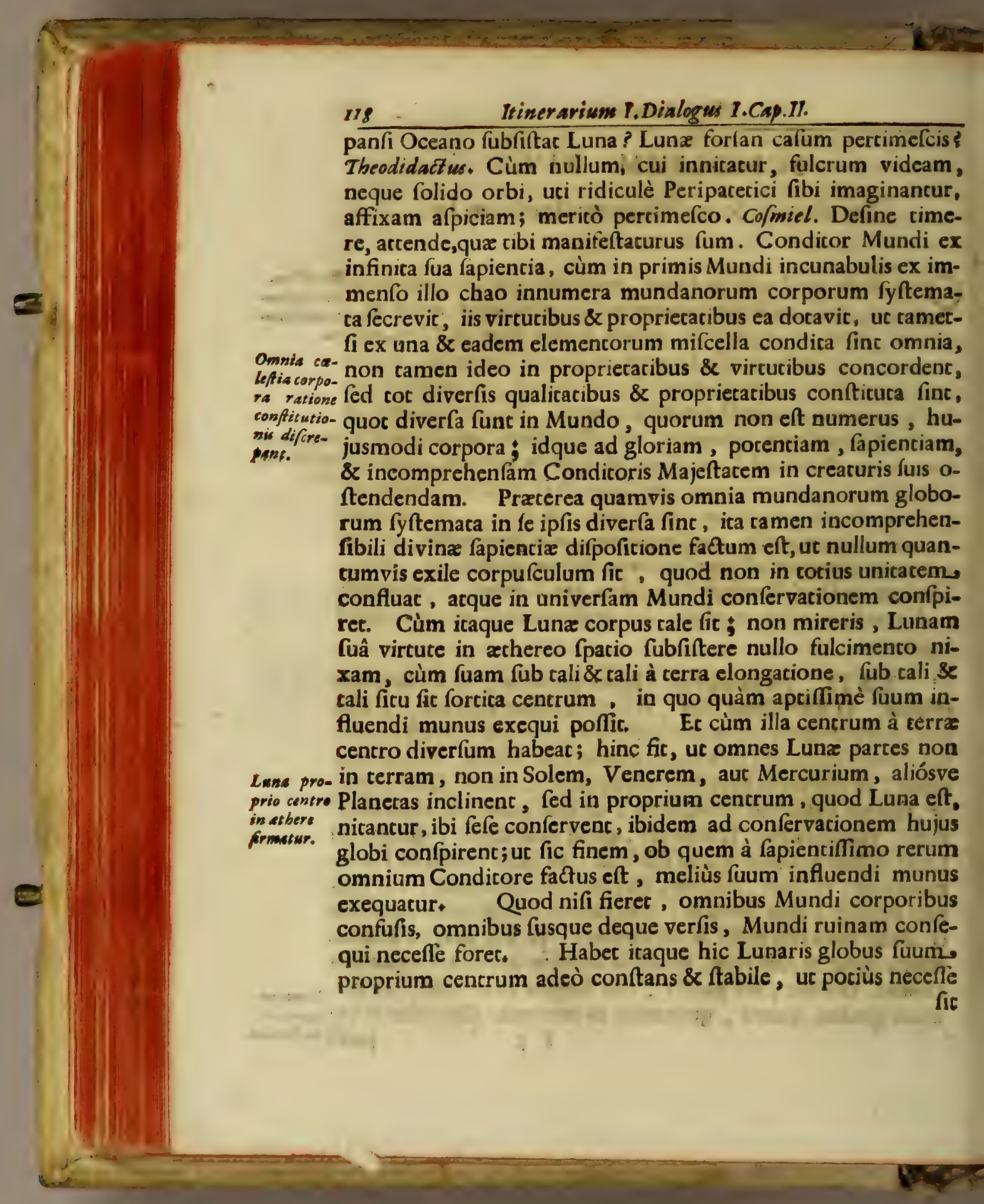


fit Mundi machinam difolvi , quàm ut illa à lege fibi dictaca Pars Lume deficiac, Si enim Lunaris corporis, cui infiftis, partem avul. abulfa $\delta$ in fam, in aliud Mundi corpus globumque deferas, fcias, ita illam terram defui centri tenacem efle, ut nullibi confiftere poffic, nifi in na- nam redicura fux appropriaco centro, quod folum appetit, ad quod fo- ret. lum confluit, tanquam pars ad totum fymparhicum, tanquam ad cotum fibi homogeneum \& fimilare. E.c quod de Lunari globo dicimus, illud de quovis alio corpore globoque mundano incelligas velim. Sed exemplum tibi dabo, ut, qux dixi, faciliùs capias. Humanum corpus conftat feptem principalibus membris, cerebro, corde, ftomacho, hepate, renibus, lie- compara- microne, veficâ. Jam certum ể, unumquodque dictorum mem-co/mi cum brorum id fibi peculiare habere, ut id tantùm, quod naturæ megacofmo. fux magis appropriacum eft, actrahat: ita cor illud cantum ex aflumpto alimento appetic, quod confervacioni fux maximè aptum eft, non aliud, videlicer omnes fpecies cardiacas, qua aliquam ad id fimilitudinem naturæ obrinent; fimilia enim fimilibus delectantur : hinc non appetit hepaticas, cephalicas, aut fpleneticas, fed cardiacas fpecies, veluti natura fua homogeneas, fympachicas, \& tanquam in centrum funm naturali inclinatione propenfas. Ira hepar non nifi heparicas fpecies ap Septem petit \& crahic. $\quad$ Et fic de cateris omnibus membris microco- principalifmi idem ribi judicium formandum efle fcias. Fr ramerfi o $\mathrm{wm}$ memmnia dicta membra naturali inclinatione diverfa fint, diverfas- cum leptem que proprietates habeant, omnia tamen hoc iplo nihil aliud in-planetis rendune, nifi totius microcofmi, id eft, humani corporis con- compara fervationem ; quod non fieret, fi alimenra confusè \& promifcuè omnibus membris diftribuerencur. Quot itaque humani corporis membra funt, tor centra tibiimagineris velim rerum unicuique propriarum homogenearumq; tractiva.Pari pacto, quot in megacofmo,i.e. majoriMundo, divina potentix incomprehensâ fapienciâ ex fuo chao difcreta funt globofa corpora, tơ quoq: diverf $z$ inclinationis centra eo ficu, proporcione, \& diftanciấ condiva funt, quorum unumquodque ea tantum attrahit, qua fuæ 
naturæ magis congrua lunc. Theodidact us. $\mathrm{O}$ quàm mirtice me tua delectan verba Divinæ fapiencıæ facramentis plena!! quàm dulciter mibi inftillas irrefragibilis vericatis argumenta! neque enim ullus alius dubitandi locus relinquirur, ubi rationis pondus tam efficaciter me convincit. O quàm jam difplicet nonnullorumPhılofophı; , qui Lunam , cxterosque globos cryftallinis infigunc circulis, ur fic fine calus periculo fubfiftere polfint.

\section{SCHOLIUM XV.}

\section{De centro Lunæ, aliorumque pla netarum.}

Centrune Luse, E a liorum

Ve de centro Lwna, aliorumgue planetarum, differsit bic Auctor, omnino congruunt cum is, que fuprà in Pralugzon: planetarum Paranetica cum ipfo de codens centro fatuimus. Ube etiam exquemo:to explicent atii.

plicavimus opisationem quorundam de natatu minorums Murnmilem opinionem tsetur Rheita lib. f.cap. 2. memb.10./ubmemb. a. ubi querit: Qua racione, fi coelum Lunx, \& aliorum planetarum fluidum fit, errones fine càlu \& decidentia in tellurem, tam conftancer in jis queant moveri. Repondet enim, sërem terram ambientem, É planetarum regiones varias, diver $\int e$ denfotatis ar raritatis effe, E ${ }^{2}$ quemlibet planetam regions fibi deputate ita innatare, ut quemadmodum diverfo globuli diverfis liquoribus fibi mutwo in vitreo tubo corcumambientibus insmerfo, furm fibi datum lockm tuent ur fine mots deor fun ant furfum fic of planeiam quemlibet Juam regionem fine alterius inwafione fulcando permeent. Hac cum cam frequenter concinganc (ut denfiora fluidis inequitent, ac fupernatent, nempe porna, \& ligna porofa aque, metalla argento vivo, ague oleum, హ.c.) quid, obfecro, impediat, quò minùs \& aérem leviorem aëri denfiori, ætherem Saturni Joviali, Jovialem Martuali, Martialem Solari, Solarem Lunari , \& denique Lunarem Terreftri innacare dicamus ? Et pasulo pof. Quid ergo impediat plane. 
planetarum fuis fluidifimus vaporibus atque regionibus innatancjum motum? Et infrà. Itaque quemadmadum navesob aërem in lumbis fuis conclufum, \& pifces in mari mocu fibi obftetricance, non fubfident; ica planetarum globos procul dubio etiam incrinfecè fuis cavernis qualicunque aére, ut \& noftra Tellus in quibusdam fuis parcibus, prægnantes, fuis in effluviis vapidis non profundiùs, quàm par êt, mergi pofle videtur. Quemadmodum igitur Terra ab Opt. Max. rerum arcifice D EO fuper Itabilitate fua in puro aére fuspenfa, fundaraque fecurè perfític, neque verfus Lunam cafum ullum metuic : ica Luna \& planere nullius lapfus fibi verfus Tellurem perrimefcunt , fed libere itinera fua in fuis vaporum oceanis peragentes DEO \& Natu$r x$ indefeffo famulatu motuque ancillantur. Hac Rheita. Sed quis unquam vidit poma, ligna, naver aquis incumbentes, aut globulos diverfa gravitatis liquoribus diverfa denfotatis innasantes, fationem fuans relinquere, o modo altiùs, modo bumiliàs, modò medıá viâ incedere? Hec tamen in planetis contingunt, qui modò apoget, modo funt perigei, modo in media clongatione confiftunt. 2uis ttem nefcit, fopredict. corpora i boco gravitati corsm convenienti dimoventur, magisque vel deprimuntsur, vel attolluntur, iea continuo boca priftiva repetere? Iden ergo in plasetis apozais 5 perigais contingeret, nimirum $f a b$. Intelligentiv motricibus vel attollerestur. vel deprimerentur. naturâ Juâ locum medium repeterent ; ô fi impedirentur, in ftatu violento perpetnò manerent. Omitto alus argumenta, que contra banc opinionem fieri poffent. Probabilims est quod nos fispris loc. cit. diximus.

XXIII. Cofmiel. Venio ad fecundò mihi propofitam difficultatem, quid nimirum fibi rantus ille montium \& marium apparatus velit ; \& cur Luna tor fcopulis \& pracipiciis, tor infulis exafperara fit; cùm enim DE US \& s ratura nihil fruftra, confticuerine, ea myfterio carere non puranda fint. Scias ita- Luna cur que, fi globus Luna forer ad glubi fpecularis formam perfectè tot apperitarotundus, ut multi perperam fenlerunt, vircutem ejus in terre tuta fis. 
num mundum influxivam nullius efficacia fucurams:-1 Nam praterquàm quòd reflexa Solis figura non nifi fub conftituto angulo terram feriret, terrigenæe quoque non veram $L$ unæ faciem intuerentur illuminatam, fed illam, quam nobis fub con ftituto angulo reflexionis radius exhiberet, id eft, Solis figur: ram; qua quidem in globo fpeculari multò minor eft, tametfi luce Lunari multò major \& intenfior, utpote qux à̀ Sole non nifi uno intenfionis gradu difcederet; unde confequenter non univerfa celluris hemifphærium ab hujusmodi lucis puncto, fed unica tantùm terræ particula, prout reflexionis radiuster: ra fuperficiem modò bî́, modò ibi feriret, illuminaretur. Accedit, nos cempore fextilis aut dichotomæe Lunæ nihil in Luna liseis, ob radium Solis non in terram, fed è latere Luna aliorfum diverfum, viluros. Ne igicur Natura in mundani hujus corporis comftiturione debito fine fruftraretur, hoc pacto Lunare corpus compingere voluit fapientifimus Opifex, ut finguli Luna partes etiam minima firam ad nos reflexionem: Solis transmitterent : quod fit in terreftribus Lunæ partubus, atque in conferta infularum Oceano Lunari innatantium congerie; non fecus atque in muro quodam, aut qualibet afpera \& impolica fuperficie contingic, qux tametfi Solis imaginem, ut in fpecularibus \& politis fuperficiebus; , haud reddat, æqualiter tamen lumen Solis in eam impactum ita reverberat, ut totam hoperficiem ex aquo quidem illuminatam videas, Solis tamen figuram non advertas : cùm enim in hujusmodi fuperficiebus, non, uti fic in fpecularibus, unum folummodò punctum fpeculi reflexam Solis figuram referat, fed fingula: punCta lucem, etfi in tanta angulorum multitudine \& ruditace fuperficiei diffipatam, reverberent; hinc fit, ut quod in intenfione lucis fuperficiei non fpeculari deeft , id extenfione, lucis in rudi fuperficie recuperec, Sic fit in Lunari corpore; quod uti ex variis maculis, lucid is, fufcis, tenebrofis, aliisque diverfi generis coloribus compofitum cernitur, ita lucem quoque inaqualem inxqualiter ad Terrigenas reverberat. Hinc, uri co-

maim 
ràm jarm vidilti, lucida illa Lunaris globi plage nibil aliud fuar, quàm terreftrium portionum eminentiores regioner?; fulcx aut maria, aut lacus exbibent; nigræ verò aut umbras moncium, aut luci inacceflas vallium profunditates cavitatesque indicane : quod vel inde apparee, quòd Sol quanoò fupra lincizontem Lumarem juxta phafes afcenderit alciùs, tantò obfcuriufculas hujusmodi plagas magis magisque illuftratas videas, donec in meridie, qui fit tempore oppofitionis Solis \& Lunx, videlicet in plenilunio, prorfus evanefcant. Theodidactus. Sed quid, rogo, tor montes, valles, \& fcopuli indicant? in quem finem ab Auctore Nacuræ conditi funt? Co/miel. Calor quid Finis horum omnium à Nacura inftitutus eft, ur radii folares in Lara in tot montium concava parietesque illapfi, prater lucem, ca-eficias. lorem quoque variâ \& multiplici reflexione intenderents quem uon minùs Lunx, quàm Telluri neceflarium efle fcias : hine enim fic, uc intenfifimâ caloris efficaciâ Lunaris globus calèfactus, calorem mari fuo communicet; mare verò Lunare nimià xftus vi rarefactum dilatatumque vim influxivam Lunx commodiùs cerreno corpori diftribuat.: Quod ut meliùs inrelligas, fcias velim; nullum in mundana machína corpus effe, .......... quod prater lucem, non peculiaribus quoque virtutibus \& pro- $\ldots . .$. prietatibus imbutum fit, qua quidem uti ab Opifice fapientisfimo corporibus ab origine Mundi infica funt, ita illas in terre- virtur tan num mundum, ob quem omnia condita funt, influere non cef- ne approfant: quia verò hæ vircutes in corporibus fuis fine calore torpi- priata da \& veluti mortua remanent; hinc Sol Mundi vita, potenti virturis fua calefactiva efficaciâ,, in Lunari corpore earundem capaci vim latencem exfufcitat; quâ excitatâ dilatatâque vis Lu$n x$ in cerrenum Mundum diffufa, fuos tandem fines, ob quos condita eft, affequitur. Novifti, quantam ignis quoque in terram vim ad proprietates rerum, mox ubi calorem igais experca fuerunt, exfulcitandas diffundendasque obcinear; vides, quàm Sole vertici noftro appropinquante, mox ubi caloris fui in cremenca diffuderit, cellus veluti à torpore quodam refurcitata .....

Q 2 frondes,


124 Itimerarism I. Dialogus I. Cap. IT.

frondes, flores, germina, fructus abundè producac. Sed cùm haec in precedentibus fusè expofuerim, hîc motari nolo. Theo Lnna cur didaotus. Omnia fcitè percepi. Sed roge', compar fapientif tot diberfis fime, quid fibi vule, quòd Conditor rerum Optimus Maximus compaziitzur: tenebrofam Lunæ faciem perperuồ à Sole averfam' , cur Lunam tam diverfo afpectu conftituram voluerit ? quid frigus ram intenfum ex Soli oppofita parce , quod expertus fum, fibi velit, non capio, Colmid. Optimè dubitas, fili mi q quare,uc omnia fcitè calleas, de hoc tuo dubio paulò altiùs ordiri vifum eft. Primò itaque fupponere debes, Detum Optimum Maxi1. mum omnia, quæ in Mundo funt, atque adeò univerfam Mundi machinami, cametfi ex contrariis conftirutam, mirấ tamen quâdam concordiâ in unionem confpirantem difpofuifle. Hinc: vides omnia Mundi corpora, fi Solem vita auctorem excipias, ita conftituta effe, ut perenni quadam vicifirudine lucem tenebra; , rarefactio condenfationem, calorem frigus exciperec. Quod quidem in terreno globo luculenter apparet ₹ ubi dies" noctem , nox diem, frigus calorem', calor frigus, aftas hyeAlteratio mem, hyems aftatem ftabili \& inconcufsâ Natura lege, per-

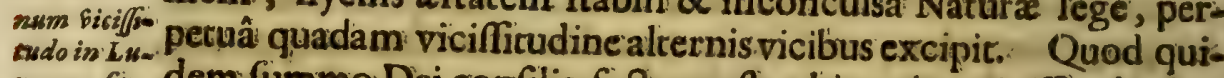
n cur fit. dem fummo Dei confilio factum eft; his enim vicifitudinibus calor \& frigus alternis: fuccemibus temperantur, gevefes rerun promoventur, \& fic tellus in operationibus fuis ritè adminiftrandis, dum inftabilibus tantarum alterationum legibus fubjicitur, cum vel maximè ftabilitatis \& conftantia robore munita perfiftit. Quia verò hane viciflitudinem rellus non habet, nifi àSole \& Luna, à quorum influxibus dependet; admirabili divisæ providentia difpofitione factumert, ut fuperna corpora ita difponerentur, ut quàm optimè \& commodifimè terreni Mundi ceconomiam adminiftrarent. His itaque fuppofi-

abiafes Lus ne Garie goo fine fient: tis, quareis, quid fibi renebrofa Luma facies, quid mulciplex ille Lunx alpectus, quid tam multiplicia phafium monftra fibi relint? Scias itaque, afpectus feu phafes Lunee adeö varias co fine à Natura rexum invenras effe, ur ils cum vis Lunæs guâ omnia cos....i 
terreni Mundi humida imbunntur, tum lucis Lunaris incrementum decrementumque temperaretur. Si enim Luna perpetuó illuftrem nobis faciem oftenderet, præterquàm. quood nulla foret mentrui temporis difcretio, terram quoque tam fuperabundanti Lunaris luminis vircutisque affluxu perituram necefle forec, ucpote humoris copiâ obrutam abforpeamque \& quemal modum fi Sol pèpecuó fub uno eodemque parallelo decurreret, terreni Mundi machinam perpetuấ zeftus violentiâ difolutum iri, nemo fapiens dubitare debet. Hinc ita Sol \& Luna in hoc Mundi theatro difpofica lunt, ut Luna Phafium perpecuò folaribus expofita radiis caloris Solem humida vir $L$ unarino

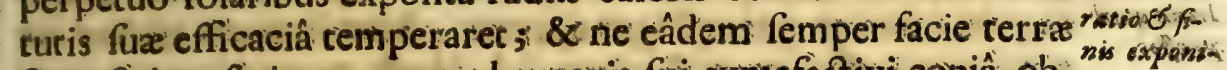
fuperficiem feriens, terram humoris fư cumefactivi copiâ ob- tur. rueret, faciem fuam ita terreno globo obvertic, ut non femper plena, nec dimidia, fed fucceffivo quodam lucis fux decremento vel incremeuto, nunc luce prorfus deficiens, nunc refumptis viribus au\&ta, adducti humoris copiam minueret, aut ejusdem defectum proportionato lucis augmento refarciret. Eft icaque Luna ita confticuta, ut tantum nobis ex tenebrofa' faciei fux parte menftrui fpacii decurfu obverteret, quantum ex lucidx fux partis facie - quemadmodun enim in plenilunio totam nobis faciem lumine imbutam, ita novilunii tempore toram tenebrofa faciei partem obvertit; hoc pacto in quadraturis dimidium lucis \& tenebrarum nobis ex æquo offert ; in fextili pariter afpectu tantum nobis renebrarum,quancum in tuberofa Lunæ illuftris facie lucis exhiber, ut fic partitis veluti juribus terrenum corpus in aqua lacis, teriebrarumi, caloris, \& frigoris, rarefactionis, \& condenfacionis proportione in fuo vigore confervaret : quod enim lux Luna in terra dif folvic, hoc frigus influxu fuo Aringit; quod illa disgregat, hoe iterum congregat; quod illa nimiâl fuâ tepiditate labefacit, hoc à pucredine confervat. Theodidactivs. Sed quid fibi in tenebrofa Luna facie tor tumultuantis aqua vortices Cofmicl. Cüm in Lan 3 globus Lunæe non fecus ac terrenus, uxi vides, terraqueus fic, \& motus cur? Oceanus Lunaris totum globum ambiat ; fieri aliter non po- ${ }^{\text {at. }}$

Q. 3 tuit, 
tuic, quil pars ad Solem colaverta radiis percuffa folaribus ingentem pacerecur rarefactionem dilatacionemque. Hiac unda undam trudens cum in oppofita Luna facie adverf fluctus concurrerint, neceflariò inde magnos vortices \& montium aqueorum acervos nafci necefle eft ; non tamen absque fingulari Naturæ intentione : Ex hoc enim vehementi Lunaris Oceani motu vis humefactiva frigori fociata, mirificos in cellure effectus producic, quales nimirum in novilunii tempore comperimus; ex hoc enim humoris in vegetabilibus \& animalibus abundantia compefcitur, frigorisque vehementia ex infita fibi

ofcillatia Lusiarequis Prefter. proprietate vacuatur confumiturque. ra flùs calorem quàm frigus appetic, hinc Lunaris globus ita confticucus eft, uc ofcillatione fuâ, id eft, motu circa centrum utrinque aliquousque vibratus, majori fui parte illuminarecur, nè diuturni frigoris \& tenebrarum vebementiá telluri irremediabile damnum adferret. Theodidactus. Omnia optimè cepi; led nunc ,ô.Cormiel, exponas mihi velim, cur DEUS Oprimus Maximus nullos in hoc Lunari globo homines, nulla amiHomines cur in Lun produlti. malia, nullum vegetabile produxerit? Cofmiel. Paucis tibi ratioferasque stellas, non nifi propter Mundum terreftrem condiderit; cercè fruftra ea in Luna producta viderencur. Cùm enim animalia \& vegetabilia propter honinem finc facta, ur illa in Lunari globo producerentur, fini fummi Opificis non erat confentaneum ; fiquidem Lune in eum folùm finem condita fuit, ut,in ablentia Solis, vicario Solis munere fungeretur, menfium tempora diftingueret, \& virture fuâ influxivầ, aliisque ab Auctore Natura ei inditis proprietatibus, quas audifti, confervarer, vires Solis caterorumque fiderum vel infringeret, vel pro. ut ejus ad illa in circulo fuo poficio requirebar, augmentaret, Homines funanimi omnium fingulorumque in Mundi totius bonum upruifent pradici in nionemque factâ confpiracione: Theodidactus. Sed fi DEUS Luma, sujus homines pofuiflet in Luna, cujus conditionis fuiffent? Co/miel. condistionii Notes velim, wi Theodidacte, omnes globos coeleftes \& athe-
fuifent. 
reos quantò majorem ad Solem vicinitatem, auc ab eodem elongationem, quoad naturalem corum fitum, nacti funt, tantò majorem quoque à terreno globo differentiam quoad vires \& proprietates fortitos eflè. Cùm itaque Luna Soli multò, quoad ficum naturalem, vicinior fit, ex continuo illo Solis afpectu ica eam alterari neceffe fuit, ut impoffibile fit, ibi homines terrigenas, ut ipfe expertus es, nifi fupernaturali quadam virture. degere polle. Quemadmodum enim illa ex differenti in Mundo pofitu, differentes omnino virtutes \& proprietates elementares fortiza eft, itafieri quoquenon poteft, ut is homo fuftentari poffit. Senfifti, ni fallor, non femel Lunaris aëris exilicatem; ad refpirandum minimè fufficientis; aquam quoque elementarem Luna vidifti nihil ad hominis vitam fuftentandam conferre; utpote tumefactivâ quadam virtute imburam quis porrò quindecim dierum diem perpetuum; inter æftuantiffimos feopulofa regionis calores fufferat - quis inconftantis Luna vicificudines quoad calorem, frigus, lucem, tenebras, careraque humana conditioni prorfus contraria incommoda toleret ? Si tamen, dato, non conceflo, homines in Lunari Mundo producti fuifent, dico, eos omnino differentis natura ' a cerreftris Mund hominibus fucuros fuille. Cúm enim Lunaris corporis qualitas ca fie , uc corpora virtute fuâ influxıvâ: dilatet tumefaciatque, homines illi omnino in infolitas figuras Monfra 0 \& formas degenerafléne; humidà enim iftiusnodi hominum rexit, is in partes, uti venter \& cerebrum eft, adeờ immodicâ diftenfione Luna prointumuiffent increviffentque, ur monftro quàm homini fimi ducti fuifliores vifi fuiffent; quod de animalibus quoque inicelligi debet. nes. Arbores \& planta talem quoque conftitutionem, quoad colores, proprietates; folia, flores, fructus, qualem non terrenos, fed Lunares incolas deceret, nacta fuiflent, Ex his quidem,ni fallor, demonftratis, fat fuperque pacet, nec homines; nec animalia, nec plantas, ejusdem cun terreftribus creaturis rationis in Lunari globo produci potuifle. Quantum autem poffic in rebus alterandis mundanorum corporum diverfus pofitus, vel 
328 Itinerarium I. Dialogus 1. Cap. 11. Iter in Lunam.

Zona torri-ex ipfo terreftri globo luculentifimè parec. An non vides, \& da res cur tantum dif- homines, \& animalia, plantasque fub xquinoctiali Zonz torriferant ab bic, dx plaga provenientes, à cæeteris hominibus fub Zona tempequa fub Zo-raca aur frigida fummoperè quoad mores, colores, ingenium, ma temperar quoad ipfam formam denique diffidere ? Cujus quidem res ra? unt tio alia non eft , nifi dispar fitûs partium terræ conditio, Solisque terram perpetuò ferientis major aut minor vis \& efficacia, Si itaque tanta in cerreftrium Zonarum ambitu rerum contingic immutatio, quantam pucas contingere in corporibus coeleftibus toso coelo differencibus? Sed nefcio quo xftu abrepti fufiùs forfan, quàm par erat, in hujusmodi dispucatione morati fumus. Quare uc majora videas, \& jucundiora promas, cempus jam. poftulat, ut reliquos nobis propofitas Mundi globos adeamus. Accinge icaque lumbos tuos, \& quacunque infolita \& admiranda videris, aut à me exponi audieris, alco pectori reconde. Agedum Theodidacte, DE US adfic aufibus noftris. Theodidactus. Quo dicto me intra peanigerum amictum complicacum, c̀ Lunari corpore in yaftiffimos atherex regionis campos proripuit.

\section{SCHOLIUM XVI.}

QUa ì Num, XXIII. huc usque dict a funt ab Auctore, partins mella indigeant explicatione. Quare ad iter in globum Vexeris. progrediamur.

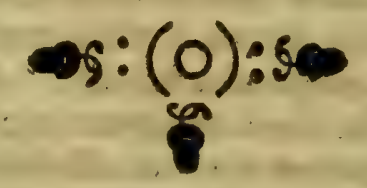

PRE. 


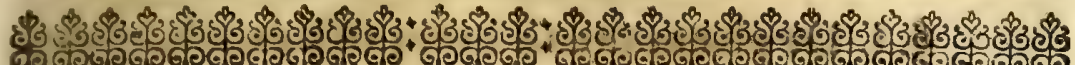
๓อ สอง

PRELUSIO IN VENEREM.

VEnus, amabilisfimum coli fidus, $\sigma$ poft So-veneris

lem ac Lunam maximum ac fulgentisfimum, omnium non immeritò nullo non tempore in fe convertit oculos, ora, ftudia, ES ftylum, mirantium Solis amulam, E Luns peciem. Adeo autem magna aliquando conpicitur, ut multi non raró aut cometam, aut novam ftellamputarint, meque non femel tum in ftalia, tum in Germania. EF quidembocipfotempore, dum bacforibo, a de reconjulturiconvenerint. Tanto praterea jubbare fulget fubinde, ut ferenis noctibus corpora ab ipfa colluf rata, umbras pargant. Poft Lunam omnium planet arum maxime in calo liquido se demittit, dum Excentricifuiperigaum (evimam abfidem attingit, ideoque colum fubeuntiprima poft Lunam occurrit. Quacaufa est, cur Aucfor nofter de eadem prius, quàm de aliis, à Luna tract andum cenfuerit. Vt ergo intelligantur facilius ab inexpertis in aftronomico ft udio, hac paucula praludere volui. 


\section{S. I. De phænomenis antiquis Veneris.}

Veneris plenomena antiqua.
$\mathrm{V}$ Enus,us ab antiquiffmis etiam temporibus obfervatum fuit, aliàs precodit Solem, or manè anie eum oritur; aliàs eundem fubfequitur, \&uepert poft cum occumbit. Alias it em conjungitur Soli, exiftens nimirum in eadem rect a linea ab oculo 1 tusentium ad Solis centrum ducta; alins ab eo digreditur usque ad gradus 48 ctrciter, iterumque ad eum accedit, alternis vicibus.

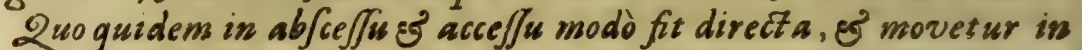
fignorum confequentia; modó retrograda, or in antecedentia retrogreditur; modoftationaria, Eं quafi haret, nec antè, nec pòft vizus nunc promota, quoad apparentiam faltem. Venus solem manè praceprait, nunc dens appellat ur ab Aftronomis Pbophorus fen Lucifer, ve periverò jequirur Solem.

Plinius. eundem fubfequens disitur Heßperus leu Heßperugo. AntiguifJims duas inter fe fimillimas ftellas crediderunt Luctferum o He/perum, tefte Plinio lib.2. cap.7. donec folertifimas Pythagoras primus delufas errore mentes veritatis luce illuftravit, on candem e/fe flellam oftendit. Hoc primum, E' ommibus obvium phoromenum eff.

Venus: alidis Alit, antiqsi ac recentiore, apparentem Veneris magnitumajor,alids dinem mutari, \& nunc majorem, alias minorem, (epe mediocrem, minor ap- apparere deprebenderunt; indeg, concluferunt, ean sunc Terreviparet.

Verseris or: sus 5. occafin beliacus. ciniorem lecs perizeam fieri, nunc ab ea remotiorem feu apogaam. Hoc fecundum, Es non omnibus ob/ervatum eft phenomenon.

Ad ortum \&o occalumVeneris quod attinet, ob/ervatum fuit, eam irungis arri fic à Sole removeri, aut Solem ab ip a , ut cofmice orcidat, aut or at is acronychè, hoc eft, ut sole eriente in ortiva bexizonte Venus occidat in osciduo, aut Sole occidente in occidus, Venus oriatur in ortivo; ninquam exim ex diametro Mundi opponitur Solt Venus, quandoquidem, ut jam dixi, nunquam ab eo digrediror ultra 48 gradss circiter. Unde poftquàm maxi orta est beliacè Veñus, id est', è Solis radiis, fub quibus invifa latier at, emerfot, digreditur quotidie magis ab iplo, eoque oriente altior ${ }^{3}$ aldior ab borizonte apparet, usque ad terminos maxima digrefjonis predicts: inde verò rurfus ad Solem accedens occultatur beliace ma$\boldsymbol{\pi c}$, hoc 
we, hoc est, iterum Jub solis radiis abfonditur, latet que /ub ejus fulgore, dones vefpere emergat beliace, (equentibusque noctibus occidente Sole, magis ac magis alta ab borizonte fact a, digreditor ab eou/gue ad terminos predictos maxima elongationis; quibus termirus fuperatis Soli densò fit obvia, dosset occidat veppere occesu heliaco. Unde patet, Venerem aliquando velociorem effe Sole venus aliwotu fibi proprio, quando foilicet post matutinam digreffionem quando beadillum accedut, illumque prevertit; aut vefpere poft ortum belia- locior, alicumabillo recedit verfus maximum digreflionis terminum : ali- quando quando autem tardiorem, quando foilicet poft vepertinam di- Solo in ef greffonem maximam ad illum retrocedit, aut manè poft ortum tu proprio. beliacum ab eo recedit in antecedentia, of verfus maxima digrefsonis cerminum. Sed bec melius intelligentur ex $\delta$. Sequenti. Hoc tertium est phenomenum, ab omnibus quidem obfervabile, fed non nifi de diligentioribus notatum.

\section{§. II, De novo Veneris phænomeno, ejusqúe in cololiquido inter planetas loco, \& motu.}

$\mathrm{P}$ Refentis feculi initio, circa crum a Chrifti nativitate Ibrr. aut 1612. poftquàm novi Promethei, Aftronomi dico noftri, armatos tsbo-picillo oculos in celum intenderunt, inter mult of anteibac invifa atque inaudita phanomena deprebesderunt $\xi$ hoc in Venere, ipferiam Pythagore, quiftelle illius curfum infatiabilibus oculs fertur perlecutus, ignotum, ean nimirum phales annuas menftruis Lune phafibus prorfus funiles exhibere. Depreben/a pbafes Lwenimest modò plena, aut ferè plena, modò gibbofa feu pratumida, naribussnurc dichotoma feu bifecta of fersiplena, nunc falcat a feu ins miles. cornua finuata, nunc tandem obfcur a penitus ac filens, Pectaculo longè jucundiffrmo, à nobis non femel, $\xi$ ab insumeris ali is in bac usque tenopor o oculis predicto inftrumento inunit is ufurpato; ut non immerito duas in calo Lunas mirari Mundus caperit. Ob Jorvationes accuratiflimas aliorum pofteadabo.

Ex boc phenomeno evidentiffmè concluferunt Afronomi, Ve-Verus circa nerem non effe perpetuo infra Solem, ut Chaldxi , Archimedes, Solem moPtolemæus, Regiomontanus, \& alii putarunt; nec perpetuo $R 2$ Jupras 


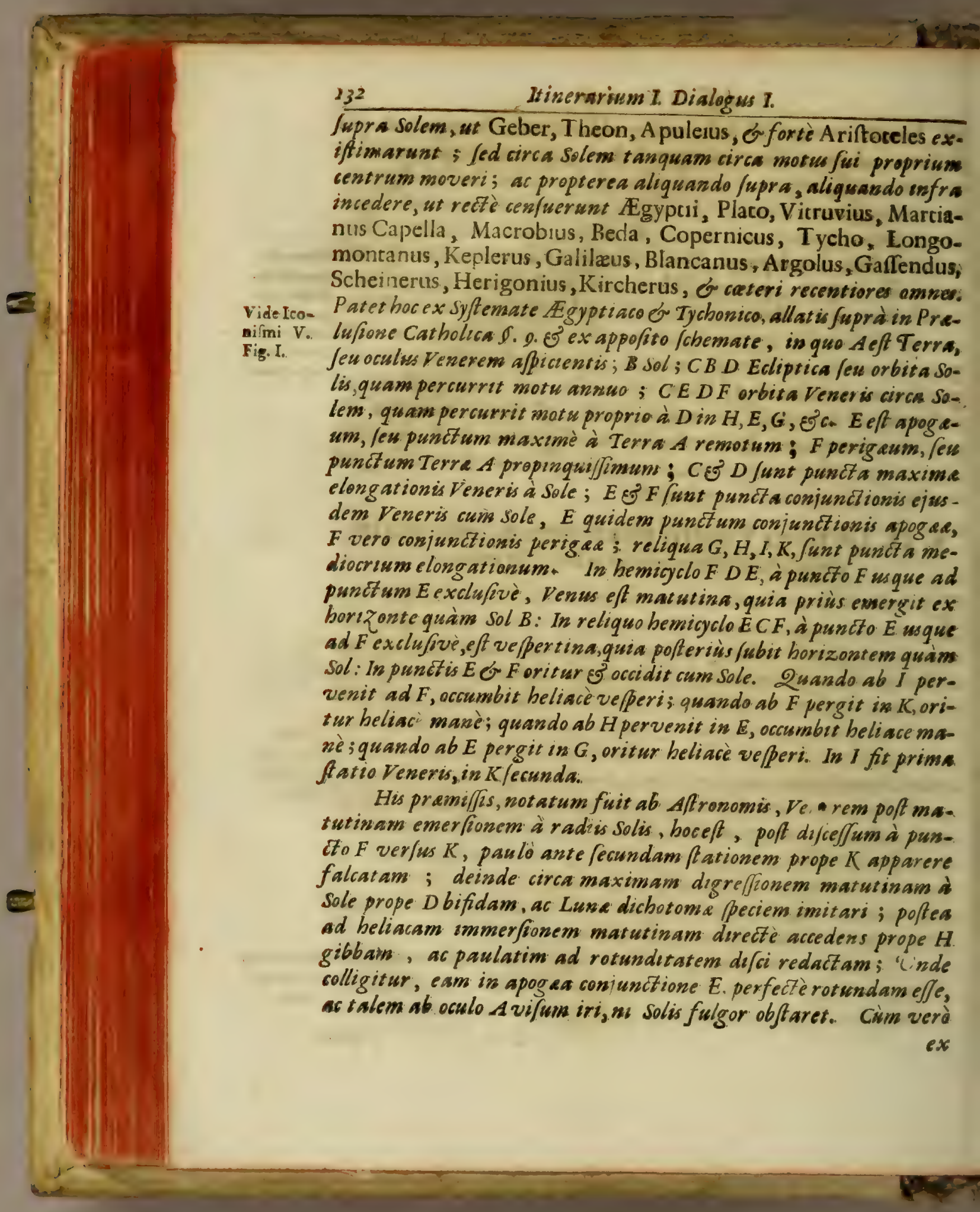




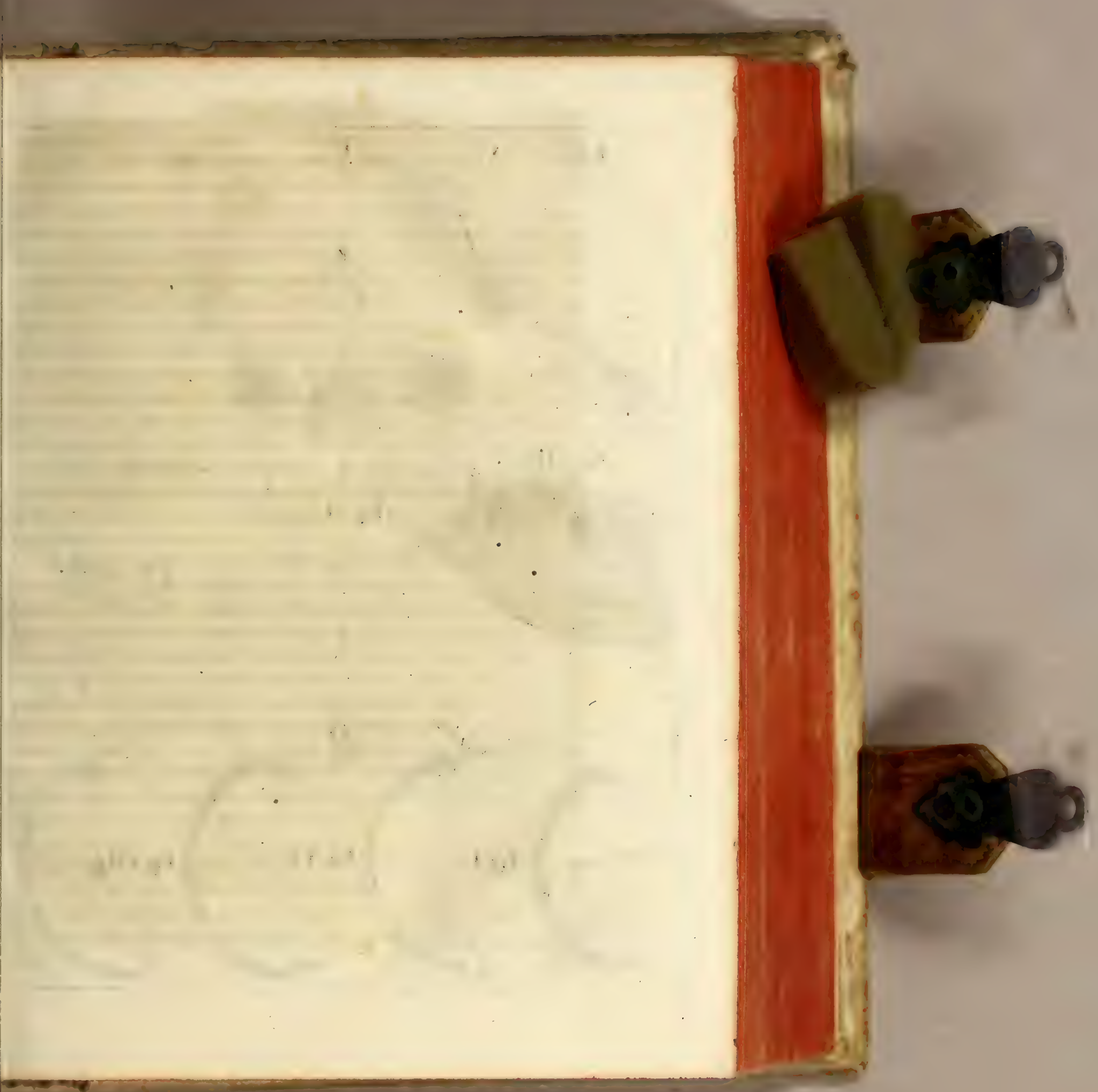




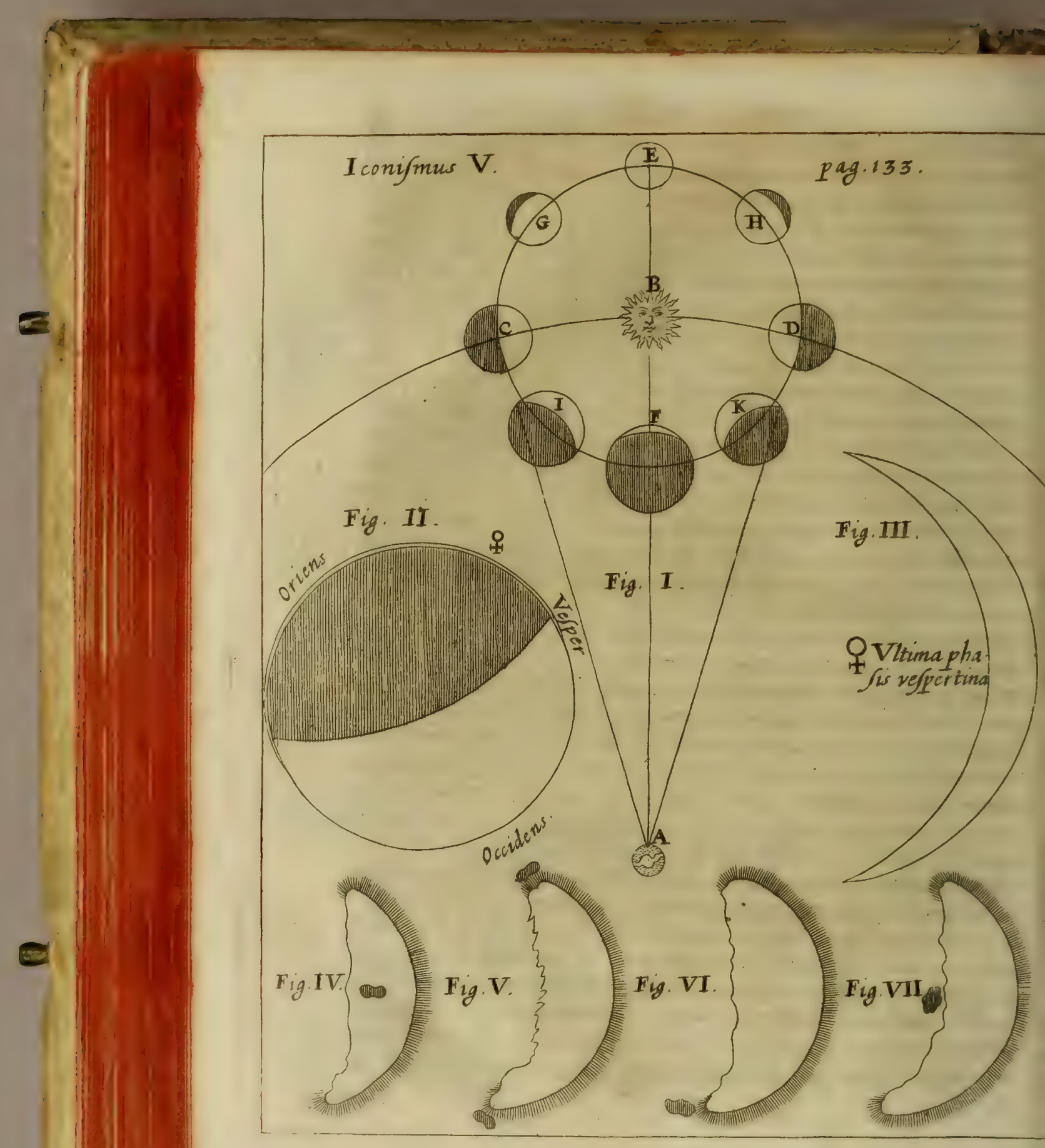


ex faftigio $E$ fri pericycli defcendere incupit, \& vefpertina fact as ex vadies solis emer/st, iterum apparet penè rotunda in $G$; $\Xi$ cir. ca algre/fionem maximam vefpertinam bifecta in $C$; acprope Patsonem proximam corniculata denuo in $1 ;$ in conjunctione autem perigea cum Sole in $F$, diebus utrimque proximis latet Jub plendoribus Solis, nec videtur, nifi utcunque propter enormen latitudisen: : teftaturetentm Longomontanus in Aftronomia Damicalib.2. Theoric. c.18. E' Keplerus in Opticis pag.261. Tychonem vidiffe Venerem prope perigram conjunctionem in borzonte Dani60, cum haberet latitudinem Borealem Gr.panè g.

Notatum praterea fuit, eandem Venerem in apogeo appare-Venus mu$r$ valde parvam; quia remotiffma: in $G$ o $H$ majorem, quiat tat magni-

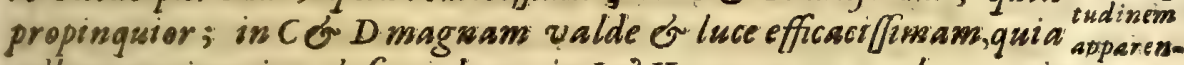
adbuc propinquior, of femiplena; in I \& $K$ tant ans per tubum opti uem. cum, quant a apparet Luna fone tubo, imò aliquantò majoren, quia vicinifima Terra: licet enim vicinior fit in $F$, ibi tamen, ut dixi, non ondetse, tum quia Soli conjunct a, tum quia privata lumine ex ea parte, quá nos refprcit.

Ex his manifefte colligitur, Venerem ambire Solem $B, E^{5}$ non lu-Venus a' Sols cere proprio lunome, Jed illuftrari à Sole. Nam fi femper infra Solem lumen nusforet, É pericyclum predict un inf fra eum decircinaret mot u fuo proprio uunquam digrediens ab. coultra 48 , aut ad fimmum, 0 gra-s dus; /emper falcat a, aut dichot ono sol fummum telefcopio appareret; fi autem femper fupra Solem verfaretur, femper rotunda, aut quafi rotunda pect aretur, ut patet; fin in pradicto fchemate dicantur à sole ad Veneris globum line illuminationis, छ' inde ad oculum A linea reflexion is , juxt a leges Optucas explicatas à nobis in Magia par.1.lib.2. Si verò à feip/a luceret Venus, femper rot unda videxetur, quando appareres, ut ex fe patet. Vide Kircherum lib.g. De Lum.Ẽ? Umb. par.2. probl.14* carr.3*

\section{§. III.De variis Aftronomorum obfervationi- bus circa Venerem.}

7 Enerem tam crebrò ac manifefte varii Auttores variis in lo-obfersatiocis vifam teftantur telefcopio midò gibbam ac ferè rot unadam; nes circa $R_{3}$ modì Venerem. 


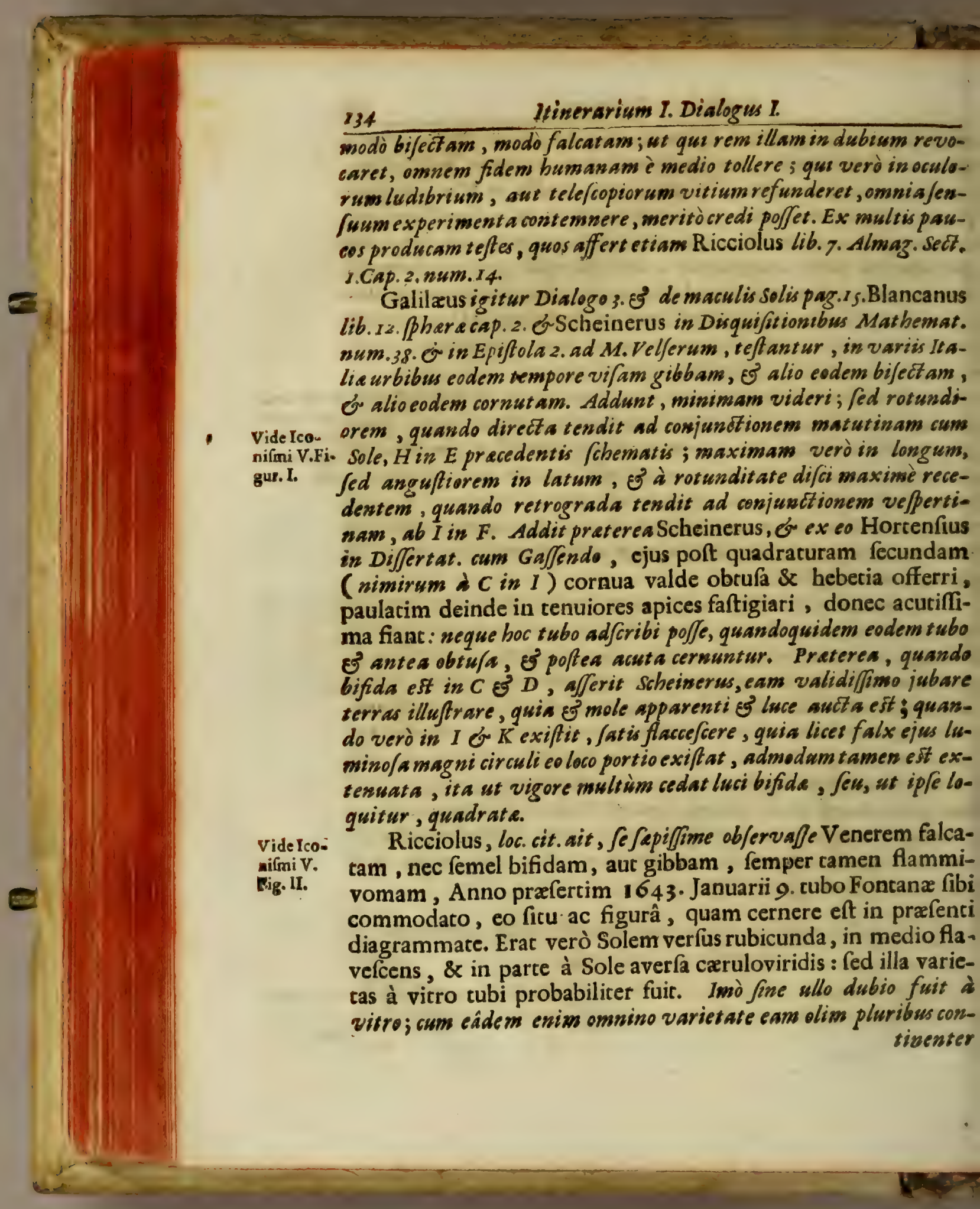


siventer noctibus ante crepu/culum matutinum (erat enim orienialis ) pectavi Panormi iss Sicilia, tubo pragrandi, latoque ac dex/o vitro convexo ad extremitatem ab oculo remotiorem msniso; quod vitrum quò mag is erat apertum, è vivaciores in Vesere apparebant pradecto ordine colores; quò vero magis tegebatur chartaceis circulis in medio perforatis, co magis extenwebaniur, donec tandem penitus ferè evanefcerent. Colores oriuntur i refractione varia lumenis in vitro, ut patet in vitris trigonis. Pergit Ricciolus: Semicirculus autem lucidus, quo à tergo coronabatur, erat fortè à Jove ac Sacurno illam illuftrantibus, ucpote orientalioribus. Eadem oblervata eft tum aliàs, tum frequenriflimè Anno 1644 . cùm vefpere ab A pogæo jam delapfa Epicycli fui poft ortum vefpertinum heliacum apparuiffec. Ec à die quidem 7. Maji evidenter gibba, usque ad 20. diem Junii, grandioribus tubis confpecta eft ; circa initium verò Julii sixóron (-), feu quadratæ Lunæ perfimilis, fed valde flammivoma verfus Solem ac Terras; deinde usque ad diem 4. Augufti, quo ab oblervando illam ceflavimus, in dies magis falcata, \& arctior in latum, at in longum diductior, adeò ut Lunam in prima ipfius phafi imitaretur: quemadmodum ejusdem Lunæ ultimam phafim xmulatur, quando manè oritur heliacè. Hoc verò luculentifimè inprimis patuit Anno Domini 1649. Junii die 29. Vide Isocuius vefpere Vefperugo ulcimò vifa eft per tubum occafui he nifmi $\mathbf{v}$. liaco velpercino, qui mox fecutus eft, proxima; vifa inquam eft prorfus ur cernis in pramiffo fchemate, cornibus acutiffmis, \& utroque margine nitidifimo absque ullis radiorum fibris \&

Antonius Maria de R heira lib. 4.Oculi Enoch \& Elia, cap.t. Memb. B.poftquam dixiffet, Stellas Veneris \& Mercurii, quas: Veteres proprio lumine præditas, \& naturæ ıgnex efle juraffent, noftri feculi nobiliffimum illud dioptricum inftrumentum, feu telefcopium, velut alreras Lunas folares, modò plenas lumine, tum gibbofas, deinde dividuas, denique corniculatas feu falcatas perfectiflimè exhibet, offertque ; addit deinde: Certè hac Veneris \& Mercurii indubicata phanomena, 


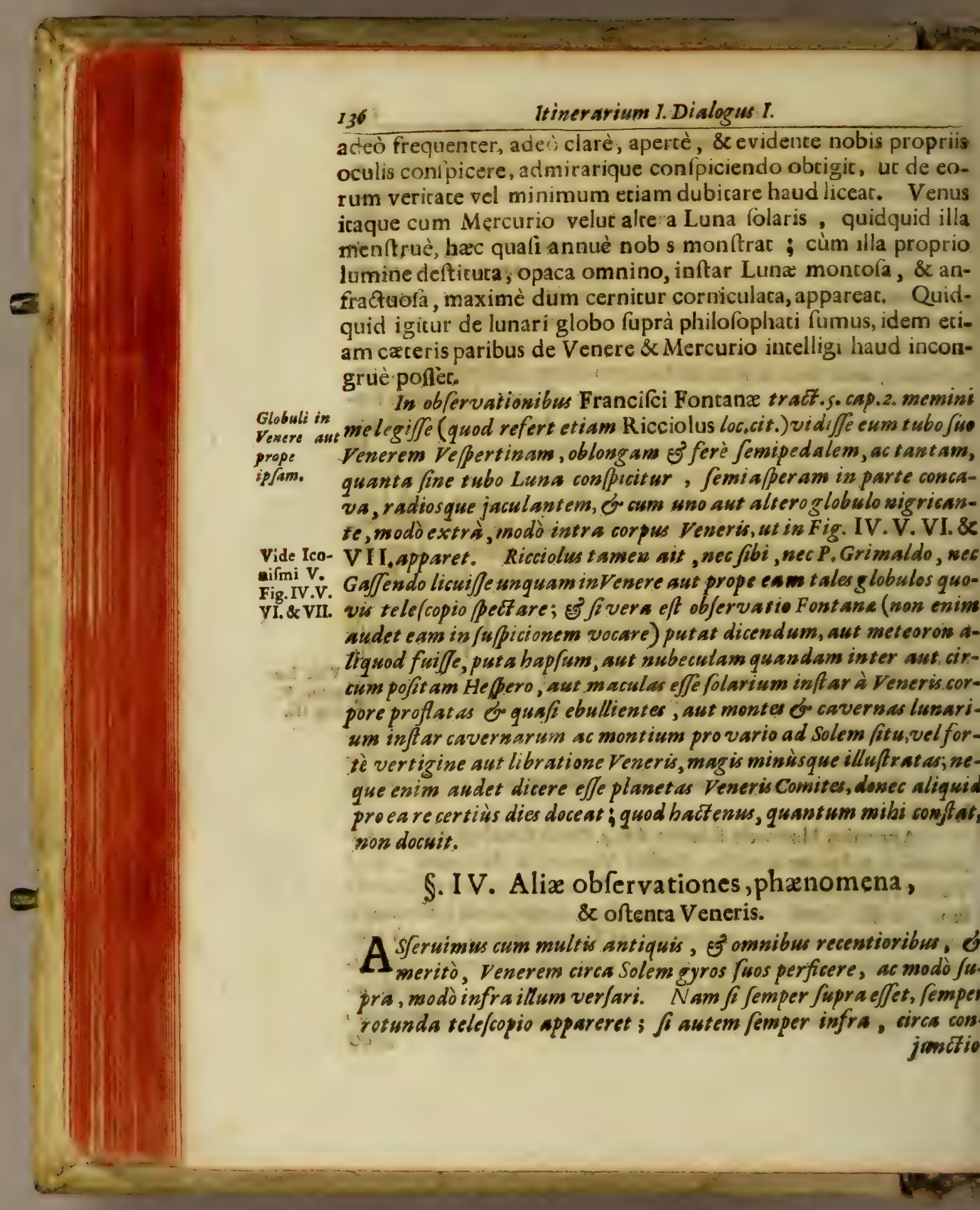


junctionem utranque cum Sole videretur falcata; at videturcirca conjunctionem fuperiorem (eu apogam rotunda, É parva, circoperigeam falcata, ut videmus; ergo g'c. Dubiums non est, quin Venus an in perigea conjundtione lape fub sole fit; Latitudo tamen magna fub Sole biplerumque tunc, aut obfervatorum oblivio, vel incuria in caufa conjunitioeft (inquir Ricciolus lib.7. Alwag. Sect. 1. Cap.4. num.s) ut fub neperigea. Sole nusquam vifa dicatur; nifi quod Scheinerus narret in $A$ pelle poft rabulam Epift.r. vifam fub eo à quodam fub ppesie cujusdam macula; at ip/emet in Epift.2. ad Vellerum refert, fe fruftra sali phonomeno, quod promiticbat calculus Magini Anni 1611 menfe Decenb.infodiatum.

Keplerus in Tabslis Rudolpb.pag.76.ait, Venerem proemerfonematutina iे sole, aut occultatione vepertina fub eo, longe missoren vifzonis feu fulfsonis arcum requirere, quia tunc est periges, of major apparet; quàm pro emerfione vepertina, aut otcultatione matutina, quia tunc est fere iss Orbis feu Epicycli fui npogeo, so dininuta lumine. Inò contingit, wt conpicua fit in- Venw imterdiu quoque, sole etiam fupra borizontem exiftente; of Riccio-serdiuconlus lib.7. Almag. Sect. 7. cap. 5. in Scholio afferit, fe fapius abortus ferì ulque ad oxafsum Solis eam stiam nudo oculo oblervafje, prefertim circa digreffiones à sole maximas, quando plurimum abest ab ejus radius; unde fequitur eam crebrò non indigere ullo arcu vificnis leu prof unditatis solis infra borizontem, ut videatur. Addit ibidem aliud peculiare ipfous oftentum notatu digniffimum, quod ait illi accidere ex magna latitudine prefertim Boreali, videlicet ut eâdem die naturali videatur vepertina paulo post So-Venus eolis occa/wm, frgue He perus, mane lequenti appareat matutinadem die paulo ance Solis exortum, futque mox Lucifer. Confirmat id ex ef metwitMaurolyco Dialogo. 3. Colmog. pag + 101. E Reinholdo in Pur-ne. bachii Theoricas planet. pag. 153. qui id haufit ex Regiomontano. Ad hanc phafon juvat amplitudo diametri apparentis Veneris in altitudinem, on in lognis fulgor ipfius, qui tantus est, ut corpora ejus radics object a umbram projiciant, ut fuprà diximus, Venus um. orteftatur Plinius lib. 2. cap. 8. ac Martianus Capella lib. s. de bram efficit Nuptin Philolog. Nikil igitwr mirwm, ficon Birantibus latitudine porwm. 


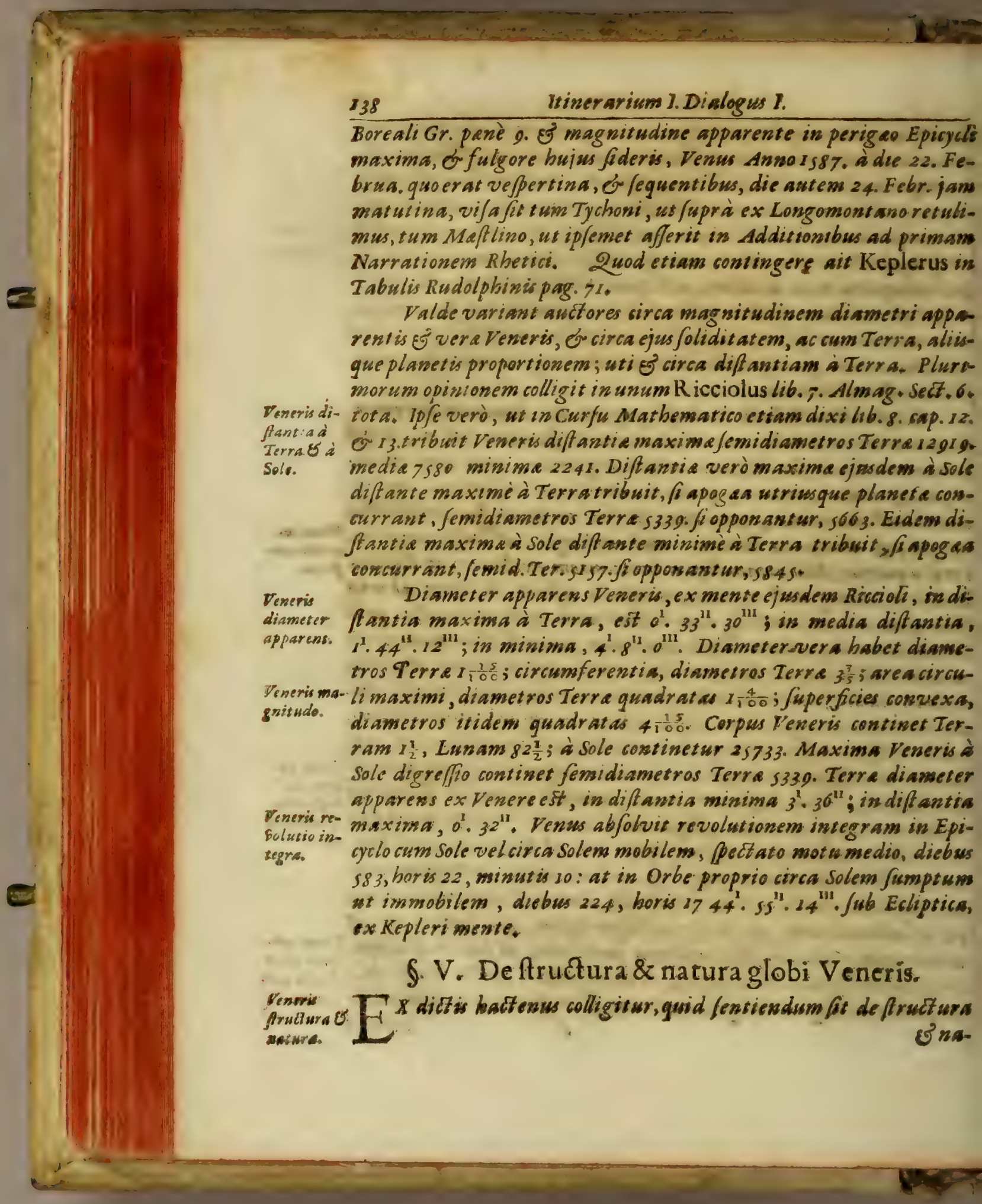


J natura Veneris. ESt simirum corpes opacum, quia nullo propris, fod solis lumine nitet: est pharicom, quia phericè illumimarser : est folidwm on confiftens, quis per caluns liquidum fine difipatione fori revolvitur: est apperum on anfractuolum , tum quios ale per telefopium apparuit, twos quia alioguin Solis lumen nor in tanis absondantia ad Terram reflecteret, nec nifi ad angulos equales gulis incidentice folarium radiorum in ip fum. Non est ignee nat ure, alioguin ex fe luceret; non ä̈red, aut aqued tantùm, quia won confofteret, fed terrea Eु aquea fimul, tum quia, fi. folisus terrea, non ita efficaciter $\sigma$ abundanter influxus Juos Terra communicaret. Haçs alia ad Veneris globi ftructuram ac noturam pertiwentia melius intelligentwr ex Fequenti Austoris Cospite.

\section{CAPUT III.}

\section{De itinere ex Luna in globum Veneris.}

I. T Heodidactas. O mi amantiffime Cofmiel, quid video? quid 1 fibi vult ingensille globus æneus, quem ante me conftitutum intueor? Cofmiel. Ifte, quem vides, eft globus Veneris, vel, Iteringloprout eum Aftronomi veftri appellant, Phofphorus, feu Hefpe- ${ }_{\text {rim. }}$ rus. Theodidactus. Rogote, mi Cofmiel, acceleremus gradum, ut quantocius admiranda hujus globi fpectacula propiùs contemplemur; fummo enim defiderio feror ad infolentis hujusmodi luminis fplendorem propius cognofcendum. Cofmiel. Complebodefiderium tuum. Theodidact us. Hoc dicto, moru Euris Zephyrisque velociore per immenfa illa xetherei expanfi fpatia traductum, ad ipfum globum Veneris meftitit in ipfo autem motu, vehementi quodam imperu nonferri, fed in morem ex alto cadentis lapidis ruere videbar. Sed, ô Cofmiel, quid hoc? Cofmicl. Ne mirere, fiquidem intra fphxram activitatis globi Veneris conftituti fumus, ex quo non tuâpte fponce, fed meâ operâ veluti in centrum ejus moveris, \& jam, ur vides, ferè terminum noftrum attigimus. Theodidactus. $\mathrm{O}$ mi Cofmiel, quam miram rerum incueor faciem ? quantam, 


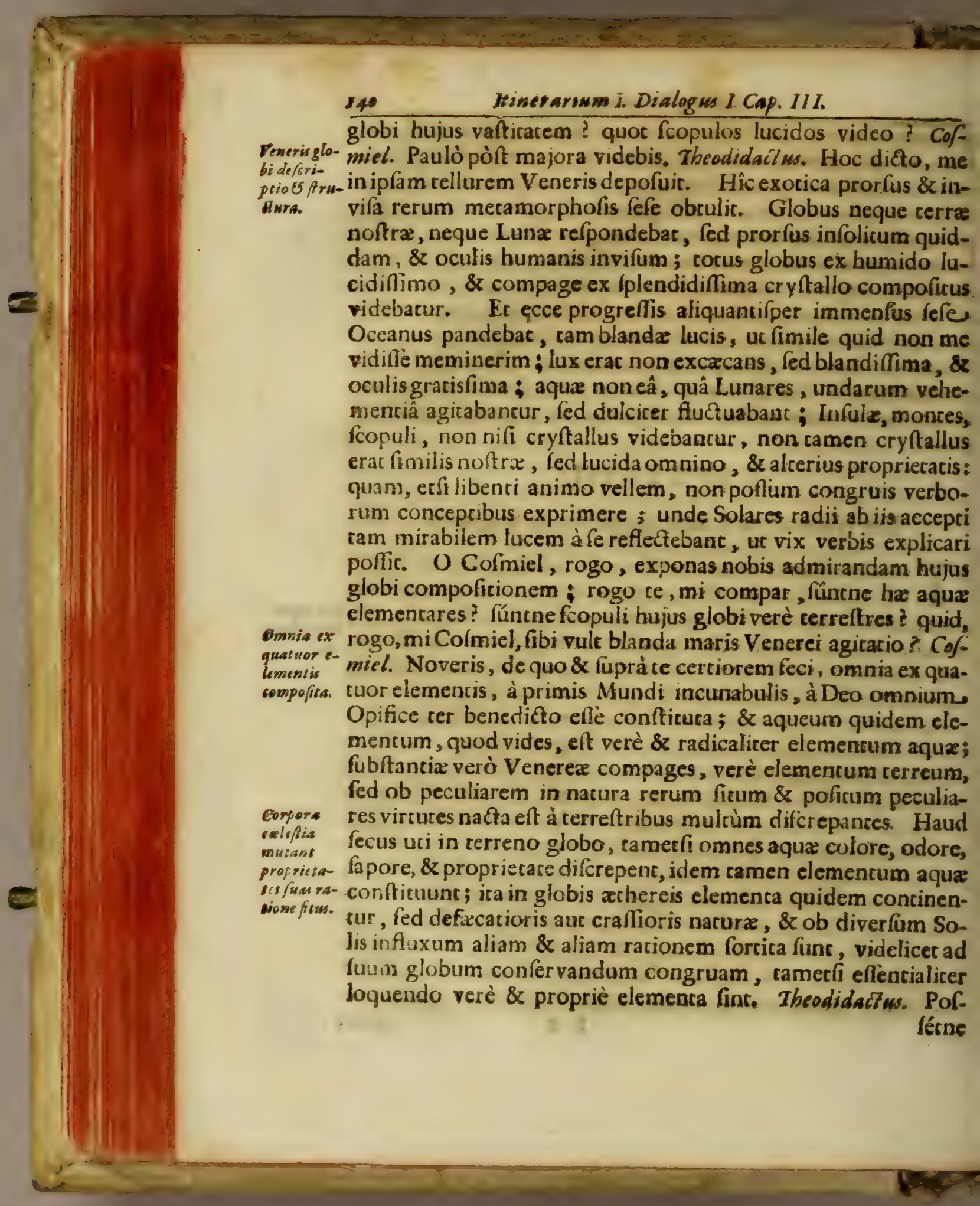


férne in hoc loco quispiam conftitutus Hebræum aut Paganum bujusmodi aquâ baptizare? Co/miel. Quid dubitas ? cùm enim Aquisglobi elemencum aqua verum \& proprium fic hujus globi, non eft Veneris ullum dubium, quin in illo baptizari poffer; quemadmodum trumbain terreftri globo confticutus, necefficate fic urgente, \& ma-fritui pof rinâ, \& acerosâ, aut fulphureâ, aut quavis aquâ occurrente, fit. baptizari poffer, dummodò immediatè ex elemento aqueo originem luam trahac : quòd enim aqua jam dulcis, modò amara, jam acetofa fic, per accidens eft ; neque enim aqueum elementum nacura terra, per quam derivacur, qux \& id tali \& rali humore \& proprietate imbuic, propriè deftruic; cùm vix ulla aqua in cerra aflignari polfit adeò pura, qua non aliquid ex loci, unde profluic, propriecace attraxerit : ac proinde ne baptifte femper in dubio verfarentur, num verâ \& naturali aquâ Sacramentum baptifmi adminiftrafient, benignisfimus Deus ita Sacramentum inftituere voluit, ut fufficeret qualiscunque aqua, dummodò elementi aquei nacura non contradicerer; hoc pacto, qualiscunque aqua (exceptá illấ, quæ ignis ope ex metallis \& vegecabilibus extrahitur, \& verè ac proprie elementaris aqua non eft ) in Sacramenti ufum aftumi poteft. Pariter cùm aqua Lunaris reipsâ fí elementaris, uti \& illa, quam vides, Veneris, ac proinde in hoe globo aliud elemencum aquae non fir , quăm quod vides, cúmque illud radicalicer vera aqua $f i x$; fi per impoffibile ibi: Paganus, aut Hebreus, aut puer confticueretur , \& in mortis articulo inveniretur, ibi baptizari pollet aquâ hujus globì propriâ, ibique, fi baprifmus conferendus effer, legicimé adhuberi poflèr. Simili prorfus ravione, fi in hoc globo vites provenirent, vinum, quod inde produceretur, tametf alterius proprietatis foret, in ufum tamen SS. Euchariftiz adhiberi poflet, cuim globus hic ex infita fibi proprietate tale \& rale vinum loco fuo congruum producerer, non aliud. Theadidactus. Optimè mentem tuam percepi; tam enim profundè \& fubtiliter omnia mihi evolvis, ut nullus $A$ /peritas ampliưs mihi dubieandi locus refinquarur. Sed, Ó Cofmiel, globr Venew cur Deus Opr. Max. tancá hos globos: fabricie \& afperitate ric. 


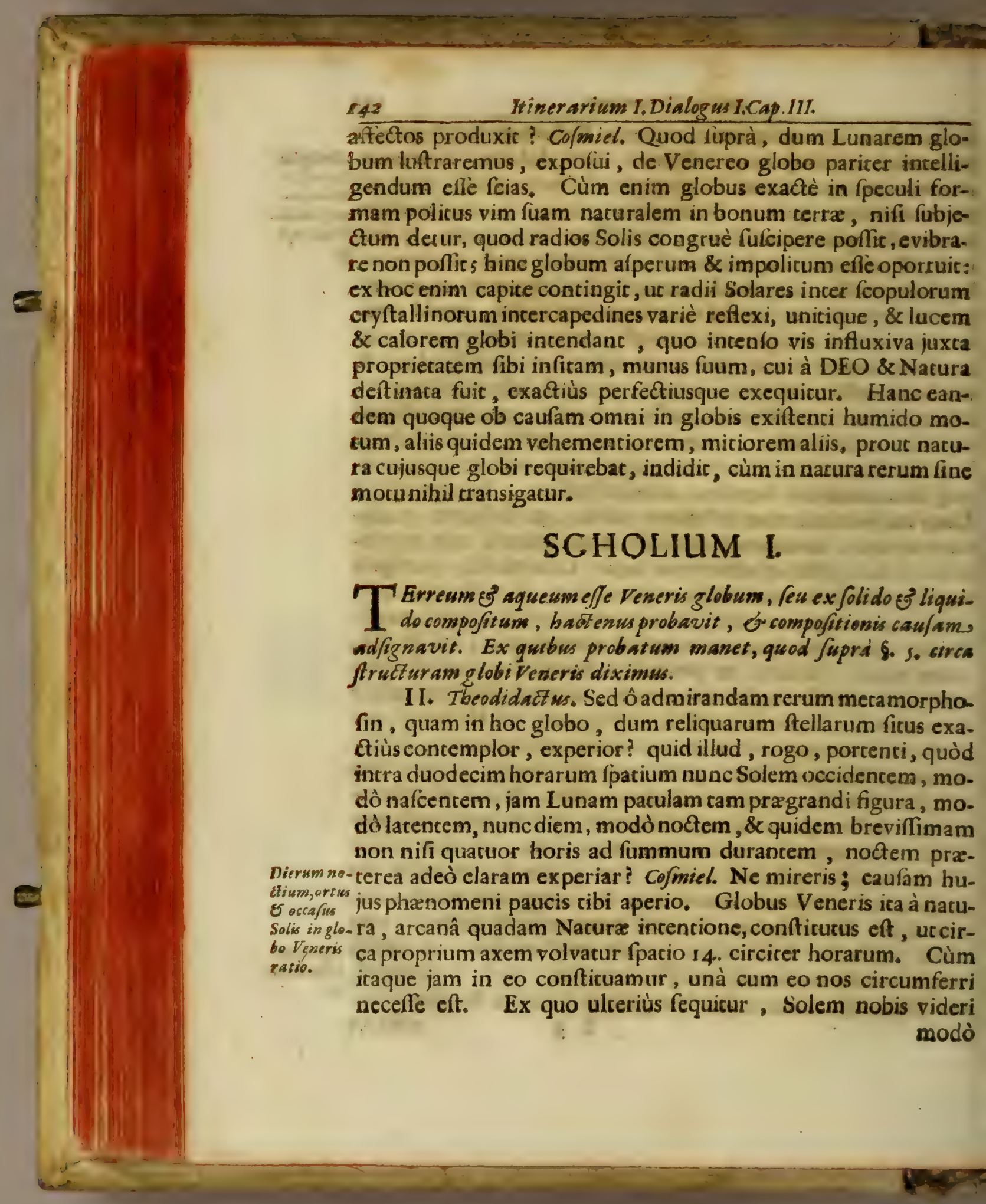


modò quafi oriri, paulò pònt culminare, deinde ad occalumus ruere, ac candem noctem fuccedere. Et tametfi motum hune minimè fentias, globumque perpetuò ftare, Solem verò cantùm moveri puces; id tamen non provenic nifi ex oculi tui fallacia, qui in navi, quancumvis celeri motu progrediente, conficutus non navim, fed lictora moveri exiftimas. Sed hac quia tibi trica func, ideo non immoror ampliùs: Porrò de noEt is brevirate hæc paucis accipe. Cùm Solis radii globum hunc, ucpote terrâ bis minorem, \& Soli viciniorem, quoad maximam ambicus fui partem perftringane, \& non nifi exigua, in averfa à Sole facie, tenebrofa portio relinquatur; nodem breviflimam efle , crepufculorumque obfcuricatem minimè excedere necelle eft, tum ob fummam aëris ex cryftallinorum montium reverberatione illuminati claritacem, tum ob velociflimam circa axem fuum proprium totius globi rotationem, tum denique ob Lunæ eum ex adverfa parte vicario Solis munere illuftrancis propinquitatem \& magnicudinem, ita ut in hoc globo perpetuus fubinde dies fine nocte, Sole etiam in oppofitis fignis conftituto, appareac.

\section{SCHOLIUM II.}

$\therefore \quad$.

De Veneris vertigine circa fuum axem \& centrum, \& de magnitudine ejusdem.

\section{Q}

$V_{a}$ de vertigine Vener is sirca fusm axem of centrum |patio vertigo V. 14. horarum bic docet Auctor, defampfit ex Rheita lib. 4. 0- nerisex cult Elia of Enoch cap. 2. memb. 3. ubi omnibus planet is tribuit mente an vertiginem, except â Lunâ, quam folum ofcillare afferit. Vt verò tempus determinet, quo finguli planete gyrationem integram, sirca axem fuum conficiant, ita difcurrit. Jam, quoad tempus gyracionis planecarum, audi ftupendum fecretum, bactenus, quancum f́ä, nemini notum. Dico ergo, planetarum omnium (Lunẩ exceptâ, quæ non gyratur, fed of́cillar) globus tali proportione \& tempore circa proprios axes gyrari \& converci, quali Sol fuper cellurem fe annuè volvic. Cum igitur Sol 
incra unam fuam revolucionem periodicam, terra 365. vicibus Rbeize do. oriatur; ex dictis fequiuir, quemlibet planetam (Sole \& Lunâ arina circe demptis) intra unam fuam periodicam revolutionem etiam 30 , sertigisem vicibus fuper proprio axe converti, jamque didas converfiones, planeta-

rwes. fuppofitis incolis in Erronibusfecundùm Cardinalis Cufani fentenciam, eis inftar toc dierum fore, ita uc fi ex fuppoficione in. Planetis inhabicatores forent, quilibet corum, intra fuum an. num (quem etiam inaqualem eflè neceflè effer à reliquorum planetarum \& noftro) præcisè tot dies numeraturus eflet in una. integra fui anni revolutione, quor nos in telluris globo demerfi numeramus, fcilicet $365^{\frac{1}{2}} ;$ hac camen differentiâ, quòd dies in aliis Erronibus, noftris auc multò breviores, autmultó eciam longiores forent, fecundùm proporcionem motus \& orbis annui, feu revolutionis planeta.

Ex boc furdamento cudit fequentem tabeltam; in cujus columna ultima conetinetur tempus feu dies folares, intra quod tempus feu dies quilibet planeta abfolvis integram periodum in fwo orbe mote proprio.

Tabula longitudinum dierum feu temporis, quod planete fonguli rotationem (super proprios axes abfolusunt, ex Rheita fensentis.

\begin{tabular}{|c|c|c|c|c|c|c|c|}
\hline \multirow{5}{*}{$\begin{array}{l}\text { Planetx } \\
\text { gyrantur } \\
\text { fuper } \\
\text { proprios } \\
\text { axes. }\end{array}$} & |Horis| & Minut. & $\begin{array}{l}\text { Diebus } \\
\text { noftris }\end{array}$ & Horis & Minut. & \multirow{7}{*}{\begin{tabular}{|l} 
Longitu- \\
do anni \\
planeta- \\
rum, feu \\
tempus, \\
quo ab- \\
folvunt \\
periodú \\
in fuis or- \\
bibus.
\end{tabular}} & $\begin{array}{c}\text { Dies no- } \\
\text { ftri }\end{array}$ \\
\hline & 706 & $38^{1}$ & 29 & 10. & $10.16^{11}$ & & 10747 \\
\hline & 284 & $45^{2}$. & 11. & 20. & $1^{3} .15^{11}$ & & 4330 \\
\hline & 45 & $6 \pi$ & I. & 21. & $01.20^{1 I_{0}}$ & & 686 \\
\hline & 14 & $45^{2}$. & o. & 14. & $45^{3}$. & & 224 \\
\hline ఫ్ & 5. & $4 r^{I}$ & o. & 5. & $45^{x}$. & & 86 \\
\hline ○ & & & 365. & 6. & & & \\
\hline
\end{tabular}

Ex bis infort Rbeita, quemlibet planetam patio faorum dierwm 36 s. abjolvere fuam periodum. Et fo queres, wnde bac ar- 
cana defump/erit, quibuisve conftent fiundament is, reßpondet cume surchangelo Tothia , Tob. 12. Fecretum \& facramentun regis abscondere, bonum efle pro nunc; opera autem D E I revelare \& confiteri, honorificum. Quod reßponfum fapienti Lectori pro nusse frofficere jubet.

Hase Rheite doctrinam, ejusque fundamentum, cum attuhifet Ricciolus lib. 3. Almag. cap. 4. num. 3. hec /ubjuxgit. Quo fundamento tam voluntario, ne dicam levi, fuperftruxit nobis fequentem tabellam. Adeò proclive eft, quibus prurit ad novitates comminifcendas ingenium, ex quantulacunque fcintilla analogia, motus in cœlo fingere. Qux porius animi, quàm fiderum auc vertigo, aut prurigo eft. Ego exiftimo, motum verriginis Veneris circa funm centrum non carere probabilitate, propier rationem, quam affert Auctor nofter tum hic, tum feq. Cap. de vertigine Martis; quamvis nullum adhuc legerim, qui motum illam ndfruat, aut ejus fognum aliquod afferat, excepto Ricciolo, qui, ut fuprà vidimus in Pralufione \$. 3. ait, maculas illas in Venere a Fontana notatas oriri forta]js ex vertigine ejus modo ibi infsnsato. 2uod veró Veneris of aliorum planetarum vertigo abfolvatur tanto precisè tempore, quantum Rheita determinat ex fuo fundamento, non credam, quim diu arcanum fuum von pardet.

2uod de Veneris magsitudine, ac proportione cum Terra do- Veneris mecet, eam nimirum Terrâ minorcm effe duabus vicibus, delumpfit $g_{\text {mente } A \text { mi }}^{\text {nitudo }}$ ex eodem Rbeit a loc. cit. Memb. s. ubi fingulorum planetaruss pro taris. portionem ad Terram ad/gnat ex co fundamento (de quo Memb. 4. praced egerat) quid omnes planet a habeant inter (e proportionem fuorum cuborus. Cum igitur (inquit ip/e) cubus Veneris 2744 . ex radice ejus revolutionis 14 . in cubo Tellures 5850 . bis contineatur ; exiftimat Venerem bis contineri à Terra, atque adeo Terram effe duabus vicibus majorem Venere, feu Venerem duabus vicibus minorem Terrâ. Sed quàm infirmum eft fundamentum Rheite, tam parum probabilis eft proportio predict a inde deducta. 2uid Ricciolus fentiat, diximus in Praluf. $\$ .4$. quid alii nonnulli, indscavimus in Curfu Matbemat. lib. 8. Auctor 


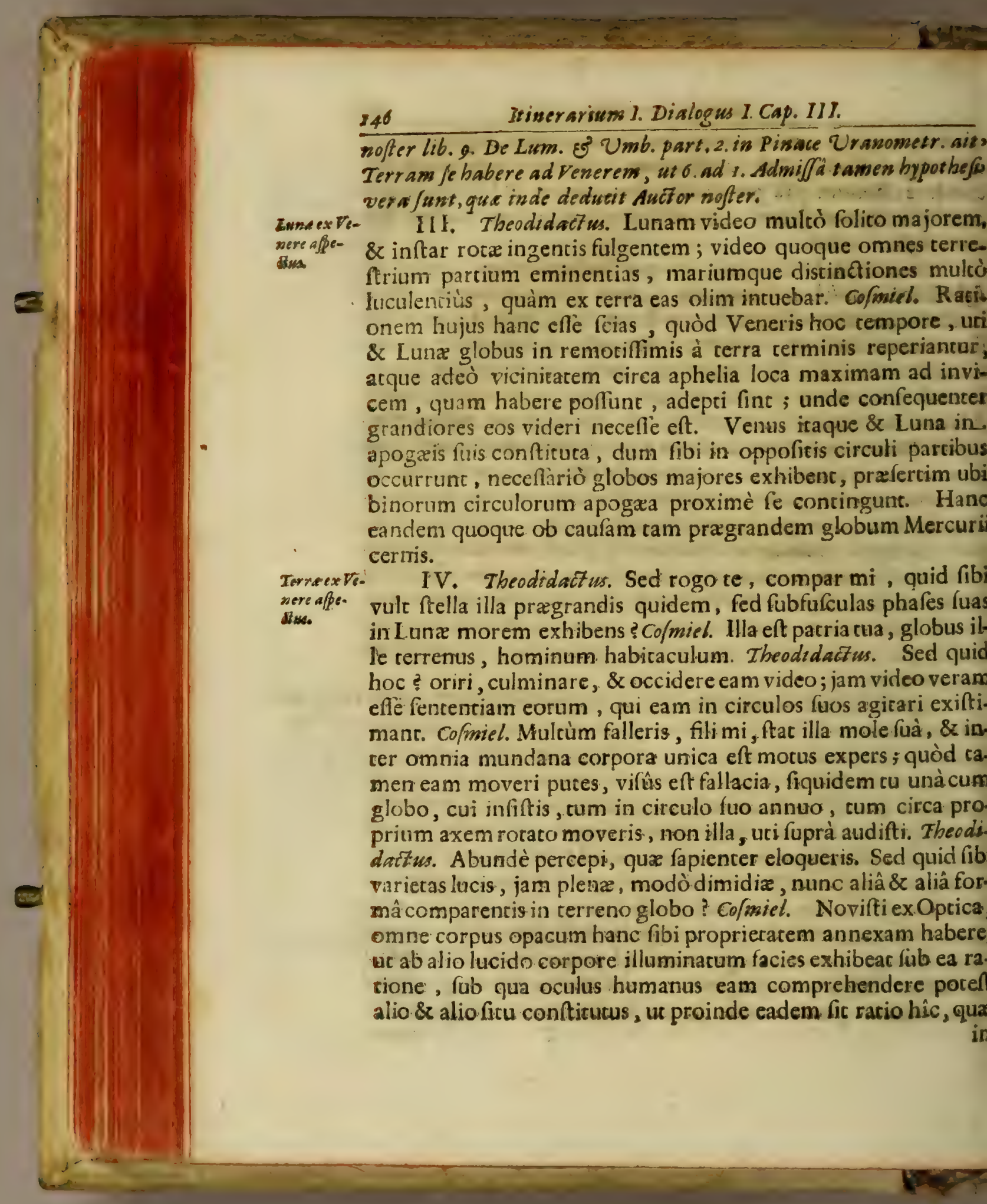


in phafium lunarium phænomenis menltruis. Theodidact us. Reatedixifti ; in Veneris enim globo, in quo conftituri fumus, ex terra Optici cubi fubfidio easdem phafium paffiones me confpexille memini. Sed, ô Cofmiel, novum portentum ! Co/miel.Quodnam illud ? Theodidactus. O miranda!Solem incueor veluti ingentem quendam Oceanum, veluri cacabum liquefacto cupro undantem. Cofmiel. Suftine parumper, fili mi, \& paulò pònt propiùs incueberis Omnipotencis DE I magnalı; modò, qua hujus. globi propria funt, luftremus.

V. Theodidactus. Vix hac effatus fuerat, cùm ecce me ve- Infala Vis: hementi impetu in Infulam quandam Oceani Venerei confti-sherrimas. euit , tantâ pulchritudine confpicuam, ut in rebus humanis nihil fibi homines fimile imaginari pofle facilè mihiperfuadeám. Odor hujus Infulæ fupra omnia mufci \& ambræ fuffimenta; arbores non quales noftre; fed ex pretioforum lapidum eftlorefentiis excrevilè videbantur, innumerâ colorum varietace imburx, qui quidem color non realiter illis inerat, fed ex reflexione refractioneque Solis in angulofa illa cryftallinæ atque adeo diaphanæ nateria longè latèue exporrecta latera caufabacur ; pavimentum lucidiffimâ materiâ ftracum videbatur , aureum dixifies Soli expoficum periperafma; aura liquida, blanda, \& mirè temperata. O Cofmiel, Cofmiel, quàm magna \& mirabilia video, \&experior. Cofmiel. Paulò pònt majora videbis.

\section{SCHOLIUM III.}

PRobabile ent, quod de Venerei globi pulchritudine on odore dicit, If vera funt, que Aftrologi de ejus beneficio in fublunaria influ$x$ sodent, qui propterea Venerem appellant beneficam, of Fortsnam minorem, repectu nimirum fovis, quers majorem Fort unam dicunt.

VI. Theodidactus. Vix dixerat, cùm ecce ex cryftallino Angelive. monte erumpit nefcio quis juvenum pulcherrimorum chorus; prefides. gratia vulcus eorum verbis defcribi vix poteft; volitabat circa humeros aurea cafaries, oculi faciesque gratiâ \& decore

$$
\text { I } 2 \text { plena, }
$$




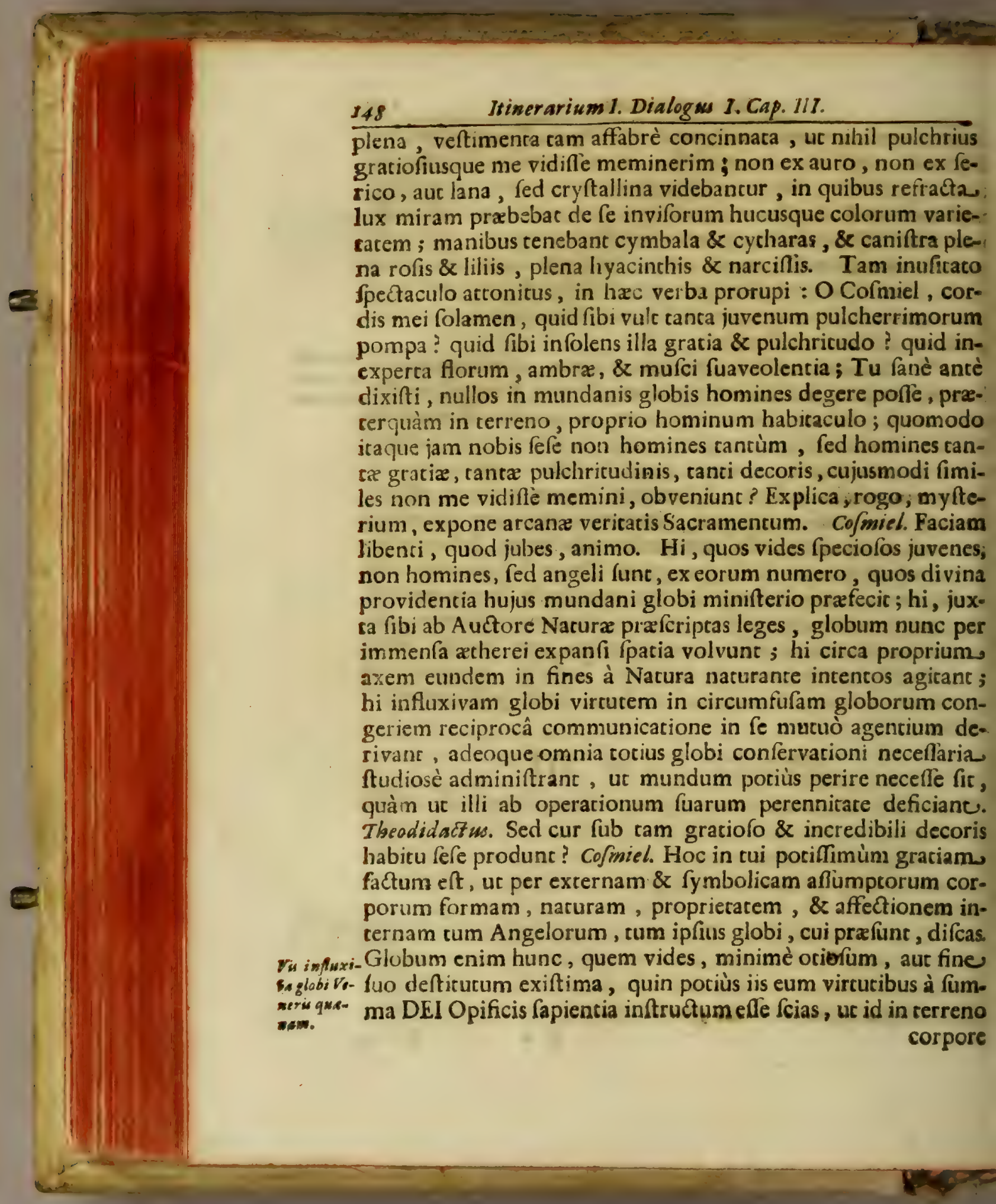


corpore efficiat, quod prafides Angeli per corpoream tibi formam exhibent. Tu, qui hieroglyphico \& anigmatico dicendi genere delectaris, facilè, quid velim, intelliges. Globus hic gracia \& decoris eft, quem præfides pulcherrimo, \& fplendidifimo corporis, veftimentorumque habitu exprimunc; odor, quem percipis, infolentis prorfus fuaveolentia, uri \& cornucopix canifraque omni pulcherrimorum florum fructuumque genere conferta, effectus notant, quos in terreno Mundo globus operatur.

VII. Tbeodidactus. O mira ! fed rogo re, mi compar Efferus $\mathrm{F}_{\mathrm{s}}$ $+4 \cdot$ ¿. $\therefore \quad \cdots$ fapientifime, cum terrenus globus ex hoc globo vifus, non ni- ${ }^{\text {mexis. }}$ fi ftellula corpus exprimat, quomodo ergo vircutem hanc cofineticam feu decorificam derivat, rebusque communicat? cùm in terreno globo paucos homines pulchros videamus, præter innumeros mancos, curpes, deformes, \& omnibus defectibus obnoxios ; \& prater flores \& fructus fuavifimos, innumeros alios hifpidos, curpes, infipidos, acerbos, inodoros". Cofmiel. Ne mireris; vis enim globi, quâ gratiam \& decorem Veneris gloin inferiora influit, agit quidem, quantum potelt, fed prare- bus quome- dratiam quirit tamen capacitatem fubjecta materix, vel, ur Philofophi ó decorem loquuntur, dispofitionem in fubjecto praviam, uc fuam virtu- imflust. tem exercere poffic. Ubicunque itaque invenerit materiem ritè dispofitam, corpusque (five id exanimalium, five ex vegetabilium, five denique ex mineralium oconomia fuerit) virtuci recipienda proportionatum ; ibi gratiam \& decorem necefta riò influit ; reliqua verò ob nacura \& propria complexionis. indispofitionem, uti dictx virtutis incapacia funt, ita quoque dicta gratix, \& decoris, odorisque expertia manent. Hoc paCto Lunaris globus tumefactivâ quâdam virtuce pollet, quam in terrenis corporibus, ejus virtucis capacibus, non in aliis imprimit. Pari ratione Sol fpecificâ fuâ virtute, alia quidemterrena corpora ficcac, alia liquefacit, emollit alia, alia indurat, quadam disgregat, nonnulla pro ratione fubjectx materix congregat; habentque, uri poftea videbis . finguli mundani globi hujusmodi fpecificas vircutes fibi folis, non aliis, pecu-

$$
\text { T } 3 \text { liares, }
$$




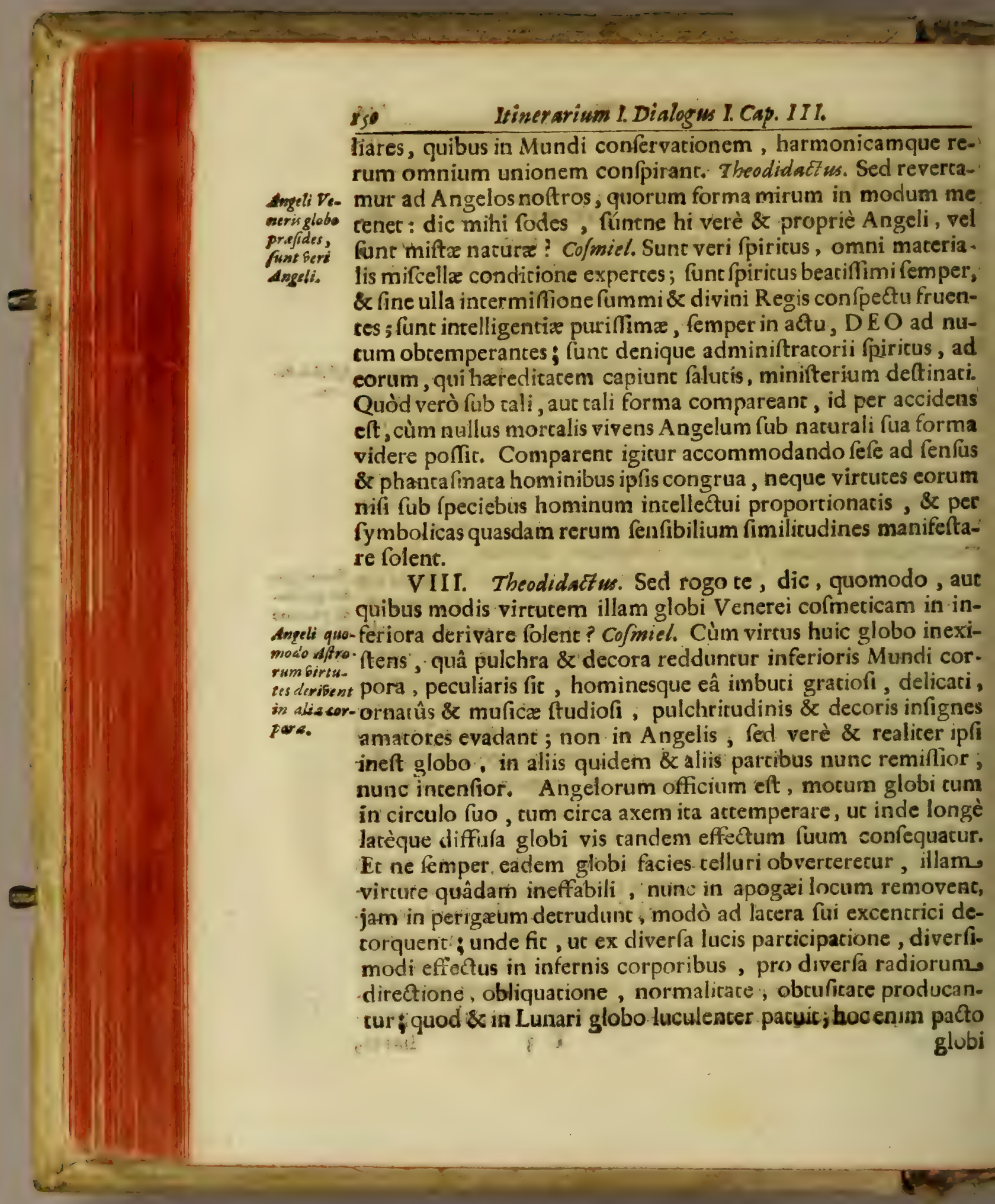


globi vis mirum in modum attemperacur, \& ne exceffus virium vehementiâ fuâ inferioribus officiat, aư earundem diminutione illa juxta prafcriptas à divina fapientia leges deficiat, hunc excesfum lucis diminuxione refarcit \& inftaurac. Sed jam tempus, eft, ut ulterius iter noftrum promoveamus.

IX. Theodidactus. Quxfo, mi Colmiel, antequam hoc fiac, permircas velim, ue frufulum quoddam in tam pulchri glubi reftimonium terrigenis comprobandum mecum deporrem. Cofmiel Jam dixi ribi, fili mi, parces nullibiconfiftere poffe, nifi in toto, cujus partes func, id ent, in hoc appropriato illis globo; unde pars in tellurem ablaca, vel infico fibi appeticu in fuum remearet globum, vel in terreftrium corporum naturam degeneraret; fruftra itaque contra ordinem à natura prafcriprum laborares. Theodidactus. Ex verbis tuis a pertè colligo, cœleftium globorum mareriam fpecie \& effenciâ à cerreni Mundi materia differre. Cofmiel. Minimè gentium, nam, ut jam Materta fape audifti, omnia hujus Mundi corpora ab origine Mundi caleffis now ex immenfo illo elementari confufionis chao educta fuerunt differtialites unde frngula uxi in diverfas Mundi fationes deducta fuerunt, i terren ita ibi manenc, tametfi ob nacuralem illorum in Univerfo fitum \& pofitum ita alterata, ut maximam unius ab altero globo differentiam, tum ex vicini Solis efficacia, tum ex reliquorum globorum influxu fortita fint; fiquidem quidquid tum in hoc, tum in aliis globis fenfibus obtrudicur, ex elemenris compofitum vides. Eft hîc aêr globo huic proprius : eft aqua, fed eâ proprietate imbuta, ut non alterius globi , fed hujus proprium fit elemencum ; datur ignis, ut lucida globi natura luculenter demonftrac ; dacur terra, fine qua pedibus huic globo infiftere non pofles; datur centrum horum elementorum, fed fuo globo proprium; vides hî́c fruftum lapidis mox ac in altam projectum fuerit, cerram fuam, non fecus ac terrenum lapidem fuum cencrum, repetere; fentísne gravitatem hujus lapidis e Theodidactus. Sentio. Co/miel. Vidésne vapores ex 2 ualitares virreo elemento exurgentes? Theodidactus. Video. Colmiel. Sen-primas fo. cisne calorem? Theodidact us. Sentio, \& quidem, nifi tu me potenti curida indextrâ funt globo 
dextrâ tuâ fulcires, non ferendum. Cofmiel. Sicutı ıtaque in cerreno globo quatuor elemenca illius fini congrua funt, ica \& in hoc globo ; \& ficut nonnulla ibidem corpora geavia, nonnulla levia fune; ita etiam hîc, fed fuo modo; \& ficuti ibidem. calorem frigus , \& frigus calor alternis vicibus excipir , ita \& hic, fed condicione huic globo propriâ : uti enim in Soli expofita hujus globi facie calor à Solis in opacum conpus reflexione intenditur, ita in averfa à Sole facie fuccedente frigore calor necelfariò remictitur. Nequaquam ergo, quemadmodum nonnulli Philofophi nullâ experientiâ fulci fentiunt, materix horum globorum fpecie \& eflénciâ à terrena, fed proprietatibus tantùm \& accidentibus, prout fingulorum globorum natura requiric, differune, neque quinta quxdam eflentia dici poreft, cùm hoc fimpliciffimum quoddam nullis qualitatibus elementaribus, nullâ certâ formâ affectum corpus neceflariò forer, quod omnino experientix repugnat : certum enim eft, omnes \& fingulos globos fuas particulares \& fpecificas facultates habere, qualitatibus quoque alterativis conftare, cùm fine his in inferiora influendo, incentos à natura effectus confequi non. poflint. Theodidact us. Verè adeò mentem meam eloquio tuo convicifi, ut aliud, quàm quod tu fapienter loqueris, credere non queam. Cofmiel. Agedum Theodidacte, tempus eft, ut gradum ad altiora contemplanda acceleremus. Theodidact us. Quo dicto ,' in momento me abreptum, per vaftiflimum atherei expánfi fpatium transtulit.

\section{SCHOLIUM IV.}

\section{Defeptem Intelligentiis, qux feptem planetis praefle creduntur.}

Intelligentle epiem planes is prafidentes. Vefor nofter tàm boc, quàm pracedenti Capite infonwavit, non unum, fed plures Angelos fingulis preeffe planetis, ad di. verfos effectus ${ }^{3}$ motus praft andos, bac nixus.congruextia $\hat{a}$, quòd cum Terre noftre non unus, Jed plurime prafint, nempe unus for- 
onfos toti, aliifingulis regnis, provinciis, urbibus, fingulisque renum peciebus, credibile fit planetis etiam plures a DEO prafixos. Sedquidquid fit de Angelorum fingulis profixorum plusralitate, fingulio ralieno aisum divinitus ab exordio Mundi prafectum. effe, adillos movendos ac dirigen dos ins fines /nos, multorumque Rabbinorum, of Chriftianorum Pbilofophorum ac. Theologorum fentemtice eF, w docent Scholaftici in 2. Sententiar. dift. 2. Imo'S. Thomas q.6.de Potentic art.3. in corp-ait, fidei fententiam effe, quid Angeli corpora caleftia faso impet u moveant localiter. Et Opufa. 10. art, 3idferit, à nemine Sandforum vel P bilofopborum negatum fo legifje, gsiò coeleftia corpora à perituali creatura moveantur. Er Opufc. Ir. art, 2. phyfices rationibus id demonftratum affirmat. Joannes Trichemius quoque, quondam ad D. Facobum bujus $\mathrm{Vr}$ bis Cenobium Abbas, in Libro de Septem Intelligentis fub initiwio wit,-Veterum fententiam effe, Mundwm bunc inferiorem ordenatione primi Intellect is, qui est DEUS, per fecundas Intelligentias gubernari. Addat borum opinioni Conciliatorem sonfentientem dicere, feptem planet is /eptem Spiritus à principio cele e cerre effe prafectos. Nonsulli, tefte Cornelioà Lapide, per feptems Spiritus, qui in conßpect u throni D E 1. funt, ut babet ur cap. $r$. Apocalyp intelligunt leptem Angelos totidem planet is prepofitos a $D E O$; $\Xi$ borum Angelorum cum fuis plasiet is tanguam lampadibus typum fuiffe candelabrum illud beptalychnon, de quo Exodi cap. 25 . advertit S. Hieronymus. Nomis a feptem planetariorum Spiriturem funt, ,ecundium aligusos, Michael, Gabriel, Raphael, Uriel, Silachiel; Iebudiel, \& Baracbich, ut not at Serarius nofter in cap. 12. Tobie, of potant ea coll gi ex lib. 3. ७ 4. Esdre, ex Genef. cap. 16. Exod. 15. E Gexef. Ig. Qua nomina ait Cornelims loc. cit. divinit ùs revelat a fuiffe B. Amodeo Anno 1460. Idem Cornelius refert ex $A_{-}$ Ais publicis Panormitana Urbis Sicilice, hac nomina feptem Angelorum, cum corum imagixibus, epitbet is, $\xi^{3}$ eimblemat ibus repert a fuife Panormi in templo feptem Angelis dedicato ; quod quidem remplum adbuc ibidem extat, os cum ego inibi effem, in templo collegii noftri unum è fex alsaribus lateralibus dedicatum fuit feptem Angelis, ibidemgus depiat a imago eorundem cum iisdem 
emblemat is, ex antigso prototypo defismptis. Emblemat a feu infognia lege apud Cornelium à Lapide, ex quo illa defumpfor Ricciolus lib.7. Almag.Sect.1.cap.1. num.2. Aliud templum feptem Principibus Angelorum erect um extat Rome ad Thermas Diocletianas, in bonorem S, MARIE, Angelorum Regine, a Pio IV. Sum, Pont de dicatum. De leptem Angelis principalibus molt s invenies in Oedipo $P$. Atbanafi Kircheri tomiz.

PRELUSIO IN MERCURIUM.

V Enerem perigeam fequitur in fyftemate $T y$. chonico,E hoc tempore communi, Mercurii fella. De buins fella globo, globigue fruct ura, viribus, ES effectibus in bec inferior a, quidquid babet Auctor nofter, clarumest, nec interpretatione indiget. Quare paucula tantium circa eivs figuram, motum, E locum attingam, recentiorum Aftronomorum obfervationibus ftabilita.

\$. I. De loco, motu, \& figura Mercurii.

Mersurii locus, mosus Figura.

DLeraque feri, que pracedenti Pralafione de Veneris motu $\varepsilon^{2} f$ I gura retalinsus, intelligi etiam debent de Mercurio. It aque Mercurius, non Jecus ac Venus, movetur circa solem velut Gentrum /wi motus ó fua orbite, fed arctiori ambitu; vix enim digreditur ab co ultra 28 . gradus. In poice Syftema Tychonioum fies prà in Praluf. Catholica allatum, of diagramma bic pofitum. Ex Vide Ice- quo fit, ut modò infra Solem verfetur, modò fupra; 's ut nosnc algifmi VI. tior fit Venere, nunc bumilior. Nam quando uterque planet a apoFig. IV. gaus eft, \& fupra Solem exiftit; Mexcurius eft infra Venerens: quan, do utergue perigans eft, ${ }^{3}$ infra Solem, exiftu i Mercurius Jupra Vere- 


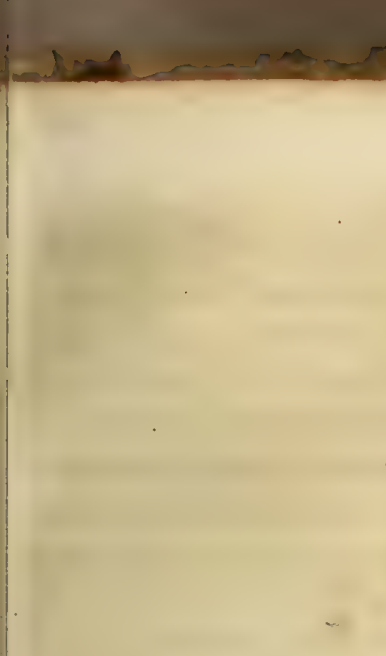




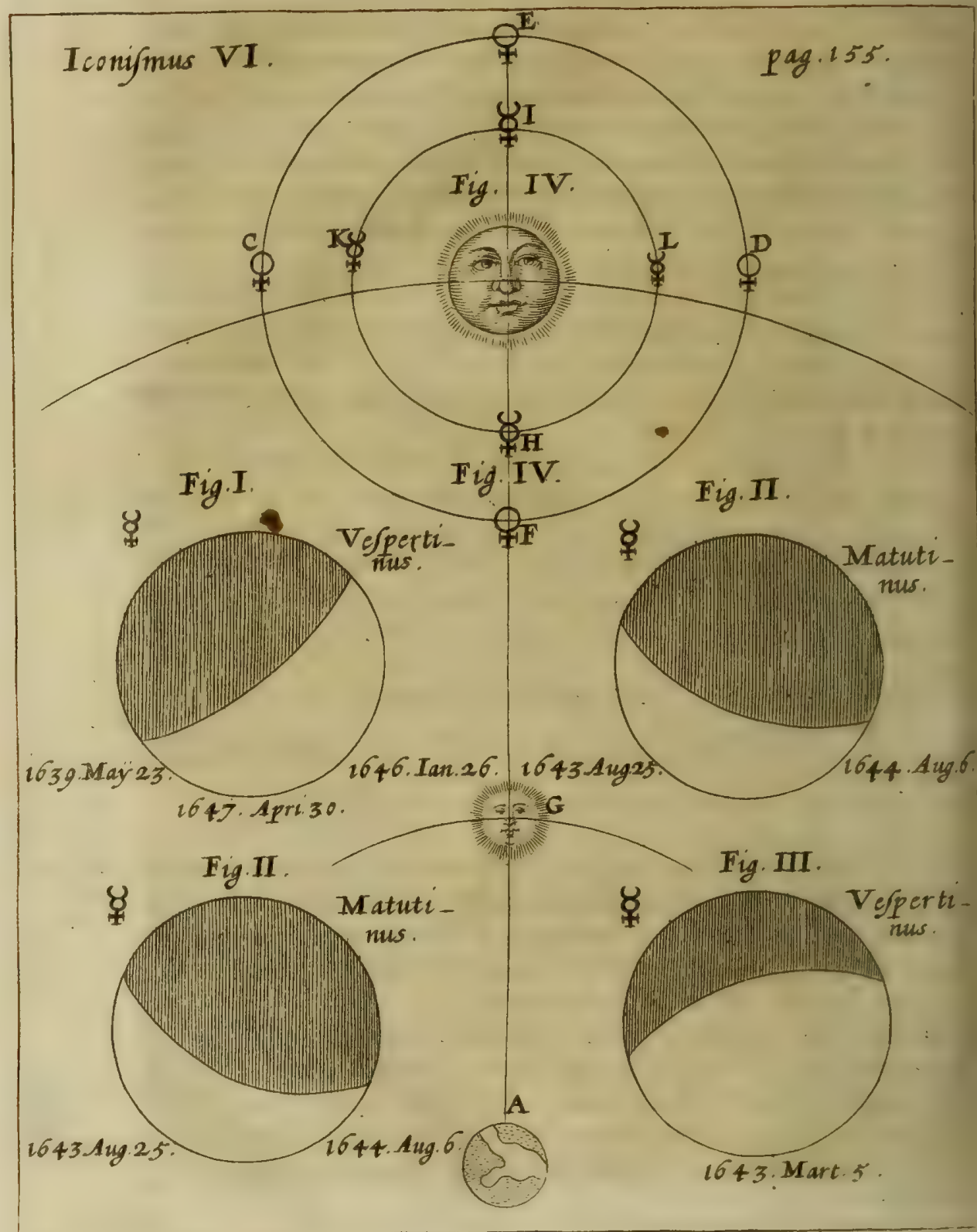


Feverem: guaindo Vessus apog es eft, \& Mercurius perigaus; bic eft. infra Venerem: quando perigea eft Venus, \& apogeus Mercurius; bic eft supra Veverem. Patent bec ex infpectione. fyftematis Tychowici citati, $\mathcal{O}^{2}$ bic pofoti diagrammatis.

Hunc Mercurii inter Planetas ordinem feu locum, छ circa So- Mercurit lem wotwn, deducunt recentiores Aftronomi ex ejus phafibus, Vene- phafes Veris phafobus fomilibus : illumisatur exim à sole pherice, ó modo bus fimiles.

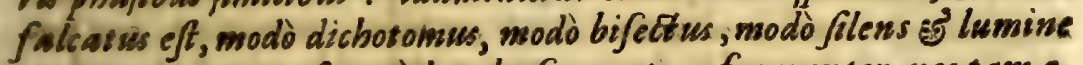
winutus. Tamet/ veró he phafes nec tam frequenter, nec tam evidenter ab omnibus deprehendantur telefcopii $\int u b f i d i o$, fecuti in Venere; de iis tamen dubitari non debet, nifi fidem deneg are accuratiffrmis Affromonorum ob ervationibus velimus. Ex multis paueis affero.

Martinus Hortenfus in Differtat cum Gaffendo de Mercu- obferbatio rio fub sole vifo; apud Ricciolum lib.7. Almag. Sed7. I, cap+2.num . 3. Mes circu affirmat, Mercurium non fecus ac Venerem, cim fub Solem fe demittit, abjervatum fibi abire in cornua; afcendentem nutem ad apogaum, fieri gibbofum, ac tandem rotundum. Id ipfum teftatur Keplerus in Epitome Aftronomie pag. 762 . adducto etiams Simonis Marii teftimonio. Idem quoque afferit Blancanus lib.ri. sphere cap. 3. $\sigma^{2} 4+E \sigma^{2} P$. Nicolaus Zucchius S. $g$. in literis ad $P$. Ricciolum datis, Et P. Jo. Bapt. Zupus Societ at is Noftre Mathe-Vide Iconimaticus Neapoli, gibbum ob/ervavit illum, eá prorfus formá, quam frui VI. Fig. appojte figure monftrant; ac primò quidem Anno 1639. Maji 23. tribus poft Solis occalum quadrantibus; deinde iterum Anno 1646. Fanswarii 26, uno poft oceafum solis quadrante. Erat autem in priori obfervatione diftans à Sole Grad. sirciter 22. छे in pofteriori grad.18. Sub eadem ferè forma vidit eum Ricciolus Anno 1647. Aprilis 30, Vefperi, cum Sole orientalior effet grad. $20 \mathrm{~T}$. Matucinum autem vidit cundem Anno 1043 . Augufti 25. cùm diftaret \& Sole grad.19. \&o Anno 1644. Aug +6.cum ab eodem sole diftaret grad. 10. Omitto alias obfervationes. Jam enim extra controverfiam eft apud recenciores telefcopii obfervandique peric05. (inquit Risciolsis loc (it.) Mercurium eodem modo à Sole

u 2 illumiVide Iconi-
frii VI. Fig.
I. II, \& III. 
Jy6.

Itinerarium 1. Dialogus 1 . Cap. IV.

illuminari, ac Lunam, fi Luna Solem pocius quàm Terram circuiru fuo ambiret.

Merewrims - Canja porro, cur Mercurius minis fregneniter od difficilius difficulcer

Exard obobjervetur lub predictis /chematibus feu pha/sbess, quaim Venus. Girliatur.

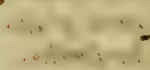
est, quia plerumgue latet lubradiis Solis, ob exzgwas ab eo digref-

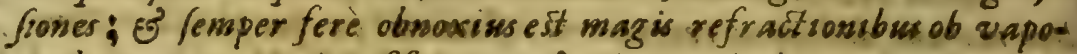

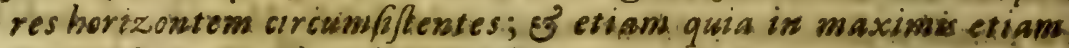
is Sole elongat ionibur obruitur à lwce crepufculi matusini, wast aca fpertini, in climatibus borizontem valde oblaqusum babentibus, *t advertit Regiomontanus, in fatetur ac doles fali eveniffe. Copernicus, qui lib. s. cap.30. ait, fe proptex Viftulevapores, of korizontis Marisburgici declivitateph i nunguam illwm potuiffes. ibi obfervare. Addit $\mathrm{R}$ icciolus, eum rarius falcatum videri, ideo, quòd vibratio luminis micantifimi, ob quam 5 in $\epsilon_{\mathrm{m}}$ à Gracis dictus eft, nifi oculi fine robufti, \& fpecillum eximium, cam. phafim impediat.

\section{I1. Deffructura \& natura Mercurii.}

Merenrir Arudiura ES Nature.

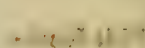
$1:$

$F x$ dictis colligitur, valde probabile effe, quod docet suctor noLiter Capite fequenti de Mercurii fr ruct ura ó natura, eum nimixum efle op asum ex fe, \& phericum quidem, Jed montibus alperatum ; praterea ex terreo of bumido conflatsm, aliague fimilia, que fequuniur.

\section{7}

Veneris $\mathscr{E}$ Mercurit abc cons ex intermodio basio.

for luns illa Atraciu Mercuritg

\section{CAPUT IV.}

\section{De itinere ex globo Veneris in globum} Mercuriz:

THeodidactses. O mi Cofmiel, quám nira in hac acherei $O$. ceani vaftitate rerum fpectacula comperio! quid rogo lla binx rota ignex, quas aquaticas molendinorum noin rocas a mbitu xquare video co cofmicl. Una earam eft globus, quem reliquimus, altera, ad quam tendimus, Equales tibividentur, quia in medio feré 
nter ucrumque intercapedinus lpacio conftituri fumus, unde $\&$ majores, ob utriusque vicinitatemsapparent. Et ecce jam reliZâ fpharâ activitacis globi Venerei, eam, qua Mercurii propria it, ingredimur; fentísne impetum,quo ferimur ? Theodid. Senio, \& miror; quafo acceleremus, uc quantocius adeo celebrem ¿ famofum Mercurii globum propiùs incuear. Cofmicl. Fiat. Thoodidactus. O Cofmiel, quî hoc? violentifimo atheris cirrumflui motu fauces mihi perfringi fentio Cofmatel. Confide iti, nil me prafence patier is impofterum. Theodid. Es infufflaione in faciem factâ, ab omni me liberavir anguftia; \& ecce, hoc impetuabreptus, fingulis pane momentis fub majori femoer \& majorinctemenro globum Mercurii intueor, donectantem is infar valtiflima \& of bicular is regionis fuam mihi facism monftraret. Theodid. Rogate, mi compar, fubfilte pauxilùm, ur admirandam rerum faciem eminus exactiùs concempler, Cofmiel. Placet mihi laudabilis tua curioficas; fiftamus itaque gradum. Theodidactus, O quàm me \& oculis, \& ingenio, prater folitum, acutum reperio! frquidem totius Natura faciem $\&$ arcana myfteria, quafi uno intuitu comprehendere videor quid quafo illud? Cofmiel. Ne mireris, Mercurialis enim globi, cui vicinus es, mirifica virturis afflatu afficeris. Sed hac paulò pònt tibi fafiùs exponam.

II. Theodidact us. Video naturam rerum ubique fibifimilem cuncta ad candem amuffis rectitudinem fabricaffe : nams Mercur \& pracelfos in hoc Mercuriali globo, \& prafulgidos montes, firutura maria quoque, \& ftagnantium aquarum diffufiones longè lare que exporrectas reperio. Cofmicl. Rectè hac notas, fiquidem nuthus globus (exceptis colaribus) exiftit, quem natura ex terreftri ficco \& humido, \& confequentibus qualitatibus calido $\&$ frigido, juxta elementar is natura requificionem, conftare non voluerit; funtque aded globis neceflaria, ut fine illis nee confiftere, nec vires fuas fpecificas, quarum fubjecta func, niff fub humido-terrea conftitutione exerere poffine; ff enim totus globus ex humidi tantim confticuererur elemento, maxima inde nafcerentur Mundo incommoda ; fiquidem homo
genea 


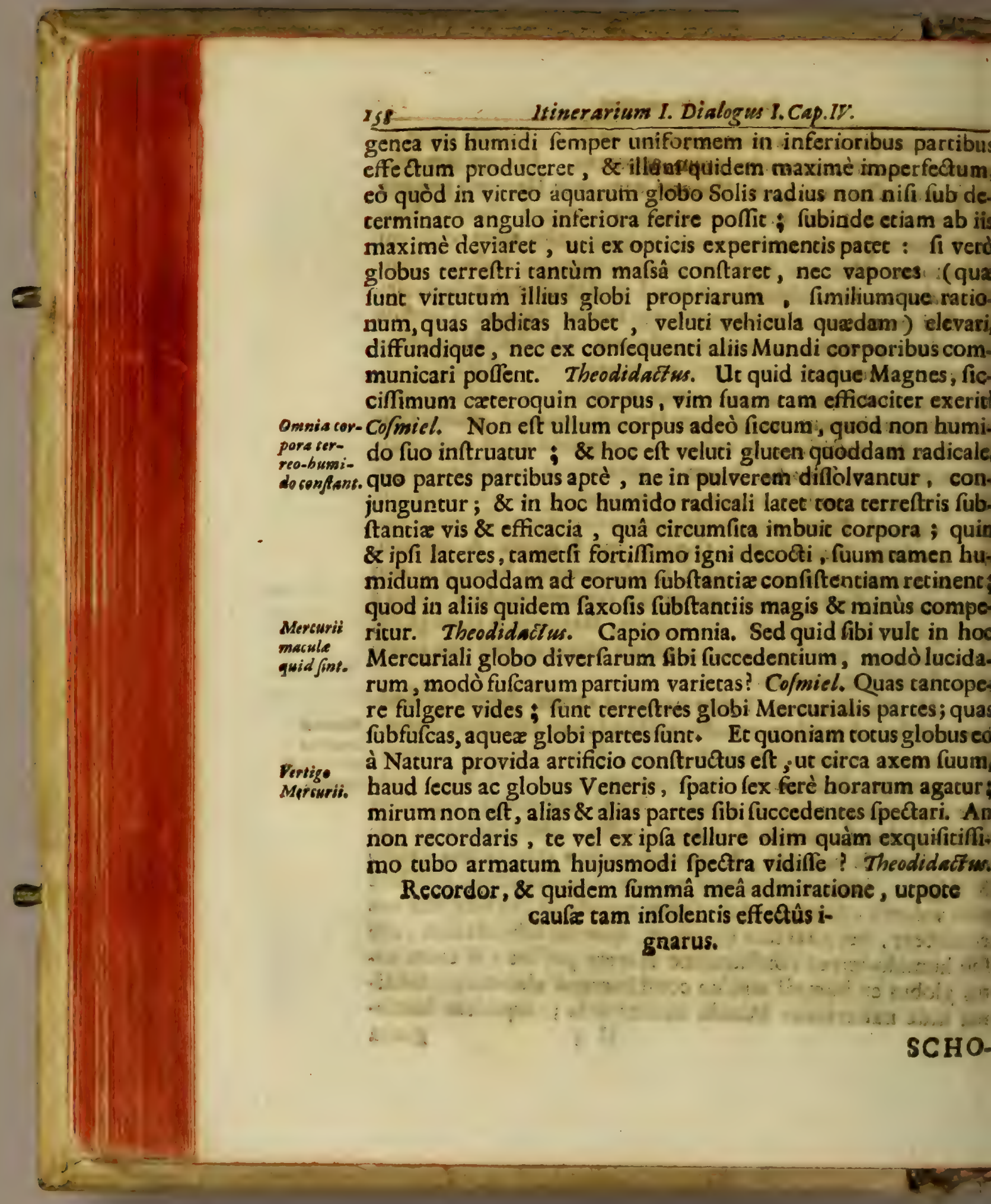




\section{SCHOLIUMI.}

M

Ercurium circa funm centrum \& axem gyrari motu vertiginis patio hor arum ferè $\int_{e x}$, a)J erit $\mathrm{R}$ heica loc.cit. in Scholio apracedeut is Capitis, ax codem fundamento, quo Veneris Es aliorum planesarmm vertiginem determinato temporis Q Qatio abfolvi foli"ums introduxit. Kide ibi didza.

co/miel. Sed jam omnia illa cominus intueamur. Theofidantus. Quo dicto, me è veftigio in ipfo globo conftitutum nveni, OColmiel ! quis eft, qui magna, \& mirabilia, quorum ton eft numerus, verbis faris explicer? Ecce aperuifti mihi novum nirabilium operum divinorum theatrum. O quàm terrigenaum circa mundanorum corporum conftitutionem Philofophiim bisce repugnancem video, dum nonnulli hunc globum necio quibus cryftallinis orbitis tanquam clavum rotæ infixum. tgitari fuperftitiofiùs exiftimant ! Jam verè nihil nos operum fivinorum, dum terreno luto infixi heremus, penetrare, fed olâ divini Numinis beneficentiâ aliquousq̧ue pertingere, soffe, luculenter cognofco. Et quidnam fibi infolita vifionis heacrum ?. Hîc immenfos ex folido veluci chryfoprafo mones conftructos video; hîc Oceanum intueor aureo colore radiantem ; hîc omnia à Veneris \& Lunæ globo difparata conlicionis reperio. Colmiel. Attendito, \& alta pectore haurito orafentem fapientix lympham. Theodidact us. Quo dicto, phiaam chryfolichinam ori adhibuic, \& ecce mirum quendam \& exoticum faporem omnia vifcera mea in momento ita corroboaffe fenfi, ut in novum vcluti hominem transformatus videer; tantaque lux intellectui oborta fuic, ut mox nihil non fcire vifus fim. Sed,ó Cofmiel, quả portenta hrec? ô quantam inzenii vivacitatem experior! quàm renacem rerum omnium memoriam! expone, rogo, myfteria. Cofmiel. Globus hic eo,à fupremo Mundi Opifice, artificio confticutus eft, eum à nacura locum fitumque adeptus, eâ proterea virtute imbutus, ut in quodcunque corpus vim fuam fpecificam diffuderic, mirificos 1. $\because$ quos-
Mercurialis globi coma pojitio.

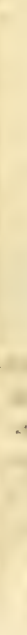




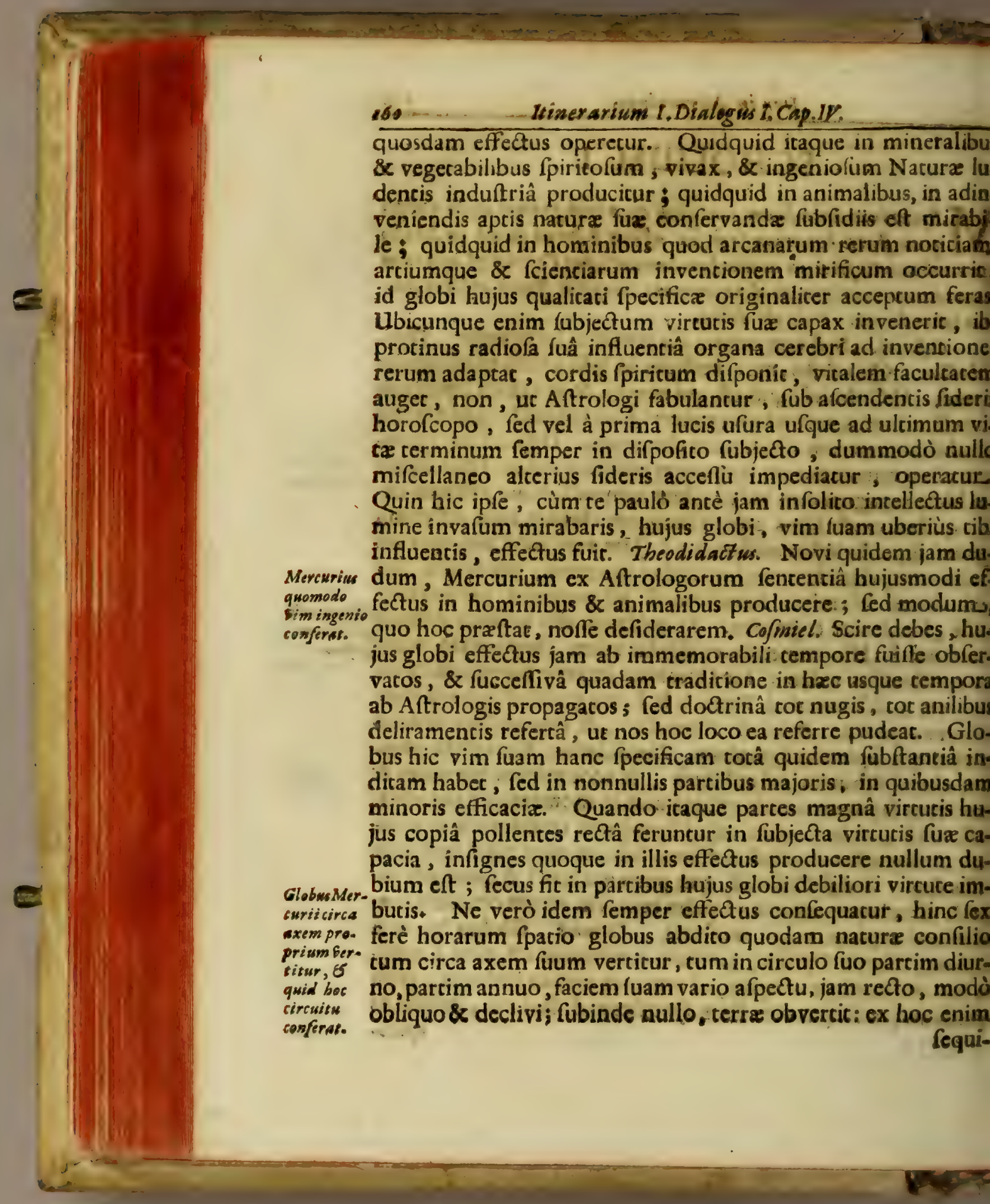


iequicur, vim radiolam non lemper adaquate influere, fed cum vel nuaximè, cùm portiones infigıi vi pollentes, nunc hanc nunc illam telluris portionem rectà atrigerint. Exemplum in magnete habes, cujus vis in polis potifimùm ftabulatur, in reliquis verò partibus tantò operatur remifiùs, quantò à polis magis receflerint. Theodidact us. Rectè philolopharis, nec eft quod ribi opponam, hoc unicum mihi exponas velim, quomodo hac facultas fpecifica in tellurem tam immensâ intercapedine dificam agere poffit? Cofmiel. Novifti ex Philofophia , omnia corpora certos \& determinatos virium diffundendarum limices obcinere, quam activitacis fphæram Phyfici rocant, extra quam corpus fympachicum minimè, intra cam verò conftitutum, mox afficitur. Noffe praterea debes, infrutabilem divina fapientia immenfitatem, tali proportione globos mundanos difpofuifle, ut unus femper intra alcerius aAtivitaris fpharam exifteret; cùm enim unus alcerius ope perpetuò indigeat, omnesque \& finguli reciprocâ virium communicatione fe foveant; neceflarium prorfus fuit, unum inrra alterius activiratis fphæram confiftere ; fecus enim fruftra in Natura rerum pofiti viderentur, finesque à Natura intentos nunquam attingerent: ut proinde non mireris, globum hunc Mercurialem, tametfi Terrâ \& Venere multò minorem, virtute fuâ oppidò multùm in telluris fubjecta virtutis ejus capacia, poffe; ui enim magnes ferrum intra fphara fux activitacem, confitucum è veftigio mover, ita \& hic globus virtute fuâ in tellure fympathica fibi fubjecta, mox ac proportionatum fibi fitum obcinuerint, ciebit. Theodidactus. Optimè, quacunque divinâ tuâ facundiâ eloqueris, capio ; hoc unum mihi expone, quomodo hac vis fubinde impediatur, aut etiam vegetior red-Neresnit datur. Co/miel. Audifi fuprà, globi hujus partes admodum quis infuxiba vario \& diverfo afpectu tellurem ferire, fiquidem globus hic liquando modò in circulo fuo Soli junctus, modò maximâ ab co elon-augetur, gacione dificus, nunc eidem oppoficus. Quandocunque ita- aut que Soli junctus fueric, aut oppoficus, \& radii Mercuriales pra-Mercuriu potenti virtute cumidi unà folaribus mifti, terra quandam por-pro diber/o 


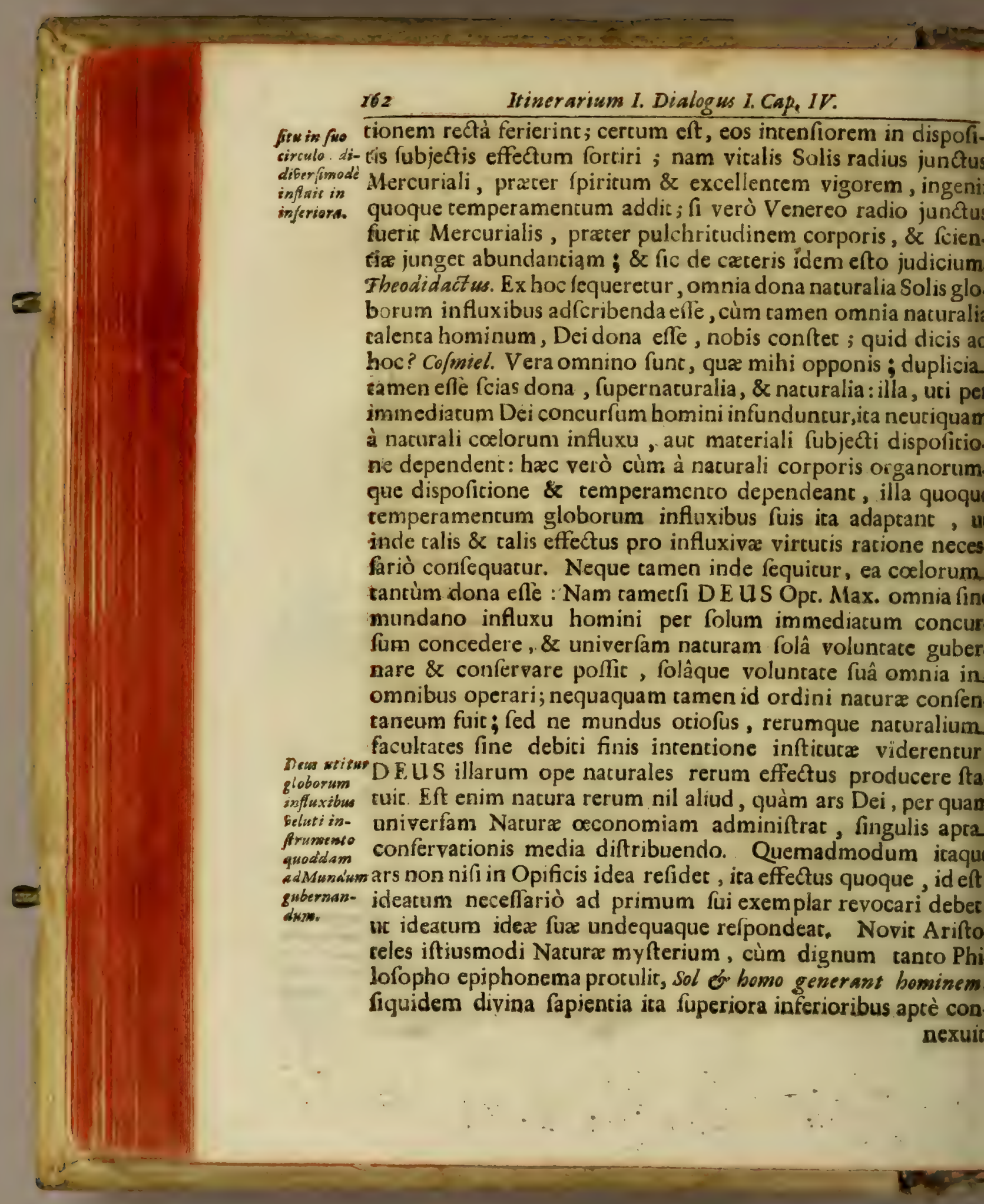


nexuic, adeo mirâ fubordinatione fingula fingulis adapravic ut infallibiliter inde in tali vel tali fubjecto, talem vel talem. effectum confequi debere, vel ab acerno pracognoverit. Theo. didacess. Hinc fequeretur, hominem, quantumvis invitum, ad affectus \& paffiones, virtuces \& vitia, quæ ex talibus refultane globorum effectibus, fectanda , facali cuidam neceflicati fubjacere. Cofmiel. Verum id eft in animalibus nullo rationis lumine pollentibus, at in hominibus, intellectu \& arbitrio inftrutis , nequaquam : pofuit enim DEUS Oprimus Maximus hoininem in manu confilii fui, ut pafionibus fiderum, à quibus ratioae organorum \& corporex complexionis, vel ad bonum, vel ad nalum inclinatur, vel confencire vel diflentire liberâ prorfus Afra non lectione poflic. Siquidem anima rationalis, utpote alcioris ${ }^{\text {necefitant, }}$ rdinis, neque naturæ fubdicur, neque ab excrinfeco ullam jed inch seceflitatem fuftinet, nifi in quantum corporis, cui jungitur, dispofitionibus, ad effectus naturali corporis complexioni conentaneos, non necefficacur, fed inclinatur. Si itaque fidea ad effectus racioni concrarios fubinde impulerint, divini ta-. nen vultus lumine, quod anima racionalis fibi divinitus imreffum geric, uti bonum à malo difcernic, ica urrumlibet, fire ad vitam, five ad mortem, eligere poteric. Hoc pacto geniles quosdam, uti \& Chriftiani nominis Philofophos, maximis jacuræ donis, intellectus, confilii, fortitudinis, prudentiæ, pulbritudinis inftructos legimus; quorum illi tamen is ad fumnam peccandi licentiam ufi, à fine fuo, ad quem condici eranc, -eciderunt; hi verò dona data ad meritorum cumulum ufurpantes, finem vitæ aterna confecuti funt. Sed de his alibi ubeior dabitur dicendi materia. Quantum porrò ad modum. Mercurit, ropaganda virtutis Mercurialis in terram, fcias Theodidacte, wirtus influquòd corpus Mercuriale, \& quodcunque aliud, ubi folaribusmodo agat radis percuflum fuerit, mox vim illi naturalicer inficam, ca in inferio. ore illo intenfifimo fufcitatam, fefe exerere per concitatio- ${ }^{\text {ra. }}$ nem humoris, cum rarefactione, tum proprii orbis motu caufatam, vel in momento virtutem fuam in terram derivare, Scias enim velim, hujusmodi propagationem non fucceffivam, $\mathrm{X}_{2}-$ fed 


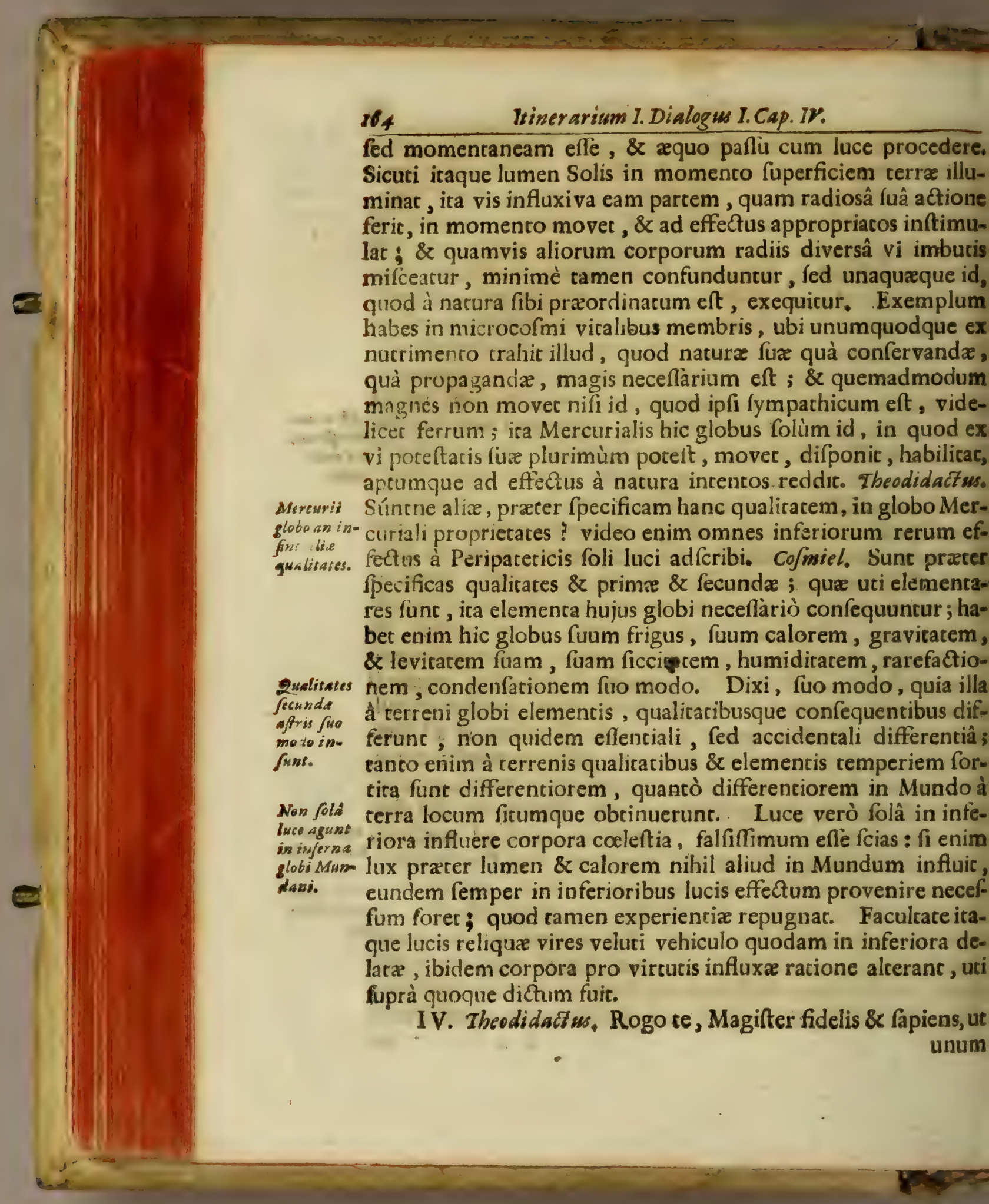


unum adbuc mihi fcrupulofiùs philofophanci dubium ex animo eximas; cùm globi hujus vis rancum in hominis animum, poffic, cur Natura \& Natura Opifex, DE US , homines in hoc Mercurie globo non pofuic ? aquum enim videbatur, uc ibi hominesglobus cur collocarentur, ubi vis in racionalem hominis portionem ma- incolas non ximè dominabatur. cofmiel. Non ex hoc tuo difcurfu bona illacio. Ignis fub proportionata diftantia calefacic, humores fuperfluos ficcac, pituitofum humorem diflolvic, fpiritus excitar, verbo, in omnibus homines benè afficit; non tamen inde fequitur, homines in ipfo igne habitare poffe : idem de aqua \& aére judicium efto ; cùm aliud fit, qualitas benè afficiens, aliud corpus qualicatem benè afficientem diffundens. Globus itaque Mercurialis , cametfi virtute luâ hominum corpora benè afficiat, fieri camen nullâ racione poreft, ut homines fuftineat is, qui in terreno func Mundo, fimiles : neque enim aér \& lympha Mercurialis humanz vikæ trabendæ proporcionata func; neque in hoc globo quicquam herbarum, fructuum, animaliumque., quo vita humana fuftentari quear, excrefcere potent. Si tamen per divinam potentiam homines hîc pofici fuiflent, illi fanè nacuram prorfus à terrigenis, diverfam difparatamque fortiti fuiflent, talem videlicet, qualem globi naturalis conftiturio jure fuo poltulafier.

V. Theodidact us. His dictis, ecce ex fummo athere in cam-Angelimerpum, ubi confiftebamus, nefcio quid alacum devolvi video, curialis det quod fub virili forma tandem nobıs fele ftitit caput radiosâ firiptier coronâ condecorabatur, vulcus iplam fapientiam f́pirare videbatur, barba fub aureo decore fuaviter fplendebat; qux humeris pedibusque afluta gerebat alarum remigia, mirificum fpectaculum de fe præbebane; manu finiftrâ Syringam fepremplici fiftularum ordine mirè concinnam. dextrâ cadüceum gettabanc miris modis effigiatum : tocum corpus innumeris fimbriarum cirris diftinctum, qua à leni aura ventilata miram oculis animoque volupcarem ingerebanc. O Cofmiel, quid infolitum hoc oftentum ? quid varius coleftis hujus hominis ornatus? oppidò nofle aveu. Co/mielt Hac una ex illa$\mathrm{X}_{3}$

rum 


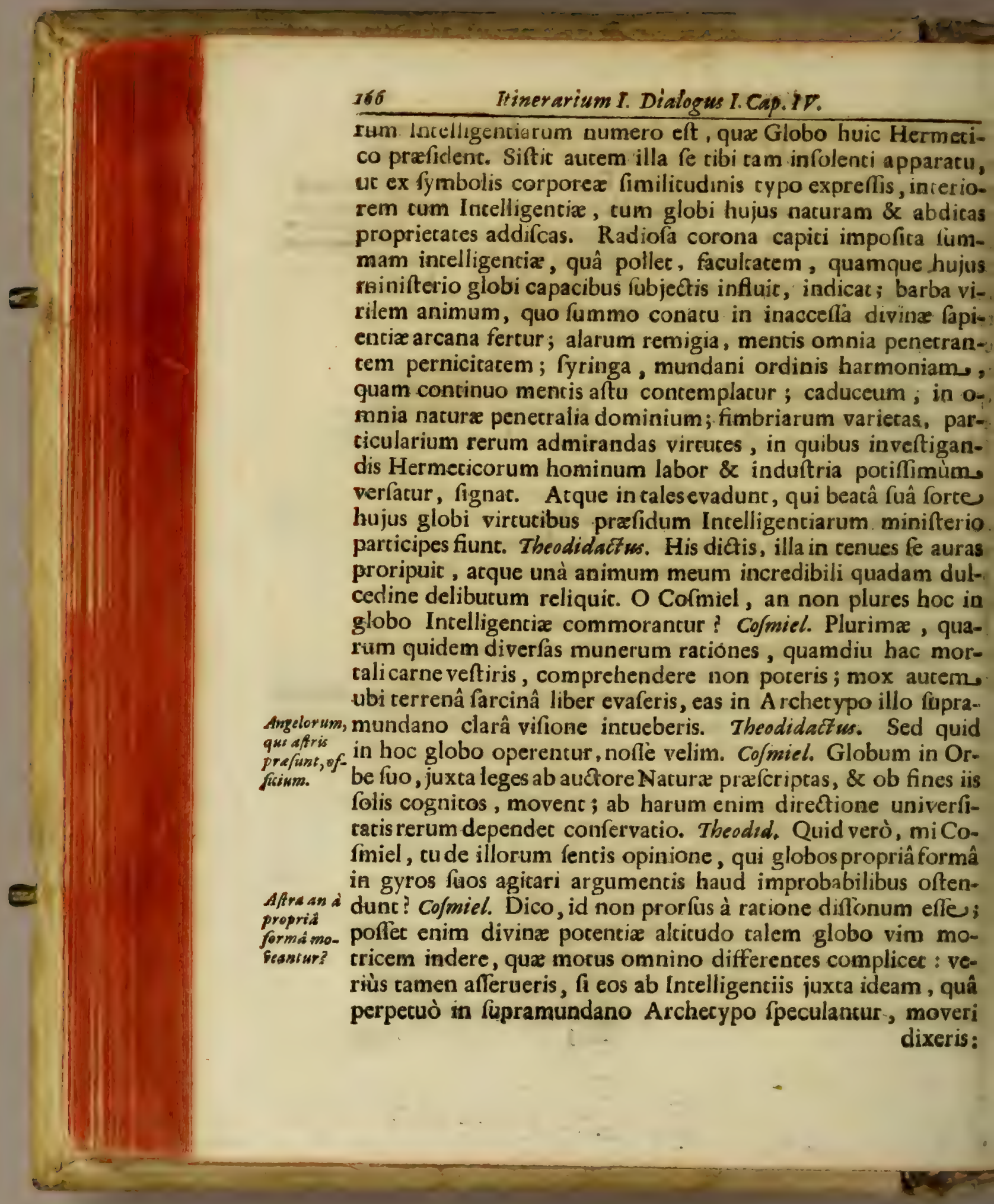


dixeris: Eft enim Intelligentiæ proprium, incertos fines operationes fuas dirigere, \& cum in univerfi confervationem, tum in cerra bonum, cujus gratiâ omnia condita funt, confpirare; quod tamen de corpore exanimi, cujusmodi globi funt, dici vix poreft, tot ac tam mulciplici motuum disparatorum diverfitare implicatio: fi enim motus globorum ex proprix forma incitamento fieret, certè otiofum foret Intelligentiarum prafidium, otiofa \& fine fine earundem operatio; quod divinæ providentix, imò ipfis facrarum litterarum oraculis repugnaret. An non legifti in Job, coram illo curvantur, qui portant Angeliafirs orbens? Ubi rectè facri Commentatores Angelos coelorum mosent. prafides \& motores intelligunt. Si enim fingulis hominibus,ipfo Chrifto, æternæ fapientiæ Magiftro, teftante, fi urbibus, regionibus : uti in Daniele legitur, fingulisque rerum naturalium fpeciebus ad eas contra inimicam \& adverfam vim defendendas, prafides ac cuftodes Angelos divina providentia actribuit; annè congruum putabis, maximis \& pracipuis totius Univerfi globis, à quibus omnis inferiorum rerum ftatus unicè dependet, prafidentes motores negare ? minimè gentium. Sed nimium forfan discurfum meum circa materiam in ultimum miffum refervatam extendi; quare ad propofitum nobis globum revertamur.

V I. Theodidact us. Omnia bene cepi, \& orthodoxx fen- Nox ing gla tentia omnino congrua video omnia. Sed ô Cofmiel, noetem in quatiso hoc globo nullam invenio, fed fubinde obfcuritatem quandam; qua tamen nox aut tenebræ dici nullâ ratione poteft. cofmiel. Hoc ex magna globi ad Solem \& Venerem vicinitate contingit : quod enim ex adverfa Solis facie non illuftratur à Sole, id à vicina Venere fuppletur, reflexoà Sole lumine, poriffimùm cùm Mercurius Solem inter \& Lunam conftitutus fuerit. Contra tamen cùm Venus Solem inter \& Mercurium. contituta fuerit, co cafu non exiguam ex adverfa parte obfcuritatem incurrit globus hic ; qux tamen ob vicinx Lunx reflexam lucem non parum temperatur, ita ut nox hujus globi nunquam crepufculorum terreftrium obfcuritate inferior fit. 


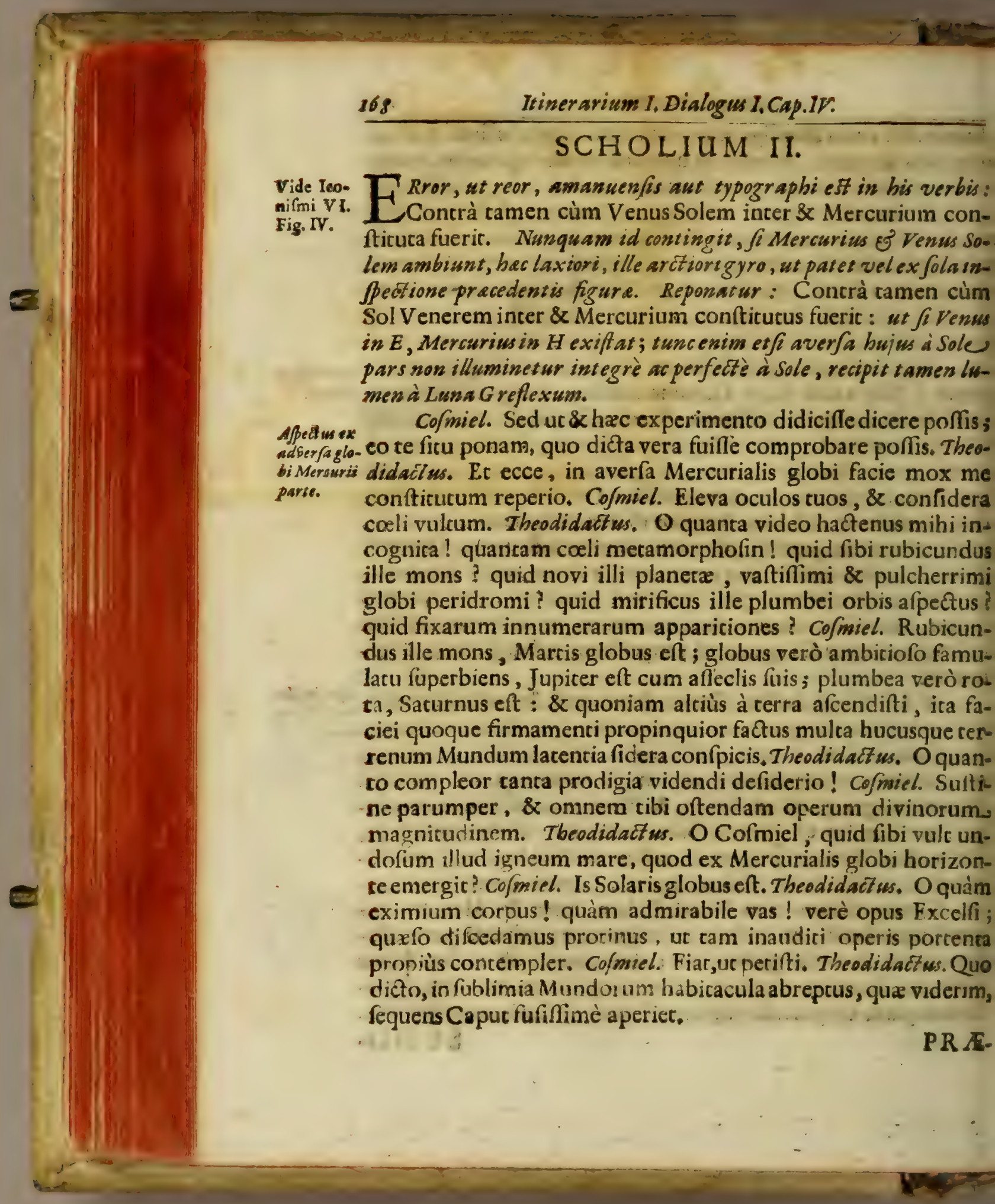


8. PRELUSIO IN SOLEM.

Dervenimus ad Solem, Mundi oculum, coli sol, jusque I gratiam Ev decus, diei jucunditatem, vite originem, cor Nature, auriES gemmarumparenem, moderatorem temporum, fiderum princisem, caleftium corporum regem, fontem tucis, Orhismiraculum, Ev pulcherrimum DEI ter Opt. er Max. fimulacrum. Hujus tanta funt excelentie, tant a in mole magnitudo, in motuvelocias, in lumine clarit as , in calore energia, in cateis perfectionibus praft antia, ut nemoeum dicere, nemopermittatur tacere. Hic benefici Numinis vicarius, luce, motu, calore, panpermiâ omnia implet, omnia coeleft is aule muner a diftribuit, ubique largus, emper munificus, nunquam non effiax. Meritò igitur Ecclefiafticus cap. 43. appellat :um vas admirabile opus Excelf: meritò idem cap. 42. de illo enuntiat : gloriâ Domini plenum eft opus ejus: meritò de eodem David P fal.I8. In Sole pofuit tabernaculum fuum $D E U S$. De hoc mundanorum corporum prefiantißimo, fiderumque choripheo cum innumera dici queant, pauca, qux $r$ jequuntur, 
Sequuntur, propono, lucem ut prafer am lecutu ris, Es antehac inauditis, qua Auctor nofter de co dem prodit, plura in Mundo Mirabili dabi $\therefore$ mus.

\$.I. Ansol fit igneùs, \& formaliter calidus.

$\mathrm{T}$

Amet/s Ariftoteles lib.2. de Calo cap. 7. so Peripatetici perme gent, fodera conftare ex materia elementari, atque adeò ne soligneiseff ignea effe, (ed guintam quandam effentiam obtisere afferant; so fubpantia. lemque non actu, fed virtute tantion calidum effe, eo adducti ar gumento, quòd five folo lumine, five etiam motu bu attritione aëres calorem producat in inferioribus; tamen igneam ejus effe Jubftan tiam, E formaliter calidum, nec nova e it, nec adhuc antiquat. -pinio ; jamque post detect as telefcopio tubo in ip/o Sole maculas faculas poft deprehenfas ebullitiones liquef acti ad inftar aris in ar dente clibano, \& poft alia phonomena luce clariùs manifeftats tam conmunis est ac firma inter melioris nota Philofophos, ut con trarium fentientes ac docentes fannis, ut fimplices Philofophaftr excipiantur. Hoc idem cium Auctor nofter in lib. 1. De Lum. o Umb. EJ/equenti capite fentiat, ftabiliendum breviter hic est d auctorutate, of ratione, $\sigma^{2}$ experientia ab oblervationibus de Sumptâ.

grnee naturesolem ef feputaruat

Philofopbi antiqui.

Ad auctoritatem quod attinet, inter antiquifirnos solem afferuit effe candentem lapidem Anaxagoras, puriffimum ignem Zeno Citicus, ma/jam candentem Democritus of Metro. dorus, ignis portioness apparentem ex foramine magne roth igne plene Anaximander, coagulum igniculorum ex vapids. halitibus collectorum Xenophanes, pumicem feu Ppossgiamign accenfam Epicurus, ex plurimo igne compactum Plato, incendium mente preditum Stoici. Et licet aliquorum ex relatis opiniones aut falf a fint, aut ridicule; apparet tamen ex illis, quid antiquisfimi Pbilofophi de Solis fubltantia ignea fenferint. In Platonis

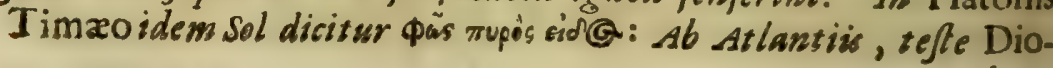
doro 


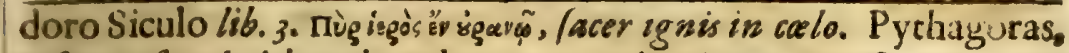
tefle Ariflotele lib. 2. de Calo cap. 13. Solem in Univerfo centro collocans, Ignem in medio Mundi effe dicebat, cumque fovis cuftodiam appellabat. Cunct a fidera, atque adeò Solem, ignea effe. Egypen pariter ac Stoici putarunt, do inde tandem futuram Orbis ecpyrofin feu conflagrationen exiftimarunt, ut est apud Ciceronem lib. 2. de Nat. Deor. Stellas omnes ignitam terram effe cenfuit Thales; ignes aiboreos cry/tallo alligatos Empedocles; lapides ex rerra ab at here abreptos, \&o circumvolutionis vebernentiâ aduftos, aique in ftellas verfos Anaxagoras; majori fui parte igneas cum aliorum elementorum mixtura Plato; carbones ex inflammatis nubibus accenfos Xenophanes. Omitto aliorum figmenta; ex quibus. tamen apparet, ut dixi, qualis antiquorum menti ine ederit per/uafro: nimirum quin ignis accidentia of effectus in ftellis videbant. ignem effe pronuntiabant. Lege Plinium lib. 2. Hiflor. Natwr.cap.g. Oे Lipfium in Phyfologia Stoicorum.

Ex recentioribus Matbematicis ac Philofophis Solem igreum, Pbilofopit aut faltem exigne liquido or folido conffiftente atque incombuftibi. ac Theologi li compofor um effe, ftaturut P. Chriftophorus Scheinerus in Ro/a ${ }^{\text {recentiars. }}$ Urfona lib. 2. P. Achanafius Kircherus lib. 1, comp. 1. Artis Magne Lam. छ $\cup m b$. hic cap. s. feq. P. Chriftophorus Borrus in Aftronomia nova part. 2, cap. 7. fol. 147. P. Jolephus Blancanus in Sphera lib. I0. cap.21. P. Ignatius Der Kennis in Opere Jex Dier. Die Mundi 4. P. Nicolaus Cabeus lib. 1. Meteor. text. 37. P. Melchior Cornaus in Curriculo Pbilofoph. Dißp. de Calo 9 ftellis q. 3. dub. 3.ubi etiam citat P. Jacobum Salian. tom. 1. Annal. in Die 4. Mundi. Afcanium Martinengum, Nicolaum Copernicun, , $\xi^{2}$ Auguftinum Steuchum. In eadem Sententia est P. Cornelius à Lapide $i$ s Ecclefiaft.c. 43, v. 4. P.Celada de Benedict. Patriarch E' alii multi, gusos citabo in Mundo Mirabili. His accedit P. F. Antonius Maria de Rheita Capucinus lib. 4. Oculi Enoch \&? Elia cap. 2. Memb.1. wbi id rationibus of auctoritatibus probat. Keplerus in Paraliponenis ad Vitellionem pag. 224. Bullialdus lib. 1. Aftronomia Philolaisec cap. 7.

In eadem fententin Junt inswmeri SS. Patres, clariffimos Sandi Po ${ }_{2}$ Escle-tros. 


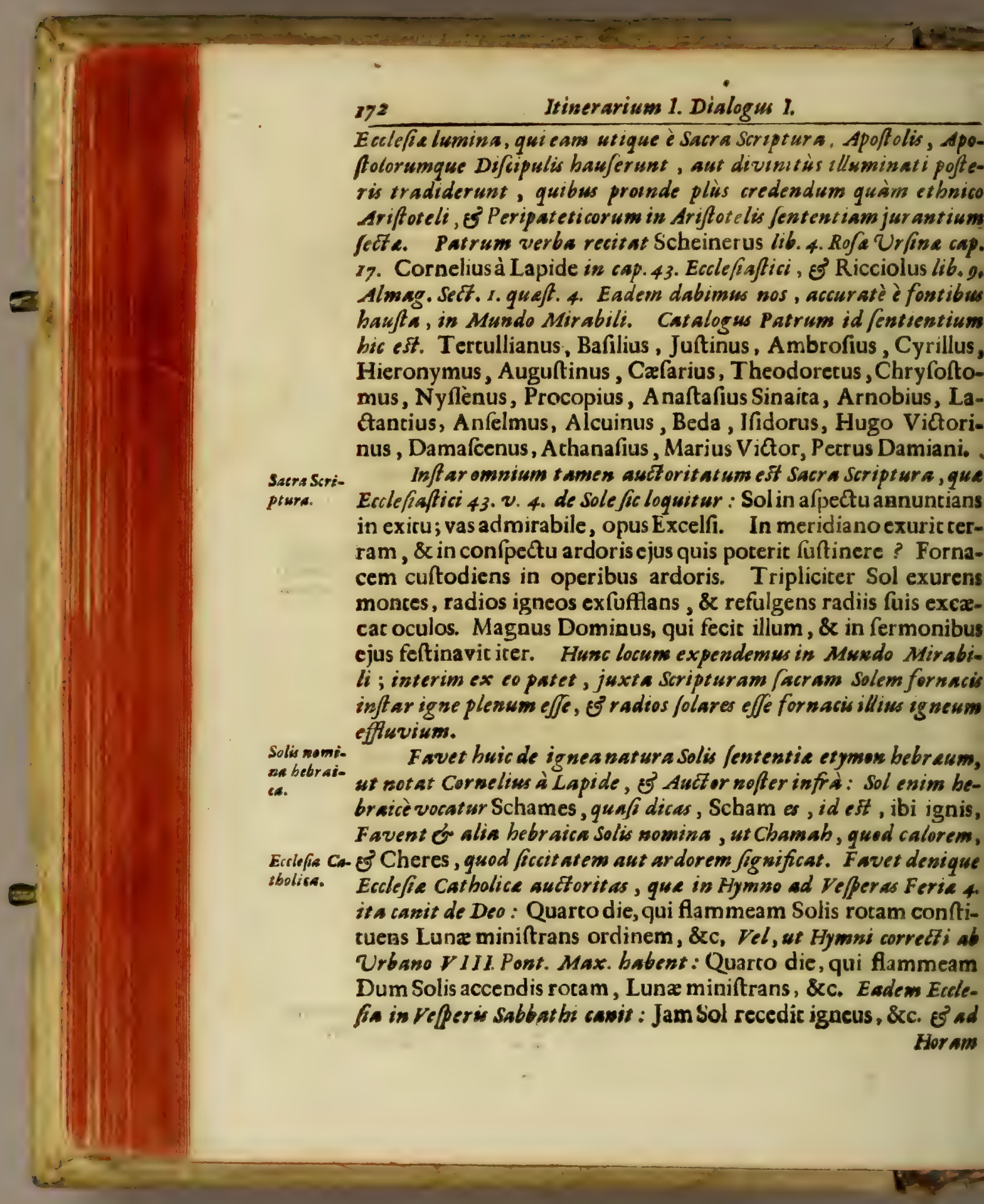


Heram fextam : Splendore manè inftruis, \& ignibus meridiem, or Feria 2. ad Veperas: ut unda flammas temperet, terra folum ne diffipent. Nec debent bac fummi in fenfus metaphorico, Jed in oroprio, quin dicti Hymni fuerunt compofiti à S. Ambrofio, qui Solencenfuit effe naturaignea.

Experientin ab oblervationibus de/umpta, Solenque ignea obferbationatura demsonftrans, hac eft, quòd quoties ferè heliolcopium du- nesprobane plici aut triplici vitro viridi (ne ocuslis damnum à solis fulgore Solem effe inferatur ) munitum dirigitur in Solem, is non undequaque lucidus deprebenditur, (ed maculis quibusdam deturpat us, faculisque interfinct us (ut poften fufius dicetur) nec faperficies ejus aqualis est of quieta, fed velut mare igneum, fluctibus a/perum, vorticibus igneis crißßum, of circumvolitantibus quafi fuliginibus variegatum; atque id non eodem modo, eâdemque facie femper, fed aliter bodie quimm beri, aliterque cras quàm bodie, ita ut vix unquam codem fchemate, eodemque vultus babitu Je vifendum prabeat. Eadem phenomena apparent, fo sol vaporibus aut nebulis tectus nudo oculo in (piciatur; aut fi ejus pecies in obfcurum cubiculum per foramen exiguum intromiffa, excipiantur chartâ candida. Fuit bac Solis fasies tam lape jam, ì tot Viris doctiffirnis, o. accuratif(3mis, in tot Mundi regionibus, tempore eodem छे diver/o notata, ut temerarium fit afferere, cos decipi; impudens, decipere. Pbinomenum boc concinnè explicat P. Kircherus lib.x. de Lum. $₹$ Umb. cap. 1. Fmilitudine eris candentis ac fuftis in fornacibus fuloris ebullientis. Qui unquam, inquit, in fornacibus sivitique fuforiis in ingentibus cuppis liquefactum as vidic, is genuinas facte in phanomeni folaris rationes aliquo modo comprehendere po-fornacibue terit. Sicuti enim in hujusmodi cuppis fuforiis undantis ma-paret sol reriei fervor tales fubinde aftus volvit, uc mari cuidam igneis fluctibus agirato, undarumque vorticibus curvato haud abfimile videatur, ubi fuligines acra flammis lucidifimis junAte, miram quandam facularum umbrarumque vicifitudinem exhibent, in quorum evanefcentium locum aliz identidem. fuccenturiantur; ses veró liquefactum, quod actu funditur, fplendorem baber ira fplendori Solis fimilem, uc nulla alia I 3 
res in natura rerum fplendorem Solis meliùs exhibeat. Hoc amictu deturpatum primò Anno 1625.4. Aprilis Moguntiæ; \& deinde variis alis temporibus hîc Romæ cum Scheinero non fine ftupore me obfervafie memini. Aptifima fanè fimilitudo (quam E' Scheinerus lib.2.cap.4. Rofa Vrfine iisdem penè verbis babet ) on rem ad vivum exprimens; quod is folus negabit, qui nestrum vidit, nec Solem inquam pradicto fchemate veftitum, nec s in fornace fufum. Videram primum, $v^{2}$ alterum videre diu defideraveram, cùm ecce non it a pridem ejus pectandi occafio fe fe bic mibi obtulit, quando as duobus ingentis magnitudinis tormentis bellicis fundendis fufficiens in fornace ampla, lateribus conftructa atque concamerata, per horas complures codturn, ac jam liquefactum, bulliebat, \& cum fragore ingenti, prafertim dum oblong perticâ agitabatur, nunc fuligines exbalabat copiofiffimas, nunc velut mare cripabatur in undas igneas, modì fulgores cater $\hat{\mathbf{t}}$ materiâ clariores inftar fulguris eruct abat, interimque fornacis. later of fornax, quà parte libera à fufili liquore manebant, non jam lateritia, fed pror/us ignea apparebant; donec tandem laxatis repagulis, per canalem difpolitum as liquefactum defluxit in fubjectos modulos. Aliam non minus aptam rei prafenti explicande fimilitudinem pect avi olim in Sicilia, quando Menis è montis Atne regione, poft ingentes multorum dierum fragores ac velut tonisus in mont is vilceribus exaudita, \& post formidabiler ejusdem mont is of vicinorum locorum conculfiones, rupt is tandem lateribus effluxit igneus in latè patentes campos fluvius; cui alia atque alia materies paulatim fuccedens, ac velut undam undh trudens, exagserabatur in igneam, led fulcis ac plicis igneis alperatam congeriem, donec tandem in petram nigerrimam ac picei odoris indurefceret.

Ex hoc phenomeno tale formo argumentum pro solis natura

ignex. 2uod apparet ut ignis, on habet onnes effectus ipfius, est ignis: atqui sol apparet ut ignis, on babet omnes effect us ipfous; ergoignisest. Major evidens est; neque enim alia indica babemus ad judicandum ignem effe id, quod nodte obfcurâ in pharo aliqua, aut alio in loco lucere videmus, quàm quod apparet ut ignis, 
ignis, on habet omnes effect us, quos conftat habere ignem; unde docliague as indocti, ad probandum ide fe ignem, non alio.utuntur argumento, quàm quod diximus. Minor probatur. Inprimis apparer oculo libero utignis fulgentiffimus, it a ut eum nimio fulgore Jwo offendat. Deinde apparet eidem ocsulo per heliofcopium non modo st ignu, fed etiam fuperficies ejus cernitur flammis ebullientibus atque undantibus afpera, of tremens, faculisque of umbris con perfa, ut patet ex pradict is objervationibus. Et certè, fi aqueus nofter Oceanus, of omsia noftra maria, flumina, lacus, \& ague quacunque, forent igneus fluor inftar liquefacti in fornace aris, \& folide partes Terre forent candentes inftar laterum fuforii fornacis, ह? apiceretur è Luna aut alio remotiori feu viciniori loco; non aliter apparevet Terra noftra, quàm nunc nobis in Terra conftitutis Sol apparet. Et fo Terraqua noftra tante molis foret, quanta Sol est, ¿o affect a paulo antè recenfit is conditionibus collocaretur in caelo in loco Solis; non aliter nobis appareret, quàm sunc Sol ip fe ap. paret nobis. Sicut igitur tunc Terram nofr ram ibi collocatam videns, bene affereret, id, quod videret, ignea effe natura; ita $\xi^{2}$ qui nuncvidens solem id afferit. Habet preterea Sol ommes effectus ignis, \&? multo magis quàmid, quod ob cour a nocte in turri lucere videmus; nam id lucet folum erninus, sol autem E' lucet, ơ calefacit, \&u ex/iccat, E'accendit, ut apparet, dum fape materia arido Jolaribus radiis accenduntur, aut guando per pecula cauftica ignisproducitur.

Ex bis colligitur, fignews ezt Sol, or igwis proprietates babet, Solformalb: formaliter calidum effe, \& $\sigma^{\prime}$ non virtwaliter tant um, feu eminenter, ter saliduso. ut Peripostetici afferunt.

Mirum ergo, Ariftotelem negaffe, solem effe natura feu fub. fantia ignea; mirum, tot Plilolophos eum Jecutos; maxime mirum, etiamnum post tan evidentem experientiam nonnullos Arifrotelis fententiam fectari, non aliâ de caufos, quàm gura in elus verba jurarunt. Certè $\sqrt{2}$ Ariftoteles predict um phonomenum. vidifet, è consepta fententia lubers disceffiffet. Mibr longè fascilius est, obrationem fact am, ob predict as obfervationes, ob tot 
SS. Patrum, Philo lophorum, ac Mathematicorum, imò of facrariom Litterarum auct oritat em, credere of alJerere, solem talem effe, quem diximus, quaim quintam effe effentiam, ab omnibus elementis of mixt is effentialiter diftinct am; malogue cum tot illuminatis Viris in luce ambulare, quàm cum howsine etbnico in tenebris errare.

\section{§.II. Solvuntur argumenta contra igneam Solis naturam.}

Arguments contraignemon Selic masuram folGuntwr.

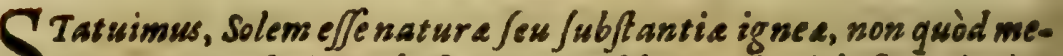
Drus ac purus fit ignis (eft enim configtens, \&o globofus, of cim

net figursm; quod igni foli fluido ac facile motu diffipabili vix conveniat ) Jed quod ex folido or liquido igneo conftet, uti poftea melius explicabimus. Argumenta, qua contrì efferunt Peripatetici, sulliws Sunt momenti.

Dicunt primò.Corpora caleftia funt incorruptibilia : ignis est corruptibilis; ergo Sol non est ignews, neque ex igne compofitus, Majorem aiunt conflare experientiâ, quia caleftia corpora à Mundi exordio ad bec usque tempora per tot fecula in codem fats per/everant, absque ulla inutationis intrinfece aut corruptionis nota.

Experientia Reßpondeo negando majorem, contrarium exim probatum, mon docet fuit fuprà in Preluf. Casbolica 5. 7. \& s. Ad probationem dico, calum effe fuit fuperientiam docere contrarium ingeneratione of corruptione bile, fedpo-cometarsm fupralunarium, \& novarum ftellarum, in macevius costra- lis solis (de quibus fufius poftea, ) in atmo/pheris planetarum, o in aliis, de quibus loc. cit. 2uamvis igitur tot a corpor a caleftis in codem femper ftatu permancant, quia tamen partes corum. corrumpesntur, incorruptibilia non funt, fed corruptioni vet maximè fubjecta : ficuti Terraqua noftra tamet/i lecundiom fe totam in eodem perfeverat ftatu, quia tamen partis agua $\sigma^{2} \mathrm{ter}$. re, omniague mift a, que in ea funt, corruptionis legibus fubjuciuntur, incorruptibilis minime dici potest, fed vel maxince corru. ptibilis. Adde, quiod tametfo nulla prorfis corruptionis figna in calegtibus 
cable/tibus corporibus not at a ì nobis fwifjent, afferi tamen non ides polfer cum fundamento fufficienti, ea effe incorruptibilia: poffent enim plurime in is corruptiones ac generationes cötingere, 5 f fort asfis de facto conting unt innumerabiles, que tamen ì nobis, ob dift antiam, wovs not antur; focut non notarentur corruptiones $\sigma^{2}$ generasiones continse, qua in Terraqua evexiust, $f i$ e Luna depiceretur: quis enim inde sotaret ortus at que interitus equorum of elephanrum, conflagrationes domorum, aliaque his major a etiam, prafersim libero oculo? ficut it aque qui tunc, ex eo quod Terraqua tot a in codem femper ftatu perfifteret, inferret eam incorruptibilem effe, desiperetur ; it a decipitur qui idem de corporibus coeleftibus a firmat abidem argumentum fen fagnum, maximiè de iis, que à nobis reme. siffma funt, cujusmodi eft sol.

Dicunt fecundò. Si Sol effet ignee nature, aut ex igne compofitws indigeret pabulo, ut in fuo ft at us confervaret us; fed non indiget pabulo; neque enin ad/gnari potest, unde id ipfs Jubminiftretur; ergo won est nature ignea. Alii, qui negant majorem, è quiod solis ignis puriffimus fit, qui vonterian fuam, quam accendit, non comburit, ani ab/umit, neque evaporat fumos, ob tenuifimum videlicet aërem, quo ambitur, ita Carcefius part. 3. Principionwm Philoloph. num. 54. Addunt alii, inferni ignem pabulo non indigere, neque eum, qui in lucernis perpetwis ardet:mon ergo mirum, fo nec Solis ignis psbulo indigent.

Ego conce]fa majore, nego misorem, of ajo, non minùs Solis Ignis Solis ignern egere pabulo, quàm ignis, qui perpetuò ardet in Atna, in pabulo indiVefwrio, in Hecla, in Vulcaniis Infulis, in mult is alies montibus, ${ }^{g e r}$. 8 quàm omnes fubterranei ignes, qui aquas calidas excoquunt. sicuti igit ur omnes predicti ignes, jam h̀ Mundi exordio arferunt continuo, 6 etiamnum ardent, \&o nec montes, intra quos velut intrafornaces concluduntur, necalia fubterranea loca, in quibus latent, it ab/umunt, ut aut montes corruant, aut loca fubterranealcollabantur, of tamen absque dubitatione interim pabulo convenienti nutriuntur, unde id fuppediterur; ita fentiendum idem est de igne folari. Auctor nofter in fequenti Capite exiftimat, materiam Jolidam, intria quam ignem Solis fluor con- 
tinetur, effe asbeftinam feu mcombuftibilem, talem nimirum, qua. lis in multis locis aped nos reperitur, ut ibidem. fe explicat. At bo non est neceffarium, quia focuti dicti ignes terreftres non ab/umun montes fuos, $E^{2}$ cavitates, etiamfi asbeftini non fint; it a nec folari ignes ab/unet /uos montes or cavitates. Ad pabulum aut em quad at. sinet, unde illud Soli fubminiftretur, ajo, gusod de pabulo ignium pre. dictorum in Terr a fatuitur, fratui fwo niodo poffe ac debere de pa. bulo ignis folaris. Sententiam meam memini me in precedentibu infinuaffe.

3olin ine. Dicunt tertiò. Sol aqualis est, \& fbi femper frmilis, ignis w gualisas fow rem in quabilis; ergo Sol non eft ignis, nes igneus. Repondeo negan - perisu. do antecedens, uti ex dict is \$. praced. de phanomeno solis relejcopi Bect ati patet. Addo, tametfiusulla inequalivates in sole appare rent, inde tamen non conffaret, eum aquabilem elje:nam fie sole so Ar a Terragua ßpect aretur, nec montium, necingentium fuctum maritimorum inequalitates of commotiones notarentur, o ta men revera inequalis foret. Eodem ergo modo tametfs in sole null apparevent afperitates, non recte de co negarentur. Qwod, igitur apparent, fignum eft, longe majorem effe in Sole, quàm in Ier ragua noftra, inagualuatem.

Dicunt quarcò. Ignis conicus est, sol phericus; ergonon es igns, nec ignea natura. Re ppondet Auttor Libelli, qui infoributur Sol flamma, Solem effe conicum, fed coni apicem projucere in pas tem is terra aver/ans. Sed hoc est divinare. Dicet forta/jis, igm nat uram requirere, ut it a fiat in Sole, quoniam ignis fur/wm, no. deor/um tendit. Sed contrà eft primó. Ignis nofter furfum ten an conisuse dit, quia recedit à centro terre, of tendit ad circumferentian feuplami- ideogue fo Terra globus igneus effet, undequague furfum tenderc ignis. Idew ergo in Sole contingere deberet, ideague etian ver jus Terram projiceres cosi apicem. Contrà est fecundò. Jgnis m. Aer/urfum tendit, guia, ut Philofophi putant, centrum ejus est $i$ concavo Lund. Si ergo Sol in conum definst, apex coni potius ver fus Terram tendere deberet, quàm ver/us celum oppofirum. Con trà est tertiò. Ignis nofter furfum tendit, quia est levior aëre no Arowapido or crablo: at Solisignis fortalis non est lovior, esher circum 


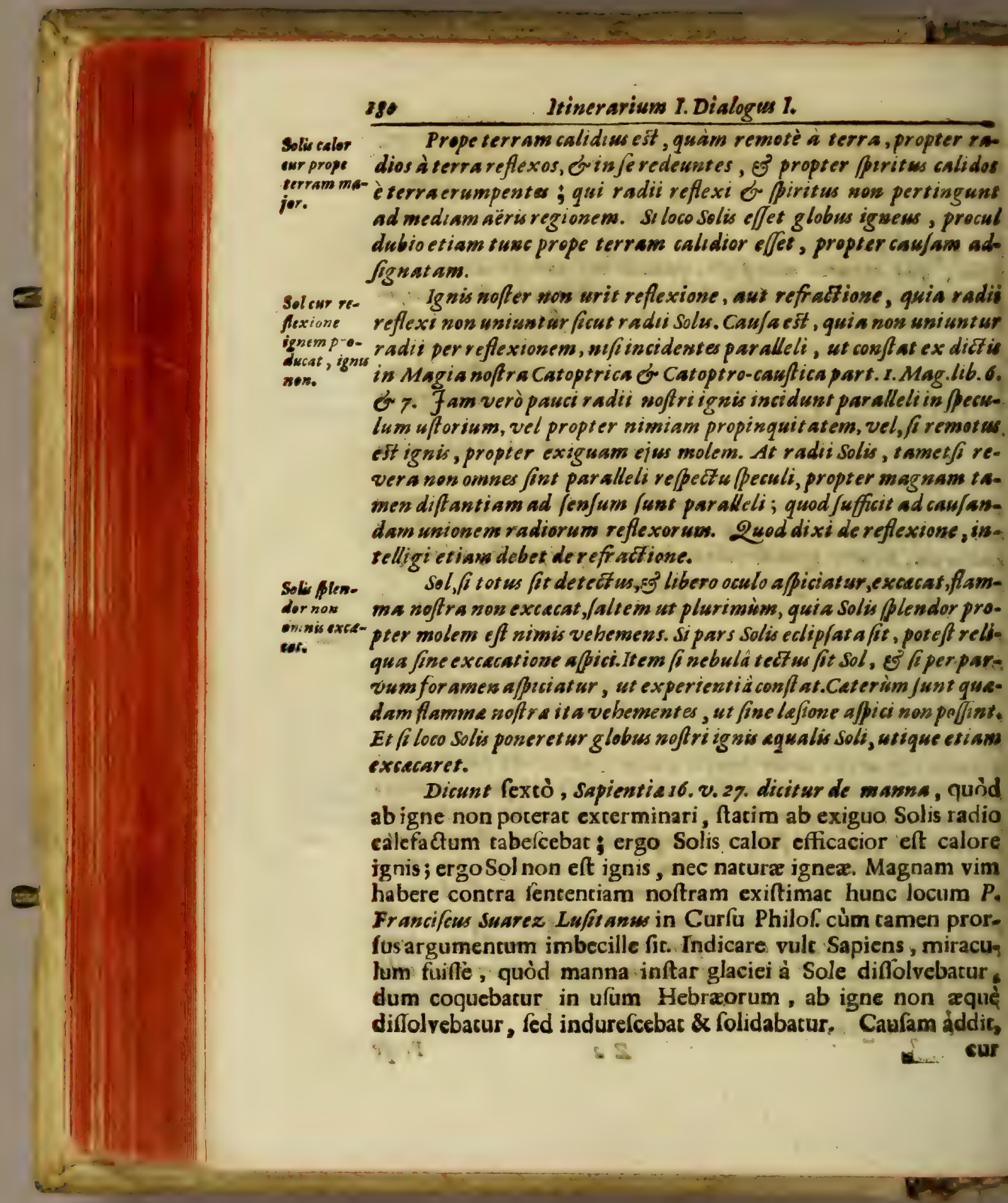




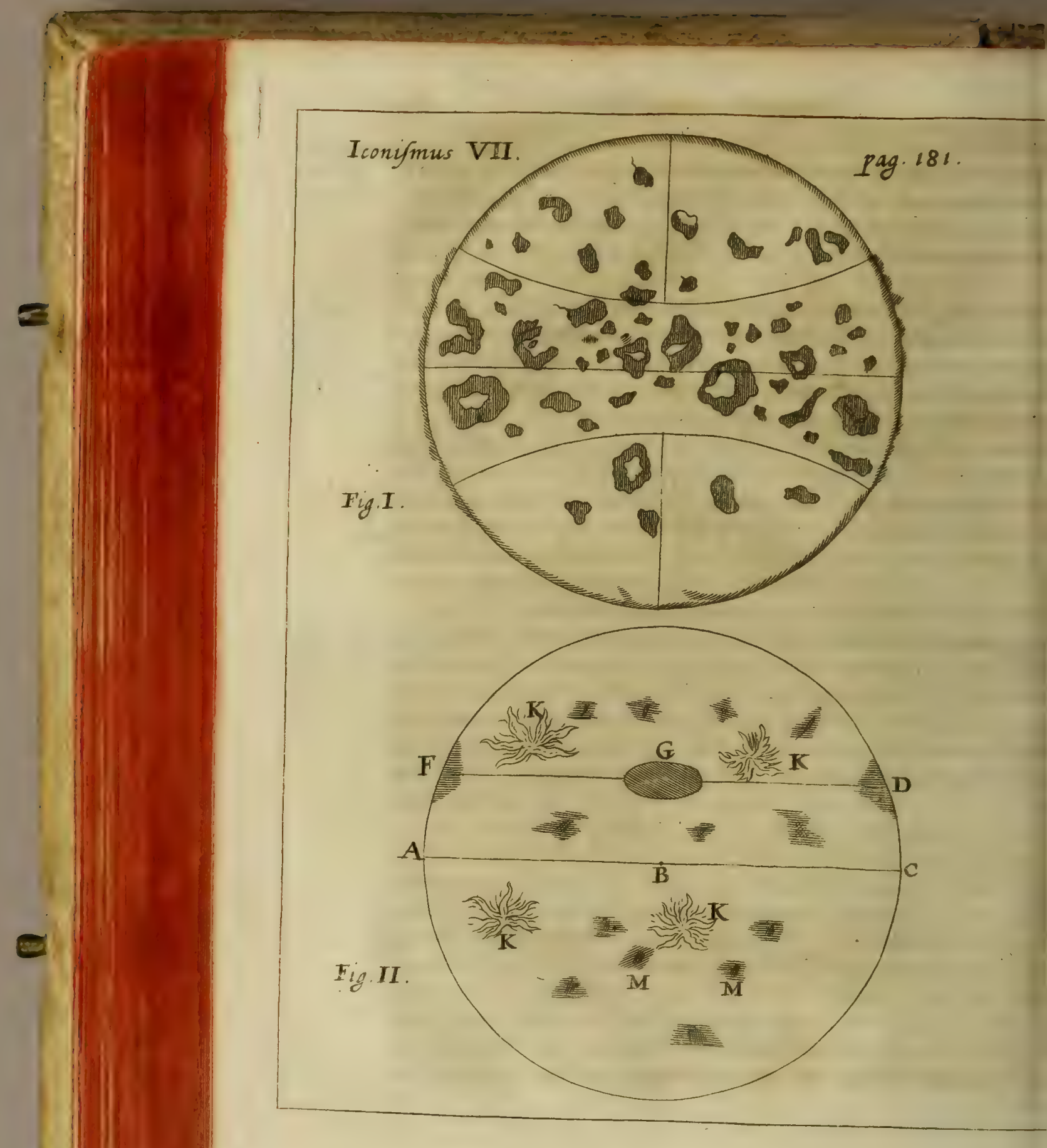


cur DE US in igne hoc miraculum exhibueric, in Sole non exhibuerit, ut nor wm omnibus effet quoniam oportet prevenire Solem ad benedic7ionem suam, $\}$ ad ort um lucis te adorare. Ingrati enim pes ianguam bybernalis glacies tabefcet, of difperiet tanquam agua Jupervacus.

Diount feprimò. Sol habet alios effect ws gु influerstias, quàm Irnis coudem ignis, wt paret in mineralibus, plant is, aninalibus $\sigma^{2} c$. Sed negatur, effetius proignis, wt pater in mineralibus, plant is, aninalibus Ec c. Sed negatur, ducit, quos media hyeme ; $\sigma$ 'varies gradibus calor is Chymici omnia met alla mirs modis alc erant, tr ansmul ant, ac transformant; of furnorum calore cacluduntur in Agyptopulli ex ovis.

\section{§. III.De maculis \& faculis Solis.}

A Beosempore, quo Lyncei Philofophi ac Mathematici armat os Macule \&5 A relefcopio oculos in solem intendere ceperunt, deprebende- Facule Solsorwor in ejus difoo, anot prope ipfum , frequentiffmè do evidentiffi- nifmi VII. wì, paries quasdams rigricantes velut umbras, $\theta^{2}$ areolas quas. Fig. I. dam reliquâ Soles juperficie lucidiores, ac flamunivomn, velut faces: quarsm illas maculas; has, appellare placuit faculas. Et olim quidem maculam quandam nig ricantem obfervavit in eodem folari difoo Adelmus Anno 807. ut iffe teftatur in vit a Caroli Magni; of aluam alio rempore Aven Rodan, ut refert Picus Mirandul. contra Aftrologos: at utergue exiftimavit ( guamvis falfo ) effe Mercurium fub sole. At poft hos primus, qui eas detexit, E⿱ ab omni alio noto fidere diftinxit, fuit P. Chriftophorus Scheinerus è So- Macnles ciet at is $\mathrm{F}$ ESU, qui Anro ion. Ingolf adii Menje Majo per occafio. Solic quitnew rimandi Solus apparentem diametrum ope telefcopit, eas anim- rint. advertit, of coram Patribus Gritfero of Tannero, per litteras verò Angelo Lynceo, of Marco Velfero indicavit. Post quem easdem lequenti anno fulpexit Galileus, as deinde wlii magno uumere, in bec usque tempora, inter guos funt Blancanus, Claramontius, Malapertius, Cyfacus, Rheita, Fridianus, Grienbergerus, Karcherus, Guldinus, Zucchius, Hortenfuss, Daniel Anconinus, Guilielmus Velius, Ẽ frequentiffimè multorum annonum ßpatio P. Molchior Cornaus, Collegameus: De bis quidquid $\mathrm{Z}_{3}$ varii 
varit tract arunt, in unem collegit P. Ricciolus lib.3. Almag. .6. . ex quo fequentia defumfi. Infpice Iconismi V I I. Fig. I.

Macule fo- Obfervatio macolarum ac facularum predictarum fit, aut modo objer. directo intuitu, Jed Sole obumbrato vaporibus raris, velulis, vela mentur. minibus fericis /ubtilioris texture, vitrísve coloratio : aut tubp optico; fed vitris viridibus inft rudto, aut faltem vitro viridi ante vitrum oculo propinquivis inferto: aut reflexì ex peculo plano reflectente invaginem solis in chartam diftantem aliquot pedibus: vel exceptâ solis imagine in charta candida in cubiculo perfecte ob/curato, per for amen exiguwm in fene/tra fact um; wut inferto telefcopio foramini pradicto, ita wt vitrum convexum so. lem, concavum repiciat cubiculum $\vartheta^{2}$ chartam obten/am, छlentibus parallelam, diftantemque ab ipfis aliquot palmis, prowt ro

Et quo tem-exigit, os experientia docet. Tempess opportuniffimum est meripere. dianum, quando sol est altifimus, ex extra vapores. 2uando per. for amenintromifja solisimago excipitur in charta, aut per opticus

- rubum macule apparent fot inver $/ 0$, nempe dextere apparent foniAre, d fieperiores fiunt inferiores.

Maewler: Veritas macularum dict is modis obfervatarum confat ex eo, folariwm quòd eâdem diei ejusdem horâ ob/ervate diverfis modis, vel abecdem, vel $a ̀$ diverfis, repert a fint eodem fit u, eâdemgue fg urâ, ac magnitudine. Non ergofunt vitrorumbulle aut nodi in charta apparentes; non inconftant is ä̈ris nubecule, que vix unguam in eodem. loco massens; non denique oculorsm ludibria; fed aliquod verum phenomenum in Sole, aut prope ipform.

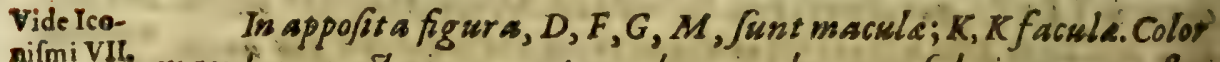

Fig.II. macularum est niger, aut ceruleus; umbrarum fubriger, aut fis. Macularï vus. Multa ex maculis nigriores apparent circa limbos solis, fo nolor. cum aliis coëant, st in $D$ \& $F$, quàm in medio $G$, ubi femidiaphane Jubilluftrantur à Sole, non it a tamen, quin fint obfcuriores consuetis Luna waculis, \& aliquibses nubilaws, ut Scheinersis notavit ; tamet $\beta$. Galileus conitrarium fentiat.

Figure ma- Figura macularum irregularis pleramque apparet, of ejusuharumso-dem macula valde incon/tans; ita ut mulla ferce poffridie talis
is. 
dens motum nobis confpicuum dicat eas moveri Occidentern var. fus, quippe tunc Sole inferiores:manè enimoriente Sale miacule af fen duns ab inferioribus Solis partibus, $\varepsilon$ vefpere defcendunt ad inf eri ores.

Locks inse. Lo maculs-

Locus macularum iu ceelo, feu diftantia * Terra, communite. rum Solis.

cenfetur fupra Meraurium Perig aum, or nemo jam est, qui non com cedat eas aut in Solis fuperfficie effe, ant illi quafs contiguas, co què major, fed codem dicesdem maculs obfervat a fuerint ineadem st lis parte, cum motu ad motum solis equaliter proportionali, $\theta$ lon

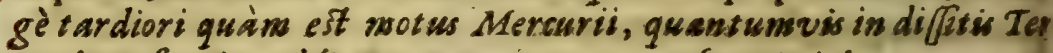
ra losis fuerime objervatores, quos recen/et Ricoiolus magno nu mero.

Subrantis macularmo Solic.

Subftantia macularum (fiquidem fupra Lunam funt, o's st liproxime, at finedubio funt ) coeleft is est, non fublunaris. Ra phaël Averfa putat, virtute anufarum caleftium nobis occult partes aliquas coli reddialiis opaciores, $E$ inde illud waculis perfum videri. Malapertius, Mattrius, Rheica cenjent, macula effeftellas perpetwo ì sole illuftratas, \&f fatellites solis opacos , so lemgue ambientes, effeque figure irregularis, ob varium ip farn. concurfum, $छ$ motium per epigyclos diverfos; faculas vero puta Rheita effe lumen Solis reflexum à maculis in ipfium difcum fo larem. Galilaus, Keplerus, Bullialdus, $\sigma^{2}$ tandem (licet olism contrarie opinionis) Scheinerus \& Blancanus negant, eas effe fellas, eo quod nec rot unde, necregularis figura fint, \& nubibn insonffants/fimis finillime, mult aque ex illis in ip lo solis medion re, antequam ad margines pervenerint, evane/cant, aut fubit in medio apparentes illeco extinguantur; ideoque exiftimant 8 gni ear de novo, $\xi$ interire, nibilque aliud efje quàm fuligine ant vapores ex fornace folaris globi ebullientes; of aliquas ex in incenfas, facularum ixftar corufcare. Eadem est mens Kircher: tum hic, tum lib. s. de Lum. \&? Umb. cap. I. \& Cornai in Curric Lo Philoloph. tract. de Calo, difput.2.q.3. $\sigma$ in Appendice de spha ra armill. cap. 4. fect. I. R icciolus relenquit rem in ambigso, potest capere, if fuligines funt, quonodo tam mulic tam diu per 
maneant, ut circa solem fwo vel Solis motu diebus circiter 27 mo. veasiar. 2uid ego fentiam, dicam poftea, wbi de Solis frubture gero.

\section{§. IV. De motu vertiginis Solis circa fuum} centrum \& axem.

PHenomenum macularum folarium, earumque motus vel circe Solem, fo a solis corpore distinat a funt, vel cum ipfo circa ejus encrum of axem, fo indisfincte, occefronem dedit earundems obervat oribus of affertoribus, tribuesedi motum vertiginis soli cir Vertige Soa fui corporis censtum, indicaturs olim à Platone in Timeo. Sive lis. mim a solari fuperficie distinct a fint, \& fisut nubes circa Terram, in ipfe circa Solem volutent, utpore fuligines os quafe nubes ipfius; ive in ip/o fint corpore folari, utpote partes ipfius folide ac terree; moniam in parte Solis fuperiori \&o inconfpicua nobis movent ur ab ccidense in orientem, in parte verò inferiore 39 nobis con/picua ab riente in occidentem, neceffe est $b^{2}$ if fum folare corpus circa cenrum fusm codem motu circumverti, ut partim ex fe evidens ejt, artim evidens fiet ex dicendes de fruct ura Solis. Agnofcunt bune sotum Keplerus in Comment. Mart is part. 3. c. 34. Scheinerus ins ofo Urfina palim, prefertim lib. 4. Galilaus de Maculis Solis pag. 2. E9 49. Bullialdus li6. J. Afronom. Pbilol cap.12. Rheita in Oculib. 4. capp. 2. Memb.3. Kircherus cap. Feq. Cornaus locis fuprà 7. Ricciolus lib. 3. Almag. cap. 3. \& alli paffim; $\delta$ frante prediZo ploenoweno negari non potest.

Ad periodum bujus vertiginis quod attinet, concedit ei Ke-Vertiginis lerus boras 24. in Hypothef Terre mot a, s' Solis fantis, fo pona Solarispeur diurnus motus Telluris effe à vi magnetica Solis eam fuá ipfins ertigine circumagentis; fed effe dierum 3. $\int i$ ponatur eadem roportio inter motum periodicum Mercurii \& motsm solis, que 7 inter fensidiametrum Orbis Mercurii of diametrum corporis laris. Sed boc est ludere alsque fundamento in caelo, inquit meirò Ricciolus. Galilæus, Scheinerus, Bullialdus, Kircherus, Coraus, \&ڤ alii, faciunt easdem vertiginem ferè menftruam, feu ierwon 27. ant 28. aut 29. camque colligunt ex apparenti mots A. macularum, 


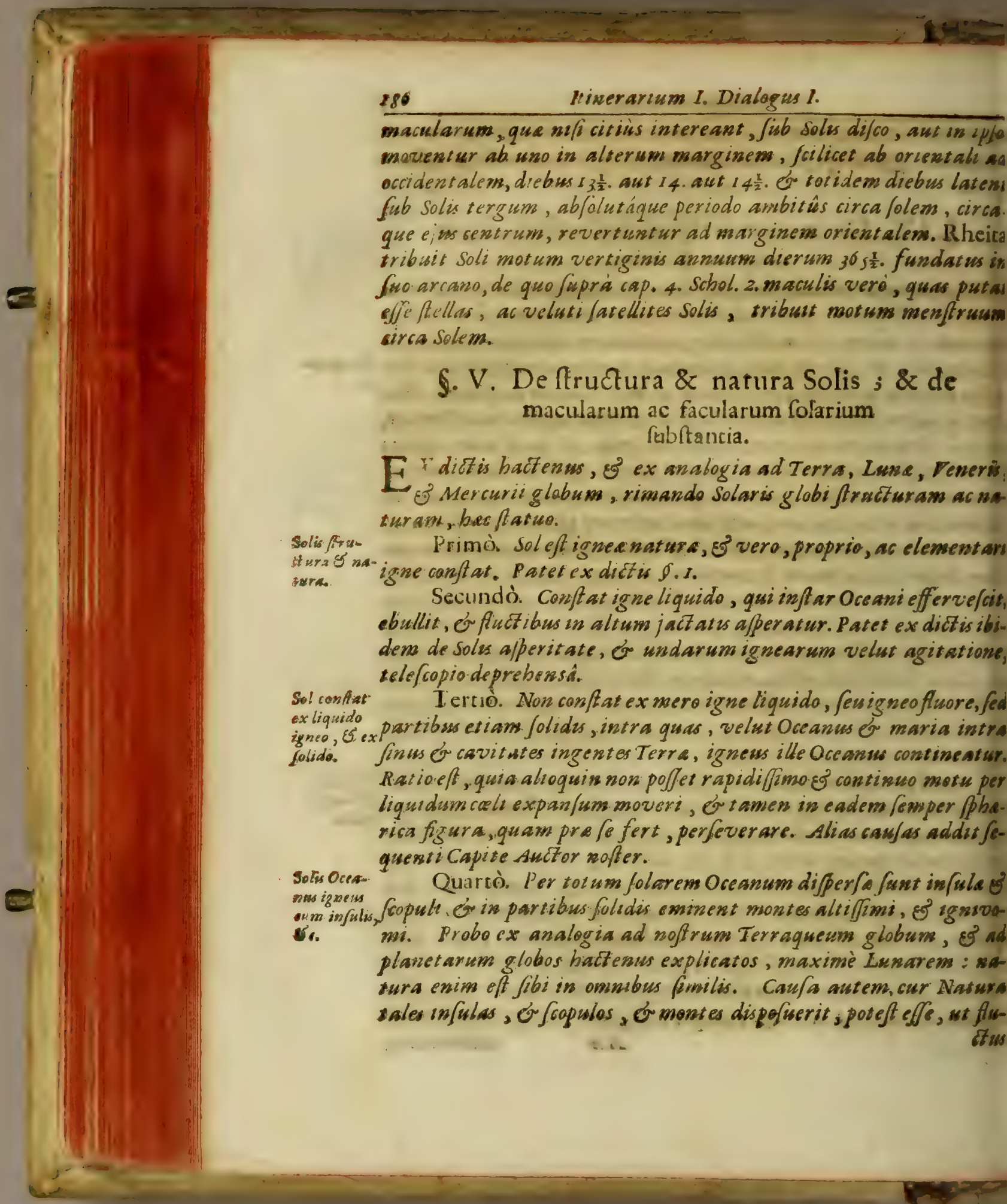


Cow immenfo folaris Oceani, femper effervefcentis ob ignis vehementian, ad extantias illas allidantur. frangantur, disfipentur. ou virtutem fuam pan/permaticam (de qua Auctor info a) circuneAnatibres of /ubjectio corporibus efficacius communicent.

Quintò. Probabile eft, quod Auct or nofter infrà afferit, ni Solis fubtermirum folarem globsem, ex folido $\xi^{\circ}$ liquedo compag inal ums in ranei cana-

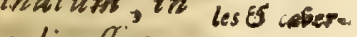
viwn at repletwm, non leciss at in Terraqueo noftro globo fact un onftat, E? probabiliter in Lunari; $g^{2}$ per canales illos communica- inter fe diverfa Solaris globi maria ignea, feu potiòs unum mare in diver a brachis divi/um; in cavernis verò $\sigma^{9}$ receptaculis coniseri ingentem ignea materia copiam, qua maximof fulgore flamavowis montibus / oubinde eructet per apertos crateres, of fubinde for a Jis è lateribus apert â fibi violenter viâ, erumpat. Si enim d in Tellure noftra conting it, ut fcimus; multò mages in globo jola- contingere est verifimile, ob longè majorem Es copian, É efficaiamillius, quàm noftrignis.

Sextô. Partes folide, intro quas igneus fluor velut intra ca-solis parta abos aut fornaces fufortas continetur, funt utique prorfus ignit:e, folida cole9 ab ignis virtute penetrate, ac velut in ignem converfa; ad eum risignei. nodum, quo fornacum fuforiarum è lateribus confruct arum laera of fornices prorfus ignita apparest, $\xi^{2}$ ab ignis feu ignea maeria inclue a colore minimè dist inct a. Ratio eft, quin Sol, wt vidiwus, conftat partibus folidis $\vartheta^{2}$ fluidis, $\xi^{7}$ nos non vácmus folum 7uidas, fed folidas etiam partes, utpote intra quas ille contincntur. se diffluast ; cum ergò to tum, quod videnns, igneum appareat, conequens eft, folides illas partes igritas feu ab igne penetratas effe, or in igreum cosverfas colorem. Eft autem folaris terra vel asbeFina ó incombuftibilis, ut Auctor nofter vult; vel faltem long mais reffitic ignis voracitati quam terra noftra. Tames 1 vero bino nde partes quadam abfumerentur, imo $\sigma^{3}$ integrimontes corrue-ent, non tamen propterea interiret folaris globus, facut mec Terriauesus nofter perit ob fimiles interitus.

Septimò. Tam ignis fuidi, quaim partium folidarum fulror, longè viwcit fulgorem noftri ignis, ơ rerum aprid nos $i$ ni- 


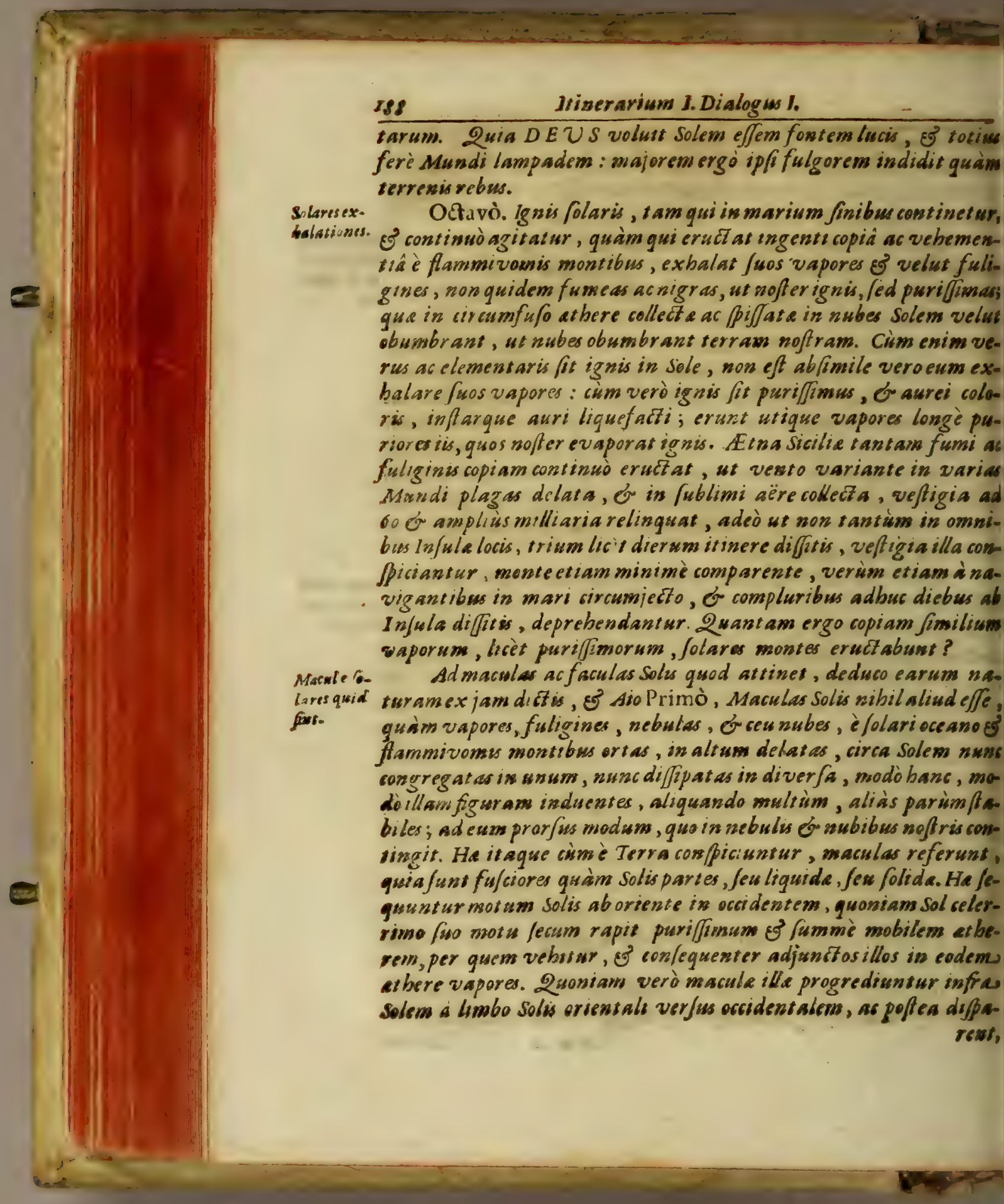




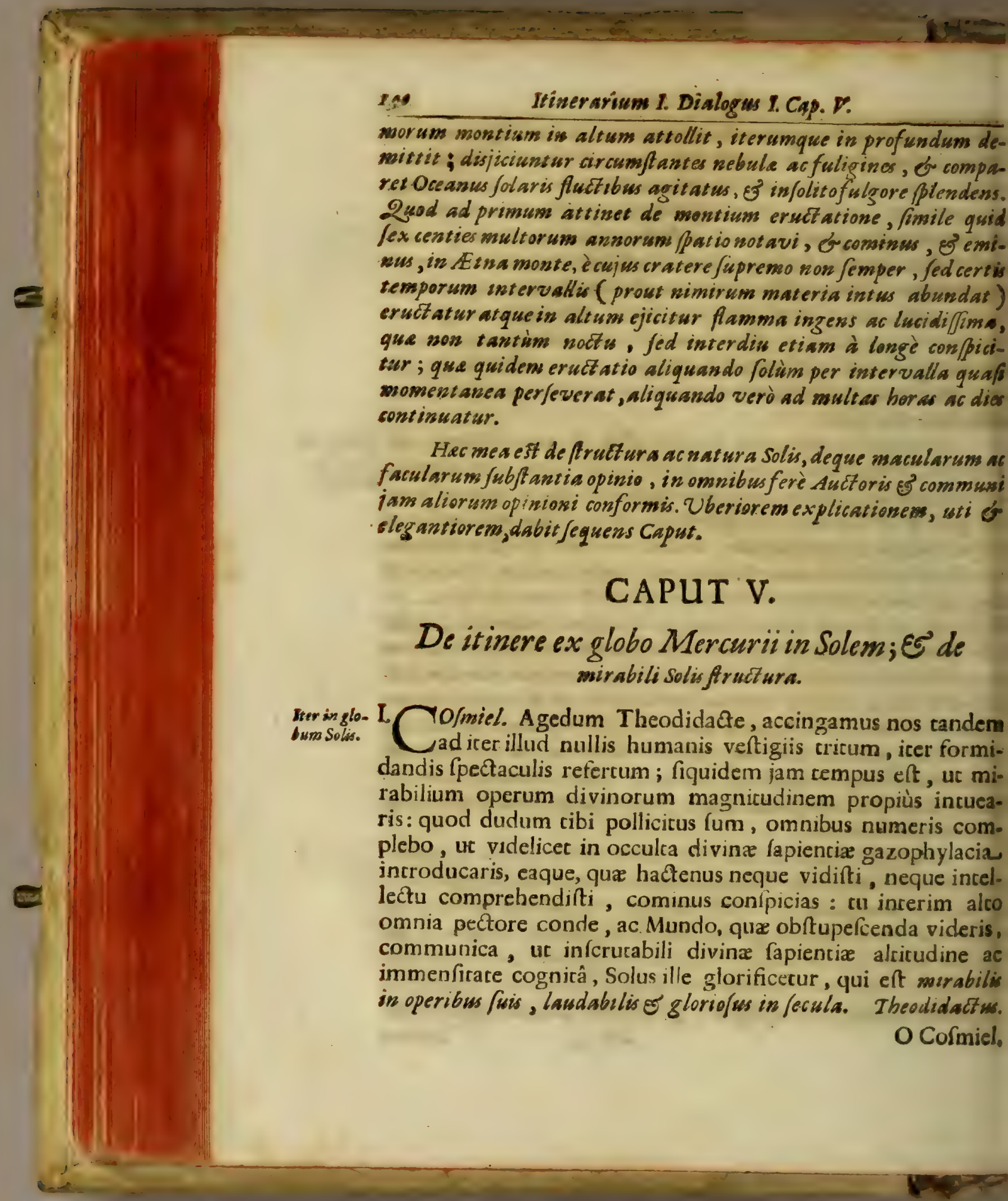


oCofmiel, minifter Dei excelii), feftina rogo, adjuva me. Cofimici. Quid pateris Theodidacte \& Theodidactus. Intolerabilisolis affus; aftus vehementiâ panè fuffocor, nimio lucis fulgore excæeor; \& fulgor ni cu mihi fuccurreris, de me actum eft. Cofmiel. Ne dubires, fili mi, nil ab inferto tibi æftu impofterum parieris, neque oculorum tuorum lumen oblcurabitur; hæc tibi contingune, ut vel ad primum folaris globi intuitum virtutis ibidem latentis ineftimabilem experiaris magnicudinem \& efficaciam, Theodidact us. Quo dicto, nefcio qua corporis parte promptum vafculum coelefti rore plenum, effudic fuper capur meum, qui in univerficorporis fubftantiam derivatus tanto me odore, tanto refrigerio, tanto denique virium robore confortavit, ut exinde ab omni aftus incendio, ab omni fulgoris vehemencia iber \& immunis exciterim. O fumme coeleftium rerum arbier! ô quanea Mundo incognita video ; quam miram rerum faciem! quantam rerum metamorphofin! Cofmiel. Quid vites? Theodidact us. Mundum igneum, innumeros flammarum solief fredes lucidiffrmarum globos eructantem video. Quid nubes illa immenfax, quibus aliis \& aliis fibi invicem fuccedentibus immenfum hunc globum veftitum video? quid lux illa incenfisina \& inexhaulta? quid tenebra mixtæ luci ? éftne poffibie, Solem illum, quem nos terrigena tanto fplendore, tam inredibili fulgore radiantem confpicimus, tot ac tantas varieates fubirepoffe? O mi Jefu, fons lucis aternæ, illumina ocuos meos, ut tanti portenti veritacem cognofcam; tu, qui veroo virtutis tur conftituifti omnia, irradia animam meam, uc e in magnitudine operum tuorum cognitum laudem \& gloificem, qui omnia in omribus operaris; deficic enim anima nea pre incomprehenfibili mirabilium tuorum excellentia. cofmiel. Perge agedum fili mi, majora femper \& majora videis. Theodidacturs.Sed ô mi Cofmiel, tabefcic anima mea prà timoe; nefcio quid faciam; fier íne poteft, ut tu me fine damno aur laione ulla in toc ignium flammarumque globos, in hunc imnenfum fervore ebulliencem Oceanum immergas ? fed \& quis 
eft mortalis homo, qui cam intenfam, tam vehementem \& lu cem \& calorem futtinear? Cofmiel. Cunfide fili, jam coeleft is ro ris antidoto à me munitus, nec flammarum ebullientem ardo rem, neclucis vehementiam timebis.

II. Theodidact us. Ec ecce, in momento in folari illo tot vo tis defiderato globo tandem me confticutum inveni.Sed ô quàn mirificum, quàm infolicum, quàm invifum, rerum æfimatio ne humanâ majorum, fefe oculis meis exhibec cheatrum? dice rem fanè, fi poffem, explicarem fingula, fi verba fufficerent; fe uri omnia fupra humanum conceptum fune, ita omnem ima ginacionis vim longè fuperane, atque adeò omni me fandi li centià defticuunt, cùm nulla res terrena verè \& propriè hui comparari jure pollic. O verè vas admirabile, ô verè opus $E x$ celfs! Cofmiel. Quisnam animum tuum tam infolitus ftupor ve ad primum hujus globi introitum invafit, cùm tamen nec mil lefimam ejus partem videris? vides hanc asbeftinam naviculan commoditati tux præparatam? I heodidact us. Video, led putás ne cam immenfo hujus ebulliencis Oceani fervori tam imbecil lem \& infirmam fcaphulam refiftere pofte ? Co/miel. Agedum ingredere magnoanimo, eft enim hæc ex ipfa folari rupe exci fa, \& à me in hanc formam adaptata; qux ex incombuftibili ma teria conftructa fic, non eft quòd ejus timeas conflagrationem Agedum, magno animo fis, ego \& nauta, \& dux cuus ero; mi præfide ab omni flammarum impecu cucus eris. Quo dicto, as beftinos remos agitavit, \& Euro velociore impetu igneum fulca. vimus Oceanum.

\section{I. De Solis ftructura ac compofitione ex folido \& liquido igneo.}

III. THeodidaczus. O Deus meus, \& pars mea, Deus in æter1 num! quis linguâ tam facundus eft, quis cancâ dicendi fa. cưfate pollet, ut incomprehenfibiliư operum tuorum magnitudinem exprimat? ftupor enim \& exftafis circüdedit me,nec concipere ullâ ratione pollum ram invifas rerũ formas, tam inaudita humanis auribus portéca. Oceanustotus liquore igneo agicabatur 
ignis multùm erat ab elementari ıne diverfus. Primò enim lu struđura ciduilinus erat, ita ut non putem fieri potuille, uc oculus huma. Solarug glonus, nili diviná potenciâ roboracus, eum ferret. Secundò lıqui $b i$. dus videbatur, cui nuhil in cerrenis rebus fimile me vidifle monis Solaris me- corrdusiones. aris aur ferri in çapaciffimis fornacibus lucem ebullicionemque contuitus fuerit, aur fulminis vehementiam videric, is aliqua moda fibi hujus ignei Oceani fulgorem imaginari poteric. Tertiò ignis flammas fuliginofas more igni noft o folito non exhalabat, fed fumos quosdam lucidiffimus, qui in aëre folari condenfaci nubium inftar totum coli afpe. Atum ab oculis incuentium adimebant. Oeeanus quoque tam horrendas fubinde voragines ex fumma rapiditate apericbat, ut fine horrore \& exanimatione nullum Terrigenum eas incueri poflé exiftimem ; jam occultâ ebullientis natura vi urgence Oceanus fluctus fuosigneos ad inftar moncium in cantam efferebat alcitudinem, ut humana mens majori admiracione dignius quidpiam concipere vix poffir, O Cofmiel, anima mea illuminacor, quis rogo vaftitatem \& immenfam hujus gloti molem aut animo concipiat, aut verbis explicet? Co/mel, Non fine caura illud ab Ecclefiaftico, cujus verba antè protulift, vas admirabile, opus Excelfa, dictum pura Fac enim hunc globum humano veft igio pervium efle, cantam camen ejus vafticatem effe fcias, ui, fi fingulis diebus decem horariarum leucarum iter conficeres, fratio novendecim annorum quoad circumferentiam neutiquam id aofolyeres; atque adeò tota hujus globi proportio ad telluris globum fe haber, ur 1000 ad s.

\section{SCHOLIUM I.}

\section{De Solis magnitudine collata cum Terra.}

Vo ratiocinio vera Solis magnitudo ex vera ejus diametro, solis ma=5 ex bac relique magnitudinis pecies derventur, docui in gn indo ad Curfu Mathem. lib. S.cap. 13. El lib.6. part. 2. 6 3. Vartorum Au- ierramiolitorum lententias circa eam rem collegit, \&unico apectu propowit in fequenti Tabula P. Ricciolus 136.3 . Alwag, caj. II. inter

$$
B 6 \text { gros }
$$




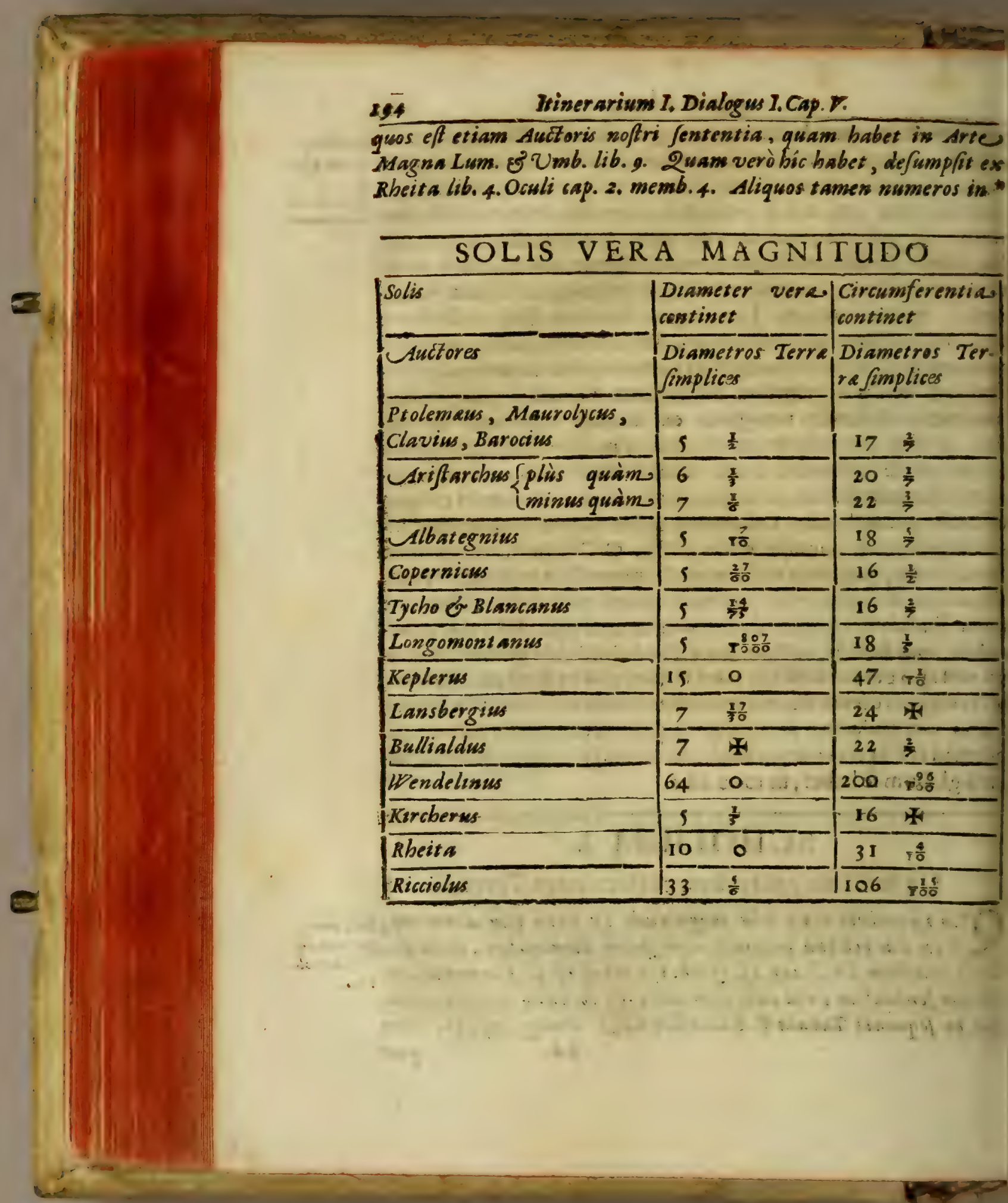


Iter in Solem.

* Jequenti Tabiula fupplevit ip/e Ricciolus, ufus proportione dismeeri ad pertplerionim, at rooind 374 .

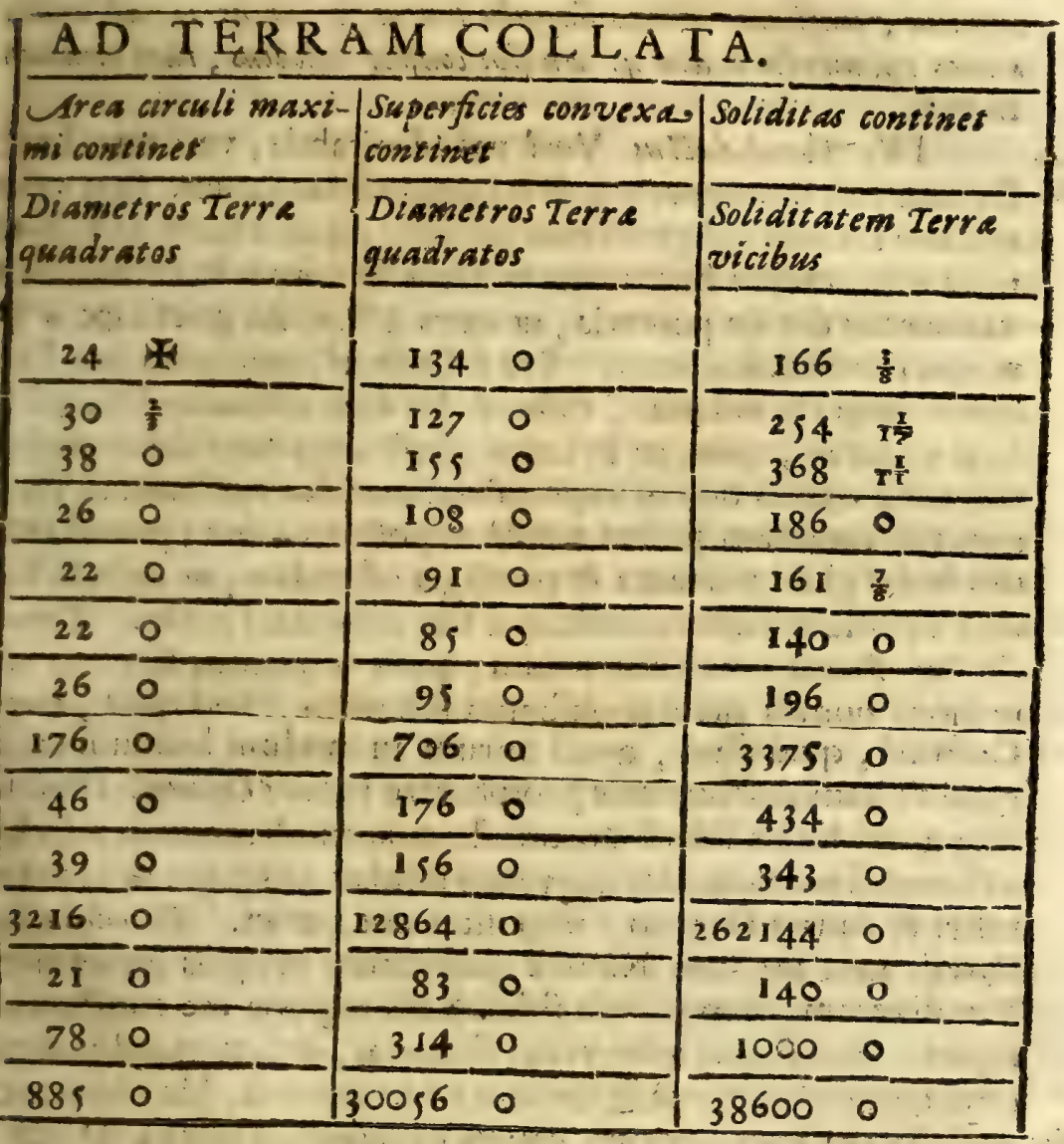




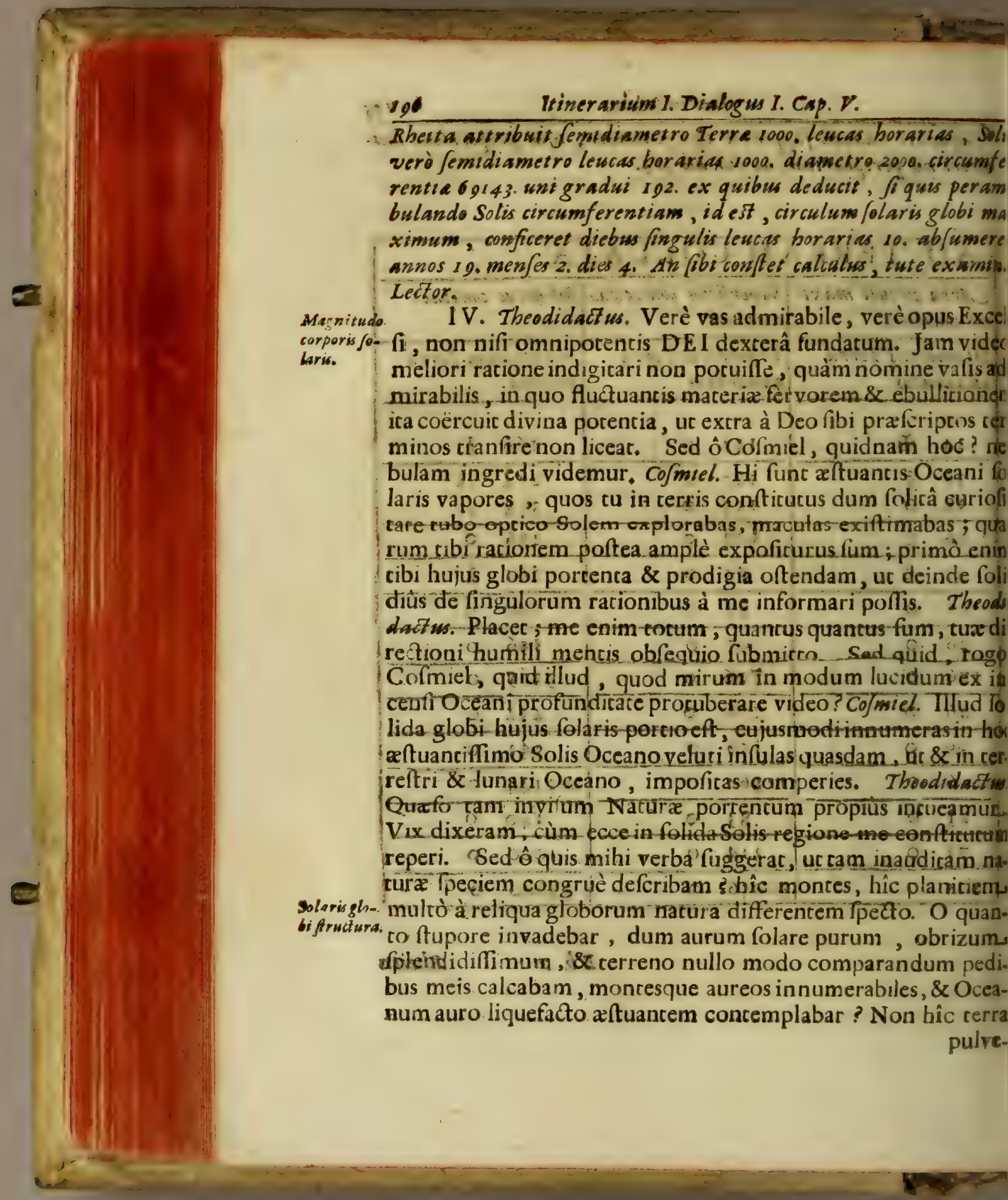


pulveribus obfica , non fcopuli \& montes acboribus, herbis, gramiaibusque veftiti, fed faxea moles eranc adeò illuftres, quàm illuftrem rerrigenx Sols faciem ètelluris centro intueri folenr, aurum limpidilfimum \& ful gidifimum referentem. Sed deficiune verba, quibus tam infolitum fpectrum aptè defcribamb; hoc unicum dico, fi vel unicum ex hujusmodi fragmentis in rerram divinâ virtuce deportaretur, illud innatâ fibi luce noftem mox in diem converfurum effe, \& quacunque lucem. concrearam habent corpora cerrena, comparatione hujus nihil efle; cujus vel una particula omnes terreni Mundi divitias pretio longè fupevarec. Sed ó miCofmiel, quàm inaudita mihi exhibes lpectacula ; fúntne omnes folida hujus globi partes ejusdem racionis? Cofimick Sunc equidem quoad fubftanciam; pares enim cotius fequiuntur naturam , suc te Philofophia docet. Quin imò \& liquidum \& folıdum hujus globi cjusdem qualikais propt iaranisque funt, palueis exceptis, qua in folaris corpobis

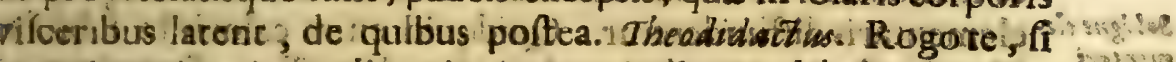
nveni gratiam in oculis. tuis, expone mihr ampliüs hujus nact- an racramentum. Cofmiel. Aures itaque arrige, \&, qua difcesà solarecor. ne, alco pectore conde. Corpus hoc folare, omnium munda-pus ex li horum corporum vaftiffimum, divina fapientia primò ex li quida 6 fow

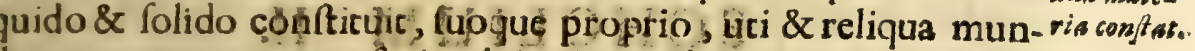
lana corpora, centro frui voluic, ica quidem, uc inde avulfum guidpian nifi in appropriato fibi globo veluci centro nullibi ubfiftere poffic; quo quidem fi non frueretur, aftuantis illius: Decini, liquorisqueignei materies aliud necellärò ( cùm naruả fuâ ignca fubftantix fir ) centrum appetere deberet Sed Inodnam iliud traut quonam vas illud admirabile liquan mo centrifa. lum diffunderet? num in circumvallatos Soli globos ? fed ille bars natin. raterquàm quòd violentam hafionem, utpoce nature fuze in- ${ }^{2 a}$. ongruam, necelları fuftiperec, ex tam violento quoque ftatu octus Mund ruina fequeretur cùm nultum ad alhum globum. ppeticum, praterquàmad illum folum, quo Solem veluri cen-

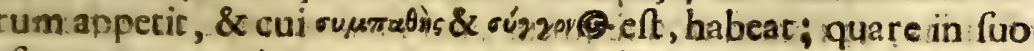
fe centro, partibus omnibus \& fingulis, , ita, rigorolâ nacuræe
B b 3
ne- 


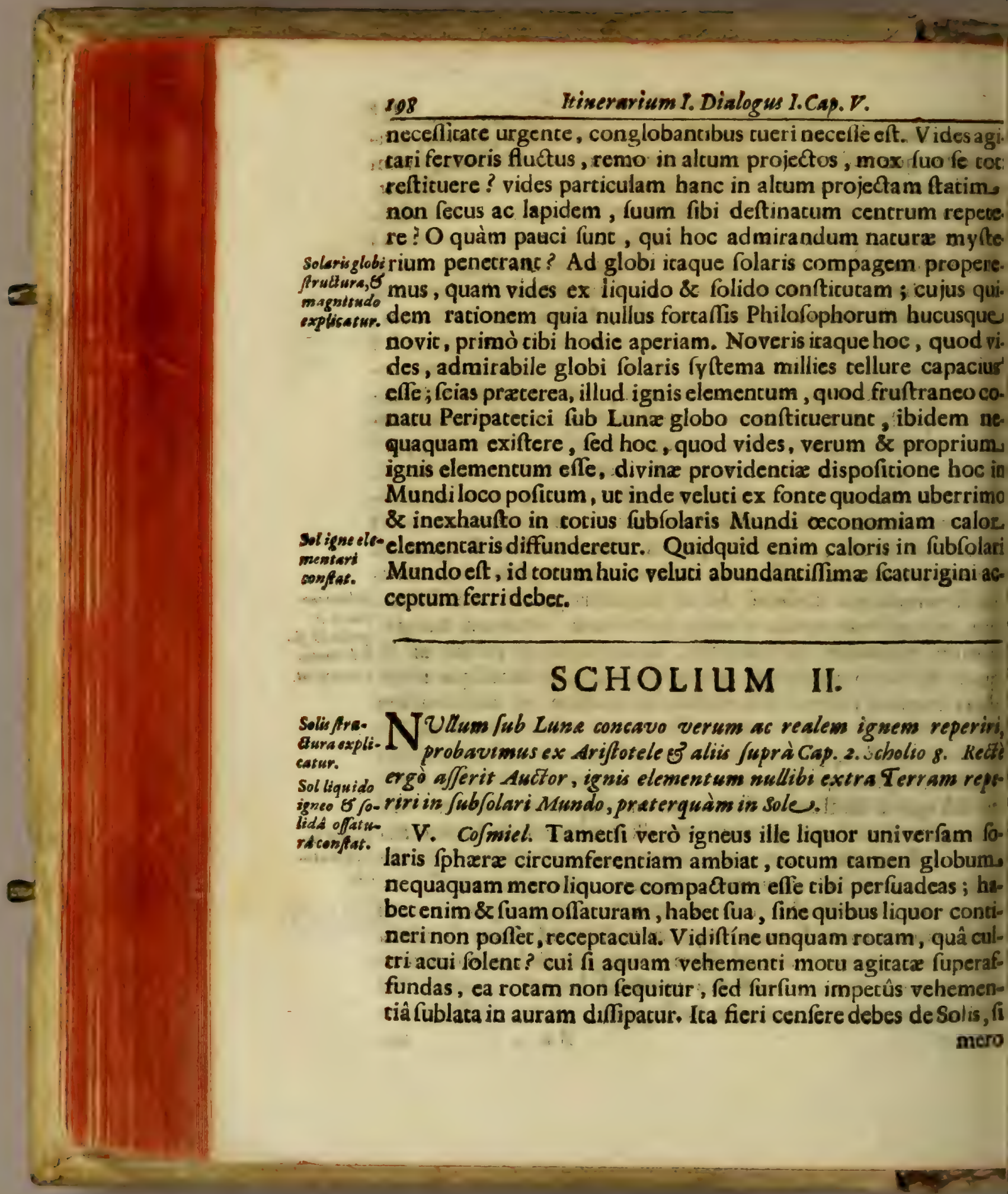


aero liquore compactus effer, globo, dum enim corpus folare b orru ad occafum circa telluris globum fpario diei naturalis ircumvolvitur, nifi folidioribus partibus veluri repagulis quiusdam liquor ille coércerctur, nullâ ratione fubfiftere poflet uin contingere neceftè foret, ut nimiâ violentiâ motûs, quo i̊tus globus liquidus in circulum diurnâ vertigine agitatur, u difliparetur, aut virtute difpersâ confusâque oppidò tumulariam \& exoticam globi faciem conftitueret; undantis fiquiim \& fummá mobilitate præditæ materiei fervor, Solem ex mia rapiditate modò in ovatam, nunc in Rhomboidem., $m$ in aliam quampiam figuram ad oculum fenfibilem dedu: tret; quod ramen experientix repugnare nofti. Nè itaque $x$ adeo inconveniens Solis effectus \& virtutis influxiva opeciones impediat, Nacura, rerum provida omnium moderaix, liquorem hunc igneum intra folidiorem partium alveos? onclufit, ut is, veluti in vafe quodam verè admirabili coércis, fui fervoris terminos minimè excedierer. Hinc vides tam reales quàm Aultrales partes magna ex parte, uti \& Solaris? rporis profundum, folidioribus partibus veluti offaturâ quâim globo totius proportionatâ, \& qua intra fe veluti in utero odam fulgidi liquoris materiem contineret, conftitutum ifle. Miratus es paulò antè immenfos hujus ignei pelagi rtices, obftupuifti undarum ex oppolitis parribus fe premen$\mathrm{m}, \&$ in alcum montium inftar fefe extollentium impetus. jus quidem rei ratio alia non eft, nifi liquidx materiz rapidấ rtigine agitatæ in obvias infulas continentesque impacta folutio, ex qua vortices \& aftuantis elementi tumores nafci

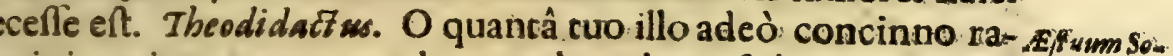
cinio animum meum voluptate demulces ! fed rogo te, Co larium finit iel, ut, quid liquidum illud tot tamque diverfis aftuum moti- quis? Is agitatum? quid cauces \& fcopuli ignei conferant, quem tanm finem prapotentioperationum fuarum energiâ refpiciant? ponasłmagnum enim fub iis naturæ myfterium relucere video, fmiel. Faciam, quod petis. Si itaque corus globus. folaris aur liquidus: 


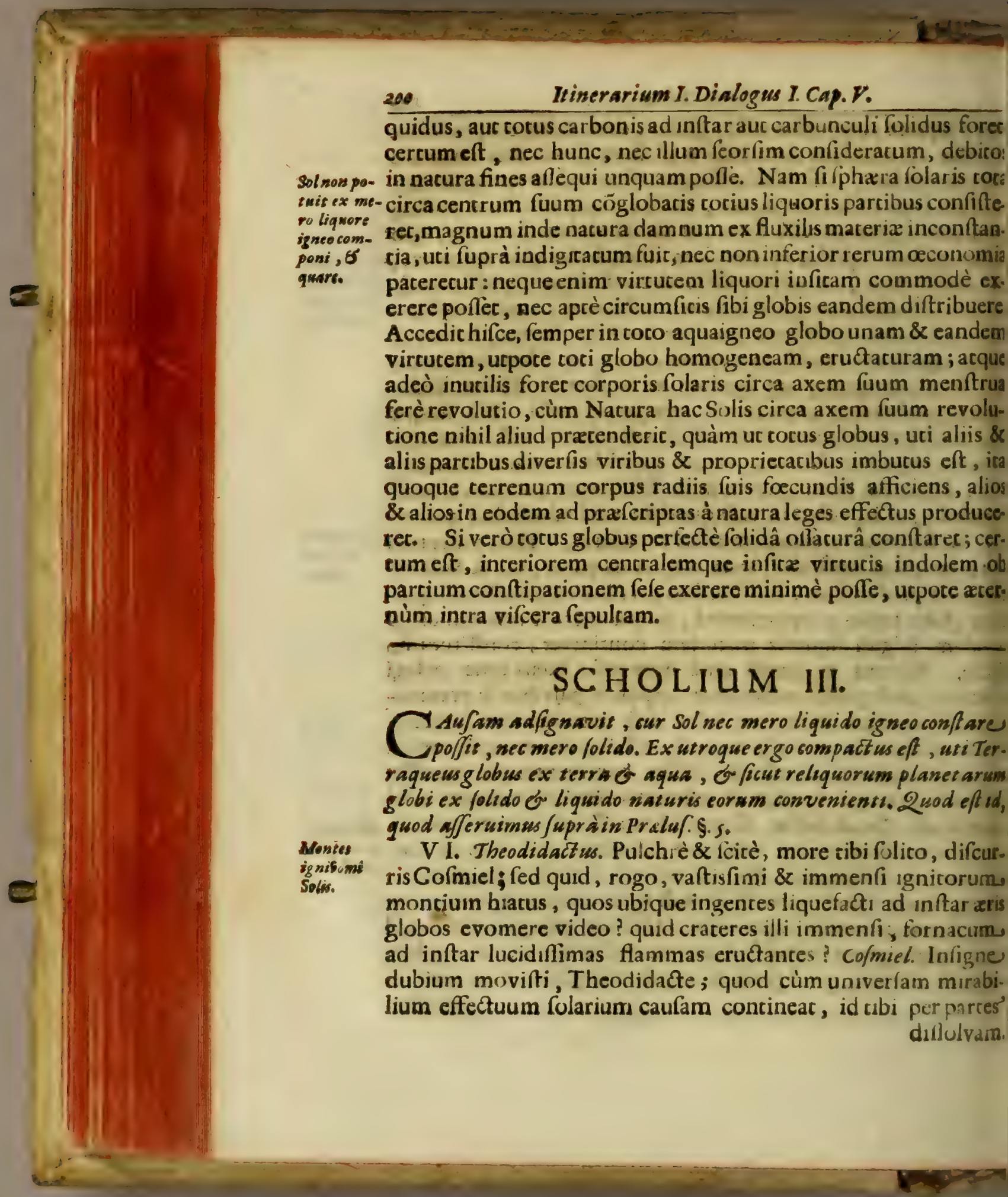


difolvam, Notare re velim, oflacuram, five fceletum hujus solida fruglobi nequaquam impenetrabili quadam foliditace, ad inftar clura solis mafla, feugluminullis rimisaut cavitatibus:pervii, confticutam innumeris efle, fed fur fibi antra, fpeluncas immen fractus fub tratares meatibus numeros, ingentibus :undique imaandris canalibusquerefertos babere, per quos vircus globo appropriata fefe ad extimam Solis fuperficiem exerat, eamque hinc in mundanos fibi fubditos globos quaquaverfum diffundar, Quemadmodum enim in terreno globo Oceamus in perpetua æintuseffervefcentia, perfe-petua aftus Ââ pericyclofi univenfam telluris fuperficiem ambic, \& per oc- agitatione culcos terra meatus comnia interiora terrie vifcera permeans in berfatur. fontes, flumina, lacus : tandem fefe juxta leges à natura fibiprzfcriptas exonerac; ita omnino in Solaris corporis globo fieri exiftimandum eft: pelagns enim hoc Solis interminum fervidillimumque uti perpecuấ fluxûs refluxûsque vicifficưdine agicatur, ita nunquam eandem terrigenis faciem obvertit, fed mirandâ quâdam pericyclofi feu circulatione novos femper \& \&novos fluctus, novam femper \& novam virium proprietatumque fementem in Mundi emolumentum exerit. Neque enim putes" velim, virtutem, quâ in inferiora influic dem efle. O quàm nonnulli Plilof ucem caloremque inferian caufam efle volunc l qux nefor iundum agentem omnium, caulam elle volunt! qua nefcioan digna fic Philofopho fententia ; nimis enim fubmiflè, ne dicam contemptim de fumma naturæ majeftate, ejusque inexhauftis divitiarum thefauris fentire videncur ; fiquidem putare nullầ akâ virtute, proprietate, qualitateque prater lucem \& calorem coeleftia corpora donata efle, parum prudentem perfuafionem effe exiftimes. Hoc tibi corpus solis certo perfua fum habeas, totam hanc folaris globi molem, non. panfermia unâ tantùm facultate, fed panfpermaticâ quâdam virtute imbu_polîs. cam effe, quâ quidem pro diverfa diverfarum partium folarium nacura, intra abdita Solaris Mundi vifcera divitias fuas abfcondente, humor igneus diverfimodè tinctus, per radiofam virtuce variâ \& multiplici imbutam diffufionem inferiora attingit, \& ro fubjecti cujusvis natura diverfos effectus producit, Unde C c ne 


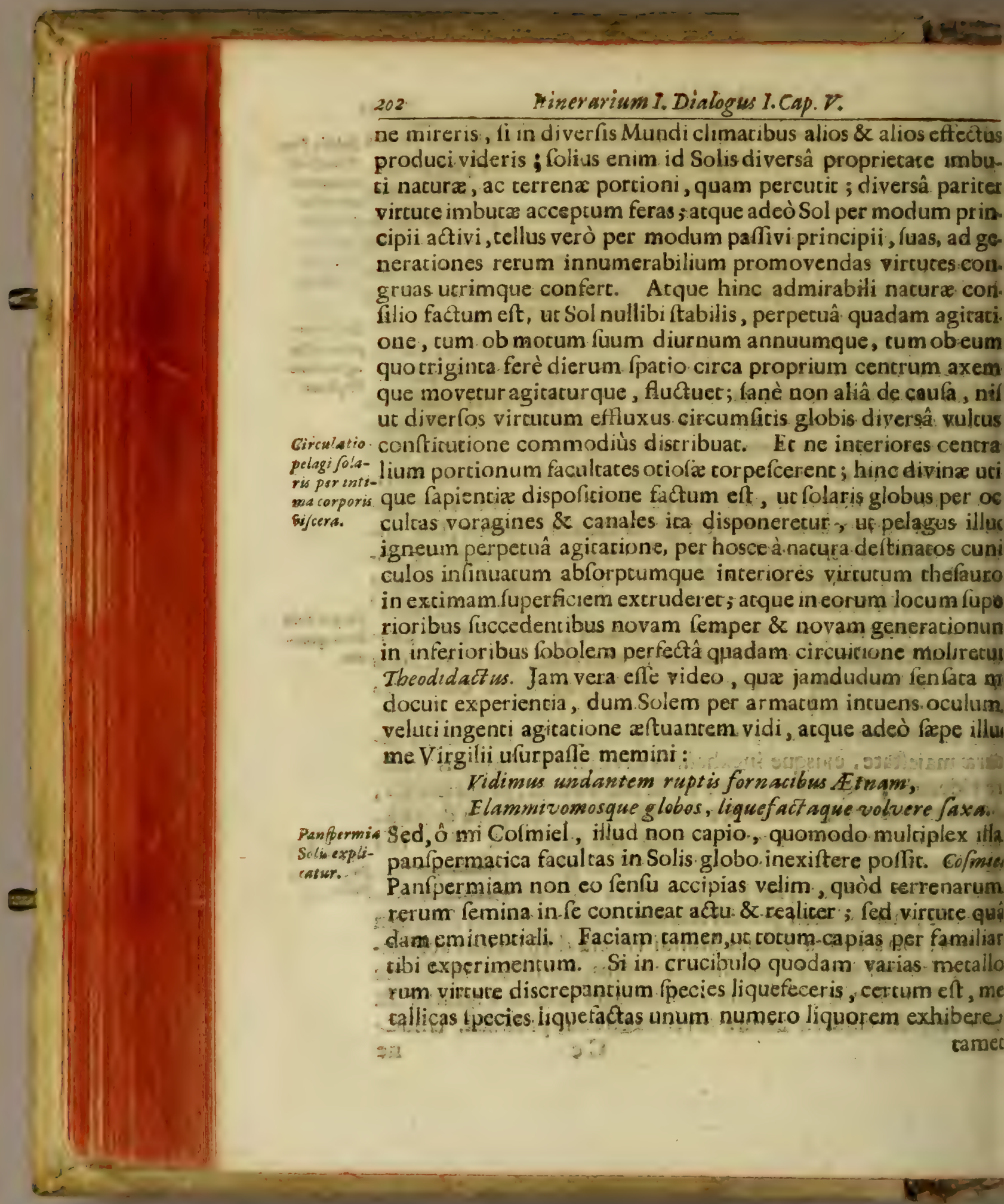


mametí omnious metallorum confufis facultatibus plurimimis discreper, nt ex diverfis colorum generibus liquidò patet; cujus quidem vapor pro diver价 nacura metallorum, nunc faluciferas, nune noxias qualitates diffundit. Pari modo \& analogiâ in. colari globo fieriexiftimare debes. Sunt in folari globo non. Solgariis omnes partes, utiPeripacerici exiftimant, ejusdem facultatis", frcultatibus cunacura homogenea, fed variis vircutibus, prout divina fa- pollet. oientia per artem fuam Naturam in fuos eas fines dispofuit, doacæ. Cùm icaque, uri jam percepifti, corpus folare profunlifinum fit, ejusque femidiameter, quấ centrum contingic , ad lecem millia horariarum leucarum excurrat ; interiorem toius compagis ftructuram aliis $\&$ aliis qualitacibus imbutam ese necefle eft; quas quidem imposfibile eft ut exerat, nifi per unlantis liquoris continuum quendam per interiora Solis vifce-Solnowest a agitatum pericyclofeos motum : hinc enim liquor ille coele-folzdus per tibus partium latentium, quibus tingitur, qualitatibus imbutus, innumeris ircutem imbibicam ad exteriorem promovet fuperficiem, ut rimis $E$ innde per inficam fibi radiorum novâ \& novâ virtuce tinctorum nalibus peraculcaten, eam fummo fubfolaris œconomia emolumento tufus. liffundere poflit. Atque hoc verum efle, tunc parebic, ubi de nodo \& ratione luculentiùs me discurrentem audieris. Ad uid enim aliud Natura motu Solis, uti \& plerorumque alioam globorum circa proprium axem facto intendit, nifi ue sol cur cirmunc has, nunc illas folaris fuperficiei partes obvertendo, fin- ce propriz ulos globos, terrenum potifímùm, diversâ virtute imbueret ? centrum uod nifi hac de caufa factum fuiffer; fruftra fanè hac Solis cira proprium axem circumvolutio inftitura fuiffet : hac enim. $i$, ut Oceanum folarem, quem motus diurni rapacitas plus quo relaxat, motus circa axem continuus colsibebat; fitque, ut olluctantibus fibi obviis undis ingens \& immenfum liquoris ceani pondus preffum, \& per fubfolares cuniculos intromisum, inde latentem liquorem fuâ jam virtute imbutum per opoficos canales, fummâ vicisfitudinis lege, fummáque, in tanta lementi inconftantia, ftabilitate ejaculetur. Summo itaque Jaturæ confilio factum eft, ut globus in perpetua quadam mo-

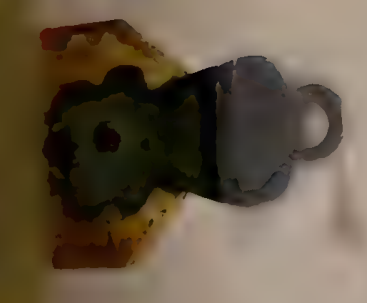
mobeatur?

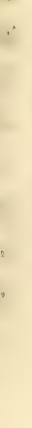


Delagus fo- cuum vehementia agitaretur: : hinc enim, præcerquàm quòr lire cur calor æeftusque folaris intendatur, vires quoque \& panspermia perpetud onoheatur.

feminaliumque rationum poteftates excitatæ;, mundoque infe riori communicace, innumerabilem illam , quam admiramu. in terreno Mundo, varietatem producunt. Et Et juxta perfe Ctas analogix leges rem penitius examines: , idem in terrea globo, fuo modo, \& in fingulis aliis mundanis globis fieri de comparstio prehendes. Ad quid enim Oceanus: terrenus tantâ tumul motus mas
ris cum So-

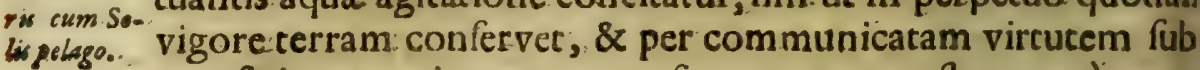
terreftrium partium naturam foveat; terreftres veró parte diverfifimis. qualitaribus. imbutre ipfum quoque aqueum ele mentum virtute fuâ imbuendo officii reciproci munus obeant Hinc Oceanus per fubierraneos meatus canalesque abforptus hîc per fontes, ibi per flumina, alibi per lacus, ftagna; palude eructatus, diverfisque coloris, , faporis, , odorisque proprietati bus juxca naturam terreftrium parcium, per quas tranfit, imbu. tus tandem fuo reftituitur principio, Haud fecus in Sole fie ri exiftimabis. Optandum fanè,ut Philofophi tum variis fui: conjecturis \& fpeculationibus, tum experientiæ, \& analogia Ars anslo-rerum animum fuum intenderent: Eft enim ars analogica mi. gre in quo rum quoddam compendium, quo veluci ad A riadnx filum. guis, confe- ductus Philofophus, fine periculo in abdita Naturæe penetralia rat. admitcitur per hanc tandem difcit, ut qualis in terreno glo. bo, qualis in microcolmo homine Mundi filio, qualis in politico, meteorologico, medico, ethico, rerum conftitucio, talis in omnibus \& fingulis Mundanorum globorum fyftemaris fuo modo \& condicione confiderata reperiatur. Qux itaque in

Omnia in omnibus. funt. terreno globo inveniuntur conditione terrena, illa in Sole conditione folari, in Luna: lunari, in: Venere venerea, \& in Mercurio mercuriali, \& fic de cæereris usque ad ulcimum Mundi corpus eâ conditione ineffe xftimari debent; qux talem \& talem, naturam cum primis decet. Theodidact ss. O quàm abdita ez divino tuo difcurfu percipio! jam enim video verum effe illud 
divın Dionyfii epiphonema, non tankùm fingula Mundifenfibilis fyitemata, fed \& infenfibilis, imò intelligibilis Mundi fabricam ad fimilitudinem \& analogiam fupremi archetypi factam :fle, in quo à fummo usque' ad infimum ens abfolutiflima quardam proportio, \& perfectus fingulorum ad fingula refponfus omperitur; atque adeò, uti S. Paulus teftatur, invifibilia per ea jua facta funt, intellecta confpiciuntur. Si itaque continua inilibilıum ad invifibilia quxdam fímilicudo \& analogia exiftac, juantó magis inter nundanorum globorum curporeas fubftanias eam incercedere exiftimandum eft'?

VII. Sed obfecro te, mi Cofmiel, éntne igneus ille glous verus \& realis ignis? Cofmiel. Imò veriffimus \& realifimus risis Gerus \& rnis, isque uti lucidiffimus, ita ardentifimus eft : neque enim elemenstaris liud in nacura elementum ignis datur, nifi is quem vides: hic igní. nim totum Mundum fubfolarem calore fuo fover, nutric, cafacit ; imò terrenus ignis (qui quidem nil aliud nifi vapor flammarus dici poteft ) ut fic, $\&$ in effentia fua confervetur, uic coelefti igni acceptum ferre debet. Theodidactus. Sed nofcuperem, cur liquidum hunc ignem natura conftituerit, on verò flammarum! pyramidibus in altum undique exfurentem ? Cofmiel. Scias fili mi, globum hunc, quemadmoum omnes cateros , duplici elemento conftitutum ; primò Siructura' bêtanciâ quâdam folidấ , qua terreftre non incongruè refe- globi Solario t elementum; deinde liquidâ, , quax aquam, tametfi ea proiè aqua non fic, fed igneum, idque efficaciffimum \& lucidiffi- um elementum. Sicuti verò liquor ob continuas ebullitioes \& circulationes hinc inde agitatus multò efficaciorem colo$m$ xftumque continet, quàm fi flammeus tantüm foret, uti: periencia in fornacibus xre fervente bullientibus docet; ita! eliori fanè confilio eum liquidum, quàm flammeum, natura Sol cur ks. inftituit; fiquidem liquor agitatione perpetuâ, uti in fabro- guidd ma-. m ignibus vehementi folium flatu commotis pater, concita- terid cone. $s$ rale incrementum fufcipic, quale ad orbes fubfolares calore undè forendos fufficiat. Accedic lucem in liquida hac ma- 
reria multò flammeâ intenfiorem effe. Num aliquanido ex pertus es, quàm vix ferendâluce liquefacti æris fufio oculos intuentium perftringat? Theodidactus. Vidi, \& intenfiorem in inferiori Mundo lucem non puto reperiri, Cofmiel. Retè fentis. Cùm itaque natura precipuo frne hunc globum confticueric, uc terrenum orbem calore \& luce perfunderet; id isnè meliùs præitare non potuic, quàm liquido fervidi ignis, \& intra vas veluci conclufi, perpetuòque fe circulantis elemento; Natura cur quod quidern, fi.flammeum efler, fieri nullà ratione pofler. De liquidwm ignem in Solepofine. materia verò fólida jam dixi, eâ fe ratione ad liquidum habere, ris.

quâ terreftris ad aqueam fe habet fubłtantiam; maceria fiquidem Solis lapidea, tametfi ex fe \& fuânaturâ ignea minimè fic, ingentem tamen igneo illo xftuantis Oceani elemento calorem pariter concipic, adeoque ficut in terreno globo carbo fuccenfus, aut ferrum igne candens, ad ignem flammeum fe habet, ita fefe habeant folidiores folaris globi partes ad igneum liquorem, quem veluti vafe quodam continent. Addo, fcoputos illos montesque, quos tantopere miraris, quosque tam inufitato lupra omnem carbunculorum, pyroporum, chryfolitho. rum, aliorumque precioforum lapidum fulgorem longè excedence fplendore corufcare vides, lucem quandam incenfisfimam naturâ fibi inficam habere, ita ut nullus mortalium nec caloris vehementiam, quâ fervent, nec lucis fulgorem nimium, quo corufcant, nifi divino adjutus prefidio, quo tu munitus es, fuftinere poffit. Et fanè vel ipfo experimento veritatem. rei in corpore tuo facerem, nifi tui noffem animi imbecillitatem, auc promiffion is tibi factæ memor eflem, de non inferenMateria fo- do tibi ullo vita periculo. Theodidactus. At rogote, mi Co Lidasolis non aduri. Surigne solis. fmiel, cur materia illa folida cantâ ardoris vehementiâ non aduritur? Cofmiel. Ne mireris, fili. Cur Ainna \& Vefuvius tanco jam tempore perenni igne arferunt, \& tamen à tot annis montes adhuc perfeverant? quemadmodum enim nacura arctis amicitia legibus ea fimul in unum colligavit, ita \& folidiori materix Solis vim quandam omnis combuftionis expertem indidics materia fiquidemá oßs ós eft, id eft, incombuftibilis ad in- 
tar asbeftina materiæ, quam \& tellus tibi affatim fuppedicat. - errè quæcunque dixi, vera effe, vel ipfa facri texcus pagina Eclefiaftici cap. 43. apertè docet his verbis: Vas admirabile, opus $x$ xelfs, in merideano exurit terram, \& in conßpect $u$ ardoris ejus wis $\int$ wofinere paterit? fornacem cuftodiens in operibus ardoris: replacier sol exurexs montes, radios igneos exfufflans, \&? reulgens radius fuis abcacat oculos. Quibus quidem verbis nihil xpreflius, nihil ad natura Solis paulò antè à me factam defcritronem aprius \& congruentius dici poreft. Theodidactus. Non it , Cofmiel, ut id mihi perfuadeas; veritatem rei non tantùm culis perluf culis perluftro, fed \& manibus tango. Video quoque, omnia lis, igneum omina hebraa, quibus Solem appellare folent, ăb ipfo huma- effe notant . $i$ generis parente in paradifo divino quodam inftinctu impota, hoc docere : quid enim Schemefo, id eft, Sol, aliud docer, uàm ibi igncm effe? quid tiamma, nifi xftum ? quid aliud berefc, nifi ardorem indicat intenfiffimum? Quin Sancta Maer, Ecclefia, cujus proprium eft de fenfu Scripturarum fenentiam decidere, ucpote veritatis Magiftra, \& infallibilis deetminacrix, id apertè aflerit in hymno fuo: 2uarto die, qui

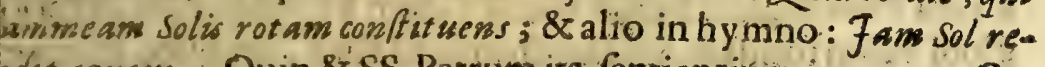
drt grvers. Quin \& SS. Patrum ita fentientium integrum Calogum atcexere poffem, fi non jam id Rofa Urfina abundè rafticiflec. Qux cùm ica fint, quis impofterum de veritate rei ubitet.

VII I. Porrò reftat dubiumì non leve', cujus folucionem ut nihi praftes, etriam atque etiam rogo, quomodo videlicer Periatecicorum fententia de calore emin̨enter tantúm Soli infito utelligenda fit. Cofmiel: Non nelcio, multosolim, \& nunc quosam Philofophos effe, qui hanc fentenciam pro aris \& ficis lefendant ; verúm, cùm meraphyficis tantùm abstractionibus. nfiftant, nec ullo experientia \& coelefts doctinna fubfidios olleant, parum illis fanè deferendum eft. Quornodo enim Sol an emb inl eminenter tantúm, uti Scholx paffim loquuntur, caleface- nenter tanet, nemo facilè compreheriderit, cùm nemo det, quod non ha- rem haberàt. et; eminentialis autem nec propriè, verè, \& realiter calor eft, 
nec ullos in Mundi œconomia inflammationes effectus prodi cere poreft; quomodo enim calor formalis ab agenre formal ter non calido, à Sole inquam, in inferioribus producatur, qu concipiat? Theodidactus. Quin imò vinum \& piper, atque adeo omnia fummo gradu calida formalem in ftomacho calc rem producere jam ab ineunte xtate in Scholis.edoctus fui , ut proinde Peripateticorum fententiam minimè vanam haben dam exiftimem. Cofmiel. O quantum à fcopoaberras fili mi Imaginare tibi piperaceum globum Solem effe; quæro ex te quid faciet ille globus? terrámne calefaciet fui eminentiâ calo ris,an non ? cerrè non plùs calefacerer, quàm glóbulus quispiar piperaceus manu geftatus, quem tamedfi frigore penè exanima tus integrum diem, menferm, annum aut manibus aut collo in fercum geftares, non tamen plùste, quàm Cryftallus, aur quod libetaliud faxi genus, calefacturus eflet. Theodidact us. Verun eft , fi extrinfecè eum corpori applicem, fed globulum pipera ceum mox in ftomachum fumprum magnum continuoo aftun excitare, notius eft quàm ut dici debeat. Cofmicl. Quantum à vera Philofophiz femita abeffe video: Ergóne rellus,czeterigu globi veluti totidem quidam ftomachi, funt, in quos folarium virtutum radii infufi, calorem formalem in globis excitant? ( lepidam philofophandi rationem ! quis, rogo, in piperaceo gra no radios, qui formalem in aliis à fe difficis corporibus caloren producant, concipiat? tam enim ad hoc præettandum glacia lem globumidoneum, quàm piperaceum effe exiftimes. Theod Ignofce, rogo, ignotantix mex, ô Cofmiel, neque imperitis fer. monibus meis irafcaris tibi enim tanquam naturx arbitroo mnia fubjicio, tibi in omnibus fubfcribo, neque hilum quidem ab inacceff fapientiæ tuæ documentis recedo: quis enim tib omnium arcanorum natura confcio non credar? hoc unicur efflagito, ut quomodo eminentialis caloris piperacei vis in fto. macho calorem producat, edoceas. Cofmiel. Faciam, quod pe Jumporiman tiifti.Scias itaque, in corporibus nonnullis latentem calorem. extra certa vafa nihil prorfus poffe, penitusque torpidum emor tuumque effe, utpote nullâ virtualiuma ationem facturâ radian. 
$\mathrm{cm}$; fed mox ubi in ftomachum piper transmifum fuerit, id ion ram calore virtuali calorem in ftomacho laticantem prolucere, quàm etundem in humani corporis vifceribus ftabulanem excitare, fpirituumque vitalium mifcellam commovere, $x$ quorum impecuofa commocione tandem calor ille, quem encimus, neceflàriò confequatur. Exemplo me declaro. [nem affrictu chalybis \& filicis facilè excitari nonti ; fi tamen teò chalybem aur filicem eminenter calidum dixeris, eò quòd 5nem exciter, certè fummopere hallucinaberis; quòd isaque tuo hac corpora ex affrictu ignem eliciant,non eft caufa,quod cerutrum holum ignem in fe five eminenter, five formaliter ontineac ; quis enim hæc auc in chalybe, aut filice ineffe conpiat? led caufa eft vehemens aëris igne fori elifio, quam in silex chace ammatio neceflariò fequitur; quod non folùm in filice, fed lybe percufel in frigidifima glaciei mole fieri experientia docet. Cùm do quomo aque Sol fons luminis fic intenfifimi, \& cuncta,ad qua ipfiuseliciat. dii pertingunt, corpora \& objecta eis illuftrata, mox calorem rmalem fentiant; quis neget, fontani luminis origini calo$m$ multò majorem intenfioremque inefle, cùm totum, uti culis tuis hîc coràm intueris, in hoc lumen condenfatum conobatumque exiftat ? Si enim lux debilior \& extenuata ab hoc obo folari emiffa tancam habet vim remotiffima etiam objea incendendi, calefaciendi, atque in eis calorem formalem. oducendi ; quid obfecro ergo virium lucem in ipfo hoc ieo elemento obcinere putas, ubi tota fimul intenfiffimè vei in caloris \& lucis quodam gazophylacio conglobata convarur? fieri autem non potelt, ut ubi lux eft, ibi calor abfit; od \& magnum Ecclefia lumen Auguftinus Serm. 59. agnohis verbis: Sol, candor, É calor, El tria funt vocabula, of tria sum; quod candet, hoc calet; quod calet, hoc candet ; tria bac cabula res una dignofcitur. Ubi certè non de eminente Socalore, fed formali loquitur. Eft itaque lumen nihil aliud, fi igneus quidam effluxus, ex ipfo Solis corpore in objecta fibi rpura propagatus, atque adeò ejusdem cum fonte, unde proIxIc, natura; quod experimentum tibi familiare fat fuperque Dd Docer: 
docet : dum enim per vitream lentem, diffufam radiorum vil in unionem cogis, ligna aduris, plumbum liquefacis, aliosqu hifce fimiles mirificos fanè uftionis effectus praftas; cerrè ing! nii oppidò obtufi, nè dicam ftolidi foret, qui uftionem hanci nef́cio quem vircualem calorem conjicerer, Hæc omnia fufii deduxi, non quòd de rei veritace te dubitare viderem; vides enil hîc propriis oculis immenfum, inftar concinuò ebullientis \& fe ventiffimi aris, lucidiffimique ignis, pelagus. Theodidact us. Igni um hunc globum efle, exceffivus calor, quo tantùm non exan mor, \& lux incenfifima, quâ cantùm non excæcor, lat monftran neque ego unquam de iis, qux hucusque expertus fum, dubitav fed ribi nonnullorum Philofophorum objectiones proponend: duxi, uc tuâ eruditione inftructior, quomodo is obviare quean à ce divino meo Magiftro difcerem. Cofmiel. Sed jam paulò mi jora canamus, ad nova te incroducam divinorum prodigioru: penetralia, ut fic tandem per partes, totius naturæ nucleum eruamus.

\section{SCHOLIUM IV.}

TN fequentibus pulchrè E' folidè explicat originem \& cauf ans m. cularum ac facularum folarium, of, que affert, adeo funt ves philolophandi rationi ac veritati confona, ut qui Solis naturam igneam defendunt, fecure bane de maculis ac faculis doctrina amplecti queant. Qua nos Juprai in Praluf. f.s.de is dem diximu $a b$ bis non difcrepant.

\section{S.II. De maculis, faculis, umbris, cateris que mirsficis in sole portentis.}

IX. Cofmiel. Agedum Theodidacte, progrediamur tat dem ad fumma \& inaudica terrigenis hujus globi portenta pes luftranda. Theodidaclus. Hoc dicto, asbeftinam naviculam quam in folidam globi folaris continentem exeuntes reliqu ramus, poftliminio ingreff, per ingentes \& innumerabiles bullutionum voragines, per humano veftigio inaccefla hucuss 
tuaria delaci, ea vidimus, qua morcalis oculus à primıs Muni incunabulis non incuicus eft. Sed ô Cofmiel, rogo te per visera mifericordia Dei, nè me derelinquas; adjuro te per nosen Deialtifimi , ut tuâ me protectione munias ; Ecce enim. imio terrore \& ftupore tabefactus animi corporisque viribus eficio. Cofmiel. Magno fis animo, Theodidacte, nec quicuam eorum, qua vides, prodigiorum meruas; recum enim. im, ut teab omnibus eruam periculis, ut te doceam ineffabilem ivinorum operum magnitudinem, ut ex ea infinicies majom fapientifimi Condicoris omnium immenficatem admire$s$, admiratam cognofcas, cognitam ames, eoque tandem in arnum fruaris. Theodidact us. O Cofmiel, fi opera fummi Conitoris tanta \& cam admiranda func, quid non is eric , qui uti ex ihilo folo verbo produxit omnia, ita ad divinam ejus immentacem comparata, nihilum funt? Moriatur, qualo, anima mea corce juftorum, ut cum videam, per quem facta func omnia.. - cujus verbo confticuuntur omnia. cofmiel. Necdum temus advenir ; feftina parumper Theodidacte, nec enim vel miimam adhuc operum divinorum particulam contemplatus? Theodidactus. Fiat icaque voluntas ejus, cujus me arbitrio to- Plubie m, quancus quancus fum, permitto.Sed ô Cofmiel, quid fibi gignea ik uit ingens pluvia illius ignea nimbus? quid metuendus nimis nnea tempeftacis curbo? quid vapor elacus in altum, termini efcius? quid flammarum in hoc æetuanti Oceano, ignearumue ebullitionum tumultuantium conflictus ? Video hîc flampas, quibus lucidius \& fplendidius quidpiam in natura rerum, oncipi non poteft ; fed \& continuò veluti nebulam quandam enfifimam, qua caliginem non exiguam offundat? Quis unuam credidiflet, auc quis terrigenis unquam perfuafurus fuif$t$, in lucidiffimo hoc Mundi oculo, in puriffimo lucis fonte, teebras cum luce, lucidum cum obfcuro, caliginem cum luce oonium intenfisfima cam ftrictum mutuæ amicicix foedus peigifle? quis lucidum ex tenebrofo, \& hoc ex illo produci, in onnium purisfimo, Terrigenarum opinione, Mundi globo conipiar ? quis mihi fidem habebit narranti, augmentationem rei

Dd 2 mini- 
minuia maximam, diminutionem fummam \& velocifliman mox confequi? O fi Philofophi mirandas rarefactionis \& con denfacionis viciffitudines, arque ex alceratione perpetua incon ftantia fumma junctam fummam ftabilitatem, opacitarem. maximam cum fumma ambientis perfpicuitate, continuam. mutationum fuccefionem fine ulla aut redundantia aut dimi soleve cor-nurione apparente, Solem præterea eundem femper, nunquan fus maxi- camen eundem intuerentur ? quàm aliter de doctrina coleft mionibus ratiocinarentur. Cerrè functè affirmare aufim,nullum in Uni - bnaximm verfo corpus tot alterationibus \& vicificudinibus obnoxium fit. ac hic pratens globus eft, reperiri. Video quidem diftınctè 8 intuitivè omnia hujus globi portenta, fed rationem tam pro diginfa foetura non capio; unde tam vehemens ebulliencis ar doris vis originem fuam crahat, mens animusque deficit. Qua re te, ô Colmiel, fanctioris arcaniorisque naturæ interpretem unice exoro, uc intellectum meum debilem \& imbecillem ape ri.s, divini Numinis me lumine perfundas, ur ex tam infolenti bus natura effectibus ad veras corundem caufas percingam. $\mathrm{cof}$. miel. Filı mi, uci te tenerrimo amoris affectu profequor, ta fiet non poteft, ut votis tuis non fatisfaciam; atcende itaque, arre
.. Risque ambabus auribus, qux tibi deSolis hujus arcanis aperturu Solis pra- fum, accipe. Quemadmodum in hoc Univerfo \& Mundo fenfi pantia. bili Deus mortalium generi , \& coti huic elementari machina quid piam Sole praftantius non dedit, cujus concurfu omnia ge nerantur, \& confervantur; ita fua fapientiæ poteftatisque quaf quoddam compendium in eo pofuiffe videtur; undè rectè : $1 \mathrm{~s}$ sole pofuit tabernaculum fumm. Nam fiea, qua inter fe contraria aut pugnantia apparent, uti fuprà quoque tu præmonuifti, ue piam alibi, profectò in boc admiranda virturis globo fapienciffimè \& lupra humanæe intelligentia captum idem rerumo. mnium prudentifimus Opifex colligavit. Sol ergo corpore rum ignium ignis eft primus, \& verum ignis in hoc fenfibil Mundo el mertum; uri fuprà dixi, empyrei Mundi imago,primavique \& luminis \& caloris lux compactifima, ignısque forrenulfimus atque ardencillimus ; Radii verò, qui exeunc $a b c 0$ 
funt ignes fecundi,recti, acuri, penetrantes, urences, quali à denra Solis mole ieftuantes ; lumen verò à radiis eft quafi ignis tertius, \& famma in exilisfima quafi materia leviter fuccenfa. Et guamvis in terrenis flammis lux à calore diverfum quid effe videacur, nibilominus in hoc purisfimi Solis globo necefle eft, acc omnia, lucem, lumen,ignem, caloremque idem effe. Talis" trgo cùm Sol fit, \& radii ab eo immediatè diffundantur, \& lunen ab his emicet; per hac veluci per inftrumenta quadam. fircucum furum propaginem in omnia inferioris Mundi corora cransfundit. Eft enim Snl, Sancto Dionyfio tefte, à fumno bono \& bonitatis corporea imago, \& bonitatis illius, quanum corporilicet, in corpora transfufor. Nam ficuti à bono lumen illud primxvum femina rerum omnium funt transufa, fic à Sole eadem rerum femina per radios, perque lumen, th inferiora transfunduncur. Intelligentiis globi præfidibus? nicè cooperantibus, \& per fpiritum toti folari corpori transfuum omnia in onnibus peragentibus. Atque hic eft fpiritus? le, de quo facra memorant eloquia : Oritur Sol, E occidit, luransuniverfa, is circuitum pergit piritus, Ecclefiaftis 1. Luemadmodum autem intellectus feiptum inzelligendo, fpeies \& ideas, qua in ipfo func, incelligit, \& intelligendo operaur, hoc eft, in animum fibi conjunctum \& fpecies eas earumue notiriam transfundit, animus verò in fpiritum vectorem. mnium agit fic fpiritus fpecies in corporum tum eflentias" um vires transfundic, unde actiones omnes prodeunt \& proeuntes res ipfas ad fui imitationem generant. Idem de Sole ntias velim; cujus Intelligentia dum ideales fpecies in fe reolvit, intelligendo fpiritum mox in omnibus \& fingulis folaris lobi particulis latentem inftimular, unde fpiritus fimulatus? xcicatusque incorpus, \& corpus vires \& actiones extra fe difandic; atque hoc pacto tandem res, qux à Sole gigni dicuntur, enerant omnes. Sunt autem Solis vires, lumen \& calor ; \& ream femina à lumine fuo recta \& in corpora hac devecta, \& a nerationis lore invecta \& fata, caufa funt generacionis rerum omnium, rerumoua in hoc lenfibilis Mundi theatro fpectantur. Lumen enim, mnium.

$$
\text { (1) }
$$

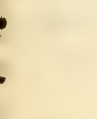

.

, $\cdots$ 


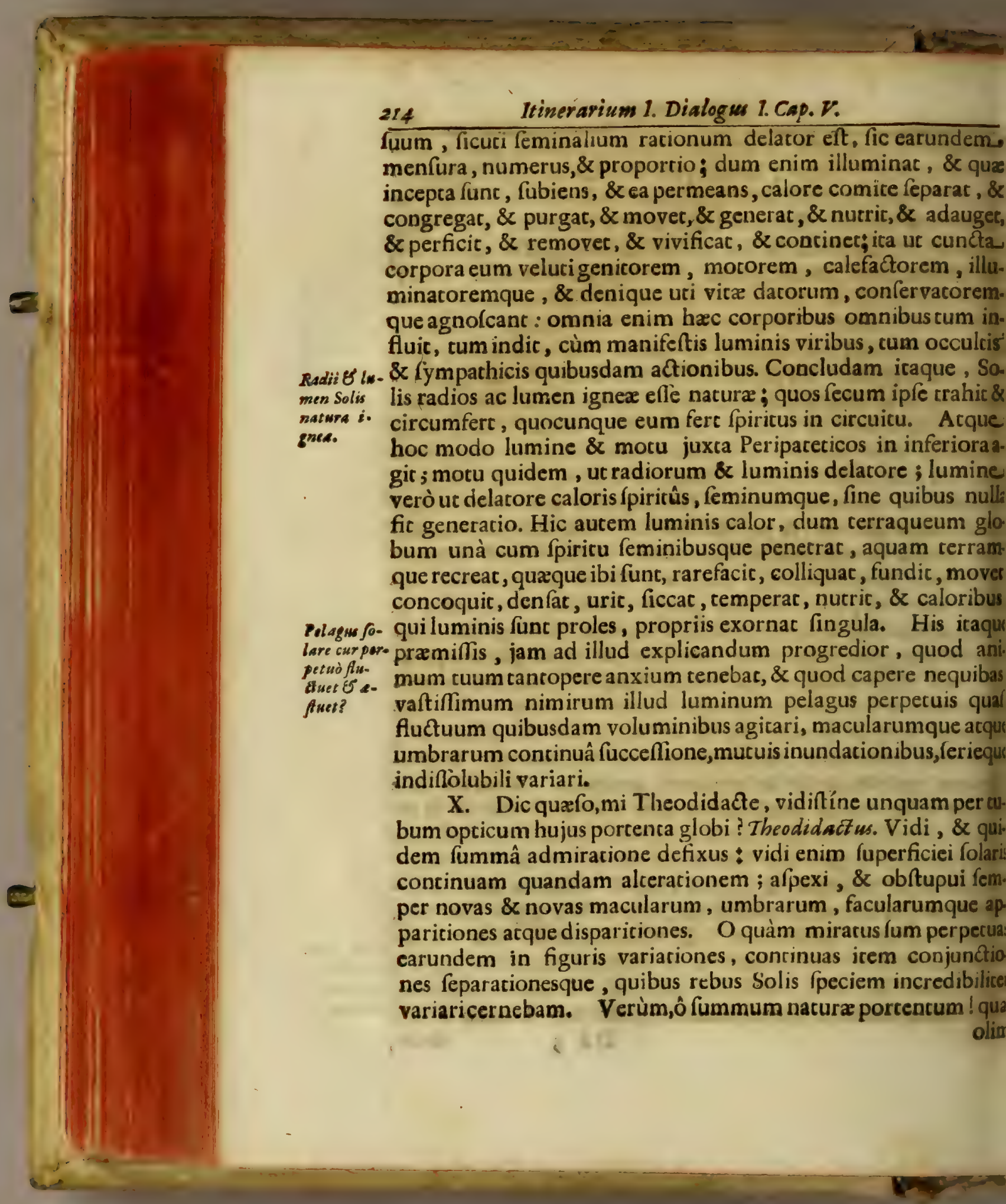


olim à terreno globo abftractivè contemplabar, modò intuitivè perluftro; videa modò hîc coràm, \& percipio macularum; facularum, umbrarumque effectus; fed, unde originem fuam. ducant, me latet. Quare,ut mihi tantum natura myfterium. pandas, mi Cofmiel, fupplex, \& eâ,quâ poflum, humili mentis

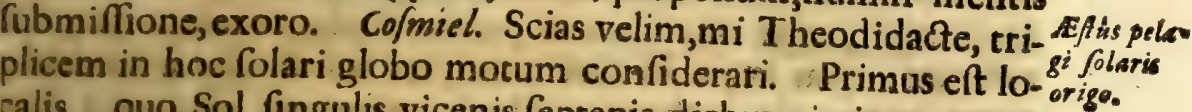
calis, quo Sol fingulis vicenis feptenis diebus circiter, unam sirca centrum proprium revolutionem conficit; \& hujus conerfionis beneficio, quidquid lucis, quidquid vircutis radiofe continet, fucceflivâ quadam propagatione tam in terram, juàm circumfitos fibi globos abundantifimè effundit ; qua quidem circumvolutio non fimplex, fed compofita eft ex anua circumductione axis mobilis, circa quem prior motus decribitur; quo fic, ut Sol circa fummitatem Borealem, \& deoffionem Auftralem, verfus terram annuat fex menfium Sole sropatio, \& abnuat ab eadem viciffitudinariâ polorum \& axiumplıx. nobilium apparitione fupra horizontem folarem, \& occultaione infra eundem. Ex quo quidem neceflariò fequitur, Som totum terrenum globum tum per annuam circuitionem, um mentruam, novâ luce diverfis feminalium rationum foeuris imbutâ afficere. Secundus motus eft folaris pelagi per abfolares cuniculos regurgitancis circulatio, quorum quidem xeandrorum canaliumque cùm innumerabilis copia fit, non iraberis, faciem folarem terrigenis tam variam afpectari, tor mbris obfulcari, tot tenebris involvi, tot lucibus fulgere, toe laculis deturpari ; fiquidem quot eructationes ex fubfolarius globi vifceribus contingunt, tot maculas, tor umbras nafoi Infeas. Macula autem, quas è terreno globo frepe intuitus Macule in , hoc pacto nafcuncur. Ouando per incimos folaris corpo Sole quemo- in 5 maandros fic regurgitatio, denfus ille xituantis liquoris do mafuaro apor, altum petens, æetherem fuâ denfitate obfufcat, oculosque rrigenûm impedic, nè Solis fülgorem videant, atque adeò b macula $f_{f}$ ecie . fectatur : cùm verò ejusmodi vaporum eruationes per univerfam Solis fuperficiem innumerz fianc, $+1$

maculas 
Canfa ma- maculas quoque innumerabiles fubinde videri necefle eft; va cularum, fa ularum, tambrarum poribus verò in alciora æecheris loca delacis, rarefactisque, fub.

' fequens vehementis ebullitionis. fplendor fub forma intenfiff. ma lucis fpectacur, quam cu faculam nominare folebas: quan do verò circulacionis motus retrotrahitur, voragines quadan fpectantur, que ob fummam profunditacem umbras quasdan referunt, quas tu paulò-antè tantopere mirabaris: quando de nique vapor ille vehementiflimâ agitatione ejaculatus ma gnam liquoris partem fecum in alcum deducic, tunc is gravita. ce praponderans per igneas gutras in globum delapfus fuo re ftituitur principio; vapores verò ignei in altum delari, ac con cinuò impetum moti Solis fequentes, nunc in ingentes nube ab humido igneo defoccatæx, raritate fuâ explicantur, jam ice rum in minuriores portiones diffipantur, donec tandem Soli virture attractx denuò,unde deducta funt, redeant; atque hoi pacto macularum , quas miratus es, fiunt nunc apparitiones nunc difpariciones : quoniam camen fubinde adeò glucinos: conftanc materiâ , ut in altius fpacium, quàm ut motum Soli afièqui poffint, fine diffipatione unicæ deferantur; fir, ut liberc motu per mobilia xtherei fpacii inania hinc inde delacx in co metas convercantur, de quibus poftea pluribus tecum agam Theodidacf us. Jam caufas macularum, facularum, umbrarum que quas fummâ meâ admiratione ex cerreno globo olim in. tuicus fum, adeò ad oculum demonftrafti, ut de generacione earundem nullum mihi prorfus dubium remanear; jam apertè cognofco, quomodo illa nafcancur, crefcant, minuancur: quomodo macula in faculas, \& ha ie illas transformentur; quid fint portenca umbrarum; \& quanam tandem omnia illa coleftis hujus globi , qua tantopere Aftronomorum ingenia nullo non tempore á prima illarum decectione vexarunt, ludi bria fint, præiens afpıcio; video luculenter, cur fubinde adeó glucinof materix conjugio compacta fint, ut à Sole tracta cum integra fua circa axem proprium revolutione peraहta, fine ulla diffipatione integræ denuò compareane; caufam quo que percipio, quomodo in comeras, dira mortalibus oftenta :

conver. 
onvertantur. $\mathrm{O}$ quàm jam miror Aftronomoruni Phy fic orum? - fant fella ue quorundam varias conjecturas, dum omnes hujusmo- circulis suis imaculas, ftellulas quasdam fuis propriis orbibus affixas, \& $\&^{\ln \ln f a_{0}}$ irca Solem circumlatas exiftimant: fi enim ftellula , quomodo tm citò modò alix \& alix nafcuntur, modò pereunt? Jam apertè ognofco, nullam philofophandi rationem fine pravia experiena fubliftere pofie.

XI. Sed quoniam immenfo tantæ veritatis gaudio \& volutate afficior, neque faciari poffe videor. veritate adeò mirabium rerum ulceriùs inquirendarum; Te,mi Colmiel, quem niil corum, qua in abditis naturx chefauris conduntur, latere ovi , ctiam atque eciam rogo, ut paucis ad nonnulla mea quaca refpondeas. Cofmiel. Nihil adeò mihi volupe eflè poteft, uàm ut votis tuis, \& laudabili curiofitati quovis modo fatisfaam; perge itaque confidenter interrogare, ad hoc enim tibi solare corinctus fum, ut interpretis munere fungar, \& tu de omnibus pus inter -acura arcanis hucusque occulcis quàm uberrimè ad omnipo- mania prantis Dei gloriam \& honorem intruaris. Theodidact us. Quidam , rogo , củm Deus Optimus Max. \& natura nihil fruftra cerint, quid, inquam, indicat tam infolitus innumerabilium. ortentorum in hoc globo elucefcentium appararus ?q quas utitaces Mundo, aur quos fines INatura fagax hisce intenderic, fcicupiam. Co/miel. Ult itaque altiùs exordiar, notandum tibi rimò eft, Solarem hunc globum inter corpora Mundum conicuentia quid praftantifimum efle, ut ipfo oculorum intuitu onvinceris : eo enim tanquam inftrumento univerfaliad fubnarem Mundum potifimùm uticur magnus ille Univerfi ondicor, Deus Opt. Maximus, unde mirum non eft, illum ram dmirando artificio conftructum, toc nacuræ portentis odoracum, ram inviolabili influxuum lege, in tanta inftabilitate onftantifimum perfeverare. Eft huic globo triplex à nacumocus infitus; prior eft diurnus, annuus alcer, tertius menruus. Prior motus, quo fpatio ferè diei naturalis, id eft, 24 . Dis motus, orarum, fuo in circulo univerfum telluris globum ambic, ad ejusque effsicifitudinem dierum \& noctium, ad quietem animalium la- cim. 


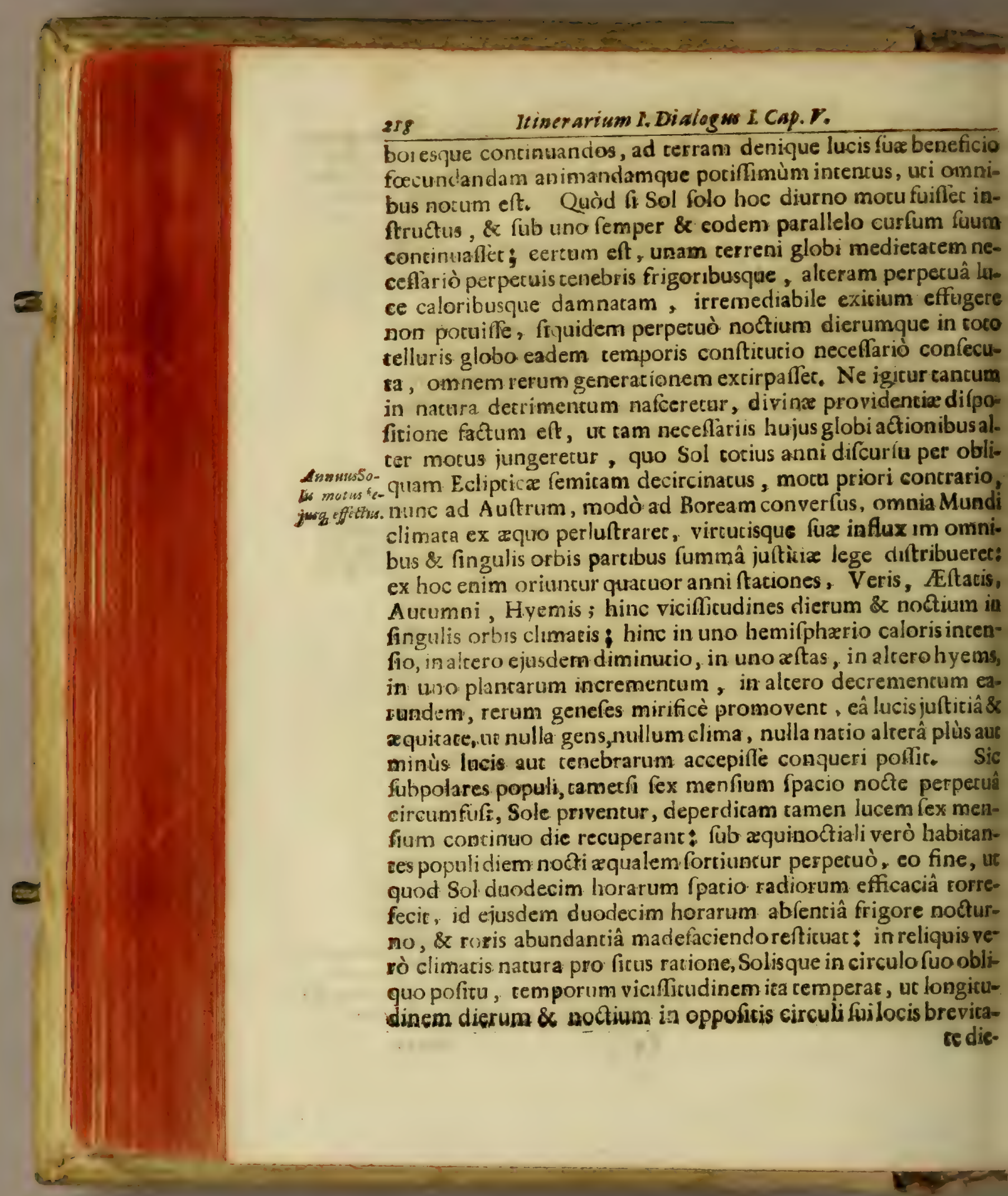


: dierum noctium recompenfer, atque ideo in omnbus rbbis limatis, rantum femper lucis, quantum tenebratum, tarium tenebrarum, quancum lucis, mirificâ quâdam fymerriẩ

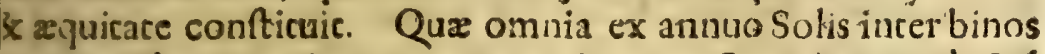
ropicos decurrentis mocu proveniunt. Quoniam verò Sol n rerrenum globum non luce tancùm \& macu, uri fuprà quozue demonftratum fuic, agit, Ced \& in eundem perpetuô mulciilicem feminalium virtutum, quibus imbuitur, nixturam inluic, folaris verò globi averfum à tellure hemifpharium, fi immobilis foret, minimè terram ferire, eique vim fuam commuicare poffet ; hinc divinz fapientia dictamen ei tertium adunxir motum, qui eft mentruus ferè, quo Sol 27. dierum fpa- metras Sali io circa proprium centrum axemque circumvolvitur, ne ulla ejusg, effeblaris globi portiuncula otiofa videretur, fed ut menftruo fe. chus, è fpacio univerfum telluris ambitum, obrerfis in eam fingulis sis partibus, fingularumque partium aliâ \& aliâ vircuce imbuurum profluvio bearec. Quoniam verò feminalium ratioum in Sole abditarum virtuces fine ingenti commotione exri non pollunc; hine iterum fummâ \& infinitâ Dci fapientiâ rovifum eft, ut folare pelagus ingenti \& inceffabiliaftus veementiâ concitaretur, atque per vaftiffimos interioris fabricæe taandros circulatum, virtures latentes ex centro ad circumrentiam devolveret : \& hinc eas per radiorum circumfufioem circumfitis Mundi corporibus communicaret. 'Sunt au$m$ in hoc ineffabili globo innumeri hujusmodi meatuum reeffus, quibus univerfum corpus à natura perfoflum eft. Atque oragines quidem \& horridi vortices, (quorum intuitu tanim non exanimatus es) pelagi ignici abforptionem notant, quoim profunditas uti nonnullam obfuritatem exhiber, ita à terno corpore vifa, fub umbrarum nomine indigitantur, Quan-Macule o verò vehementi eructatione \& ebullitionis imperu, quod ab-facu:a Solat rptum eft, regurgitacur; tunc terrigenis hujus tam exceffiva $x^{\text {unde profe- }}$ uctationis vapor ignitus ad inftar furni zeftuantis eructatio$c$, in folari atmolphara condenfatus, veluti macularum in fuerficiem Solistemerè difperfarum fpeciem exhibet. Quia ve- 


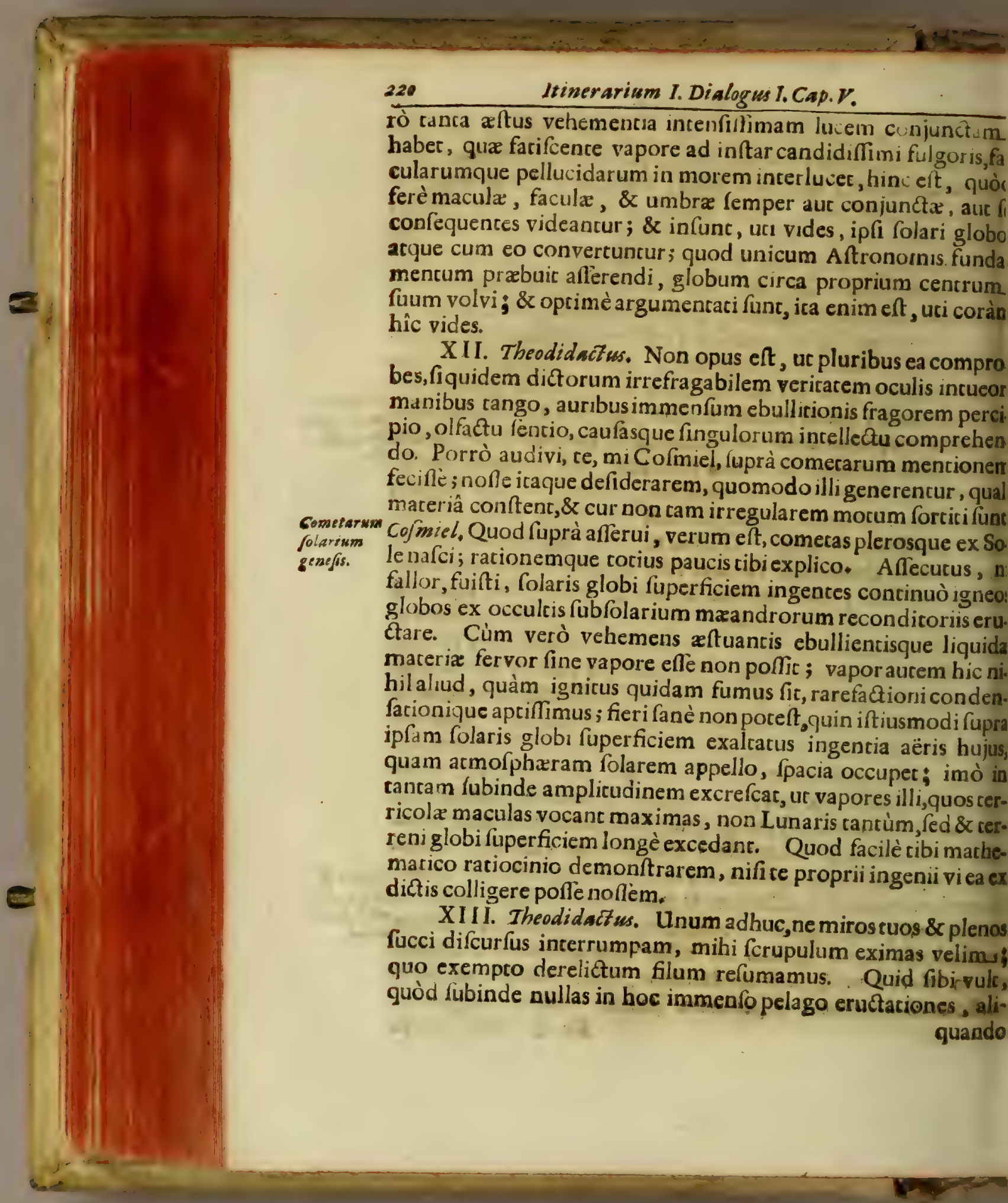


juando plures, nonnunquam innumeras, imò totum veluci Macule orpus iis confperfum, exterreno globo noremus? \& illas qui- nulla cur em lub tanta figurarum diverfitate, ut nec Proteum in plures pareant is : formas cransfigurare pofle credam. Cofmiel. Infigne du-Soles. sum mihi propofuifti; quare illud ampliori verborum rarioinio tibifolvam. Nolle debes, Ocelle mi,Solem non tantúm in feriora virtute fuâ agere, fed \& à circumfitis fibiglobis, Ter, Lune, Veneris, Mercurii, Martis, Jovis, Sacurni, quin \& ab fis fixis reciprocum quendam influxum pati, Contingit aum fubinde, cam effe fiderum conftitutionem, ut globus Solas benignâ quadam vi percuflus, \& velutiligatus, ab ebullitioum fervoribus contrariâ fiderum qualitate mitigatis ceflet; uod tunc vel maximè contingit, cùm memorati globi humo\& \& frigoris vi fingulis appropriatâ, quâ eum veluti factâ quám confpiratione opportuno ficuadoriuntur, nimium aftuanmaterix impetum fregerine, \& ad moderatum quendam acum perduxerint; quo facto, pelagus fervidum intra cuculos fuos conclufum, \& ad mediocritatem reductum, i mio fervore ceflat, ac proinde deficientibus eruetationibus pores quoque, quas maculas vocatis, deficere neceffe eft; atie adeǹ folaris globus à tam moleftis vexationibus liber, pla. dum, ferenum, maculisque expertem terrigenis vulcum exbet. Er optimo fanè Natura confilio vicifficudinem hane eò conftanter a ppetir, ut illud intendife videatur; quod caret ernâ requie, durabile non eft: quod uci in folari corpore, ita omnibus cæteris globorum fy ftematis ufu venit. ubi verò fil fiderum globi eam habuerint ad Solem conftitutionem., illum contrariâ radiorum virtute, id eft, igneo quodam in is conclufo vigore percutiant; tunc globofa Sol is moles, haud us ac cacabus fubjecto igne ferventi ære ebulliens, in ingen Curfubinats mox motus fe explicar; intima folar ebulliens, in ingen-totus plenus ncitata, per meatus abditos, maturam jam, in nam excludunc foruum novorum $\mathrm{m}$ jam, in fuperficiem exnam excludunc foctuum novorum mifcellam; ex vehementi utatione femper nova \& nove nafeuntur vaporofe fumogue exhalationes, qux in longum latumque diffufe, in tan- 
12 tanto nunciabantur oftenco. Si enim vel exigua Solis Ecli-; is tantum terreno officiac Mundo, quantum tancarum in Sofacie coacervatarum Eclipfium mulcitudinem Orbi terramobfucuram dicemus? Theodidact us. Cùm nacura nihil egeric ntra, quid cancus macularum apparatus in natura rerum. nferat nolle cuperem. Cofmiel. Primò fcire te velim, corpus is, non fecus ac corpus Terra, fuo tamen modo, hererogeum efle, , ejusque lucem non omnino puram, fed mixtam; curei apertifima indicia tibi prabec tanta calorum varietas, am in cerra conftitutus fape numero in folari globoadmiraes , \& tanquàm fenfatâ experientiâ tibi notum fuppono. Prí- Nacula icaque ucilitas harum macularum eft, quòd à faculenta cor- rum folariri folari inexiftente materia per fumorum vaporumque humodi fecretionem, igneum pelagus quodammodò purge- expurgatumque novasad illuminandum calefaciendumque es acquirat. Secunda, quòd aftuantiffimum Solis corpus" cee fumorum vaporumque interpoficu quadantenus temecur, quemadmodum in terreno Mundo nubes Solem inter erram interpofita caloris temperant vehementiam; atque eò macula folares umbrarum munere fungunitur. Namu. andocunque corpus Solis hujusmodi maculis expers invenn fuic, extraordınaris Terra noftra caloribus exaftuavic ; madmodum contigic poft ulcimam palliditatem anno 1652. ervatam ; evaporatis enim hujusmodi facibus Sol integro anno, fine ulla macula fulgidifímus appartuit, atqué adeò ipfo rempore Orbem univerfum immodico aftu laboraffe. obfervatum fuic. Theodidaílw. Sed quomodo, mi Co- Solcorpus el, colores, quos olim in folarif facie fanè diverfiffimos intur- beterogenome effe memini, heterogenea natura indicium efle colli- "m. n ? Colmiel. Si Sol corpus fimplex \& homogeneum forec, eter lucis colorem, nullum alium admitceret : cùm verò eximento didiceris, Solem corpus effe mixtum, varìs altera- Coleres in hibus obnoxium, variisque condenfationis \& ratefactioniso sole quid bus fubjectum ; neceffario diverfos colores admittere coge-" ob macerix , quât tingutur, diverficatem, Eft hoc adeò cer-:
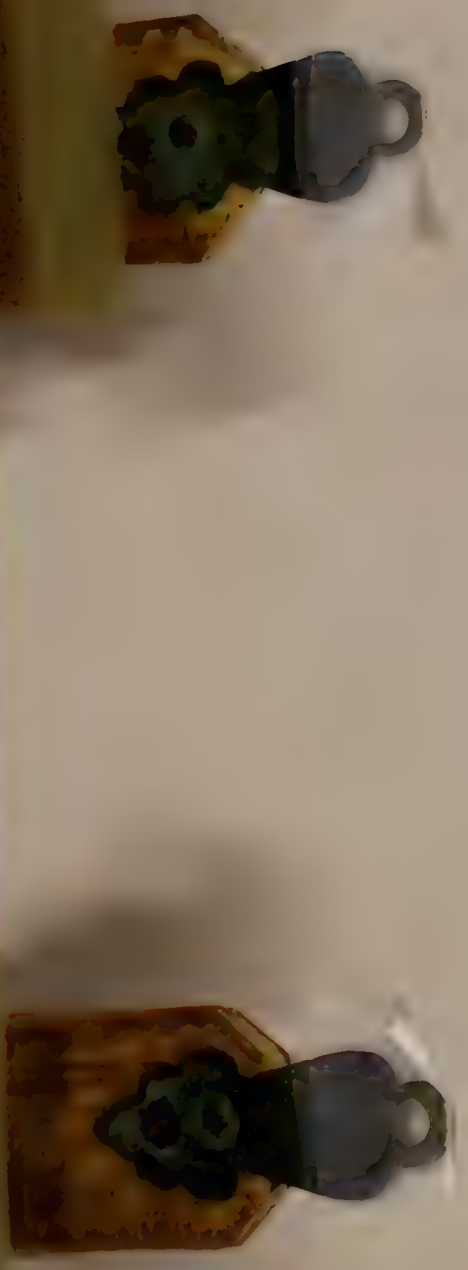
tum, ut Aftronomi non alia de caufa planetarios globos ex dispari materia compactos aflerant, nifi quuòd finguli diverfam coloris fpeciem exhibeant. Num unquam obfervafti terre. Atris flammæ diverfitarem? Theodidact us. Quin imò obferva. vieam, \& quidem fapiffimè: aliam enim in ligno ordinario, aliam in picex natura plantis, in camphora accenfa, cæeterisque gummofis glutinofisque corporibus aliam, aliam denique in farmentis vitium, aliam in aliis combuftibilis marerix ignium fomentis reperi ; imò quot diverfe naturæ ligna funt, tor in accenfis diverfi coloris, fufcas, fubfucas, candidas, nigras, virides, flavas denique flammas deprehendife recordor; \& apertè cognovi,talis coloris efle flammam, qualis eft color ac proprietas, quâ lignum imbutum eft. Cofmiel. Rectè obfervafti, \& fic eft.Idem ergo de folari luce, ob caufas jam antè indicatas, tibi fentiendum efle exiftimes,

\section{S. III. De Cometarum folarium, aliorumque genefo, motu, difolutione.}

$\mathrm{XV}$. Obfecrote, fodes, ur jam ad eam dubii partem, quie de Cometarum genefi nobis fupereft, diffolvendam progrediamur. Cofmiel. Faciam, quod jubes, filum interruptum refumGometarum pturus. Cometx communi opinione Philofophorum funt exin Solgene- halationes calida \& ficca ; five coeleft is, five elementaris natufis. $\quad$ ra fint. Si porrò corporis terreni ad reliquos mundanos globos analogiam rectè confideraris, videbis, quòd quacunque te experientia docet in globo terreno fieri, illa omnia modo fuo in reliquis mundanis globis contingant : omnia fiquidem. mundana corpora, non fecus ac terrenum, ita à natura conftituta eflè nôris, ut perpetuò quædam effluvia emittant, pro raAtmo/phe- tione corporis, quod illa emittic, five illa fint vaporofx exfpira-a boliso. tiones, five exhalationes calida \& ficca: qua cùm è totius fuperficiei ambitu eructentur, periti atmof phæras dictorum corporum nuncupant; de quibus \& in fequentibus fufiùs tecum agam.Inter cetera verò Mundi corpora, folaris potiffimùm glo. bus tantò abundantiùs dicta exfpirat eftluvia, quantò cxeteris? 
î̀ vircure igneâ efficacius, \& aitus vehementiâ potencıus cờ pus eft; ita quiden, ut macula illa, quas olim in terra confticucus vidifti, \& jam in formam immenfarum nubium coràm incueris, reetè Solis effluvium dici pofint. Hx itaque fumofrexhalationes in alciora $x$ cheris fpacia ejaculatæ, uri rarifima funt, ita mox ingens atheris fpatium maximâ fuâ dilatatione Dccupant. Et tametfi eæ tenues fint, opacitate tamen fuá non zarent: fi enim diaphanæ \& pellucida forent, Solis lucem minimè impedirent; at terrigenis fpętatoribus lucem eripiunt,ergo opacitare fuâ pollent, Quoniam verờ hujusmodi halitus non :x aquea fubftantia, fed ex glutinofa, \& veluti bicuminofo quo. tam vapore condenfati funt; ideo divi durane: nam uti rectè blervafti, fubinde ad duos circiter menfes, binis circa axem iolis periodis abfolucis, eodem adhuc loco nonnullas durafle omperifti. Quarum quidem alia ratio non eft, nifi quodd ex ifcofa \& tenaciori materia compacti fint. Quòd fi hujusmoli in maximam atheris alcitudinem vehementi globi folaris :tu ejaculentur, \& perfectam in remoriffimis illis atherea reionis recefibus libertatem nactr fuerint; tum ecce, hujusmoi exhalatio atheris motu agitara, in inæeftimabilem amplitudit iem extenditur; \& củm opaca fit, folarem lucem, quâ tingitur; d terrigenatum oculos reverberar, nafciturque cometa, dirum nórtalibus omen.

X V I. Theodidact us. O quanta animum meum voluptate am admirando difcurfu demulces! Unicum reftat, quod ut exlices, obfecro, id eft, quomodo Cometx hi moveantur '? cur une circulares circa Eerram periodos affectent , nutic relicto ramite longè etiam ultra Tropicos in Boream Auftrumque, unc declivi motu in hane vel illam Mundi plagam deferanIr? quis illis hunc impulfum praftet? \& cur non more cæereroum fiderum regulari, fed anomala prorfus ac irregulari divaatione ferancur ? Cofmiel. Quzeftionem acerrimis Philofo. horum concertationibus agitatam, nec in hunc usque diem, lanè definitam movifti ; quam tamen cibi per parces, eâ quă offum perfoicuitate ac brevicate diffolvam. Primò itaque

If tibi 


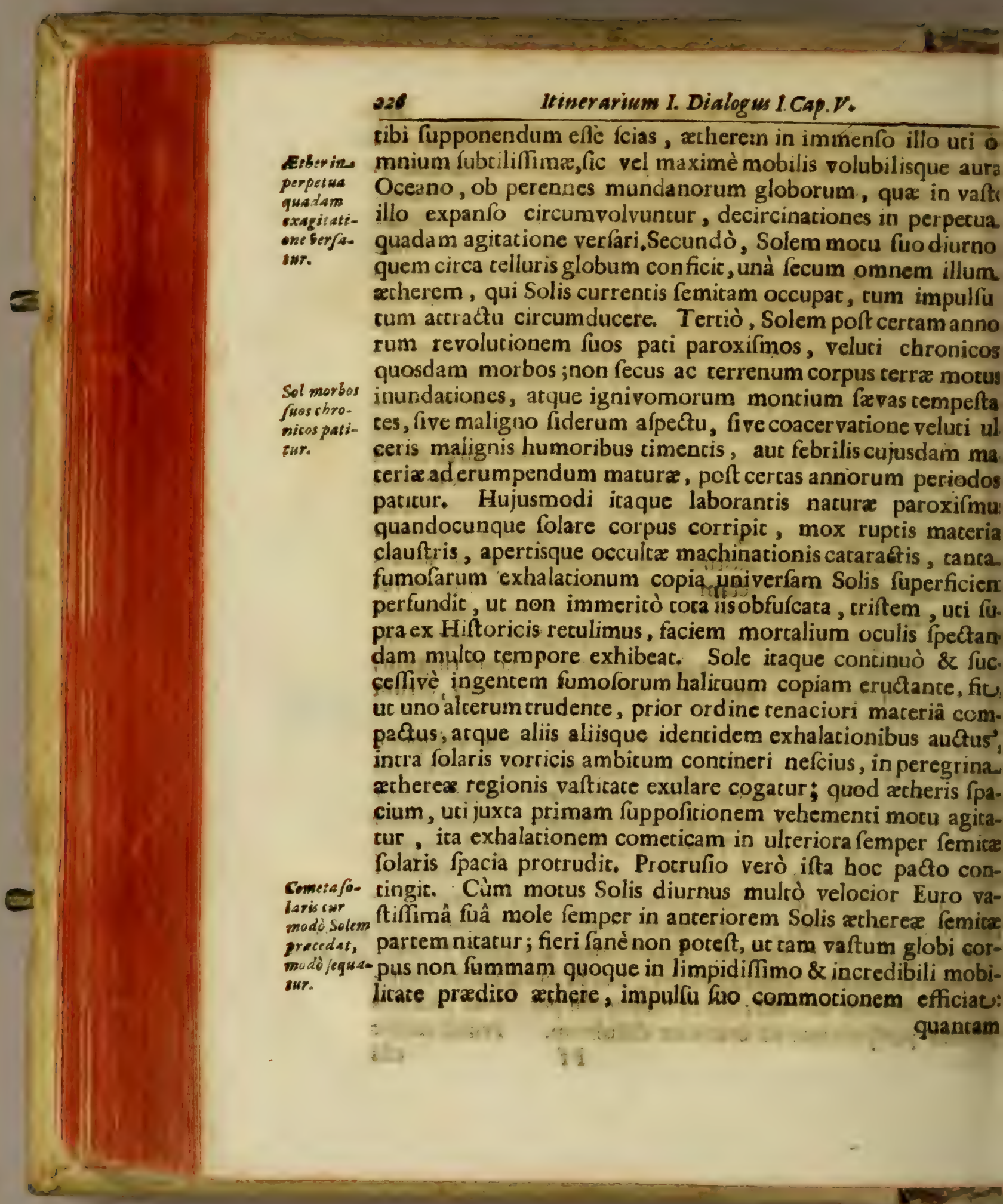


quantam enim in aëre terreno agicationem, quantum fumum vel unica bellici tormenti explofio emifto globo caufer, rerre domuumque cremor, feneftrarumque ftrepitus \& ruptu-l ra, offufaque caligo fac fuperque demonftrant. Quoniam verò ærheris commotio, quantò Solis vicinior, tantò velocior \& impecuofior; tantò verò cardior, quantò ab eo remotior eft; hine fic, ut comeca vehementiâ atherís in anteriora folaris femica promotus, femper Solem anticipet tantò velociùs, quantò liquidifìma aura, arque adeò cometica exhalatio, corpore folari levior eft, donec languefcente virtute impulfivâ ; cometa oppofitum Solis locum attigeric : tum enim verò ab atheris violencia exfolutus, plenamque divagandi libertatem nactus,in eam coli regionem, in quam eam aecheris impecus impuleric, fercur: Theodidact m. Sed nunc nofle cuperem, cùm cometa fubinde vefperi poft occafum videatur, quomodo id contingat ? Co/miel. Hoc ica fieri cenfeas, Quandocunque materia exhalationis cometicæ in eam folaris curfus femicam evibracur, qua Solem fequitur, cunc neceffariò materia tractivus refultat motus; unde poft Solis occafum terrigenis fupra horizontem terrenum apparet fluxum atheris fequens: quia tamen corpus cometæ craffiusculum nonnihil acheris agilitati refiftir, fic, ut illud femper majorem \& majorem recardacionis moram in occiduam plagam patiatur, donec fernitz folaris fluxu relicto, atque in alias Mundi plagas abreptum , volubilis aure arbitrio relinquatur, easdem pofticipando leges fervans, quas anticipando tenuerat. Atque bacc eft caufa, cur comera cam irregulari mocu, ex ortu in occalum, deinde in reliquas -Mundi plagas motu transverfo, declivi , recto, prapoftero feratur." - Sed exemplo fulci navis, quem motu fuo conficit, totum negotium apprimè difces: $\mathrm{fi}^{-}$ qua enim corpora leviora mari innatantia fluxilem fulcum navis intrarint, illa vides in anteriorem prora partem protrudi; qua verò navis motum à puppi fequuntur, tractivo quodam impulfu unà cum navi rapiuntur qua camen mox, ubi fulcum \& femitam navis undarum vi avulfa reliquerint, tunc ea vafto mari commilta ventorum arbitrio, quo ea fors culeric, expoIf 2 nuncur. 


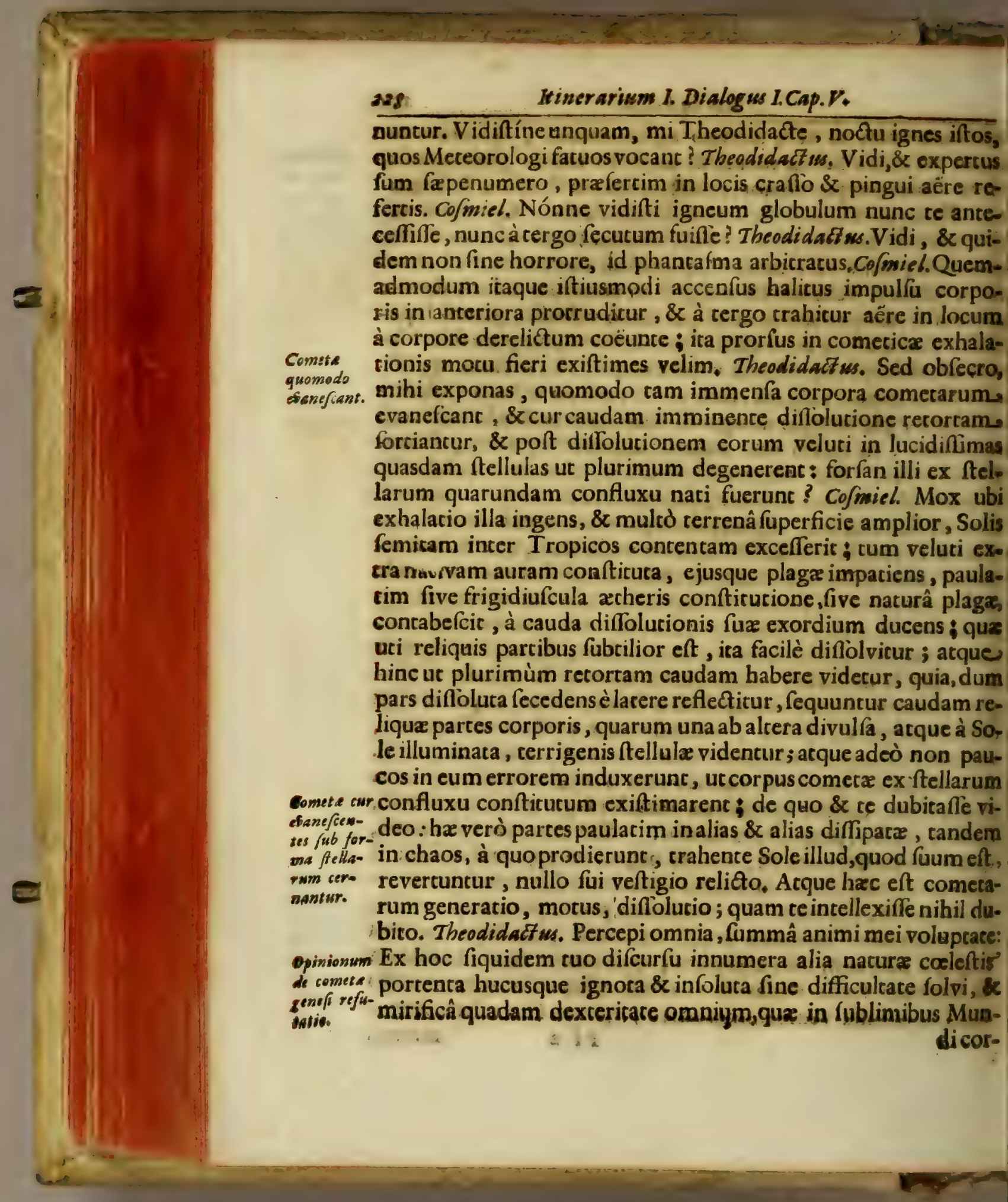


di corporibus contingunt vulgo incredibilia, rationem darr polte cognofco. O quàm eos hallucinari video, qui cometas? ctereraque infolita ftellarum novarum phxnomena, nefcio quibus ingentibus concentricorum epicyclis affigunt;aut qui comerarum quorundam in fluido æthere innacantium, nobis infenfibilem ftellarum confluxumeffe arbitrantur.

XVII. Tbeodidactws. Benedictus fic Pater luminum, qui per te miniftrum fuum tam luculencam veritatem intelléctui meo tot erroribus hucusque obnoxio, pro infinita fua bonitate providere dignacus eft. Sed rogote, peritiflime divina fapiencia incerpres, Colmiel mi, omni nectare \& ambrofiâ fuavior, dic rogo, ánne omnes, qui ab hominibus in terra conftitutis obfervantur cometa, folares funt? Cofmiel. Haudquaquam; quin- trum omnes imò ex omnibus mundanorum globorum halitibus, vaporofis-folares finto. que effluviorum exf́pirarionibus, generari poflunt. Nam uti fuprà audifti, ç ita fingulis globis à natura comparatum, ut Ginguli quadam veluti halituum vaporumque circumquaque exfpirent effluvia, quæ atmofpæram iftius globi conftituunt, quam in omnibus fagax horum cemporum ætas fingulari tubi beneficio detexit. Quandocunque itaque five ex fiderum circumficorum infaufto afpectu, five propriâ globi conftitutione fic exigente, five denique permiffione divinâ, cercis temporibus vehementes bujusmodi effluviorum ebullitionumque tempeftates in globis dictis concitantur ; certè fumofæ hujusmodi exhalationes in extremos vorticum, quorum finguli fuos proprios habent, receffus ejaculatæ, deinde vafto atheris ( licet non lemper, ob diftantiam, à terrigenis obfervari poffint) commif(æ,cometam, vel ftella noviter exortæ fimilicudinem exprimunt; ut proinde ftellarum noviter exortarum phænomena nibil aliud quàm cometas non caudatas putes; quod \& breve, stellarum quo durant, cempus fat fuperque demonftrat. Theodidact ws. Igno- nofiter on fe, rogo, nimix mex curiofitati, quomodo quafo ftellix novi- farum gentex exortæcometæ dici poffunt, cùm eodem femper loco fixa maneant, uti in illis paruit,quae in Caffiopeia anno 1572.8 in eauda Cygni, in Serpentario, ceterisque afterismis noftrorum 


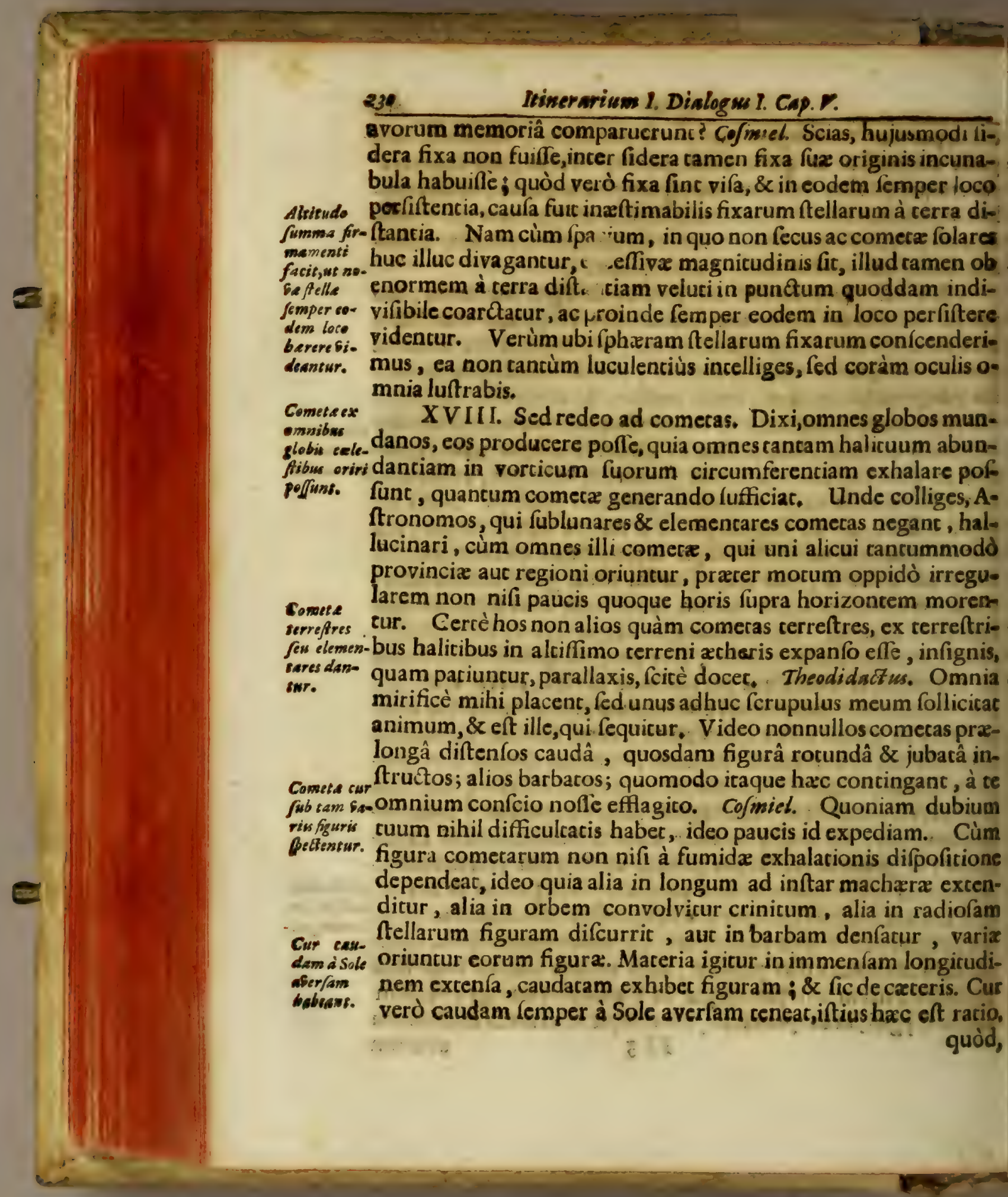


quòd, uti corpus fumidum fubciliffimum inftar nubis tenuiff$m \approx$ conftituitur, ita radii folares id facilè penetrare queunt ; in medio verò rariori refracti lucem intendunt, unde caudata videcur : fubinde quoque fumofam exhalationem in globum. condenfatum pervadens, ex oppofita partebarbam feu caudam exhibet, non fecus ac in pila cryftallina Soli expofita fit, quam. mdii tranfeuntes in conum terminantur lucidum. Effe autem rarifimamexhalationem, inde pater, quòd per caudam comecx,anni 1618 Mundo comparencis, ftellas majores transluxiffe, mulcis aliis Aftronomis idem acteftantibus, propriis oculis te, vidifle teftaris,

\section{SCHOLILM V.}

N Agna quaftio, os que multorum bactenus faitigavit ingevia, de Cometis est, unde fusim duccant ôriginem; coli hojpitea fint, as incole; terream an caeleftem nacti materiam; a que noveantur; cur hoc vel illo progrediantur motu ac modo; an, \& in quid defonant; aftrane etiam, of quae. illos progignant, $\delta^{3} c *$ quam tamen quaftionem adeò folidè ac diftinctè Auctor nofter enodavit, noullus ut dsbitandi locus amplius fupereffe queat rems. aguà trusiná penfótanti.

XIX. Theodidact us. Ita eft; fed cùm paulò antè vorticis mentionem feceris, medullitùs noffe defiderarem, quid fint, hu Vortices So: jusmodi vortices, \& quid operencur in neru \& alceri commifceri poffic? Cofmiel. Infigne dubium movifti um corpeoTheodidacte, quod uci magnum, \& hucusque minis moviti, rmm. um naturæ arcanum conciner, ira ampl lucidandum duxi. Vidiftíne, una ampliori quoque difcurfu diTyberi,caterisque fluminibus? Theodiom vorticem in Danubio, Cervaftíne quomodo quacunque residactus. Vidi. Cofmiel. Obduplicem motum exhiber formam helicis defcripeat, quorum prior cochloidis, feu in. involvat; Vidif́́l omnia innatantia unà cum cencro prium centrum defcriptum motum rei innatantis circa proobfervaffe 


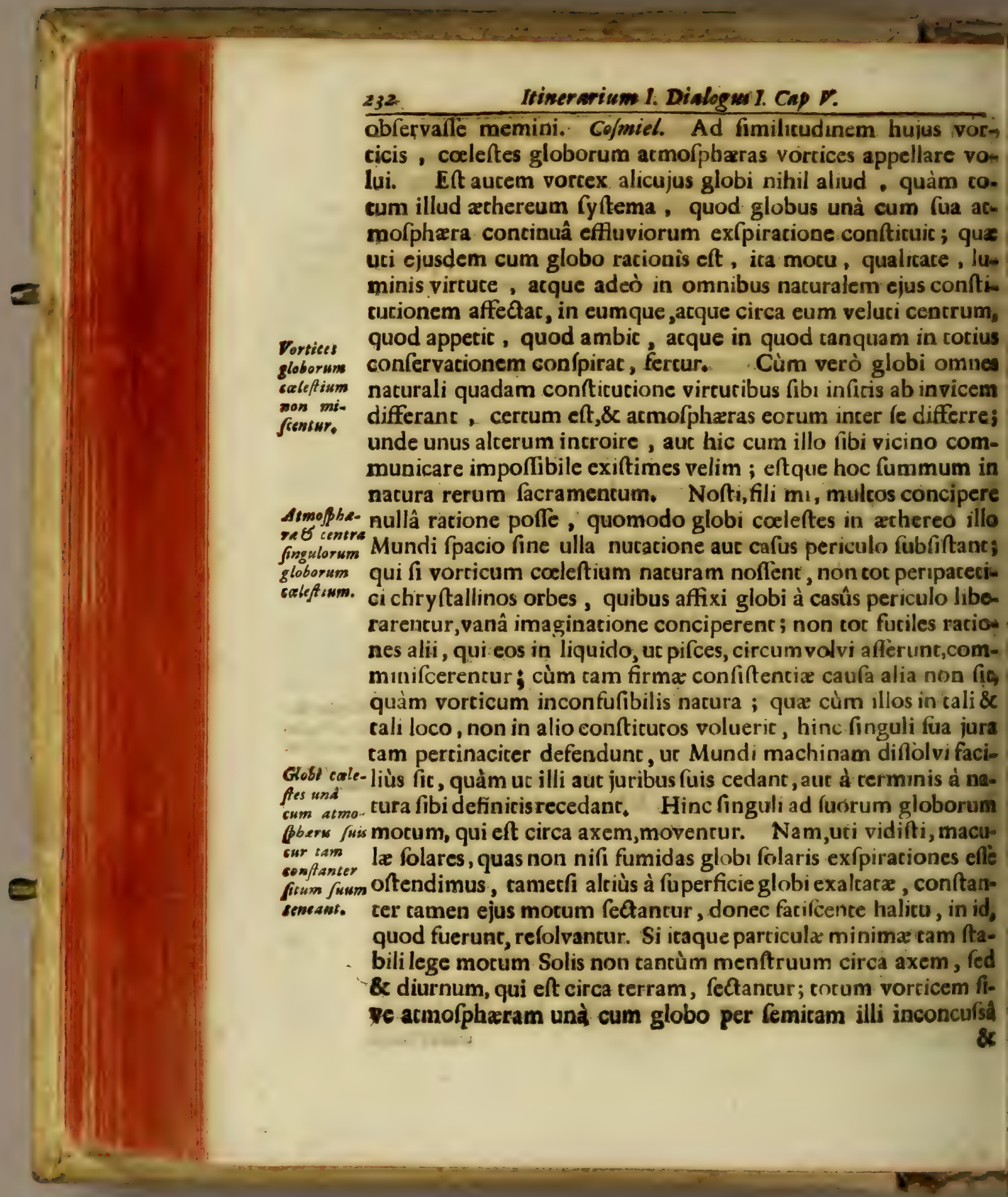


\& irrefragabili Natura lege deftinaram, circumagi ratio dictat. Quod \& de reliquis globorum vorcicibus fencias velim: utienim finguli fuam fibi armofpharam ftrictâ quadam amicitia \& fympathia lege crahunt, ita finguli quoque tramitum iis defini-torum confinia tam inviolabili obfervantiâ defendunt, ut fi vel hilum à decerminaco jis tramite recederent, tunc haud dujiè confufis vorticum juribus mundum perire neceffe foret. Qua cum ribi ex Aftronomia nota fint, is non immorabor. impliùs.

\section{SCHOLIUM VI.}

\section{De vorticibus globorum coeleftium.}

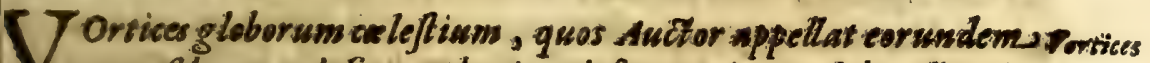

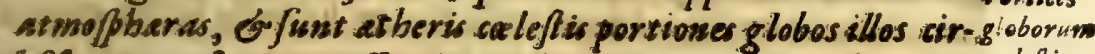

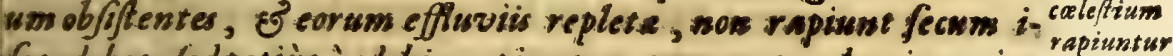
ros globos, fed poticis à glebis rapiuntur, twm motw ab oriente in rapiunsur ccidentem, tum mosu vertiginis circa globorum sentrum, lowendo de illis globes, qui preducto vertiginis motu gyrantur. Proabile autem eft omnes illo mots moveri, ut (quod fape Auctor mmuit) efflusera fua ac virtutes è commodiùs circumquaque difundant. 2uod porrò dicit, vortices pradictos effe inter fe inconinfibiles, intelligo ego de folis effuviis, szon de at beris portione, in uibus effluvin funt; puto enim athera per fefe effe indiffereneno, \& nullam partem appetere, uni potius globo circumfundi wàm alteri. Fortafis tamen improbabile non est, quiod ficut aër Telluri noftre circumfufus Tellsrem affectat, \& non Lunam; $5^{2}$ icut at her Lawe circumfus us affectat Lunam, ơ non Tellurem, F ideo ä̈r nofter $\theta^{2}$ at her lunaris inconfufbiles funt; it a etians theris portiones diverfs planetis \& globis caleftibus circumfun- font impermifcibiles, eo quìd fe mutsio fuperent in levitate ac. lenfitate, $\varepsilon^{3}$ in aliis qualitatibus, ob quas altiorem aut bumalioen in celefti expanfo locum requirant. Et hoc eft. quod innuit theira loco cit. à wobis luprà sap. 2. Scholio 1s. 2 wod fo verum ft f facilè explicatur, guomodo finguli planesa babeant fus pro- 
priacentra in atherea regione. Non taven propterea affixa funt certe ac determinate à Terra diftantice intre fuas regioner, fed ab Intelligentiis nunc exaltantur altix's, nunc bumilius deprimun sur, juxt a leges fibi à fiderum Conditore prafcriptas.

XX. Theodidactus. Unum adhue dubium animum percomete ex- plexum tenet; quod ut folvas, eà quâ fieri poteft animi fubmifinfti fax flone efflagito. Dixuftifuprà, comeras per athereas plagas hine km reser- inde vagarı; quomodo itaque,cùm ejusdem cum globo nature swur. fint, ad Solem non ampliùs revertuntur, fed extra vorticem longè latèque exfpaciantur ? Cofmiel. Rectè dubitas. Scias itaque, aliud efie xthereum illud expanfum,omnium vorticum commune fubjectum \& veluti vehiculum, aliud vortices ipfos; hi enims quemadmodum fuprà dixi, uti naturarum diverfitate difcrepant, ica fieri quoque nun poteft, ut cometa folaris, vorticem verbi - gratiâ Martis,Natur $\approx$ quadam repugnantiâ fubintret,uti nonnulli adfruunt ex iis, qui eum infra Solem fubinde in fuo excentrico defendere docent; hinc enim folùm fequitur, excentricorum mutuam fierifectionem, nullam verò vorticum, qui in excentricis idem funt, quod gemma in annulo; fed unusquisque in id, \& quo originis fux primordia babuit, à fuo globo diffolutâ materiâ tractus, tandem refolvitur.

\section{SCHOLIUM. VII.}

Tortžces 500 dis EMartis non permiJesmikr.

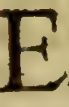

Puntricus orbis Solis eft totum illud caleft is expanfo patium: in quo sol cur/um fusm exercet, nunc remotior a Terra $\sigma^{3}$ :pogass, nunc propinquior eidem of perigans. Idens intellige de Excentrico Orbe Martis, $\mathcal{O}^{2}$ aliorum planetarum. Nortex astem Solis, ut in pracedenti Scholio dictum fuit, eft folium illa Exsentrici predicti portio, quse Soli circumfufa eft, E' Solaria effirvia recipit, ac cum is folarem atmofpheram conftituit. Idemo intellige de vortice Martis, $\mathcal{O}^{\circ}$ aliorum planetarum. Tamet 8 igitur Mars perizans ingrediatur orbem Excentricum solio,

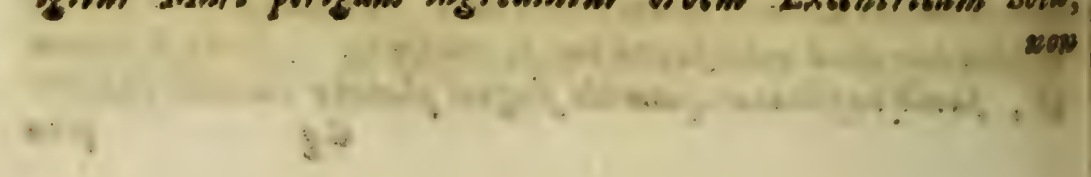


non tanen ingreditur Solis vorticem, nec ingredi poteft, ut Aubtor. afjersic: : id eft, ut ego explico, tamerfo Mars fit in Orbe Solis, nunquam taimen it a fit Soli propinques, wt Aartis atmophara mifoeasur atmophere Solis.

X X I. Atque hinc tertium dubium refultat, quod non-solcor non bullorum Philofophorum ingenia tantoperè torquet, dum con deficiat,excipere nequeunt, Solem, cantam fumidarum exhalationum co balando piam perpetuơ exhalancem, nihil tamen de fubftantia fua per-sopiam. dere; qui fi memoratum in natura rerum fecretum noflent,acque tantam veritatem penetrarent, nunquam ampliùs dubica:uros omnino mihi perfuadeo, Exemplum habes in terra, quze à rerum conditu non ceflat ingentium nubium moles?. xhalationumque innumerabilium copiam eructare, nec tanen in hunc ufque diem defecille comperitur; nec mirum eft; iquidem codem fonore, quo in alcum abierunt terreftrium. xhalacionum vaporumque agmina, eodem mox origini fua n pluvias, grandines, nives refoluta reftituuntur. Idem in Soe, caterisque planetarum globis fieri tibi perfuadeas velim. Ut caque mulca tandem paucis concludamus. Quemadmodum rortices in athereo expanfo unà cum globis circumaguntur, ca \& cometa in athereo Oceano fine ulla repugnantia proveii , \& hinc inde agitari poreft; Vortices tamen à narura fua alienos, Natura quodam dictamine vitat. Sed hac de Comearum folarium genefi fufficiant. Theodidad us. Certè ex hoc idmirando tuo ratiocinio latentem hucusque veritatem tam uculenter apprehendo, ut nullum ampluus dubirandi locum nibi fupereflè videam; imò nibil aliud in fublimium corporum atura recondicum, inlolitum, invifumque efle video, quod ton ex cuis principiis fummâ facilitate juxtà ac amœnitate folvi offit.

XXII. Porrò nihil reftat, nifi ut mihi exponas, mi Cofmiel, soleve corquomodo tam ingens atque adeò immenfum corpus, cujus fi. pus quomones explorare necdum licuit, moveatur; cujus tamen hucusque $t_{t u r}, \delta$ nullum motum fenfi, neque etiam hucusque ulla ftella apparuit, qua. Id cujus motum, folarem motum conferre polfim. Co/miel. Gg.2 Cùm 


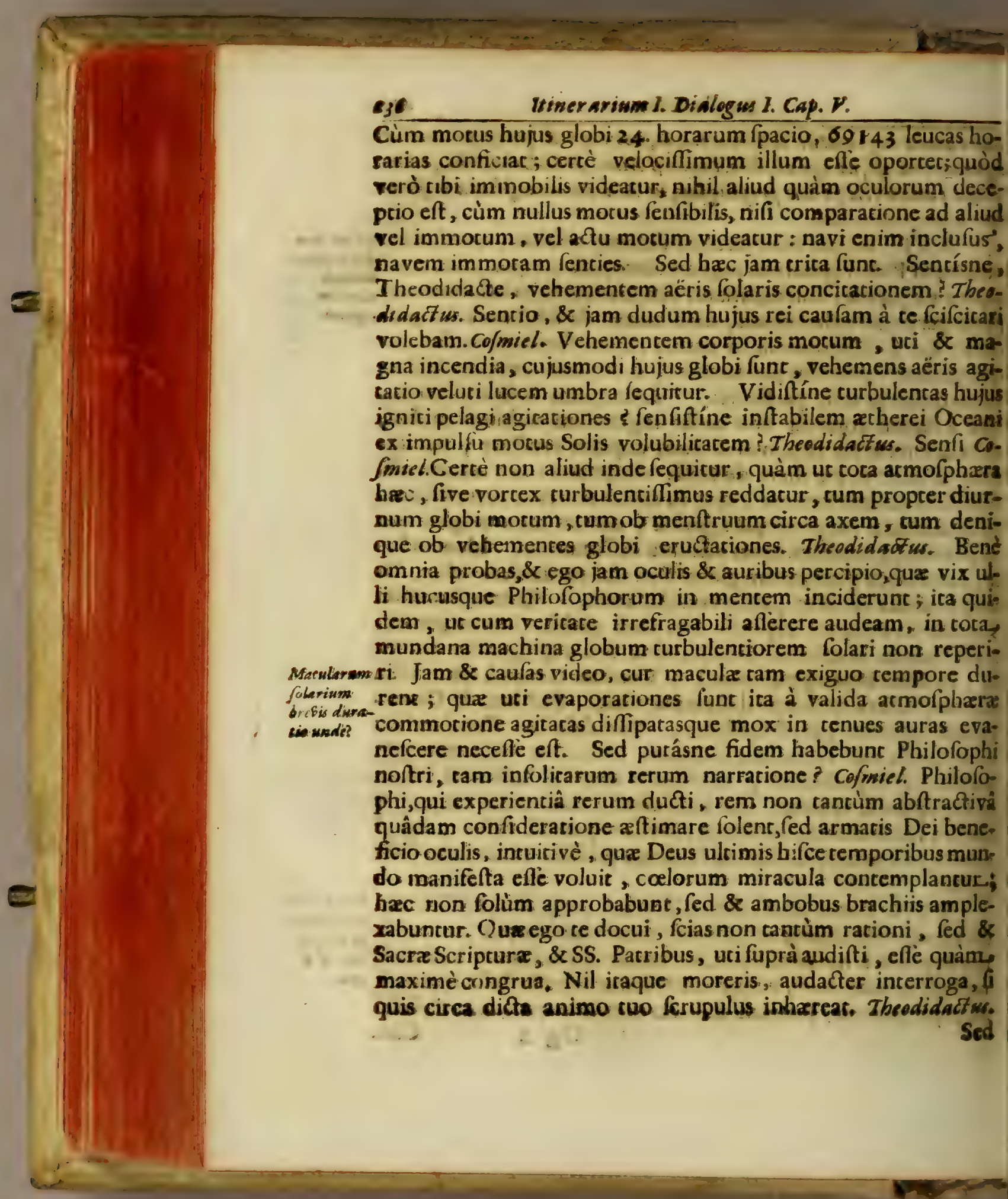

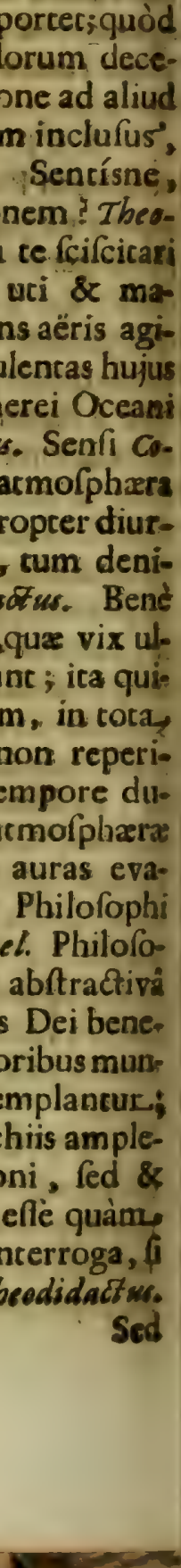
Cum motus hujus globi 24 horarum fpacio, 69143 leucas ho-
rarias conficiat; certè velacifimum illum effe oporter; quòd verò tıbi iminobilis videatur, nihil aliud quàm oculorum deceptio eft, cùm nullus motus feufibilis, nifi comparatione ad aliud rel imsotum, vel actu motum videacur : navi enim in navem immoram fenties. Sed hac jam trita func. Sent gna incendia, cujusmodi hujus globi funt, vehemens aëris agitatio veluti lucem umbra fequitur. Vidiftíne curbulentas hujus igniti pelagiagirationes ș fenfiftíne inftabilem $x$ therei Oceani ex impulfu motus Solis volubilitatem? Theodidactus. Senfi cofmiel.Certè non aliud inde fequitur, quàm ut tota atmofphera hat, five vortex turbulentifimus reddatur, cum propter diurnum globi motum, tumob menitruum circa axem, sum denque ob vehementes globi eructationes. Theodidact omnia probas, \& ego jam oculis \& auribus percipio, li hurusque Philofophorum in mentem inciderune, ita qus: dem, ut cum veritate irrefragabili aflerere audeam, faberium bribis dinerasie wadk?

$$
\text { n }
$$

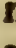
phi, qui experientiâ rerum ducti, rem non tantùm a bet quâdam confideratione aftimare folent, fed armatis Dei bene. ficio oculis, intuitivè , quæ Deus ultimis hifce temporibus mun do manifefta eflé voluit, coelorum miracula contemplantur; haec non folum approbabunt, fed \& ambobus brachis amplezabuntur. Qua ego te docui , fcias non tantùm rationi Sacra Scripturxe \& \&S. Patribus, uti fuprà audifti , efte maximè congrua, Nil iraque moreris, audacter inter quis circa dicta animo tuo ferupulus inhareat. Theedidact mor. 9. 
Sed dic, rogo, quomodo globus hic, auc à qua moveatur? Co sol motetur fmiel, Scias divino confilio globo huic, ficur \& omnibus aliis" sentive" naturalem quandam inditam fuille inclinationem, ad talem \& talem motum, non alium, tum circa terram, tum circa axem. cochloidem in forma helicisconftitutum, qui tamen vircucem fuam complere non poftet, nifi à prafidibus lntelligentiis juxta prafcriptam Naturæ legem in certos fines dirigeretur. Quemadmodum enim operationes ac mirifici brutorum inftinctus? directione prima caufa fubltane, ita motus globorum juxta. ideam in mente Opificis fupremi inexiftentem ab Intelligentiis diriguntur. Cùm verò ratio archetypa fit ærerna,infallibilis, \& neceflaria, hinc fieri non potelt, uc unquam à prafcripto fibi tramire finibusque deficianc.

\section{SCHOLIUM. VIII.}

\section{De velocitate motus folaris diurni.}

Olis velocit as, quâ |patio 24 . horaran ab oriente in occidentem, Motur Solas indegue iterum in orientens moventur, donec integrum circu- ris Bilociono. um aut piram conficiat, tanta est, ut non tantum vulgo , fed Coerrico etiam of Copernicanis, magnis Viris, incredibilis ac impereptibilis videat ur, ideoque illum imasot uns centro Mun di alligans, \% circa ip/um retant Terram cam tota Element ari fphera, tum

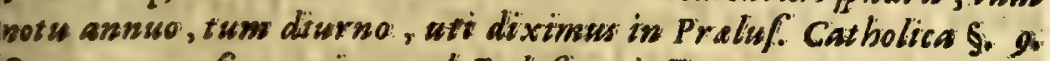
2uam tamenfententiam, ab Ecclefin reject an', utpote Sacre Scriture contrariam, rejecimus cam Orthodox is Philolophis as Mathevaticis in Curfo Mathencat. Lib.7.par, 2icap. 3 .

Retentâ igitur: Catbolucâ de motw Solis fententia , ut increibilis ejus velocitas indagetur, ac numeris expriwat ur, qua boris 4 circulum maximum Orbis fo integré abfolvit ab oriense in. scidentem; afumendus est dres aquinoctialis, quasedo sol Equiodtialem circulum notu fwo diurno percurrit, ant de/cribit i his: ism esf circulus Orbis Jolaris maximus, reliqui verò, quos prope ropicos defcribit, non Junt maximi. Praterea affumenda est eferminate Solis à Terra diftantia, nimirum vel maxima, vel 


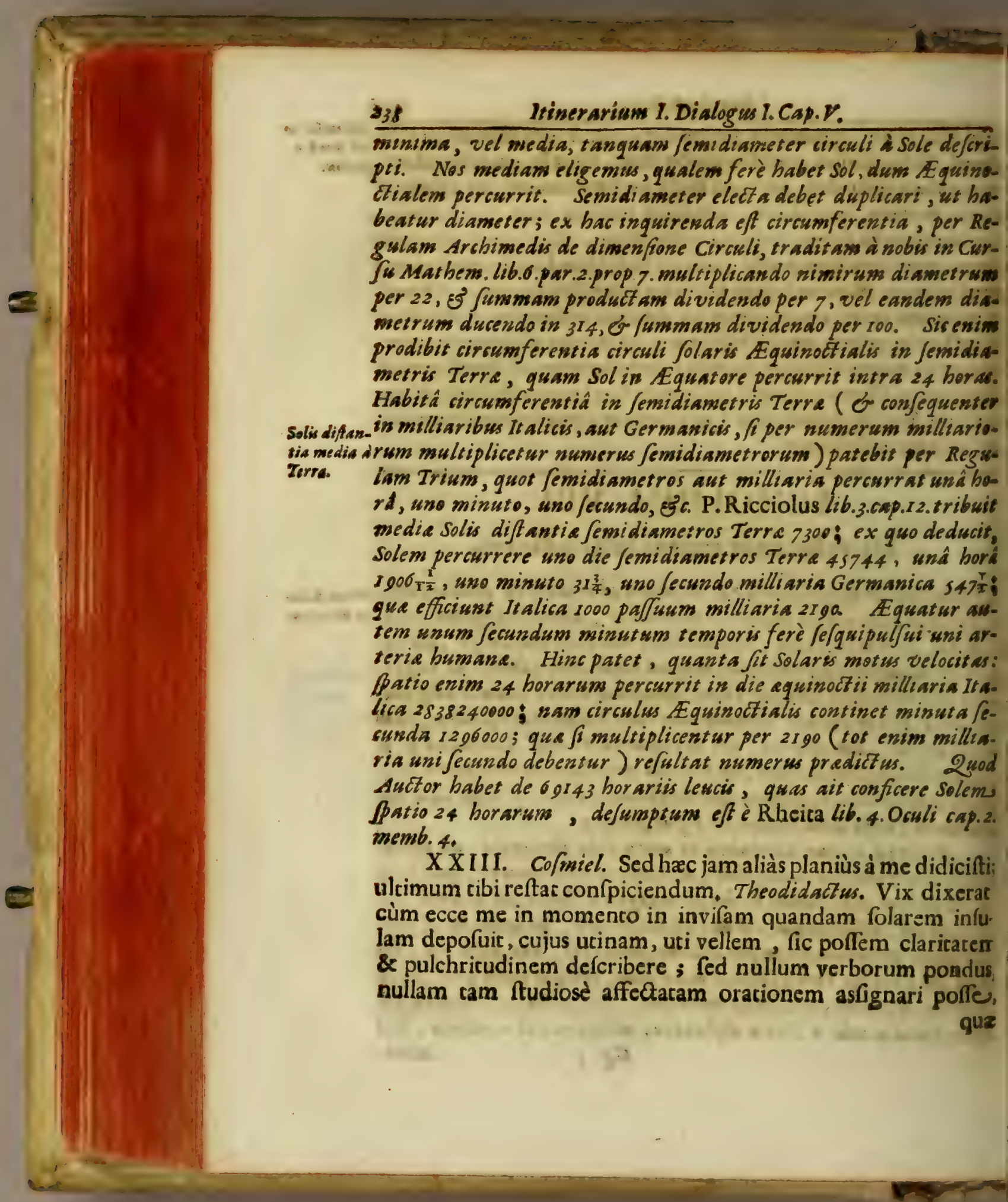


que id praftet, cognofco: omnia hic auro lucidifimo \& veluci diaphano ( quod fi cryftallum auream dixeris, non malè dixeris) corufcare video, neque quicquam in rebus cerrenis concipi poreft huic comparandum ; carbunculi, fmaragdi, faphyri, chryfoliti, amechy fti, nihil obcolorum, quá mifcebantur, varieme in paradifum introduxiti ? aut in Empyrei coli atrium, myficha for

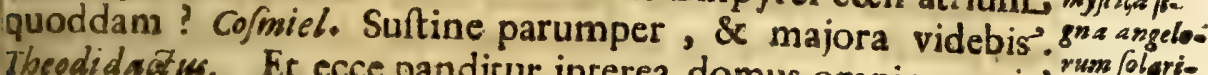
Theodidacus. Et ecce,pandicur interea domus omnipotentis rum folariolympi, \& derepentè admirandum quoddam pulchritudinis" heatrum obvium video : viri inufitata magnicudinis fefe fitunt, quorum fplendorem nulla tam folix penna eft, quae decribere fufficiat ; tot animatos Soles dixiffes. O Cofmiel, fifte Jauxillùm, ut cantæ pulchricudinis decorem propiùs intuear. leficit enim anima mea in tanca beatitudinis contemplatio. 1e. Quid fulgur ille, quem evibrant fupra omnes fulgores, gra. Defcriptio iolus ! quid aftus vehemens, quem continuè fpiranc? quid pa- Jumbalice Idamenca, quibus operiuncur; ex vena lucis puriflima confti babitus an. uca? quid fulguris inftar concitata membrorum uid alarum remigia fuper omnem iridis colorum varietatem dmiranda? Cofmiel. Hi, funt lucidiffmi fpiritus, fummi reum Monarcha miniftribeaciffimi hi funt hujus, quern vides? Jlaris globi præfides, quorum virture \& perenni concurfu, adairanda virtures in univerfas Mundi femitas juxta idea arhetypa rationes, quibus conformantur, in Mundi bonum. onfervacionemque diftribuuntur, nacuralesque hujus globi icultates, uri \& munerum, quibus funguntur, diverfitatem, hoc, uem vides ac fupes, fymbolico apparacu exprimune; neque pus eft, ea ribi probo fymbolicæ fignificationis interpreti fuus exponere : intelligenti pauca. Theodidactus. Dic rogo, ex uo choro tam ineffabilis pulchricudinis fpiritus funt? Cofmiel. $x$ Seraphico ordine, qui dum faciem Dei fine intermiffione stuentur, divini amoris aftu inflammati, fine temporum fyllabis, uod aterua ejus voluntas velit, legunt, eligunt, ac diligunt, fem- 


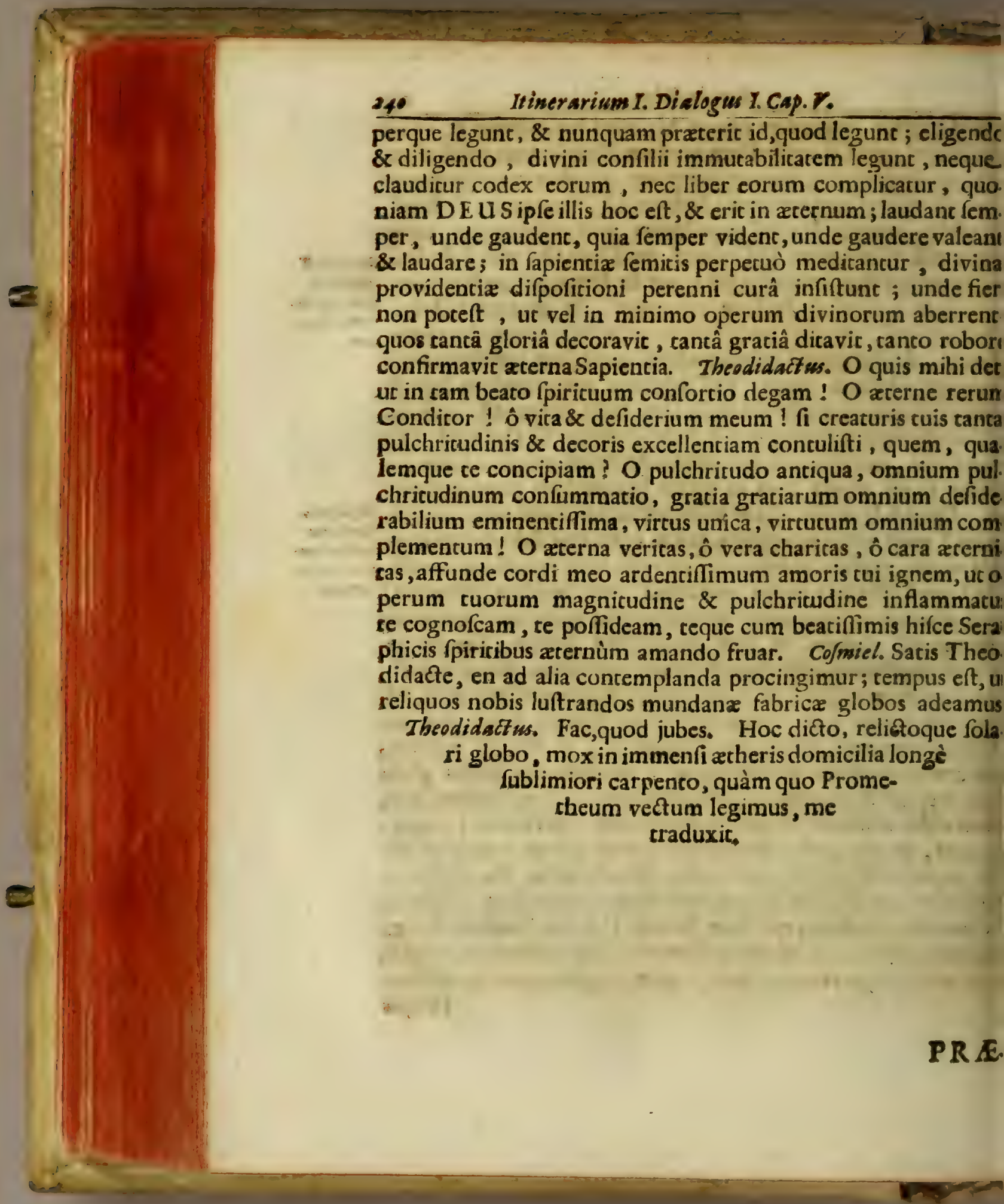




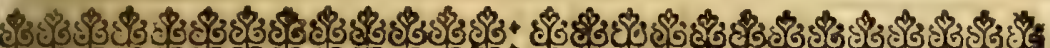

PRELUSIO IN MARTEM.

NVulum ferè bonum eft fine mixtura mali, nulla barmonia fine diffonantia, pax $E^{\circ}$ tranquillitas nulla fine difcordia, fine turbis. In Terra, ubi elementorum pugna $\sigma^{\sigma}$ tumultus, id not isfimum eft, Ev asfidum ; in colo, ubi pura E tranquill a cogitamus omnia, minus quidem no. tum, at non minius frequens. Fulget ac rubet ibi Marti inter Solem ac fovem Mars planeta, luceque nomimo. igneâ $\sigma$ rubicundâ minas jpirat $E$ flammas. Q) ui nudo oculo eum apexêré bactenus, tali chemate notarunt; qui per majores tubos opticos ab bujus faculi initio in hac usque tempora pect avêre, ignes quali ex fornace erumpentes propexerunt, E nigrum montem, aut vor aginem cacam medio infert am; E,, $\mathcal{L}$ aliis credimus, balt heum $E^{\circ}$ difcum inft ar casfidis ; omnia feva, omnia Martia. Meritò ergo Maadim Hebrais, hoc eft, fanguinis inft ar rubens; Platoni ES Capella nupóes ab igne; Agyptiis Meloch, boc eft, Deus deftructionis; Aftrologis Infortuna minor ( Saturni repe(fu, qui major est) nominatur; cujus proinde. $\mathrm{Hb}$ character 


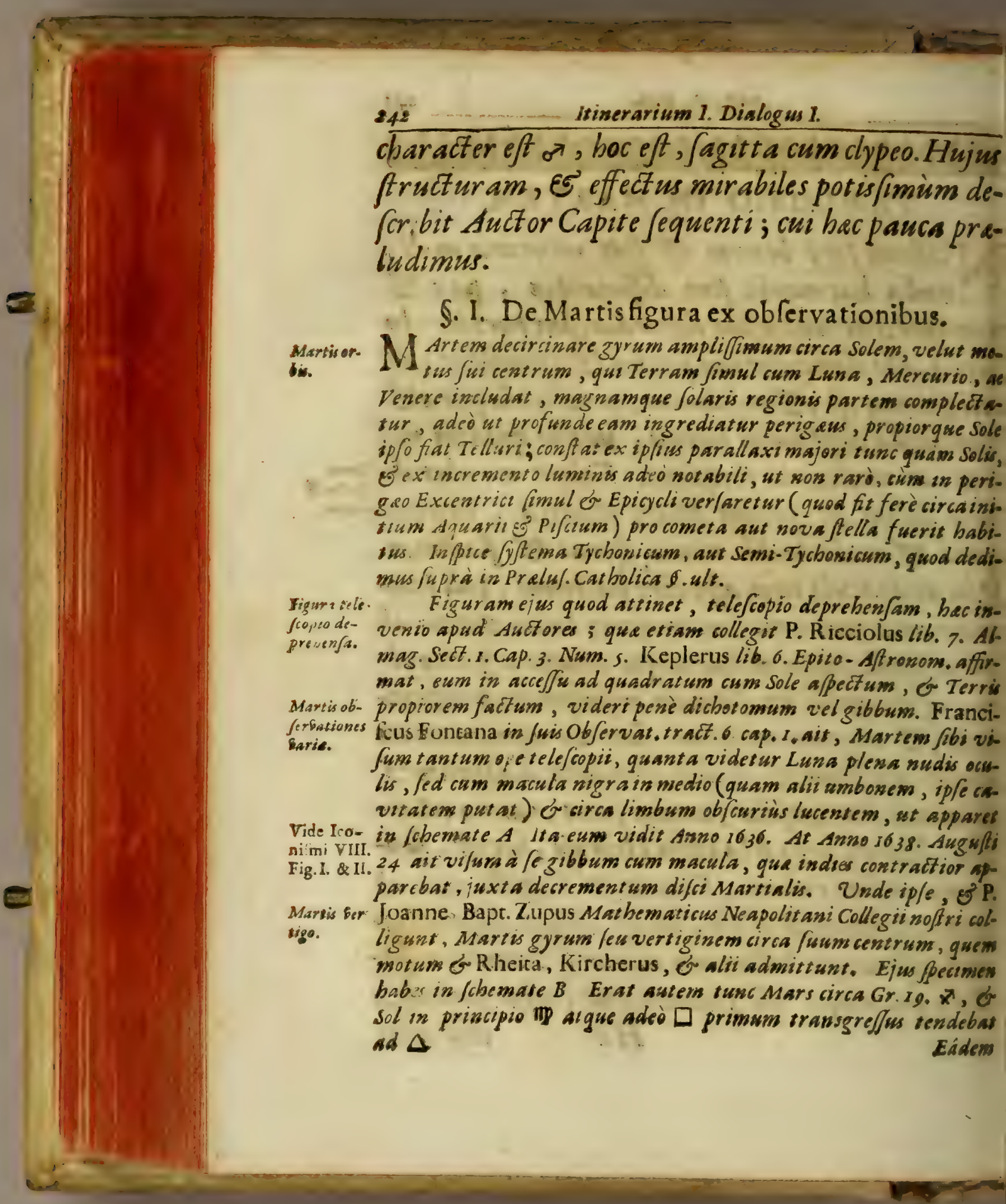



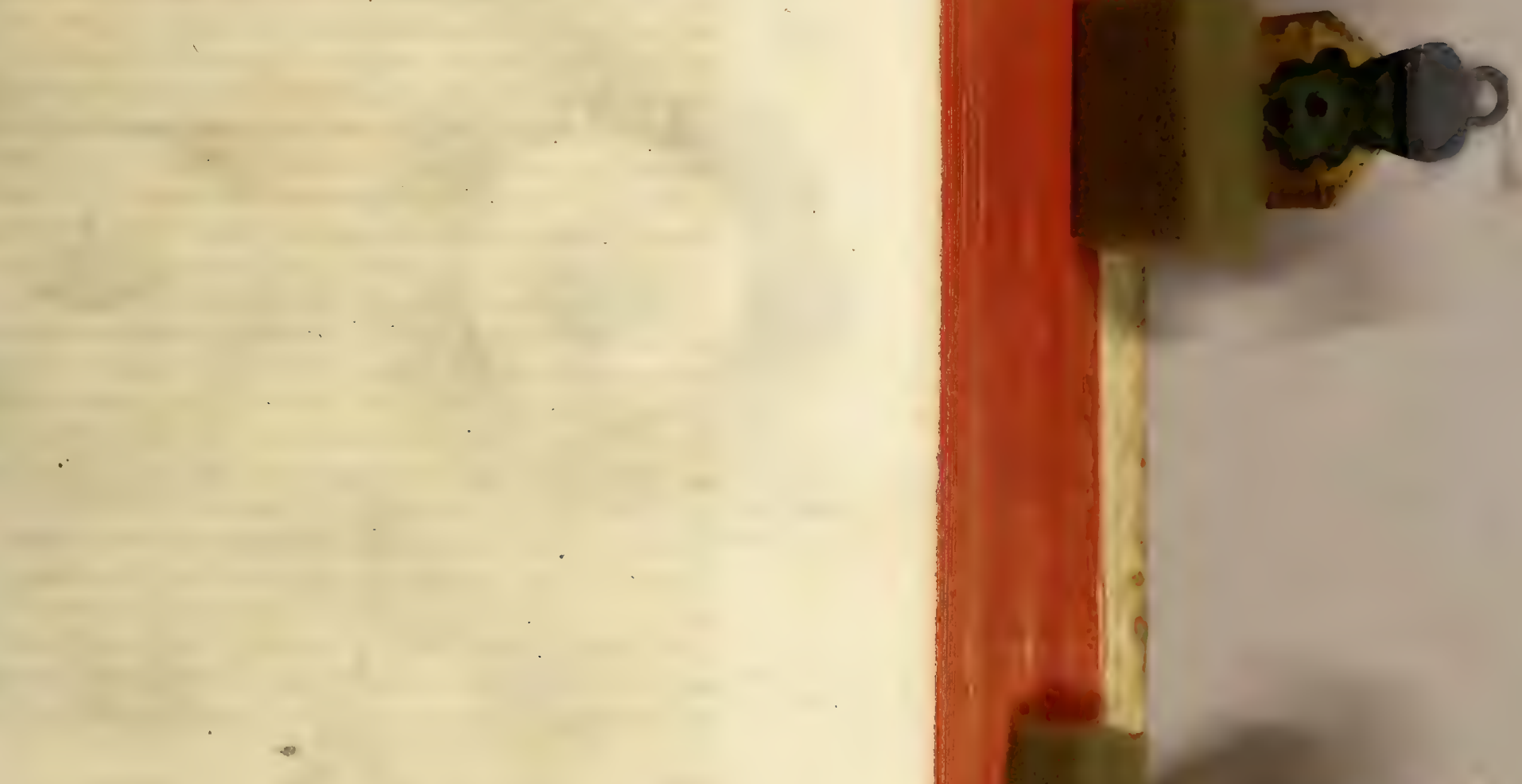

an.
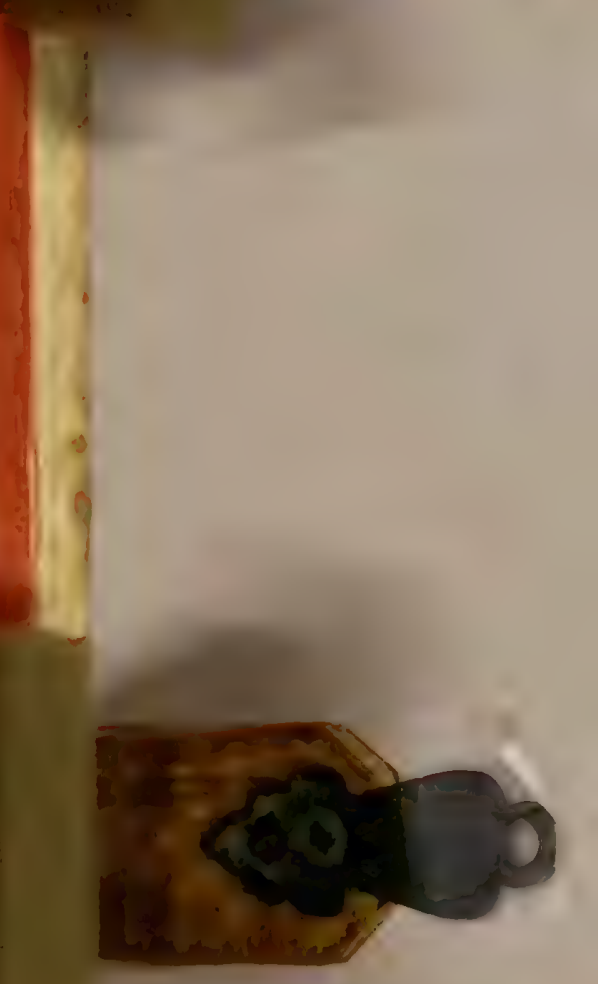


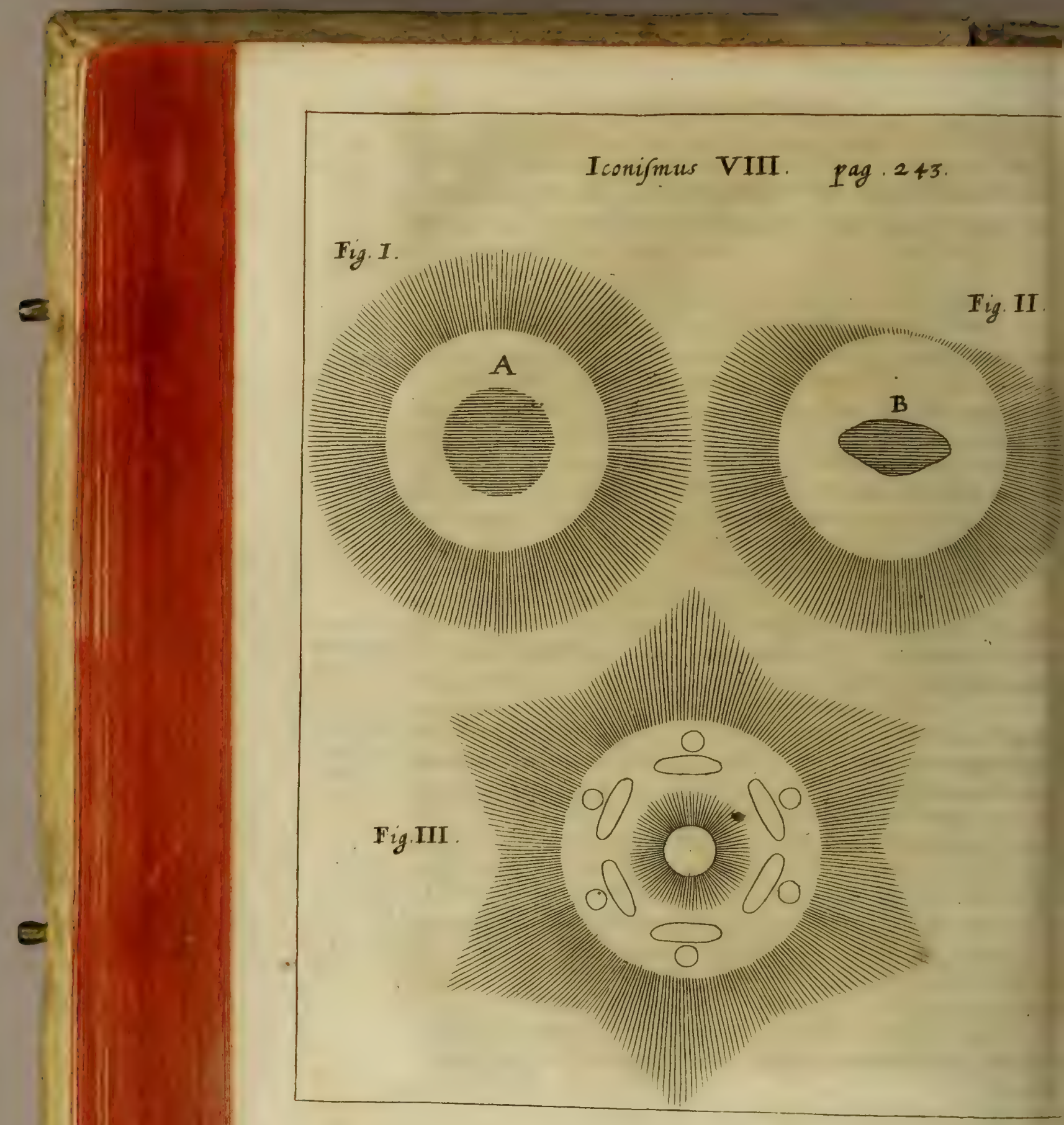


Eâdem prorfus fgurablervatum Rome a /e Anno 16 40. Maje 23. Fed fine macula aut rubra, aut nigra, teftatur P. Nicolaus Zucchius, in litteris adP. Ricciolum dat is. Erat tunc ol in Gr. 2. II, G Mars in Gr. J4. proindeque trino alpectu Juperato rendebat ad fecundam cum sole quadraturam. Gaflendus in in. titut. Aftronors. lib. 3. negat à fe vifum Martem cum macklas rubrs. P. Daniel Barcolus é Societate noftra, in litteris ad P. Ricciolum Neapoli datis Anno 1644. Decemb. 24. Foribit, vilum à fe telecopio eximio Patris Serfali ex eadem noftra Soc. Martem non cum wacula in medio, fed cum dreabos macules in parte inferiori difci.

R heica lib. 4. Oculi Enoch \& Elia cap. S. memb. 1. aut, non deDe, quii Martem quoque fuis comtibus Jeu lat eronibus flipatum. sferant, fed fortaflis potiiss ratione quàm experientiâ inductos, ut antes nimirum Martem inter Juperiores planetas baud tam 'xigue of vilis conditionis effe, ut prorfus comitibus deftitutus esb debeat : fobi tamen mibil de hujus fideris comitat u adftruere licere, aut licere; dossec certiora pandat tempus $E^{2}$ experientid. dem ibidem addit, eum fbi /apiffime quafi jubatum effe vifum, ideò ut Mars nunquam rocund $x$, fed perpetuod jubatæ figuræ ap- Mass jubareat. Iubs tamen in fhematismo nullas Marti adpingit, Jed $d^{\text {tus. }}$ orpora quedam ipfo propinqua, of circa extimam ejus /uperfiiem quafi fluitantia ac circumvolitantia. In Epiftola tamen ad Carawnelem dat a Coloniâ 24. April. 1643 . dixerat, Mart is comiatum efse indubitatum. Infpice Figuram II I. Ricciolus nullas Vide Ieoroprias affert obfervationes : nec alias apud alios preter dict nifmi Vur. neveri.

\section{§. II. De Martis influentiis \& effectibus in fublunaria.}

E Martis influenties noxiis, \& effectibus infauftis in fub. Martis in. lunaribus, ex diverfis, guz ea ab immemorabili tempore ob. Aluentia 8 ervarunt, collegit Rheita Lib. 4. Oculi cap. 0. Memb. I. qua Je-ffectus. unntur.

Mars eft immoderatì calidus is ficcses, comburens, $\xi$ defissnes. Cujus tamen caliditus of faccitas quandoque ita temperan$\mathrm{Hb}_{2}$

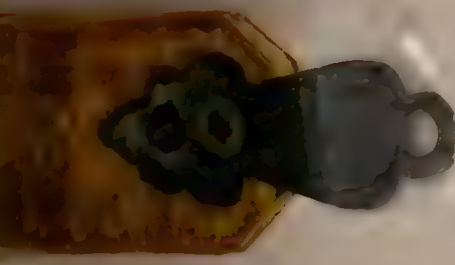


our, ut humiditatem aliquam vergere potius vidcaiur, prou fonum aliquod humidum peragraverte. Orientalus calorem, oc ctdentalis verò ficcitatem auget. Cùm folus aëri dominatur, in gentem plerumque calorem of ficcitatem affert, corrumpeniem omnia, producens in aëre ventos calidos, peftilentes, El tabificos incendia, fulgura, tempeftates, \& grandines, pluviarumque ino piam gignens; in mari verò /ubitanea naufragia per vento turbulentos, \& fulmina. Exficcat quandoque fumina, El fontes Animalium quoque, if fructumideftructione generat. Caufa morbos, febresque aftuantes tertianas, fanguinis eruptiones, pe filentias (maximè Saturno malè junctus \&े configuratus.) $\sigma^{2}$ re pentinas bominum extinctiones. Mitigat denique byeme qui dem frigess, fed aftate calorens mirè auget, Hac Rheica, Simi lia apud alios leges.

\section{§. III. De ftructura \& natura globi Martis.}

Martis firuatura É na-

inre.

$\mathrm{F} X$ dict is, fimulque ex analogia ad alios globos jam explicatos, as que ad Terraquan noftram, ingeniefiffine concludit Auctor no fter, frueturam ac naturam tum proprietatibus globi Martii. No mirum effe, ut cateros planetarios globos, compofitum ex folido of $h$ guido. Et folidum quidem effe fuliginofum inft ar fulphuris, arfeni si, auripigmenti, durifimum tamen, incombuftibile, evapor ans mo lignas ej exitiales qualitates, /udansque veluti bitumen quoddan

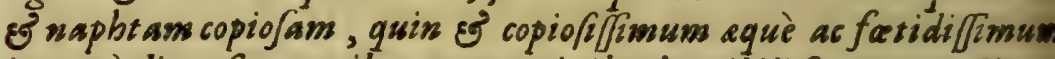
ignew è diverfis montibus ac voraginibus horribili fragore eruct ans Humidum verò effe lentum, pici noft re liquefact a baud ab/rmile.

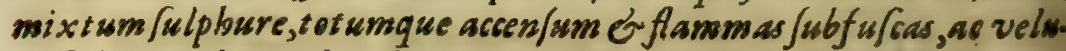
ti fuligine plenas einculans.

Martionse.

Nigram porrò aut rubram maculam, quam aliqui in medio cula fow Martis notarunt /ubinde, of umbonem alii, alii cavitatem eximobo guid fimarunt, putat Auctor noffer effe ingentem gunndam voragifo. new, Af ricâ fortalfis non minorem ; quie tamen è Terris non femper appareat, è quòd globus Martis circa centrum fum vertiginis wot u gyretur, ficque fiat, nt plag a illa nunc recto, nunc obliquo ftu Jpect antium ocwlis obvertastur. Hinc it ague est, wt aliam at give 
aliam fubinde figurem induat, nuncrotundam, nunc oblongam of coniractam.

Fubes denique, fen corpora in extim a Mart is /uperficie veluti Martio jube fuitantia, putat effe ingentes vaporum exhalationumque fu-quid fort. mos, gui tamen non /emper, Jed tunc tantiom appareant, cim vebementivis globus eftuet; post aliquantum vero temporis refoluti globo fwo reftituantser. Atque bine cenfet orivi litem Afronomorum, dum aliidicta phanomena le obfervafe affirmant, alii contrì negant. Alia buc pectantia leges apud ip/um Auctorem fequenticapite ; itaesim clara funt, ut explicatione non indigeant.

\section{CAPUT VI.}

\section{Deitinere in globum Martis; E de mira cjus confitutione.}

$\mathrm{T}$

THeodidactus. O Cofmiel, fidelis dux \& director meus, ubi- Iter inglo: nam locorum heremus ? \& quando tandem noctem bum Mar: operiemus, quâ reliquam cœleftis hujus domicilii œconomiam contemplari poffimus; frquidem ad hoc usque tempus (fi tamen tempus in tam exatico rerum ftatu concipi poffic) in perpecua eaque intenfifima globi folaris luce morati, neq; noctem, neque tenebras ullas, neque ullum ex reliquis mundanis globis videre contigit ? Sed neque quis menfis, aut quis jus currens dies fit, recordor? Cofmiel. Cùm omnis temporis nenfura fumatur ex comparatione immotæ Telluris, ad eum; jui perpetuò circa eam fit, fiderum motum; in Sole verò ob ntenfam lucem omnes reliquorum globorum fplendores : vanefcant; cercum eft, in eo neque temporis menfuram, neque ierum noctiumque vicificudines, neque ulla horarum dicrimina affignari poffe, cưm hæc omnia ex ortu \& occafu filerum, quorum hucusque nullum vidifti, dependeant. Scias amen, hoc eodem remporis momentoSolem Romæeffe meidianum, feftumque SS. Apoftolorum Petri \& Pauli fummâ H b 3 folenni- 
folennicace celebrari. Theodidact us. Fieríne poteft; tam parum nos temporis à primo itineris noftri aufpicio confumplifte? Cofmiel. Ita elt , fed miranda rerum fpectacula , qux intuicus es, omne tibi hucusque impenfum tempus breve reddiderunt. Sed agedum, profequamur iter. Theodidactus. Ec mox incredibili velocitate in remotifimum me achereæ'regionis locum. conftituic. Cofmiel. Eleva oculos twos. Theodidarius. Orormiel, horreo, cunctosque meos ftupor occupat artus: Cofmiel. Quid vides tantâ admiratione dignum? Theodidactus. Infernalem ego globum non oculis tantüm intueri, fed \& $\&$ incredibili foetidâque mephici cancúm non exanimatus fentire, quin \& ingenti turbinum vertigine agitari videor: define, define, obfecro, ulterùis provehi; magna enim mihi mala ab hoc globo imminere auguror ; fiquidem cholerico me pathemate penitus, \& nefcio quo irz \& indignationis motu incandefcere fentio. Cofmiel. Nê timeas, fili mi : cùm enim intra vorticem feu acmofpharam Martii globi confticuaris, mirum non eft, te vehementi ejus influxu in tanta cholerica affectionis pachemata concitari ; contra qua hoc balfami vitx coleftisque liquoris antidotumaccipe.

II. Theodidactus. Eoque cùm nares, aures, os imbuiffer,protinus confortatus refpiravi, rapidåque vertigine in globum Martium ad nefcio cujus Vulcanii montis crepidinem me depofuit, cujus vertex fine numero piceos flammarum globos eru. Martic glo. Ctabat. Vidilies undantem ruptis fornacibus Etnam; flammiva difirutis-

mosque globos, liquefact aque volvere faxa, tantâ foetoris globo proprii graveolentiâ, ut fieri non poflè credam, hominem. non divino præfervatum fubfidio, híc vel ad momentum vitam rolerare pofle. Saxea montium moles veluti fuligine quadam imbuta videbacur ; ipfa verò fubftancia quafi fulphur, arfenicum, auripigmentum, cæteraque malignæ \& exirialis qualitatis corpora, qua veluti bitumen quoddam \& naphtam copiosè fudabant, mentiebatur; neque tamen horum quicquam erat: neque enim graveolentia, neque mineralium fpecies fimiles noftris comparebant , fed quia verba, quibus jlla expri- 
mam, defunt, uficatis mihi mineralium corporum fpeciebus fecundùm analogiam quandam ad dictas fpecies comparatam, mentem meam explicare cogor. Eo loco confticutus, fic ductorem meumalloquebar. Rogo te, Cofmiel, per magnum Dei cetragrammaton nomen, ut mihi exponas tam exocicam erum faciem; deficit enim anima mea præ tantorum incuitu nirabilium. Cofmiel. Suftine, paulò pònt majora videbis, jam Martioglon antum in primum hujus globi veftibulum introductus es. Glo- bidefiriptio ous enim hic Martis dicitur ab Aftronomis ; ac rectè quidem analoga î́ enim perpetuâ martiorum elementorum pugnâ confligi-bus Martiaur; hîc Mars furore omnia complet; hic Vulcanus arma bobsingloudit, quibus terrigenum genus perpetuâ calamitatum iliade nfeftet; hîc ignis \& aqua piceæ perpetua lucta ; hîc omnia olari globo cacerisque contraria intueris. Theodidactus. Quo icto è veftigio me fublacum, ad immenfum Oceanum, quafi ice \& bicuminefuecenfum conftituic. O Cofmiel, fi graciam oveni in oculis tuis, abeamus obfecro; quis enim hujus globi xedicacem fuftineat? quis fumos, fumorumque peftiferorum alitus, graveolentemque mephitim exprimat? non equidem uto in natura rerum fcabrofius, afperius, inæqualius, fqualiius corpus reperiri ; montem pice fuccenfum veriùs dixeris, uàm globum. Comiel. Modica fidei, quid trepidas? Quid uereris? Quid indignaris? Nónne ego tecum fum, quite $a b$ onibus eruam periculis? patet certè, te plùs æquo radios haufiffe rtutis Martia. Ne foedum aur peftiferum dicas, quod DE$S$ ad Mundi confervationem \& ornamentum tantâ prodentiâ dispofuit. Theodidactus. Condona, rogo, tantæ mea firmicati acquiefco tibi, meque totum, quantus quantus $m$, tuo relinquo arbitrio. Nunc itaque explices hujus globi yfteria. Cofmiel. Faciam, quod petis, ubi priùs globi corius onfticutionem oftendero. Theodidact us. Quo dicto, me fo-Martizgion o inclufum vehiculo, ad fingula globi luftranda deduxit. bs frutiure lobus videbatur ex lento quodam humore conftitucus; quem plicatis. cum pice noftra liquida fulphuri mixca comparavero, non errabo ; ita tamen cocum fuccenfum erat , ur flam. 


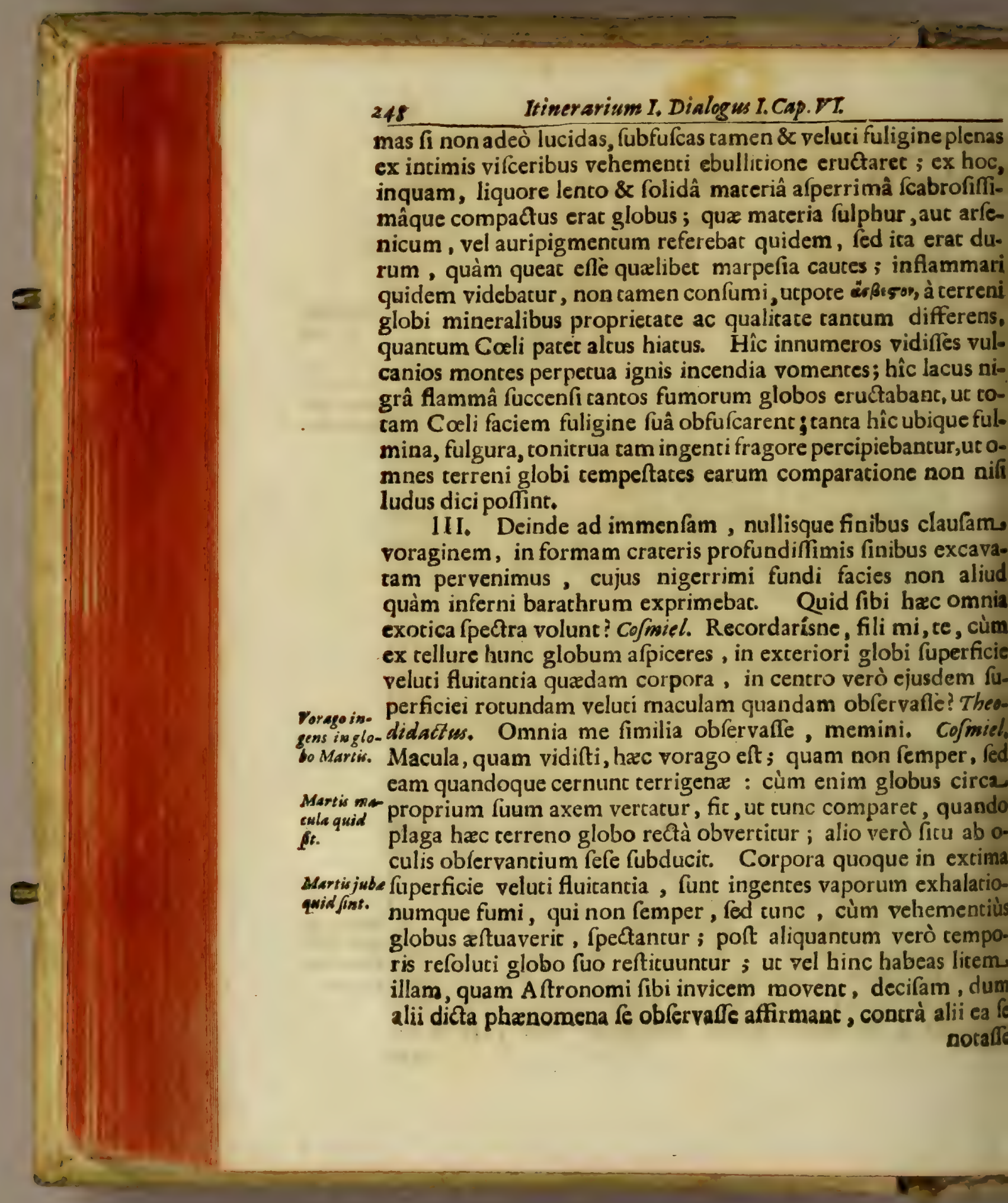


nocalle negant ; utrique benè lenciunt de phænomenis, diverfis cemporibus obfervacis. Theodidactus. Sed in quem finem im-Vorago in menlam hanc voraginem (quam fine dubio toti Africa aqualem Marre ad aftimo ) in natura rerum conftitutam putes, noffe defidera quid a narem. Cofiniel. Vides crateres innumeros fundo hujus voragi- tmba. ais inficos ? cernis uc liquefactum fulphur unà cum bitumine miftum bulliar? Theodidact us.Miror, \& pra formidine vix fpiro, cofmiel. Scias, hunc globum immenfis undique maandris cuiculisque perfoflum, ac cavernis ingentibus excavatum ; cazales veró per caca globi vifcera longè lareque exporrecta deluctaque, bullientem materiam in cavernas interiores, deinle forinfecus in crateres fibi à natura deftinacos cvolvere. gne incrunfecus lacente fluxilis materia apparatum in fuos files urgente. Nam, ut fuprà de folari globo difieruimus , fieri Ion poteft, ut globus appropriatam fuam virtutem in finem., b quem Naturæ Opifex eam globo inferuic, exerat, niff per netarius oncinuum mocurn, \& motum quidem circulationis. Totus quomodo nim globus in inferiora virtute fuâ iufluxiva agit ; totus au birtutes fume em agere non poflet, fi fuperficie cantùm tenus virtutem. uam exfpiraret, atque adeò interior centralium partium conticutio otiofa à natura infticuta videretur. Quare certò tibi erfuafum habeas, perennem hanc liquida materia pericylofin inftituram, ut ea corporum in vifceribus globi latitanium, vi ignis pariter ibidem à natura reconditi, virtute multilici cincta imburaque vim acquificam ad extra diffufam, dende per radiofam diffufionem circumfitis mundi globis ditribuerer, quemadmodum de Oceani terreftris mocu ad femialium racionum miscellas cxcis vifceribus latentes concitandas afticuto, fuprà diximus.

IV. Theodidactus. Eftne globus bic éx quatuor elementic Globu onfitutus? Cofmiel. Dixi jam tibi aliàs, non hunc tantim. Martisex lobum, fed \& careros omnes totius mundana machina non qualu ir eliis elementis conftare, quàm iis, quibus Conditor fapientif compofitum. mus chaos illud fuum primordiale conftitutum voluit, ut, is ade in mundi globos difpercitis, pro fitus ratione aliud ac 
aliud temperamentum forcirentur. Ignem hîc paffim vide fed à terreftri, caterorumque globorum, quoad accidentia di verfum ; tametfi radicaliter fumptus propriè \& eflencialice Veni ele- ignis elementaris fit. Nam, ut audifti, terreftris ignis eorum mensum in corporum, qua ei alimentum prabent, naturam odore \& cc fingulis glo-lore refert. Ignis folaris lucidiffimus \& purifimus purif botius globi $\mathrm{ma}$ fuae fubftancia naturam fequitur: Martius hic ignis par consenio. ter naturam fapit materiz Martix, à qua alimentum fufcipi \& fic de cxereris; hinc plenum vides veluti fuliginibus, \& va riâ bituminis piceæque materiæ commixtione imbutum ; 0 Aquew e. mnes tamen hax ignium differencia hoc habent ex natura fue lem: ntum ut fint calidi, penetrantes, \& perpetuò zftuantes. A queum el in globe Martic gmals. $\therefore$ mentum hujus Martii pelagi liquor exhibet, tametfi à reliquo rum globorum humore diverfifimus ; eft enim lentus, fqua lidus, confufus, \& fummâ materialis variecatis commiftione pollutus ; fi quis tamen chymicâ arte, eâ alembico impofit purum ab impuro feparares, is haud dubiè aqueum humorer inveniret, terreno, lunari, carerisque haud multum difimilen Ais Mar. Aër Martius ita fe habet ad globum Martium , ficuti aẻr terre aime. nus ad globum terreftrem, \& ficuti folaris ad Solem, lunaris a Iunam. Cùm enim aér rihil aliud fit, quàn: quoddam velut proprium globi cujuscunque effluvium ærheri commiftum. certè aërem ejus globi,à quo exfpiratur, naturam fapere necel fe eft, quamvis naturâ fuả non fecus ac terrenus, folaris, lu narísve fluidus fit, \& fummè mobilis; qui tamen adeò incer differunt, ut impoffibile fit, hominem in ullo dictorum glo borum aêre, nifi in eo, quem refpirationi ejus Conditor asfi Terreum e-gnavit, videlicet terreftri, naturaliter vivere. Terreum elemen dementum tum tibi faxea hujus globi moles exprimit, quamvis \& hoc in globo Marriso terreftri toto coelo differentibus qualitatibus difcrepet : nam. ut vides, faxis \& fcopulis conftat duriffimis, fulphuri, arfenico auripigmento, antimonio, ferruginofis molibus cautibusqu noftris mineralibus, quoad afpectum haud diffimilibus; qua faxa arte chymicâ in principia fua refoluta, pulverem relin guent cum pulvere terreno guoad audam fubstantiam fer eundern 
undem, Habes icaque hîc quatuor elemenca, non quidem :ondicione terrenâ, fed, pro Marcii globi condicione, Marcia.. ?orró fi per continuam puri ab impuro feparationem elenenta ad ulcimum gradum reducerentur ( quod tamen fieri Ion poteft ) certè omnia globorum elementa ad hunc termium reducta, cadem prorfus quoad nudam, ut dixi, fubftantiam orent. Hincluculenter colliges, diverfas elementorum qualiates hucusque confideratas, non aliam tanta diverfitatis caum habere, nifi diverfas globorum vires \& proprietates, quius imbuuntur : caterùm quoad naturalem motus inclinatioem à terrenis non differunt; habent enim fingula globoim elementa fuum centrum, quod appetant, fi gravia; à quo centrum imoveantur, fi levia : fic folida corpora hujus globi, cujuseí. artes funt, naturali fympathiâ Martem expetunc, eique fe inmâ pronitate, nulli alceri conjungete geftiunc; levia verò fluida, uci igne $x$ exhalationes à centro globorum furfum. ergunt, quia hoceft corundem natura confentaneum, \& ad opriam atmofpharam confituendam neceflarium. Theodactes.' Jam ita diftinctè, clarè, \& fcicè fingulorum hujus obi arcanorum raciones juxta analogica arcis amuffim adnatas defcribis, ut is convictus fidem non polfim non bere.

V.Sed agedum, nunc expone ergo, quænam, \& qualis fic propriata hujus globi virtus influxiva. Co/miel. Virtus pro vis infuxiia eft cholericum in inferioribus movere humorem; aftusa Marti rniciofo, \& caufticâ quadam vi imbuto omnia infeftare : un. quamam? $\boldsymbol{h}$ vis influxiva in terreno globo fubjectum invenerit prortıonatum, illud virtute fuấ imbutum ad vindıctam, furo$m$, cades, carerasque iracundo homini proprias qualicates clinar. Unde ab Aftrologis longâ omnium feculorum exrientia doctis, \& univerfo nationum confenfu, jure merito obus hic Martis nomen, ab effectibus,quos caufac, introduam obrinuir. Theodidactus. Ergóne tu judiciariam Aftrogiam approbas? Co/miel. Abfit, fili mi; eft enim aliud aftrogia judiciaria, aliud vircus influxiva,de qua ago: illa,pracer-

$$
\text { I } 2 \text { quàm }
$$


Afrologis judic intia Ganitas.

afection Moriji.

quàm quòd Deo humanaque voluntacis arbitrio vim inferat, vera impietatis magiftra; incercis quoque \& arenaceis fundamentis nixa, innumeris nugis fabulisque mentes mortalium involvit; hac autem veræ Pbilofophix fundamenta docet, quibus nixus Martiarum influentiarum caufas attingere poffis ; \& uti illa plurimùm mentitur, ita hæc plurimùm experimentis irrefragabilibus fulta meticur, vera coleftis phyfica directrix. Theodidacl w. O divine magifter, expone, quafo, effectuum Martiorum racio. nem \& modum. Cofroiel. Ne quicquam arcanorum te celaffe videar, totum te myfterium familiari experimento edocebo Fiat globus ex fulphure, antimonio, auripigmento, arfenico naphta, bitumine unà fimul commixcis : quem fi in loco clau So accenderis; continget, refoluto vapore globi, mox capu fummâ vertigine infeftari, cor heparque vehementi aftu ac cendi, tandem membris tam perniciofo vapore invafis, totum maniaco quodam furore, tremore membrorum, roriusque cor poris convulfione corripi fenties, Idem in globo Martio fier cenfere debes, qui cùm analogâ ad res memoraras mifturâ con fter, hinc fir, ut virtus influxiva globi effectus quoque dict is i terreno mundo effectibus analogos, ubicunque proportionatun difpoficumque fubjectum repererit, five id ex fentientium, fiv ex vegetabilium, mineraliumque oconomia fit, efficiat; pluri mùm tamen fitu globi recto vel obliquo ad terrenam fuperfi ciem comparato ad effectuum intenfionem conferente, uti \& alterius fideris maligni cum Martio globo coitu, quo miftis u. triusque globi malignis qualitatibus dici vix poteft, quantum $\nabla$ influxiva ad effectus noxios \& peftiferos producendos intenda tur.

V I. Theodidact ws. O quanto intellectum meum,tam ele ganci \& pulchrâ comparatione, lumine imbuis ! Sed hoe u num fummoperè me angit, cùm concipere nulld ingenii v polfim, cur Natura, quæ bonum femper incendit, tam perni perniciofus ciofum \& exitiale globi monftrum in natura rerum conftitue cum in calo rit. Cofmiel. Theodidacte, parum te in arcanis philofophia confitusks.

- profecifle video, Si nolles, quare Deus Opt, Mar. in aaiman 
tium œeconomia viperas, bufones, araneos, dracones, oppidò perniciofum mortalibus venenum ; inde vegetabili narura herbas, plantasque lechifero toxico refertas; nec non in mineralium regno arfenicum, auripigmentum , fimiliaque produxerit ; malignos quoque globi Martii influxus non miraeris. Scias itaque,globum hunc eo fine à fumma Dei providentia hoc in athereo fpatio collocatum fuife; primò,ut quidguid virulentia ex reliquorum fiderum malignorum influxu 2ualitates abalaretur, id totum hic globus infitâ fibi aviditate in fui liquorum autrimentum attraheret, non fecus, ac bufo co fine conditus fiderum asof , ut quidquid veneni \& exitialis qualicatis in terreftribus trabuntur lebis lateret, tanquam in vivam veneni burfam atcraheret; globo, icut puod idem de ferpentibus \& draconibus dictum fit. An nefcis, in terreftri raneum omne venenum, quod in aëre difperfum laticat, ne globo malierpendo longè lateque aêris inficiac fubftantiam, in fe mirâ tases qualiuadam fympachiâ attractum derivare? quod nifi fieret, non na à benearum humani generis falus ex tam perniciolo intoxicata nofis reptium terræ, tum aëris afflatu periclitarerur. Ne verò Martis iolentià tellus impetita manifeft $x$ pateret ruinæ, natura eum Martios n omnium maximo excentrico collocari voluir uri infri glubes cus

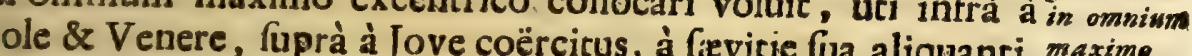

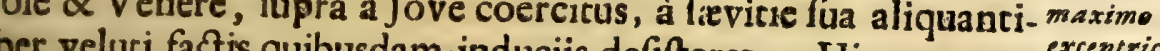
per veluti factis quibusdam induciis defifteret. Hinc quoque excentrica
conftitum eft, ut globus Marcius circa axem fuum revolutus non emper easdem peftifera qualitatis plagas, fed fucceffivè nunc Marscur irulentas, modò temperatas, paulò pòft efficaciâ vircutis in-circa prognes oftenderet; ande in excentrico fuo motu, qui circa axem ${ }_{\text {trum fols }}^{\text {prito }}$ [, temporum fucceffu, novas differencesque femper effectuum basur. ombinationes molitur. Non aliam quoque ob caufam inter lartis \& Saturni diffonos globos, ex guorum evaporatione mnia mundi fublunaris mala originem habene, Jovem beigniflimum fidus, \& mirâ quadam harmoniâ refertum, inrmedium, veluti litium exortarum diribitorem conftituit, ujus falutifero influxu utriusque prorfus perniciofa vis coibita \& attemperata refrænaretur, ne laxacis faculcatum exialium habeais, globus folitâ fûâ malignitate in apertam to- 


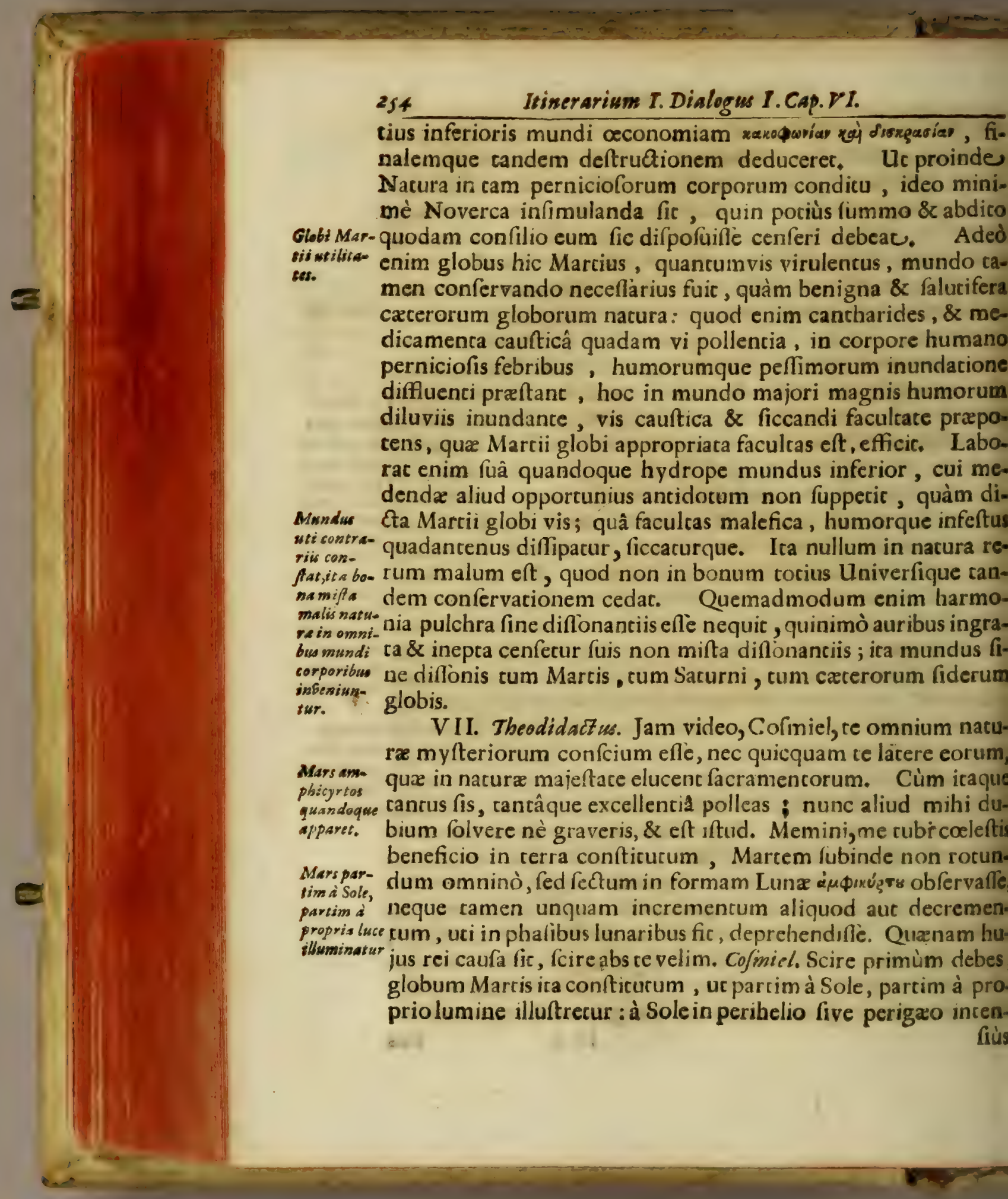


Giis cum illuminari experiencia docer, in aphelio five apogzo verò non item, fed notabile lucis decrementum pati eum, fubfulcus, rucilus \& panè fanguineus color fac fuperque docet. Atque hujusmodi color non nifi à propria luce hujus globi efficiur ; vides enim omnia hîc veluti fulphureâ quadam \& bitumiosâ flammâ ardere; atque hrec ad globum illuminandum fuffiit in abfentia Solis remotifimi. Eft autem in hoc globo quax- Mars bifelam plaga immensâ intercapedine exporrecta, planities lu- quando ấa: is omnino expers, \& veluti luculentum quoddam mare, feu parest. iceum pelagus, ob lentorem fuum neque ullo humano veftiio, neque navigii fubfidio pervium. Theodidactus. Oftende, ogo, hocce globi prodigium. Cofmiel. Fiar. Theodidactus. Luo dicto, procinus fublatum me in locum defideratum translit. O horrorem! ó fpectaculum formidandum! verè,uti diifti, piceum mare video, non tamen liquidum, fed pulcis inar condenfatum, ubi nullum flammæaut lucis veftigium, fed mnia horrida, confusâ caligine fqualent, nec lucis directæ, nec Alexæ capax, vel ipfum diem atrâ fuâ fuligine in noctem. ertens. Cofmiel. Harc eft illa pars globi Martii, quam tubi eneficio è tellure frepe non fine admiratione intuitus es, Cùm Pasceum ing iim lucis omnis fit incapax, mirum non eft, terrigenas, qui globo Mars cidas tantùm globi portiones intuentur, hanc non percipe- ${ }^{t i s}$. , ac proinde neceflariò globum Marcis veluti fectum, in for-

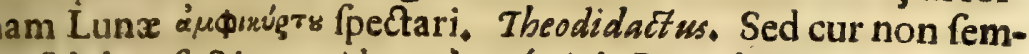
ar fub hac fectione viderur? Cofmiel. Ratio hujus rei eft globi rca centrum fuum circumvolutio, quấ dicta plaga modò mafeftatur, modò occultacur, ficuti \& de voragine fuprà dixius: hanc quoque modò prodit, modò recondit,diverfús gloin fuo excentrico fitus. Theodidact us. Rem optimè capio; quis/fth th rogo te, cùm natura fruftra nihil agat, quo fine tanti fqua- planititie ris plaga in hoc globo pofita fuit? Co/miel. Ult effer velutipe- pabe pelaggi uarium quoddam feu promus condus alimenti iftius, quo glo. picti. is nutritur : Ex hoc enim per intima vifcera copiofum igni renni, qui hoc globo continetur, veluti fomentum quoddam tribuitur ; ignearum verô exhalationum fuligines in altum

cructa- 


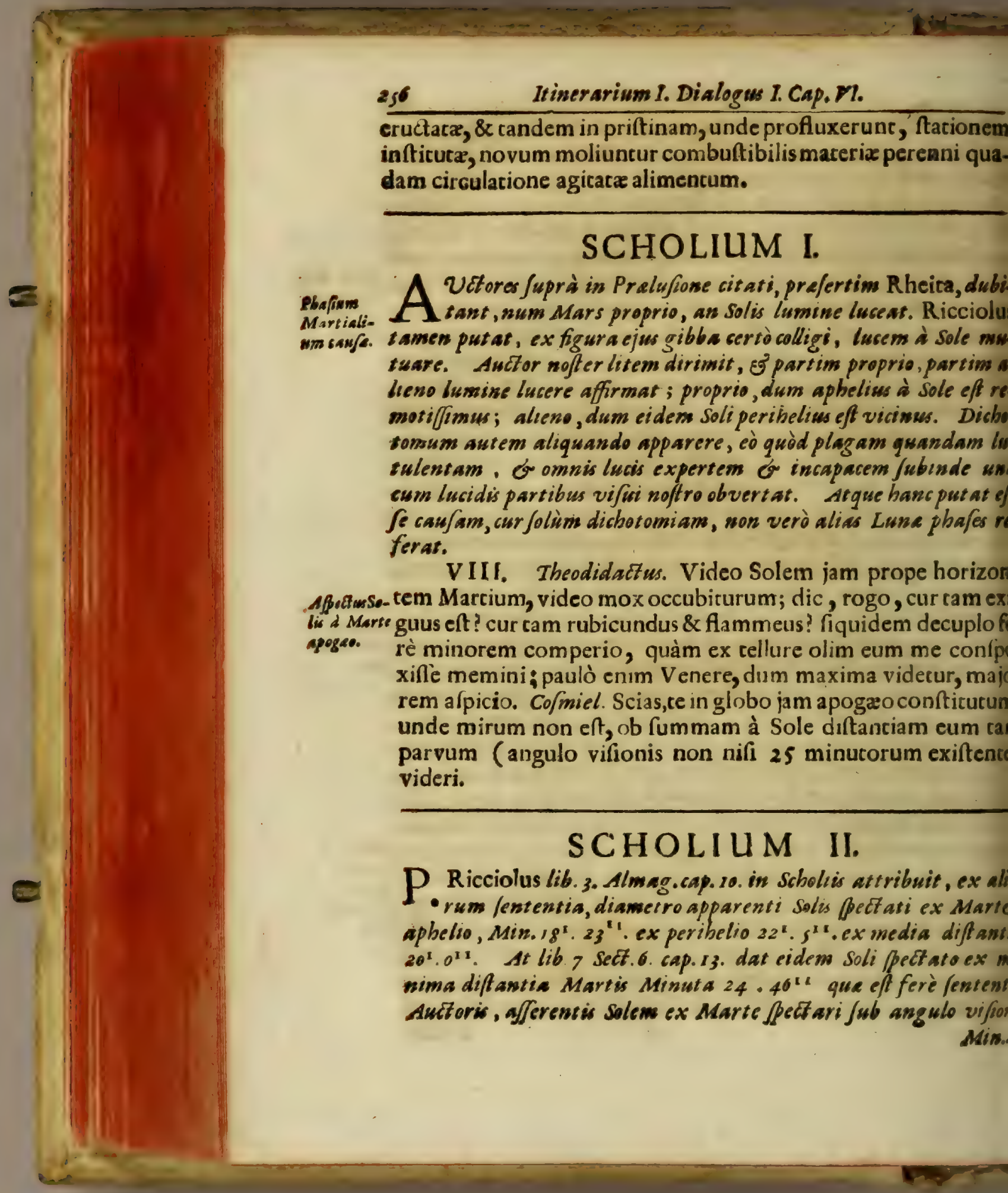


11n.25. Auctor tamen videtur loqui de diftantia maxima Martis: obely.Rheitalib.4.cap.2.Memb.s.afferit, ininediadiftantia ßpecta-i Solem ex Marte fub angulo $20^{x}$.

IX. Theodidact us. Miror equidem, quomodo tam exigua Marslumine, diem camen claritate acualem faciat noftris diebus, men propriIm Sol fuper horizontem terrenum emergit. Cofmiel. Caufa ujus claritatis eft propria globi lux, quam tum fulphureus $\mathrm{O}$. tanus, tum crateres Vulcanici perpetuâ ignium flammaImque eruftatione efficiunt; qua luci Solis tametfi debili îta, lumen tamen mirificè intendic. Qua luce propriâ fi obus hic Martius deftitueretur, Sol vix tantâ claritate gloim hunc illuminaret, quantâ Luna plena illuminat tellu$m$. Et hoc intelligas velim de eo tempore, cùm Martius reotiffimum à Sole terminum attigerit : ubi enim proximum li fitum obcinuerit, tunc dies hujus globi clariffimus eft; $i$ ò ob caulas dictas diebus veftratibus multò clarior luminorque. Pater itaque, pro motu globi in fui à terra receffuacfiuque, dierum quoque claritatem vel decrefcere, vel creere.

\section{SCHOLILIM III.}

I Sol ex maxima à Marte diftantia apparet Jub angulo minutorum, non $25^{\mathrm{x}}$, $/ e d 18^{\mathrm{I}} \cdot 23^{1 \mathrm{x}}$ ut Ricciolus ex aliis habet in predenti Scholio; merito dubitatur, an Martem illuminare queat. $d$ de hac re iterum erit Jermo infra, cium de lumine ftellarum arum agemus.

X. Theodidactus. Sed cur tam fanguineus apparet. Co/miel. Mars sanper vitzum rubro colore tinctum Solem afpiceres, quonam zuineo colo$m$ colore vifurus effes? Theodidactus. Arbitror, quòd colore tur ? $^{\text {recket }}$ , qua vitrum tinctum eft, videlicet rubro. Cofmiel. Ob eanent rationem ex hoc globo Solem intueris rubrum; quia m medium five aër Martius, eo colore, quem fulphurei macolor fubfufcus refert, \& flammigeræ evaporationes hujus $\mathrm{K} k$ coloris 


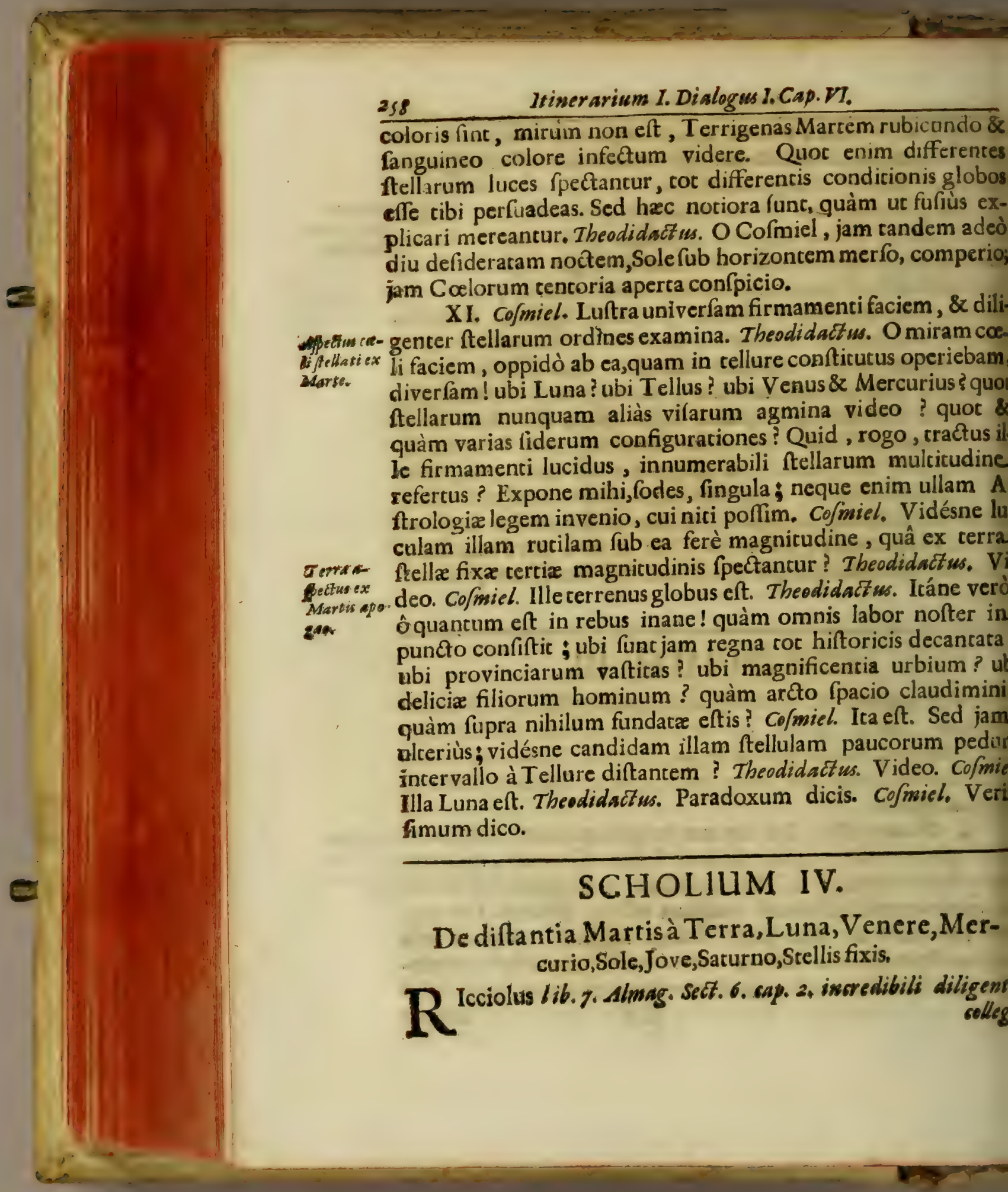


Ilegit in unum fententias variorum Audtorum circa pradictam Laris diftantiam. Ipfe verò determinat eam, ut fequitur, in feoidiametris Terre; quas fo multiplices per $344^{\circ}$, babes eandem ise villiaribus It alicis.s.

Maxima diftantia Martis; in femidiametris Terre, ex Jententia Riccioli, ì

Cerra
21005 $\left|\frac{\text { Luna }}{21079}\right| \frac{\text { Venere }}{19776}\left|\frac{\text { Mercurio }}{17725}\right| \frac{\text { Sole }}{13932}\left|\frac{\text { Jove }}{52947}\right| \frac{\text { Saiurno }}{95550}\left|\frac{\text { Fixis }}{207627}\right|$

Ne mireris diftantiam Martis à Luna majorem effe, quàm Terra, quia,ut babeatur utriusque planete diftantia mutuas axima, debet inter utrumque intercedere Terra, ut Luna fit reectu Martis apogea: diftat astem Luna tunc à Terra jemidiaetris pliss quàm of ex fententia Riccioli lib. 4. Almag. cap. I 40 ui numerus fi addatur ad 2100 s, diftantiam vid. Martis a Ter3, refultat diftantia ejusdem à Luna (emidiametrorum 21069, on 2:079. Simili de canfa major eft diftantia Martis aे Venere, sism à Mercurio.

Theodidactus. Sed cur tam immotam video? cur Telluri Lnne abem vicinam ? Co/miel. Scias, tantam à loco, quo confiftimus, Mus ex Lunam Terramque diftantiam effe, uc totius concavi Luaris diameter non nifi 6 pedum intercapedinem oculis no-Difantia ris exhibeat; hinc pro diverlo Lunz in fuo circulo fitu, mo. Martis 2 o vicinior, modò remotior fpectatur :, tametfi nunquam di. Terra, Lktam intercapedinem excedac, fiquidem excelliva diftantia rio, $V$, nere, ujus globi 21079 femidiametrorum terreftrium, toram \& a pettus oncavi Lunaris diametrum 2736 femidiametrorum terra, ex Marte

in hasce anguftias juxta opticas leges coarctat: unde mirum non eft, eam cotam immotam videri. 


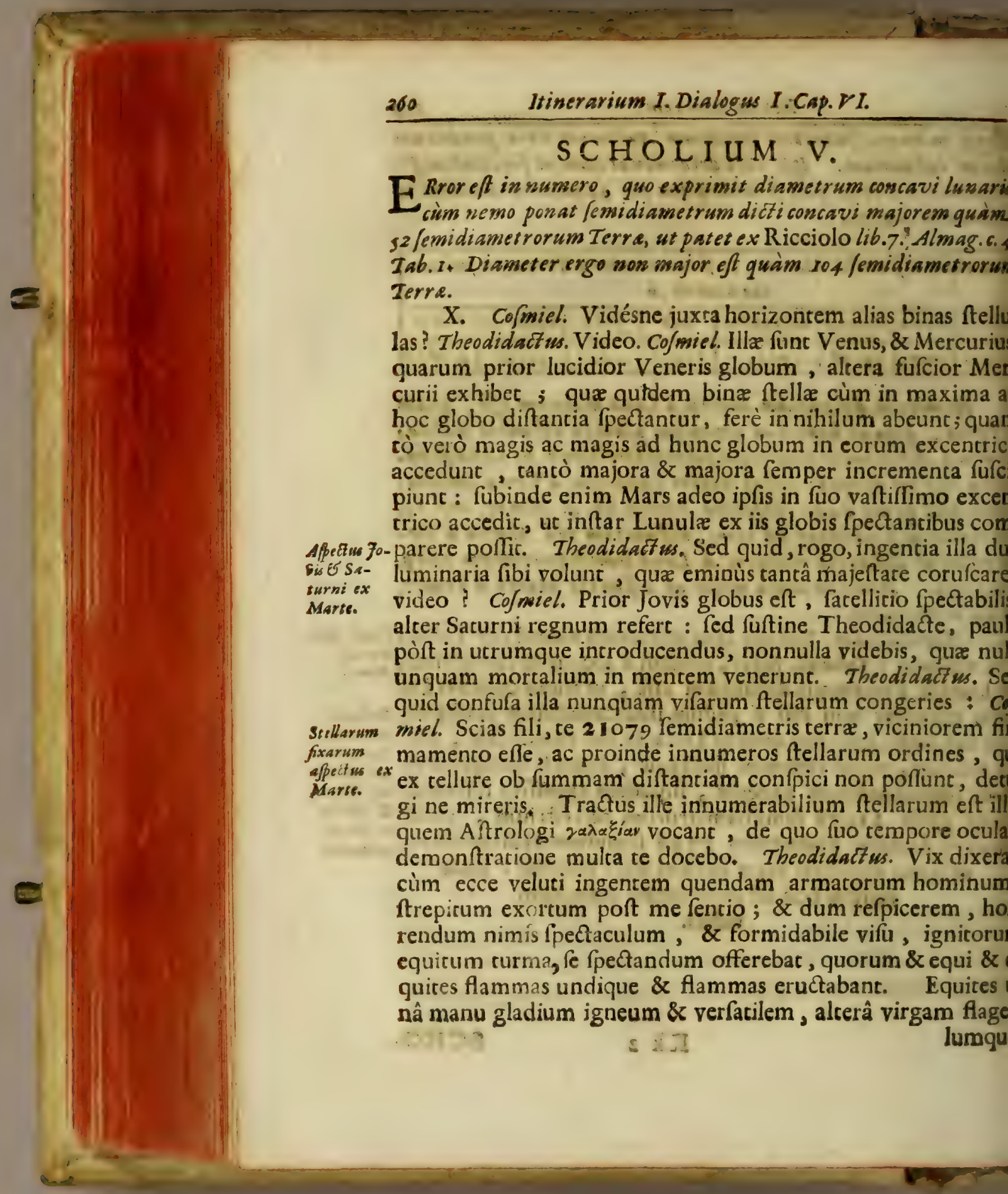


umque, furoris indicium, paricer igneum geftabanr; vultu ummam pra fe ferebant ferociam; oculis igneos fundebant adios. O miCofmiel, veni, adjuva me, formidine enim panè oncidit cor meum, membra horrore rigefcunc, \& ad horrenum hujusmodi fpectaculum vox faucibus haret. Co/miel. Ne imeas fili; hi quos vides, non damones, fed prafides hujus lobi funt, divina juftiria miniftri. Hi fi quandoque juftâ Angeli fablei permifione, \& hominum iniquitate ita exigente, glo- inde in glo- bis pernicium hunc in ulcionem \& vindictam concitaverint; in inferio- ofas qualii mundo omnia fusque deque feruntur, fediciones, pralia, ca-tates concies, urbium atque regnorum everfiones, peftilentia , fterilicas, cant ob bec- bomiui hujus globi effectus funt, Orbem terrarum in ultimam tan- $n$ um. im non ruinam deducunt; \& hoc fymbola, quibus hi præfides renii adornantur, fatis demontrant: Theodidact us. Sat eft, mi :ofmiel, fat eft , fiquidem operum divinorum 'magnitudine \& sajeftate pænè obruto mihi nihil reftat ampliùs, quàm videre um, qui omnia in omnibus operatur, cujus magnitudinis ac poentia nec numerus, nec terminus eft. Agedum, relinquamus xtidum hunc globum, \& purioris atheris aurâ fruamur. Vix ixeram, cùm ecce relicto Martio globo, in excelfa mundi fparia erimur.

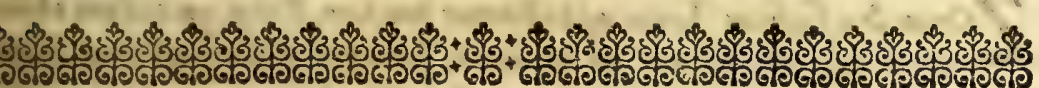

$$
\text { PRELUSIO IN JOVEM. }
$$

Upiter, planet a celebris ac proper, majorque ob fupiter. id fortuna ab Aftrologis nuncupatus, Jupra Martem baud dubie fuos exercet circulos, quia 2 mutuis amborum fynodis ab ipfo Marte ocultatur, Ev oculis noftris furripitur bujus obje7u, non fecus ac Sol intercurrente Luná. Sidus Kk 3 hoc

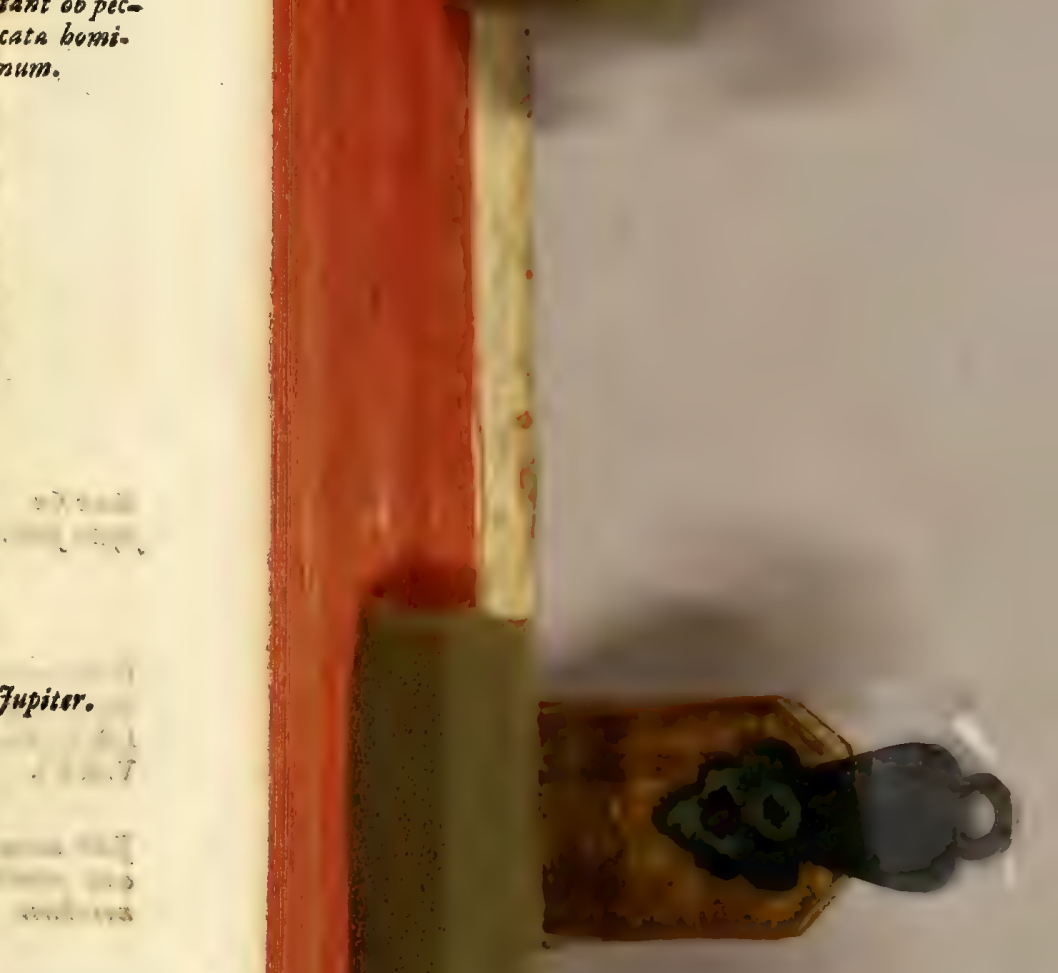


boc celebrius adhuc reddidit, primum quidem de novo deprebenfus ab Aftronomis noftri feculi comitatus quatuor Satellitum, antehac invijorum, E5 Anno I610 à Galileo in It alia tubi optici beneficio detectorum : deinde ipfins fovialis corporis multiplex ac varius zonarum feu fafciarum ornatus, quo non raró pect andum fe intuentium oculis aftronomicis fe exhibet. De utro que phenomeno hac Pralufione paulo fufius agemus, ex iis que deinde for is fructuram ac naturam mirabilem cum Auctore noftro rimari conabimur; quod pracipuè praftat ip/e fequentiC. pite.

6. I. De Zonis leu fafciis Jovis.

Zore fen

7 Onas feu fafcias fovis appellamus hoc loco, frias quas dam obfow

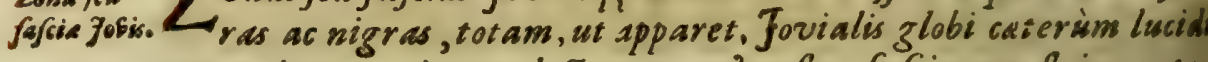
convexitatem circumplect entes, $\sigma^{2}$ inflar fafiarum fringente nunc plures numero, nunc pauciores, $\sigma^{3}$ modo in redtam lineam ex. Vide Iconi-ten/as, modò arcuat as arcuumque cavit atibus Jubinde fur/um, alids fmi IX. Fig. deor/um vergentibus, nec cum eadem femper inter fe diftantia, ne I.II. III.IV. ejusdem aut amplitudinis aut gracilitat is femper, pront in appofi.
V. \& VI. V. \& VI. ejusdem aut apuris apparet.

Fo6is zones quis primo motaferit.

Has Zonas feu facias notarunt primi, quod fiatur. Nespoli P. Joannes Baptifta Zupus, \& Francifcus Foncana, of P. Danie Bartolus. Easdem deinde lapiffme vidit Boxonia P. Joanner Baprifta Ricciolus, \& P. Franufcus Maria Grimaldus, qui now modo earum wumerum, (ed fitum eriam ad Eclipticam of Aqum serem objervarunt, \& accuratifimas carum figuras in charin 


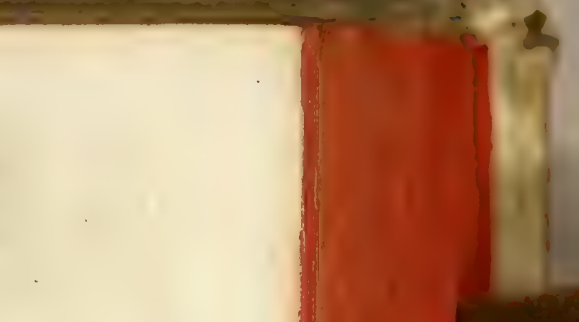

(11)

ifiti
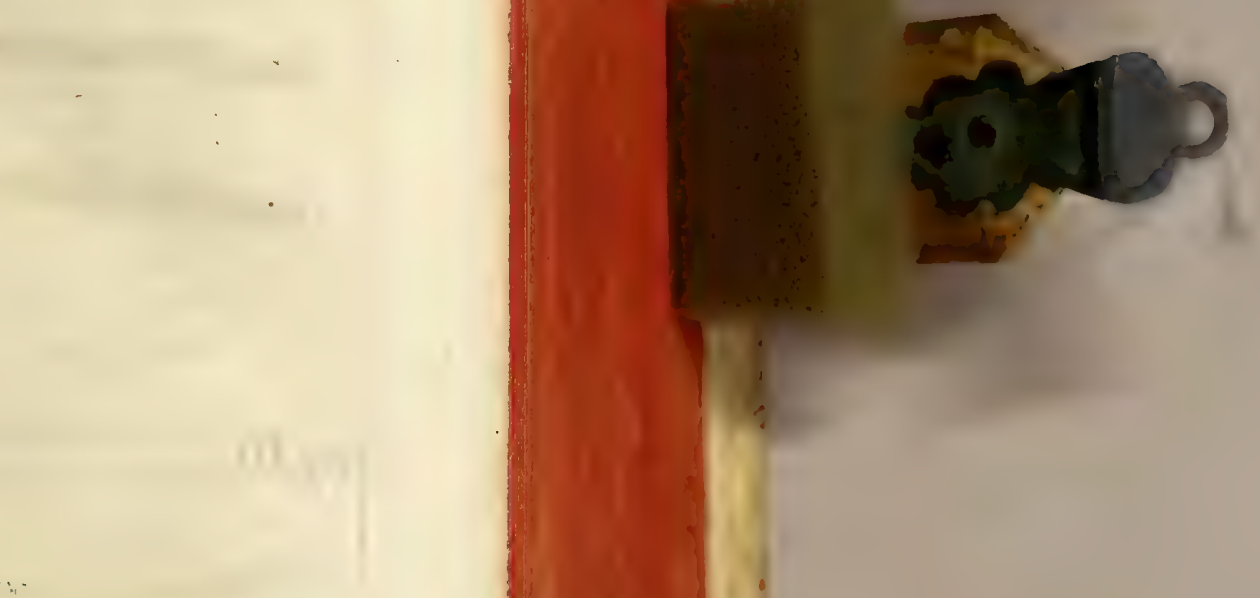

.

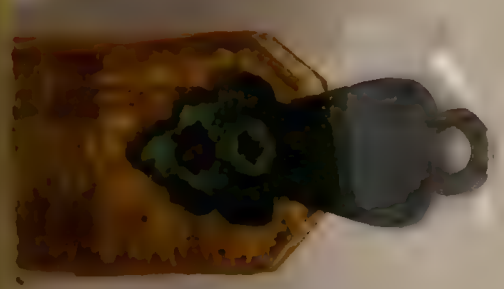




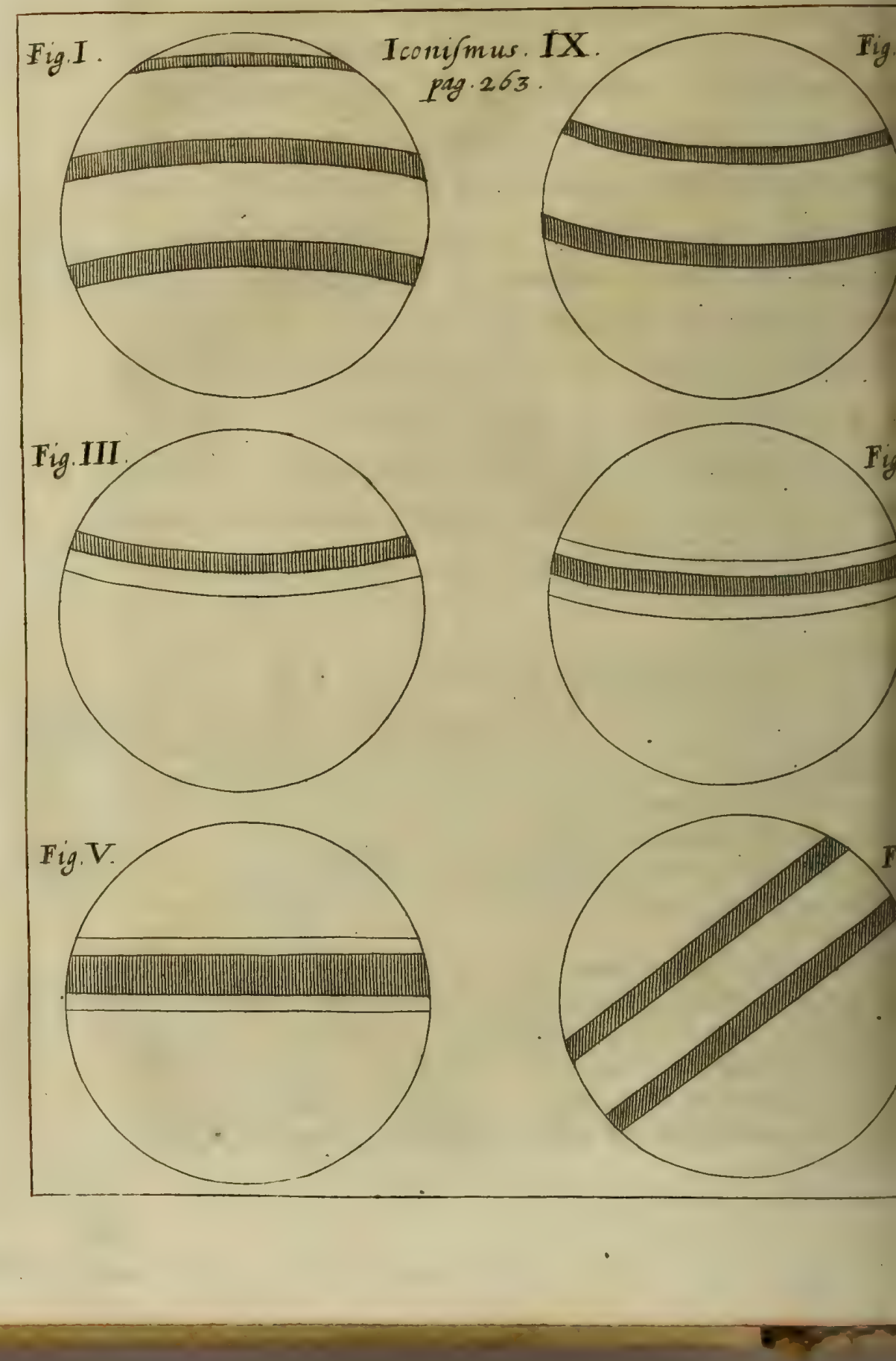


linearunt, gwarwmiamen fex tantum fequentes, omnem ferènaetatem bujus phonomeni continentes, inferwit Almagefto lwo icciolus lib.7.Sect.r.cap.2.num.6. in quibsu tamen Fovialis difci agnitudo minimè exprimitur. Explicationem ipfis Ricciolt veridnumero,omesfos nonnullis.

Prima Figura fovew ex bibet cum tribus Zonis, fupremâ taen anguffiori, quarum convexitas furfum, cavitas deorfum vert. Ita vifus est Anno 1039.Maji22. die uno ante oppolitionem vis cum Sole. Tres quoque fafcias vifas Neapoli narratur. in ontane Obfervationibus tract.6. Amno 16 43. \%1646 Jan.28.quaim tertia erat in margine orientali : fuerat verò oppofitio fovis m Sole Anno 16 45. Decemb.21. Sed Ricciolus ait, tunc vifum effe cum rabus tant ism falcios, ust mox dicetur.

Secunda Figura babet Fovem cum duabus falsiis, valde inicem diftantibus, $E$ convexitate deorfum, cavitate fur/univerme. Talis vifus est Neapoli Anno 1644. Jan.20.21.22. \&े P. Zu0 , cim effet Sole orientalior Gr. prope 80: E' Rome Anno 1630. 1aji 17. \& P. Nicolao Zucchio circa quadratum cum sole appeim : Eै Bononia Anno 16 47. Jan. 23. qua nocte fuit soli oppofius: E⿱ iterum Neapoli Anno 1645. Fan. 21. borâ noctis $2 \frac{1}{2} ;$ qua. octe fuit cjus cum sole oppofitio: Gu iterum ibidem eodem Anno, ec. 31. ac denuò Anno 1646. Jan. 1. E 20. Fanuarii autem die : emerfot in margine orientali fovis tertia Zona, de qua in prima ig.dictum.

Tertia Figura oftendit Fovem cum duabus fasciis, fed fibi inicempropioribus, \& inferiore valde gracili, vifis à Ricciolo Bomia Anno 1643 ab initio Octobris, per plures noctes, us que ad oppoionem Jovis cum Sole, qua incidit in diem 13.

Quarta Figura Fovem offert cum latiori zona, do paule uàm antea inferiori, duabus gracillimis zonulis utrimque $p a-$ allelis circum/ept $\hat{a}$. Talis fuit vifus Bononie paulo post oppofitioem Fovis cum Sole, Anno 16 43.aे die Is, usque ad 20. Octobris, Semer prope Mersdianum. Hujus phonomeni meminit etiam P.Kirherus lib. 1. Artis Magne Lum. Eq Umb.cap. 4. adducto eodem bemate Bonowia ad Je mijJo. Et hactersus exhibwimus fovem 


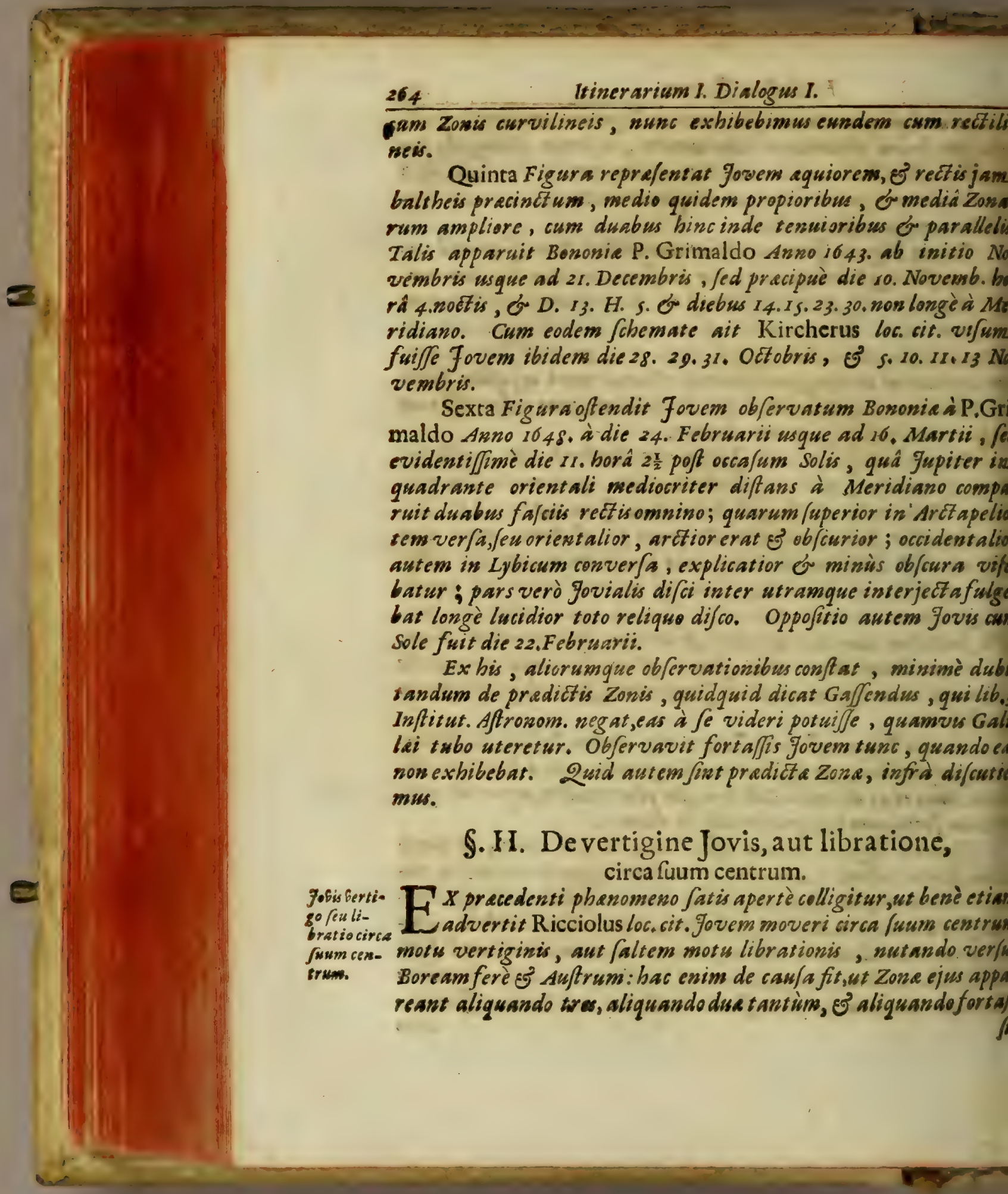


snulla ; $\sigma^{2}$ ut videantur modo fibi efle vicine, \& exiles, modò d invicem remotiores on ampliores; ofe.

Rheita tam conftanter defendit motum bunc vertiginis, wt deat etiam tempus determinare, intra quod integram juam, ertiginem abfolvat, $\}$ definire, quot vicibus vertatur circa Jun strum toio illo tempore, quo unam integram periodum in orbe perficit motu proprio, nimirum toties, quoties Sol gyretur circa rram featio dierum 365.bor. s.min. 48. quo nimirum temporis stio perficit periodum integram in fuo Excentrico. Fundamenmaliud non babet, nifi magrum illud $\&$ nemini revelandum (etum, de quo /uprà Schol. 2. in caput 3. ex ipfo lib.4. Oculi Enoch Elie cap. 2.memb. 3. Cujus fententiam cum lequatur etiam inAuctor softer in Jove, ut fuprà fecutus fuerat in Venere 8 ercurio; ejus fundamentum iterum repetere, of clarius explienon pigebit in corum gratiam, qui Rbeitalibro carent: lufortafis prabebit aliis, quam wos non videmus. Sicergo difrit Rheita: Planetas circa proprios fuos axes continuo gy-Rheita opt i rotarique ( exceptâ Lunâ ofcillante folummodò ) apud me niode ferdem indubitatum eft. Sicut enim impolfibile eft globum. tigine plaplanum currencem non illicò, dum motu progreffivo movetur, etiam circa proprium axem gyrari interim ; fic nino vix poffibile auc credibile cenfeo, planetas periodice fuos orbes delatos, non etiam circa proprios axes rotari. Et dem Jovem ita diurno motu gyrari, phænomena Jovialia nino arguune \&C. His premiffis determinat, Solem gyrari Vertiginic a funom centrum or axem patio annuo, ita ut tempore eft at is gutorum ertat Terra hemi phorium Jum calidius, tempore verobye phanecarum alterum hemipherium minus calidum; quia bacratione pu phi ius,ex caufam phyficam ad/ignari poffe, cur Solinaftate, dum in apo tentic. est, intenfius calefaciat Terram, quam in byeme, dum est in geo. Hoc ft atuto, tanquam indubitato (quod tamen aperte faleffe demonftratur ex maculis Solaribus, ut fuprà vidimus) globos planet arum omnium, exceptâ Lunâ, taliproportione $8^{3}$ pore circa proprios axes gyrari or converti, eo temporis \$patio, Ll 


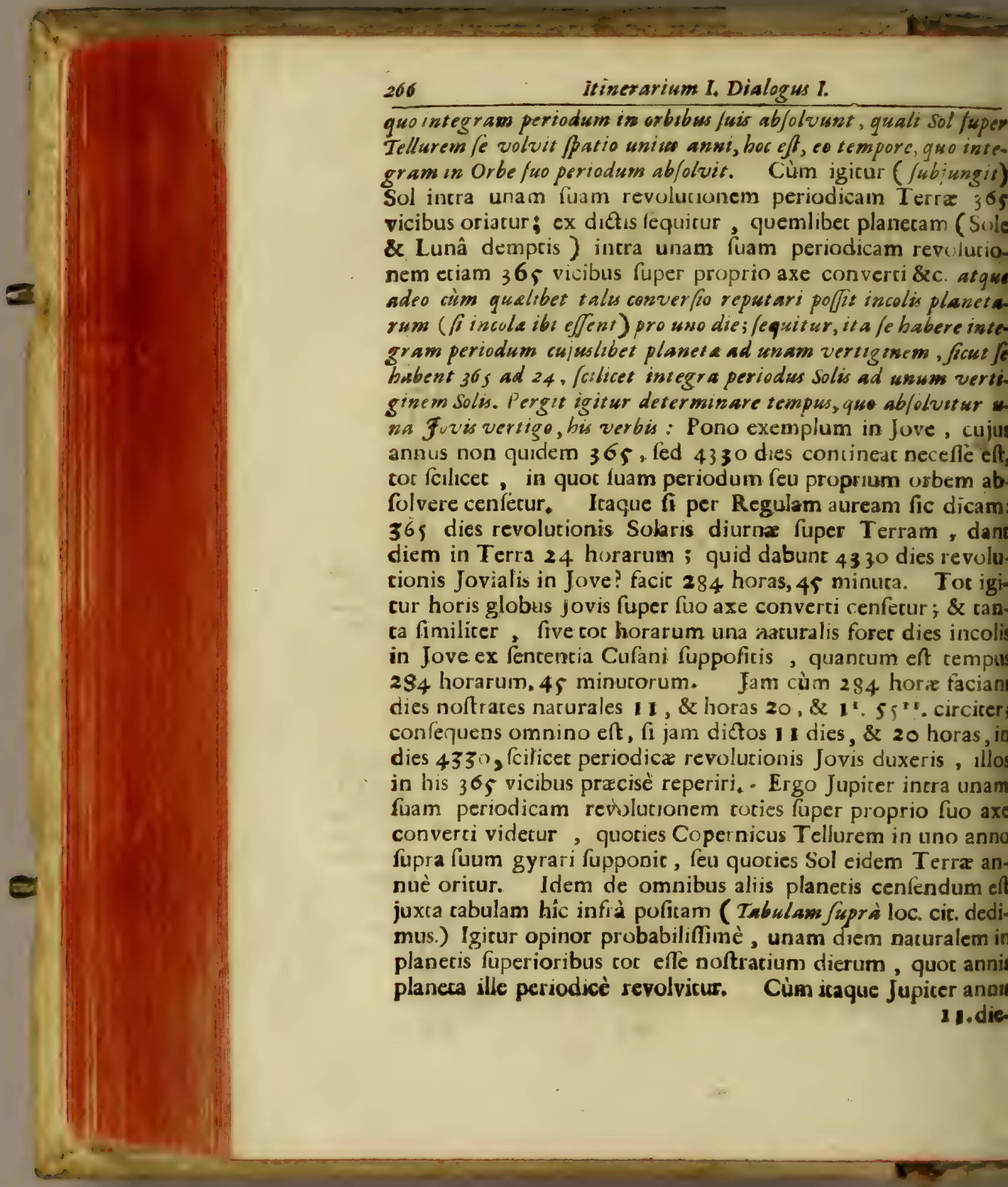


11. diebus 3 I 5 . orbem fuum emetiatur; eric una dies Jovialis, feu tempus unius gyrationis ejus, 1 1. noftratium dierum , 20 . horarumI'. $55^{\text {" }}$. circicer. Hec Rbeita. Sed nec fundamentum, ari innititur openio hac.folidumest, nec calculus bic exbibitus fibi undequaque conftat, oomnia tantum preter propter ac rudi Miuerva determisnntur; quodutique in re santi momentinon exirusum est visium. Egocum Ricciolo ob aliis effe indubitatum judico, Fovem aut vertigine aut libratione moveri sirca centrum fuum; ster autem è duobus ei conveniat, of quanta fit alterut risus periodus, adbuc incompersum puto.

\section{§. III. De Jovis atmofphæra, \& a peritate.}

Irca Govem vapidam videri atmo.pheram, alferit $\mathrm{R}$ heita in Epiftola data ad D. Caramuelem Antverpiâ :0. Augufti 1644 . in qua, indag ans quid effe potuerint nova illa quinque ftelle cira Govem i f $f_{6}$ ante biennium vifa, inter alia bac babet. Reor ergo, (cùm obfervationes mex fuerine fanè fidelifima) aliguid mirabile in \& circa Mundum illum Jovialem tunc foran actum fuiffe, monitrataque prcsligia verifimilia noftris Comeris, aut forfan etiam majora. Cùm enim Jovem fuâ quoque vapidâ armolpharấ undique circumfưfum cinctumque exactè ceneant, ut hodie haud fine Itupore fapius obfervamus, quid impedit, eadem (catera fi fint paria) in Jovis circumfula regione \& athere gigni poffe phenonena, qux in noftra telluris imperio vapido fapiuculè miramur? In exdem opisione est Auct or nofter quilape in boc Opere afferit, omnes Planetas habere Jwas at molpharas, prefertim in Prafatione Parenetics, ut ibi vidimus; ubietiain rationem addit, quia nim. omnes corftanst quatuor elementis. De Jovis igitur atmo/phara nulluns mibi dubiumest, eamque admistit etiam Galilausin fone Nuntii fiderei.

Aperuinquogue effe Fovem, \& quidemetiam circa margines montibus ac turnoribus evidentifime extantibus apparere, ait Ricciolus loc, cit. fuprà, ex frhemate in Italiam miffo ex L 62 Flan- 


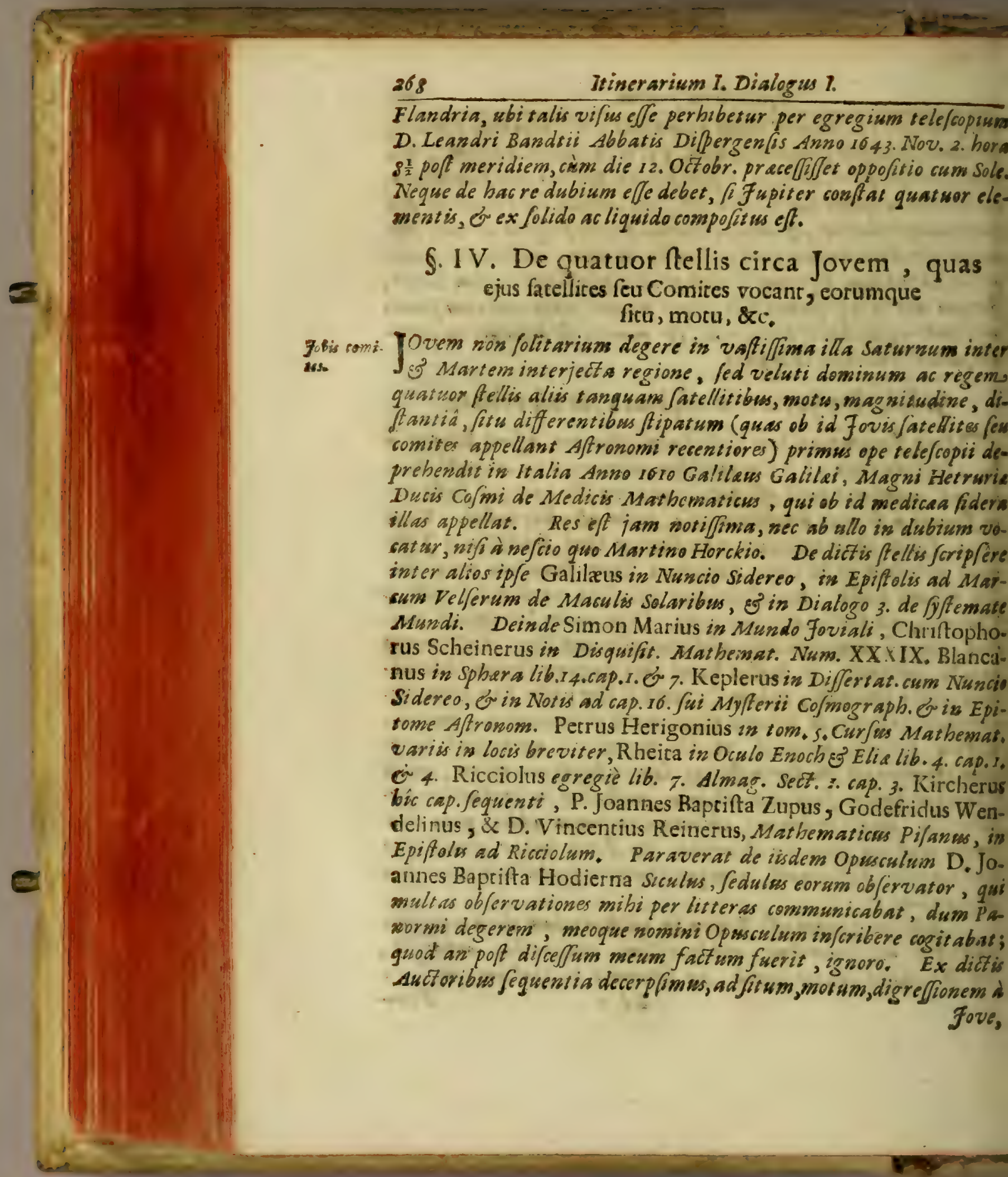




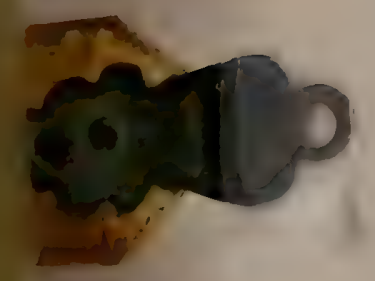

-

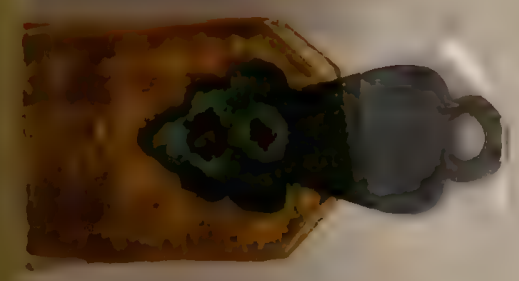




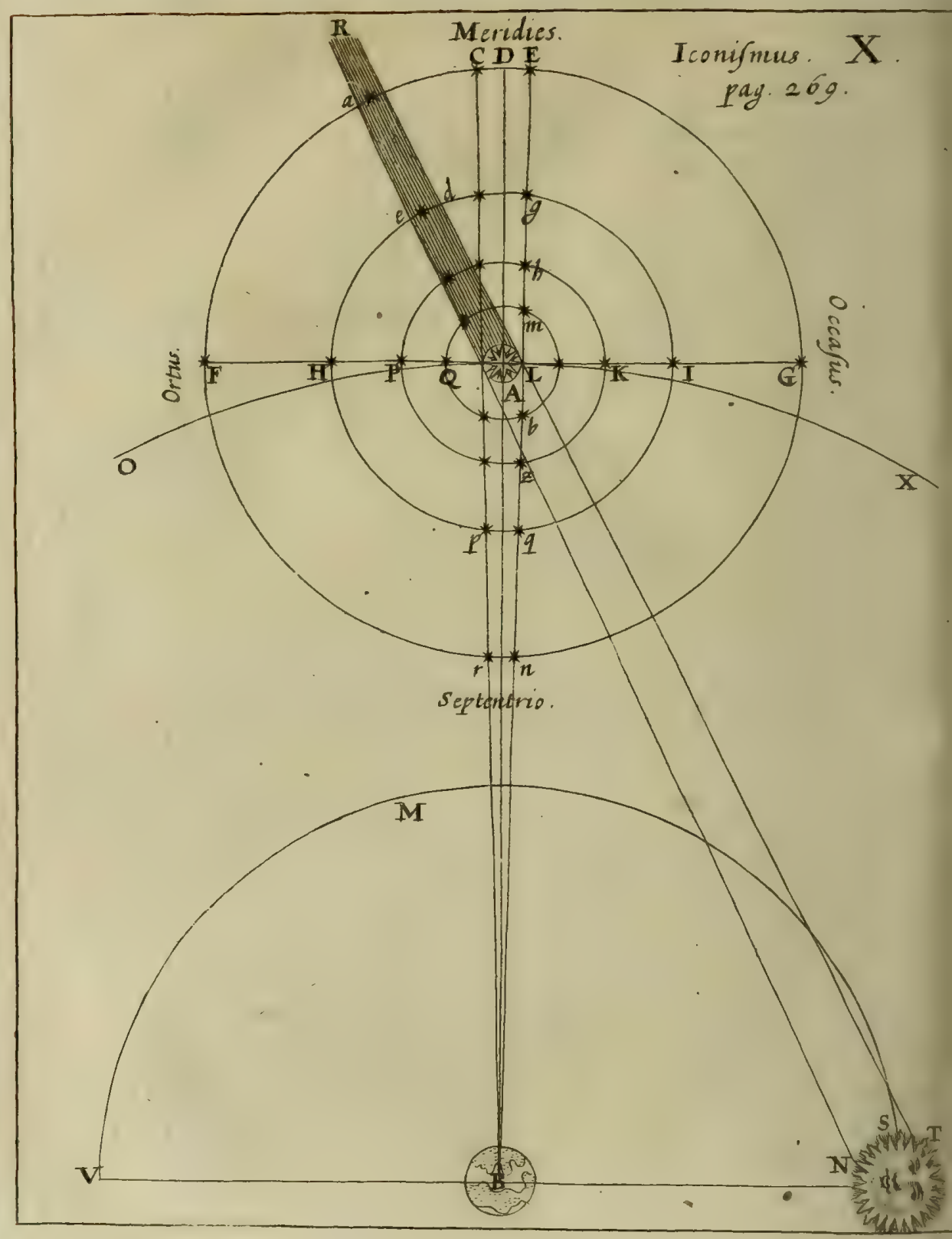


Quoad ficum of motum fatellitum Fovis, certum eft, onnes 70 bis conte noveri circa Fovem circulariter (vel faltem elliptice, aut alio fomi- tum fitus, mosu) non in codem circulo, feu in ejusdem circuli peripheria, alias accidin diverfis, quos reprefentat appofitum fchema Scbeineri, dentia.
lancani, Ricciobi, \& aliorum; in quo A eft Fupiter: B centrum Vide Icoerre, feu oculus ob/ervatoris in terre luperficie; circa quod est nifmum $\mathrm{x}$. rlum Solis $U M S$, calum Fovis $O A X$; Sol in S, illuminans Fovem, tumque costingens extremis radiis $N R, \Xi^{2} \tau R$; Fovis umbra coica (licet bic detruncata) A $R$. Circa centrum Fovis A defcripti ent quatuer circuli concentrici, in quibus totidem Jovis fatellites ovent us circa Fovem: nempe maximus of extimus $G D F$, in quo crimus $\sigma^{2}$ a Fove remotiljimus fatelles $G$ circumvolvitur in furiori parte pericyali in confequentia, fou ab occafu in ortum, mpe a $G$ in $D, E$ inde in $F$ \& in $\mathrm{r} \xi^{2} \mathrm{n}$, donec redeat in $G$ : deinde nextimus circulus Ig $H$, in qua penextimus Jatelles I volvitur I ing, is $H$, in $\mathrm{p}$ \& $\mathrm{q}$, donec revertat ur in $I$ : pofte circulus perztimus $K$ h $P$, in quo penintimus fatelles $K$ vertitur a $K$ in $h$ bc. tandem intinnus circulus $L \mathrm{~m} 2$, in quo intirnus jeu fovi prounus farelles $L$ volvitur ab $L$ in $\mathrm{m} \mathrm{J}^{2} c$. Effe autem quatwor dios fatellites focos in quatwor diverfis circulis, $\sigma$ in iis circa Jomoveri, colligitur tum ex diverfis eorum periodis, cium, ut poa videbimus, intimus longè celerius abfolvat periodum fuam. àm extimns; tum quia in majoribus a fove digreffionibus, mpe in lineis $A F, A G$, nunquam videntur coxjuncti, fed valSejuncti, ut in $F, H, P, 2$, velin $G, I, K, L$; at prope govem fimul Ssipati apparent, ut in $E, g, h, m, \&$ quo moggis ab co removen,eo naggis à fe invicem fejunguntur.

In bis sirculis cum fint pradicti comites fuperiores, ut in $E, g$, $m$, apparent reßectu Fovis auftrales, Eo in plaga antarctica, a ibi tendunt ad eclipfin fasi; at quando funt inferiores, ut in , 9, n, apparest boreales, \& in plage arctica, as in pari digrefpinquiores junt nobis, quàm ibi. quan ibi, quoniam bîc reveras 


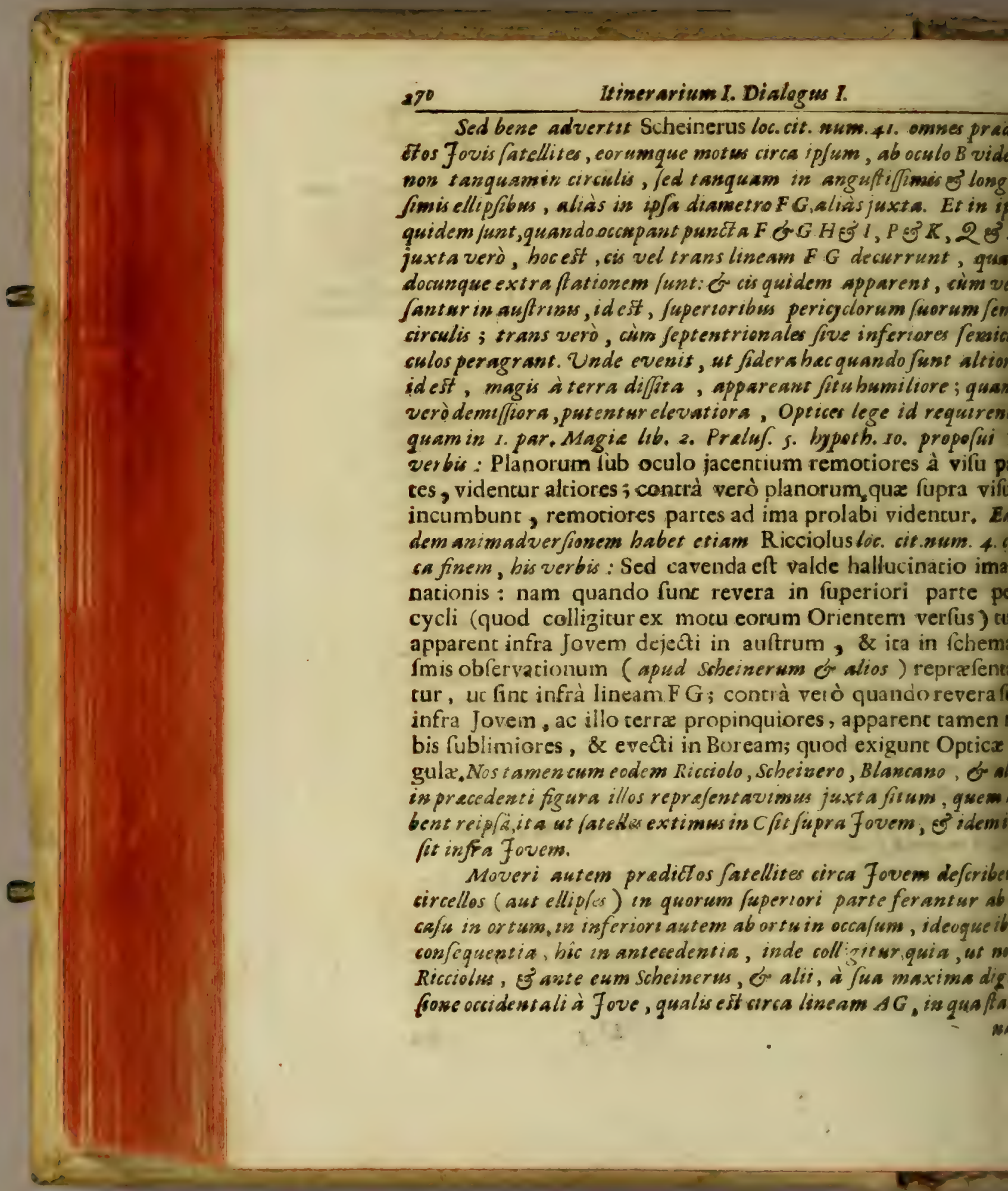


arii videntur, accedunt deinceps ad $F$ ovem orientem verfus, $b$ bis dejectiores deinceps in auftrum, \&o lemper minores apparent, inec ipfo conjungantur oc occultentur circa $\mathrm{C}$ a inde autem rur. verfus orientalem plagam emergentes, E' tendentes ad maxians digre/fionem ortivam, que fit circa lineam $A F$, minus as miis dejecti ad auftrum apparent, Jemperque majorenapparent, perta jwe ibi morá feu ftatione alterá, revertuntur verfus fovem ad identem, El tunc quoad apparentiam videntur nobis magis maque evecti in boream, it erusw que fovi conjunguntur. Et in boc in feasper extimus fatel: $G$, eft nobis in meridiem pect antibus xier, quawdiu eft in parte fuperiori peric) cli, E⿱乛龰 quamdiu ab ocus in ortum promoventur; at in altero bemicyclo femper apparet bis fonifter. Ex his igttur manifefte patet, fouis comites moveri edicto modo circa ip/um.

2uoad digrelfiones fatellitum maximas 1 fove, varies modis fobis comsdeterminane Ancteres. Et alit quidem utuntur in ea men/ura tum digrefsnetris aut femidametris apparentibus fovis, alii verò etiam atdiametris terre. Scheinerus ait, proximum a Fove diftare a tro jovis lemidiametru fovialibus qua/i $6:$ Jecundum tanquam ust paulo plis; tertium so plis minùs ; quartum 20 circiter. Gaeus, quem /equitur Wes delinus, dat diftantia primi diametros vis 3. ecundo s, tertio 8 , quarto, 14 . Simon Marius, quem fe guitur plerus es Herigonius, dat prime diametros. 3, Jecando s, tertio 8 , aro 3 . Rheica primo dat diametros Fooss 3, fecundo 4, tertio $\sigma_{3}$ Irto 10. Idem dat /enidiame: vos terra primo $2 x_{3}$ / ecundo 27, tertio guarto 6 g.

Periadus motuum finguloram fatelfitum circa Fovem, certiùs fofis camineratur ab una conjunctione ad eandem, quam ab una ma-turis periodi xime digreffione adeandem. Revolutioni periodica motum. plerigue tribuunt tempus, ut leguttur.

$$
\text { ( }
$$




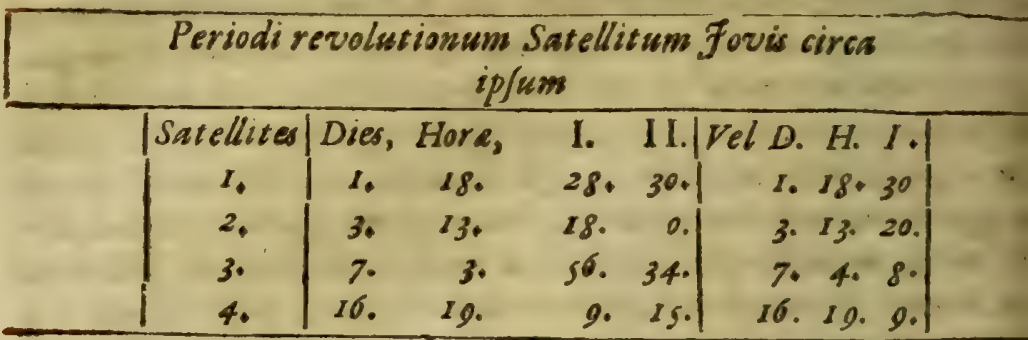

His motibus luppofit is, fo dividas integram circulum, feu gra dus 360 , per motus periodicos pradict os, babebis mot um diurnum fin gulorum in /uis circulis feu pericyclis; E' fi diurnum motum divida per 24, habebis horarium motum corundem.

gobis satel. Ad Ecliples dict arum ftellarum quod attinet, eft jane com bitum echi-munis opinio, o crebris experiment is confirmata, eas quando ac press. cedunt proximè ad conjunctionem cum fove, five inferiorem, dun feruntur ver/ous occafum in inferiori parte pericycli /ui, five fupe riorem, dum ver/us oricntem moventur, ob fulgorem fovis nol videri, fed occidere (ut Ricciolus ait) Zeufiace, feu Fovialiter, qui simirum intra fovis lumen ab/cossduntur; imò extra conjunct io nern etiam aliquando eclipfin pati, in eaque delitefcere major velminori mora, juxta diverjas inclinstiones coni umbre Fovi o' diverfam ejus latitudinem, diverfamque viciniam fatellitun ad Jovern. Argumentum barum edipfium eft, inquit Riccio lus, quia poft oppofitionem fovis cum sole, in pari remotione à $f_{0}$ ve fecundum longitudinis lineam, quando feruntur ver/us Foven occtdentaliorem, apparent; at ab eo recedentes verfus orientem non apparent.nifimajorem adepti diftaniiam, quia foilicet latebant in umbra Fovis; of exempli gratia fatelles a non emergit nec primo effulget, nifi in magna diftantia a Jove, qui in retro. ceffu ad occidentem in mult o minort diffantia a Jove folet appareve. Et fic de coteris. Pratereáremotiores i Jove, quando dejeCti in auf rum accedunt ad fovem, occuli antur; qui tamen quando ad eum accedunt, fed evecti in Boream, apparent; quod non nis. 


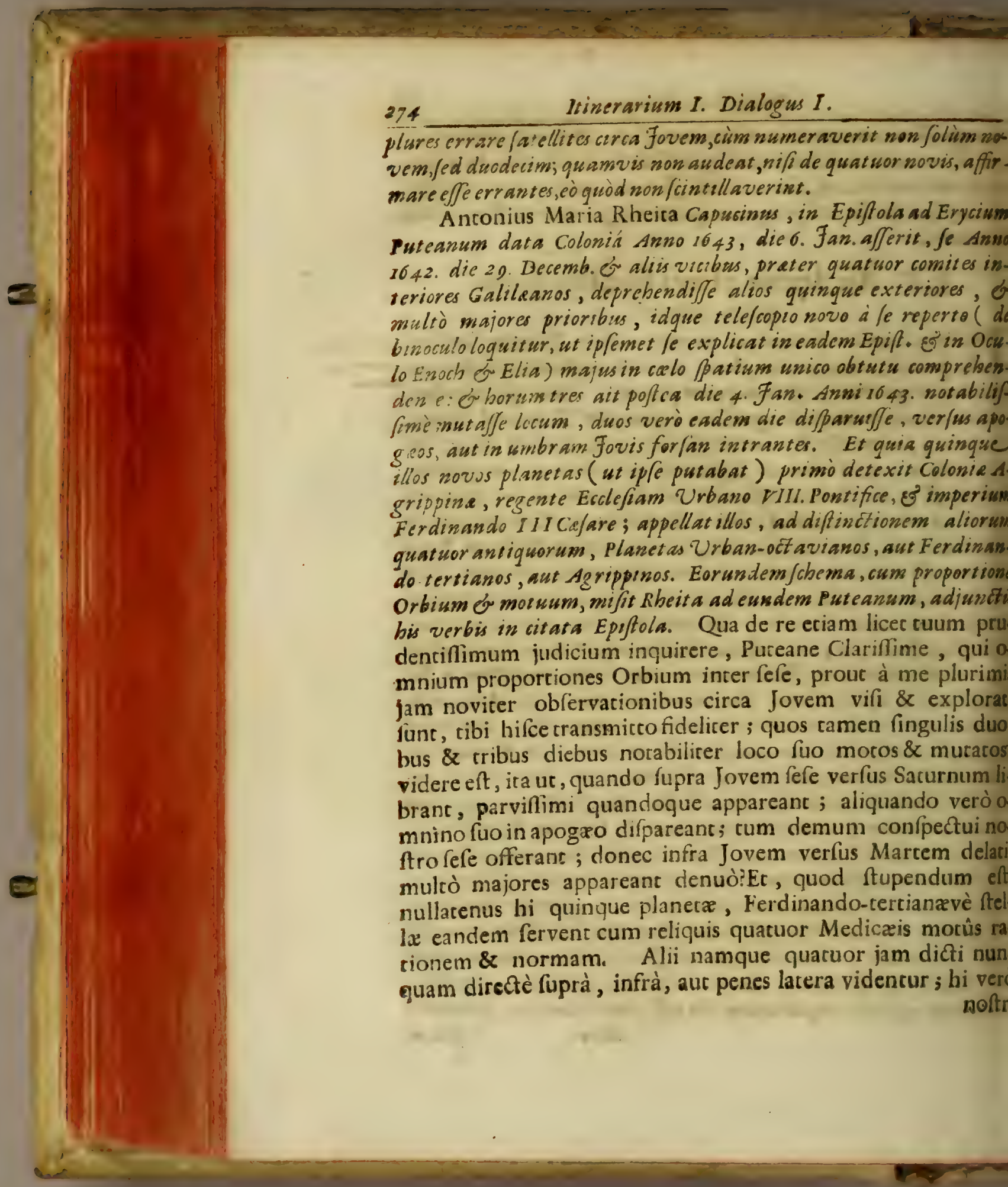


noftri nullam differentiam loci refpune, auc refugiunt, led Jlenâ majeftate perpecuò fuum regem Joven fupıà, infrà , \& areraliter ambiunt, in circulis Veneris, Mercurii, \& Luna, mò ipfo ambitu folari majoribus; fed, quod mirum , fpatio emporum minori illis: adeò quòd, quantum mila hactenus juidem compertum eft, quidam fpacio 33 dierum, 12 . horaum, alius tempore bimeftri ferè, alius fpario minori, \& majori Iter, \& extimus, circa Jozem revolutiones fuas compleant \& $\mathrm{x}$. ost fcriptam Epifolam, petit eam communucari Fromondo alisseve viris eruditis. Monet deinde, non poffe ftellas illas novas vilevi celelcopio conmuni, fed folium fuo novo à Je reperto; de quo ile in Oculo /uo Enoch, $\sigma^{2}$ nos 1. parte Mag.lib. 10. Addit preterea, wingue novas predict as fellas moveri ab occafuinortum, cim: eliqui quatuor ferantur è contrario ab ortu in osca/um. Quod It d ( / wbic ) evidens fignum, plana interiorum ad Eclipticam aclinata \& difpofica incerfecari ad angulos rectos à planis fie circulis quinque exteriorum; quod quidem ftupendun Ret. Revolutionis tempus necdum planè \&u exactè compertum fe abere fatetur;putat tamen penextimsum $\beta$ atio circiter 6.dierum volvi, medium veròinter quinque patio dierum 33, o borarum guas. H.ec Rheita.

Fixemplum predict e Epifola ex Belgio in Galliam transmifan ad Gaurielem Nadeum, Cardinalis Mazarini Bibliotbecainm, ab eoque cownunicat um PetroGa/Jendo,excitavit eum; aut au. arium boc quinzque planetarum circum. Fovialium examinaret, i judicium fuum de illo eidem Nandac trawsmisteret; quod o deede typis ( unà cum Rbeita Epiftola) vulgatum fuit in O.pufculo. 7obis fatele it titulus est, Novem ftellacirca joven detecta: $2 u$ in $E$ litesnosi frola Gafferdus in controverfiam vocat dictum auctarium a tur. beita osfertum, ob jequentes caufas. Primò, qui ipfe Gajfendus idem nocte diei 20. Decemb. Annt 1942, obfervavit quatuor Meecos 90 vis comites omne: Fove orientaliores. Es in eadem quaja ct a linea, nifi quod lecundus, inter primum numirsm é tertium aximum medrocris, fuut infenfibiliter bujusmodi lineá boreasor i ques canen Rheite fchema occideniales reprafentat, Eq A $m 2$

extinum 


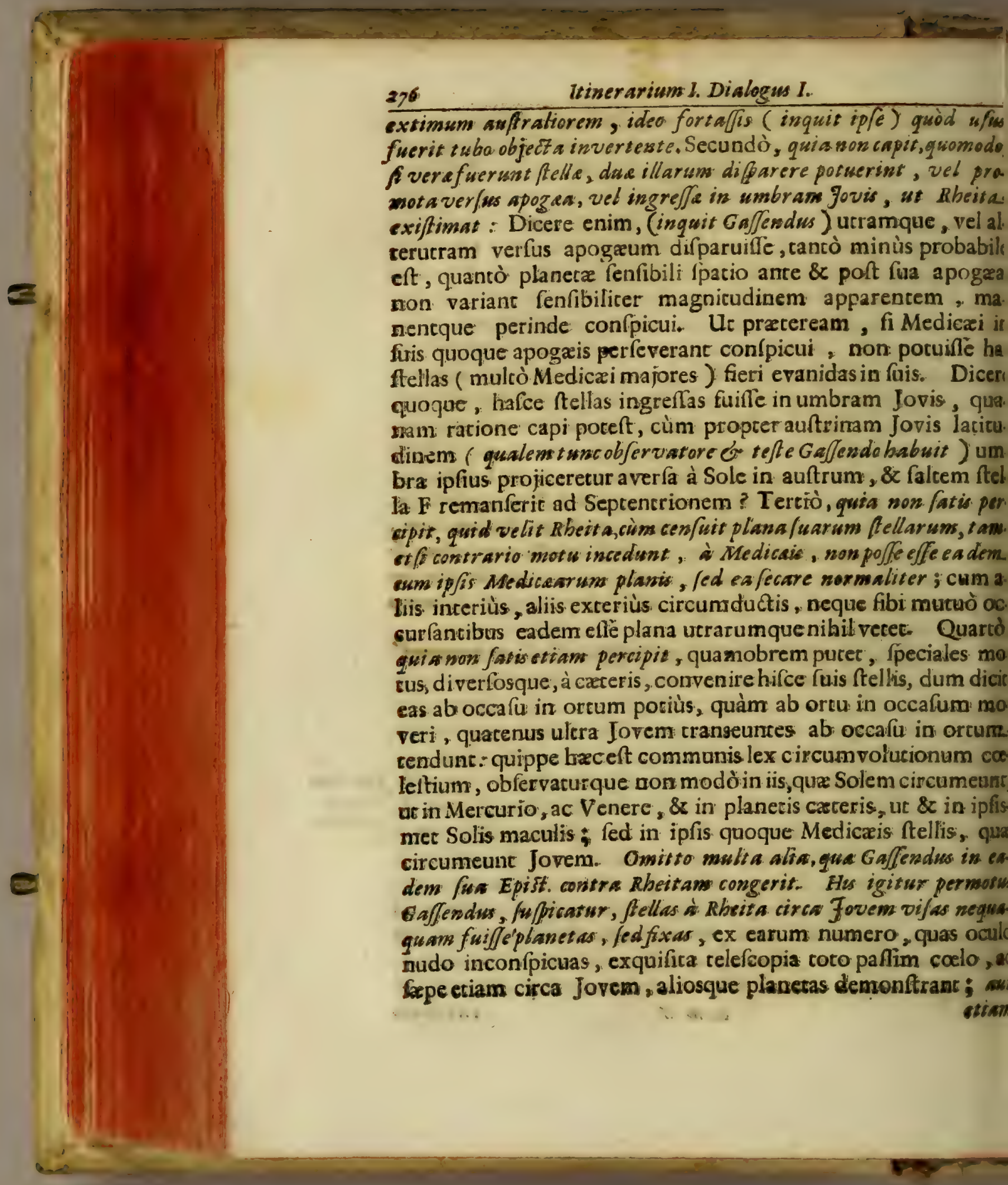




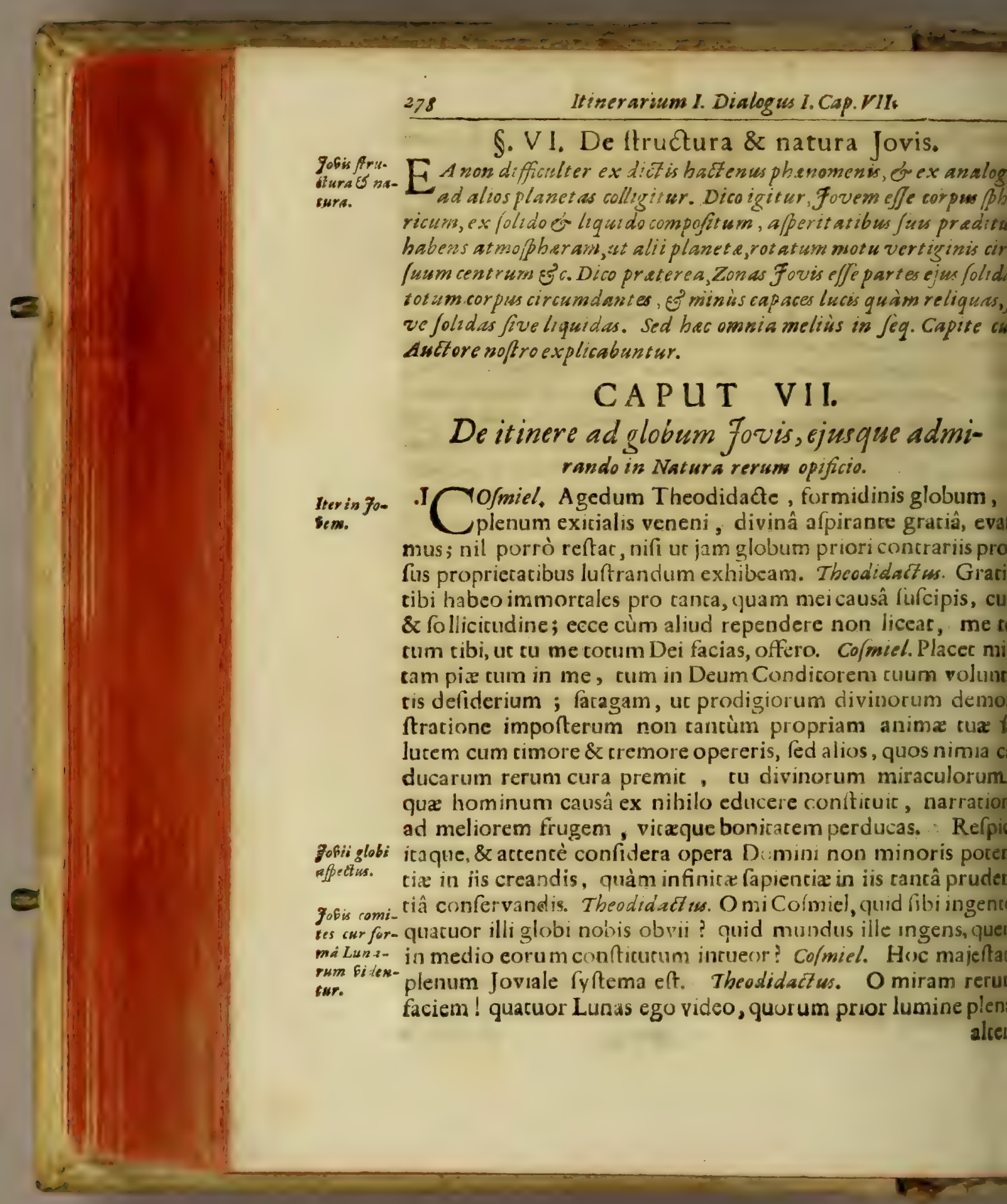




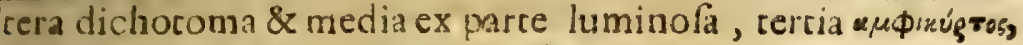
larta cornutâ facie fpectabilis eft. Exponas, rogo, tam infum narura portentum. Properemus, obfecro; nec enim diefcere pofle videor, usgue dum mirabilium operum diviorum magnicudinem \& varietatem propiùs contempler. Imiel. Fier, quod petifti. Theodidactus. Sed quid rapidus ille heris fluxus libi indicat? Cofmiel. Nè mireris; inter vortices vialium comicum haremus, qui cùm velocillimo motu cirglobum Jovium ferantur, mirum non eft, ex ingenti quaor globorum agitatione ingentem quoque atheris fluxum, fulcare. Theodidactw. Capio myfterium. Sed quid odor ille

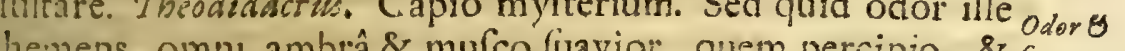
hemens, olnnı ambrâ \& mufco fuavioi , quem percipio, \& fragrantin 10 cantopere recrearime fentio ? Cofmiel. Ille eft falutifera il.globi Jobiz. Jorii globi exfpiratio \& effluvium, fignum apertum nos m juxta atmoíphram ejus conftitutos efle.Theodidactus. Sed ô iraculum, quod video. Cofmiel. Dic rogo, fili mi, quid tantore miraris? Theodidactus. Mundum immenfum video, luce Luciditas dique \& undique fulgidifimâ refplendentem.Cofmiel. Hic eft globi fobii. bus ille Jovius, cujus videndi defiderio tantopere follicitaris.Theodidact us. Quodicto, me in ipfum Jovium globum ser alcifinum montem depofuic. Hîc ego longè laceque imenfas intuitus regiones, aquis lucidifimis refertas inveni ; jurafn, alterum Veneris globum me intrafte, nifi quòd hic globus tò Veneris globo grandior, quantò gallina ovo ovum ftruthiis majus videtur.

II. Theodidactus. OCofmiel, unde tanta hujus globi clari- solis ex $70-$ ,cùm Solem non videam? Cofmiel. Refpice in plagam con- Geraßectus. te politam; vidésne globuhm illum lucidifimum ? Theodid. deo.Cofmiel.Ille Sol eft.Theodidactus. Fierine poteft, ut globulus , cujus ego diametrum non nifi fub angulo fex minutorum mprehendu, tam immenfum Jovis globum illuminet? Co/miel. ctè ambigis; fiquidem Solis lumen nonnihil in hoc bo illuminando præitat, fed minimè id ad tantam clarita$n$ inducendam fufficiens effe, vel hinc paret, quòd vix tan$\mathrm{n}$ illuminare poffit remotis aliis illuminationis fubfidiis, 


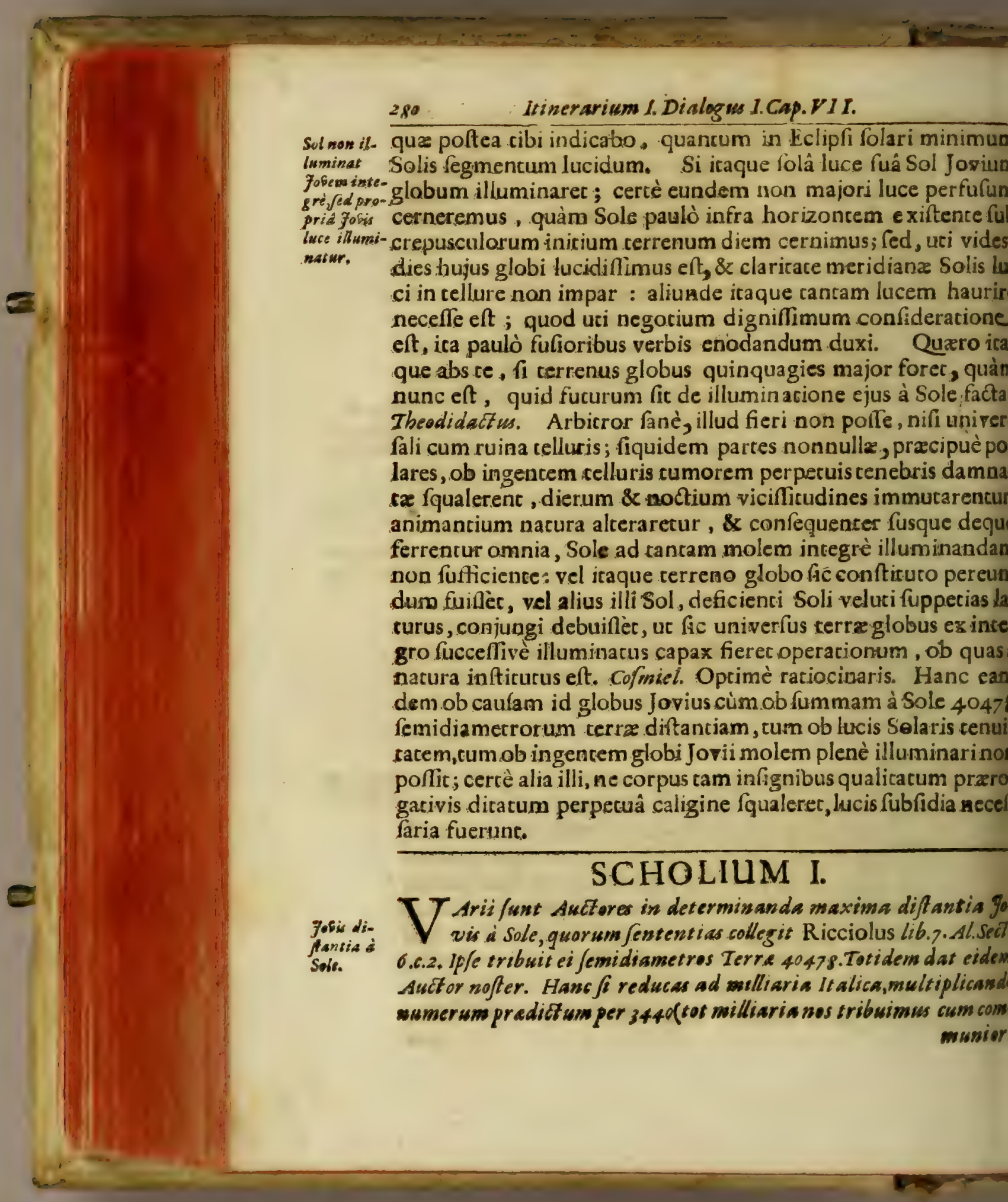


muiori fententia Terre femidianetro in Cur/u Matbess. lib. 7. 14r1. 2. cap. 5.) reperies milliaria 39244320 . In tanta dift antia Sal hed atus ex Jove, vix fub angulo fex minutorum appareret; nam s minima ex eodem Fove distantia vifus, non apparet niff jub ungulo feptem min. ex Riccioli fententia. Vide jam, num tantilun luminofum corpes apparens posfot fufficienter illuminare tam orensi do integrì tantum Fovis globum, cujus (ex ejusdem Ricciofententia) diameter vera babet dianetros Terre $8 \frac{4}{5}$ circumfeexion diametros 27 ro! arca circuli maximi diametros quadratos. erre6 4, fuperficies convexa diametros item quad.242; laliditas erò ipfus continet Terram 685 vicibus. Sed de hac re iteram rediit formo infrà, cuim de fellis fixis.

III, Cofmiel. Vides hos quatuor Jovios globos? Theodidact. Comites foideo, \& quidem majores multò quoad apparentiam, quàm nos fis illumi2 terra Solem \& Lunam intuemur; quod equidem facis mirari nant gloon poflum. Cofmiel. Hi funt ifti quatuor globi, quos tu fuprà bum fobis. uacuor Lunas, phafibus fuis confpicuas, efle putabas : horum. nguli præcer lucem, quam à Sole accipiunt, propriâ quoque Ice fruuntur; quæ tamen binæ luces conjunctæ unitæque,gloprum lumea mirum in modum intendunt. Theodidactus. Sed aid fibi novi phanomeni prodigium? ecce globos intensâ priùs ce radiantes, modò mutato lucis fulgore, nefcio quo fubfuifo dodam colore fuffufos confpicio. Co/miel. Scias, hosce globos Comites roprio lumine nonnibil fplendere, unde umbram Jovii corpo fobre pros intrantes, cùmà Sole lumen non hauriant ampliùs, innatam que luse folummodò lucem nonnullam Solis vice demonfrant: atque fulgenc. ec eft ratio, cur fubfufco colore fuffufi in umbra Jovis cernanIr; qua propria iis innata lux eft, uti poftea, cùm dictos globos ftrabimus, comperies. Theodidactus. Quomodo hoc fieri po$\mathrm{ft}$, cùm nunquam in terra conftitutus, eos in umbra Jovis hoc com re fuffufos me obfervafle meminerim ? Co/miel. Ne mireris: im enim ob diftantiam horum globorum lux, nifi folariluce borata, oculis fefe intuentium fiftere non poffic; hinc mox uumbram intraverunt, penitus evanefcere necefle eft : at cùm c loco globi nonadeàà globo Jovio diftent, quemadmodum

$\mathrm{Na}$ 


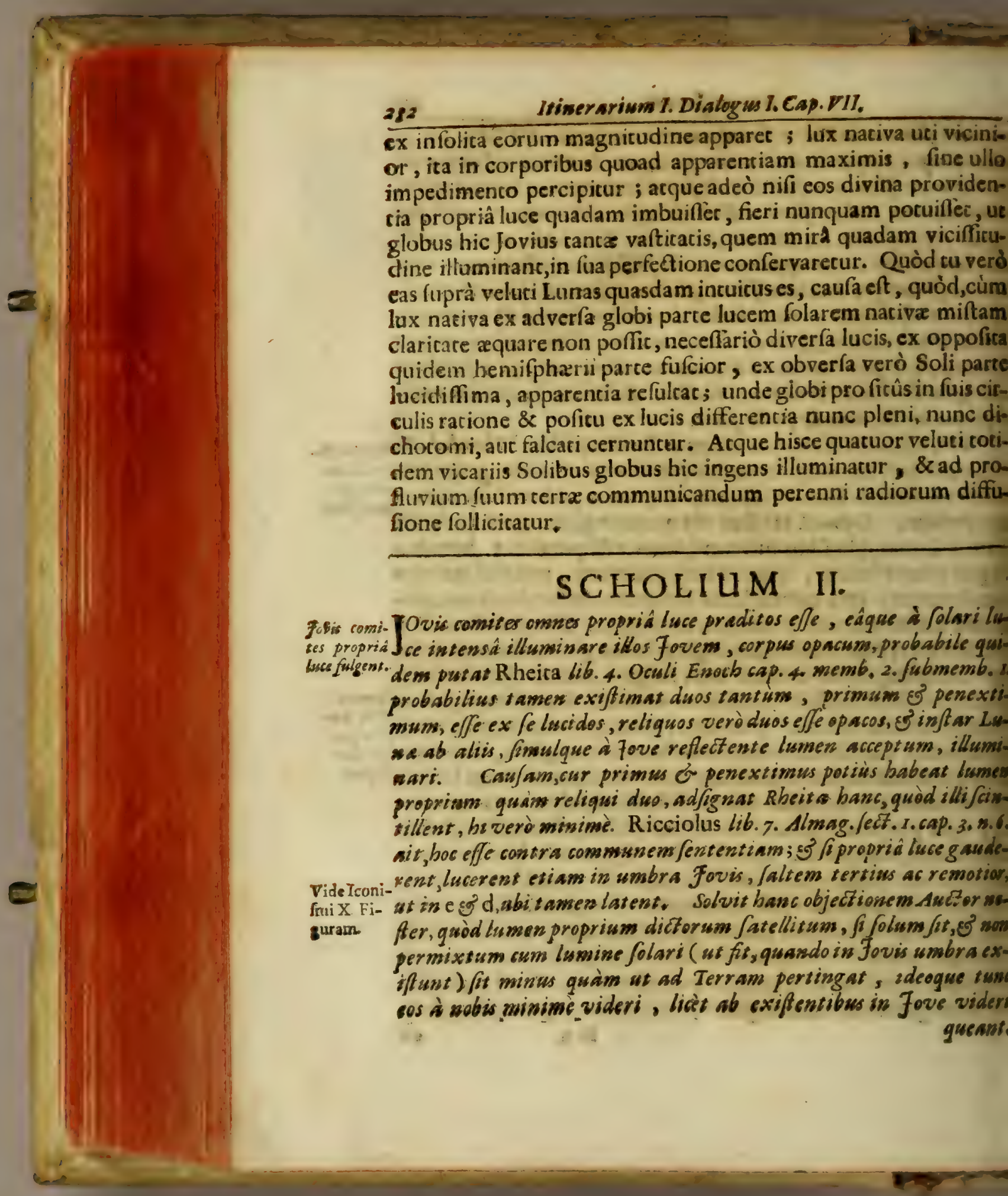


1reans. Mibi cum Aubtore noftro probabilius videtur, onnes abere lumen propreum, \& Foven fuum mirà viciffitudine slluvinare, etiam tursc, quando in equs umbra nobis delirefcant; tametfo lebilins tunc for lume corsm, quaim quando cum folari permix tum fr.

IV. Theodidactus, Sed jam tempus eft, ut hujus admiran-Strudure am globi fabricam exponas. Vix dixeram, cùm ecce me ad O. s lobi jobii。 cani prorfus immenfi, innumerâ infularum difcrecione ftuendi, ripam fticic. A queum hujus ylobi elementum tam erau mpidum, ut nullam ei cryftalli diaphaneitatem comparari ofle cenfeam ; folidiores verò continentis partes tam immoicâ luce fulgebant, ut \& montes \& valles non nifi ex argento e:to ac fplendido conftitutas purafles;odor verd tancus erac, tomnes terreni eriam inxftimabulis pretii odores nihil comaratione illius duxerim. Hîc ego aperto ore naribusque, pleno eclore tantam horum coeleftium aromatum fragrantiam hauebam ; totius enim corporis vitales fpiricus mirificâ hac fuacolentiâ corroborari fentiebam,\& nefcio quas cogitationes foRegibus dignasalto animo volvebam. OCofmiel, ô in quem lobum me incroduxifti? omnino ego hunc globum, atrium, aradifi cenfen; fiquidem nihil five falubricatem aurx, five obctamentum oculorum, five aurium delicias ex tam harmoniaquarum agicatarum fufurro fpectas, ad felicitatem humaam defiderari pofle viderur; im efle video pronuntiacum Aftrologorum, Jovem regiam. ellam, qui fuis natis dignitates, honores, \& imperia promittat. ofmiel Ex parce, fili mi, bene fencis; fed ex aitera parte fuperftiofis Aftrologorum deliris nimiam re fidem habere nolim. Visinfexite beodidact. Expone itaq;, obfecro, quaenam magnifici hujus glubi globs fosm. is fic, quomodooperetur in inferiora? Cofmiel. Dixi tibi fupeùs, fingulos mundanos globos à natura quasdam f́pecificas ualitates fibi habere infitas, qux uti ab aliorum globorum viracibus differunt, ita diverfos quoque effectus in inferior ibus caltint. Globus hic Jovius præx creteris poft Solem eâ virtutum. rærogativâ gauder, ur fi quod in rerrego globo fubjectum fuze NI 2 virtuci 


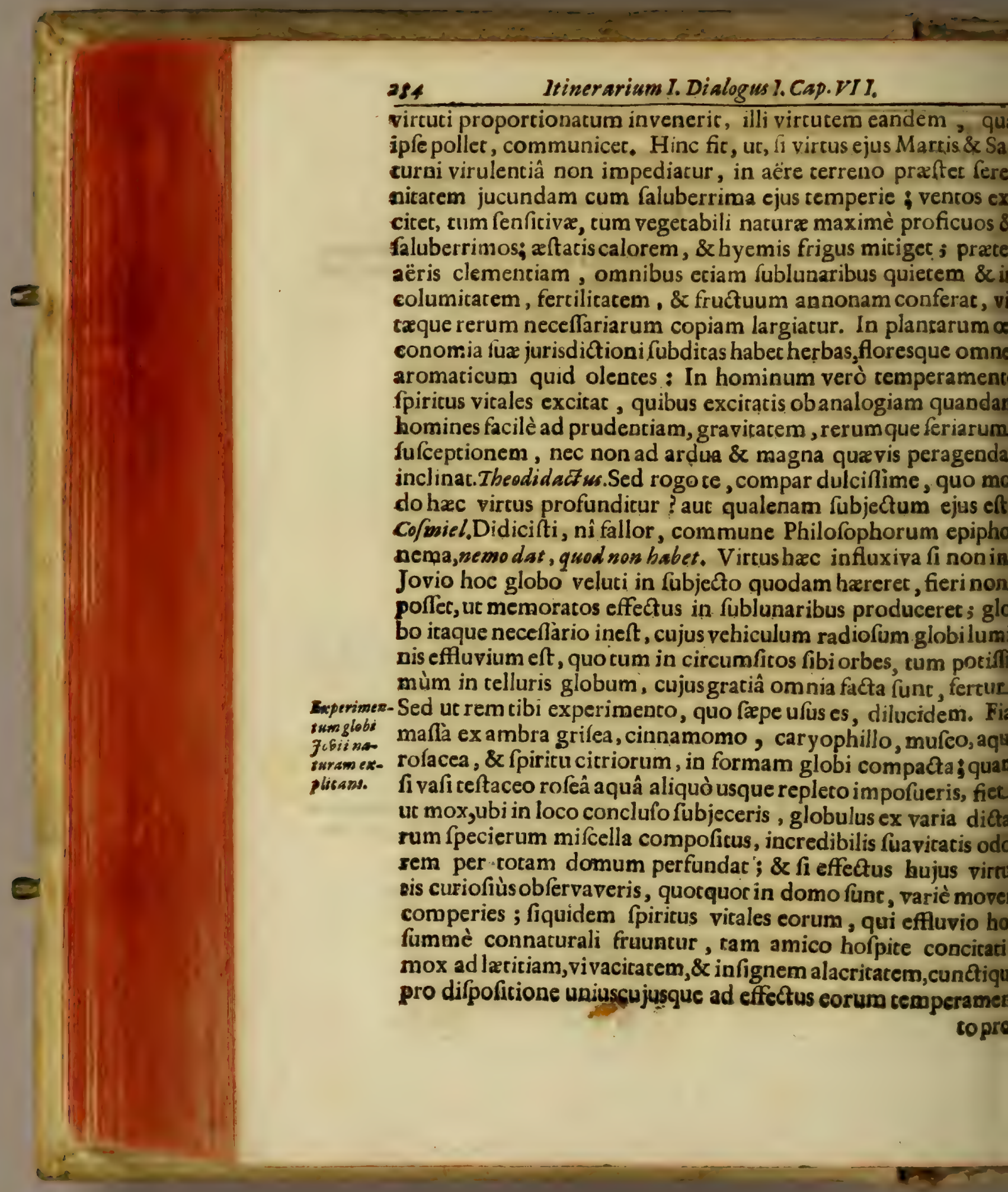


o propriosinclinabuntur.Idem in Jovio globo fieri exiftimes elim. Cùm enim hic globus ex materiâ conftet nobilifimis \& naximè falutiferis virtutibus pragnante, \& ad fupradicti glouli compofitionem prorfus analogâ ; certum eft,eum perenni uatuor globorum Jovialium lucis diffufione percuffum , virutem excitatam per radiofum luminis profluvium, fublunarius influere, in omnibus is fubjectis, qua teperamentum haent vircutis recipienda non ineptum. Si itaque homo nafcatur, jius temperamentum Joviali influxui fic proportionatum, in lud vim fuam mox influet,\& ad dictasanimi carporisque dotes o tempore exercendas inclinabit; plùs tamenaut minùs, pro Itione concurfus Jovii cum maleficis aut beneficis planetarum fluxibus: idem enim fit,dum Jovius globus maligno planetat um congreflù conjungitur, quod fieret, fi quis paulò fuprà diaromaticæ maffx picem, bitumen, naphtam, fulphur, alias- $C_{a u} / a$ dit te foetidas fpecies admifceret:is enim haud dubiè totam beni-berforum ae virtutis exfpirantis efficaciam deftrueret. Atque hinc parer, effetzum Ir inferiora tam differentes effectus fortianturtnon al in pater, Fobis in teffanè nifi pantimob variam diver lortian lane, nifi partim ob variam diverforum planetarum, quà begnorum, quà maleficorum radiofi influxus mifturam; partim variam Jovii globi, quâ cęreros planetas refpicit, in circulo fuo nfigurationem. Qua omnia cùm innumeris combinationum gibus implicentur, non poffum non improbare improbam quo- Afrologia ndam Aftrologorum audaciam \& temeritatem, qui tam tutò samitas. confidenter de fortuna \& eventibus,tum regnorum, tum naonum fecuturis vaticinantur, dum Aftrologiam infallibilibus ritatis regulis aftringere fe poffe putant. Scias Theodidacte, $x$ in toto orbe terrarum duos homines reperiri in omnibus? orfus fimillimos, qui per notabilem aliquam differentiam $a b_{V i x}$ dantu vicem, non dicam quoad vultus, fed quoad voces, quinimo duo bomi. cam ampliùs, quoad inceffum \& naturalem corporis confti- nes in oionem dignofci non poffine. Qui arris combor

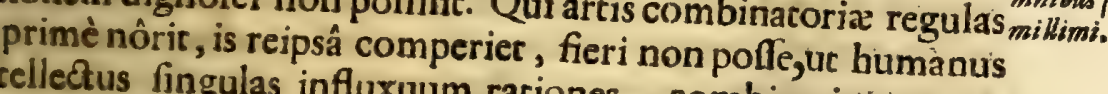
cellectus fingulas influxuum rationes, combinationtum vatatem, variamque influxuum mifturam, quancumpis fummi No 3 


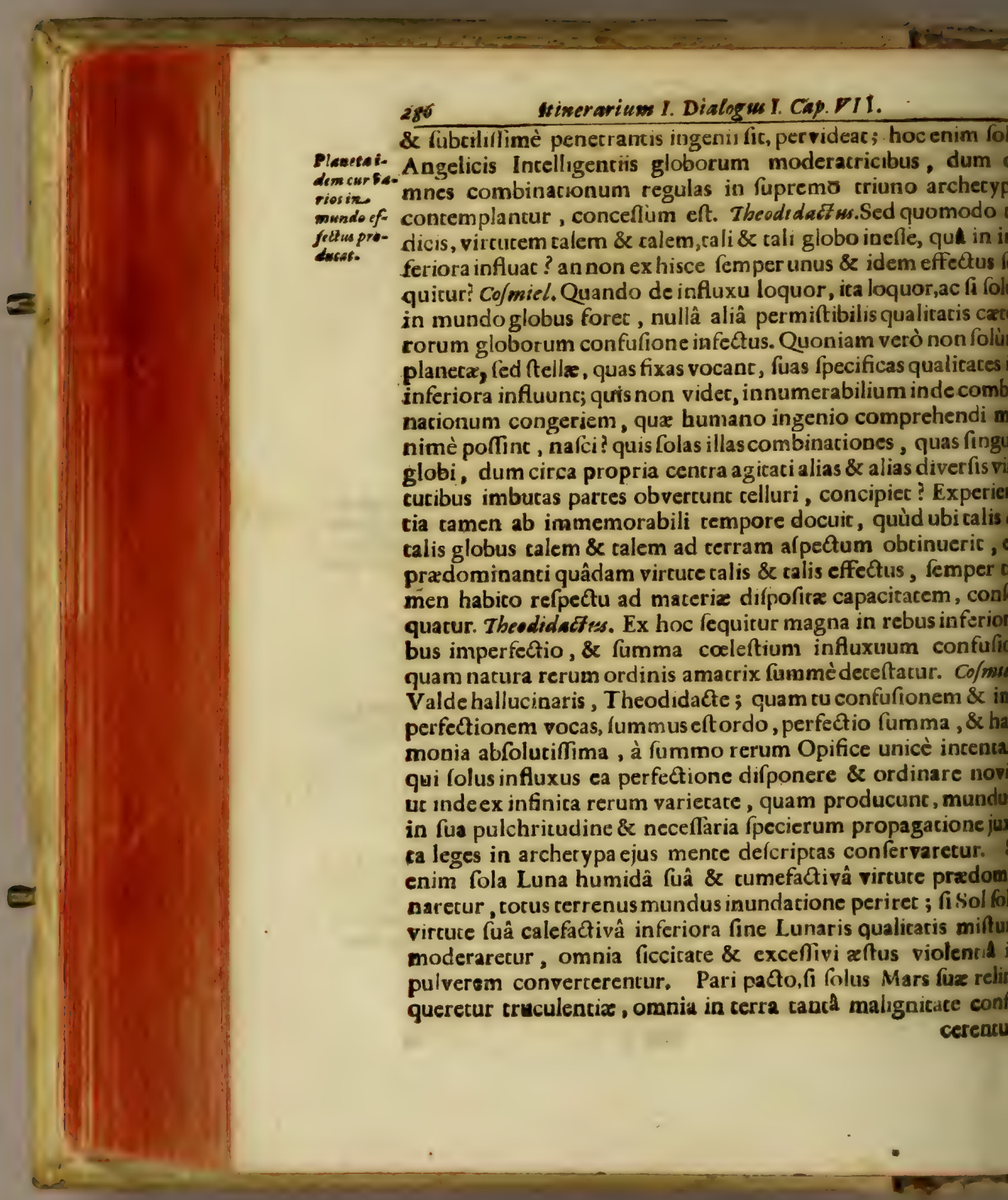


entur. Hinc fapienti divina difpofitionis confilio factum. , ut Sol, Luna, Venus, Mercurius ita difponerentur, uc unus erius impetum per virturis mutua communicationem inggeret, \& ad remperiem reduceret; Jupiter verò, inter Mar1 \& Saturnum confticutus, infidias confpiracionesque utriusin ruinam inferiorum conceptas benignicace fuấ \& impesâ majêtace eluderet ; hic verò utriusque renifu obnifuque flus, ne influxu fuo dominarivo jurisdictioni fux cuncta fubarer, fafces fuos non duntaxar hoftibus aliquò usque fubmic- Munfus. - , fed \& ab amico fibi foedere junct is auxiliares lucis fuppetias agicare cogerecur. Atque hoc eft, mi Theodidacte, unio illa inanimis omnium globorum mundanorum in Univerficonvacionem confpiratio, quá veluti admirabili quadam harniâ ex confonis \& difononis compofitâ mundus unicè fubli-

\section{SCHOLIUM III.}

E Jovis influxu $\sigma^{2}$ efficasia in bac inferiora, multa Aftrolo-Ignis infor gi. Aliqui ejus effectus, quoniam ab immemorabili tempors xus 8 effiasnt wotati, of experientiâ comprobati, negari penitus non feriers. int. Rheita lib.4. Oculi cap.6.memb. x. hos enumerat. Jupiter folus aëri dominatur, temperatè calefacir, \& humectar; gis tamen calidus quàm humidus exiftic, Occidentalis aucalorem, Orientalis verò humidicatem. Praftat aëris feretem jucundam, \& oprimam, cum faluberrima ejus rempemaximè fi fuerit in bono afpectu cum alcero planeta.Moves que pluvias temperatas \& falubres. Ventos etiam feptentrio, animalia \& femina confortantes, producit faluberrimos. atis calorem, \& hyemis frigus mitigat, inducens, prater aëlementiam, incolumitatem \& quietem omnibus paffim unaribus rebus, Fertilitatem \& agrorum fructus auget, reque vitz neceflariarum copiam præitar. Sed malè cum Sa10 , aut altero, affectus, vel impeditus, hac, quae dicta f $\mathrm{t}$ ar, refiùs etiam praftat ; quandoque exiam intemperiem \& aẻris cupcionem concaufans. HacRheito. Aftrologi palfm appel- 


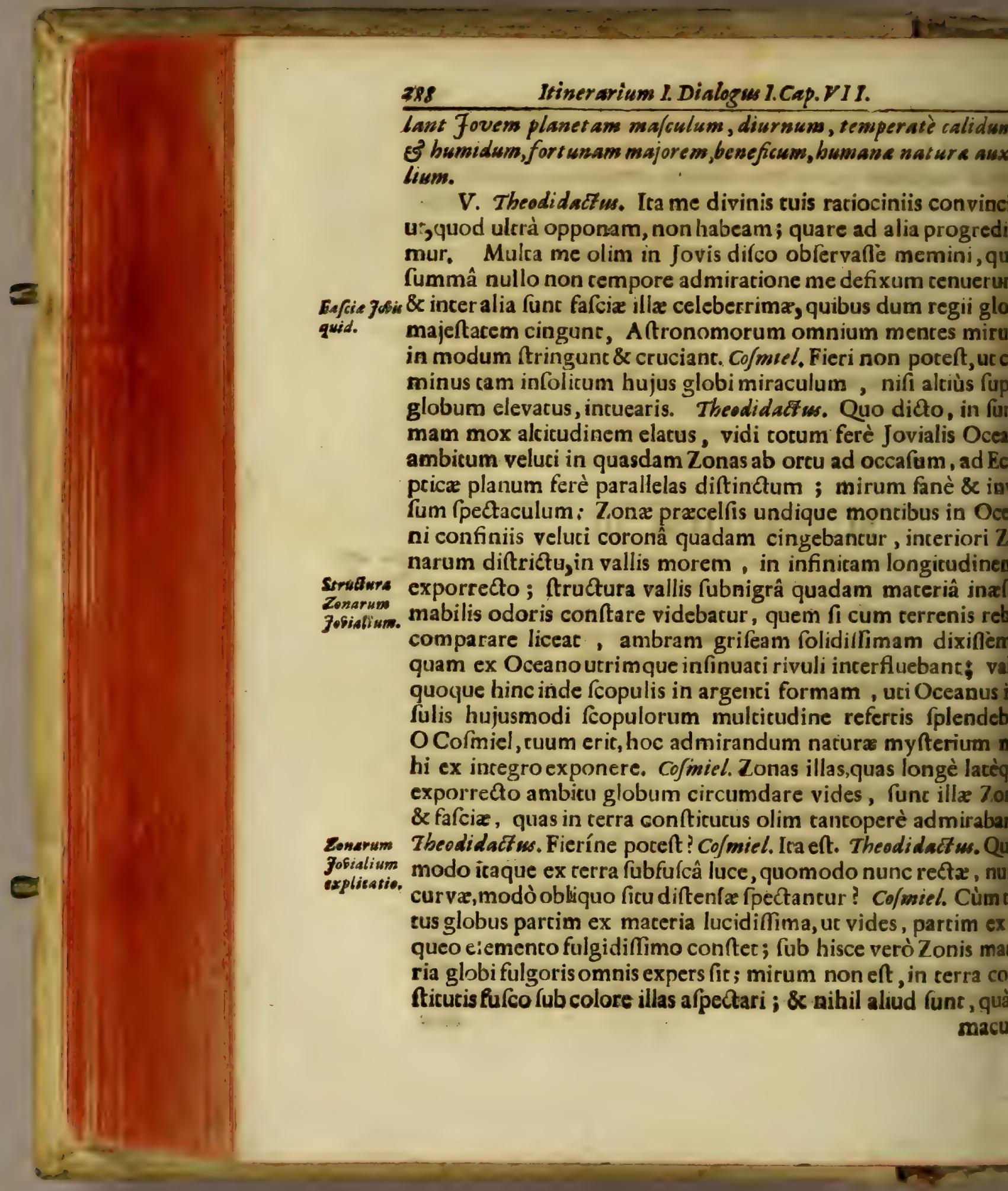


acula quadam in formam talciarum circa globum fub contiuaco arcuata fuperficiei,circuicu procenfarum, quas racione fubati, lucis uti minús capacis, ica lacis minús intenfa radıofa vi"atjo ad nos transverberac. Qüod veró modò rectæmodri cure compareant, id torum depender à confticurione globi, qui olis fuis, fupra quos circa axem fuum volvitur, nunc in Boream, Inc in Auftrum, nutando, vifui noftro eas nunc rectas, modò rrvas exhiber, uti ex opricis ribi notum eft: cum enim axis gload rquinoctialem fueric rectus, tum \& illa rect $\$$ cernuntur in eridiano fita : quia camen poftea circa horizontem Jovium liquitatem quandam, nucante in alterutram partem axe, feanrur ; neceflariò illa curvæ fpectancur. Theodidactuss. Jam imverò caufam fafciarum Jovialium tam clarè mihi demon-

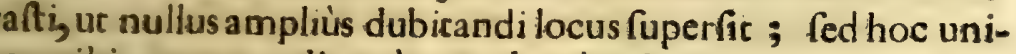
$m$ mihi exponas velim, cum toc la cubus \& rivis hosce Zonarum trictus perfufos videam, cur ill exterra non videntur? funt im lucidifimi, Cofmiel. Quia,cim ii ad cerram comparaci non i indivifibilis puncti rationem habeant, fieri non poreft,ut illos mani vifus imbecillitas atcingac. Theodidactus. Sed quem in Finisfafid: em hasce Zonas tam concinnè difpofuir Natura rerum ? Co-rum furiaiel Scire te velim, Theodidacte, hasce Zonas effe veluti qux- inte tus $m$ virturum Joviarum feminaria, ex quibus ceu promocondo natura odam cum Oceanus Jovialis,cum reliqua continens virtutis laancis fementem ad fe provocet, actractamque, qua data porta, inferiorem mundum diffundac. Theodidactus. Dic,rogo,amintne hæ Zonæ univerfan globi fuperficiem, Cofmiel. Ambichaud dubiè, tamerfi transfufo nonnullis locis Oceano Joviali errumpantur, aliisque in locis terræ quoque continenti Joviæ ajunganeur, cum hiatu immenfo; quæ \& nonnunquam ab obvatoribus pro maculis fumpex funt, tametfi id ob fummam dinciam è terra adverti non poffit.

\section{SCHOLILM IV.}

Ua de Zonarum Jovialium satura ac fructura, fotu, appa-

$$
\text { D. rentia }
$$




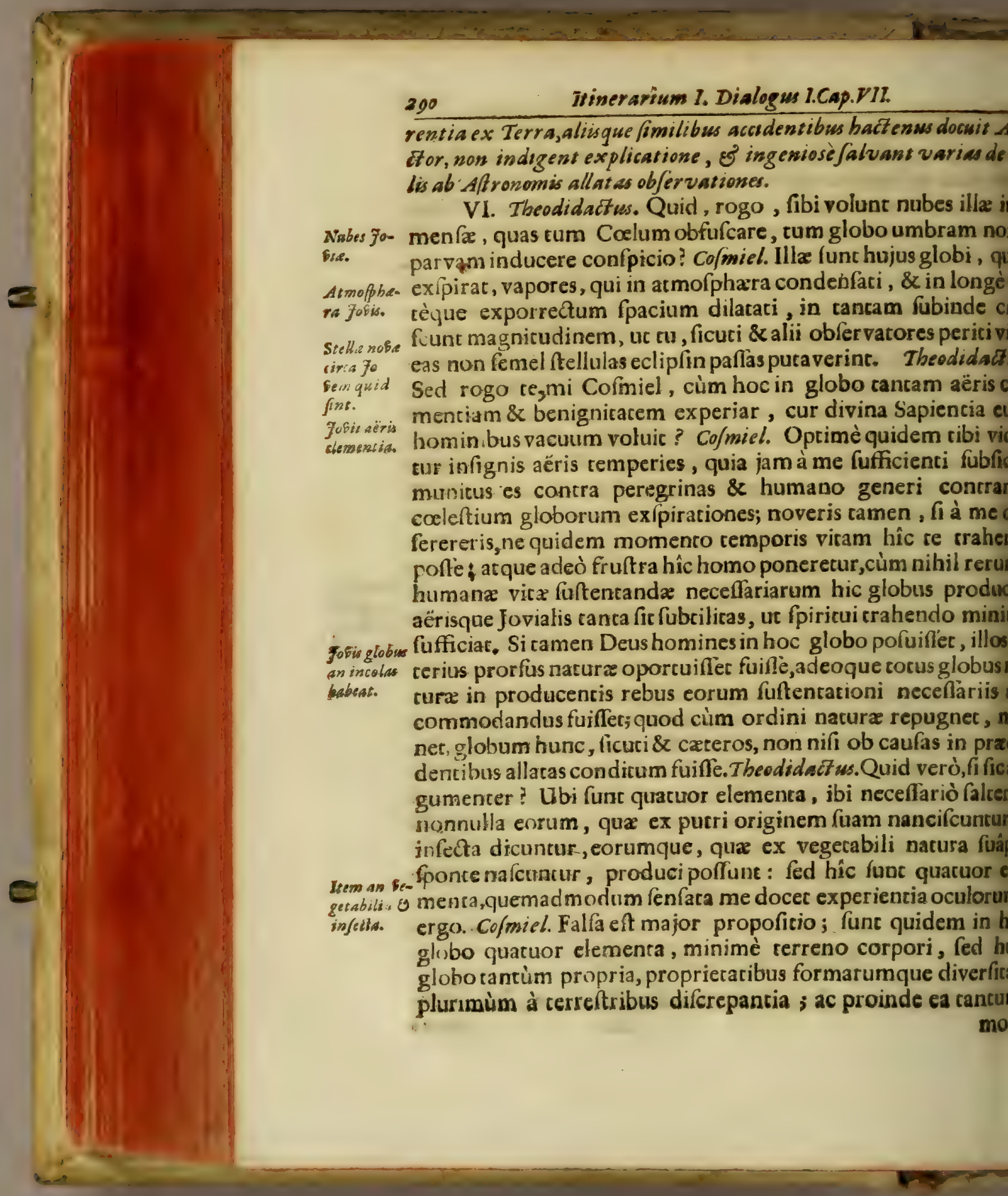




$$
\text { Iter in fovem. 20t }
$$

odò producunt, qux fini hujus globi pocifimùm congrua at, minimè verò iis, qux ex terrenis elementorum mintionis originem nancifcuntur, fimilia ; unde ne infeata hic quaras, in vegecabilis natura fponte nafcen , neque quicquam eorum, $x$ in cerreno mundo cernuncur, effectuum. Theodidactus. Sed divinâ porenciâ in hoc globo mas \& foemina ponerencur , an n fecundùm fpeciem fe mulciplicare poflent? Co/miel. Miror iè fimplicicarem cuam. Theodidacte, an non vides, negocium jusmodi dedrator ? ubi enim in hoc globo nucrimentum in nfervacionem individuorum inftitutum ? ubi proporrionaaéris hauftus ? ubi reliqua humanæ viræ fuftencand $a$ fubfiI? Cùm icaque nihil hoc loco eorum, qua humano generi prozando neceffaria funt, reperiatur ; fruftra hîc ponerentur mines, fruftra animantia, fruftra herbx. Theodidact us. Igno, rogo, fimplicitati mex. Aliud mihi dubium lolvi velim. òd fi femina rerum terrenarum huc afporcarentur, an non reno Jovio infita nonnihil fimile producerent terreftribus? miel. Jam dixi tibi frepe fepius, \& omnia probavi in pracetribus copiosè; cùm femina cerreni mundi ad nullum alium nundo globum appetitum naturalem habeant, nifi ad eum, us partes funt connaturales, cercè fieri nullâ ratione poffer, îc, utpore extra Iphxram naturalem conftitutæe, quicquam ducerent; vel ergo ad fuam fphæram naturalem remearent, in materiam globo Jovio proprian mox convercerentur. od. Rectè \& fapienter omnia decidifti, neque quicquam amis animum meum perplexum tener eorum, qua tibi ex fimicate cordis mei ftudio proficiendi propofui. Sed quid fibi mi Colmiel, quæ nobis ingruic repentina noctis facies? Nox ingruwiel. Quid miraris? an non vides omnes Jovialium Solium ens $n$ globe bos infra horizontem conftitutos ? fuftine parumper, paulò fo6io. $t$ mirandam lucis dierumque hujus globi vicifficudinem in Jubis illwoberis. Theodidact us. Et ecce, poft aliquanculum tempor is, pri. minatio

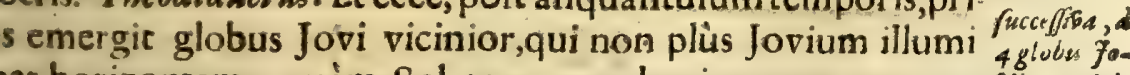
at horizontem, quàm Sol terrenum horizontem tempore bivis omitio pufculorum illuminar, tameti duplo Lunâ aut Sole major bư fatâ. Oo 2 appa- 


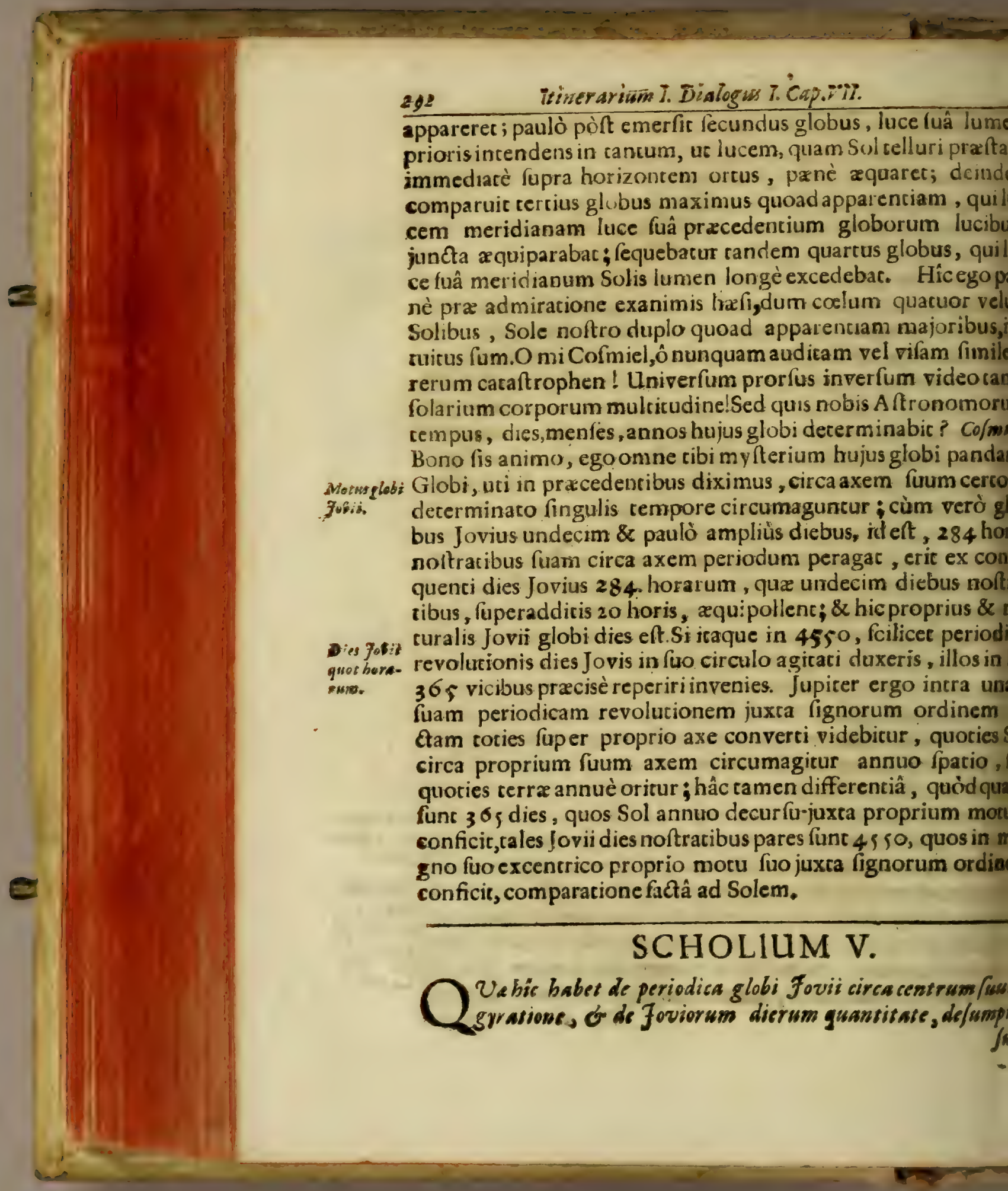




\section{SCHOLIUM. VI.}

De diftantia Jovialium comitum à Jove, \& à fe

invicem; \& de eorum molibus.

R Heitalib.4. Oculi Enoch cap.4.memb.r.fubmenb.1. (ex quo Au

- itor precedentia defump (it) ait, diftantias fatellstum Joviali um quat uor a fove, ó moles corrom, tales efe, quales fe guens tabu la exhibet.

\begin{tabular}{|c|c|c|c|c|}
\hline Satellit. & $\begin{array}{l}\text { Dianset. } \\
\text { Fours. }\end{array}$ & $\begin{array}{l}\text { Semidiam. } \\
\text { terre. }\end{array}$ & $\begin{array}{l}\text { Leuca bora- } \\
\text { rie. }\end{array}$ & Molium diam, \\
\hline 4 & 10 & $69 \frac{2}{2}$ & 69460 & $1736 ?$ \\
\hline 3 & 6 & $41 \frac{1}{2}$ & $4^{1676}$ & $1185:$ Leuca- \\
\hline 2 & 4 & $27 \frac{1}{2}$ & 27784 & 822 rum. \\
\hline$I$ & 3 & $20 \frac{3}{4}$ & 20838 & $549 \mathrm{C}$ \\
\hline
\end{tabular}

$E x$ his deducit Rheita, Comites fovis revera multo mag is à $\mathrm{fov}$ diftare, quam Simon Marius determinavit. Deinde, minimun Comitum effe Lune noftre quafi aqualem, tàmetfiex Jove pecta tus duplo quafi majorem exbibeat diametrum vifibilem quin nobis è Terra fpect at a Luna. Secundum verò effe proximè tant molis, quanta Mercurius. Tertium mole fuà non mult ium ceder Veneri. Quartum tandens ac extimum Tellure nof trá haud mis tò minorem effe. Addit, omnes ì fove fub multò majori angul pect ari, quàm à nobis è Terra Sol ó Luna. Hac Rheita, of cun iplo AuEt or nofter.

Alis aliam diftantiam, (eu maximam à fove digreffionem ad fignant: nam Galilæus', Marius, Keplerus, Herigonius, Wende linus, Hevelius, tribuunt primo diametros fovis 3, Jecundo s, ter tio 8, quarto 13 aut 14. Ex his autem deducit Ricciolus lib.7. Almag Sect 6. cap.12. adhibitâ corsudem diametro apparenti à fe obferva Jobis comi- $t \hat{a}, \xi \exists$ diff antiâ mediá fovis à terra, quan ponit femidiametrorun tescur sam Terra 36500 , at tribuit inquam primo à $\mathcal{F}_{0}$ ve diftantiam femedin Jobe com- metrorum 'Terra 24, Jecundo 44, tertio 7l; quarto 115, aut 124. Leg pareant. ipfum.

V I I I. Theodidact us. Sed cur tam immodica magnitudini viden 
idencur \& fiquidem ferè plerosque multò majores, quàm quo n tellure conftitutus Solem \& Lunam comperi, intueor;luciiflimi fiquidem mihi umbones videncur. Cofmiel. Túne Aftroomiam \& Opticam tanto tempore profentus ignoras, corpora ưantò viciniora oculis,tantò fub majori ; quantò verò remo-Magritudo ora, rantò fub minori vifuali angulo comprehendi ̨̇ Cùm ica-comitum ue Sol \& Luna multò majori à terra diftantia, quàm hi qua- fobis. .or globi removeancur à globo Jovis;mirum non eft, te hosce ib majori,quàm illos, angulo videre. Hinc confticutus in prio 10 globo, fecundum criplo $\&$ ampliùs majorem videbis, quàm mo ex globo Jovis intuitus es;hoc pacto ex fecundo globo rtium, \& ex hoc ultimum majori \& majori fub forma conmplaberis,uc poftea cibi propiùs oftendam. Theodidactus. Uum valde achirandum in hisce globis noto, cujus rei caufam irum in modum nofle cupio. Cur dic fodes,fingulos veluin plafes quasdam Lunares, nunc plenos, nunc dichotomos, odó falcatos cerno?non dicam Lunæ inftar (neque enim teneofa in illis ulla portio obviam fit ) fed quantam differentiam lufúfce à candidiffima, quâ phafium diverf $x$ conftituuntur fora, intueor. Cofmiel. Jam hoc fuprà tibi infinuatum eft. Globi omnes propriâ luce fulgent, minimè tamen tam intensâ ac ]; fi itaque intenfus Solis radius in horum fuperficiem incide; ex Solis propriaque lucis miftura neceffariò infignem lucis tenfionem confequi neceffe eft. Atque hæc eft fulgida illa lux , lam dufca feparatam vides. Cùm praterea in oppofitam glorum partem lux Solis penetrare non poffit, fir, ut, quamyis it- Phafes bas propriâ luce ex dicta parte fplendeant,ea tamen minimè ad ria Comicis claritatem obverfa portionis pertingere valeat; neceflaigitur inde fequitur varia lucis in globofis corporibus fe comites fo. 0 , haud fecus ac in Luna contingere videmus. Theodidactus. Eis duo fuped cur fuperiores plù inferioribus illuminatos incueor? Co. riores plins iel. Ratio eft, quia,certo cum Solis, tum globorum in circulis ferioribuse. s fitu pofito, pracer Solis illuminationem, accidit illis pratenon exigua lucis iftius, quam inferiores globi in fuperiores erberant, intenfio; unde nonnulli ex hujus luminis acceffu motis 
mori ,ex illis binos veluti Soles quosdam, \& alios binos velu Lunas quasdam opinaci funt; \& $x$ in eadem aliquamdiu opin one hafifti.

\section{SCHOLIUM VII.}

PHafum Lunaribus finilium caula, earumque varietes, intellig pur ex diclis de Pbajibus Lura artbus fuprà cap.2. Rheita, gui h 4. Oculi cap. memb.2. Jubmemb. I. probabilifimum putat (uti Jup? etiam diximus) fi non omnes, falcem penexcimum, \& primum J vi, inftar Solium efle illuftrantium; fecundum verò \& quartu à jam dict is, inftar Lunarum illuftratos,ait, hos cosdem nece (Je e exiftenti in fove jam falcatos, tum Jemiplenos, deinde gibbo/c candem etiam plenos apparire. Sed, ut /uprì etiats dixi, probat lius eft, omnes gaudere propriê luce, $E^{2} i d e o$ Juperiores femper app rere mages illuftratos inferioribus, propter saujam ab Awctore all. tam.

IX. Co/miel. Sed jam effectus, quos horum globorum i anes somi-fluxus in globo Jovio operacur, exponamus. Cùm icaque Jupit ses in Jobe -perastur. circa proprium axem roracione fuâ in dies in circulo maxin 1844 , unâ verò horâ 77 leucas conficiat ; fequitur, eum con nuó tele rali motu circumambulonibus fuis obvolvendo, fe fim etiam eorum lumine, diverfimodè quidem à diverfis ill minari. Nam cùm primus \& vicinior Jovi , fuâ luce in fuper cie Jovialis circuli maximi, feu $æ$ quinoctialis, Ipario 24 horaru 12704 leucas horarias conficiat ; è contra Jupiter fe ei obvo vendo 1844 leucas fuâ circumvolutione perficiat; neceflè primi globi lucem Jovii globi fuperficiem duplo ciriùs pe fringere perluftrareque, quảm lux Solis fuperficiem Tellu folet ; \& proinde Deus Opt Max.omnium Conditor ita dict rum globorum mocus difpolust, ut jucundinimâ \& perpet reciprocatione primi globi luci, nimis citò Jo' i fefe eripien mox fecundi lumen fuccederet; hujus autem lumen rer globi lux fequerecur: \& tandem hac occidente, lumen uki 
lobı orirecur, Ex quibus fequicur primò, dies noctesque Jovias fummâ non tam duratione temporis, quàm interfione luinis, effe inaquales: quis enim dubitar, duos, tres, aur quatuor reidiflimos globos Jovis fimul orientes, plùs diei \& lucis ei$\mathrm{em}$, quàin unum folum adferre? Secundò, duobus quafi dieas in pluribus Jovialibus plagis, feu potiùsfpario 4. horarum. re quandoquenoctem, co videlicet tempore, cùm omnes fibí vicem fuerint copulati, in partibus fcilicet Jovialibus ejusmodi onjunctionidiametraliter aut quafi contrariè oppoficis. Tertid quitur, frequentiores inter Joviales globos eclipfes, quàm luares, easque valde notabiles, fed qux parum durent, continge- Atque ex his omnibus luculenter patet, cur hunc ingentem vis globum, cùm à Sole fufficienter illuminari non potuerit, ei osce veluti vicarios quosdam Soles, id eft, folaris naturx globos Tocia verit, qui tanquam difpertitis quibusdam vigiliis Jovem ipantes, mirâ quadạm viciffítudine co illumlucis remperamenmoderarentur, quod ejus finibus à natura prafcriptis quàm aximè effet confentaneum. Hac enim vehementi quatuor oborum luce, praterquàm quòd globus Jovius ferè femper itenfiffimâ luce illuminecur, calorem quoque \& xeftuum ajus fummum \& vehementifimum fore neceffe eft, uc oc pacto virtures fpecifica ex centro tanti globi, ad circumrentiam elicitæ, in circumfitos mundi globos, pociffimùms rram, ad uniuscujusque requifitam neceffitatem diffundar1r.

\section{SCHOLIUM. VIII.
Ec ommia defsmpta funt ex Rheita lib.4.cap. 4 . memb. 2, fub-
memb. 2. Sed somnsulli erreres irreplerant tumin calculum,} vm in verba textus iquos /uftulimus.Plura,, 5 non injucunda dewit Rheita loc.cit. quem vide. Reliqua usque ad finem Capitis nen adigent explicatione.

$X$. Theodidactus. Harc magno verborum pondere vix eloutus erat, cùmecce ex lucidiffimo quodam moncis receffu mi-

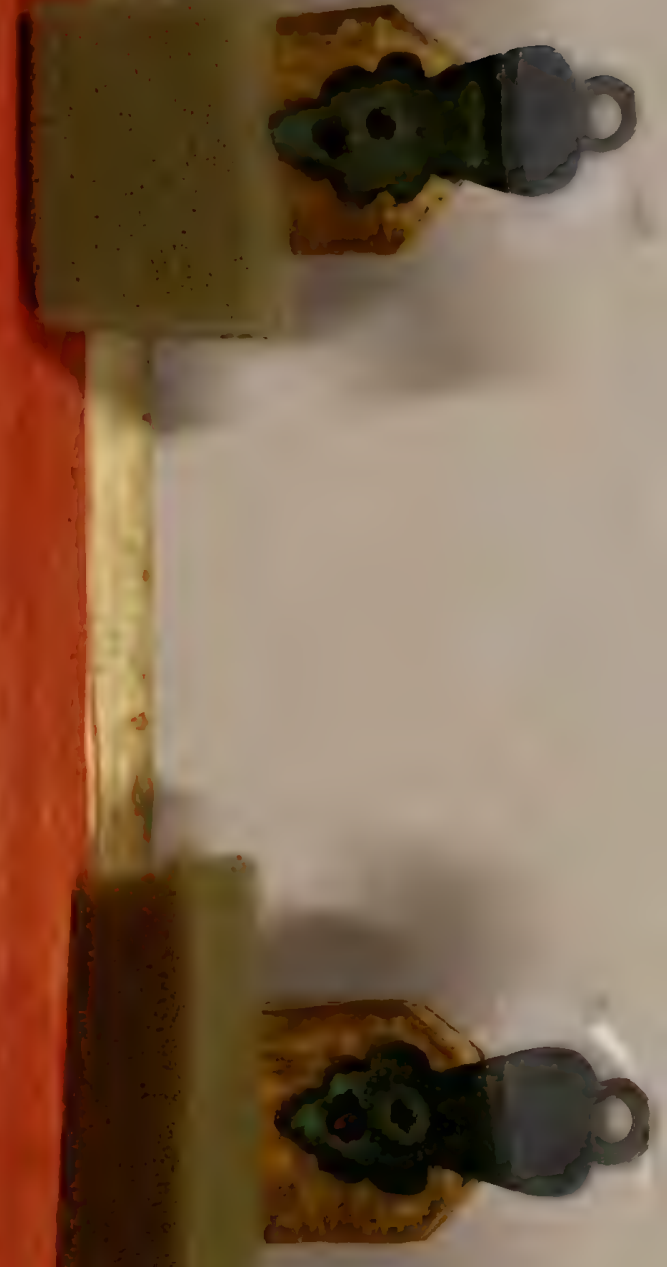




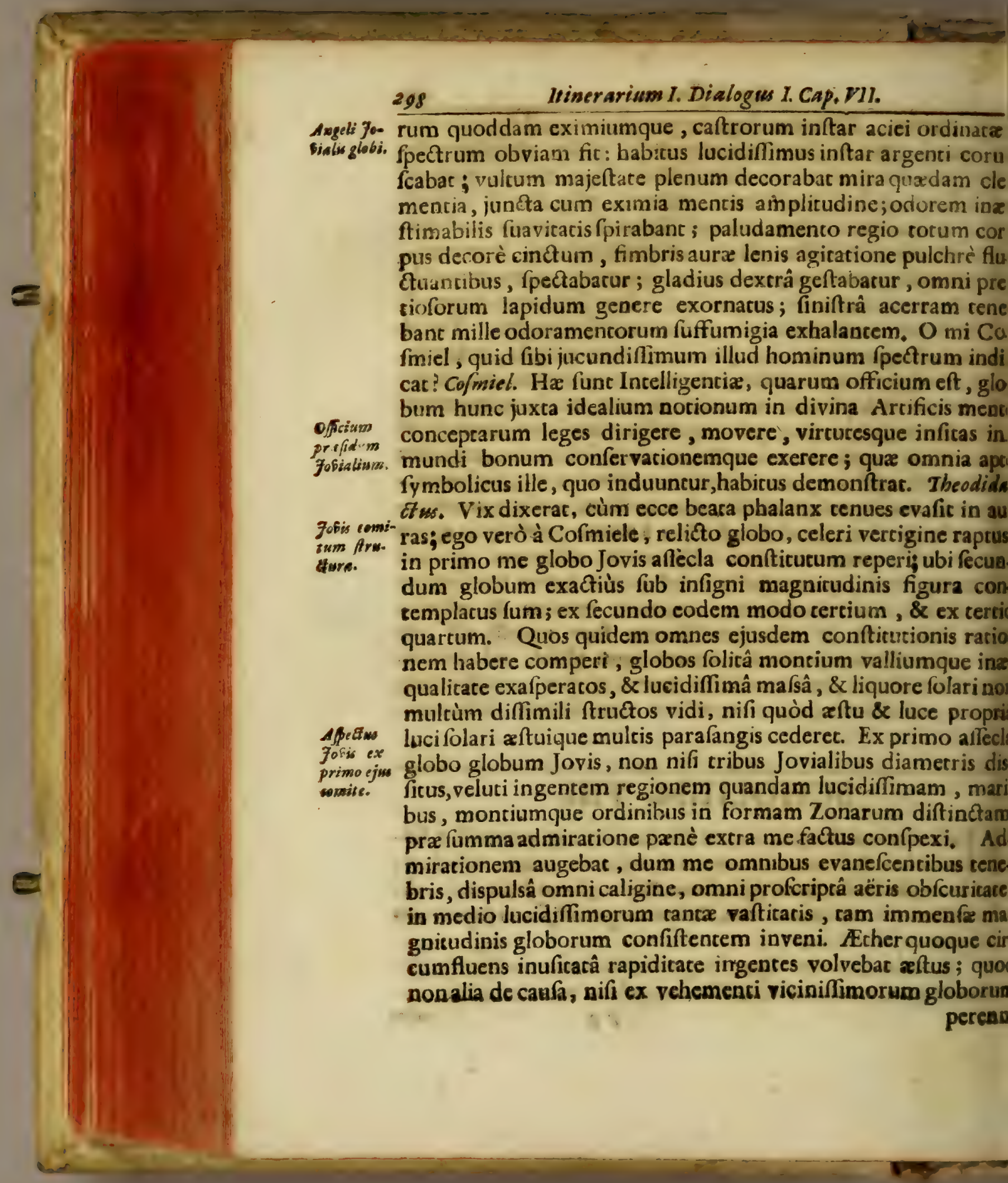


erenai circumvolutione contingebar. Hîc, prater Solem \& 1artem, nullus alius inferiorum globoram comparebat, tum b diftancia magnicudinem, cum ob lucis circumflux magnidinem, cujus exceflu reliqua omnia, tecta perpetuâ caligive, jualere videbantur. OColmiel! jam video verificatum illud cclefiaftici : Mirabilia opera Altiffimi, \& glorio/a, \& abfcondi- orinvifa opera illius, multaque efle abicondita majora his, finis globo: pauca nos vidifie operum ejus. Sed dic, rogo,cur benigniffi- rum fosieus Conditor, cujus natura bonitas eft, ab hominum intellectu lium. t ac tanta mirabilia à tot freculis abfcondere voluit? \& quid indem in natura rerum utilitatis conferunt tot abfcondita ream facramenta Co/miel. Scias, fili, mulca in rerum natura sortales latere, qua tamen fuos efficaciffimos effectus \& virites in fublunares creaturas diffundere non ceflent; \& uti niil in natura rerum fruftra conditum exiftit, ita ignorantia. tortalium quoque nihil virtucum, influxuum, exiftentiarumque sllere poteft. Nam fi à te pecerem, quid tuo in corpore proint tot minutiftimi venularum ductus? quid tot cartilaginum : minucifimorum offium ftructura ? quid in renibus tor gloulorum ordines coacervati ? Certè,quamvis horum particulaes \& individuales effectus ignores, tunc tamen aliquali racioe effectus virtutesque corum refpectu corporis tui compertos aberes, cùm vel unicus tibi è renibus globulus unà cum venu8, aut mufculis \& cartilaginibus extraheretur \& ô quantum pronus totius corporis harmoniam turbatam fencires? quàm citò cum actum diceres? Pari ratione fi vel unica ftellula ex aftris ivinâ virtute tolleretur, an non totum mundum in confufioem redigi pofte exiftimes ? Theodidactus. 'Prorfus exiftimo, nò quantum vel unica Solis aut Lunæe eclipfis inferiorum rerum ftacum turbet, frequens nos experientia docer. Co-

fowiel. Sed hac jam tibi ulceriùs expendenda relinquo; quare ad alciora properemus,

Pp 2 PRE. 


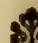 \\ 2.}

- PRELUSIO IN SATURNUM.

S Aturnus, omnium planetarum hactenus co $\checkmark$ gnitorum altisfimus, E' àterra remotisfimis juos decurrit motus/upraomnes planet as, infr omnes fixas ftellas, uti ex parallaxi ejus ornniun. minima É penè nulla Aftronomicolligunt. $H$ tam lento gradu ab Occidente in Orientem repeda revidetur (30.enim ferè annorum patium con/a mit in una pericyclofi conficienda) ut merit ab Hebrais Schabtai feu quies, à Grais xpórece $/ e$ tempus, ab Egyptiis Rephan feu Deus tempor dicatur; utique à tarditate temporis, quá peric dum fuam jub Zodiaco abjolvit. Unde chara Eter ejus Aftronomicus est hic, 5 videlicet fal $x, q u$. tempusedax cunct a demetit, at que abfumit. Hi tanto licet patio à nobis difideat (ultra 12,14,16 $17,18,20,22,25,37$, imò 60 go femidiam trorum Terramillia aliqui ipfi tribusunt) non ta men eff ugit tubioptici aciem;cujus op? Lincei Mat bematici notarunt fequentia. 


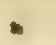

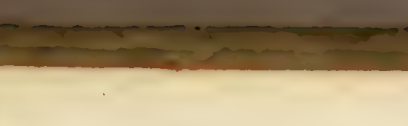

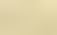




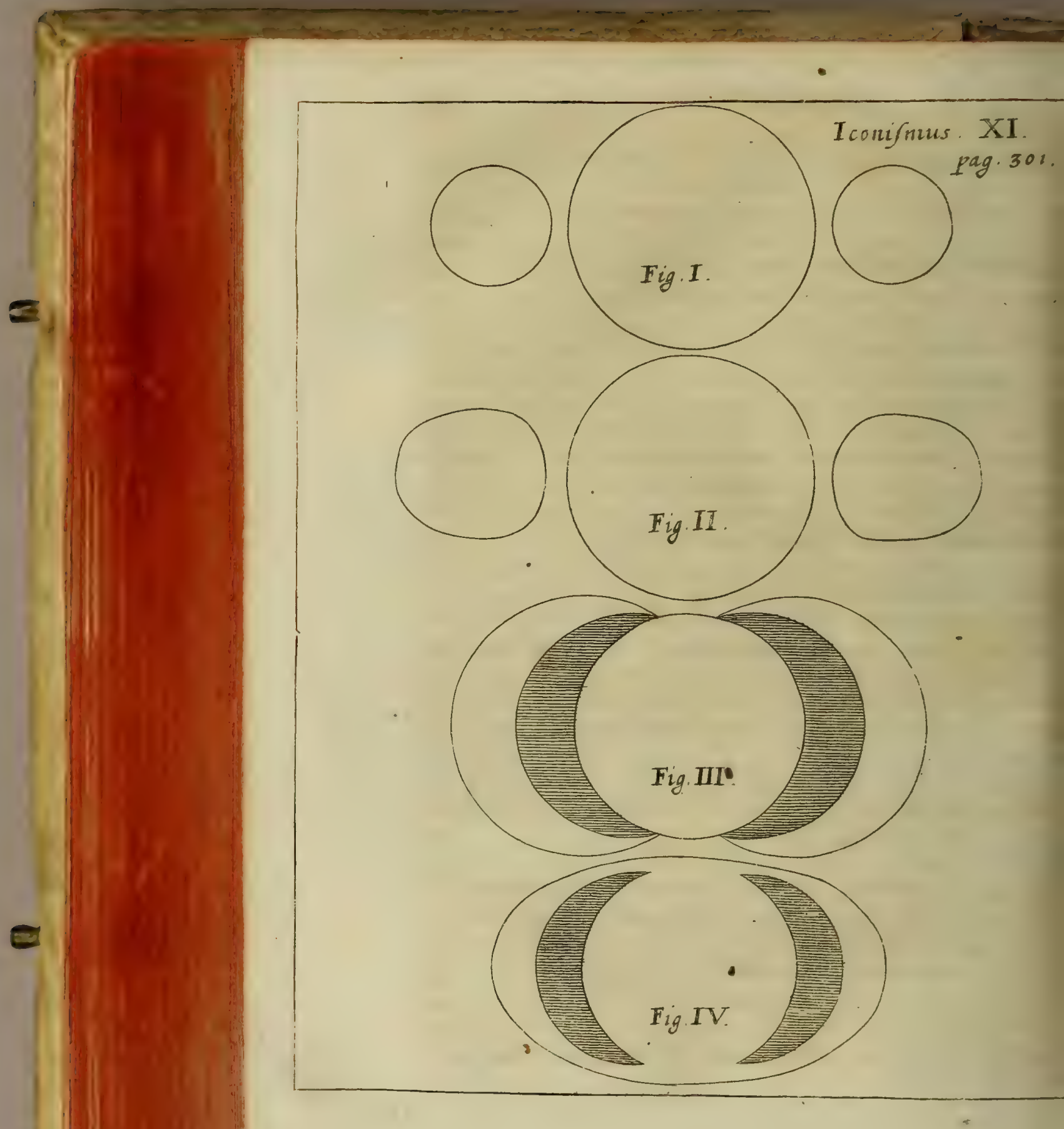




\section{1. De obfervationibus Saturni \& comitum} ejus, ope telelcopii.

A stronomiens oculus, tubses inguam telofcopius, Sat urnum novo fohemate indut um, novo comit at u fipatum, omnium pri- Saturni wo. so derexit in Italia Galilao Anno 16ro, deinde in Germassic mitum cheinero Anwo 1614 , tandem pue plurimis aliis Rome, Venetio, Garin. Teapoli, Parme, Bononice, of alibi i detexit inquam, (ut accurate otat Ricciolus lib. 7. Almag. Sect.. . cap. 2. num. 7. G fect. 6. 17. 10. "1кm. 8. on in fine dicti labri; ex quo Jequensia defump/sius) aut tricorporem, aut enormiter oblongum, aut duobus comibus vel lateronibus arct:[fimè circumfultum; qui quidem interun unum idemgue corpus cum allo, fed oblongum, efficere videntur wir alt is hinc inde intervallis ver/ws extremas cupides; interdum erì exporrectis bracbiis, relicto medio intervallo, quafi anfula Sauno adberent; interdum ab eoprorfus feparati, vel tanguam roundi of minores planete; vel tanquam pyra, vel tanquars Luna, Vide Ices' rmibus illum velut forficibus conftringentes, vel alio habitis, uti nifmumXi. appoforis figuris apparet.

Prima fgura exbibet Saturnum à conitibus plane rotundic varatum. Talem vidit Neapoli Fontana Anno 1630, Junii 20; - Bonzonia Ricciolus Anno 1643 , tribus diebus post oppofítionem e$\checkmark$ cum Sole, feu abinitio Octobres per aliquot dies, tubo Galilet ज? $^{2}$ ontane.

Secunda fgura dat Saturusm feparatum quidem at comi. bes, led jam cucurbite aut pyrigrandioris figur am adeptis. Tain vidis Rome P. Nicolaus Zucchius Anno 1640, Maji 23, prope pectum quadratum cun Sole; É Bononis Ricciolus Anno s6 43. 2g. 0 atob.

Terra fgura monftrat saturnum lunatis jam comitibus of vicisian ab co inumbratis ac femlatentibus poft ejus dor/um, -fie con:unctum. Talem fpectavit Neapoli Fontana Anno 1633 , 34,1036; 8 ibidem P. Daniel Bartolus Anno 10 44, mense Dembri ; sononia Ricciolus cum Grimaldo Ansio 1640 , die to fobris; $\theta^{2} 1647$, die $38^{3}$ \& Februarii. Et is priori quidem ob.

$$
P_{3} P_{\text {fervatione }}
$$
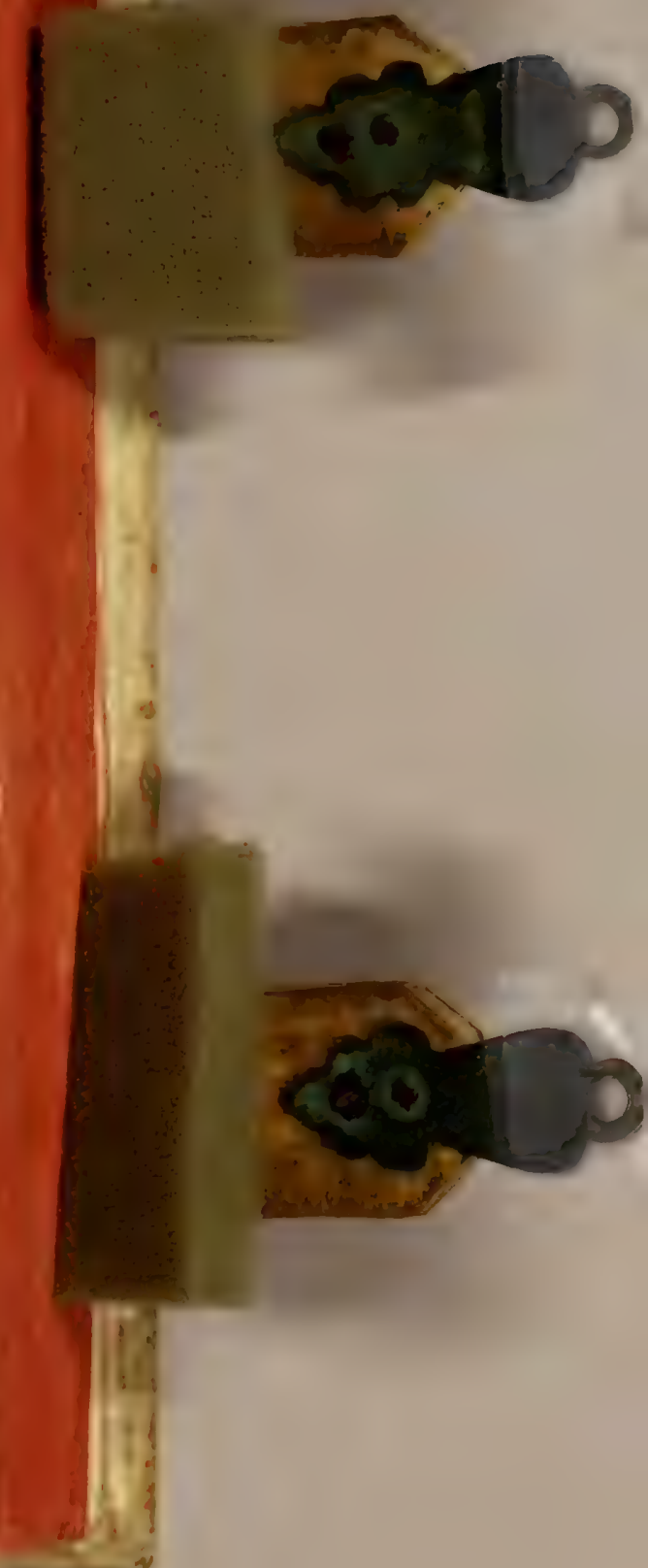


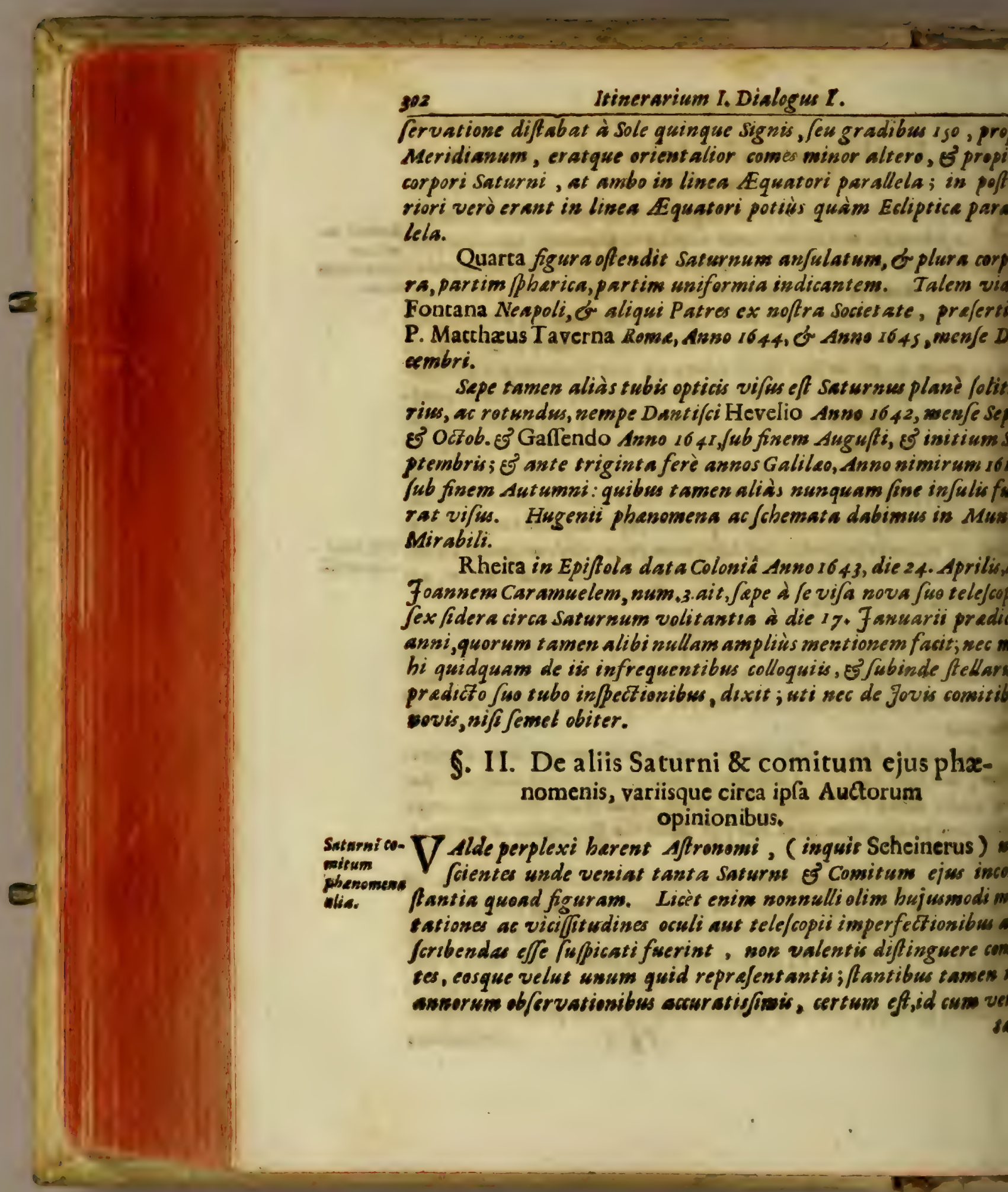


Prelufio in Saturrum.

ie dici non poffe. Aut ergo(infert Scheinerus in Difquifit. Macheat. num. 44. ) motui locali hac attribuenda fune, aue erendum hosce Saturni focios abfumi : fed hoc nemo adic dixit; motui ergo locali totum tribuendum. Sed quinam e motus ? Hxrent Aftronomi. Aut enim volvuntur ftelle - circa Saturnum motibus propriis, auc ipfius motu trahunr.Si primum, neceffe elt ad Saturnum accedere, \& ab eo redere, tandemque occultari \& $\mathrm{c}$ : quæe tamen hactenus certò ndum funt animadverfa; licèt hujus rei non obfcura exa indicia ex co, quòd Saturnus modò folitarius cernatur, in njunctione videlicet; modò ovi inftar, in digresfione vel ceffione;modò triformis, cùm verfatur prope ftationem. Si undum, oportet id altero duorum modorum fieri: Aut en Sacurnus iplemer circa fuum axem rotabitur, \& fic iftas Ilas fecum gyrabit, \& in conjundtione occultabit; qui taen modus licèt poffibilis fit, non multùm arrider, quòd foquâdam conjecturâ niti videatur : aut oportet id fieri ex eo, òd idem Saturnus annuâ Epicyclifui converfione hosce fecum cat famulos, fibi aliàs veluti immoto pede affiftentes. Sed hîc lendum, an \& quomodo id fieri poffer \&c : Sed in his omnibus icium adhuc furpendimus, experientis \& phænomenis ulceribus ea relinquentes; hoc folùm arbitramur, iftas viciffitudiè motu potiffimùm locali oboriri, five ftellularum (comitum) Saturni proprio.

Hec Scheinerus, Anno 1614, cum quo ferè etiam Ricciolus lib. Almog. SeC7. 1.cmp. 2.nsm.7.fentit, dum ait, pradictes comites ro \& poft tergus Saturni alternis acceffibus ac receffibus ad um \& abipfo, hujusmodi phafes nobis objicere , prafertim viformes fint : putat enim, Saturnum umbram in eos prores projicere, \& ex projectione illa fermè conftare, tam iscarere luce propriâ, quàm Saturnum, nec nifi â Sole lucere, Interea tamen duo difficillima conciliatu effe afferit. m ut umbra Saturni phafim eam, quam cernimus, faciar, erur debere effe calathoides, \& comites ipfos à Saturno valdiftare debere, fiquidem nigra illa Iunæ, feu lunatx um- 


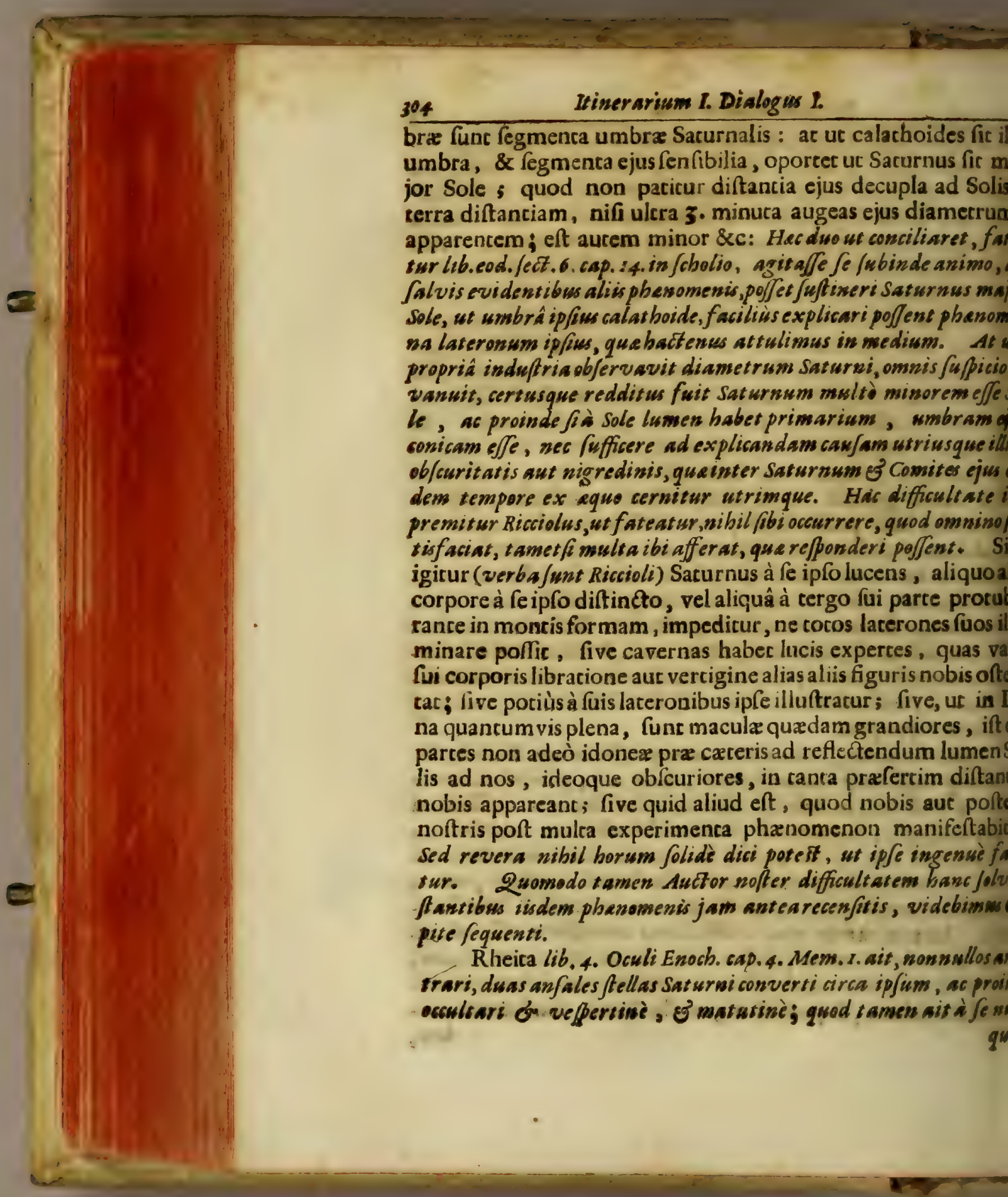


anm obfervatum. Si tamen it a conting at, infert, motum bure ebere effe tardiffmum, nec nifi poft multos annos obfervabilem: em, in conjusctione ipforums cum Saturno, unius quidem ve/perm, alterines verò matutina, neceffariò Saturnum, utpote tunc licariwm, debere appareve rotwndum; in quadraturis verò ipfoun, dum nimirum ad latera funt, tricorporem. Praterea infert, cossedatur laterones predictos circuire Saturnum, \&,ob illouns motum, eum aliquando folitarium of rotundum apparere, ccederdum etiam, ip Jum pofje aे lateronibus quandoque occult w\& ecliplari; vel, quia boc nunquam vifum eft, necefJario unums deobus concedendum effe, /cilicet dictos laterones aut citra Sarnum fe gyrare, aut proprio lumine preditos effe, saturnoque minarium inftar effe, quorum lumine, iple proprio deftitutus, illuftretur. Et quia exiftimat, Saturnum adeo aे sole diftare, ab ip o fufficiens lumen recipere nequeat; addit : Probabiliffium icaque, imò neceflarium arbitramur, fcilicer Saturnum. nnino aliunde quàm à Sole remotiffimo lumen fibi fuffins conquirere. Cùm verò ejus dua laterones ftella lucidifnè cernantur ; profectò necefle videtur, Saturnum ab eis $\mathbf{u}$ mque potifimùm fui luminis radios mutuare. Hec RheiEx quibus, tamet $f$ multe ingenium $\xi^{2}$ acumes viri pre $/ e$ ant, quedam tamen Ricciolo minime probantur. Vide ipsum cit.

\section{§. III. De fructura Saturni \& Comitum ejus.}

$x$ premiffis phenomenis, \& ex analogia Sepitus inculcat a cum Saturni 8 cater is planetarum globis, ftat no cum Auctore noftro, Primò, comitum turnum effe ex folido \& liquido coloris plumbei compofitum, \& ojus fruericum quidem, at fcabritie or apperitatibus fuis maigis, quàm eros planetas, defedatum. Secundò, effe ex fe opacum \& alide illuminari. Et tametfi solis lumen ad eum pertingat, nor men fufficienter ab co illuminari, fed aliunde etiam lumen reere. Tertiò , Comites Saturni babere lumen proprium, coaut fomul, aut vicifom illuminare Regem fusm. Quartò, Co29 mites 


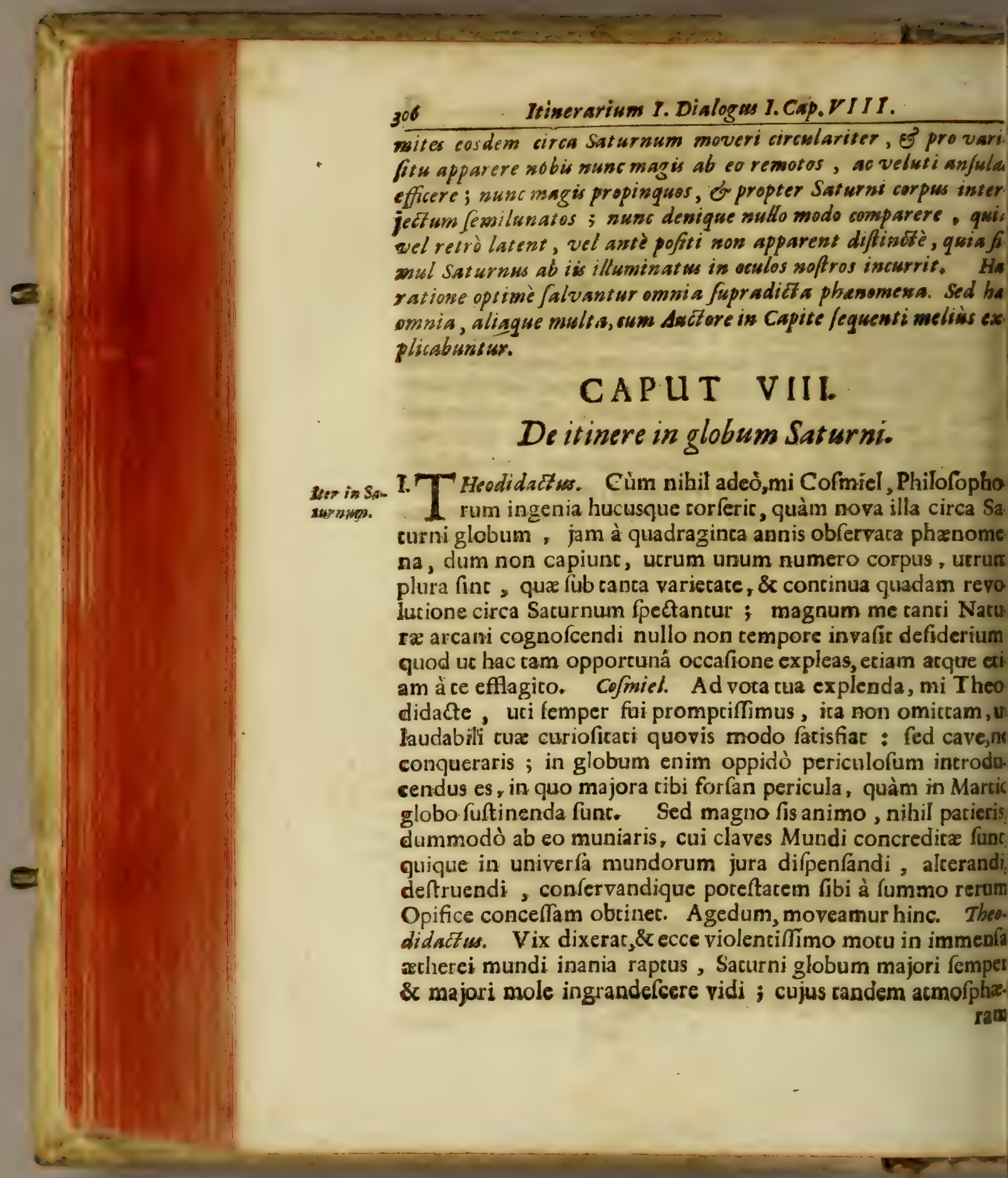


am felicibus Euris exiguo à diccllus noftri rempore atrigi3uo. O mi Colmiel, quænam bæc adeò denfa nebula eft, quâ uncùm non fuffocor? O quanca animum meum melancholia. orquet! quàm ingrato odore infeftor ! quàm enormi frigore oncremifco ! lechargi imminentis mihi aperta indicia leno. Jam enimverò me pœnicet hunc me globum petiille. Comisl. Nónne pericula tibi imminentia prædixi ? nónne adonui,uc à querelis abftineres? Sed hac jam in foenam moca fidei cuare fuftines. Theodidactus. O dulcis dux anima nex, parce pufilli animi timiditaci, parce infirma mentis ex imporencia: ecce enim totus ego in manu tua fum, ficuri rum in manu figuli: Scio enim, \& devorifimo tibi corde faor , me in tam remoris \& inacceflis mundi limitibus fine ratia \& protectione tua vivere minimè porfé. Quare dirige e, mi Cofmiel, præbe mihi dexteram tuam, cujus vircure \& ocentiâ unicè fubfifto. Co/miel. Confide fili , faciam,quod oftulas, tibi femper afticurus. Tbsodidactus. Hoc dicto, coeftis ballami mirifico quodam liquore perfufus confeltim reiravi, pulfoque melancholici humøris affluxu, priftina anii tranquillitaci refticucum me fenfi. Sed rogo te, cur tanta iftitia animum tneum hoc loco invafit? cur tam repentè inrclufo faucibus halicu animo corporeque deficere videbar. miel. Ne mireris ; incra exitialem Saturninæexfpirationis mofpharam conftiturus eras, cujus proprium eft, fimilibus, de corripuerunt, fymptomatis omnia infeftare, uti poftea debis.

II. Theodidacf us. Veráne contueor, an oculi phantafmate adam illudor? Colmiel. Quid miraris? Theodidactus, Quid opidò peregrina illa fpecies fibi vult? quid monftri ? quid inaditi prodigii eft? Co/muel. Ne dubites, fili; vera vides : hic aim eft celebris ille Saturni globus. Theodidactus. Globúm- illum dicis, quem ego tantum abeft ut globum judicem, ut glob. fat criùs rhombo nihil fimilius viderim, immenfa fcabricie, \& inequalitanninentium hirc inde fcopulorum exorbitantiâ mirè defor. tes. latum protenfumque? fed \& luce adeò plumbeâ pollentem

Qq 2 video. 


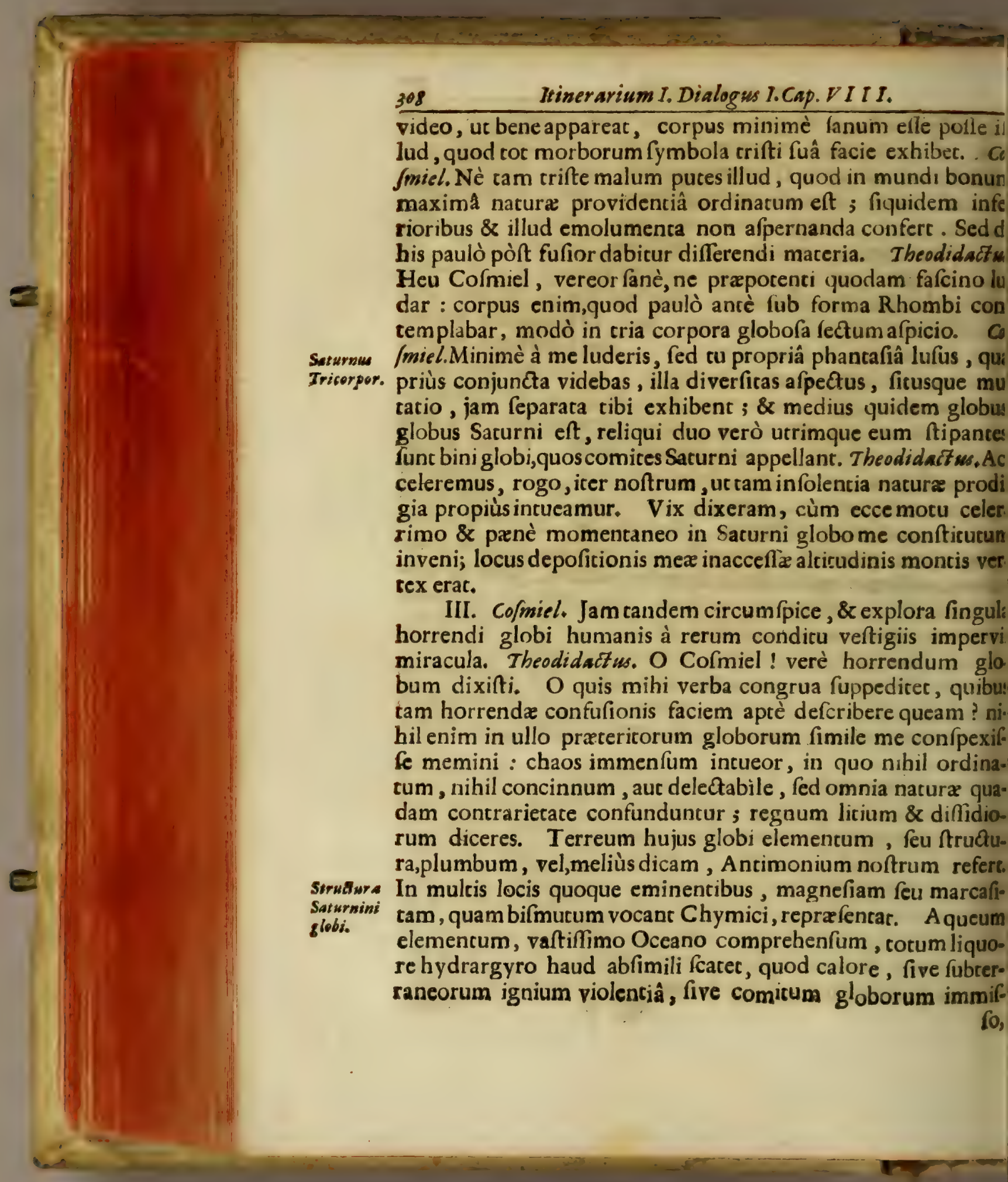


, fumos ingentes fublimat; plumbeum quoque terreftris bitancia pavimentum perenni fluxu fudat hydrargyrum, nde canca vaporum exhalacionumque perniciofarum copia afcitur, ut impoffibile putem, hominem vel ad momentum. c degere poffe. Hîc nullam diei claritatem, fed omnia initabili caligine involuta incueor. O Cofmiel, quis mihi obi hujus horrorem narranti credet? quis in animum untam inducere potueric, hæc vera elle, quæ tam luculento proiorum oculorum teftimonio plùs quàm vera cognovi? Quid, go, natura rerum in tantæ confufionis globo intendit, tanm contrariarum rerum mifturam pariendo ? Co/miel. Fili mi, Finis Sa i, non dubico, hic meræ confufionis globus videcur. fed val turnini hallucinaris, cùm omnia fummâ providentiâ ordinata tura intenst, \& ad fines infignes in nacura rerum difpofica. Si nofles, natura rerum tor noxios ferpentes, infecta, reptilia in aniancium oconomia; cur in vegetabilium familia aconitum, pellum, fcammoneam, thoram; cur in terreno Mundo toc hium eructationes, rot aquarum fontiumque exitialium difcrina in metallicorum corporum familia, tot noxios vapores, fuccorum exhalationes prorfus peftiferas; cur cotmontra minum, tot morborum differentias, tor impios unà juftis ftos nafei permiferit ; forfan ad hujus globi arcana pertines. Theodidactus. Tu, mi Cofmiel, qui omnium confcius explica mihi,obfecro, tam recondicum natura facramenn. Co/miel. Argumentum, de quo tibi diferi poftulas, uci luum, lubrile, \& hucusque parùm cognitumeft, ira paucis bis tibi minimè illud explicavero ; quocirca altiùs exorr. Ita humanx menti comparatum eft, ut fieri non poffe et, fimile quid earum rerum, quarum continuo ufu afluefit, ucidiffimis illis mundi globis latere ; unde globos cœlettes mentarium qualitatum mifturâ defoedatos, vario aquei elenti liquore perfufos, montium valliumque fcabritic exaratos, fumis \& halitibus obnoxios, fimilibusque terreno bo propriis effectibus refercos efle, meræ apud quosdam. ; \& meræ fabula videntur : qui fi paulò profundiùs natu-

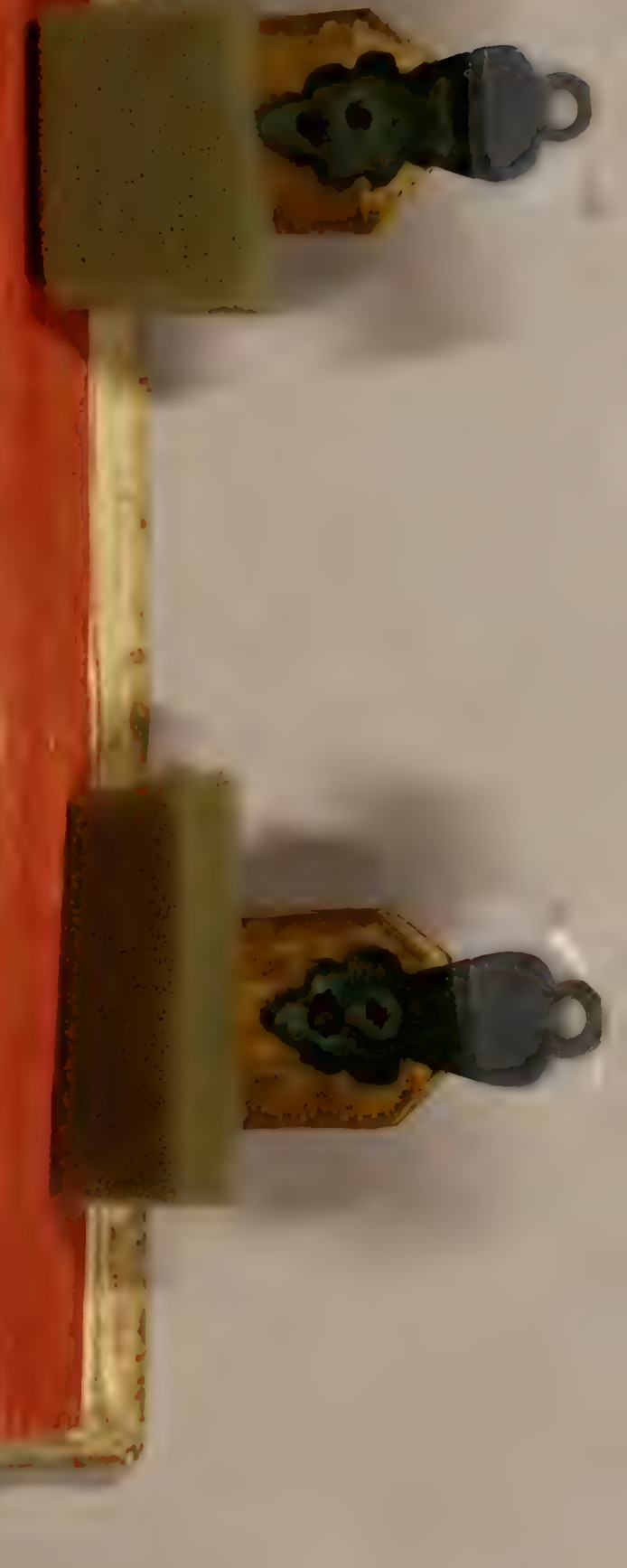




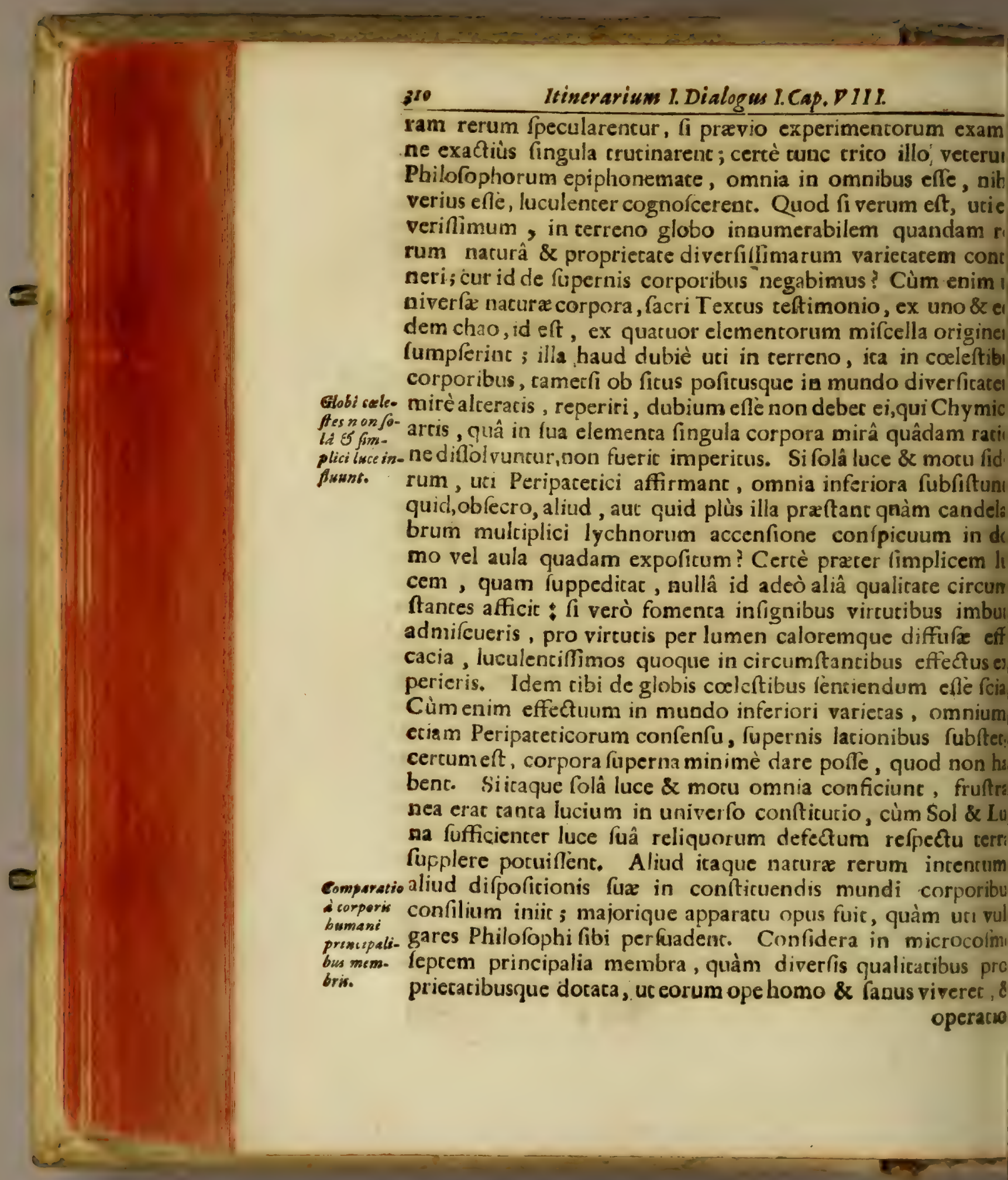


erationes fuas ricè obirer. Hæc eâ lymmetrâ conítıcuıc atura, uc humorum officina cerebrum, humidicatis affluenreliqua membra aprâ diftributione lubrica redderet; cor alem fuppeditaret calorem ex vita veluti officina quadam. iquis membris diftriburum ; hepar in fanguine conficiendiftribuendoque omnem induftriam fuam poneret ; ftoschus per nutrimencum ritè digeftum, materiem præpara, quam in officinas fuas atcractam fui juris facerent reliqua alia membra : pulmo cordis aftum continuâ diductione nperaret, vera vitalis aurx officina ; renes, microcofmi criim, purum ab impuro per ureteres ac veficam fecerneret; en denique impurum à fubrili, ne miftum puro corpori oforet, in fe veluti cloacam quandam microcofmi inficâ vi occulcos meatus atcractum, craflum verò \& faculentum. imentum per inteftinorum finuofa volumina feceflumdeductum exonerarer. Vides igitur, Theodidacte, quodo membra microcofmi tametfi difparatiflima compofinis fint, diverfisque virtucibus quantumvis contrariis polat in hominis tamen majoris mundi imaginem mirâ quan unione confpirent; quorum fi vel unum defecerit, totum rocolmum in apertum exitium ruere necefle foret. Idem negacofmo feu majori mundo evenire certò cibi perfua$\mathrm{s}$; in quo Terra ftomachum, cerebrum Luna, cor vicæ fonSol, renes cum reliquis ad extra adnexis Venus, pulmo $n$ Mercurius, Mars fellis ciftam, hepar Jupicer, fplenem veSaturnus abfolutiffimâ quâdam analogiấ exprimunt. TolI unum ex his, \& totum univerfum mundum in confufioa, imò in ulcimam ruinam deduxeris. Sed hisce fufiù forfan,quàm par erat, demonftracis, jam poftliminio ad Saturninum globum revertamar. 


\title{
SCHOLIUM I.
}

\author{
De Saturni natura, \& effectibus.
}

Suturne epitheta, of effedin.

Q Aturnum appellant Aftrologi planetam ma culum, diurnum. Dinfortuxam ajorem, tnimicum nature humane, frigidum focum, contrarium calori naturali, complexione melancholicun omnia Juis qualitatibus deftruentem. Rheita lib. 4. Oculi Enoc cap. 6. memb. I. hos enumerat effectus ipfius. Sacurnus itaqu omnium planetarum altiflimus \& fupremus, dominii aér. quando folus director exiftic, orientalis (id eft, dum ante So lem manè nobis oritur) eft frigidiflimus : fed è contrà occi dencalis, \& poft Solis occafum nobis perfpicuus, maximè fic cus oblervatur. Naturâ autem fuâ cenfetur maleficus ; tar difimus omnium progreflu ; fecundùm Pcolemæum \& alic artifices, generaliter frigore fun corruptiones mundo affe rens, aërisque conftitutionem horrendo gelu conftringen! glaciofam, nebulofam, impuram, \& peftitentem efficiens. Pra rerea caufare dicitur plerumque validiffimas $\&$ adverfas i aëre tempeftates, pluvias infructuofas, \& copiofas nebulas, 8 caliginem, aërem, præfertim hyemalem, nivibus \& pruini: prout tempus fert, replens; in mari \& fluviis tempeftates bye males, naufragia, \& longas infirmitates, impetus humorum defluxiones, febres quartanas, terræ motus, \& egeftatem ter: reftrem, devaftationem, \& alia mala producens, prout mali cum alio malo in maligno figno fueric affectus. Caufat verc propriè hyeme intenfiflimum frigus, xftate è contrà caloren. fupprimic \& excinguic, maximè dum vertici appropinqua \&c. Hac Rheita. Similia apridalios invenies. Plura etiam. Auctor nofter in fequentibus babet de Saturni malignu infiuxi. bus.

IV. Cofmicl. Miracus es fummum hujus globi fqualorem: fed,fi pradicta probè intellexeris, mirari defines : quo enim in microcolmo fplen fungicur officio, eo in majori mundo fer megacofmo fungitur globus bic Saturninus, vifeus verè coe. 
te, Quidquid enim in inmenio sllo arherex aur expanto, perennibus coeleftium corporum effluvis, maligiritatis conctum eft, Id in fe inficâ quadam virtuce attractum globus hic rivat; ubi proprietate globi actuatum in ufus neceflarios, fisque foli rerum Opifici Oprimo Maximo cognitos converur. Theodid. Mirum in modum me cuum tam concinnum. tiocinium capit: fed noffe cuperem, quomodo hic globus in eriora influat, \& quid ueilitatis issdem conferat, cùm non leam, quid tanta globi inertia emolumenti habeat, quo inferibus fubvenire poffic. Cofmiel. N'egare non poflum, maligna Saturnus tura hunc globum efle, præfertim maleficis junctum com quomodo litonibus ; qui fi, fui juris effe permitterecur, frigiditate fuâ \& influat in citate immodicâ fusque deque ferret omnia fed hisce incomdis damnisque fagax providit natura, dum benignâ ac imtiosâ Jovis vicini dominatione \& vigilantiâ tam exitialis $\mathbf{S a}$ ni potentas mitigatur, ftringitur, compefcitur, \& ad melion tandem frugen reducitur; qui tamen mox, ubi Marti maum archirceto focsarus fuerit, ad ingenium fuum reverfus, lum non malum intetstat \& attentat, donec foluco amicitia dere in remociores circuli fui receflus abeat, \& opportunâ nique vigilantiâ Jovis in officio contineatur. Theodidactus: pio quidem, qua dicis, fed nondum capio, quid memorat maleficentid in mundo utilitatis conferat; quare obnuxè te recor, ut tuam paulò clariùs métitem explices.

V. Cofmiel. Totius rei negotium fequenti experimento tibi nifeftum facio. Fiat globus ex plumbo, antimonio, bydraro, fuccis fcammonii, napelli, acconiti, hellebori, mandragounà fimul mixtis compofitus; quem fi igni aut carbonibus enfis loco conclufo impofueris, is calore ignis coneiratus x latentem perniciofarum qualitatum mifturam agitabit, tatam verò per vapores fublimabit, quórum pernıciofo hahominum animos veluti ftupore quodam \& lethargo cont, frigiditate \& ficcitate fuâ nimiâ radicalem húmorem exguet, anginam, paralyfin, nervorumque convulfionem, \& dem interutum haud cubiè adducet, nüi mox neceflaris anc

$\mathrm{R} r$ tidotis 
Strudura Saswrni.
Animalia Saturnine que 8 quid wtilitatis prefient. tidotis cordi , fpiricibusque confortandis appropriacis, malun. ferpens praveneris. Talis eft globus hic Saturninus. Vide! ftructuram cjus paffim ex materia plumbo \& antimonio fimil. lima compofitam ? vides maria, lacus, rivos lentore fuo hydrargyro quiddam haud abfimile referre? fcopulos montiumque crepidines nefcio quem graveolentem liquorem fudare con. fpicis? cujus quam exhalat mephicis, larentium venenofarun qualitatum verus \& unicus index ent. Hisce itaque noxiis quali. cacibus omnia inferiora fibi infeftac, iisque omnia prorfus con ficerer, nifi falubricate Jovis, vitali caloreSolis, \& Luna tanden repore \& vi humedtativa vistam exitialis temperarecur; unde mitior factus, idem in inferioribus, quod medicamenta pur. gantia intra corpus humanum fufcepta, praftat $;$ qua vitiofo: alicubi humores in corpore humano difperfos, ex centro ac circumferentiam virture quadam magneticâ attractos tander excernunt, corpusque ab inimici humoris invafione liberant Totum hoc corpus, quod vides, perenni virtutum malignarum profluvio feric tellurem , \& ubicunque fubjectum ex rriplici en

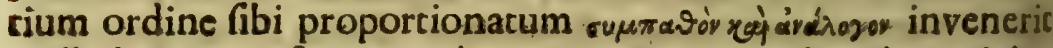
in illud virtutem fuam unicè exerit. Et guemadmodum globu: hic omnia atherei mundi impura \& nociva, ut fuprà dictun. fuit, in fe derivat ; ita in terra Saturnina naturæ corpore huir globofubjecta, qua nocivâ influxus virulentiâ parta funt, illa naturali quodam appetitu attrahunt, \& hoc pacto reliqua cor-

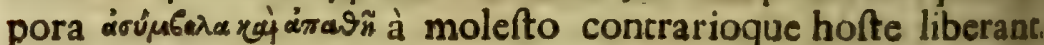
Quid vefpertiliones, bufones, aranei, forices aliud funt, quàm Sacurnina animalia qux perniciofum nocturni aëris virus un. diquaque viSacurni difperfum in unum collectum in fua deri. vant corpora ? Quod idem in terreftri Sacurnino veneno atcra. hendo præftant ferpentes, bufones, \& ex infectis volatilibus mulcx, bruchi, crucx, fimiliaque Saturninz propriecatis anima. lia : hoc enim nifi fieret, nihil in rerum natura $a b$ hujus glob offenfione immune forer.

V I. Theodidactus. Semper mihi malignitacem hujus influ xus globi inculcas, \& jam fatis capio omnia ; fed quod cotie 


\section{Iter in Saturnum.}

nofic defideravi, quid utilitatis in mundana R epublica globus hic conferat, ut mihi magis explices, iterum iterumque depo(co, Cofwicl. Globus hic, ut dixi, non femper malignos dispenfar utilitates influxus, fed opportuno loco fituque fuis minimè utilitatibus quat pres carere cenfendus eft : ubi enim reliquorum fiderum efficaciâ reftrigloelluris corpusaltu immodico contabuerit, hic frigore fuo id bocaterise mutigat \& $\&$ ubi cacaractis coti folutis, tellus, aut alius quispiam lobus nimio humore in hydropifin incideric, Sacurnus eum a anto malo ficcitate fuâ vindicat, omne fuperfluum \& noxium ive caloris five humidi deftruendo; in hominum corporibus olaciles fpiritus plùs aquo inquietos figit, \& ad licterarum futia tractando ficco-frigido, quo pollet, apta reddit. In infirmicaibus humorem Sacurninum in deftinatum membrum fibi anaogum cogit, arque adeò per paroxyfmos febris quartanx cum empore hominem, digefto egeftoque humore, liberat. Immolicum pracerea Solis aftum frigidicate fuâ temperat , Luna rumorem nimium ficcitate fuâ cohıbet, omne denique fuperluum \& in globis nimium fringıc, \& ad mediocritatem reduit. Quemadmodum itaque medicamenta falutem conferre guod meton poffunt, nifi mediantibus qualitatibus, qux in is latent, na- diremente ura contrariis corpus vitiosâ humorem congerie aggravacum preftant in vacuetur ; ita \& Mundus terrenus vitiosâ humorum congerie carpore, id ggravatus priftinum fanitatis ftatum, nifi mediantibus dele- Saturnuw eriis hujusmodi, qua nonnullis mundanis globis, uti Marti \& Mantis. aturno, infunt, qualitatibus, confequi non poteft : funt enim à lacura veluti medicamenta quadam alexiterica, antidota. Mundi morbis oppofita, quibus curantur.Ne itaque medicamena pures inutilia ex hoc, quòd aut ingrati odoris fint, inteftina, ellicatione fuâ crucient, aut ftomachum naufeâ fuâ invertant ; OC enim nifi fecerint ; fruftra defideratum fanitatis effectum jerabis. An nefcis, vel ipfa venena in falucis remedia cedere ? Venene mnia itaque, qua hucusque fufiùs dicta funt, eò tendunt, ut de. Jubinde fas nonftrecur, exitiales hujus globi Saturnini exfjirationes tantum diatis rems. befle, ut ad deftructionem omnimodam vergane, ut potiùs in aximc̀ falutiferam Mundi medicinam cedant.

Rr 2 VII, Theo- 


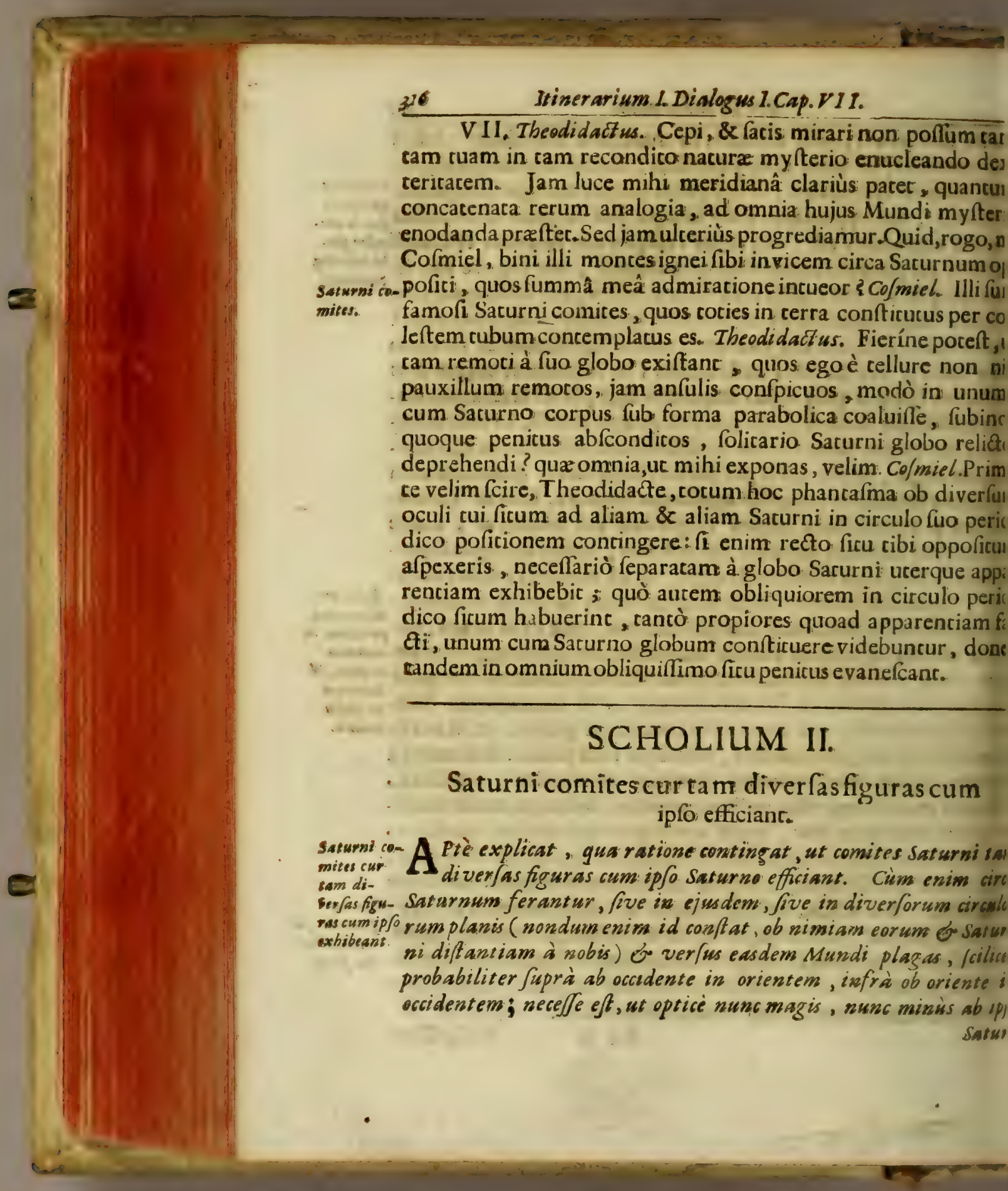


ofurno tanquam /ui mot wo circularis centro diftent. Exiftentibus itur Comitibus in maximis digreßsionsens, aut non procul abip/is, wes binc, alter inde, ad Saturni latera ; apparent nobis ab ip 10 /eirati, \& vel rotundi, vel pyroformes, fortaßus quia in Saturni atophera tunc folito denfiori refracti, tali figurâ is oculos intuenum incurrunt. 2uò magis verò conjunctiones accedunt, è̀ viciorer apparent eidem Saturno, ac velut ellipticum cum iplo efficiunt pres. Quando denique unus ex parte poft dorfum Saturni eft conditus, alter ante eundem ex parte collocatus (refpect u noftri turcus) anfulas efficere videntur. Umbra verò, gue tunc inter Sarnum $\sigma^{2}$ an/ulas apparent, /unt fortaßis partes obfouriores of luincapaces ipfius Saturni \& Consit um, quas partes tunc oftendunt, oniam circa proprios axes probabiliter gyrantur. Certè umbre e non polfunt, nec Comitum, nec Saturni, st confideranti patet. enique quando jam conjuncti fisst cum Saturno, \& unus dor/um, ter frontem occupat, latet uterque; alter quidem, quia videri ob7u Saturni corporis non poteft; alter vero, quia nequit difcerni ab uminato d le Saturno. Similia habet Auctor nofter in Jequenus; hac enm in mentem mibi venerant antea, quà ip

Cofmiel. Scias quoque, hos globos abdito quodam naturæ comitum nfilio ita conftitutos effe, ut nunc recedendo pedetentim, Saturni Gas nc accedendo, tum propriâ circa axem vertigine circuma- ria fécura. - tum circa globum Satur ni xquâ femper diftantiâ agitari, iverfalem Saturnini globi fuperficiem, prout ejus neceffitas ftulabat, illuminarent; quae proinde periodus caula inter ceras, quas innui, prior eft, cur fub cam diverfo firuac figura mpareanc incolis in tera confticucis quod nifi factum fuif- globus Sacurninus nonnullis in locis perpetuis tenebris daacus fqualuiflet. Theodidactus. Sed explica, rogo, mihi,cur ti globifub figura modò rocunda, jam pyrorum ad inftar, alò pòt inftructi anfulis, quibus veluti forficibus quibusdam bum Saturni concinere videntur, denique prorfus folicario bo relicto evanefcant. Cofmicl. Nonnullas harum apparenrum caufas paulò ancè aperui ; modò relsquorum ribi phæ$\mathrm{Rr}_{3}$ nome- 
nomena explicando reftant. Quòd comites ex rotunda ovalem formam fubinde degenerenc, caufa eft obliquus $f$. fiderum; quo per vitream Saturni atmofphxram fpectant quod medium cùm aëris terreni fimilitudinem exprimat , corpora illi infita potenter refringat ; hinc per dictam rel Ctionis vim eo ferè modò , quo Solem horizonti vicinum cueri fubinde foles, ex rotundo in ovalis figura-fimilicudin deflectunc. Cur verò fub forma anfularum, aut cornutx $n \boldsymbol{x}$, vel pocius fub forma forficum cancri, quibus $S_{a t}$ ni globum veluti ftringunt, fubinde compareant, vaufa quòd corpora illa globofa à corpore Saturni pariter glob intercepta talem fectionem faciant, qualem vides, \& ex opt luculenter pacet. Theodidact us. Benè quidem omnia expo. fed hoc me angit, quid fibi velic obfcura illa vacuitas, que turnum inter \& cornua comitum interponitur. Cofmiel. gnum quid petis, fed, ne voris cuis deeffe videar, illud te edor Primò fupponere debes, globum Sacurni non fecus ac reliq mundi globos circa proprium axem circumagi. Secundò, bum, uti propriis tuis oculis vides, omnes reliquos munda globos tum montium concarenatorum afpericate, tum $p$ tenfarum molium deformitate fuperare, Tertiò, Sacurnin corpus lento quodam, hydrargyro non abfimili, liquore cumfufum, qui uti lucidiffimus eft, ica minima quoquelus cum illuminandum fufficic. Contra terreftres ejus porrio ob vallium receffus, \& hiatuum ingentium obfcuritates, ita luci, nif dubia, patent. Quandocunque icaque partes obf ræ Saruraina concurrunt cum partibus obfcurioribus cot tum, neceflariò in medio veluti quosdam obfcuros hiarus umbras caufabunt, reliquâ comitum portione, propriâ luce f

Comitum Saturni anterior curnullam glibo Saturnino aclepfin in: gente, in anfatas \& cornucas phafes tranfeunces, donec tand unus retro Sarurnum, alter ex oppofito veluti in redtam line: unà cum Saturni corpore conjuneti, ex oculis terrigenûra e' nefcanc. Theodidact us. Sed jam explica, quafo, cur ancerior comitibus inter Saturnum \& vifum noftrum interpoficus n lam unquam Sacurno eclipfin caufallé hucusque comper fert. 
: nigram enim utcunque maculam in Saturno relinqueret ipfeos peracta indicium. Cofmiel. Quæro ex te, fili, fi tu ilninato cuidam corpori aliud lumen apponas, patietúrne id juam ex oppofici corporis lucidi fymptofi eclipfin ? Theodi7w. Arbitror, quòd nullam. Si enim candela accenfa, em incer \& vifum meum interponacur, experientia docet, aen candela, luci ignis junctum, torum fub forma lucida reentente. Coforiel. Ita fit in hisce duobus globis Saturni affe, quorum prior ille, tametfi inter oculos noftros \& corpus urni interponatur, nullam tamen eclipfin caufar, cùm. naturâ fuâ lucidi fint, \& ip ipfo facto corpus Saturni illumiIt : quandocunque enim globus minor lucidus cum ro majori luminato conjungitur, eos miftis lucibus fub illuminati majoris globi facie fpectari neceffe eft Si comitum ien globus hic affecla purum opacum fine luce corpus fo- Saturni , tunc certè maculam quandam in ipfo Saturni illuminato phafes uma bo exhiberet. Quod quidem luculentifimum fignum eft, omites fuâ luce fulgere, ac proinde nullam hucusque in Sano comitum ejus occurlu eclipfin deprehenfam enle. Unde um colliges, tàm varias comicum phafes non provenire, nifi otatione eorum circa Saturnum facta, quâ nunc remoti featique fub forrna rotunda apparent, modó per rofeidum. ofphera diaphanum vifi in ovalem figuram refringuntur, à globo Saturnino fecti cornutam induunt faciem, jam in " ica pofticaque Sarurni facie conftituri penitus evanefcunc.

\section{SCHOLIUM III.}

Ullus corwm, qui Saturni Comites hactenns obfervarunt, soltm non

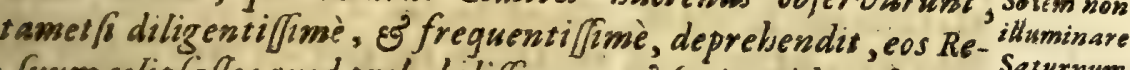
furm eclip ajfe ; quod probabiliffmum, E? (at is evidens fogrum saturnum eos norr effe corpor a opaca, fed propriâfulgereluce, fiverum eft, mites fuffi. lucem eo pertingentem nom elfe Jüficiens ad illos illuminandos cienter columine, grantum nobis exbibent,
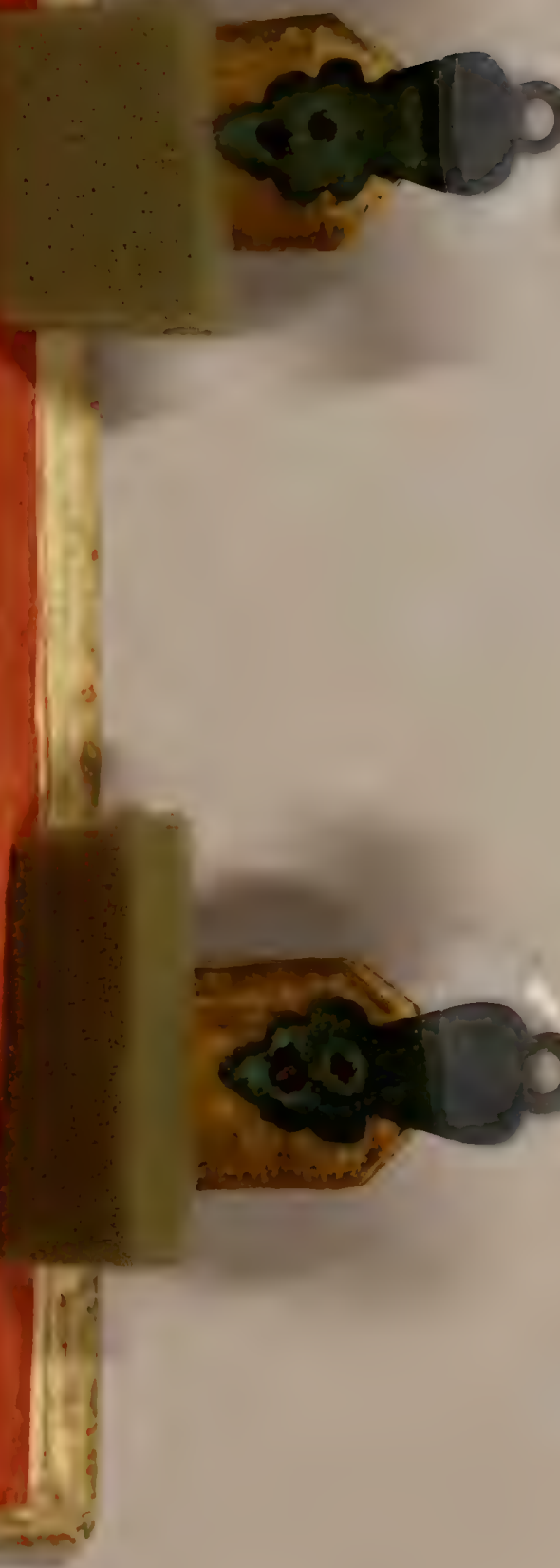


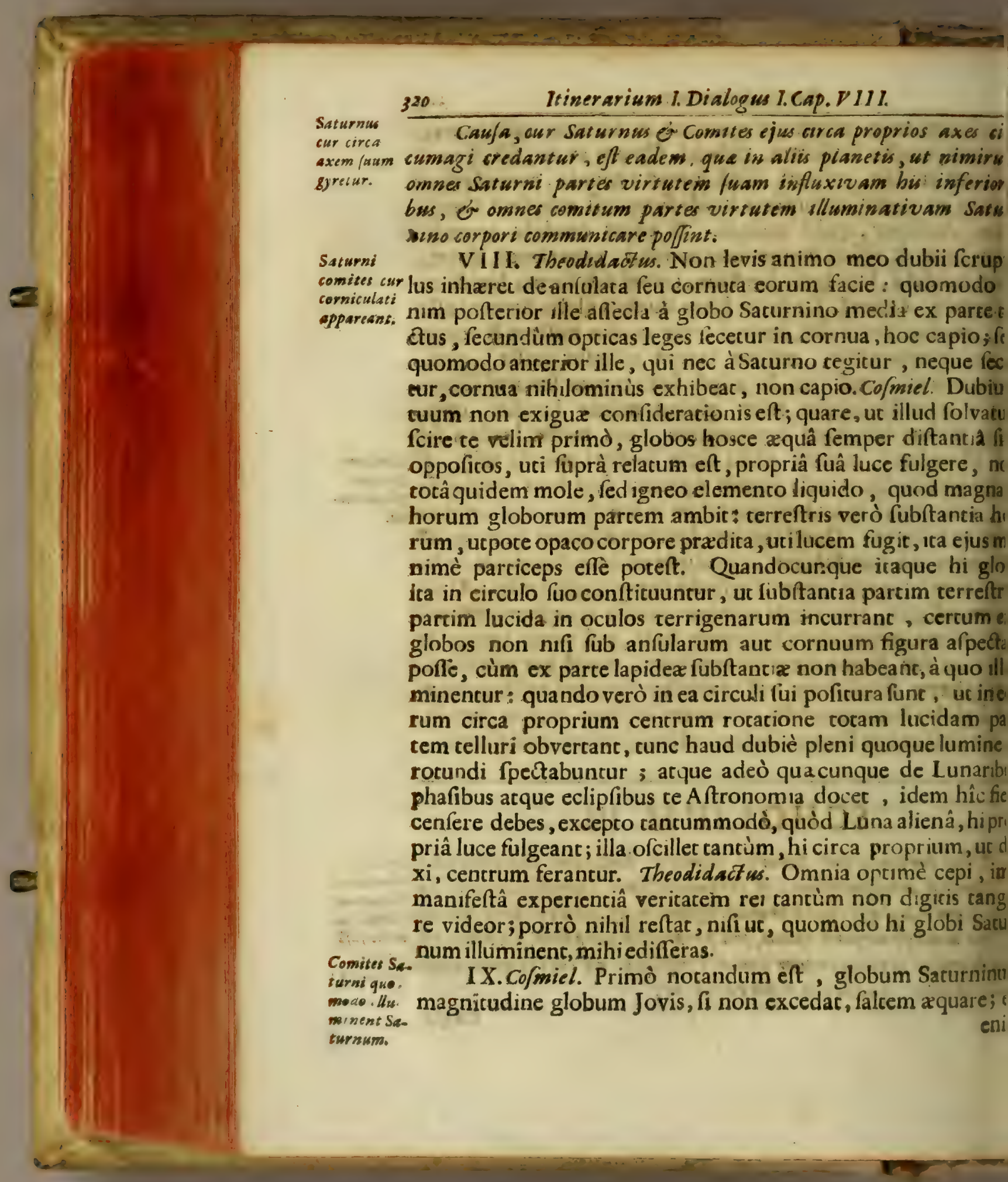


im in fe immenfus, \& 165 vicibus cerrá major; nam ejus 'diaeter ad minu's $1 / 262$ leucas horarias in longitudinem extenxquat. Cùm itaque rantus fic, uc iftiusmodi à Sole remariffi- tam exorbicantis molis fuperficies fufficienter illuminari pofit; hic à natura illi de aliis binis vicariis Solibus, id eft, laris nacurx corporibus, ne ingens mundani globi moles fufienci tumine \& calore defticuta fruftrà in nacura rerum inftita viderecur, provifum eft; \& funt hi bini globi, gui veluci duo carii Soles, tum circa proprium centrum verfaciles, cum æquâ nper ab invicem diftantiâ, Saturnum circumeune, ne ulla inncis globi pars lucis eorum beneficio expers remanerec. Quia men non obftante comitum fub uno femper $\&$ eodem parallelo cumeuncium illuftratione, cam ingens moles circa polares reones perpecuâ caligine damnata fqualeret; hinc \& iple globus ogue Saturninus fagaci nacuræ difpoficione, praterquàm quòd ca proprium axem rotecur, is quoque in oppoficas mundi paraliquô usque nutar, ut nihil adeô in hoc globo reconditum quod bina hae globorum lux non atringat. Ex ne tarditate mirum partes globi,obliquifimâ comicum luce verberata, dasum incurrerent, huic quoque provifum voluit rotacione eirca pprium axem menftruo ferê fpacio factâ, quâ alix partes lucis ligæ mirâ quadam anticiparione lucidis fubduntur globis, aliis n luce facuris in lucis in digarum locum mirâ quadam vicificune fubmotis.

\section{SCHOLIUM IV.}

\section{De magnitudine Saturni, \& diftantia} ejus à Terra.

Vebabet Auctor de magnitudine Saturni, defumpta funt Saturni ex Rheita lib.4. Ocusli Enoch cap. 2. memb.4. O5 5. ubi tamen magnitudes,

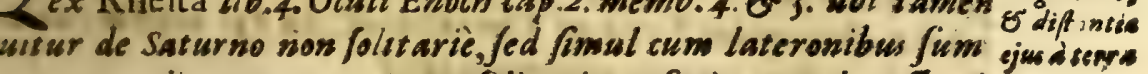
; nom alioguen Saturinum folicarium facit equalem fovi. 


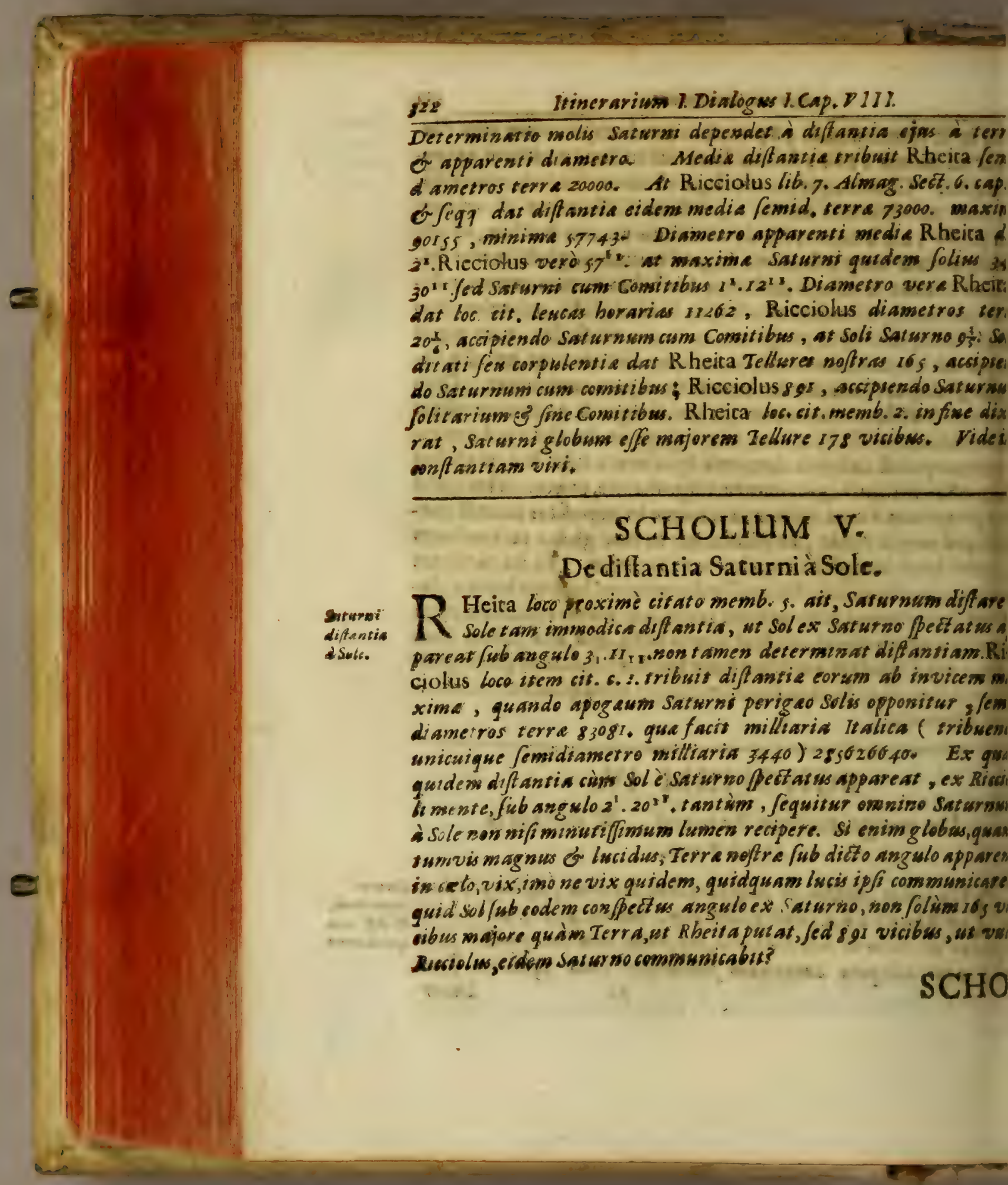




\section{SCHOLIUM VI.}

\section{De motu vertiginis Saturni, \& ejus co-} mirum.

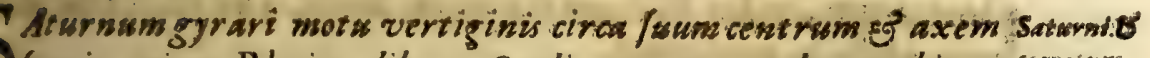

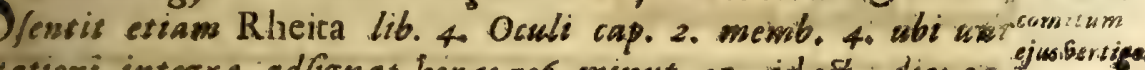
ationi integre adfignat horas 706. minsut. 38 , idest, dies $290^{9}$ res 10, min $I^{3} 16^{13}$. Lot enim ervit e fuo arcasso, ds quo Capice prelensi, Eै alibi jam egimus. Gyrari Saturnum motu dicto, concefacile, proprer rationem alis planetis cemmsemen, wit videlicet undism omnes fusas partes influat in inferiora: gyrum unums. Tolvere precise tants tempore affirmere non audeo, quia funmextsum est incertum, ó prorjus valuniarium. Huic motui

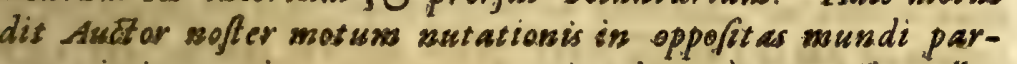
, simirsm etiams partes Saturni polares d Comitibus illuariqueans. Addit ş vertiginem ipforum Comitums. Vtrums- probabile quidem est, fi analog iam ad alios planetas ßpectemus; neutrum eft eertuss.

X. Theodidacts ss. Sed explica modò,cur globi comites non Comites Sar jper plená luce Saturnum feriant, fed nunc hanc, nunc illam eum non idiorem luminofioremque portionem circa proprium cen femper ple$m$ agitati globo obvertant. Cofmiel. Summo fanè confilio ; máninceillw. - enım vicifircudine concingic, ut quod continuầ lucis affune nonnullis in locis vehementiüs concicatum eft, id reminfiolucis ad neceffariam temperiem reducatur; atque adeò quod rigen is eft dierum \& noctium vicificudo, id in hoc globo eft enfio \& remifio lucis à binis Sazurninis afleclis effufr. Theo-saturnus adz ws. Sed rogo te, mi Cofmiel, annon illuminatio Solis huic an ilumibo nonnibil fuâ luce confert? Co/m. Quin imò; globus enim hic netur eti$n$ ex lento quodam liquore, hydrargyro haud abfimili conftet, ${ }^{\text {am }}$ is Sole. ut Sol, eciamfi non nifi fub angulo trium minutorum confpitur, luce ramen fuâ materiae dietx caeteroquin lucis capacinfie luperaffusâ, in abfentia comitum non parum illuftret, 
quod nifi fieret,certè Saturnus fubinde ex lucís abfentia velur eclipfin paltus ex oculis cerrigenarum evanefceret, quod tames experientia repugnar, Imò addo, lizem Solis, comirum lucibu junctam, cantó incenliorem lucem caufare; quantò fe rectius \& viciniùsafpexerinc. Quin \& reliqui globi Saturno vicini, tan , planetarum, quảm fiderum fixorum, mulcùm ad illuminandun hunc globum conferunt.

\section{SCHOLIUM VII.}

\section{De phanomeno anfularum Saturni. \\ Dercophes}

Sturni anfularmos pbenowoes. anye.

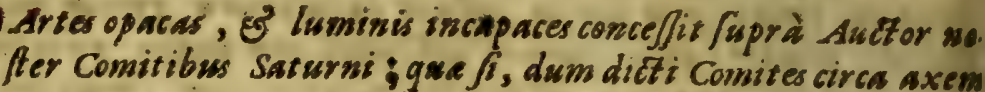
fuum moventur, Saturno obverterentur, vel strimgue, vel una Saltew ex parte ; neceffe foret ipfum deftitui lumine aut sorali: ser, aut una faltem ex parte. Huic incommodo ut obvietser, sol fuis radiis Saturnum feriens defect um fusplet. 2isod fo ita est: saturno lumen turse valde debile effe fatendum est, of tam exiguam ejus porsionem illuminatam, wt oculos soff ros adè diffitos - wovere fufficienter non polfit. Ad falvandum nibilominiss pha somenwos anfular um fovis, afferendume eft, strumque fubinde partem opacan Saturno obvertere, 2wid fs (quod fospicarur R heita ) prater duos laterones nobis jams vifos ac cognit os, aliif o. rent nobis incos/picus, qui eum tunc,ut aliàs etiam, illuminent? At fs boc concedatur, concedendum pariter est, anfular sum phenomsenum non ab unbbr , fed aliunde caufari. Idems etians feguitur. fi conscedatur, Solem tunc fufficienter illuminare Saturnum. Dici tamen poffet;partem à folo Sole illuminat um effe volde exiguam, o laters les partes tanti globi Saturnini manere adbuc ob/cur as, of foc confarefibi adhuc an/ularumiphersomersum.

XI. Theodidact us. O quàm tuus me rapit discurfus, adeò re bus omnibus congruus! fed nunc, rogo te, fac, ut coeleftem tandem faciem alpiciam; jam enim multo tempore prater globos 
hosce comites neque Solem, neque Lunam, neque terram, neque ullum ex caceris planetis, quos pertransivimus, nec firmamenti fplendorem (obfufcante prafenti binorum comitum. luce fplendorem exterorum, quemadmodum lux Solis in terraconftitucis omnium reliquorum fiderum lucem obfufcare (olet) intuitus fum. Cofmiel. Fiat. Theodidactus. Ec ecce, mox siderum $m e$ in cenebris ex adverfa globi parte conftitutum reperi. $O^{a / \beta e c t u s}$ ex Cofmiel, fomnióne, an vigilo ? oculísne illudor? an revera omnis fafcinationis expertia fint, qux confpicio? Co/miel. Quid vides? Theodidact ws. Totum mundum immutatum video, neque allum earum ftellarum, quas è terra contemplabar, five fitum, ive magnicudinem, five ordinem denique fpectes, veftigium reerio. Ubi ergotellus noftra? ubi Luna? ubi Sol ? ubi Venus \& Mercurius? Cofmiel.Vides lucidiffimum illud eorpusculum, tanto adiorum amictu circumdatum ? Theod. Video. Cofmiel. Ille Sol ft. Theod. Serióne loqueris, Cormiel ? Cofmiel. Seriò cibi loquor, eque ullus unquam apud me jocus locum haber, qui fum veritais acerna magifter. Theod. Credo,credo,domine mi,ne, obfecro, ictis meis imprudenter prolatis irafcere, neque ullam iis maliiam fubeffe putes; nimia enim admiratio adeò me rapic, ut exme pofitus videar. Sed fi Sol adeò minutus fic, quid de ter? quid de Luna? quid de reliquis inferioribus planeris fiet? omiel. Vides ibi juxca Solem quatuor ftellulas penè nebuloIs? Theodidactus. Video. Cofmiel. Er quasnamillas tandem pucas fe? Prima, quam vides, Tellus eft ; fecunda obfcurior, Luna; rria lucidiufcula, Venus; quarta prorfus nebulofa, Mercurius t. Theodidaćlus. O mi Cofmiel; ergóne ego terram ex hoc co veluti fub minimi puncti cujusdam figura incueor ? $\mathbf{O}$ ubi m eft terren a ambitionis pompa? ubi fuperba regum domiia ?ubi regionum, urbium, palatiorumque magnificentia द̧ ubi populorum exercituumque robur \& fortitudo ? ubi delitia liorum hominum? omniane in punctum coaluerunt? cofmiel. a eft. Theodidactus, O filii hominum, quid diligicis vanicatem queritis mendacium? ubi eft jam fpes veftra? ubi magnarum gitationum cura? ubilabor vefter impenditur lecrtè omnis in 
326

Itinerarium I, Dialogus 1. Cap.VIII.

terra labor, in puncto luditur, omnia in punctum definunt, omni: nihil funt. O Reges \& Principes! ubi toc triumphi veftri ubiopum jactantia? cur pro infenfibili terra puncto tot exerci tus parantur, tanta fanguinofis praliozum cataftrophis morta lium ftrages commictitur? omnia in puncto, ex puncto, propre punctum: jam enimverò exclamare poflum, ô quìm fordet mi bi terra, dum celuma/picio ! ô quàm mihi modò omnia , qua cantopere ambiunt mortalium animi, vilefcunt! quàm nihi efle video omnes terrenæ dignitatis honores, divitiarum uber tatem, honorum ambiciones, famz gloriofa tripudia! Sed ha nefcio quo mentis raptu effufa fufficiant; perge, divine Magi fter, ô mi Cofmiel, perge reliqua mihi Mundi arcana pandere nihil enim adeò me divini amoris aftu inflammat, quàm tam infinicx bonitatis \& fapientia Conditorem ex operum fuorun magnicudine contemplari; hic fitcibus meus, hadelicia mex hoc centrum meum. Co/miel. Gaudeo candem votis cuis fatis. factum, erfi non nifi per rimam quandam inxtimabilem De Optimi Maximi bonitatem \& fapientiam afpexille, immenfas Conditor is fummi delicias deguftafle dici poffis; quare paulc majora canamus. Vidésne binas ftellas illas, primam rubicundam \& fanguineam,alteram fulgore majeftatis pleno radiantem. Theodidact us.Video.Co/miel.Prima eft Martius, alcera Jovius glo. bus eft, quos jam perluftravimus, Theodidactus.Video; \& quidem Jovem Sole multò majorem.

\section{SCHOLIUM : VIII.}

\section{De diftantia Saturniab aliis Planetis, \& Terra,} in femidiamecris terræ, \& milliaribus.

SasnrwidiArii Auctores variam adfgnant diffantiam Saturni i reliciolus lib.7. Almag. Sect.6. cepp. 3. quibus ip/e Juam addidit, wt fogustur. 
Maxima diltantia Saturni $\grave{\lambda}$ planetis inferioribus, \& tellure, in femid. terræ.

\begin{tabular}{|c|c|c|c|c|c|}
\hline \multicolumn{2}{|c|}{ Auctores } & \multirow{3}{*}{$\left|\frac{\text { Prolensens }}{29990}\right|$} & \multirow{2}{*}{$\begin{array}{l}\text { Copernicus } \\
\begin{array}{l}17436 \\
13117\end{array}\end{array}$} & \multirow{2}{*}{ 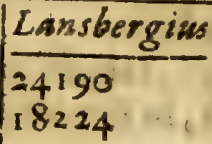 } & \multirow{2}{*}{ 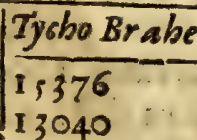 } \\
\hline \multirow{6}{*}{$\begin{array}{l}\text { Satur- } \\
\text { nus di- } \\
\text { fat \& }\end{array}$} & & & & & \\
\hline & & & I I 262 & 15792 & I1150 \\
\hline & & 19992 & 12155 & 16955 & \\
\hline & & 20096 & 11823 & 16561 & \\
\hline & & 20039 & 12424 & 17294 & 12405 \\
\hline & Terra & 22612 & 12356 & 17227 & 12340 \\
\hline & & Longomont. & Keplerus! & Bullialdus. & Ricciolus. \\
\hline & & 19991 & 52377 & 22733 & 122873 \\
\hline & & 15260 & & 17165 & 95550 \\
\hline & & 1307 I & 33961 & 14735 & 83081 \\
\hline & & 14023 & 36426 & 15800 & $\begin{array}{l}88926 \\
86875\end{array}$ \\
\hline & & $\begin{array}{l}13046 \\
14465\end{array}$ & $258 ; 4$ & $\begin{array}{l}19420 \\
16285\end{array}$ & $\begin{array}{l}86875 \\
90222\end{array}$ \\
\hline & & 114405 & 37399 & 16221 & 90155 \\
\hline
\end{tabular}

Ex bic facile conjicies, quàm exigui appareant plerique plaet arum, ó guàm ferè evane lcat terra, fi è Saturno pect ent ur.

XII. Theodidact m. Sed quid fibi vulc, rogo, illud, quod So- Lura, Vom quafi immotum cum reliqua fuprà enarrata corpusculo- nss, ÉMerm curba, Terra inquam, Lunæ, Veneris , Mercurii, video ?̧ fmiel. Minimé immora cenferi debent, fed lentilfimo ad fpe solem ims sident$\mathrm{em}$ aretifinoque circa Terram immoram moru vehuncur; tur ex $\mathrm{S}_{\text {a- }}$ uód verò immota appareant, exceffiva ab hoc globo, cui in- turno. timus, videlicet 99304 femid. terra diftantia caufa eft, ad quam circulus Solis und cum circumambulonibus fuis ira

coarctatur, uc vix ullum motús nobis veltigium manifeltum faciac. 
planetarmm 2 Heica lib. 4. cap. 2. memb. S. ut adfignet planetarem at Terr diffansie i diftantias, ita difcurrit. Diftantias jam eciam planecarun cerra ex à cerra paucis habeto. Quarum femidiameter eclipcica ef Rheits. parriam 10000 , calium orbium planerarum radii , \& media : cerra diftantia, in femidiamecris terr 2 , \& leucis horariis, ita ff habet.

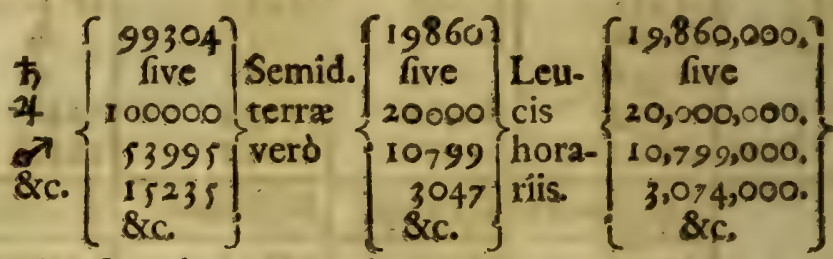

Cùm enim femidiameter ecliptica continear 2000 femidiame trosterreftres; ergo neceflario per auream regulam in femidia metris terra \& leucis tales prodeunt planetarum à cellure medi: diftancix, quales in fuperioricabella noratas vides. Verbi grarió cùm Sacurni orbita radius partium radii ecliptic $x$ in 20000 par riculas divifi contineat 99304 , five probabiliùs omnino jooooc refpondebunt primo numero per auream regulam neceffari 19860 femidiametri terra, leucæ $19.860,000$; fecundo auren 20000 femidiametris terra, horaria leucæ 20,000,000.' Simili -.. ter de alis intellige. Calculnes fibi conftat, Jed fund ament un debil eft. Non igitur femidiametros Terre 90304, fed 19860, tribuit Rbes ca diftantice iturni ì cerra. At quanta efl bace, ficomparetur cun Riccioli diftanties?

X III. Theodidactus. Cerrè qualem nos in terra contticuci jo vem cum quatuor fuis comítibus fpectamus, talem jurarem e: hoc globo Solem cum quacuor globis, Terra, Lunx, Veneris, 8 Mercurii,fpectari. Sed, ô Cofmiel, quid, rogo,fune lucidiffima il la corpora multuplò Venere \& Jove è tellure confpect is majo ra,qux intueor neque enim ullum amplius fixorum fiderum of ficuum differentiam cognofco. Colmiel. Qux vides lucidifima So lium inftar nutilantium corpuscula, illa primæ magnitudini Sirius, Lyra, Aldebaran, lucida hydræe, \& caterz ftella funt,d - 14 : : 
quibus poftea.Theodidact ms. Sed quid fibi innumerabilis illa ftella. ARetus rum mulcitudo, quarum ex cerra ne miliefimam quidem par. frrmament em intuebar, notant? Co/miel. Ille eft cractus ille firmamenti,

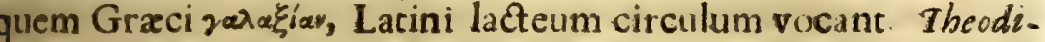
dactur. Jam enimverò illud facri textus verificatum video, suspice calum, of numera frellas, fipotes. O vanas Aftronomoum machinationes ! ô quàm pauca divinorum operum vobis comperta funt! ô quàm nihıl cognofcimus earum rerum; quae in valtiflimis illis mundi reconditoriis abfcondita funt; tædet enimverò jam animam vitæ mex, donec eum, in quo omnia unum funt, quique omnia in omnibus ineffabilı providentıâ gusernar,intuear. Cofmiel. Suftine Theodiciacte, paulò pòft, maori divinorum operum ftupore rapieris. Theodidactus. Si me Imas, Cofmiel, unum adhuc mihi à te exhabere velim.Cofmiel. Edifcre. Theodidactus. Qualesnam funt Intelligentia hujus globigusernatrices?\& quodnam munus corum? Cofmiel. Refpice montis olumbeivallem longè latèque exporrectam, Theodid. Et ecce, vi- Symbolice rorum fenili majeftace confpscuorum phalangem gradu tar- Saturnino. do, uc ne teftudinem tardiori repratione procedere polle pu- oum defcriem, nobis obviam factam confpicio; vultus corum fubrrift $\&^{p t i o .}$ pallido colore fuffulus, oculis inficitiis, fronte rugis afperatâ, coto vultus habitu \& compofitione, profundâ comremplatione mœrori juncta mentem implicitam arguebant; nigro paludamento in veterum philofophorum morem fine ullo ornatu, barbitio ramen (pectabiles fe exhibebant : dextrâ manu acerram atros fumos perniciofosque exhalantem, finiftrâ falcem tenebant. Hac exotica virorum fpecie mirum in modum terrefactus, in hac verba errupi: O Cofmiel, híne funt Angeli illi totâ felicitace æternùm beatı? híne Spiritus illi,quorum vita perpecuo gaudio \& ineffabil bonorum invifibilium voluptate tripudiat? \& cur tam fuberifti facie?cur ram infolito habicu vel ad primum afpectum horrorem incucientes fefe nobis fiftunt? rogo te, mi Cofmiel, ut hocce myfterium tam abfcondicum mihi explanes. Co/miel. Hi funt veri Angeli hujus globi miniftri, à Deo ad iftusmodi munus deftinati; qui tameti aternùm bea-

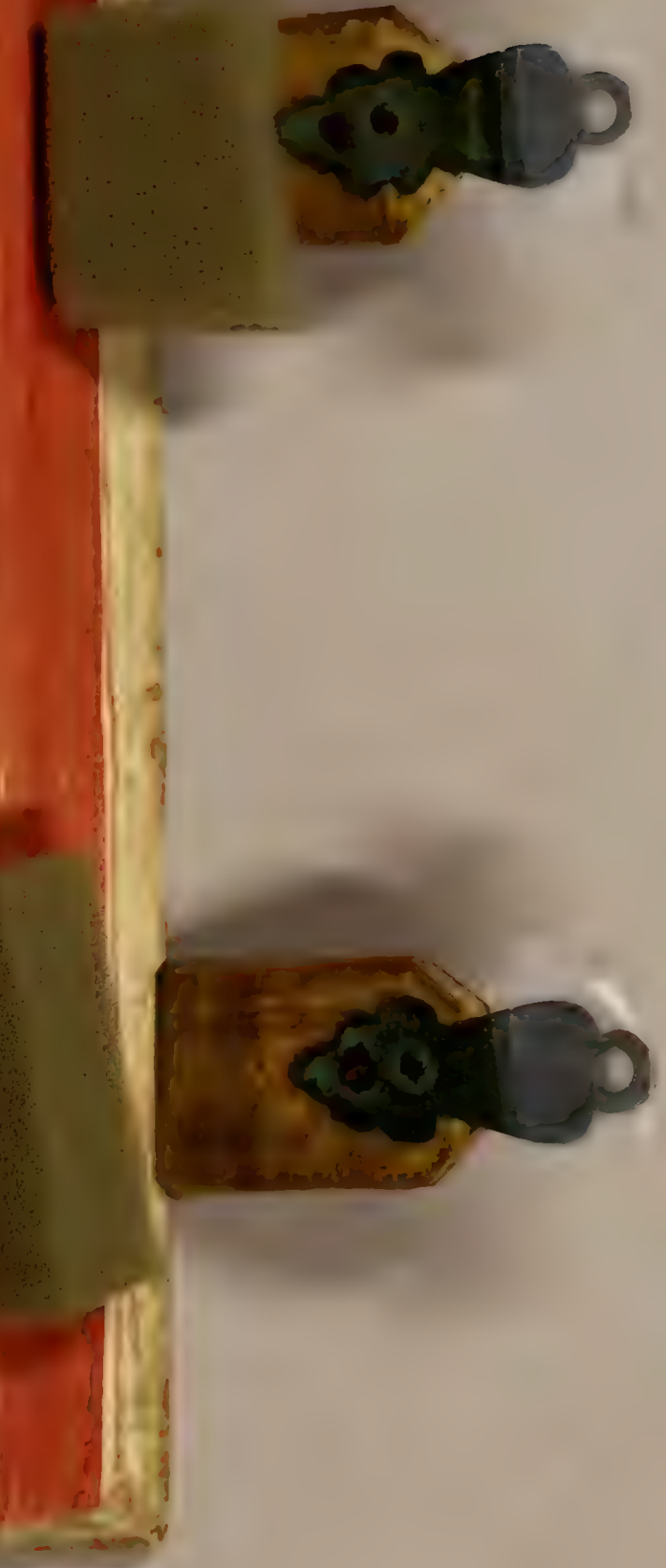




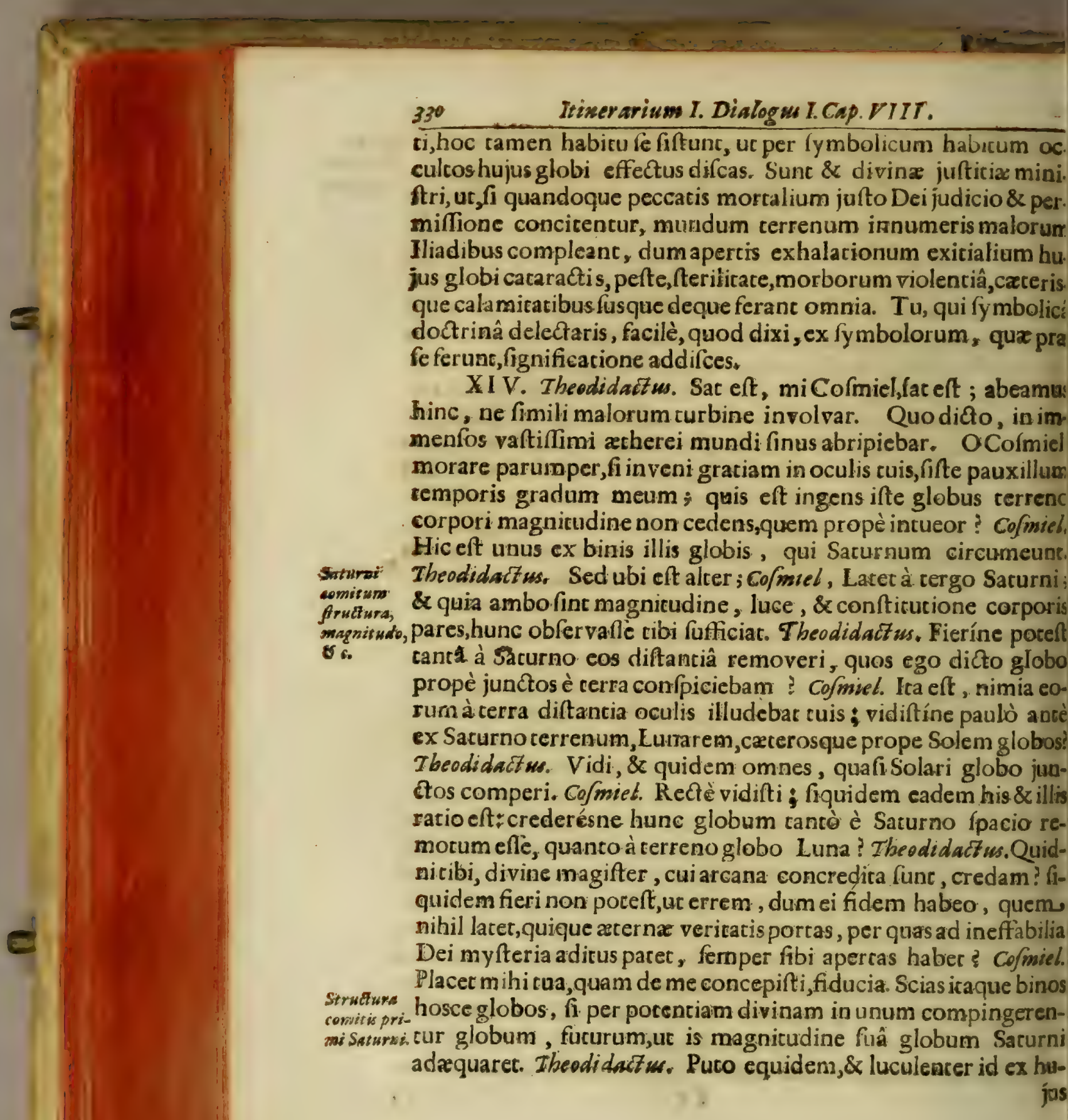


us globi comitis vaftitate paret. Sed, ô mi Cofmiel,jam omnia, ure paulò antè de hujusmodi globorum natura me docuift, veitaci confentanea effe comperio, Jam globi if ructuram ex una arte montibus exafperatam, ex alcera igneum pelagus fplendoe folari haud mulcum diffimili,corufcum cum ad miratione afpiio; video quoque lucida à non lucida regione difcrimen; phaes quoque diftinctè cerno : fed fieríne poreft, ut fimile quid foaris materia in cateris mundi corporibus reperiatur ? Co/miel.Mnndas? uidni? fquidem fcire debes, Magnum illum mundi Opificem globi ignew n principio nonnihil primigeniæ illius lucis ignex, quâ corpuspolleant, olis coagmentatum eft, cateris quoque mundi corporibus, fine an polleant ua confervari non poffent, uniplus, alteri minus pro mundafabrica neceflitare commifcuifie; quod quidem prorfus, So- ad omnes Mundi globos illuminandos minimè fufficiente, neeflarium fuic. Sed de his in fequentibus fufiùstecum agams. heod. Sed rogo re, habétne proprium fuum centrum hic glous ? Co/micl. Haber: quod enim de uno globo dictum eft, idem saturnt e reliquis omnibus judicium efto : fi enim hic globus ejusdem comites um globo Saturni natura foret, is fanè fuo loco confiftere mi-propria fusa centra ha imè poffer, fed ob parcium fympachiam naturalem ad eum uti- bent. jue mox confluerer; quod cum impoffibile fit, certè luculenter acer, eum differenci corporis partiumq́ue ftructurầ dotatum, oc coeli pofricu,juxta fines ei à natura prá́criptos, coaluifle. Iem de altero fenties dum effe fcias. Sed nunc divini Numinis uctu icer noftrum profequamur. Surge, accinge lumbos tuos, randis enim tibi reftar via.

\section{SCHOLIUM X.}

Vidfot primigessia illa lux, quam Mundi Opifex DEUS pri2 ino crestionis die fieri jueffit; $\sigma^{3}$ an in coelefter globos fuevit diviarsardo die Mundi quarto fecit Solem, Lusam ac ftellas; difoutiemus vel infrà, vel in Mundo Mirabili. Hec de planet is,eorumg Comitibus /ufficiant; plura, E" accuratiora trademus in Mundo Mirabili.

Tt 2 PRE- 


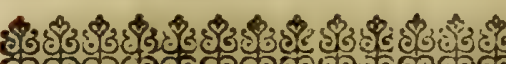

PRIELUSIO $\mathrm{T} \mathrm{U} \mathrm{M}$.

Praturio in A Tria coeli, feptem veluti diftinct a porticibus, luftravimus, in quibus errones totidern fine errore excurrunt, EF magno Regi DEO, regieque foboli Homini, ftat is fuis, at nunquam exorbitantibus excurfibus famulantur, per omnes Zodiaci domos euntes, E'modò in feptentrionem elati, modo in aufrum inclinati, nunc inter fe conjuncti, nunc ingentibus spaciis divifi. Nunc Domús DEI intima penetrabimus profundius, E ftellas in eadem (emper cali parte, five auftrali, five feptentrionali fixas, eandemque inter fe diftantiam conftantifimè retinentes (unde $\sigma^{\circ}$ fixis nomen eft) contemplabimur. Hac funt magna Mundi pectacula, illuftria munifici Creatoris dona, evidentißima divina potentia argumenta. Hafaces jugiflammâ ante ar as potentißimi Numinis accen/e verius, quàm laquearis athereifunalia, aut occumbentis Solis faces funerea, aut Lune lucentes chori. Hec denique celi militia, ac veluti acies caftrorum ordinat a, facro quodam 
guodam fulgoris fui horrore territans impios:unde Debbora in cantico fuo: De coelo dimicatum eft contra eos; ftellæ, manentes in ordine \& curfu fuo, adverfus Sifaram pugnaverunt. Et Ecclefaafticus: Vas caftrorum in excelfis, in firmamento coeli replendens gloriosè. Species coli gloria fellarum, mundum illuminans in excelfis Dominus. In verbis fanctis ftabunt ad judicium, \& deficient in vigiliis fuis. De barum ftellarum numero, magniindine, dift antia, motu, velocitate, aliisque adinct is pauca, que' fequenti Capite lucem prabitua int, pralibabimus.

S. I. De numero ftellarum fixarum, \& de ftellis recenter ope telefcopii detectis.

DUnctum eft Terra, quam incolimns, quam perambulamus quow stellaram tidie, quam tot exercisibus \& clafjbus, tantà bominum frage, ste arum am infariabili cupiditate dividimus; nec tamen adbuc omnian numermo egna adivimus, nec ommes penetravimus regiones, totâ licèt $A$ mericé quàm antea ditiores; imsmen/f adbuc tractus à Magelinica ad polum antarcficurn usque perluftrands juperfunt, Sere nollus dubito) refervati pofteritati. Quid lupereffe ergo puamus in vaflifimo caeli pacio, in magno regno DEl, in tam grandi Creatoris domo, humano veftigio impervia, $E^{3}$ folis adeundas coslis? Arrogantic profect ó est non tolerande, credere, obtutum oftrum, lynceis licet viribus nuper invento telefcopio adauctum, mnes luftraffe ftellas; ftultitia, certis numeris $\sigma^{\circ}$ nominibus conIringere velle. Hoc DEl opus eft, qui numerat multitudinem. tellarum, \& omnibus eis nomina vocat, $P \int a l .146$. Multa nos in colo femper effugient; nova fixe, novi etiam ptanet a, propius. 
rimantibus fefe prodent. Aftris celum ornavit, now ut fibi,non Ano gelis, Jed nobis ut ufwi forent; quidni ergo, ut sobis aliquando innotefiant, \& magnarn DEI glorian cum aliis enarrent, volet?

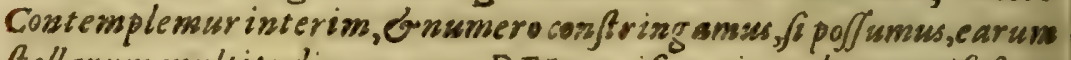
fellarum multitudinem, guas $D E I$ morificentic nobis manifeftare eft dignata.

Afferifmo-

Quid ea in re prafticerint antiqui, quant $\hat{A}$ surâ $\xi \vec{J}$ labore fe.

rum.

bumana acies potuit, ad certum numerum revocaverint, $\delta$ in fuos quasque ordines feu afterifmos diftinxerins, diximus fupri in Pralufione Catholicâ f. 2. Et Beda quidem ex alius numernt afterifmos /ew conftellationes 43; Germanicus Cafar Arati Interpres 44; Virruvius 45; Manilius, Eigginus, E' ex ipfis Apianus, Tycho, Lansbergives 46; Martianus Capells 47; Ptolemeus, \& popl iplum Alphon/ins, Copernicus, Clavius, \& alii.48; Grienbergerms so; Proclus j2 ; Bayerus 60 ; Keplersus, \& Recentiores omnes 62. Caufa tante diverfitatis est, quòd vel aliqui aliquas omittunt, vel duas in unum reducunt, vel unam in durs flurésve dividust, vel noves in coelo auftrali recenter detect as addunt. In bisce conftellationibus Ptolemeins exumeravit fellas 1022, Grienbergerus 1225, Keplerws 1302, Bayerus 1709 . Cosufarm diverfir atis dedi in Curfu Matbematico lib.7.par.3. cap.3.

Omnium ferè conftellationu nomina (qua fuprácit. loc. recenfuimus) de fabulis fumpta furst apesd Gracos of Lattnos ; five boc Pö̈tarum ingenium an fingendum pronum effecit, five poten. tium bominum ambitio, qui fua nomina ftellis imponi ab adula soribss ftudebant, ut jam non in are \& marmoribus, fed in arerna materia inanifima gloria fruerent monumenta, isquit eleganter Caufinus lib.2. de Donso DEI cap.22. Sic Conon Mathematicas, Alexandrine aule adulator sotiffimses, Berenices comam in aftre retulit: fic Hadriasus Antinoum Gany medem fusm confecravit: fic antiquiores his bomicidas, adulteros, proftitutos, of id genus monftra calo intulerunt; ut non inmerito Sancti Patro abjiciant, eos purifimam DEI domum feediorem quovis lupanari fecijle.

Huire 


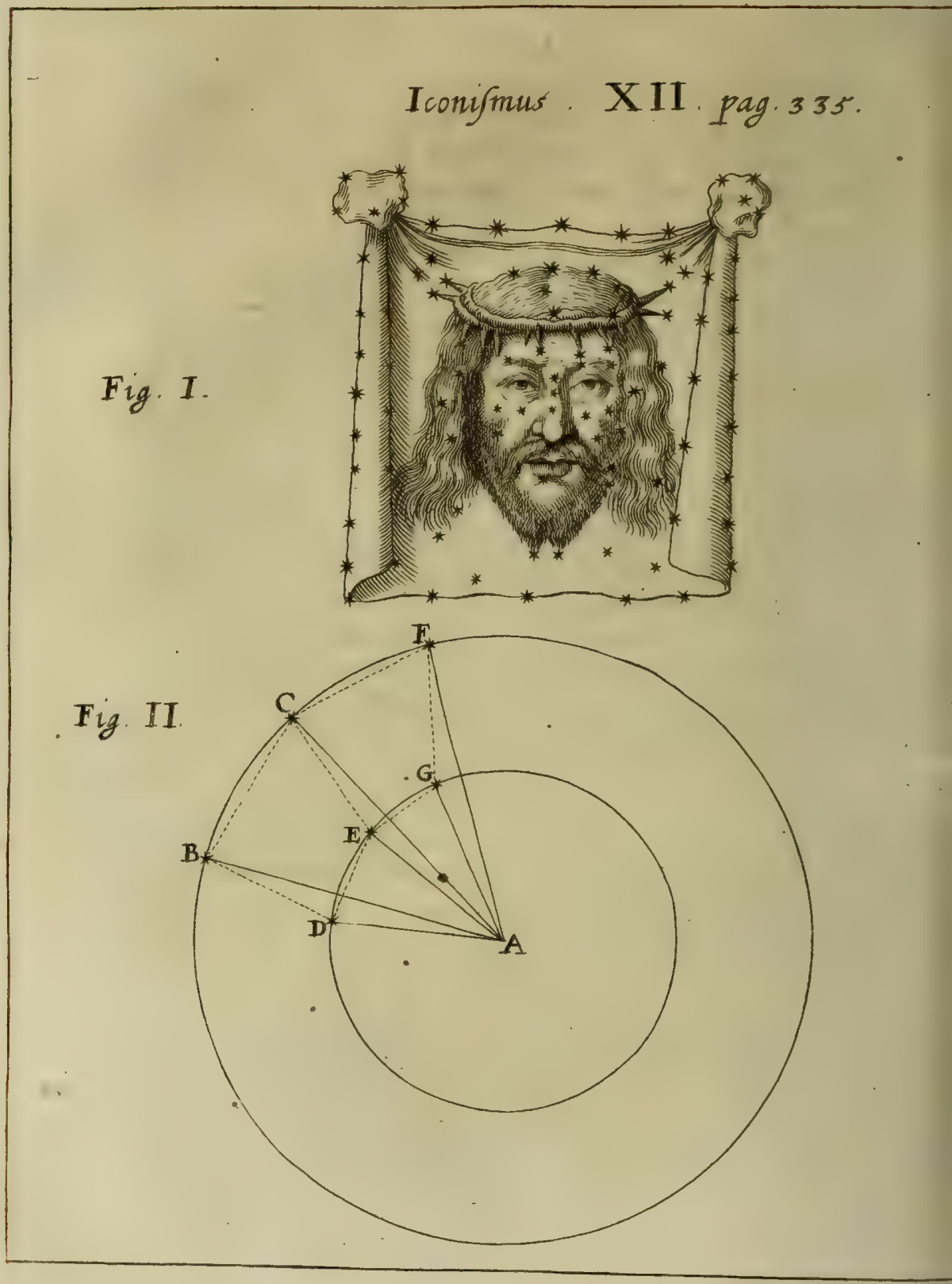


Huic malo ut quoguo modo vel ferómederetur, Julius Scillerus 1.C. Auguftanes, Anno 1627. edidit Celum Chriftianum, w6i mustatis antiquorum nominibus, fingulas conftellationes novis ac pis appellat nominibus, facitque ex Ur/a minore S. Michä̈lem,ex Coma Berenices flagellum Chrifti, ex Ariete S.Petrum, exPerfeo S. Poulum, ex alic alia.Sed nomina antigua tam alt as jecêre radices, wt ca vel inviti retinere cogamur.

Prater enumeratas ftellas, innumer abiles ali a telefcopiofunt stelle wotdesecte, prefertim in Vialactea, in Orione, in Pleiadibus, of in to telefromubeculis cali. Aadi Rheitam de is loquentem in Epiftola ad Joannem Caranuelem data Colonià24. April. 1643 . Quid? \& adhuc heri cum ftupore \& fummâ admiratione atque delectatione fudarium Veronic , five faciem Domini maxims fomilicudine in aftris expreffum in figno quafi Leonis, incra quinoctialem \&c Zodiacum circulum clariflimè detexic \&c : (loquitur de novo fuo tubo binoculo, de quo in Magia noftra Tele(copica par. f. Magia, lib.ult.)Continet autem hac pulcherrima conftellatio ulera i 20 , aut 130 . lucidiffimas ftellas, denfiffimè uri agmen apum, in medio compactas, quatuor majori- Vide Icebus in angulis quafi conclufas, uri hec figura qualicercunque nifmi XI. exhibet. Quin \& Aquilarem Lyram adhuc heri plusquàm. 150 ftellis conftare, fignum Tauri ultra 200, didici. Sed \& micantes Pleiades, ceu ftupens intuitus frepius quafr apiarium, denfifimo agmine apum circumdacum confpexi plusquàm. 100 faculis decorum. Sed quid de Orionis etiam à facris Licreris commemorata inugine \& majeftace dicam ? Credin', fi illum tunicæ talari Jofephr,languinis guctis(hoc eft, infinirâ ftelarum ferie conficum \& finitum) fimillimum dicam ? Seu potius pfitunicæ Domini inconfurili oprimè affrmilare velim? Permis', fi ei soo ftellas folùm intra quadrigam contencas tribuam? Pró DELM!nec 600, nec 700 fufficiunt ; fed neque 900 ejus numerum \& exercitum claudunt. Dicam egoulceriùs: folus Orion omnium fixarum hactenus ab Aftronomis cognicum numeram abforbet, ita ut revera ultra millenarium numerum ejus" exercicus folus excrefcat. Quid hic Aftronomi? Torius coli 
fpectabilem faciem, hactenus n:que temiplenè cognicam, oct lo armaco luftrant, \& ignorantia illicò fefe prodet noftra, dur prodicor aftrorum (it appellat tubum funm) infinitam ftell: rum feriem proditurus elt. Hac Rheita, qui bis etiam majon Jaripfit poftea in li6. 4 Oculi Enoch cap. 1.memb. 7.ubi ait: Enin verò novo telefcopio aftronomico, uno obtutu plus quàm ftellas oculo exhibente, in fola Orionis conftellatione dup quafi plures ftellas fxpius numeravimus, quàm Vereres in un verfo Furmamenco, fcilicet quafi 2000 . In via lactea omnin quafi non eft numerus, Repetit deinde, fe in Orionis conftells tione quafi tunice Domini inconfutilis figuram ; aliam verò il fra Leonem, Jadarii Veronice fimilitudinem referre deprebendif] In Tauri verò figno effe Crucens qua/2 Teutonicam, in Orione cal cem, circa ftellam polarem quafi manum claufam cum indice exter. to. Item in, aut propè cingulum Orionis vidiffe fe tricorporem fie lam; ine Pleiadibus verò, maximá multivedine coru/cantibus, circt lum, or in circulo quafi inf antem jacentem. Ita ur ( (wbjungit) tc ta coeli fpectabılis facies longè alıa fit, quàm Veteres cum Tycho ne depinxerunt.

Stelle Sidencurefte innumerabiles.

Non male ergo Auctor nofter, qui innumerabiles effe cenfl fellas fixas. Certe idip/um Sacra Scripura innuit Gervef. $c_{0} 12$. DEVS Abrahamo dicit: Sulpice coelum, \& numera ftellas, pores. Et cap.22. addit: Benedicam tibi, \& mulciplicabo feme tuum ficut ftellas coli, \& veluc arenam, qua eft in litcore mari Et Feremia cap.33. disitur: Sicuc numerari non poflunt ftell coli , \& metiri arena maris ; fic multiplicabo femen David, fer mei. Non ergo veritatis limices excesfit Galilæus, qui non dn bitevit ftellas effe ultra 10000 ; nee Ricciolus, qui lib.6. Alma cap 0. num. 5. putat, fi quis afferat,ess effe ultra 2000000, nibsl in credibile afjerere. 2 sis ergoftellarum numerum iseat, nif / Im $D E \cup S$, qui numerat mulciudinem fellarum., \& omnibus eis nomina vucat?

P/al.146. 
§. Hi. Dediftantia fixarum à Terra,

TOn minus incerta, \& bumano ingenio imperforutabilis est ftellarum fexarum a Terra deftantea, quan numeru; ;ideo ut st Darum bicfolum D EU Magnolcit Arithmeticum, it a illa eundem foluwn lerram diGeomestram, vel potius Afrometram veneratur. Alcicudinemfantia. coel, \& latrudinem terræ, \& profundum abyni quis dinenfus elt? inquit Ecclefiafticuss cap. I. Et it erum cap. 17. Vircutem alcitudinis caeli ipfe confpicic, Prudenter yzutur veteris rift ronome principes, Hipparcbus $\Xi^{\circ}$ Ptolemeus, banc partem de ftellarum Exarum deftantis, tan yuam nimis abstrulam, of mortalibus ocuis impervian reliquerunt. Neque enim, aut Caufinus lib. $2_{0}$ de Domo Dei cap.24. latis verecundum illis videbatur, nec cantâ nominis claricace dignum, ea tentare, qux fupra humani ingeaii vim eflent; ea affeverare, qux dubiis omnino rationibus, \& evi conjecturá niterentur. Et Plinius lab. 2. cap. 2 loguexs de arsundesoflellarum diftantis : Furor eft, inquit, menfuram ejus unimo quosdam agitalle , atque prodere aufos. His taneene 1on obftantibus, prinus Albategenius, Vir Arabs, incitatus alioum ante le induftrià, quiplaxetarus diftantiam à terra defiire tentaverant, improbo aufu $\xi^{\circ}$ affixarum diffantians est agreffus : quem pofteriores Aftronomi fecuti, eam multo fe clarius

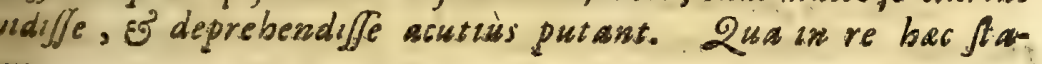
ma.

Primò.Certum est, aliquas ftellas fix as effe altiores Saturno: 2. probabile, onnes effe eodem altrores. Nam, ut optimè notat Riciolu, lib.6. Almag.cap.7.num.2.certum videtur, Aellas thas qua nois occultaniur ab aliquibse planet is, cujus.modi / unt omnes ferme, arant intre Zodiacum, altiores effe planet is illis , Jaltem tunt, usondo ab iss occultant ur:ciom igitsur mult a ex illis fuerint a Satur-

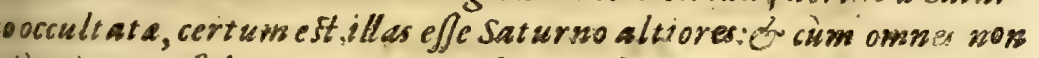
ium intra, fed etiam extra Zodiacum. fervest eandem lemperiszer fe dift antiam.eandengse in motu aquabilitatem: probabule est, mises effe Saturno altiores.

Secundò. Incertum esf, an aut alique ant onnes ftella fixe V* 


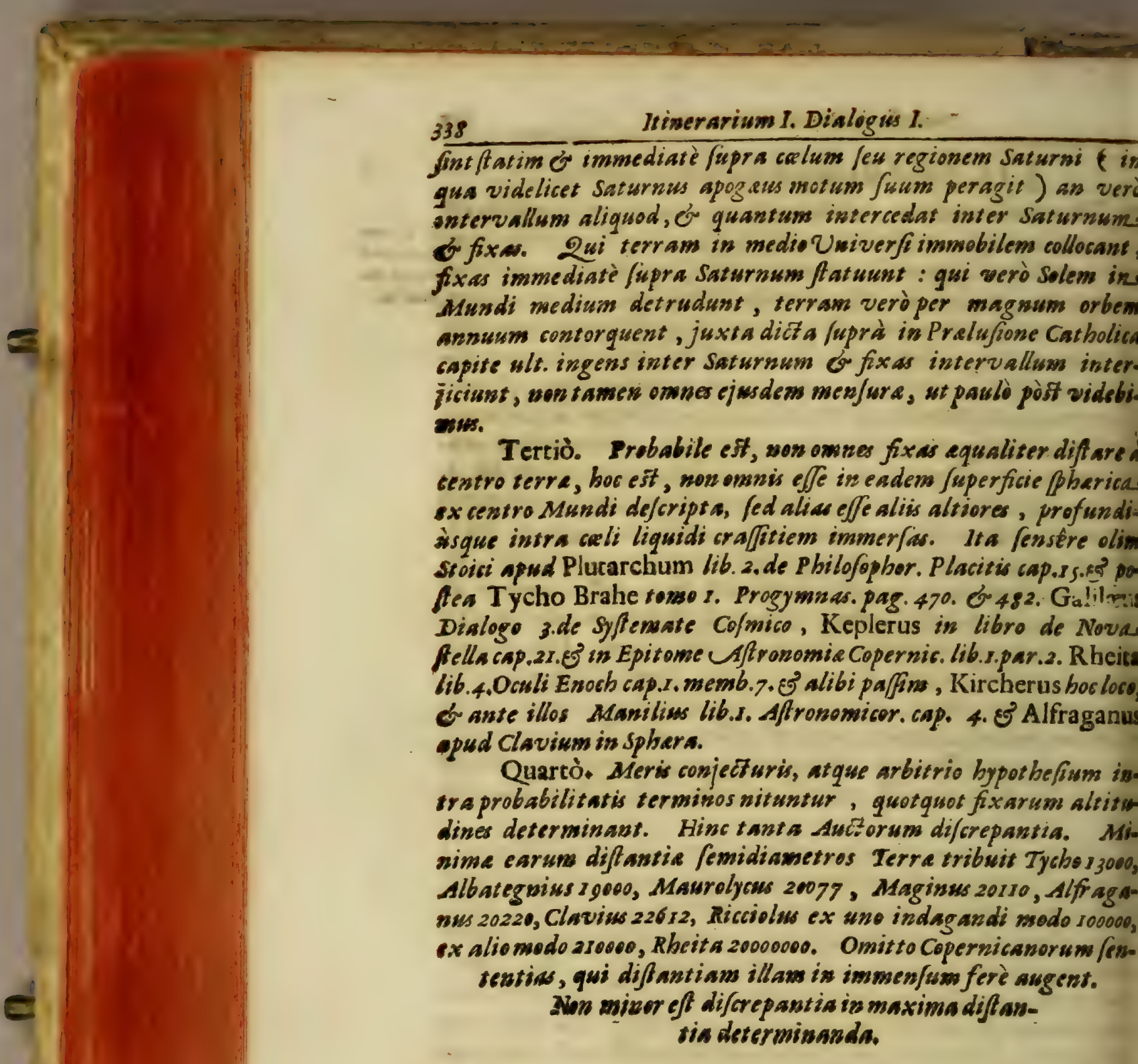

S. III. De 


\section{§.III. De velocitate motus diurni ftellarum fixarum.}

Mnes Aftronomi ac Philofophi, qui Terram in musodi mediostellarum immobilems collocant, tribusunt ftellis fixis motum circa Ter-fiaram am \atio 24 borarum, oculorum experimento, Scripture facre motitas. Seloufforitabe, io ratione ipsâ id exigente. Quem quidem motum dè velocem effe oportes, bu bumano ingenio comprebendi vix - Tir. 2ue etiam caus a eft, cur Copernicus cum sequacibus eums eget, ac potivis Terra motum, aftris quietens affingat. Sed nos un commonsiori o vera fontenstia fentimus. 2uantus autems sille motus, certò ftatui non poteft, nifs ftellarum diffantia d ntro Mundi certo determinetur. Equèigitur ac ipfa diftantia sert us eft motws; of quid quid ft atuat ur, probabilit at is limites nons ssedit. Sic autem colligitur, affusoptâ probabiliter quâcunque dientiâ earum i centro Univer $\widehat{s}$.

Diftantia ftellarum fixarumat terva duplicatur, of fit dia- Velocitas eser circull maximi,gues ille patio 24 horarum percurrunt. motum fel fixaec diameter vel ducitur in 22, of fumma dividitur per $7 ;$ vel lrum qua 3'4, \& Jumms per yoo dividitur; E⿱ babetur circumferensia modo inds. chi circuli maximi in Jemidiametris Terre, ques Fixe uno die getsr. otu diurno percusrunt. Hic numerus dividitur per 24, \& batur numerus femidiametrorum terreftrium, quas Fixa una bopercurrunt. Huc rurfus deviditur per 60, \& babetur numes lemidiametrorum, quis uso minusto abfolvunt. Hic demum viditur denuo per 60, of habetur fenvidiametrorum terra numerus, ques abjolvent Fixe uno fecundo horario. Juxta has regulas Riccolus confecit fequentem Tabehlam ex mente appofótorums Ass. Etorum.

Ues relocites 


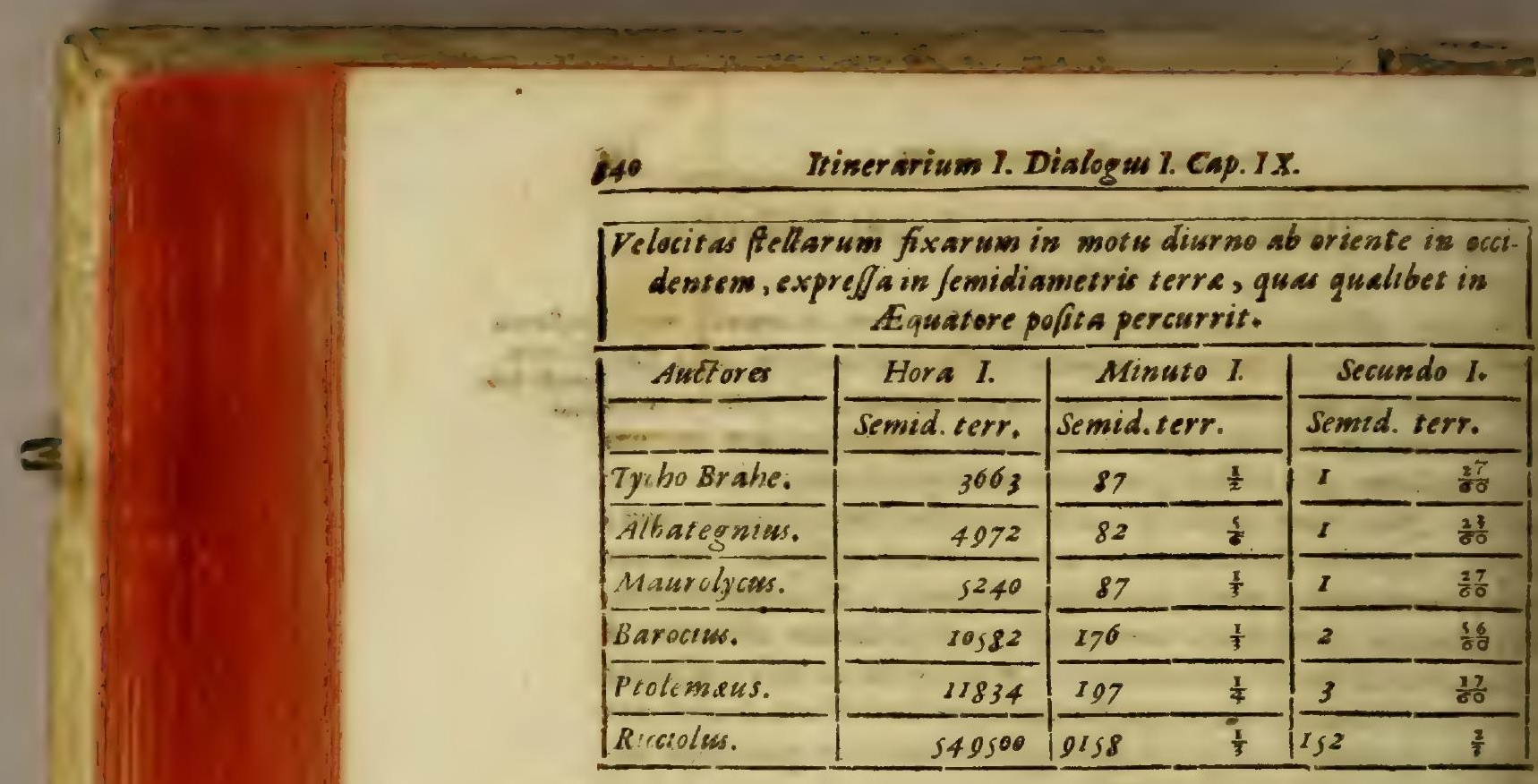

Has men/uras fi vis in midtiaribus It alicis, nultiplicas numbros pradictos per 3440 .

Ex diftantia of magnitudine apparente fixarum deducitur carum magnitudo vera; de qua, uti \& de fructura ac nature obus adjunct is, dicomus aliguid in Scholiis.

\section{CAPLT IX.}

\section{De itinere in Firmamentifeu ftellarum fixarum regionem.}

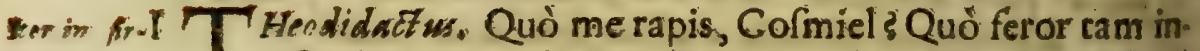
mis ine

งมี⿻.

1 effubil motus velocitace? Quis tandem irineris mei finis? ubi jam Sol, ubi Terra, I.una, caterique planetx? omnes fiquidem difparufle video. Fieríne poteft, tam brevi tempore tantum nos Ipacium confecifle ? Cofmiel. Ne mireris; non enim hun ano, fed angelico moru raperis ; cujus comparatione omans naxuralum rerum motus tarditas eft; neque tu impecum 
une fuftinere pofles, nifi confortatus ab alco. Theodidact ws. Ec uando candem cryftallinam ullam firmamenti molem atngemus ? Quando immenfum illum \& nullis finibus clauin fixarum ftellarum orbem intuebimur ? Eq quomodo tam nmenfi corporis \& tanquam ære fufi folidiffimam molem peetrabimus? Properemus, rogo, ut fummum Dei Optimi Maimi infinica fapiencia opificium propiùs intueamur ; magno aim defiderio aftuo videndi, quonam arcificio ftella illa, uas nos ideò fixas appellamus, cryftallino illi incomprehenbilis vaftitatis orbi figantur, quâ induftriâ illi infertæe fine, uâ luce fulgeant, quâ proprietate polleant; an materia orbis ientialicer à materia elementari diftinguatur. Hæc omnia. Firmamem. mihi exponas, \& cominùs monftres, obnixè deprecor. Co- tum non foiel. Mi Theodidacte, jam verè video, te nimis fimplicis in- lidum, fed nii efle, \& ad quorumvis fententias amplexandas plùs aquo eduli. Sphra illa cryftallina, quam quaris, in rerum nara non reperitur; ftellas autem hujusmodi fphara infixas e, nullo prorfus fundamento nicitur. Gyra oculos, luftra nnia in circuicu, perambula fingula, totum Univerfum perra, neque aliam tamen, prater hanc, quam fentis, limpifimam xtherei Oceani nullis firibus conclufi, volubilem. bilifimamque auram reperies. Fixorum fiderum, ut me voterrigenis accommodem, regionem, regnumque, quod tanpere defiderare videbaris, illud jam ingreffus es. Theodidactics. radoxa dicis. Ubi eft ergo diftantia ftellarum à fe invicem, llo unquam xvo mucabilis? Cofmiel. Vobis rerrigenis ob fumrm \& inexplicabilem diftantiam videntur immutabiles, licèt feipfis mulcùm mutentur quoad fitum, \& , ut jam vides, diftanearum toro colo diverfa fit. Sed,ut propiùs rem contemplerefpice, Theodidacte, expende fingula in vafta firmamenti fadictorumque veritatem comperies. Theodidactus. O Coiel,totam coelifaciem novis\& nunquam hucusq; vifis fideribus, a,magnitudine, difpolicione, lumine, mirum in modum diffeutibus ornacam video. - Sed rogo te, ubi funt Arietis cornua? i pląuftrum Bootis? ubi Cafliopria ? ubi cingulum Orionis? ubi

Ulu 3 cauda 
cauda Scorpii ?ubi cum pullss Gallina ? ubi denique finuofa volumina Hydre ? ubi reliqua cancopere mili nora fidera ? Siquidem ex iis ne veftigium quidem reperio. Co/miel. Ita eft, oculus enim cuus jam intra firmamenti regionem conftitutus omnia diffipara, omnia diffolura, omnia in alium redacta orStelle fixe dinem contuetur. Theodidact us. Habéntne omnes ifta ftelmon dift an equalister omnes i serra. tarum coacervationes eandem à terra diftanciam, vel non. Co/miel. Minimè, fed fingulæ quoad diftantiam differunt. Vides nebulofas illas in formam circuli conglobatas? Theodidact us. Video, Cofriviel. Illas tanto ab oculo tuo intervallo removeri fcias, quanto vel primam firmamenti ftellam à centro Terrz diffidere videmus; reliquz verò nunc majores, nunc minores è tellure intervallorum differencias fortiuntur, quemadmodum in planecariorum globorum luftratione ocularis te docuit experiencia.

\section{SCHOLIUM I.}

\section{An omnes ftellx fixæ diftent æqualiter à Terra.}

Diféntes equaliter dTerra omoes felle fxe.

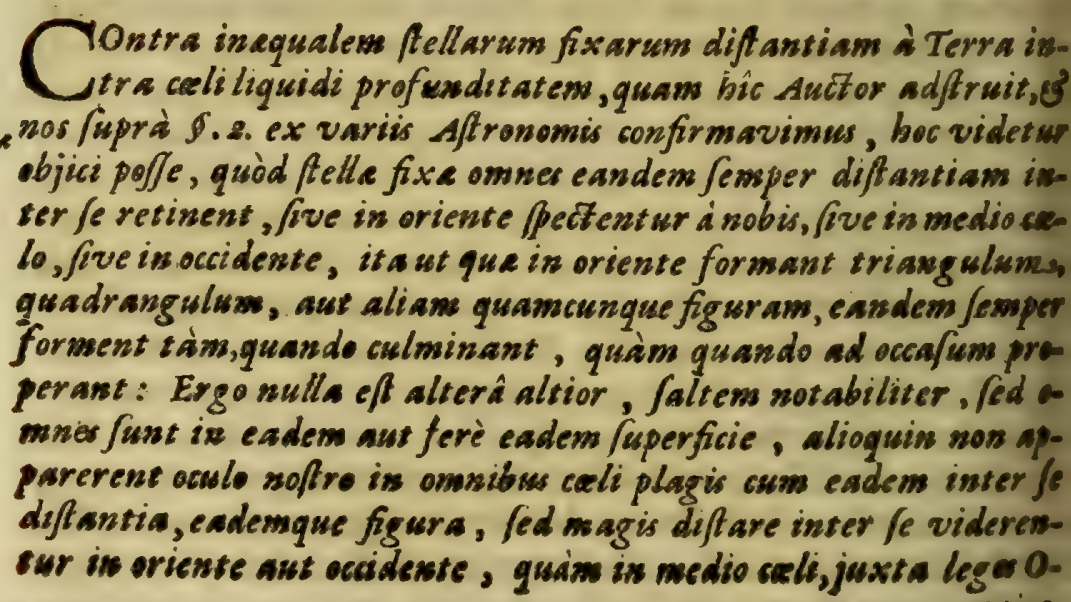
pricen 
tica. Re pondetur ramen, tametfivalde enormiter alua fint aliws liviores, whuct amen E' quoad fe, s' quoad vi/urs noftrum, easem jesper in ornnibus plagis diftantian fervare. Sit enim cen. un Univerfo $A$, duse ftelle $B$ G $C$ font altiores of magis remota dicfocentro, duse vero $D Q V^{2} E$ minis remote, efficiant que figs- Vide Ison:Im quadrangularem BCDE, dum exiftust in oriente. Pro- II. rediantur deinde, fervat gur am guadrangularem CFEG. Dico, quatuor dict as ftellas trobigue videri a centro $A$ cum eadem diftantin inter $f e$, st an- 2uoniam enim tam inferiores, quaim fuperiores, uniform: otu pregrediuntur, percurrent equalibus temporibus equates cus, Gocirca centrum conftituent aguales angulos, ac proinde eando $B$ erit in $C, \xi^{\circ} D$ in $E$, erit $C$ in $F, \sigma^{2} E$ in $G$. Est ergo arcus $B C$ walis arcui $C F$, 6 arcas $D E$ arcui $E G$. Eodem modo angulus $B A C$ it aqualis angulo $C A F, E^{2}$ angulu $D A E$ aqualis angulo $E A G$. srobique ergo tàm /uperiores, quàm inferiores, videntur fub dem angulis; ergocum eadem diffantia inter fe. Idem est diodum, in quacunque fint plaga celi.

1I. Cofmiel. Sed jam nos fingulis vicinius fiftemus. Eleva ulos tuos, \& confidera fingula. Theodidact ws. Nefcio verè, i morer, quídve mecum agatur. Ingentes ego fellas, quæ lisluci \& magnitudine \& lumine vix cedant, afpecto ; video rerea nonnullas in modum Lunat mirâ phafum variecace ferentes. Fierine poteft, corpora in hac expanf immenfic exiftere, qua cum Sole aut Luma quicquam fimilitudinis stehle sols. beant? Cofmiel, Quid dubitas? Anne omnes hujusmodi ftel- ris É Lana à Sole illuminari putabas? Theodidactus. Ita purabam.Co- ris naturn. iel. Valde hallucinabaris. Vidésne illam tibi diametraliter ofitam ftellam,Canicula haud malè comparandam? Theoactus. Video. Cofmiel. Quam illam effe puras. Theodidactus. ma magnitudinis ftellam, aut lucidam hydræ, aut cor Scornis, aut ex fimilibus quandam prima claffis ftellam. Cofmiel. puantum aberras! hic eft Sol vefter, vasillud admirabile, sol ex fir nihil in inferiorum natura rerum majus aut mirabilius maments ganari poteft , cujus fplendore lueisque efficaciâ omnia in- "Appar ctfab

Geriora 
a magni feriora vivunt, cujus vircute ineffabili omnes terrigene fuften tudine,/ub cantur \& confervantur ; purásne jam tancillam ftellam ad illu. berra Cans-minandum hunc mundum fufficientem efle? Theodidact us. Mi cwla. nimè,quinimò non tantùm illam luce fuâ præêtare pof̉è exifti mo, quantum (Canicula, aut Lyræ fidus, aut fimile quoddam, ac illuminandum terrenum globum poffic : cùm enim centuplo plu diftemus à Sole, quàmSolà terra;quis credat, tantillú fidus vaftifi mos hosce mundi globos, \& remocillimos alios nobis incompercosilluminare poffe?

\section{SCHOLIUM II. Sol nofter non poteft illuminare ftellas fixas.}

Sol men poeeftillumiv nare fiellas faxas.

\section{.}

Ol diftat ì fixis in maxima diftantia fensidiametris terre lecundùm Tychonem 12880 , Fecuredum Ptolensaum 18867 , Jecum. dum Recciolum 202926, fecrendum Rheitam 20000000, Secundiom Lansbergium 41950́ss4, Jecundium Keplerum 59906040. Idem Sol a terra diftat in minina diffantia, fecundium Tychonem III fécundium Ptolcrnaum 1126, Secundium Ricciolum 7000, (ecursdìm Rheitam 1027, Jecusedium Lansberginn 1446, Fecundium Keple. rum 1736. Ex bis patet, verum e/fe, quod offerit Auc? or, in ommium. ferelententia, fixas fellas diftare centuplop pliss à Sole, quàm So i terra. E tanta diftantia Sol apparet exiftentibus in Fix is, fub

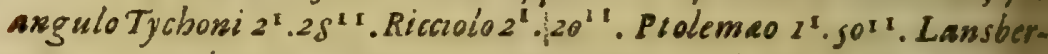
gio g" $^{11}$.Keplero ${ }^{11}$. Maxima Fixarum, nimirum sirius, continet terram, Jecundum Ptolemaum, vicibus 42, at fecundism Ricciolum vicibus, 3552 uis credat, tanta corpora, in tanta diftantis à Sole, recipere lumen exiguum, nedum! uffic iens?

III. Colmicl.Vidésne in oriencali angulofidus illud Sole \& magnitudine \& claritate quoad afpectum haud multùm inferius? Theodidactus. Video; fed dic, rogo, non ifte Sol nufter elt? Valde enım dubıto, ne forcè, dum lucidamillam mihi So- 
$m$ clle noftrum monttrabas, ego minuti corporis mole deeprus unum pro alcero acceperim. Cofmiel. Falfò dubitafti, la enim lucida minuta, quam vidifti, verus ifte Sol vefter eft, acc autem, quam coràm incueris, illa ftella eft, quam veftri fronomi Caniculam vocant. Theodidactus. Nifi à te, divino stelle in eo Magiftro, omnis falfitatis \& doli cxperce inftruerer, ut id frmamex. ederem, nullâ racione induci poflem. Ergóne credi poteft, nature remociflimis firmamenti recellibus Soles reperiri ? Co/micl, slobi junt. uidni ? Solaris enim nature corpora hîc reperiri, non canm congruum fuit, fed \& prorfus neceflarium, ne cor ac tanmundanorum globorum corpora perpetuis damnata teneis otiofa torperent. Si enim fola Canicula terreno globo, mpro Sole, affulgerer, quid de terreno corpore futurum tas? Theodidactus. Certè illud aternis cenebris \& caligine rpecuâ oppreflum, interiturum arbitror. Co/miẹl. Idem de aumeris globorum firmamenti fyftematis contingeret, fi neffer, quica illuminaret, \& ad fines à natura intentos calofuo exftimularet; cales omnes illa ftella funt, quas primx gnicudinis vocanc. Theodidactus. An non unum hujusdi folaris natura corpus ad omnes ftellas illuminandas fecifler? Cofmiel. Ah mi fili, nondum firmaménti immenfi. solin firem expertuses; fed tunc fidem meis verbis adhibebis ubite mamento interminata firmamenti habicacula traduxero. Hoc uni- pofis us ne$n$ ad te convicendum argumentum fufficeret $\mathrm{Si}$ unum- quaquas. corpus in firmamento, uti cu putas, fufficiat; jam quaro curs fitas ife, urrum ftella ei in circulo fuo appofica illuminencur, vel pusers. ? Theodidactus. Puto, quòd fic. Cofmiel. O quám parum. cica \& Aftronomiz te peritum monftras! O quantum abas ! Cum enim ftella in circulo firmamenti folari huic glooppoficx duplò plùs diftent, quàm Tellus, aut Sol, aut Luna, hoc folari firmamenti corpore ; Sol aurem vefter ex hujus namenti loco non nifi fub diametro trium minutorum vitur; quid putas de oppoficis Soli firmamentali ftellis condemus ? aufim fanctè affirmare, folarem hunc firmamenlobum ex oppofica circuli fui parte fpectatum non dicim $\mathrm{Xx} \quad$ videri 


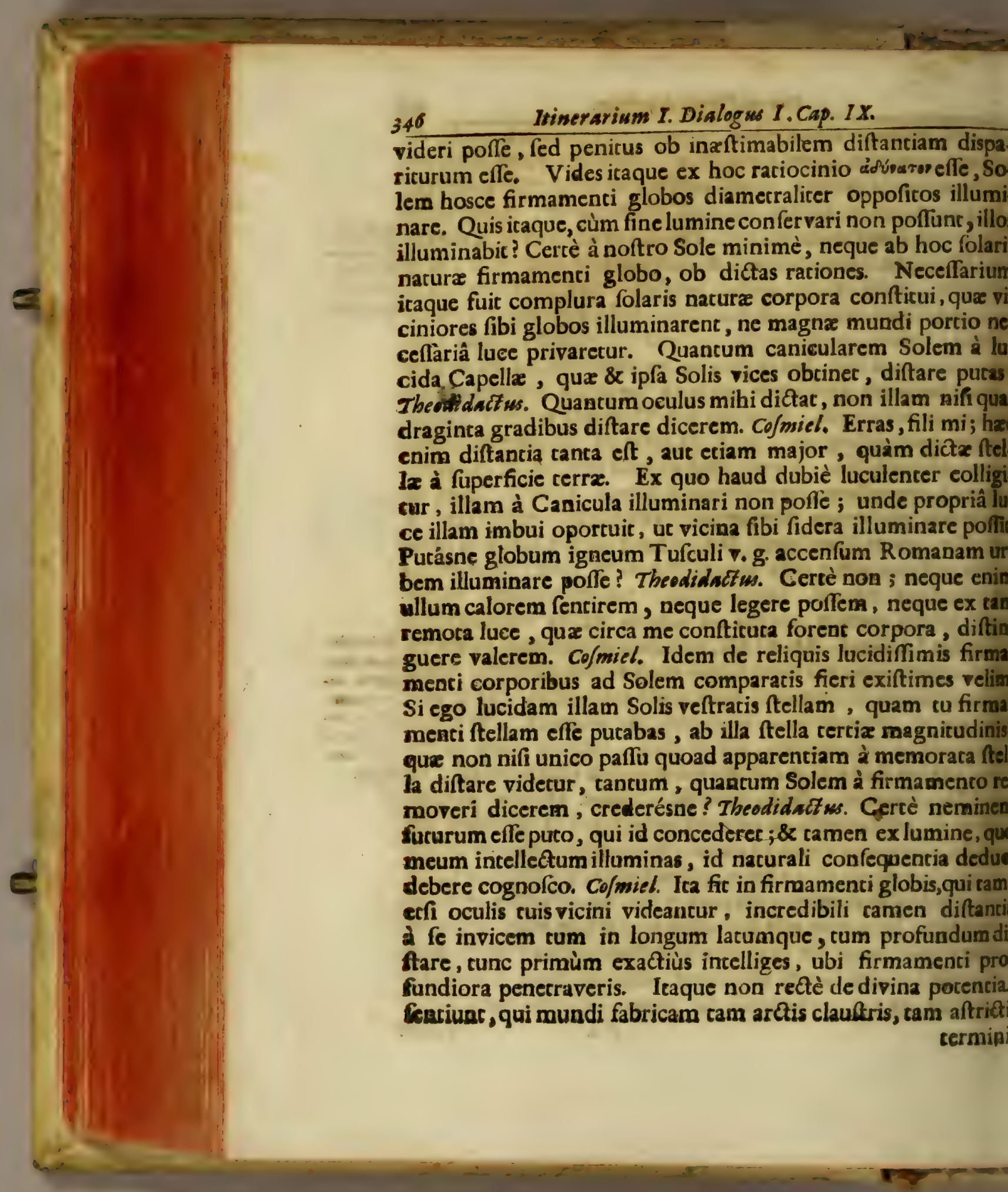


menti profundo exiftune, qua nullo unquam tempore huma no oculo attingi poffunt. Sed hac omnia in ifthoc Lunaris naturæ globo conftitutus luculentiùs incueberis. Theodid. Quc dicto, Lunaris nature in globum me depofuir. Globus erat ex liquido\& folido conftans, prorfus ejusdem cum globo Lunar conftitutionis, nifi quòd ab eo viribus \& propretatibus, toto ut ajunt, coelo differret. Mi Cofmiel, lumen, quo oculi mei per. ftringuntur, nimium eft, neque ullam ampliùs firmament faciem intueri poffum; duc itaque me in adverfam globi partem Innumers. bilis fiellarum multi formamensum. ut veluti ex nodte quadam omnem coeli faciem exactiùs ex. pendam. Quod factum fuic. Hîc ego primùm ea detexi, quæ nul lis verbis, nullo eloquio facis defcribi poffunt. Vidi fiquidem fu pra me innumerabilem ftellarum mulcitudinem juxra fextu. plicis magnitudinis ordinem, quarum iconifmi omnes varia \& differentes figuras exhibebanc. O mi Cofmiel, quàm infoli. tam rerum faciem intueor! Num hæ ftella firmamenti fune vel non? Certus enim, nihil ex hujusmodi ftellis è terra videri Co/miel.Firmamenti funt; \& benè dicis, nullam harumè terra wৃ. deri: eft enim adeò immenfum firmamenti expanfum, ut id non dicamoculus, fed ne humana ratio quidem atringere poffic Theod.Monftra, rogo, mibi jam Solem, Lunam, Terram, çecros que globos circa Terram verfaciles.Cofmiel.A pplica oculum ruum Theod. Secundæ magnicudinis ftellam ego video. Cofmiel. Ille So Apeciusso vefter eft, quem \& veftri Philofophi tocum mundum illuminar lis, Lum a, opinantur. Vide jam, utrum hoc verum efle poffic? Theodid. S Terre, cete- vera funt, qua dicis, impoffibile effe arbitror. Sed ubi eft prumque: Tellus, ubi Luna, ubi reliqua planetica fidera :Cofmiel. Omnia ox frms- ob nimiam diftantiam jam evanuerunt, prater Jovem \& Samentialtio-turnum, quos vicinos Soli, inftar quartxe magnicudinis ftellarum, nifitw. intueris.

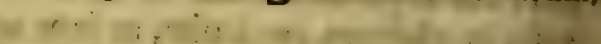


ere 207830, à Mercuerio 205961, Luna 209949. Ex bis facilè colgitur, quanta magnitudinis appareant dict a corpora ex fixis.:

$V$. Theodidactus. Sed quid hoc portenti? Nam neque So$m$, neque Jovem, aut Saturnum moveri video, æquali fere mper ab invicem diftania diffidentes. Co/miel. Tantam effesol, Fupiter, ias horum globorum ab oculo tuo diftantiam, ut tota folaris Saturnus, eli circumferentia in unum ferè fpatium folari corpori aqua- ex frma, uti \& reliquorum memoratorum globorum coli, coar-motißeentur : hinc mirum non eft, eos quafi immotos videri, aut dantwr, iam penitus, fi Sole reliquisque fuperioribus planetis mino-femper difint, evanefcere. Idem fieri tibi perfuadeas velim, dum, fantia. terra confticutus firmamenti globos confideras : videntur im' omnes aquá femper diftantiâ , \& immutabilibus interilis ab invicem diftare; quod tamen falfum eft, omnes enim ec, qua vides, firmamenti corpora, feu ftella, non fecus ac Sol, stelle fir. ina, creterique inferiores planetr, in ingentibus circulis cur- mamenti ix suos peragunt; quòd verò motus earum di cerrigenis non fibi circulis, fervetur, inconceptibilis illa ductorun globorum à terra non fecus at ftantia in caufa eft, qua omnes illorum globorum circulos planete solluti in unum punctum collectos abforbet. Cujus tibi reifenfibilibur e propono exemplum. Si compluribus rotis currulibus ali- tamen, ob, lankulum ab invicem diffris, fingulis fingulas accerfas fa- distantiam $s$ alligares ; experientia docet; faces tametfi ex rotarum cirmvolutione è propinquo fpectancibus fitum mutenc, unâ men arque alcerâ leucâ diffitis neque locum, neque ficum, que diftantiam mutare videri, utpote tơtâ rotâ in facis nınirtudinem, ob ninuiam diftantia enormiratem, coarctatâ. idésne ftellas fempèr novas \& novas fupra hócizontem hus. Lunaris globi nuno afcendere, alias verò defcendere? mnes ha ftella curfum fuum circa Solem \& Lunam hanc mamentalem conficiunt, fuasque afcenfionis, defcenfronis, elinationisque leges uti in inferior bus planetis fibi prefcrias habent. Theodidadius. Sed quis unquam eas AftranomoIm obferwavit ? Si vera eflent, qua dicis, Uranofcopi nof ri and dubiè hujusmodi motuurm differentias nocaflear; Lunas $\mathrm{X}_{3} \mathbf{3}$ quoqgue 
quoque jam plenas, modò dichotomas, nunc cornibus fulgida tandem penitùs evanefcentes tum prateritis feculorum curri culis, cum noftro potiffimùm, tot ad rectè \& incredibili indu A triâ obfervandum fubfidiis inftructi obfervaflent. Cofmiel. U video, quasfuperiùs ribi innui rationes, nondum percepifti. Di co itaque, eò quòd $a b$ Aftronomis nunquam obfervaca finc iftiusmodi Mundi phanomena, non argui filla non effe; fedo inxftimabilem enormemque horum globorum à terra diftan stam, illa non videri, utpote omnibus illis circulis, in quibus ver fantur, in infentibile fpacium, prour optica nos docet, coarda tis, in quo is tantummodò oculos noftros incurrit, qui interd atos globos maximus \& lucidiffimus eft, cujusmodi eanicular ille. folaris natura globlis eft : quemadmodum tu ex hoc glob ex inferioribus globis nihil aliud nifi Solem intueris, reliqu immenficate diftantix unà cum circulis fuis abforptis.

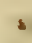

\section{SCHOLIUM V.}

moliarma fxrarum alogue an

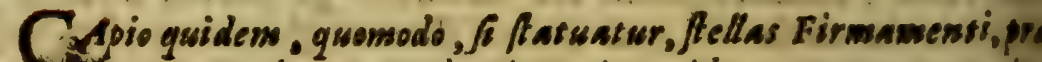
Ly motum diursum ab oriente in occidenten, moveri ctian arsa alies circulariter in ingentibus cirenlis folari circulo band wisen

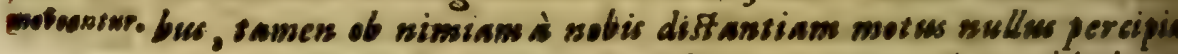
tur, queniam cotus circulus quafs in urews punctum abjorbetw eons samen capio, quomodo, $\sqrt{6}$ circa aliquas fiellas moventur ali velusi circa Solem Luse noftra 8 o planete, moten ille non pers piatur. Nam ex hoc maifefte fequitur, Rellas Luwares moin circs Solares, effe illis modó ad dexternmi reßectu nofri, modi a funiftram, o puns ad orientem, nume ad occidentem. Percipion ergò à mobis motus ille, of ftelle fixe non fervanit femper eande inter fe diftantian quoad apporentiam, nec coden femper on dine fervato inter fe progrediuntus. Quod samen quotidian experientia ropugnat. Nifi dicas, frellas d nobis è terra vila

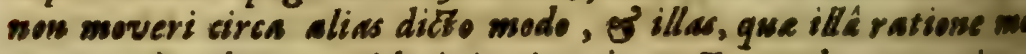
ventur, à mobis nos videri. Hec iswesit Awefor. sed res rota inst conjecturas maset. 
VI. Theodidactus. Rogo ce, videamus jam Solem illum anicularem, ur, ex qua materia compoficus fit, quac ejus fabrica im admirandx ratio fit, mihi innotefcat. Co/miel. Fiat. Theoidact us. Et ecce, in ictu panc̀ oculi me Soli caniculari fiftic, Canicula mi Cofmiel, globum video Soli noftro prorfus fupparem fresturne îc ingenti aftu volvunt æequora fluctus; hîc ebullientibus fc2bris ingentes agicat pelagus intenfifimâ luce vortices fuos; lida fubftantia nonnihil differc; diceres omnem pretiofum Ipidem operimentum ejus. Rogo, Cofmiel, explices mihi finula. Cofmiel. Non eft quod moremur, ejusdem enim liquida la fubftancia cum folari noftro rationis eft. Nam, uc dixi cibi, IEUS Opt. Max. dum in primordiis rerum, lucem divific à te. ebris , fingulis magnis hujusmodi corporibus, lucis illius priigenix portionem indidit, uc cxtera corpora lucis indiga fun ice illuftrarent, \& ad confpirationem confervationis Univerfi nimarentar fingula: quod nifi factum fuifter, mundum magna s parte cenebris ( quod fummum natura malum eft) oppresim interire necefle fuiffet. Scias tamen, omnes hujusmodi lobos folares vircure \& proprietate maximè ob fitum pofitio. emque, quem in Univerfo obtinent, differre; qux uti foli IEO,fupremo mundi Opifici, note funt, ita non opus eft, illas ifius hoc loco deducere; fi enim fingula tibi demonftrare vel$m$, fcias, mundum non capturum, quide iis fcribendi forent, bros.

\section{SCHOLIUM VI.}

\section{A lusem primizeniam, primso Mundi dic dे DEO product am,}

1 dispefcuerit DEUS die Mundi quarto in Solem, \& Lunam : quid illa luss fuerit, ignis, nec ne ; examunabimus in Mundo oftro Mirabili.

VIl. Theodidactus. Rogo te mi Cofmiel, fac, ut polum Polerio fist rmamenti, vicinamque ei Cynofuram propiùs contempler, ut, ${ }^{\text {ho. }}$. nomodo tanta fuper polum fuum machina volvatur, \& cur ynofurze fidus è terra confpectum prorfus immobile, \& guafi 


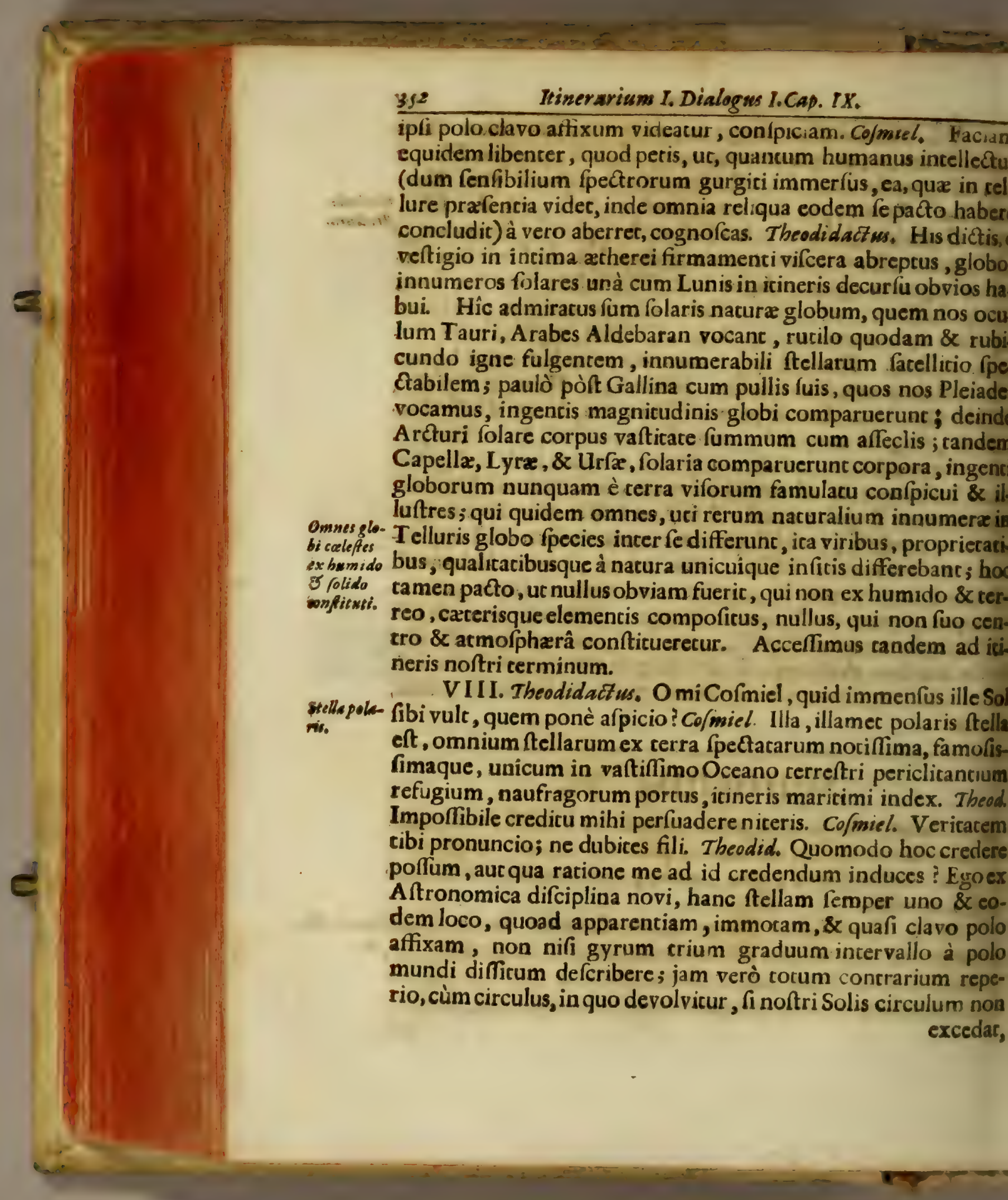


xcedac, falcem optimo jure eidem aquiparari poffit ; fed $\&$ Lunis fuis, licet oculus terrenus ad eas non pertingat, ftipatum ideo. Sed ô divine Magifter, hæc faciat cibi DEUS, \& hæc adlat, fi ableonderis à me hoc maximum natura arcanum. Cowiel. Attende itaque. Stella polaris, quam intueris, in maximo irculo verfatilis, tanto à terra intervallo diffidet, ut oculus in elluris corpore confticutus, eam non nifi fub puncto, circulum erò cjus, non nifi fub diametro fex graduum comprehendat; ade mirum non eft, eam femper immocam quoad apparenam confiftere, tardiffimo gradu in circulo fuo procedere. beodid. Hoc quidem capio, fed cur id non reliquis ftellis obtinit? Cofmiel. Quia non eundem firum obtinent, fed omnino iverfum.

IX. Theodid. Quafo, antequam ulteriùs progrediamur, Polus in ftende mihi, ubi eft Borealis ille celeberrimus mundi polus, cir- datur reaquem hac ftella fuos volvic motus. Cofmiel. Ne tibi imagine- lic, fed imss hoc loco polum aliquem materialem ; eum enim nullibi in- snarim. $^{\text {in }}$ enies: poli enim, quos Aftronomi \& Philolophifibi imaginanIr in mundo, mera phantafia ludibria funt. Theodid. Túne luibria dicis, qua ratio ipfa \& experientia quotidiana nos do$x$ ? quis tam infana mentis eft, qui polos in mundo non adiferic? An non quotidie ftellas ex ortu in occafum 24 horam intervallo circuitus fuos conficere videmus? An non. ellas illas quantò polis viciniores funt, tantò minores femper minores circulos, usque dum cum polis coincidant; tanto erò majores, quantò aquinoctiali viciniores funt, defcribere ernimus? Apertum fanè \& luculentifimum fignum, munum in globi figuram fabrefactum, ac proinde polis fuis conare : quid dicis ad hæc Cofmiel? Cofmiel. Fateor, hoc aternat eritatis argumencum elle iis, quifolo fenfu fulci, interiorem. culorum vultum altiùs attollere non poffunt; ac proinde irum non eft, eos ftellarum veluti globo cuidam folido afxarum motum non nifi fub fpharico corpore polis fuis inructo concipere potuiffe. Verum ego te totius rei fanè aruz vericatem docebo. Theodidactus. An nibil majori avi- 


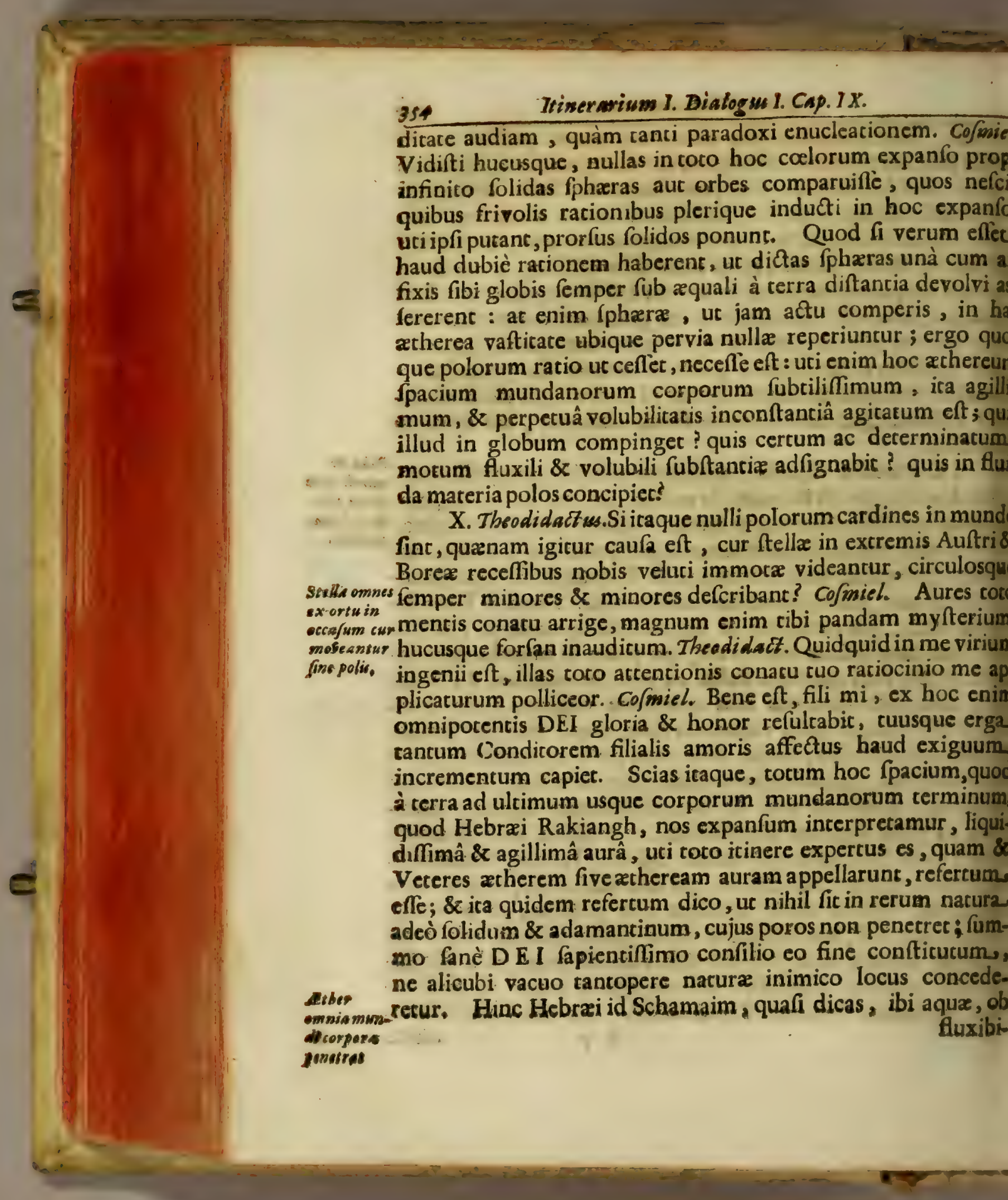


uxibilis natura inconftantiam, haud ineorigruo nomine appelindum cenfuerunt. In hoc iraque ingenti xtherex auræ ex-cubidetur. anlo mundi Conditor innumerabilium hanc globorum coneriem ita ad globi terreni fitum conftituit, utomnes \& finguex ortu in occafum motus fuos aufpicarentur , \& perenni abilitatis lege eosdem circa terram juxta divinx idex immubilia decreca continuarent. Cùm verò athereum illud exanfum nullâ certâ figurâ conftet, fed vago \& incerto fluxu undum permeer; fupremus Archicedus globos in eo ab orine conditos eâ harmoniâ, fymetriâ, ordine, \& proportione I invicem dispofuit, ut nullus alteri impedimento foret, aut curfibus mutuis fe impecerent. Et quoniam finguli quoque Motur fat ater motum diurnum, motus quoque proprios in fuis circulis, rii. metfi Terrigenis infenfibilibus, peragunt; neceflarium fuit, unus altero altiorem, aut in codem diurni circuli ambitu motiorem fedem obtineret, ut fic medii veluti vicarii Soles idam fingulos fibi fubditos globos lucis indigos, noftro t2en vifui occultos, fuo in circuitu luce debitấ perfunderent; iniores verò ad invicem folaris naturx globos cali diftantiâ llocavit, ut muneri quidem fuo fatisfacerent, nec mutuos taen jurisdictionis terminos confunderent. Elucet \& in hoc miranda divini Opificis fapientia, quòd dictos globos cirpartes Boreales \& Auftrales, eo circa terram pacto verfari luerit, ur finguli mirifica quadam proportione minores nper \& minores in liquido illo expanfi fpatio juxta Auftrum Boream circulos defcriberent, uti in Urfa majori, minori, llis Draconis luculenter apparet; quorum quidem poli alii n funt, nifi ipla centra circulorum, quos conficiunt; atque eò zternus Opifex fphæræe materialis circulos in idea fua exeffos in hac mundi fabrica affectafle videcur. Et quamvis inmeri ftellarum globi alii tantò à primis firmamenti ftellis alres, quantò à firmamento Térra diftat, \& alize illis adhuc ttò altiores \& altiores fedes fortitz fint; omnes tamen ean$\mathrm{m}$ mosus rationem fub dicta circulorum proportione ineunt. que hrec eft ratio, cur vobis in Terra confticutis verfus Auftri

$\mathrm{Y}_{2} \quad$ \& Bores

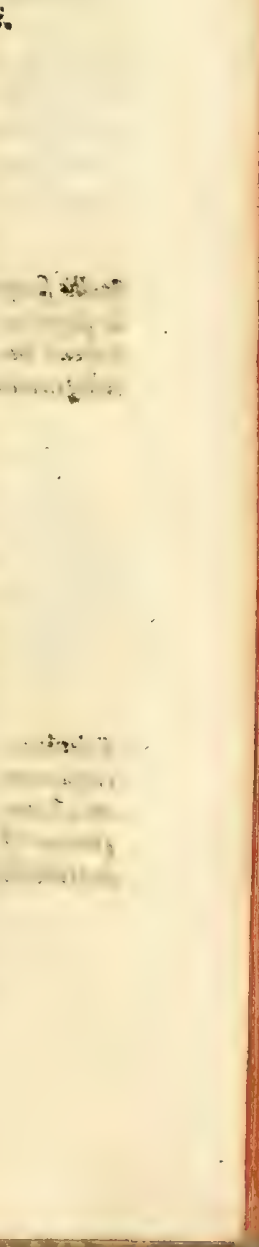




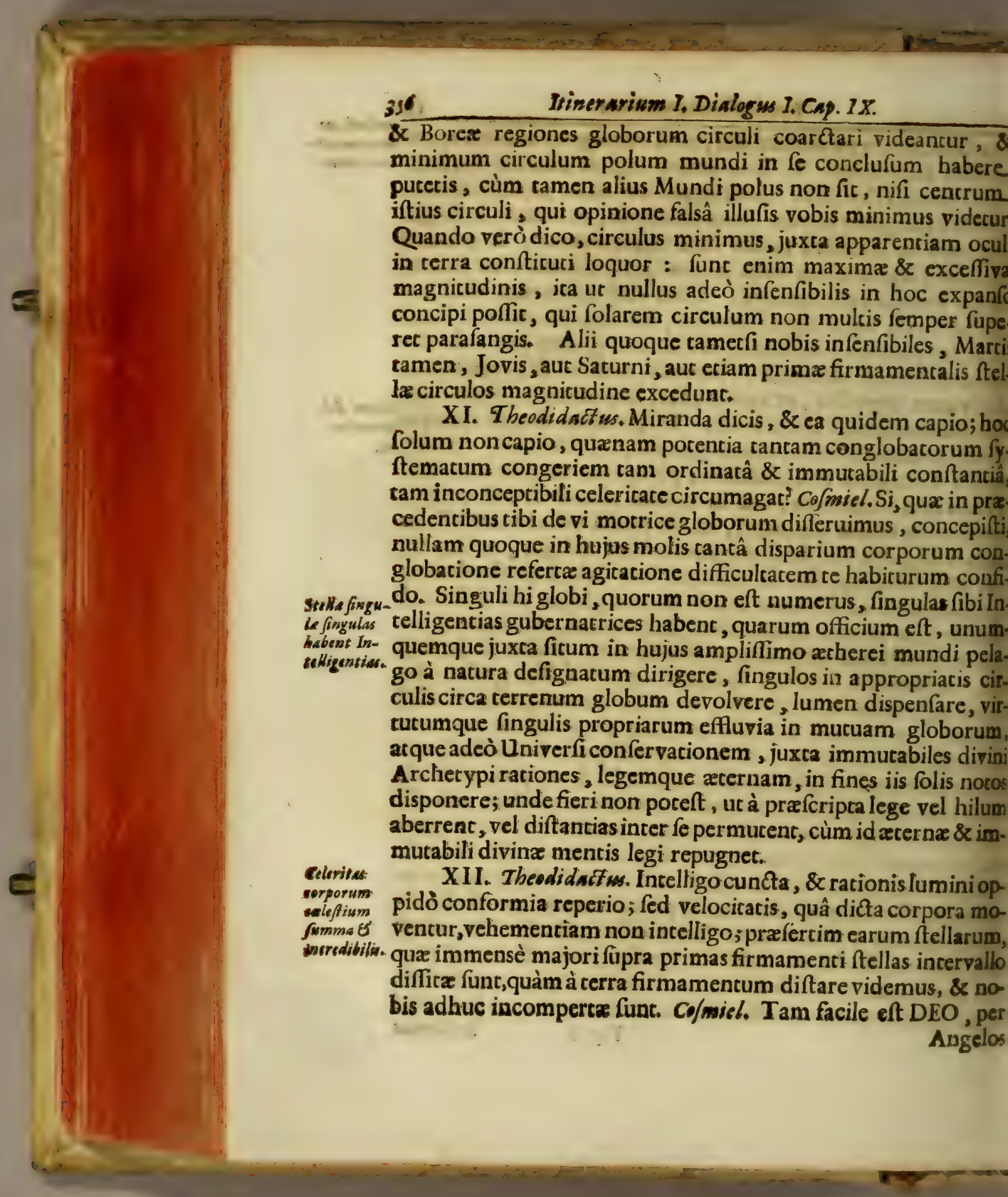


ingelos fuos adminiftratorios Spiritus, globos hosce viginti uatuor horarum tempore circumagere, quàm facile mihi tit tam exigui temporis fpacio te ex caniculari ftella in hanc olarem deducere. Si enim, quemadmodum tu alibi demonftra$i$, molaris lapis in firmamentum abductus, \& in terram demis15 , in fpacio tamen tanto emeriendo non nifi fex horas, uti cheinerus \& Merfennus probant, conficerer; quid de ftellarum, uâ concitantur, velocitace dubitas? Si fulminis celeritatem intelgis, forfan per fimilitudinem quandam, licèt difparem, velocitem tamen hujusmodi globorum non incongruè concipies:Inomprehenfa enim funt opera DEI, \& longè ab humanæ menaftimatione remota. Theodid. Habéntne finguli globorum, ros in hujus immenfitate firmamenti perluftravimus, fua proia centra \& Cofmiel. Singuli fua cencra habent propria. Củm Stelle ommes im in fluido xthere volvantur, fieri non poteft, nifi propriis babent fuse incris in locis à DEO ipfis ordinatis firmentur, ue confiftant propriasen. bfiftantque; unde \& confequitur neceffariò, omnes \& fingul mojphare. s proprietatibus, \& viribus differre, quamvis ex liquido \& terno facta globorum compofitio omnibus communis fit; unde \& gguli fuas exhalicuum ipfis propriorum expiratione armohæras fundant. Theodid. Sed quomodo fit motus ille firmaenti proprius, quo fe contra fignorum fucceffionem ex occafu ortum provehit? Cofmiel. Hic motus fit helicis linex defcri- Stektarum ione ex ortu in occafum factâ, quâ 24 horarum fpacio dum motus ab eridianum non precisè attingit, fic \& fpacium illud ad meri occidente anum refiduum, dierum, annorumque multorum multiplica- tem quomo. one tandem femper \& femper pofticipando in fenfibile au- do fart. nentum, uti jam nofti, excrefcie. Theodid. Sedcur in fixis tam fenfibile eft, non item in planetis? Co/miel. Quia maxima à rra diftantia facit, uc fpacium ad meridianum refiduum tami maximum fit, vix tamenoculi nifi poft cencum annorum tervallum difcernatur , ac fenfibile reddatur. Sed haec tibi pas$\mathrm{n}$ nota funt. Theodid. Rogo te, mi Cofmiel, unde fubinde no: in firmamento exorta ftella originem habent? hoc enim

$$
\text { Yy } 3 \text { jam }
$$




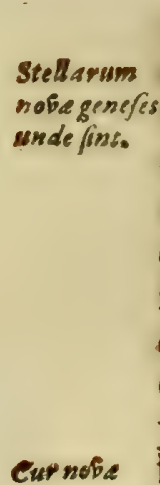

Cur nobe fellarum in \& non ficut noftri cometa mobiles? Cur fine cauda ? cur Sole no

jam dudum à te mihi exponi cupiebam. Cofmiel. Củm hace tib nova phænomena jam fuprà in Solis luftratione expofuerim non cam totum negotium denuò exponam, quàm paucis ver. bis definiam : eadem enim, quam cirato loco adduxi, ratio prc cœleftium in firmamento exorientium fubinde ftellarum origi. ne pugnat. Solaria enim firmamenti corpora, fic à fimilicur dine Solis veftri dica a cùm ingentes fubinde exhalationum. cumulos ejaculeatur, illæ in æchereæauræ finibus condenfatæ, \& perpecuâ luce Solarium globorum irradiatx, novas ftellas no. bis exhibent. Theodidartus. Sed, cur femper loco fixx videntur exorta,fem Atro majores æftimantur? Co/miel. Primùm fcire debes, eas veri per fixa bi- non fecus ac cometas hinc inde vagari, fed fpacium, intra quod deantur.

$$
\text { in }
$$

$$
\text { vimis }
$$
verò cauda vareas, cau for quod in an  fintum compareat, exiliori cauda parte evanefeente. Sole vero, diametro vifui noftro objiciantur, quàm Sol terrenus ex firmamento vifus. Neque te magnitudo earum perplexum reddat: uti enim materia rariffima eft, ita in immenfum fefe fpacium facile dilatat: ut vel hinc appareat, quàm non fubfiftat eorum fenten-

Nobaftelle tia, qui hujusmodi nova ftellarum phænomena in nefcio quibus won Gebunour in excentricis eireulis. ingentibus excentricis vehi putant; quod quàm falfum fit, hinc patet, quòd hujusmodi ftellam femper proportionato incremento decrementóve fub certa temporis menfura fpectari oporteret; quod experientix reclamat, cùm uti fubitò comparent, ita quoque fubitò definant effe. Non itaque in excentricis vehuntur, non de novo à $\mathrm{DEO}$ producuntur, neque ex reflexione fpherarum cryftallinarum oculis noftris objiciuncur, aut ex confluxu ftellarum nafcuntur, fed naturali vi ex vehementi globorum folarium firmamenti exhalationum vaporumque eructatione originem fuam deducunt. Vel etiam contingere poteft, ut exhalationis expanfa materia à globis vicinioribus firmamenti 
mamenti illuminata latentes vicinos \& opacos globos lunaes cantâ lucis reflexione perfundar, ut illa hoc tam lucido 2nictu fulgens, in noftrum tandem fefe confpectum exponav. Inde \& illud colligitur, cùm hujusmodi ftellas in firmamento acales fuos habuiffe, ab origine demonftratum fic, firmamenm nec folidum, nec incorruptibile efle pofle ; quod tantâ ta- Stellarum pertinaciâ complures defendunt. Certè terra non minùs genefis corruptibilis eft, quàm reliqua mundi corpora, cùm tamen cerruptibiquartes maximis corruptionibus obnoxia fic , uci ex litatem en conflictu fatis fuperque patet. Idem de eliquis mundana fabrica globis, utpote omnibus fuis ex ele- Terra nor entis pari ratione compoficis, intelligendum effe exiftimes, corruptibi ti in pracedentibus oftendimus. Vides igneum hujus polaris lis eff quaim lis globum, quomodo aftuat? quàm ingentes fumorum glo- religui gloos evomat? Si itaque tales cum reliquis globorum exhalationi- rotam fub. us in unam lucidam nubem commilla in longè latèque expor-fantiam. :tum atheris fpatium diftendlantur ; quis tam ftupida mensef, qui eam fub figura ftellæ nova Terrigenis apparere poffe egaveric दे Sed ita plerumque humano ingenio comparatum. t, uc in rerum abdicarum fcrucinio, neglectis caufis proximis certiffimis, eas potiffimùm inani \& fruftraneo labore fecte$r$, qua nec. verifimilitudinem quidem babene, neque cum reus confiftere poffunt, ucpore abfurdiffimis erroribus obnoxia. seodid. Certé ego tuam hanc fententiam non probabilem tanm puto, fed \& veluti apodicticam prorfus amplector ; nibil Sententie im contra eam i modo difficultates omnes, quantumvis perplexas, \& tricis genefsomnos numeris pla

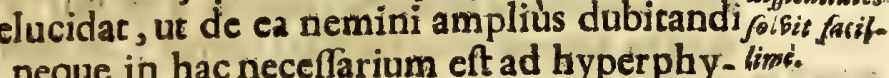
as five fupernaturales caufas, \& novas denique rerum produiones, aliaque abfurda commenta recurrere, cùm hac omnes, rca novarum ftellarum genefin, ab Aftronomis factarum. fervationum circumftantias \& conditiones, fine difficultadiffolvar, \& ad naturalia principia reducat :unde \& ridiculas aleferiatorum Aftrologorum de novis hujusmodi ftellarum. nova- 

Nobaflelle 360 novarum portentis, crifes ceflare neceffe eft. Q purums na.

Luot tric $x$ circ sure opus.

quanca Q Cùm tamen tuâ inftructione peritior, caufas tantæa genefec a pertas videam; funt enim, ut in itinere per tranfennam com 2uomodo peri, omnes ferèftella, quæ in Caffiopxia majores fpectantur, fo orta fit $f$ tel- lar is natura; potuit itaque tum temporis Chronico feu Clima

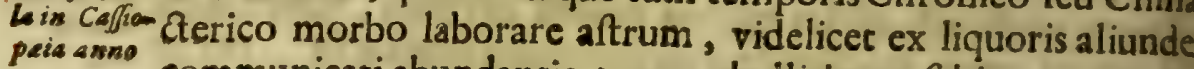
8572. communicati abundantia tantas ebullitiones fubire, ut in in menfam xcherex auræ regionem inde exorientes vaporum ex halationes extenfær, aftrisque vicinis illuftratæ, inufitatum nc va ftella fpectaculum exhibuerint. Uti tamen fpacium, intm quod agitatum eft, ob fummam diftantiam infenfibile fuit, ita

Deisopers oculis noftris motum fuum explicare non potuit. Cofmiel. Reet infrustabi- difcurris, Theodidacte, neque enim alios habebis philofophi lia bumano
intellechui. tua contradictores, nifi qui Dei Optimi Maximi incompreher

fam potentiam ad fui ingenii capacitatem (quafi veró DEU facere non poffic, nifi quod captui eorum turpiter aberran congruit) detorquere aufint; cum talibus minimè tibi concel tandum effe fcias. Theodid. Veriflima loqueris, \& ego fempe miratus fum, quî fieri tandem poffit, ut tales inaccenta divin potentia opera adeò illotis, ut ajunt, manibus tractare audean dum, ne fi firmamenti regnum plùs aquo magnum concedan Conditorem fapientiffimum in eo illuminando aut confervar po defecturum fibi perfuadent; aut fi liquiditatem coelorum cor cedant, à ruina ftellarum jam metuunt, quafi verò fine fixione aftra confiftere minimè valear.t. Ego multò jam aliam, dum $m$ coràm omnia concemplari fecifti, de immenfis DEI operibr Mire 8 in-exiftimationem concepi. Ec tametfi in ignorantix mex ten ofsalis Dei bris natus \& educatus, nullam operum tam fublimium racionet difabrick. inveniam; ca tamen fingula adeò mirificâ arte conftructa vi deo, ut attonitus, quid de iis dicam, quid fentiam, vix reps riam. Nam dum paulò actentiùs fingula confidero, tantâ eum i Mundi conditu arte ufum effe comperio, ut diverfitatem illar rerum omnium cum fumma concordia junctam mirari fat 
on poftim ; cujus potencia magnicudines ftellarum quoad $\sqrt{\mathrm{f}}$ im, mocum, numerum, pondus, menfuram ita trucinavit, eo rificio ftellarum diftantias difpofuit, ut, nifi quxlıbet atherei: undi regio ita effet, ficuti eft, nec ipfa effe, nec in rali ficu \& orne manere, nee ipfum Univerfum fubfiftere poffer. Erquoam fupremus ille Archerypus intellectus infinitis omnium. mibilium rerum ideis foetus eft, ica mundum hunc, quanrum Ifiva ejus potentia capacitas permific, innumerâ globorum, ji omnes viribus, proprietatibus, claritate,figurâ , colore, luce, lore, influentiis, latentibusque feminalium rationum foturis fferune, varietare juxta inexplicabilem archetypi ratio- dijpofitio em conftitutum voluit, tam proportionat ad invicem fingurum partium difpofitione, ut in quoliber globo fit motus parim ad cotum, deorfum ad medium in gravibus, \& furfum à edio in levibus, \& circa medium. Qux omnia in unoquoque oborum reperiuntur; in quibus partes tantâ a viditate, \& naræ impetu fe toti jungunt, ut nifi in toto, \& tali toto, cujus parfunt, requiefcere non poffe videantur. Humidum verò illis" exiftens, ambientium globorum luce $\&$ calore percuffum refactumque, in atmorpharas extenditur. In quibus quidem Imadmirandam rerum diverfitacem luculenter experimur; demus nullam nos operum divinorum rationem fire pofle, Homo al eorundem inæítimabilem fublimitarem admirari cantùm tantìm de. bere; quosziam magnus Dominus, of laudabilus nimis , ejusque bet opera ugritudinis non est finsis; qui uri eft operum fuorum auCtor DEl,r.on cognitor,ita \& finisiut in iplo fintomnia,qui eft principium; edium, \& finis omnium, centrum \& circumferentia; ut in nnibus ipfe tantủm quaratur, fine quo nihil funt omnia; quo' o habico, omnia habentur; quia ipfe eft omnia; quo fciuntur nnia, quia veritas omnium eft; cui \& nihil acceprius eft,quàm inadmirationem ejus ex tanta Mundifabrica ducamur. Quam men nobis tantò plùs occultat, quantò plùs admiramur ; quoam ipfe, ut folus toto cordis conatu \& diligentia,nobi à quxtur , inquiratur, acquiratur, fibi complacet ; cùm verò lucem Disin im biter inacceflibilem, qua per omnia quæritur, is folus poteft menfitw; 


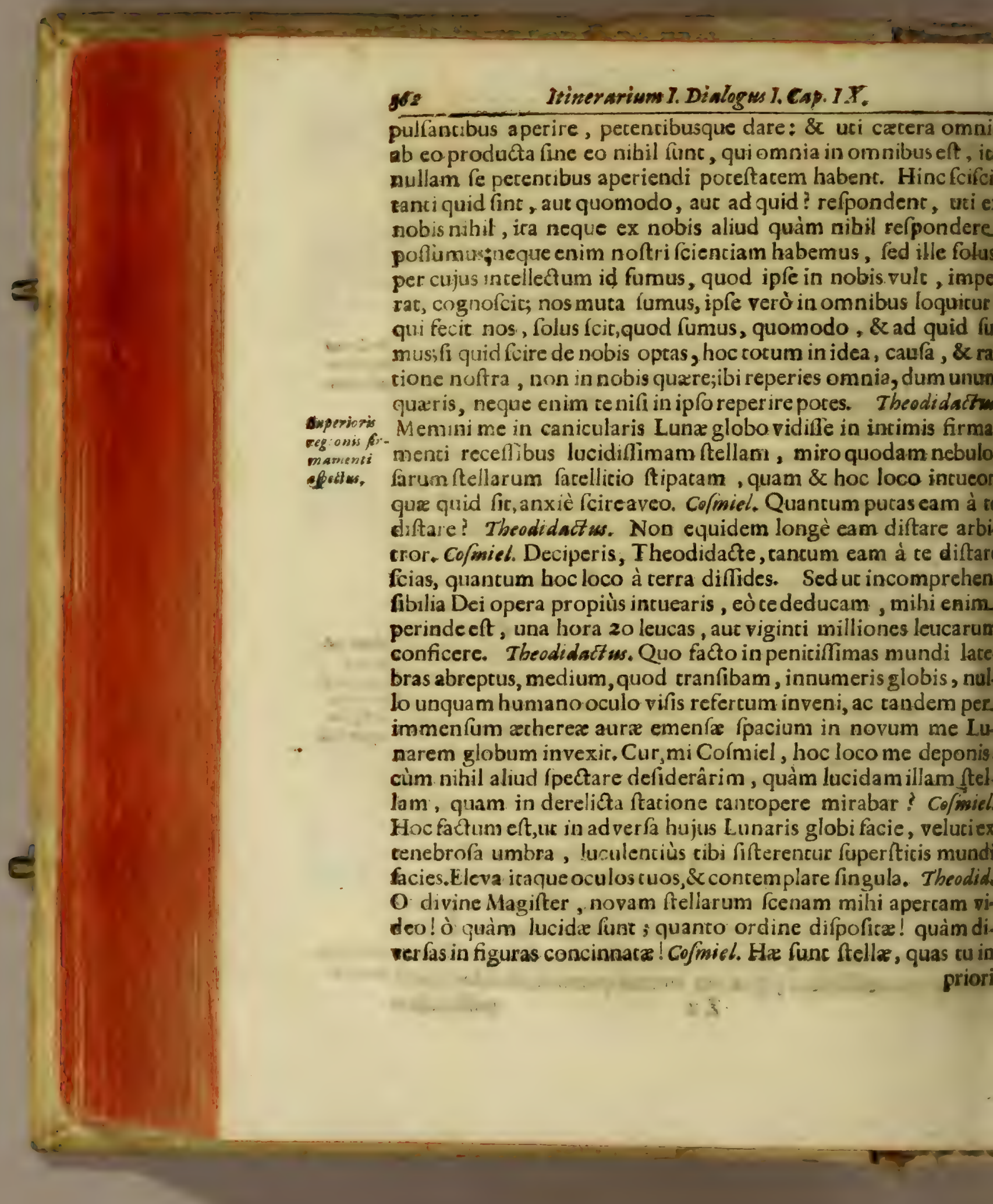


rioriftatione nebulolas pucabas, \& cancum à caniculari sole liftant, quantum terra à firmamento. Hoc loco non amphù folom veftrum quæras; nihil corum, quos hucusque vidiftı,glosorum; omnes enim ob incredibilem diftantram in nhulum. bierunt; alii hoc loco Solares globi, alii Lundres, alia fidera uullis mortalium oculis penerraca exhibentur ; eleva uculos uos, \& expende coti faciem. Theodidactus. O Cofmiel, ftupore zanè exanimor ; toram coeli faciem novâ ftellarum foeturá imrragnatam video. Co/miel. Tanto ex is nonnulla fpacio à te Intant, quanto à fecunda ftacione fpacio diftac hic,cui infiftis, lobus; id eft, rertiò remoriores fedes habent, quàm primx firnamenci ftellæà terra; \& fi cencies altiùs te eveherem,nondum amen novarum femper \& novarum ftellarum finis foree ; uc el ex hoc difcas, mundum tam arct is clauftris non efle concluum, quàm quidam putant. Sunt enim opera DE I humano ngenio incomprehenla, \& pauca divinorum operum novit umana caducitas. Sicuti enim ipfe magnus, excelfus, \& cerninorum magnitudinis fua nefcius eft ; ica mundum, quantunı ofius in hoc ftacu rerum materialis conditio permific; immen- Nour dit ta um efle voluit; tantum nimirum, quancus effe potuit, \& debuit; fitas quafe ion quòd majorem non potuerit efficere, fed quia ifta creatux corporex potentia, qua limitationem ex fe \& fua natura halet, majorem extenfionem fuftinere non poterar : quemadmolun veftri Philofophi ac Theologi, dum quarunt, utrum Deus nfinitum actu creare polfic, mulci rectè \& fapienter refponent , quòd non; non quòd potentiam Conditoris infinitam xhauftam pucenc, fed quòd illud implicet ex parte materix. beodidactus. Ceffa, ceffa mi Cofmiel, nihil ampliùs videre deidero, timeo enim, ne à nimia majeftate glorix Conditoris oprimar ; malo enim humili mentis obfequio, \& cum timore ac remore ei fervire, quàm incomprehenfa ejus opera, quorum con eft numerus, nec finis, curiofiùs fcrutari. Tolle, tolle aninam meam ; jam enim nihil ampliùs fenfibilium rerum me blectar; ei jungi æterno amore defidero, qui tanta pro me viifimo terra lumbrico in nacura rerum operatus eft; ill con$\mathrm{Zz}_{2}$ censrani 


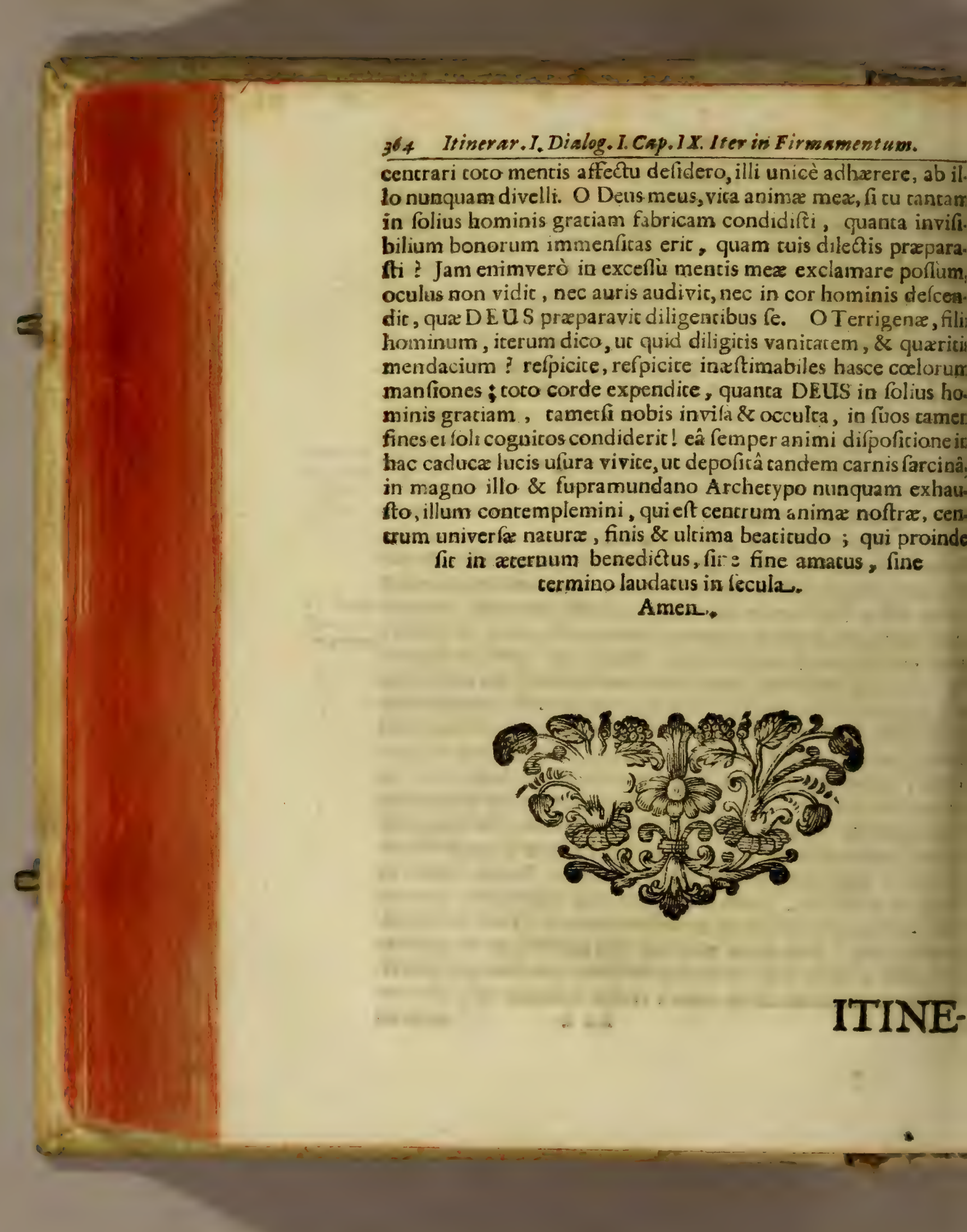




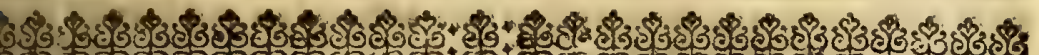

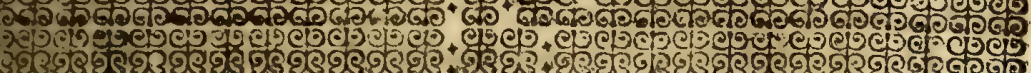

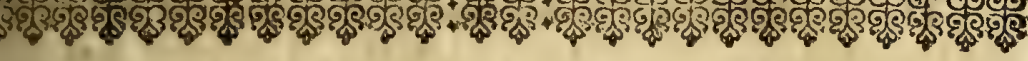

\section{T I N E R A R I I EXSTATICI DIALOGUS II.}

De providentia Dei in Mundi opificio elucefcente.

\section{Interlocutoríns Cofmiele $E^{G}$ Theodidacto.} CAPUT I.

\section{De Productione Mundi.}

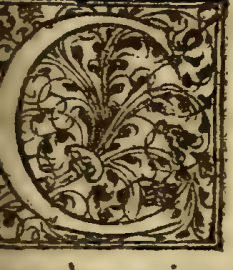

O SMIEL. Agedum Theodidaete, jam tempus Mund eft, ur luftratis Mundi globis, immenfis Univerf productio pelagi finibus peragracis, tuo pontliminiò globo exponirur. refticuaris,ur arcanorum, quae à me didicifti, $\mathrm{Na}$ tura facramentorum Terrigenas tuos participes facias, Theodidactus, Ah mi divine Magifter,

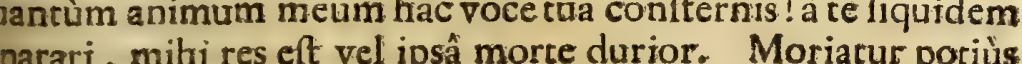
parari, milii res eft vel ipsâ morte durior. Moriatur potiùs ima mea morte jultorum, ur terrena hujus contagionis fece coluta, tecum femper vivat, recum Archetypum illum fupraundanum, in quoomnia unum funt, aternum contempletur. fmiel. Nondum tempus turum advenit; multos ad hucad divine ajeftatis notitiam erudire te oportebic, ancequam tam incomehenfibili felicitate beeris : neque meam à te feparationem oleftè feras velim; te enim non deferam, fed invifibili quấ- 
dam affiftentiâ me in omnibus tuis atıonibus prxto cibi $f \mathrm{~cm}$ per fucurum polliceor.

11. Theodidacz us. Ego quemadmodum tua me voluntat qua Dei eft, femper conformavi, ita modò, fi uaquam tuo fub fcribam imperio, nihil unquam defideraturus, mifi quod cu ad fa lutem, majusque anima mex bonum fururum judicaveris. Ho unum à te obnixifimè contendam, ur,antequam globo me me refticuas, dubiorum quorundam, qux jam dudum animum meun , circa mundi fabricam , \& divina providentia , quâ Uni verfumgubernac, raciones, torferunt, folutionem pares. Cofmic Uti,mi fili, rem æquifimam pecifti,ita iniquus forem, fi vocis tu is non obfecundarem. Macte animo, ex me confiderter omnia quacunque defiderac anima cua, interroga, teque non camai quærendum promptum, quàm me ad refpondendum exi fimes velim. Theodidact. Accepto tuam tam benignam erga fer vulum tuum roluntatem. Verùm ne confusè in negotio catero quin incricatifímo verfer, primò nonnulla tibi de is, qua mundi opificium concernune; deinde de fumma Dei pro videntia, quâ mundum \& fingula ejus, quantum vis etiam abdi ca inceflancer gubernat; terciòdenique de mira providentia. quâ genus humanum in ulcimum finem dirigit,proponam. Tuu: portò erit, mentem meam caliginofam magifterii cui lumine per vadere,uc, qua fapienterad fingula relponderis,comprehendan Cofmiel. Ne dubires fili,fier, uti poltulafti.

11I. Theodidastus. Quid itaque fuerit propriè mafra illaw quam lacer textus Genef. $x$. terram vocat inanem \& vacuam. quamque Deus Opcimus Maximus in principio rerum creavit

Coces in

fcire cupiam. Co/miel. Rem propofitam majoris confideracio primordis nis efle fcias, quàm uc paucis verbis defcribi poffic; quare alciù ditum quid exordior. Deus, cujus potencia non eft finis, nec numerus, in fit.

ineffabili decreci fui confilio mundum ab xterno conceperat: \& mundus in ipfo Deo, nil aliud quàm Deus erat. Poftquàm ergo venic completa temporis menfura, quo concepum mur dum ad excra evolvere fibi complacuit; primùm immenfa \& infcrucabilis virtucis fuæ potentiâ, in alco æternicatis puncto, fo. 
unfinitz voluntaris fua efficacia ex nihilo creavit colum \& arram. Ec quamvis non nefciam, nonnullos facri cextus Comnentatores hoe loco per cœlum, Coelum Empyreum, Dei in- Calinomtens \& immenfum palacium, Angelorum, hominumque bea- se quid in orum fedem intelligere; quod non nego; fed camen aliquid eo telligatur. nplius indigicatur; id eft, intercapedinem illam immenfam., otius mundana fabrice fpacium \& locum, in quo juxta aterm providencia fua difpofitionern mundanos globos ordiare decreverat , fpacium, inquam, longum, latum, proindum, produxic : non fecus ac Rex quidam exercitum maum producturus, priùs de loco tanta multitudinis capaci gitar, in quo caftra difponat, acies dirigat, fingulos legionum dines in fua membra aptè deftribuat ; $\&$ ad munia ritè obeuntexerceat. Sparium icaque ad tantum globorum exercitum, eleftis militia caftra aprè diftribuenda cumprimis neceflaun fuit ; \& hoc coelum dicitur. Terranaten erat inanis $S^{3}$, , \& tenebre erant fuper faciem abys/fi. Per terram hanc Terrains: nem \& vacuam, renebrarumque abyfum, nihil aliud incel- quid fit $G$ en itur, quàm molesilla chaotica, five chaosillud immenfum, nnium eorum, quibus poftea mundus formandus erac, femilium rationum mixcurấ foetum. Et uti nihil adhuc in co ornatum, nihil diftinctum, nihil fuâ propriâ formâ conftiturum periebatur ; frc omnia in unum confufa, omnia fqualida, fine dine \& diftinctione ulla, fine ullo formarum difcrimine, vei in tenebrofa quadam abyffoconvoluta jacebant. Quo rem ftacu, ut tandem fingula fuis aptè locis diftributa formis opriis inftruerentur, ecce vox Dei infonuic: Fiat lux! Et lux, primigenia mundi forma; que uti omnium maximè Lux prims. undo neceflaria fuit, utpote fine qua mundus aternis tenebris quid, mnatus confiftere non potuiflet; ita ante omnem reliquam formarum apparentiam pracedere debuit. Hæc verò erat veluti pravia quadam lucis globorum in mundo forindorum materia; \& nihil aliud fuic, quàm calidum quod$\mathrm{m}$ radicale, omnibus muadi corporibus poftea infitum, quo 0 formancur \& fuftentancur. Lucidum erac, uc omnem for- 
marum fecururarum apparatum in afpectum deducerec. $\mathrm{H}_{a}-$ bes jam primum cocius Nacuræ principium activum, lucidum illud calidum , generationis rerum unicam originem \& radi cem. Quoniam verô calidum illud fufficiens non crat, nif

Aque quid, aliud principium prapararetur, cum quoillud mixcum rerum. dequa Geomnium generationes perficerec; hinc facer textus ftacim in nef.s. principio aquarum, quas Spiritus Dei incubabat, meminit; ratque humidum radicale, pafivum rerum principium, quibus duobus principiis, calido \& humido, omnia, qua in mundo funt, entium genera originem habent. Quibus prafuppofitis, fapientifimus Conditor mox ad difcretionem parcium, globo. rumque mundanorum rudimenta confticuenda fefe accinxit qux quidem hoc pacto peracta func. Divinâ voce perfonance:

Discretio partium mundi. Fiat firmamentsun in medio aquarum, oridividat aguns ab a quis; mox totum illud terreftre, quod in chaotica 1 lla mole confufum fqualebat antê, voce Domini excitatum ; in in numerabiles mundi portiones difcretum fuit, atque adeò portiones fingula locum in mundana fabrica, actionibus muniisque, quibus deftinabantur, proportionarum adepta fune. Quoniam verò humido immenfo immer fa, aggravatzque, nullum mundo emolumentum conferre poteranc ; hinc divina fapientia juffu congregate funt aque in locum unum, or apparuit arida, id eft, fingulis globis mundanis jam firmatis, \&zcerreftri fubftantiâ concretis, ex magno illo humidi chao aqua portio ceffit, qua partim inter alveos globorum diftributa, partimad extima mundi confinia relegata, firmamentum, id eft, colefte globorum perenni lege tabilicum fpacium aquis vacuum reliquit, atque adeò duo alia principia rerum, frigidi \& ficci, emerferunc.

IV. Theodidactus. Suftine parumper, Cofmiel ; magnum enim me dubium premit, à quo ut me liberes, medullitùs defidero. Quæ tu dicis, apertè Sacr $æ$ Scripturæ diffona re videntur; Dixit enim Dews: Congregentur aque, que fub calo funt, in 10 cun unuse $\sigma^{2}$ apporeat arida; ego fanè per aridam hoc locn nibil aliud intelligo, quàm terram noltram; quomodo tu ergo dicis 
aquam non terræ tantùm, fed \& fingulis reliquis mundanis globis diftributam? non enim dicit facertextus : congregentur aqux in loca diverfa, fed in unum lacam. Cofmiel. Infigne fa- Solutio. nè dubium movifi, guod multorum non parum torfiringenia; quarequomodo illudintelligendum fit; te docebo. No-

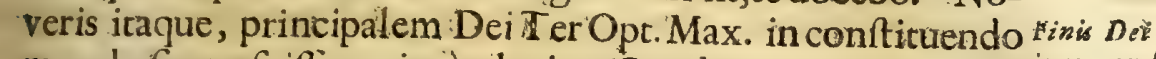
mundofinem fuifte, primò gloriam Conditoris; demde Ter-in creasdo renum globum, in quo humanumgenusadimaginem \& fimilitudinem fuam condicurus erac: fruftra enim corporeus mundusconditus videbatur, finon eflet rationalis creatura corporea, quæ operum divinorü potentiam \& majeftatem a picerer, afpiciendo admiraretur, tantæque potentiæ Opificem admi rando inquireret, in quifitum amaret, atque tandem co perpetuò frueretur. Terra itaque tanquam potiormundi pars, cưus gratiâ reliqua ommia condica erant, primò nominanda fuit, careri verò globi, ei famulaturi, non nifi implicitè. Terrenu globus eft veluti prototypon quoddam reliquorum; unde ob finem in quem deftinatus erat, globorum omniummund no rum merito praiftantifimus, \& majori rerum omnium vita humanæ neceffariarum ubertate \& varietate inftructus; cæteriverò globi, uti famúlantes, iis potiffimùm natura dotibus inftruebantur, qux ipfis ad à Deo intentum finem confequendum necentaria erant; quos quidem terrenus globus:infinitâ quadam virium, proprietatum, entiumque non folum animầ expertium, fed \& vegetabilis fentientisque naturæ varietate \& copiâ longè fuperar. Quando itaque facer textus loquitur de congregatione aquarum in locum unum, \& dearidxdete. ctione; id tocum diftributivè intelligendum elle fcias; quafi diceretur: congregentur aque, que fub caelo funt, in locum unum, छी appareat arida, id eft, in locum unum fingulis globismundanis appropriatum, \& arida fingulis propria appareac. Quemadmodum enim Deus ex communi chaotica malla terra materiam fingulismundi corporibus formand is aptam deprompfit; îta \& de aquarum mafla chaoticafingulis humidi porrionem, fine qua nec fubfiftere, nec virtutes nativas exerceAa re 

non in terrenum folummodò, fed \& in cxteros mundi globos, five altra, unicuique juxta fitus \& pofitionis rationem, diftributum fuifle. Ex inde luculenter paret, quòd humana mens concipere non poflit, quomodo Terrenum corpus ( quod ad fuperna colorum corpora, non nifi punctum effe videatur. ) folum tantam aquarum congeriem intra fua vifcera concludere potueric, nifi \& fingulis reliquis mundi corporibus earundem, tancuam immenfi iftius aquarum Oceani, in innumeros rivos cieducta portio obrigiflet. Nam ut in pracedentibus dicturn fuit, uti manà illa chaotica quatuor elementis confufa mundo formando communis fuit, ita fingula quoque mundana corpora participarunt portiones elementares, quibus compofita in hunc ufque diem perfiftunt.

\section{S C H O LI U M I.}

Q Vofenfu dicatur, DEVM eduxiffe intellect um è venalucis, explicatur in Apologeticis circa Propofitionem 6.Cenforis.

- objectiv. V. Theodidactus. Multum fanè me perplexum tenent verba hac facritextus: Fiat firmamentum in medio aquarum, \& dividat aquas, qua fub firmamento, ab iis qua funt fupra firmamentum: qua verba nifi mihiprobè exponas, dictorum hucusque vix capax videor. Ego enim femper hocfirmamencum, antequam propriis id oculis intuerer, concipiebam veluti immenfum quoddam cryftallinum cœlum, folidifimum. \& durifimum; quod uti intermedium fpacium immensâ fux bliditatis amplitudine occupat, ita aquarum ejus loco ftabulancium congeriem in extrema mundi confinia, hinc verfus centrum, illinc verfus circumferentiam detrufit. Atque ha funt aquz, quas partim infra, parcim fupra firmamentum Deus

Solurio. mediante firmamento pofuit. Cof rriel. R ectè quidem dubitas; fed ubi ratiocinium meum probè intellexeris, videbistotum. contrarium in facra Scriptura contineri. Repetamus verba Gcra. Dixit Deus, fiat firmamentum in medio aquarum, $8{ }^{\circ} 6$. Firma- 
Firmamentum,ut paulò antè infinuafti, olim nil aliud eflè putabas, quàm octavum ftcllarum fixarum coelum duriffimum. \& impervium, in quo aftra variis ima ginibus transformata, veluti in pheræ cujusdam fornice colata fpectarentur. Corrigenda eft ifta imaginario, naturæ rerum mirum quantum. incongrua.Sciendum icaque, firmamentum minimè hoc fenlu accipi pollè, fed firmamentum propriè dici rakiangh, id eft, Firmaexpantum illud immenfum, ubiaqux priùs ftabulabantur, in- quid protra quod omnes mundanæ fabricæ globi, finguli propriis fuis priè fit centris ita firmati funt, ut mundum faciliùs fit interire, quàm, ur illià fede fibi divinirùs defignata vel hilum removeantur. In hoc itaque expanfo Deus Condicor, Aftrorum feu globorum rudimenta delinea vit,affignando unicuique ex chao terreno fubfiftentix fux materiem; alveos in is excavavit, in. quos chaoticx aqux pars reciperetur, pars ejusdem extra firmamentum in vaftifimas fedes relegaretur, parstandem in $x-$ therem fubciliffimum \& levifimum converteretur. Hinc Aftra, non fecus ac Terra,mole ftetêre fuâ, ac in vafto illo expanfo curfus fuos circa Terram, juxta leges à Natura prafcriptas, hucusque peragunt. Hoc verò expanfum innumeris corporibus foetum non ftellas tantummodò fixas, fed \& planetas comprehendere, adeo verum eft, ut vel ipfe facer textus id apertè aflerat, his ver bis: Fiant luminaria in fromamento coeli : \& pau- Firmanélò pòft; Fecitque Deus luminare majus, E' luminare minus, go tum non pofuit ea in firmamento cali, \& cæera quæ fequuntur. Nofti, accipitur Theodidacte, luminare majus, qui eft Sol, \&luminare minus, ftellarum quxeft Luna, in firmamento, quam omnes ferè Aftronomi fi- fixarum, xarum frollarum fphæram dicunt, nequaquam contineri; \& fedpro toto tamen exprefsè facra Scriptura dicit,Solem \& Lunam, duo fci-panfo illo, licet luminaria magna, in firmamento coli efle pofita; unde quem atbeapertè colligitur, firmamentum haudquaquam profphæra oAtava,fed pro omniillo fpacio immenfo \& expanfo xthereo, à Luna usque ad ultimum mundanorum corporumterminum exporrecto, in quo divina providentia globos mundanos firmare voluit, recté fumi. Ab hac iraque firmitate, quâ finguli

$$
\text { Aaa } 2 \text { glo- }
$$


globorum fupra propria fua centra ftabiliuntur, curfusque fuos peragunt, totum illud arhereum fpacium firmamentum dicirur; minimè propter fpacii; quod coelum octavum occupat, ,oliditatem. Quid putas majoriadmiratione dignum, globum. rotæinfixum una cum rota circumvoluere; an eundem in aëre fuis fuftentaculis.firmare? Theodidactus. Hocut humanas. vires. fuperare puto, ita illud ludum prorfus puerorum efiecenfeo. Cofmiel: Ex hoc itaque inferas, potiťs nos incomprehenfibilibus. Dei operibus, quàm iis qua humanâ induftriá fieri

Afrein: atbere, $u t$ Terra in. cère, libra. cafunt.

Solintion. poffeconcipinus, fidem habere debere. Qui ter sam inaëre libravit , an non is eâdem ratione in ætherelibrare potuit reliquos globos e: Itague fpacium: globos in æthere libratoscircumfluens, facer textus aprè coelum yocat, Hebraicè Schamaim, î̉ eft, ibi aquar, quòd tockim illud fpacium aquâ. cha oticâ , ante' feparazionem aquarum,abaguis replerenur.

VL Theod. Jamtandem experior, nihil te rertum, five divinarum, five naturalium latere; convictum me in omnibus fa«eor; folùm unicus mefcrupulus tenet circa verba illa facri textus: Divilat que Dews aquas que funt fub firmamento, ab aquis qua funt fupra firmannentum, \& co. Ex quibus ituculenter patet, per hafce aquas nihilaliud intelligi, quàm aquasterrenas, \& fubblunares.. Cofmiel. Jam dixitibi füprà, facram Scripturam. capacitati hominum fe accommodantem, terrentum globum folum, irrcujus alveisagux recepte. fins, utpote qui hominibus? tantùm cognitus eflet, denominaffe; reliquos verò globos. fubticuiffe, etiamfi finguil: fuam quoque portionem aquarum receperint, \& luculenter pater ex verbis fäcritextus.: Vocavitque Deus aridam terram; congregationesque aquaruma viacavit maria, id eft, id quodin finguils globis folidâ fubftantia cerreftris portione-fubfiftit, appellavit aridam; aquas verò,qua ipfis ex feparatione.jungebantur, intra alveos globorum conclufas, voeavit maria.. Atque hæcquidem prima erant globorum rudi-

Lueis proa ductio in globisicalegibus. menta; deerat jama lux, feucalidum radicale, quotanquam in. foeturamanimarentur: Quemadmodum igitur æterna Dei Sapientia fingulos globos ex chaotica mafla depromptâ materiâ formavit, 
formavir, ita ex primogenia luce fingulis fuam porcionem, ad eos in operationibus fuis \& faculcatibus naturalibus corroborandos, fine qua omnia torpida \& mortua manebant, diftribuit.

VII.. Theodidactuss. Cüm experientiân nobis confter, multaa ${ }^{a b j e s z i o: ~}$ ex mundanis corporibus luce propriâcarere, uti funt Terra,\&: I unares mundi globi ; quomodo ergo tu dicis, omnes mundi globos, feu Aftra, à principio rerum primigenizelucis portione ditata fuifle? hac enim minimè fibiconfentire videntur.. Cofmiel. Nèd dubites fili; ; hrec maximèfibi congruere videbis, ubi solutio. nonnulla ad faciliorem expofitionem facientia premifero.Verum eft quod objicis,nomulla mundana corporaluce propriâ. carere, nonnullislucem propriam: concreatam fuifle, urifoforibus mund li corpon bus: inde tamen non fequitur, fngula. Calidum raticale non fiam habere deputatam lucis porrionem: fiquidem per, in mandi Incis portionem:illud calidum radicale corpor ibus innatum, corporibus. fine quo, quemadmodum homines, ita \&omnia ac fingula. quidfit. mundicorpora nullam prorfus actionem exercere pofenc, inteligo; eft enim hic fons vitramaibus inexiftens, \&x proprietatum fingulis inditarum origo. Et ut à Terreno corporeincipiam; annè Tellurem bac lucedeftitutam putas? Theodid. Minimè ; nam etiamfi illam lucem non videam, Theodid.. Mi-Terra manime, nam etiamf illam lucem non videam, adeo tamen ne- $x$ zmè radi ceflariam eam effe judico, ut fine illa nec confintere, necufibus.cali calore frumanis tellus.fervirepoflit in generationumpropagineper-eft pradipetuanda. Sed nonintelligo qualeillud fit, \& quomodo ei in-dita fit? Coffintel. Annonvides, univerfam telluris molem hujus lucis,\& innati calidi, figna uberrima prabere?? Quid aliud therma, \& calidiflimarum aquarum ubique locorum fcaturientiumorigines? quid montium perpetuo igne ardentium xeftuaria? quid ignem fubterraneum, peruniverfos Telluris: canales diffufum, aliud pucas effe, quàm lucisprimigenix feu Elemens' caloris inmati \& radicalis portionen, quod nos elementum i- tum ignis gnis appellamus? Etmeritò: hocenim eft elementum fingulis ineff. globis infitum, virtute efficax, \& minima quxvis penetrans, activum principium, fine quo omnia reliqua elementa torpida 
manerent \& mortua. Quod quidem elementum in Sole, caterisque Solem affectantibus corporibus, non calidiflimum. tantùm, fed \& lucidiflimum, uti expertus es, exiftit,fummâ fá-

Solis effieitu. nè divini Opificis providentiâ. Cùm enim Sol eo fine conditus fit, uc lucis fux intenfione circumfitos fibi globos illuminaret,\& vitalicalore omnia compleret ; perneceflarium fuit , ut lucidiffima \& ardentiffima illa lucis calorisvè portio, in fingulis vicinis globis abdita, ex fimilitudine quadam naturæ excitata, foecundo hoc lucis radio (rerum concatenatione ita poftulante) imprægnata, fructus proferret effectusque à natura. rerum in fingulis globis intentos. Cùm verò aftra plurima remotiora fint, quàm ut hujuslucis beneficio pociriqueant ; Natura alios globos lucidifimos dif poltit, qui veluti quidam Soles vicarii circumfita fibi corpora, lucis uberioris expertia , illuminarent, \& calorem in iis latentem ad effectus illis proprios producendos excitarent, uti in itinere noftro, ni fallor, abundè expertus es.

VIII. Theodidactus. Omnia cepi,nequequisquam eorum amplius, de quibus cubitabam, me lcrupulis torquet : jam ut mihi exponas velim, quomodocoelum operetur; \& num Aftra

Aftra an ex elemen. tisconftent. Materia coleft is 8 fublunari non differunt efjer. iialiter. verâ \& reali elementorum mifturâ conftenc. Cofmiel. Coeleftia globorum corpora mixta effe, nullo pacto eft ambigendum. Neque enim cohrerenter dicetur, Deum ex una \& eadem chaotica maflà coeleftem eflèntialiter à fublunari differentem materiam produxifle. Siquidem Deus Optimus Maximus in hoc potentiæ fux magnitudinem oftendere voluit, quòd ex una \& eadem chaotica maffa ; tantam tamque innumerabilem rerum in hoc mundi opificio elucefcentium varietatem \& copiam. produxerit,eodem \& fimili artificio elementa fuperiora \& inferiora in unum compegerit, ut nullum mundicorpus fit, quod iis careat. Hinc aër,aqua, ignis,terra omnibus inefle comperimus,utiarcanior Chimiz ars apertè demonftrat. Si enim in. aëre perfpicuas lucis fcintillas, aquæ \& terræ portiunculas fubtiliores comperiamus ; fi in aqua \& terreftribus corporibus" eandem elementorum mifcellamlatere experientia nos do- 
ceat; eandem coleftibus corporibus mixturam negare velle, plusquàm inexperti in natura rerum hominis effe putem. An. non fingulos coeleftes globos fuis aëreis atmofphæris involutos vidift? an non perpetuas humorum, quos exfpirant, effluxiones obfervafti ? vides ex varia \& mixta luce, quàm igneâ efficaciâ polleant ? an non terreftres in iis eminentias, montiumque juga obfervafti? Quis igitur jam omnia mundicorpora quatuor elementorum commixtione concrevifle neget? Sed hæc paulò fufrùs deducam. Rectè dicitur : Nibıloritur novum, ni-Materia bilinterit. Quod de materix permanentia intelligas velim; quidfit $_{\text {pima }}$ qua tota ab initio creata, cor ruptioni minimè cenfetur obnoxia. Sunt igitur omnia, priùs quàm fiant, aliquo pacto in materia ; \& poftquam efle defierunt, in materia quoque perfeverant. Materia priùs eft omni fenfibili fubftantiâ, ante omnem fenfibilem fubftantiam creata à Deo,\& ad extrà producta. Nam divide omnem fubftantiam fenfibilem in partes geminas, in. duo extrema quibus ipfa conflatur \& conftat, ut in eflentiam, \& apparitionem, in principium \& finem, in inchoationem \& perfectionem, in potentiam \& actum, in materiam \& formam; duncaxat fecundùm pofteriorem ipfius partem rei mutatio- Materia nem, ortumque \& interitum fieri comperies; prioreautem, non patiparte permutationem fieri nullam, fed fixa effe \& ftata univer- ${ }^{\text {tionem. }}$ fa,fimul facta ab initio, \& fimul in ævum perfeverantia. Materia quoque principiumeftomnium, inchoatio, \& potentia. Jtaque per materix creationem omnia fimul inchoata funt, \& fubftiterunt ab initio, erantque in principio, non erant in fine; habuerunt priùs quoddam efle, carebant fuiapparitione; poffibilia erant,nondum tamen actu erant; erant in tenebris, non in luce; nó quoq; in fui difcrimine, aut in naturalibus fuis locis. Educta funt ex potentia in actum, è tenebris in lucem, ex principio in finem; quæ inchoata erant,perfecta funt; qux erant, apparuerunt; qux confufa \& indifcreta, in ordinem digefta. funt, \& fuis in locis collocata. Oritur igitur quotidie nil fimpliciter \& ex toto novum, cùm fuerint omnia ab initio in prima. \& anciquilfima fui confiftencia, id eft, in materia. Nilindies inter- 
vum, ficutiomnes Peripaterici facencur (nam ut rectè Stagyrita, inferna fupernis lacionibus fubduncur;) hinc certò concludi poteft, \& fuperiora, \& inferiora ejusdem materiæ efle: cùm enim omne producens producat fibi fimile, quis jam productum \& producens ejusdem naturæ, quoad materiam, elle negabir? Annè coleftium radiorum \& influxuum, quibus c $\propto$ lum ad inferiorum rerum productionem concurrit, eflentia m \& nacuram (cum nihil aliud finc, quàm fubriles quidam \& tenues fpiritus, naturaliumque virium, \& inferiorum feminum mifcella,quam globus exfpirat)quantum eft ex parte materia. diverfam aut à globi,aut inferiorum natura purabimus?haudquaquam. Quis unquam audivit,diverf naturæ femina, vires \& proprietates rerum eflentiâ differentium, aut coire, auc ad effectum in materia effentialiter diverfa producendunz. concurrere polle? Omnia itaque, quæcunque in mundana machina fenfibus fefe noftris fiftunt, quoad materiam ejusdem rationis \& entitacis effe, luculenter hinc concluditur:non enim aliàs mutuò fefe foverent, minimè fe mifcerent, auc unirent, fi diverfam genere nateriem, vel quintam quandam effentiam ad invicem obrinerent. Nullâ igitur ratıone ex parte materiæ, fed fecundùm raritatem, levitatem, duritiem , mollitiem, grofficiem,crafficiemque, fimilesque hifce qualitates, individuancesque atque fubltantiales formas, qux materix fpeciem non mutant, fed veluti ariis modis exornant, diftingui debuerunt. Verüm cùmtu,mi Theodidacte, hæc omnia propriis oculis, dum globos mundanos examinaremus, perifurtraveris; non iis.immorabor. Theodidactus. Ita eft, neque ego de iisab eo tempore, quo tuo me divino ratiocinio imbuifti,unquam dubicavi; nihil enim veriủs, quàm omnia in omnibus quodammodò eflè, \& omnia amicâ quâdam neceflitudine, fympathicoque confortio in fe invicem influere, fe fovere, fe confirmare, \& ad mundi confervationem,unionemque partium confpirare comperi; qux etfi corruptiones quoad partes admittane, ita tamen finguli globi quoad totam eorum fubftantiam firmati funt,ut impoffibile fit, eos aut à naturali a$\mathrm{B} \mathrm{bb}$

gente 
gente corrumpi,aut in fuis operationibus naturalibus deficere pofle. Verbo enim Domini firmatifunstcali, E" piritu or is ejus omn is virtus corum. Sicut itaque in terra innumeras quotidie generationes \& corruptiones, roto tamen femper incorrupto permanente, fpectamus; ita pari ratione in cæteris mundanis globis fieri experientia fenfata fat fuperque me docuit. Sed jam univerfalibus mundi principiis præmiffis „ad particularia defcendamus:

\section{S C H OL I UM II.}

2ux Auctor noffer toto hoc capite fusè tract at de Thundì productione, de caeloinitio rerum creato, de terrainani $\sigma^{3}$ vacus, E abyfJa tenebris opertâ, de chaotica masfa feuchao, de luce primigenia, de bumido o calido radicali per omnia aftra diftributo.

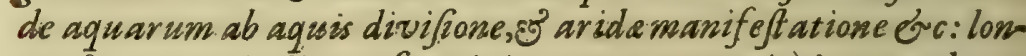
go $\delta^{3}$ accurato indigent forutinio, eaque nos merito in Mundum. Mirabilems refervamus, tum quia paucis explicari nom.poffunt, tum quia non pawams ab. Aubtore noftrodifcrepamus, put anzusque longe aliam creati Mundi rationems à Sacra Scriptura innui, quam bicpropofit af fuit. Ad alia ergo pergimus.

\section{CAP U T II.}

\section{De Mundimagnitudine.}

1. Cofmiel: Divina potentia adeo incomprehenfibiliartiffscio mundum difpofuie, ue fieri non polfit, homainem. mortali carne veftitum ad rerum in eo conditarum magnitudinem, mulcitudinem, varietatem,quantumvis magno \& fubtili ingenio, maximâ quoque rerum noticiâ inftruêtus fit,nllatenuspercingere Nam ut rectè Ecclefiafticus, Paucas operum divinorum novimus adeo quidem, ut divina majeftas hominem compataz: exadmirari tantùm, non verò comprehendere voluiffe videatio machi- tur. Prodierunt hoe foeculo nonnulli artifices, qui automara. na munda- feu machinas fuapte foonte fe moventes tantâ mentis induAtriâ 
frjâ concinnarunt,ut fiderum quidem fingulorum curfus ju- infrumom$x$ ta exemplar Naturæ inftitutos huculenter extrinfecus con- ${ }^{t} t$ is. remplentur multi, ftatuarnm matus mirencur, vocibus fonifque prodigiofis, quos reddunt, mirificè afficiantur; quæ verô interior machinæ conftitutio, quæ rocarum difpoficio, quæ motricis virturis ratio, omrrem eorum fugit intel lectum; folus arcifex omnium confcius, fingulorum de caufis \& rationibus" machinæ difcurfus tacirus audit, \& nonnullorum quidempueriles conjecturasridet,aliorum nimiùm à vero hallucinanrium ratiocinium reprobax, probat verò aliorum à vero quidem,tamerfi non tantum, abludentium conceptus; nemine interim, qui genuinas machinæ rariones attingat, exiftente. Idem in hujus mundanæ machinæ conftitutionefieri putes;cujus magnicudo, corporumque multitudo, \& varietas motuum tanta eft,ut luculenter appareac, divinum prorís, incomprehenfibile, atqueimpenetrabile opus efle, quod humani intellacicis perplexam opera ditantâ opinionum varietate confứm involuit. Cùm enim per-poffunt perfecta Dei finc opera, incongruum eft, mundum primo mobili cip i perfesphararum raptore, quod in rerum nacura non eft, velle con- $t e l l e$ e $u$ bucludere; aut divinæ potentiæ opera fub numerum \& menfu-mano. ram pondusque redigere. Quemadmodum enim Deus ter Dess ab/o-

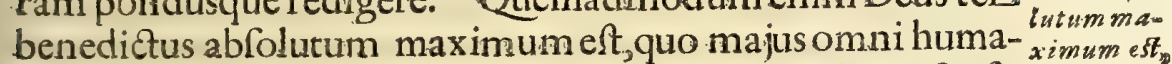
ni ingenii conatu fingi non poteft; ita mundum hunc fenfi-ficut munbilem, naximum quoddam contractum effe fcias, magnitudi- dus maxinis prorfus incomprehenfæ, nec numero definitæ. Theodid. Er- tratim. go mundum hunc inf nitum tu dicis, Cofmiel ? Cofmiel. Mini- est. mè : hoc enim pacto redderetur æqualis abfoluto maximo; quod imponfibile ef. Theodidact us. Explica itaque mihi, quid fit illud maximum abfolutum, \&quid maximum contractum. Cofmiel. Vereor nè intellectu in tanta myfterii fublimitate deficias: quareomnes ingenii tui nervos intende, ut quantum. mentis tuæ infirmitas permittit, comprehendas.

II. Maximum abfolutè fumptum nihil aliud eft,quàm id Maximum quod omnia actu abfolutè eft, qux effe poflunt, Deus Optimus abfolutu*

$$
\text { B b b } 2
$$


Maximus in æeternum laudacus, in quo omne id quod concipizur non effe, non magis non eft, quàm eft; fed ita eft hoc,ut fic omnia; \& ita omnia, ut fit nullum; \& ita maximè hoc, ut fit minimè ipfum: non enim aliud eft dicere, Deus qui eft maximum abfolutum, ita lux eft, ut tamen minimè lux fit; ;alias e. nim non effet abfolutum maximum, omnia poffibilia actu complicans; hoc autem humanum intellectum tranfeendiv;, qui nequit contradictoria in fuo principio combinare viâ rationis; cùm enim fenfibilium fpectronum gurgite immerfus fit, longè ab.hacinfinitæ virtutis potentia cadens,ipfa contradictoria per infinitum diftantia conneetere fimul nequic

Contras:

Aum maximum quid? Contractum verò maximum, quem nundum dicimus, cùm. ab abfoluto maximo omne id, quod eft, habear, certè id quod eft maximum abfolutè, quantum poteft imitatur, ita ut qux abfoluto maximo maximè conveniunt, illa de contracto maximo contractè confirmari poffe affirmemus; ita ut Univerfum maximè unum fit. Eft tamen illa ejus unitas inhac contractione fua ab unitate abfoluta \& effentiali in infinitum diftans. Et contracta quidem eft infinitas abfoluta per finitudinem, fimplicitas per compofitionem,per fucceffionem aternitas,neceffitas per poffibilitatem ; adeo quidem, ut per hwjusmodi contractionem mundus major efle non poffit,nec minor, fed quantum materialis ejus conditio,\& quantum proportio corporum permifit, maximus fit, \& quafi contractè immenfus, \& ut ita dicam, infinieus; tametfi ab infinico abfoluto in infinitum diftet, imò nihil fit, nec fieri poffir, ut ad $x$. qualitatem abfolutam pertingat, materia poffibilitate repugnance.

- bjeltiocar-

habeot. Theodidact ws. Mira \& inaudita profers, Cofmiel, fed habeo tamen quar obiiciam tibi. Vel enim Dens mundum infinitum producere potuit, vel non : fi non, fanè divina poten-

Solutise. ria funditùs exhaufta videtur. Cof mielel. Falsâ imaginatione illuderis, Theodidacte, dum res divinas humanâ æft timatione definis : minimè enim fequitur ex hoc,quòd Deus mundum infinitum facere nos potuic,potentiam ejus exhauftam fuiffe; 
cum operis faciendi intinitudo non fumatur ex parte Dei Condicoris, cujus potentia non eft finis \& numerus, fed eft obfaculum quoddam, quam implicantiara Theologi vocant,ex parte objecti, quod nimirum, cùm ex fe \& fua natura limiratum fit,fieri fanè non poteft ut limicacionis fuaterminos e $\mathrm{x}$ cedat, acque per infinitudinem coaquetur illi, qui per eflenriam fuam eft æqualicas abfoluca. Unde quamvis Deus infinitus fit, \& mundum fecundùm hoc infinitum creare potuillet : Mundus sus quia tamen poftibilitas neceflariǒ contrąta fuit, \& non peni- infinitus

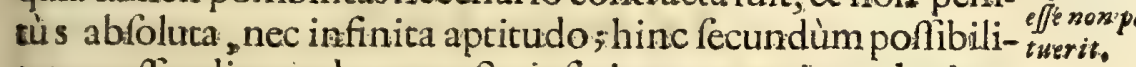
tatem eflendi mundus nec acturinfinitus, nec major vel minor quàm eft, efle potuit fine totius mutatione. Contractioautem poffibilitatis ex actu eftiactus autem ab ipfo maximoactu. Quare cùm contractio poflibilitatisfit ex Deo; \& contractioaatus ex contingenti ; hinc mundus necellarió contractus ex contingenti finitus eft. Unde ex notitia poffibilitatis colliges, maximum contractum nafci ex poflibilitace neceffariò contracta. Quapropter cùm poflibilitas abfoluta fit Deus, fi mundum confideremus, at in ipfa pofibilitate abfoluta exiftit, tunc eft inDeo, \& eft ipfa aternitas; fi verò ut in pofibilitate contracta eft,tunc poffỉbilicas tantùm naturâ pracedere intelligitur: \& fic confiderata poffibilitas contracta, nec eft aternitas, nec Deo coxterna,fed cadens ab ea,ut contractú ababfoluto; quze diftant in infinitü. Ent enim infinitas altitudinis adeoincom- ${ }_{\text {intellect }}^{\text {Infinit }}$ prehenfibilis, ut nullus intellectus creatus, quantumvis abftra- inteato perEtus, ejus capax effé poflit;utpote' quamfolus Deus, qux eft ip fa feate ceminfisitas abfoluta, plenè\& perfectè comprehendere queat.Quä ${ }_{\text {non. potes. }}^{\text {preh }}$ fi creatus intellectus, five is fit angelicus, five humanus, plenè compreherideret; cam haud dubiè etiam fub eadem ratione formali,quà Deus,comprehenderer; atque adeo ipfäm Dei effentiam, quæ cum infinitate convertitur, comprehenderer; quod impolfibile eft,cùm ad Deum comparatus intellectus? creacus nihilfit. Vides igitur, quod quemadmodum infinitas nullo intellectu capi poteft, ita quoque impoffibile eft, mundum corporeum à Deofub infiniti racione condi potuifle.

$$
\mathrm{Bbb}_{3} \text { Mundus }
$$


$3 ? 2$

Itinerarium I. Dialogus II.

Mindus tamen uti maximum contractum quoddam eft,ita. infinitudinisumbram \& fimilitudinem induit, adeo quidem, ut mundus, stante hâc conditione rerum, nec major nec minor à Deo fieri potuerit,quàm eft; quod quidem maximum contractum tantum eft, ut id omnes humani ingenii vires longè fuperet. Verùm cùm de his alibi pluribus tecum egerim, iis non immorabor, fed ad parriculares globorum naruras explicandas progredior.

\section{S C HO LI U M.}

E Tmihi, \& multis viris doctis, difficilia videntur, qua Aubtor boc capite de Mundi magnitudine docet. Neque enim fat is intelliginns, quomodo Mundws hic Jenfibilis maximum quoddam contractum fir, magnitudinis prorfus incomprehenfe, nec numero definitr; nectamen in finitus fit quoad molexn. Non capimus, UniverJum,è quod maximum quod dam contractum, est, nec majus effe poffe, nec minus, fed tantum exiftere, quantum materialis ejusconditio, \& proportio corporum permifit, adeout maximum fit, \& quafi contractè immenfum, \& ( ut it a dicatur) infinitum; \& tamen ab infinito abfolutè in infinicumdifter. Perfcripfi hanc meam perplexitatem Romam ad Auctorem Itinerarii, fimulque, in quo ejus fententia ì Cufani fententia difcreparet, inquifivi. Ad qua in huncmodum refpondit.

Irineraria eundem in Germania, quem in Italia \& Gallia, plaufum inveniffe, gaudeo. Placer aurem, Reverentiam Veftram manus admovere ad ea Commentariis exornanda. Pergảr itaque uci cæpit; utrique communem inde gloriam emanaturam, nihil dubito,ad DEI,Societatifque noftre honorem. Quòd verò $R^{a m} V$.am turber de Mundi magnitudine à me pofita fententia, neque mentem meam capere videatur; paucis" eam hifce explicandam duxi. Dico, Mundum effe contractum maximum, minimè infinitum, tantâ tamen magnitudine à Deo conditum, quanta effe $\&$ debuit, \& potuit , pofito D E $1 \mathrm{M}$ Mundum fub tali mundanorum corporum difipofitione, 
ficione, quam hodie incuemur, efle voluifle. Cúm itaque DE perfecta fint opera, dico, tantum factum efle, quantum materialis conditio ei eflè permifit : non quòd abfolutâ fuâ potentiâ majorem \& majorem facerenon potuerir ; fed quòd ftante tali difpofitione rerum, nec major, nec minor, fine totius confufione effe potuerit. Ita dico, $\mathrm{D} \mathrm{E} \mathrm{U} \mathrm{M} \mathrm{humanam} \mathrm{naturám,}$ utpore contractumquoque maximum, in canto perfectionis gradu condidifle, ut ea perfectior in fua effentia,nec imperfectior, effe potuerit. Quod \& de omnibus alis fpeciebus rerum intelligendum eft. Et fic intelligendam velim meam de magnirudine Mundi fententiam. Condidir enim DEUS Mundum fubtali corporum diftantia \& proportione, fub quali me liori modo quo eft Mundus, per mucuas corporum ftellarium in fe agentium vires influxusque confervari poflet. Quod: non fieret, fi aut major, aut minor factus fuifer : tunc enim Sol, caterique planetæx, tum àfe, cum à terra diftantiores, aut viciniores eidem,omnia in confuffonem deduxifent, uri in Arte Lucis \& Unbræ fufe deduxi lib. 8. Sed hæc paucis.indigitafle fufficiat. Si conera hæc alia occur rerine dubia, mihi fignifica bit, \& fufiǔs mentem meam illi expandam. Cufanus incongrua baber mex fententix, dum Mundum infinitum afferic quod in omni bona Philofophia implicat. Ego'dico; Mundum effe contractum maximum, nonquidem, uci fuprà dixi, infinitum, fed tantum tamen, ut ejus magnitudinem \& amplitudinem, capacitatemqne nullum humanum ingenium comprehendere poffit. Quodut ita fierer, divinam decebat potentiam : indignum enim erat, creaturam divinæ potentia opera fuo metiri ingenio; qux non capere, fed admirari tantummodò conveniebat. Sed hæc fufficiant. Et cumaliud non. occurrat, me R.x ${ }^{x}$ fanctiffimis Sacrificiis \& orationibus commendo. Romæ 29 Martii 1659. Tuus quem nolti Athanafius.

Hec Auctor; fat is quidem clare, fed qua non mag is probent Musdimagnitudinem maximam, छ? humano ingenio incompre benfibilem, quim maximan \& incomprebenfbilem hominis e- 

Legectiam qua habet Auctor infrà cap. S. Num.IX.

Dispofitiog

ordo corpo. rum Mun-

danorum

mira.

\section{A P UIT III.}

\section{Deordine globorum, ET mir a dipofitione mundi $\epsilon^{2}$ de centrisrerum.}

Lofmicl. Creator omnium Deus Opt. Max tantâ mundum varietate condidit, tanto ordine difpofuic, utrametfi omnia ex chaotica materia produxerit, nullum tamen. mundi corpus alteri præcisè coæquetur, aut prorlus fimile reperiacur; unitate in dyadem, hac intriadem \& tetradem fe diffundente; ex qua omnium rerum diverfitas, \& indiverfitace unitas nafcitur. Theodidact us. Non capio qux dicis;neque fieri poteft ut intelligam qqux proponis, nifi mihialkiùs propofiti myfterii abfconditam profunditarem exponas. Cofmiel. Me ad ea cogis, qux non nifi ab omni materialis naturæ conditicne abftractum insellectum requirunt : quia tamen ita jubes, haud illubenrer votis tuis obfecundabo. Intende itaque quantum potes ingenii tui nervos, ut eorum, quæ dicam, compos fias.

II. Sicuri igitur unitas maxima omnium eft in feabfolutè, ita unitas Univerfi eft in pluralitate concracta, uti fuprà audifti. Plura autem in quibus Univerfum actu contractum eft, ut præcisâ\& abfolutâ æqualitate conveniant, fieri non potent: hoc enim pacto plura efle definerent. Omnia igitur ab invicem aut genere, aut fpecie, aut numero differrenecefle eft,ut unumquodque in numero, pondere, \& menfura fubfiftat; \& nèunum cum altero coincidac, ab invicem ea gradibus diftingui

Contra- oportuic. Confiftunt igitur inter maximum \& ninimum o-

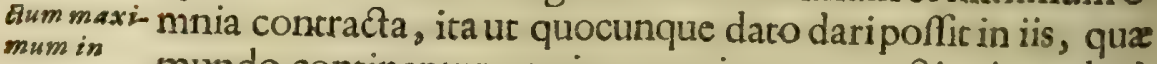

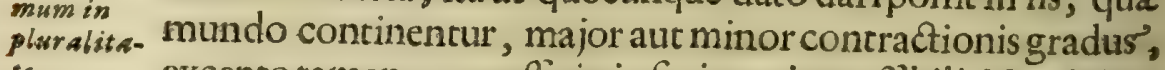
te. excepto tamen progreflu in infinitum imponibili, Non igitur alcenlus 
afcenfus defcenfulvè in contraetis ad maximum vel minimum abfolutè effe poteft. Quemadmodum enim divina natură, qux eft abfolutè maxima, nunquam ita dimïnui poteft, ut ad finitam \& contractam pertingat naturam; ita quoque natura.concracta nunquamita minui, ita ingrandefcere poteft,uc ad minimum, vel maximum, qux in maximo omnium abfoluto coincidunt, tranfire pofit. Omne igitur contractum cùm femper plùs minusvè conractum eflè poiffit, terminum tamen neque univerfi, neque generis, nequefpeoieiattingere poreft: quemadmodum in divifione continui nunquam ad individuumperveniri poteft. Nam Univerfi prima generalis contractio per generum mulciplicitarem exiftir, quamveluti per gradus quosdam diftingui oportuit; nonautemgenera, nifi in fpeciebus, neque fpecies nifi in individuis folum actu exiftentibus s contracta fubfintunt. Sicuti igitur fecundùm naturam contractorum, individuŭ nifi infra zerminum fpeciei affignari non potent;ic etiam ind ividuü qualecuncis ut univerfi \& gene- nus, indiciris te: minum attingat, fierinon poreft. Inter plura etenim, dusumque, alterius ejusdemfpeciei individua graduum perfectionis diverficatem perfettiocadere necefleeft. Quarenullum fecundùm daram fpeciema-nem attindeo perfectum aut imperfectum dabitur, quo perfectius aus gerepotess. imperfectius darinon porfit. Non eft igitur nifi unus tum generum \& fpecierum, tum Univerfi terminus; quod eftcentrum, circumferentia, \& connexio omnium Deus in facula benedictus. Non itaque infinitam Dei potentiam evacuat Univerfum,neque fieri poteft ur maximi abfoluti terminum attingat Univerfum, neque generaterminum Univerfi, nequeterminum generum fpecies, neque individua terminum fpecierum; quare? ut omnia fint id, quod funt, meliori modo intra Deus foltus maximum \& minimum terminum, qui eft Deus, principium, perfectio medium,\& finis Univerfi,fingulorum que qux in eo continentur. Quapropter inter genera, qua Univerfum contrahunt, talis eft inferioris fuperiorisque naturæ connexio, ut in medio coincidant, ac inter fpecies diverfastalis combinationis ordo exifti, ur luprema generis fpecies, cum infima mediatione fu-

Cec

perio- 
Nibilad perfectionem afcendere potef, nifip pritis extragradum furm exceflerit.

perioris coincidat, non alia de caufa, nifi ut fit unum continuum perfectufimumque Univerfum, Vides igitur, fpecies? diverfas fuperioris aut inferiorisgeneris non connecti in individuo quodam, quod magis aut minus non recipiat; neque defcendit, ut fit minima alicujus generis,quoniam antequam ad minimum deveniat, in aliam, priusquàm minima fit, commutatur. In genere animalium, fpecies humana altiorem gradum inter fenfibilia dum attingere nititur, in intellectual is natura commixtionem rapitur; adeo ut nihil fit in Univerfo, quod non quadam fingularitate, qux in nullo alio reperitur., gaudeat. Neque tamen æqualitatem cum altero præcisè attingit: principia enim individuantia in nullo individuo in tali poflunt harmonica proportione concurrere, ficuti in alio ; \& hoc ideo, ut unumquodque per fe fit unum, \& eo modo, quo poteft,perfectum exiftat. Hinc nullus globus mundanus, tametfi ex generali chaoticæ materiæ mifcella fit factus, æqualisalteri effe poteft; quin potius adeo omnes inter fe differunt, ut five fitum, five formas unicuique proprias, fivecompofition is rationem, five denique vires \& proprietates fpectes, nullus alteri præcisè fimilis fic : præcisè enim \& abfolutè æqualitas foli Deo Conditori convenit; qui omnia in omnibus eft. Atque in hac varietate \& pluralitate rerum, mundiconfiftit perfeettio. Verùm his premiffis, jam tempus poftulat, ut totius ordinem varietatemque Univerfi tibi pandam, ut qux fub univerfalium principiorum ratiocinio tibi expofita funt, in particularitatibus luculentiùs intuearis.

III. Theodidactus. Sed hoc unicum à te efflagito, ut ingenii mei paupertati \& imbecillitati condefcendas,nec me nimiâ abftrufioris fermocinationis profunditate obruas. Erut majori fructu tuarum imbuar initructionum, nonnulla primùm dubia, qux jam dudum animum meum torferunt, tibi proponam; ad quxut mihi refpondeas, etiam atque etiam rogo. Es funt, utrum tellus noftra fit univerfe naturæ centrum? An fola inter omnia mundana corpora, fuâ librata mole immobilis permaneat? An iterum aliæ fimiles terræ globi in rerum natu- 
rahujusmodi immobilitate præditæ reperiantur? Et cur Divina providentia terram immobilem effe voluerit.

IV. Cofmiel. Quoad primum attinet, fcias, variè centri ra- Centrusu tionem hoc loco confideraripoffe. Vel enim centrum fixum duplex.。 in corpore mobili, vel fixum in corpore immobili fpectas. Si prius,certum eft, omnia mundi corpora fuis centris inftructa efle, quenaadmodum in irinere noftro expercus es. Eftautem cencrum alicujus corporis mundani illud, in quod omnes \& fingulx cujuscurque globi partes graviores naturali appetitu inclinant, ad id folum feruntur, ad nullum aliud; unde circa illud, ad totilis confervationem, arctê fe premint, \& naturali utilitasio quâdam fympathiâ eidem fe uniunt: leviores verò portiones" ab humido exfípirat $x$, à centro ad circumferentiam feruntur; quod quidem effluvium globi corpus ambiens, nihil aliud quàm atmofphæra quædam eft, ficut1 in terreno globoaëris quædam regio ad iftiusmodi mundi corpus perpetuâ quâdam elementorum pericyclofi fovendum \& fuftentandumà Natura ordinata. Quod nifi fieret, continui partibus mox difolutis difperfisque, enfluvis quoque cefíantibus, mundi corpus ut fubfifteret, fieri non poffet. Theodidact us. Et quanam caufa cerporis cu eft tanti nifus partium circa globorum centra? Co/miel. Si pro-petant par fundâ mentis artentione, qux fuprà dixi, percepiflès, mentem. tes esusdem tuam nullum ampliùsteneree dubium. Dico itaque,caufam ef- ${ }^{g}$ fe, quòd cùm nullum mundi corpus five globus cum alcero quocunque præcisâ æqualitate conveniat, lè finguli à fingulis, five ob fitum quem in mundo fortiti funt, five ob circumfitorum globorum aliam \& aliam conftitutionem, five peculiaridivinx providentiæ difpofitione, à fe invicem differant, neceflàriò fequitur, fingulas globorum partes tantùm id appetere totum, quod ipfis quàm maximè naturale eft,neque ullum alium appetitum ad alios differentis naturæ globos habere; ut videlicet in proprio globo meliori modo, quo effe poffunt, exiftant, tum ad propriam perfectionem confervationemque, Centrorum tum ob unionem Univerfi. Quod quidem fieri non poterat, fi inceffitas finguli fuis inftruati centris non fuiffent. Et .ertè nifi in me- in corpor

$\mathrm{Ccc}_{2}$ dium $\mathrm{kerj} / \mathrm{s}$ 
dum globi centrum nullâaliâ ratione niti, neque tenuioris leviorisque fubftantix corpufcula ad atmofphæram confttuendam, quze corpori prorfus neceffaria fuic , exfpirari fine centro potuiflent : hoc enim centrorum fitu \& poficione, quam à primordiis retum divini muneris difpoficione globi adepti funt , diftantias ab invicem femper habent impermutabiles; fuaspariter finguli femiras æchereas metasq́ue, juxta quas ad Intelligencia motricis nutum unàcum atmofphæris voluunsur, à primo motoreomnium, quas transgredi non pofliunt, as. fignatas habent.

V. His itaque pramiffis, modò ad' dubia mihi paulò antè propofitita refpondeo; qua funt, utrum terra fic univerfæ naturæcentrum?: Anfola inter cætera mundanorum globorum Terwanni- corpora immobilitate gaudear:Quod ad primum attinet, dico,

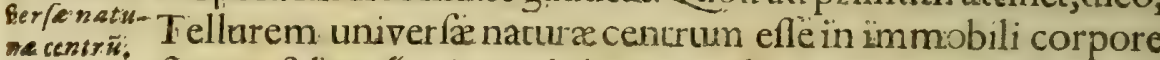
fixum, folamáue immobilitategaudere, cæteris omnibus circa eam circumactis corporibus. Cüm enim Deus $\mathrm{C}_{\text {f }}$ rinus.Maximus Terram ab reterno in humanigeneris fedem deftinaverit, in qua infcrutabifis divinæ fapientiæ altitudo cccultis providentia fux decretis hominem ad imaginem \& fimilitudinem fuam condicurus erat; in qua ad lapla natura reftaura-

Omniaz propier. Tellurem: condita: funt.

Stellarum Gires omne aluce/eunt in terre.

Aris globi xebuov. tionem Filium \& V erbum fuum naruram humanam afiumere; terreftris mundi concivem fier,omnia invifibilis mundi arcana patefacere, ad aternx vitæ beaticudinem confequendam bominibus viam demonftrare, eicomplacuerat; conveniens ${ }^{2}$ quoque fuit, tale iis habitaculam propparare,quod inftar regii throni fuâ niteretur firmitudine \& irnmobilitate, reliquis.omnibus mundanis globis eidem, utpare cujus grariấ conditierant, perenni motu famulancibus. Et quoniam homo, mundi filius, ad vitam fuam trahendam magnẩ rerum copiâ \& varierace opus habebat ; hinc quidquid in omnibus mund'icorporibus exiftir, id in Telluris globum veluti in mundi majoris quandam epitomen conditor congeffit, nèullum aftrum aut ftella foret, cujus virtus non in aliqua T elluris fobole exhibererur. Quod verum effe, innumerabilis rerum, quas in hujus infimi 
intimi mundi theatro quotidie contemplaris, varietas far fuperque demonftrac. Quin \& ipfum hominem telluris incolum eâ dotium prærogatıvâ cohoneftare dignacus êt, ut non incongruè in huncusque diem microcolmi, five mundi minoris, nomine triumpharet. Quoniam verò Iellus.memoracarum virtucum eftluxus, quos lidera in eam unanimi virium. confpiratione derivant, velut finem fuum aptioribus mediis confequi non poterat, quàm fi immobilis fuo ftabiliretur cen- peterat as tro, atque hoc pactoranquam paffivum rerum principium coe- ptaeffe geleftibus \& neceflariis.imprægnaretur influxibus; ideo necefla- nerationi. rium fuit eam ftabilem in Utiniverfö fitumobtinere :id enim, finon im. fieri non potuiflet, fi vel circa proprium axem, vel in circulo mobitis of annuo devoluta, perpetuis inconftantix.legibus fuiffet fuppo-fet. fita. Eftenim paflivum principiumadeo motus, impatiens, ut: finequietefeminaliumethuriorum que aftra ceuprincipium axtivum in id influun; cxpax efle non poflit. Qux quidem immobilitas firre centro efle ron potuit.. Imò univerfie natura: centrum, in quod omnia infuerent, effedebuit:

$V$ I. Theodidactus. Sed quomodo intelligam centrumuniverfie creaturx, cumtamen finguli globi fuis quoque centris" inftructi finc? Cur non potiùs Solem centrum Univerfi dici pofle credam Cofmiel. Reliqua mundana corpora fuis ftabiliuntur centris, nè partes globorum diffluant, \& fic unitæ commodiüs vires fuas diffundere in inferiora queant z quorum fyftemata per immenfa athereaauraexpanfa mobilia fint, eo folüm fine, ur terram feraci radiorum foeturấ circumeundo focundam redderent, inftituta. Terram verò, cujuscausâ omnia reliqua condita funt, neceflariò centro fúo ftabilitam, \& immobilem, ut ambientium fiderum radios commodiùs fixcipere pofet, eflè oportuit. Atque exhoc capite centrum Terra fubUniverfi rectè appellatur,củm illa unica ex omnibus mundi ${ }_{n \text { is corpori. }}$ globis immobilicatefuâ gaudeat; aftra verò catera eam peren- bus, bsluti ni motu, ad ei veluti Regi cuidam globorum fua officia impen- princidenda, fummo ordine circumeant.

VII. Theodid. Sed quomodo id fieri poffit, noncapio, cüm

$$
\mathrm{CcC}_{3} \text { mun- }
$$




\section{CAPUT IV.}

\section{De dif antiis corporummundanorum, tum in:- ter fe, tumad terram comparatis; in quo mira divine providentia ratio elucet.}

I. T Heodidactus. Mirâ cor meum dulcedine zam concin-Corporum no ratiocinio rapis. Agedum, mi Cofmiel, nunc expli- ${ }_{r u m}^{\text {mundano- }}$ dicare aggredere, quænam illa fir diftantia quâ Deus,fupremus il- fantia le har mofta,omnium mundicorporum, tum inter fe fingulo- mutua. rum, tum omnium ad terram comparatorum diftantias difpofuit. Cùm enim Deus Oprimus Maximus omnia in numerc, $M u n d i$ pondere, \& menfura fecerit; certè uti eum mundum in admi- Jymmetri randa quadam fymmetria, \& proportionatifima unius corporis mundani ad aliud intercapedine, tum in quantitatis five magnitudinis unicuique ad finem fuum confequendum appropriatæ menfura exactiffima arbitror conftituifle; itacertus fum, ineffabilem divinæ potentix fapientiam omnia ad $x-$ - ternx legisamuffim difpofuife. Cofmiel. Rectèfentis, Theodidacte, \& aliud fine injuria Conditori fapientiffimo irrogata. fentire \& affèverare non poflès.Dixitibi fuprà,mundum à Deo Conditore fub tanta vaftitate conftitutum, ur nulla humani ingenii vis \& acies tanta fit, quæ ejus magnitudinis terminos \& limites animo comprehendere quear; ut hinc vel potiffimùm liquet, quòd divina potentia vel minimum terræ vermiculum iis naturæ dotibus ornaverit, ut nemoPhilofophorum tam acuto fit ingenio,qui eas penetrare poffic. Tunè igitur pusas, Univerfi hujus terminos, \& conftitutionis rationem concipi poffe? Non eft hrc hujus caduci temporis conditio, fed ei, quo eum facie ad faciem in verbo vitæ contemplaberis, ftatui refervatum.Et tametfi mundus talis \& tantus fit, eoillum nihilominùs ordine \& proportione, quoad fingulos mundanos globos ordinavit, ur nullum in eo adeo exile corpus reperiatur, quod non ad aliud,\& omnia ad fingula, perfectâ unione \& harmoniả abfolutiflimâ confonent.

II. Qux 


\section{$392 \quad$ Itinerarium I. Dialogus II.}

Mundiglo. II. Quæx ut omnia luculentiùs pateant,à Terra,Luna,\& Sole borumque incipiam; quæ mundi corpora utifenfibustuis maximè patent, atrapuicem ita dietze proportionis leges meliùs faciliusque apprehendes".

Quoniam verò amnia mundi corpora non contıguâ corporum mole, fed viribus \& proprietaribus fpecificis unum alrerum contingit ; fumma quoque \& abfoluta urius ad alterum, proportionecellaria fuit, nè pioportione deficiente effectibus' fuisà narura intentisfruftrarentur. Quod ut intelligatur, Notandum, igneis corporibus ( cujusmodi Solem elle dicinus, \& quidem totus naturx inferioris ignem ) itacomparatum elle, ut in corporibus fub alia \& alia ciftantia remotss, alia \& alia temperamenta efficiant. Quod non tantùm Natura, fed \& empyrica ars nanifeftè nos docet. Früsquidem nos luculenrerArschymi-radii Solis in terram aliter \& aliter reflexidocent; qui fub Zona

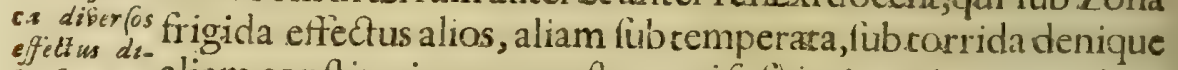
Berfis ignis aliam confticutionem preftant, utifulè in Arte Anacampticn incenflioris demonftrafti. Ex fi admiranda hac effectuum diveriorum

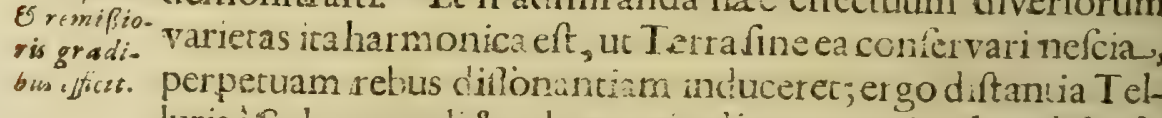
bus afficet. luris à Sole cum tali \& tali magnituỏne coiporis,talem difpofitionem Terrx, non aliam; cale temperamentum,nonaliud; talem varietatem harmonicam, non aliam, producit Iterum diftancia haccum tali magnitud me Telluris, lucis, \& umbra, in omnibus locis portionem æqualifimam, utiin citata arte Anacamprica multis modis oftendifti,efficir.Quòd fi diftantia ma.

Ex:emplesm jor aut minor foret, jam tota harmonia in diflonantiam quana mufico dam confufiffimam redigeretur;quemadmodum chorda fub infrumen tali \& tali longitudine confonantes, mox ubi à debita fibi longitudine defciverint, loco melodix nefcio quid inconcinnum $\&$ dißonum pariunt. Sic $\Gamma$ erra,fi fub eadem magnitudine Soli vicinior foret, aut ab eodem remorior, quàm revera eft ; $\mathrm{ea}$ vicinior à radiis Solis efficacioribus, aut remotior à debilioribus radiis percufla, praterquàm quòd maximam lucis \& umbræ inæqualicatem induceret, temperamentum quoque humanæ vitæ non noxium tantùm,led \& prorfus incongruú produ-

ceret. 
nos incongruosque in Terra effectusproduceret. Contrà, fi ea Soli vicinior; Sol in Lunam efficaciùs agens, confumptâ ejus. humiditare, omnia in Terreno mundo calore fuo excefivo perderet. Unde Natura igneo corporiSolari, aqueum Lunare objecit, eâ proportione diftantix, ut unum alcerius in Tellurem impetum cohiberet, \& veluti difonum confono ftringeret, ligaretáue. Quia verò Sol non femper Tellurem eodem calore ferit, fed pro ratione afcenfus defcenfusque tum annui, cum diurni diverfo ; ita Lunam quoque eodem femper humiditacis \& frigiditatis gradu Terram ferire noluit, fed prodiverfa phafium Lunarium alteracione, item afcenfus defcenfusćue

Diberfitax: motuum. Salis $\mathcal{E} L \mathrm{~L}$ na, phafrumque, adgutd conferat.

\section{Venms 8} Mercurius quidpreAent. in apogæis perigaxisáue ratione, diverfo. Ita vides, in calidifima eftate Lunam plenam humillimam parumpoffe ; contrá gelidifímâ hyeme, Sole humili loco conftituto, Lunam plenam veluti vicariam Solis aflurgere. Ita abdito Naturaconfilio factum eft, ut mundus inferior exactâ hâc varierate, veluti. confono- diflónâ quâdam mixturâa ${ }_{2}$ in perfectione fua confervaretur..

I V. Quia tamen Sol ferventifimus unà cum humidiffima Luna perfectam humorum in terreno globo harmoniam fine interventualiorum corporum conftituere non poterunt; hinc divina providentia inter Lunam \& Solem duoalia con. fticuit munóana corpora, Venerem filicer, \& Mercurium, diverfis virtutibus prapollentia conpora, un quibus Solarium radiorum vehementia carminata quafiobtunderetur, atque in deauct is viribus humiditati Lunari neceffariis, Tellurem majori varietace bearet. Nam Venerei corporisfoecundativâ quâdam vipollentis influxus Lunæ communicatus, humiditatem ejus fimilirer foecundat: Mercurius verò confonià difiono difcretor, quod noxium eft , \& fuperfluum, tàm in Sole, quàm in Venere, infe derivatum temperat, atque fic tandem aliud fundat harmoniz genus inferiori mundo neceflarium; quæomnia fucceflu temporum varias, pro varïs afpectibus, \& excentricis fiderum dictorum fedibus, diver fas femper effectuum combinationes moliuncur. Quia porrò nullum organum ràm perfectè 
perfectè concinnatum eft, quod non fucceffu temporis, chor- Marbi gigo dis vel laxatis, vel plus æquo ftr ictis, diffonanciam incurrat; ita modo cus fieri non poteft, ut in inferiori mundo cùm elongatione vel ap- rentur. $_{0}$ proximatione dictorum corporumà Terra, cum variâ fubirtè̀ configurationis confticutione, cum tempore in sorkpes sizo non abeatur; quæ tamen, non fecus ac corpus variis fucceflu temporis humoribus oppletum, febriq́ue correptum., per humidi fubtractionem tandem evacuatum, fanitati reftituicuc.

V. Atque hunc in finem Deus per Naturam artem fuam, duo in Coelop rorfus difiona corpora pofuic, Martem \& Satur- Mars Es num, exquorum pernitiofo effluvio feu evaporatione omnia maligna mundi fublunaris.mala originem habent. Qux nè torius infe- pdera ad rioris mundi øeconomiam in apertam \& infignem rexoфwriav, quid confor deducerent, intermedium ipfis pofuir Jovem ftellam benignam, cujus falutifero influxu utriusque exitialis \& prorfus perniciofa vis, quam evaporant, cohibita refræenaretur. Et nè Martis virulenciâ Tellus impetita manifeftac pateret ruinæ. Natura eum in omnium maximo excentrico collocarivoluic, ut infrà à Sole \& Venere, fuprà à Jowe coërcitus, à favitiealiquantifper defifteret. Nequetamen Natura in tam pernicioforum corporum condita ideo noverca infimulari debet; quin poriùs fummo \& abdito quodam confilio ea fic difpofuifle cenferi debet, utpore fine quibus mundus confervari non poffic.Idem enim in mundo majời magnâ vitioforum . humorum congerie aggravato preft are videntur,quod in microcofmo perniciofis febribus, humorumque peflimorum abundantiâ cantharides, medicamentaq́ue cauftica quâdam virate pollentia: his enim morbifica materix confluxus attratus, \& à centroad circumferentiam diffi patus, hominem peticlitantem liberat. Ita nullum in rerum natura malum eft, Nullum in quod non in bonum totius, Univerfique confervationem tan- natura dem cedat. Quid enim Mars \& Saturnusaliud funt, quàm dis- malums conantiæ quadam ? quæ tamen à Jove confonantiâ perfectâ ab bonum Yyncopatæ ligatæque, non dulcedinem tantùm muficx, fed \& conferst. maximum ornamentum conciliane. Quid aliud Mercurius, Ddd 2 nifi 
396:

Itinerarium I. Dialogus II.

nIfi dillonantia quardam inter Lunam \& Venerem veluci duas confönantias fyncopata ligataque, nè libertatem nacta, nullique obligata;terram ipfam benigno Solis, Veneris, \& Eunx influxu foedaret?

Qlobicure eircapro-

V I. Cùm verò Naturaperpetuò varietatis ftudiofa fit , nè prismicen: irum; femper ficceflu temporis eandem harmoniam inferiori munalisg, tam centrum; rum elongarione \& approximatione obinvicem in do offerrer; fingulorum Planetarum motu circa proprium. sibus in in excentricis fact tâ, rumivaria afpectuum füb.Zadiacifignis pofifrrula fint tionerelationevè, novafemper.\& nova fundare harmonix generavvoluit ; femper tamentub determinatis \& à naturainten-. tis límitibus ; itaut in excentricis; qui motuum planetariorum Mira Plas veluri limites quidamfunt, afcendentes vel defcendentes, tonetermm nosfive modos gradarim mutarent "nunc ex dónio in phrymaxmonis gium, \& hime in lydium; mox in zolium, \& fic decæreris,procedentes, donec tandem ad aflumptum initio tonum, circulatione integrâ tonorum peractâ: reverteventur. Rartes verò globorum five corporum planerariorum cùm heterogenex fine, . \& naturam; qualitates, proprietates; viresque ob diverfum firum refpectumquead reliquos circumjacentesPlanetas diverfás fortite fint; Natura eos circa proprium centrum:verfári volúit; utalias femper \& alias partes. Telluri obverterent; idemque in Mufica coelètti, quod in Muficaartificiali diffononum. cum confonis commiffurâ praftàrent. Vides igitur, Planeras. eo ordine effe difpofitos, ut vel uno à determinato fibi limite, veluti harmonico intervallo recedente, ${ }_{2}$ ota harmonia merito. deftruatur:

\section{SCHOLI UM I.}

MUndanacorpora:Terram, Lunam, Solen, ceterosós Plane. tas, tali inter fe diftantia effé de/pofita; talig mole ac magnitudine pradita; ut harmoniam: veluti muficam perfectiffimam efficiast, unanimi onnium hactenus-fáculorum confensu

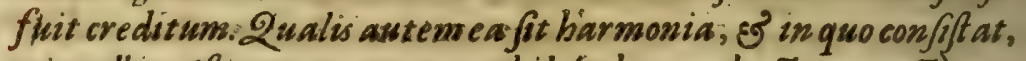
vix ullise Aftronomorum aut Philofophorum hacterno recte ex- 
plicavit, ut ut multi idtentaverint.Peffinè omnium fensêre, qui e calorum folidorum collifione muficum quendain concest um oririexiftimarunt, cum nulla upiam, prater fiderum, in coelefti expanjo foliditas reperiatur. Ques porro fit corpor um mundialium ad fe invicem proportio inter fe, tum quad dift antiam, tum quoad molem:; of num ea fit revera. barmonica; examinabimus in Miundo Mirabili:

VII. Theodid.. Cepiomnia optimé, qux de providentia divina circa difpoficionem Planetarum differuift; ; Sed non capio, quomodo hac difpofitio circa corpora; in inexplicabili illa firmamenti profunditate latentia; intelligenda fit ; cùm. nullam hujusmodi corporum ad terramproportionem, utpote qua: extra ommem: humani oculi aciem conftitutafine, reperiam. Cofriel: Theodidâte, remardumà me petiifti, quam tibi quidè exponere vix liceat, nifi per alcifima quadain. principia non omnib̈us obvia, quaveriffima tamen funt: \&: mox apertè videbis, quod tamerfi mundusinconceptibilis ; \& immenturabilis fit; \& glóbi mundant innumerabiles ; thihil-Ormia in ominus tamen omnia in omnibus, fingula in fingulis, quodli- omnibu bec in quoliber racione ineffabili exifturt, \& omnia ad invis? cemnexu \& proporcione adimirandâ , cum reciproca influxuum receptione difpofita func:- Et fi acutè füperiùs dicta di-: fpexeris, minimè tibi veriffimum illud divini Dionyfii epiphonema, quo mixus, ommia in omnibus, \& quodlibet in quolibet afferuit (quod \& nonnullí ex prifcis Philöfóphis fenferunt) difficile credicu fucurum confido:- Nam cùm manife-Deus in ftum fit, Deum ita efle in omnibus, ut omnia fint in ipfo, $: \mathbb{Q}_{\text {ommia in }}^{\text {ommibus }}$ conftet, Deum quafi mediante Uhiverfoeffe in omnibus; hinc $D e$. omnia in omnibus efle, \&quodliber in quolibet conftac: Uni-verfumenim quafi ordine naturæuti perfectiflimum; fic ut quodlibet in quolibet efle poffer; praceffic omnia. Univerfum fcias efle ipfam rerum omnium creacarum compagem; \& ita quodlibet recipere omnia', ut in"ipfo fine iplum contractè ; cumquequodliber non poflit efle actu omnia , cum fint contractum; contrahic omnia; ut fint ipfum. Si igitur omnia fint Ddd 3 in 


\section{8}

Itinerarium I. Dialogus II.

in omnibus; omnia quodl bet pracedere videntur. Non igitur omnia funt plura, quoniam plural itas illa quodlibet non. pracedit; unde omnia fine pluralitate quodlibet ordine natura precellerunt. Non funt igitur plura in quolibet exiftente, fed-omnia fine pluralitate funt idipfum. Non eftautem Univerfum nifi contractèin rebus, \& omnis res actu exiftens contrahic univerfa, ut fint actu id, quod eft; omne autem actuexiftens in Deoeft, quà spfe eft actus omnium; actus autem eft perfectio \& finis potentix : undè cùm Univerfum in quoliber actu exiftentefit contractum, pater Deum, qui eft in Univerfo, effe in quolibet, \& quodliber actu exiftens immediatè in $\mathrm{DeO}_{\text {, }}$ ficuri Univerfim in eodem. Non eft igitur aliud, dicere, quodlibet efle in quolibet, quàm Deum per omnia effe in omnibus, omnia efe \& omnia per omnia eflè in Deo.Unde colliges, quomodo Deus in omni- fit abfque diverfitate in omnibus, quia is eft quodlibet in quoquodlibet liber; \& omnia in Deo, quia omnia in omnibus.Sed cùm Uniin quolibet, verfum ita fit in quolibet, ut quodlibet in ipfo; eft Univerfum quidfit. in quolıbet contractè id, quod eft ipfum contractè \& \&uodlibet in Univerfo eft ipfum Univerfum, quamvis Univerfum in quolibet fit diversâ ratione, uti \& quodlibet in Univerforatione diversâ, Theodid. Nimis fubtili ratiocinio intellectum. meum, tantum abeftur illumines, ut potiùs obcundas. Oftende itaque fenfum dictorum aliquâ fimilitudine, ut eorum caLinea infi- pax efle queam. Cofmiel. Faciam quod jubes. Manifertum itanita a fi altu que eft, lineam quandam actú infinitam, fià Deo producereefet circu- tur, non folum lineam, fed \& triangulum, circulum, \& fphreluss, 85

triangu. Iแm $\varepsilon_{5}$. ram complicaturam, ita ut hujusmodi non tầm linea, quàm. triangulus, non ràm triangultis, quàm circulus, aut fphæra dici ponfet. Omnis autem linea finita cùm effe fuum habeat â linea infinita, quæ eft omne id, quod eft ; neceffariò fequitur, in linea finita omne id, quod eft, effe lineam finicam, v. g linea uti confideratur in triangulo, circulo, fphæra, eft linea finita; omnis ergo figura in linea finita eft ipfa linea, \& non eft in. ipfa aut triangulus, aut circulus, aut fphæra actu exiftens, quoniam ex pluribus actu non fic unum actu, cùm quodlibec actu 
non fit in quolibet; fed triangulus in linea eft linea, \& circulus in linea eft linea, \& ita de reliquis. Et.ut clariùs omnia tibi paseant, linea actu eflé nequit, nifi in corpore; in corpore autem longo, laro, \& profundo omnes figuras complicari nemo dubitat. Sunc igiur in linea actu omnes figurzeactu ipfa linea, in triangulo triangulus, \& in fphæra fphæra : nam omnia in. lapide funt lapis; in anima vegetabili, ipfa anima; in vita,vira; infenfu, fenfus; in vifu, vifus; tatio, in racione; in intellectu, intellectus; in Deo, Deus. Vides itaque quomodo rerum unitas $_{x}$ five Univerfum eft in pluralitate, \& pluralitas in unitate. Confidera attentiùs, \& videbis.quomodo quxlibet res actu exiftens ex eo quiefcit, quia.omnia in ipfa funt ipfa, \& ipfa in Deo, Deus. Vides mirandam rerum unitatem, aqualitatem, \& inexplicabilem connexionem fingulorum cuin fingulis, ut $\mathrm{O}$ mnia fint in ommibus. Atque hinc colliges quoque, unde diverfitas \& connexio nafcatur. Cùm enim qualiber res actu omnia effe non potuerit, quia fuiflet Deus; ideofecit omnia in diverfis gradibus, uc hoc pacto omnia fint id, quod funt,quo-

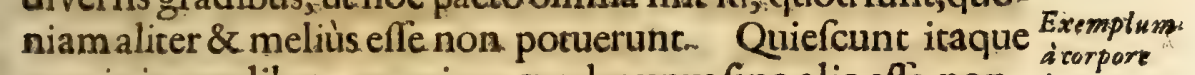
omnia in quolibet, quoniam gradus unus fine alio effe non, a corpore potuiffer.Sed explico totum tibi per.familiare exemplum. In humani corporis, membris quodlibet confert cuilibet, \& omnia in omnibus quiefcunt : cùm enim oculus non poffic effe: manüs; ideo contentus eft oculus ur fic oculus,$\&$ pesut fit pes, \& omnia membra fibi mutuè conferrunt, ut unumquodquemodo meliore quo poreft, exiftar id quod eft; neque enim. manus, manus.efle poteft in oculo, fed in oculo eft oculus, in quantumipfe oculus eft immedatè in homine; \& ira fingula membra in pede:funt, in quantum pes, \& in manu, in quantum manus, inquantum pes \& manus immediatè funt in homine, ur quodlibet membium per quodlibet immediatè fit in homine, \& homo five totum per quodliber membrum fitine. quoliber, ficuti totum in partibus eft, per quamliber in qualilibet.Ita Univerfum per naturam in omnibus omnia eft, \& ita omnia quoquein mundo, tametfi nobis.occultâ,\& humanoin. 
genio incomprehensâ proportione connectit, ut tametfi o mnia \& fingula mundana fyftemata diverfa fine, in unum tamen perfectè confpirent : \& quamvis innumeri in mundo globi fint nobis incogniti, \& extra omnem fenfuum comprehenfionem: longè remotiffimi; ita tamen per naturam, qua eft ars Dei, \& fpiritus. Univerforum, feu anima mundi, apte connectuntur, \& per motum in tantam harmoniamconcin-

Catenaberacleotica que. nantur, uc unum fine altero, fine cotius diflolutione, efle non poffic. Ató; hrec elt vera illa catena heracleorica, ex ulcimis coelorum confiniis, in ultima mundi corpora deminta; ex qua fi vel unumannulumaut globum feparares; totum, utpate folutâ compage, concidere necefie foret. Vides igitur, quomodo corpora mundana, quantumvis remota, per occultam tamen proportionem, hominibusque incognitam connexionem, cum omnibus \& fingulis confonent

VIIL. Theodid. Quxecunque hucufque fapienter juxta principia atciflima difleruifti, ita sera funt, ut intellectum. meum prorfus convincat, neque quicquam habeam, quod iis

Cur Derss tantam caleftium globornm: opponere queam. Sed modò nofle cuperem, cur'Deus, \& in quenfinem ram innumerahilem corporum mundanorum. multitudinem produxeric. Nam que' admodum, dum per. mult itudi-immenfa firmamentiexpanfa iter ageremus, curiosè.obfervanem condiderit. vi, eorum nullum nec numerum, nec finem reperiri; uc vel inde in hanc opinionem devenerim, non tantùm toteffe in. munda Aftra diverfa, quot diverfa in Telluris globo rerum. Enjeetura, fpecies exiftunt, fed \& numerum aftrorum; numerum homiqus aftroe numab origine mundiufque in ejusdem confummationem. rumo. prædeftinatorum nonadrequare modò, fed \& fuperare. co/m. monium elco Rectè fentis, mi Theodidactes neque enim Conditor fapien-
tlorum multitudi- tiflimus omnia humano intellectui in hoc corruptibili munnems /upe- do pervia eflè voluit, fed innumera feliciori fæcula\&z aternæ perare, as- beatitudini refervavit. Paucula tamen operum fuorumaliis fe-
ferisur. culis veluti per rumam quandam detexic, ut glorix fux potentiæque magnitudinem, quantum humanæ conditionis ratio concederet, oftenderet. Etriamfir enim homines intentio ejus 
areat, non ideo tamen efficaciflimis fuis privantur effectibus; fufficiat illis fcire, omnia in unam confpirare harmoniam: Certè fi in inferiorum rerum natura nil adeo exile \& minucumelt, quod non in certos fines fapientiflimè conditum fic ; ratio tamen vel minimi vermiculi, curvidelicer Deus eum tali \& cali ratione condiderit, \& quis ejus in humanis rebus ufus fit, homines lateat ; quantò plùs maxima illa $\&$ ingentis magnirudinis mundana corpora, qux maximos \& emmentiflimos ufus, non-nifi in alcera vira revelandos habent, humano intel- Pauca nolectui impervia efle cenfere debes. Quis ex medicis hucusque Git bom in certum mufculorum, cartilaginum, venularum, fibrarum, alia-sonfitut as. rumque minuciffimarum humani corporis partium:numerum \& multitudinem indicavit? Vel unicâ tamen à coco corpore feparatâ, totius corporis harmoniam deftrui certumeft. Nefcimus quidem modò particularium aftrorum virtutes \& effectus; red tunc fortè fciremus, eaque experturi eflemus, fivél unica Stella ex aftris divinâ virtute tolleretur. Certum quoque amnia nobis fit, omnia propter terram hanc, utpote in qua divina propter majeftas carne induta cum hominibus converfari dignata, o- gellur is perumque fuorum magnalia oftendere fibi complacuit; \& condits terram propter hominem ejus incolam conditam effe, ut vi- funt; 65 delicet nobilifima creaturanum homo, mundi filius, \& hæres, pter bomihanc admirabilem mundi machinam confiderans, Condito- $n e m ;$ E risinfinitam \& inexhauftam potentiam, fapientiam, bonita- ${ }^{n i b e r f a s i-~}$ remque cognofceret, \& concinniflimâ fingularum partium naliter muficâ excitatus, in laudes fuaviffimi Conditoris continuò Deum. conftamerque perfolvendas animaretur, \& fic tandem polt corruptibilis hujus vitæ tranfitum Deo plenus, in verbo vita, veluti rerum omnium, totiusque mundial is machinæ pulcherrima idea, eundem, \& in ipfoomnia xternùm contemplari mereretur.

Difcant igitur ex hifce mortales, quantisad minimam portiunculam in anguftis terreftris hujus puncti garguftis acquirendam laboribus, fudoribus, periculis, afflictionibus fefe exponant i quantula fit portio ejus quod obtinent, refpectu ea- 
rum quas Deus elect is fuis praparavit in altiflimis coelorum. habitacul is mantiones; qux, non dubito, hominum prædeftinatorum ab origine Mundi ad hac ufque tempora exiftenrium numerum longè excedunt: nam reétè æterna Dei Sapientia dixit; In domo Patris mei manfiones masha funt, id eft, innumerabiles, \& ingenio humano inconceptibiles. Excirent itaque in fe frequenter defiderium collium ærernor um morcales; refpiciant frepe animo oculisque ad lucium iftarum lucisæernæ veluti umbras quasdam: fic enim fiet, ut terrenarum rerum amore exuti, uberiùs cum lucis filiss, \& in confortio filiorum Dei converfensur.

\section{S CHOLIUM II.}

MIfferia fant qua hactenas Andfor nofer enarravit, pro-

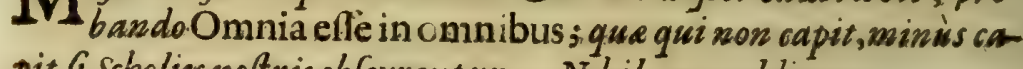
pit fi Scholizs noftris obfcurent ur. Nibil ergo addimus.

\section{CA P U T V.}

De motu incomprebenfibilis velocitatis, quocirca Tellurem voluuntur aftra.

1. T Heodidact oss. Inter coetera, mi Cofmiel, quorum appre1 henfione meus intellectus vacillat, morus globorum eft. Củm enim fuprà dixeris, præter terram omnia reliqua mundana corpora, qux aftra dicimus, loco moveri, moxu urique non rectilineo,non transverfo \& diffipato, fed cir culari, eoque circa terram fixam immotamq; ad exemplar archetypi :Cùmqueà te edodtus, innumeras ftellarum congeries in intimis firmamenti perretralibus compererim, adeoà terra, Sole, Luna noftra remotas, ut eas nec fenfus, nec intenta mentis fixio capere poffit, \& tamerfi tertiò mealtiùs à prima firmamenti ftella fuftuleris, quàm eadem à terra difter, earnm tamen nec finem, nec numerum deprehenfurus fim; cercècurfum quo 24 hora- 
rum fpacio diurnam circa terram circumvolutionem defcribunt,incomprehenfex velocitatis motum efle necefle eft; adeo ut nihil in terrenis rebus ita citum \& velox reperiatur, quod Velocitas cum concitatifima dictorum corporum velocitate comparari fixarum queat, \& omnis fulguris ac fulminis, omnis fagittæa arcu excuf-quants fit. fee velocitas,tarditas potiùs, quàm velocicas comparatione velocitatis dietorum globorum dicenda fit. Cùm enim Aftronomi noftri ftellarum fixarum quampiam in æquinoctiali pofitam, fingulis horis tantum defcriberefpacium dicant, quantum eft intervallum femidiametrorum terræ 3663 , qua in milliaria reducta, 2550180 milliaria germanica conficiunt; uno minuto fecundo, quæe eft 3600 pars horæ, \& penduli vibrationi æquivaler, fpatium emetietur 3580 milliarium ger-

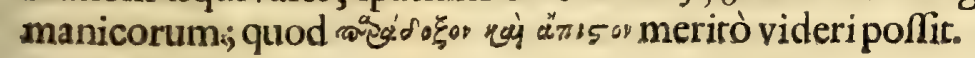

\section{S C HOLI U M I.}

CAlculus Auctoris non videturfibiconftare. Motui horario Aftellarum fixarum, in Equinoctiali pofit arum, tribuit cums Tychone ßpatium aquale 3603 femidiametris Terra Tycho unifemidiametro Terra dat milliaria Germanica 860. Per bunc numerum fi multiplicentur $36 \sigma_{3}$, proveniunt milliaria Germanica 3150180, non 25sorgo. Idem Tycho tribuit motui unius minutifecundifemid. Terre j $\frac{27}{60}$, id est, milliaria Germanica 1247 , non, 358. Ceterùm quanta fit ftellarum fixarum velocitas inmotu diurno ab oriente in occidentem intra unam horam, unur minutum primum, \& unume minutum fecundum, juxta varios AuEtores; determinavimus fuprà Pralufione in Firmamen. S. 3 .

II. Sed rogo te, mi Cofmiel, quomodo, aut quibus verbis? mihi, ut hoc credam, perfuadebis? Cùm enim ftella, ut vocant, fixæ nobisfenfibiles tam incomparabili velocitate cieantur,; quantâ putas eos firmamentiglobos,qui ter, quater, quinquies, imò decies plùsà prima firmamenti ftella diffidene, quàm terra à dictis ftellis; quantâ,inquam, putas velocitate, quàm indicibili celeritate periodum fuam diurnam conficere? Co $\int$ miel.

$$
\text { Eee } 2 \text { Malè }
$$




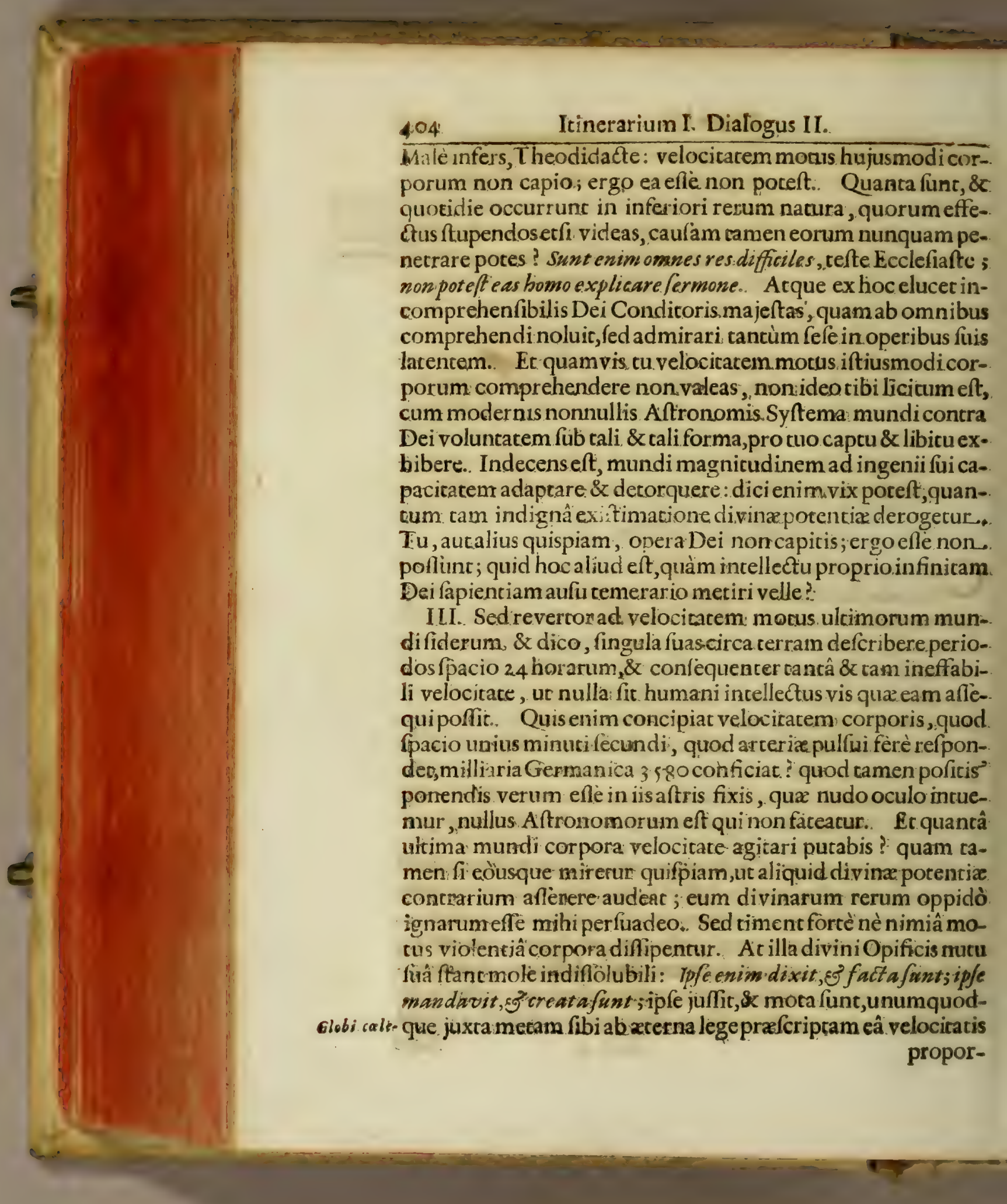


proportione, quam fúo veluti jure:poftulabat, tum ficus à terra, fies quó at. tum moles globi, \& circuitus conficiendi valticas \& amplicu-tiores, вiे do, qux ipfi fubeunda eft.Divinus Opifexorganum mundi ita Gelaciorem infticuic, uc totum innumerabili motuum ${ }_{x}$ nunc tardorum, motu: modò mediorum, tandem velocifimorum varietateconfter, uc omnia in eoincervallis conjuncta fine difparibus, fed pro rata proportionediftinotis, acutisque cum gravibus temperatis"; eaque rerum. fymphonia , quam nemo non ad miratur, efficiatur. Pendet itaque totum ab.ordine \& difpofitione globorum, qui quantö terræ viciniores fünt, tantötardioresmotus habent; quantö remotiores ầ terra, tantò celeriores, proportione globorum veluti jurequodam id poftulante:

IV. Theodid. Omnia fitè capio. Sed cur jam inhoc corpore fixus,nullum motum percipio; cùm ramen juxta tua eloquia uno minuso fecundo plüs quäm 5580 milliaria:Germanica. confezine dicipolfinus? Alcerum dubiun quod me torquet, illudeft, quod magnam motuum varietatem hîc intuear reliquorum fiderum; puod tamen fieri non deberer, cüm globi in firmamento omnes rquali velocitate moveantur.Cofmiel. Ad primum quod atcinet, nullumte globi progredientis motum. Globo crelefentire ais ; \& verum dicis : fed \& caufäm tibi hujus fallacix infideret, jam rxpe. frepius in præcedentibus inculcavi. Quando novi im_motum non pofitus, alteramnavim contravio motu ferri comf picis; certum eft,oculum infigniter falli, dum fuam navem immotam purat; Idem contingit tibi hoc in loco conftituto: Si itaque extra hunc globum, fixus alicubi in athererofpacio hrereres, tumcerzè incredibilem globivelocitatem experireris: Theodid: R ogo te, mi Cofmiel, quiefcere non pofle videor, donec tam notabilem motus effectum fenfaca experientiâ comprobem. Cofmiel: Faciam quod peris. Ecce jam zoo leucis à prioris corporis ftatione remotus es, \& in æthereo fpaciofixus. Afpice igitur nunc, \& diligenter confidera derelictiglobi motum.Theodid: O Cof miel! video; far fuperque video paulö antè àte mihi propofitosum veritatem; globum ingentem motu Eurovelocioriconcitari video.Sed \& quid hoc? globumquem uno minuto primo

$$
\text { Eee 3 fub }
$$




\section{6}

Itinerarium I. Dialogus I I.

fubangulo 80. grad. comprehendebam, jam altero minuto fecundo non nififub angulo 60 , tertio minuto fub 12 , quarto fub 3 , quinto denique fub magnitudine Lunæ, fexto minuto jă fub forma Jovis, feptimo jam fub forma ftellæ fixx, octavo jam fub forma nebuloła, nono jä fub forma ferè infenfibili, decimo jam in nihilum evanuifle comperio. Cofmiel. Mirum non eft, re globum tam immensâ proportione decrefcentế intueri; fiquidem hujus alia caufa non eft, nififumma globi per æthereum. expanfum delati velocitas; qux tanta eft, ut à primo min.temporis quo eum intuebaris, ufque ad fecundum, fpacium confecerit 9 I 58 . femidiametrorum terreftrium, qux conficiunt milliaria Germanica 79 i $5 \mathrm{~S}_{80}$; qui numerus multò major eft maximâ Lunæà terra diftantiâ. Et tametfi hoc fpaciumunius minuti tempore confectum tantum fit, motus tamen in eo fenfum non fugic.

\section{S C H O LI U M II.}

Pauloantè Num. 2.afferuerat Auctor nofter cum Tychone,ftellam fixam in Equatore pofitam conficere intra unam horam pacium 3663. Jemidiametrorum terre: nunc afferit cum P. Joh. Bapt. Ricciolo, eandemftellam intra unum minutum primum. conficere fpacium g1s8. Jemidiametrorum terreftrium. Addit, has femidiametros equivalere milliaribus Germanicis 791588 . Ego autem invenio folum milliaria 7875880 . fitribuam uni femidiametro Terramilliaria 860.

V. Theodid. Noncapio, quid fit, fenfum non fugere. $C o / m$. Siaccipias binos trochos feu girgillos, quibus pueri ludune, quorum unus parvus, alter notabilis magnitudinisfit, \& uterque æquali impetu gyretur; apertèvidebis, punctum coloratum in minori trocho impreflum, ob velocitatem motus, perfectum mox circulum defcribere, ita ut punctum illud oculos planè fugiat, nec punctum efle exiftimes, quod motus violentia circulum exhiber; cujus quidem oftencialıa caufa non eft, nifi circumferentix exiguitas \& coarctatio : in ea enim punctum, dum vel unico ictu oculi principio fuo refticuatur, ocu- 
Jusqui ob velocitatem motûs determinatum puncti locum discernere non valer, atque adeò eodem temporis momento in. omnibus \& fingulis circumferentix punctis veluti ubique effe videatur, fub forma circuli eum lpectari neceffe eft; in majori verò trocho, uti punctum coloratum eidem impreffum, majorem circumferentiam conficic, ita fenfibiliùs quoque punctum illud obfervatur, \& tantò femper fenfibiliùs diftictiùsque, quantò circumferentia major \& major fuerit; adeò quidem, ut fi crochus inftar tholi, quam cupulam Sancti Petri vocant, daretur, is circumactus, figno aliquo in maxima circumferentia impreflo, non jam circulum exhiberet, fed punctum unà cum circumferentia circumactum diftinctam fui in circumferentia poficionem oftenderet: quad non fieret in minori dicta cupula circumferentia; ibi enim, ob circumferentize circumactionem, motus velocitas principium fini faciliùs jungit, atque adeo circulum videri necefle eft; in maxima verơ circumferentia ob ejusdem amplitudinem, eadem velocitas? non tam citô principium motus fini ejusdem jungit, atque adeò oculus puncti curfum faciliùs \& diftinctiúsobfervar. Ex his, ni fallor, pare, , quomodo motus velocisas in maximis circumferentris concipienda fit; oculus enim in hoc rthere fixus; criamfi motum ex fe \& natura fua velociffimum videat, amplitudo ramen circum ferentiz facit, ur morus velocitatem liumano ingenio inconceptibilem non notes. Et in exemplo familiarirem difces. Elephas, autgygas quidam, etiamfi oculo tuo tardos greffus facere videatur, eâtamen velocitate procedit, ut vix fit qui eum affequi poffit; cum greflus elephantis aut gygantis mukos hominum paflus in fe complicet: Hinc colliges, Stelia firfi diatus ftelle motus, quo uno minuto remporis 7915880 . mament milliaria germanica conficit, in Lunæ circulum coarctaretur, sirscklo Luneceffariơ fucurum, ur velocicas mocus adeo velox aftrum fub ne calloca-

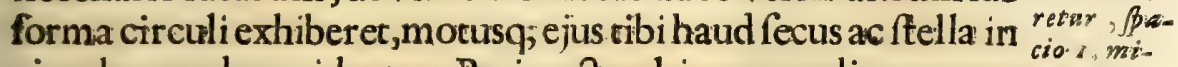
circulum cadens videretur.Pari pacto ultima mundi corpora nuti perios tantæ velocitatis efle exiftimes, ut uno minuto temporis tar- dum jusm

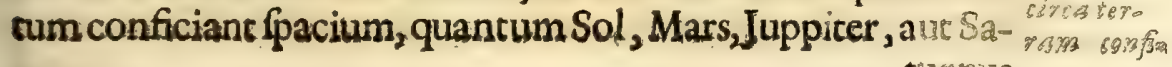


408

Ttinerarium I. Dialogus II.

ceret; quod turnus (pacio 24. horarum peragunt; ut fi motus hujusmodi idem de alicujusiftella coarctaretur intra circulum Solarem, Sol uno
Sole cete-

ris plane- temporis minuko neceffariò integram diurni motus periodum

tis lentien- conficeret; atque adeo velocitas Sol is eâdemratione tuis comdumes. pareret oculis, ac fi quifpiam candens ferrum in circulos agitet, quod oculorumintuitus, dum fitum ferridifcernere non valet, circulum igneum concipere cogitur. Elucet itaque mira quxdam corporum mundanorum velocitatis proporcio, ut, quantò circulus, quem conficiunt, major \& major eft, cantó velociùs quoad $\mathrm{fe}$, tardiùs verò quoad oculos moveantur,o mnia tamen ita adaptata, ut 24. horarum. pacio integram periodum fuam conficiant. Haud fecus in rota quadam molaria, etfi partium extremarum circumferencix rocx inter canchum \& canthum fpacium vigecuplo majusfit inferioris circumferentia fpacio inter inferiores canthorum partes contento; illud camen tardius, hoc velociùs moveri videbitur, non obftanre quòd illud vigecuplo, utidixi, celeriùs cieatur, id eft, vigecuplo majus f patium conficiat in unius circumferentix circumvolutione. Non vides, Ciconiam in fublimi aëris expanfo decuplò plùs fpacii conficere, quàm in aëre terrenæfuperficiei vicino? \& tamen tardiùs in remotiori à terra, quàm in eidem viciniori f pacio procedere videtur; cujus quidemrei rationon elt alia, nifi amplitudocircumferentia aëris, ejusque puritas, qua fine obftaculo ullo, quod ex aëris craflitie obvenire folet, velociffimè ingentia peragunt fpacia, eciamfi id aculis, ob diftantiam, non pateac.

VI. Theodid. Optimè cepiomnia, \& jam fat mirari non poffưm, quòd multi ex modernis nefcio quâ temeritate in transverfum acti, dum tantam fixorum fiderum velocitatem comprehendere'non poffunt, ut divini operis capaces fierent, fixas ftellas immóbiles, terram verò mobilen ftatuerint? An non mamenhoc eft, divina potentix terminos prafcribere, 'opusque intum immo-comprehenfibile ad proprii ingenii capacitatem detorquere, bsleftasue- \& adaptare ? Quafi verò Deus Optimus Maximus nihil proquid frlo- ducere poflit, nifi quod ipforum ingenio undequaque quadret. 
Nequehíc fiftunt; quin imò tantâ pertinaciâ fuum tuentur er- citetem rorem, ut velipfas divini verbi paginas, 'eirumque fenfus, ad pros.cumtium opinionem, velint nolint, pratumptuofiustrahere noil pon posucverecundencur.

\section{SCH OLI UM III.}

FNgeniofofinie fimul ac.clariffrmè explicavut hactenus Auct or nofter, quomodoftellarum fixarü motus, tametfi velociffimus fit. id eft, exigno tempore immenfum ferè pacium coli percurrat; fenfum t amen non eff ugiat: grod utique fieret, fiftella aliqua codem feu aquali tempore incalo inferiori, Luns v.g. idem feu aquale fpaciü percurreret. Nan eodem tempore quo in fupremo caelo fellato percurrit unü minutum fecundum Equatoris, percurreret fapius integram peripheriam circuli maximi in calo Lunc, ac proinde ftella illa non appareret moveri, fed putaretur effe unus circulus non interruptus, cae lo Lune circumfcriptus; adeum videlicet modum, quo punct um coloratum in trochocelerrimè circuneacto non apparet moveri, fed exiftimaturcirculus effecoloratus trochocircumf Griptus Ex quo etiam deducitur; quo mag is remot. à vobis ftella funt, eò velocius moveri, $\xi^{2}$ è tardiorein nibilowisus videri earum motum.

- VII. Sed jam ad alterum dubium procedo, cur videlicet ex hoc firmamenti globo confpecta circumfita nobis fidera, ram diverfos motus mentiantur? Cofmiel. Dixitibi in prace- Caufa disam ram, alios particulares habere motus, terræ excentricos; quo- ftellis fir minùs tamen ii ex terra videantur, caufam efle immenfamà terra diftantiam; qua particulares horum fiderum circuli veluti in unum punctum contrahuncur; atque adeaftellas, in quacunque circuli fui parte funt, femper fub puncti forma fpectari, \&abaliisæquâ femper diftantiâ disjunctas:Theodidactus. Mira refers; led rogote, in quem finem peculiares ifti motus cond iti tum fide. func? Cofmiel Cum multiglobi in firmamento fint, quiad inPtar Lunarum luce indigeant; certum ent, hujusmodicorpora ì folaribus globis illuminari non poffe, fi ea non circumirent: Fff cir- 
circumeunt itaque, ut illuminando ea ad virium foetura $\mathrm{m}$ follicitent, quibus, dum unum corpus airerum fovet, omnia in fuo vigore conferventur, \&"harmonia mundi compleatur. Theod. Sed quis unqua $m$ hujusmodiLunares globos in firm amento ex

Iunaria carporatin firmamento can. tineri, quomodopro. betwr. Terrigenis vidit? Quis mihitalia narranti credet? Cofmiel. Etiamfi ob diftantiam, quam dixi fummam, à terrigenisconfpici non poffint; ratio tamen dietat, ita efle debere, ex congzuentia quadam omnino probabili \& verifimili, cùm om nia in mundo globorum fyftemata eodem modo fe habeant. Quis tibi perfiadere poffet, circa Solem, quem ex hoc loco non nifi fub forma nebulofe ftellie contueris, 'Terram, Lunam, Mercurum, Venerem, Marrem, Jovem, Saturnum, aliasque ftellas" contineri, quarum inferiores propriâ luce privatæ, luce Sol is" tantummodò, reliqux fuperiores exucroque fulgeanc? quas tamen etfinon videas, non tæmen ea non efle cenfere debes. I. dem prorfus in vaftiffimis firmamenti penerralibus fieri exiftimes velim. Imò quis prioribus feculis credi potuiflet, circa. Jovem quacuor a lios globos terræ excentricos contineri?quos samen hoc feculo derectos quocidie fummâ admiratione intuemur.

VIII. Theodidactus. Vera funt qua dicis, \& ordinimundano prorfus congrua. Sed rogote, cur Aftra è terra tam conftanti \& præcifo femper intervallo ab invicem diftant cof Co Stelle fix misel. Ratio ejus reifunt centra, quibus ftabilita funt; qux uti cur femper talem\& talé in ather eo expanfo fedem fortiza funt, ita fieri non inaicem dim poteft, ut ab eo unquam vel hilum recedant. Nofti quàm T ellus fantiam fuefter fixa centroin athereo fufpenfa fpacio? Quamnam puobtineant. tas tantam ventorum potentiam efle poffe, qux eam à fede divinitùs deft inata removeat? Certè nullam. Idem fanè de omnibus \& fingulis mundi corporibus fentias velim. Unde mirum non eft, easà fede fua revelli nunquant poflè. Ergo femper, quoad apparentiam, eandem à fe invicem diftantiam habere confpiciuntur. Dixi quoad apparentiam : quia etfi finguliglobi, non fecus ac Planetre, differentes motus habeant, \& pecubiaribus circulis, ob rationes in præcedentibus dictas 2 periodos 
fuos conficiant; funt tamen hi circuli, incra quos motus fuos peragunt, ob exceflivam à terra intercapedinem, prorfus infenfibiles. Sive iraque ftella quapiam in peculiari fuocirculo fic in conjunctione cumaltera quadam ftella, five in oppoficione, five in quadrata configuratione confticuta; alpectus tamen Circuli fow lujusmodi prorfus, ob illud, quod dixi, incredibilis inrercape- bus telle dinis difcrimen evanefcic, urpote circulo in punctum inlenfi- fxa bolbile contracto, in quo prater lucis punctum nihil aliud videa- untur, tur, neque poficionis ulla in eo differentia fpectecur. Eâdem tur, ob diprorfus rarione, quâtu ad primumcuum in firmamentum in-ftantiam troicum, cùm intuereris Planeras, Solem, Lunam, Venerem, excefsa ame Mercurium, Marcem, Jovem, Sarurnum, illos fixas Ptellas pu- in pun-1 rabas, eâdem femperà Sole dintantiâ difficas, quia videlicer eo ctum conrum circuli ob nimiam diftantiam abforpti centris planetarum coincidebant, quamvis non negem illos in Marte, Jove, Sacurno conftituris apparere, \& motus fingulorum viciniorum in fuis propriis \& peculiaribus excentricis, obfervaripof fe; quemadmodum tu cùm dictos globos luftraremus, cum. admiratione ponè atconitus obfervabas. Theodid. Ita eft, mi Cofmiel, jam recordor hujusmodi phœnomena ex Saturno me potifimùm obfervalle, caufarum tamen nefcium : recordor quoque, fixa me pucafle illa fidera, qua ex terra in tam vaftis excentricis agitariolim confpiciebam, \& jam incipio ultra vul. garem Aftronomiam reconditiora quadam de cœieftidifciplina fapere. O miram rerum metamorphofin! Jam in eo me loco conftitutum reperio, ubi nec Sol, nec Luna, necullus aliorum Planetarum, quorum motus olim è terra tantopere admirabar, omnibus in nihilum redactis, apparet. O quantum miror eorum opinionem, qui eos, qui Solen rotum mundum illuminare negant, in Aftronomica difciplina hæreticos arbitrantur! O quantum fluctuant mortalium animi! Quantoperefenfibus fafcinantur! Quàm omnia alia quàm in fe revera. fint, contuentur ! Sed \& ego tametfi præfens omnia intuear, adeo tamen intellectum meum impotentem reperio ad incomprehenfa divin $x$ potentix opera concipienda , quàm. 
ma contracta forent; quod abliurdumeft, \& contradictionem involuic : eflent enim maxima contracta, \& non eflent;\& quod debeant efle maxima contracta, fupponimus ex definitione mundi féu Univerfi,nó effè veröpofle maximacontracta, inde paret, quòd impoflibile fit, in eodem genere rerum plura contracta maxims daripolle' fed unum maximum nateriale, contractum dari neceflë elt, quod omnia intra fe contineat. Praterearquod conftat ex univerfa materia, imó id de cujus ratione eft, ut ex maceriauniverfac conftet, unum eflè neceffè eft: : at illud quod eft contractü maximum, mundus feuliniverfum, Rationes hujusmodi eft' eftergo Univerfüm neceffariò unum. Quod cur unus. enim pendet abuno, id neceffäriò debet efleunum, non abfolu - tantüm tè quidem, led contractè : fed Univerfüm immediatè pendet à Deo creatus Deouno; ergo contractum debec effe unum.. Namut divinus Diony fius loquitur, unitas omnis unitatis eft effectrix ;ab hac enim omnia fluune, perficiuntur, fervantur, \&unitatis unionisque munere efficiuntur:. Pofito enim quöd Deus plures mundoscreaflet, jam quxro, vel illi aquales inter fe effent, vel $m$ iores, vel minores : aquales certè effe non poftmo;non enim eflent concracta maxima, củm contractum maximum fimile aut æquale habere norr poffit : neque unumaltero majus aut minus efle poffer, cùm eadem ex illo contradictio fequatur: Ergo unus neceflàriò à Deo mundus feu Univerfüm productum fuit, ut fic idea funmi Opificis ideatoundiquaque refponderet,\& unum abfolutè maximum, qui Deus, unum contracté maximum, qui mundus eft, fimilicudine \& analogiâ quấdam. oppidò congruâ exprimeret. Theodid. Convictus in tua verba. jurare non vereor; ad majora ergo progrediamur.

\section{S C HO LI U M I $V$.}

PHyfica eft hac quaftio de Mundifeu Univerfinnitate ac plit 1 ralitate, atque a Philofophie foriptoribus in Libris de Caelo of Mundo abunde difoutitur, ideofupervacaneum' effet, eam hic plurbus difcutere: An, Ê quấ ratione fit immen tos Mitondus, of anfieripotuerit a $D E O$ major acperfectior, difcutitur infra in Apologeticis Cap. ad Reponfonemoriacz: Cenforis:

CAP. 


\section{CA PUT VI.}

\section{Debarmonia mundibujus fenfibilis, E' analogia cum rationali, politico, intellectuali, \& Archetypo mundo; ${ }^{3}$ quomodo fingula in fingula influant.}

Tribus omoia confant.

I. $\square$

Tofmiel. Tribus Deus mundum difpofuit,numero,pongerunt veficis \& omnum numerorum fonte habent; pondus abilla fapientia, quæ omnia librat; menfuram ab illo Artificis fpirıtu, qui unicuique congruam diftribuic portionem. Hinc tria juxra Magorum dogma mundo dominantur, Deus, Mens, Anima. Deo propriè comperit monas five unitas; Menti vel fapiencia ordo vel pondus; Animæ verò velSpiritui menfura motusque. Puichrè hoc explicat anigmaticum Platonis ad Dionyfium. Regem pronunciatum : Circa omnium Regem cuncta fiunt, ipfius gratiâ omnia, ipre pulchrorumomnium caufa: omnia namque funt circa Regein ejus unitate connexa, \& ipfius gratiâ omnia ponderata funt, \& ad ipfum cuncta ordinata,ipte verò omnia numerando, proportionandoque, pulchrorum omnium caufa eft,tam efficiens, quàm finalis,\& gubernans, \& fuftentans principium, medium, \& finisomnium. Dionyfio fervo DeI tefte,ab eoomnia profluunt, in eum omnia tendunt, \& in eo omnia ftabilita conquiefcunt. Deus fiquidem f phria eft,cujus centrum ubique per potentiam eft Parer; circumferentia verò per incomprehenfam immenfitatem nusquam, Filius fine Sapientia eft; Relatio verò mutua centri \& circumferentix, vel radii,fpiritum \& Amorem reciprocum fignificat.

Monas primanece]ará trina.
I I. Prima iraque \& fuprema monas trina eft, à trino ordine \& numero fonoro conftituta. Omnium enim perfectiffima harmonia folis tribus vocibus conftare deber, infimâ,mediâ, \& fupremâ;quæ unitæ dant diapafon,ex diapente $\&$ diateflaron 
compoficum,confonantarum perfectifimam, \& primam harmoniam, \& pulchrè in tribus hilč numeris cernitur, $1,2,3 ;$ ubi I fe haber per modum fimplicis \& ifophonæ,omnium confo- Harmonici nanciarum originis,qux Deo Patri compecit; 2 ad I relata per numeri modum octavæ five diapafon, Filio; 3 verò ad 2 relata diapen- ${ }^{-2}$ rinitatem te refert, fpirituique compesit virtuti connectendi. Sicuti enim. media vox diapente infima $m \&$ fupremam in trium vocum. harmoniam connectit,ita \& Spiritus,Patris \& Filii,principii \& firis, in unam incomprehenfibilem harmoniam nexus eft; in. qua ineffabili foecundiflimæ Triadis harmoniâ omnis inNarura harmonicus concentus quomodo propagetur ${ }_{2}$ ex plicandum eft.

III. Ternarits itaque fimplex Deofimplicifimo ateribuitur, qui fumma \& indivifa Unicas exiftens, in tres tamen hypoftales modo quodam humanæ menti in effabili diffunditur. Hinc ternarius extra fe in multitudinem abiens, triplatus, triü enneadum admirandum producit fymphonifmum, fignarque novem Angelicas ordines, novem cœlorum regiones, novem corposa, Elementarisque natura genera. Qux omnia dena- Harmonia rio non fine admirando myfterio perficiunturyt poftea dice-ponitur per tur. Ternarius autem cubicatus, five ternarius in quadracum numeros. fui, hocelt, in nové ductus, producit omnium myfteriofiflimú numerum 27 , omnium enneadum complementum, omnium harmonicarum proportionum feminarium.Ec prima quidem Prima trias increata, foecundâ propagatione in tres intellectualis mú-creat di triades creatas fe diffundit, ita ut ordo Seraphicus amore inflañatus,Spirituiamori, Parris \& Filiinexui; Cherubicus ordo; Sapientiâ,\& Scientiâ plenus,füpremæ Sapientiæ, Filio; Thronorŭ verò ordo Patricompetat, qui uti,ceftePfalmiftâ, In judiciopofuit thronum funm, ita\&perFilium in iisdem judicabit orb $\vec{e}_{.}$ Atque hrec quidem Trias eft perfectionis \& fimilieudinis Dei. Cùm vero fummumbonum fit diffufiuum fui, hinc per triadé fuam alium trinum ordinem produxit,ut per eam creacuras in- Secunda feriores perfecto \& harmonico ordine ceu Princeps \& Opifex trias creafupremus gubernarer. Et Pater quidem Dominus omnium o tho 
nem alios affumi neceffe erat; nullos alios nifi homines,juxta eum virtutis gradum, quem in terris Deus ipfis contulerar.

IV.Patec hinc quoque,cur Deus populis fubditisque timo- Reges $8 \mathrm{re-}$ rem Principum incuflerit. Nonnè Rex homoelt, cateris ho- gnacur in minibus fimilis? Videmus omnes eifummâ fe reverentiâ \& ti- conferbenmore fubiicere; quod quidem fieri nullâ ratione pollè, nifi tưr Get ab Deus illicimor is fui characterem impreflillet, quo Princeps fi- eo remobegnatus evectufque, careros cimore quodam reverentiali, \& occultâ quâdam vi fubeflec compellit. Quod cotum per Principaruum illorum fupremorum principum ordinem exequitur. Quòd fi verò per indignam, fceleribusque contaminatam vitam,fibi Reges Principefque tum Dei,tum Principartum influxuiobicem pofuerint; ecce protinus veluti per peccata publica deleto in Principe charactere timoris Dei,populusà con-Rebelliones rono in diffonum deflecticur, rebelliones moventur, jugique populorum Principis,tanquam charactere timoris Lei indigni,ficabjectio; ut proinde mutationes imperiorum regnorumque translationes, principatuum rerumque publicarü extirpationes, aliam, quàm diximus, originem non habeanc. Meminerit igitur. Princeps ita vitam fuam infituere, ita juftitiam \& pieratem colere, ut Principatus five prafides Archangelos femper fibipropofitos inveniat, utpote fine quorum perpetua tutela \& alfiItentia,nec Regnum,nec Regnator fubfiftere queant.

V. Eadem de caufa Deus an imalibus etiam ferocifimis ${ }^{3}$ Dem ipfis characterem rimoris impreflit, ut videlicet homini, propter anzma!iquem condita erant,fubeflent, eique obedirent. Videmus de- bus cherebiliorem puerum vel ingentem Elephantum, ferocifimumque berentic 8 Leonem manuducere, regere, verberibusque quòcunque vo- timoris erluerit, imperiosè ducere, belluamq; ei in omnibus fefe fubmit- $\mathrm{g}_{\mathrm{nam}} \mathrm{hm}_{\mathbf{i}}$ tere; certè nonalia de caufa, nifi quòd ordinis ratio ita præ- prefjic。 fcribat, \& quia homini character timoris Dei impreffus omnia eidem fuberle cogit. Eadem in ordine animalium fpectantur: quòd enim unum animal aliud timear, etfi robore \& magnitudine multò eo inferius ( ut Elephas Arietem, Gallum Leo) caufa eft,quòd fub prefidiofunt ordinis altioris, characterem-

G $g$.

que 
que principatus gerant,quem inferiora naturali inftinctu, dü: cognolcung, reverentur. Vides igitun quàm omnia mirabili: uexu conjuncta confonent. Relucet $\&$ hic concentus vel in ipfis fortuicis rebus; fi camen aliquid in rerum natura fortuicú. \& cafuale dici poteft. Vc cùm tempore Pauli V.Poncificis", Aquila Draconis imagini, quem Gregorii X LII. Pontif. gentilitia infignia continent, infra tiaram infidens, \& Burghefiorum ftemma figurans, ex eadem familia Pontificis electionem defignavit: non enim abfurdè dicimus; quod nonnullis tunc in mentem venit, voluiffeDeum per Angelos Principatus, principis.volucris augurioprincipatum Orbisindicare. Quia verò principatus terrenus:diflonus ex feeft, \& deformis,nifi confonus fié in feipfo,\& cum aliis, \& perhana confonantiam decoré \& pulchritudiné acquirat;ideoSuperiorum minifterium Principi neceflàrium ent. Ethoc Vircutumefficitondo,quorum fa vore comparatâ conftanciâ acrobore, fortes contra vitiorum voluptatumque irritamenta efficimur: Sed ut \& contra has" aëreas poteftates invidiâ \& maliciâ plenas pravaleamus, fupercoeleftium divinarumque. Poteftatum prafidium nobis neceffarium eft. Nèetiam mundanis affectibus prapediamur, fed. illos appetitui rationali harmonicè fubiicientes dominemur. nobis ipfis, Dominationum afliftentia erat neceflaria. O. mnium itag; inferiorum obtento dominio, reftat, ut:ad Deum converfi ipfif foli vacemus; quod fit, fi memoriam fupercoleftium per Thronorum fubfidium retineamus, eademque Cherubicâ illuftracione contemplemur, dỏnec tandem cognacione quadam Parentifummo ac divina monadi per ardorem Seraphicum uniamur: Unde quemadmodum per Ángelicos? gradus Opifex rerum in nos fuâ virtute defcendic; fic \& per cofdem ad ipfum,à quo proceffimus, redeamus oportet; veluti per:quofdam virtutum gradus; quorum primus racionalis na: turæ gradus per fenfus nos conjungit:Angelis, imaginatio Arch. angelis, timor Virtutibus, Poteftatibus dolor de peccatis, ra. sioPtincipatibus (ut enim Hæ Spiritibus, ita ratio fenfibus \& ef. fectibus praet) Amor Dominationibus, Thronis incellectus; 
Cherubinis intelligentia, fpes denique unit Seraphinis:hi enim proximèconducunc adDeü quieft fpesomnium finium terræ

Vides igitur, ut miniftrihi ordines Harmoftx fummitri- Dewr per" bunaliafliftentes, ut fidi fint, omnia in confonantiä cum Prin- Hierarchi-a cipe eorum deducere fatagunt ? preveniunt enim conjuncti osmnia mo-

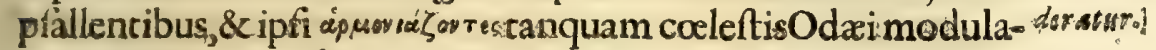
tores,omnes chardas vocefque in fummo illo Dei monochordo adaptantes, ut ithad reddant concinnum fuaviffimumque, iutif qua fint mutila fides, vel moduli diffentientes, eas abiiciant; refcindant, reprobentque; nè in mundano coelefti vel humano polychordo aliquid difionum reperiatur. Gaudente itaque omnia movente.Patre,tefte.Dionyfio; à Deo fiquidem: moti movent Orbem, \& iftacorpora noftra, cœereraque inferiora ad'eam confonantiam difponunt, quam jubet ipfe primus rerum omnium Motor.

V I.Theodidactus. Hæc omnia cepi. Dic iraque, cùmtanta fit corporex naturx multitudo, quomodounum in alterum. influac: hocenim caperenon poffum ; mulcò minùs, quomado:moveantur:namutiin itinerenoftro per firmamenti immenfitatem peracto obfervavi; fingula fyftemata, prazer id -quod circa Tellurem eft, circa centra fuos proprios motus in. propriis circulis, tametfi nobis infenfibilibus, habent: certè tantam motuum varietaremà proptia corporum forma nafci,credere vix poflum:ab alio iraque,præter Motorem omniŭ, in finesfuos dirigi debent. Co/mial. Nofle debes, Theodida-ete, mundum hunc confiftere minimè pofle, nifi cum dependentia ab intellectualimundo,ad quem perfectâ quâdam analogiâ conftitutus eft. Nam ut univerfæ Naturæ Auctor \& Mundus Opifex mundum minorem, propter quem omnia facta eranc, verporeteus in abfolutiflimâ harmoniâconfervarer, aliam enneadem mo- dependet ì vit, Coeleftis videl icer mundi fyftemata, quorum influxu infe- Deo, qui rior mundus gubernarecur; Coolum primum Empyreum, CoeJum ftellatum fen firmamentum, deinde globosSaturni, Jovis, tem munMartis,Solis,Veneris,Mercurii,Lunx. Verùm cùmhæec cor- dum guberpora ex fe \& fuânaturâ effent inanimata, motûfque eflent in mnibmo
$\therefore$
$\mathrm{Ggg}_{2}$
capacia; 
capacı; fingulis fuas attribuit Intelligentias, quarum virtute variis motibus agitata varios effectus, profublunaris mundi exigentia producerent,atque adeo corporeæ naturæ confticutio à fuperiorum corporum influxu dependeret; Intelligentia verò Coel is afliftentes omnium difponendorum curam haberent, Deo Chorago fupremo fupremis infina, media fummis" in unam perfectiflimam harmoniam colligance. Verùm ut

Ordines

rerum

creatarum

mofem, rom parate cum yintelle-

Ci. ales mundior dinibisu. harmonia fingulorum luculentiùs patefiat

VII. Nora,novem efie Regiones caleftes. Primo Empyreú Coelum,æterniR egiscuriam,\& fupramundanamillam Motoris omnium domum, quæabordine \& infinita luce non incongruéSeraphinorumordınicongruit, ex qua \& omnes animarum illuminationes tanquam ex fonte quodam uberrimo procedunt. Secundò fequitur Regio ftellarum inerrantium quoad noft rum vifum, five fir mamentum, in quodOpifex vel. uti in numerofa inftrumenta rerum efficiendarum fe diffundir,\& pulchrè Cherubici Ordinis Intelligentix convenit: funt enim ftellæ in homine nihil aliud, nifi notionum in anima humana velutiquadam fymbola, ex quorũ conceptibus formalibus nafcitur fcientia Cherubinis propria. Tertiò Saturni globus rectè Thronis five Intelligentix, quam Hebræi Schabtael vocant,convenit: nam virture fuâ influxivâ in nobis firmam, fixam, inconcuffamque prudentiam generat, hominem praterea in throno confiliorum fúorum fixum veluti ligat; unde haud fine cauia ab Hebreis Schabtai, hoc eft feffio mea dicitur, cui omnia in mundo fublunari Sazurninam naturam redolentia, in lapidibus, plantis, anımalibus fubfunt. Quartò fequitur globus Jovis, qui naturâ \& proprietare pulchrè Dominationum choro congruit: eft enim, planeta beneficus, " egius, \& majeftate plenus; unde fub ipfo natis dominationem \& imperium promittunt Aftrologi, fi ipfis fides habenda eft:Intelligentia verỏ ejusdem rectam juftitam confert. Sub hujus imperio, omnesfublunaris mundi res Jovialem naturam redolentes fubiiciuntur. Sequitur globus Marcis, qui ob igneam quandam \& aduftivam vim optimè 
Vircucibus quadrac; nam igneầ virtuce fuâ in nobis dum bilem urit, ad res arduas cum facilitate fuperandas a ptos facit, roburque \& forcitudinem augec. Hinc globo omnia inferior is mundi Marciali naturâ pradica fubduncur. Globus Solis, urimedium mundi corpus obtinuir, ita non fecus ac Rex \& Princeps. rotius,omnı virture \& poteltace fuẩ moderatur; unde oprimâ rationemedia ordini Poteftatum convenit : Intelligentia verò ejus in nobis vitam, profperitatem, gloriamque produciu. Solaris naturæ in fublinari mundo corpora huic perfectè confonanc. Globus Veneris, benevolus \& pulcherrimus Planeta, Principatibis quadrat; cujus. Incelligentia Haniel, id eft, gratiofie intelligentix genius, nobis rerum pulcherrimarum a moren inftillat, gratiam \& benevolentiam omnium canfert. Huic globo, rutcl.ę̧ ejus Intelligentix fübüunt omnia naturæ quâdă analoglả ipfi correfp ondentia. Globus Mercarï Archangelis aptè comparatur: ficuti enim Archangeli cum imagine fummi Principis omnia conformare; \& uc libi perfectâ unione copulentur, componere ftudent $;$ ita \& Mercurius numeros vocales, formales, \& racionales in eandem confonanciam reducere laborat, præcipuè rationalis numeri compofitionem cum divino ; docetque Intelligentia ejus veram concordiam \& unionem cum Den, animasque conatur in Deum deducere illâ confonantiấ, quấ ipfí perperuö conjuncte femper prorumpant in perpetuos hymnos \& laudes illius majeftacis æternæ: Hu comnia fublunaris mundiMercurialia fubfunt. "'Itimus deniquecoleft is Enneadis globus eft, Luna; unde optimë cum Angelis , inter novem Ordines ultimis, confonat: frcuri enim, hæc nobis proxima, ita \& Angeli, ficuriluna omnium fuperio um Planerarum vires in fe recipic fublunariomundo communicandas, ita \& Angeliilluminationes à fuperioribus mentibus acceptas in nos derivant. Innumera hos loco de peculiarium virturtus influxudici poflent; fed iis non immorabor.

VIII Visấ itaque enneadis rarimeas by. ne,concentuque quodam a din prima cum fecunda cognatio ti a a quone, concentuque quodam admirabili; jam quomodo certiẩ en - modo cum neade, five ternario quadraco, omnes fublunaris mundicrea- Triade in

Ggg 3 turas creata in.


tellectuale compare.

tur.

Nobem vib. isnarium entium gredus.

Omnia in omnibus font.

truras omnium produxerit Artifex, videamus. Monasitaque primæva, principium omnium, in rempore in dyademfeexplicans, indefinitam dualitatem five materiam produxit; fquidem ex monade \& dualitate numeri,exnumeris puncta, ex punctis linea, ex lineisfuperficies, ex fuperficiebus denique folida corpora profluxerunt; quacuor videlicet elementa, primaria rerum fundamenta, de quibus,utalibi traditis, hîc fufior efle nolo, fed folùm hocloco oftendam,quomodo dicta Elementa quatuor cum quinque miftorum entium gradibus tertiam enneadem conftiruant, \& quomodo elemenca non in corporea tantùm natura, fed intellectuali enner de, imò Deo jpfo,fuo modo, ut muficus mundi conceprus cum. Archecypo Juculentiùs patefiat, reperiantur. Enneadem continent quaEuor elementa cum quinque corporex nacura gradibus; qua conjundta, novem; ut fequitur, conftiturunt : terram, aquam,aërem, ignem, lapides fivemecalla, plantas, Zoophyca, animalia. bruta, hominem, quibus inferior mundus conftat. Quxtamen etfi corporea, fapientifiimus tamen Condicor \& Ita sma ta ea tali harmoniâ cum reli quis duobus mundis colligavit, un fingula fuo modo inunoquoque mundorum fint. Eft primò Terra inferioris mundi bafis \& ftabilimentum. Eft \& in Coelisterra,ut in pracedentibus oftendimus : $E$ ft \& in Angelis fue modoterra, in quantum funt firmaDei fedilia, \& fcabellum pe. dum ejus: Eft \& in Archetypo omnium firma foecundiffimaque natura, juxta illud; Aperiatur terra, Es germinet Saluatorem. Ef fecundòaqua elementar is levis, lucida,mundans, \& lavans omnia. Eft \& in Colis aqua,fuo influxu terram irrigans, \& commixtibilis virtus, qualem Luna, Venus, \& Juppiter hominibus influunt : In Angelis eft docens \& mundans, juxta illud; qui tegis aquis Juperioraejus: In Opifice verò ayua falutis, quâ peccara abluuntur, homo regeneratur,mundatuc, collutratur. Terciò, aére elementari refpiramus, videmus, audimus, \& odoramus: Eft \& aërm coelis; diaphana illa natura, mundanum ornacum divitiasque oculis exponens : Eft \& in: Angelici mundi fpacio, ubi beatarum mentium concencus? 
refonant, vitalis flatus, \& aura tenuis :In Opifice fumma \& perfectiflima vita \& fpirıtus, quo in omnes fpirat, ut vivant refpirentque. Quartò,quod elementaris ignis apud nos, hoc Sol in coelo; hoc in Hieraxchico mundo Seraphicus ardor, impeass queigneus, juxraillud: 2uifacis. Angelos twos Spiritus, or Miviftros twos ignem urentem; hoc in Archerypo deniquè-ignis idealis, \&lumen fpirituale, quo ommia gignentur,confervantur, fuftinentur,aluntur, augentur... Sunt igiturElementa in - Connexio Deo feminaria quæda $m_{\text {, \& producendarum rerum idea,femi-rorpores }}$ naria prima \& origimes; In Angelis diftributa poteftaces; In mundi cums. colo virtuces analogx; in naturatrerum fenriva ; in mundo intelleci was mun inferioricraffiores formæ. - Arque hincnafcitur admirabilis dis, barmo. ille mundi concentus; quo Terra cum Iuna, Terra coelefti," "iam mun Aqua cum Mercurio \& Venere; Aër cum Jave \& Venere I- di conftignis cum Sole \& Marte; lapides iterum cum Saturno; metalla: cum Jove; Zoophyta cum Marte; infecta cum Sole;cüV enere. volucria ; amphibia cum Mercurio; cum Luna quadrupedia; omnia cum omnibus mirâfympachiâ confonant tum inter fe, tum cum anima racionali; cujus enneas collectaeft ex quinque fenfibus exterioribus, quatuor interioribus, videlicet fenfu. comuni,imaginativa, cogitativa,memorativa, terminaturque: ad intellectum tanquam ad decimum; cui \& alia enneas purior in fimplicibus numeris; videlicet novem Angelorum Ordinibus, convenit, utin eo plena fit Angelorum Deique imago,terminaturque indecimum fontem, filicet, fupremum o-. mniumque Patrem. Eftque ei triplex operatio pronfus confonans \& harmonica.cum mundohacinferiori in natura,cam. coelis infenfibus,cum Angelis in intellectu. In tetradem emer git per fimplicem animx potentiam; in enneadem per novem fenfus, quinque corporeos, quatuor incorporeos; in icofibe. pradem five 27 ; totius confumationis rerum ideampervenit, dum intelligendo, omnia fic. 


\section{A P U T VII.}

\section{De Aquis qua fupra colos funt; ES an propric $\exists$ verè aqua fint; $\xi \xi^{\circ}$ destilitate earum.}

1. T Heodidactus. Jam tanto tempore in immenfis firma-

1 menti penerralibus hinc inde divagati,nullum nec globorum numerum, nec finem af́picio; unde magnum pectus" meum difiderium invadit cognofcendi,quid tandem poft tor globorum congeries, củm mundus infinitus non fit, rerum fuperfit. O fi tantumà te beneficium obtineri polèm, ut ad ultima mundi confinia me perduceres, quantâ me felicitate affectum arbitrarer! co miel. Ea à me petis, qux homini mortali concedi nec polfint, nec debent; quantum tamen Deus \& $\mathrm{Na}$ tura permitcic, tibi globorum finem oftendam. Theodidactus. Fiar. Et ecce, motu multò cœlorum globis velociore, exiguo cemporis fpacio, eò ufque ne perciuxit , ubi omnibus globisevanefcentibus, nulla coli fax ampliùs ocu lis meis Illucelcebat. Itineris hujus longitudinem, nulla adeo acuti ingenii vis, nulla canta mentis focunditas efle poreft, qua animo comprehendere,nè dicam verbis explicare valeat SedôCofniel, ubifum? $V$ bi me conftituifti Sentio tocum corpus meum miro quopercaleftes. dam \& fenfibili rore perfufum. Cofmiel. Nè mirare; jam enim aqueum illud expanfum ingreflus, cujus facre paginx mentionem faciunt: aqua qua fupra calos funt, laudent nomen Domini. Hæ funt aqux illæ, qux à primis mundi exordiis f6parata fuerunt, quarum pars globis mundiceffit in fomentum, pars ad mundi confinia in fines paulò pònt dicendosrelegata. fuir; de quibus facer textus : fiat frmament um in medio aquarum, E' dividat aquas ab aquis. Theodid: Omnia bene fe habent; Sed aquas non fentio,nec ullos fluctus aut undas (cujusmodi in ingentibus Ocean is me vidiffe memini) video ; \& cur tu dicis", me jam aquas fupercoleftes ingreflum eflè? Cofmiel. Spacium in quo conftitueris, veriflimas aquas continet, fed minimè, uti 
in Terra,coterifque mundanis globis,craffas, fœculentas, cơrpulentas; quin maximè fubtiles, pellucidas, \&abomni terrena contagionis mifcella purgatifimas. Quòdenim corpustuum nefcio quorore perfufumfentias, illud aquenm quad pertranfis, medium efle fcias; cujus fubtantia tamet féfuibiliflexibilitate ob fummamfubcilitatem careat, madorem itamen inducit cantò penerrantiorem, quantò hæa aqux inferioribus fubtiliores func. Nonnè qui manèad auroram Solis per herbida prata ambulant,corpus quidem madefierifenciunt, etiamfi aquam non videant, \& tamen eos per aqueum medium tranfire certum eft? Pari pacto hocloco (fi camenmagna parvis com parare fas fic) evenire cenfeas.

II. Theodidact us. Suntnè hxiverè elementares aqux?:Cófmie'l. Aque'uQuid dubiras, fili? Hæc enim fuit primordialis illius aquxpercaleftes cliaoticæ congeries, fupra cujus faciem, tefte facrâ Scripturâ, an fint ele. Spiritus Deiillam incubando, \& ad faruram animando agitabatur; quam poitea recundo die, pofitofirmamentodivific, Terræ globisque mundanis parte, parte verò, quam jam vides, huctranslatâ, Uti igitur primordialis illa aqua chaoticalunius \& ejusdem effentia fuit, ita poft facta m feparationem quepermanfit, folis accidentibus diftincta. Theodidactis. 1- Aqueune num quod non capio,mihi ut exponas obfecro, undelaxilla expanfuma fpacii tam immenfi affulgeat, cum nulhum Solem, neque a- quomodo ftrum, quod fpacium illuminet, confpiciam? Cofmiel. Divina tur. Opificis Sa pientia, uti nec in minimo quidem animalcalo, quin illud omnibus ad fe confervandumneceflariisfubfidiis inftitueret, defuit;ita inxitimabilem hanc aqueiOceani vafticatem, maximè omnium neceflariâ luce inftructam voluic. Lux quam vides, primigenixillius lucis, quam in primordiis rerum produxit, porcio eft; quam ita aquex huic molicommifcuit? tam aptèconnexuir, ut quemadmodum partem illius fingulis coeleftibus corporibus indidit, ira \& illâ quoque hoc fpacium minimè deftituit: primò quidem nè ulla mundi regio perpetuis opprefla tenebris, Natura tantopere inimicis, perpetuò Hhb qquale- 
Aquat fur. Dercaleftes que wh nabe-

Aqueum expanfam jupercostefiequantheor fito.

Primum Mobile w trum, है w. Gijich.

An moficas

twr.
426

Itinerarium I. Dialogus II.

fqualeret : deinde quoque, ur fingul $x$ mund regiones, hoc vel. uri calido quodam radicali in elle fuo confervarencur.

III. Theodidact us. Omnia, utifoles,tam fcitè \& fapienter. exponis,ut duin veritatem rei tangis, intellectui meo plenè fatisfacias. Sed rogote; habetnè ulum aliquem in natura rerum - tam ingens aquex molis Oceanus? Co/miel. Imò tantum, ut fine eo muncius confiftere non poffit. Ex hoc enim, veluti qua dam promocondo, tum rthereum mundiexpanfum, cum finguli mundi globi neceflarium attrahunt alimentum, fine quo haud dubiè contabefcerent. Hæfupercœleftes aqua fingulis futrm conferunt vigorem, calidum \& humidum radicale inexiftens corroborant, augent,perficiunt; verbo idem quod in microcofmo homine praftat nutrimentum, id in megacolmo has aquas præftare unicè tibi perfuadeas velim : funt enim totius Natura veluti ubera quadam, quæ omnibus mundi corporibus fufficientifimum \& inexhauftum alimentum prabent. Theodidacius. Ex hoc ruo ratiocinio colligo, exceffivam hujus fpacii vaftitatem. Cofmicl. Hllam tantam elle fcias,ut firmamenti expanfum innumeris parafangis fuperet. Cùmenim id torius mundipenuarium fit, ex quo fingula mundi corpora,neceflària, nè deficiant, fubfidia depromunt; illıd utiø; ingentis magnitudin is eflè deburt, cùm id omnia intra fe, veluci malum punicum innumeros fuo cortice acinos, nundi corpora involuta concludar:

IV. Theadidactus. Habetnè aqueum hoc expanfum, motum coreris ftellis fimilem? Cofmiel. Motum circularem veluti circa centrum in eo nè quaras, Cüm enim fubtilifimum fit,\& rofcidi intar vaporis pellucidum!', xtherique, fr humiditatem excipias, fimillimum; ita quoque atheris aërifque motum perpetuâ inftabilitate agitarum im itatur.

V. Theodidact us. Vti dicis, ita fieriexperior. Verum ubi, quxfo, tam omnium Philofophorum \& Aftconomorum monimentis decantarifimum illud primum Mobile? An forfan. aquashafce fupercoleftes fun includet ambitu ? Cofmiel. Nè quaras, Theodidacte; in mundo primum Mobile, cum tale, quale 
quale id Peripatus defcripfit, in rerum natura non fit. Quod verò fufpiceris, nè forfan ordine Nacuræ expanfum hoc aqueum includat, illâ tuâ fufpicione oppidò falsẩ illuderis: quomodo enim coelefte corpus fupercoeleite includere poffir, non video. Neque imagineris tibi folidifimam quandam fph $x-$ ram, qux mosu fuo creteras omnes fphraras \& globos rapiat: hoc enim quàm fenfatze experientix repugnet, an non vides? Quomodo enim liquidum fpacium, nullum certum fubfirtentix ftatum fuftinens, à fphrera folida rapi poflir, quis eft, qui concipiat ? Ut interim folida globorum corpora tam remota fubticeam.

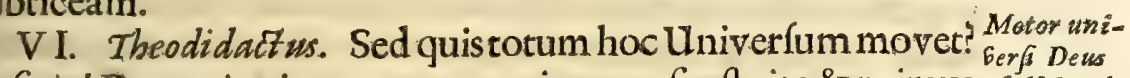
Cofmiel. Deusuti prima rerum omnium caufa eft, ita \& primus $e f t, E$ Intebomnium Motor ; Intelligentix verò, feu exercitus coeleftes, ligentia. ftacionibus fingul is fibi diftributis, à Deo motæ, particulares \& individuos mundiglobos ad nutum \& voluntatem primi Motoris movent, ac in mundi emolumentum juxta legesæternas atque ideas in Archetypo fupramundano elucefcentes, quas" femper contemplantur, difponunt, adminiftrantque. Illas autem à propria forma moveri, dici nullâ ratione potent, tum ob fines innumeros, quos in mundana adminiftratione præfixos Afra non habent, tum ob motuum tam difparium diverfitatem, quam. mobentur is fingulos globos complicatam habere comperimus. Unde rectè forma. Ariftoreles, opus natura, opus Intelligentia dixit. Corpus autem nacurale exanime,cujusmodi Aftra funt, ut diverfos illos, diurnum, annuum, \& qui circa axem fir, motus, ofcillationesadhæc, \& mutationes axium, finilesque revolutionum leges à propria fua forma depromat, tantùm ab ejus naturali appetitu alienum eft, quantum alienum eft à gravium leviumque natura, alio præterquàm à circumferentia ad centrum, vel à centro ad circumferentiam ferri. Complura tibi, Theodidacte manifeftare poflem circa hujus fupercoeleftium aquarum expanfum, arcana myfteria ; led nè inaccefforum miraculorum multitudine ingenium tuum obruam, plura dicerefuperfedeo ; tuú

$$
\text { Hhh } 2 \text { erit, }
$$


erit, ex paucis hifce nocitix feminibus, jact ts, uberiorem ingenii wit foeturam educere. Quare.ad alia progrediamur.

Fimpyresum

\section{C.AP U T VIII. De.Colo. Empyreo.}

1. THeadidactus: Uti nilil Coelo. Empyreo in Scholis tri1 tius eft, ita nihil eo obfcurius \& ignotilis effe comperio. Quare rogore,mi:Cofmiel,utquiliucusque toriusmundi compagem oculismeis exhibuifti, maximum illud \& praftantiffimum omnium mundi habicaculum oftendere nè graveris. Cofmiel:Aitimi: Theodidacte, nefcis fanè quid peras. Tunè putas fupremam:mundicuriam, Dei;Angelorum, electorumque fedem, mertali carne veftitum hominem adirepofle; auteam, oculis mundanis fordibus defoedacisluftrare? Noneft id hujus cadirc vitz, fed aternæ felicitatis ftatui refervatum. Theodid. Ignofce temeritatimex, \& oppidò nimiümqueaudaci, nè dicam przefumptuofx, curiofitati. Ita dívirâa afpirante grariâ impofterum me vidturum propono, utex folutocarnis mortalis" debico, illud multò eminentiori modo, quàm carneis oculis contueri merear. Non tamen omittes ad nonnullacirca hoc coéium obvia mithi dubia: refpondere: , ut fic quovis modo f́ciendüidefideriofâtisfiat. Primò̀ itaque profümma:tuaerga me humanitate \& benevolentia mihi exponere-non abnuas, turum iftiusmodi coelum pars mundifit conftituriva? deinde, utrum corporeum? denum, utrum verèä nomine Empyreum feurigneum fit:

1. Cof miel, Caclum hoc; cum tanta excellentix \& füpereminensiffima dignitacis fic, uthumanx mentis vis \& efficacia eam non dicamexplicare; fed nec animo quidem concipere, multò minùs imatginatione apprehendere poffit;nonopus eft, Illud varis rationum momentisexponere: Illud Dei domum. coelum coeli Thronum Excelfi, tabernaculum Dei cum hominibts, (uriid Aquila Evangelica defcribit) eflefufficit, Effe ta- 
men partem mundi contiturivam, nulli dubium efle deber; cùm illud non fit extra mundum, féd intraillum veluticlauftrum totius conftiturum. Undefequitur, illiud vere \& propric corporeum effe,cüm fit Corporis Chrifti, \& Bearze Matrisejus, omniumque:Beatorum locus, adquem poft piè.\& fanctè trans " promen emactos vita morcalis dies, transmigrances recipiuncur: Efte-re corponim locus nihil aliud, nifi fuperficies corporis locari, tocus au- reum, 8 rem diciminimè pofler, fi, uti nonnulli perperam crediderunt, murdit fpiritualis: fubftantize föret; nec mundi corporeiconftitutiva tutisa; pars eflèpofler. Empyreumverö dicicur, fetlquodidemeft; gneum; quòdluce fümmâ, \& \& füpra omnia mundicorporafulgidiori liceat; quæ tamen nec: cæcitatem fuis incolis, necmoleftiam afferatullam;; quin:potiùs.ob inæeftimabilem pulchritudinem, lectitiâ inconceptibili, fuavitate inenarrabili Beatorumoculos afficiat. Theodid:Cün illud tantâ claritate fülgear, Empyreum

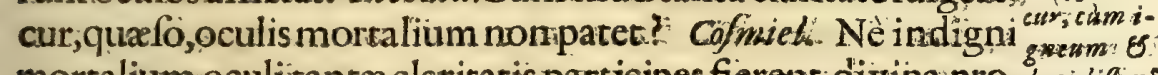
mortaliumoculitantæ.claritatis participes fierent,divina pto- - lues diffim videntia: colium hocaqueum vos inter \& memoratumcolum fit,non ficolorum, veluci velamentum quoddaminteriecit. Cüme destur a: nim fjaciumboc aqueumadeo expanfum, \&adeo incomprehenfibili intercapedine exporrectum fit;utunemo facilè hominum id ingeniifuicapacitate penetrarequeat; hinc fic; urtamerfiid diaphanumfit:\& pelluftre; \& vix fubtilitate:ærhericedat; adeo tamenex innumerabili fuperficierum coacervatione: conftipetur, utnon fecus ac:Solemi nubes denfa, ita Empyrei coeli afpeetumaquei hujus expanfi diffiufa nubesobnubilando. auferat:quodverum efépaulö pònt fènties. Theod.Quiefcere: non pofe: videor, donec aliquem hujus tam divinatacis $\sqrt{a} \mathrm{l}-$ tem mihi radium oftenderis Cof miel Factumeft, quod peri-. fti; aperioculos tuos;\& vide. Theodid. O Cofmiel! ceflä;ceflä; excefliva lucis hujus efficaciamimpofibile eft ut feram; $\mathrm{Sol}_{3}$ Aftra, ignis,omniatenebrafunt comparatione ad hanclucem factâ; füfficit,füfficit; Còfiniel; meo me reftitueloco; malo e nimomnia humillimo mentis obfequio, qua mihinarras;creHhh: 3 ; dere, 
dere, quàm ultra condıtionem humanam plùs.xquo fapere; neque iralcaris temeritati mex, cùm hæc non tam curiof mentis impecu, quàm coeleft is patriæ, quam expectamus, amore, \& nelcio quo pio affectu impulfuque videre defiderarim s Cofmiel. Ecce jam tuo reftitutus loco; perge dubia, qua tibi fuperfunt, proponere.

Empyreum avexmaterias 8 forma compofit
III. Theodid. Eftnê coelum Empyreum ex materia \& forma compofitum? Cofmiel. Cùm fuprà dixerim, Empyreum efle partem conftitutivam mund 1 ; erit id neceflariò corporeum: fi corporeum, id fanè aliud nô erit,quàm corpus phyficum : omne corptis phyficum ex materia \& forma componitur; ergo coelú Empyreŭ ex materia \& forma componitur.Quod fi quifpiă neget, is pariter negare cogetur, omnes affectiones corpori phyfico \& quanto competentes; pariterq; fateri debebit, empyreû null is vifibilib. colorum qualitatibus, nullis auditivis, nullâ duritie, mollitie, condenfatione, rarefactione, nullâ quantitate affectú efle ; ergo totum invifibile, fpirituale \& non nifi intellectu atcingibile; quod abfurdú, \& contra finem Conditoris fapientifimi efle, nemo eft qui non videt. Hoc tamen fcire debes, formam \& materiam, ex quibus componitur, adeoq; totum. compofitum, infinities, ut ita loquar, nobilioribus, excellencioribus, fubtilioribusque partibus, fublimiorique formâ quàm. qua omnia catera mundi corpora conftant, conftitutum efle, utpore quod in Electorum fuorum voluptatem \& aternam; oblectationem Conditor benigniffimus, hac qualitatum eminentifimarum prærogativâ docatum efle voluerit. Nil dicam ampliùs. Quale \& quantum fit hoc ipfius Dei, Angelorum,\& beatarum mentium habitaculum, apertè demonftrat Sanctus Paulus in fua Epiftola r. Cor.2. Oculus non vidit, nec auris audivit, nec in cor bominis afcendit, qua Deus praparavit diligentibus $\int$ e. Et fanè incongruum videbatur, illud coelum, quod rationalem creaturam ex anima \& corpore compofitam recepturum erat,fine corpore purè fpirituale feu intellectuale conditum fuiffe. Corporeum ergo effe debuit,ut anima in contemplatione Conditoris fui abforpta, corpus quoque fenfuum oblecta- 
lectationi proportionatum reperiret objectum, nè fruftra ad seternam glotiam aflumptum videretur.

IV. Theod. Eftè Empreum IV. Theod. ERt ècoelum Emprotut quadrato an rotun. conclufum ? Nam multi è Sanctis Parribus ex Evangelicæ A-dum, aut quila defcriptione, illud in Apocalypfi indigitatum, quadra- quadrasum efle volunz quoad exteriorém fuperficiem; ita enim dicitur: Civitas fupraquadratum pofit a eft. Cofmiel. Non incelligashac velim ad litteram, fed fub allegoricofenfu omnia intelligenda efle tibi perfuadeas: innuit enim fummam hujus do-

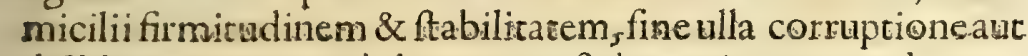
diflolutione perpetuò durantem; fed terminasur modo quodam humanæ menti incomprehenfibili; ut proinde fruftra. fufioribus verbis id ribi explicem, cum ejusquamdiu bumanxe mortalitatis farcinâ circumdaris, capax efle non pofiss

V. Theodid. Eftnè colum Empyreum adeo vaftum, ac id Empyreum Sancti Patres defcribunt? Cofmiel. Ita eft: uri enim id univer-fum fat. fam mundi machinam concludic, ita meritò omnium mundi corporum capacifimum, omnia reliqua mundifpacia longè fuperare videtur : imò aufím dicere, totum hujus fupercoleftis aquei f pacii concavum, quod omniacontinet, comparatione ad colum empyreum factâ, non nifi punctum cenferi debere. Theodid. OCofmiel, paradoxa dicis, \& humano:intellectui in- CelumemTheodid O Cofmiel, paradoxa dicis, \& humano incellectui in- pyreum ad comprehenfibilia'; vera ta men efle non dubito, cùm infinitam reliquum Dei majeftatem cumprimis deceat palacium habere tantæ ma- fibi inclugnitudini majeftatis congruuin. Jam video verificacum illud dum /e bafacri textus: Magnat est domus Dei, \& ingens locus poffefionis bet, uti cirgjus; wagnus est, so non babet finem; excelfus, e? immenjus Crea- culus ad for omnium. Et, in domo celeftis illius Patris manfiones multe Junt, $\sigma^{2}$ inexplebilia tabernacula ejus. Sed jam, mi.Cofmiel,aliquid mihi de fummis hujus coleftis patria delicis recenfeas. cofmiel. Faciam quod poftulas. Nil hic de interna beatarum, Gaudia mentium pace \& tranquillitate, a nimorumque choreis dicam; mihil de incomprehenfibili Angelorum hominumque in æer- in crioEmno illo Archimufei Odeo Symphonifmo: certè omnis hujus pyreo. mundi pulcherrimarum rerum afpectus delectacioque adil- 
lum comparata, quid aliud fune, nifi vile ftramentum, palex puerid $x, \&$ exigua quædam arena foecium terrx : omnis imaginabilis, ,qux humani ingenii folertiâ unquam inveniri powit, harmona \& mufica , omnis inftrumentorum harmonicorum conceptibilis fuavitas \& dulcedo, omnis humanarum vocumexcellentia \& perfectio, quid ad fupremam illan muficam comparata aliud funt, quàm diffonancifimus:belluarum fremitus, luporum ululatus, grunnitus porcorum? Quidomnis odorum, faporuin, taetusq, harmonica fuavitas, dulcedo, mollities, niff fxtor, amaritudo, \& mera immundities? Cujus ordinatifimam \& fupereminentifimam difpofitionem ficuti oculusnon vidit,nec auris audivit, nec in cor hominis afcendit; ita eadem nec ullo verborum conceptu explicari, nullâ ftyli felicitate foecunditateque declarari, nec ullo profundifimo mentis fcrutinio penetrari poteft. Ubi non trium,quatuor, quinque, fed ineffabili Yupereminentiffimarum vocum .ymphonifmo tosa coeleftis Regis curia \& auila fupramundana diverfis Senatorumclaflibus, velutin choros quosdam difpofitis, in perpetuas refonabuntæxternitates : ubi.Chorus Virginum Choris Confeflorum, hi.Martyrum, Apoftolorum, Patriarcharumque Choris inter fonantes, omnes fimul cum tripartitis Angelorum Hierarchïis concordantes, ad perennis aquæ vitæ fontem, xternum conquiefcentes, xternum illnd Alleluja indeficiente exultatione, Deo ceu fupremo quodam Chorago per fapientiam fuam fymphoniam dirigente, fpirituque oris" fui organum animante, modulabuntur: Ubi Agnum Dei, qui in hocæeternitatis domicilio \& organedus, \& organum, \& Mufica eft, feqtentes cantabunt canticumnovum, admirandum. illud Verbi Dei cum humana natura in utero immaculatæ Virginis defponfati epithalamium \& hymenæum : ubi laborum, tormentorumque in hac mundo pro amore Dei exantlatorum recordatio, velutidiffonum quiddam $x$ ternæ beatifimæquevitæ confonis miftum fyncoparumque, in omnium. dulcifimam perfeitiffimamque harmoniam coalefcet. Theod. O infelicem eorum fortem, quiadfallacia momentaneaque 
calamicof $x$ vicx hujus bona, ad mundanx ambitionis ftrepitum,immundarumque affectionum ac voluptatum diffonantiffimas catadupas obfurdefcentes, fpe fuâ ad eam pertingendi Muficam, quam defcripfifti , aliquando percipiendam excidunt! O magne rerum Harmofta, qu1 omoia in numero, pondere, \& menfura difpanis; difpone animæ mex enneachordon juxta divina voluntatis tuæ beneplacitum; incita omnes anima mea nervos in laudem \& gloriam nominis tui, ut Seraphico ardore te diligam, Cherubico mentis fcrutinio inceflanter te quaram. Sis anima mex thronus ubiquiefcas, ubi cubes in meridie; adfic Domithationum, Virtutum, Poteftatumque prafidium; Principatum ponas fuper omnem animæ indomitam rebellemque affectionum turbam ; ut Angelicâ tibi puritate perpecuò ferviam. onet wox tua in auribus meis; Vox enim tua dulcis, E facies twa decora. Difpone in me eam Virturum. harmoniam, quam \& tu in te, \& in fupremis Virturibusab inirio difpofuifti, ut de virtute in virtutem veluri de tono in tonum procedens, ad virtutum omnium diapafon, totiufq; perfectionis complementum pertingam; atque hoc Virtucum. prafidio munitus, in debachordop falterio p fallam tibi, teque in fxcula frculorum laudeth \& glorificem. Amen.

\section{CA IIT IX. \\ De pratoimaginario.}

I. THeodidactus. Pervimus tandem ad ultimum mundi Iterminum; ut proinde nihil reftet, nifi ut mihi explices, quid extra ulcimum huju. Empyrei Coli terminum fit reliquum. Philofophi fiquidêm nonnulli nefcio cujus imaginarii fpacii extra mundum mentionem faciunt, cujus tamen rationem nemo eft, qui explicare valeat. Cùm enum corporei mundi machina, uti fuprà fcitè docuifti, infinita efle non poffit; quid igitur mens mea concipere poteft polt ultimum totius

Iii crea- 


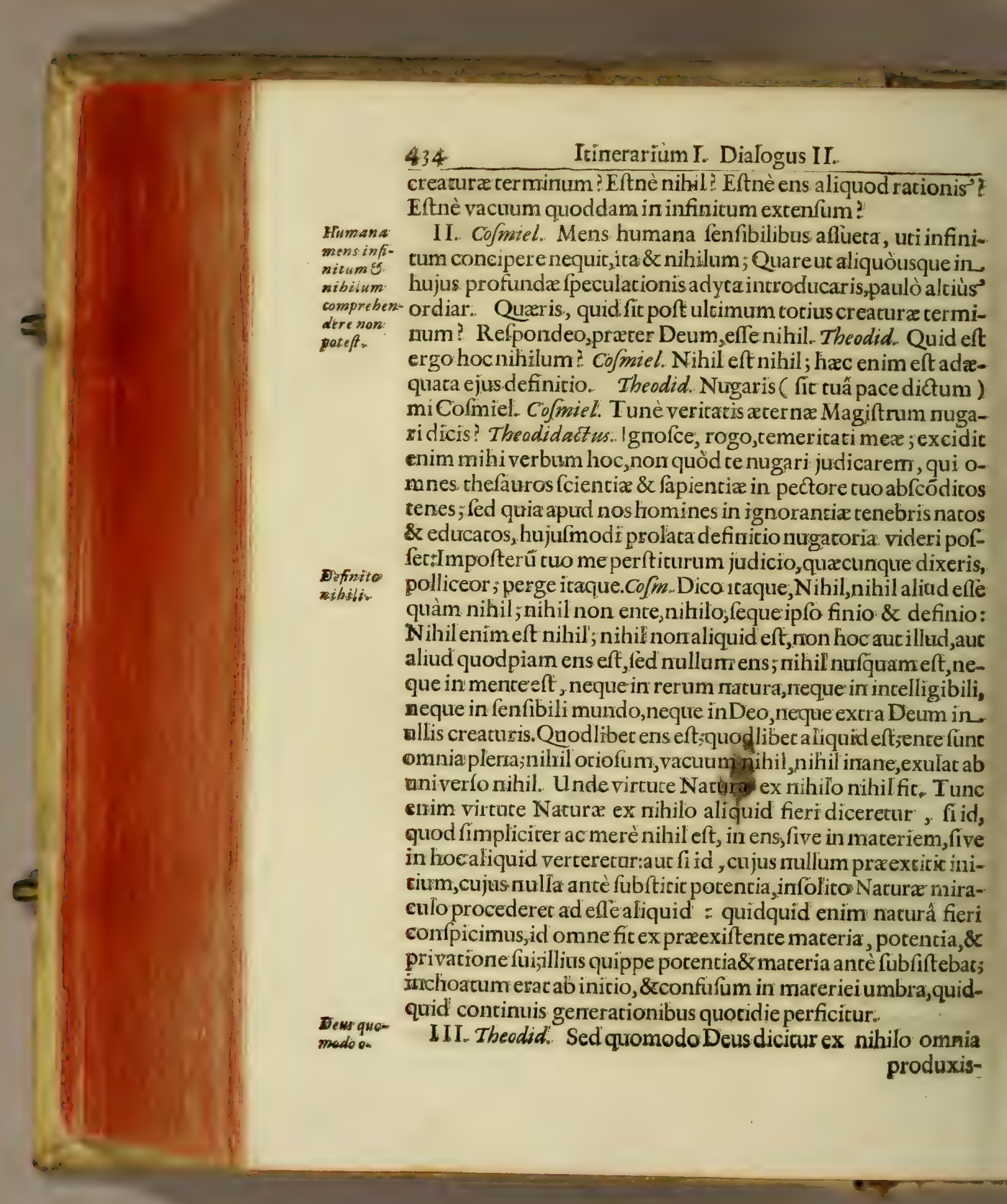



feorfim \& extra Deum fumi nequit ; quidquid divinum eft, nibilogres Deus eft, conjunctum \& counirü Deo infeparabilis à feipfo, \& imparticipabilis eft : fi enim participabilisfieret, pars ipfius exrra tocĭ , aut extra partem fumeretursea igitur pars divideretur, fieretque aliena à totius fubftantia, \& externæcujuipiă fubrtantix praberet initium, conflareturque ex ea partefubitantia, quædam exterior; quoduciabfurdum eft, ita nullâ ratione fieri pofle putare debes. Cùm igitur Deus infinita \& immensâ poteftate fulciat feipfum, ita ut avellià feipfo \& non eflènequeat, \& non pofe non poffit,\& noneffe non fir ;ideoneque dividi, neque participari potent: creatura fiquidem hoc pacto ex fubftantia Deidecifa, divinæ foret fubftantix portio, \& feparata à toto Deo; quod prorfus rationi repugnat. Reftat itaque, ut fi Deus non de fua fubftantia,neque de externa ulla alia ipfi coxterna, omnia de nihilo produxerit, denon ente, de eo quod non eft, genuerit feceritqueuniverfa. Is enim qui verè eft, \& qui omne efle tranfcendit, ei quod non eft effe dedit, quod quidem fieri non poteft, nifiab eo,qui infinitâ potentix fur efficaciâ, folo voluntaris nutu facit, quxcunque vult in coelo \& in terra: nonutique ex ente, cüm nullum præcefererit go ex nihilo, quod erat oftendendum. Porrò quemadmodum de nihiloà Deocreata funt omnia, ita in nihilo librata, \& f tabilita funt. Sicuti enim materia eadem ent ex qua educitur omnis actus naturalis, \& forma, utpote ex qua omnis fic fenfibilis fubftantia,omnium fulcrum, fundamentum, ftabilimentumque, ica \& nihil, \& non ens ad Deumin univerforum creatione umbratilem quandam materiei fimilitudinem expreffic. Sicuti enim materia omnis naturaliactui fubeft, ita omni creaturæ fubeft nihil, \& omnis creatura recepta eft, \& pofita ftabilitaque in nibilo :ubi enim nunc iunt, \& fubfiftune omnia, nihil erat priùs, \& in eo nihilo recepta funt omnia,ex quo 2 facta funt: non enim in aliquo recipi potuerunt, tum, quia non erat ipfum aliquid, aut ens quodpiam, in quo fifti \& collocari potuiffent; tum quia fi fuiffer aliquid, in eo recipi non

$$
\text { I ii } 2 \text { potuif- }
$$

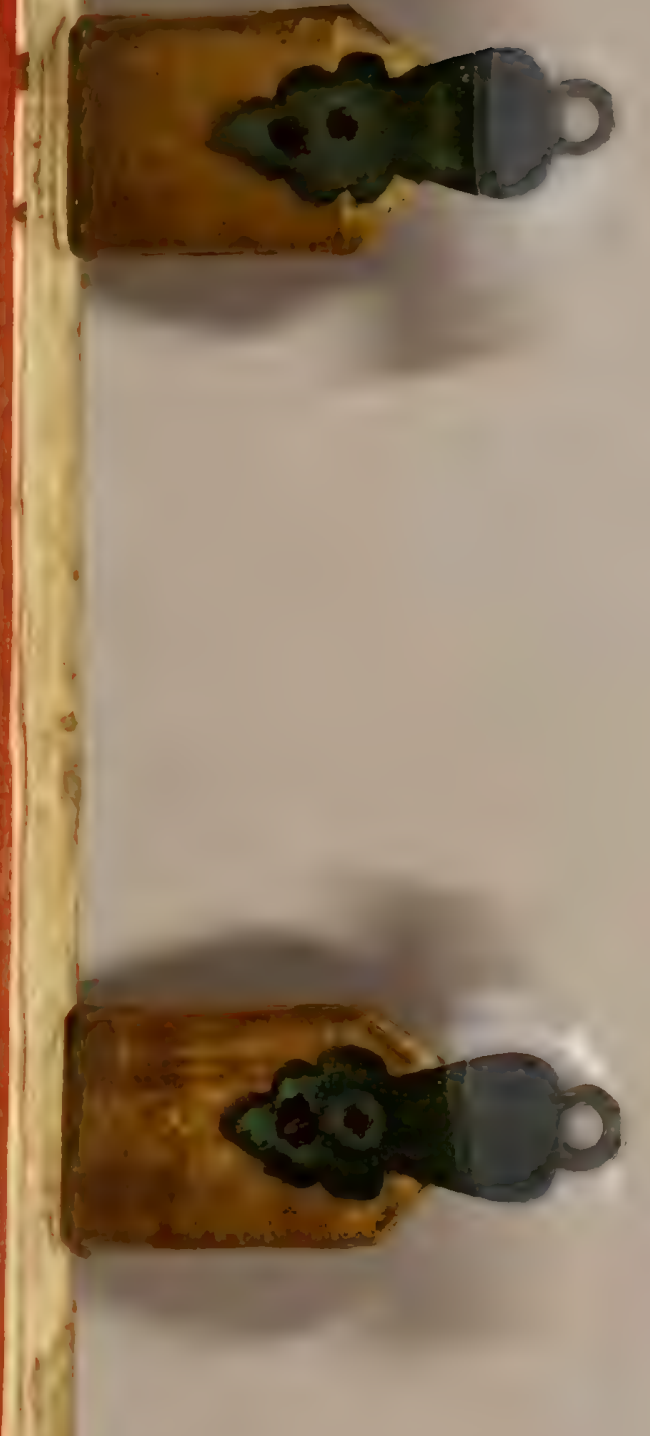


finitum minimè comprehendi, omnemque fine modo \& ratione tuam exuperare capacitatem. Haud enim Deum nofti, quòd mente tuâ illum capias;neq; cenfes eum finitum;quòd finito mentis tuæ gurguftio illú complectaris; fed ita Deum infinitum noverunt homines, quòd eum inacceffibile, infcrutabilem, actu immenfum certâ fide credant, intelligant, fciant. Deus igitur cùm fic actu infinizus, neceflariò quoque is omne fpacium vacuum \& inane (quod immenfum \& infinitum tu extra mundum concipis ) fuâ fubftantrâ \& prefentiâ implet, ab eodem omne exterminans nihil y imò omne vacuum, inane; \& non ens $z^{*}$ adeoque extraDeum neque nihilum, neque inane, ${ }_{j}$ xtro neque vacuum relinqui neceffe eft: fienim nihilum illud extra Deum nut. Deum fir, confiteri cogeris, Deum minimè eflè infinitum ; eo ${ }_{b}^{\text {lum eft }}$ niquippe nihilodivina fubitantia conftringeretur, concludereturque : quod impoffibile eft. Unde iterum fequitur, mun- Mundus dam non in nibilo, fed in. Deo receptum fubfiftere. Cüm igitur non in nifpacium illud extra mundum imaginarium imagineris, non , biloseded in nihilum, fed divinæ fubftantix plenitudinem in infinitum dif- $\beta$ tit. tenfă ut concipias oportet.Quia enim omnia perfecit\&defert, creavit, ille eadé in femetipfo, fuaq; plenitudine excipit,geftat, claudit, continet, fervat:funt enim totus múdus \&omnes creaturæ ejus ad Deú comparatæ nihil aliud, quàm punctú, \&nihil.

V. Theodidactus. Si ergo Deus omnia fuâ fubittantiâ implet, Nibilum ergo falsò dixifti id, quod nos extra mundum concipimus, ni. Jen du conclicihilum effe. Cofmiel. Scias fub duplici refpectu iftinsmodi fía- pi potessts cium nihili, confiderari poffe; vel prout refpectum dicit ad Deum, vel ad ordinem naturalem entium. Priori modo confideratum, verè nihil eft extra mundum,quod non divina fubftantix plenitudine impleatur; pofteriori verò modo rectè nihil dicere poffumus, cùm revera præter Deum nihili ibi fit; \& fic hoc loco femper impofterum accipiemus. Sed ut luculentiùs omnia intelligas,paulò fufús dicta tibi exponam.

V I. Tria in æternicate confideranda funt, xuum duplex, \& Tuam diuinter iflud medium rempus, quod eft metrum feu duratio crea- plex inter tionis \& perfectionis omnium, five fecundùm fpeciem, fer fe- brastumos,

$$
\text { Iii } 3 \text { cundùm }
$$


cundùm individuum \& fingularia. Nam tempuscreationis rerum omnium, hexaemeron fluxus eft; Tempus verò creationis, abfolutionis, \& confummarionis omnium per fingularia \& individua, tora mundi hujus duratioent. Statuit autem Deus mundum corporeum vifibilemque in tempore, definiuitque illi extrema, principium \& finem; libravis illum inter duplex æuum; complet den ique in prafentimundo, perficic, ablolvit tocumid, quod in futuro toto xuo cantinebit, fervabitque in fuo efle. In primo xuo nihil creavic Deus, in futuro nihil creaturus eft, nullum nova fubftantiæefle largiturus, neque quidquam erit in futuro æuo, quod ortum non habueric in præfentaneo tem pore in mundi hujus duratione. Angelos ex nihilo produxit in inftanci, \& in initiotemporis; materıa poft Angelos in mundi fenfibiils formationem; in zuo futuro fervabit Deus Angelos, \& animas rationales, ob quas \& materiam in idem ævum introducer, cælorumquemateriem in electorum domicilium.

\section{S C H O L I U M. I.}

$A$ Ngrelos ante fenfíbilis Mundi creationerr fuiffe productos, non paucorum exantiquis/ententiafuit. Pro ca adduximus in Phyfica Curiofa lib. $x$. cap.3. S. Bafilium Homil. $x$. in Hexaëm: D. Gregorium Nazianzenum Orat.28. \& 42. D. Chryfortomum to. 5. Hom.2. \& to.6. pag. 86. D. Damafcenum lib.2. cap. 3. D. Dionyfum lib. de Divinis Nominib. cap.5. D. Ambrofium, Hilarium, Hieronymum, Calfianum, Bedam $\varepsilon^{2}$ alios. Nos tamen cum aliis f atuimusibidem, nequaquam ante corpoream omnern of apectabilem creaturam extitiffe Ang elos, fed cum Mundocorporeo. Rationem or Auct ores vide ibi.

VIL. Infuturo xuo nihil erit,quod non fuerit in præenti; pleraque tamen funt in præfenti, qux futuram illam immortalitatem non videbunt, nec in æuum tranfibunt. In primo itaque æuo Deus tantum erat, in præfenti tempore creavit omnia, in futuro auo nonnulla confervabit, ut Angelum, hominem, materiam. In primo auo Deus infoccundus ad extra; in tempore focundus exiit: in primo auo nihil, in tempore \& fecundo 
cundo æuo omnia. Nihilum ergo Deo fuic coxuum, \& ater- Nibilum num; nihilum fubeft'cunctis, \& extra omnja eft; Deus benedi- Deo coan $\vec{x}$ ctus in frecula omnibus:fupereminet; \& fuper omnia eft. Deus. femper eft in eflè,nthilum in non effe, Creaturæ quandoque Nibili cum in efle, \& non efle:- Deus fưmma neceflitas; nihilum verò i- Deo compapfum impoflibile, \& quod ad efle nullam habet poteftatem: eft enim nihilum actu immenfum \& infinitum non efle, \& in tantom non ens;in quantum Deus ens eft actuinfinitum. Theodid. Sifte parumper; quare tu dicis nihilum imponibile, cùm tamen Deus omnia ex nihilo produxerit ? Cofmiel. Verumeft, Deus non Deum ex nihilo omnia produxilfe, fed non ex nihilo actu infi- poteft folum nito non efle, cuim Deus.nullum ens extra feipfum fibi æquum nibilum in \& infinitum proferre valeat; eft enim omne infinitum con-tiam con junctum \& confubrtanciale omni infinito. Siergotocumni- Gertere. hilum in fubftantiam convertiffer, illa haud dubie forec infinita : at hoc repugnat ; ergo Deus totum nihilum in fubftantiam convertere non voluit ; exhaufiferenim totưm nibrilum: fibi coxternum \& coxquale, urpote actu infinitum non effe".

VIII. Theod Optime omnia cepi atque oppidỏ fanè miror, fub nihilo tanta latere myfteria : jam enim luculenter video, quomodo mundus in nihilo; quomodo ante mundumomnia nihil,\&quomodoDeo corquetur nihilü, atque adeo quomodo nihilü nihil fic; Deus verò omnes tum mundi finus, tum extra mundü nihilum totum fubłtantiâ, potencia \& præfentiấ fuâ $x$ ternâ zeternùm impleat.Sed unü adhưc dubiü intellectum meú. torquet,\& eft; cùm nihilum illud, quod imaginamur; fpacium: infinitum dixeris, uri revera eft, ar non forfan Deus plures in eo: mundos condere potuerit? Cofmiel. Sidivinam potentiam refpicis, certum eft, Deum infinitos mundos in dicto f pacio con-nibilo pludere poruifle; Si creacuræ conditionem, id prorfus impoffibile res mundos fuic. Quod ad primum, ita probo. Intelligexternitatem per potuerit. rectam lineam actuindimenfam \& infinitam; hæcxternitas", hæc linea, totius divinæ fpheræ \& fubftantixe diameter eft; in. hac tota aternitas diametro, quodcunque punctum defignarerisjid totum erit medium ab extremis aquê diflicum. Cüm 
enmmaternicas quidpiam infinitum fit, omne quod in xter nitate de gnamus punctú,eft ab æternitatis principio,medio,\& fine æquidiftans. Quæcunq; itaquè de diametro hujusfphæræ, de tota Phæra jure meliori dicenda funt, in quo quot puncta, rotcentra conftitui poflunt; qux tametfi infinito fpacioà fe invicem diftent, à circumferentia tamen, qux finem non habet, femper æquidiftabunt. Quæ cùm ita fint, Deus ex omni hujus fiphæræ puncto mundos infinito intervallo diffitos, fi abfolutam Dei potentiam attendamus, educere potuit ; nont tamen inde fequitur verè eductos fuifle, cùm ex parte materix nef́cio quid cum infinito irreconciliabile interveniat; quod uti infinitum nunquam atcingere potert, ita divinam potentia ad fure conditionis capacitatem conftringere $\&$ coarctare videtur, ut cùm infinitum eflè non poffit, id fit, quod effe poteft. Unde Deus tantum abeft ut infinitos mundos condiderit, ut Mundus potiùs preter unum hunc ntillum alium creaffe cenfendus fit. Accedit quòd củm mundus hic omnia contineat, fitqueconmeximum.tractum maximum, quo majus dari non poflit; fruftra alii mundi conditi viderentur. Vel enim uti hic, ita ifti mundi omnia continerent, vel non continerent : fi prius, ergo fruftra fieret per plura,quod fieripoflet per pauciora; Si polterius, ergo mundis ift is aliquid deeffer, nec omnem corporea perfeCtionis plenitudínem continerent; quod dici minimè poteft. Reftat itaque mundum unícum à Deo Optimo Maximo conditum fuiffe, eumque omnibus numeris perfectiflimum, ita ut quemadmodum maximum contractum eft, ita melius, perfectius,abfolutiusque fieri non potuerit ; hoc enim pacto ideatum idex fux, qux inArchery po intellectu fubfirtit, meliùs conformabitur.

\section{S C H OLI UM.}

Ide qua habentur infrè in Apologeticsis, refponfione ad Propo-
fitionem I. Cenforis. 


\section{CAPUT X.}

\section{De Confumatione E Inftauratione bujus mundijenfibilis.}

1. Cofmiel. Dixi fuperiùs, interduoæva mundumfenfibilem libratum efle; quorum prius avum principiocaret, \& cerminatur in primo inftanti creationis rerum omnium,; pofterius ævum haber principium, fed finecaret, cujus initium fumendum eft à principio innovationis rerum omnium, id eft,poft ultimam fententiamæererni Judicis prolatam. Temporis itaque fpacium inter utrumque :xvum folùm principio \& fine conftar, in quantum mundus fucceffivo fluxuinftabilis corruptionibus \& generationibus obnoxius confideratur $\mathrm{Dat}$ nuplex a.

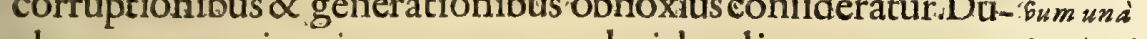
plex: ævum conjungitur tempore, veluti duæ lineæe ex utraque cum tempon parte in infinitum exporrectx punzto quodam. Quemadmo- retrnitatem dum enim nulla proportio eft punctiad lineam, ita nullapro-conftituit. portio temporis, quantumvis diuturni,ad æeternitatem, quam, binx linex puncto temporis copulatanotant.

II. Theodid. Cur Deus Opcimus tempus fluxum \& caducum zternitatiinferere voluit? Cofm. Finis DeiOptimi Maximi in mundi productione furt, primò ut in temporegloriam. \& operum fuorum majeftatem fupremam homini mundi filio oftenderet; Homo verò ex fenfibilium operum magnitudine ac præeftantia Conditoris ineffabilem fublimitatem agnofcerer, Conditoremque cognitum amarer, eoque tandem æternùm frueretur. Omnia enim propter feipfum operatus eft Domiwns. Secundò, cùm hominem formaturus effet ex anima rationali \& corpore, mundum fenfibilem creari neceffe fuit, tum ut hominis corpus ex quatuor elementorum crafi conftitutum, ubi fifteret, haberet; tumut omnibus ad propagandum fe neceffariis rebus inftitueretur; tum denique ut exiguo hoc temporis fpacio homo fuam operaretur falutem ; quam quidem confequi non porerat,nifi permundi corporei fubfidium: $\mathrm{Kkk}$ neque 
neque enim corpus à ratione, nec ratio à corpore disjungi debuit; mundus enim fruftrai conditus videbatur, fi creatura qux eo ureretur, tum ad corporis fuftentandi neceffitarem, rum ad animum in divinum opus fublevandum non daretur, Mandis Eropier bai minem. nonditus if: cùm mundo corporeo fpiricualis fubftantia opus non haberet. Hominé igicur producere voluit,\&ipfum veluti mundū quendam parvum, ex.omnium mundi entium gradibus confticutü.

Nam qua fuper cœlos funt entia beatiffima, \& primæ mundi fubftancix, utiomnium exemplaria, Archetypi, \& abftractifl mæ formæ funt, ita mundum conftituunt pure intellectualem.

III. Er nè mundus fenfibilis \& corporeus otiari videretur, Deus alium providit mundum intellectualem in humana, mente confticutum, in quo abditus ent omnis rationalis fulgor, \& fpiritualis emanatio $;$ :in quem etiam,tanquam in fenfibilis" mundi epitomen, omnium mundientium gradus congeffit, quibus humana mens non jam mundo inferior cunctarum rerum intellectuali ubertate vigens, nullisnon impragnata fpeciebus, in alteram fe' intellectualis mundi.regionem extendit; Hómo fìn. atque adeo fit \& animo \& corpore univerfá, Natura opus ex culum uni-materia longè fpeciofiffimum, mundi urriusque vinculum \& Berfi, $\mathbb{E}$ me- connexio, \& totius materiz finis. Linde fit, ut humani com-
aistor in. ter mundum enfibilem 8 intelte-

diualem. mercii interceflione, intelligibilia in fenfibilium regionem, traducantur, fenfibilia verò in intelligibilium regionem, transferantur. Et quemadmodum ex immaterialibusfubftantiis, una tantùm natura humana in mundum huncfenfibilem. inferta fpectatur ; itaè cunctis corpor eis.fubftantiis folum hu. manum corpus è terris in fupracoelefti mundo perpetıò duraturum poft transactam temporaneam corporexcreaturæ, id eft, Univerfi durationé emigrabit, admirandâ quadam metamorphofi.Etficutihominisanimus per intelligibilium notionum conceptus fit omnia, \& mundus quodammodò intelligibilis: ita contrà in futuro per humanum corpus, fenfibilis narura: \& corporea in intellectualem immigrabic regionem, materialis in immarerialem, corporea in incorpoream, elementanis in fimplicem. Ex quo colliges, hominem efre velutianimam quandam 
444 Itinerarium I. Dialogus II.

turâ infecta, in fururi ævi principio, in nitidifimam,\& ultra quàm animo concipi poteit, pulcherrimam, lucidiffimam , agillimamque fubftantiam, ineffabili quodam arcificio elevabit. Theodidactus. De omnipotentis Dei virtute nunquam. dubitavi,nec adhuc dubito; fed facer textus Ifaix meanxium. reddir: Ecce areocolos novos, s, terram novam, $\sigma^{2}$ non erunt in: memoria priora. Quid aliud inde concludam, nifi materiam. novam creandam, quâ formentur coeli, quâ Terra, quâ humana corpora ? Si iraque coli hi folummodò forent innovandi, \& non omnino corrumpendi; perperam à facro textu de novo creandidicerentur. Imò expreffiùs. id Apocalypfis Sancti Joannis docer : Et ecce vidicalum novum, Ë terram novam; primum enim ccelum, ó prima terra abiit; qux quoad fubftantiam potiùs, quàm quoad accidentia: intelligenda effe planè mihi perfiadeo ; quomodo enim quæ peribunt, innevaridici. poflint,non video.. Cofmiel. Scio Propheram dixiffe, Deum. creaturum Coelum novum, \& terram novam; fed f́cio etiam., eum qui in A pocalypfi.fedebatin throno, dixifle, ecce nov a $\mathrm{far}$ cioomnia: qux fi tu decreatione ex nihilo.intellexeris, multum fanè hallucinaris. Dic ergo, Theodidadie,nonnècredis corpus. tuum cum unjverfo hominum coeu, in novifimo die refufcicandum? Theodidactus. Credo equidem, \& tanquam principalem fidei Catholicæarticulum quotidie in recitatione fymboli profiteor: Cofmiel. R ectè credis.; quæro itaque jam ex te,utrum tuum illud corpus, quod refufcitandum eft, proprium wuum corpus futurum fit, vel aliud de novo creatum ? Theodid. Quidni de novo creabisur? Cofmicl. Tace;tace, Theodidacte, harefir tua verba. fapiunt. Sicorpustuum de novocreabitur, ac prius deftruetur; quomodo Deus remunerabitur aut caft gabit merica ac demerita ${ }_{2}$ qua homo proprii corpor is fui fubfidio fibi accivic 1 quomodo unusquisque, Chrifto teftante, prout geffic in corpore fuo, recipietbona vel mala in tremendo illo \& univerfali judicio ? in corpore fuo dixit,non in corpore novirer creato ex nibilo; hujusmodi enim corpora mini- 
Caput X.

445

mè bonum aur malum in mortali hominis vica operata fuife dici poffent; unde nec pramii nec fupplicii capax foret homo. Vides itaque, quid ex tua illa conceflione refulter. Theodid. Erravi,erravi,Cofmiel, non nififubtili tuo raciocinio ad illud deductus. Execrof íaque errorem ; clarè fiquidem video, Prophetas decreatione pracisè fumpta, uci eft productio rei ex nihilo, minimè locutos, fed creationem citatis locis anngogicè \& lare, dum eam cum innovarione plerimque confundunt, fumplifiè.

V. Sed' de coeleft is materia creatione fcrupulus adhucreftat. Cofmiel: Siqua fuprä.dixi,\& fusè̀ expofui tibi, incelligeres; nè minimus quidem dubitandilocus cibi relinquerecur. Nonnè mundus, uti exprimordiali illa elementorum confuforum chaotica maffa prodiuctus fuit; , ita: mundana corpora. fpecie \&eflentiâ quoad materiam non differunt nifi dicere velimus, Deum feorfimpro colis:aliam, aliampro fublunari-- Materis bus materiam condidifie; quod præterquam quòd eft contra cateffium illud, Dens qui vivit in aternum, creavit omniafirnuli, confen-a terreftri tiencium quoqueSS.Patrum expofitioni repugnat, cúm ex eo- non differt dem chao Deum omniaproduxifle; facer textus luculenter in - $t e r$. nuat.. Quid enim lucis productio, quidaquarum difcretio; quid arida decectio, quid poft aquarum in alveos fuos derivationem fpacium reliquum corporibus vacuum, quàm quatuor: elementorum exchaotica mallà difcretionem, atque munda-norum corporum pro neceffitate uniuscujusque diftributio nem à fupremo. Opifice peraćtam, aliud notent, non vïdeo. Qux itaque ex una chaotica materia prodierunt, illa utique feparata quoad materiam eflèntialiter, uri Scholafticiloquuntur, differtenon polünt. Omnia igitur mundanæ machinæ: globofa corpora uti elementata funt, ita radicaliter differre minimè cenfenda funt Fruftraitaquein Coelis aut quintam, aliquam efentiam,aut toto Colo differentem materiam qux-Cueli quin. res: materia enim globorum, ex qua globi colleftes confructi ${ }_{\text {effentia: }}^{\text {ta quadam }}$ funt, eadem illa eft, ex qua terra, \& qua telluris ambitu conti- conftiare nentur, conftituta fuit. Formâitaque folummodò differre cen-n." pō ponto.

$$
\text { Kkk } 3 \text { ferda. }
$$


fenda funt, haudquaquam materiâ, quæ femper una \& eadem numero manens, uti ad variam corporum compofitionem concurrit, ita ad corporum corruptionem in eandem refolvi-

Corrupt:bilitas corparum cas leftium. tur. Corpora verò coeleftia corruptibilia efle, jam fúprà ex facra Scriptura patuit : namS. Petrus ait : Per quem Coeli ardentes falventur, EJ element a calore ignis tabefcent; novos ve rò Caios, o novam Terram fecundum promiffa ipfius expectamus, ins quibus juftitia babitat. Si itaque quandoque Coelidiffolvendi, \& igni refervati fint; ad quid, obfecro, incorruptibiles facti cenfentur? fruftra enim in illis forec incorruptibilitas, cum, fint corrumpendi; fruftranex dicuntur illix potentix, qux non reducuntur in actum,perpettio videlicet duraturæ incorruptibilitatis. Omnia itaque in Mundo corporeo elementari compofitione conftare, vel hinc patet : ubi enim terreftre \& igneum, ibi ficcum \& calidum, bi calidum \& humidum; \& ubi hæc, ibi raritas \& denfitas; \& ubi raritas \& denfitas, tbi gravitas \& levitas, \& confequenter quatuor elementa eflè necefle eft: féd coeleftia corpora atmoíphær is circumdantur, quæ quidem originem fuam non nifiex evaporatione globonum trahunt; ubı vapores funt, ibi necefiariô raritas \& denfita; \& calor \& frigus; ergogravitas \& levitas, quæ neceflariô confequuntur. ilti igitur terrena corpora iftiusmodi qualitatibus imbuta corruptioni obnoxia funt, ita coeleft ia corpora, iis pariter imbuta. Sed hae cùm fuprà fufiùs demonftrata fint, iis hic non immorabimur.Sufficiat tibif́cire, quòd univerfa Mundi machina, uti quoad formarum corruptibilium ftatum diffolvenda eft, ita ex materia remanente Deus alium mundum millies pulchriorem, lucidiorem, excellentioremque inftauraturus fix.

\section{Quid de} globis cale ftibus fiet pof confumationem feculi.
V I. Theodid. Nosfcimus, Cofmiel, poft ultimam mundi eonfumationem electos in Coelum empyreum, reprobos verò in ultimum Mundi centrum abicuros; quid ergoctum reliquo Mundo fiet ? Cerrè fruftra factus aut transmutatus fuifle videretur,cum nullus, qui eum inhabitet, fit futurus. Cofmiel. Abfit uthoc fentias. Nonnè legifti : In iis diebus Solfepties plùsfut-

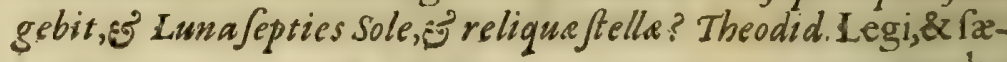
pealto 
pe alco hujusmodi verba animo recolui. Cofmiel. Ad quid enim illatanto fplendore, tantâ majeftateadornarentur , fi non ellet,qui is frueretur? Scias itaque, poft univerfalem carnis'a-Catum ensnaftafin, Coelum empyreum unà.jungendum reliquo Mundo pyreum fenfibili,adeoque totum Mundum, \& univerfos.Mundi globos, foct finem in unum Dei electorumque quafidomicilium evafuros, atque jungetur taliactam ineffabili pulchricudine \& majeftate refulfurum, ut ${ }_{\text {mundo, }}^{\text {rel }}$, nemo id mortalicarneinducus,animo concipere valeat. Tune mundo, mundi globifive Aftra, quorum non eft numerus, in tor lapi- num Dei edes pretiofifimos \& lucidiffimostran'sformabuntur, quothu- letzorum manamens in natura rerum præftantifima cimelia fibi imaginaripoteft. Theodidact us. Sed de Terraiquid fiet? Annè Terréftris difioluta, \& omni fplendore privabitur? Cofmiel. Abfit; quin. globus quaea pracateris omribus mundanis corporibus majori folendo- pof futurus. ris apparatu confpiciendam fe exhibebit, ut ubi verbum ater- confumanum caro factum eft, ubi pro mundi falute unigenitus Dei fi ${ }^{\text {tionem: }}$ lius crucis mortem fubiit, ubi omnes elc çi beneplacitâ Deo vitâ, veluti in agone certantes aternæe felicicatis bravium meriti funt, ibi ad Sanctorum coronam, præteritorumque dulcem, Terre in, recordationem, maximè divina providentia difpofitio fe mi-praft antif rabilé oftendar.Quod quiden exprérè docer $S$. Joannes in fü finum for Apocalypfi: Et vidi celum novum, o terramnovam. S. Petrus bitur poft quoque in Epiftola : Navos celos, \& novam terram fecundivm finem fictspromiffa ejus expect amus, in quibus juftitia habitat. Quid enim aliud per juftitiam intelligit, nifi aternam illam \& ftabilem ab omni.iniquicatis navo remotiflimam ftacionem ? cujusmodifunt terra,globique mundani in excellentiorem ftatum transformati. Atque hoc primum argumencumert, quo colliges: electos corpore gloriofo \& immortalitatis dote beatos, non Empyreum folum, fed \& mundum univerfum inhabitaturos". Neque verifimile eft cos uno in loco fixos manfuros, fed ubi-status elscunque voluerint efle, ibi mox efle futuros: Cujus rationem, ttorum. nobis expreffic in gloriofa corporis fui alcenfione Chriftus Dominus nofter, mox poftquàm à nube fufceptus, non huma- 
no more pedetentim progreflus, fed quod colum petebat, in eoquafi in momento temporis fe conftituit, quale eftempyreum, immentầ à terra intercapedine diffitum. Alterum argumencum tibi fit, quòd Deus ita mundum confticuerit,ue pauca divinorum in mundo operum cognofcerechomo; non aliofanè fine,nifi ut in hoc felicitatis ærernæ ftatu, funmmam $8 x$ ineffabilem divina potentix magnirudinem, fapientiam, amoremque erga genus humanum incomprehenfibilem, non. intel lectutantum in hemine vira incueretur, fed \& fenfibus eadem corporeis, in fingulis mundanis cor poribus divinæ providentia rationes, immenfosque divina fcientix thefauros cognofcerer, cognitos admiraretur, \& amoris divini extafi,ex tantis divinæ inexhaufta:bonitatisoperibus raprus, xternum tanta bonitatis Opificem, tantix pietatis Redemptorem collaudarer. Tertiumargumentum. Cùm Deus Optimus Maximus univerfam corpoream creaturam, qui mundus eft, eumque ob quem condirus eft hominem æternùm confervare confticuerit; certè fruntră homini fenfus in illo felicitatis ftatu conceffi viderentur, $f$ iis non utererur: non uteretur sutem, fi non eflet objectum fenfibus corporeis proportionatum. Ergo licitè inferri potent, mundum corporeum, quamvis in fúpereminentiorem ftatum cransformatum, non alio tamen fine à Deo confervatum iri, nifi ut fenfus etiam corporei hominis, in immortalitacis ftatum transłati, tantâ corporeæ naturæ pulchritudine, in qua ipfe Deus omnium Conditor veluti in. fpeculo quodam eluceret, ineffabili voluprate \& gaudio perfruerentur.

VII. Theodidact us. O quàm me rapis tam divino tuo ratiocinio! Ovitam felicifimam! Oregnum verè beatum, quod caret morte,vacat fine; cui nulla tempora fuccedunt per ævum; ubi continuus fine nocte dies nefcit habere tempus; ubi victor miles gloriofus, Angelorum choris fociatus, Deo cantat fine ceflatione canticum de canticis in Sion. Utinam concefsâ mihi peccatorum veniâ , ac depofitâ carnis farcinâ , in tua gaudiá veram requiem habiturus intrarem ! O utinam mihiliceret 
cum beatifimis firitibus gloriæ Conditoris affiftere; præfentem Chrifti vultum cernere; fummum, ineffabile,\& incircumf́criptum lumen femper intueri; prolcriptâ morte, perpetuo incorruption is munere lactari! Cofmiel. Et viam fcis, \& oftium fcis quo, quod tantopere defideras, regnum intrare poffis. Qui in hac mortis umbra, perpetuâ amoris unione:Deoadhærerit, illud haud dubiè intrabit, cùm ab eo,cuiadharet, abersare non poffit, quia eft via, ditix, oftium, veritas, \& vita.

VIII. Theadid. Dic ergo, Cofmiel, quid fiet de globis mun- Utrum polt danis., que Aftra vocantur? facion danis., quxe Aftra vocantur? facientnèconfuetas revolutio- lorum $\varepsilon x-$ num periodos? \& motufinè continuabunt? an perpecuæe quie- lorum cortis munere fruentur? Cof moiel. Cùm ftatus Berorum null pora mot

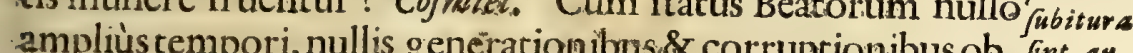
amplius tempori, nullis generationibus \& corruprionibus ob- $/$ int, an

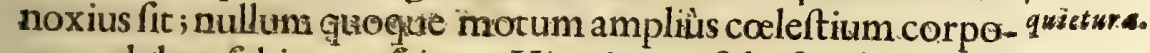
rum globos fubituros feias. Hi enim eo folo fine àbenigno Conditore adornati fune, ut diem \& noctem, temporumque difcrimina conficerent; ;u influxibus fuis generationes rerum promoverent; ut terréno globo in kominum gratiam fervirent; uti verò in xviterno ftatu dicta ceffabunt, ita queque à muniisfuis, à motibus \& influxibus æternùm vacabunt; atque adeo in nobiliorem fubfiftentia rationem, uti dictum eft, transformabuntur, tum urbeatisfighum \& veluti mnemofynon quoddam effenedivini erga fe amoris; bonitatis, fapientix,\& providentiæ,tum ad novismuindiornamentum, Beatorumque oblectamentum.Nam, ut dixitibi, cùminnumerabilis fit coeleftium corporum feu globorum mulkitudo, finguli tamen omnibus difpulfis tenebris tam ineffabili per divina pro-pulcbrittmvidentia difpofitionem majeftatis decore fulgebunt, ut in fin- $d_{0} 0 \mathrm{~S}$ mulgulis novum quid, \& admirandum, \& quod verbis exponi non titudo corpoflic, contemplatione digniffimum eleatifint reperturi; ac- porkm a que adeo quotquot ad viram æeternam pradeftinati funt, iis tocidem aftris manfiones Deus præparaffe videatur, ut finguli in fingulis,\& omnes in omnibus, quando \& ubi voluerint, fe fiftere atque fine impedimento mox effe poffint, \& tanquam. 
fincillix in arund inetis dicurrere. Ut proinde hinc colligas, cur Deus Optimus Maximus tam pauca operum fuorum homini, quamdiun hac mortalis vitæ umbia verfatur, maniferta efle voluer it; non a la fanè de caufa, nifi quia futuro immortalitatis fta:ti illa : efervaverat elect is fuis, in omnipotentix fure arguriestum, atcjue in accidentale quoddam corporum glori l. um pramium. Namut facra Scriptura docet, Dan. I2. 2 ui mult tos adjuftitiam erudierint, tanquam Solfulgebunt in tapetuas aternitates. Theodid . Jam enimverò tadet animam neam vitæ mex: ibitoto mentis affectu effe defidero, ubi vivis. margirit is hurgunt axdificia; auro celfa micant tecta, radiane triclinia ; folis gemmis fpeciofis hre ftructura neetitur , auro mundo tanqunin vitro pavimentüfternitur, abeft limus, deeft fimus, Yues nulla cernicur; hyems horrens, xftus torrens illic nunquam frviunt; flos perpetuus rofarum, ver agit perpetuum; cadunt hia, rubefcit crocus, fudat balfamum, virent prata, vernant fara, rivi mellis affluunt.

BarmatoIV. Sed rogote, Cofmiel

$\min _{\mu b \text { carcer }}$ ubi fit fur
turus pof deem judi ciis. tantani claritatem aflurgent, ubi erit damnatorum carcer? Cofmiel. Fternum reprobatorum clauftrum erit terreni globi concavitas, æterno cruftæ duriffimæ repagulo circumdata. \& munita,per quod nihil amoliüs penetrare poterit, nullum. lumen locum ibi invenier, locus fempiternihorroris \& confufionis. Theod. Sed quomodo innumerabilis damnatorum. multitudinis locus adeo ftrictus capax efle poteft? Cofmiel. Omniporentis Dei virture in eum damnatorum corpora ftatum redigentur, ut quemadmodum glorificatis corporibus penetrabilitatis donum conceffic in gloriam ; ita corporibus damnatis in pœnam conftitueric : ut odio æerterno fefe arctèconftipent, unus alterius vifcera rodat, ut à quo horrendo objecto abeflevellent, illiadeflex eternùm cogantur. Theadid. Ohorrorem ! ô confufionem ! ô mortem fune morte ! ô vitam.perpettú fociatam morte! Sed togo te, An non alio for fan locorin aliquo Mundiglobo hic carcer condipotuiflet? Cofm. Nequa๑ฺ!am, fed carcer ille erit in infimis terra vifceribus, ut qui in 
terreno globo nati, terrenis à Deo conceffis bonis malè ufi funt, terrenis quoque ponis æternùm puniantur. Theodidact us. Damonum Quid autem fier de domonibus? quem locum ipfis attribues? locus $n b i$ Certum enim eft, illos novâ illâ Mundi ftructurấ, folis Beatis futurus conceflä, frui non poflè : neque enim decet, immundos fpiri- polt contus,inimicos Deifempiternos, \& confufionisauctores, puriff- nem Anenmis Angelorum ordinibus mifceri. Cofmiel. Quemadmodum dis. corpora damnatorum terreno globoxternas ignis pœnas laituri includentur, ita doemonies cum reprobis focietatem habebunt, in centrali terreftris globi fentina, pro delicto cujusque aternis repagulis detenti; ut qui à divina gratia fe voluntariâ prevaricatione fepararunt, ii ab omni vifibili creatura feparari,in intimo terreni corporis clauftro, ex quo nunquam exire licebic,compingantur, juxta illud aternæ Veritatis pronunciatum: It male dictiin ignem aternum, quiparatus est diaboLo, 5 angelis ejus. Theodidactus. Quomodo tam horrenda, clauftra cum tam inæftimabilis pulchritudinis globis confiftere poffint, non capio, Cofmiel. Electis Deinihil horrendum videbitur, ubi juftitix divinæ rationes ineffabili animi voluptate contemplabuntur ; contrả immundis fpiritibus nihil pulchrum videbitur, ubi fe aternâ Judicis fententiâ fulminacos,pœnæ ignis æterni addictoscomperient.

\section{A P LIT XI.}

Finis ob quem Deus Mundum condiderit; $\Theta^{\circ}$ de Chriffi incarnatione; sं de Eccle fia \& Fide,per guam Deus homines fervare voluit.

I. THeodidactus. Immenfam Mundi molem tantæ globorum diverfitati junctam paulò penitùs ponderanti, non pauca, qux animum meum dubia pulfänt, occurrunt; cur Deus Optimus Maximus tantam machinam condiderit ? an proLl1 2 prer 
452

Itinerarium I. Dialogus II.

Mindis

prer hominem folum? an proprer alios homines forfan in glo noprer bis alicubi latentes: Racio mei dubii eft: fi propter hominem lofolsum hoo sxinem conditus. lum illam condidifee, fruftra fanè innumerabilis illa globorum TF: multitudo condita fuifet, cùm multi eorum nullum in natura. rerum ufum habere vide antur, neque etiam fub fenfum mortalium unquam cadain. Cùm enim corporeus hic mundus eo fine conditus fit, ut corporeus homo illum fufpiciendo,fapientiam, bonitaté, amorem, potentiamque Conditoris admiraretur ; ita eú condere debuillet, ut eo toto \& integro frui licuillet. Co $\mathrm{m}$. $\mathrm{O}$ quantum aberras, fitil Coelü empyreí omnia mundana corpora, quin vel ipfa terra humano ingenio abfcondica pœeıè omnia tegit, \& tu putas,omnia homini patere debere? An nefcis illud Sapientis: Cogit at iones mortalium timide, ac incerte providen-

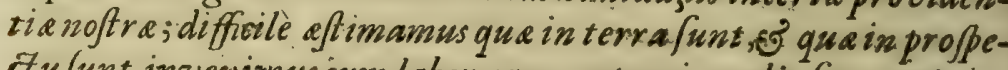
ctufunt invenimus cum labore;que autem in calis Junt; quis onveftigabit? Tuum cantum mirari eft,non comprehendereoperum divinorum magnitudinem \& varietatem; funt enim omnia felicioris vitæ ftatui refervata : Pauca enimopera Dei,ut Sapiens ait, novit horno, \& qurecumque fcit, \& illa corporeis? phantalmatis acquifita, tantumabeftur integram \& perfectam Icientiam pariant, ut potiùs eam obfcurent.

LL Theodidact us. Dic, rogo, cur Deus terram omnium finem efle voluerit,cùm tamen colis comparata non nufi indivifibile punctum fit?'Fugit mens, ratio vacillat, intellectustrepidat,dum tam innumerabilem mundanorum corporum varietatem. tantummodò propter hominem, \& locum habitationis ejus conditam, \& quidem omni humanâ vacuam creaturâ, confiderat.Co/m. Sane hi humanx imaginationis conceptus funt, cuis fimiles. Dic mihi, Theodidacte, quid majus putas, mundü hunc à Deo ex nihilo productum, aut Deum hominem propter hominem factum, punctum hocterrenum inhabicare,ac operum ftupendorü perpetratione homini viam falutis aterna monftrare voluifle? Theodidactus. Arbitror, Filii Dei incarnationem multis parafangis majus opus efle, imò operum divinorum maximum. Cofmicl. Rectè feptis. Si iraque Deus ater- 
nus, innenfus, \& incomprehenfibilis, non Solis, Lunæ, aut Jovis Mundus globü, aut aliud aliquod ex coeleftibus corporibus, fed terreni propter bo: globi maflàm pro patria fua eligere,hominú concivis fieri ibi azzus. $^{2}$ humani generis falutem operarı voluit ; fruftra fanè in aliis? Mundi globis rationales creaturæ conditæ fuifent. Cùm. itaque Deus terreni globi incolam hominem tanto honore dignatus fit, ut per humanæ naturæ aflumptionéfuper:omne Coelı\& Terræ dominium, \& $\mathrm{fe}, \&$ unà fecum humanum genus exaltaverit; certè mundum univerfum non alio fine-quàm: prepter hominem fecifle cenfendus eft Chriftus enim, uti Deus \& homo univerfac creature finis eft, \& ratione humanitatis divinitati hypoftatice junctix, in quantum hromo quoque finis univerfec corporex creatura cenfendus eft. Acceffit enim Excelleñ homo ad cor altum, \& exaltat issest Deus. Contractum maxi- tiacbriffit,

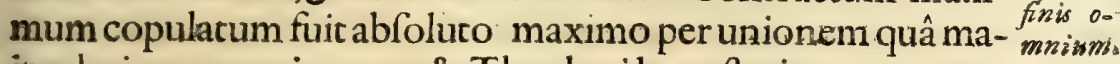
jor dari norrpotuit, quam \& Theologi hypoftaticam vocant; non quidem unione infinitâ \& abfolutâ maximâ \& eflentiali, qua folæ tres hypoftales uniuntur in divinis, fiquidem humana natura in eflentialem cum divina natura unionem tranfire: non poteft, quemadmodum finitum non potelt infinito infinitè uniri; tranfiret enim humana natura hac ratione in identitatem infiniti , \& fic defineret efle finitum, naturâ humanâ in divina penitùs abforptâ,nulla naturarum diftinetionerelietâ.

III. Theodidactus. Videtur difcurfus tuus contradictionem: involvere: quomodo enim naturarum diverfitas cum unione, qua major dari non poffic, confirtar, non capio; quare ut ea. mihi pautò clariùs explices,obferro. Cofmiet. Dic mihi, Theodidacte, fi Deus produceret maximum contractum infpecie, quod actu fubfifteret; an nontipfam fecundùm datam con-: rractionis fpeciem omnia, qua ingeneris aut fpeciei illius po. rentia effe poflent, actu foret? Theodidactus. Planè id dicideberearbicror. Cofmiel. Qurero itenum ex te, utrum talemaximim infrecie v. g. humana contractum, per fefubfinterepoffiv ? Theodidactus. Cùm maximum contractum, tale fit futuIII 3

rum; 
Humana

naturain

Chrifto

maximum

contraltü

non nift in

Verbo fub

fat.
454

Itinerarium I. Dialogus II.

rum,ut illius generis aut fpeciei omnem comprehendat plenitudinem, imò vıtam, formam, rationem, atque verıtatem in. plenitudine perfectionis omnium, qux in ipla fpecie dari polfent, complicet; non arbitror tale per fe ut purè contractum. fubfiftere poffe, ficuti bumanitas in aboracto fubfintere non. pollet, cum nihil talem plenitudinem perfection is in genere perfectx contractionis attungere polfic. Cofmiel. Scirèfentis, Theodidacte. Cùm iraque tale nec per fe fubfintere pontec, neque etiam maximum abfolutum, qui Deus eft, ente ponec; necellariò fequitur, tale contractum maximum taliunicum. abioluto maximo,Deum fimul \& creaturam futurum, neque fubfiftere nifi in maximo abfoluto pollè. Cùm enim unum maximum abfolutum fit, à quo contractum maximum fit; fi potentia maxima tale fibitaliratione uniret, ut falvis naturis" - magis unire non pofiet ; certum eft, tale unitum omnes intellectus humani limites exceffurum. Talis fuit humana natura, qux per unionem hanc fupra omnia Dei opera elevata, intellectualem \& fenfibilem naturam complicans, vinculo intra fe confrinxic, rectè microcofmus dictus : hac enim cum maximo abfoluto in unionem affumpca, omnium perfectionum, Univerfi \& fingulorum exiftit, ita ut in humanitate omnia fupremum gradum adipifcantur; adeo ut Chriftus ità fit homo, quòd Deus; \& ita Deus, quòd homo; perfectio Univerfi, in omnibus primatum tenens, in quo maxima, infima, \& media. abfoluto maximo unita ita coincidunt, ut ipfe omnium perfectio fit; \& cuncta contracta in eo, ut in fua perfectione quiefcant ; cujus menfura hominis eflet, \& Angeli,\& fingulorum., quoniam eft univerfalis contracta entiras abfoluta univerforum, per quem cuncta initium contraction is atque finem refpiciunt, \& per ipfum qui eft maximum contractum à maximo abloluto omnia in efle contractionis prodeunt, \& in abfolutum per medium ejusdem tanquam per principium emanationis, \& per finem reductionis redeunt. Et talis fuic unio hypoftatica, quâ Verbo aterno humana natura unita Chri- 
fum Deum \& hominem humanâ carne veftitum mundo exhibuit.

IV. Theodidactus. Sed quomodo hanc admirandam unionem concipiam ? Forfan illa conjunguntur ut partes in toto? Cofmiel. In peffimum errorem incidis; fi hrec ita fiericredas: quomodo enim Deus pars antmo conicipi poffic, non video. Theodidactur. Ergo jungentur uc forma ad materiam? Cofwiel. Unionis byError omnium peffimus : quis enimi dicat Deum compofici: pooflus bupartem conftitutivam efle', cùm fit impermifcibilis materix ? mano in Theodidactws: Quis.igirur ramalto \& fubrily ingetrio inftructus tellettu im erit,qui ad tam admirandamunionem perringat:Cofmiel. Cer-prilis. xè uri omnia divina opera funt incomprehenfibilia, ita \& hoc omnium divinorum operum maximum, humano intellectui impervium, non nifi fide atringitur. Sufficit itaque Chriftum ita concipere, ut fit Homo; ; ita concipere hominem, ut fit Deus; adeo Deum \& hominem absque confufione \& compofitione phyfica ut apprehendas, necefle eft. Theodidact us: Fieri non polle videtur, ut fine aliquali faltem compoficione hanc anionem concipiam; à tanto itaque dubio ut me liberes, obnixè à re efflagito. Cofmiel. Notum tibi fit,certumque fuppone; nonnullam inChrifto compofitionem admittendam effe, ratione cujus hriftusaliquo modo compofitas dicipoffic ; \& id apertè colligitur ex Synodis, Conciliis; communique ferè S S. PP. fententia; non phyficâ qưdem \& raturafi, qua unumè duobus invicem incompletis conflatur,quorum proinde quolibet per mutur unionis nexum compleatur,perficiaturque; fed purè numerali, intrinfecè, uti Theologirloquuntur, fupernaturali,\& exiftente per modum quendam ineffabilem, qưo,refte D. Thoma;unum per fe èduobus, quorunraltertim eft imperfectum \& incomplerum, atque complebile\& perfectibiie,per. alterum conftituitur, alterum verò eft eflentialiter ultimò completum, minimè tamen complebile \& perfectibile peralserum excremum, sujufmodi eft Verbum divinum. Quaprooter unjo hypoftatica tametfi Verbum humanitati, \&humanitatem Verbo uniat, nontameneodem modo afficic ucrum- 


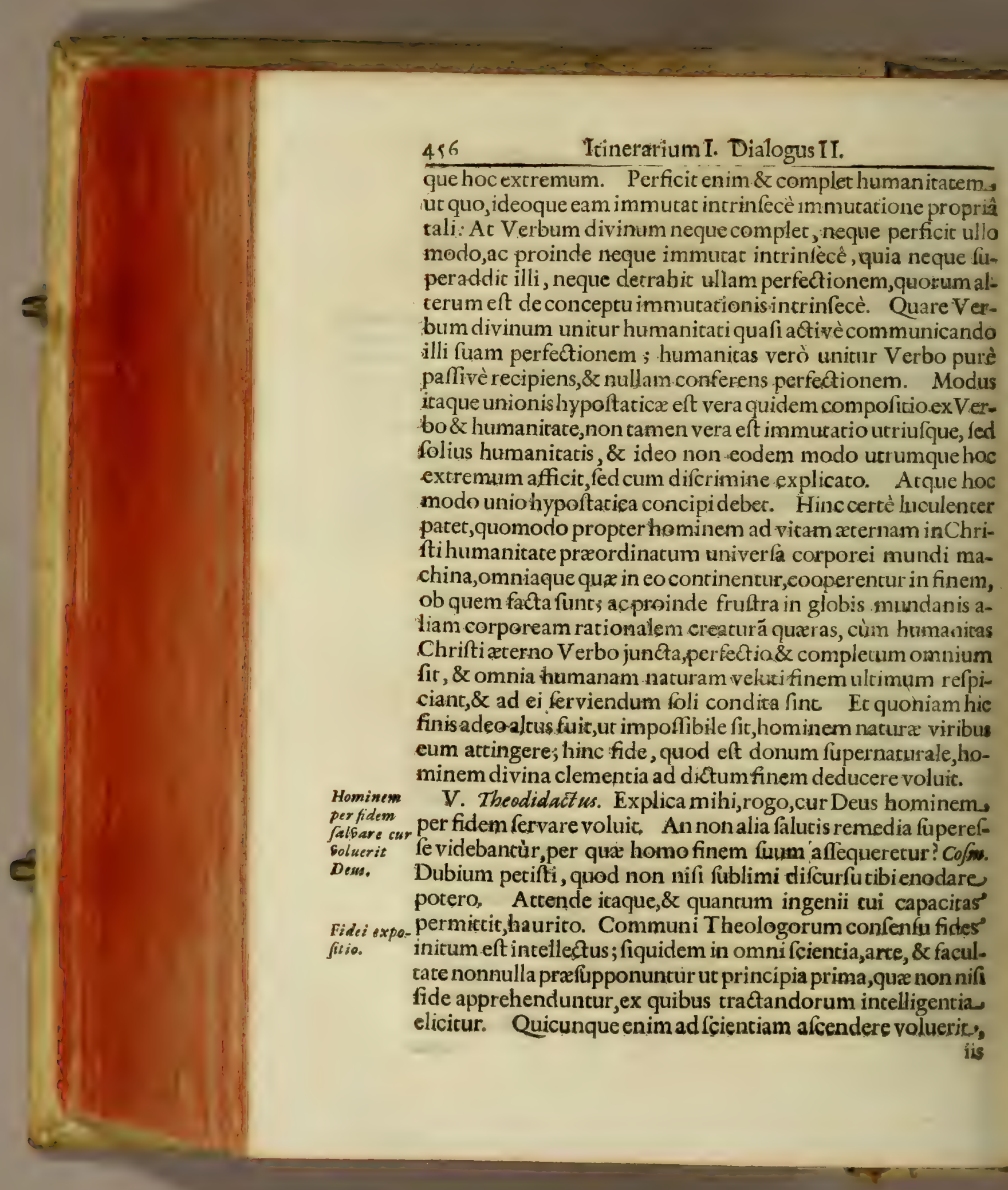




\section{Caput1X.}

is fine quibus afcendere nequit,credere necefle eft, cefte Ifai $\hat{a}_{n}$ nificredideritis,non intelligetis. Fidesigitur eft in fe complicans omne intelligibile, intellectus autem eft fidei explicatio. Dirigitur itaque per fidem intellectus, \& fides per intellectum exrenditur. Ubi igitur fana fidesnon eit, nullus eft verus intellectus, fed error principiorum, \& fundarenti debilitas; ut proinde fieri non ponfic, ut talis veram conclufionem inferat. Quoniamverò fides eft fubitancia rerum fperandarum, \& argumentum non apparencium; ac præterea nonnulla principia fidei, quos Articulos vocatis, ea funt, qux intelledus humani capacitatem excedunt, adeo tamen certa, ut intellectus tis, utpote infallibili Der auctoritate nobis an'oredendum propoftis, abnuere nullâ ratione polfit (Deus enimuri exiftens ipfa bo- Fides bsenitas, fallere non vult, ita quia eft infinita fapientia, fallere non manis biri poteft) \& cum fidescirca ineffabilia divina Sapientix oper 2 , non potes. objectaque fupernaturalia verfecur; fieri non poteft, ut homo naturæ viribus ea attingat, fed fupernaturalem Dei concurfum, ut attingantur, accedere necefle eft. Abfintigiturab hac fideomnes perfuafionishumane rationes; abfint acuta mentis frutinia; abfnt omnia philofophici ratiocinii argumenta: hanc nullus fapientum, nullus Ariftoreles, nullus Plato, ingenio quantumvis fubtilis penetrare potuir. Theodidadtus. Sed Fides in in quo potiffimùm fides furdatur? Cofmiel. In ipfo Chrifto, in qua sonfe. quo omnes fidei articuli complicantur, tefte Divo Joanne, hec foripta funt, wt credatis, quoniom $\mathcal{F} E S U S$ est Filius Dei; Chriftus enim eft, in quo omnes Sapientia of foientiarum the fawri abfconditifunt; fine quo remo quicquam facere poteft:nam \& Verbum eft, \& Potencia Patris,per quem fecit \& fecula,verbo virtutis portans omnia. Chriftus finis eft omnis intelledtionis, quia Veritas æterna;finis eft omnisfenfus, quia Vita;ommis Chrift us denique eflentia finis, quia entitas infinita; \& totius creaturx $f_{f}^{o m n i a}$ compli. perfectio, quia Deus \& homo. Omnia igitur creata, figna cat. funt VerbiDei; omnisvox corporea verbi mentalis fignum.; omnis mentalis verbi corruptibilis caufa eft verbum incorrupribile, quxeft ratio, Chriftus itaque eft incarnata ratioo$M \mathrm{~mm}$ mnium 
458

mnium racionum, quia Verbum caro factum eft qui finisomnium, \& f pes omnium finium Terre.

Quomodo Beteres, in: Chriftum necdum natum crediderints

VI. Theodidact us: Si vera funt quxe dicis, quomodo in veteri Teftamento fides haberi potuir, Chrifto nondum exiftente? Cofmiel. Certò tibi perfuadeas. velim,neminem illis ante Chriftum temporibus falutem confecutum fuifle; nifi fide in Chriftum, faltem implicitấ. Hinc omnes facrarum Litterarum, paginæe de illo loquuntur; hunc veluti lapfi humani 'generis Reparatorem promittune in hunc omnia colludunt myfteria, ritus,cerimonix; hiunc omnes hiftoriæ făcræ, hymni, cantica, pfalmi, Propherarum oracula ${ }_{2}$ veluci typi quidam \& venturi Chriftifigure refpiciunt. Hic ftatim in nafcentis mundi primordiis Protoplaftis,omnis quam per peccatum incurrerane noxæ reparator fuit promiflus, à quo hujusmodi promiffionem uffque ad Chriftum reliqui omnes traditione fucceffivâ acceperunt.

Theodidact'us. Rectè dicis,Cofmiel; meminienim me legifé in Cabala Hebræorum ( fi tamen ulla tantis nugatoribus Thalmudiftis fides adhibenda eft ) mira quadam de Meflia in lege promillo. Cofmiel. Recita, quxfo, ut te forfan nimis credulum in veræ Cabalæ femitam reducam: funt enim Cabalicæ traditiones multis erroribus obnoxia, \& facilè legentes in erroremabducere poffunt.. Dic ergo qua legifti de hujus farinx tradirionibus. Theodidactus. Faciam quod jubes. Sic ergo inveni feriptum in Cabalifticis traditionibus. Humanigeneris Protoplaftus Adam, cùm infelici forte contra præceptunŁ Domini de fructu guftaflet, atque adeo totam humani generis. pofteritatem,ob inobedientix peccatum contra infinitam Dei majeftatem commiflum, unà fecum in perditionis ruinam. traxiffer, neque efler nifi Altifimo æqualis, qui damnum \& jacturam refarcire poflët; ad imminentis defperationis efficax

Cabialice remedium prorfús divinâ revelatione opus erat. Nè igitur figmentum fuum plafinator Deus abfque omni medelæ fpe deferuifle videretur, fpem quandam injecir, firmamque fiduciam; fiturum ur hoc tam immane originalis noxæ crimer, 

lerecurque. Et cùm ad myfterii fublimitatem, \& in forutabile de Chrife divinæ fapientix confilium, humanx mentis infirmitas pertingere minimè poflet; Angelum fuum mifit, cujus inftructione pleniüs tantæ ruinæ futuram difceret reparationem. Angelus itaque his verbis Adamum moerore plenum allocutus ${ }^{3}$ eft. Nèimmodico gemitu \& triftitiâ conficiarıs: nam ex feminetuo nafcetur homo juftus, \&pacificus, vir heros,cujus nomen erit יהורי mittens manum fuam, fumet de ligno vitæ, \& ejus fructus eric omnium fperantium falus. Quibus verbis confirmatus Adamus, incredibiliconfidentiâ, \& in Conditorem fuum amore tactus, divina clementia gratiamolsinuit. Atque hæe fuic omnium prima Cabala, feu rraditio accepta, primordialis falutis nuntia fecundùm Hebræos. Hæc eft illa Chrifti venturi promiffio,ad quam omnes divinorum eloquiorum traditiones reducuntur, omnes coeleftium eruditiones,Prophetarum. vaticinia, Doctorumque ftudia \& meditationes refoluuntur; unicum omnium Cabalicarum receptionum compendium, \& finis. Verùm uti omnis revelatio effentialiter, ut Scholæ loquuntur,obfcura eft, fic \& Adamus, quis nam tam illuftris? homo, tam fublimium dotium inftructione beatus, futurus ${ }^{*}$ eflet, ignorans, cùm ex femine fuo illum nafciturum cognoviflet, uxorique revelaffer arcanum: hæc eum futurum exiftimans, quem concepifier,Kain,mundi Salvatorem; mox ac peperit,pra gaudio clamavit ארת יהור. קניתי איש poffedivirum illum tetragramamaton five quatuor litterarum.Sed enim,cùm hunc perverfis \& præferocibus moribus praditum, imò peffi$m æ$ frugis cognofcerent; alium genuerunt, quem \& A bel vocaverunt; atque hunc eum futurum fperabant. Verùm illo à Kain occifo, tandem fpem promiffionis factre in Secho primùm pofuerunt, \& deinde in nepote Enos; qui, uc habet facer

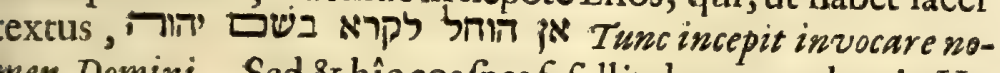
men Domini. Sed \& hîc eosfpes fefellit,donec tandem in Heach firmaretur. Verùm illo difparente, \& traditione ab AGenturo. $\mathrm{M} \mathrm{mm} 2$ damo $_{2}$ 
Weas.

damoad pofteros nepores propagatâ,tandem Noë vir juftus \& perfectus in æatatefua, omnium opinione habitus eft faluris" amifix per lignum.reparator. Verùm ob intervenientem ebrietatisconfufionem,Sem filium ejus hujus ruinæe reparatio-

Sem. nem fufcepturum fpeserat. Sed Angelo Semi ipfi aliter deAbrabam; clarante, reparatio in orcum Abrahx fuit dilata; quiab Angelo inftructus, ex femine fuo nafciturum illum, in quobenedicerentur omnesgenerationes terræ, putavit hunc futurum filiü:

ZJas!! fuum Iface, qui ligno vitæ accepto falutem humani generis" effet procuraturus : unde tantâ animi jucunditate, lignis humerisfibi impofitis, eumfacrificio, jubente-Deo,deftinavit, unicâ fpe ductus, futurum,ut expletâ Dei voluntate in filii oblatione, falus promifla acquireretur. Sed Ifaaci Angeloaliter.

Mayfes. eum informante, ac aliter Angelo Jacobi inftituente, fpes protelata fuit in ortum Moyfis, quitùm ob prodigiofam infifcella. junceaconfervationem, educationemque,tum ob Dei, in edu\&ione ex Egypto filiorum Ifraël, admirandam vocationem, miraculorumque innumerabilem in Egypto perperrationem, legifque in deferto,innumeris miraculis confirmatæ promulgarionem, is,quem diximus, abomnibus habitus eft perdita falutis per peccatúAdær, reftitutor.Sed cùmAngelus aliud decer-

Babid: neret, dilata fpes ufquead Davidem, \& Salomonem;quem,quia à Deo electus Rex erat fapiens, \& pacificus,\& primus Templi adificator,promiflum illum pacis Principem \& Or bis inftau-

Salomon. ratorem exiftimabant; fed fruftra. A Salomone itaqueillius terreftris templi conditore,ufque ad Regem Joachim, expectatio falutis univerfa apud omnium coetum Prophetarum in

Frophota: venturo Melfia collocata fuic , ab If́áia ufque ad Malachiam., cumdixit; Statinz veniet ad Templum fuum dominat or Dominus, quem vos quaritis. Poft Prophetas autem, falutiferiadventus Meffix expectatiostotaque Cabalica exercitatio, quam in Meffiæ fempiternam liberationem reducunt,ad Scribas legis Seniores, \& ad magnı Concilii viros, quos Sanedrin vocant, defcendir, fúccenivè recepta ab Ezra, qui Cabalam hanc 
tradidít Simeoni jufto Sacerdoti magno, \& Synagogæ Præefecto,\& tandemad Chrifti adventum continuata fuit. Vides igicur, quomodo fides in Chriftum femper durârit. Cofmiel. Scias Theodidacte, nonnulla rectè quidem fefe in tua illa enarratione habere; non de efletamen falfa quxdam; Rabbiriorum fuperftitione introducta; non ad eo facro textuicongrua. Sienim Abraham Ifaac flium fuum, Chriftum Adamo pros. miflum credidit; quomodo eum ad mortem per facrificium. deftinabat? Non itaque Meffiam filium faum credidit, fed? Meffia venturi veluti Typum quendam. Multa fimilia in Cabalicis hujusmodi traditionibus reperies:qux tametfi non' nihil catholicx \& orthodoxe fidei congruum teneant; itatamen Thalmudiftarum Cabaliftarumque figmencis depravata' fint omnia, utiis fides adhiberi minimè poffit:. Scias tamen, Chriftum primis mundi Patriarchis per revelationem promif fum, uti SS. PP: opinio eft, ita de illo nullum dubium effe de bet:

VII. Theodidactús: O' quantầ illo tuo difcurfü animum: meum luceimbuis! Jam video, verum effe, neminem fine fide: in Chriftum vel impliciaa, vel explicita fervari poutuife. Jam: apertè cognofco, Chriftum verè légis finem \& ultimum complementum eflé. Sed rogote, mi Cofmiel, unum: mihi exponas.velim \&c.

\section{Monitio Scholiaftx ad Lectorem.}

$\mathbf{R}$ Eliqua qua in boo Capite ad finem usque fequnstur in Romas$\mathbf{R}_{\text {naeditione, quoniam Afcetica ac Polemicaf funt, neque buc ado }}$ modum Jpectanint,omittendabrevitatis causâ cenfui.

$M \mathrm{~mm} 3$ CAPUT 


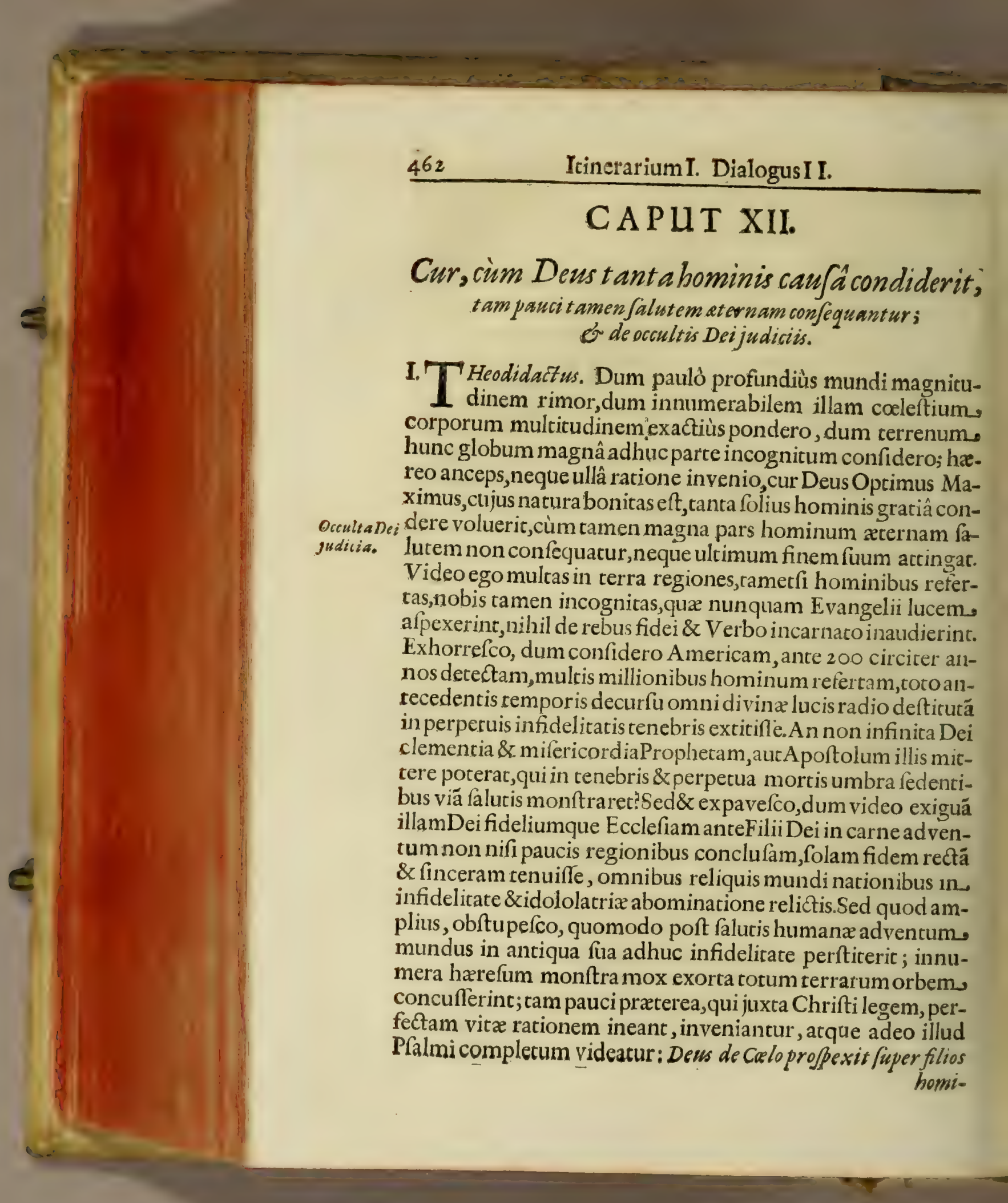


bominum, ut videat,fic st intelligens, aut requirens Deum. $O$. mnes declinaverunt; fomul inutiles factifunt; non est quif aciat bonum, non est ufque ad unum. Hæc fune qux cor meum torquent; hæc funt, qux omnes animi mei facultates veluti turbine quodam involuunt; ad te confugio, mi Cofmiel, àte aliquă intellectus lucem exfpecto.

II. Cofmiel. Inacceffa humano, nè dicam angelico intelleEtui divinorum decretorum facramenta tibi à me exponi poftulas, qux adeo abftrufa funt, ut quamdiu homo in hac mortalitatis umbra verfatur, eorum capax effe non poffit: funt enim Judicia Dei abyffus multa; femicx providentix ejus nulli creatr fagacitati inveftigabiles; Quis enimn novit fen furm Domi- FudiciaDed ni? aut quis confiliarizus ejus fuit? aut quis dicere potest, ,ur fic feciffi? Hoc unicum tibi fummo folatio fit, Deum nihil fruftra facere, fed utiab xterno omnium praecognicas rationes habuit, ita infallibili infinitæ providentiæ fuæ difpofitione; omnia in, fummum bonum, eciamfí cœeco mortalium generi nonnulla extrema mala videantur,coordinaffe. Uti enim omnia propter hominem condita funt, ita homo non propter mundum, fed ad Deunr divinamque gloriam in vitam æeternam deftinatus eft ; cujus quidem beatitudinis finis non eff proprium commodum \& emolumentum hominis, fed manifeftatio glorix Conditoris, ut glorificetur in omnibus fäcrofancta \& fuperbenedicta Trinitas: ownioc enim propter feipfum Dominus operatus est. Hinc Deus non fcientiâ,fed fide incomprehenfa opera. fua attingi voluit , ut hoc pacto per meritum fidei bominem. tandem ad intuitivam Dei vifionem, in qua omnia ineffabili quadam ratione hî́c nobis incognita videbuntur, difponeret. Omnia itaque quxcunque humanus intellectns perietrare nefcit in hac carne mortali conftitutus, in æternæ vitæ ftatum refervata effe fcias; ut proinde non mireris,fi arcanorum divinorum Sacramenta hominem lateant: hoc enim eo fine factum effe fcias, ut homo imbecillitaris fure conditionem intuitus, cum timore \& tremore Deo ferviret, \& per fidem adhæreret arctiùs; per fpem ad divinæ fruicionis delicias anhelaret ardentiùs; 
Malacur permittat Dear.

dentiùs; ac per charitatem tandem ei uniretur perfectiùs, donec carnex farcinæ pondere folltrus eotandem æternùm perfrueretur. Ibienim omnia in ltimine viræ fpectabunt homines; ibi omnes divinorum operum rationes, mundi ftructuram \& fabricam,omniumque in eo contentorum caufas perfectè,jucunditate ineffabili,\& aternùm duraturâ contemplabuntur; ibi perfectè bonitas \& fapientia Dei, omnium operum divinorum radix \& principium, cognofcetur ; \& bonitas quidem Dei illis effentiam, fapientia leges conferet. Ex fumma itaque \& infcrutabili divinæ fapienciz abyllo, mundus fub tali \& talimagnitudinis mole, fub tantoftellarum corporumque cœleftium numero, non majori,nec minori proceffic; qui diiftantias fingulis difparatas, influxuum virtutumque difpares" nationes aflignavit, quas nemo nifi ipfe folus novit, fro tamen. loco in Verbo vitæ manifeftandas. Ex hoc infisitx fapiencix promptuario proceffit, quod homines cantopere mirari folent, cur tam difparis conditionis jugum humanum gentro preferit,dum unum pauperie depreflum, alium głoriâ \& diviciis exaltatumvoluerit; hunc perpetuâ morborum vexacione miferum, illum robore \& fortitudine florentem; hunc iniqua fortunæ telis proftratum, alium falici omnitim rerum fucceflu profperantem; unum fummæ fapientix dono mirabilem, alium brutâ penè ignorantiâ miferabilem effe, fibi complacuerit. Cur etiam unam creaturam fecerit fenfu tantùm pollentem, aliam fenfus vicæque expertem; unam ratione confpicuam,aliam omnis rationis impotem; cùm tamen omnia, teite Ecclefiafte, opera Dei bonafint, \& non fit dicere, bocest nequius illo. Hre, inquam, omnia fuotemporecomprobabunGur. Neque infernum coelo pejorem effe exiftimes: ficuti cnim, uti infignis quidam Dei feruus rectè dicit, cœelum fíderibus, ita infernus damnatis hominibus, \& doemonibus ornabitur: tamenim commendat juftitiam Judicis iniquorum devaftatio, quàm innocentium defenfio. Licèt enim, tefte Divo Paulo, DEr Judicia mundo fint incomprehenfibilia , \& inveAtigabiles viax ejus tam de iis, qui ad vitam, quàm quiad mortem deftinan- 
deftinantur ; in pacria tamen luculenter parebit, univerfas vias Domininon efle nifi mifericor diam \& veritatem, ad judicandum; ubividebitur,quomodo juftitix rigorem reftrinxerit clementia, \& juftitia mifericordix indulgentiă temperârit.

III. Theodidacius. O quàmocculta funt in prefenti temporjs ftatu divina judicia! Dic ergo,mi Cormiel, quis inveftigare poteric, cur Deus Jaceb dilexerit, Efau autem odio babue it, Abyffus jwantequam natieffent? quid demeritus eft Ef fau, aut meritus Ja diciorwan cob,cùm divina bonitas nullum nifi fecundüm prafentem. jufticiam judicet? Car duo infantes portantur ad baptifmums, unus natus ex fideli ance baptifmum moriens defcendic adlimbum, alter netus ex infideli port baptifmum moriens evolat in coelum cur binis latronibus fecum crucifixis" tam difparem exitum permiterit? Cur præter Judam, alium. Apoftolorum neminem reprobaverit? Hæc enimverò funt qux concipi ron poflune, animamque turbant. Cofmiel. Nonnè dixi tibi? Hac eo fine permittuntur à $\mathrm{D} \mathrm{E} \mathrm{O}$, ut homines caltiùs follicitiufque in via fervitutis ejus procederent: ex hoc sirim contingit, ut nullus adeo fanctus fit, qui non impenetrabili divinorum judiciorum profunditate perculfus" rimeat, nè cadat; nullus adeo impius qui converfus ad Dominum per deliftorum condonationem latronis exemplo, falutem xternam non fe confecuetrum fperet. Itaque D EUS, qui vel in Angelis reperit pravitatem, fanctos fragilitatis fux memores humiliare fibi complacuit, impios verồ contrà ex peccatorú luto emerfos fpe venix erigere,nemine, amorenè an odio dignus fir,fibiconfcio.Hoc fcias velim, Deum fapientiff- Dess oo mú divina, angeliea, \& humana femper converteread optimü mnia in hoc eft,ad gloriæ fuæ manifeftationé, \& Angel is, \& hominibus bonum coknad divina naturæ fruitionem. Eclicèt malum in fe, nec f́peciem habeat, nec $\mathrm{O}_{i}$ iginem ullam; fingula tamen mala opera ad magnum aliquod \& infigne bonum fapientifimus Conditor or-

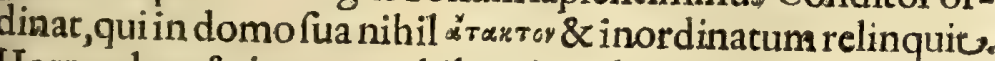
Horrendum \& irrecuperabilem Angelorum cafum, obftinasamque eorum malitiam, ad exercitium \& coronam ordinavic Nna juito- 
Quant a: bena.Deus educat.ex matio.
Itinerarium I. Dialogus II.

juftorum, juxta illud magni cujusdam Dei famuli, Juperbus ille Bumilium malleator, ipfonefciente e is coronas fabricat, ipfos imspugnando. Parimodo humani generis cafum, in admirabilem totius humanx natura exaltationem convertic: Ex hoc enim humana divinæ nacuræ infeparabili nexu juncta adeo emicuit, ur nec quicquam digniusaut excellentius, humano inrcllectu excogitari poffit,juxtaillud Chryfortomi : Revera ma-

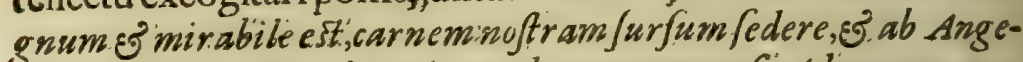
lis of Archangelis adorari; quod nequaquam, $f$ Adam non peccaffet, fact rum fuiffet. Underectè cantat. Ecclefia: O felix Ade peccatum, quod t antum babere meruit Redemptorem. Si enim bomoad imaginem Dei creatus, infux naturx honore perfttiflet,nec diabolicâ frauded deceptus,à l'ege fibi pofica deviaflet: Creator mundi creatura non fieret, nec fempiternustemporalitatéfubiretDeus, vel æqualis PatriFilius formam férvi \& fimilitudiné carnis peccatiaflumeret. Án non proditionem Judx, \& ex ea paffionem \& morté Filii Dei confecuturam( quod reverapeccatumomnium maximum fuit). benigniffimus Deus" in peccatideftructionem, diabolicæ poteftatis diminucionem; coeleftis janux apertionem, \& tandem in æternam felicitatem convertit? Annevides, infidelitatem Thomæ dum vulnerum Chrifti cicatrices, tetigit, unà in: Fidelibus infidelitatis vulnera fanaflè, atque adeo plüs nobis ad fidei augmentum Thonæx incredulitatem, quàm vel A'ngelorum cœeterorumque A'poftolorum reftimonium profuife? Hoc pacto Pauli converfionem Deus in fälurem omnium convertic Ecclefiartum, dum frviffimus Ecclefiæ perfecuror, factus eft verbi divini fideliffimus\&ardencifimus prædicator. Paripacto Propherarum, Apoftolorum, Martyrum, gloriofiffimosagones in fulcimenaum convertit féi cunctis fidelibus: niff enim fidem Cacholicam ftio fanguine defendiffent, nequaquam Domini JESU: nomenad noscum fide Catholica tanto cum robore perveniffer. Leve enim \& momenstaneum tribulationis tormentum. fupra modum magnum: Gloris pondus operatur in electis Chrifti membris: Harefes \& icandala ad fervorem fidei intepidis acuendum, 
virtutum omnium exercitio nemo ea fe confecuturum fperet: Tibi pro gloria \& honore Dei primo affiduo allaborandum tibi Deo cum timore \& tremore ferviendum; tibiomni mentis conatu, omnibus virium medullis Deus Optimus pra omnibus ardentiflimè amandus; tibiomnia terrenarum caducarumque voliptatum irritamenta magno animoafpernanda funt, ut fic in diviniamoris ofculo carnis mortalitate exutus, ea inenarrabili mentis gaudio æeternùm poffideas. Vale, dilecte mi.Theod" Ah dulcis magifter,adhuc modicum perfiftas. Cofmiel. Divinx voluntati refiftis, fi me diutiüs tecum morari cogis. Theodidactus. Fiat itaque divina voluntas, \& in ea tua. Sed rogo te, mi Cofmiel, unicum mentis mex folatium, nè̀ abiturus tuã me in vifibili impoftetum prafentiâ deftituas, fed me in dubiis illumines, in periculis liberes, in adverfis confoleris; ut tuâ directione femitas mandatorum Dei cum latitia percurram, ufque dum tecum exutâ mortalitate in perpetuas vivam æeternitates. Cofmiel. Fiat, fiat. Theodid. Vix dixerat, cùm eccetenues" in auras abiens, ex oculis non fine ingentidolore meo evanuit. Ego verò veluti ex alto quodam contemplationis fomno emerfus, in meo me Mufeo confticutum reperi. Faxit Divina bonitas, ut hoc Itinerarium Exftaticum adOmnipotentis Dei honorem \& gloriam, cui me meaque omnia dedico ${ }_{3}$ unicè cedate. A men.

\section{O N CLUSIO \\ OPERIS, Cumproteftatione Auctoris.}

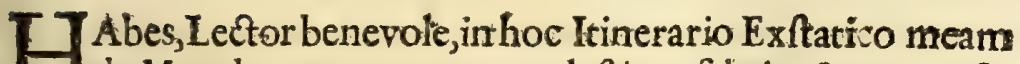
de Mundo,corporumque coeleftium fabrica \& compofitione fententiam, fub ficti raptûs integumento \& velamine indigitatam. Hoc unumâteconsenderim, nèaudaciosem for$\mathrm{N} n \mathrm{n} 3$ 


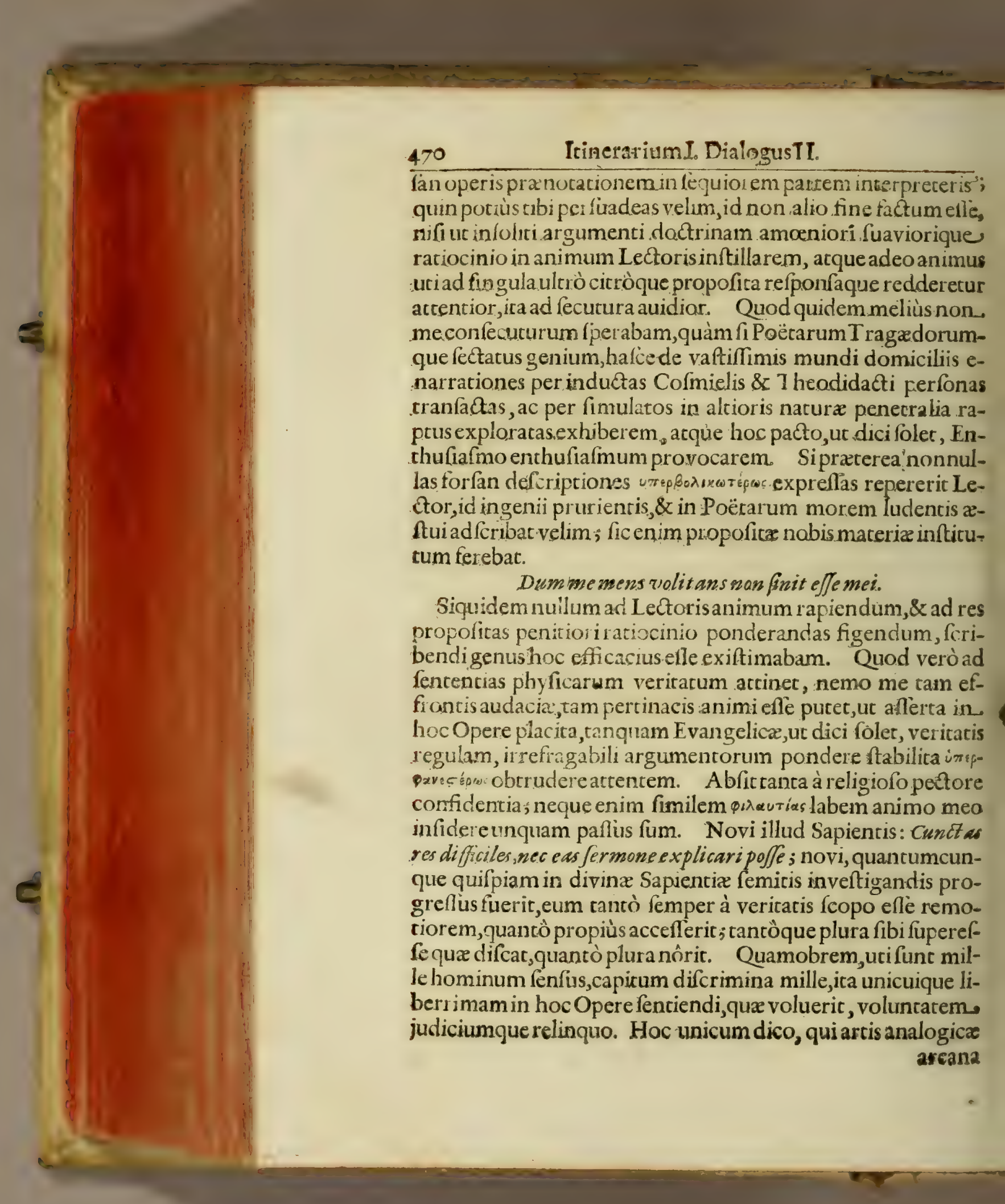


arcana noverit, is veriffimè comperiet, hanc unicam incellectus humani infirmitativeluticlavem quandam divini muneris largitate conceflam efle; qua ad interiora coleftis fublimiorifque naturæ. penetralia nobis aditus:concedatur; apercèque fatebitur illius veterum epiphonematis veritatem; Omnia in omnibus (fuo modo) exiftere: Hac ego hoc in Opereufus, nonnullam coleftis philofophiæa adeo abftufæ notitiam, nifi fallor; derexiflè videor; quâfi pariter ufurus Lector, veritatis? fcopum non ufquequaque attigerit, faltem abeo nnn longè aberraturumautumo. Ut ut fit, quemad'modum hoc Itinerarium Exftaticum,abditafque fub eo veritates non nifiad aternæ Sapientix honorem \& gloriam; animarumque fructum. concinnavi, , ita'quoque quantum quantumeft, Sacræ RomanæEcclefiæ, quæunica infallibilis vericatis regula eft; judicio, humillimo mentis obfequio fubjectum volo:

Nova aut paradoxa nonad duxi,fed ex iis; qux jam aliiante: menobilinimi Scriptores, quos partim in parænetica epiftola. allegavi, partim inferiùs allegabo, yeluti corollaria quædam., confequentium rationum efficaciâ impulfus derivavi. Sed ut concatenato quodam illationum forite me declarem;ita argumentatus fum: Si immenfum illud colorum expanfum: gumn folidicate profcriptâ fluidà \& 2 the- inter gloreâaurầ refertum eft,uti. jam communis ferè fententia \& ftrem Es verifima eft; \& ex multorum annorum obfervationibus o- calefes. mnium ferè Áf tronomorum calculo confirmata ;"ergo aftrorum corpora in eo mota, (cüm alirer fubfiftere nequeant,)haud fecus ac terra, propriis centris fubfiftunt; ergo uniufcujufque globifeu Aftri partes, partim ad centrumunicuiqueproprium naturaliappetitu confluent,partim ab eo effluent: Sihoc, ergoutifolidarum partiumad fuum centrum,ita'levium ab eodem expiratarum expulfus datur; ergo fingula conftant fuis" atmofphreris: fiatmofphreris,ergo humidum ab iisabefle non poteft: fi humidum; ergo \& folidum, quod humidum veluti in vafequodam continear: fed hac confervari non poflune 


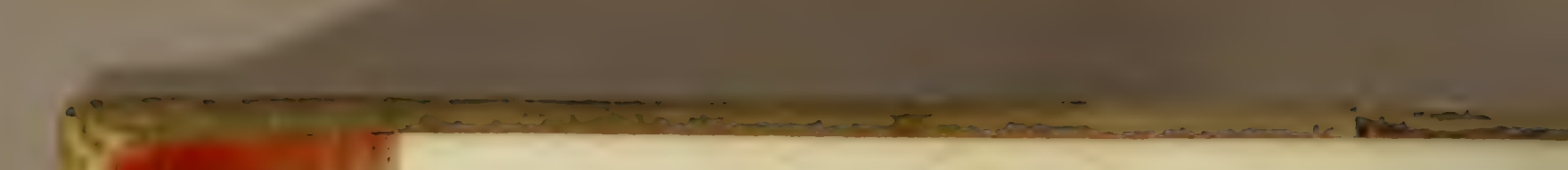

474

Auctoritates infignium

Ludov. Lacerda S.I. in Adverlariis fuis. Calos effe corruptit. biles,plurimiex SS. Patribus nituntur probare ex Scriptura, non ex Platonis fententia. Ambrof. I. Hexam. c. 6. irridet eos, qui dicunt cum Ariftotele, Colum elfe qrint am effentian, non de numeroelementorum. Altera ententiatenet, Colos incorruptibiles. Quid ego dicam in tanta variet ate? Exiftimo Jane, priorem fen. tentiam effe verifimam, ou omnes Coclos effe corruptibiles. Cur aperât antâ infiterint Philofophi in probanda incorruptibilitate Coli, diu hafi, Go quidem dispicere in quantum po/fum,nulla alia cos res movet quain ut faloum of integrum Ariftotelemprabeant. Egregia quidem laus, illum anteponere tot calefibus viris. Egonilambigo, eum errajje, so' quat quot ejus fententiam defendunt.

Marinus Merfennus ex Minimorum ordine, com. in Genef. pag. 843. Calos omnes, in quibus Aftramoverividentur, aïris inftar fluidos efle; qua fententia tot incommodis, quot adverfa, non urgetur, est que onnium facillima, s? quoslibet aft rorum motus, dift antias, aspectus, cometarum agitationes $F^{2}$ altitudines, novarumque ftellarum, E" omnium phoenomenorum productiones \& apparentiax explicare potef.. Quem videcitato loco, ubiocto rationibus fuam fententiam probar, ex optica neceffitate, ex cometarum anomalo moru, novarumque ftellarum. productione, ex Luna corniculata, inæquali, afpera, lacunis \& vallibus undique obfica, ex maculis Solaribus, ftellisque. Jovialibus \& Saturninis, ubi neceflàriò gener ationi, corruptioni \& alterationiaftra obnoxia dicit; quacùm fufiùs tractata fine, quàm ut hîc poniqueant, Lectorem ad citacum locum remitto.

Raphaci" Aver fa Ord. Cler. Min. pro tempore Generalis, tom.2.9.3 4. pag. 160. Tandem ergof ateri oportebit, maculas folares verè or realiter effe in Sole, quia Solem per tubum intwentilus vehemens qua dam comperitur fointillatio, Ev veluti ebullitio Solis in toto circuitu; qua eadem reperiuntur in maculis per totum Sol is medium difperfis. Ergo be maculia realiter funt in Sole, El finul cum eo agit antur. Quomodo verò hoc fiat, E' quenam tandenfit harum macularum ratio, dwo occurrunt modi: 
primus est, $f$ dicatur sol non effe corpus quoddam folidum, fed fuidum, in fuo loco tanquam in vafe quodam contentum, or in fe agitari inftar metalli ferventis, atque in illo inveniripartes quas damopacas \& obfcuras, Eृ?.

Petrus Hurtadus de Mendoza S. I.1. T. de Univerfo. 2uod verò Ariftoteles afferuerit, Caelum non fuifle factum, est tam celebrisinjania, ut non egeat refutatione; ac.multo minius; quid di$x$ it, Deum fat ali necel/itate it a wovere celum, ut non poffit à moincelfare. Nam fic dixit textu I 34. de Colo. Eft am com oo fic confiderarequod impolfibile eft, awt facturn aliquando quidpiam incorruptibile perdurare, aut quodingenerabile eft, ó femper prius exifens, cori.rmpi; ergo hinc infert, colum non generabile,ncc corruptibile efle. Nam omne, nquit, qreod irscipit effe, aliquando definit effe; nam quod tale ef, fact um est ex materia; quare corruptibile; quod autem corruptibile est, aliquando corrumpetur. Unde recte concludit, Ariftotelem, fi ex hypothefi coelum in tempore incepifie afferuit, a liquandoeciam \& naturaliter defiturum \& corrupum iri, afleruifle.

Ifmä̈l Bulialdus Parifnus, Mathemaricus Regius P.c. 4.ad Aftronom. Philolaicam. Vix fanè capio, cur tam folidam materiamocelis attribuerint Peripatetici. Quomodo enim, quafo, ex eadern materia conflat a effe poterunt corpus Lunare, ejusque orbis, in quo fixum movetur? corpus Luns folidum est, Es tenebroJum, vifurnque terminat; ergo cu orbis. Et paulò pòft : si repondent, ex denfiore parte $\beta$ pher conft are corpus Lunare; retorquendum eit telum in illos: cum enimex eorum fententia, orbes, \&u aftra ipfis infixa, (int corpora fimplicia \& bomogenea, ex partibus fimilaribusionf antia; si ergo ex eadem materia conftant छ Luna, \& Orbis ejus, erit \& Lunc corpus fimplex, E? materia Orbis homogenewn; non ergo finul contrarius formis affici poßibile erit, Lunam fcilicet opacitate,/pharam verò pelluciditate. Ciom it aque Luna fit opaca, e orbis e; us, quo ve bitur pellucidus; tali corpora beterogenea effe neceffe eft. Perperam itaque argumentatus eft Ariftoteles, qui heterogenen fect homogenea, ò à diparibus or disimilibus, paria of finilia colligut. Deinde quomods OOO 2 
reum, ficuti bic globus nofter bylaus; $\Xi^{2}$ qua Luna pars lumine solis plendet, ean effe aquan at heream alteram. Quagravitate fuầ non equidem ad nos cadit ;non enim centrum hoc, Luna centrum eft, ad quod aqualllatendit co modo, quo nof ra aqua ad centrum iftud tendit, of partes fimiliter alia Lunaris terra , ficuti partes nof trat is terra. Quid verò etiam mirum fuerit, $\sqrt{2} i b i$ font, facuti in terranofs a planities, E' montes, \& convalles? Et paulò pòft. 2uin छ' tota noftra maria ad Lune apectus varios cert un est varie commorveri, \& mariafluxus refluxusque, $E^{2}$ coteri afins buneoresque à Lund lumine trabuntur for retrabuntur manifeftiffime. Hoc autem wainime fierent, nife magna inter eam of noftratia intercederet fympathia. Hac autem. Jympathia non nif in magna est tim virium, tùm actionum cons. venientia; hes autem non nifin efferstid fimulitudine conffatit. Hrcille.

Godefridus Wendelinus Canonicus Cameracenfis in fua: Teratologia Cometica, fol. 23. Sol Syferrat is planet arii centrum Super fuo axi gyrat ur motu perpetuo, ab folvitque gyrum unum diebus ferè 30 . Solfornax indeficiens, ignis \&oluminis aterni ex fuo corpore corpora minus lucidat anquam vapores quofdawn,non fecus ac Tellus noftra è crateribus juis Atria, Vefuvio, Hecla aliisque fuos furnos aperit, E' interdum incendia evomit, nullis perio dis certis, ant temporibus ftatis. Ef fol. 24. Si Sol è arateribus fis eruct et prof undius corpus cometicum, projiciat que illud vel longius, vel remotius, pro ratione majoris vel minoris impreffi impetus. Si Sol ejaculet ur Comet am extrap planum Eclipica,confpiciet ur primum ad partes vel Septentrionales, vel Boreales.

Joannes Petrus Faber. Montispeffulanus 1. 2. Panchymici c. 3. Calum corpus efje mixt um, nullo pacto est anatigendicm; \&. nefcio quibus mientis tenebris obcecati philofophorum quim plurimi fuerint, qui coelum alterius $\sigma^{3}$ diverfe effentia cum element is inferioribus effe putant; of tamet fi nat uram rerum wnam हु? candem cum omnibus fuis partibus effe velint, celum tamen ultimum nature clanffrum extra natur ann collocari volunt : quafe 
verò Deus aliam peculiar ern babuerit materiam ad hujus mun dinferiora producenda, diver $\int a m$ penit is ab ea, ex qua exterio ra Ė ult ima mundicorpor a fecerit. Certè ex una eademque ma teria ac fimili prorfus Dens fecit utraque elementa, fuperiora of inferiora, $\xi^{2} c$.

Ignacius Derkennis S. J.in tract. de Deo Triuno Conditorefol.606.\& 607. Hic auctor, quæcunque de liquiditate \& corruptibilitate cœli dicta funt, omnia magno rationum pondere fic fe habere confirmat. Sed nonnulla adducamus. De Solis natura, ita loquitur citatoloco. Longè tamen putoverius, flammam feu ignern folarem prorfus uti nobis fublunarem materiam, it a fuam abfumere, ac proinde egere nutrimento. Est autem valde vero/imile, effe in ipfo sole, eo quod fit quedam Vulcania fornax, flammas ingenres undique ou continue eruct ans, qualis effet globi terreftris, finbique effet Vefuvianis of Etnais mont tbus plenus flammas jugiter evomentibus; quod utinodo in fuis montibus per intervalla tempor um bucusque contigit, it a fieri polfe continuo facile intelligi potest, fi terra tot a plenacfjet materia inflammabili, quan exvifceribus wd exteriora egereret, atque exufta rurfus in terra cavitater $\mathcal{S}^{2}$ voragines relap $\int_{a}$ continuâ circulatione rorfus in mat eriam igneam of inflamwa bilem transmutaretur. It a autem fieripotuiffe in olobo folari, non video ex quo capize redargui posfit. Hecla mons ferè femper ardet; in Indiis occidentalibus prof undisfima vorago est, in qua perpetui ignis pecies exbibetur; calidifontes jugiter fcaturiunt per fecula, haud dubiè per fubterraneos ignes femper durantes calorem illum adepti; Quidni in ingentiillo Jolari globo fum mus Opifex disponere omnia fic poffet, ut in exterioribus partibus perpetwos flammarum vortices, lentum pabulum in partibus centro vicinioribus continuâ vicisfâtudine gener at win nutriret?

Idem de Luna fol.609. De Lunari corpore dicendum eft, globu effe terraqueum, fluidis partim ac aqueis, partim confiftentibus ficcisque partibus, conft antem. Suadet primo apparentia, qua fe perinftrumenta tele fcopica Jpect andam exhibet. Partes enim umbrofa feu culo e, of minus lumine perfufa, optimie explican- 

Bentes; quod magna inaqualitas, s montium eminentiamanifeftè declar ant. Nam in hujusmodift abili fitu permanere non poffent, if fluide efferat. Sicex alt is fimis montibus, terra, \&u maria compect a, Sole lucente, hac minus, illa magis apparerent illuftrata. Sicterraqueus nofter globus è Luna compectus, in aqueis parnibusminus, in terreis magis illuftratus appareret, quernadmo dum in phafibus Lunaribus fit: unde fuadentur partes bumida ex influentiis ejus; que ciun valde humectent, ut patet in plant is

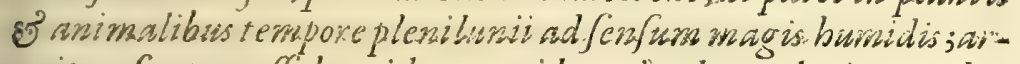
guitur fontem efle: humidum, qui luce छ̋ calore Solarium radio mum in plenitunioexcit atus terra ('e uberius communisat, quàm sum minuis est plena.

Idem deftellis fol.6 12. Certum eft, omnes planetas femper à Sole directè afpici, cùm fint fupra verticem coni tenebrofià cerreno globo alisque planetis projecti, Jove forfan, \& Saturno,qui altifimi funs, exceptis; nunquam tamen obferuatum . eft, fixarum ullamab his eclipfari, adeo ut huic modo nihil deeflè pofit, nifi nimiâ à Sole dirtantiâ; quam quia alii plures fupponunt, volunt illas propriâ lucefplendere, \&zeflealios quafi igneos Soles.Nam fiex fe luceant, iisdem de caufis, quas pro Sole igneo attulimus, \& ipfas propriè igneas efle dicendum ent.

Idem de centro Lune, coeterorumque aftrorum fol. 6 I th Neque periculum eft, nèad terram labantur partes Lunares, feu rota Luna, fi mareria ejus cum noftra fymbola fit, \& forma haud difimilis. Nam partes omnesad centrum globi, cujus funt parces, inclinancur iisdem de caufis, quibus id in terraufi venit; qua etfinalia ætheris parre pofica fuifler, ibi perinde fixa manfiflet; non enim ad imaginarium univerfi centrum. tota tendit, fed partes tantùm nituntur ad totum.

DominicusPlacus MonachusMontisferrati,ibidemque Philofophia Profefor, in obfervatione Eclipfeos Solar is 26 . Jan. an 1 65.6. ab Illuftrifimo \& Reverendiffimo Domino Joanne Caramuele fummo ftudio \& fagaci. induftriâ,ope Euftachii de 
Divinis, oblervata, \& imprefla Roma,num. 7. Preterea Solis marginem undofum \&o procellofum effe vidimus, \& fubdubitare coepimus, an effet liquidus? Si enim corpus solare effet folidum. non perciperemus a terra tantas ebullientium umbrarum ${ }^{3}$ plendorum tempeftates. Hic unumquemque in fino fenfu abun dare permifi; mult uim enim Sol removet ur à nobis, \& in re fubli mi \& Jubtili varis funt virorum illuftrium fententis; inter quas illa abtinet, qua afferit plane tarum /pher as effe pervias, of inglobis errantibus duas reperiri materias, alteram folidam of terra fimilem, alteram liquidam ơ aqua analog am. Et pauiò pòn, ubiidem tempus majori solis prodigio videbatur ab A per FCE contra fignorum fucce/fioncm gyrari fummá velacitate; $\xi ?$ cur id quafo? Annè Sol movetur circa centrum funm velocisfimie? $E^{\circ}$ fi movetur, an ab Ortuin Occafum contra fignorum fucce ijios nem? Si diffiditur oculis, omnia funt falva; at que a enfus nos dirigunt, \& illis tenemur cyedere, quam diu err are non conftat. solem it aque quà folidum, Jupra axes fuos mexftrio jpacio ( quanturn macule pofulant ) torquer affirmo; at eundem quà liquiaum, in varias partes fiuere, quì vel materia gravitas, vel folariun ventorum impetus undas pracipitat, $\varepsilon^{6} c$.

Joannes Eufebius Nürembergius Hiftoriæ naturalis 1. 2. c. I3.Decorruptibilitate coeli. O quàm ridiculifumus, cim foinmus frde nof trâ corrum pendos calos, $\sqrt{2}$ a a huc incorruptibiles facia. mus? Multi Philofophi, nunquam corrumpendos put antes, adbuc corruptibiles dixerunt. Deus nilfacit fruftra. Curfabricaret orbes incorruptibiles, ficorrupturus erat? 2uid mirariscorruptibiles effe caelos, \& non corrumpi, licet quidem mirari ad hocutique factos. Hoc inter Dei mirabilia lancto viro fob proponitur. Tu forfan cum eo fabricatus es colos, qui folid int imi quafi are fufi funt, foilicet boc mirat u dignum, col lum videlicet fubtiliffmom, atbera continere integrum, fecurum, ac fi alidisfs. mus ac ereus effet, poteft Deus firmare tenue, inde $\sigma^{2}$ firmamenti nomen coelis inditum, quiaverbo os potentia Deifirnat:,non ut is que firni ex fe funt, fed firmati; ideo Ifaias corporalis fumi frmilitudinem curn firmitate conjungtt, Coelum, ait, tanquam fumus firmatum eft. 
Joannes: Baptifta Zupus.

Joannes Baptifta Cyfatus:

Joannes. Eufebius. Nieremb gius. Joann pefluilanus.

Ifmaël Bulialdus Parifinus.

Ludovicus Lacerda S.J.

Marinus Merfennus.

Martinus Lafarina Abbas, S. Lucir Siculus.

Michaël Langrenus:

Nicolaus Zucchius S. J.

Petrus Gaflendus.

Petrus Hurtadus de Mendoza Soc. Tefii.

Raphael Averfa.

Reinerius Magni Ducis Math.

Renatus Defcartes.

Seneca.

Simon Marius.

Wincentius: Mutus.
Lireræ de novis Phonomenis. Cometographia.

Hiftorix Nat.de corruptibilitate coeli.

Lib. 2.Panchymici.

C.4.ad Aftron.Philolaicam.

In adverfariis fuis.

Commentar.in Genefin.

. Obfervationes necdum editx.

Selenographia.

Obfervaciones proprix.

Varia Opufcula.

Lib. I. de Univerfo.

Tom.2.9.34 pag. 160.

Obférvationes. Jovialium Comitum.

Fundamenta novæ Philofoph Lib.6.q.Nat.c.63.\&.1.7.c. 3 I. Mundus Jovialis.

Libellus obfervationum Solatium.

D. A. M. D. G. V. M. 
ด้อง

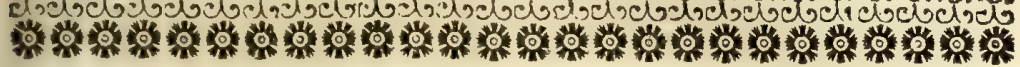

\section{APOLOGETICON}

CONTRA CENSLIRAM NONNLILLARLIM Propofitionum, exItinerarioExltatico Kircheriano excerptarum.

\section{PRO OEMIUM.}

Dumbilicum propè perduxeram Pre2. InfionesE Scholia, qua in Itinerarium, Exftaticum Colefte R. P. Athanafii Kircherifcriptitabam, cum Roma adme perforiptum fuit, tum ab aliis, tum ab ipjo etiam Auctore, Virum doctum nefio quem, aut quo zelo ductum, Propofitiones qua dam, Eformulas loquendi minus ufit at as, in dicto Itiner ario binc inde occurrentes, geverioricenfurânotaffe, ut pote vel doctrine fane contrarias (ut ipfe quidemexifimat ) vel Superiorum nof trorum Ordinationibus, quibus ex è Scholis noftris eliminantur, repugnantes. Miratus fum vebementer, mecumque aliiViridoctisfimi, ut qui fedulö antea, nec femel, totum Itinerarium evolueramus, nec

$P P_{3}$

quidquam 
486 Apologeticön contra Cenfurả nonnullarủ Propofit. quidquam trali dignum cen/urâ notaveramus. Hefer amus quidem circa nonnull a, nec ment emL. Auctoris affecutipenitus fuer amus; unde E per litteras explicatianem uberiorem petiver amus', Eobtinueramus, prafertimcirca illa, qua de Mundi immenfitate non minis doctè, quàm myftice propemodum adftruit : at necifta, nec alia certo nobis perfuadebamus talem mereridicam, quali a dicto Viro notata inaudier amus. Frequentibus igitur acponè importunis litteris expetiiactandem extorfl cenfuram pradict am, non alio fine, quain ut fi quem errorem, aut minis rectum loquendi modum, qui meum doctorumgue Virorum judicium effw giffet, deprebenderem, eum aut cum Auctoris venia expungerem, aut fanum in fenfum traberem, aut denique Auctorem ab injuria, fiopusforet, vindicarem. Quod dum bic eá, quá par est, moderatione praft are contendo, nemo mibivitio vertet, quoniam nibil à Scholiaft a officio alienumfacio.

Ut verò intelligant omnes, in quo precipuè peccaffe Auctorem roftrum cenfeat Vir doctus, fciendum est, cum magna femper cure fuerit Societati Noftre foliditas of uniformitas doct rine, tums zradende in Sckolis, tumfcriptis libris in publicum praponesda; 
aut um, provifumque jam dudum fuifle a Jupremo Societat is Nofre capite, ips âque Congregatione generali non unâ Virorum ex -adem Societate doctifimorum: toto Orbe collect a, quâ methodo, quoque fententiarum delectu doctrina fanior ins Scholis, prafertim fublimioribus Philofophis as Theologie, tract andaf foret. Cum nibilominius in tantodocentium acforibentium numero timeretur, nè aliquifortafjs ob prefervida ingenia praforiptum ordinempraterirent, aut nimia libertati opinandi indulgentes, fieot arentur fubinde, aust etiam procuderent. (ententias novas, vel eertè obfoletes antiquat af que revocarent ie tenebris ad noftras scholas, friptisuic libris Mundo propalarent; optavit Congreg abionoftra Oct ava, ut texeretur Elenchus earum fententiarum, quas preft at non doceri in noftris scholis. 2uod E' factum, Or: dinatione $q u e$ novaproftudiis Superiosibus confect c. Inter a lias porro Rropofitiones, qua in Scholis Societ at is noftra ab eo tempore non funt docende, funt 20,30, ह5 39:

Propofitio zohacest. Poflibilis eft creacura perfectifima, quâ perfectior crearià $\mathrm{DEO}$ non poffit ; item imperfectîfima, quâ nulia imperfectior à DEO pollic creari.Propofetio 30 est. Infinitum in multitudine, \& magnitudine, poteft claudi intenduas unitates, vel duo puncta: Propofitio 39 est: Dux tantùm funt qualicates prima, calor \& frigus; humor verò \& ficcitas non funt qualitates:

Contrabas peccaffe Itinerarii Auctorem contendit Cenfor, a liaf que docuiffe Propofitiones multò plures ablurdas (verba funt ipfius ) \& contra communem Philofophiam temerè, \& fine probatione aflèrtas; Imò \& apertè pugnantes inter fe. Quod' an itafe babeat, ex Jequentibus patebit.

\section{S.I. Propofitiones fex, ex Itinerario Exftatico} Kircheriano collectx, \& cenfurâ à Viro docto

$$
\text { notatie. }
$$

WOtalector,paginarum numeros in fex fequevtibus hifce Pro* pofitionibus defumptos effe ex primaieditione Romana, $\frac{2 u i-}{b \text {. }}$ 


\section{A pologeticon contra Cenfură nonnullarǔ Propofic.}

bus locis noft ra hujus fecunds editionis eadem Propofitioner ba beantur, infrai in reponfionibus indicabo.

Propofitio I. D E U S ex omnihujus fphærx puneto ( fermo est de (pha ra patii imaginarii) Mundos infinito intervallo dif fitos, fi abtolutamDEI potentiam atenda mus, educere potuit. Iter Exftaticum pag. 39 I Prohibita Propoficione. 30.

Propofitio I I. D E U S non potuit facereplures Mundos, neque hunc majorem quìm reipsâ fic,quòd id contradictionem implicet. Hoc non aflèrit modò P. Kirchertu, féd pluribus paginis demonftrarenititur, nempe pag. $351,352, \& 391$; in cujus fine expreflè ait, Mundum neque perfectiorem, neque abfolutiorem fieri potuifle. Prohibita eft Propofitione 29.

PropofitioIII. Neceffe eft,hrecomnia,lucem, ignem, caloremque, idem effe. pag. 148. Sic lumen definiens pag. I44; Eft itaque lumen (inquic) nil aliud, nifi igneus quidam effuxus, exipfo Solis corpore, in objecta fibi corpora propagatus, atque adeo ejufdem cum fonte, unde profluxit, natura. Hac Kircherus. Jam igitur lux, lumen,\& calor, ex mente Kircheri, nec accidentia func, nec qualitates, fed fubftancia, \&xcorpora, nempe ignis. Siautem calor accidens non eft; neque frigus accidens erit:contraria enim in eodem funt genere : igitur frigus vel fubftantia etiam erit, vel mera caloris five ignis ca. rentia. Similiter quoq̨ue pag. 6o. Kircherus aliam humiditatem non agnofcit prater eftuvium rofcidum, quo abundau Luna,\& hrec inferiora humectat. Siccitatem autem non aliter induci ait, quàm per affufi humoris fecretionem. Ita primas qualitates omnes negat P. Kircherus. Prohibita Propofitione 39.

PropofitioIV. Quomodocalor formalis ab agente formaliter non calido producatur? \&c. pag. I 4 I , quâ, \& fequentibus, P. Kircherus non folùm probare nititur, impoffibile effe, dari caulas, qux fuos effectus eminenter folùm contineant, fed eciam Peripateticos ignorantix arguit, quòd caufas tales agnof́cant. Sed ut de caufa prima nihil dicam, qux æquivoca eft; 
hac unâ Propofitione formas omnes fubftantiales de medio tollit: fi quæ enim dentur, neceflè eft eas plurium effectuum. effe caufas æquivocas; ut cùm futum fubjectum, aliunde alteratum, ad nativum ftatum reducunt, producendo fcilicet in proprio corpore qualitates ad torius confervationem neceflàrias.

Propofitio V. Natura eft Ars D E I,\& fpiritus univerforum, feu anima Mundi.pag. 33 ร. Mundus itaque animatus eft, ac vivit. Unde confequenter ait idem pag. 37 I. coelum iplum, mundanaque omnia corpora nutriri.

Propofitio V I. Tolerari non debuit, quod P. Kircherus five fud o, live ex inadvertentia dixit pag. 38.intellectum hominis ex vena lucis à $\mathrm{D}$ E Oeffe eductum. Sufpicionem verò movet, id non tam cafuexcidifle, quàm praconcepto errore promanaffe, quòd alibi pag. 293 air,lucem primigeniam primum efle totius Naturæ principium activum, generationifque rerum unicam originem \& radicem.

Conclufic Cenforis. Multò plures in eodem Libro continentur Propofitiones abfurdx, \& contra communem Philofophiă remerè, \& fine probatione affèrtx; imò \& apertè pugnantes inter fe. Sed fuperiores periculoræ funt in fide.

\section{§. II. Refponfiogeneralis ad predictas. cenfuras.}

$\mathrm{P}$ Radictarum Propofitionum cenfuris antequam fingulation. refpondeam, premitto, Societatis noff re Scriptorum libros, qui Roms cenfentur, maximo rigore, antequàm pralo cömittipermittantur, difcuti à Viris doctiffimis, of rerum argumentorumque ad mentem noftre Societat is tract andorum longo ufus'experientiâexercitatis; viris inquam, quorum judicio univerfa Religionis noftre doct rina uniceftat. Qhatuor enim eruditißimos Theologos (Revifores, feu librorum Cenfores nos appellawns) è tota Italia, Hijpania, Gallia, atque Germania collectos, \& qui non. paucos annos in Pbilofophia ac Theologia publice tradenda celeberrimis in Academiis infumpferunt, alit Romanum Societatis

$$
299 \text { noftre }
$$




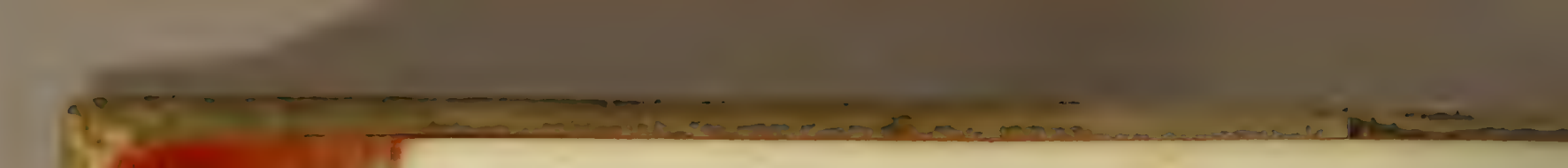

490. Ápologeticon: contra cenfüã nonnulfarũ Propofit. noftra Collesium: qui ab omni alio onere liberi, Scriptorum no. ftrorum libros,ab Adm. R'. P. N. Generale fibi traditos, legunt,

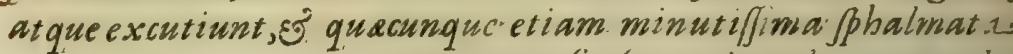
annotant; quacunque communt confen/u corrigenda, mutanda, omittenda, apponenda cenfent, dicto: Adm. R:P.N. General foriptoproponunt:quinon antea imprimendifacultatem impertitur Auctoribus, quàm correct a fint que corrigenda cenfuere Revifores: Correct um deinde o. approbatum Opus, Reverendifo fimo. Sacri Palatii Apoftolici Magiftro traditur, novam ut cenfuramfubeat; qui denuo uni alteriue doctiffimo Theologo è.fuo, id est, Sancti Dorninici Ordine illud tradit; nec: ut pralum. Jubeat, permittit antea, quàm eodem, ut prius à Noftris, rigore à Suis excufum, correct um, at que approbatum fuerit. Mibicerte non femel, dum: Rome opellam: meam qualem qualem Kircherianis $O$ pexibusimprimendis impenderem, tum à Reviforibus nof tris, tum à Sac. Pal. Nagiftro, ant Socio ei us, integni catalogi monutiffimonum vel adpecienn erratorum fuêre exhibiti, qua ab Auctore fublatavoiebant:

Hoc itaque eodem rigore iidem Revifores; neo non E Sac. Pal. Magifier, Exflaticum cenfuerunt Itinerarium; $\mathcal{J}^{\prime}$ tanto majori quidem feveritate; quanto in nnvo caleft is Pbilofophia Opere mentes corum de praconcept a nefcio cujus latent is novit at is um bramaiorinvaferat fuppicio. Unde difcuferunt omnia of fingula, Sं prajudicio quadam futura ( ut Auctor ad me (cribit) expunxerunt, in obf curis E? dubiis non pauca ad clariorem rerum. notitiam addiderunt; opufque tandem eâ qú par eft, diligentiâ amer ditum, dignum quod publici jus is fieret, folito teff imonio, un. animi confenfu, approbarunt. Tantum vero, abest ut in eo quippiam fidei catholica prajudiciale (quemadmodum Cenfor exiffimat ) invenerint, ut pot ius Sanct orum Patrum placit is confor. me, $\xi^{2}$ ad piet atem excitandam oportunum, non fine commenda. tione fingularijudicarint.

Hec premittenda duxi,ut Lector in primo fatim veftibulo videat, quàm cautè perforipta, quàm feverè examinat a quàms sorrect a fu udiose, s' quam aliena ab errorejudicat a fuerint, qua 
Cenfor tam feveropungit obelifco.Sed nuncadjangula difouties daprogredianur.
I. I11. Refponfio ad Propofitionem primam, ejuf́gue Cenluaram.

P R O P O S I T I O. Deas'exomni hujus fphæræe puncto Mundos infinito intervallo difitos, fi abrolutam D E I potentiam att ndamus, educere pocuit. Iter Exftaticum pag. 39:I. CENS UR A. Prohibita Propofitione 30.

Verbacitata babentar in Itinerario Exflatico editionis Romane pay 3 gi, editionis ve rò noftra Dialogo 2. cap. g. mum.8. Jub finew. Propofitionem 30 ,probibitam doceri a noftris. Doctoribus, attulifuprain Procemio.

RESPO NSIO I. Concedo,Auctorem Itinerariiaflerere pradicta verba; at nego eum peccare contra dictam Propoficionem 30 prohibitam. Auftor loquitur de pocentia DEI fecundùm fe confiderata, \& de fpatio increato, hoc eft; de fphæra intellectuali divin $x$ eflèntix, in qua omnia funt infinita, immenfa,\& incerminata, atque adeo vicina ac remota, diflita ac propinqua,conjuncta ac difiun $\{t a, c o i n c i d u n t$. Propofitio 30 prohibita loquitur de potentia DEI reducta in actum, \& de fpatio creato; in quo tantum abeft ut Auctor contendat educi poffè à DEO plures Mundos infinito intervalloà fe diffitos, fi creaturæ conditionem refpicias, ut potiùs neger conftantifimè,plures in eo creari poffe: fic enim critato loco ad quaitionem, an DE U S in infinito fpatio imaginario plures Mundos condere potuerit, refpondet: Si divinam potentiam re/picis,certumest, DEUM infinitos Mundos in ditto patio condere potuif$f e ; f$ creature conditionem, id pror fus impoßsibile fuit. Nihil ergo peccavit Auctor in Propofitionem illam 30 Ordinationum noftrarum. Quomodo verò intelligendum fit, $\mathrm{DE} \mathrm{U} \mathrm{M}$ in quovis imaginarii fpacii increati puncto producere poffe Mundos infinito inter fe intervallo diffitos, fi potentiam DE I - fecundùm fe confideres; explicat ipfe loco citato : rectè \& effi-

Q99 3 caciter, 


\section{Apologeticón contra Cenfură nonnullarŭ Propofit.}

caciter, nec nè,non eft hujus loci difcutere; fufficit oftendifle, Auctorem immunem effe ab intentata cenfura.

RESPON SIO II. Dato tamen,quid tam Auctor, quàm Propofitivilla 30 inter probibitas, loquatur de Jpacio creato; ajo eum non docere quod in illa probibetur, Jed apertè contrarium. sùm exprefse dicat, id repugnare ex parte materia five objecti, licèt non repugnet ex parte divins potentia per fe pect ate, que simirum cum fit prorfus illimitata,potest de Je facere etiam ea. que alioquin exparte fua fiern non poffunt. 2ui Auctoris fenJus manifeffus est ex verbis panlà antè citat is: Si divinam potentiam refpicis, certum eft, D E U M infinitos Mundos in difto fpacio condere potuifle; fi creaturæ conditionem, id pror fis impoffibile fuit. Et juxta huncloquendi modum reliqua onnia funt explicanda qua ibidem affert Auctor; neque est cur reiciciatur, cum offendi po/fit etiam in antiquis Scholufticis fundamentum habere.

R ESPO N S I O III. Accedit quiod, cium eolocoperfenon quarat Auctor, polfant ne produci plures Mundi infinito pacio da Se dift antes.sedid dicat dunt axat ad explicandam infinit atems pacii imaginarii, five divina phara immenfitatem; nibil fit quod cogat, id prorfus rigorosè accipi de infinito categorematice, fed ita ut folum fongificetur,eame effe divina immenfitatis ampli tudinem, ut intraillam produci poffint infinit Mundi quointo vis patio a fe diftantes, adeoque majori 3 o majori in infinitum Syncaítgorematice.

R E S PON S I O IV. Etiam admiffo Senfurigorofo, facile intelligy i $\xi^{3}$ afferi potest, id dict um folìm quafi permiffive; quafl dicatur, eam effe divine illius phara imimenfir atem, ut poffent intra eam praduct Mundi infiniti, quantoves spacio,etiam (fo voles ) infinito sategorematice diffantes, qui tamen ab ejus circumferentia, qua finem non babet, femper aquidiffabunt, id est, Spacio infinito.

R ESPONSIO V. Propofitio 30 probibita afferit, Infisitum in multitudime, \& magnitudine,poffe claudi inter duas

unitates. 
snitates, vel duo punct a. Efto igitur, evm qui affereret, $D E \cup M$ ex onni imaginarii pacii puncto poffe educere plures Mundos infinito intervallo difititos,peccare contra dict am Propofitionem; Auctor tamen Itinerarii id nunquarn afferuit, fed tant ün, civin dixiffet: Quxcunque itaque de diametro hujus fphxræ diximus, de toca fphxra jure meliori dicenda funt, in qua quor puncta, tot cencra conftitui pollunt; quæ tametfi infinito fpatio à fe invicem diftent,à circumferentia tamen, quæ finem non habet, femper æquidiftabunt ; fubjungit: Qua cùm ita fint,DEUS ex omni hujus fphæræ puncto Mundos infinito intervallo diffitos, fi abfolutain D E I potentiam attendamus, educere potuit. Non dixit, Mundos infinito intervallo inter fe difitos educere potuit, $\int e d$ Mundos infinito intervallo difficos, nimirum a circumferentia phere divina imemenfit at is, cujus centrum ubique, circumferentia nufquam, ut Trifmegiftus enutatiait. Quodjs paulo ante dixit Auctor, quatamerhinfinico fpatio à fe invicem diftent; id tant um quafi permijive afferuit, ut dixi.

Ad hos, aliofque fimiles fenfus fi explicetur Propofitio Au Etoris, nibil in ea apparet vel perfe abfurdum, vel repugnans Ordinationi proftudiis: multo autem minus umbra ulla periculi in fide, quod nefcio ex quo fundamento timet doctus Cenfor.

\section{§. I V. Refponfio ad Propolitionem. fecundam, ejufque Cenfuram.}

PR O POS I T I O. D E U S non pocuic facere plures Mundos; neque hunc majorem quăm reipsâ fic ; quòd id contradictionem implicet. Hoc non afferit modò P. Kircherus, fed pluribus pagin is demonftrate niticur, nempe pag. 3 i I, $352, \& 39$ I. incujus fine exprefsè air, Mundum neque perfeEtiorem, neque abfolutiorem fieri potuiffe. CENSLIRA. Prohibita eft Propofitione 29.

$D E \cup M$ non potuife facere plures Mundos, afferit Auctior

Qgq 3 Itine


194 Apologeticon contra cenfură nonnullarü Propofit.

Itinerarii pag. 352 , \& 353 ,edition is Romana, five Dialogo 2. cap. y. num. 10. noftra editionis, ut bene advertit Vir doctus: ibi enim idex profeffo probat adduct is aroument is. Non potriffe quoque bunc Mundum facere majorem quàm reipsâfot, quiod ed contran dictionem implicet; afferitidempag.39I.edit. Rom. five Dialogo z.cap. 9. num. \&. circa finem noftr a editionis, ut idesn Vir doat us recte obfervat : it a enim babet cir. lo. Reftat itaque, Mundum unicum à D E O Opt. Max. conditum fulle, eumque omnibus numeris perfectifimum, ita ut quemadrodum maximum contractum eft, ita melius, perfectius, abfoluciufque fieri non potuerit; hoc enim pacto ideatum idex fux, qux in. Archerypo intellectu fubfiftit, meliùs conformabitur. Similia dixerat antea Dialogo 2.cap. e. circafinem.

RESPO NSIO I. Fateor, me quoque,cum aliis viris doctis,circa haceadem Auctoris dict a perplexum diu bafiffe, donec acceptis Româlitteris ( quas Juprà in scholio ad cit. caput 2. recitavi) edocti de ejus mentefuimus. Qua mens. fi explicetur, \& recte intelligatur; clarè conftat, eum nequaquaim peccafje contra Propofitionem 29 Ordinationum nof trarum, qua probibetur fententia docens, poffibilem elle creaturam perfectuflimam, quâ perfectior crearià DEO non poffit.

Dico it aque, Auctorem noftrum locis allatis non afferere, contradictionem involui in eo,quiod dentur plures Mundi, fub ifto nomine; aut quod poffit feri alius Mundus hoc noftro perfectior; aut quod hic nofter poßit effe major acperfectior: fid tantiom, quod dentur plura Vniverfa fimpliciter, aut plura maxima contract a, quorum unumquodque omnia in fe contineat: :ub quibus terminis clarum est, id contradictionem involvere. Inde autem fimpliciter infert, dari non po/fe plures Mundos, Jupponendo quid Mundus छ? Univerfum idem fint,ex ipfa Mundi niverfi definitione. Quod autem in horfenful loquatur An ctor nofter,patet ex ratione quâ probat pag. $39 \mathrm{e}$ edit. Rom. five Dial. 2. cap. g. in fine, unicum tansum à DEO creatum effe Mundum: fic enim difcurrit : Accedit quòd cùm Mundus hic omnia contineat, fitque contraftum maximum, quo majus dari non. poffit; 
poflic; fruftra alis Mundi conditi viderentur: Vel enim uti hic, ita ifti Mundi omnia concinerent, ve non continerent : fi prius, ergofruftra fieret per plura, quod fieri poflèt per pauciora:fi pofterius,ergo Mund is intis aliquid deefler, nec omnem corporex perfectionis plenitudinum continerent ; quod dici minimè poreft. Reftat itaque, Mundum unicum à DEOOpt. Max. conditum fuille, eumque omnibus numeris perfectifnmum, ita ut quemadmodum maximum contractum eft, ita melius,perfectius,abfoluciufque fieri non pocuerit: Vides,quonodo fupponat, Mundum bunceffe contract um maximum; \&omnia continere; $\sigma$ quomodo ex hac hypothefinferat, necplures effe poffe uno;nec alium hocperfectiorem, nec huncfeiplo? Idem etiam pat et ex cap: 2. cit. ubiexplicat quo ensu Mundus dicatur Univerfum, Es contract um maximum. Que autem Auctor nofter habet locis allegat is de contracto maximo; congruunt iis que babet Cardinalis Culanus in libro de Dociaignorantia, ut meminime legiffe Roma; jam enim non habeo Culanumad inanum:

R E SPO NSIO II. Quando AuCt or nofter pag: 39 r. edit Rom: Seu Dial. 2. cap. g.num.s. noftr e ealit.alivque in loiis, afjerit Mundum non potuiffe perfectivis fieri, determinate loquitur de Mundo qui reipsáf act us est; ó tantùm vult, Mundum de lege DE I ordinat a, \& ecundim finem ad quem fact us est, iternque -pecta. tâ ế proportione, quam babent ad fe e partes illius faltern principales, non pot wiffe convenientius \& abfolutiüs conftitui f quod cornmuniter dicitur à Philofophis acTheologis. cum S. Thoma s.par. q. 2 s.art.6. ad 3.) quidquid fir de alio Mundo abfolute creabili., nut de buius Mundiperfectibuli ate accidentali. Effe autem. hanc, 5 non aliam, Auctoris nof rimentem, patet ex variis: ejus locis, que ex It me rario adducere libet. It aque Dialogo z. cap. s. num. g. noft ra edit. Jive pag: 35 I edit. Rom. fichabet : Mundus" non adeo perfectè à DEO Opt. Max. Conditore creatus fuic; ut in ejus productione DEUS omne quod facere pntuit, fecerit; tamerfi cum ea perfectione factus fit, ficuti effe potuit:quare, uti Mundum perfectiorem, ita etiam imperfectiorem DEUS

facere 
mifero. Celebre Peripateticorumepiphonema eft,eflentias rerum fe habere ut numeros; \& habetur lib. 8. Metaphys. cap. tex. I I. Quas eflentias rerum fi confideremus quoad gradus metaphyficos, \& præedicara effentialia; prorfus in indivifibili confiftere,omnes fatentur. Si enim, exempli gratiâ, quinario numero unitatemfubduxeris, vel eandem addideris eidem.; certum eft, eflentram \& perfe ¿tionem numeri quinarii inaliam differentem numeri fpeciem (quierit vel quaternarius, vel fenarius) degeneraturam. Cujus rei ratio eft "quôd unitatis" additio vel fubtractio formaliter diverfificet divifibilitatem. numeri: cujus fignum eft, quia ex pari facit imparem, \&.ëcoaverfo. Atque hæ proprietates,\& differentis fpeciei proportiones, in numeris quibufcunque diverfis reperiuntur. ulcima itaqueunitaseft forma numeri, uti docet Philofophus Io. cit. Inrelligitur autem,\& verum eft in ordine ad rationem, qux in finguls numeris ordinem concipit unitatum ; inter quas easqux eft ukima, numerum complere cenfetur, \& abaliis quibufcunque diftinguere, ficuti forma effentia m reicomplet,eamque in certo quodam gradu ac fpecie indivifibiliter conftituit ; quia unitasultima numerum in fua fpecie conftituit per modum formæ determinantis fubjectum: quo fit, ut priorum unitatum multitudo fuo modo comparetur ad illam, ut quid actuabile perillam. Qua etiam de caufa per additionem vel fubtractionem ultimæ unitatis, ulcimum fpeciei numerica Conftitutivum manere non poteft, $\mathrm{fed}$ mutatur in aliam numerifpeciem. Quod itaque de numerorum effentia \& perfectione diximus,id pari pacto de qualiber fpecie cujufcunque gradus entium intelligendum eit. Atque hoc eft quod nos contractum maximum diximus. V. G. humana natura in eflentia fux indivifibilitate ita perfecta eft, ut eiaddi quidpiam aurdeminon poflic, quin proprix effentix ratione deftructâ, mox in aliam fpecie differentem eflentiam degeneret, quemadmodum P. Francifous Suarez in fua Metaphys.difp. 4. fect. 4. num. I 1. fusè docet. Neque putet Lector, nos hîc de perfe- 


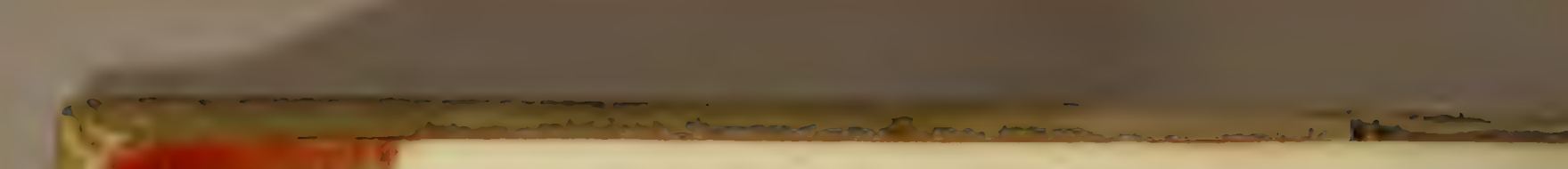

998 A pologeticon contra cenfură nonnullarŭ Propofit. etione accidentalr, fed de eflentrali loqui; qux uti omnum. confenfu in indivifibili confiftit, ita quoque immutabilis eft.

Sub hoc itaque fenfu nos Mundum neque majorem, neque meliorem perfcetwremque à DEO Opt. Max. quàm reipsâ eft , fieri potuifle aflerimus. Unde difficultas à Cenfore propofita,non nif fimplici diftinctione folvi poteft, fic : Mundus à DEO neque major, neque melior perfectiorque fieri potuit, fi effentialem perfectionem, \& finis rationem attendamus, concedo; Siaccidentalcm, nego. Explicome.Cùm enim Mundus omnem corporeæ materialifque perfectionis plenitudiné in fe contineat, plenitudo autem hujus perfectionis formaliter. confiftat in fumma coeleftium corporum, elementorumque ad invicem proportione, cum exactifima intervallorum. unius ad alterum,omniumque ad Terram, $\&$ in ea contentorum menfura; certè,immutabili ordinis lege fic poftulante, Mundus harmonico corporum nexu ita conftitutus eft, ut ftante hac rerum combinatione, neque major ${ }_{3}$ neque melior perfectiorque fieri potuerit. Quod non ego tantüm, fed $D$. Thomas, aliique plurimi ejus fectatores fentiunt. Confirmat bac dict a allat is teftimoniis S. Thome, $P$. Suarez, Durandi, $S^{J} S$. Augultini; post qua fubjungit. Habemus itaque ex citatis Auetoribus,DEUM, fiultimi finis rationem \& ordinem attendar mus, Mundum neque majorem, neque meliorem perfectioremque facere potuifle; quod \& nos paffim aflerimus fub hifce verbis, fante bacrerum conditione. Unde rectè infero, ftanwe hac rerum conditione DEUM plures Mundos ejufdem fpeciei,\& per omnia fibi fimiles \& $x$ quales $s_{\star}$ efficere non potuifle. Atque hoc nos pacto Mundum hunc maximum contraetum. dicimus,five, quod idem eft, in quantum immitabili DE I lege, $\&$ divinæ voluntatis efficaciâ ${ }_{x}$ eflentialem tiniperiectionem fub hac actuali rerum combinatione, Opific is DE: munere adeptuseft. Attamen DEU M quoad intrinfecan? firan poreftatem fub alia \& alia combinationis lege accidencalitc i lures Mundos condere potuifle,neq; rego, neq́; unquam negari: po- 
tuiflec enim DEUS abfolutè Mundos alios hoc majores, fervatâ fingularum parcium proportione, condere, idque fine termino,v. g. fingulas partes centuplo aut millecuplo hujus Mundi partibus majores, Terram Terrâ,Sole Solem, Mare Mari, Coelum Coelo,Mundum Mundo majorem. Et quemadmodum Le/fius lïb. s. de Perfect. \& Attrib. Divin. docet, potuiffer DEUS Mundum adeo facere magnum, ut ad illum hic Mundus non aliter fe haberet ac granum milii. Omitto alia multa., qua in eundem /enfuri congerit Auctor Itinerarii in eadem reiponfrone adme miffe.

RESPONSIO III. Cum Auctor Itinerarii locis fupri citatis de Mundo loquens, mupiam meminerit Intelligentiarum, ut que propriè non Junt partes iffius Mundi corporeis dicere potwit abfque abfurdo, DEU $M$ de facto produxiffe creaturam corpoream perfectiffimam, \& quâ perfectiorem eo in genere condere son polfit, hominem videlicet, quem probabilifinum est dividi non poffe in plures ßpecies, it a ut detur bomo pecifice perfectior eo, qui est creatus. Neque fic incurritur in Propofitionem 2ointer probibitas, dummodo in Intelligentiis nulla admittatur creat as effe, aut creari polfe tam perfect a, quin dari fernper poffit alia perfectior, faltem quaintum est de potentia D E I abfoluta.

\section{§. V. Refponfio ad Propofitionem tertiam, ejufque Cenfuram.}

PR O P O S I T I O. Neceffe eft,hæc omnia,lucem,ignem, caloremque idem efle. pag. 148. Sic lumen definiens pag. I44. Eft itaque lumen (inquit) nil aliud, nifi igneusquidam effluxus, ex iplo Solis corpore, in objecta fibi corpora propagatus, atque adeo ejuidem cum fonte, unde profluxit, naturx. Hæc Kircherus. Jamigitur lux,lumen, \& calor, ex mente Kircheri, nec accidentia fune, nec qualitates, fed fubftantix \& \& corpora,nempe ignis. Si autem calor accidens non eft, neque frigus accidens erit; contraria enim in eodem funt genere: igitur frigus vel fub ftantia etiamerit, vel mera caloris five ignis" carentia. Similiter quoque pag. 60. Kircherus aliam humiditatem 


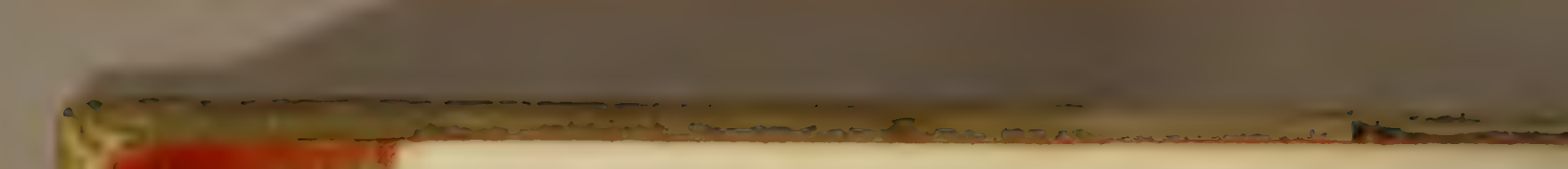

950 Apologeticon contra cenfúră nonnullarú Propofit.

elitarem non agnofcit, prater effluvium rofcidum, quo abundat Luna, \& hæc inferiora humectat.. Siccitatem autem non aliter induciait, quàm per affúfi humoris fecretionem: Ita primas qualitates omnes negat P. Kircherus。 CENSURA. Prohibita Propofitione 39.

Primus locus babetur in nof tra edit. Dialogo.r. cap. 5. S. 2.num. 9. paulò postmedium. Secundus locus babetur eodem Dialogo o" cap. S. I. num. s: circa finem. Tertius locus citatur ex cap; 4. num.

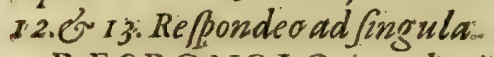

RESPONSI O 1. adprimum locum: In bocquod dicit P: Kircberus pag. 148 edit. Rom. five Dial.i. cap. 5. I. 2. num: . noftre edit. in Solis globo, lucem, lumen, ignem, caloremque idem effe, imitatusest $S$. Auguftinum à fe citatum S pracedenti,docentem id Sermone sq: de Diverfis cap. II. ubi explicans myfterium Sanat ifs. Trinit. pen comparationes aliquas, ait : Sol, candor, \& $\mathrm{ca}$ lor, \& tria funt vocabula, \& tria unum. Quod candet, hoc calet; \& quod caler ${ }_{x}$ hoc cander.. Tria hæc vocabula res una. cognofcitur. Ita: Pater, \& Filius, \& Spiritus Sanctus, tres perfo$1 n x$ in Deitate unum funt \&c : Vbs tamera $S$. Auguftinus; per illa verba;quod cander, hoc calet; \& quod calet, hoc candet, inmuit if a tria effe idem fibjecto duntaxat, non autem effentia ratione. Explicetur ergoeodem moda F. Kircherus. Et certè ad buncmodumz ipfemet fe explicat in Refponficne ad Cenfuramcitator um verborum ad me miffa, ubi fic loquitur. Quando itaq; dico,calorem cum luce, lumine, radiis, igne; idem eflés quomodo hoc intell igi debear, expono. Dico ergo,calorem cum luce. lumine, igne, qua corpora diximus, non idem effe fubftantialiter : nequeenim tam infenfatus füm, ut quod pueris etiam notum eft',calorem fecundùm fe corpus dicam; abfit: fed idem dicoper modum concreti, in quantum calor qualitas \& proprietas effentialis eft lncidicorporis, infeparabilis à fubjecto cui ineft. Neque hî́c loquor de calore elementari, quod purum. accidens eft, \&i adeffe atque abefle poreft aqux v. g. fine fubjeeti corrupcione s. fed de calore; uti dixi, licidorum corporum., qux proprietas quxadam effentialis eft, itaut ab is fine deftruatione 
ctione fubjecti naturaliter feparari non poffit.A tque hoc fenfu ciraco loco calorem accipi velim idem effe cum igne, luce, lumine : abftractum enim fubinde vim concreti obtinere, apud Philofophos notum eft, uti in odore, qui nihil aliud quàm vaporofa quadam fubftantia eft, pater. Innumera hoc loco adducere poflèm exempla; fed iis, củm nota fint, non immoror. S. Auguftinum appello, qui hanc meam de calore fententiam adeo apertis verbis expreffir, ur quid luculentiüs dici poffic. non videam: Verba ejus habentur in Äppendice Serm. 59. ubi de lice fic difleric. Sol,candor, gol calor \& $\&$ c: ubi candorem \& calorem corpora nequaquam dixille putandus elt, fed' candorem \& calorem folari corpori ita infeparabiliter connexum effe, atque adeo proprium eidem,coeterifque lucidis corporibus; ut fine is fubfiftere minimè poffint. Hac or alia multa. in bunc fenfum Kircherus; quabrevitatis caufa omitto. "In fine concludit: Atque ex hifce pater,quomodomea de'calore cum. luce, ltwmine, igne identificato incelligenda fint; nec contraria efle Propofitioni 39. Ordinationum. Hec Kircherus:

RESPONS I O II adfecundum locum: Ex eoquòd AuEtor Itinerarii pag. 144. Rom. edit. Jive Dialogo T. cap. 5. S. I. num. 8. circafinem, dicat, lumen aliudinon effe, nifi igneum quendam effiuxumiè Solis corpore; ejufdem cum ip fo natura ; zon continuo fequitur, in folari radio v: g: idem prorfus effe lumen \& $i$ gnisfuóft antiam: ficut ineque cuim nos dicimus; odores v: g. quos naribus attrahimus, non effe aliudquàm piritus quo/dam feu effluvia odorat a fubft antise,per boc fignificamus; odore in abftra¿to furnptum non diftingui à fuljecti jui fubftantia, aut qualitatem primam non efle:

Sed quocunque fenfu dict us Auctor hoc, quod objicitur, prot ulerit, cium reftricte loquatur de globo folari, Jignificet que aliorum,

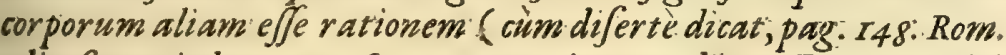
edit. fave Dial. I cap: s. I. 2. num. g circa medium. Er quamvis? in terrenis flammis lux à calore diverfum quid efle videatur, nihilominus in hoc puriflimi Solis globo necefle eft hæc omnia,lucem,lumen,ignem, caloremque idem efle; non potest 


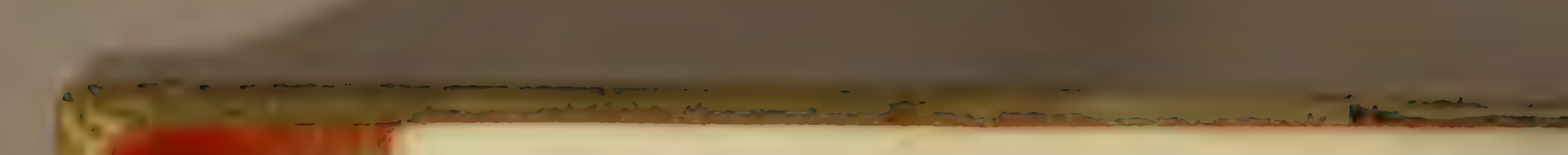

502 Apologeticon contra cenfüä nonnullarü Propofic. ex eo convinci, omnem calorem accidentalem, five qualitatem, primam, negare. Sed boc evidentius conft abit ex fequenti reSponfione.

R E S P O N S I O III. adtertium locum. Tertiuslocus ex pag.60. Rom. edit. fove ex Dial. 1. cap. 2. num. 1t. W 12 . noftre edit. ibi non reperitur, nec quoad verba, necquoad Jenfum, quantum quidem ego post fedulam \& Sepius iteratam lectionem col ligere potwi. Demus tamen, P. Kircherum afJerere, humiditatem Lunarem aliud nibile ele prærer effluvium rof́cidum, quo abundat Luna, \& hxc inferiora humectat; inde tamen non revte concluditur, eum aliam hurniditatem non agnofcere, prater effuvium allud rofcidum: frquidem छ' nos paffim dicimus, faltem virtute Luna excitari vaporofos halitus, (eu rof cidum quiddam, quo bumectentur corpora; nec tamen idcirco negamus, opinor, dari bumiditatem qua fit accidens, aut qualit as prima.

Mult to minùs rect e infertur, eundem $P$. Kircherum negare omnes primas qualitates, cum illas exprefsè paffim cum aliis in $O$ perisfuis, tum in boc Opere agnofcat. Nam pag. si. Rom. edit. five Dial.r. cap.2.num. g. noftre edit ait : Et tametf prima quaruor qualitates omnibus infint corporibus mundialibus, quia. tamen aliam pofitionem refpectu Mundi, aliofque admodum differentes influxus aliter \& aliter participant, non quidem effentiali quoad materiam, fed accidentali differentia eas (primas quatuor qualitates) inter fe differre necefle eft. Similia. paffim toto boc Opere babet. Non ergo peccavit Auct or nofter in Propofitionem 39. probibitam.

\section{§. VI. Refponfio ad Propofitionem quartam, ejufque Cenfuram.}

PR O POSITIO. Quomodò calor formalis ab agente formaliter non calido producatur? \&c pag. 141. CENSURA. Quâ,\& fequentibus,P. Kircherus non folùm probare nititur, impoffibile effe, dari caufas, qua fuos effectus eminenter folùm contineant, fed etiam Peripateticos ignorantix arguit, quòd caufas talesagnofcant. Sed ut de caufa prima nihildicam., 
quæ æquivoca eft, hac unâ propofitone formas omnes fubftantiales de medio tollit \&c. Locus cit astus est in noftraedit. ex Dia logor.cap.s.num.8.

R E S PONS I O L Non nititur probare Auct or Itinerarii; impo/fibile effe dari caufas, qua fuos effectus eminenter folumn con. tineant, fed tantiom Solem non effe talem caufam. Nam pag. ills I4I. Rom.edit. feu Dial. I. cap. s. num. 8.noftre edit. ait : Porrò reftat dubium non leve \&c. quomodo videlicet Peripateticorum fententia de calore eminenter tantùm Soli infito intelligenda fit. Cümque reßpondiffet, fententiam hanc fubffiftere non pofle; fubjungit: Quomodo enim Sol eminenter tantùm, uti Scholx pallim loquuntur, calefaceret, nemo facilè comprehenderit,cum nemo det quod non habet; eminentialis autem nec propriè, verè,\& realiter calor eft, necullos in Mundi œconomia inflammation 1 effectus producere poteft: quomodo enim calor forma lis ab agente formaliter non calido, à Sole, in inferioribus producatur, quis concipiaz? De Sole ergo loquitur, non de omnibus aliis caufss, Cùm deinde objeciffet fibi exemplum vini, o piperis, formalem in fomacho calor erm producentium;ait, aliam horum effe rationem: piper enim,ait, mox ubi in ftomachum tranfmiflum fueric, non tam calore virtuali (en, agnofcit calorem virtualem in pipere) in ftomacholatitantem producere, quàm eundem in humani corporis vifceribus ftabulantem excitare \&c. Tamet figitur Solem neget effe caufam virtualem; non rectz tamen inf ertur, eumniti probare,impolfibile efle dari caufas, qux fuos effectus eminenter folùm contineant ; \& mult ò miniss, eum formas omnes fubftantiales de medio tollere. 2uodf $f$ ratio à $P$. Kirchero allat a contra Peripateticos ( neminem fcilicet dare, quod non habet; eminentialem autems calorem, non effe verè calor em (jo.) parit ate quadam contra alias caufas aquivocas adferatur; érit $P$. Kircheri oftendere,non eod $\vec{E}$ modo rationem iffam in illis valere, Es it a tuericonfequentiam. doct rinafua.

RESPONSYO II. Sed audiamus ipfum Auctorem mentem fwam exponentem; qui in reßponfione ad quartam banc do- 
504 A pologeticòn contra Cenfură nonnullarū Propofit. ctiffimi Cenforis ad me miffa, fis differit. Sed, ut quid fentiam, quid afferam, patefiat, paucis explicandum duxi. Dico itag, primò, Solem, uti juxta noft tram doctrinam formaliter verus \& propriè dictus ignis eft, ita \& fimiles fibilucis, luminis,calorif $q_{\text {; }}$ effectus in inferiori hoc Mundo non formaliter tantùm producere, fed \& eos quoque, non ut Peripatetici volunt, eminenter, fed formaliter in îe continere. Quæ quidemftante hypochefi ( quod Solformaliter calidus $(i t$ ) aliter fehabere non polfunc. Sed urgebit hocloco Cenfor: Ergo Sol caufa univoca eft? Refpondeo, quoad hunc certum \& determinarum effeAtum, quem fibifimilem producit, id verum effe; quoad innumerosalios difpares effectus, quos producere poreft, nego univocam caufam effe, led æquivocam effe affero. Quis aucemnefcir,Solem efle caufam univer falem? qux in quantum vim habet producendi plures,eosq́; difparatifimos effectus, indifcriminatim concurrendo cum caufis particularibus, æquivoca rectè dicitur: in quantum verò certum \& determinatum effectum fibi in omnibus prorfus fimilem producir,caufa verè univoca. aflericur : arque adeo Solem Eanfam univerfalem, fimul \& univocam \& xquivocam effe refpectu dive1 forum, ut abfurdun nemodicet. Er quoad hunc fenfum ego Solem afferui producerelumen, lucem, caloremque formaliter. Dico fecundo, Solem, fi eminenter tantìm calorem igneum in fe continerer, non plùs eum in inferioribus calorisignei, quàm fi piperaceus aut cryftallinus globus foret, excitaturum; cum nemo quod formaliter non habet,formaliter producere poffit. Atque hæe eft doctrina, quam citato loco exhibui. Hac Kircherss. 2uid fentiendum de ratione ab ipfo adduct a, jam diximus.

$$
\text { §. VII. Refponfio ad Propofitionem quintam, }
$$

PR O POSIT IO. Naturaeft Ars DEI,\& SpiritusUniverfo1 rum,feu Anima Mundi.pag. 335 . CENSURA.Mundus itaqueanimatus eft, ac vivit. Unde confequenter ait idem pag. 37 I,cœlum ipfum, mundanaque omnia corpora nutriri. 
Locus primus habetur in nof tracedit. Dialogo 2.cap. 4.num.7. circa finem. Locus fecundus eadem Dialogo:2.cap.7.num. 3.

R ESP.ONSIOI. Natura dupliciter fursitur.Primó, proNatura, ut vocant, naturante: que reipsâ est Ars DEI, \& Mundi Anima, non informans fed ajistens, ut fibbinde dicunt ur cali effe quodammodo animati ab Intelligentia aßifente. 2 unquam to quendo de Mundo fecundiun effe funm idesle, in fenju aliquo mo $g$ is proprio dici pofjt, ars DEI effe ejus anima feu vita, juxta illud: Quod factumeft,in ipfo vita erat; juxta explicutionem nominatim S. Auguffine. Secundò,pro Natura creata: qua bob fenfu dici potest ars $D E 1$, quid, fit quadark art is divina rebus ipfis inherens impreffo; unde E illud:Opus Naturæ,opusIntelligentix: quegetiam dici potest Spiritus Univerfor $\tilde{u}, \xi^{3}$ anive a Mundr, in quant um est intrinfecusn prizcipium onn is operationis acmotus, quo res naturales agitantur, $\xi^{2}$ tendunt in fines Juos. Solent enim ifti modi loquendi Platonici, in foriptione rhetorica potius quàm fcholaftica tolevari, ôper met aphoramin fenfunn commadum accipi.

2uod autem proindiciofumitur,quafi Mundum animatum, fentiat P. Kircherus, quod corpora celeftia dicatex aquis fupercoleftibus nutriri; folidum non est: alioquin enim cogemur omnes admittere,ignem noftrum effe animatum, cum eurn quoque nutriridicat Scriptura facra Levit. cap. 6. v.J.2. \&.c.

R. ES PO N S I O II. P. Kircherusita ad hanc Propofitionem, ejufque Cenfuram respondet, in responfionibus ad me rni Bis.

Exprobrat mihi Cenfor, quòd Naturam artem DE I, \& animam Mundi dixerim. Sed \& idem mihi licere exiltimo, quod Sanctis Patribus Dionyfio, Auguftino, cum Tertulliano, \& aliis recentioribus, licicum fuit \&c. Et paulo pòst : Verùmut omn is dfficultatis nodus dissolvatur, Notandum eft, animam tripliciter confiderari poffe. Primo, in quantum fumitur pro forma fubftantiali, quæ eflentialiter concurrit ad naturalium rerum. compofitionem, $\&$ in vegetabilibus, fenfitivifque, uti \& in homine propriè anima dicitur informatrix. Secundo, dicitur animaafiftens,cujufmodifunt Intelligentix motrices corporum S ss coleftium, 


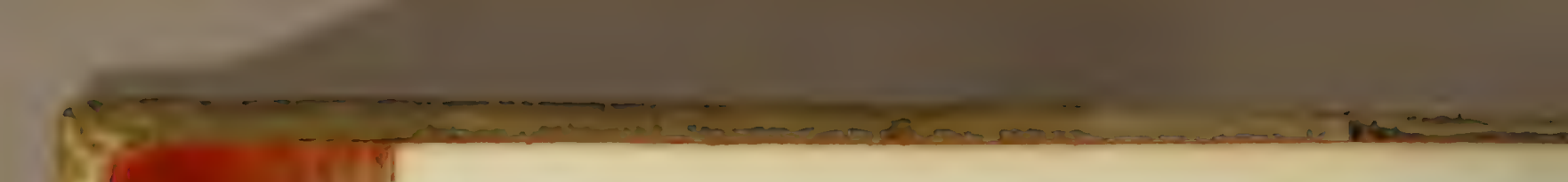

305 Apologeticon contra cenfură nonnullarŭ Propofit.

coleftium, qux iis perpetuò adfunt, non per modum informationis, fed directionis. Tertio, dicirur \& anima vis illa, quam Natu: am vocamus, qux per Univer fum diffufa, omnibufque \& fingulis infula, non quidem ranquam anima propriè dicta fed ut principium motus \& quietis eft; quam \& Ariftoteles vim motricem Univerfi vocat. Arque fub hoc fenfu nos Naturam hoc loco nomine animeappellamus. Quam cum impropriè \& metaphoricè tantùm dixerimus, non debebau Cenfor ftatim fufpicari, Naturam nefcio quam animam informantem nosafleruiffe; multò minùs inde deducere, cœeluma eò quòd omnia inferiora nucriar, animatum effe: has enim illationes nullas eflè quis non videt? An non Sancti Patres coelum uberibus comparant, quibus omnia inferiora alantur, \& fuftententur: Qui metaphoricas \&tropicas locutiones tollitè medio, \& Poëiñn, \& R hetoricătollere necefle eft.Cur Cenfor pari pacto non accufat SacrasLitteras, qua D L O manus, oculos,pedes, brachia, ubera, nulla non loco attribuuns?

§. VII.Refponfio ad Propofitionem fextam, ejufque Cenfuram:

PR O P OS I T I O. Tolerari non debuit, quòd P. Kircherus five fudio,five ex inadvertentia dixit pag. 38 . intellectum hominis ex vena lucis à DEO efie eductum. CENSURA. Sufpicionem yerò movet, id non tam cafu excidife, quàm $\mathrm{ex}$. præconcepto errore promanafie, quèd alibi pag. 293 ait, lucem primigeniam prinuma efle torius Nature principium astivum, generationifquererum unicam originem \& radicem.

Primus locus est ex Dialogo x.cap. 2. numn. 3 .noftra edit. Securduslocus ex Diatogo 2. cosp. I. num. 3.

RE S P O N S I O I. In hac faltem Cenfura videripoffet, parum fe aquum Cenforem oftendiffe, ut qui cüm poffet illa verbow Auctoris Itinerarii pag. 38. cit. in fenfuin commodum ax fanums accipere, maluerit in ilis jenfum odiofum at falfum, \& qui nulli Catholico:in mentem venire poffet, /üpicari. Certe fi foripfiffet P. Kircherus; intellect um borninis educt um ex vena Lucis divine o increata, nulla effet vel umbra falfitatis. Atqui ina buse. fenfum 
Senfum, tum ex katurarci, tum ex iplo contextu debuit dict um intelligi; edroctum foilicet ex vena lucis illins, quam ibidem Auctor appellat Luiem Lucium, boc est, ipfitus divine mentis; cujus Lucis participatio, est intellectids.noffer, juxta illwä:fignatume ent Guper nos lumen vultus tui gे $^{2}$.

Neque buc trahendum fuit, quod foripgit pag. 293 cit. lucem, primigeniam primum effe totius Natur o principium activum.: 2uia. ficut iftic apertè agitur de tuse corporea, it manifeftum estjean danstaxat dicieffe principiwmverum corporearum.

Loqui autem Auctorem noft rum inprimo loco de luce increat in. sut dixi,patet ex Apoftrophe ipfius ad DEV $M$, contexta ex variis locis S. Auguftini, Alberti Magni, \& aliorum qui Soliloquido fripferunt: fic enim ait.: Sed tu Lux lucitim, vita vitarum, fpes \& dulcedo condis mei, mex condonabilis temeritati; fiquidem tu ex vena lucis intellectum hominis eduxifti; tu eum lur mine ex veftimentis:glorix tux defumpto induift \& $\&$ : In alteroloco apertè fermo eít de luce materiali. Quàm ergo abjurdü effet dicere, P.Xircherum tribuere $D E O$ veftimenta, aut dicere in tellect ü effe indut ü à $D E O$ veftimextistàm parum credibile est, cundè velle intellect $\vec{a} \in f f e$ educt ü ex vena lucis creat a $5^{2}$ corporea. R E S P O N S I O II. In eundem planè fenfum refpondet ipfemet Kircherus in reponfione ad me miffa. Ait enimu:D EUM dixiex vera lucis hominis intellectum eduxile. O grande piaculum! An non fimilibus plenus eft facer Textus? Amictus inmine ficut veftimento. Pfal. 103 . Vapor est virtus D E I. Sap. 7. Similia innumeris aliis locis leguntur. Sileo hîc Sanctos $\mathrm{Pa}$ tres Auguftinum,\& Anfelmum, quorum in Soliloquiis nihil hifce frequentius eft. Quid itague tantopere exaggeret, quid. minimè tolerari deberedicac,non ca pio. Quis neficit,aut quis Auctor Catholicus negat,aut negavit unquam, omnia creata bona in tantum bona efle, in quantum à divinæ Bonitaris communicatione participativè procedunt? Cùm itaque ex veñ lucis intellectûs eductio nihil aliud fic , quàm divinæ lucis" participatio quaedam, fruftra me Cenfor, tanquam de crimine intolerabili, increpat\&c. Hac E', familiaKircherus.

6.IX.Con- 
508 A pologeticon contra cenfură ronnullarũ Propofit \&c.

\section{§. IX. Conclufio Cenforis, \& ad eam refponsio.}

CONCLUSIO. Multò plures in eodem Libro continentur

Propofitiones ablürda, \& contra communem Philofophiá temerè, \& fine probatione affertæ; imò \& apertè pugnantes inter fe.. Sed fuperioses periculofe funt in fide.

RESPONS I O I. Sex Propofitiones bactenus excuffas, neys contra Ordinationes Superioruzn noftrarum effe, neque periculofas in fide, apertèmongtratum fuit. Credibile ergo non est,prater illas, multo plures in eodem Libro contineriabsurdas, \& contras communem Philofophiam; effent enim smultò mag is quàm Jex pradict e, in Ordinationibus iisdem probibit ..

RESPONS IO II. Incalce Operis Anctor adducit plurimos $\xi^{\prime}$ doctijfinos: Scriptores, tum Societatis noftra', tum exterwos,ex quibus doct rinam fuam, छ Sententias illas que novitatis, \& conjequenter admirabilit at is aliquid babent, de fump fit : Non ergotemexè funt prolateinec contra communem Philofophiam af ferte. Quòd verò Auctores in ipfo Operis contextu non allegaverit P. Kircherus, id ea de caufa fact um est, quòd id flylo, quo utitur, Dialogetico repugnare videbatur. Sententias Suas non probat argument a coacervando, e fyllogifficas formas texendo, quia non pbacuit Scholafficis tricis, probationumque Eं objectiozoum concertationibus uti,fed amano, of Pbilolog is confuetoftylo opus funm contexere, ob caufas initio Operis indicatas. It af fere refpondet ipfemet P. Kircherus in re/ponfione ad me miffa.

\section{§.X. Refponfio generalis ad tres priores} Propofitiones.

A Dextremumaddo velut pro generali re/ponfione ad tres priA mas Propofitiones,quibas afferitur Auct orem Itinerariipeccaffe contra Soccetatis noftre Ordinationes pro. ftudiis; ut quis Scriptoram aut Doctoram noff rorum cenfeatur peccaffe in dict as Ordinationes, non fufficere, quiod ex ejus dictis aliqua Propofitio probibita dedusi videatur, etiam per consequentiam probabilem; 

jedveldebet illam docurffe in ipfis terminis, velcertè aliquid it a cum illa connexum, ut nullâ ratione probabili declinari poffit confequentia. Quorum, ut vidimus,neutrum fecit Auctor nofter. Itamecumifentiunt viri doct i.

\section{APOLOGETICON}

\section{R. P. MELCHIORIS COR N ÆI.}

D Melchior Cornacus, ommi doctrinarum genere excultif\}1- mus, ${ }^{2}$ in Philofophia ac Theologia quà voce in mult is Gallie acGermanix Academiis explananda, qua fcriptis libris illufranda,jam dicdum clarus, quam primuim in Exftaticum Itinerarium P. Athanafii Kircheri Româ buc allatum incidit, adeo fuit ejus recondit â doct rinâ raptus, a deo lectione delect atus, ut ex/aturarinon poffe videretur. Et tametfinnonnullis de mente Auctoris fubdubitaret, nunquam tamen in fequiorem fenfum trahere quidquam fuit oufus, ut cui per/pectiffima erat Auctoris eruditio,cum probitate vite, ac in opinando modeftia fingulari conjuncta. Lectâigitur cenfurâab Auctore mifsâ,temperare fibi non potuit, quin paucis eam, Sed efficaciter depelleret, ut Jequitur.

Exegefis Propofitionum, qua in Itinerario ExftaticoR. P.A THANASII KIRCHER I cenfurâ dignæ alicui funt vifa.

Propositio I. Krrcheriana. Deus exommihujus fphæræ(imaginalis fpatii) puncto Mundos infinito intervallo diffitos, fi abrolutam DEI potentiam attendamus, educere potuit. CENSURA. Prohibita eft Propofitione 30 Ordinationum.

DEPULSIO CENSUR E. Propofitio 30 probibitaram it a habet : Infinitum in multitudine \& magnitudine poteft claudi 
claudinter duas unitates, vel puncta. Atqui hoc $P$, Athanafius mininè dicit, neque dicere est cenfendus. Nam ficut fi DEUS infinit a poma punica crearet extra fé, accuparent illa, non fingu-

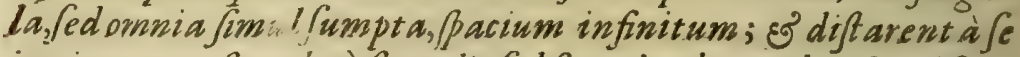
invicem, non fingula à fingulis, fed fing ula ab omnibus fimul fumptis,pacio infinito:itafi DEV Sin pacio imaginali conderet infinitos tales Mundos, qualis bic unius est, cui infuneus; diftarent à fein pacio infinito, intervallo infinito, finguli non à fingulis, fed ab omnibus fimulfumptis. Ergo bacres non coincideret cuan Propofatione zoprobibitarum, quinnon ideo fatweretur infinitum intrinfece terminatum.

PR O POS I T I O II. K I R C H ER I A N A. Deus non pocuit facere plures Mur dos, neque hunc majorem quàm reipsáfit, quòd id contradićtionem impricet. CENSIIRA.Pro hibita eft Propolitione 29. Ordinationum.

DEPULSIO CENSUR $\&$. Propofitio 20 probibitarum ficbabet. Poffibilis eft creatura perfectiflima, quâ perfectior à DEOcreari nequit. Atqui $P$. At hanafisss non afferit bocde Mundo abfolurè \&o fimpliciter, fed facile apparet quód intelligat fecundiun quid, \& in certa quedan ratione; utietiam communiter afferitur ab omsibus, quod manendo intra terminos provi dentia finis à $D E O$ confituti, non potuerit $D E U S$ meliorem aut perfectiorem Mundum condere, quam nunc condiderit. Quis inimimagineturfibi, $P$. Athanafium putare, non potuifle $D E$ $\checkmark M$ abjolute aut majorem Terra' globum, aut Lunam, aut Solem facere? aut Mundum buncfimpliciter it effe perfectum of magnum, ut folâ a feitate DEO fit inferior? Ego arbitror, verba Auctoris Exftatici berignè interpretanda, $\}$ non ita rigidè cenfendaeffe.

PR O POSIT IO III. KIRCHERIA NA. Necefle elt, hxc omnia, lucem, ignem, caloremque idem efle \&c. CENSURA. Primas qualicates omnes negat P. Kircherus; quod eft prohibitum Propofitione 39. Ordinationum.

DEPULSIO CENSUR Æ. Efto P. Athanafius in sole lu. cem,calorem, ac fubftantiam putet realiter indiftincta, non ideo 
in aliis element is of mixtis id putat. Vti is, qui unum alterumnèmodum, v. g. Subfffentiam, aut durationem ne gat, non conziniò omnes omnino modos vel entitates modales negat. ISt ergo durior equo bec Cenfurasprefertim cium Auctor fe explicet longèaliter, Góper eq verba intelligat non indiftinctionem. talium rerum à fe invicem, (ed tant im infeparabilitatem.

PROPOSITIOIV. KIRCHERIANA. Quomodo calor formalis ab agente formalizer non calido producatur? \&c. C E N S UR A. Hac Propofitione P. Achanafius negat caufas eminentiales \& rquivocas, \& omnes formas fubttanciales de medio tollit, qux plurium effectuum caufæ funtaquivocar

DEPUISIO CENSUR Æ. Non est hac Cenfura, fed illatio haud_fat is (ut milor quide videt ur ) out aquanaut fizma. Pot est $e_{0}$. quide optimieftare, Solem reßsect u caloris non effe caulam aquivocam, er tamen alias dari cauf as aquivocas. Et licet $P$. At banafius, vel alius quis teneat, solen non continere calorem eminent er, $\int e d$ formaliter; non ideocenfendus est tenere, nullam caufam effe qua aliquem effectum eminenter tantum contineat.

PROPOSITIO V. KIRCHERIANA. Natura elt Ars DEI, \& fpiritus univerforum, feu anima Mundi \&c. CENS URA. Mundus itaque animatus eft, ac vivit \&c.

DEPULSIO CE N S R R. Locutio Auctoris Exfta ticiest palam tropica o tranfatitia, ex quanibil recte infer as cum de ejus rect amente conftet, quid referíverba in invidiain. vocare?

PRO POSTIO VI. IKIRCHERIANA. Intellectus hominis ex vena lucis efteductus. CENSURA. Su fpicionem movet, id Auctori Exfatico non tam cafư excidifle, quàm ex pracon-cepto errore promanaffe \&c,

DEPULSIO CENSUR Æ. Non est rqua fupicio in Auctorem Exftaticum, de cujus mente erroris experte. \& innocente, fastis conftat.

CONCLUSIO CENSORIS. Multò plures in eodem libro. continentur propofitiones abfurda. \& c.

DEPUL- 


\section{S12 A pologeticon R. P. Malchioris Cornet.}

DEPULSIO. Nirnis acerba hacest cenfura, \& abfque fufficienti fundamento prolata. Vereor ego,ut ne quid aliud potius quaimveritatis ingenuus amor, Cenforis feverioris antmum in tam finifrum judicium impulerit.

\section{Itacandidéfentio}

Melchior Cornaus.

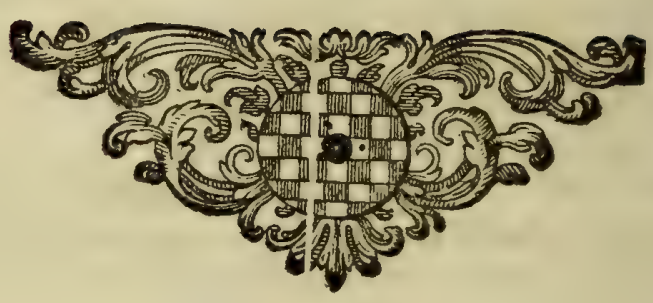




\section{ATHANASII KIRCHERI}

E SOC. JESU

ITER EXTA TICUMII

Qui \& Mundi Subterranei

PRODROMUs dicitur;

QuO

\section{GEOCOSMI OPIFICIUM',}

SIV E

Terreftris GlobiStructura, unà cumabditis in ea conftitutis arcanioris Naturx Reconditoriis,per ficti raptus integumentum exponitur ad veritatem.

In 111. Dialogos diftinctum, \& hacfe. cundâ editione à mendis, qux in primam Romanam irrepferant,expurgatum.

Acceffit in fine SYNOPSIS Mundi Subterranei ejusdem Auctoris. 


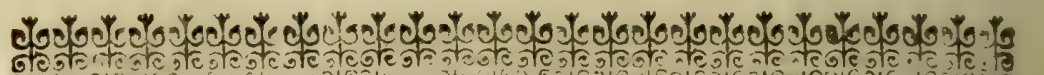
वू.

PREFATIO

\section{AD LECT OREM.}

PARS PRIMA:

Decopti ExftaticiItineris Scopo.

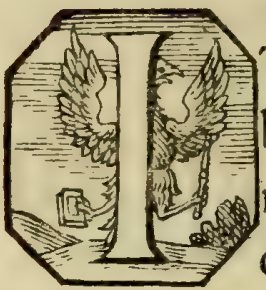

TINERARIUIM exftaticum, Lector benevole, quod in cœleftes fublimioris Naturæ Mundos, fidâ Cofmielis directione \& aufpicio, jam dudum fufceperam, mox publicijuris factum, uti peritorum virorum approbatione, opinione meâ majori exceptum fuiffe cognovi, ita haud exiguos ad aliam novi atque inauditi itineris expeditionem. mihi ftimulos atque calcaria addidit. Sed quodnam dices iter? Vin' fireLector? paucis id tibiexpono. Iter aggredior haud dubiè longè fublimiori carpento, quàm quo olim Proferpinamà Plutone raptam ferunt, in incognita hucufque fubterranei mundiregna, in intima Geocofmicx Monarchix penetralia peragendum. Audax fanè,infolens, 
lens, \& pectori forfan Alcidæ formidandum facicinus. Ergonè iter nullis in hunc diem mortalium, non dicam attentatum tritumque veltigiis, fed nè humanæ quidem mentis perfuafione penetratum inire audeam? Audeo id, audeo in quam aggredi, non tam meâ voluntate fúfceptum, quàm Illufrium virorum armatâ deprecatione extortum. Et quanquam propofitum mihi inftitutum eorum in pectoribus, qui rerum ufu \& experientiâ deftituti res juxta extimam tantùm, uti dicifolet, fuperficiem oppidò fallaci judicii trutinâ ponderarefolent, Ultopiæ cuipiam, quàm veræ itineris narrationi fimiliorem videri polfe probè norim, nil tamen moror, immò apud veræ philofophiæfectatores, quibus unis tum Divinorum operum. Majeftas, tum fublimium à natura conftitutorum finium providentia innotvit nonnullam me, ob preftitam quantumvis exilem \& tenuem opellam meam,gratiam initurum confido, ubi rationum adductarum, incitamentorumque pondera $x$ quiori lance expenderint. Ad Rhombumita. que nos accingamus. Quemadmodum Philofophorum quidam falsâ perfuafione delufi, terre- 
niglobi molem aDeoGeoplafta,ex limo terrævelut cafu potiùs ac fortuitâ luti congerie, quam certâ ratione formatam coagmentatamq; fuifle opinantur; ita omni quoq; interioriconclavium apparatu, omni reconditoriorum naturæ diftributione, omnibus aquaductuú incilibus deftitutain, folo limi,luti, fedimentique fuffartu, haud fecus ac calei coagulum condenfatam, verè ceu quoddam telluris inutile pondus confolidatam defiderefibi pervicacimentis contumaciâ perfuadent. Placitú fanè tantò Phyfiologis indignius, quantò quod profitentur dogma, futilius \& magè ridiculum eft. Novi, non defuiffe hocilluminatifæculi decurfi viros geographici ftudii cultu illifires, qui ad externam Geocolmi faciem: egregio fanè conatu, nec minori cum laude, \& nominisimmortalitate explicandam, impigre defudarine; qui tamenad interiorem telluris Oeconomiam, at j; occulta latentis naturæ facramentx, non dicam penetrarit; féd nè mente quìde pertigerit, inventus eft nemo. Cùm igitur ita mihi naturâ comparatum fít, ut nullus a deə in naturâ rerum abditus abftrufusque effectus lucefcat,clijus caufæ cognofcendx penetrandæq; defiderio non $x$ tuem; cujus reconditos ratio- 
Prafacio ad Lectorem.

rationum fines, finon asquequaq; indefelfo mentis fcrutinio attingam, faltem in laudabili vel ipfius attentationis conatulaudem reponam: Hinc natumeft, ut.vel maximè mentis oculos in fubterraneiMundiftructuram, hucusque ob inacceffa naturæ latibula neglectam, atque ob ineluctabiles in ea penetranda difficultates ignoratam reflexerim. Siquidem fieri non poffe cogitabam, quin util \& natura nihil fruftra faciunt, ita fuprema Sapientia Cofmotechnitis in ea mirâ arte eläboranda ac juxta architectonicam amuflim in ea ritè difponenda, \& ad neceffarios totius naturæ ufus in in numera elementorum conceptacula difpefcenda, cum ineffabiliquadaminduftrialuferit. Qua de caufafolito molientis ingenii ardore inftimulatus nullum non lapidem movi, ut quantum fieri poffet;ad adeo abitrufam in Subterraneo Mundolatentium rerum conftitutionem aliquòsqs penetrarem ; minimè is, cxteroquin opportunis , \& magniponderis, luculentisq, quæ adinteriorem telluris ftatum concipiendum facere videbantur, quæq; ex variis Scriptorum monumentis congefferam, contentus indiciis, nifi \& ego abditze veritatis Spartam, proprii experimenti indagine \& a Itt 3 Atabi- 
Atabilitam exornarem. Unde quidquid in Geographicarum relationum monumentis, quod tum. totius globi,tum particularium regionum conftitutionem concernebat; quidquid dico rarum, infolens, \& paradoxum obvium fuit,id exemptum fummo ftudio adnotavi.Mira Oceanearum expeditionum, qux in novarum regionum, mariumque incognitorum inventione detecta funt naturæ prodigia paricurâ collecta ponderavi. Miratus fum multiplices Oceani motus,nec non affluxûs refluxûsque ftatas reciprocationes. Vorticum quoque, Euriporumque inftabilis æftûs viciffitudinem obftupui; ad inexplicabilem abyfforum. compluribus in locis profunditatem expavi; ad occultam Oceani, intra penitiffima montium., fubterreftriumq; partium vifcera infinuationem; ad fluminum quoque plurium in uno loco abforptionem, corundemque in altera longo intervallo diffita regione regurgitationem attonitus hæfi. Lacuum quoque cum fubterraneis montium hydrophylaciis, uti \& totius Oceani cum cæeteris maribus, lacubus, fluminibus, rivis, fontibus, nefcio qux occulta negotiationis commercia exercere primùm fubolfeci. Nechîc deftiti ; intima metal- 
Prafacio ad Lectorem.

licarum fodinarum receptacula, ad incredibilem. negotiantis naturæ induftriam explorandam,, fcrutatus fum. Etnè quidquam omififfe viderer, Ætnam confcendi, Strongylum exploravi; Vefuvium quoque, vel aliquò usq; in eum intromiffus, exactâ curâ dimenfus fưm; crateres fingulorum, \& occulta antrorú molimina, tum ad inacceflam æltuantis naturæ originem propiùs contuendam, tum ad congrua inftituto nieo confectaria ex is deducenda, uti retuantis animi impetu, ita non fine fummo vitæ periculo inveftigavi. Quibus quidem omnibus exactè perluftratis, dici vix poteft, quanta animum meum ad rerum fpectatarum. portenta incefferit admiratio ; admirationem verò quàm ardens caufarum inquirendarum exceperit defiderium. Unde dum fingula cum finguis ad combinatorix artis incudem reductis, exaotiùs confero; multo fanè interiorem Geocofmi, ive terreftris globi fabricam aliam effe, atque opoidò differentem à communi hominum conceptu confitutionem habere deprehendi; quippe in qua fcitè adornanda æterna fapientia non minori cum induftria, quàm in humani corporis, tot vitaium membrorum officinis diftincti, tot venarü, nervo- 
nervorum, fibrarumq; ductibus inftructi, tot cæcis meatuum fiphonibus pertufi, fabrica conftituenda allaborarit. Llt proinde Opus illudjam. dudum Reipubl.literariæ promiffum, quod Mundus Subterraneus infcribitur, cui multorum annorum elucubrationejam infudo, cujus inveftigandi causâ tot laborum periculorumque difcriminibus in Subterranex Naturæ officinis indagandis perfunctus fum, (cujus \& hæc præfens diatribe non. nifi Prodromi cujusdam officio fungitur ) titulo magis confentaneo triumphare non poffit: cùm quidquid in Univerfa Mundi machina, infinitâ quadam rerum varietate diffufum cernitur, id in . Geocofmo,velutiin Epitomen quandam contraEtum videatur. Habes itaque,Lector, meum in . hujus Subterranei MundiProdromo expediendo confilium ; in quo fi non usquequaque tibifatisfactum effe compereris, id non tam mihi, quam. Prodromo ad uberrimum fecuturi Operis argumentum feftinanti,adfcribas velim. Siquidem in illo quidquid hîc vel temporis brevitate intermiffim, aut difficultate impeditum, vel varietate aut miltitudine confufum fuit, ordine digeftum, ab occurrentibus difficultatum fcopulis expeditum,

nec 
nec non multiplici experimentorum authoritatumque apparatu cumulatum exornatumq; veluti in quodam totius naturæ Gazophylacio, infignicumfenore te reperturum confido. Porrò ficuti in Itinerario Coelefti fimulati Cofmielis magifterio ad inacceflanature Superioris arcana exploranda ufus fum, ita \& in hoc Subterrane Mundi Itinerario methodo priori prorfus parallelâ procedendum duxi; ut proinde non te moveantraptus, extafes, Genii familiaritas, fimiliaqueà Deo agitatorum hominum loquendi diatamina.Hifce enim non alio fine, nifiad lectionem. tum variis ingenii lufibus condiendam, tum ad fingula naturæopera,per interrogationes refponfionesque ultro citroque factas, faciliùs luculentiùsque exponenda, fub allegoricis hifce rerum. verborumque involucris, ufum me effe Lectorfbiperfuadeat. Atque adeo totum hoc commentum, nihil aliud exiftimet velim, quàm profundam quandam mentis agitationem, in reconditiora naturæ phylacteria diffufam; quæuti occulta funt, \& ab humani ingenii comprehenfione femotiflima, ita ingenti mentis æftu, \& anxia qua dam ferventis ingeniifolicitudine, ut penetrentur,

Lluu opus 
922

Ténerariurm II.

opus effe, is folus nefcire poterit, qui hujusmodi philofophiæ labyrinthos nunquam tentaverit. Denique quia in omnibus hifce explorandis unicus Divinæ gloriæ fcopus mihi propofitus efle debuit, ut videlicet illuc, unde veluti à bonorum omium origine cuncta profluxerunt, reducantur, nè à nobis in hoc argumento fufceptus labor pio Lectori infructuofus foret, vifum fuit ratiocinits noftris Afceticorum more femper nonnihil ad ar nimæ paftum interferere, ac fcalam quandam. Myfticam conftruere, qua pia mens per vifibilia. qux facta funt, ad invifibilium bonorum nunquam periturorum copiam adipifcendam afcendere poffet, ut dum de virtute in virtutem rerum ab Eterna Sapientia in ufum folius hominis conditarum contemplatione affurgit, ea tandem ad totius pertingat felicitatis apicem, qui eft Deus Deorum in Sion; qui proinde fit femper laudatus, fine menfura benedictus, femper omni polfibilium creaturarum affectu, in perpetuas aternitates amatus.

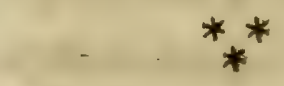

PARS 


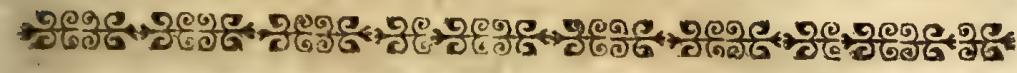
PARS SECUNDA.

De caufa E ordine bujus Opufculi.

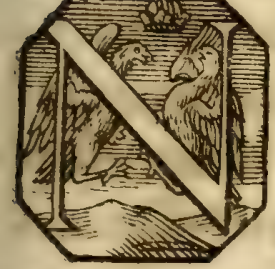

E Lector in hujus Opufculi infcriptione exotici tituli novitate deceptus , primâ ftatim fronte dubius perplexusque hæreret; hoc loco eâ, qua par eft, finceritate, nec non eâ, qua potero verborum paucitate, inftituti mei rationem oportunè exponam.

Cùm itaque ex multo jam tempore à magni nominis viris ad Operis jam dudum promifli (qui Mundus Subterraneus infcribitur) editionem. continuâ literarum follicitatione urgerer; Opus verò memoratum, utiargumentorum hucusque inexploratorum varietate $\&$ copiâ confertiflimum,ita majus quoque otium, temporisque copiam quàm quis credere poffet, ad tot abditas rerum caufas,ad tot Naturæ miracula, quæ non fine ingenti animi aufu, non fine innumeris præviorum experimentorum tentaminibus exploranda Luu 2 erant, 
erant,fummopere neceffariam exigere videretur; hinc factum eft, ut Opus jam quafi in fuo faftigio conftitutum, tum ob truculentam peftiferæ luis, quæ ingenti mortalium ftrage Italiæ dominabatur, tyrannidem, aliasque horum Martialium. temporum calamitates, tum obluctuofum FERDINANDI II I. Cæefaris,Mecænatis fanè munificentifimi, obitum, novas femper \& novas remoras inverrerit ; quibusaccedente neceffarii defectu fubfidii, id non tantùm oppidò retardatum, fed finifterioris alex jactu veluti attonitum ftupefactumque, aliquantifper fufpendendum fuit, donec melioris ei fortis fpes affulgeret. Veruntamen nè Opusillud communi malorum turbine involutum, unà extinctum fepultumque videri poffet, atque ardentia id exfpectantium defideria diuturniori morâ flaccefcerent; hoc præfens opuficulum, quo rerum in Magni Operis apparatu traetandarum feries non nifi $\theta^{\prime} \mathrm{o}^{\prime}$, ws exhiberetur, five ad peritorum virorum judicia circa intituti mei rationem exploranda, five ad nonnulla dicto Operi oportana fublidia comparanda, concinnare vifum fuit: Sedquxnan, dices, fubfidia? Paucis votorum meorum fummam ribi pando. Diutur- 
Prafatioad Lectorem 525 nâ experientiâ ductus doctusque novi,mirificos quordam effectus, quibus natura renum in Orbe terrarum ludit, ita per omnia mundi climata diffufos effe, ut vix territorium fit adeo exiguum, quod non exoticum quoddam ac prorfus infolens ludibundæ naturæ fpectaculum exhibeat, quarum abditarum rationum medulla, uti in intimo rerum receflu refidet, ita quoque non nifidiuturno ac profundo mentis fcrutinio, pervarias combinatoriæ amulfis leges tandem attingitur: de quibus à diverfis certior factus, cùm tantam rerum molem non unius hominis effe, nec fine aliorum, qui neceffarias mihifuppetiarum copias conferrent, contributione perfici poffe, probè cognôfem; ideo literarium cum Medicis, Chymicis , aliisque reconditioris philofophix Magitris commercium inftituendum duxi; ut qux ab iis circa locorum quorundam particularium naturam, nativamque terreftrium partium conftitutienem,aliorumque prodigioforum effectuum, qui in fontium thermarumque exoticis qualitatibus,in ventorum unicuique locorum peculiarium abditis proprietatibus, in mineralibus quoque metallicisque corporibus, uti \& in variis fuccis;oUuu 3: leis, 
leis, aliisque, quos fola nonnulla exudant, liquoribus in animalibus denique plantisque naturæ $\mathrm{Oe}$ conomia fefe exerit, ingentem mihi memoratarum rerum copiam, tum ad argumenta in opere magno propofita folidiori fundamento ftabilien$\mathrm{da}$,tum ad operis f plendorem,compararem. Hoc enim peracto, futurum fperabam,utnatura, qux prædivites fuas in occultis Subterranei Mundi adytis officinas conftitutas habet, atque in iis perenni motuad rerum genefin intenta negotiatur, faciliori modo explicaretur, effectuumque infolentium cauf $æ$, quæ tantoperè Phyficorum ingenia vexant, magno tandem Reipubl. literariæ emolumento panderentur. Habes hîc rationem confilii mei, pro tanta rerum mole, paucis defcriptam.

Quod verò ad ordinem hujus præfentis Operis attinet,eum paucis pariter expedio. Divifum. eft Opufculum, utivides, in tres Dialogos: quorum prior, Interlocutoribus Hydriele \& Theodidarto, de Aqua, univerfali rerum principio, ejusq; in natura rerum neceffitate \& utilitate agit; quem uti Cæfaris juffu jam dudum condideram, ita oportunè 
Præfatio ad Lectorem.

portunè fanè eum binis fequentibus Dialogis veluti veftibulum quoddam præponendum cenfuí, ut quod anteceffor hic nonnifi fub univerfali quodam ratiocinio attingit, id fequentes, Interlocutoribus Cofmiele \& Theodidacto, proximarum. caufarum inveftigatione explanarent.

Atque hre funt, de quibus te primùm, Amice Lector, monendum duximus. Porrò fi quiclin. hac diatribe laude dignum repereris, id Deo, cui unicèvivo, \& fervio; fi quid mancum \& deficiens, id mihi,ut humanæ conditioni fubdito, adfcribas velim; fidenique tibi quicquam melius, quod ad meam rem facere poffit, occurrerit, ut id mihiomni affectus pravitate depofitâ fincerè \& candidè conferas, obnixè precor; meque , cui nihil antiquius eft, quàm ab omnibus erudiri, præftiti beneficii baud immemorem, cum debita nominis tui commendatione futurum, fanctè polliceor.

Vale, \& coptis fave.

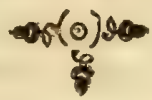

DIALO- 
ซ้ำ

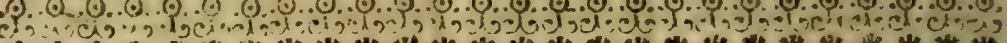

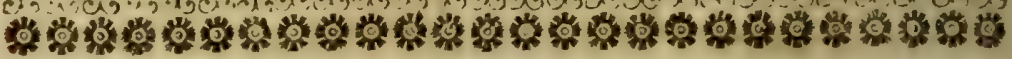

\section{DIALOGUS I.}

DeElemento Aqux, \& Univerfali rerum principio.

Interlocutoribus Hydriele, $\sigma$ Theodidacto.

C A P U T I. De AqueiElementiinnatura rerum nece Sitate,
Gैutilitate.

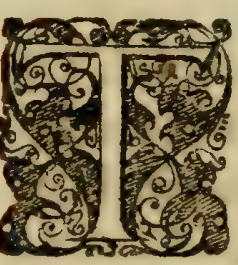

HEODIDACTUS. Luftratis,examinatisque, Cofmiele duce \& doctore,alriflimis" Colorum habitaculiśs visâ naturâ, proprietace, magnitudine, \& quafi infinitâ globorum Coeleftium multitudine; exploratâ totius mundi fúperioris ineffabilis conftitutionis fabricâ; tandem veluri ex altifimo quodam fopore in me reverfus, ad vifarum rerum dignicatem \& præftantiam, longo tempore attonitus prorfus \& ftupefactus hæefi, animusque jam defiderio collium æternorum prægnans,fummâ mencis dulcedine, \& ad ea quæ viderat ineffabilia propiùs contemplanda afpirabat, \& afpirando in ingentes æternx Sapientix, tantarum rerum Architectatricis, amoris rapiebatur exceflus : hoc unicum deprecabar à totius Sapientix fonte, ut invifibilia per ea qux facta funt propiùs contemplarer, ita mecum raciocinatus. Si divina bonitas foloamoris ductu \& inductu, tanta \& tam ineffabilia in hujus Univerfi amplicudine in ufum \& confervationem rarionalis creacura condidit; quantò eam in infenfibili infinicx eflen- 
Cap.I. De Aqux Natura.

eflentia fux receflu \& abyllu ir icomprehenfibili homini præparafte cenfebımus? quorum quidem ratio, dignitas, \& excellentia uti divinæ eflentiæ propior fimiliorque, ita tantò omnem corporearum fenfibiliumque rerum pulchritudinem. excedic longiùs, quanto lux folaris denfifimas tenebrarum caligines longiùs fuperat: Et quandotandem, ô fapientia Cofmotechnicis, fatiabor gioriâ zuâ ? quando tibi,à quâ profluxi, recidar? quando tabi, in qua omnia unum funt, uniar? quando divinæ effentia Tuæ fpeculum Tri-unum intuebor? in quo \& te, \& unà res omnes tecum, cum Univerfi mundi fabrica, fingularumque partium fymmetria contemplabimur ? ô quantâ deliciarú ubertate, quanto torrente voluptatis fanati replebimur?quando in a moris tui aby ho ineffabili abforpti, unum tecum per graciam \& vifionem beatificam, qui tantum per natură differimus,efficiemur? O Deus, quid mihi eft in coelo, ó à te quidvolwifuper terrā? Deus cordismei, \& pars mea, Deus in eternum : tolle, tolle quod tibi fimile eft ; tolle fpiritú méum immortalieflentix tux charactere infignitum; tolle cor meum an nulo amoris aterni tibi fubarrhatum; isrumpe vincula corrupribilis carnis, ad facrificandă tibi hoftiam laudis; diflòlve moleftam corporis farcinam, ut in libertate filiorú Dei conftitutus te poffideam, te amem, tibi uniar in æterni amoris centro, cujus longitudo, latiudo, \& profunditas, uti nec finem, nec numerum haber, ita quoque centro ejus ubique exiftente, circumferentia fuæ extenfionis terminos nusquam reperit.

Hife itaque \& fimilibus effufis in Divinæ potentix incomprehenfibilem majeftatem animi affeetibus agitatus, dum nefcio quo tempore hortum quendam fuburbanum ingreflus, pulcherrimum arborum in quincuncem difpofitarum ordinem, infignem lucorum amænitatem, \& potifimùm falientium fontium jucunda triptidia, icatebrarumque occultas origines attentiùs confidero; per quofinam venarum ductus femitas fuas tanta aquarum moles difponeret, quomodo adeo perennifluxu \& nunquam interrupto motu agitaretur, \& undenam tandem proximam fui originem traherer, ingentico$\mathrm{Xxx}$ gnofcendi 


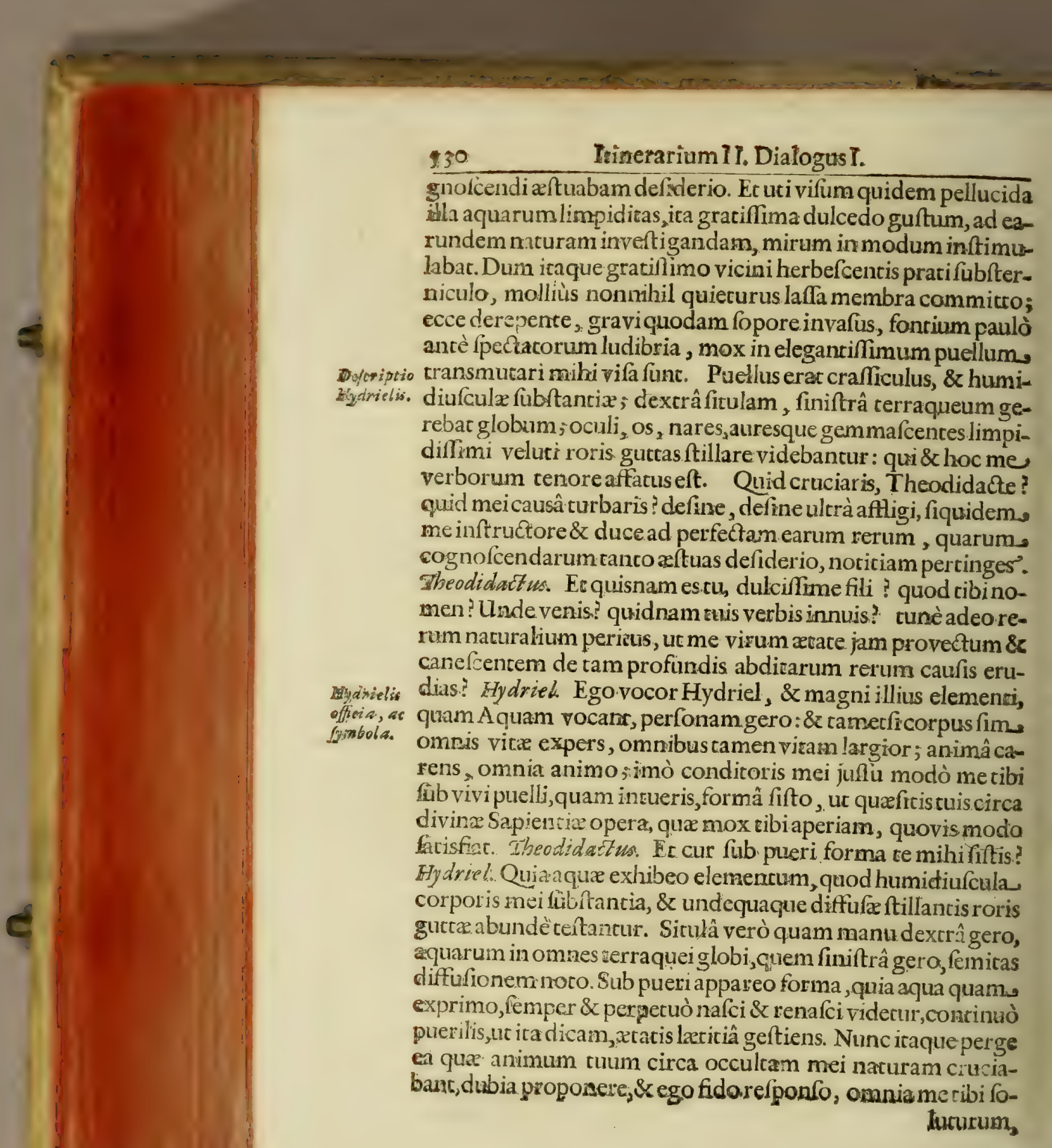


lucurum,polliceor. Theodidactus. Næ nimiùm vereor, nè forfan unus ex eorum numero Dxmonum fis, quas Nymphas veteres vocabant, \& facrilego cultu ceu Deas adorabant; quem. ego cultum, veluti Cacodæmonum dolum, \& peffimam impofturam,omni qua pofium animi proreftatione execror \& abominor. Hydriel. Nè turberis, Theodidacte, neque animum, Hydrize! tuumulla formido percellat: calis enim minimè fum, quem tu quis; firs. falsâillufione perfuafus tibi imaginaris. Neque enim ex fabulafo Nympharum fum choro, neque Lilith aut Lamia quxpiam, neque quem Poëtx Neptunum vocant; fed purum putum elementum fum, cui aqua nomeneft: \& tametfivitâ caream,conditorem tamen meum eo, quo licet, mex condiciond congruo modo laudo \& benedico, atque ad nucum ejusuniverfas telluris femitas indefeflus percurro, tum ad orbisconfervationem, tum ad humanigeneris ufum, obquem pociffimùm condittis fui. Neque aliud tibi, quam quod dixi,perfuzdeas velim: quare audacter tantummodò quxcunque circr. naturam meain defiderat anima tua, minutim examines. Theow $a^{\prime} i d a c 7$ us. Cùm itaque nefcio quâ internâ animi dulcedine inductus, vocis tua oracula verifima comperiam, faciam quod jubes, \& invocato Dei Tri-unius nomine, te, mi Hydriel, obteftor, ut afleras mihituas quastendis Yemitas. Hydriel. Faciam id quod peris perlubenter; arrectis itaque auribus quænarraturus fum percipe. Videfnè montem hunc tỉbi contrà pofitum? Theodid. Video. Hydriel. Ex eo hodierno die primum Semita aprofluxi. Theodidact wss. Et quidnam, rogo, eo in monte eft, quantur. quod tanta aquarum diluvia profundere pofik? Hydr. Scias in monte hoc ingens mei elementi conceptaculum efle, feut recondicorium aquaticum, quod ex omni parte indeficiente, diffufione in bonum agrorum camporumque hanc, quam miraris, copiam evomit. Deficere itaque non potent, quôd fluxus fuiterminum non habet. Theodid. Sed undenam aqueumillud reconditorium originem fuam trahit, cùm in altifímo loco conftitutum fit? nec enim video quomodo aqua contra ataturam illuc afcendere poffic, aut fine novo femper affluxa cur- 
Aquain montibus curnun-

quam defi.

iath fum lutum contirua e valeat? Hydr. Ex nari originem meá traho. Theod. Quomodo hoc ficri poreft, cum mare remoriflimú fit, ac eciam mulcò hos monte humilius? Hydr. Scias, Theodidacte, influxu fiderum perpetuo me fluxu refluxuque in latè patente Oceani fuperficie agitari ; unde fic ut vılentiâundarum, flustuunique pondere preffus, per occultos meatus, quibus Oceani fundus haud fecus, ac cribrum pertufus eft, quà data porta, cedere cogor, ac fic per tortuofos anfractuofosque telluris maandros viam mihi a perio, conec elaptus per eam,tandem fontiunde dimanavi, per exteriorem terra fuperficiem. vagabundus reftituar. Ihecd. Si tu ex mari originem tuam. trahis, mare aucem naturâ fuâ falfédine imbutum fit,quomodo Lqua a-tufalfedinem deferuift, cum culcifimi faporis fis? $H y d r$. Nof rur in fon fedebes, Theodidacte, meam deponifalfedinem partim per. tibus du- cerrentrium portionum, quastranfeo, dulcisfaporis glebas, aiv. partim perfubcer ranei eftus calorem, qui in gurguftis montium fubinde tantus eft, ut pror fus ibidem veluti in cacabis quibusclam fuppofitis ignibus ebulliam; quâ ebullicione peractâ, veluti coctus \& digeftus, omnem depono nativa falfedinis acrimoniam : atque hac operatione duplicem mundo prabeo ufum, \& aqua dulcis in exteriori telluris fuperficiefcaturigi-

Aqua manem, \& interiorem Oeconomiam in incredibile terreftrium. ris per mul. glebarum bonum hofpitii praftiti remunerarione relinquo tos canales falem, fine quo telluris corpus confiftere mininiè poflet, uri fe in terram infis. nuat. portea fufiùs à me intelliges. Scire verò debes, me non unum rantủm hujusmodi habere canalem, quo me exOceano, \& maribus, in intima terra vifcera infinuo, fed innumeros protfus in univerfi Oceani tellurem a mbientis fundo, quibur non fecus ac fanguis in humano corpore venarum ductibus iniverio Microcofmo, \& fingulis membris communicatu in vita fomentum, ita \& ego per univerfas femitas weos tendo aquaductus usque ad ipfum penè terræ centrum, ne ulli defim loco, ubi mea prafentia, \& beneficia tantoperè neceflaria funr. Theod. Sed hoc mihi exponas velim, quomodo tu, cùm naturâ gravis fis, ex infmis terræ partibus in altiflimorum montium jug te fultol- 


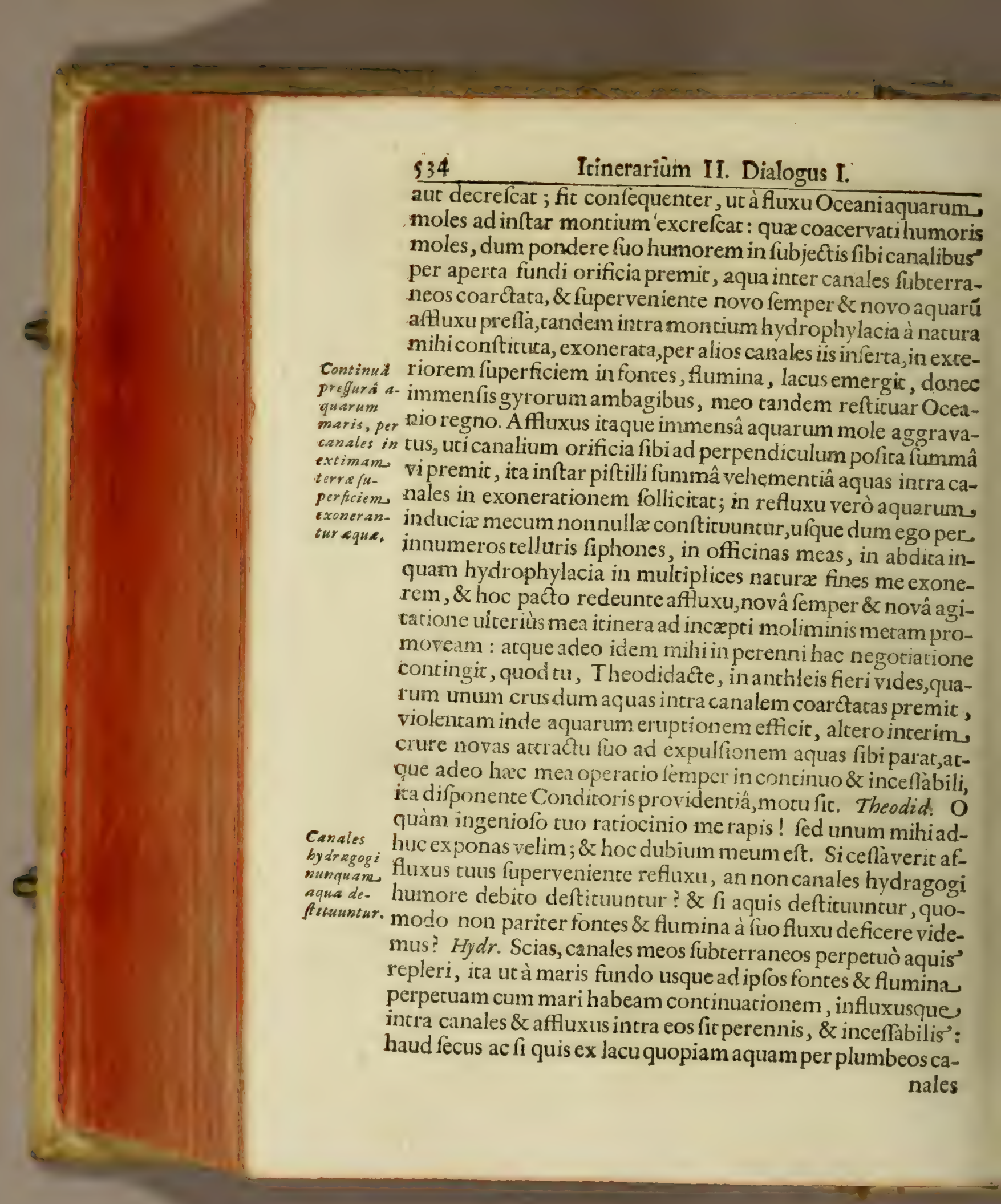


frium regionum, continentiumq; fub aqueos parietes ingref- Canalium fum habent, granditatem, totiusq; maris intra eos impulfi im - fubmaripetum, tti \& ponderis aquarum profundifimarum incun- narum bentis vim \& efficaciam, qua fubterraneas aquas premic; nihil ${ }^{\text {sonftitution }}$ forfan de tantorum mirabilium magnitudine, \&.multitudine, dubii haberes. Uti enim naturæ mea arcana abfcondita funt, \& inacceffr mortalibus femitæ; ita non facilè humano captui pitent, \& nè vix quidem etiamà quantumvis magni ingenai phyfiologis penetrantur: adeo paucorum eft, ad tantum naturæ Sacramencum pertingere, eorumque forlan folummodò, quos Deus peculiari prærogativâ, hujusmodi rerum notitiâdignos fecerit. Theod. Sar fuperque percepi,qua fapienter retulifti, \& jam de rei veritate ampliuis non dubito; qquare ad alia progrediamur. Dic, rogo, tude provenit tanta colorum., Aquarum, faporum, odorumzque, quibus fenfus noftros afficis, varietas, color, apunde aqua? modò enim fallam, jam dulcem, nunc calidam, uc pluri-praseniat. mùm frigidam, fubinde aufteram, nonnunquam odore differente imburam, interdum falutiferam \& varis infirmitatibus medendis aptam fundis; nec defunt, qux peftiferâ quadam \& venenosâ qualitate polleant; quæ differentiæ qualitatum non in exiguam admirationem rapiunt omnes naturx fcrutatores. Hydriel. Scire debes, Theodidacte, hæec omnia pendere à nacurali conftitutione terreftrium partium, per quas canales mei porriguntur : neque enim putare debes, telluris interioris corpus homogeneum effe; hoc enim fentire, præterquàm quòd infenfari \& imperici Philofophaftri foret, vel ipfa exterior telluris tantâ varietate rerum pragnantis conftiturio,heterogeneam terreftrium partium naturam fat affatimque demonftrat. Qux cûm ita fint, jam vel primâ fronte differentium. aquarum rationem, qux in meis fontibus elucefcunt, caufre patent : quandocun que enim canales meifefe per diverfos ramos intra cavernas, fale, vitriolo, aut fulphure, bitumine, naphrâ, antimonio, hydrargyro, arfenico, auripigmento, fimilibusq; mineralibus refertas infinuaverint; certum eft, aquam talis mineralis qualitate, cujus locus nativâ vi fuâ farax eft, tinctum iri.

$$
\text { Yy y Hine }
$$



lum q; virtute imbutarum, varietas paffim fpectatur. Continit autem, ut fubinde per loca toxico \& venenofis qualitatibus referta mihi rranfeundum fit; quod potifimum fit in cavernis, peregrinorum falium fpirituumque furriorum violentâ \& mortıferâ virtuce pollentibus : tunc aqua iisimbuta, ubicumque foras ertuperit, ibi non hominibus tantùm animantibusque extremam perniciem affert, fed \& locum,ob lechiferam. mephicim, omni habitarore privar. Nihilampliùs dicam:f enim dicta probè penetraveris, nullum in elemento meo tam infolentem, \& prodigiolum effectum reperies, cujus non caufam proximam è veftigio affignare poffis ; quare intelligenti pauca. Theodidact us. O quantum me vel per rimam quandam, te duce, ingens naturæ arcanum introfpexile gaudeo! Et hæc quidem à te mihi narrata, uti rationi confentanea funt, ita eadem optimè capio, \& ambobus, ut dici folet, brachiis ample. etor. Unus me fummopere vexat effectus tuus, quo mirum. fit. quoque in modum Philofophorum ingenia corques, eftque aqua tua perpetuo calore æetuans, quas thermas vocant; cum. concipi non poffic, quomodo adeo perenmi calore $x$ tuet, ebulliarque? Hydr. Si quacunque paulò antè tibi de propiecaribus aquarum enarravi,cæperis, modumque yuo à natura canalium, per quos tran feunt, tungantur, nôris, uti jam verè te noffe puto; de thermarum quoque origine nullum tibi dubium fupereflet: verùm ut \& circa hujus difficultatis diflolutionem. tbi plenè farisfiat, originem \& caufam ątûs aquarum tan$\mathrm{gam}$. Scias velim, Theodidacte, non me tantùm interiori Geocufmi regno praefë, fed \& conforcem me habere perpetuâ \& individuâ necenicudin is fociecate mihi conjunctum, quem. Vulcenum, feu ignem fubterraneum vocant. Hictamedicontrariânini naturâ conłtare videatur, ita tamen nos opifex rerum iupramundana Mens conjunxit, ur nec egofineillo, nec ille fine me quidquam in Geocoimiregno peragere pofit : ille me attrahit profuo, nèdeficiat, nutrimento; ego illius calore 


\section{0 \\ Itinerarium II. Dialogưs I.}

Bijopby!acia quomodointra. culnns domefticis in leberibus cacabifque,aqua fummâ effervefientiâ bulliant; atque hoc pacto coctx, digeftrque, in inomniacepi: féd dic, fodes,quomodo officinæ Vulcans. Probe serra bi/ces tuo illo igne flammisque nutriantur, cüm deficiente nutri- a fobean. infentw\%. mento, \& combuftibilis materia fomite ceflante, \& ipfum ignem deficere ac cellare neceffe fic. $H y d r$. An nonaudifi, Naurræopera ob neceflariam caufarum connexionem perpetua effe, neque unquám durance opificis providentiâ deficere poffe? Theodidart us: Novi id apprimè, fed modum quo id contingit,nofle vellem: Hydr. Me vectore \& directore omnia concingunt; mecum enim; nullo unquam tempore defiturocommercio, ingentem ex. Oceano combuftibilis materix congeriem addico, ex montium quoque intimis rimisbitumen, napitam, fulphir; fimilemq; combuftibilis materix fomitem elicitum excractumque fubminiftro; quam materiam veluti necellàum fibi nutrimencum, Vulcania officinæ moxinnatế quadam vi, \& fympathico appetitûis magnetifmo attrahunt. Cüm verò mex.vectura mercis unà cum affluxu aquarum fic perpetua;perpetuum quoque igni fovendo nutrimentum fuppeditari ratio dictat: Accedit deinde quòd vel jpfeconfors meus ignis meam naturam in ipfis faxofartm rupium fifturis, proterreftrium porcionum natura nunc in fulphus, modò in bitumen, jam in alias intiammabiles materias, pro naturâ loci, uc dixi, mox coneoquat, convertatque; ut proinde deficere non polit, quod novam femper \& novam generationi aptam ciactrum indeficientemque materiam habet. Theodidactus: Dic, rogo, sempore an non in Vulcaniis. oricinis fornices perpetuis iftis incenmonexe- diis; haud fécus ac in fornacibus calcariis faxa, in calcem \& cineres fuccufutemporis vertuntur ?:Hydriel: Minimè : nam. $\&$ huic natura providit, dum meos lebetes canalesque femper Vulcanils officinis junctos effe voluit; ex hoc enim cápite respetuo quodam frigido \& humido ardentium culinarum. fornices parietelque convexi ita irrorantur, temperanturque, urà fubjecto igge noxamincurrere non poffint; haud fecus? ac ollax 
Montes quoque Vulcamos fubinde à fuis ceflare incendiis, multiplici de caufa contingit, vel eo loco, è quo fuum fib folitum officina Vulcania mutrimentum haurebar, ruinâ fornicum fubterreftrium deftructo, vel fpiraculo feu camino Vulcanix officinx obturato, vel nutrimento quod confumpfit, non nifi multorum annorum spatio reparabili; atque femper una ex histribus caufis infolitum illum, quem mirabaris, effectum producic. Theodid. Adeo luculenter tam infolentium. effectuum quas affignafticaufas cepi,ut eas mihi demonftraffe videaris,neque ampliùs ullus animum meum de dictis du-

trilitas a. bium pulfat; reftat modo, ut quid utilitacis Geocofini tan inqua 8 i. gnas fub. trinfecis quàm extrinfecis partibus conferas, me doceas; \& ubi serranei. snaxime tuam irduftriam demonftres. Hydr. O vn1 Theodidacte, longum effet tibi meas, quas mund confero, utilitares \& emolumenta enarrare; Mathufala tibiannis opus forec ad eas non dicam animo penetrandas, fed vel minimâ ex parce calamo deferibendas. Univerfus mundus meâ utitur operâ;quod \& Cofmiel tibi in fuperioris mundi luntratione fic fiperque demonftravit: nunc verò nè tifficienti à mé inftuctione non informatus difcedas, ufum tibi meum, at non nifi G力o

Eternus rerum opifex Deus in primordiali illa rerum omnium productione, utialia omnia, ita \& me ex nihuliabyllo produxit, tali tamen fuper amnia reliqua, qux in Chaorica illa maffa latebant,prædominio, ut nihil eflèt in rerum Univerfítace, quod meâ non indigeret operâ. Hinc Divina fapientic quem finem ineffabili fpiritus fui incubitu, ante omnia calore divino fuo is.o crea-frecundavit me, mox ad chaotica mafla divi onem perrexit; \& quoniam durâ univerfam indigeftæ molis maftam tyrannide premebam, nè mundicorporibusimpedimento forem, divinæ opifici menti placuit me partim in ultimos fupercoleftis mundi receffus, partim in univerfos mundiglobos feu aftra,ac potifimùm in terram, quein Geocofmum appellas, in numero, pondere, \& menfura, diftributione exactifímâ , nec non omni-varia proportione difpefcere. Hinc ego omnibus 
mundi corporibus junctus, veluti mundi quoddam gluten \& vinculum indiflolubile omnia neeto: nam ex terreftrifubftanzia producta mundicorpora, fine memox ficcitatis fuæ causâ in pulverem converterentur. Sunt autem hæà divina providentia commifli mihi officii partes, Univerfum mundum fuper-coleftium a quarum fomento animare, àfolarium aftrorum æitu, frigiditate \& humiditate meâ defendere, Quin à me, tanquam ab inexhauftis uberib. , univerfa mundi machina necenarium fibi nutrimentum trahit, ut fi quandoque nimio perennium igniúx ftu deficiat, mex fubminiftratione humiditatis refecta inftauretur. Quin \& colefteillud in finitx capacitatis expanfum athereum, quod perenni motu colertes aftrorum globi permeant, fpatium nihilaliud eft, quàm tenuiflimum, agillimum, fubtilifimumque fubftantix mea effluvium: unde \& Hebræi illud non alio meliori nómine quam. Schamaim, id eft, $i b i$ aque, indigicandum duxerunc. Sed quoniam de his omnibus fufe à cuo Cofmiele inftructus es, illis reliatis ad Geocofmum, velutiad infticurinoftriunicum fopum, progrediamur.

Geocofmus, magna illa tellurismoles, meo unico fuftine-Aque urs: tur fubfidio. Hinc non duntaxat totius globi peripheriam per ${ }^{\text {litates in }}$ Oceanum meum ambio, fed \& interiores penetralium recef uniberfam fus permeoadmirando quodam motel- terram reoccafum Solis \& Septentrionem perenni quadam revor, ex Auftro verò in fub axe Boreo abenni quadam revolutione agitor ; \& uti tils, ab oppofito Auftraliaxe per fubterraneos inciles revolu- circular tibi defcripfi, per innumere gurgitos; atque adeo, ut fuprà qua ex polo

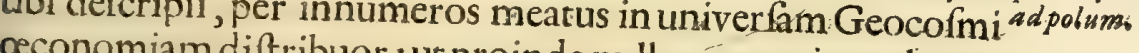
aconomiam diftribuor; ut proinde nullus ram exiguus locus, five internam, five externam telluris confticutionem fpectes", exiftat, qui meâ pr:efentiâ.carerepoffit. Theodid. Sifte parumper,fodes. Dixifti paulò antè,te in perpetua quadam agitatione fub quadruplici motûs differencia verfari. Primò ex ortu in. nccafum, poftea ex Auftro in Septentrionem, deinde perpeuifluxus \& refluxus reciprocatione, ex qua demum quartus

refle- 


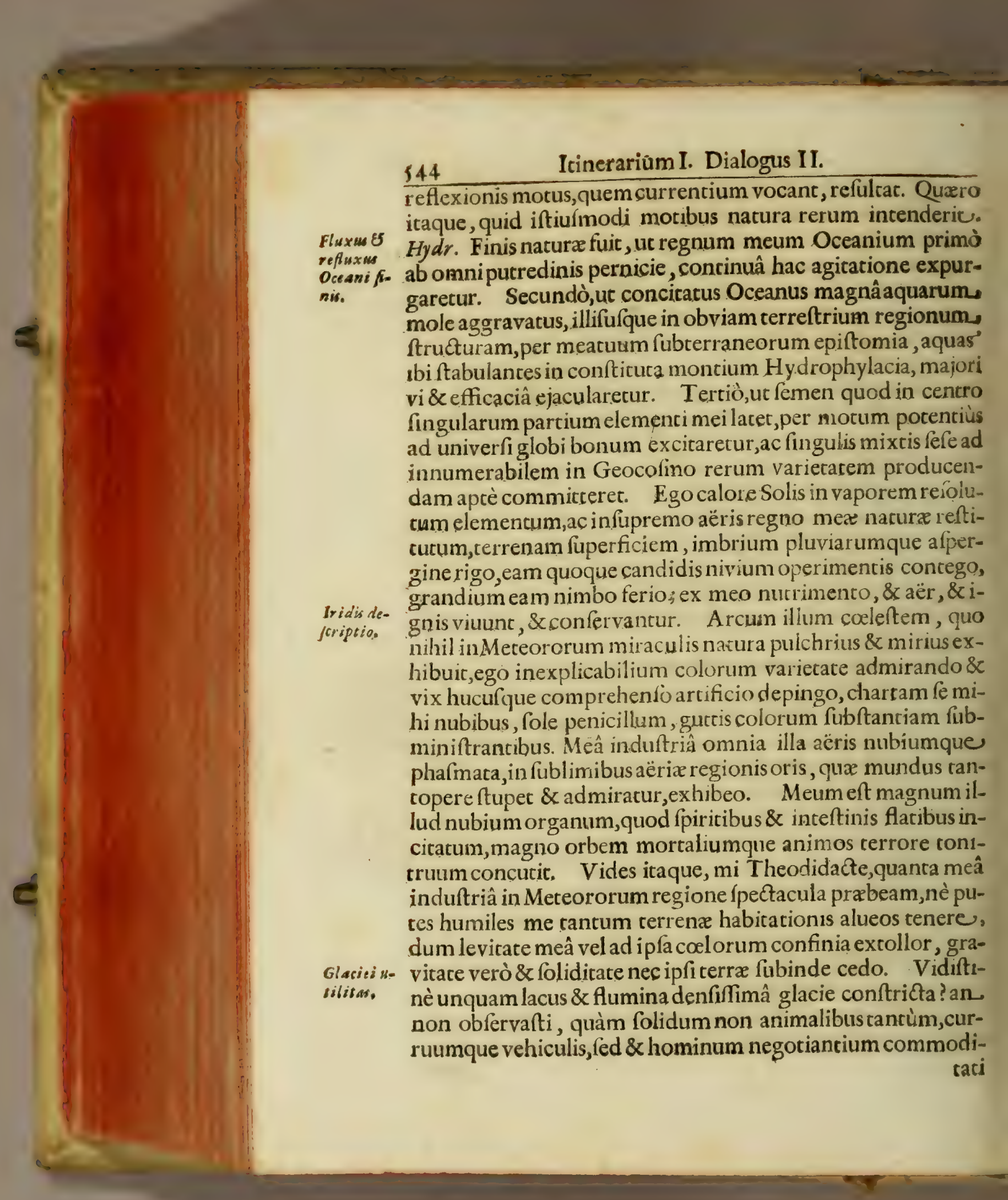



nibus in relaxandis animis occafionem in cryftallino meo pavimentopraftem? meum dominium Morphei regnum jure dicere polès, cùm nilhil fit in quod non repentinâ mutatione transformer. Theodid. Mira fanè refers, ô.Hychriel; fed dic, rogo, quidnam in intmisterraviferibus moliaris? quomodo te in fibterreftrium generationum Metamorphafi geras? Fydr. Secreta à me quaris, qua nif tibi, non a!ceri mortalium revelarem; quia tamen arcana mirificx mex poteftatis facramenta unicè fufpicis \& veneraris, fincerè tibicuncta aperiam. In abditis meis fubrerraneartum regionum hydrophylaciis commorans, mox ubi Vulcaniarum officinarum æftu conci- Minerwcor, in fubrilifimum tenuiflimumque vaporem refolutus, per : wizem pro

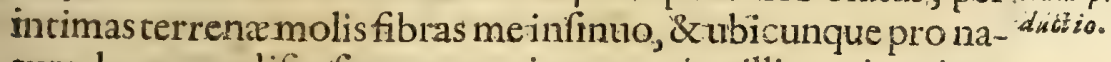
tura locorum difpofitam materiam reperio, illi protinus.junous, jam univerfalinaturæ femine foesus, nunc in metaltum, modò in quandam mineralium fub́tantiam, jam in preiof lapidis formam, laboriosâ quidem, at ncbilifiman coagulatione transmutor; ut proinde nullum metalli, nullum mineralium, nullum pretioforum lapidum genus, fine me debitam fibi perfectionem confegui porfic: ut exindenon fine ratione veteris fapientix magitri me femen mundi, \& menfunum UI- iqqua $/ \varepsilon_{-}$ niverfi efle exiftimarine. Ofi occultas itinerum meorum fe- men munmitas, mi Theodidacte, videres, quantum ftuperes? quanta admiratione defixus ad incomprehenfas operationum mearum rationes hæreres? ego abdito quodam præxpotentis magnetismifafcino, vel ad primum occurfum, mox in amorem meam omnia difpofitarum materiarum fubjecta converto, ut ipf tota mei fe juris, ego totum me ipforum xrisadmirando quodam conjugio factam,eâ Mctamorphofi, uc nemo me ampliửs dignófat. Vidiftinè cryftallum, beryllum, adamantem, amethyitum, carbunculum, \& fimiles iftiusmodi non fplendore magis, quàm raritate inæeft imabiles lapides? Theodidact us. Vidi, \& admiratus fum natura in iftis formandis induftriam. Hydriel. Illiomnes mei funt partas, illi meum coagulum, quo- 


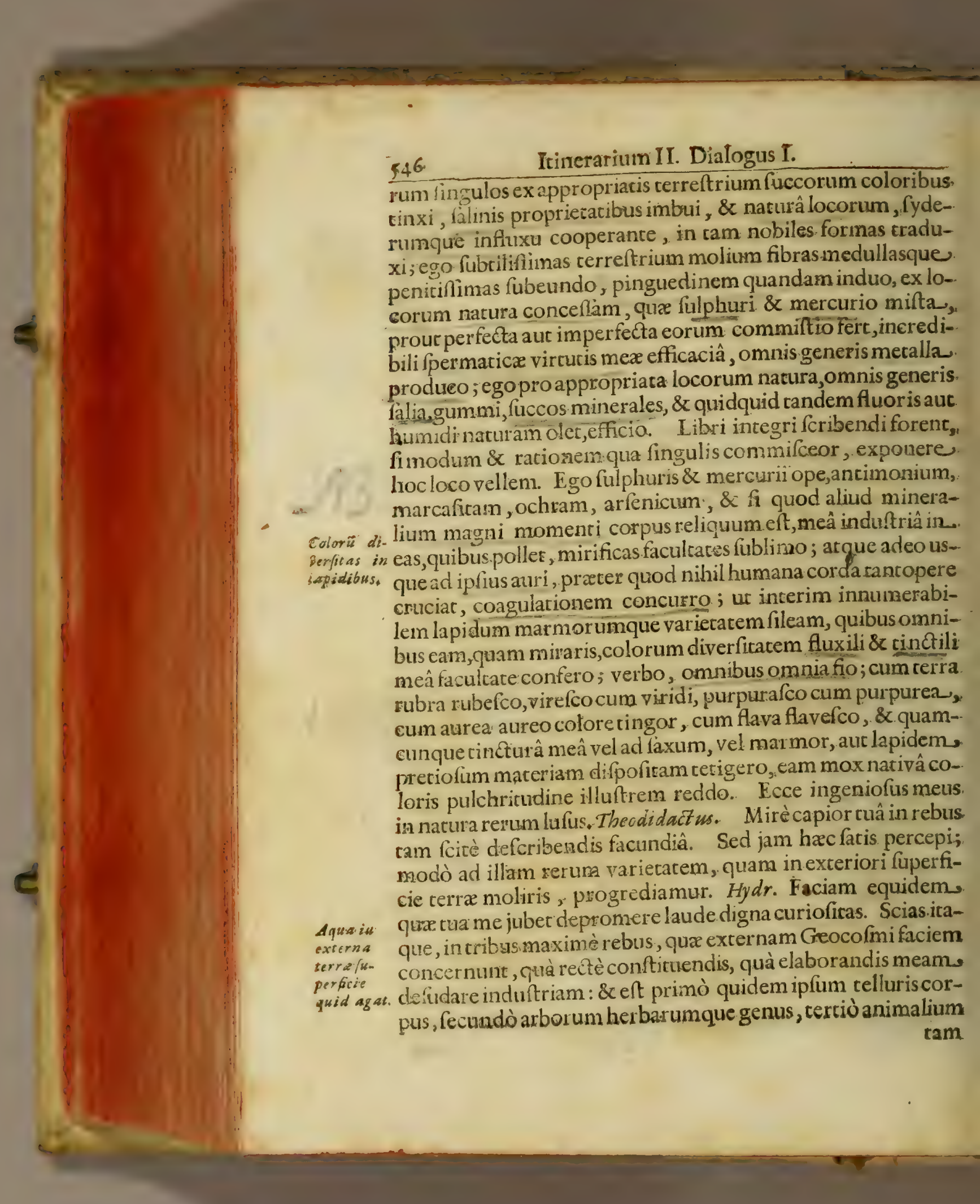


tam quadrupedum, quàm volatilium, aquatilium, reptiliumque varietas. Ad primum quod attinet, annon vides, univerfam me celluris fuperficiem innumeris fontium rivorumque fcatebris, veluti quibusdam Geocofmici fanguinis venarum ductibus veftire, ornare, rigare, nutrire? ur vel ex hocipro colligas,omnia me fubtili virtutis mex penetrativæ efficaciâ attingcre, necullum êle locun cui defim, aut ex commiffo mihi aba arternâ fapientia officio non fubveniam : \& fi quan- Aqua *doque naturâ locorú ita poftulante alicubi, uti in defertis are-mnis aliz. nofis, deefle videat, antignacos tamen mihi jurisdictionis terminos minimè defero, fed quod folar is æetûs vehementia aduItum, languidum, aridum, exficcumq; reddiderit, id nocturni roris, in quem refolvor, abundanciâ mox inftauro, reficio, \& ad frugem reduco, atque adeo muneri meo nullibi defum, ubi femper adfum, \& ad omnium neceflitati fuccurrendum præfo fum. Venioad fecundum, qux eft vegetabilis natura, à Aqua in qua tam anxiè quaror, tam follicitè ambior, ut nulla fit tam, natura $\psi_{-}$ exigua plantula, nulla tam exigua arbufcula, qux non omnitilitas:: me naturæ conatu attrahar, alioquin repentinâ ariditate \& nutrimenti defectu conficienda. Eft \& hoc mirum dictu,quòd cum innumerx fint plantarum $\&$ arborum fpecies, formis $\&$ fpecificis proprietatibus diftinctifimæ, earum tamen fingulax, infitâ vi attractum in fe fuamque me naturam convertunc. Ec quoniam ego pro natura \& conditioneloci operor, primò terreftrem glebam ad talem \& calem qualitatem feminali meâ virtute, \& falfugineâ facultate, quam femper centro meo involutam gefto , difpono; hrc difpofita, mihique immixta,germinat ralia \& talia, tales plantas \& arbores, non alias, ex mira quadam terreni cum humido, aliisque abditis locorum qualitatibus concurrentibus, temperie \& mixtura profert. Ex hujus verò infinitæ combinationis adaptatione, nafcitur infinita illa herbarum plantarumque varietas, quæ deinde adolefcentes, concepri exclufiq; feminis propagatione, univerfam relluris fuperficiem in ufum hominum animaliumq; replent, unde vulgatum proverbium, non omnis fert omnia tellus, fiqui-

$$
\mathrm{ZZZ}_{2} \text { dem }
$$


$\Gamma 48$

Itiverarîum II. Dialogus. I.

derne.go fingulare quid producere non poflum, non concurrente appropriatâ locorum naturâ \&conditione foli. Hinc in India, \& Zonze torrida fubjectis regionibus plantasarboresfuxta dif que toto coeloab. Europxis differentes produco. Et hoc quare? firentem caliconfti twtionem

diberfa ge cuia alium ad Solem, Lunam, ftelliasque fitum abtinent, quo umeriantur.

ti aliter atque ahter, rum fupernorum influxuum virtutes, tum

Archai fubterranex Oeconomix miniftri \& archirecti, opera-

ciones participunc, ica mirificè quoque iis terreftrium partium natura alteraur. Theodidact us. O quàm f citè \& peritè naturam rerum exponis!: Jam video verum efle; quod veteres adeo confancer afleruerunt, aquam videlicet rerum omnium principiun; femen mundi,menftruum, \& fermentum totius nacuræconfticuentes. Sed jamulteriùs ex te perciperecupio,quomodo animalium generacioni \& temperamento temifceas ? Aque uti: Hydriel. Paucis ribi modum oftendam, ut inde colligas; admi-

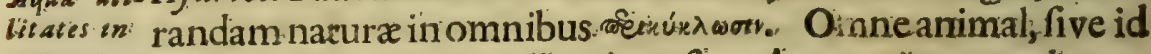
natura fic ex ordine racione pollentium, five eâ expertium; quadrupedum, volatiliumque, five ex aquarılium, iniectorumque familia: ortum ducant, omne inqua m animal; ut vivat, nutrimento in diget; ;utrimentum verö illud fuppeditant, aut animalium. carnes, aut herbarum, fructuum, olerum, leguminumque pa. ftus: Omnia hrac à meradicalem originem, uti paulò antè demonftravi, traliunt, fiquidem fineme eflentia fux perfectionem confequi misimè poflenc. Ego fubtili admodumac tenui fubftantiâ meâ, primö plantarum radices, non tam ingredior, quằm nefcio quấ occultâ magnetifmi vi ab iis attrahor, hifce robus jungo ad plantam fuftentandam neceffarium, deinde proprix plantx fubtantia peculiaribus jam viribus ditatæ commifcer; \& hoc' pato externo folis calore rarefactus, paulatim extraterram eturnpo, atque fuccedente novo femper \& novo nutrimeni meraugmonto, randem in caulem, ramos, foVia, flores, fructus, femen condenfor, dilator, concinnor, protubero, animor; fernen verŏ macurum jam digeftumque denuo ser: $x$ mandatur, ur meấ operâ fermentatum in novam plantæ wobolem exangat, perenni quadam \& natura propriz propa- 
gationis pericyclofi; equus verò, a w bos, five fænum, five gramenaflumptum nutrimentum, humido à me ei priús conceffo tumens, incra ftomachum dimiflum, ibidem digeric, dige fum partim in fanguinem, partim in femendeftinac, femen. verò humidx \& calidx fubfiftentia in ucerum transfufum., fux fpeciei fobolem producit equum aut bovem $m_{2}$, qui denuo innato quodam appeticu, ad id ex quo vitam fumpficnutrimentum carpendum fertur : eftque hrec mira illa naturæeperiodus, atque in omnium fingulorumque animalium perpetuanda fpecieproceflus. Vides igitur, quomodo egoomnibus rebus per occultiffimas nature femitas commifta vitam. largiar? Theodidactus. Ex ruo illodif curfu fequitur, te tum Aqua cum: in herbis, tum inanimalibusfëminis, naturam comfiruere,; que reine cui-. quod facro textui repugnare: videtur: creavit enim Deus o-prio quomnia tum plantarum, tum animalium genera ex ipfa terra ${ }_{3}$, modo ag afo. non exaqua, in perfecto nacuræiftatu, quæ femerrad fipeciem. propagandam haberent in femeripfis, non ex aqua nutrimento acquifitum. Neque ego quidquam divina: difpofitioni: contrarium hodiè dixerim; novi enim facra pagina textum: ( producat terra herbam virentem producat animalia; \& jumenta ) \&cc. \& fic oportuit facere Divinam providentiam. Hydxiel. Produxit, fateor, ea ex terra, \& in perfecto corum naturæ confentameo ftatu in primis illis mundincunabulis, tum. plantas, tum animalia,fed non ex terra arida , pulverea, dura, ficca, fed mea jam fubftantia maceraca, \& plasmandis corporibus opportuna ; \& quemadmodum in primo illoproductionis actu ego neceflariò ad unicurique füm attribuendum. temperamentum, ita ad feminis unicuique five plante, five animali appropriatam naturam, \& ípecificam, ut ichole loquuntur, differentiam conftituendam, radicali meo humido concurri, quinimò à Deo conditore fapientifimo jam produEtus, atque in huncusque diem in immenfum propagatus, meo nutrimento conf́rvo, \& productionis peracta ferieminceffanter continuo, fiquiden fine me nihillvivere; nullus generationis ordo continuari poteft. Vides igicur; quomodo Di-

$\mathrm{ZzZ}_{3} \quad$ vina 


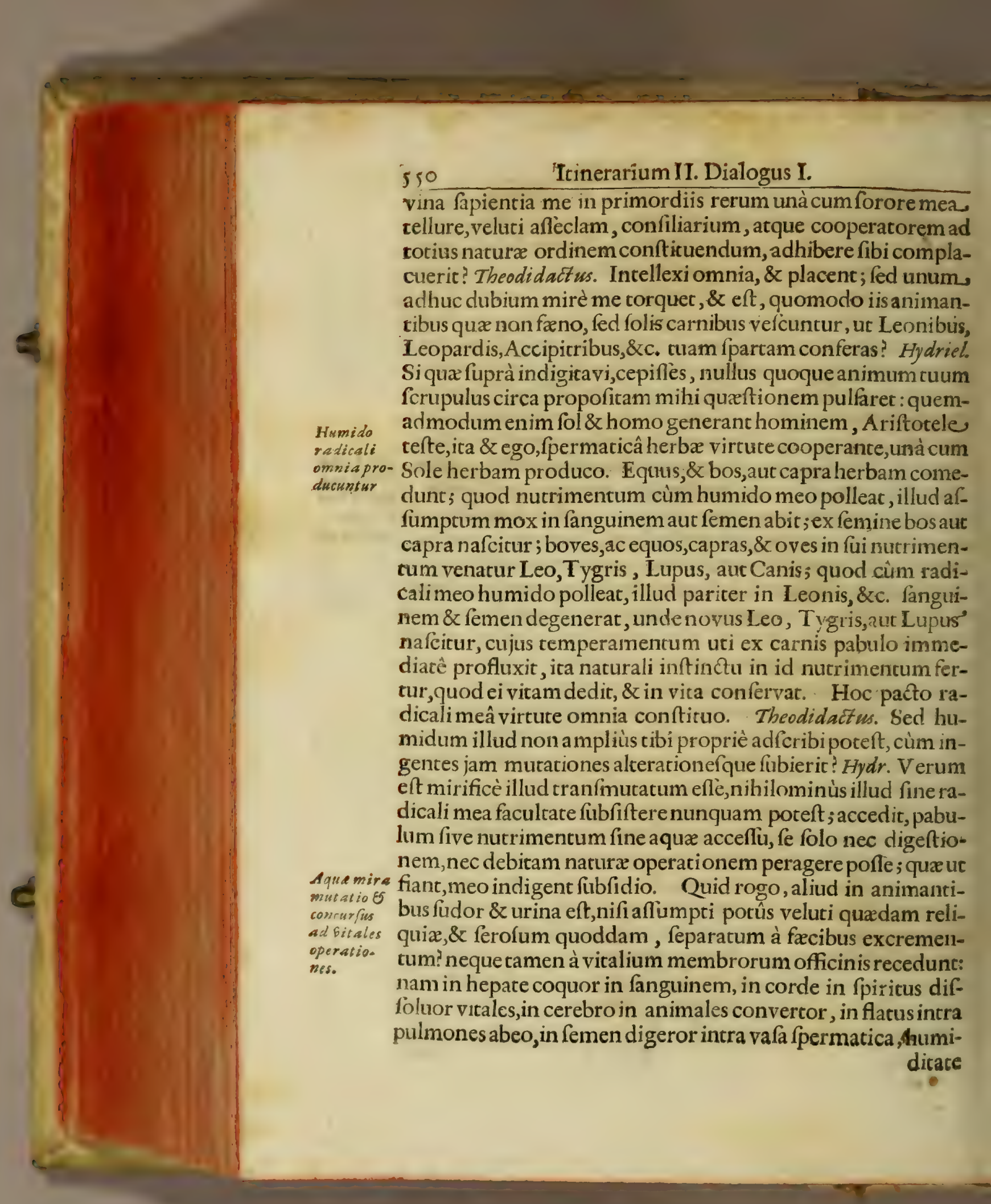


Cap.I. De Aqua Natura. $\sin x$ dicare mea fanguinem, nè coaguletur, in venis fluxilem facio; nervorum propaginem, infeftinorum volumina, adeoque omnia interiora membra humiditate \& mollitudine meấ, nê้ obrigefcant, lubrica facio; per aures, nares, os, linguam, oculos, mucofam mareriam, humectarivâ vi mea exonero, atque adeo nihil eft in majori minorique mundo, quod meâ non admini- Aqua quasftretur perennieurâ, induftriâ, follicitudine. Ad volucrum, modóad genus venio, quod cum feminibus, fructibus, carnibus vivat, if- conffitutution lud autem utia me tanquam principio originem duxit, ita pa- nem conriter nihil fine me poffeclarè paret. Ego illis \& potum in rivis foñtibufque, \& humiditatem in aëre fubminiftro; quam. tameffi non ut ter reftria animalia per urinam excernunt, non zamen ideo meo fubfidio defticuta cenfere debes, cùm omne humidum, nutrimentumque affumptum, partim in lubftantiă aliti,partim in fermen \&ova, in utroque fexu, in fanguinem. firicufque, in exteriori verò in penmarunx innumerâ colorum varietate imbutarum ornatum, nativâ f́peciei proprietare deverer. Pux verồ in aqueo mèo regno narales fü generes. Quz vero in aqueomeoregno natales ftos fortiun- fine aqua tur, videlicet innumerabilis pifcium variecas, ea nifi in elemen- non poffint to meo uti vivere nequeunt, ita aliam fefe originem quàm $\mathrm{ex}^{\text {bífere. }}$ me non habere,palàm teftantur, ut proInde de hifce fufiùs tecum fermocinari fupervacaneum ducam. Reftat illud anima- Aqua ut lium genus, quæ infecta vocantur, \& infinitus eorum numerus ad infectoeft : qualiacunque tamen fuerine, illa certè non alterius, fed currit pro. mex fubftant jurifdictioni:cúm enim pleraque ex putredine ductzionem. nafcantur, ego verò tum terreftribus glebis, tum plantis, animalibus, malignantis etiam naturæ mixtis, facilè me infinuem; putredinem, cujus ego fermentum fum, nafci neceffe eft, uti ex putredineinfecta. Theodidactus. Nunc verè video, univerfas te mundi femitas penetrare, neque quidquam effe, five fubterraneum Geocofmi promum condum, five exteriorem fenfibus expofitum rerum apparatum fpectes, quơd tux curæ \& prafidionon fubdatur. Hydriel. Ita eft; qux fi penitioni mentis trutinâ ponderaris, te procul dubio to- 


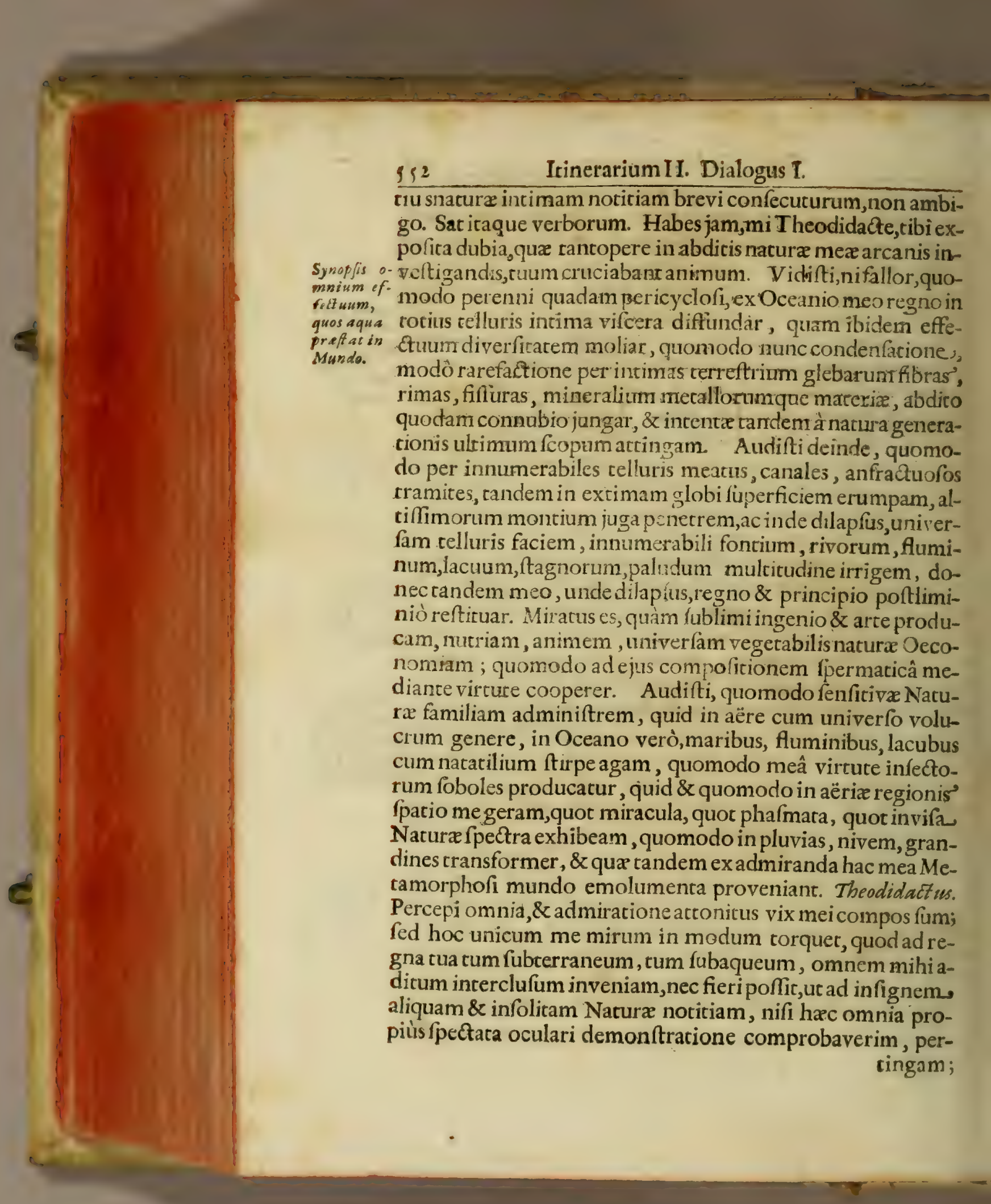


xingam; qux dico non tam ad curiofitatis pruritum filtendum,quàm ad folius immenfi \& fapientifimi conditoris gloriam promovendam, ut videlices infipedtis omnibus Narurx myfteriis, de gradu in gradum, per ineffabiles divinæ fapientix femiras paulatim progreflus, attingam Deum Deorum in Sion; ibique perpetuo \& indifolubili amoris nexu ei, qui tantumin homin is folius gratiam molitus eft, jungar,eundem ærernùm. amem, amando finetermino pofideam.Hydr.Scias, Theodidaete, jurifdiction is mex terminos non eò'extendi,ut te fine mundi prafidis confenfu \& imperio cui,foli coli \& terræ,adeoque rotius Naturæ archivium concreditum eft, in regnum meum. introducam; fed audi confilium meum. Audivijam dudum, te gratiam in confpectu Mundipræfidis, qui Cofmiel dicitur, invenifle; qui ficuti te in inacceffa huculque fuperioris mundi cœleftifque exercitûs armamentaria introduxit, atque omnia ex ordine demonftravit, ita quoque continuâ precum tuarum fervido cordis affectui conjunctarum follicitatione fururum fpero, ut omnia regnorum meorum arcana, \& tibi demonftrare, \& totius Naturæ fubterraneæ conftitutionem detegere non fit intermiflurus. Sed jam rempus eft, ut in chaos meum. revertar. Vale,mi Theodidacte, verborum meorum memor. Theodidactus. Hifce dictis, Hydriel fummiffo capire, in tenues evanuit auras; ego verò ex fopore evigilans, vifarum rerum admirandam feriem, alto voluebam pectore. Relicto itaque horto, domum reverfus,Mufeolo meo me abdidi, ac qua compereram, mox chartæ ad gloriam Dei,\& Reipublicz litterariæ emolumentum, committere vifum fuit. Quid porrò factum fit , narrare aggredior.

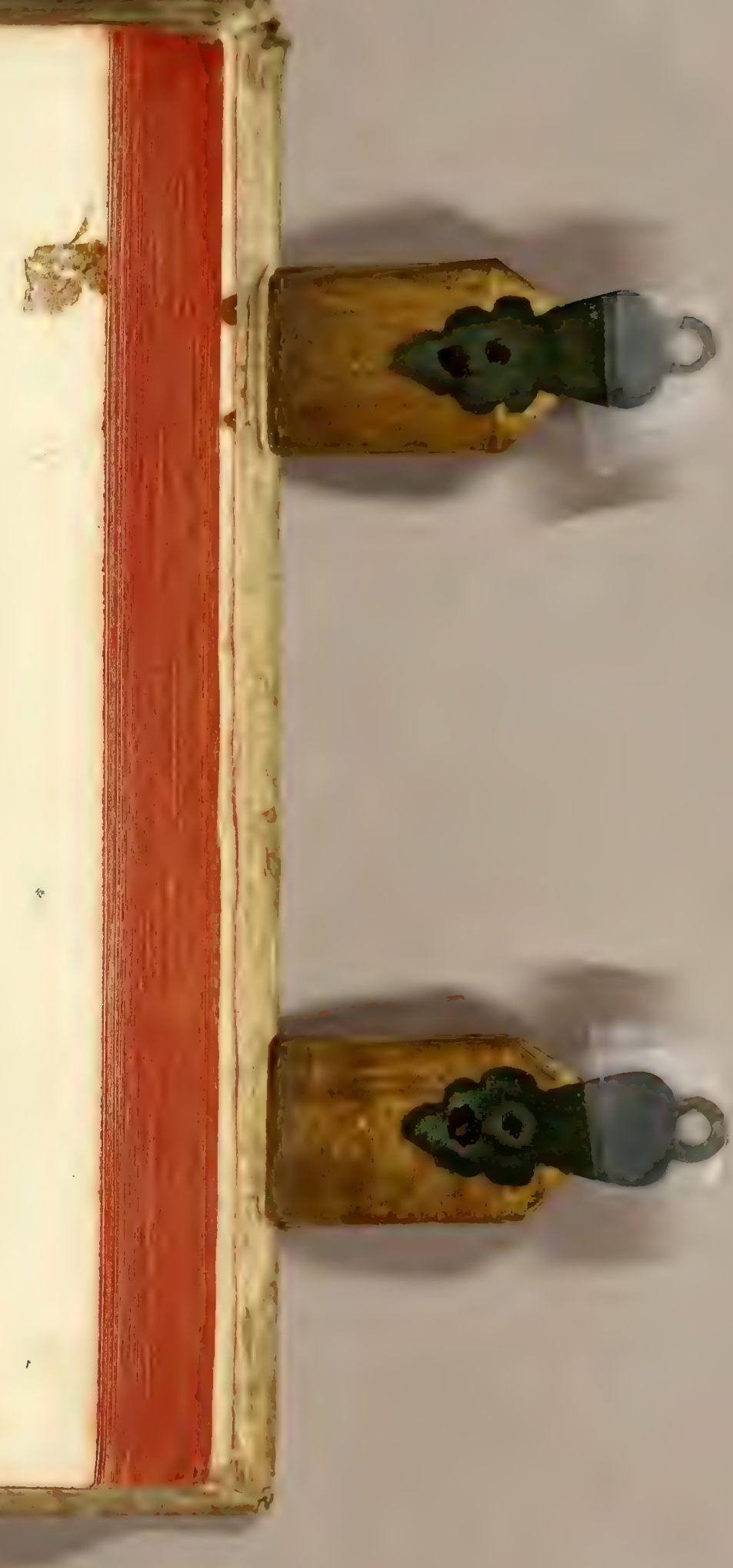
A a a a
DIALO. 


\section{De admirandis Geocofmi,five Terreftris} mundi arcanis.

\section{Interlocutoribus Cofmiele, $\in$ T Theodidacto. C A PUT I.}

\section{DexterioriGeocomifacie.}

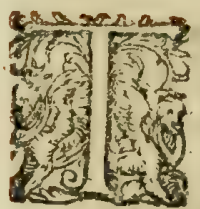

HEODIDAC'TUS, Dumitaquein. genti rerum ab Hydriele narratarum voluptate delibutus, fingula mecum accuratiùs pondero, ingens fanè cor meum earum rerum, quas abipfo circa incerionem Geocofmiconft titucionem narrare audieram, cominus fpectandarum defiderium invafir, eo potiflimum fine incitatum, ut ex hac infcrutabili Divina fapientix difpofitione, \& admiranda telluris ftructura, novos mihi \& novos ad invifibilium rerum pulchritudinem, pervifibilia: gradus difponerem. Interim fuaviffmi Cofmielismei memor, eum ferventi precum inftantiâ follicitabam, atque incredibili fiduciâ fretus futurcam fperabam, ut qui fupremam. mundi monarchiam, coeleftilımque corporum apparatum., tanto clraritacis humanitatifque officio mihi demonftrâraty is pariter pro infita in meaffectus pronitare, fubterreftria Geocofiniregna, \& arcana ejufdem facramenta, porrò demonftrare noneflet dedignaturus. Vix dixeram, cùm ecce novofopore, eoque profundiffimo fuperveniente occupor. Pandi- 
tur interea domus omnipotentis Olympi, toto corufcante folendidiffimo jubare in loco, ubi commorabar; Cofmiel fefe fiftic, fed longe à primæ paraftafeos habitu difparatus. Caput apparttò tantâ fulgebac luce, ut vix tantæ majeftatis incuitum fufferre noba cofpoffem. Manu dextrâ tenebat globum terræ, innumerâ re- mielis, noo-̣ rum varietate confertum : hîc Oceanus terreftribus partibus tus deforifues difterminabat limites; illic maria intra cerreftrium por-ptio. tionủ alueosfefe pulchrè infinuabant : hî̀ flumina, velutifimbriis quibufdam decorè fluctuantibus, \& originem fuam unde prorumpebant, \& cum Oceano furm medicabantur conjugium ; ibi lacus, \& ftagna orbis terree veluti totidem oculis condecorata fuum decorem, ufum \& abdita in humani generisemolumenta; fubfidium, \& facunditatem demonftrabant immenfa aquatilium multitudo \& varietas; monftra \& cete grandia omnis generis mirificum fefe præbebant intuenti fpectaculum;terreftres verò portiones innumeris concatenatze montibus penè in extafim rapiebant ; arborum porrò, plantarum, herbarum, animalium tum terreftrium, tum volatilium mulcitudo \& differentia, nec numerum, nec finem obtinebant. Siniftrâ baculŭ tenebart Cofmiel ex omnibus, quas natura rerŭ in prædiuiti fua gaza exponit, pretioforum lapidum metallorumq; fpeciebus compofitǔ.Cingulo annexum gerebatCornucopix,omnibus rerum humano ufui neceflariarũ fubfidiis inftructư. Cærterùm pennato alarü,apparatu, habitufq̣; invifi decoretantú rplendebat, ut eum, cui ex rebus naturalibus comparare debeă,nefciam. Ego verò ad tam infolentia rerum feectacula, vix mei compos, ardenti mentis æêtu, in folitos ejufdé amplexus irruere mirü in modum geftiebam;tantx tamen Majeftatis reverentiâ deterritus abftinui, hoc verborumtenore eum affacus. O mi Cofmiel! ò Cofmiel cordis mei folatium, antiqux familiaritatisconfors, coeleftiumque myfteriorum fidelis interpres! quid fibi vult tam infolitus habitus? quid mira illa fymbolorum fchemata quibus gravaris, portendunt? dic, rogo, compar, veteris tutelæ memor, quænam tui fit adventûs caufâ? Cofmitl. Preces tuax, mi Theodidacte, fummumque quo artuas

$$
\text { A aa } 2 \text { earum }
$$


carum terum, qux ad ultimi finis tui confecurionem pergunt, cognofendarum defiderium, conditorem tuum moverune, ut nbicuoque fervitio ad maximam ejus glofiam reftituerer. Venio itaque ad te, ut poft demonftrata divinæ lapientia argumenta infuperiore raindo elucef́centia, jam \& mandum fibrerraneum, fuperterraneumque, quem publicæ luci jam dudum parare incepifti, unà cum myfteriis,\& arcanis facramentis tibi detegerem; accultas divinx fapientix femitas, nor. folum qux in exxerna globi fuperficie,fed qux in intimis vifcerum receflibus, à paucis hucufque mortalium penetratas tibi demonftrarem, rerum fingularum rationes docerem, ut fic, ad impigrè pro honore Dei \& boni communis emolumento la borandum,aptior fieres \& inftructior. Theodidactus. O mi Cofmiel,fierinè poreft,ut tu præcelfus cæleftium exercituum. princeps, tantum gratiâ tuâ me pauperem \& humillimum fervum tuum digneris? \& quis ego fum, favilla \& cinis, qui tantâ prærogativâ exorner, ut or acułorum hucnfque defideratorum particeps te doetore fierem, \& per ineffabilia Divinæ fapientia Gazophylacia ductus,ea cognofcerem, quae oculus non vidit, nec auris audivit? Novifti, me, poft quàm per excelfa fuperioris mundi domicilia fervum tuum traduxifti, infolitarum rerum confideratione ftupefactum, prater invifibilium rerum intuitum nihil ampliüs defideraffe, nihil ambiifle. Cofmiel. Laudabilia quidem tua funt defideria, \& Deo optimo peraccepra; fed nec dum tempts, qlio votorum tuorum compos fias" advenit. Oporiet re primùm incomprehenfibilia Dei ma. gnalia, quæ in folius hominis gratiam in hac terreni globi fabrica operari dignatus eft, mundo exponere, atque omnium morcalium corda, dum tantorum beneficiorum cumulos af piciunt, divinoamoris æftu accendere, donec tandem juxca votorum fummam, ea in archetypo mundo ærernum contempleris. Theodidactirs. Sicuti femper tuo me arbitrio plenâ anımi refignatione tradidi, ita porrò circa me, quod \& tibi, \& Deo in te, beneplacicum fuerit, exfequere. Nihil enim antiquius unquam habui, quàm Divinæ voluntatis amufim in. omnibus 
omnibus ardentifimè fectari, eique conjungiper affectum, quicùm infinitè bonusfit, amore utique infinito dignus eft.Sed rogote, $\mathrm{miC}$ Cofmiel, quid fibi globus ille tantâ rerum varietare confpicuus? quid baculus? quid cornucopix, quibus oneraris? explica,rogo, arcana rerum facramenta. Cofmiel. Globo quem Explicatur vides,mundum fcias, ex terreftri \& aqueo elemento conftitu- Jymbolicus tum,exprimi. Vides in hoc Oceani longè latèque diffufam_costmielis aquarum molem ? Vides marium intra terrenos finus diffluxiones? Vides lacuum, fontium, fluminum, ab origine fua in. innumeros rivos deductorum propagines? Vides animalium, aquatiliumque multitudinem, \& varietatem ? num intueris" cerreftrium portionum montibus diftinctorum concatenationem? quamarboribus, plancis, herbis decorè veftiantur? filvafnè, camporumque planicies, à quadrupedibusalitibufque habicatas cernis? Theodidactus. Cerno omnia, \& ftupeo, \& quid hujufinodi mihi fignificare velis,nefčio. Unde quâ poffum humilianimi devocione rogo, ut mihi fcopum omniunz, inquem collimas,aperias. Cofmiel. Argumensum, quo jam dudum diftineris, mundi fubeerranei hifce indigito ; \& quoniam circa multa hæres incertus \& dubius, \& magnâ animi anxietate terreftris globi myfteria rimaris, tibi preftofum., ut quemadmodum per inaccefäs coleftium globorum manfiones te deduxi, jam pari pado per occula atque inaccefle. Geocofmiadyta à me deducaris, nè quidquam frr, quod te in abdita naturz Majeftate pentetranda lateat. Theodidact uss. Ee quomodo hoc fieri poffe putem, cùm Geocofmus naturâ fuẫ folidus \& impenetrabilis exiftat ? Cofmiel. Valde erras, fili; funt hæc imperite philofophantium phantafmata, ¿x falfx perfuafiones eorum, qui praterquàm quæ fenfibus expofita func, nihil adeorectax racionis trucinâ penficant. Theodìdactu us.Vix dixerat, cúm ecce Geocofmús, quem manu dextrâ gerebat, in duo è veftigio hemifpharia diffilit. Cofmiel. Vide jam, Theo- Terreffiris dida

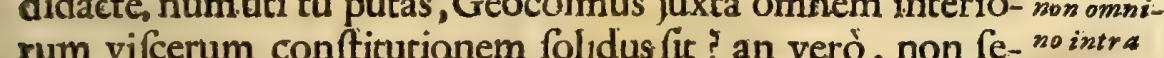

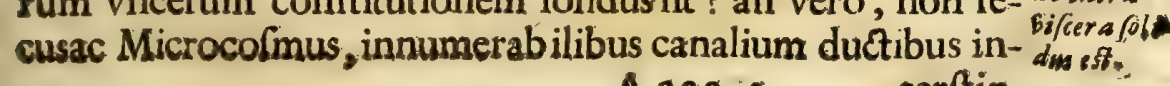
A aas 3 serfin- 
terftinctus? innumer is ingentium cryptarum receptaculis divifus fit? Theodidactw: Video, \& quidem fatis mirarinan pof fum. Cofmiel. Per omnia itaque, hoc in globulo non nifi typo quodam expreflà, naturæ adyca te traducam; rationes fingulorum oftendam; fines alciflimos, ob quos ab authore natura fingula conftituta fint,pandam. Ex quoniam hreaptè concipinon pofunt, fine exterioris Geocofmi fuperficiei exacta no. titia; primò univerfam telluris fuperficiem luftrabimus, deinde ufque ad ipfa centri adyca penetrabimus, carceres Vulcanios, Æolios, Neptunios, \& fi quid aliud reftar, arcanorum oftendam ; fic enim, voris ruis plenè farisfactum iri confido. Theodidactess. Equidem non expedire judico, ut per externam. globifuperficiem me traducas; eft enim ob Geographicum. multorum annorum ftudium, regionum fitus in ea defcriptus, mihi fat fuperquenotus: hoc unicum à se contendam, ut quacunque mihi dubia circa occultam regionum, montium, aquartum, marium naturam occurrerint, pro eo quo me profequeris benevolentix affectu, difioluere non graveris, donec iis omnibus inftructus, in fubterraneorum meatuum cavernas \& lacebras,penitifimaque naturæ gazophylacia, qux uri in hunc ufque diem inaccefla manferunt, ita ingenti eorum videndorum defiderio crucior, à te introducar. Cofmiel. Votis tuis uti nunquam reftiti, ita fatagam, ut eortim qux ex me quaris, plenam folutionem nancifcaris. Perge itaque magno animo, eas qua intimo pectoris fcrinio condicas habes, de naturaGeocofmi dubitationes proponere.

\section{A P U T II. I}

\section{Varia dubia folvunturcirca externam Geocofmi conftitutionem!}

Geocofmus ex nesndi corporibus 1 tidiepanè lego,terreftrem mundum,quem Geocolmum fimus eff. $-1$ for. 
Cap. II. De globo Terra.

fordidam elementorum amurcam, elementarium excremencorum faburram,perpetuâ generationis \& corruptionis viciffieudine fummè derurpatam aftimari; cùm ego tantum abeft ut id fentiam, ut eum potiùs omnium mundanorum corporumpræeftantifimum exiftimem. Tuam itaque circa hoc argumencum fententiam operio. Cofmiel. Rectè judicafti; fed ut oimnia ritè tibi ingerantur, paulò altiùs de eo ordiri vifum. fuic. Nofti, mi Theodidacte, illud in fcholis tritum, operis alicujus excellentiam à fuo potifimùm finefpecificari? Scias" itaque, finem terreni globi adeoaltum \& eminentemente; ut, Terreffi is non dicamulli mundanorum yloborum dignicate \& excellen-globu- otiâ fuâ non cedat, quin vel folo empyreo colo inferior fic. quosante Nonnè audift hac à me tibi fufiù, dum fupernum mundume cedit, contemplaremur,exponi ? Theodidactus: Memini, \& alco pectore divina tua dictamina impreffa confervo. Sed perge, Finis Geofodes. Cofmiel. Geocofmus, uti dixi, tanta excellentix eft, uc tura ratio. ob hunc folum, totius mundi machina à DEO producta videa-nalis sat. . tur. Certè non propter nos, nullo corporea compofitionis? amictu indigos,corpoream hanc mundi molem conditor fapiencifimus confticuit, cùm vitx intellectualis beatitudine. contenti,corporeis rebus non utamur. Ergo non propter. aliud quàm rationalis creacuræ, ex amimo \& corpore conftitu$t x$, ultimum increatis finem, eumque altifimum \& eminenrifimum, conftitutum quis negabie? Unde eum, velutiin univerfi fabricamedium, ceu thronum quendam conftituit, quem: innumerabilis aftrorum exercitus, noetu diuque circumeundo fuis virturibus foveret; cui foli veluti Regi fuo, influxu \& com- ${ }_{\text {car orom }}$ municatione virium fuum famulitium impenderet; quem $\&$ mobieatun ideo immozum fixumque effe oportuit, ut tanquam principium paflivumaptiùs fupernis inflixibus fubderetur, adeoque: nihil in fupremo mundo effet, nullum tam exiguum aftrum cujus virtutes nomparticiparet, \& cai non quapiam fupernarum virtutum particula infita eflet : quod ex fumma rerum varietate, \& hominibus incomprehenfa multitudine fat fuperque pater ; qua profectò tanta eft, uc fi Myriadem annorum. 
in îis evoluendis intenderes, in eo tamen latentes naturæ thefaùros minimè exhaurires, femperque ibi ubi finieris, rerum, identidem novarum cognofcendarum inveniendarumque daretur principium. Vera majoris mundiepitome quædam, rotiufque naturæ compendirm abfolutifimum, in quo condicor omnia fuperioris mundiarcana complicata efle voluit, uc rationalis creatura in hoc veluti centro quodam conftituta, dum altiora inacceftaque fupremi mundi habicacula fenfibus attingere non poflet, illa tamen omnia in Geocolmo veluti iz compendio quodam convoluta intueretur. Sed hac nihil funt refpectu eorum,qux jam tibi aperiam. Dixi, mundum. propter terram,terram propter hominem, hominem verò propter Deum folum productum fuiflè. Cùm verô in zterno Sacrofanctx Iriadis confiftorio, xterni patris verbum \& filius, aterno decreco, in humani generis per peccatum lapfi redemptionem ad carnis humanæa altumptionem deftinatus fuerit; certè nihil ad Geocofmi excellentiam ampliủs accederes

Geoco/mi excellentiam fine comparatione auxit incar. netio Verb Disini. poffe videtur,dum dignus effectus eft, qui Unigenicum Patris Fílium, Verbum æternum, Sapienciam increatam, humanâ carne veftitam exciperet; dum Deum hominem cum hominibus in hujus terra gurgurtio con verfantem, innumera beneficia conferentem, immò concivem fuum vidit.O dignitatem! ô excellentiam!non fibifolarem,non jovium,non lunarem, aus alium quemvis ex nobilioribus mundi globis felegit, fed terreftrem globum, ut in eo ftupenda magnalium fuorum, operationumque divinarum miracula monftraret, ut qui omnipotenti virtute fuâ ex nihili abyfto produxerat omnia , omnia propter hunc globum, quem fibihabitaculum idem videliceu Terre glo- Deicum hominibus confticuerat, produxifle videretur. Rebumbate omnes ma ximéchtant $A n$. Leli. ctè itaque, mi Theodidacte, terram omnium mundanorum. globorum,obdignitarem finis, præftantifimum judicafti; ita enim eft,\& nos Angelici fupernæcurix afleclx,præ omnibus? mundi globisad ejus confervationem quàm maximè incumbimus; fingulari curâ , \& mirâ quadam ordinum noftrorum. diftributione, juxta divinæ providentiæ nutum \& difpofitio 
nem factâ, omnia in ea adminiftramus, dirigimus, confervamus; quod nullialteri globorum conceflument. Tantâ enim aterna Sapientia curâ in hunc globum incubuit, ut nullam. regionem, regnum, provinciam,urbem, nullamufque ad ipfos privatos homines domum, nullam five brutorum, five plantarum,mineraliumque fpeciem, angelico prafidio immunem, efle voluerit. Uinde coeleftium prafidum tanta eft in hoc globo multırudo, tht non tantum onnium hominum, fed \& pecierum, individuarumque quorumcunque entium numerumlongè fuperet; quii guidem prafides vigili folicitudine ad inimicre \&ata nicze poteitatis infidias, quas in humani generis exicium perpetuo moliuntur, perfringendas, unicè incumbunt, \& ad bonum, finemque ulteimumà Deo deftinatum. conducurt. Theodidactus. Uti abundè Geocofmi praftantiam \& excellentiam demonftrafti,ita pariter-dubiis meis adeo fatisfecifti, utampliừs quicquam defiderare non poffim :; hoc tamen alięuem mihi fcrupulum injicit circa terreftris gløbi Imperfon imperfectionem, quöd videam eum in multis regionibus tanta triones fterilitate fqualefecere, ut prater innnumeros ferpentes, bafili- Gecofofmi fcos, dracones, \& venenefæ faturæ fobolem, nithil reperias?. Nonnulla quoque loca ob defperati aëris, aquarumque inclementiam, deferta \& inhabitata relinquuncur; multa quoque rot ferocium belluarum latibulis. referta funt, ut eanon dicam habitare, fed nè tranfire quidem impunè liceat. Video quoque magnam Geocofmi portionem in hunc ufque diem incognitam, inacceffamque remanere, ut funt ex qux polis fubfunt regiones. Ad hæc itaque ut mihi refpondeas, fupplex \& obnixèrogo. Cofmiel. Ad fingula tibi ordine propofitadubia refpondeo. Et ad primum, yuòd multæ regiones incultre, defertæ, \& habitatore priventur, tancùm abeft ux imperfectionem telluris arguat, ut potiùs ejus inde pretium maximè dignofcendumfit. Tametfi enim hrec paffim occurrant, fcias tamen. Deo's nas. nihil Deum \& naturam fruftra feciflé, quod non in altiffimos tura opefines, hominibufque incognitos difponatur. Quemadmo- $\begin{gathered}\text { rante nis } \\ \text { bil frufre }\end{gathered}$ dum enim Divina fapientia totum mundum contrariorum, fito Bbbb luetâ 
luctâ, licibus \& camicitiis confervarivoluit, ita mala bonis mixta. efle, \& confóna dillonis aptâ connexione: fociata: voluit, fine. quibus:mundus confiftere minimëpofët, ,utpote: harmonico fuo temperamento deftitutus. Etiamfíigitur defertainveniantur fabulorqualida; \& in imenfäm longitudinem porrecta; qux juxta hom inum fenfum \& judicium otiofa \& inurilia: videantur; ficamen intenioreminfra pofitam deferto fubterraneam. ftructuram viderent, quemadimodum füo tibi tempore oftendam; forfanmiraridefinerent; \& conceptam de fimilium loNistum in corumanucilitate:opinionem deponerent. Nullum: eft adeò natura: in natura' grande malum, quod non adjunctum fibi habeav. bonum;,velutiantidotum quoddam, quo viciniores regiones" mperitur. roborentur, $\&$ c in effefuo conferventur. Miraris deferta, fed nefcis utilitares, inde provenientes. Theodidactus: Eas, iraqueut explices,obnixè rogo: Cofmieli. Cümfabulofa deferca ut plurimüm ob ficcitatis veliementiam aduftior is aëris finc;

In 1 gyypto flantibus: Eentis: piubie: impediun tur ä̈rque ficseficit:

In: Etbiopianaquas ruminun. dationes. putredinis Q beneno. jorwm ani matium cosufa:

Defertorumutili: tasi, obnoxialbominibusefero. cirianimabiatibl las ritantia: primö hocutilizatis conferunt,ut nubes nimbis gravicas, qua regionjbus vicinis imminent, ficcitate fuấ confimant; nè humoris abundantiâ cum magnâ h้ominum animantiumque

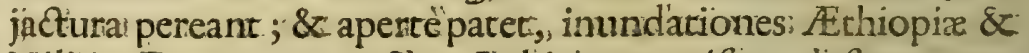
Nili in A gypto non ceflare; Lybicis coeterifque defertorum. ventisnon firantibus, quibus tamen exortis , mox imbres \& nimbi ceffänt,atqueaër priftina ficcicatii reftituntur, diluviifqueimminutis,ceflàt irundatio. Secundö,magno 压hiopiz: incolarum commodo tot defertis tota regio circumdatur: culm enim ex frequentibus fluviorum ingentium inundationibus magna humidicas nafcatur, ex humiditare verò indigefta. terra perniciofäs generec putredines ex quibus omnis generis". fenpentes, dracones; bafilifci,cxteraque monftruofa animalia, toxico plena propullulent,ex integras regiones circumfitas? venenifüi virulentiâ inficerent, hominumque habitationi inepcas redderenc,nifi naturali quodam inftinct ', mox in interiores defercorum receflus, ceu in fidam eorumque natura: confentaneam ftationem féfe reciperent. Quod idem de Afix; carerisque America defertis dictum velim; atque adeo vel ipla 
ipla deferta à natura in bonum incolarum circumiacentium. contra com̆une omnium judicium, deftinatavidentur. Accedit hilce, quöd pleræque ferociumbelluarü;utifunt Elephantes. Leones, Tygrides, allix que hujus gener is bellux znaturali quačă inclinarione defertas \& vaftas : petant Colieudines, utpore ab hominum infidiis in iis liber:iores nè in cultis'locis facundiori provencu propagatæ, extremum hominibus animalibufque exrerminium \& exirium ad cifcerent. Nèverò deferta per- Solitwiini petux:Aterilitacifine ullowemolumento confecrata cenfeantur, now huma. Natura femper in hominum ufum, eximium quidpiam in its pretio $^{2}$ pradtacere ?tatuit; in nonnullis quidem bdellium, \& manna produchnt. nobilifimum, refque raritate preciofas, ut in arenofo I artarix deferto'R habarbarum, in aliquibus palmas dactylisfacundmimas; non defunt qux volucres, quadrupedé que ex imiasalant; irautnihil propè fre, tam hominam judicio fqualidum:, quod nonfua conferac emolumenca. Ecce paucis tibi defcripfi de-

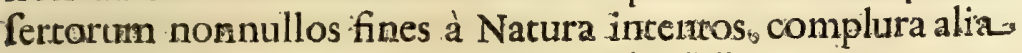
allaturus nifite impatienté morx ad alia feftinantem coganofcerem. Theodidačus. Jam verè video extua tamexima relatione, Naturam minimè ut novercam incufandam, quæ tartâ providentiâ omnia conftituit, onnia tam exactâ trutinâ ponderavit. Sedperge,miCormiel, reliquosmihi proporrorum dubiorum nodos folvere. Cofnzel. Alcerum quod tibi itapores ext isputridis afcrapulum movebat, erant loca paludibus \& aquarum tta-iquis.ac ftagnantium fqualore oppleta;quæ cùm pernicioforum vaporum gnis ä̈rem fuligine aërem perperuò inficiant, ij innumeras quoque in ac- bomines colis infirmitates ut phrimü accerfunt, ut proinde hujuf modi aquarum colluvies fruftra in natura rerum conftituta videatur. Hoc dubium turm prorfus nullam difficultatem haber. Nè quafo, mi Theodidacte, naturamaccufes, quafi minùs fe benignam erga homines in tanto locorum fqualore exhibuerro. Paludumbs Non elt id natura vitium, fed hominum otioforum neglectus' squalida. \& ofcitantia qui cùm pofient iftiufmodi malum removere, rum aquaid tamen nefcio quâlabor is imparientiâ,vel fumptuum magni- natura, fed cudine abfterrici, confultò omittunt. An nefcis, totam olim bomines $\mathrm{B} \mathrm{bbb}_{2} \quad$ Egy- canfa furte 
Matura nork ince(anda, $u b$ interfenit defect us. baminum.

Eg yptum paludibus tectam, hominum tamen induftria, \& impigris.laboribus, aquis in certoscanales corrivatis, non tantùm aquarum diffufione liberatani, fed \& in cocius orbis fertilifimam faluberrimamque tegionem evafife? idem de alis ftagnantium aquarum fqualiditate defadatis Geocolmi parribus fentiendum eft; hoz enim pacto terra ab aquarum tyrannidelominum:labore vindicata, \& fecundifimos fundos, \& fubtractâ vaporum materiâ, falluberrimum aërem fubminiftrarec. An non tota Germanix inferioris ora maritima, olim maritecta fqualuit ? qua tamen pofteris temporibus in omnium populofiflimam, \& quæ f́lendore ac magnificentiâ. nulli cedat,regionem evafic.. Innumera hujus.rei exempla non tibi in tho deerunt Geocofmo, ut proinde dubiumà te mihr propofitum, fuaptè fponte cadat. Quare ad majoris momenti: dubia te accingas, nè tempus in rebus pafim obviis teramus. Theodidact us. Verifima, qua dicis, invenio, \& fat jam novi,naituram non femper incufandam, ubidefectus non nifiab hominum neglectu depender; quare paulò majora \& reconditiora proponamus. Nullo non tempore ingens me defiderium tenuic; cognof́cendi earum partium ficum, qux immediatè polis: mundifibbrtant. Novi multos multa de is retulife;'quia tamen nemo mortalium repercus eft qui cò penetraverit,quicfcere non poffe videor, donec nonnullam à re de iis notitiam, Terraqueiacquiram. Cofmiel. Ad profundum Nature arcanum apeglobi con* riendum me adigis, \& forfan hucusque incognitum. Sed ut Aitutio in- melius mentem meam comprehendas, rem ab ovo, ut dici fo-
ztrna. let,ordior.. Conditrix fapientia ita Geocofmum hune conftituic, ut à polo ad polum fit coag mentata, faxosâ concatenatorum moncium ferie. Tellus, fivead firmiorem totius confittentiam, five ob particulares naturæ fines, perindeeft. Non, ut multi, putant, torius globi. ftructuram \& fabricam, inrus folidam, \& conftipatam, quin potiùs innumeris canalibus perforfam, immenfis receptaculis refertam effe tibi perfuadeas velim; quorum anfractuum nonnulli funt in univerfalesufusà provida $`$ aturâdeftinati, quidam 2 d particulares, ut poftea o- 

que polo fubfunt, hominum quidem habitationi inepti funt, gionum adeotamen toti Geocofmo uciles, ut is.fine illis fübfiftere non comf itutio. pofiic.Nofti,Oceanum continuo fluxu\& refluxuagitari,nunc ex ortu in occafum, nunc exauftro in Septentrionem? Scias i- Exponitur taq;, talem efle partium fuppolarium conftitutionem, uc feme- ratio fitia Atri fupra Horizontem morâ dominunte Sole, ingens vapo- xus maxiso rum copia furfüm tollacur, undemare circumfitumaquarum.

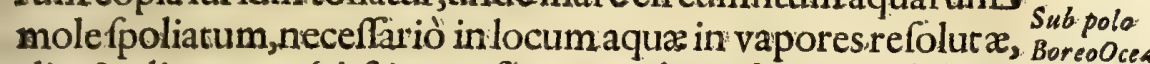
alias \& alias.aquas.fubfticuere fátagit, unde undequaq;ad fe cir- nus fub bcumjecti Oceani aquasà natura fibi inditâ vi trahic, qux in im- mergitur ,

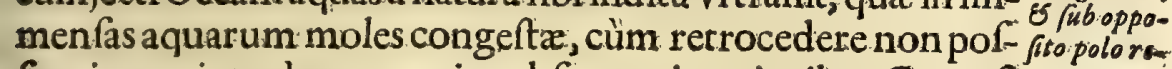
fint, ingenti quadam voragine abforptx, interioribus Geocof-gurgita-

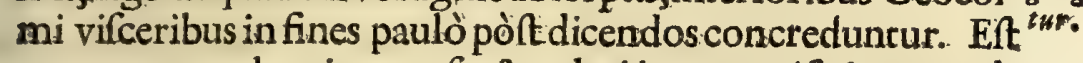
autem vorago hæc immenfa, \& veluti ingens orificium quoddamaqui - ductûs fübterranei principalifímü, per quemiaqua in occultas terræ cavernas, accacas latebras, \& naturæ fubterranex conclavia derivata, tandem fub polo antarctico exitum fuum invenit : canális veró hicà polo ad polum conftitutus univerfæ rerra.profunditaté metitur. Oceanus itaq;in. dicta voragine, quam aretico polo fuppofitam diximus,abforptus, per memoratum canalem aquas devoluens, poft expleta.arcanioris Natura receptacula, atq; decoctionis defeccatione peractâ, per polo antarctico fuppofitarum partium orificium denuo regurgitatur : eft enim hoc fimile prorfus ei ${ }_{n}$ quod fúb arctico exiftit voraginis orificium, ita ue quod voraginis arcticx orificiumabforbuit, id orificium antarcticæ voraginis revomat, ut proindenonampliùs mireris, concitatifimü ex Auftro in SeptentrionemOceani fluxum:Et fluxus quidem abarcticoincipit polo, ab antarctico verò refluxus. Quòd veròn nemo morta- Suppolares: lium dictas plagas viderit, aut adierit, caufa in promptu eft, plage ino quia fluxus maris in memoratis partibus adeo vehemens eft, ue nullus tam validus ventus dari poffit, qui, ubi naves in hunc xeftum inciderint, ${ }_{2}$ eas retroagere valeat. Si verò aut datâ ope-

$$
\mathrm{Bbbb}_{3} \mathrm{râa}_{2} \text { vel }
$$


rávil calu hamines in dictos tractus ventorum impetudelari fuerine; iis mox ir revocabili fevientis naturæ contumaciâ in abyllum raptis, neceflariô pereundum eft, nullo evadente tancx perditionis ac mina nuncio. Theadidactas. Planè admiranda:\& vix audita mihi narras, Cofmiel : \& jam vera eje Geographo. video qua tum fuprà ab Hydriele audivi, rum Geographitux rum reta- relationi haud abfimilia narrant de Monacho quodam Oxotio de Mo-

nacho Oxp- 1

nienfl, de.

que ali is

partium

illarum inirabi nienfi, arte magicâ ad partes fupuolares delato, ubi dicicur rapem immentin 33 Leucarum in circuitu imvenifi, ifub qua infunuatus per quatuor Euripos Oceanus Septentrionalis, per ingentem voraginem abforbeatur. Teftancur quoque vehenentifimum aquarum verfus polum tanquam in cenrrum nicentium cuftim, quotquo in vicinioribusinfulis infelicis" orafedem nact funcincolx; inmò \& Bacavi hunc maris concitatifimum motum nullo etram ftante venro obfervarune. Ex polo verô antarćtico aquas à polo arctico.abforptas reddi, celerrimus pariter ato; impetuofifinus verfus.Boream Oceani âtus fer fuperq; declax quem manioni eorum, qui hujusmodi partes explot are tentarunt, confenfu, hujus temporis Neptuwi teflantur, quemque adeo impetuofum ajunt, ut etiamficontrapofito validifimo vento incitentur, nulla tamentam valicla navis fit, qux impetum fuftinere poffic ruenciumaquarum; ut prónde hinc colligas, nemini ob xfuantium fluctutum, ac veluri ex monte quodam prxcipitatorum contumaciam, dictos tractus adire conceflum eflè. Cofmiel. Quidquid fit de Monacho Oxonienfi, \& de ingenti rupe magnetica; qua tibi dixï,ca non aliterfe habere tibi perfuadeas : quare fi quidcirca dicta dubia animum tuum pulfer, id liberè propone,ut ab omni ambiguitatis remorfulibereris.Theodidact. Utiomnia Dei opera incomprehenfa funt, \& ultra omnem ingenii captum remosa, ita nihil aliud à te defidero, nifi ut aliquo tantùm luminis radio, circa profundum hujusmodi naturx arcanum, intellectum meum imbuas. Qurero itaque primò,quodnam fit principium motus Oceani, id eft, cur aquarum abforptio orte potiùs poliBoreatis, quàm Auftralis incipiat? cum. cadem 
naturalem abforptionis imperum ruentium aquarum pondere plurimùm promovere: hinc fit,ut expulfæ per polumter $a$ antarcticum aquæ, atque in omnem circumferentiam diffura, denuò fuas verfus polum Borealem femitas teneant, qux tametfi variis occurrentibus obftaculis impediantur, alibitamen fluxum recompenfant. Theodidact us. Sed cur frequenti cbfervatione notatum eft, inOceano Athlantico, qui fluxui aquarum à polo Aufrali exoneratarum verfus polum Borealem omni impedimento vacuam viam praftat, tantum abefic TIuxus 6 ut verfus polum ruere videatur, ut potiùs contrarium obfervarefsaxus in tum fit? quamnam hujus reirationem affignas? Cofmiel. VaOceano 6a- rii in marimotus confiderandifunt. Primus, naturalis \& cirrii. cumvolutionis, de quo hîc potifimùm quæftio eft. Secundus,fluxûs \& refluxûs quotidiani, qui plurimùm naturalem. motum promovet. Tertius reflexionis dicitur, five currenrium, qui merè accidentalis eft,à cercorum ventorum impulfu certis anni temporibus dominantium caufatus; \& hunc poriffimum Nautx obfervant, \& folam extriniecam maris fuperficiem commovet, \& reflexionis quoque dicitur, eô quòd ad liccora continentium infularumque illifus, Oceanum in circulos agat. A tque hic ent motus de quo tu dubitabas, qui nihil commune habet cum motu circumvolutionis, cùm hic totam $\mathrm{O}$ ceani fubftantiam in circumvolutionis periodum agitet. Etiamfi enim aqua infuperficie ex Borea in Auftrum proruere videatur, tota camen fubftantia aqux ufque ad fundum naturis fub polo rali fuo curfu Boream petit. Eft \& illud confideratione diBerce. gnifimum, quòd hujulmodi particulares in vicinis fuppolaribus partibus voragines complures conftituantur,quibus aqua abforpta, \& per varios ramos in unum corrivata, impeturn ingenti pondere aquarum in magno canali jam incitatarum, augmentet, atque adeo idem in Geocofmo contingat, quod in fanguinis microcofmi perpetua pericyclofi \& circumvolutione contingere experientia jam noviter docuit: eft enim naturæmotus perpetuus,ad perpetuandas in Geocofmo operatio. nes fapienti fanè naturæ confilio inftitutus, qui fi vel minimùm 
ab operatione fua ceflàrer, tota è veftigio natura languerev, arq ie 11 c nfurfonem omnes mundi officina deducerentuL:

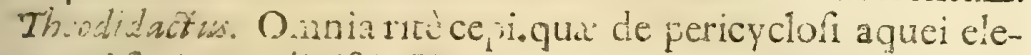
menti fipienter dixifit. Hoc unum me torquer, urrum canalis ille, five magna Geocolmi vena,per ipfum terræ centrum du- Caralis cacur, an non? Cofmiel. Non tibi inagineris velim, canalem fubterras hunc diametriinftar per ipfum centruin terra extendi; hoc e- neus an per nim neceflarium non eft; fufficit, ut portea cibi demonitrabo, trrrac cen-

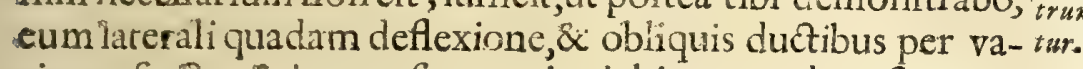
rios anfractus, \& immenfre capacitatis hiatus,tandem finem evolutionis fur attingere. Exqua quidem laterali deflexione meatuú, \& fluxus facilior redditur, \&exonerationon tam violenta, quemadmodnm ex Hydroftatica tibiconftat, accidit. Theodidact us. Ulti dífcurfus tuus veritati quàm maximèconfentaneus eft, ita eum quoque ambobus, ut ita dicam, brachiis amplector. Sed rogote, ut explices, quis tam ftupendx pericyclofeos in natura rerum finisfir? Cofmiel. Nofle debes, mi Theodidacte, aqueum elementum, quemadmodum audifti ex Hydriele, uci eft veluci fperma quoddam Geocofmi, ita nulla portio effe poteft, qux non ejus indigeat fubfidio: latet enim. in aquei eiementi centro fpiritus omnium Opifex, qui qui- Aqueum dem non nifi per continuam pericyclofium feu circulation $2 m$ elementume in intimis terræ vifceribus, veluti in utero quodam, per fubter- $r a$. ranei ignis calorem digeritur, \& in variorum mixtorum compofitionem preparatur. Hinc aqueum elementum, cujus fons Oceanus eft, univerfam telluris fuperficiem ambit, ut nihil fiv ex terreftrium continentium portionibus, quod non néceffarium ex eo nutrimentum in fe derivet, veluti magneticâ quâdam viattractum. Et quoniam generationes \& productiones rerum in humido \& calido confiftunt, certè necerfariú fuit, ư aqueum elementum per fupradictam pericyclofim primò Solis calore in externa fuperficie fpermaticâ mundi virtute imbueretur,quod deinde in fubterraneis culinis calore ignis hypogari digeftum, per terræ canales in omnia Geocormi membraad generationes rerum diftribuat. Hinc quemadmodú in C c cc Megaco- 
Sol E Lu: na, (unt:gncum'es. aqueum corpus, ad aemperiem murs laconeitrandum

Aquaco suesdat. mniafar.

570

Itinerarium II. Dialogus II.

Me egaco Creator omnium Deus Solem \& Iunam, id eft, i-

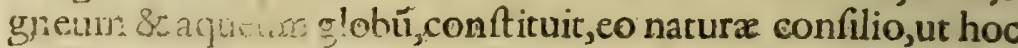
pacto urius alter ius impetum frangeret, \& ad temperiem reduceret ;itu in Geocofino 1 grrem \& aquam fimul efle voluit ; aqua momi $\mathrm{l} m$, nè fubrerrane i ignis $x$ ftu \& ardore omnía in cinease ¿c favillas converterentur ;ignemverô,ut aqua digefta. per calorem, ${ }_{2}$ permaticam vim ex centro eductam, \& generationibus rerumaptam exereret :atque unum alterum dum fimul foveret,utrumque in perpetuo hoc operationum tenore confervaretur. Nam uti Hydriel te docut, igñis fine humido. ejus nutrimentro uticomfiftere non poteft, ita nequeaqua fine igne: illa enim in vapores fpiritibus turgentes refoluca, omnia interiora ufque ad ipfäm terræ fuperficiem, fpermaticâ fuâ virtute \& efficaciâ. imbuit, quemadmodum fufiùs fúo loco \& remporete docebo: Eft prærerea aqueum hoc elementum ita Geocof mo receflarium, ut nifi illud ubique reperiretur, omnia. fterilitaie \& fqualore deficere necefle foret. Hinc illud influxu luminarium in reciprocos æffus concitatum, praterquàm quod univerfam tellurem ambiat, per occultos quoque meatus.in intima mortium vifeera propulfum, ad fontium, fiuminum lactuunqueorigirrem conftituendam fefe infinuat: Fontes in innumeros rivos divaricati, univerfam fuperficiem. facundo humore rigant, in animantium, plantarumque vita: fuftentand $a$ fubfidium: adeoque nullibi id deeft; fine quo nilhil vivere poteft. Habes, mi Theodidacte, defideraros fines pericycl'seos, \& elementiaquei utilitates; quas quidem opportuniùs tunc tibi exponam, ubite paulö profundius in Natura adyta introduxero. Siftamus itaque hî́c, præfertim cừm de hac ipfa materia fufiffimam ab Hydriele inftructionem acceperis?. Theodid Summẫ animi mei voluptate ratiociniun tưm audivi,ut proinde quid' eicontraponam, non reperiarm. Quaremihimodö explices velim, cur montium carenæ à polo ad polom conftitutx fint?nefcio enim quodna m naturx my fferium Montium fubeolateat. Cofmiel. Rectè conjecturafti; neque enim com- atena cur policio hujufmodi terræ tantüm propria eft, fed\&omnibus reliquis 
liquis mundi globis communia:omnes enim,ut in lrinerario dißpofite calefti cibi expofui, fuam à polo ad polum corporis confticu- int a polo tionem habent ; atgue hic eft magnecifmus illenatura potenrifimus, quoomnes mundi globi pertedum habent, \& indeflexibilem in determinatos mun di limites fitum \& difpoficionem, eamob caufam ä provida naturæ fagacitate iis inditam, nè incerta volubilitate , omnibus mundi juribus confufis", fufque deque Univerfi verterecur machina. Nam fecundüm hunc irmmutabilem ficum optimè fefe invicem fovent, \& ad influxus reciprocos communicandos, unus alterum follicitat; quod minimè fieret, fi globorum poli incertâ \& inftabililegehinc inde, prout fors ferret, fluetuarent. Cùm itaque omnes, ucidixi,mundi ghobi, tamerfi perennimotu verfatiles", hoc ficu gaudeant; Geocofmus tamen pre omnibus aliis'hoc fitu gaudere debebat. Cùm enim naxurafolum eum fixum effe volueric, eum fub polarifitu extendi neceflarium fuit, particulari quadam magneticâ vi ad hoc práítandumei äNatura inditâ, nè confusâ volubilitate in incertum fluctuando, mutaris juribus irreparabili ruinæ fubftarer, omnemque hoc pacto fuperiorum globorum influxum impediret;quod fieret, fi globus hoc magnetifmo veluti fræen quodam non cohibirus, incertâ \& fortuitâ fluctuatione oberrareț quæ omnia alibi fufiùs à te expofita funt. Atque hoc primum eft. Alterum, quad Telluwis of montium à poload polum concatenationem atrinet; fcias hoc fatura factum fuifle, quia fabrica conftitutio id jure veluti quodam. "quabs. naturali requirebat. An nefcis, in Sphæra máterialicirculos ita difponi,utin polis fefe interfecando firmiorem confiftentiam nancifcantur? Etfi enim alii circuli ad $Æ$ quinoctialem paralleli conftituantur, ii tamen confiftentiam obtinere nom poffunt, nifi meridianis circulis ad firmiorem partiumnexumfibi invicem committantur. Idem deGeocofmi compaginatione dictú velim, ec fi in terrena compagenon adeo fub Mathematico rigore confiderari debeant; habent enim fuas fimbrias \& plicas montium catenæ Boreo-notiæ, quibus longè latèque diftenduntur, neque eâdem femper altitudine eminent, fed in-

$\mathrm{C} \operatorname{ccc} 2$ fra 


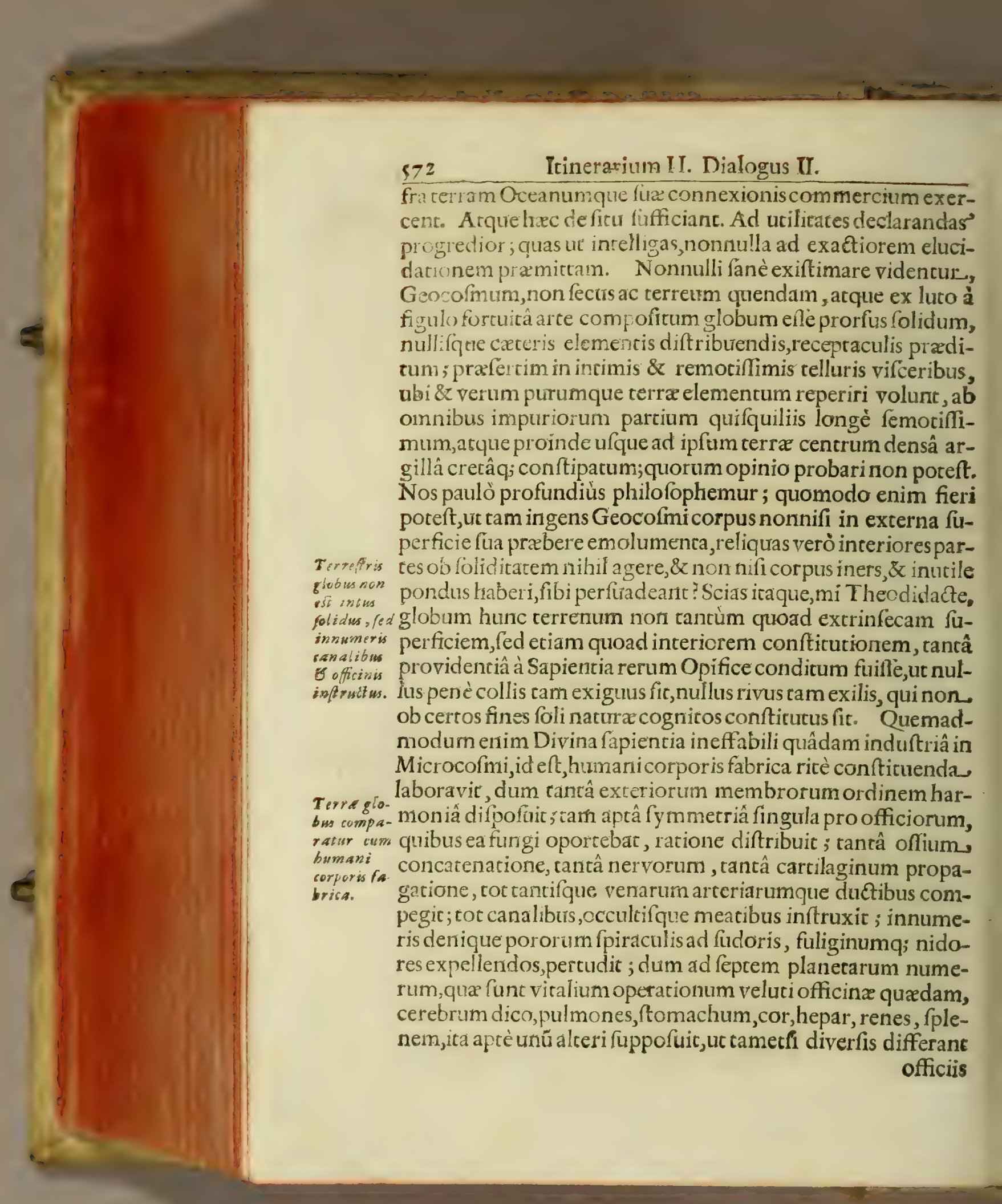


officiis \& muniis, in unum tamen fcopum, qui eft hominis confervatio,unanimi confenlu confpirent; quxe profectò tantâ fymmetriâ difpofita funt, ut qui Deum nef́cit, is eum in tam. in comprehenfibilis fabricæ contemplatione ignorare non poffic. Neque fortuitum aut cafuale cenfendum eft, quod tantâ fapientiâ juxta ac prudentiâ conditum cernitur; ; atque adeo rectè huc quadrat illud Philofophi digniffimum axioma., opus Nature, opusintelligentie. Cerrè non minori induftriẩ eirca Geocofmi fabricam Divina fapientia lufit: primò enim . univerfam molem ad firmiorem confiftentiam oflảturâ quâdam, id eft, diverfo montium connexu inftruxit, cujus extrinfecam fuperficiem pratorum, fyl varum, valliumque efflorefcentiâ herbaceâ, arboreâque, vèluticopiosâ pilorum foeturâ veftivit, quam \& innumeris fluminum venis, contra ficcitatis ${ }^{3}$ fterilefcentiam variè diftributis digeffit; in interioribus verỏ vifcerum penetralibus varias neceflariarum operationum officin as Vulcanias, Æelias, Neptunias conftituit, in quibus per Offrine elementorum virtutem \& efficaciam femen Naturæ ad in- nees rentam foeturam digereretur, digeftum per innumeros canales porofque terræ vapore \& exhalatione veftitum egereretur, ut ubicunque aptam difpofitamque materiam reperiree, ibi varias rerum formas fixatione, coagulatione, calcinatione,putrefactione, fimilibufque operationibus induceres, adeoque eam mineralium varietatem produceret in interioribus terra vifceribus, quam naturx fcrutatores fatis mirari non poffunt. In exteriori quoque fuperficie per innumeros occultifimofque meatus, quibus univerfum pertufum eft telluris corpus, hîcaqui-ductus panfpermiâ quâdam refertos, virtucum occuliąrum egeftores, illic Vulcanios caminos, veluci fuliginum exhalatores, fapienter ordinavit; adeo ut nihil penè fir nequein. Megacofmo,neque in Microcofmo, quod fecundùm analogiam quandam in Geocof mo non reperiatur. Qux ideo tibi fufiùs deduxi, ut oftenderé, Geocofmum non tantùm quoad extrinfecam, fed quoad intrinfecam conftitutionem ita fabrefactum, ut à fuperficie extrinfeca ufg; ad ipfum centrũ, querind-

$\operatorname{Cccc} 3$ modum 
S. Cla Co- 574 574 Irinerarium II. Dialogus II.

ci, mi fa- modum tibi poftea oftendam, per omnia ingentibus canalibus, bricaquo- immenfis crypris, ignubus, aquis, aëre, ventoque inftructis, quæ adinterio-
rem conffitwtionem. rafemen, uti dixi, ab opifice natura ad innumerabilium rerum generationes digeritur, fummâ anè perfectione,\& ideâ abfolutifimâ, cum ineffabiliquadam arclicecturx fymmetria conftitutus fit. Theodid. Verè,mi Cofmiel, magna \& incomprehenfa narras,qux tamen ita rationiconfona funt, ut nemo fit quilis contradicere aut poflic, aut debeat. Perge modoulteriùs nonnullos mihi fcrupulos eveliere, quæ \& plantarum,\& animalium, quam fpectannus varietatem concernunt ; utrum videlicet ea fux naturalis conftitution is rationem ex Geocofmi vifceribusforciantur,utrum ex propriifeminis virtute.

\section{A P U T III.}

\section{Quomodo ex interioribus nature reconditoriis Permaticis plante E' animaliaviziant; $\Xi$ unde originem fuam trabant?}

$\mathrm{T}$ Heodid. Unum, mi Cofmiel, abs re obnixè efflagito; $\mathrm{Ec}$ eft : cùm infinitam ani mantium multicudinem ubique intuear, \& telluris quidem.fuperficiem innumerabili quadrupedum, volatilium, aëreum, aqueum, natatiliumque regnum, omnes infuper elementorum diftrictus infinitâ infectorums varietate refertos contempler, ut mihi, unde fumma illa varietas originem fuam trahar, undetanta formarum fpeciedifferentium diverfitas, unde vires illæ mirificx, ingenii dotes, \& induftriæ animalium, cæteræque, quibus ditata funt, proprietates prorfus paradox $x$ emanent, exponas. Cofmiel. In eam. me, Theodidacte, argumentivaftitatem trahis, quod non dicam paucis, ut tu putas, verbis, fed nè multis feculis magnorum Tomorum editione prodignitate fatis explicaripoffic. Tunc̀ materiam illam, quam ab immemorabili tempore innumeri 
de natura animancium fcriptores exhaurire non valuerunt, adeo brevi tempore, paucifque verbisexponi poflè exiftimas? Theodidact us. Eam de te, mi Colmiel, exiftimationem concepi,ut id exiguo temporeà te præftari: pofféputem, quod fupradicti fcriprorescaligine intellectus obvoluti, multis annisconfequi non potuerunr; tibi enim natura claves ab Opifice fápientia concreditas jam dudum novi, \& nihil tibi earum resum; quæ in abdito naturæ finu delitefcunt, imcognitum effe, jam frepe frepius experimento comperi. Cofmiel. Agedum, itaque, mi T heodidacte, utramquearrigito aurem, omnes ingenii nervos intendito ad ea qua dicturus fum. Et in genere quidem tantüm tibi nonnullarum rerum oftendam veritatem, complura folùm indigitaturus, plurimorum verổ rationem, intermiffurus, utpote qua ingenio tho fuperiora funt, \& ad. qux humani intellectus caducitas pertingere vix poffit. Theod. Tuo me magifterio plenẩ refignatione fubmiteo ; quod in omnibus tuis beneplacitum füeric oculis, ex fëquere: Cofmiel. Alriins itaqueargumentum ordior . Dixicibi,fi meminifti, in itinere noftro cœelefti, Deum omnipotenti voluntatis fux efficaciấ primùm chroticam maffam ex nihiliabyffơ creaffe; hane autem chaoricam maflam nihil aliud, quàm rudem,confufám, indigeftam que fuife rertm producendarum congeriem, five $\mathrm{Cb}_{\text {a ot ica }}$ elementorum hylen quandam, ä primocreationis fuxe inftan- maffa con- $\mathrm{fupata}$ moles. ti rerum omnium in univerfo producendarum panfpermati-

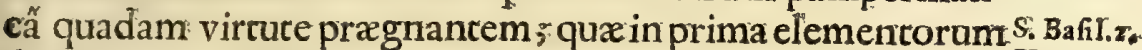
divifione, ineffabilidivinæ vocis potentiâ \& energiấ percuffa' ${ }^{H}{ }^{\prime} \mathrm{Cxam}_{\text {。 }}$ in eam emerfit rerun diverfitatem, quam in mundo fatis admirari non poffine mortales. Theodidactus. Quomodo tam, chaos;'Aineffäbilis elementorum divifio facta fit, noflecuperem. Co $f_{-}^{\text {bulenfis in }}$ miel. Voce divinẩ intonante: Fiat luxx (quazquilem nihil a- guatiter

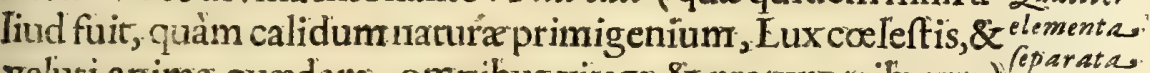

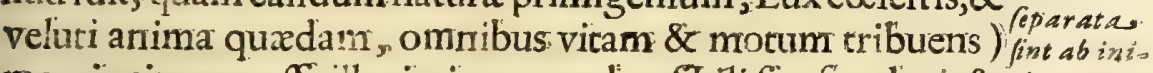
mox incitata maffa illa, in incomprelienfibili fio fqualoris \& tio rersms confuínonis chao abforpta, benigizo illo primigenix lucis ca- ayid fis 


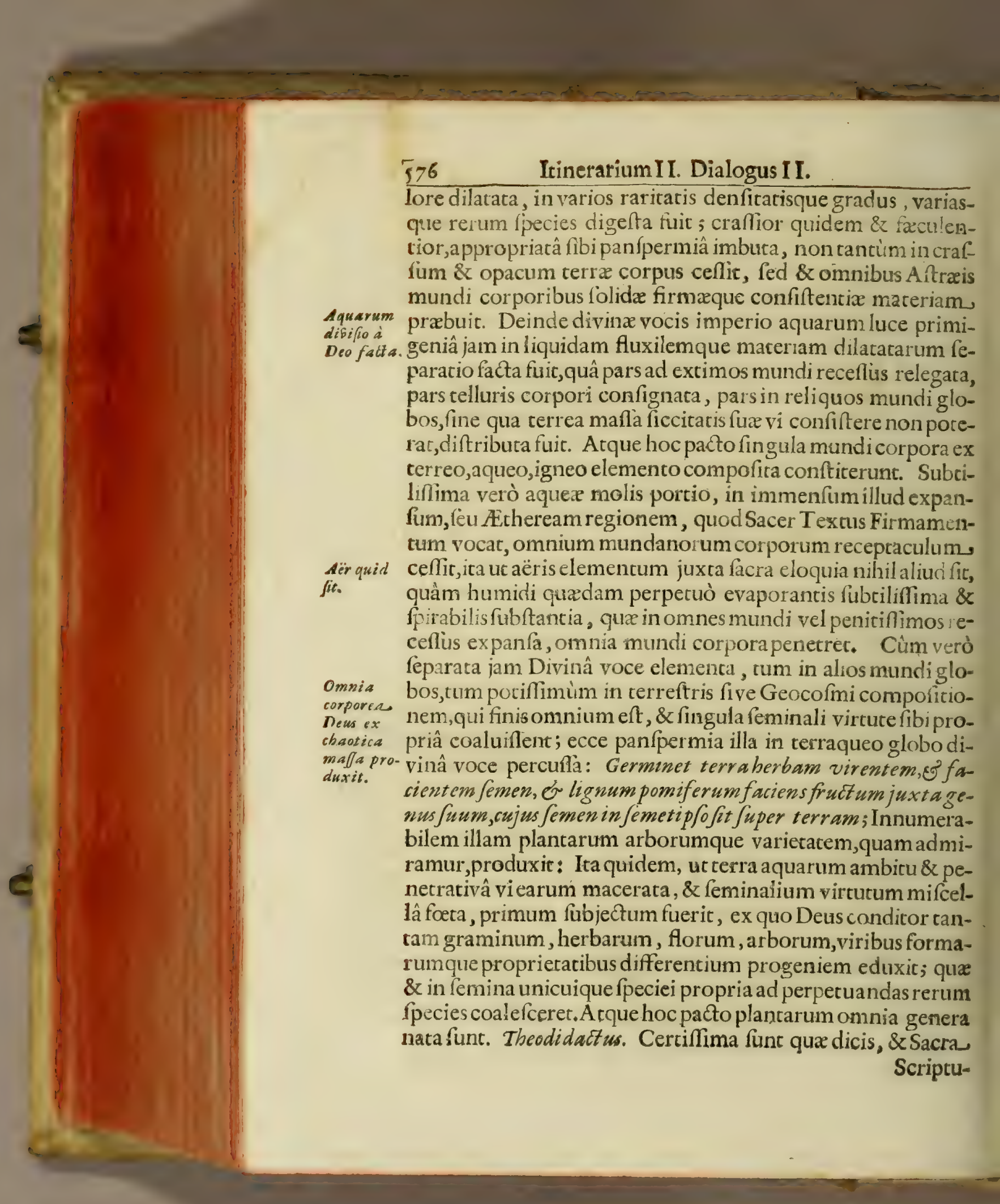


Scriptura id apertè docet; fed noffe defiderarem, utrum tanta plantarum varietas ex femine pravio in elementis delitefcente, urrum de novo in ipfis plantis femen creverit unicuique plantx proprium: ita enim facer Texcus innuere videtur. Cofmiel. Cùm ex Elementorum commixtione omnia mundi Planta ex corpora conftent \& componantur, certum eft \& herbas pror-quosreata. fus ex nihilo crearas non efie, fed ex terra \& aqua fimul juncta, \& f́permaticâ iis concreatâ virtute imbuta, veluti ex praxexiftente fubjecto de potentia, feu virtute, qua omnia continebar, in actum eductas fuine. Siquidem Opifex verbum, præter coelum \& elementa, feu lucem primogeniam, aquas \& terram, nihil corporeum omninò de novo creavit, fed omnia ex præexi-creata, oftente jam elementorum materia, veluti in principiis produ- ${ }^{\text {mnium }}$ xit, tuti ipfe Sacer Textus fat fuperque notat : nam fic dixit rum priseDeus: Germinet terra herbawi virentem. Certum eft, in ea jam iipia, 8 fpermaticam vim præextitife, qua herbas produceret, cùm matoxia nemo quod non habet, dare poffit : fruftra enim creaffet materiam, fi in ea non virtualiter excitiffet, unde reliqua educta fuif- Animaliă fent. Pater id quoque in productione reptilium, \& volucrum, productio dum dixit: Producant aque reptile anime viventis, \& volatile facta fite. Juper terram, fub firmamento cali. Creavitque Deus Cete grandia, at que omnem animam viventem at que motabilem, quam, iroduxerant aque in Jpecies fuas, Es omne volatile fecundum genus fuum. Eccehîc apertè docetur his verbis: 2 uam produxerant aqua in pecies fuas, \& omne pifcium genus, aviumque fpecies, immediatè ex aquis veluti ex fubjecto præexiftente producta fuifle. Ergo jam femen in is præextiterat,quo in tantam fpecierum varietatem, voce Dei percuffa erumperet. Et iterum ex verfu 24 Producat terra animam viventem in gene-Omnia car.

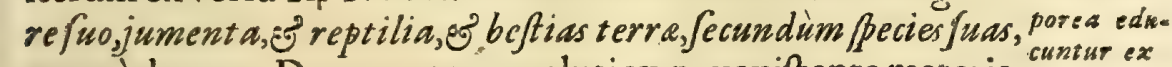
apertè docetur, Deum ex terra, veluti ex præexiftente materia, untur tex tam omne genus animantium produxifle. Terra autem ad idim-quamex

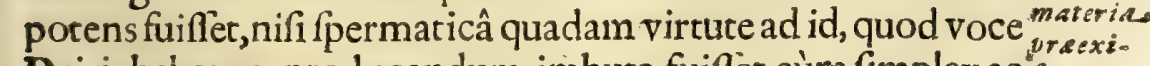
Dei jubebatur, producendum imbuta fuiflet, cum fimplex ac fente.

$$
\text { Dddd nu- }
$$




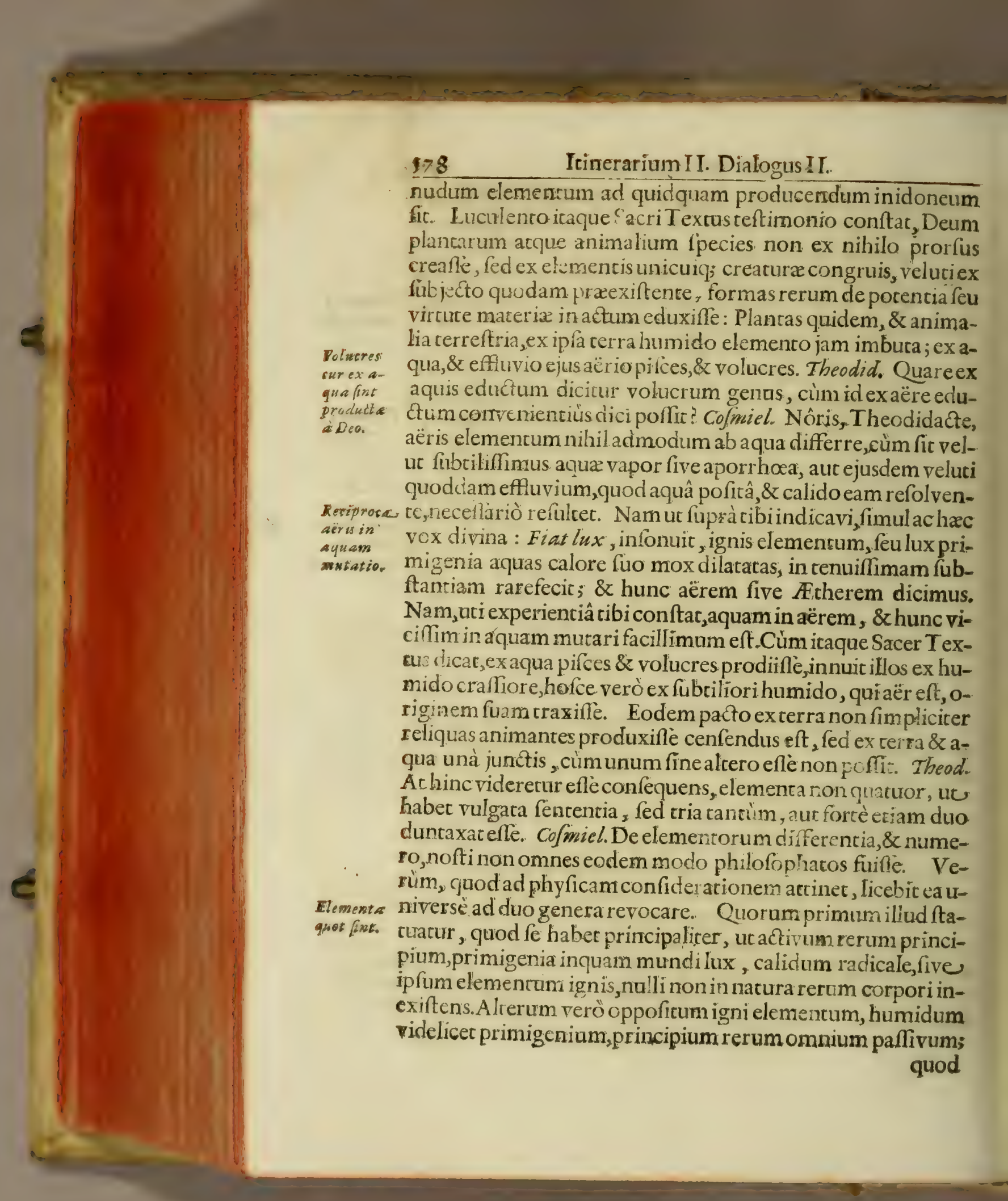


quod tamen in pluresquali fpecies jixca diverfos fubtilitatis auc crafliciei gradus dividatur. Sic enim craflior \& foeculenrior cjus humidi portio eft veluci fedimentum quoddam, in. principio rerum in terreftrem fubftantiam coalefcens, interræ elementum evafit; at verò media aquæ naturam obtinuit; fubcilior verò ejusdem portio calore lucis primigenix evaporata, in aërium five athereum evafit elementum, tantò fubtilius, quantòà fupernælucis primigeniæ calore \& ficcirate, ab humiditate fuperflua magis expurgatum, digeftumq; fuit. Sunt igitur, in genere \& univerfum loquendo, duo principaliter inter fe invicem diftincta elementa, calidum, \& humidum: quo tamen humido, juxta variam fubtilitacis aut craffitiei rationem, in cria alia fubdivifo, vulgatus ille elementorum quaternarius exurgit. Theod.Sed velim ampliùs explices, Cofmiel,quomodo qua fuperiùs dicta funt, cum Sacro Textu Genefis I. congruant, ubi de terra fermo eft, quafi elemento per fe confiftente, \&à reliquorum admixtione feparato. Co/miel. Scias itaque, Sacræ Scriptur ita comparatum effe, ut veritas ejus fubinde non poflit, nifi per diverfos fenfus exprimi. Quando itaq: dicit Sacra pagina: In principio creavit Deuscolum, \& terram: Terram, hoc loco, non fumendam putes eo modo, quafi jam feparata $a b$ omnibus aliis elementis creata extitiflet: nequaquam; fed terra continebatur in illa chaotica maflà, in magna illa hyle, inani, iterili,\& vacua, aquarum involuta abyllo. Nam fpiritus Dei ferebatur fuper aquas, veluti incubando focundanseas, \& fpermaticâ, ut ita dicam, virtute impragnans; \& deinde in divifione aquarum dixit Deus : Congregentur aque in locum unum, \& appareat arida. Undeluculenter concluditur, materiam illam aquis involutam, polt detectionem tandem veluti quoddam fedimentum aquæ, terreitri fubftantix deftinatum, in mirificam illam Geocofmi architecturam, \& fabricam coaluifle.Quando itaque facra verba dicunt, In prin- Terra ine cipio calum छ terram creat am fuiffe, non id intelligendum pu- principio tes velim de puro elemento terreno, fed de globo illo terreftri, creat $a, \varepsilon$ cujus jam rudis indigeftaq; moles, in abyfo aquarum involuta ante o-

$$
\text { Dddd } 2 \text { jacebat. }
$$


Certum eft, elementa fingula, prout fub corporum fimplicium confiderationem cadunt, nullam virtutem mixtorum geneticam ex fe \& fua natura habere;uc proincle perperam fentiant illi Philofophi, qui elementa fimplicia in rerum naturá aftruere conantur : effet enim hoc pacto elementum inutile, nec ullâ ratione polfèt in feparato hoc exiftentix fuxe ftatu durare. Cùm enim elementa ita à natura invicem fibi connexa fint, ut unum fine altero confiftere non poffic, unumq; fit fem- plex non per nutrimentumalterius, \& omnia fe invicem foveant, ani- datur. ment, conferventq; adeo ftrictis amicitia legibus, ut mundum potiùs perire neceffe fit, quàm uc unum alterius mutuâ ope defticuatur; patet vel ex hoc capice,eam elementorum fimplicitatem concedi non pofle. Scias igitur, miTheodidacte, nullum in natura rerum fimplex elementum reperiri, cùm unum fine altero neque confiftere, neque quidquam operari poftit. Sunt itaque elementa, utpote qua non tantùm reciprocâ quadam fingulorum ad fingula comparata mixturâ conftant, fed\& fingula proprias fuas, \& qualitates fpecificas obtinent, unà cum. fpermatica quadam facultate, in centro fingulorum delitefcente, quâ ad omnium qux in mundo pectantur, mixtorum com- Elementa: pofitionem concurrunt. Quomodo autem id contingar, dicen- runt adodum reftat. Datur in Univer fo fpiritus quidam omnes mundi mnia mixfemitas pervadens, quem veteres perperam mundi animam. feu mentem, alii rectè ipfam rerum naturam, nos fumpto ab Ariftorele vocabulo Entelechiam mundi appellare poflumus. Quam ego nihil aliud effe dico, quàm partem tenuiffimam omnium elementorum,cxlorumque, quæ in globorum centris fimul unita, tranfit \& mutarur in femen mundi, à quo deinde producuncur omnia, quæ naturalicer fiunt in hoc mundo, \& facta confervanour. Et duplex eft,fixa altera, altera volatilis : illa in terræ viferibus, atq; in toro ejus corpore, elementorumque quid fit, incimo centro fuum conftituit dominiü; hæe, uc omnibus natu- É quotu. re rebus, qua continuo fotu, \& perenni alimenti fubmini?tra- $p$ lex, tione egent, fubveniat, per univerfas mundi partes, intimofq; recentus diffufa, nihil non implet. Arque ficur hanc primogeniá $D$ ddd 3 illam 


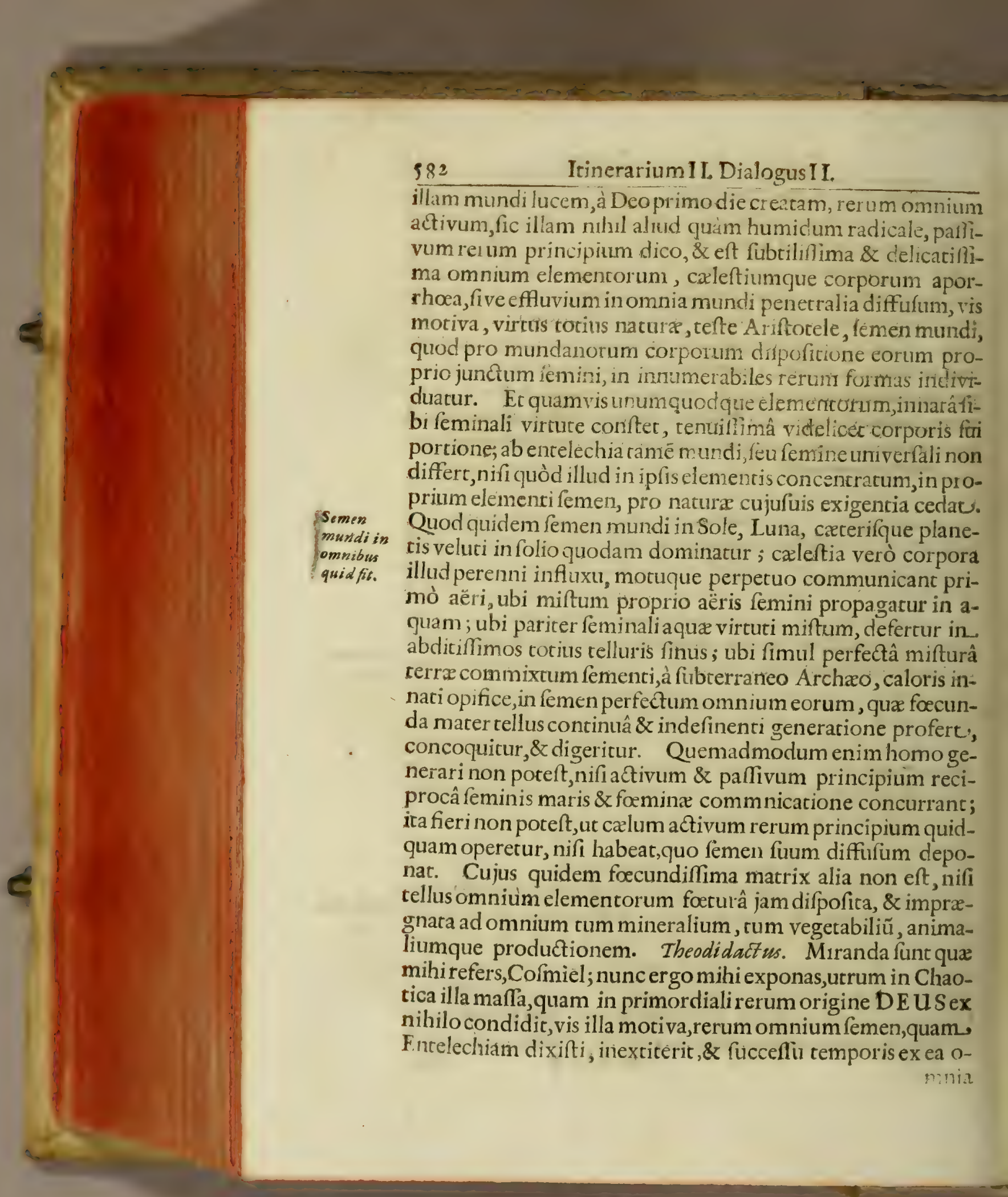


mnia educta fuerint, veluti ex rerum omnium primæva materia. Cofmiel. Cùm ex prima illa chaoticæ mafiæ materia \& coelos, \& elementa, \& quxcunquc univerfi ambitu continentur, Deus rerum Opifex eduxerit; certum eft, eum omnia ad confequentium rerum productionem neceffaria in dictam. materiam primó infudine. Quod apté infinuat Sacra Scriprura : o piritus Deiferebatur Juper aquas, ad eas focundandas, veluti ijs incubans, ut alii textus docent. Poftquàm verò Verbovirtutis frae, five lumine Verbi,cuncta diftincta \& feparata fuerunt, minimè cenfere debes, materiam chaoticam, variam illam \& verè infinitam producendarum rerum potentiá Materia \& virtutem in hac actuali elementorum feparation potentia initiocreaabfit : hanc enim materiam in hunc ufque diem, omnium re ta, thiam rum feminibus refertam, adhuc retinet, \& poffidet; ut proin- ${ }^{t} i$. de ex hife facilè paceat,quomodo prima illa chaoticæ mafle maceria, abuniverfi Entelechia diftinguenda fit. Eft enim. dicta Entelechia,five lux illa primigenia mundi,chaotica maffæ veluti forma quædam, quâ quod rude, confufum, indigeftumque in ea exiftebat, illud Entelechia à ruditate, indigeftreque molis confufione vindicacum, ordinatum, concinnum, pulchreque digeftum reddidit; utpote primævæ matériæ unica virtus \& efficacia, actufque informans, ita tamen, ut rerum. omnium productiva virtus \& aptitudo Entelechiæà materia. primæva dependenter inexiftat; materia tamen eidem originaliter, ut ita loquar, \& radicaliter infit. In hac enim fola. opifex Mens potentiam illam variam, feu vim productivam. rerum omnium pofuit, ut proinde, quòd ex quolibet præviiss variis alterationibus mutationibufque quod libet fiat, \& omnia Materi omnibus ineffe poffint,aliunde non proveniat, nifi quòd ma omnibus teria illa primava fit in quolibet, \& quodlibet per actum fuum inest, E ex producere poffit : ut vel ex hoc capitequoque pateat, hahc primavam poteftatem, rerumque omnium producendarum a- ducitur. ptitudinem,minimè â diverfis rerum feminibus, quæ in natura reperiuntur, dependere, fed ex fola, ut fuprä dictum eft, \& unica primæva materiæ, five chaotica mallæ vircute; utpote qua 


\section{4}

Itinerariüm II. Dialogus II.

fola verè \& realiter femina illa diverfa, \& omnia per lucis primigenia actum feu Entelechiam confticuit, \& pont ejus dificetionem omnibus indidit, tanquam fundamentale rerum oSemencha. mnium principium. Semina enim in materia erant confura otica maf. \& indiftincta, opifex verò verbi mens \& ratio, virtute \& efficaSa quomo- ciâ, Fiat lux, femina rerum diftinxit, \& feparavit; \& hoc pacto form. mareria primò individuata, \& fenfibili elemencorum amictu veftita in lucem prodiit : qux quidem elementa, ut fecundùm. externas \& fenfibiles qualitates corruptioni alterationique obnoxia funt,ita juxta internas \& invifibiles virtutes \& proprietates, utpote quæ in centris rerum, \& intimis corportım, thalamis fedem fuam fixam habent, neque à natura ipfa e ;usque principiis differunt, perpetuo incorruptionis munere $l x-$ tantur. Theod. Mirum in modum tuum tam concinnum de, abditis rerum principiis ratiocinium placet, tum vel potiffmùm,quòd non rationitantùm confentaneum fit, fed velob eam maximè rationem, quòd ex ipfis facris oraculis ipfum. tam aptè deducas, arque adeo fidei documenca rectæration is dogmatis fcitèconjungas. Quare in iis, quæ tibi propofueram, dubiis folvendis progredere.

\section{A P U T IV.}

\section{Quomodo univerfale femen Mundi concurrat ad mixtorum compofitionem. Et primò quidem de ortu, natura, viribus veget abilium.}

Tofmicl. Dixi tibi fuperiùs, Deum rer benedictum, omne Q vegetantium \&animantium genus, immediatè ex unicuique propriâ elementorum mafsâ produxiflè, non verò de novo ex nihilo propriè creafle. Namur rectè Sacer Textus; qui vivit in aternum, creavit omniafomul; nihil autem Deusex corporea creatura creavit, nifi chaoticam illam primævæe materię maflàm, in qua utiomnes rerum producendarum formę, omnia 
- omnia rerum feminajveluti fub confufa \& indigefta mole, virtute \& poteftate continebantur, ita in vegetabili\& fenfutiva naturax productione, ea non nifi de potentia in actum, latentemque feminum energiam, primigenii luminis actu vivificandoeduxit-inlucem. Theoild. Bene capia qux fape jam mihiinculcalti. Sed quomodo, aur quarationeexvirtuce: femi-

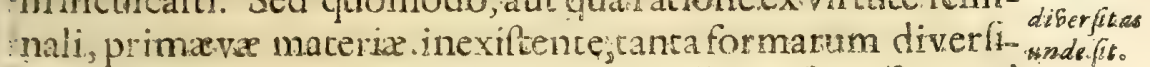
ras emanarit, illud eft quod non capio; illud iplumelt, quod :tantopere caliginolum meum incellectum.crucist. Cuare us meabhoc ingenii meitormentoliberes, etiam atqueecram rogo. Cofmiel. Tantaeft Deigloriofi\& benedicti Maieftas, ut vaci ejus intonanti, Fiat, omnia mox, etiam vitzexpertia, ipfiad nutum obediant. Vixenim in prima illamundi nativitare pientia Opifex verbum provulerat, Fiatlux, cùmea moxenio : ruit, ec fact a eft:lux; lux illa primigenia, act vum rerum omniu principium, \& vera mundientelechia. Iterum intonuit: Fiat

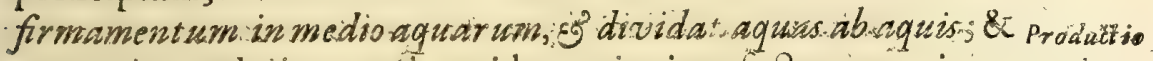
ecce primum hujus cerm humidoconjugium factum, aquis in- omnium tra alveos parcimmundanorumicorporum, parcrmintrater- quo : modo ræconcava conclufis, ac fic detectararida fuit. Creata mox fydera,Sol,Luna, ftellæ, quorum foecundo primigeniæ lucis Entelechiâ imbutorum influxuterraimpregnata, veluciex utero quodam eam rerum varietatem Dei voce concitata predidit, qua m.um ad miratione intuenur. :Quøtiamverò Entelechir, qux in Sole, Iuna, ftell is, fuum potiflimùm folium pofuit, tantavis eft, ut pro diverfo Solis; Lunæ, ftéllarumq; ficu, di- verfimodè quoq; fubjectx teliuris parces afficiat, fuof f; infuxus diversâ rationecommunicet"; hinc factum ent , ut vix exigua fit terræ cxterorumque elementorum portio, qux nonpeculiarem aliquam fibi infitam vircutem fyderum munere adepta fit. Atq; adeo Entelechia elementaris, fixa omnibus \& fingulis differentibusterræ portiunculis, juti fuprà decuimus, Entelechio inexiftit,eique femper præfens eft. Divina iteq; voce irronan-indibiduete; producat terra berbam virentem, foc. mox concicatautraq; in in $_{\text {mintis }}$ Entelechia, coeleftis \&elementaris, aretifimü meditataconjuEeee gium, 


\section{$50{ }^{\circ}$}

Itinerarium II. DialogusI I.

gium, in terræ partibus, pro difpofitione cujufuis, in innumerabiles plantarum formas individuata fuit. Hinc India pro naturali fitûs fui, \& terrenæ difpofitionis ratione, fyderumque refpectu, cinnamomum, piper, cariophyllum, caterafque innumeras aromaticas fpecies, juxta diverfos intenfionis, lucifq; tum cæleft is Entelechix, tum fixæ terreftris gradus, produxit; quæ quidem pro diverfa infinitæ combinationis ratione fimul juncta, eam produxerunt, quam cum admiratione fpectamus" rerum variesarem. Hinc Afia, A frica, America, Europa, fingulæ appropriatas fuo folo plantas, fine numero formis, frgnis, proprietatibufque diverfifimas produxerunt. Theodidact us. Galos no Ex fuperioribus jam percepi, calorem illum nativum, feu lurifus in materiem perpesuciaitis. cemillam cæleftem, quamDeus in primævam materiam difpofitam radicalizer \& fubftantialiter implantarat, perpezuò in. materiam agere, eamque fuâ actione ad qua cunque rerum formas fecundum materix difparatas conditiones adaptare, \& nunc banc, munc illam ex illius centro formam edtucere: hoc unicum tamen mihi explices velim, quomodo id dicta difpofitionis beneficio contingat? Co/miel. Votis tuis quiburcunbue potero modis.fatisfaciam. Attendeitaque quæ dicturus fum. Poftquàm calidum illud radicale, lux primigenia, ignis? naturæ, mundi Entelechia, five univerfi femen (omnia enim. hæc unum \& idem funt; quæ diligenter advertas velim, nè fynonymornm multitudine, quibus in fecuturis ratiociniis utar, confundaris ) Poft quàm, dico, calor ille primigenius mundi materiæ centro inexiftens, omnia rerum confufa \& indiftineta femina,virtutis fur efficaciâ divifa, ad quidpiam peculiare deftinavis,mox eodem temporis momento, ex deftinata illa. sur in ma. suriam. Grua \& debita, fpiritus quidam particulares ed cicuntur, quitunà cum for ma rei \& materia, femen aliquod in ipfo individuatx materix centroconfticuunt; quod femen quamdiu viget, fimile fibi producendi facultarem acquirit; atque hoc pacto le in nacura rerum, quoad fpeciei confervationem propagando perpetuat. Quan diverfá verò forme rerum, five fpecie diftin- 
diftinct $x$ res in mundo fpectantur, cam diverfæ quoque in peculiaribus materix partibus dif́pofitiones ad eam, quam diximus, formarum diverfitatem confticuendam præcefferunt. Nam, ut exemplo rem propiùs attingă, memor fis eorum, qux fuprà diximus,cæleftem Entelechiam panfpermiâ quadam refertam effe, quam primò aëri, aër aqux, a qua terræ tandem perpetuo\& incellàbili influxu fuo communicac. Quemadmodum itaque magnes intra infinitam rerum congeriem conftitutus, non tamen nifi ferrum fibi fympachicum, \& fimilitudine naturæ appropriatum appetic,omnibus aliis immotis; ita vegetabile infitâ fibi naturâ per radices, veluti per os quoddam, elementum terraqueum cælefti jam panfpermiâ imbucum crahit: ex qua tamen illud tantùm trahic, quod naturæe fuæ quàm maximè confentaneum eft, neglecto reliquo, à natura fua diffono, feminali virture imburo alimento. Ita abfynthium $V$. $G$. 'ex terra aquæ mixta, \& fpiritu calefti imprægnata, id cantùm. trahitalimentum, ex quo primævam fui originem duxit, fub tali \& rali mixcionis humidi radicalis, calidi primigenii , \& fic. citerreftris combinatione, videlicet fub ralifulphuris, mercurii,\& falis compofitione, non fub alia; quod quidem fulphurcalido innato\& primigenio, mercurius humido radicali, fal verò ficco terreftri fecundùm analogiam quandam refpondev, \& omnia in ipfa mundi Entelechia concentrata funt. Ita rofa, ita poeonia, ita pomus, ita quercus \& fagus, illud fibi alimentum proportionatum, ex quo conft terunt, attrahunt, \& non. aliud; quod quidem intra terram à radicibus propagatum in. caulem,excra terram deinde ab aëre ambiente cælefti nectare pariter imbuto per poros in plantam femenque penerrantealitur, animaturque in vegerabile, diftenditur in ramos, in flores germinat, in fructus femenque procuberat; quo deinde in tertam relapfo,putrefactoque, mirâ quâdam \& perenni pericyclofi in novam progerminat plantam, priori prorfus quoad fpeciemfimilem. Mirantur homines unde in prato quopiam, innumera herbarum varietate veftito, tanta tamen ex u- 
halicus funt; ita in vegetabilium familia prater propriam animam vegerativam funt \&:Spiritus, qui nihilialiud; quàm tenuiffima alımenti in vegetantibus portio fünt. Dum enim humidum radicale per poros vegetabilium infinuatum, ac per. radiceseorum in alimentum \&.vitam attrahitur, tunc quoque. tenuiflima dicti humidi radicalis jam ad talem \& talem for-. mam individuaci portio fíiritus ille-vegetabilium, de quo fiiprà locutus, fum, appellatur. Quod enım:fpiritus in Mi- 2 mold in crocofmo,id in Phytocolmo; id eft'; plantali mundo firitus, dem agunt appropriati preeftant;cùm peruniverfas totius corporis plantx in plantis minutifimas portiunculas virtutes \& facultates vegetantis a- ${ }_{\text {propristio. }}^{\text {piritus }}$ p nima. deferant. Theodid: Hinc.fequeretur; animam \& fpiritus idem invegerabilibus effe: Cofmiel'. Haudquaquam; differunt enim fpiritus \&anima in vegetabilibus, quòd anima eorum. fit forma quædam fubftantialis, primævum vitæ.principium;, \& quafipura cæleft tis Entelechiæ, five feminis nature.virtus in. Brincipis vegetabilium radicata \& implantata, ex qua omnes $\begin{gathered}\text { Diffrimen } \\ \text { inter Gege- }\end{gathered}$ vires, proprietares, facultatefiue fcaturiunt :. fipiritus autem , inter bege. partim quardam funt dictze purioris cxleft is lucis portio, par-animam tim connexam permiftamque: fibi habent fubtiliorum ele- $\delta$. Biritus mentorum portionis magnam quantitatem. Quemadmo- ${ }^{\text {fuos. }}$ dumenimradii folis verifunt folis fpiritus, per univerfum. mundum diffufi; ita quoque quod $a b$ anima, five fubftantia. illa fixa vegetabilitum, in qua fedem fuam pofuit, effluit, líx: videlicetcaleftis in planta individuata; unà cum tenuiffimorum elementorum portione, veliuti radius quidam effluxufque? intius fubftantialis form $x$, verus ille \& proprius, genuinufque: vegetabilium fpiritus eft. Theodidact us.Dic modò,quomodo Anima bes \& qua ratione anima illa producatur in vegetabilibus; hoc e- getatifa nim non parum me torquet.. Cofmiel. Cæelum, uti füprà au- quaratiodift, in intima terre vifcera, ceu in matricem quandam: fub- $t w r$. siliffimum fuum fëmen mediante aquâ projicit, quod unà elementorum fubtilioribus partibus commixtum Archaus, id eft,caloris nativi intra Geocofmum opifex in vapores fublimat, qui per univerfos telliuris poros delari, atque in aquam,

$$
\text { Eeee 3: denuò }
$$


denuò frigore nativo condenfaci, verum fiunt vegetancium. alimentum; quod,uri dictum eft, à radicsbos plantarum acrractum, coctum, digeftumque, in fui fubftantiam convertune, \& fit vegetabile, Ex alimenti verò hujus puriori fubtiliorique parte five femine anima exoritur, intra intimos parcium, fimus latenter diffúa; ex crafion verò alimenti parte corpus exterius ac vifibile plante fic, videlicet f́capus, cortex, ramus; ex fubtilioribus verò eftluviis in crafforifedimento exiftentibus frunt folia \& flores, \& ex foliorum forumque fubrilioribus partibus fit fructus, ex hujus tenuioribus partibustandemfemen fit, in cujus medio veluti in corpufculi centro latitat vis illa fpermatica verèadmiranda, \& ipfa anima vegetabilis, arbor videlicet virtualis cum radicibus, trunco, ramis, foliis,

Deus mini. momaxi. mäetiam Girtutem indidit. floribus, fructibus, quibus tota vegetabilium fubftantia componitur : ut proinde vel hinc divinæ porentix magnitudinem. agnofcas, qux tam exigux portioni, qux vix octomillefimam. ducentefimá feminis partem æquat, tantamad fimile fibi producendum facultatem indideric, \& qua vix atomi quancitatem ad fpermaticum fuum corpus comparata exæquet, in. praamplas tamen \& altifimas arbores, quemadmodum de finapis grano rectè Veritas in fuo enunciat Evangelio, enafcacur. Unde quoque pater,hujufinodi f permaticam portiunculä

Inomni] reliquis omnibus plantæ partibus corruptioni obnoxiis folam mixto du- incorruptibilem in fua operatione perennare. Hincquoque,

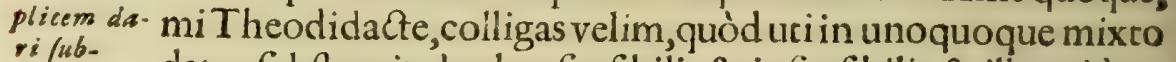
Pantiam. datur fubftantia duplex, fenfibilis, \& infenfibilis; \& illa quidem effentiam \& naturam corporis, hæc animæ five formæ fabftantiam confticuir; ita pari pacto in vegetantibus duplex alimentum confiderari debet, fenfibile, \& infenfibile: \& ficuti fenfibile externam naturam corporis conftituit, ita infenfibile ad animæ effentiam producendam conducis; illud in terraqueo continetur globo utriufque elementi confluxu, coelefti luce paranymphâ conftitutum, hoc aëreo elemento cæleftis lucis beneficio infufum; quod uti fubciliffimum ac tenuifimú eft, ita animæ quoque effentix comprimis eft attemperatum. 
Theod. Dic modò, Cofmiel, cùm dixeris formas vegetantium efle materiale quid, quomodo illæ è potencia materiæ edu- utrum 8 cantur? Cofmiel. Certum eft, Philofopho tefte, vegetabilis \& quomodo fenfitivæ naturæ formas omnes educie potentia materię;quam forma fise tamen eductionem è potentia materix, ex dictis fic intelligas velim, quòd videlicet ex primæva poteftate materix chaoticx, ducantur quàm fusè fuprà tibi defcripfi, quæ adhuc in omnibus mundi ex mattcorporibus individuata maner, velut è potentia proxima in aclum educantur. Hæc verò materia cùm fic mixtum quid,\& elementatum, formæ verò educantur ex potentia five virtute hujus materix omnigena feminalium rationum elementorumq; commixtione gravida; maner,formam, qux inde educitur, non ex pura quadam \& prorfus informi potentia, fed ex is quæ mareriæ infunt, videlicet ex fubtilifima \& tenuifima elementorum, lucifque primigenix five feminis naturæ portione originaliter formari atque conftitui.Theod. Dic ergo mo- unde tan. dò, mi Cofmiel, unde tanta in fructiferis arboribus variotas in diber/afigura,odore, fapore colore originem furm figura,odore, fapore, colore originem fuam ducat' unde miri- rum fariefica quarundam herbarum proprietates emanent? Cofm. Di- tass,earum. verfitas arborum, v. g. tanta pomorum pyrorum, aliarumque que qualitatum s fructuum varietas originem non aliunde acquirit, quàm primò birtusum ex vario fitu \& tranfplantatione, nunc in hoc, nunc in illud fo- ${ }^{c a t} / \alpha_{0}$ lum differentibus qualitatibus imbutum. Ex cujus agri aut foli, ab aliis agris differenté difpofitioné fortiti conditione diverfítatem tam ejusdem fpeciei,quàm alterius cujufpiam nafci necefle eft. Semen enim permiftum alteri diverfe fpeciei femini,diftinctum quid, \& ab utroque femine diverfum producit. Hoc pacto pomus Europx in Indix folo plantaca, toto Arbores ucoelo differentem fructum parit,five figuram , five col, colorem, plantate faporem, odorem, fpectes. Hinc eft quod Perfica arbor in Per- ${ }^{\text {in diber/is }}$ fia veneni virulentiâ plena, inEuropa tamen tranfplantata, fua- regionibus vifimum faluberrimumque fructum producat. Innumera hu- $t i f f_{i m o s}$ in jus rei afferre pollem, fi tempus ferret, exempla. Qux tamenali- ter fere et unde non proveniunt, nifi ex differenti natura \& conditione produsur foli, in quotranfplantantur. Secundò, dicta arborum five fru- 
ctuum diverfitas caufari poteft per inficion is artificium, dum. diverfa arborum fpecies in tunum:tranfplantantur truncum; de quo naturæartifque conjugio, cùm tu in Arte Magnetica. fusè egeris, non iis immorabor. Tertiò,fumma hæc diverfitas quoque ex multiplici principiorum naturæ (qux fụprà calidum innacum, five primigeniam lurem, humidum radicale, \& ficcum hylzum diximus, \& fulphuri, mercurio \& fali correfistantarumin fructibus qualitatum. fpondent)pro diverfis arborum fpeciebus in terreno folo permixtione provenit,pro quorum combinatione aliter \& aliter. ad nature leges facta, alia \& a lia nafcitur fruduum qualitas.A€cedic hifce elementarium vircucum energia,ex quorum omniü complexuemanat illa qualitatum diverfitas fumma; ita ucex calido innato, five fulphure nature, odores \& calores; ex fale verò naturæ, quod omnia fapida reddit, lapores propriè prove niant; cooperancibusin omnibus ad diverios effectus producendos elementorum qualixatibus primis \& Lecundis. Nacura verò ipfi aqux implantata, \& plantica feminis facultate pollens, ipfa potinimùm eft, quaz mira'bre preftat, five qualitates fruetuem, five v res mirificas.ppectes:nam piritibus fuis" ar hitectonicis matel iam variè agitatam difponit, \& plattica faculeatis ope in differentes figuras diftendit, coloribus variis" exornat, faporis oderifque diverfitatem, mediante diuturnâ concoctione \& digeftione, qua in ipfis plantis fir, imbuit. Concoctio enim quod́ priùs durum, tandem mólle;quod acerbum, dulce; quod afperum erat, lene reddit, uti in omnibus"

Exotica* rum firtu- immaturis fructibus experientia docet. 'Si quasverò in plantum ip r is tis prorfus prodigiofas 'virtutes \& proprietates admireris, ilf r rma сан- las certè aliam originem non habere pures, quàm ex ipfa vegefa exiffit. tabílis forma ; qux uti peculiari combinationis principiorum naturæ lege, five calent is feminis, feu lucis primigenix in planta individuatze diverfa contemperatione conftituitur, ira exoticas quớ; \& pærnè paraduxas vires \& proprietates herbis confert. Atque hæc funt, quæ in genere tantüm de vegetabilium ortu,naturâ, \& viribus dicenda putavi. Et non dubito,quin tu, mi Theodidacte, ex hifce principis jactis individualem illam. mixto- 
Cap. V. Deglobo Terræ.

mixrorum compofitionem, qux in fingulis plancis elucefcic, facilè fis penetraturus ; fingula enim quoad intimam eorum. effentiam attingere non eft hujus temporis, fed eirefervatum. vita ftatui, in quo cuncta cै rй rypo quodam, in quo omnia unum funt, contemplaberis.

\section{CAPLT V.}

\section{Deortu Ev viribusfenfitive Naturs.}

THeodid. Jamtempus eft mi Cofmiel, ut qua de animalium ortu \& genefi te mihi expofiturum pollicebaris, folicâ dicendi claricate expedias. Cofmiel Faciam equidem libenter quod à me contendis, Theodidacte, fed non nif in genere tancùm, particularem fingulorum inveitigandorum, rerumque ex meis principis deducendarumracionem , propriis ingenii tui conatibus relicturus. Scias itaque velim, quadru- 2uadra-

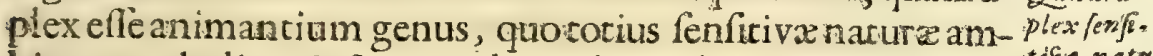
bitus concluditur, \& funt quadrupedia, volucria, natatilia re- $_{\text {ra }}^{\text {tibenut }}$ nats ptiliacum his qux infeota vocantur. Quorum omnium rationes recenfito tibi ordine exponara, aliquantulùm slciùstrerum rractandarum feriemordituras.

Percepinti,nifallor, ex pracedentibus , qua ratione in primordiali mundi Genefi ex primava cbaoticæ mafix materia lucis primigeniz exortu à fuâ confufione vindicata elementa $\&$ in proprias natur $x$ eorum confentaneas regiones diftincta fuerint, \& quomodo opificis Mentis omm ipotenti voluntare ex iis veluti ex przexiftentemateria, omne genus animamium eductum fuerit ; ex terra \& aqua quadrupedia, ex aqua \& aëre volucria,natatifia ex elemenco ipla,cui infunt; ex omnibus fimul reptilia.Fis pofitis, \& ex facris eloquiis confentaneè comprobatis, dico, quadrupedia ex terra producta fuifle, juxta illud $24 \mathrm{atrw} \cdot$ divina vocis oraculum : Producat terra animalias of jumenta. bes ex ter- 
Differentiam quadrupedum coriftituit infrita for ma lubfantialis. Efentia formu guaLisnam fit.

ta formarum differentia proceflerit; fed audi qua tibi expono arcana naturx. Omnia quadrupedum genera fpecificam. fuam differentiam non aliunde fortiuntur, nifi à forma fubftantiali is infita, à quâ veluti ex fonte quodam omnesanimantium facultates, vita, motus, ingenium, induftria, vires, \& operationes tam manifertx, quàm occulta prodeunt. Eft enim forma nihilaliud, ipfo Philofopho tefte, nifi id, quod dac effè rei, videlicet natura ipfa \& effentia animalis . Cùm verò omnes formæx, exceptâ hominis, ex poten tia materiæ educanwur, illke utique divifibiles erunt \& materiales, cum nulla alia. forma fubftantialis indivifibilis \& immaterialis fit præter formam feu animam hominis à Deo ex nihilo productam, \& corpori humanoorganis jam ritè inftrueto infufam. Siergò formæ animantium funt divifibiles \& materiales, illæx neceftariò à materia, ècujus potentia edưctx funt, dependebunt; ergo necenlàriò aliquid ipfi materix inefle deber, cujus virture \& potentiâ formæconftinuantur. Atqui nos hoc loco, cum S.Bafilio materiam primevam affignamus, ex qua tanta formarum. diverfitas educatur, chaoticam fcilicet illam maflam,à primis mundi incunabulis à Deo productarn, veram \& realem rubftantiam, qux omnigenam feminalium rationum mifcellam, tametficonfufam \& indiftinctam, in exordio rerum obtinebat, donec per actum primigenix lucis verbo Dei incirata, per univerfas mundi femitas, \& intimos receflus diffufa, tum fingulos mundi globos aftræos, tum elementa propriis fuis formis. exornavit; unde prepotens illius lucis primigenix efficacia, unà cum principiis fuis, calido, humido, ficco, primigeniis naturæ fundament is, qux intra fe, uti alibi jam dictum eft, complicat, neque ab iisdem fine tocius confufione feparari poteft, vera illa mundi Entelechia, motiva rerum facultas, activum ommiam principium, unicum mundi femen, omnium formarum diverfitatem non in vegetabilium tantùm, fed \& in animalium Deconomia elucefcentem inducit. Eft autem primigenia illa ab Optimo \& Ter Maximo Conditore Deo verbo virtucis fux producta lux , de qua modò loquimur, miñimèacciden- 
cidental is quadam forma \& nuda qualitas, fed vera,realis, \& actualis fubfiftentia, univerfalis mundi forma, omnium mundialium feminum mifturis foeta, qux deinde Dei voce excita ta, atque diftincta, Solem, Lunam, ftellas, in quibus excellentior \& porior ejus pars, veluti in proprio regno refidet; deinde elementis communicata, omnia quæ videmus, conftituit. Porrò in animalium productione, voce Dei intonante, elementa, terra, aqua,aër,prodifpofitione materix cujusvis elementi,eam quam admiramur, non in mineralib. tantùm, fed \& in vegetabilib.,fenfíivęq; naturę mixtis,formarum varietatem caufavit. Quando itaq;Divina vox infonuit:Producat terra animalia, छ゙'. ecce mox creatæa lucis portio elementorum conjugio defponfata,omnisgeneris animantes quiadrupedes produxit,juxta $\mathrm{Di}$ vinæ fapientix ideas, in omnibus ad nutum naturæ obfecundans.Theodid. Hinc fequeretur animalia fpecie non differre, cùm omnia ex eademluce coaluerint. Cofmiel. Valde hallu- Animalia. cinaris; non enim omnia animalia eandem lucis quantitatem netura

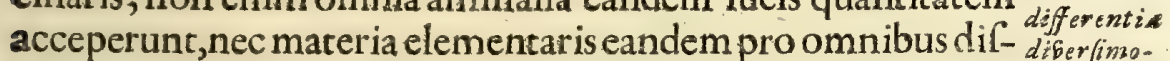
pofitionem habuit, fed ineffabiliquadam tum combinationis dè particilege,tum triumnaturæ principiorum, corporumque elemen-pant calitarium ( qux jam ex ipfa totius naturæ mifcella feminibus cur dum radigebant ) concurfu eâ temperie \& harmoniâ coaluit unicuique animali formando deftinata terreftris mafla, ut exilla per certam formam fubftantialem hoc, non aliud animal, hoe pracisè,non aliud vegetabile; hoc, \& non aliud minerale emerferir. Er quantò quidem animal quodpiam majorem coelert is luciso ${ }^{3}$ Animat portionem ad fui compofitionem fub tali \& tali elemenrorum bel impermiftura adeptum fuit, tantò cærteris perfectius, \& naturæ doti- fect ius dibus inftructius evafit: quantò minorem, tantò quoque in ́pecie ${ }_{\text {ex' majori }}^{\text {gnofitur }}$ quidem fua perfectum, at in gradu \& dignitate naturæ fenfiti- bel minoré væ, quoad temperamentum, imperfectius emerfit. Hac ratione $e^{\text {lucis }}$ part - Leo, quia maximam dictx lucis porcioné adeptus eft in fui pro cipalione. ductione, ideo omnibus animalibus generofitate, fortitudine $\&$ igneo quodam pollente vigore, veluti Rex quidă quadrupedú Ffff 2 ante- 
anceponitur, und cum dictis dotibus diuturnitatem vica confecucus. Afinus verò qui plis terreftris fubftantix, minùs primigenia lucis adeptus eft, ideo impigræ, lentę, \& ftolidæ natu= ranimal evalis. Idem decareris judicium formabis. Theod. Hinc fequererur, piantam efle pofle adeo primigenix lucis munere beatam, ut animal, qualecunque tandemillud fit, fuNullum in peres. Cofmiel. Nequaquam. Scias enim, nullum efle animalseft tane culum tam vile \& abjectum,cujusmodi v.g. humbricus, auc abundan. its lucis frui,quania fruisur Gibens Gilifimum. eruca effe pollet, quod non majorem lucis five caloris primigenii ubertatem, quàm excellentifima quævis planta calore luce turgens, cujusmodi piper, Cinnamomum,aut Cariophyl lum,atr Crocus efle pofiunt,adeptum fit. Quia fieri non pa teft, ut quodlibet ad fenfitivæ naturæ gradum, nifi eximiâlucis portione,\& fub gradu tali,\& talianimali formando appropriato imbutum pertingat. Habent enim finguli entium gradus, ita dífponente Divinâ fapientiâ,fuam determinatam lucis latitudinem, cum dica elemencorum miftura vel ad fenfitiva narura animai, vel ad plantam,aliudvè conftiruendum. Theod.

Q2ualis $6 i$ ia ingegerabilium jeu mineHinc fequeretur, mineral ia uri lucis munere non deftituntur, . vita quoque hand expercia ente. Cofa. Lucis portionempafor ene nemo negare poteft, cùm \& ralinm. formâ fuâconftene; \& $x$ confequenter, non vitam illamainjmantibusplantisque propriam, fed viex nonnullam fimilitudinem, condicion tanen eorum congruam is inefle, pariter. verum eft; fed lux ilia terreftris mifturæe foculantiâ \& craficudine adeo obcunditur \& abforberur, ur in actum vitalem e. mergere, fapiencis finè nacuræ confifio, non poffit. Qui tamen actus hus incer omnia mineratia porifimum in magnete elucer,cuim tractivâ vi fuâ neficio cuịus vitalis facultaris veftigia pandat. Theodidactus. Sed quid cenles, Cofmiel,de forma. mixti \& remperamenti e Cofmiet. Forma in mixtis fe habet per modum regina; qu qua tota mixti monarchia regitur \& gubernotur. Ab hac enim omnes, vires \& propriecates emanant, \& fi in " fird eft in mixco elemencarium qualicatum, id cotum forma mixio. hibdirur imperio, neque qualitates elementorum poflint agereni- 
re nifi à forma ad ayendum impulfex; foli formæclaves mixtionis concreditę func, quibustotius mixtionis Oeconomiam vel aperic, vel claudic; ab hac qualitates, five manifeftæ, five occultæ promanant, hæc fola leges condit, easque fervare cogit elementa five temperamentum. Theod. Optımècepi omnia, neque habeo quod opponam,cùm juxta præfuppofita principia oppidò confequenter loquaris. Nihil igitur reftat, quàm. ut ad volucrium natatiliumque naturam indagandum fermonem convertamus.

\section{Avium Genefis.}

Tofmael. Omne volucrum genus ex femine nafcitur, femen exalimento, alimenta verò partim ex aëris infenfibili,partim ex fenfibili, quo vefcuntur, nutrimento primam originem trahunt. Infenfibile quidem nutrimentum aër eft vir-Auium nutute coleftis feminis foetus, quo carere minimè fine vitæ di-duplex; 3 m fpendio poflunt. Senfibile verò nutrimentum eorum funt $0-$ fot ile,E in mnia ea,quibus aves vefci folent. Ex urrog; tam occulto, quàm (enfibite. manifefto, tam fenfibili, quàm infenfibili alimento unà juncto nafcitur volucrum femen, quo in actum deducto, in innumerabilem multicudinem \& varietatem propagata, univerfam. infimam aëris regionem implent, ut id, ex quo ortafunt, elementum incolant. Concurrunt itaque, haud fecusacin mixcis, ad avium compofitionem omnia elementa, quæ uni genevali naturæ femini pro fubjectæ materiæ difpoficione individuato mifcentur: \& uti activâ coeleftis lucis five feminis virtuceunicuique forma conftituitur, ita \& ab eadem proindividuate lucis in diftincta materia ratione, variæ avium vires $\&$ proprietates,tanquamà fonte emanarunt. Unde verò tanta diverfitas \& multitudo originem fuam habeat,reftat explicandum. Major eft haud dubiè a vium multicudo, major fpecie-Auium cur rum varietas, quam quadrupedum, ut experientia quotidiana tanta abdocet. Cujus reiratio eft multiplex ovorum, ex quibus na-6xiantiatas. fcuncur, multicudo; vel commiftio unius fpeciei cumaltera,ex Fff: 3 


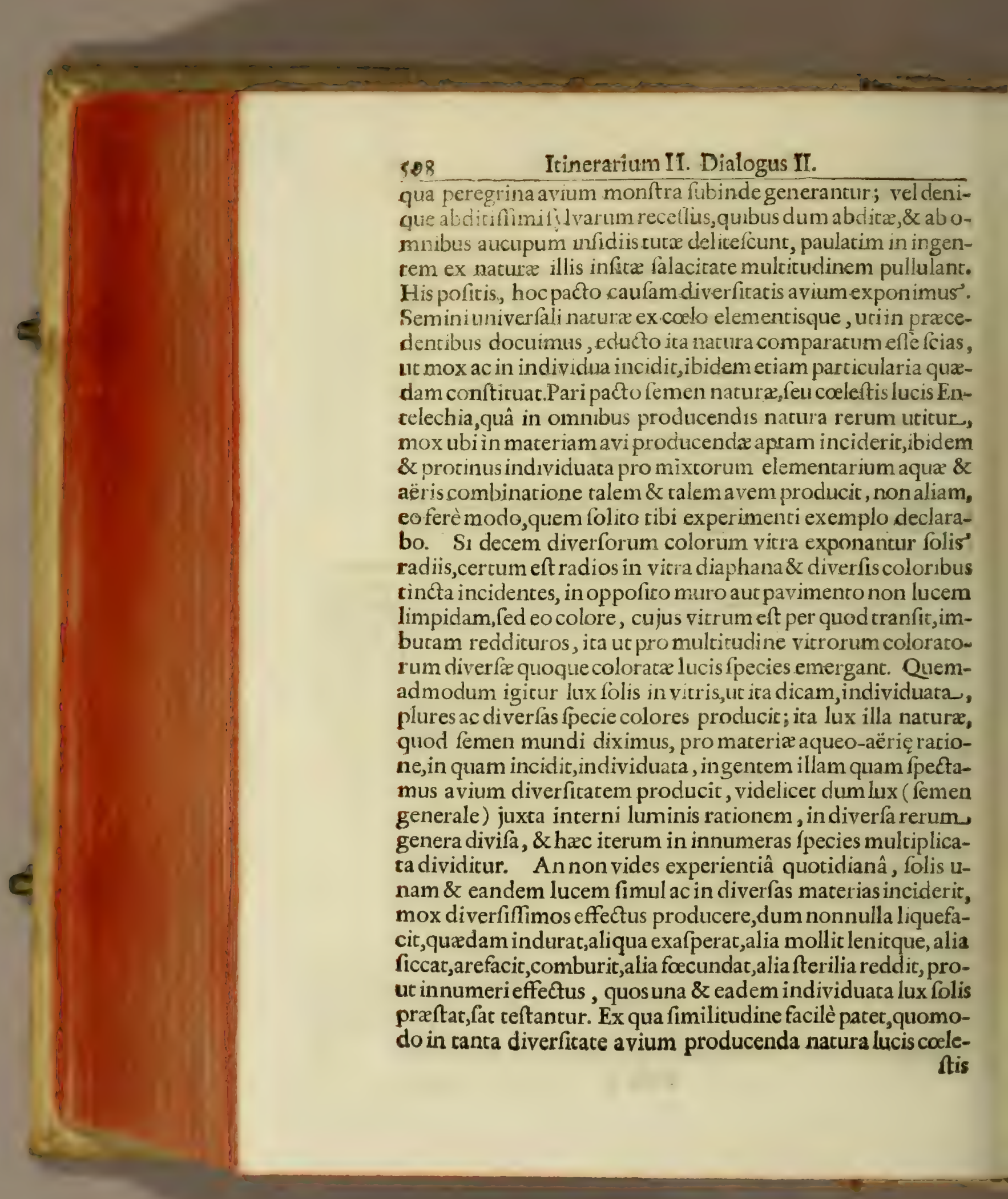


ftis minift re fux \& opificis fubfidio procedat. Semen itaq; naturæ mox ac divifum, acà fonte fuo feparatum, aptisque materiis infintatum fuerit, non poteft non dictam diverfitatem adferre, ut audifti. Theod. Pulchrè, 'moretibi folito, modurn quo avium tanta varietas \& multitudo producatur, explanafti. Duo interim qux capere non poflum, mihri explices velim :un- oborum Es de videlice mira ovorum, quxe fune volucrum femina, \& colo- diberfifizrum in pennis avium elucefcentium varietas fit? Cof \& in uis def, miseris quis defrauderis,negotium totum ex ordine pandam. Er primò nom nam canfa. varietate, quâ volucres mirum in modum ornatæ cernuntur. acturus. Nihil in rerum natura occurrit femmali virtute admiratione dignius. Quis enim non miretur in tam fubtili \& tenui feminis fubftantia tantam rerum congeriem latere? uti in femine vegetabili vel integram arborem, unà cum radicibus, trunco, ramis, folris, floribus, fructibus s in fenfitivæ verǒ natura femine cum tota vitalium membrorum fabrica, carnem, nervorum mufculorumque compagines, ftructuram of fum, venarum ductus, ineffabili quodam artificio condi, quis non obftupefcat, dum vel maximè Divinz fapientix arsin ovo volucrum femine lufit. Quis plafticam \& formatricem femin is facultatem verbis fufficienter explicet, dum in vegetabilibus tantam in ramorum, foliorum, fructuum figurâ diverfitatem,tanta in omnigenis florum coloribusfpectacula exhibet, tanta tamque exotica in fructibus fchemata inducit? Cer- Virturtis fetè non alia, nifi plaftica vis feminis à natura providentiffrma minalis ef fetzrs, rerum matre in hunc finem ei indita. Hac eft qux in animan - mira a bis tibus figuram adaptat cuicunque fpeciei aptam, oflibus com- plaftice pingit, tendit nervos, derivat venartum ductus, omnia mem- facultatic. bra pro cujuslibet fpeciei conditione muniis fuis exequendis apta difponit; in volucrum verò familia ovum fabricat, magnü naturæ arcanum, in quo ceu in coelo quodam feminalis feu plaftica vis omne id fabricatur, quod admirandum in volucri- 


\section{Itineratium II. Dialogus II.}

Orwm in

Solucribus

mature

bus videmus; de quo modò nobis dicendum eft. Duplex itaque femen in volucrum genere confiderare debes, miTheoSeminis eft ; prius in maribus nikil aliud eft, quàm purifimæ lucis pri-

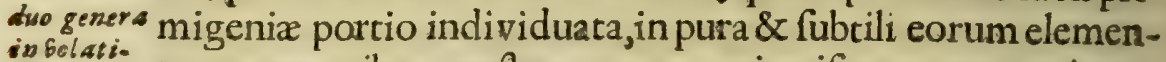
irbue. torum, ex quibus conftane, parte, cui mifcetur vera unione in eam fubftantiam, qux in fe continet omne id, quod ad avium productionem necefiarium eft. Hoc pernacuralem. congreflum marrici famellax indic $x$ in ovum naturali matriciscalore convertitur; feclufum verò caloris externi, five avium, five hominis cum proportionato caloris gradu foru \& incubitu, tandem ruptâ têtâ in volucrem parentibus fimilem osi confi- emergit. Es craffior quidem pars feminis in putarnen \& re-
sutio. ftam abit, aquofior verò pars in aibuginem convertitur, pars verò qua aëris \& ignis fubtiliores partes habet, in vitellum. mutatur, cuigermen fupernarat fubrilior efficaciorq; feminis? portio, atq; huic vitalis \& fpermatica virtus omnis ineft, ex quo folo vita pulli \& multiplicaxio deperdet animx \& vitęradix, reliqua omnia in alimentum cedunt jam maturo inter teftam conclufo foetui. Et reliqua quidem animalia fine ove intra matricem contenta per varios materni uteri ductus fuum fibi a limentum ex toto corpore attrahunt, at folis volucribus Diviobonws fi- na fapientia per artem fuam, ciuæ narura eft, peculiarem juxta
gure mundi formam, teftaceam manliunculam adimirandâ lảnè induftria à matricefeparatam fub Elliptica figura conftruxit, in qua tanquam in orbe fuo, feu mundo omnia illa, quæ quovis modoad vitam neceflaria erant,paravit. Theodidact tes. Pulchro quidem \& concinno difcurfu ovum defcriplifti, fed modum nofie defiderarem, quomodo calore illo excerno vis feminalis trü prists, intra teftam latens è potentia in aftum educatur; \& utrum. sel folucris priùs, ovum, an volucris, in primordiis rerum extiterit. Coffueris. miel. Scias, Theodidacte, Deum rer benedictum omne genus volucrum ex aqua produxilie, ati ex precedentibus oftenfum fuit. Quod non ita intelligi deber, quafi ex fola aqua in quantú purum elementum eft. fed exaqux purior is portione reliquis elemen- 
elementis fub minori gradu mixtis productx fuerint. Neque Deus ovum priùs, fed vo lucria, unaquæq; juxta fpeciem fuam, in perfecto effentiz fux ftatu produxit; ex quorum deinde femine, naturali nexu confequente in perpetuùm, volucrum propagatione faeta fuit; quod ordininaturæ maximè congruum confentaneumque fuit. Si enim ovum priùs productum Cur ofum fuifter quis illud fo iffer? quis ad exclufionem foetura incu- non potuebuifler? guis pullum exclufum aluifler? Decuit igitur nature pritus, folkMajeftatem, primüm volucrem, ex qua per quoddam utriuf- ${ }^{\text {cre. }}$ que fexus conjugium deinde ovum nafceretur, pullo per. fotum producendo, atque educando aptam generare. Atque in principio quidem rerum Deus produxic ex communi primigenix lucis,quod nos calidum radicale, \& femen mundi diximus, cum purioria yux feu bumidinadicalis portione, ter- Elementoræmodicâ portiunculâ additâ,omne genus volucrum; fub ea rum qualis tamen portione, ut in avibus minor eflet terræ, major aquæ, ait mixtura maxima aëris a d earum productionem portio. Atque hæc cendum bo. quoque fub infinita graduum diverfitateprogenerum fpecie- latile. rumg; producendarum multitudine \& varietate affumeretur. Et quemadmodumad formam volucrum conftituendam ma- Volucrum jor fubtiliorque lucis primigenix portio accedit, quàm in dotes En na. quadrupedibus; ita pulchriores quoque natutx dotes adipi-propriet afcuntur. Quis enim non miretur volucrum innidis ad ampes tes unde architecturæ leges conftruendis induftriam: quis modulationum ad muficx artis amuffim expreffarum dulcedine non. capiatur ? quis aftutias \& induftrias tum ad imperendas alias inimicas, tum ad hoftiles infidias eludendas, venandique fagacitacem non obftupefcat? \& cum homini, five formam, five naturalem corporis confticutionem fpectes, diffimiles" fint, lingua tamen \& ingenio, loquelâ \& inventione, hominis operationes maximè affectare videntur. Qux quidem naturales avium proprietates non nifi ex forma earum, qux aliud non eft, nifi excellentifima dictæ lucis portio cum nobiliori fubtiliorique elementorum parte, juxta Divinæ fapientix archetypum prodierunt, qux in appropriatis materiis indivi-

$$
\text { Gggg duata, }
$$


duata, haud lecus ac un quadrupedibus, eam quam mirabaris diverfitatem effecit. Ex ut exemplo rem tibitotam propius demonftrem, Aquila avium regina, puriffimi aëris incola, profua forma eam lucis five calidi primigenii portionem accepit, quam talem volucrem talibus naturæ doribus inftruAtam cumprimis decebat; qux puriori aëris, \& minùs fubtili aquæ femini cum modica terreftris portionis fubftantia fefe, infinuans, verbo Dei ineffabili, eam, quam tibi defcripfi, volucrem exhibuit. Idem de cateris judicium fit; qux uti ex varia lucis cum elementorum partibus combinatione coalue. runt, ita differentibus quoque naturæ ingenii, indolis dotibus inftructæe fuerunt. Volucres itaque dictâ ratione Divina vocis efficaciâ ftatim perfectum eflèntix fux ftatum nactx funt; femen autem earum mox intonante Dei voce, Crefcite б. multiplicamini, $\xi^{2} c$. perfectum fuic, quâ incitatæ volucres. fine mora ad generation is opus fe accinxerunt, \& in innumerabilem multitudinem juxta fpeciei cujufuis exigentiam fefe propagarunt. Semen vero ex appiopriato ipfis alimento, \& fimilitudine quadam naturæ earum quàm maximè congruo affumpto reparatum fuit, perenni propagatione duraturum. Nam ut fuprà à me audifti, later in alimentis fingulis animantibus deftinatis lucis quadam portio, prorfus ad lucis" avium conftiturivæ rationem fimbolizans; ac proinde iftiufmodiex infita quada $m$ iis fymparhia, naturali inftinctu, feu feminis fuf reparativum appetunt. Theodidactus. Omnia mili luculenter expofita percepi: fed modò explices, cur natura ovumà frmella volucrefeparatum, feclufumque effe voluerit. Quifnam fit archirectus ille, qui externo tantùm adhibito calore,tantam \& tamadmirandam volucris ftructuram ex ovo refufciter ? fiquidem capere non poffum, qtomodo externus calor, internam f permaticavirtutis energiam excitet, non avium folummodo fotu, quin vel ipfo attemperato hominis", \& quod maximum ent, ipfo for nacum calore, uti in Agypto moriseft,ad infignem temperiem reducto. Cofmiel. Audifti jam fuprà,calorem externum fubfintere minimè poffe fine lucis 
lucis primigenix five calidi innati miftura. Calor itaque calor exexternus, in cujus centro latet vis ifta mirifica lucis primige- terntes las nix, cùm ejufdem rationis fit cum eo, qui latet in fpermatica e.so birtuovi foetura; neceflàriò ei tametfi extrinfecè applicatus, idem nalemper tamen $x \alpha \tau \alpha$ eilv on $\mu \pi \alpha \theta$ trav agit, quod calidum innatum, five nampathiā id volucri, five homini, five elementari calori infitum, dum-excitat. modò temperamentum effectui producendo aptum, adeptus? fuerit. Vitalis enim ille internus calor utiopifex fuicorporis, ita verus fuæ domûs faber eft, quâ fabrefactâ, difpofitâ, feclusâque,tunc ultimum actum educit, ex potentia fui ipfiusfuícitando fpermaticam vim, \& animando informandoque ope caloris externi fibi congeneris corpus illud perfectione ultimâ, quam calor nativus in illam materiam introducit. Theodidact us. Jam dic, rogo,cur natura ovum, quod intra osum cur volucres producitur, feparatum, non vero reliquarum ani- fe paratums mantium more fremellæ conjunctum effe voluerit. Cofmiel. balatilinum. Hujus rei rationem hanc effé fcias, quòd id natura volucrum repugnabas. Cùm enimhumidifimæ naturæ fint ex aqueo-aểreo elemento productx; contingit, ut mox humiditas illa unà cum excrementitiis foecibus in neceffarium. Pennas so: pennarum ornatum veftitumque, fine quo nec vivese, nec lucrum ex volucres effé poffent, perperuâ exhalatione degeneret. Cu- ${ }_{\text {te numaditarale }}$ jus quidem apertum fignum ert, quòd nec per urinam quidem ' generario fuperfluam humiditatem exonerent. Tota itaque partim per excrementitias foeces, partim per cutis poros in pennas abit. Hinc fifemé intra volucres foeminas multô maribus humidiores ingeftum fine ovi providentia inextitifet, certum eft, totum id per halitum, haud fecus ac reliquam humiditatem, in pennarum apparatum degeneraturŭ fuiffe. Nè itaq; tanta naturæ in- Ooo in efconvenientia contingeret, provida natura illud intra matri- $u$ t natura cem fimul ac infusŭ fuerit, mox pellicula circumdare voluit, nè bumidd $f_{-}$ interno matricis calore conceptú femen , unà cum cærera hu- minis sub miditate evanefcente naturæe effectu intento, exhalares. Hoce- probides $^{2}$ nim pacto,intra pelliculá conclusú confervatumq;, veluti intra ${ }^{\text {rit. }}$ peculiarě matricé vires fuas illkefas unicè côfervat, donec paula-

$$
\text { Gggg } 2 \text { tim }
$$


Calorinnatis diGerficolorum plu. marü cau (a)

tịn rurgefénce feminali fæcura, \& idencid dilatatâ pelliculâ, fib determinaca exten ione in teftam indurefcat, \& fic veluci fructus quidä volucris debitam maturicarem nactus excludacur,ac candem fotu\& incubitu volucris per naturalem calorem extrinfecè applicatum, defideratum pullum ruptâ teftâ exhibeat. Arque hoc pacto ex ovis volucres, \& ova ex femine volucrum nalcuntur. Theodidact us Abundè mihi facisfactum eft; quare jam ad ejus folucionem progredere,quod erat de colorum in avium plumis pennifque elucefcente varietate. Cofmiel. Nôris,ni fallor,ex chymicis experientiis, internum lumen, feu calidum innatum unicuique inexiftens, quod \& fulphur naturæ dicicur, decoctione fui ipfius colorum omnium. fontem efle: nofti etiam, ni fallor, quam innumerabiles colores mercurialis illeliquor unà fali mixtus producat. Theodid. Novi equidem, \& fape fưmmâ admiratione contemplacus' fum iftusmodi naturæarcanum, quam caudam pavonis Chymici ob admirabilem colorum diverfitatem appellant. Cofmicl. Bene fentis, \& ita eft. Cúm itaque in volucribuscaliExcremen: dum innatum, five fulphur naturæ, fit oppidò calidum, nitrofa $E$ fale refer. atque ex humido radicali maxima ex parte coaluerint, fai4. le quoque abundent, uti videre eft in excrementis earundem.

Pe inesale abundantia falis adeo refertis, ut ex gallinarum columbarumquumodo decoloren. iur. que ftabulis calidiffimis ingens nitri copia extracta, hand exiguum lucrum conferat iis, qui hujus artis notitiâ vitam colerant; certum eft, humidum volucrum unà faliciciem inexiftenti mixtum, mox ubi per poros corporis exhalatum radices pennarum intraverit, à calore internovariè jam concoctum, \& calore aëris ambientis induratum, falino-fulphureo-mer-

Auescur fintalize nigre, a:curiali vi refertis plumis in pennas alasque paulatim dilatari expandique, eâ colorum varietate, quamfal \& mercurius nacantide alie turæ virtute in fe continer, \& volucrum fpecies veluti jure fuo Bariegari coloris. poftulat. Theodid. Hoc capio bene, \& rationi experimentifque congruir. Veruntamen cum nonnullas aves nigro, uticorvos ${ }^{2}$; nonnullas, uti cy gnos, candido; quafdam ex utroq; miftas colore, uti picas; alias, uti Pfittacos, upupas, pavones, gallinas, \&rc. omni 
omnicolorum genere veftitas videam, unde hoc proveniat, fcire cupiam. Si enim quod tu dicis, verum eflet, jam omnes omnino volucres diversâ colorum mixturâ adornatæ fpectarentur ; quod experientix repugnac. Co/miel. Rectè dubitas, ac proinde ut naturæ leges exactiùs calleas, \& latentes rerum caufas luculentiüs poffideas, noffe. debes, pro vario in fubjeEta materia fulphuris, mercurii, falis mixturæ gradu fieri, ue dum fub iis æaquali mixtura colores omnes vigent, aliis quifquiliis non fuffocati, volucris inde enafcens omni colorum genere exornetur. Sitres folùm vigeant, reliquiverò temperamenti mifturâ fupprimantur, tres folùm in volucris pennis" fpectabuntur; fi duo, duo tantùm; fi denique unus folummodò vigeat, reliquuis terreftri craffitie fuppreffis, unum tantùm, emergere certum eft: Et fi quidem terreftris portio elementi pravaleat, volucris atrocolore veftita, uti coruus; exibit ; fi aqueus pradominetur humor, candida volucris nafcetur,ur cygnus ; fi füb æquali gradu humidum cum terreftri mifceatur ${ }_{2}$ volucris nafcecuc ex albo \& nigro mifta , uti pica; fi denique terr - aqueo - aëria miftura conftet fub mifture graduum æqualitate, avis inde emerget vario colore imbuta. Continuati verò colorum mirificè digeftorum diıctus, quorum in pennis avium pulchrum ordinem ac difpofitionem. miramur,dum in nonnullis fpeciebus.volucrum capur, in aliis cauda,collum in aliis,alæ; venter, dorfumque tantâ colorum varietate difpofita cernuntur, id plaftice in femine latentis virtutis opus eflè nôr is, qux pro.officio fibi à natura commiflo unius fpeciei aves tali tantùm colorum picturâ ornat, non aliâ, \& hoc femper, \& in omnibus individuis eodem femper artificio præftat. Theodidactus. Perplacet mihi folucio. Jam doceas me velim, quanam ratione coloresifti, quos Phyfici intentionales vocant, \& in pavonibus, halcyonibus, \& collis anatum,columbarumque elucefcunt, \& tantopere Phyficorum ingenium torquent, oriantur. Cofmiel. Non equidem miror, cranfa colo. hujufmodi colorum phafmata phyficos oppidò torquere, cùm $^{\text {irum inten- }}$ caufam hujus rei reconditiflimam habeant, quam \& tibï modò tin collis co-

$$
\text { Ggg } 3 \text { exponen- immbarkm. }
$$


exponendam duxi. Theodidactus. Nihil mihi gratius accepriufque accidere poteric. Cofmicl. Tu noft jamex ea arte, Quam jam àmultis ann is pubłici juris fecifti, \& Anaclafticam five Refractoriam appellas, omnia diaphana corpora fub angulorum obcuficate, aut acurie, vel fub inæqualium fuperficie-

Refrexione 1 um fcabritie extenfa, id proprium habere, nt reflexo lumine

luminis

Eariicolo.

resexbi-

bentur in

corparibus

diaplassis.

Pennelu cem refrin gentes colores dictos effingunt.

Colorum Earietatis etiam imaginatio caura elfe potest. ex uno in alceruxn, bidcnque variè refracto, mox insumerabilem colorum varietatem exhibeant, $\&$ experientia in vitris trigonis Polygonis, five polïdris omnbus luculenter docet. Hoc itaque fippofto, cum volucres, utifuprà diximus", falis copia mirum in modum abundent; fic,ut id volacilis fui fpiritus agilitate intra volucrum pennas infinuatum, externi aëris \& humidi virtute mox in plumas coaleficat, ex fe $\mathcal{Z}$ fuâ naturâ diaphanas, \& vitreâ quâdam formâ praditas; qua pluma pennæque, uti in gnifcabricie, tamet infenfibili,pollent, ita lucem iis affufam in tanta fibrarum plumearum \& virco quodam humore concretarum agglutinatione mirificè refringunt, quæ pro varia ad lucem applicatione eam, quam Philofophimirantur, mutabilium colorum in volucrum pennis varietatem producunt, atque adeo nihilaliud illi colores fint, quàm intra fibras plumarum vitreas \& diaphanas variè refracta lux. Et nè experientia refragari videar,accipe Smicrofcopium,quo in minutioribus examinand is uti foles, \& dictas pennas exactius lufra; inveniefque verum effe quod dixi. Videlicet ingentem plumearum fibrarum in morem vitreorum filorum cranslucencium ordine digeftam copian. Atque hac genuina illa,quam tantopere phyfologi mirantur, colorum intentionalium caufa eft. Quod verò natura quafdam volucres nullo certo coloris veftitu ornarit, fed omnigenâ colorum varietate imbuerit, id ut plurimùm vi phantaftcâ feu imaginativâ ex objectis varii coloris imbutâ proveniu; de quo cùm tu alibi fusè egeris, diutiùs immorari nolo. Theodidactus. O quantâ me voluptate afficis, dưn tantúm mihi naturæ arcanum aperis! adeo enim fcirè caufam hujufmodi

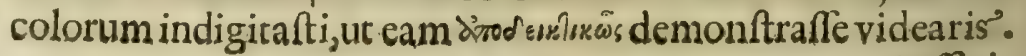
Sufficir 
Sufficit enim, quidquid me tantopere circa avium genefim: angebar, abundè à te mihi explicatum fuiffe. Quare jamad animalium genefim progrediamur, qua intra aquas natales fuọshabent.

\section{Aquatilium Genefis:}

\section{Oofmiel. Dixi tibi fuperitis, Theodidacte, Iucem illam} radicalem, feu mundi femen, omnibus mundi corporibus fefe infinuare; \& in coeleftibus quidem corporibus puriffimum, uti in fe ipfoeft, in aëre quoque minùs tenue quàm. in coeleftibus, in aqua minus tenue quàm in aëre, in terra denique minùs tenue quàm in aqua, id eft, fub crafliori forma exiftere; in fingulis tamen elementis, ubique diffufum, nbique prafens, ubique foecundum, ubique admirandos effectus caufans. Er quemadmodum ex aëre \& aqua femen utriufque ad volucrum conftitutionem, ita illud in aqua latens folùm ad pifćium generationem, in terra verò \& aqua mixtum ad quadrupedum vegetabiliumque productionem. concurrit, aquâ in omnium viventium, imò \& mineralium productione, ceu paffivo quodam rerum omnium univerfali principioconfluente, cùm fine hac nullum elementum effectu defiderato potiatur, nec ignis, terra, aër, fine hac ullatenus confiftere poffint; omnium quippe fomentum, omvium reliquorum elementorum bajulus, cujus ope omnes mundi thefauri, unà cum coeli elementorumque feminibus, in fubterranea natura gazophylacia ibidem digerenda, atque in omnem circumferentiam diffundenda, tranfrehantur ; ut proinde mirum non fit, tantam \& tam innumerabilem, quintam in nullo alio elemento videmus, five diverfitatem fpecierum, five multitudinem fpectes, hoc velunicum ele-

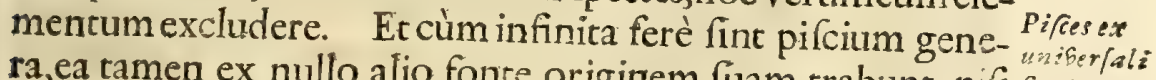
ra, ea tamen ex nullo alio fonte originem fuam trahunt, nifi emine oriex varia 8 multiplicialteratione feminis univerfatis, in aque $g_{\text {bunt }}^{\text {ginem }}$ tr s= elemento individuati', pro va ad diverfarum e em 
partium difpofitione, quod femen uti infinitis ferè combinationum legibus in aqua veluti in utero quodam, utià calore centrali fui ipfius \& à calore coelefti íemini individuâ quadâm focietate perpecuò junţo, alteratur, difponiurque; ita quoque id ipfum infinitas pænè natarilium lpecies, provaria dicti naturæ feminis divifione atque individuatione, producere necefle eft. Theodid. Hinc fequeretur, Deum in principio rerum pifces non ex aqua produxifle, fed aquam ex fui ipfius femine illos generafie, quòd Sacrx paginx incongruum videtur. Cofmiel. Opificem mundi fapientiam in principio rerum pifees \& omne natatile divinæ fuæ vocis imperio produxillè, fălvâ fide negare non poflimus. Siquidem ad Divinæ vocis nutum., in momento innumerabiles pifcitm fpecies ex feminis natur in aqualatentis divifione, in minuriflimas portiunculas facta prodierunt, quarum unaquaque ad fpeciem à conditore Sapientiffimo intentam conftituendam, fub tali \& tali combinarionis temperamento concurrir, ha verò deinde per fpermaticam facultatem pifcibus inditam, fefe in infinitum, in totam temporum fucceffionem mulciplicarunt, atque hoc pacto pifces in primordio rerum àDeo conditi fint: non tamen inde fequitur, aquam ex proprio fui ipfius femine pifces producere non pofle,cum hoc ipfum experientix repugnet; atque in novis pifcinaram feu vivariorum foffis apertè patet, qux aquâ aliunde introductâ repletæ, non ita multò pònt diverfis pifcium generibus replentur; certè non aliunde, quàm ex varia illa lucis radicalis, feufeminis naturæ in fubiectæ materiæ variè difpofitæ divifione \& diftributione: quâ facta, \& caloris cæxleft is fotuaccedente, in animal aquarile fub tali combinationis lege mox exfufciratur, \& fimile fibi fub determinato magnitudinis limite producit in perpetuas generationes tantâ multitudine \& varietate, ut nemo fit qui ijs nomina imponat, nifi is folus à quo condita funt, Deus benedict us in fecula. Theodidact us. Non opus eft ulteriùs progredi, cùm ex præcedentibus illuminatus, mentem tuam abundè intellexerim: funt enim tua Phyficæ principia adeo rationicongrua, adeo veritaticonfona,ue 
Cap. V. Deglobo Terra: qui ea uni animantium generi applicata viderit, reliqua nullo Aquatititu negotio propriâ ingenii vi , quantumvis profundi fcrutinii magnitude fint, attingere poffit. Jam verò hoc folùm mihi explices ve- wnde fito lim; unde belluarum marinarum immanitas; unde tanta a quatilium formâ\& figurâmirè transformatorum varietas; ut proinde mare non meliori nomine, quàm Proteiregnum, frepe ficpius indigitarim. Spectamus in Oceano immenfa magnitudinis Balenas, mediocrium pificium ingentes exercitus, minimorum omnis numeri expertem mulcitudinem; ur interim cruftaceorum, teftaceorumque, atcque exfanguium variis" freciebus differentium infinitam diverfitatem fileam. Caperefiquidem non pollum, unde ex aqua fimplici tanta rerum. varietas refultare poffit, prafertim in elemento tam inftabili, \& perpetua agitatione volubili, praterea acri falfugine imbuto, quibus tantum abeft ut generatio concupito fine potiatur, ut potiùs hu jusmodielementi inftabilitas, unà cum corruptivi falis ubertate omnem generationis effectum impedire videarur. Cofmiel. Quodad varietatem attinet aquatilium, jam fuprà dixi , id totum ex varia primigenix lucis in differentibus" materiis individuatione contingere; unde te falsâ perfuafione induci nolim, aquam homogeneis partibus præditam,ubique ejusdem femper rationis effe. Nequaquam. Sicutienim terreftre corpus ex maxima partium diverfifimarum commiftione conflatum eft $;$ ita \& elementum aquarú, tum in fe ip To $_{\text {Situs ter }}$ cxterorum omnium elementorŭ miftionem continet, tum ex reftrium ipfo fundo maris differentis conftitutionis, tũ naturalibus in- partium fularum regionumque, quas perpetuâ alluvione terit,proprie- naturat tatibus imbutum, tüm perpetuâ mineralium fpirituum è fun- aquas. do maris exhalatorum mixtura, corpus aqueum fummopere redditur heterogeneum. Accedit hifce, varia marinæ aqux vifolaris æftûs concectio, ex qua diverfiffimæ inferuntur materix aquex difpofitiones ad rerum adeo variarum productiones. Namtametfi aqua maris limpidiflima videatur, fub illa tamen limpiditate fulphur, mercurium, falem, naphtam, bitumen, innumeras deniqque rerum fpecies, fub infenfibili tamen Hhbl

fpiri- 
Piciume ing:ns in wh gribiulo

unde. genera una de fint.

Experimentum.

finituis hubtilis \& tenuis veftimento coacervari, fola ratio \&e cxperientia fpagyrica docer. Unde mirum non eft, fi coelestis femmis portio in tenaccm \& vifcofam bituminofis.piritibus turgentem féfe materiam infinuaverit, tum ob copiofifimum femper prafensalimentum, tum ob tenacitatem \& vifcofitatem, qux facili negotio in omnem dimenfionem diducitur, ingencis magnitudınis pifces enafci; fi verò dicti luminis portio, in excrementitias hipidofx materix quisquilias inciderit, cruftacea tertaceaque inde nafci necefle ent, qua deindeeodem, ex quo coaluerunt, alimento vivunt. Hinc femper fundo hærent, id fuctu infe \& attractu quodam derivantes, exquo conftant. Ex mercurialis verò abundantia liquoris, fquamigeri gregis agmina nafcuntur ; quæ omnia tibiulteriùs examinanda \& digerenda relinquo. Harum enim rerum mutuâ combinatione factâ,nullum tam prodigiofum in aquatilibus, five colorem, five formam \& figuram, naturalefque proprietates.fpeetes, effectum reperies, cujus caufam non ftatim ex indigitaris? paulò antè principiis fis aflignaturus. Quod verò ultimò objiciebas de falis deftructiva virtute, falleris; tantum enim abeft, uc fal five falfugo illa marinagenerationem rerum impediat. ut potiüs.nihil fit quod eam tantoperè promovear:eft enim, uti ex Chymicis nofti, fal, femen quodda m natura, omnibus rebus inexiftens , fine quo nulla res focunda efle poreft, fed illudor mnia foecundat, \& animat, utpote in centro fuo conclufum tenens totius naturæ fèmen. Et fi experientiâ vem comperire velis, plantam quampiam in falem arte tibi nocá converte; quem falem fi terræ purifim $x$ inferueris, ftacimille in eam, plantam, è qua extractus fuerat,, repullulabit. Of reis quoque in falem converfis , mox ubi arene maxis dictum falem commiferis, ingentem novorum oftreorum fobolem cum tempore inde prodire reperies. Idem de omnibusaliis fentiendum.. Abfit itą̧ue,ut quò nihil natura foecundius produxit, tu fterile dicas. Quöd verö inftabilitatem mar is velutigenerationibus minimè idc neam accufes, perperamagis; cum in mariad rezum productionem non neceflaria fir quies illa, quam reliqua. 
extra aquam animalia jure fuo vindicant : fiquidem innumerabilis illa ovorum multicudo, quam pifces mox, ubi intra deftinata vafa ad maturitatem pervenerint, effundunt, non more volucrum fotu excluduntur, fed arbitrio maris, coeleftifque ca- osa picicié loris providentix in omnes maris femitas effufa committun - non exclum tur, donec virture coeleft is Iucis exclufa, tandem totum mare, crumm more. tum in ufum \& fuftentationem hominis, tum aliis pircibus in. nutrimeritum impleant. Theodidactus. Quix dixifti, probè inrellexi; perge modò id quod ultimo reftabat, de infectorum reptiliumque genere mihideclarare.

\section{Genefis Infectorum.}

Cofmiel. Notandum, infectorum, paulò latiùs in rem no- Infeteturum ftram fumpro hoc nomine, triplex efle genus. Aliud gents trienim fub fe volatilia, aliud reptilia, aliud multipedia infecta plex. continet. Quæ iterum in varias differentesque fpecies dividuntur. Prius genus mufcas, cynjphes,bruchos, fcarabæos, locuftas, papiliones, quorum nutlus eft numerus, fub fe comprehendit. Secundum genus omnium ferpentum, vermiumque genera. Tertium animalia tum quaternis, tum multis pedibus inftructa complectitur, uti funt forices, mures, lacertæ, crocodili, \& quidquid tandem ex putri partim, partim ex feminis proprii commixtione in infinitam pullulaginem multiplicatur. Multipedia,omnia aranearum,pedicuilorum,cimicum. erucarum, cruftatorumque vermium genera \& fpecies continent; qux quidem ex putredine mixtorum originem habent, vel ex vegetabilib!s natcuntur,vel ex animalibus, vel ex putridis terreftris materiæ quisquiliis, qua in aëre, aqua, terra confluxerunt, oriuntur.Hoc autem pacto animantur. Putredoni- infecta hilaliud eft, quàm indigeft i humoris confluxus, five is fiat in quomodo

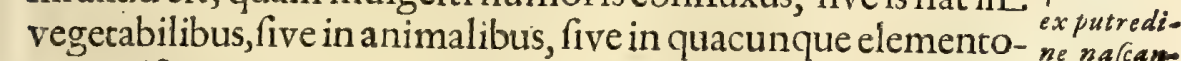
rum miftura; qux uti pinguedine \& calore pollet, ita lux pri- tur. migenia, five femen mundi in ea materia individuata calore fuo interno derepente, ob proximras ad gencrationem difpofiHhhh 2 tiones, 
Ignis non tiones, animal excludit, juxta eam materiam, è cujus putredine producit infécta, nec educitur. Ita quidem, ut non fît ullum vegetabile, ullumaniilla produ- mai, elementum ulìm, quod non, excepto igne, aliquod infecunt mixta ctum producat. Eft \& hoc notandum, nullum in mundo mixGita-exper. titis rum infectum aliquod producere poffe, nifi.llud primò viam. habuerie: unde fola netallica \& mineralia corpora, utinullis putredinibus obnoxia func, ita nulla quoque infecta animalia. generant. Si qui verò vermes in poris lapidum fubinde inveniantur, id non provenic ex eo, quòd ipfi immediatè ex faxo geniti fuerint, fed quòd in poros faxialiunde delatum fit femen, ex quo vermes, profluxerunt. Qux omnia cùm tu fufiùs Infecliorum in operibus.tuis ofterderis, hic longior efle nolo. Theodidact. fisis. Dic, fodes, hoc unicum; quem ob finem natura cam differentes infectorum fpecies, \& cur tam innumerabilem copiam excluferit é cum tamen pleraque homini \& animalibus tantopeInferta Gé re noxia funt, \& pleraque exitiali quadam virulentiâ imbuta.

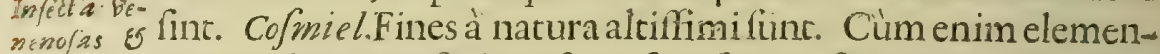
roxins ta putridis corpufculis referta fint, fit ut infecta animalia aëris, astrabunt aqux, \& terre pucredinem venenofam in iis latentem in fe veluti in vivas quasdam burfas attrahant, colligantque, nè putredinis contagione in vicinas elementi partes ferpente totum. Infect a ai-paulatim cum extrema viventium pernicie inficiatur. Hifce rem, aquā, fiquidem infectis, \& aër, \& aqua, \& terra à fuis noxiis qualitatipurgan bus, velitiabinfirmitatibuis quibusdam purgantur, \& defæcantur, atque ad meliorem ftatum reducuntur; quod \& de vegetabilubus, animalibusque dictum velim. Hoc pacto infecta. quædam infitâ vi, \& nefcio quo magnetifmo, quidquid vitiofum \& inquinacum in aëre fqualer, ad feattrahunt. Infecta verò ex aquæ profapia exorta, idem in aqua, quod aërea in aëre, \& terreftria in terra operantur, unoquoque fui fibielementi purgationem actractu quodam magnetico vel fympatico in. bonum natura procurante. Hæc verö infecta ubi munere fuo Nibil in. probéfuncta fuerint, fapientinaturæ confilio, tandem in alinetura jimentum cenunt terreftrium, volatilium, \& natatilium, vitæ confervanda necellarium. Vides itaque, nibil in natura re- 
rum fine optimo fine effe confticutum, nihiladeo opinione hominum malım \& perniciofum, quod non in faluberrimum mundi medicamentum deftinatum fit. Theodid. Abundè mihi fatisfactum eft; adeò enim intellectum meum fapientia tux radiis illuminafti, ux ex his animum ad magna \& ardua ; boni communiscausấ obeunda extollam. Cafmiel. Satis eft, paulò majora canamus. Audifti modò totius exterioris telluris confticutionem, percepifti ni fallor Elementorwn mutuo quodam officio decertantium collufionem. Vidifti quornodo \& qua ratione ex iis omnia componantur, \& in hunc ufque diem \& à primordio rerum producta fint, quorum quidem omnium Iux illa primigenia in huncusque diem peromnia mundi corpora diffuf $a_{\text {, verum }} \&$ univerfale mundifemen, \& Entelechia nacura rerum, qux unica ars. Dei eft,caufa eft. Hæc enim materix pro infinita difpofitionis \& alterationis fur rom tione individuata omnia conftituit,omnes rerü formas educic omnia animat, fovet, alit, confervat; hæc in faxo faxum, metallum in merallo, in plantis planta, animal in animali, in elementis elementum, in coelis coelum, in aftris aftrum; eademque ipfa natura rerum fúo quodam modo, fed ratione abftractior in homine homo, in Angelis Angelius, in Deo tandem, us ita dicam, Deus ipfe optimus maximus, quiomnia in omnibus operatur, ac proinde benedictus in fecula.

$$
\text { *** }
$$

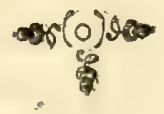

Hhhh DIALO. 


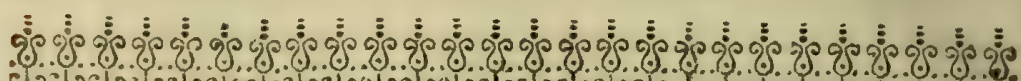
粠

\section{DIALOGUS III.}

\section{Iter Extaticum in Mundum Subterra-} neum.

\section{Interlocutoribus Cofmiele, ES. Theodidacto. C A P U T I.}

Exploratur maristum extrinfeca,tum intrinfeca conftitutio; animaliumque in comultitudo, औै varistas defcribitur.

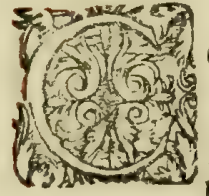

O SMIE L. Examinatâ jam externâ Geocofmi fuperficie, ejusque admirandis qux in herbis, plantis, animalibus, elementorumque operationibus elucefcunt, fpectaculis; jam iter immenfum nobis reftat fubeundum, iter nullis humanis tricum veftigiis, nullo mortalium intuitu perluftratum; ubi tocius naturæ conftituta funt Gazophylacia ; ubi cernere licet fumma fapientiflimi Opificis in Geocolmi architecturâ magnalia : jam. tandem, quod fuprà tibi pollicebar,complebo, ut vifis ineffabilibus Dei operibus totus in laudes tui exardefcas Conditoris. Theodid. Certè uti nihil ad votum mcum acceptius accidere poteft, ita quod jam dudum tantopere defiderabam,ut in executionem deducas, pro eo quo poflum intimo cordis affectu abste contendo. Hoc unicum à te efflagito, mi Cofmiel, ut pri= mò modum doceas, quo me per tam intricatos calles, marisque abyflos incognitas, per tot difcrimina terræ,ignis, \& aquæ, fine ullo corporis mei decrimento deducere ftatuas. Novi 
Cap. I. Irer Submarinum.

quanta à belluis marinis nobis pericula immineant; novi interioris telluris fpiracula peftifera, \& prorfus exiciali vaporum exhalationumq; virulentiâ referta. Novi quot Vulcania igniŭ fornaces nobis fubeundæfint; quot, quàmq; innumeræ aquarum abyfi nobis tranfuadandæ. Sed intua confifus pietate, \& incredibili bonitate, tuam accepto plenam benignæ in me voluntatis invitationem. Cofmiel. Nofti, mi Theodidacte, per quanta te in itinere colefti pericula, per quor igneos coleftium corporum Oceanos, per quor maria peftifero halitu obnoxia, ab omni tamen noxa immunem traduxerim. Et quid dubitas de mea in te fide in incerioris hujus Geocofmi luftratio ne? annè putas eam, quam in itinere coelefti obtinebam, in. Geocofmi peragratione poteftatem mihi ademptam?an ignoras coli, terræ, atque adeo totius nature claves mihi concreditas? an nefcis, quòd uti fum præfes Inniverfi, ita quoque omnia, qua in naturæ Majeftate elucefcunt, divinâ fic ordinante providentiâ, meo fubfint imperiơ? Hinc nulla eft tanta tumultuantis aquæ contumacia, quem non ad voluntacem meam protinus domem; nulla tanta incendiorum fubterraneorum. torrentiumque ignivomorum violentia, quam non juflu meo è veftigio fupprimam; nulla tanta exitialis vaporis atrocitas ${ }^{5}$, बุuam non mitigem; verbo, nullum adeo ingens periculum tibi imminere potêt, à qưo non meâ cure lầ \& protectione libereris.Magno itaque fis animo, mi Theodidacte: fierifiquidem non poteft, ut ullus tibi finiftrior eventus accidat, ubitanta fortitudinis, potentiæ, \& fapientiæ ducem tibi perpetuò affiftentem habueris. Theodidactus. O mi amantiffime Cofmiel! poft Deum unicum cordis mer folamen! de tuo inexplicabilis benignitatis affecturerga me indignifimum \& humillimum fervulum curm concepto prorfus entbefco. Et quinam ego pauperrimus \& vilifimę conditionis homo fum, ut tantum. merear animi corporisque tutorem, tantæ fapientix magifrum? ô Deus, gratias tibiago de trau, fmiflo mihi tanti tutoris fubfidio; laưdes tibi ommium operum tuorum ineffabilium. vocibus unà junetas perfolvo, ob ingens, quo me tanti prafid is cutelâ 


\section{TtinerariumII. Dialogus IIT.}

Eutelâ munîfti,bene ficium. Teitag;,ô Cormiel, quem veluti Divini archtvii prafidem, eâqua pollum animi fubmiffione veneror, eumq; qui arcanorum Omnipotentis Dei operum confiliarium ag is, unicè fufpicio \& admiror; te inquam obnixè \& eo quo pollum mentis obfequio obteftor, ut qua per te fieri pore cogicavi,p rficias: ecce fervus tuus; fac guod jubes, \& jube quod vis.V $\mathbf{x}$ dum hęc pleno mentis ardore effuderam, cum ecce ad ripam Oceani conftitutus, nefcio quid fplendidum \& mirè corufcum contueor; \& cùm vehementer attonitus hanerem, his me verbis affatus eft. Cofmiel. Quid miraris, Theodidacte? Theodidact us. Miror ibinefcio qued cryftallo fimile opus, \& quodnam illud fit, nofle defidero. Cofmiel. Hæc eft naviculaquam tibi preparavi, ex puriffima cryftallo meâ rmanu conftructa; huic in pofterum inclufus, per unvverfas Oceanifemitas, abyforump; fubterreftrium immenfa hydrophylacia,me Nautâ \& Gubernatore vehêris. Diaphana eft, ut per ejus parietes vitreos veluti per feneftras quasdam omnia naturęarcana cominus intuearis, ab omni periculo aquarum tutus \& $\mathrm{fe}$ curus. Theodid.Et quomodo navicula haec intra intima Oceani vifcera fundiosque fcopulis impeditos fine ullo rupturæ detrimento promoveri poterit? quis neceflàrium nobis aërem füppeditabit? quis lumen in tantarum caliginum abyflis ? Cofmiel. Non eft tuum de rerum tibi neceffariarumfubfid iis follicitum eflè; ego fum qui potentix mex viribus omnia fubminiftro; ego naviculam fummo artificio à me conftructam ita gubernare novi, ut nulla fit adeo dura cautes, qux ei vim aliquam inferre poffit. Ego humorem ipfum mox in limpidiffimum aërem. converto;ego lumen \& lucerna fum, qua vel denfifimæ cavernarum caligines in lucidifîmum diem convertantur.Agedum itaq; , Theodidacte, nè rerum humanæ induftriæ minimè fubjectarum faragas; hoc enim meum, meique fimilium officium effe fcias,utpote qui fcientiâ rerum naturalium tantò fublimiorieminemus, quátò natura humana abA ngelica diftat longiùs. Theod. Hifce dictis, per oftiolum intra naviculam cryftallinam 
ingredi juffus. Erat navicula eo artificio conftructa, ut ad inftar vitrimundi\& cryft allipurifimx, qualibet fine ullo obftaculo, intra vitrei oceani meditullium objecta exactè exhiberet; nulli ibi remi,nullustemo, nuila velisfubtenfa arbor, fed illa pro nutu \& voluntate Cofmiel is agitabatur,aut fiftebatur; neque hîc ullum aëris, neque luminis defectum experiebar, ubiad mundi prafidis imperium \& nutum omnia obfecundabant elementa, \& officiofa fua obfequia offerebant. in hanc itaq; naviculam myfticis fenfibus refercam inclufus ego iter occepi. Cofmiel verò utrum inclufus fuerit, nefcio; certè \& inclufus,\& exclufus, intùs \& extrà omnia operari videbatur. Tantæe itaq; atque tam in follitix rei admiratione atronitus, in hacc verba erupi. O Cofmiel, quo per avia\&devia fine remo, fine remone me ducis? Cofmiel. Brevi videbis;neque enim remo \& temone opus eft ei, qui \& mundum imperio fuo ex commiflione, Conditoris gubernar, \&vaftiflimos coelorum globos fine labore perenni motu verfar. Theodid. Perge itaque, uti coepifti,Euris faventibusitertuum urgere. OCofiniel, quanta per vitreos hofce parieres in Oceano montra video quanta pifcium fpectacula? quàm innumerabiles natatilium exercitus? Co/miel. Omnia hrec magni maris foetus funt, hucufque hominibus incogniti. Theodidact us. Sifte parumper,Cofmiel; quid hoc monftri ? ecce video ante me ad inftar montis ambulantis molem: eftnè pofibile, eriam fcopulos rupefque in mari mobiles effe? Cofmiel. O quàm luderis, Theodidacte! Non hic mons eft, fed Balæna feu Coetus ingens, quorum haud exiguus in hoc Oceanio regnonumerus ftabulatur. Theod. Rogote, miCofmiel, ut ad ejus figuram \& magnitudinem propiùs confiderandam aliquantùm viciniùs me fiftas.Cofmiel. Fiar. Theod. Certè quidquid tu dicas, mi Cofmiel,ego montem hunc fine radicibus natantem, non cœtum comperio; ingens enim hic in eo antrum video; cerno veluti duas arbores vertici infiftentes; for fan una ex earum infularum numero eft, quas natantes vocant. Video quoque graminibus \& herbis marinis, unà cum faxis arena. mirtis, lacera ejus mirum in modum exafperata. Ecce \& aliud 
fignum, corallinam plantam è latere emergentem i ecce híc pratulum quoddam comparet, algâ herbifque marinis refersum. Nec defunc huic prodigiof $x$ moli congefta infertaque'omnis generis oftrea \& conchilia. O miCofmiel,quid modǒvideo duasingentes rupes ad intar carbunculifeu pywopi.fulgentes:ô quantum de fe lumen fundunt ! ò quàm mirum phafma! Cof miel. Sac apparet, mi Theadidacte, te nec dum mirabiliü: mund inocitiă habere, dum tam pertinaci nutus cui ductu, quae. verè bellua marina eft, tu monremaut infulam natantem pures. Annon vides antrumillud, quod ufpeltuncam montis putabas, id apertum, faucium balenæ hiarum efle? Theodid. O pro-

Bualone curfemper bizanties aperie ore. digium! ò miraculum! Dic ergo, quare femper illum a pertum haber, \& cur ita plenum pif́cibusr eperio? Cofm. Cúm bellua hac plurimo femper, obcorporis fui vaftitatem, nutrimento ind gear, dies noctefquead fufficiens fibi alimentum comparandü, folitavenationiinrendit; \& quoniam occulto naturæ inftinctu os in venatione femper apertum haber, pifces forte fortuna obuij,\& ipfrvanâ imaginatione elufi, dumidirupis cujufpiam. fubmarinæ foramenputantes incautiùs ingrediuntur, macurali belluxaftutiâ decepti,captique, in prædam fimul \& efcam cedunt ingeniofi venatoris. Quod verò te moveant gramina, herba, cryftallinus frutex, '\& fimilia; qua ab externa corporis bellusini fuperficie excreta cernis; fateoradmiratione non carereapud eos, qui fapientifimi.Conditoris opera non explorarunc. Quaretu, ub i hujus: vegecabilis ad hrefentis foeturæ caufam cognôris, mirari defines Cùm enim univerfum belluinum. corpus ingenti vifcofitate ob pingued inis adipifque abundantiam polleat, accid it, ut certis temporibus, locoque in fundo maris opportuno, intra algarum, cærerarumque marinarum. ftirpium ftratum; ;eluti in congrao fibi ac deliciofo prato, $\mathrm{fl}$ ve veneris explenda gratia five fumma prurigini qua fubindeagitatur remedium queress, fe voluat revoluatque; cujufmodi locus cumarena, faxis, conchiliis, oftreis fimilique fundi maris progenie refertus fit,certum eft illa intra vifcofam pell is belluina fcabriciem conglutinata, tandem velutiin pingui\& vif́c ofa 
wifcofolimo, quobellux corpus imbutum eft, cum ingenti incremento fucceliu temporis in petrofam fobolem fallugine maris indurefcere. Arche hac cauda eftcur beftam cor plantis, \& conchilis, teftaceifgue animalibus coopertam videas". Quas vero binas arbores in vertice notafti, illæarbores minimé funt, fed fpiracula bellux, quibus aquam nunc attrahic, nunc immenfis diluviis denuò aëri commilà evomic. Quos Balene deinde pyropicos putabas fcopulos, illi nibil alizd quam oculi ocule. belluæ funt, quibus iratum fibi lumen vibrat, tumad neceflaria pabula in caliginofo pelagi fundo comparanda, tum ad illifionis contra fcopulos pericula hife binis veluti praviis lucernis ad obviorum impedimentorum offendicula, infitâ fibi ut dixi, luce propriâ commonftranda, mirâ Dei optimimaximi Providentia, \& fngulari naturæe munere illiconcefláfubfidia; quibus fi careret;ei haud dubiè pereundum foret;tantâ mole motu fuo intra aquas vel ad primam cautium allifionem, haud fecus ac navi impactâ, fatificente. Atque hæe eft ratio cur Balın ralis bellua;terreftres \& fcopulofas aceani partes cane pejus \& curprofumo angue periculorum exantandorum probè fibiconfcia fugiat, tum petat undelatè patentis Oceani medio, \& fundo planiore nullis fco- oceanum. pulis exafperato gaudet : nè mollioribus ventris partibus illis" illifis, exitium fibiex inflicto vulnere ad fenfat. Theodidactss. O quàm miranda mihi narras! Sed rogo te, mi Cofmiel, ue, hiatus belluini fabricam propiùs mihi montres, nullâerìn re majori admiracione me cáprum dicere poßum. Cofmiez. Non hiatum tantümtibi defideratum oftendam, fed \& te per eum. ad interiora ventricofa domus penetralia ducam, ut nihil fic quod te lateat. Agedum perge,à bellua nihil tibi timeas"; ego enim fum, qui ei imperiosâ licentiâ fræna inijcio, 8 ad libicum meum quò volo, dirigo. Theodidactus. Vix dixerat, cün ecce agitatâ naviculâ monftrofum intramus hiatum, \& deinde per faucium gurguftia, veluci per angiporcus quofdam in latè patentem quandam interioris ventris cryptam aquis offufam penetramus. Ubi tam exceflivam caloris vim fenfi, ut Balana in-
intra fornacem me conftitutum putarem. OCofmiel, quo teriora exI ii 3 me 

p'oransur, meducis! quid vehemens ille aftus quem fentio, portendit? tur ejus quid magni illi vicalium membrorum loculi? Cofmiel. Hic confitutio aftus eft nativus bellua calor, ad concoctionem nutrimenti, interna. quo valido indiget, à nacura dacus. Sed jam adverte ad fingula qux tibi monftro. Vides ingentia duo illa foramina, palato ad inftar caminorum longo ductu foras prominentium _? Theodidact us. Video، Cofmiel. Hxc funt illa duo fpiracula, quibus aquarum ingentem copiam, nunc attrahit, modo evomit. Videfnè dentium ordines? Theodid. Video, fed non mihi hi dentes animalis, fed connexa in ordinem fiopulorum acumina videntur ; palatum inftar fornicis cryptæ cujufdam mirè exafueratum videripoflè, tantæ capacitatis \& amplitudinis, ut currum fano onuftum intra fe facilè concludat. $\mathrm{O}$ mira Dei magnalia! Cofmiel.Sed ultrà progrediamur. Videfnè comeatum quem in alimento fibi venando comparavit bellua? Theod. Video,\& quidem inter innumera pifcium genera, cadaver. forfan naufragi, \& natando evadere conantis hominis belluæ.

Balence cor quale.

Ba!ans puimones ficus Gelum ranticum.

Balene Hitpar.

Batens Inteftina in efcam ceflit. Cofmiel. Sic eft. Theodid. Quid tibi protuberar? Cofmiel. Ille eft cordis protuberantis aftus. Theodidact nes. Ecce novum fpectaculum, ingentem lebetem video perpetuò fumantem,ei,quo in cerevifia coquenda utifolent, non abfimilem, \& tu nè illud cor putas? Co/miel. Omnino cor illud eft bellux perpetuâ fpirituum exhalatione fumans. Theodidact us. Sed quidnam hoc; quod inftar veli nautici inflatum video? Cofmiel. Hi funt pulmones belluæ, quibus aërem fibi neceflàrium artrahit; quin vel ipfa aqua ingenti caloris xftu attenuata, hoc loco in aërem convertitur. Theodid. Quid illud,miCofmiel, quod cupulæ adinftar, five tholi ( cujufmodi facellis imponi folet ) rotundum \& tumidum afpicio ? Cofmiel. Hllud hepar eft. Theadidact uss. Quid intorti illiaqui - ductus, quos finuofis" voluminum fpiris protenfos video. Cofmiel. Illa funt animalis inteftina, quibus nutrimenti fres exonerat. Theodidact us. O quis unquam credidiflet tali in rerum natura monftra reperiri? quis infinitam Conditoris fapientiam fat dignis laudibus celebret? qux tanta \& tam admiranda opera ad porentix 
fux Majeftatem atteftandam produxic? Dic,rogo, quem in. finem à Deo animalia hujufmodi funt condica ? non enim videoquidemolumenti in natura rerum afferre polfine; quin potius in magnum detrimentum, obtantam pifcium confumptionem, qua vel iṕe Oceanus fuâ viduatur prole,cedunt. Cofmiel. Nè putes quidquam in natura rerum tam perniciofum ellè, quod non altifimos in narura fines habeat. Nam præterquàm quòd ad Creatoris Omnipotentiam declarandam producta funt, innumera alia preftant in Oceanio regno emolumenta. Imò verò quidquid in eo facculentum, vilcofum, pin- rina ad gue, fordidum, id totum ubi fibi hujufmodi bellua attraxe- quid utilirit, à nocivis facibus aqueum regnum liberat. Secundò, pin- tatisfint guedo hujus animalis tanti ufus eft, ut complures nationes." deftingta. ejus fubfidio carere non poffint; oleum enim ex decoctiones, pingvedinis extrahitur, non tantùm ad lampades fovendas, fed ad eo naves contra aque irruptionem illinendas, \& ad coria. atcenuanda magnum ufum præetat iis, qui fulloniam, ,baphicam five tinctoriam, coriariam, oleariam, nauticam, fimilefque artes profitentur. In Medicis quoque dictum. oleum non contemnendos ufus preftat; cum illud inftar frigidicujufdam balfami corruptis inflammatione membris, id ent,contra eryfipelis ardores, fimilefque morbos nobiliffimum medicamentum fit; eximiumq; contra veficæ dolores, prafertim fi atcenuatum \& diftillatione multoties iteratâ,fótorem \& cupyremma amiferic, arcanum fic. In Islandia quoque vel unicum hujus belluæ feleton in integræ domus ftructuram. feruit. Sed jam ex obfcura hujus bellux aluo emerfi, ad alia. progrediamur. Theodid. Video nobis fuperimpofitum nefcio quod umbraculum, fub forma immenfi veli aut umbonis protenfum: dic, rogo,quidnam fic monitri. Cofmiel. Teftudinem marinam vides. Theodidactus. Fierinè potent, tam vaftas.monftrorum moles Oceanum producere? O mirum rerum prodigiofarum theatrum! Rogote, mi Cofmiel, feftina lentè, ut fingula exactiùs diftinguam; video enim hî́c fưmmâ meâ admira tione, quaccumque tellus \& aër animalia producit, ea \& Ocea-

$$
\text { I ii } 3 \text { num }
$$


num timilıtudine qua dă fingere. Afpicio hîc plíces in equos, vitulos, ce: vos, fues, canes, lupos, elephantes, leanes, mir quadam metamorphofrtrant mutrates; video hirundines, vul rures, \& in collium fimilitudinem montra; Delphinorum. praterea, thinnorum, falparum, halecum, ceterorumque minuciortm pifcium ingentes exercitus, comibus, enilious, malkis, fpiculis mirificè metructos; atque ex hile quoriam videa veluti fugitivos, \& metu conternacos alios ludentium in morem, nunc fupinos, modò pronos mirum in modum gefticulantes. Cofmiel. Quos mecu confternatos vides,illif funt, qui ab infequentis boft is aut Balenæ, aut Orcadis, autDelphini infidis tutum fỉbi queruntafylam; innullo fiquidé elemento tot praxBelle inter liis; tor conflictibus, tocatrociffmis pugnis, ac in aqueothoc pifers. $\quad$ regno belluæfe mituò infectantur: majores adoriuntur minores, mediocres verò implacabiliodio ad necem quarune. majores, quibustametif corporis mole \&̊ robore cedant, aftutiâtamen \& calliditate ipfis innatâ nodos norume, quibus illis proftatis rikgriâ potiantur. At minor pircium grex folus"

Pifcium Garia col.

lufiones guidfigni-
ficent. trum in commune onnium alimentum, tum potifimumbelluis pelagityrannis deftinatus videtur. Quòd verò videas varias illas picium collufiones, modò fupino, modò prono inctrEnu fe fricantes, fcias Theodidacte, intufmodi motibus geftibufque nihil aliud indicari, quàm nacuralem foemina cum mare congreflumad fobolem propagandam,qui per attritiones affructionefque ad fe invicem factas potiffimùm contingit, à natura inftitutum. Mas enim fricando foeminam in partibus à natura deftinetis, ejufdem matrici vaporofum quemdam ipiritum immitrit, qui deinde in ovorum condenfatur foeturam; quæ mox ubi ad maturiatem pervenerit, in maris fuperficien effufa,calore folis, pelagique naturâ, in pirces juxta fpeciem à

Pifcium genus quodoba, fed ca. eulos por. ret. qua profluxit animatur. Nèverò putes omnem maris progeniem ex ovorum foetura fecludi ; funt enim pleræque immaniores Oceanibeflux, uti Balenæ, Vituli marini, Maniocx, \& fimilia vivipara; id eft, fufcepto fermine non ova,fed catulos excludunt; cujufmodi, uti dixi, funt Carti,OrCx, Phyfiteres, Del- 
phini,Phocr, fimilefque. Theodid. Scitè omnia. Sed ò mi Cofmiel, nefcio quid monftri meo modò obtutuife fiftic. Fierind poteft ut in Oceano quoque homines reperiantux? Video enim,quàmvis remotè;nefcioquænă humanæ figuræ phafmata: quare te obfecro,ut eorum propiùs infpiciendorü mihi poreftatem facias. Cofmiel. Fiat. Theod. Verè urriufque fexus homines hîc reperio. Cofmiel. Falleris, Theodidacte, hominesenim sirenes minimè efle aut dicipoflunt, utpote omnis rationis expertia, quid.jngt fed marina funt monftra, fuperioré folummodò hominis parzem exprimentia,inferiore verò in pifcium caudam terminante ; atque ex eorum numero funt, quas firenes antiqui fabulofie doctrinæ conditores poêtræ ftolidè inter Deas numerabanc. Cerne caput hujus fæemellą longấ quadamcafarie, at minimè Sirmás fan pilosâ,fed in cirros quofdam carneos \& pulpofós diftensâ ve - melladeftitum. Vides faciem quidem pulchram, oculorum vivaci_fiription. tate decoram \& blandam, fed, qui ad decoris complementum unicè defiderabatur „nafo deftitusam ? cernifnè brachia folitis?" hominum longiora, manufque monsirs digitos more humano difcretas, fed adinftar pedum anferimorum cartilagine intereepras, arl natandum à nasura fic conftitutas? afpice rotundas" \& rumidas mamillas; quàm candore niveo pectus venterque niteant,quantofplendore corufcent. Theodid. Mihi,nifi oculi me fallant,carnis humanx pulpofa fubftantia viderur. cofmiel. Falleris', fed ea quam pellem putas, illa nihil aliud eft quàm candidiffimis minutiflimifque fquamulis contextum natura opus; quod, ut in onanibus aliis pifcibus, eximio nitose fulget. Videstandem \& fexus difcrimen in caudam pifcis, eamque pralongam terminare? fed jam \& mafculum. contemplare. Theodid. OCofmiel,non hominis, fed Cacodx- Sireni monis mihi figuram referre videtur. Quàm omni formâ maris desodeftituta facies! quàm torci oculi! quàm genas inconcinnas", "rriptiorugifque oppletas!quàm barbam ridiculam! verius pulpam? sarnis dixeris : quàm incompofitos capillos! fi tamen capilli dici poflent. Ego Medufie caput verius putem, auc polypum cirris longèlatèụue exporrectis ex capice emergentem, quàm. monitrof 
monftrofx manus, alisvefpertilionum, quam humanis fimiliores! quàm alperum fqua mis corpus ! verbo, fabrica proı fus' à formina difparaca, \& humanx tamen figur , fi mes brorum ordinem \& ficum attendas, atque ingentem, in quaniterninatur,caudam excipias, non diflimilem. Tale olim monftrum in

Disbolim marinus capeus in Sicilia.

Pifees bol minis figuram referentes.

Finis rerumpimili tudinnm babensium cum bomi-

ne.

Sirenum bires fen biriukes. infula Melitenfi, quen \& dabolum is, inuisi cupellabant, maris xtu in litcus prope ædem D. Virgini Sacram, vulgò della Maleca, projectum me vicille memini; quod in Sicilam delatum, non exiguam quæftús occafionem pifcaroribus dedic. Sed rogote,miCormiel,ad quid natura hujufmodi monftra. efle voluit? Cofmiel. Sinofles, Theodidacle,cur nitr anmalia quadrupedia,fimias, \& cercopithecos, hominibus \& figurá, \& moribus haud abfimsles conftuer it; cur inter aves, Pequinos, maris Magelaniciaccolaserecto corpore hominis ad inftar incederevoluerit; cur inter plantas florem Orchidis perfectum. utriufque fexus hominem abdito quodam molimine machinata fic ; radicibus quo gue, uti in mandiagora , hominis corpus exprimat; cur in mediis quoque lapidibus, achatibus, marmoribusaliifque in profundifimis telluris caveis recondicis laxis", tum humanie figuræ formam, tum cæterorum animalium vegetabiliumque figuram infculpat \& excudat: forfan non tancủm mirareris. Gaudet natura hujuf modi rerum ludibriis; \& uti omnia in omnibus efle intendit, ita pro conditione fingulis entium gradibus laborat, quantum poteft, ut fi non fenfum, falrem vitam ; fi non vitam, faltem figuram nudam iis ad fuam. in univerfi decoris Majeftatem atteftandam imprimat; appetunt enim omnia ulcimam fui perfectionem, \& pocifimim, fimilem homini, qui eft poft D E U M immediatè rerum omnium finis, figuram; quam cum debitis naturæ clauftris impedita confequinon poffint, noñulla quantum pollunt agunt, ut eandem fi non veram, faltem fecundùm analogiam quandam conftitutam confecuantur. Vides itaque, cur tanto ingenio \& induftriâ natura in conftituendis firenibus luferiv. Sed quares,utrum peculiarialiqua, quæ in hominum ufum ce. dat, virtute polleant. Refpondeo, ipfum figillum \& charaEterif- 
cterismum, quo ipfas opifex mens imbuic, quin vel ipfam aftutiam \& calliditatem ingenii hominibus fimillimi, magnum aliquod naturæ arcanum fub illis latere, affatim teftari. Tritones enim, \& firenes, utifimia in tellure, ita hax fuo tamen modoingeniosâ induftrià pollere vidertur; fiquidem ad littora Oceani in inacceffis hominibus latibulis, atque extra omnem mar is injuriam longè femotis, domos fibiadinirando quodam arcificio, ex conchis conchiliisque congeftis mutuâ utriusque ope exftruunt, commeatum venatione interceprum intra loculos quosdam condunt ad neceffarium illis temporeurgentisfamis alimentum; arenam lurofam in formam lecti, quolafla membra recondant, congerunt; terram quoque infolationis gratiâ adinftar amphibiorum petunt, undeab Barbaris Sofa le oram. incolentibus, ubi maximè ftabulantur, in nefarię veneris ứ quaruntur; fructibus quoque \& rerrenis radicibus mirificè delectantur, undeillas follicitè ad virides ripas hominibus inacceflas quarunt,acceptas in folitisloculis condunt. Theod. O admiranda naturæ magnalia! jam video, vera efle qux Maphxus in Indica hiftoria de feptem Sirenibus à pifcatoribus in Indæ̌comari prope Maldivas infulas interceptis fcribit,\& tum Patrum noftrorum, tum medicorum prafentium reftimonio oculari comprobatis, non verè minùs quàm pulchrè \& eleganter refert. Adferunturquoque ex infulis philippinis nonnulla offa eorum monitrorum, qux Pefce Muguer vulgò Hifpani vocant, \& haud dubiè ex eorum, quæ hîc intuemur, numero funt. Cofmiel. Ita eft, fed paulò hifcemoniftrofiorifigurâ inda- In oceani ta. Sicutienim in telluris fuperficie pro foli aërisque natura In diberfis $_{100}$ $\&$ conditione in uno loco pulchriores homines animaliaque, 'cis confor forquàm in aliis gignuntur; ita \& in Oceano, peculiari aquarum miora boproprietate, hujusmodi monftra humanæ figuræ nunc con- monfras formiora, nunc eidem minüsconformia producuntur. Theod. reperiunHabentnè ifta nonnullum in rebus medicis ufam? Cofmiel. ${ }_{\text {Mon }}^{\text {tur }}$. Immò maximum, \& praftantiffimum : ofla fiquidem miran- marinor $\bar{u}$ dâ quadam ad fanguinis fluxum virtute pollent; \& fi homines $m$ rus in experimentum facere poflent, horumque monftrorum rarita $-{ }_{u \text { sus }}$ edicin Kkkk te non 
per hucusque putabam, montes, fylvas, prata, in terreftritan- Monter,

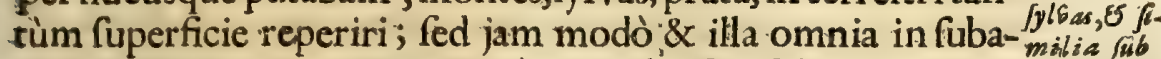
queo hoc regno invenio. $\mathbf{O}$ quàm condenfata fylvarum fruti- - aqua repecumg; conftitutio, \& inexrricabilis fcopulorĩrtepiumg; laby - *irk. rinthus! O mi Cofmiel, caveas rogo, nè illifa in illis virrea noftra navicula periclitetur.Co/m. Quid murmuras, Theodidacte? adeonè vilem de me meap; peritia exift imationem concepifti, tot naviculam hanc comra omnia illifionis pericula inumem: auc confervare, aut gubernare non peflim? aut fi dato,non conceffo, rupturam fuibiret, illam nonè veit igio inftaurare, aut etjam te in media aqtarú abyffo contra omnesfluctuu m injurias fervare valeam? Theod. O mi Cof miel, condona, obfecro, pufillanimıtatimex; neq; enim talia effutii, quòd in periculis confritutus in ullo de tua potentia dubitarem, ant tibidiffiderem, aut in concepta de te exiftimacione vacillarem: Abfit; novi enim quantus fis, \& quantâ virture polleas;utpote cujus imperio fubftent univerfa. Sed more humano ad tam exotica rerum. fpectra formidine quadam invadente.cor meum conqueftus in hæc verba imprudenter prorupi.Cof $m$. Tux mihi fragilitatis probè confcits condono perlubenter; fed jam ad infticucum. noftrum revertamur. Mirabarisfylvas,prata, montes in mari reperiri; \& ego tuam miror fimplicitatemingenii. Putafnè fub mari fub mari ahiam effe rerum conftitutionem, quam in externa terre fimitelluris fuperficie? Minimè. Si enim divinâ potentiâ Oceanus lis reperifublatis aquis exficcaretur, nihil aliud videres nifi vaftiffimas ${ }_{\text {tutie. }}^{\text {tur confiz }}$ regiones, concatenatos altifimorum montium ordines, valles profundiffimas, fluvios ingentes, planities longè latequein immenfum exporrectas; fylvas quoq; \& prata, fed alterius conftturionis arbufculis, fruticibusque corallorum, mineraliumque efflorefcentiisfalis virtute enatis.confita, qualia ex fe \& fua natura producere poteft; nec flores deftunt, nec fructur. Quid enim infulx aliud funt, quàm fubmarini môtes vaftiffimi, quorum non nifi apices extra aquam caput fuum extollunt, \& hoc pacto in infulas hominum habitationi aptas evadunt? Vide faxofos hinc inde parietesängenti intercapedine diftenfos, pro-

$\mathrm{Kkkk} 2$ fun- 
fundifimorumque moncium itructuram. Iheod.Video,\&ad-

Profundi-

tes maris. miror, nec unquam in animum meum inducere pocuiliem, uc

curbenetantam Oceani profunditatem crederem: neque enim ullum bricufilame ar, mi Cofmiel, lumine tuo illud haud illuftrares, prorfus mihi reluti in Cymmeris quibusdam tenebris vagabundo pereundum foret. Et unde hoc? Cofmiel. Scias Theodidacte, radios Colares aliquòusque tantùm mare pervadere; fed in profundioribus hifce locis, ob conftipatarum partium intermediarum denfitatem, nulla tanta lucis efficacia ent, qua corpulentamopacitatem penetrareaut fuperarequeat. Theodid. Unde itaque in tanta caligine marinæ fobolis progenies in neceflàriarum rerum conquirendo commeatu: vivat, f cire cupiam. Cofmiel. Magno huic incommado naturæ benignitas affatim. providic.Refpice in fubjectam nobis obviamqueplanitiem; a-

Euxfubin marine qualis. quedam lucem in: natambs bebo. fice faxorum rimas, fillurasque. Theodidactus Quidnam hoc prodig1i? innumerosaftrorum lucidiffimorum exercicus ego video; ignem quoquecerno mobilem; forfan fatuus eft? forfan fubterranei ignis, expiratio? fed \& foopulorum rimas undique amplifimam lucem profundere obfervo. Dic,rogo, Cofmiel,quid tanta lucium multitudofibi velit? Co/miel. Luces iftæ nec ignis elementaris, nec fatuus, necfubterraneus ullo modo cenferi debet. Quomodo enim hi ignes.ingentibusaquaram acervis tumulati vivere valeant, nemo eft qui capere pofit.. Theodidact.ws. Quid ergo,obfecro, rei eft ? Cafmiel. Luces quas vides, funtomnis generis conchilia, oftreacea, cruftacea,creteraque fundo adhrefefentia, \& lumine indiga animalia; qux utiob naturæ fux imbecillitatem ad faxa \& fundum. maris naara religavit, ita quoquenè in necefiariis operationibus hicis defectu perirent; divina fapientia lucem illis nativam unà cum calore concreavit , cujus, veluti benigno fomento confervarentur, \& ad fundum maris, ceu lucerna quædam, $\mathrm{O}-$ pificis Mencis induftriã conftitutæ funt, ut reliquis quoque pifcibus tum contra omania illifionis pericula, rum ad neceffarii alimenti conquifitionem pralucerent. Neque ideo putes ve$\lim$, 

more aliorum animantium inftructa efe, hæc enim in imper- jusmodi afectis hujusmodi, verius Ichtyoph ytis, paucis exceptis, non ex- nimaliwm tant, fed luce illâ concreatâ ; cumadaliis pralucendum, tum, genera, oad nativicaloris robur confervandum gaudent. Quamverö ex montium parietibus lucem emicare confpicis, iftifunt ver-Vermes mes vaginâ inclufi, quos dactylos vocant, in anguillarum for- mar ini, mam faxorum in rimis ftabulantes; \& lucem pariter concrea- $l i$, in moñ tam habene. Immo dico tibi quid ampliùs; vixullum pifcium ${ }_{\text {tium fifus }}^{\text {tis }}$ genus eft,quod non hujusmodíluce fibi innatâ turgeat: adeo- ${ }^{r h}$ que is neceffaria eft, ut fine illa in caliginofo xquoris gurgite vitam fuftinere non poffint, quemadmodum fuprà quoque, cum Balæenam infpiceremus, fusề oftendi. Theodid. Sed quonam modoilla fefelux habet? Cofmiel. Vidiftin" cicindelas? "Aquatilis-? five vermiculosillos alatos; qui eft ivi temporis noctibusinftar dam lacem fcintillarum oculos irinerantium feriunt, \& Lampyrides vo- effe ad incantur? Theodidactus: Vidi frepe frepius. Co/miel.. Quemad- Alar cicin. modum igitur illa innatam fibilucemadoperationes ritè exequendas à natura adeptę fünt, ita\& marina animalia. Vidiquend unquam quercusputridas, quantoperè noctu radient? \& putride haud fecus ac lucernæ: quapiam in obfcuris fylvarum receffi- noctu lubusceu viarum indicescuncta illuminent? Comperiftin' un- ${ }^{\text {cent. }}$ quam fcintillantes nonnullorum animalium, eorum præfertim, quæ nocturnis venationibus, vitam fuftentant, oculos? Theodidact us.Vidi,\& obfervavi id fexpius in felium, \& noctuarumoculis. Cofmiel. Si itaque terreftribus, rebus ad ufum neceflärium hujusmodi lucem divina fapientia ineffe: voluit, quanto magis marinis? Sed nunc ad fundimarini incolas oculos amimumque convertamus.. Vide.Theadidacte, \& diligenter examina inexplicabilem rerum varieratem, naturæ beneficio in hujusmodi tractibus conftitutam. Theodid. Tota hæc, quam video, planities fundi non mihi pratum, fed vivum, quoddam periperafma incredibili concharum margaritarumque varietate \& fplendiore, veluri lapidibus pretiofis contex-

$$
\mathrm{Kkkk}_{3} \text { tum }
$$




\section{0 \\ Ttinerarium II. Dialogus ITT. \\ Eonebylio-}

tum videtur:O quanta conchyliorum fpecie differentium va r. $m$ m dario dori. rietas! quàm affabrè in iis natura lufit! quot colorum differenptio. tias imbuit! quanta \& quàm exoticâ figurarum diłcrepantium fculpturâ expreffir! Video nonnulla (uti ea quoque defcribic Author'hintorię naturalis) convexa, plana, concava; quæedam in Lunę morem falcata, aut in orbem circumaeta, aliqua dimidio orbe cafa, intorfum prozuberantra, levore quodam: fṕlendidiflimo perpolita; alia velati dentibus quibusciam interftincta ; alia ftriarum multiplici ductu miro artificio adumbrata; nondefunt qux muricarim intorta, margine in mucronem cuncatum foris effufo, intus replicaco, jam diftinctione virgulata, crifja; modò in formam cancelloram,imbricum, pectinumque undulatâ. fuperficie exporrecta; alia in undarum fluctuantium morem exprefia , \& cancellatimreticulata, uunc obliqua,jam in rectum expanfa, denfáta, porrecta, finuata,\& ad buccinæ morem repanda. Er undenan tanta mi Colorigo Con- miel rerum diverfitas? Cofinict. Illa omnia, quantumvis innuwyliorum. meris fpeciebus differentia, ex invifibili îllo \& univerfitli naturx femine, quod Oceano potiflimùm dominatur, formarum. diverfitatem fortiuntur; fiquidem ex aqux particula vifcofiori \& tenuiori caro conchiliorum nafcitur, ex parteverò craffiori \& falis copiầ referta concha viventi ipfa domus conftituitur in lapideam molem indurata; nam fal ex fe \& fura natura duram firmamque omnibus prabet confiftentiam, plaftica verò feminis vis illas procombinatx materix difpofitione in innumeras efformar figuras; colorum verò varietas hane fuam ex diverfa fulphuris albi rúbrique, quo mare refertum eft,mixtura originem trahit: vivuntque ex eodem, ex quo orsum duxerunt alimento elementoque, quam vis nonnulla quo-

In conchisbis qua, ratione

mature fupplebit

defedtum

bifures

dentium. que pifciculos, vermiculos, cxteramque minutiorem maris fobolem in fuum trahant nutrimentum. Theod. Quomodo id fieri poteft,cûn vifu \& dentibus careant. Cofmiel. Natura uti fagacifima eft, ita'\& iis quoque de neceflariis ad vivendum fubfidis mirum in modum providit. Vifus enim defectum fenfin perfectiflimo tactus fupplevic; dentes verò ejus quibus.pradam 
dam fibi venatur, eft ip̣a aperibilisconchæ ftructura; quâdum voluncario animalis mocu nunc clauditur,nunc aperitur, fit ut animalcula iis vicina fimulachiantibus conche labris feée infinuaverint, aftucus intus latens pifearor predam prafentiens" mox claufis labris in efcam indito fibi inftinctu eandem confervet. Theodid: Reperio hîc inter alia Tritoniasbuccinas, purpureo liquore refertas. Cofmiel. Illæ funt murices, \& purpuræ nullo non $æ$ vo celeberrimæ , unicum Regum arque Imperatorum ornamentum : harum enint naturali liquore panni: illi rigo Enfwo einguntur, quos tantopere inquirit anbitque principum $\mathrm{Nia}$ jeftas, ortumque habet ex puriffimo fulpirure rubeo, tincto fpiricu cynabrii, quòd in centro virtutis fpermaticx horum pifcium delitefécit, \& naturali hepatis.frcultate concoctivâ, unå

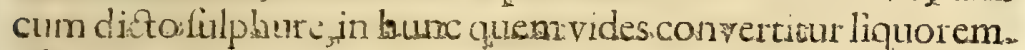
Theodid. Ecce lingurnas purpure five nutricis acutifimam, quana exarit; habonenè har animalia linguam, aut reliqua, membra diftincta? Cofmicl Membra diltincta non habent, fed fimile quid membriscaterorum animalium. Hinc quamtu. linguam dicis, lingua propriè non eft, fed f́pina quædam oflea, acuta, \& dura, qua certeras fibi vicinas conchas, quodam aperit, apertas exfugit; pif́ciculos quoquevicinos.eâ transfixos intra fe trahit Theod.Ergo os habent, \& ftomachum. Co/miel.Dixitibi,fimile quid eas habere, meatus videlicet, intra. quos nutrimenzum astrastum deponant, veluti in ftomachum: quendamà natura ipfis conftitutum. Depofitum verò calore nativo in propriam fubftanriam convertunt; funt enim quotguot hî́ contemplaris conchiliorum genera., nithil aliud, nif Gonchzlis carnex quædam maflix, animatæ, quętametfindifereto mem- carnea brortım fituà natura difpofita fint,acutiffimo tamé taçus fén- mafja es fus pollent; neq; generant aliorum pifcium more, fed univerfali naturx, \& peculiari naris femine, uti dixi,pro diverfitate dif:pofitionis materį̧ generantur, \& ex urroq; fenfibili \& infenfibili alimento vivunt. Quæ verö conchilia hifeefcopulis nativâ. fede \& innutabiliadhærere vides, illa IchŁyophyta-verius, quàm animalia perfecta. dicenda funt, \& Zoophytisadnumerantur, visamq; merent ex communis natura fémine, intra petraruma 


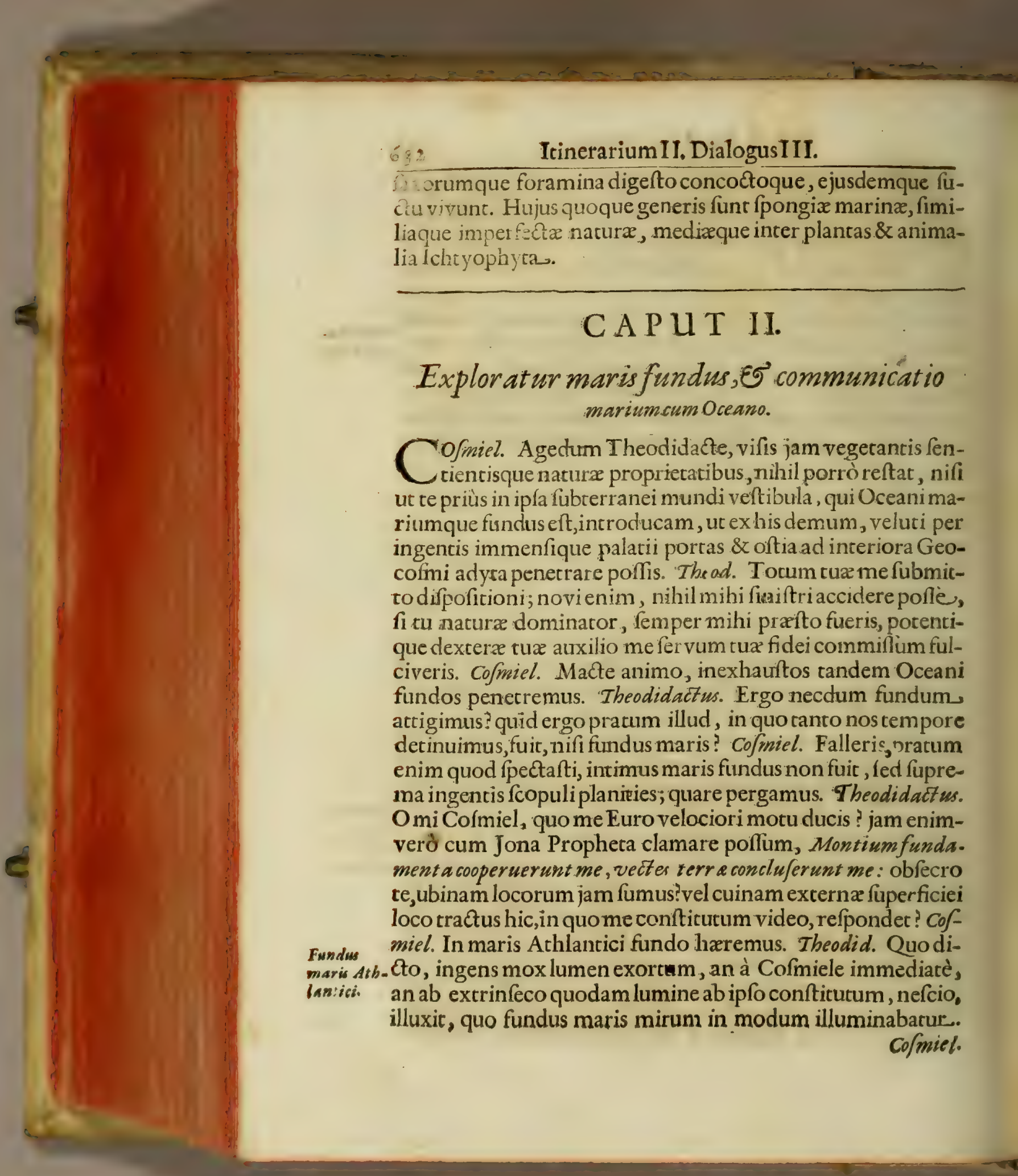


Cofmiel. Jam contemplare, Theodielacte, in hifce inferioris" mundi corporibus nature' 'Majeftatem. Hoc loco nullum animal, ob continuam horrendamq; vorticum voraginumq; vehementiam, fine ultimo exicii periculo commorari poteft. Theod. Quid fibivolunt he fubmarine in immenfam longitu- dinem montiurn fubitructiones? quid ingens aqux fulgencis calor \& xftus? quid înenf $x$ voragines, quibus fundum ubique pertufumvideo? Cofiniel. Hiquos vides dúperos \& tortuofos, Montiurs

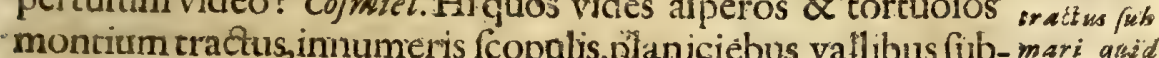
marinis diftenfos , fübftructiones funt. ongenris cujuldam in-fignento fulr, fiveculturam fipectes, five rerum omnium ubertarem, 'olim omnium beacifims, qua tamen' fuccéfu temporis $\mathrm{ex}$ vehementibusterræ motibus concufitis fornicibus, columnisque montium, unà cum hominibus lapfa fubmerfaque , hujuśs, quam vides, ruinæ veftigiareliquir; terræ verò motus ex magno Vulcani cratere huic fabjecto originem trair; cujus mui-TerramoGno Vulcani cratere huic fabjecto originem traxic; cujus qui- tus origo.
demapera figna funt, caloris \& xftus quem mirabaris vehementia, cui in hunc ufque diem infuke, quas Terceras vocant, In/ula Ter- ex vereri ruina fuperftites, fubjectre, nullo non tempore in- re motur-

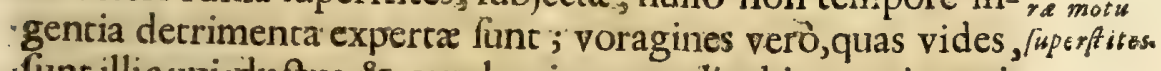
funt illiaqui-dıctus, \& canales, in ceca alicubi montium vifcera aquam Oceani exonerantes, de quibus poftea fufius tecum agam. Theodidact ths. 'Ecce novos femper \& novos vorrices \& voragines, ingentefque fundi hiatus; quorum nonnul-immensis los majoris capacitatis, quam vel ipfos craceres Vefuvii auv quorfiam Aernar olim à me dimenfos depréhendo. Et quonam aquas deribewt. immenfi hujus Oceani deportant? Cofmiel. Ecce jam Americx infulis,atque adeo ipfi continenti vicini fumus. Nonnulli itaque distorum canatium intra infularum circumiacentium montes, quidam incra Americæ valtiffima montium receptacula, ad fuviorum lacuumque originem conftitnendam per. immenfas fubterraneas anfractuofafque ambages derivantur. Theodidact us. Suntnè plures hujufmodi hiatus, \& canalium oceanum hifcefimilia orificia? Cofmiel. Plura omnino funt, \& majord, Athlantiper rotum huncOceani tractumà natura difpofica. Nofti, Theo- cum canas a $_{\text {libus. }}$ Il11 didacte, dibars. 
Firumina quedam dimerice ex Atlantico marí ortaper meandros tandema in monsitus. effil uunt.

Salfedinem quomodo. mare in montibus deperdat.

\section{Oisan:}

Aisf ralio

cum Acblä:

sico com-

municatio.

Subierra: sei meatus fruct uraes deferiptio.

634 Itinerarium II. Dialogus III.

didacte, ex Geographica difciplina, vaftifima fluminum maria, ctijurmodi in America funt Flumen Amazonum, Maragnon,Flumen S. Januarii,Laurentii, aliaque innumera univerfam Americx faciem rigantia; qua quidem non aliam, nifiex hoc vel Occidıo, vel Ortivo Oceano aquarum, per occultos horum hiatuum crcofque voraginum mæandros in montium vifcera deductarum originem forciuntur. Ad flumina itaque ingentia conftituenda, ingens aquarum transfufarum. visnecenaria eft. Theodid. Sed quomodo mare,cùm falfum fir, nativam fuam falfedinem intra montes delatum ita fubitò deponit? Cofmiel. Nofle debes, terreftrium partium naturam. itaconfticutam effe, ur mox ac aqua per eas colatu quodam. tranfierit, illæ naturaliattractu falem aquis infieum, in fe attractum, in neceflàrium debicumque fibi alimentum, fine quo nullæ in terra generationes: fieri poffent, derivent.: Et hoc pacto aquæ marinæ, fal fedine fuâ exuræ, exfuctæeque, in dulcem fapor enr convertuntur. Sed hæe alibicopiosè tibi ab Hydriele expofita funt. Theodid: Nodum omnem difficultatis foluifti, \& ego experimentis convictus in aqua marina per arenam, argillam, cretamque colata, veriffima qua dixifti comperi; prafertim fi calida, uci in montibus per fubterraneos ignesfic, colata dictas materias tranfeat. Sed ò Cofmiel, quàmingentem portam hî́c apertam video! quàm immenfum intra montium fauces hiacum intueor! Cofmiel. Nemireris; hic enim eft magnus ille fubterraneus meatus, quoOceanus Áthlanticus Auftrafi Oceano,occulto quodam conjugio maritatur : qui nobis modo tranfeundus: eft, ut urriufque Oceani abditam \& nunquam vifam conftitutionem exactiüs contempleris. Theodidactus: O quanta \& quàm mirifica ftructura! quàm horrendis rupibus omnia rigent! quanta hiacuum orificia panduntur! quantum canalis modò coarctatur, modò in immenfü dilatatur !ut jure Subterraneum Pelagus dici poffit: quàm fornices alti,quantâ lapidum varietate contexci, omnia tamen afperâ, folidâ,, firmâquecompage connexa, ferè ærerni laboris opus. O miCofmiel,forfan Ifthmum inter Panamam, \& i iombre de Diós 
Cap. II. Iter Submarinum.

635

Dios conftiturum tranfimus. Cofmiel. Ita eft, Mare fiqui- Mare Audem Auftrale Boreali hoc ponte Ift hmico difterminatur. Theo- mus termedidactus. Fe quando cundem frishorummirabdium? Cofmiel. nat. Jam jam finem àttigimus; refpice oppofitam priori Auftralis? Oceani portam hanc fubaqueam. Tizesdid. Non portam video, fed multorumnuilliarium hiatum incra montem excauatum. Sediò Cofiniel, eftnè poffibile, Oceanos \& Maria fubterraneam communicationem habere? Cofmiel. Quid dubitas fili, rem. ita fe habere, uti modò in hoc, ica paulò pòft in multis aliis" fpectabis. Theodidactus. O magnalia DEI! O ineffabilem. Opificis mentis Sapientiam! O quàm pauca,jnon dicam cxleftium rerum, ied \& hujus fenfibilis Geocolmi , quem pedibus? calcamus, quem quotidie oculis evoluimus, myfteria humani intellectus caduciras novit! Sed pergamus. Er ecce, per innumeros manftroforum pifcium exercitus tranfeuntes, juxta innumeras variarum infularum fubftructiones, inexplicabili navicula motu delati, ubique Oceani fundum innumeris? paffim hiatibus, canaliumque orificiis pertufum, fub -aqueis nunc montibus, fcopulis, planitiebus, nunc vallibus in immenfum exporrectis refertum offendimus; conec tandem ad infularum Philippinarum fubmarinum Archipelagum delati, intra canalem quendam in Auftralem polum vergentem. defleximus. Hîc ego fummâcuriớtare exxttuans cognofcendi incognitai um Auftralis terræ regionum ficum, fic ducem meum affatus fum. O mi Cofmiel,fi inveni graciam in. oculis tuis, duc, rogo, fervum tuum aliquantulùm in extimam marisfuperficiem, tum liberiori aurâ fruendi gratiâ , tum ad regionum, fi qux funt, auftralium in huncufque diem latentium fitum explorandum .Cofmiel. Fiat uti poftulafti. Theodidactus. Et ecce, in patentiffimo pelago me conftitutum reperi. O mi Cofmiel, quantopere mihi confuetæ auræ liberioris limpiditate \& dulcedine gaudeo ! revivifcit fanè fpiritus meus prodigiofarum rerum fpectaculis pænè exanimatus, ad coleft is hujus lucis intuitum. Sed ecce, continentem ego video ingentibus montibus cinctam. Quxnam, rogo, hæc regio eft? L III 2 quod- 


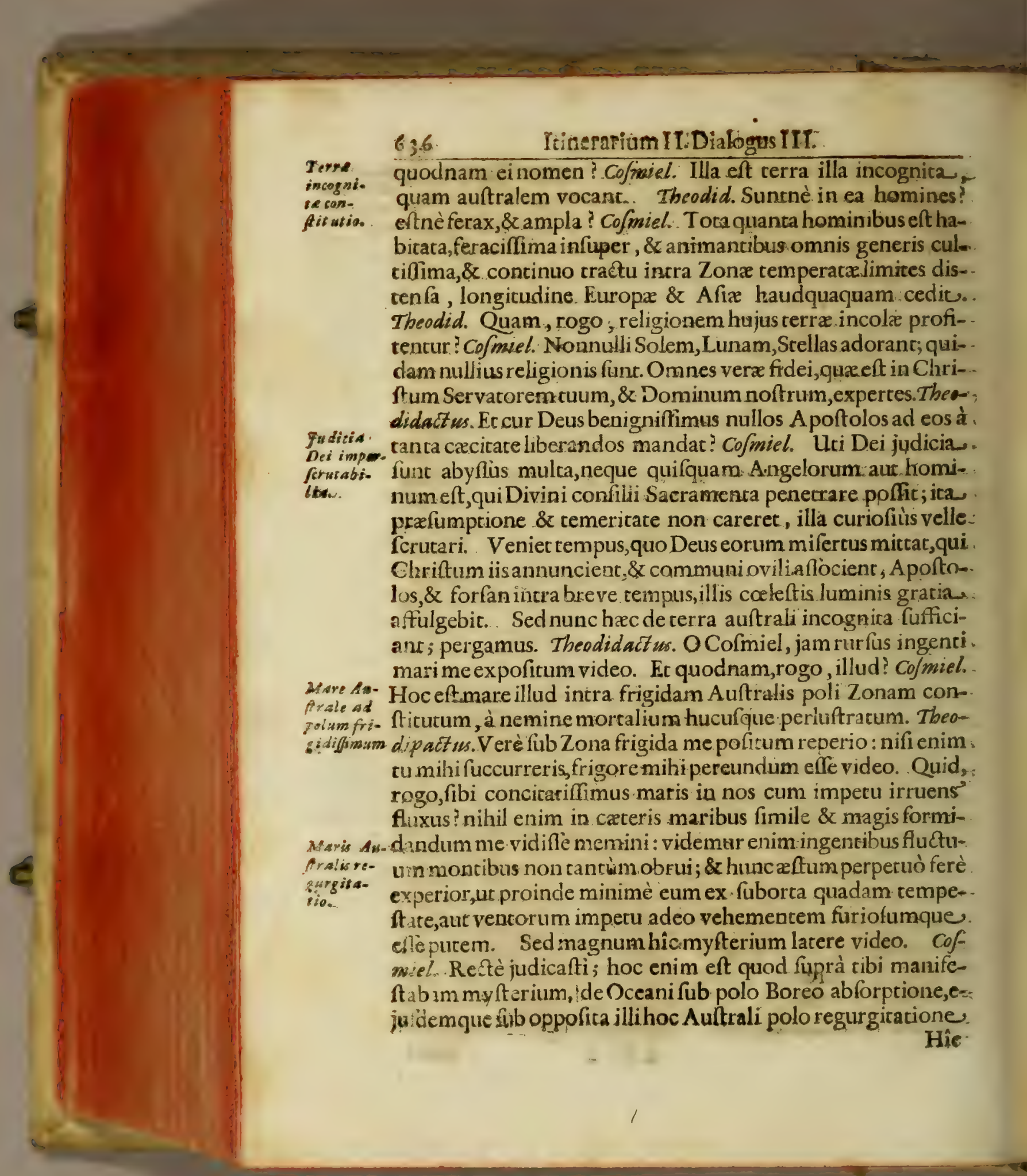


Hic enmex fubterraneo fuo aquax ductu, aqux. inexplicabili vehemenciâ \& impetu revomuntur, ur denuo perfecta pericyclofi illuc refluant, ubi abforpre fuerant. Seias veró, hunc Mare ad locumbuculque manfiffe inacceflum, cùm nemo invencus fic, polos inasqui impetum hujus maris frangere, \& quavis vifuperare valuerit,fed om res quotquot inconfultiùs hre loca veladierunt, vel ventorum ad ea vi delati fuerunt, inevitabilibus fluctuum turbinibus \& Euripis miferè perierunt: Theodidact us. O.quàm inaudita mihi narras !quàm nullis unquam mortalium oculis? vifa demonftras! Cofmiel. Video te, Theodidacte, totum. frigoris vehementiâ trementem tantùm non emori: quare ad derelictam itacionem revertamur. Theodid. Placet. Oquàm Calor in calidam repetitam ftationem fentio Non eft dubium quin findo mo fündus hic alicujus fubterranei ignis fpiraculisurgeatur. Cof miel. Rectè dicis. Sed progrediamur, grandis enim tibi reftar. via. Theodidact is, Quidnam illud eft? Video enim fundum. maris, adeaque totam ą̨uzrum ei.incambentium molem, "veliementi nefcio quo motu concuti. Co formiel. Iftafune illa Mareat

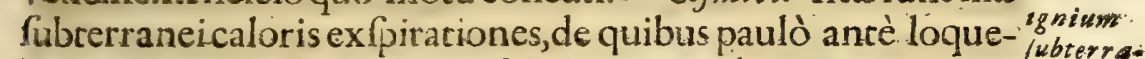
baris, qư uti vehementium fpirituum copiâ turgent, ita mi-neovrum exrum in modum, dum violentã irruption em moliuntur, aquas halat tones:

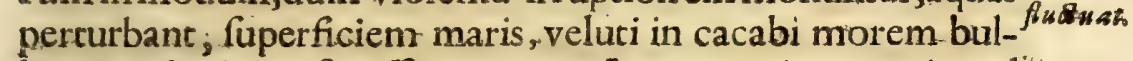
lientis pelagi, in fevifimas tempeftates concisane, quin vel." aërem liberiorem nacti ventos impecuofiflimoscum extremo navigancium periculo efficiunt. . Theodidact us. Omnia ritè cepi. Sed quis.ille fuavifimus odor, qui tantopere odoratum meumafficis? Cofmiels. Scias te jam intra Molviccasconftitu. tum, in quibusingens aromatum copia quotannis provenic. Vides hîc ambræ gryfiæ ubertatem ?'. Vides Cariophy lorum. acervos? Sentifnè Cynnamomi, nucis my rifticx, piperis, aliorumaromatum odorem ? Theodidact us. Sentio, \& miror intraaquam quoque hujufmodiodores fenforium organum afficere porfe. O quot vortices, quoc hiatus, quot æftuantium aquarum fluxus\& refluxus, incer harum in (ularum angiportus, uri\& per toum hunc Indicum Oceanum intueor? Cofmiel:

$$
\text { IIII } 3 \text { Oinnes. }
$$


Omnes hi vortices canalium epiftomia funt, qui intre Imai, Caucafi, \& Parapanifi concatenatorum montium vifcera in. coriftituta ipfis à natura receptacula, ad Gangis, Indi, $\mathrm{H}$ j dafpis, caterorumque innumerorum fluminum orcum, Oceanium,

Canalis quo mare Indieum communicat cum maricielpio. humorem perpetuâ quadam circulatione deponunt; quod qua ratione fiat, jam fuprà audufti. Theodid. Ecce nova porta non abfimilis ei, quam in Oceano Auftrali reperimus; quid rogo ea indicat? Cofmiet. Hic introitus eft fubcerranei ingentis? longitudinis Maandri. Agedum, magno animo fis Theodidacte, hic nobis modò tranteundus eft, \& tunc tıbi, ubi, \& in. quonam mari terminum fux exoneration is inveniat, aperiam. Theodidactus. Oquàm in torcuofum me labyrinthum ducis!' in quàm vafta terrarum fpatia mecrahis! quanca lateralium. meatuum mulcitudo \& vaftitas ! heu quâm horrendas ingentium aquarum Catadupas audio! hîc non lacus, non planicies, non flumina defunt; prata quoque video virenti gramine ve-: ftita,regnum jam Subterraneum ingreffi videmur. Cofmiel. Minmè hoc tibi perfuadeas velim; eft enim hic canalis fingu-' larinatura artificio intraterre vifera ad communicationem aquarum excauatus. Theodidactus. Et quando randem hujus" cranficus finis ? Cofmiel. Eccejam finem attigimus. Ecce naviculam in akum educam, ut noviaër is hauftu reficiaris. Refpice modò. Theodid. In mari patentiffimo me reperio, altiflimos tamen montes èregione afpicio: quonam, rogo terrarum loco fubfiftimus? Cofmiel. In mari Calpio commoramuc, quod per eum, quem tranfifti, canalem cum mari Indico occulta aquarum commercia exercet. Theodid. O quàmaberrant Geographi,qui hoc mare lacum appellant, ed quòd omni exitu carere videatur." Ego verò jam apertè comperio, nullum effe mare,quod cum Oceano per fubterraneos immenfa magnitudinis canales ei, quem tranfivimus, haud diffimiles? non continuetur. Cofmiel. Rectè judicafti. Seduc hæc omnia tibi luculentiùs pateant, ad defertam ftationem revertamur. Maris Caf Theodidact us. O quàm fcopulofum hujus maris fundum video? piiconsfitutio. quanto fubterranei ignis calore eftuantem; quàm miris contrariorum 
trariorum fluctuum agitationibus fevientem ? Euripos innumeros hîc à natura conftitutos video; \& unde hoc? Cofm. Quia id ex omnibus partibus circumfitis maribus, $\&$ montiü hydrophylaciis per fubterraneos canales communicat, qua cum contrariis fluctibus ei inferuntur; inde hoc æftu, his Euripis, hifce ingentium fluctuum globis illud agitari nihil mirum eft. Accedis fluctuum ad conclufa undique littora illidentium reverberatio,quâ mare quafi in perpetuos circulos agiratur. Theodidact us. Sed quodoam novum hocorificium intra montium fubftructiones fefenobis exhibet? Cofmiel. Tranfeamus illud, \& exitus dabitrei veritatem. Theodid. Canalem non imparem priori ingredi videmur; fed rogote, nè fiftamus; unum enim. vidifle fufficiat, cüm natura ad eandemamuffim omnia metiatur. Cofmiel. Jam terminum attigimus; ecce in fuperficie maris Euxiniconfturus es. Theodidactus Fierinè poteft quod aneris? Mare CafEuxini conititurus es. Theodidact us. Fierine potelt quod alleris? pium ewm Ergonè mare Cafpium cum mari Euxino mifcetur? Co fmiel. mari Eu. Omnino, \& per hunc quidem, quem tranfifti,fornicem fubter- $x$ inolcomrareum, qua fupra fe ingentem caucafum, \&omnem Colchi- municat. dis regionem, quam hodiernâ die Georgiam \&Megreliam vocant,fuftinet. Sed inferiorem ftationem poftliminio reperamus. Theodidactus. Non minùs impetuofum hoc.Euxinum., quàm Cafpium mare reperio, fcopulis innumeris, \& profundiffimis aby fis refertum. Quanta porrò pifcium diverfitas \& multicudo? Sed dic,rogo, quid vehemens ille impecusaquarum è lacere ruentium ? Cofmiel. Hoc in loco fefe Tanais,magnâ aquarum mole gravacus, exonerat. Hinc ille impetus. Sed - progrediamur ulteriủs. Theodidactus. Ecce novos æftus ex-Boryft bea perior,prioribus non abfimiles, luctantium aquarum. Cofmiel. nes ${ }^{\circ} \mathrm{Da-}$ Ill à Boryfthene \& Danubio,ingenti aquarum coacervatione nubins exo. fefe in elictis locis deponentibus, efficiuntur: Theodidactus, inmari Quid fibi angiportusille in quem tranfimus? Co/miel. Jam, magnos aConftantinopoli vicini. Propontidem atringimus, in Archi- tant. pelagum irer facturi. Theodidactus. O quor æitus, quot Euripos, quot fine fundo fundos hoc in loco reperio! quot \& quantas infularum vicinarum fubftructiones video I quov 
calidas exfpirationes fentio, luculenta fubterranei ignis veft igia! Co/miel. Veritatemtetigifti; ingens enim huic loco Vulcani culina fubeft, qux continuis exhalationibus hoc mare oppidò infeftum reddic. Sed de his paulò pòft. Theod. Et quando mare Mediterraneum-fubibinus ? Cofmiel. Jamin eo aCtu - moraris. Theodid. Cercí Naturam emper ad eandem normam omnia eonticuife, ex rochiacibus \& Maand ris fundorum pelagi hujus fac fuperque conftac. Sed quid ingens ulla vorago, quam hîc intra montium fauces apertam video ? Cofmuch. . Hæc prope Egy ptum conftitura eft. Sed ut omnia tibi pareant, ea nobis fubeunda eft. Theodid. Fac,quod beneplacicurn fuerit in ocus is tuis. Eheu ! quàm horrenda rerum facies? quanti fornices? quăm incompofita ftructura? quantum falkis, quantam bituminis copiam exfudant parietes? quxfo feftinemus, miCofiniel, fiquidem mephytim ex crypris exhalantem amphìs fufferre non pofium. Cofmiei. Factum eft quod petifti; eleva oculos tuos, \& vide circumfitas regiones,jam in. pelagifuperficiem elatus. Theodid. Verè ubi fin, ubi morer,

Matie p. Gremen. nefcio; flumen ingens nos introifle puto, Et quidnam fibi vutt fanguineus aqua color? Cofmiel. Scias te jam in mari rubro confitutum efle; quod color aquarum fac fuperque demonfrat. Et eo quidem in loco, quem Moyfes quondam unà cum populo Ifraëlitico divifis ftupendo miraculo aquis ficco pede tranfivit. Theodidackus. Fierinè poteft nos in mari rubroconAtituros; \& quomodo, \& per quam viam in illud ingreffi fumus? Somnione, an vigiliis fallor? Cofmiel. Non falleris : per fubterraneum enim meatum, in quo graveolentem illam Mephytim fentiebas, in hoc pelagus ad fubterraneum marium communicationem lueulentiùs demonftrandam, id eft, ex

Mire in masriva4.0. Mediterraneo in rubrum emerfimus. Theodid. O qùàm ftupenda,eaque nova in natura rerum miracula experior!ecce ingentes hîc exCorallinis fruticibus plantatas à natura fylvas reperio; fed \& fcopulorum intricatiffim $x$ feries me pænè attonitú reddunt. Sed ecce novum prodigium. Video hic fcopulum. ingentem, omni ferramentorum genere onuftum, \& veluri 
trabalibus quibusdam clavis inftrumenta ferrea affixa: quid rogo illud? Cofmiel. Hic eft fcopulusmagnericus (quippe magneibus hoc mare refertum ent) gui natiaga ratis ferrarias merces ad eattractas, indifollibili arcanionisnacura vinculo senet. Theod. Heurquot hiaribus, \& quot ftupendis aperturis fundusfcater! Cofmiel. Hiomnes aquis perfuos canales inter Aithopia Arabraque felicis mencium vicinorum hydrophylacia ceduvendis ad originem fluminum à natura deftinati funt. Sed jam icer profequamur. Theodid. Videor ex monte quodam in imam vallem defcendere; qridnam hoc indicer, logo explices. 'Cofmel. Rubri maris alveusea fe rationead Oc. inii Indici funcum habet, quemadmodum fuperior montis "maras al cujus plancies ad longè latèque circumfufam vallem fe ha- bricum o-

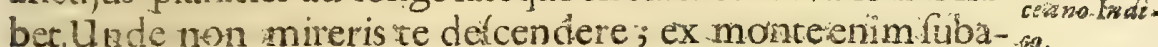
queo,ad fubaqueam vallem deponeris. Jam in Oceano Indico verfamur. Theod. Heu Cofmiel, ecce novam monftrorum marinorum curbam. O quàm funt horrenda, quàm vafta-, quàm infolenci corporis fipecie deformata! quantâ luce tadiant, \& in carbunculorum capitinfertorum moretn lucent! nonnullorum capira cirris innumeris intricata, quxdam ttimore torius corporistantùm non fariftent, furt qui cornibus flumina aquarum profundere videntur. Cofmiel. Hlax varix func Cætorum fpecies, quorum naturam fuprà tibi expofưi. Theod. Feftinemusrogo, ut ex rot actantis icopsilis, ex totfundi vorazinibus exeamus: far enim jam novi, quid illa ex tra inftructione fibivelint ; revertamur per hunc Indicum Oceanum in Athlanticum, unde digreffi fumus. Cofmiel.Compleantur vota tua. Theod. Vix dixerat, 'B ecce vehementifimogrodam fluxu in Boream ferimur'; incipiunt horrenda mox favire frigora, ego totis artubus contremi(cere. $\mathrm{O}$ Cofmiel, ubinam locorum hæremus? Quid cóncitatiflimusillemaris æétusverfus Arctum, quo veluci rapidiffimo flumine fecundo vento ferri videmur? Cofmiel. Jam intra areticum circulum conftio aquam fus tuti fumus,ubi Oceanus occultâ parturiencis naturze violentiầ polo artetiabforbetur. Recordaris, ni fallor, quantam intra cirrulum an- ${ }_{r i}^{c o}$ abjorbe$\mathrm{Mmmm} \quad$ tarcti- 


\section{2 Itinerairum VI. Cialogus. IIT.}

carcticum undarum concra nos irruentium vehementiam expertifimus. Habes jam limpidam horum effectuum caufam. Oceanus enim perfectâ pericyclofi hoc locoabforpus, fub oppofito polo revomitur. Unde ficutiillum invitâ naturâadimus, ita in hunc fecundo fluxurapimur. Theodid. O quàm horrendastempeftates-experior! quàm formidabiles ruentium. aquarum trepitus percipio ! diceres mundi machinam fatifcentem ruere. Cofmiel: Difceex his admirandis naturaoperibus, Deum cognofcere, illum amare, illum ærernùm poffidere. Sed jam facis eft : luftravimus admirandam incerioris $\mathrm{O}$. ceani.Oeconomiam, occultas \& abditas femitas luftravimus" omnes, reciproca marium cum Oceano fpectavimus commercia ; monftrorum, \& quidquid mirum Oceani vifcera gignunt, incuitifumus-; reftat modò id', qui unicus erat propoficus noftri itimeris fcopus, relicto fubterranei Mundi veftigio, ejus interiora penetrare, ineffabilem nacuræ majeftatem in omnibus contemplari ibi initium facturi, ubi.primùm natura. fui motus exordia ponic.

\section{CA P U T II I.}

\section{Subterranei Mundiarcanaexplorantur:}

Crofmiel. Geocolmiffructuram, mi Theodidacte, non ca$\checkmark$ fu aut fortuitò ex limi confluxu coaluifle, fed ineffabili quodam Divinæ Sapiencia opificio conftitutam, ex is qua paulò pòft tibioftendam, patebit:ita ut non minorem in hac adornanda , quàm in Microcofmifabrica conftruenda, induftriam pofuiflevideacur. Agedum,mı Theodidacte, nè formidandis, qua intueberis, fpectaculis terrearis; ego enim tecum. fum, ego te ab omniaquarum violentia, ab omniaëris coinquinatione, ab omni ignium voracitate defendam.Theodid.OCofmiel; ego,ficuti hujus tam ardui \& inauditi itineris author fui\& $i$, ita illud ad defideratum finem ce conducturum confido: 
euis en in in manibus conftitutus fum, ad vitam \& mortem $x$ què promptus, dummodò tuo me fubfidio non deftituas. Cofmiel. Pergamus itaque in nomine Domini ter gloriof \& benedicti. Ecce per immenfam hanc voraginem, in interiora terra vifcera penerrandum nobis en. 'Theodid. OCofmiel, Cofmiel !circumdederunt me gemitus mortis, dolores inferni circundederunt me. O quuò me rapis? Circumvallarunt me fund menta montium, aquæ operuerunt animam meam, intra. abyllos cordis terræ conclufifti me. Onè medeferas ? formidine enim tantùm non morior. Cofmiel. Faceor, mi Theodidacte, nullum tam cordati animi virum effe, qui hujusmodi locorum horrorem fuftinere queat; verùm cüm femper me cibi præfentem funurum pollicitus fim, quid rimes? quid angeris? quid trepidar cortuum ? an nefis coli \& terræclaves mihi concreditas effe meo omnia fubefie imperio an ignoras? Sed nè in pofterum hifce immenfe caliginisterroribus concutiaris, \& luculentiús omnia nacuræarcana confiderare poffis, \& nè fruftra in tanta tenebrarum denficate confticutus, omni reruin fpectandarum fructu priveris; ecce ego \& menicus turus ero,\& illuminatrix lucerna. Theod. Vix dixerat, dum ecce nefcio quo nectareo liquore me imbuit, \& tantâ luce vafta fubterranearum cryptarum fpacia illuftravit, ut in aperto folis lumine conftituri videremur. Quibus mox ica confortabar, ut in poiterum nulla animum meum formidinis trepidatio perculerit. O Cofmiel, gratiastibiago, protantis in me collatis beneficiis ; jam enimverò te fideliffimum \& ducem, \& cuftodem experior; nec non veluti univerfæ naturæ prefidemeo quo poflum humili mentis obfequio revereor. Cofmiel. Refpi$c e, \&$ luftra primùm hoc naturæ veftibulum. Thead. O quan-Canalis tos aquarum ftrepitus pereipio ! nihil Cafpix, nihil Niliaca magnus Catadupæ in comparatione funt, ad horrenda hæc \& inaudita fralis inaquarum undique ruentium præcipitia ; non fontes, non flu- traterram mina, non lacus, fed ceu rupto fundo ac magnæabyfli apertis clautris totum Oceanum effudiffe videntur. Cofmiel. Rectè

Mmm 2 dicis


64.4

Ttinerarium IT. Dialogus IIT.

dicis; hic enim eft canalis ille abylli magna, per quem perennis fir àpolo Areticoad A ntarcticum totius Oceani circulatio. Theod. Oquàm immenfáalcitudinis fornices !ô quanta,quàm inexplicabilis, hujus aqui-ductus laxitas! certè nihil in fuperficieterræ huic fimile reperiri pofie exiftimo. Sed,ôCofmiel, ornes panè parieres in falem, nitrum, alumen, virriolum, fimiliaque efflorefcere video ; undehoc? Cofmiel. Horum parietum proprieras hree eft, ut omnem aquarum mar inarum faliuginem ad fe attractam in varia genera falium procujusvıs loci natura convertant. Theod. Sed quid, rogo, fibivult calor ille Calor quid quem fentio?. Cofmicl. Ille provenic ex vicino Pyrophylacio, terra cons- quod poft quàm perfectâ coçtone aquam digeflit, id quod in. fale volatilis eft fpiricus, intra incimas faxorum glebarumque, filluras exhalatad univer $\mathfrak{x}$ celluris fomentum, focunditatem, \& condimentum. Theod $O$ quàm ingens Mephytis nares meas excruciat?. Video hîc nefcio quid corufcum,quod in immenfun troctum fe porrigit auro lraud abfimile; quid defluxus il-

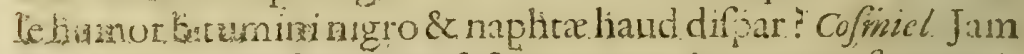
disi,calor quem fentis, rarefactamaquam in vapores fpernacicâ virtuce refertos exaltat; qui mox terreftribus glebis per rimas infinuati, ubimateriam terreftrem fulphuriproducendo Sulphur; aptam repererint, ibifulphuzgenerant Ubiin pingue \& cralb.tumen, fium latum inciderint, ibi aut bitumen aut naphtam, aut alium natiotal *ninde. oleaceim liquorem generant, Mephytis pesepta caufam. Sed hec omnia inferius fufiùs declarabuntur. Jamenim primò hydrophylacia, feu aqua promos condos; deinde pyrophylacia, five Vulcanias:officinas jemum aërophylacia; fet fibterreftris aëris recondicoria infpecturifumus: Sic fiet, ut lulus naturæe in comnibus tibiclariüs innotefát. Frogredian ur.

Canalis. Borec - A : fralas inzBegraregioni imi in Gisietur. isaque in boc totius tellieis primcipali aqui-ductu. Theod. Ingenrem regionem ingredi videmur. O qur tmontes, qucu masia, quot lacus quot hiacus aquarum flumina vcmentes videos Jam veluti ex alto quodam monte in mam vallem devolvimur mos ox valle in celfosmontes exiltamur; Jam, inter liow ida pracipita axctaci; $;$ modò exangiportibus elanfi 
in laté patentes: planicies ferimur. Nullibi recta nobis \& plana via; fed cortuof ubique; \& avir femitx; per horrenda fcopulorum gurguftia devehinur; omnia tamen immenfis aquarum molibus, formidabilicum:murmure, ftrepitu incredibili, unà junctisoppleta: Quis unquam credidiflet, tantas aquarum coacervationes in fubcerraneum hunc aqui-ductum cadere pofie? Rogo te,miColmiel,ut \& alterius mihi effectus caufam exponas. Quacuor enim anni ftationes, in hoc magno nacuræ. aqui-ductu experior; jam enim hyberno frigore quafiobrigefco; modò verno quodam tepore recreor; modò æettus æftasqueintolerabilis me cruciar, eâ füdoris vehementia,ut ejus fèrendæ non fim par. Cofmiel. Ordine tibifingula pandam. Mirabaris ingentem aquarum copiam, \& perinnumeroshiaeus ingentes aquarumenuctationes: \& meritò.. Vidifti enim Ruentium illud arctica voraginis præcipitium intra terræeviferainntl- aquarum meris aliis aquarum defluxibus auctum infinuatumque: $\mathrm{Si} \mathrm{Ni}$ - ingens liacre ruentium cum impetu aquarum Catadupęaccolas fur-ditate fèriast, quin futurum putas, fi hî́c alicubihomines ponerentur? illos haud dubiè non dicamobfurdicuros, fed nè ad: momentum quidem victuros arbitrarer, ubiOceanus.tanto aquarum pondere, in ima terræ penetraliapræcipitatur. Quod Aque queverò alios hiatus innumeros, qui continuis proftuxiis aquarum liter prefingentem molem fundant, mireris; fcias hunc pariter efle $\mathrm{O}^{2}$ la fe efolceani humorem, qui per alias \& alias voragines intra appro- Gat per popriatos.canales infinuatus, per hrec tandem oftia: exitum inve- cum. nit. Hinc fit, ut aquarum: pondus is in hoc aqui-ducturau- gmentatum, coacervationes aquarum canali inclufarum, pondere fuo in antecedentia promoveat atque hoc pacto præcedentium aquarum mole fubfequentium aquarum congeries prefla,cùm alium quàm per Äntarcticum: polum exitum non inveniat, eam illic per ingens voraginis oftium, quod vidift, egerat; atque hoc pasto contingirperennisilla, de qua fuprà actum eft, pericyciofis. Neque putes velim aquam confiftere alicubi poffe füecontinuato circulationis motu: Theed. Certè

$$
\text { Mmmm 3, diffi- }
$$


difficile captu eft, quomodo, cùm aqua fubinde intra hunc aqui-ductum contra naturam confticuta, ad altiflimas editiffimafque parteselevari debeat, qua virtute id faciat? Cofmiel. similitudo Noftin' quomodo.intra corpus humanum languis, qui eft in ex fanguine bumano fefe percor. pus circu. infima corporis parte, pede inquam,quamodo ille idem perpetuâ fui circulatione mox intra caputcontra naturam afcenlante. dar, ac inde iterum in infimas partes relabatur. Vidiftinè unquam aqui-ductus, quàm hereroclitâlege, nunc eximoin altum, nunc ex alto in imas valles, modò in dextram, modò in finiftram per plumbeos canales deducantur, neque un quam tamen aquam perpetuo fluxu in loca dentinata deponere ceflant. Idem accidit in hoc principali naturæ aquæe ductu. Theodidact. Optimè cepi ratiocinrim tuum, illidque ex Hydroftaticis principis fatis comprobatum video. Sed jam perge reliqua. mibidubia folvere. Cofmiel. Nefciebas curdifferentes caloris gradus in hoc aqui-ductu, velutiad quatuor anniftationes difpofitas à natura conftiuti finc. Quare fingulorum rationes" tibi affigno. Canalis hic Geocofmi principalis eò naturæ incentione ordinatus eft, ut totius telluris molem innumeris fibris, rimis, finuris, hiatibus refertam naturæ illo femine, quod in aqueo elemento latere diximus, per fubterreftrium calorem ignium, qui in pyrophylaciis hunc aqui-ductum circumdanti- bus perenni alimento fovetur, imbueret, \& ad generationes mineralium, promateriarum obviarum difpofitione excitaret. Semen verò hoc cùm fine calore exeri non pofiet, hỉnc tot natura ordinata funt pyrophylacia, quorum ope femennature aqueo elemento infitum mirum in modum per differentes hofce caloris gradus digeritur, \& concoquitur, corpusque acquirit producendis rebus confentaneum. Atque hoc pacto aqua cocta jam, digeftog; femine focta in vapores refoluta, fublimata, atque intra terræ fifuras fibrasque impulfa, tum primùm naturæ molimen ad innumerabilem rerum varietatem. producendam orditur.Sed de hoc fufiùstecum fuolocoagam. Theodidact us. Sapienter ratiocinaris, nec quidquam de quo in. pofterum dubitem reperio. Sed quando tandem fnem hujus" 
Cap. III. ItcrSubmarinum.

aquadictus lpectabimus? Cofmiel. Accelerabo gradum,ukex intricatifimo hoc labyrincho quantocyus te educam. Theodid. Fiar. Cùm enim natura idem in omnibus femper operetur; partem hujus canalis præcipuam vidifle, totum vidiflefufficiat. Sed ô miCofiniel, quo inexplicabili aquarum impetu rapimur? in tartara clefcendere videmur. Cofmiel. Non defcendis, led afcendis violentiâ aquarum in altum raptus. Jam brevi finem fpectabis. Theod. Quid illa lux dubia fibi vult, quam incueor? Cofmiel. Jam folaris lux hiatum ingrefta affulger nobis Theodid. Vix dixerat, cum ecce navicula hiatumantarcticum egreflà,tantis aquarum turbinibus involuebatur, ut formidabilius quidquam non dican humanus oculusfpectare queat, fed: nè humana quidem mens concipere:valeat: Jam, mi Cofmiel, video luculenter cur polusantarcticus mortalibus inacceflus ${ }^{3}$ fic. Quis enim hofce aquarum cumultus, quibus fefe in omnes mund i partesper hunc hiatum cum inexplicabili impetu fundume,feperarequeat? Cofmel Vidiriitaque, Theodidacte,aqui-ductum pracipum, quem natura in Geocolmo, ob fines? jam tibi expofitos,fapienter difpofuic. Nunc reftat,ut particularium nonnullorum aqui-ductuum, hydrophylaciorumque: conftiturionem oftendam. Iheodidact us. Exequere totum id, quod optimum fini meo futurum judicaveris. His dictis, per. avia \& devia ad ingentem me abynum, feu.hydrophylacium. conftitutum reperi, cujts magnitudinem verbis exprimere vix liceat. Verbo, mare videbatur, in quod flumina rantæ vafticatis per oftia canalium evomebantur, ut Rhenus, Danubius, Rhodanus, Eridanus in comparatione eorum rivi vide-rentur. OCofmiel, totus Oceanus merito huc confluxifle: videtur ; explica rogo prodigium, \& mirum natura fpectaculum. Cofmiel. Hæc eft una ex principalibus abyffis terræ, à natura in tereftris molis irrigationem deputata, habetque occultum quendam cum magno, quem vidift, canali correfponfum : in eo enimaquas fuas exonerat, ut aqua tandem per antarcticum hiatum exitum fuum reperiat denuò huc circulanda. Theodidactus. Sed quisnamillecalor, qui tantâ me mole- 


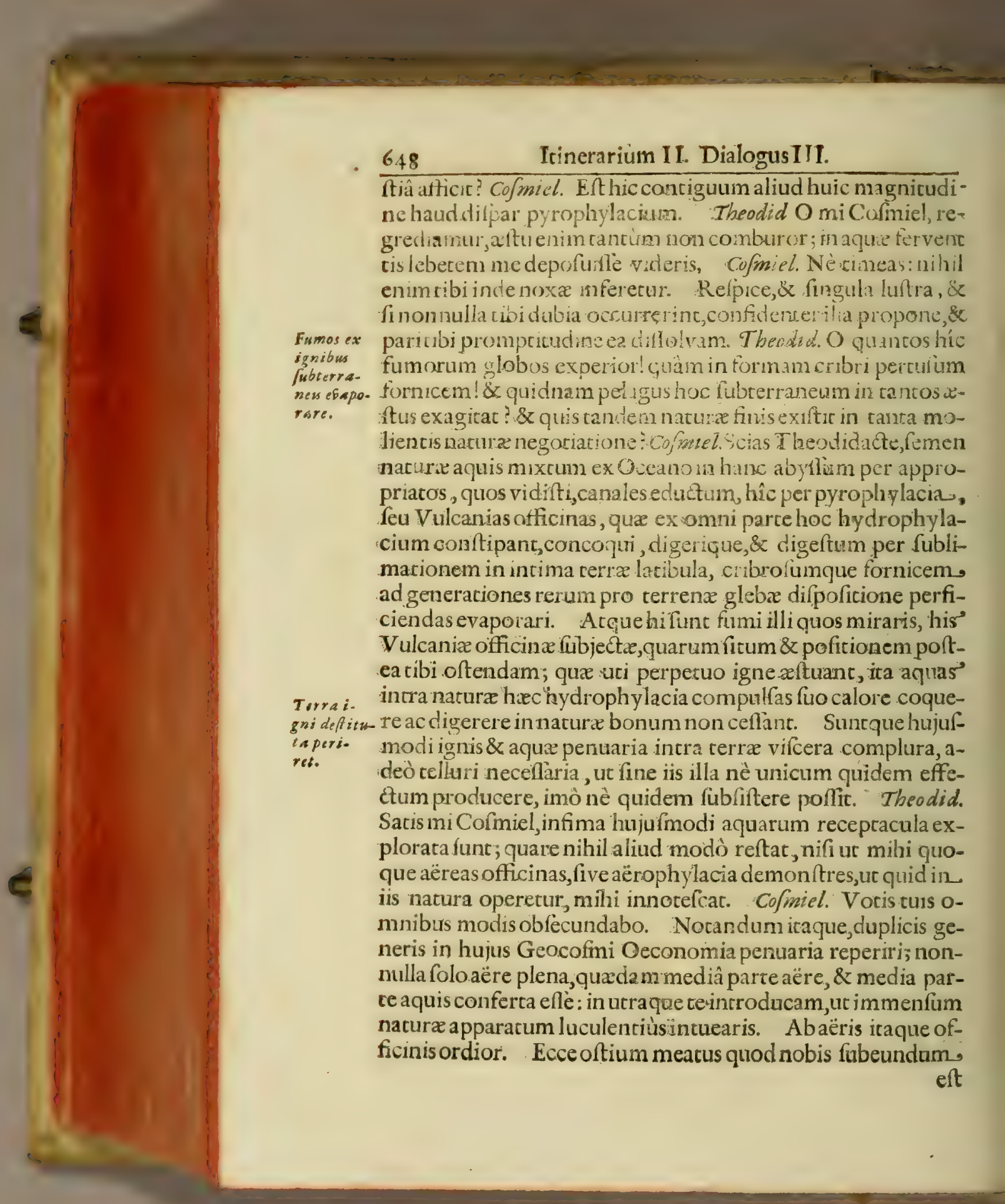


Cap. III. Iter Submarinum.

eft. Theodid: O quàm mirum naturæ opus? quid fibi exoticus Aëris füb. ille \& ingentis 'vafticatis 'neatus, portendit? Cofmiel. Viden' terranei quot \& quibus lateraundique \& undique pertula fint forami- rerboitur. nibus? Awd is quomodo fuis illis ntlicidis , \& perenni rivulorum murmureperftrepant? Alii æituancifimos perpetuò halitus cum fremitu exfpirent? Theodidactus.Video,audio, $\&$ admiror. Neque in hoc fubterraneo regno huic fimilem me vi"dille memini. Unde non capio quare tu cum meacum dicas", qui fubrerranexregioni non incongrue comparari peffit.Hîc enim implexi fcopulorum ordines, hic intercufantes aquarum trivi pifcibus referti, hic planities uberrimo veftira gramine, hîc parietes fcopulosâ rupium fcabritie, varias effundunt mineralium merces. Sed quàdná fibivuĺ ninfolicum modò frigus, quo pænè obrigef co ? nunc caloris æitus, quo tantùm non füfacor? rogote, ut abfcondica fingulorü myfteria mihi expöere nè graveris. Cof $m$. Hic eft meatus ille Acolius, unus ex præcipuis Geocofini canalıbus, in q̣uo f piritus, quos cum hydrophylacia , tum pyrophylacia illi fuppofica \& circumfira percacas cerræ: latebras diffundunt, inaturæ femine foeti ulteriùs elaborantur, coquuntur, digerunturq; digefti verò per fyphunculosillis à natura deftinatos in intima terrarum latibula infinuati pro difpoficione materix glebacex, quam incurrunt, metallorum, mineraliumque generationesmoliznner: \& apertè id toc hiatus, foramina, fifluræ, rimæ laterum, quibus circumdantur, indicant. Calor quoque frigưque alternâ vicifficudine opus naturæ follicitans hoc efficic, ut concentratum femen naruræ intra humido-frigidum calorefuperveniente diffolutum in loca deftinata ad fines à natura intentos tranfigatur. 'Theodid. Sed quis ille validiffimus, quem experior, ventus, rantrque vehemenrix, ut nec Ecnephiam,necCyrcium, neque Africum ei comparari polle putem? Cofmicl. Hujufmodi ventifunt frequentirli- Ventovinas $\mathrm{mi}$ in fubterraneo hoc regno, oriunturq; exlucta \& prelis a- - tißimerum trocinimis, qua fibi invicem intra abdita hæc naturæ clauftra fub zerr ignis \& aqua inferunc. Calor enim æftuans rarefactam a- origo हs quam, quamalicubi intra monrium recepracula incurric in cassa.

$$
\text { Ninn fun- }
$$




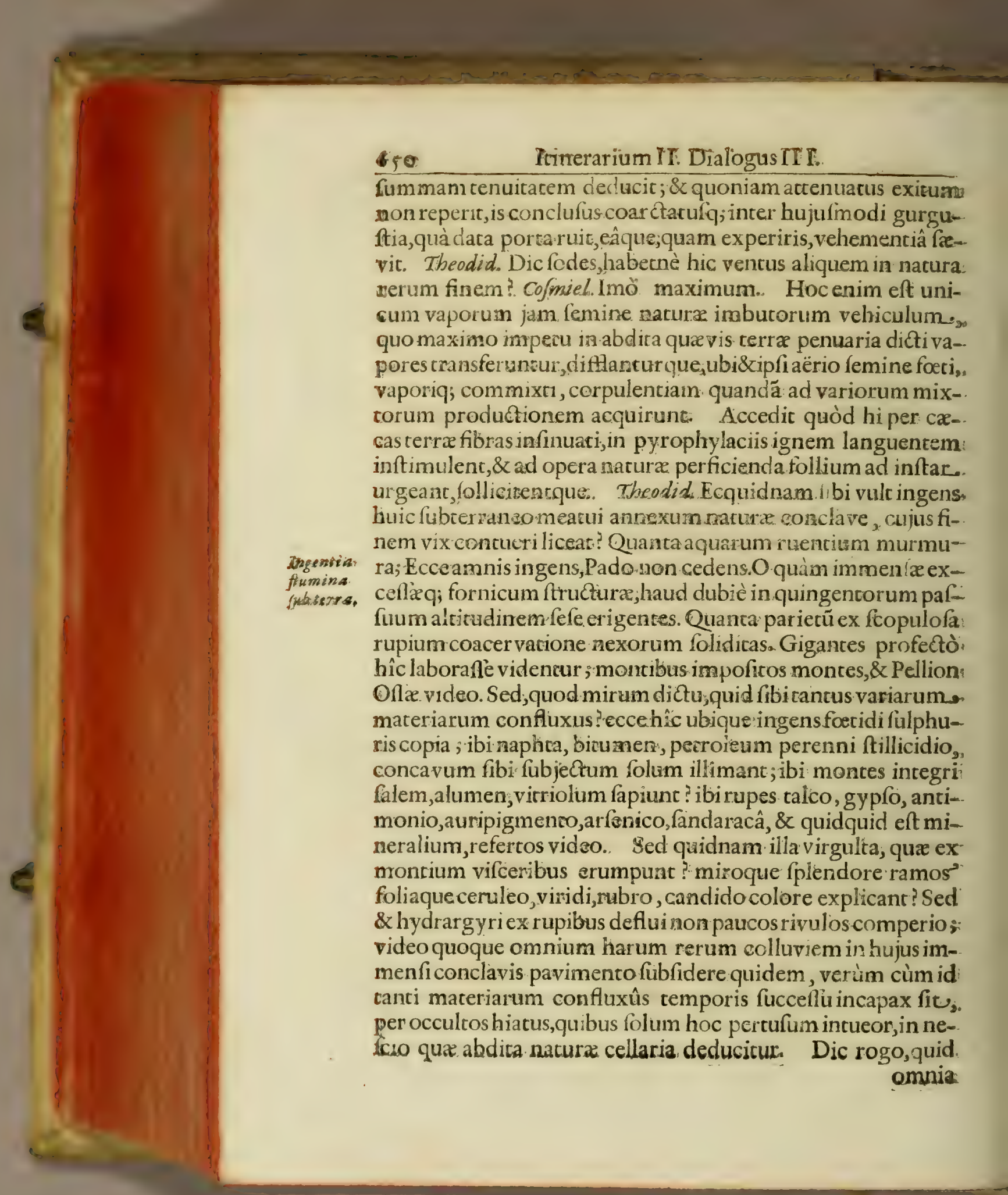


omnia ifta fibi velint? Cof $m$. Hocce quod vides, magnum natuxæ promptuarium ef, in quo calorefubterraneo,mineralium. remina coquuntur \& digeruncur, pars verò jam digeftione fubctior in alia nacura penuaria ad mineralium metallorumq; omnis generis productionem elaborandam per filuras rupium evolando derivaeur; unde cor locum hunc hiatibus referrum efle, non eit, guod mireris; craffior verò \& foculentior. pars per foli hujus hiatus in py rophylacias. feuVulcanias officinas derivata, in ignis hypogai pabulum cedit. Theod. O miram Crafle 8 Opificis Mentisfapientiam! ô heffabilem providentiam! Sed foculenta unde, roge, hac tantarerum colluvies primat fui originem mineralit habet Com divibi est a

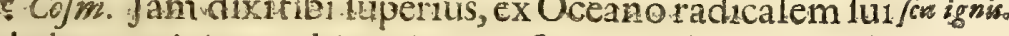
omnia habere originem; hicenim per fuos canales, in occulcos terrx frus ejaculatus, cùn fale, fulphure, \& pinguedine naturaliturgeat, ibi pro varia terrentrum glebarum difpoficione variam mixtorum mineralium fobolem generat, qua proinde pyrophylaciosum entu per inaccerlos caminos glebâ liquefactâ in Aluxum urgecur, atquerarandem hoc loco exonerata ac magis magifque elaborata, per alios ac alios canales, miis \& aliis naturæ laboracoris ufque ad fuperficiemterræ propagatur. Theod. Explices, rogo, jam, quid fibi virgulta illa velint. Cofmieh. Scias, mi Theodidacte, quòd ficuti externa fuperficies fuas" easque innumeras vegetabilium fpecies producit: Oceanus ${ }^{3}$ Simetin quoque fuas, quemadmodum dum fundum ejus exploraremus producurits vidifti, vegetabiles, merces exponit; ita \& fubterranea natura terra, $O_{c-}$ Aeolia penuariâ,fuas, cujufmodi jam intueris, plantasproducit. canus ac Et nihil aliud funt, quàm efflorefcentix quædam mineralium, gna fubtem fpecierum, diverforum potifimùm falium, qux follicizante ranes. latentisfubterranei ignis vi,omni humido fuperfluo exutæ in truncos, ramos, folia diffunduntur, diffưæque loci naturâ frigidiufculâ in petrof $x$ fublantiz virgulta \& germina indurefcunt,cujusmodi innumera in aliis reconditoriis tibimonitrabo.Theod. Suntnè plura hujusmodi Aeolianaturæ ergafteria.. Plurim 3 Cofmiel.Quinimò plurima; hoc enim ordini naturæ erat quàm effe Ventemaximè confentaneum; fine his fiquidem neque hydrophyla- pram rece- 
Aerquim necefarins igniE a: que.

\section{3}

Itinerarium II: Dialogus III:

cia,neque pyrophylacia quidquam potuiflènt,çum hac aërias:

fubterranei Geocormi regiones exprimant. Quemadmodum enim ignis nihil potert fine aqua, hæc nihilfine igne, uterque nihil fine aëre; ita hujufmodi aëria reconditoria, fagaciffimo naturæ confilio, ad totius natura bonum, mutuumque elementorum fomentum difpofita eflé fcias: V erùm iftiufmodicibi unum è pracipuis loco omnium demonftraflé fufficiat Reftat jam ut te eximis abyffis ad vicinos terrenæ fiperficiei : promos condos adducam, ut hocpacto totius fubcerranex Oeconomix concatenatos labores luculentiùs perfpicias. Theod. Uri nihil in natura rerum tantâ admiratione, quàm hujusmodi. promos condos aqueo-aërios contemplatus fum ; ita-nihil votis meis acceptius accidere poterit, quam te doctore \& inftru- Etore fingulorum rationes oculari demonftratione edoceri. Vixdixerat, dum cece per occultos variof telluris angiportus in vaftifimum fubteraneum lacum inexplicabilis vaftitatis: \& altitudinis fornicenbtenfüm devecti fumus. O Cofmiel,quò: terrarum me rapis ? quid fibi vult tanta aquarum colluvies?: quid ingensundique ruentium aquarum ftrepitus mur murLaens fubl que horrendum : Cofmiel: Hydrophylacium, quod intueris, fiCaucafo, ES Imao montibus. tum fium haber intra montes immenfos, quos nunc Caucafum, nunc Imaum veteres vocabant; in interiorem Afiam longè: latèque exporrectos. Hic natura fluminum ingentium recon-ditoria\& imenficellaria univerfa Afix \& India riganda fuffi-. cientiflima pofuic. Theod Ergonè fub Caucafö\& Imao conftituimur? colmiel. Ita eft Theodid. Jam mili explices relim; undenam hixc cellaria tantam aquarum congeriem depromant? cum indefinentifiuxu, tantastamq; ingentium amnium moles Aquarắex egerant: Cofniel. Ex Oceano Indico \& Tartarico originem fuá Alia, In- nancifcuntur. Ex quibus per complures fibiappropriatos aquimontibus

Asientium origo. duEtirs fubter raneos perenni afluxu implentur. Theod. Quomodo id ficri porelt, cùm reconditoria Oceano multòaltiora, fint ? Cofmielísi qua füprà ab Hydrielé audifti,\& à me multis? argumencis confirmata percepiffes, nulia tibi in modo apprehendendo difficultas fiperefler. Recordarifièdum fündium 
maris exploraremus, ingentium voraginum; quas tantoperè admirabaris? Theodidactus. Recordor.. Cofmiel.Illi nihilaliud erant, quàm aqui-ductuum in hujufmodi cellaria feu hydrophylacia per imenfas fubterreftrium fintumambages difpofita orificia, perquæ aquarum molès perpena Oeeanii æeftús reciprocatione veluti per hydiaulicos quofdamSyphones preflà expreflàque; in hunc, quem vides ; lacum fubterraneum exoneratur. Theodidactus. Sufficitnè unus aqui-ductus tantæ.vaftitatis làcui explendo? Co/miel Nequaquam, fed diverfi fune aqui-dùctus,immenfo lócorum intervallo diffici, per quos $\mathrm{O}$ ceanus féfealcernâ ærtùs viciffitudine exonerat,nè alicubi æitu ceflante aquarum quoque affluxus in conftituto hydrophylacio deficiat:- Nonnulli enimirmari. Ińdico, quidam in finu Gangetico;alii in Orientali; in Tartarico alii Oceano; meatu - Multos in um hydrogogorum principià fündảnţoptimâ fanè naturę in = Gaxis locis ventione, ut quiefcente aftu unius, natura-fuam folaretur pe- reperiri nuriam afluxu aliorumalternis officiis in Gèocofmin confer- it us. vationem confpirantium: Mirabaris paulo antè formidabiles? ruentium aquarum Catadupas; quas jam ex diverfis iifue immenfis rupium fubcerreftrium hiatibus, arcuatimeructari vides? hrec funt orificia meatuum hydragogorum, per quos $\mathrm{O}$ ceanus in diverfis locis, perhujufmodi Epiftomia in ifthoc hydrophylacium fe exonerat.Vides quomodo alternâ eructatione,veluti perfyftolem \& diaftolem quandǎs perennibus naturæ laboribus inftent? Theodid O Omnipotentis virturis dexte $\div$ Dei opere ram? quis eft quiopus manuum tuarum explicer ? quis eft ita ineffabilialinguá calà moque difertus, qui ea etiam quàm ftudiofiffimè âffectatâ oratione fufficienter exponat? Sed ad inftitucum noftum: Ulbi jam funtorificia fluminum; per qua tanta aquarum moles in amnes effufa egericur? Cofmiel. Hoc ut intelligas, findus nobis luftrandus eft Theodid.Fiat. Cofmiel.Vides hofce hia- Orifcia tus, parvos, magnos, maximos, quibus cum fundum; tum latera intelligi ex pertufa fpectas? Theodidact ius: Cèrno mirandam rerum faciem; fundi con$\&$ vorticibus horrendifque turbinibus omnia involuta reperio. cofm: Majores funt;per quos in amnes \& lacus hoc penuarim Ninn 3: fele 


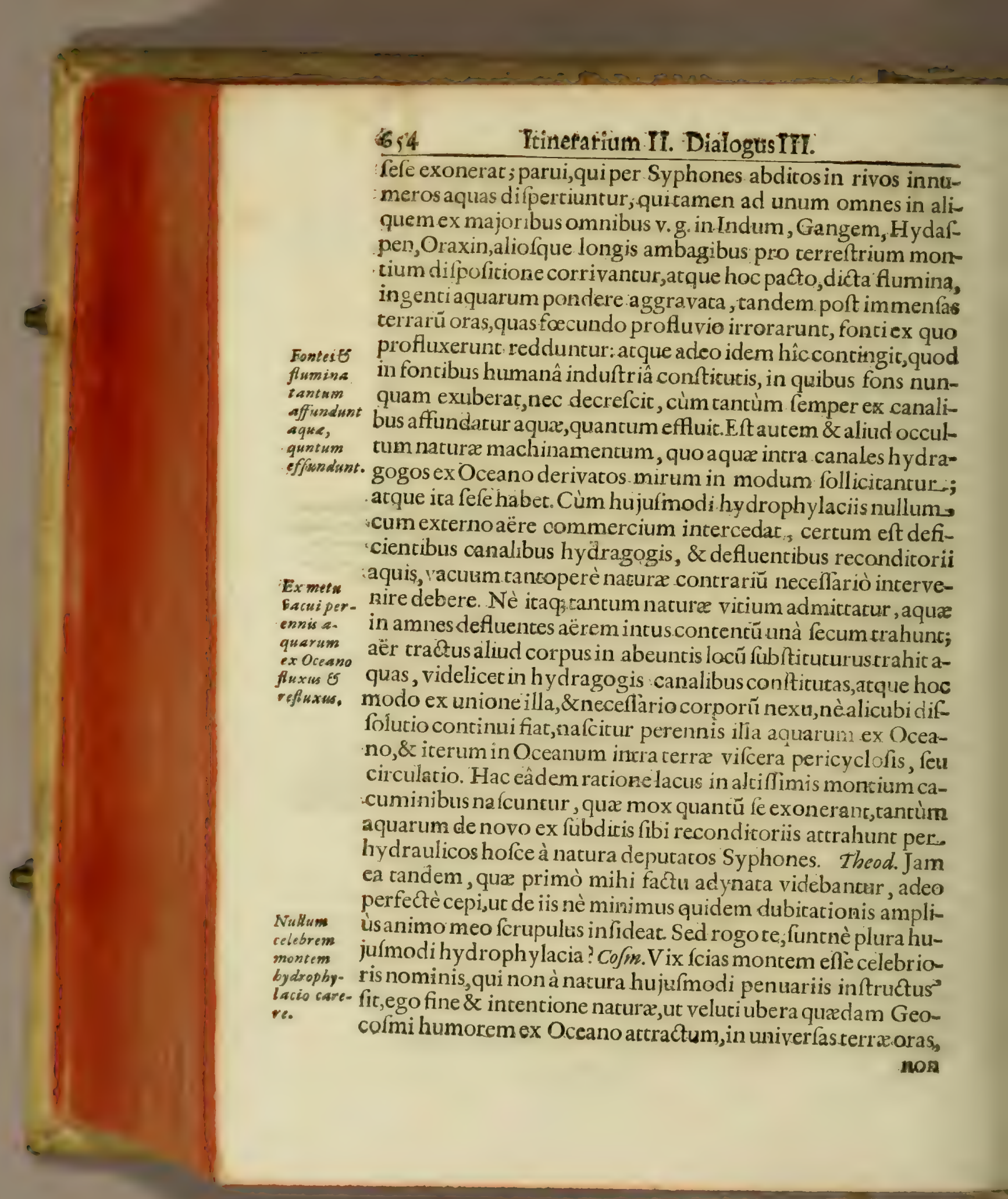


Cap.III: IterSubterraneum:

non in vegetabilium tantù fomentum, fed \& in hominum animaliumq; neceflarium ufum diffundant; quod fine montibus fieri nullâ ratione potuiffet. Sed ut omnia propiùs videas, te ad precipua hydrophylacia ducam, non ut ibi moremur, fed ut fimplici oculorem conjectu ingentes nacura divitias luftres. Theod: Imperio tuo utinunquam reftiti, ita totum me tax difpofitioni committo. Fac itaque quod placet; \& more tibi follto, quàm cellerrimè. Vix dixeram; cùm ecce defertâftacione in aliud me cellarium per iñumeros meatus, lacus, fumina, ftagnaque fubcerranea traductum conftituit. O quis unquam a-Tirre in nimo concipere potuiflet, tot fubterraneum Geocofmum via terna dift rum ambagibus difriminatum?tot abftrufarum vallium clau-poftio. fris cohibitum? tot torsuofis anfractuum ambulacris intricatú? tor meacuam frfitiris hiancem? toe conceptaculis camerarum que fubitractionsubus folidarum, cor fuminibus, lacuburque irvigutim totvenarum metallicaram duể bus omni colorum. genere depictis, veluci aulais quiburdam exornatum? O Ater na Sapientia;omniumque MensConditrix;verèłconfideravio-pera tua,\&ad infinica potentię tuę miracula expavi.Si.tu,Deus cantus es in operibus tuis vifibilibus, quantus eris inte ipfo? $O$ mi Cofmiel, magni Condicoris Minifter.. Dic,rogo,ubinam: modò heremus? quodnam hoc novum recepcaculum, in quod me introduxift Cofmiel. Hucufque te per concava concate-Hydrophy. natorum montium, Cafpiasinquam, Tauricas, Thraciaspar- lacia Aly vicularibus hydrophylaciis refertas fubterraneas regiones $\mathrm{du}_{-}$pium.. xi ; modò te inter Alpium cellaria confticutum effe fcias. Theod. Fierinè poteft, intra tam breve tempus tantas labyrinthorum: ambages nosconfecife? Verùm cùm tuam progreffum non. humano pede, aur arte facto vehiculo, fed Angelico metiar,ecquidem mirari cello.. Ergonè inter Alpium hydrophylacia. conftituimur? $\mathrm{Co} / \mathrm{m}$. Ita eft. Theod. Sed ubi manfit cryftallina noftra navicula ?' Cofmiel: Non fis follicitus de Navicula, hacenim; ubi eâ indiguerimus, femper nobis præfto erić. Confidera hanc,ecce;præfentem latè patentibus aquarum diffufionibus immerfam. Theod. Ingrediamur cam. Sed, ô miram rem! marij: 
Aqua in. tra Alpes unde conflwat.

Ingentium fubiorum exAlpibus ortus.

Intra Alpesauri, argenti, 5 mineralium copia.

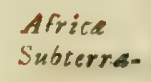

mari,quàm lacui fimilius video hoc hydrophylacium. Cofmiel. Audilnèftrepicum Caraduparum? Theodid. Audio. Sed quid hoc: Cofmiel. llla eft aqua, partim ex Boreo, partim Occidua, Auftinoque; Oceano, percanalem IIthmi . Egypti, quam nuper luftravimus, in mare Medicerraneum, \& inde in hos montes derivata; quxper accultos.canales hydragogos incra hac montium conca va tumOceani, tum intimm maris âfu corrivatur: qux cùm perenni atr actuaquarum vas hoc impleant, mirum non eft, tot ingentia flumina, cujumodifunt Rhenus", Danubius, Rhodanus, Mofa, Padus, Ticinus, Oenus, A thefis, pari diftributione in omnes Germanix, Gallix, Italizque regiones diffundere. Theodid. O vasadmirabile! O verè opus excelf $!$ non hominum, fed Omnipotentis Dei dexterâ fundatum; ô quot hîc reperio auri \& argenti venas? quot, \& quàm. diverias mineralium fpecies? Cofmicl. Satis eft:modum quo coalefcunt hæc omnia;opportun iori tibi loco indicabo; quaread alia properemus. Theodidactus. Ecce nova femper, \& nova naturæ cellaria nobis accurrunt. Cofwiel. Quadamad Cotias" alpes Galliz, \& maximum quod híc vides, eft Pyrenæorum. montiun, quorum omnium eadem eft ratio. Vides quot \& quantis fluminibus tum Galliam,tum Hifpaniam irrigent? reftac modòu \& A fricæ fubterranea exploremus. Theodidact us. Fiat: \& Eurovelociori motu per innumeros labyrinthos fubterraneos deducti, ingens hyerophylacium, prioribus haud impar,introivimus. OColmiel. Quodnam eft hoc fubterraneum mare ? Cofmiel. Iftud eft magnumillud naturæ cellarium intra montes Lunæ ad totius Africx irrigationem conftitutum: quod uti ex Oceano Africam ambiente fuum acquiric aquæ commeatum; icaillum per ingentia flumina,Nilum, Cuamam, Cairem, Nigrum, quibus A frica irrigatur, fonti, unde profluxit,reddit. Theodidactus. Sed unde ingentes illi lacus., quos" partim hîc, partimin luftratis jam Afiæ \& Europa montibus circumfufos video, derivantur? Cofmiel. Ifti omnes lacus funv continuati cum fubterraneis montium hydrophylaciis, \& pectanr ad ea,hac tantùm differentiâ, quòd natura bydrophyla- 
cia fornice inftructa, lacus verò hofce in ufum negotiationis humanæ detecta effe volueric. Theodidact us. Non capio myfterium, cùm flumina multò altiorem hifce externis lacubus originem habeant. Cofmiel. Videfnè inter hofcemontes, varia à natura conftituta cellaria? Theodid. Video. Cofmiel. Vides quoque nonnulla alciorem aliis fitum habere? Singula tamen fuis kydragogis meatibus indefinenti fluxu implentur; quorum clanalium orificia ucialtiorem à natura ficum fortita funt, ita appropriatos quoque fuos, in quos aqua diffunduntur, lebetes, altiores obcinuerunt. Accedit alcenfum aquarumattractu naturali, quem fuprà tibi expolui, multùm promoveri. Theodidactus. Jam omnia perfectè cepi, neque de naturæ potentia ampliùs dubito.Progrediamur itaque.Vix dixeram,cùm ecce pari velocitate, per ingentes fubterreftrium terrarumtractus, Oceanique fundum traducto, ingens modò rerum mỉrabilium theatrum aperitur. O miCofmiel, eftnè poflibileterre-Terra in: nam molem tot meatibus perfoflam, in tantam Regionum, numeris fubterreftrium amplitudinem excavatam fubfintere polle? peatibus Cofmiel. Tu femper morehumanoloqueris, \& divina opera hu_confiftat. man is inventionibus perperam affimilas. An nefcis cadere non poffe id, quod potens Dei dextera excelfi, ineffabili opificio, inviolabili foliditate firmavit? Theodidactus. Condona, quæfo, fervo tuo; neque enim hæc elocutus fum, ut de divina, potentia quidquam dubitarem, fed quia admirationetantorum attonitus fpectaculorum mei ipfius vix compos fum. O Sen/us in ridiculas illorum Philofophorum f́peculationes, quiterram, , is, qua wove prater eas quas externa nobis fuperficies exhibet, nullis aliis atting it, cavicatibus inftructam, fummâ fanè imperitiâfibi perfuadent. O quantoperè in ris, ad quæ fenfus nofter non pertingit, concipiendis dijudicandifq; deçipimur? Cofmiel. Rectè fentis;proindeque par eft in hifce rebus cognofcendis itudiofiùs allaborare: neque enim alia fapientia humana concipi poteft, quàm rerum naturalium exacta cognitio, quam \& fapientiffimus mortalium à Deo fe accepiffe gloriabatur. Theod. Ubinam, quxfo, locorum fumus? Video enim hîc non dicam cellaria, fed inteOooo 
Americis monibus majores pepriri nellas.

Elsuminum ex AndiAus, orige. $\epsilon: ?$ Foneraritan II. Dialogus IIT. Sri ús idihina luberranei mundiregna. Cofmiel. Nollectr 4isubi moremur 2 Sub. Andibusverfamur Americaconcatem.tcis in immenfun fortium montibus, quibus natura in exterra Geocofini liper ficiemajores altioresque non fundavic,vulgò Condillefa dictis. Vides hic integra veluti maria quadam. congregata, qux amnia rum ex. A chlantico \& Athiopico, tum. ex immenfo \& incognici adluc rermini Oceaso auntrali fum e.,yuo dixi, modo orizinem rralun . Neque mirum tibivisierideber, ram valta hic maris larifundia contineri, cümilla, wiveriam Americam Meridionalem vaftifimis totus orbis" serrarum annibus, (cujusmodi func flumen Amazonum, Maragnon, fumen Sancti Janaarii, vulgò Rio della Plaøa) aliisque innumeris minoribus, prater maximos lacus, irrigent. Theod. Sed ingentem hoc loco:eftum fentio. Cofmiel. Audifti. fuperiùs, hydrophylaciis individuâ quâdam fociecate femper: juncta ele pyrophylacia, feu officinas Vulcanias, excoquendis. digerendisque ayuis, fubterraneis neceflarias: undequemadmodum natura nullibilocorum majora promptuaria aquatica, quàm hoc loco conftituir; ica nullibi quoque majora \& frequentiora pyrophylacia, qux nobis modò perluftranda refant.

\section{CAPUT IV.}

\section{Introductio intraignea fubterranei Mundi conceptacula.}

Oofmiel: Vidifti, mi Theodidacte, naturx Majeftatem in. admiranda hydrophylaciorum fubterreftrium fabrica, ufum quoque tum quoad excrinfecam, tum quaad intrinfecam confticutionem, fingulorumque rationem me duce \& magiftro didicifi. Nihil porrò reftat, nifi.ue modò arcanam naturæ induftriam in conftituendis fubterranei Geocofmi Pyrophykaciis fou reconditoriis. Vulcaniis oftendam, fine quibus naturahaud 
ra haud dubiè manca,mutila, \& imperfecta maneret;cum nul1a quarumvis rerum generatio fine hilce innati caloris æeftuariistranfigi poffit,quemadmodum oculari experımento comperies. Theod. Nihilmihi acceptiûshac ftupendâ rerumexhibitione effe potert. Sed quis tor flammarum globos, rot inexhaufta ignirm xhluaria impunè tranfeat? ego prafertim uta natura fragllimus, ira impendentium perieulotum timidifimus lum. cofmiel. Nè timeas, Thendidaute; quemadmodum, enim à principio impunitatem tibi pollicitus füm, ita eamillâ, quam meCofmielem mundi præficem decer, fide exactè fervabo. A gedum matte animo, Theodiclacte. Theod. Solútuá benignitate,\& potentiâ confifustuam accepto invitationem longè humanifimam. Er è veftigio, in horrendum guoddam incomperta à me magnitud inis antrum introduxit. $\mathrm{O}$ mi Cormiel, quò trahos? quò me cum fummo vitæ mex periculo ducis? Cofmiel. Confide fili , \& nunquam ab humano oculo vifa. tibi montrabo. Neverô quidq̧am ab ignium violentia patiaris, hoc accipe antidotum. Theod. Hisdiet is; effuro liquore quodam praftantifimo, mir um in modum refrigerance, fuper caput meum, totum me incredibili quadam virtute contra omnes flammarum noxas munivit. O amantiffmedux vita mex, quàm horrendam rerum fcenam hic video? Forfan in inferni barathrum meduxifti non enim hîcalund, nifingentes

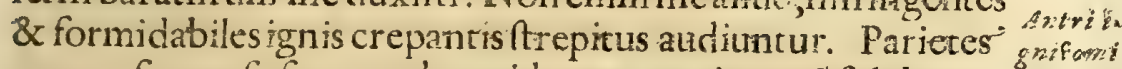
omnes fuccenfo fumo ardere videntur, pavimentü fulphureis defcriptra lacubus, ardentifimisque flurvis refertrm. Hiatus formicis, innumeri veluticamini \& fpiracula in altum porriguntur; latera ingentibus hiatibus fatifentia video,qux partim naphram, bitumen, pinguifimamoque marcriam accenfam, partim fulphureas flammas unà cum liçuefacta ignini liquor is materiầ, perenni fluxu fundunt. Heu quis fumus? quis foetor? eft nè follbile tantam rerum confufionem emolumentum aliquod in. natura rerum adferre poffe? rogo itaq; teobnixè,ut fingulorum rationé mihi exponas,idg; quoad fieri poterit pauciffimis yerbis, nè longo tempore in tan formidabili ignij habizacrn-

$$
00002 \text { locim- }
$$


lo commorari cogamur. Cofiniel. Quid omnia notent, quos ufus in nacura habeanc, fingula cibi pandam. Vaftifimum hoc antrum?, leu Vulcanium barachi um minimè, utitu puras, in fernus eft, cid eft pyrophylacticum naturæ recondicorium, quod intra intima terræ vifcera natura ad cotius America Meridionalis.bonum \& emolumentum conftituit In hocenim natura femen, tum ad mineralium cujusvis generis metallorumque litas. productionem perfêtè excoquitur; tum ad hydrophylaciorum fluxum continuandum, qux fine hoc calore mox intenfifimâ fubterranei frigoris vehementiâ in glaciem coalefcerent. Quemadmodum enim incolefti expanfo Deus Solem igneum, \& Lunam aqueum cor pus pofuit eo fine, ut unum alterius impetum frangerer, nè alcerutrius exceflu omnia infeSunam $E$ borum nation factum eft, ut permixcis unà radis calidis \& huriora fusque deque ferrentur. (hacenim contrariorum gloproco infum midis ad temperiem reducta corpora tum mutuó fe foverent, zu tempe- tum reciprocâ mifturâ feminum acceptâ in inferiorem rerum rari. Oeconomiam ad intentan generationem efficiendam apriùs. influerent ) ita pari ratione cum Sol, Luna, Ste llæ rad iis fuis intima terræ vifcera penetrare nequeant, fapienti fane naturæ confilio Sol \& Luna fubterranea, qux nos pyrophylacticos \& hydrophytacticos fundos, Solis\& Lune vicarios, fecundùm. analogiam quandam vocamus, conftituta funt, ut mutuo calidi \& humidiconfortio univerfus Geocofmus iis velutianimatus, \& ab intenlo frigore fummo naturæ vitio caloris accentu vindicatus globus a dneceflariam rerum generationem juxta. intentas. Divini. Archetypi rationes incitaretur. Miratus es fornicis hiatus* llios nihil alind effe fcias, quàm fpiracula quædam, feu canales pyrogogos, qui hujus æeltuarii calorem inalia fuperiora æftuaria, quorum in hocAmericæ fubterraneo traPyrophyla. Atu quatuordecìm funt, traducunt, \& propagant. Hęc verò per. cia Amern fimiles alios pyrogogos caminas, in extima Vulcaniorums sR. montium, quorum itidem pariter quatuordecim numerantur in Andipus. Chile crateres, ingenti fumo flamma mixto, egeruntur. Quomodo verò hæc ignium receptacula durent, quo- 
modo \&unde nutrimenti fomentique neceflariam fuppeditationem acquirant, \& quomodo poft perpetuas ignium eructationes tandem non extinguantur; fusè tibifuprà expofui.Dantur præterea \& alia fpiracula, qux in hoc antro fe offerunt, ad hydrophylacia calefacienda à natura deputata, ut videlicet in . iis naturæ femen perfectë concoctum;, corpus acquirat in materiis appropriacis ad generationes rerum perficiendas. Accedic \& hife ingens horum meatuum pyrogogorum emolumentum, quod intra montium vifcera terræe tuperficiei vicinos lebetes hydrophylacticosà natura difpofitos ingenti fúo æftu calefaciant, quicalefacti deinde perappropriatos.fibi ca- Thermarï 7u cararum nales foras in thermas tantoperè humanis infirmitatibus cu-ratio $\&$ o. randis neceflariasprorumpunt. Si itaquecanales hujusmodi rigo. fulphure abundent, thermæ nafcentur fulphurex; fi per falinos \& vitriolatos meatus, aut aliud quodpiam incile alio falium genere refertum tranfierit aqua, thermæ falem, vitriolum, aut fimilequid fapient. Si per loca bitumine, petroleo, 1milibusqueoleagineis materiis referta tranlierit, tum ecce nafcentur thermæejus naturæ, cujus funt meatus, per quos tranfeunt aqua. Sivero canales pyrogogilongiores fint, quàm ut Aqua fri- 10 aftus eos ad exitum ufque calidos confervare poffint, tum a- gidiffima qua per loca fimili virtute mineralium imbuta tranfiens, frige- unde fit. facta in externam fuperficiem emerget vel in fimplicem aquam frigidiflimam, vel in acetofam, aut vicriolatam, aut fulphure bicumineque imbutam. Ex his paucis tibiobiter indigitatis,nullus tibi occurret aquarum tam exoricus effectus, cujus, caufam protinus non fis affignaturus. Theodidactus. Vidicg in nonnullis locis, fummâ admiratione attonitus, aquam cali- diffima. diffimam frigidifimę junctam, unà cum diverfís aliis aquarum proprietatibus; quomodo id fieri poffit, a te fcire conten-junct a. do. Cofmiel. Caufa hujus rei eft diverfitas canalium, quorum unusquisque ejus naturæa quam fundit, cujus naturæ locus eft per quem tranfic. Si enim canalis ex lebete aquatico æeftuariis" fuppofitis calefacto aquam devexerit, illa urique calidifima, erit. Si verò canalis ex lebete hydrophylactico frigido deve-

$$
\text { Oooo } 3 \text { xeric }
$$

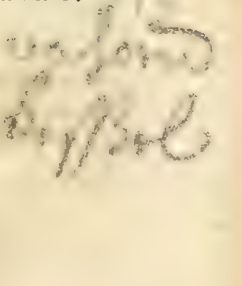


xerit aquam, illa haud dubie frigıdiffima erit. Et quoniam or ificia differentium canalium in unum aliquem locum fubinde concurrunt, hinc mirarifolent homines, quomodo in uno \&c eodem loco tanta aquarum diverficas per diftinctas fcarurigines oriatur. Theodidact. Mirifice mihi placet dubii à me rsbi propolici folutio. Nunc porrò utrum plura finthujusmodi naturæ æRuaria in Geocolino conttituta, edifieras. Cofmiel.

subterve- Plura omnino. Nonnulla ima terræx vifcera obtinent, \& dinea af tua cuntur Principalia: hxc deinde per pyragogos mearus velıti porramos quofdam in univerfa tellaris vifcera deducta, in diverfis partibus alia \& alia fundauc pyrophylacia, \& hæc per. atios caminosalia \& alia fundant vicina fiperficiei terræ; ita. ut fit perpetua quxdam calefactivæ ex uno in aliud virturis propagatio, eo tamenordine uc eftuaria hujusmodiunà cum canalibus pyragogis individuum quoddam cum hydrophylaciis eorumgue canalibus confortium inexplicabili quadam, naturæe induiftrià nacta finc, atque adeo tocius celluris corpus innumerabilibus cañalibus, quà pyragogis, quà hydragogis, aërogogıque, haudfecus ac Microcolmi fabrica percufum fic: ut jam oculari demontratione in hoc fubterranei itineris noAri decurfu edoctus es. Er fi placer, ad alia jam te ducam $a^{2-}$ Atuaria.Theodidactus. O mi Cofmiel, fi in veni gratiam in oculis tuis, filte hîc; neque enim amplius hujusmodilocorum horrorem fuftinere ponum. Quare cùm reliqua ejusdem cum hoc rationis finc,unum demonftrafle loco omnium fifficiat. Jam ad votorum meorum complementum nibil aliud defiderari videtur, nifi ut me ad eas officinas perducas, in quibus tantante cudit metallorum mineraliumque diverfitatem induftriofa. hatura, ut quomodo, \& ex quibus fingula principiis coalef cant, addifcam. Cofmiel. Defiderio tuo facisfaciam. Theodid. His diÄrophyla etis, peranguififima montium gurguftia in amplifimum me ciiconfi- introduxit aërophylacium. OCofmiel! Quid fibivult ingens foriptio. hujus lociaftus? in balneum fervidifimum me introduxifte videris. Qund illi inftar fumi continuativapores, qui ex omnibus paviracnci cilluris exlalantur? quid parieres omaimodis 
C.p. IV. Lrer Subterraneum.

663

cylorum ductibus effigiati cofmiel. Hoc aërnphylacium à nacura ordinacum eft, at lemen nature, qwd in elementis aqua, aëris, terra fpartim lacet, intra hoc unicum, per circulationescontinuas elaboratum, depuratumque, randem ad generaciones metallorum adaptaretur. Vides quomodo fumi veJuti in alembico quodam nunc afcendant, nunc defcendant? Vides quoque ingentem terreftrium glebarum diverifatem, \& variasad recipiendas formas difpofitiones? Vides.inrumera foramina, filluras, rimas, \& fibras rupium ? per hafce enim, vapores ingreff, ubicunque mareriam ad aliquod metallum aptan invenerint; $\mathrm{V} . \mathrm{g}$. vapor unituofus uná cum nacuræ $\mathrm{fe}$ mine ei concentrato, nativo loci frigore coagulatus, n̂xacusque $h$ intra fibras rupium, illud producet metallum, ad quod materia terreftris apticudinem habuerit. Theod. Intelligo qux dicis, fed Metallo. modum quo hocadmirandum nacuræ conjugiü accidie, nof- taionic fe cupiam. Cofmiel. Ut \& hos intelligas, allquantulùm fufuis saufa. me explicabo. Notandum iraque,omnia \& fingula elementa. juxta divinæ fapientiæ leges archerypas, puriflimum fui ipfus, id eft, femen, in alterum elementum fibi inferius projicere $\mathrm{Hoc}_{\text {otemento- }}$

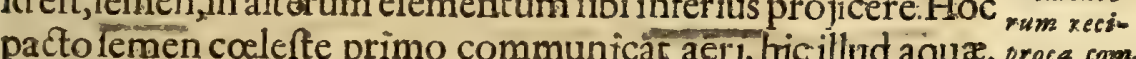
hre illud fibi intra primo communicat aer1, hicillud aqua, proca combus variè digeftum interioribus parti- municasto. bus variedigeftum,columq; communicat.Ex hifce intraGeocofmi uteros varì̀ commixtis, mediante igne, nafcitur vapor. qui in liquorem tandem refolutus per poros \& fibras terra continuâ \& iteratâ circulatione, veluti per mulriplicata quæedam alembica depuratus defacatusque, unctuofitatem quandam, vifcofitatemq; acquirit: atq; hoc eft illud humidum unctuofum, feu aquę vifcofum, omnium metallorum proxima. materia.Hocitaq; continuâ concoctione ac digeftione depu- Humidum racum, tandem in terram falfuginolam convertitur, quxecon- unctuofüm tinua liquoris fui irroratione foluta, per poros \& fibras terra metallorī. quas hic $\nabla$ ides, quafi filtrata, fublimataq;,ab omnib.terreftribus lutofisq; recrementis eò usq; depuratur, donec fulphuris cuiusdam candidiffimi \& incombuftibilis formá inducat;quod fïlphur hoc pacto lotư defxeacumq̨; in cốcavís \& faxeis tellur is fi-

bris. 


\section{4 \\ Itinerarium II. Dialogus III.}

Argenti product io 8 minere

bris conclufum, tum calore fubterraneo luperveniente, tum, fui ipfius calore proprio interno, magis magisque decoctum. tahdem in argentum fixatur, quemadmodum hic vicies. Theod. O miram rem! Ergonè illa fibra in gypficandidiffimi morem longè latèque exporrectx mineræa argenti funt? Cofmiel.

Auri gene- Ita eft. Sed ulteriùs progrediamur. Si porrò hæc eadem materia intra intima supium, id eft, fulphur hoc candidum \& incombuftibile, eò usque adhuc fortiorisignis âtûsque vehementiâ concoquatur, donec rubedinem acquirat, venæque fint ex puriffimo fine illa lutofe \& argill lacex materix miftura faxo; tunclongotemporisfpatio, nec non proportionati temporis coctione, tandem in aurum purum degenerat. Videsnè hafce venas, partim caruleo, partim aureo colore corufcantes? Theodidactus. Video. Cof inniel. Illæ funt venæ five miner auri. Vides in quantum fiatium fibras fuas extendant? quàm variis \& tortuofis duct bus fefe explicent? Theod. Video,\& oppidòadmiror. O quarta Divina Sapientia per naturam, artem fuam, in hominum emolumentum molita fuic. Sit Deus in æternum benedictus, qui tuâ me inftructione propiùs cernere voluit inexhauftos omnipotentix fix Thefauros. Cofmiel. Praterea fi humidum illud unctuofum vifcofumque aqux lutoils excrementorum terreftrium quisquiliis vitiatum contaminatunque coctione diuturnă figatur, neceffariò inde imperfectum metallum nafci neceflè eft, \& rantò quidem imperfectiùs ignobiliusque, quantò mareria, cuihumidum illud unctuofum vifcofumque mifcerur, fordidior imperfeatiorque fuerit. Sed jam hac propiùs te videre faciam. Videfnè hîc virides illos ftriatorum parietum ductus? Theodidactus. Video. Cofmiel.Illæ funt mineræ cupri feu æris, quod quidem fià principiofordidis quisquiliis \& glebis terræ inquinatis, non fuifer Earis. contaminatum,id longâ tandem coctione, \& defarcatione, in aurum evafiffer. Sec quia ex rubro quodam fulphure, fed im1:- puro \& minimè fixabili conftat, nec fe ratione locs à dictisimpuritatibus per circulationem liberare poteft; hinc metallum

Cuprum. imperfectum, videlicet cuprum, evadit : quod quidem nihila- 
liud eft, quàm corpus metallicum durum ac folidum, fufibile \& malleabile, quod ab humido vifcotóaqua \& aëris lutulenta \& impuramateria contaminato, necinon fulphure rubeo impuro \& adufto, infis:abili cel buto, producicurs iterum fin intra humidrim il lud unctuofum vifcofumque, unicum metallorum femen, inciderit in venas terra innumeris heterogeneis? excrementis refertas, cùm fulphure crudo \& indigeito turgeat, neque féfe à tantis excremencis \& foria expedire polfitu, coctionetandem in metallicum corpus imperfectum conge- Ferrig genelatur, quod ferrum dicitur. Quod verò difficilis fit fufionis" \& durifimæ fubrtantix, iftius caufa eft, tum falis \& fulphuris $A$ crudiabundantia; tum, paucitas Mercurii hylæi; hinc:maximè Corruptiillud corruptieni obnoxium effe rubigo las Juperque often- bilitatem dit. Siquis tamen id ab impuritatibus fuis eximere' noffev, go gazdicatio is haud đubie inveniret fub eo, quod chymici tam anxiè hucufque quafierunt. Vides hic varias faxeas fibrase? Theodid. Videa: \&non recordor in toto hoc itinere noftro ftrias hifce frequentiores me inveniffe. Cofmiel. Rectè obfervafti:utienim humano generi ferro nihil eft utilius, \& magis neceflarium, ita nulli loco ejus copiam natura deeffev voluit, a deoque rotáaxea Geocofmi à polo ad polum compaginata ftructura Magnetica, utitu in arretua Magnetica rectè docuilti,ferreis abundat mineris. Sed ulterius progreniamur. Videfnè in hoc antro inmumeras fibras, venafque in immenfum productas ? Theodidactus. Video. Et quamnam illæ metalli fpe- Stannum ciem referunt? Cofmiel. Ex hilce ftannum eruitur; quod corpus metallicum eft durum \& firmum, facilis tamen fufionis? ductilis naturæ, \& malleo obedientiffimum, ex abundantia. five exceflu humidiunctuofi \& vilcofi, puri tamen, copia na- $2 H$. tum: quiia verò cruditate $\&$ incocto fulphure exigux quantitatis conftat,\& volatilibus fpiritibusturget; hinc perfectam fixionem non fuitinet, fed ignis vehementiâ facile in auramevaporatum evanefcit ; unde fi fulphuris cocti perfectio refpon- $\mathrm{N}_{2}$ deret perfectioni humidi, illud haud dubiè cum tempore in. argentumevaderet. Porrò videfne in altero hoc antro cine-

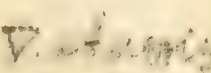
, ...
P ppp
reos 
Rtumbum e.jefque differenti if A anno. $\cos x$

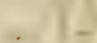

Argentum Gibuman unsm ex nature principis.

Argentum Bibum 5ubgare:

Mercuris proprictates.

Mercurise ob calidum innatum femper mo bilis. i. reos linearum ductus. Theod. Video, \& quodnam illi metalli: genus continent? Co/miel. Illa minera plumbieft, \& differcin. hoc foloà ftanni natura, quòd uti hoc puro humido, unctuofo vicofoque, itaillud impuro\& faculento, fulphureque excrementitio ortum fiv. Vidiftijanı, Theadidacte, metalloruin generationes; jam nihil reftar, nifit ut\&cæcerorum mineralium lpecierum, lapidumque prerioforum productiones tibi oftendam. Vidifti paulò ante nonnulla bydrargyri, feu argentivivi tillicidia. Theodidact us. Vidi,\&equidem miratus? fum,cum tu hydrargyrum, feu Mercurium, unum ex tribus naturæ principiis efle dixeris, cur tam exiguam ejus copiam intra: rerræ vifcera obfervarim. Cofrniel. Quod vidifti argenrum vivum, non eft illud ex univerfalibus naturæ principis unum quod humidum radicale diximus, fed argentum vivum quod vidifti, commune \& vulgare eft, \& nihil aliud eft,quàm humidum inctuofum, vifcofumgne aqua \& aëris leviter coctum. digefumque, quod quidem proximè non concurricad metallorum generationes, fed in centro ejus Tatet humidi radicalis? vifcofi, ex aqueo \& aëreofemineconftituta portio, qui verus? ille à Philofophis intentus Mercurtus, à fulphưre \& fale natura: infeparabilis, invifibilis \& incorruptibilis dicitur, ad omniu m. metallorum mineraliumque compofitionem concurrens. Eft: tamen communis Mercurii hujus fubftantia miris naturæ dotibus inftucta, ex humido æquè \& ficco, ex calido \& frigido paricer temperata, unde ob innati calidi in centro ejus latentis ab. undantiam in perpetuo quidem motu eft, ob ficcitatem verò ei. concentratam nihil quod tangit, madefacit; miranda quadam: naturæ libertate gaudens, neque ad humidum magis quàm ad. ficcum, nệ; ad calidum magis quàm ad frigidü determinatur, quamvis manifeltam qualitatem in humido, occultam in calido maxime exhibeat. Thead. Sufficit, $\mathrm{mi}$ Cofmiel. Ex ruis hifce fapientiæ thefauris tantum me profecifle puto, ut omnium reliquorú mineralium rationem nullo negotio tuis pofitis principiis dare poffim: quod \& in opere MundiSubterranei nomine infigni- 
Cap. IV.Iter Subterraneum.

$66 \%$

infignito, quantum fieri potêt, exactè \& minutim, divinâ favente clementiâ,tuâque directione me prattiturum confido. cojmiel. Progrediamur itaque. Thodid. Quo me per horrenda antra, vialque tortuolas \& mixè intricatas ducis? num remoti fumus ab extrema terræ fuperficie. Cofiniel. Vix uno slceroque milliariâbeadem diftamus. Theodid. Unam rem miror, videlicet, cur tantâ mineralium multitudine \& varietate, taircis meral orum venis vicina fuperficieiterreftris receptacula fcateant, quxtamen in profundioribus terræ receptaculis non inveniuntur. Cofmiel. Nèmirer is : Siquidem vapo- ob faporores femine metallico foeri, exhalationefque ex intimis tellu-nis uniris aftuaris \& hydrophylaciis in alia \& alia viciniora terræ berfalis fuperficiei receptacula per variam transfionem, conco fubfannemque elaboratx filcrataque, tandem in hos intimos mon-neralia . cium terrenorum promos condos elevantur; ubiultimam jam non in ime perfectionem confecure, in illad metallum, cujus naturx locus terra, fed ef, in quem penetrant; coalefcunt, provido fane natura confi- perficiem lio, ut humano videlicet generi ufui efle pofent, \& nè intra in- reperiri. acceflà terræ meditullia, quod fieri nullâ humanâ induftriâ poterat,penetrare adea eruenda cogerentur. Accedit quòd in dictis meditulliis nullum perfecte elaboratum metallum. reperiatur. Verùm ordo naturx poftulabat; ut priùs in hydrophylaciis, per æftuaria illis juncta, per metallici feminis concoctionem digeftionemque debita præparatio fieret, atq’ hâc peractâ randem per occultas terræ fibras, meacufque, vapores ${ }^{3}$ in alia plùs elaborandi elevarentur; donec intra montium vifcera terræ fuperficiei vicina coalefcentes, tandem juxta naruræ arbitrium, varias mecallorum mineraliumque fpecies, procujufuisloci matura difpoficioneque producerent. Theodidactus. Rectè cepi omnia. Sed,ô mi Cofmiel, quàm hor- Tempeftza. rendos tonitruorum fragores audio. Video \& grandinum plu- cula. viam,floccofque nivium, ex alto in pavimentum proruentiü. $\nabla$ ideo,\& expavefco,horrendas fulminum projectiones, fulgurum corufcationes, \& fimilia Meteorologicarum impreffionú fpectra. Fierinè poteft, \& illas in hiftce fubterraneis mundi P ppp 2 regio-
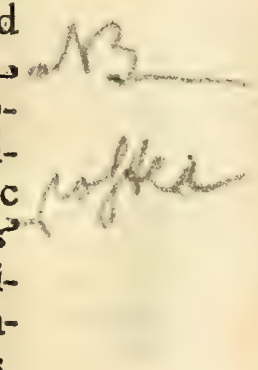
. 


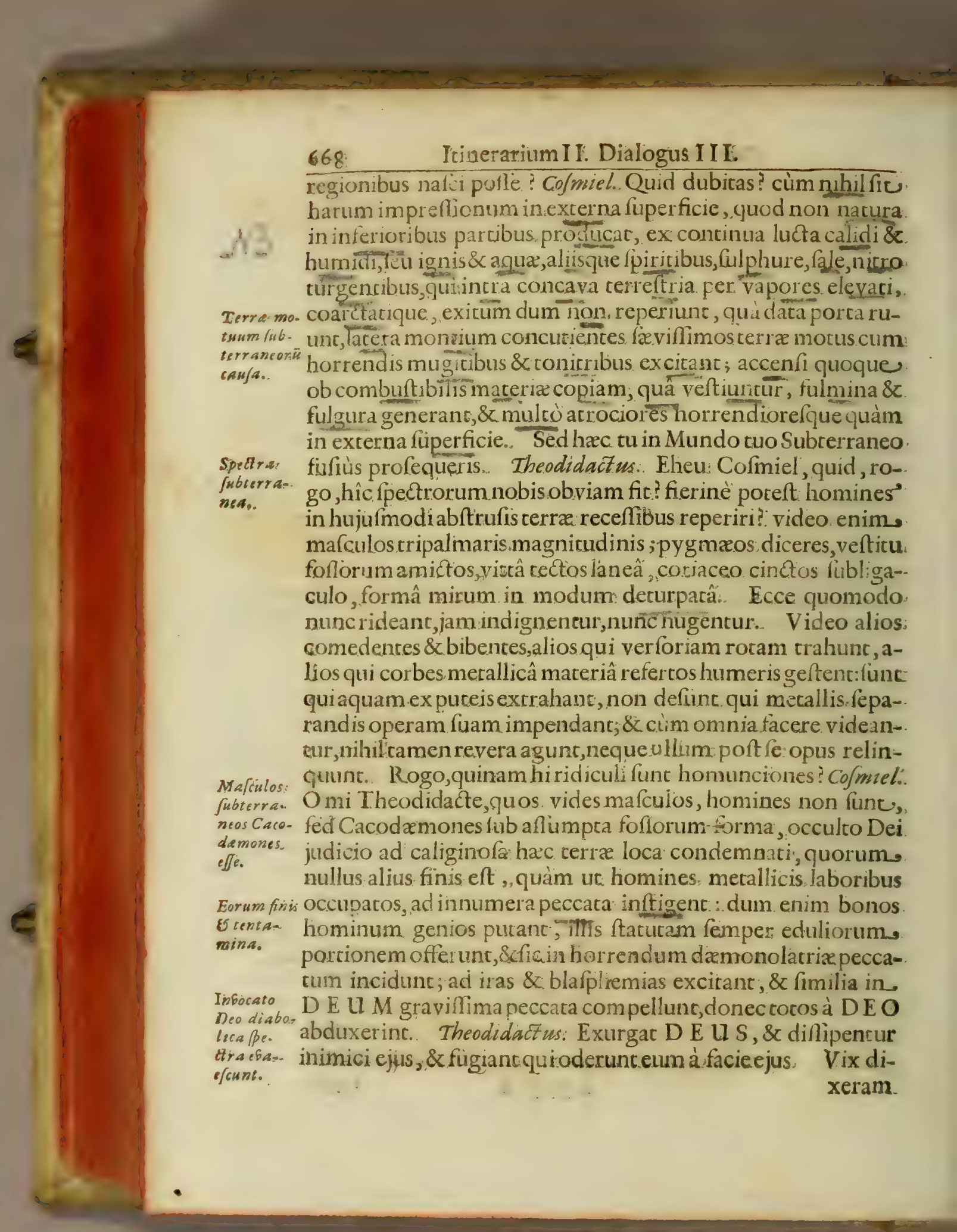


xeram, cum ecceinftar fumi, omnia diabolicx illufionis fpeetra evanefcunc. Sed de.hifee \& fimilibus fubterraneis monftris ex profello in Mundonoftro Subterraneo,Deo dante, tractabimus.

\section{CAPLT V. \&ultimum. \\ EPILOGUS ASCETICUS, \\ In quo de variis aterne beat itudinis confequends mediis agit ur..}

Cofmiel: Intuitus es, ni fallor, fufficienter, Theodidacte;, Deioptimi maximi iin hac terreftris globi fubterraneâ fa.. bricâ magṇalia; \&̇ंquacunqueæeterna Sapientià per naturam artem fuam in emolumentum generis humani operata eft, me: duce \& doctore didicifti : nihil porro reftat, nifi ut omnium corum,quorum meâ inftructione factus es particeps, notitiam ad divini Numinis gloriam in ufus tuos convertas.. Verùm. jam tempusadvenit, utce.fub vifibili hujus halitus fpecie deferam, \& ad commifum milhi mundi prefidium revertar - Theodidactus: Ahrogo; te, mi.Colmiel, fifte adhuc pauxillum remporis, ut quę ærernam animæ mex falutem concernunt, à. te divino meo magift ro priùs addifcam; ufq; dum corruptibili : hujus carnis.farcinâ depofitầ, te in Deo meo aternüm fruą. Cofmiel.' Uti æquiffimam tuam petitionem video, ica ex mea. partenonomittam te meâ directione eò"deducere, quò \& tua te vota ferunt, \& ego id unicè in hoc toto itineris noftri decurfü intendi; ; ut videlicet per vifibilium rerumi variecatem \& multitudinem, per Divinorum operum magnalia in natura majeftate elucefcentia, ad invifibilium borrorum ubertatem, qux omnem: fenfum, omnem mentis humanæ conceptum. longè fuperant, tandem pertingeres laborum tuorum metam. confecutus?". Quxre itaque confidenter, \&comnes animx Pppp 3

tux 
ture latebras, circa ea, quorum defiderio cognofendorum. aftuas, excucito, \& fidelem me (incerumque omnium propofitorum interpretem obtinebis. Theodid. O Divine magifter, quas tibi gratiarum actiones pro tot tuis in me meritis \& innumerisbeneficiis in indignum fervum tuum collatis referam.? Cercè cùm aliud guod tribuam non habeam,ecce omnes ordinis tui Hierarchici commilitones invito, ut quas ego non poffum, illi tibi in D E O ter gloriofo \& benedicto debitas gratiarum actiones perfolyant. Jam verò audi quafo qux mihi in mentem venerunt. Tantoperè mihifemper hucufque invifibilium bonorum fruitionem inculcanti, ut juxta A portoli verba, invifibilia videlicet per ea qua fact a funt, con/piciantur; imò in præfatione Epiphanix Ecclefia Dei idem canit , ut dums vifibiliter Deum cognofoimus,per buncin invifibilium amorem, rapiamur. Qua cum ita fint, rogo te, oblecro, \& obteftor, ut mihihujufmodi invifibilium bonorum rationes exponas? Non enim video, quomodo hơmo ex anima \& corpore conftitutus ad illa pertingere poffit?cum intellectus in fenfibilium fpectrorum gurgite immerfus, invifibiliü fpecierum, ob phantafmatum fenfibilium interpofitionem, fit incapax.Quomodo itaque illa attingemus,cùm nihil, juxta Philofophi Epiphonema, in intellectu fir, quod non prius fuerit in fenfu ? Etcums Sapientis propriam fit, tefte, Philofopho,phantafinata fpecularia ; an non fufficic invi fibilium bonorum ubertatem fub ineffabili Humanitatis Chrifti pulchritudine nobis fenfibili, intelligere,admirari, eam xternùm amare ? Cofmiel. Ah fili mi, bene apparet, te necduin abftracti intellectus rationem noffe. Verum eft,humanum intellectum in hac præfenti vitaphantafmacum umbris impeditum, luce fuâ obícurà ad invifibilium bonorum rationem pertingere non pofle; hoc enim totumalterius beatitudinis vitæ ftatui refervatum eft, de quo rectè Gentium Doctor dicit: Oculus non vidit, nec auris audivit, nec in cor borninis afcendit que Deus preparavit diligentibus $\int_{e}$; quibus verbis expreflè docet, fenfibus ad ea cognofcendaopus non effe,cum illa omnium fenfuum poteftatem in- 
tinitis parafangis fuperent. O ficibi liceret $v c l$ per ninimam rimam videre ineffabiles bonorum invifibilium delicias, quemadmodum illastum noftrum genus,tum animæ jam ad falutis portum appulfre cognofcunt; præ nimiis gaudiorum exceffibus, tuptis cord is penetralibus, haud dubiè expirares. Theodidactus. Hoceft quod femper miratus fum, \& capere non potui,cur divina bonitas mundum hunc corporeum cum tanto rerum apparatu condiderit,certè non propter fe tantùm, quaz. mundo corporeo non indigebat, quem infinities quippe pulchriorem, in æterno fuo archetypo contemplabatur; neq; pro- Finis In. pter veftrum genus Angelicum;ergopropter rationalem crea-carnatioturam, qui homo eft. Preterea prorfus attonitus hæef, dum, nis Cbriffi exactiùs ponderarem: quodnam inciramentum $C$ hrifum Domini. Servatorem noftrum in noftre carnis anguftias traxiffer, cur humana carne veftirifub vifibili fervi forma apparere, 0 mnibus fele humanæ conditionis miferris, excepto peccato, ufque ad probrofifimamCrucis mortem, demittere voluerit.Dicesforfän,ad hominemà fervitute peccati liberandum, Deoque reconciliandum. Id verum efle fcio; fed non ufquequaque miki fatisfacis. Latet itaque haud dubiè fab hoc aliud quoddam prorfus incomprehenfibile myfterium ; quod ego nihil aliud effe exiftimo, quàm fuperexcefivam, ineffabilem, omnem humani intellectus longè excedentem gloriam, quam fuâ nobis facratiflimâ incarnatione promeruic. Sed uti hæc homini in hujus corruptibilis vitæ ftacu conftituto eft inconeeptibilis,ita te rogo, ut ejus vel unicâ lucis fcintillulâ animum meum ardentibus fuccenfum defideriis imbuas, ut ferventiùs ad tantorum bonorum invifibilium confecurionem inpofterum afpirem. Cofmiel. Magna funtquar tibi exponı poftulafti ${ }_{2}$ \& nefcioan in hac vita mortali conftitutus eorum capax effè poffis. Quare füb nonnullis tantùm tibi fimilitudinum umbris, eam defcribam; ubi tamen priùs materiam adeo profundis ${ }^{2}$ contemplationibus refertam altiùs orditus fuero.

Sacrofancta \& Individua Trias, Deus Opt. Max. cùmabæterno in inacceffæe lucis fux caligine abfconditus, in Idearü divinarum: 
8 amare,eique foli fervire debebant, ii Idololatrix impietate Idololeinvoluti,fenfibilia Solis, Lunæ, Aftrorum humina, Elemento- trie orige. rumvires \& proprietates, quin vel ipflus fenfitivæ \& vegetabilis naturx beneficia, homines denique rerum geftarum gloria celebres, locoConditoris coluerint \& adorarint; fenfibilibusque afliefacti, cùm in vifibilem Deum aut non cognorint, aute aliquid efle non crediderint, quisque quod fibi maximoperè arridebat,ex vifibilibus objectis in Deum aflumpferit. Toto itaque terrarum orbe, abominando Idololatria fcelere contaminato, cùm nulla nec in Coelo, nec in terra creatura effer, qux tam conclamatæ humani generis calamiratiremedium. aliquod adferre poffer; eccetor mal is incitata, hominumque irreparabilem ruinam, laboresq; miferata æterna Dei Sapien-Cbri/pw tia, Verbum \& filius Parris, nè quod tanto amoris impulfucon quod percia, Verbum \& filus Patris, que quod tanto amoris impulfucon- ditum, re

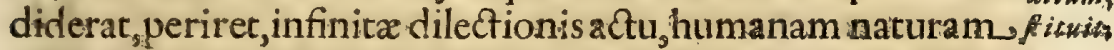
aflumere fibicomplacuit. Ult Deus, qui priủs in incomprehenfibilicaliginis fux receflu recondicus, omes mortalium fenfus latebat, modò fub formæ vifibilis conditione compareret,cum hominibus converfaretur, pauperis oppidicivis factus, latentem tamen divinitatis potentiam, ineffabilibus operum miraculis proderet, doctrinầ coelerti novâ, \& in illum usque diem. nunquam auditâ,animos mortalium inftrueret, eosque aterno Patri infinicè offenfo reconciliaret. Neque hîcftitit fe divinæ clementiæ alitudo. Cùm non reperiretur, qui plenam. \& perfectam, pro infinita offenfa fatisfactionem daret; ipfan DeiSapientia, ineffabili amoris infinitiæettu languida, imnumeris fe humanæ mortalitatis miferiis fubjiciens, tandem poft atrocifimatormenta Crucis paffronem fubiit, ut hoc pacto deleto mortis chirographo, hominem perditum ad vitam revocaret. Theodidait us: O infinitam Dei charitatem! O novas" amoris divini inventiones! Et quid, rogo, tam exceffivam Divinæ pietatis magnitudinem movic, ut tanta \& tam indigna. hominis viliffimi, fui ex luto figmenti , inimici infuper irreconciliabiliodio cum Deo diffidentis causâ fubierie? Hoc eft

Qgq9 qrod




\section{4 \\ Ptinerarium II. Dialogus ITI.}

quod capere non pollum, hoc eit cujus admiratione tantopere rapior. An non forfan incerfuit Divinæ clementix nonnihil, quod in hoc negotio proprii commodi rationem fpectaret? aut quo fine hominisanimam tantis beneficiis lucrari intendit?

Denu folo latet hîc haud dubiè a dmirandum quoddam \& ineffabile my--

amoretra fterium. Cofmiel. Deus nullius indigus, fibi ipfi fufficiens, \& in amo, incer- fe ipfor beatiflimus, fole innato \& xrerno bonitatis fux comnarti soff i- municandx defiderio accenfus, \& infinito amoris æeftu impulawit. fus, erga rationalem creaturam, quam ad alciffimos fines defti-naverat,omnia hæc prefticis. Ut videlicet homo cognitis im-. menfis,\& inenarrabilibus Amoris Chriftiargumentis, legem. cjus fervaree, , vitam ejus fanetiffimam imitarerur, meritorum-. que ejws.fe participem faceret, \& fic à peccatorum veterno erutus, poft hujus corruptibilis vitzufuran, ad eam, quam dixi, invifibilium bonorum copiam pertingeret. Theodidast. Ad idem femper revolvimu, mi Cofmiel; nofledefiderarem, in. wabifbiliza qto potifimùm invifibilia illa bona, quar Deus diligentibus fe bewa, i Deo \& mandatorum fuorum obfervatoribus promifit, confiftant. jup pris pre: Explica, quxío, exemplo quodam, ut tantorum bonorum capax fiam; debent enim haud dubiè effe fuperexcelfa, nullounquam humano intellectu penesrata, utpote qux omne bonum, qued animoconcipi\& fingi poteft, longè excedant. Cofmiel. Reetè dicis: \& ur omnia luculentiùs concipias, fub fymbolico. quodam fimilitudinis sypo;tamerf non nifi umbratili, totum. Earaboles negotium ob oculos ponam... Si itaque; Theodidacte, famâ ấ bonic a- certâ perciperes, in infula quadam fcopulis innumeris impedita,ad quam non nifi per mare fyrribus, yadis, fcopulis, fummis ${ }^{3}$ tempeftatum procellis, infeftum aditus darerur, in quo innumera tibi ob bellua rum ferociam, wentorum rabiem, vorticum rapiditarem, difcrimina fubeunda forent, fpeculum quoddam contineri,in quo omnia quacunque ab origine mundi, ufque, ad confummationem ejusdem, five qux hominum potentiâ geft a funt, five qux à natara abdita arcanorum my fteria peraQta funt, ${ }_{2}$, uni-. 
univerfi mundi machinam cum omnbus qua in ea continensur, lucidiflimè explicatam intuereris, fi innumeros mundanorum globorum five ftellarum exercicus, fingularumque individualem naturam; monum fyftates, influxum quibus in inferiorem mundum agunt rationem, unà cum unitscujusques naturali litu, parciun differentia, elementorum fingulis congruorum, ex quibus efformata funt, conftitutionem in memorato fpeculo cognolceres; intervalla præterea unius globi ad alcerum exeodem cognof cere pofles; quid non ageres? Theod. Certè incredibiliillud videndi defiderioæftuarem. Cofmiel.Si rurfus in eodem fpeculo, torius globi-terreftris, quem Geocofmum appellamus, conftitutionem. omnium regionum, marium, infularumque fitum, naturam, proprietatem, velutiomnibus \& fingulis prafens, actu intuerer is; metallorum quoque, mineraliumque inexhautos fundos, herbarum, plantarum, arborum, fruticum, feminum, fingulorum individuâ cognicione \& notitiâ , vires \& facultates naturales ex eodem addifceres; fi nteriùs omnium animaĭ it mquadrupedum, volucrium, natatilium, infectorum que naturam intipiam, virestam occultas, quàm manifeftas fingulorum, unâ oculorum projactione cerneres? quid de hoc tam admirando fpeculo diceres? Theodid.Certè opus prorfus ineffabile allererem. Cofmiel. Rectè dixifti. Si praterea Monarchias imperiorum, fingulorum hominum ab Adamo usque ad ultimum, ab uno quoque gefta, five bona, five mala; fi Imperiorum regnorumque vicifficudines, declinaciones; erectiones novorum,omnes feculorum fucceflus, non præteritorum folummodò, fed \& futurarum rerum eventus graphicè in eo exprefla monftrarentur; quid diceres? Theodid. Mille viræ pericula nihili ducerem, dummodò illud contueriliceret. Cofmiel. Si ultra hæc in dicto fpeculo, omnium fcientiarum arciumque arcana hucusque incognita, intellectuituo panderentur; fi derepente in fummum TheoJogum,Philofophum, Medicum, Mathematicum , Logicum, Ethicum, Jurisconfulcum, Politicum, Rhetorem, Poëtam,

Qqq१ 2 Gram-


Grammaricum folius ejus intuitu evaneres; fi in eodem magnum illud lapidis Philofophici fecretum manifeftaretur :fi quadratura circuli ratio demonftraretur; fi ad arcanam motus luminisque perpetui, aliarumq; abditarum artium in hunc ufque diem defideratam notitiam pertingeres; quid non ageres,ut illiuscompos fieri ponles? Theodid. Certè nullum fururum eflet tantum vitæ difcrimen, nulla laborum exantlatio tanta foret, qua anımum meum, quò minùs ad illud contuendum proficilcerer, retardaret. Cofmiel. Sed nihil hre funt ad ea qua dicturus fum. Si in hoc eodem fpeculo,Angelici quoque mundi conftitutionem ; fi ftupendam Hierarchiarum cho rorumque coeleft is exercitus diftributionem, innumerabilem quoque fingulorum Angelorum, qui in unoquoq; choraconsinentur, multitudinem \& varietatem, quomodo in loco fine \& moveantur, quomodo adinvicem fecreta mentis pandant, quomodo fuperiores inferiores illuminent, quo quisque modo operationes fuas inftituat, quo modo \& quâ induftriâ aftrorum globos moveant, dirigant, \& circumvolvant; fi denique omnia divinæ naturæ Sacramenta folo ejus intuitu penetrares: quis tibianimus foret, quodnam defiderium, quxnam mentis" anxietas, donec tam ineffabilis f peculi intuitu fruereris? Theodidact ws. Certè nullum iter tot periculs expofitum, nulla tam infefta latrociniis loca, nulla tanta fcopulorum impediment?, nullus tempeftatum horror tantus, nulla tam occulta Charybdis \& Scyllæ fevientis naturæ vis, nulla tribulatio, fames,firis", nuditas tanta, nullæ tantæ egeftacis xrumnæ, quæ meà tanco actam inaudiso fpectaculo retardare poffent, Quare teetiam atque etiam rogo, $\mathrm{mi}$ Cofniel, ut apertis frmilitudinum um-

Parabola compoficio. bris, quid tam longâ parabolâ indicare volueris, aperias. Cofm Faciam quod poftulas. Illud fpeculum nilrilaliud eft, quam. beatificæ vifionis fruitio, omnibusiis, qui verấ fide, fpe firmâ,

Beatifice Sifronis poffiffio. perfe đ̂tâ charitate in hac mortali vita Deum diligunt,à Chrifto xterna veritate promiffa. In quo fancti Dei homines glorificati videbunt Deum, omnifidei velamine fublato, ficutiert. EE 
quecunque hucusque recenfita func, in hoc voluntario Divinæe eflèntix fpeculo perfectè concuebuntur, cum xterna gaudii poffentione; qua quidem tanta eft,\& tam fuperineffabilis, uv nullus humanus intellectus, aut etiam Angelicus, omni poffibili conatu,eam fatis defcribere valeat. Ubi immenfum illud, \& ineffabile Sacrofanct $x$ Triadis Myfterium , totiusbeatitudinis cta Triametam \& complementum, inenarrabjli gaudio intuebitur. Ibi incarnati xeternam Divini Verbi generationem, \& Spiritus Sancti à Pa- clara in tre \& Filio proceflionem apertè cernec. Azque hic eft torrens. ille voluptatis, quo Deuselectos fuos potabit; hic eft fons vitre xternæ, de cujus guftu nafcetur gaudium illud fempiternum., de quo veritas loquitur, Intra ing audium Domini tui. Siquidem in hac vita mortali totum divinum gaudium intratin. gaudentes, quia modicum eft, momentaneumque quod hîc percipicur; in patria veròtoti gaudentes intrabunt in torum. gaudium Domini. Suprà quoque quàm dici aut fingi poteft, corporeâ formâ Jefu Chrrifti, qui eft candor lucis ærernæ , \& fpeculum fine macula, in quod vel ipfi Angeli defiderant profpicere, oblectabuntur.Cujus tanta eft gloriæ magnitudo,tansa claritatis ubertas, ut fi mille Solium molliones in unum coacervarentur, illiomnes ad tantam claritatem comparati,nihil nifi tenebre fint futuri. In hoc potiffmùm immenfa \& incomprehenfibilis Dei bonitas elucefcet; qua Deus nullân neceffitate coactus, fed folius bonitaris inftinctu compulfus, mundum hunc corporetrm, ad fuam ei palchritudinem \& bonitarem quadamtenus communicandam,condidit. Ex eadem in- Chriftus effabili bonitate Deus irreconciliabili odio à fe fejunctum hu- cur tant as manum genus redimere, in libertatem filiorum Dei vindicare, no genere aterni boni fui participeseffe, fibicomplacuit , dum in infini- tulbritt. tam humilitatem quafi depreflis, , amore prorfus fupraomnem humani \& Angelici intellectus capacitatem incomprehenfo languidus amoris æeftu, noftrẫ mortalitatis farcinã gravatus, in hoc mundo lub vifibili fervi forma, ad confufionem diaboli,deftructionem peccati,\& mortis extirpationem, comparere dignatus eft. Qux bonitas tanta fuit, tantus. A mo 
Amor $D_{\ell s}$ ris aCtus, uc fi omnes Angelorum ordines, omnia hominum: quantw. aborigine mundiusque ad finem ejus genicorum corda in unum confluerent, illud tanta boniratis \&amoris argumentum ponderans, præadmirationis, gaudii, amoris excelli fciflum, iri necellum forec. Hæc Divini A moris incomprehen fa alcittdo tanta fuit, ut fi omnia colorum expanfa in chartam, ommia vegetabilis \& fenfitivæ nacura organa in calamos, omnes aquarum in univerfo Mundocongregationes in atramentum. converterentur, illa omnia ciciùs deficerent, quam ut vel.minimam ejus particulam atcingerent. Theod. O incomprehenfibilis boniras!ô ineffabilis A mor! Video, Eheu, videofatis.lucửenter, inexhauftum, immenfumq; divina Bonitatis \& AmorisOceanum. Sed ò fapientillime Caleftis doctrinæ magifter, mi Cofmiel,nunc te rogo per eum anorem, quemDeum nobis ingratis impendiffe dixifti, ut quid milhi in pofterum faciendum fit, ut tam infinita bonitati ac Diviniamoris magnalibus quovis modo correfpondeam, atque adeo fuperexcelfi illitus finis, quem divina clementia per oreationis, redemprionis, feu incarnacionis opus, pro hominis glorificatione intendit, particeps fiam. Cofm. Si infinitas vitas ejusfervitio impenderes, fi in totius mund vitam animareris, fi in omnium creaturarum corda conglobareris;nihil ageres, nifi ipfe te amori ejus cooperan-

Omwis 60. wiscas re. Bettun nei nolisia eqf. tem gratiâ fuâ dignumredderet, củm omnis cresturarủ bonitas,omnis operum humariorum excellentia, ejus bonitati comparata, non bonitas, fed meramalitia fit. Theodid, Quis engoad tam altum finem pertinget? aut quibus modis \& mediis tantum bonum confequar? Co/miel. Volendo. Theodid. Et quid velle facilius eft, \& quid jucundius gratiufque eflè poteft, quitm ad ram omnibus voris defideratam beatitudinem, folẩ voluntate pertingere? Explica,rogo, nonnihil tuum hoc abfcondicum myfterium. Et fi nihil aliud quàm voluntas mea defideretur, ecce eá tota quanta eft,tultro Deo meo trado.Cof rus. Voluntas hæc fanè intelligenda eft : ron enion omnis, Chrifto atteftante, qui dicit mihi: Domine, Domine, introibit in regrum calorum Jed qui facit voluntat ew Patris wei. Ecce habeshic 
fub paucis verbistotum myfterium tibi apertum. Voluntas itaz. que Patrisæeterni exigitur; quxe quid fit, \& in quo confiftat,, $\mathrm{a}-$ perciùs revelo.Cùm divinitas folo bonitatis inftinctu, quæcunque infenfibili hujus mundi theacro fpectantur, per opifex fuú. verbum fecerit, hac verö antequam eflent, in ip̣o omnia vita eflent, id eft, in æeerno illo divinitatis fpeculo, veluti in Idealium rationum. Archetypo quodam ab aterno relucerenv; \& cùm omnia extra fe producta, divinz unionis-incapacia, ad tain excelfum finem, qua eft Theomorphofis,feu unioDei-formis,pertingere non valerent; ex corporeis creaturis hominé elegir,qui intellectu \& voluntate ad tam fuperexcelfum unionis.T heomor. gradum, in hac quidem vita per con formationem fuz.volunta- $p$ bo/sos riscum divina per gratiam, in altera verò per gloriam beatifice vifionis fruitionem confequererur. Siquidem voluntratisnoftre Magswm cum divina uniformitas, tantæ porentiæ \& energiz eft, ut per quid folwo purgatifimas mentis operationes, \& contemplationis donum \& stre cum unus cum Deo fpiritus efficiatur; tă firmo \& indiffolubili unio- díbina coses. $\mathrm{n}$ is nodo, ut nihil adeo in hoc mundodurum fit, nihil tamafpenum, nihil tot adverfitatibus.involutum, quod eumà Divina. voluntaze feparare poffit. Si profiperitas eum extollat, ecce. mox totus in Dei voluntate abforbetur ;-fiadverfis prematur.,

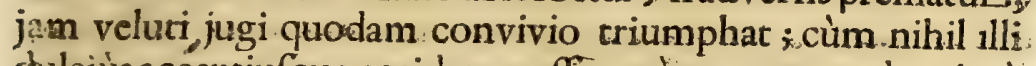
chulciùs accepriufque accidere poffis, quàm magna,ardua, imò̀ mille mortes.pro D E $O$, cui per amorem nectitur, pati; defyectum contemprumque fummo honoris loco repurat, to. tus. DE O per triplicem, fidei inconcuff $x$, fragrantifimæ fpei, \& ardentiffim $x$ charitatis nodum junctus, in D.E UTM tocus? conformatur, quæ eft vera aternæ felicitatis arrha, \& invifibilium bonorum atrium, quo intromiflius, defpectis omnibas fenfibilium rerum vanitatibus, \& periturarum voluptatum deliciis, unico mentis oculo D E O fixus, hunc folum. ardentibus affectuum ftimulis noctu diuque meditatur, utpote qui vitam in Chrifto, lucrum in morte repofitum habet Angelorwm Preterea per Chrito, lucrum in morte repofitum habev choris afoPron mens tua ad fupernam tranfit Je-ciatur, , so-

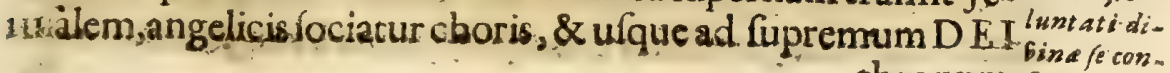
thronum ferposss, 
chronum penetrat, ubivoluptatibus deliciacur æternis. Theod. Quomodo amor hic Angelicis me choris fociare poreft? Cofm. In Seraphinis Deus te amat ut charitas; in Cherubinis te novix ut veritas; dominatur in Dominationibus ut Majeftas; in Principatibus te regic ur principium ; in Poteftatibus tuetur uc falus; ut virtusoperatur in Virtutibus; in Archangelis operacur ut lux in Angelis ut pietas. Omnia denique operatur in omnibus is mentibus, in quibus habitat per donumaffluentiffimæcharitatis. Necefle eft itaque, Theodidacte, ut isdem. gradibus ad eum, \& ad defideratam felicitatis pofleffionem, pertingere fatagas; quod fiet, fi trium fequentium documencorum notitiam in hac vita mortali tibi compares, id eft, mentis tranquillitatem, virturis fplendorem, \& char itatis dulcedinem. In hifce enim divina Majeftas, tanquan in folio fibi proprio requiefcit, quibus per Purgations, Illuminationis, \& Perfectionis viam adeptis, anima ad divinos amplexus admifla, meritorum incrementum, veluti cum æternæ vitæ pignore, quodam fufcipit. Porro voluntatis noftræcum Divina unio, in hoc potifimùm confiftit, ut perfectè in nobis Chriftum exprimamus; quod per virtucum, quas Chriftus in hac mortali vita nobis ad imitandum propofuit, fequelam contingit quo unico Deus Opt. Max. tantoperè fibi complacet, ut nihil fit in. religiofę vitæe exercitiis, quod hominem ad dictum unionis" gradum,majoricompendio perducat. Hac eft verailla \& regia via, qua fine ullo errore, ad tantoperè defideratum fcopum pervenias. An nefcis, quancum Chriftus in omnibus fuam. femper voluntatem Paternæ voluntati uniformem habueric ? quis unquam Chrifto majus humilitatis argumentum,cum. Dominus glorix \& totius Majeftatis Deus effet, in hacterra prabuit? quis atrocifimum paffionis, immò mortis cormentum, majori conftantia \& fortitudine fuftinuit? quis unquam. pro Crucifixoribus fuis, creterisque inimicis, tanto cordis affectu Patrem interpellavit ? ut interim nihil dicam de infinit $x$ charitatis actibus, de patientia, manfuetudinis, orationis, innocentix virx, inauditis exemplis, qua ex Evangelicis oracu- 
lis conftant. Hocitaque, mi Theodidacte; divinum virtutum omnium exemplar, noctu diuque ob oculos pofitum contemplare; hæcunica tua cura fit, ut eam in anima tua, perfecta , \& fumma fimilitudine, haud fecus ac figillum quoddam in pix affectionis \& voluntatis ardentifim $x$ ductili cera, divinam. formamexprimas. Hoc pactoad defideratam tuæ cum Divina voluntace conformationem, atque adeo ad illam, ita omnibus votis concupitam Theomorphofim, id eft, ad divinum unionis Amorofex of culum in hac vita, quantum humanx conditionis ratio permittee, admitteris; in altera verò totus Deo per apertam vifionem junctus, totus uniêris toti, qui eft omnia in omnibus. Theod. O Cofmiel, magnâ fanè hodie te magintro fcientiâ imbutus fum: cujus comparatione omnis humana fapientia,ftultitia eft, omne fapientum hujus freculi lumen mera crecitas eft; ò Deusmeus \& omnia! OChrifte humanigeneris" vindex, transfige cor meim igneis amoris tui jaculis, ut confumptis omnibus humanarum ambitionum vanitatibus, omnibus caducis hujus infelicis vitæ cupiditatibus extinctis, omnibus quæ mundus tantoperè quarit \& fectatur repudiatis', tibi in pofterum foli adhæream, tibi foli ferviam, te folum in. vita \& morte actionibus meis exprimam, carnem meam cum vitiis \& concupifcentiis crucifigam, actandem totus inte abforbear.Amen. Cofmiel. Quare, Theodidacte, frquandoque animum tuumad ea, qure tibi in hoc itineris noftri decurfuoftendi Divinæ Bonitatis,Sapientiæ, \& Amoris argumenta, folius humani generîs gratiâ in hac mundi machinâ exhibita artuleris: ea non alio fine condita efle tibi perfuadeas,nifi adillum, quem tibi fupra defcripfi finem confequendum, utdum, vifibiliser Deum in Chrifto cognofcimus, per hunc tanquam. totius naturæ, \& condifarum rerum unicum fcopum, in invifibilium amorem rapiaris. Quem tibi impertiatur is, qui utite ab reterno amavit, ita te attraxit ad fe miferans. Theod. Sed tu magne humanarum rerum arbiter Deus, totius pietatis, clementia, mifericordix, \& aterniamoris fons \& f caturigo; difpone Rrrr hunc 
682

Itinerarium II. Dialogus 1 II.

hunc animæ mex ftatum fecundùm divinæ voluntatis cur beneplacitum, incita omnes cord is mei nervos in laudem \& gloriam nominis tui, ut Seraphico te amore diligam, Cherubicâ. mencis indagine incellanter quæram ; fis anima mex thala- mus, ubi quief́cas, ubi cubes in meridie ; jugum tuum fuave pone fuper indomitam rebellemque affectionum terrenarum. curbam, ut in pofterum Angelica tibi puritate ferviam; fonec vox tua in auribus meis, vox enim tua dulcis, \& facies tua decora; difpone in me ea virtutum ornamenta, quæ tu in fanctîlimâ tuâ vitâ expreflà mihi ad imitandum reliquifti,ut de. virture in virtutem progreflus, ad totius perfectionis apicem. pertingam, ad te videlicer DEUM Deorum in Sion, qui es tocius beaticudinis noftræ meta,ac univerfa creacuræ finis ultimus, \& centrum. Amen. Cofmiel. Sed jam tempusert, ut ad mund mihicommifi adminiftrationem revertar. Theodid. O Cormiel, Cofiniel, finveni gratiam in oculis tuis, colle animam meam, ucunà recum moleftâ hujus corporis farcinâ fubLaxâ, in æternis beatitudinis atriis degam. Tua enim mihi morte ipsâ durior difceflio videtur. Cofmiel. Nonnè dixitibi, vcluntatem tuam in omnibus Divinæ efle conformandam? Annè tam fubitò verboru m meorum oblitus es? doctrinam tibi hic traditam priùs exequere, ut meritorum cumulo plenus, tandem finem tuum confequaris. Theodid. Voluntasitaque Dei in omnibus compleatur; fed hoc unicum à te contendo, né fervum tuum in pofterum deferas, fed mihi femper in cmnibus neceflitacibus affiftas, ut tandem dulci tuo, \& fuprà quàm concipi potent, jucundo conforcio in patria fruar.Cofmiel. Nè dubites fili,cibi femper affiftam, te protegam, tibi uti petift $i$, in omnibus operibus tuis fubveniam. Theod Sed ôquibus modis, ò dulciflime Cofmiel,ô Divinze Sapientix Magifter, ob innumera tua in me collaca beneficia graciam rependam ? quo verborum pondere, qua argumentorum gravitate,tuam, in me ineffabilem benignitatem mundo exponam? Co/miel. Deo in me,\& per mequicquidtibibonortm obtigit, id ádfcrip- 
Cap. V. Epilogus Afcericus.

dile idficuc. Paxtecum, dilecte mi Theodidacte, morere mundo, vil'e Deo, mei meorumque verborum femper memor. Vale. Theodid. Hifcedictis, mox in tenues evanuit auras. Ego verò veluci ex altillimo quodam fomno evigilans, totum füdore, qui fummæ membrorum omnium debilitari fociabatur. me fuffulum reperi; donec patilifper refectus priftinas mihi vires reftitutas fenf. Quare nshil ampliùs reftat,nifi ut quxcunque in hoc Itinerario continentur, unicè ad Dei gloriam, proximiquefalutem

$$
\text { cedanu. }
$$

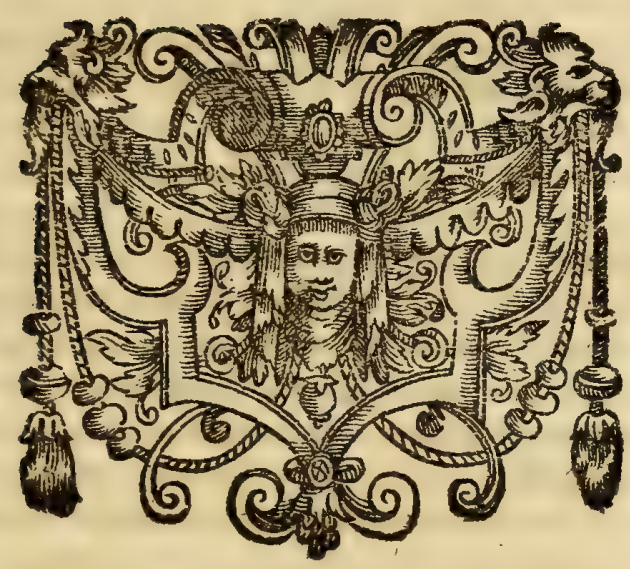

Rrre 2 
อั6อั

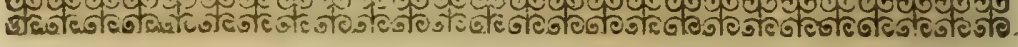

\section{SYNOPSIS}

Earum rerum, de quibus in Opere Mundi Sub: terraneiper decem Libros fusé difceptatur:

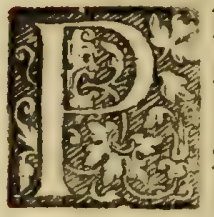

ROD RO M U M fineliteris negotiationis fur te: ftibus expedire, prorfis incongruum videbatur: Quare Synopfim hanc prefentem, qua Univerfum Mundi Subterranei. argumentum Lectori curiofo exhiberetur;annectendum duxi; hac potillimùm ratione impulfus, quòd complures jamdudum id à. me popofcerint, dum capere non potuerunt; quidnam in Subterraneo Terreni globireceffuefle poflit, quod aut Mundinomerr mereretur, aut quod argumenta fubminiftrarepoffit, Mundi nomine digna; falsâ utique \& plebæâ perfuafione illufi, qui uti terrenum globum nonfecus ac cafei coagulum fortuitâ conglobatione compactum putant, ita tantum abeftues. fibi perfuadeant, præter cryptas quasdam \& fodinas fuperficiei rerrenæe vicinas, alia intus recepracula conftitui, ur potiùs omnia immensâ foliditate conftipara, non fine mentis quadam percinacia firmiter credaurt. Ut itaque error tam palmaris ab imperitis rerum auferatur, rotius noftri infticutiferiem. hoc loco ob oculos curiofi Lectoris exponere vifum fuit. Ex quo quidem luculenter patebir, nullos effectus adeo infolentes: in hoc fenfibili Mundo elucefcere, qui.in intimis terræ vifceribus fecundüm analogiam quandam non reperiantur; atque adeo omnium rerum genefes fuam non nifi ex Mundo Subverraneooriginem derivare, luculenter patebit: Sed hifoe:

premiffis, jam rerum tractandarum feriem, operisque divifionem fupponanus.

$$
{ }^{*} *^{*}
$$

MUN- 


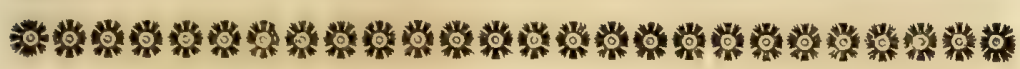
MUNDUS; SUBTERRANEUS,

Sive:

Deinterioris exteriorisque Terreni Orbis, quem Geocofmumappellamus, conftitutione,\&. fábrica.

\section{O P U S :}

In decem Libros digeftum:

\section{Quio.}

Univerfe Nature majeftas E. divitia fummâ: rerum varietate exponuntur; ab'ditorumeeffect unm caufa acri indagineinquifita demonftrant ur. cognitaper Artis : Nature: conjugium ad bumance vitc: neceffarium: ufum vario. experimentorumbapparatu,necnon novomodos Gratione.applicantur:.

\section{LIBER I. CENTROGRAPHICUS.}

PARS I. De admirandà natura centri; \& maximo in eo) elucefcente Deiopificio:

PARS II. De Arte Cofmocentrica;noviśqueinftrumentis; queis ad fümma naturæarcana, motuumque; naturaliumnoticiam déducimur:

\section{LIBER II. COSMTCUS,}

In qùo fúsè agitur de connubio Còli \& Terræ; de principiis rerum naturalium; de Elementis; de Coelo, Aftris, eorumq; influxibus:fecificis in terrentrm Mundum, five Geocofmum, \& quod ex his omniaquæfenfibus patent, originem habeant;multis variisque modis demonftratur.. 
In quode admirando Geocolmi Opificio, de cjus figura,magnitudine, de varia locorum, regionumque divilione agicur.

De.Ollatura Geocolmi Magnerica à polo ad polum;ubide montibus, eorumque altiflimis in natura finibus, uti \& de altitudine eorum variè difcurritur.

De Panfpermia Globo Terreno indita : de venis,arceriis, \& carcilaginibus Terræ, ad exemplarMicrocofmi,intra terram difpolitis.

De ingentibus Terrę receptaculis, qux membris tum majoris, tum minoris Mundi, fecundum analogiam quandam. refpondere docentur.

De innumeris mearibus, voraginibus, hiatibus,canalibusque fubterraneis, quibus perfollum eft I erræ corpus.

DeOfficinis Vulcaniis, feu pyrophylaciis, id ent, igneis receptaculis.

De Officinis AEoliis, aërophylaciis, id eft, de aëreis receptaculis.

De Officinis Aquaticis, feu Abyfis, vel quodidem, de hydrophylaciis, id eft, aquarum receptaculis, intra terra vif́cera. conftitutis.

De fpiraculis, \& fyphonibus Terra innumeris.

Demontibus, campis ingenribus, maribus, infulis fubterraneis,

\section{LIBER IV* METEOROLOGICUS,}

\section{In quo de Meteoris.fubterraneis potißimum agitur.}

Primò. Defluxu, \& refluxu Oceani, \& in quem finem Natura eum conftituerit ; item de varietate \& mutatione in variis regionibus æêtûs maris. De caufis fingulorum \& omnium. Defundi Oceani mira conftiturione, \& communicatione ompiun marium.

Secundò. 
Secundò. De igneis impreffionibus, \& fpiritibusterra vifceribus inclufis. De vaporibus \& exhalationibus fubterraneis. De Terræmotibus, caufisque eorum. De varia tum, intrinfeca, cum extrinfeca terreftrium partium mutatione ex Terræmotibus, \& aquæ inundatione proveniente. De centrigravitatis, \& qux inde refultat axis terreni mutatione, qua \& faciem Coeli mutari necefle eit.

Tertiò. De Ventorum genefi, \& mira varietace; de exoticis proprietatibus eorum : irem de ventis diurnis, menftruis, annuis, climactericis, qui nonnullis locis propriifunt.

Quartò. De fontium fluvionumque origine \& genefi ; quorum quidem caufe fufifimo difcurfu compluribus experimentis demonftrantur.

Quintò. De thermarum origine \& genefi, reliquarumque, aquarum variis qualitatibus imbutarum racionibus \& caufis; qua quidem omnium rerum diverfitatem, fuam ex fubterraneis officinis origirem trahere, oftenditur:

\section{LIBER V. METALLOSCOPUS,}

In quo Primò potifimùm de miñeralium metallorumque natura,proprietate, generatione, depuratione, machinisque. metallicistractacur.

Secundò. De terris variis five pulveribus mineralibus, uti Cimolia,Lemnia,Melitæa, \& fimilibus,eorumque viribus.

Tertiò. De offibus intra Terram repertis, fpodio,unicornu, glofloperris, offibus Gigancum putaticiis, ligno foffili,carbonibus, \& caufis eorum.

Quartò. De variis ac innumeris rebus 1n petrofam fubftantiam converfis; uti de animalibus, fofflibus, hominibus, quadrupedibus, volatilibus, pifcibus, infectis. Itemde, floribus, fuccis, oleis, gummibus, coloribus, \& venenis. Terra.

Quintò. De diverfis lapidibus, marmoribus, ftriatis picturis, 


\section{8}

caufisque eorum; de lapidibus denique preciofis, eorumque virtucibus per varia Syntagmata agitur.

\section{LIBER VI. PHYTO-ZOOGRAPHUS,}

In quo Primò de plantarum $\&$ animalium,tum intra terram, tum in externa ejusdem fuperficie provenientium origine, natura, \& proprietate agicur.

Secundò. De plantis fubterreftribus; defylvis, \& pratis fubmarinis hiftorico ratiocinio difceptatur.

Tertiò. De animalibus fubterraneis, eorumque forma, ingenio, proprietate; quibus vivant, \& in quem finem natura illa conftituerit.

Quartò. De hominibus fubrerraneis hiftoriæ mirabiles.

Quintò. De Drmonibus fubterraneis, eorumque operationibus, illufionibus, fimilibusque.

\section{LIBER VII. CHIMICUS, id ent}

\section{Geocofmus Applicatus,}

In quo propriè tractatur, quomodo plyyjiologus ad Natur e exemplar,per applicationem palivorum oun activis mir as rerum productiones efficerepoffit.

Ubi Primò de Alchimia, ejusque in operando modo, pofribilitate , \& imprimis de lapide philofophorum, \& quid de eo fentiendum fit,fufilfimè agitur.

Secundò. De admirandis metallorum mineraliumque effectibus, proprietatibus, fympachiis; de diflolutione, compofitione metallotum, cæerisque in arte Chimica operand peciebus, firgulntiontrina difeurritur.

LIBER 


\section{LIBER VIII. MAGICUS,}

In quo Magia naturalis fupenda opera, que Chimicá arte exhiberi pofunt, docentur.

It Primò de Arcano Megacolmi,ideft, quomodo Mundifimi litudo arte Chimicâ in vitro exhiberi poffit.

Secundò. Depalimgenefias myfterio, five plantarum refufcitatione, arte Chimicâ perficienda : de Phoenice, id eft, de herbarum ex propriis cineribus refufcitatione; de plantarum metallicarum productione; de machinis Mercurialibus; de fieta lapidum pretioforum confectione; de infectorum producendorum modo\& ratione, \& fimilibus magna varietate tractatur.

\section{LIBER IX. TATRICUS,}

In quo de mirifcis $E^{\circ}$ arcanis.mineralium, vegetabilinumque in Medicina effectibus agitur.

Ubi detincturis, menftruis, firiritibus, quintis eflentiis, extractis, fimilibusque fusè \& propriâ experientiâ comprobatis agitur.

\section{LIBER X. MECHANICUS,}

In quo de varits artibus agitur, quibus mirandead exemplar Naturain Geocosmooperationes perfciuntur.

Primò. De Arte diftillatoria,fuforia, figulina feu plaftica. Secundò. De fpecularia, pyrabolica, filatoria metallorum.

Tertiò. Deferraria, aurifera, vitriaria, aliarumque, quæ quovis modo huc revocaripolfunt, artium mirabilibus effectibus,fusè tractatur.

Omnia ad aterns Sapientia, Virginis q. Matris bonorem, proximig utilitatem $\mathcal{S}^{3}$ delectationem. Ssss INDEX 


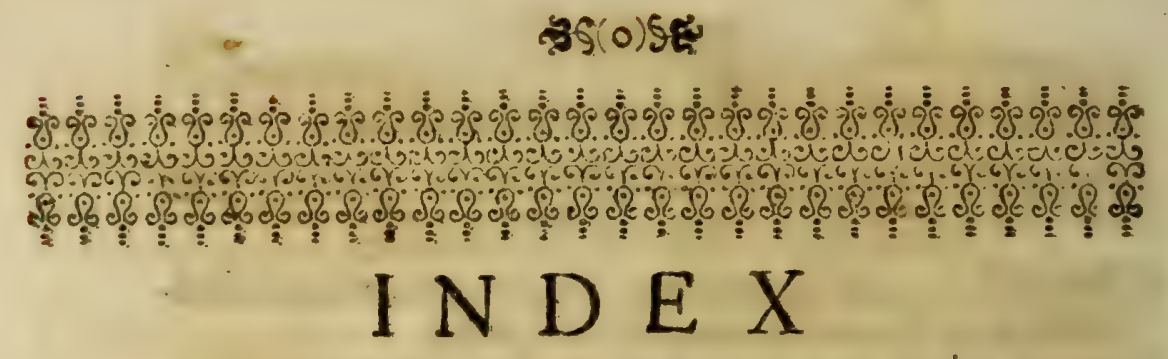

\section{RERUM PRECIPUARUM.}

A.

A ërquidfit. s76. Aëris lunaris. fubtilitas.96. Aër Martius.2so Aieris fubterranei regio defiribi*ur.6 49. Aêr quàm mecefJariusigni fo aqua.

Aeropbylacii conftitutio of deFriptio. Ether in perpetua quadamagitatione est. 226. Omnia Mundicorporapenetrat.

Avum duplex usia cum tempore. eternitation conftituit.

$44 \pi$ Alterationum vici]ftudo in Lunacur fit.

1.24 Altitudo mrxima Firmamenti facit ut novs ftelle femper in eodem. loso herere videantur.

230 Americis montibus majores nulli. reperiuntur.

Amor Dei quantus.

6.58 Analogia inter globum terreArem or caleftes:

$47 t$

Angeli-caleftium corporum Prafides.s2. Singulis aftris plures prafident.ibid. Angeli Globi Veneris pra- fides.147.x.so. Angeli qusonsodo aftrorum virtutes derivent in alia cor-at" pora.Iso. Angeli Mercurialis deforiptio.16.5. Angelorum qui aftris prefunt,officiumn:166. Angeliaftramovent 167 . Aliquando in globis caeleftibus perniciofas qualitates excitant ob peccasta hominum.361. An geli concreati Mundo.67.2. Angelorum choris affociat ur voluntatidivina fe conformans. $67.9 .8 \% 80 . \sigma^{2}$ feqq.

Animalia Saturninaque: "3,14 Animalibus imprefit Deus characterem reverentis erga bominem. 417. Animalium productio quomodo facta. 577. Eortizn diverfit as unde fit. g9r. Unimalia quadam lusem. innat am habent. Animavegetativa quomodo generetur.589. Senfitivaitem.' 5ol Annums Solis motus, ejusque effectus: 218 Antrignizinmi defcriptio. $\sigma_{59}$ Apologeticon contra cenfuramo nonnullaxum propofitionum, Itinerarii 
96( 0$) 5$

rarii Exftatici. 485. Apologeticon

P. Melchioris Cornes. Aqua lunaris inflativa. 96. Cur fufca, terreftris viero lucida. 107. Aquarsem motus in Luma cur fit. 125 Aquis glabi Veneris baptifines cong erripoifit. I4I. Aqueum elementrun ing globo Martis quale. 250 . Aque Gen.r.cap. quid fint. 36 s. Aque jupercaleftes. 424. Or fegq. Aquain montibus cur non deficiat. 532 . Aqua maris falfa cur in font ibus fit dulcis. ibid. Quomodoafcendat injuga, montium.533.534. Aquarum color, Sapor, odor, unde proveniat. $537 . \xi^{\circ}$ 538. Calor earundem unde.538. Aqua in quem finem aे Deocreata. 542 Ejus utilitates. $443.6 j$ Jegq. Ejus dem circulationes à polo ad polum in globo terraqueo. ibid. Aqua Semen Mundi 545.569. Alit ominia.547 Facundat omsia.570. Aquarum divifio aे Deo fact a initio Mundi. 576 Aque Juperficies ex alto pectata, minus lucet. 84. Aqua fub polo Arctico abforbetur.64I. Aqua qualiter preflafe evolvat per polum Arcticum.645. Ejus fimilit udo ex Janguine bumano $\int e$ e percorpus circulan. te.646, \& 647. Aquarsmex Afie, Indisque mont ibus fuentium origo. 65z. Aqua intra Alpes unde confisat.0 50. Aqua frigidifima of acetofa unde fit.66r. Aqua calidiflima. cum frigidifina juncta.
Aquatiliumgenefis.60\%. Eorum. dem magritudo, on figura. 609. $\varepsilon^{2}$ feqq. Aquatilibus quibusdam lux ad inftar cicendelarum. $629.5^{\circ} 64^{2}$ Aquiduct us multion variis locis reperiuntur.

653

Arborum varietas unde fit. sgI Argenti productio of minera. 664

Argentum vivum an unumex nature principiis.660. Argentum. vivusulgare. Ariftotetis opinio de fontium origine. S35 Arsanalogica. $=204$ Afterismorumnumerus. 334 Aftra ex folido \& fluido compofita.34.48. Corruptibiliafunt. 35 2 ualitatibus fecundis predita. $i b$. Movent ur in colo liquido ab Oriente in Occidentem.ibid. Eorum motus ab Occidente inOrientern est motus retardationis. 35. Aftra ex quatuor elementis compofita.45.46.374. Corruptibilia funt. so. Singula babent centrafuarum partium intrafe.s7 Non petunt certas regiones cali ex naturafua.so. Movent ur ab Intelligentius. 6o. Nonnece/fit ant boninem,jedinclinant. $\mathrm{I \sigma}_{3}$. Nan agunt foláluce in inferiora.164. Aftraan a propria forma moveantur. ibid. Aftraizathere, ut terrain aërelibrata.372, Etiarn remoti]fimafamulanturterre.390.Afroruminul Ssss 2 titudo

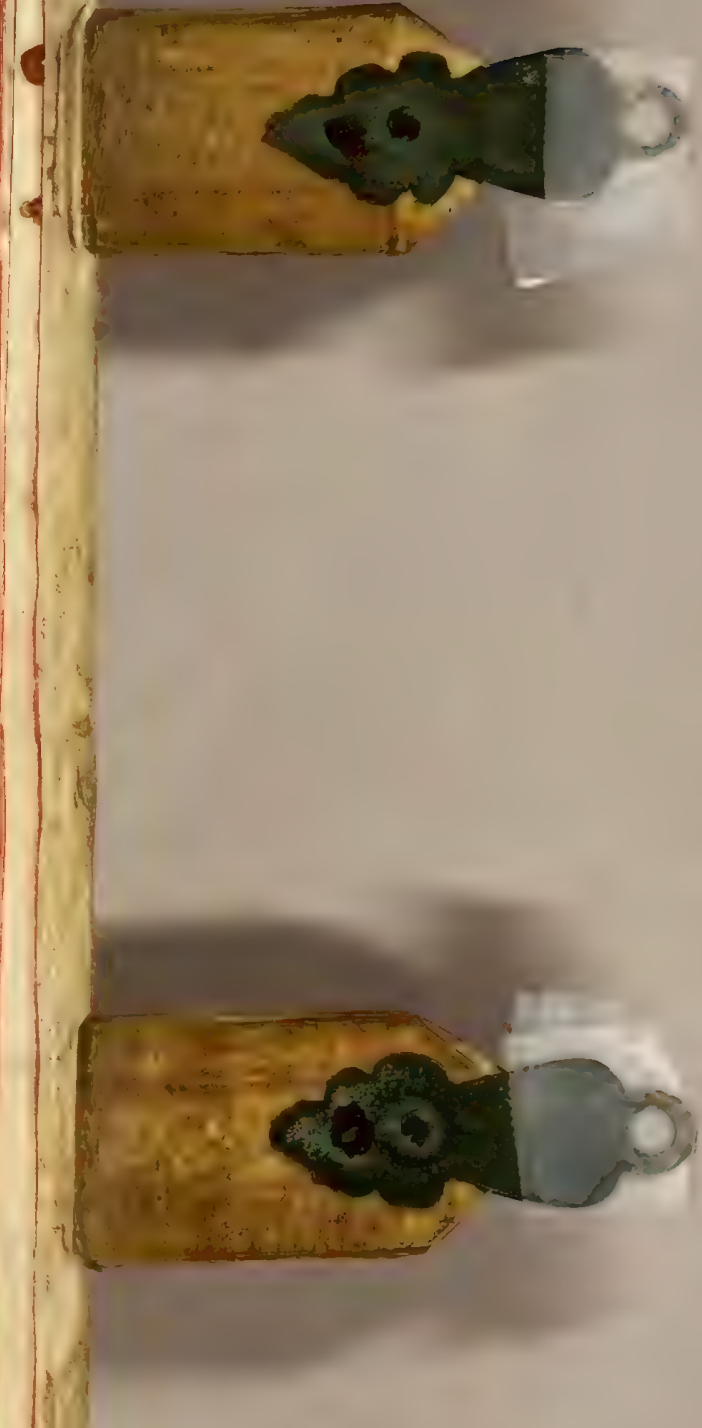




\section{कै}

titwdo. 400. Aftra non moventur ì propriaforma.

427 Aftrologie,judiciarie: vanitas.

Aftronomiaft udium commendatwr.

Atmosphera omnium fiderum. 49. Atmosphara Luna. 103. AtmoPhera Terra lumen Solis refringit. 111. Atmosphera Solis. 224. AtmoBhare Es centra fingulorum globorum caleftium.232. Atnosphar 9ovis.

Anftralis terreportio.

2.90

Avium genefis, nutrimentuv, varietas, foc.

597

Auri, argenti, s'mineralium. copia intrac Alpes.6 so. Aurigenefis.

664

B.

Baldna 6x 7:Cur femper ore hian th.618. Herbex ex balanis excrefcentes.ibid.Balene oculiorg: Balene. cur profundum E. altum petant. ibid Earum conftitutio interna. 620

Beatifica vifionis poffe [jo.

Bellainter.pifces.

Bellus marina quid utilitatis Mfferant.

Bonitas omais re (pecku Deimalitiaest.

Borealis poli terreftris pars eff altior. Auftrali. 607 . Caufat fluxum of refluxum maric. ibid. sub eovarii vortices:

Boryfthenis of Danubius exonerantes fe in maxi magnos fluct us excitant.

6.39:

C.

Cabalica traditiones de chrifto. $450.5^{2}$ egg.

Calidum radicale in Mundicorporibus quid fit.

Calor in Luna quid efficias. 123 .

Calor natiuns in materiam perpetuò agit. 586. Calor in fundo maris. 637. Calor quid terraconducat.644. Canales: bydragogi intra terram.

534.535 .20537$.

Canalium pyragogorum in Terra conflitutio.

Canalis magus fubterranes canalis magins fubrerraneus. an penterrecentrum tranfeat: s6g: Canalis quo mare Indicum communicat cum mari Ca/pio.638. Canalis magnus Boreo-Auftralis intraterram.643. Idem integra regionifimilis videtur:

Canicule ftellieftruct ura. 6.44 351

676. Catena heracleotica quid fat. 400 622: Celeritas corporum celeftium? fumma. 356.403

Centrum magnitadinis of gra: vitatis Terra quoad. fenfum idem. funt. 55. Centra fua propria babent aftra.s9. Centrum Lune os aliorum planetarum quomodo explicent alii. 120. Centrifolaris watura. 197. Cen- 


\section{$2(0) 5$}

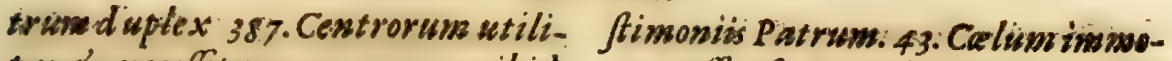
tas, \& nece/fitas.

ibid.

Chaos in primor dies rerum quabe.366. Chaotica maffainitio Mundi.575. Ex illa Deus omniaf fecit. 576 - Chrifi excellentia finis ominium kerum: 453. Chriftus omnia in fe implicat, 457. Chriftus quod perditum xeft it wit. 673 . Chriffus cur tant a pra bumanogenexe tulerit. ilaid.

Caleftia corpora ejusdem nature cum ineferioribus. so. Eorum qualitates.ecunda.s2. Ceeleftia corpora omnia ratiane conftitutionis difcrepant. Irg. Post confummationem Aundiquiefcent.

Creleft is philofaobic arnor. Calum an fit fluidum acpermeabile.2s. Soliaum effe, qui, or quonsodo probent.2 9.2ui, Equomodoprobent effe fluidum. 30: Cali foliditatens quinam introduxerint. 3 r. Ejus fluiditati favet Scriptura a acra. ibid. Ejusdem foliditatem adfruentivm rationesfolwuntur.ibid. Calum isdereum est unicum. 32.Colum liquidum son movétur ab Oriente in Occidentem.ibid. Moveri tamen eo modo concipinas. 33. Calum est corpus compofitum.ibid. Ejusmateria eadens cum fublumarium materia. ibid. Calumathereum est effentialiter aër.33.Corruptibile est. 34. Est.

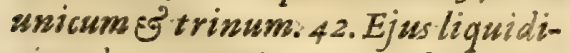
tas of naturaignea, probatur tetum effe, affratant ìm moveri, afferit S.Chryfoftomus.44. Caelos multos negat idemibid.Colum non est folidum,fed liquidum. 47. Calum effe incorruptibile, experientia non doset,fed pot ius contrarium. 176. Caeli nomine quid intelligatur Genef.r. 367. Caeli quintâ quâdam effentiâ conft are non poffunt. 445. Corruptibilis.

Colores in Sole quidnoten colorum realiequia notent. 223 colorum realium of intentiona lium caunfa in pernois avium. 60.04. छ requ.

Cometa.25. Cometarum folarium genefos. 220.224. Eorum motus.22s. quomoda evanefant. 228 . Cometa Solaris cur modó. Solem pracedat, modò Sequatur. 226. Cornetic car evanefcentes , fub forma ftellarum cernantur.22g:Vtrum ommess fint folares.229.6 230. Cur. fub tam variis figuris cernantur: 230. Cur caudarn is Sole averfam habeant.ibid. Cometa extinctif ax an in Solem revertatur.

Comites fovis, eorum que accidentia.26 ge Jeqg: Habent propriam. Incem, \& fovemilluminant. 281 Diftantia eorumaígove. 293.28 gnitudoeorum.29s: Phales corum. ibid. Effectus corrim in Govern. 290 Structura corsudem.298. Finis eorum.

$$
\text { SISS } 3 \text { com- }
$$




\section{9.}

Comparatio microcofmi cum megacofino.IIg. Comparatio alueimaris.cum Oceano Indico.

641

Conchilia, ${ }^{3}$ alia hujusmodi animaliumgenera,aculiscarent. 629 Concbiliorsm variorum deforiptio. 630. Orgo.ibid, In iis quaratione naturajupplevit defect usa vifus o. dentium. ibid. Conchilia funt casynea quedam maje \& animat $a . \sigma_{3} I$

Connexio corporei mundi cum. intelledwalibis mundis, barmoniam Mundi conftituit.

423 do.

Conftellationum numerus, $\varepsilon^{\circ}$ or-

Copernicei falsò ftatuunt ftellas firmanentimmobiles. 408

Corpora caleftiamutant proprietatos fuas ratione fitus. 140

Corpus Lunse quatwor elementis compofitum.

Cuprum.

D.

Damonum carcer.

Damnatorum carcer.

$D E \cup S$ utitur globorum colefium influxibus velutiinftrumenro ad mundum gubernandum. 162 Deus est abfolutum maximum. 379 Deus in omnibus, $F^{2}$ omnia in Deo. 397. Deus per bier archicos ordines omnia moderatur. $41 \mathrm{~g}$. Deusomnia. in bonum convertit. 40 5. \&o Jeqq. Dei operaineffabilia.6s3. Deus folo amo re tractus, incarnari inflituit. 674 Invijibilia bonajuftis promifit.ibid. Diabolus marinus.

624

Dies lunares. 116.117 ctus.

Diurrus Solis motus, jusque effe-

Doctrina bujus Opufalicanfona facre Soripture, Sanct is Patribus, experimentis, or rationi.

Draco marinus. 626. Ejusvirselentia.

ibid.

E.

Eclipfis Solis annular is effe poteft. 79. Eclipfis Solis quid, of quotuplex. so. Totalis dari potest.

Effectus Martis. 81 Electorum ftatus.

252

Elector un ftatur. 447

Elenwenta folum ex nibilo creata. 577. Eorum numerus.578. Elementum fimplex non datur. 581 . Elementorum reciproca commutatio. $66_{3}$

Empyreum coelum. 428. \&o feqq. Jungetur reliquo mundo poft ultimi judicii diem.

447

Enneas bylea quomodo cum Triade increata, o creata intellectuali comparetur. $421.6^{2}$ Jegq.

Entelechia quid fit, quid agat. 581.2 uomodo individuetur. 585

Exhalationes fubmarine tumorem maris carefant. F.

Facula Solis quid font.
535

189 F.afoide 


\section{की}

Fafcie Jovis. 288.8289 Ferrigeneratio 66s. Ejus corruptibilitatem rubigoindicat. ibid. Fidei expofitio. 456. Humanis viribus acquiri non poteft fides. 457 In quo confist at fides. ibid. Figura Solis annularis. $\quad 78$

Finis motus lunaris Oceani expogoitur. 10x. Finis Dei in creando Mundo.36g. Finis moturum fiderum.

409

Firmamentum quid fit ex D.Baflio.43. Firmamentum. 332. ES feqq. Nor est folidum, fed fuidum. 333 2uid fit proprie.

Fluidam celi fubftantiam afferit S. Ainbrofuse.

44 Fluminaingentia fub terra. 650 . Fluminum orificia intelligi ex fundi conftitutione:6 53 . Fluminum ex. Andibiss origo.

658 Fluviorum ingentium ex Alpibus ortus.

Fluxus छे refluxus Oceani finis.

535.544

Fons lucis in Luna quidfit. I0s

Fontes $\varepsilon^{2}$ flumina cur fubinde. ceffent. 54 $I$. Tantum aff undunt aque, quantum eff undunt. 6.54 Formarsm diverfitas unde fit. s85. 2uomodo introducantur in. mat eriam: s6. Forma quid fit offan ciat in mixto.

Foffe lunares.

596

Frigus in facie Lune à Sole a- verfa.

Fumos ex ignibus fubterraneis evaporare. 648 Furdor maris Atblantici. 632

$\mathrm{G}$.

Gaudia beatorum in calo empyreo. $\quad 43 \mathrm{I}$ Geocofmus ex mundanis corporibuspraft antiffimum. 5s8. ES fegq. Ejus finis est homo.ibid: Cur non moveatur.ibid. Eum maximè curant Angeli:gao.Geocofmi internaconftitutio.56.4. OJJatura ejus qualis. 571 Non est intus folidus. $57^{2}$. Officine ejus fubterranea.

573

Glaciades Eq nivofe terrepartes ex alto pect at e;intense lucent. 85

Glaciei utilitas.

Globiterreftris ex Luna apectus. IIx. Globi coleftes unà cum atmoJphar is fuis cur tam conftanter fot $\vec{u}$ Jum teneant.232. Globus planetarius quomoda virtutes fusis exerat. 249. Globi coeleftes non folá luck influunt.310. an ornnesigneâ naturâ polleant.331.Globi calleftes quì altiores,eòvelocius moventur. 4 os. Globo colefti motoqui infideret, motum. non fentiret.ibid. Globi creleftes post mundi confummationem quales fint fut uri:

Gravia: fublunaria omnia appetunt centrum terra, of confequenter. Univerfass. Non appetunt perfe

centrum 
centrum Univerf.

H.

Harmonici numeri trinitatem. exhibent.

Harmonia mundi.

Hiftoris Monachi Oxönienfis.

415 ibid

Homines an fint in luna, \& aliis afris.g2. Cur in Luna non fint producti.l26. Cujus conditionis effent, $\sqrt{2}$ ibiprodusti effent. ibid.dor.727

- Howo vinculun univerf. 442 veluti anima mundi.443. Hominem per fidem falvare cur voluerit Deus. 4 s6. Horninis lapfies.

672

Humana natera inchrifto maximum contractum, non nifi in. Verbo jubfiftere poteft.

454 cuntur.

Humido radicali omnia produ-

Humidusn unctuofum metallo $r$ uss materis.

Hydrophylacia Alpiem.

$6 \sigma_{3}$

I.

Jdololatria origa.

65s

Igris an fit in Luna. 96. Ignis non est in concavo Luna. 97. $98.6 \mathrm{deq}$. Ignis eosdem effectus producit quos Sol.181.Ignis folaris est verus or elementaris.ignis. 205. Ignem liguidum cur natur apofuit in Sole. 206. Ignis elementum in fingsalis globis mum (o) 54

danis.250.Idem omeibus Mundi cosm poribus ineft. 373. Ignis fubterranci finis of utilitas. 660 Incarnationis Chrifti Dowini fimis. 671 Incolas Lunxe \&ं aftrorum aliqui advattunt, aliimelius negant. 93 Infreitum isstellect ss sreato perfecte comprehendr nequit.

Infeitorum gene/is, Es diffexen tix.611. O Feqq. Elementa purgani.

Infulainglobo Veneris. $147 \mathrm{an} / \mathrm{u}$ le Tercere ex terre motufippentites.

Intelligentise feptem planetis prefides. $1 \mathrm{~g}^{2}$ Iridis deforiptio. $\quad 544$ Iter inglobum Veneris.139. Iter inglobum Solis.I Do.Iter Exftaticum fecundum.

$I^{13}$ Itimerariuse exfatioum placet doctis.

Judicia Dei imperforutubilian 36 Jupiter planeta.261. Ejus Zone feufafcia.262. $\sigma^{\circ} 258$. Illas quisprimo notaverit. ibid. Fovis verrigo. 264 Atmosphara.267. Aperitas. ibid. Comites. 268 . E' Jeqq. Fovis ftruct ura,E' natura.278. \& Jeqq. Fupiter lucet propriâ aliquâluce.280. Govis diftantiandsole.Ibid. Fovis Comites propriam lucem babent.28I. $\sigma^{2}$ Jeqq. Illuminant fovemibid. Fovis Rruct ura, of ris influxiva.283. Effe-

Ësurs 
c.

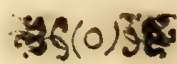

Tum diver.forun in terra cainfa. 285. Fovis influxus o efficacia in inferiora.287. Fovis Atmosphara. 290 Fupiter an incolas babet. ibid. Fovis illuminatio Juccesfiva qua tuor comitibus fact a. 29i. Motus ejus.292. Dies Jouis quat horarum.

ibid.

K.

Kircheri confenfous ut Itineraria reimprimantur.

Kircherus frequenter de colorum coft rorum natura loguitur.

\section{I.}

Lacus fub Caucafo of Imao mon: tibus.

$6 j 2$

Lapis ex Iunari corpore in terram portatus, in Lunam rediret. $g I$

Lapides pretiofi.545. Color um diverfit as in illis.

Lines infinita 540 triangulum, \&c. bus.

Lucis productio in globis caelefti-

372

Luma montibus exaperata. 48 Iune atmosphara.ibid.\$6 g. Lune phafes.63. Macula.64. Lune macularum novarum nomina. ibid, $\mathrm{Nu}$ merus \&o figura.65. Magnitsdo, $\sqrt{2}-$ tus, color.66. Macule antique quid fint ibid. Maxula nove quid fint. 67 Luns aperitas of in equal is fuperfroies, ibid. Ejus dominium in bumi- da.6 9. Luna est corpes opacum. Est pherica,non tamen geometrice. ibid. Luna now est ignea, fed terraquen. 7t. Conft at partibus folidis or liquidis.ibid. Luna,etfiterraquen, plendet. s6. sub quafgrurapectatafit. 89 . Luna globus qualis fat. gI Luna non habet tsomines, nec herbas,nec animalia. g2. Lune virtes influxina qualus. 95. Ejus influxus infublunaria.104. Ejus officia.ibid. Ejusftructura. 10s. Lunaris oceanus. 106. Lunaris globus cur tam inaquatis.107. Lunia peculare corpos effe non potest. ibid. Luns faciesis Sole averfaqualis fot.1.10. Luna cur non cadat in terram. 1r7. Proprio centro in athere firmatur.118. Pars ejus avutfa, 6 in terram delata, rediret in Lunam.IIg. Luna cur tot afperitates habeat. Is $x$. Cur tam diverfas exhibeat phafes. 124. Lune appectus ex Venere.I46. Luna for Sol reciproco influxu temperantur. 660 Lumaris nat urie ftellas effe in firmamento. 410

Luxprimigenia mundi quidfit. 367. Lux quid.jt. 575 . Lux primigeniaquid fit, Esoperetur 594. Inomnibus eadem. 002. Lax fubmarino qualis.

628

M.

Macularum in terra vifarums ex alto varietas.g3. Macula turvaTtte res

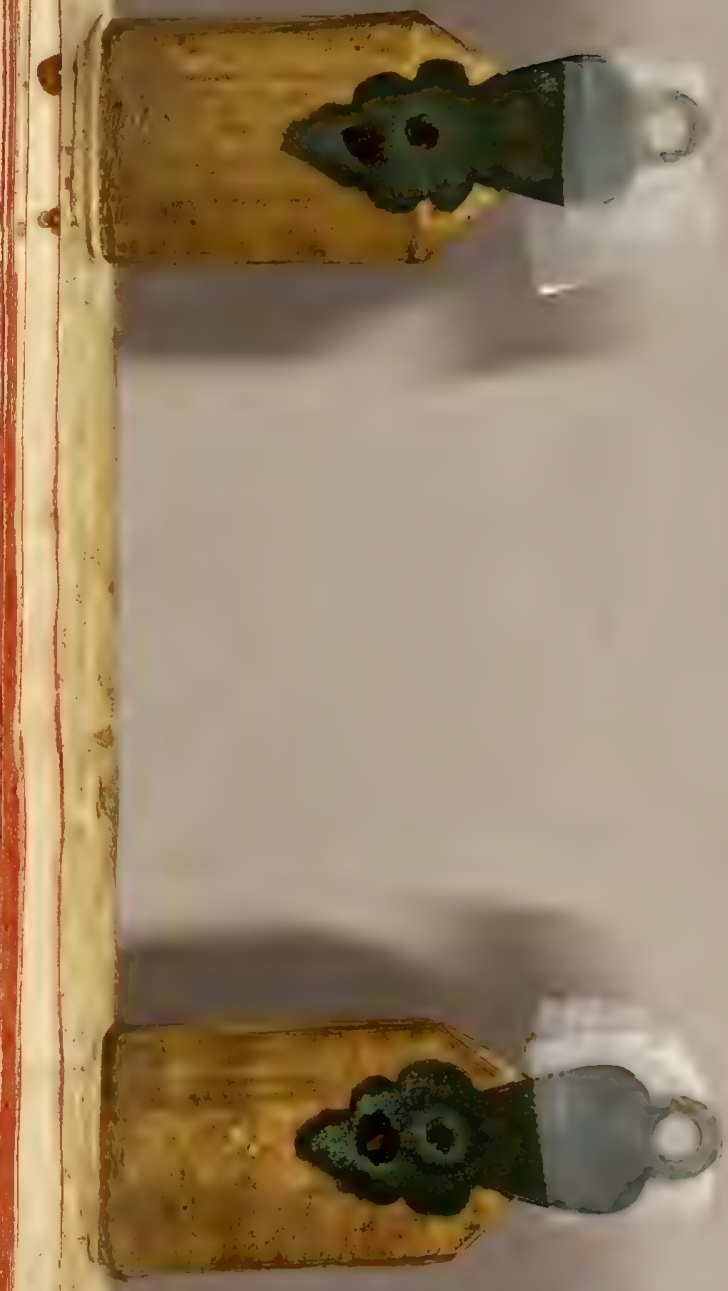




\section{- कीร $(0) 5$}

res quales.100. Macula Solis, earumque variet as, color, magnitudo, locus, fubftantia, E'c... I\&I. ¿́r feqq. 2uidfint.188. Quomodonafcantur.2I S. Macula Solis non Jint ftella.

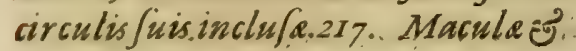
facule Solis.unde proveniant... 2Ig. Macule nulle cur fubinde appareant in Sole. 22I. Maculis cur Jubinde plenus totus Sol:ibid. Macularum folarium utilitas.223. Duratio brevis undefit: 236

Mala cur permittat: Deus. 464 Malum nullum in nat ura fine adnexobono:

562 .

Mare Aufrale Ifthmus terminat.635. Mare Auftrale ad polum frigidiffimum. $\sigma_{36}$. Ejusdem regurgitatio. ib. Mare, ad polos inacceJum.6 37. Mare ob iznium fubterraneorum exhalationes fluctuat.ibid. Maris Ca/pii conftitutio. 638; Idem. sum mari Euxino communicat: 639 Mare rubrum.640. Ejus mira. ibid.

Maris ebullitio in lunari globo.

108 ;

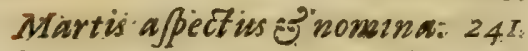
Orbis, vertigo; figura, infuentic ejus.242. $\sigma^{2} 243$. Mart is objervationes varie: $42 \%$ Marsjubatus 243. Mart is fruct ura, of natura: 244 246.247. Martis macula (ew:umbo: ibid. Jub e ejus quid fint.245. Martii. globi defcriptio analogaoperationi. bus Martialibus in globo terreftri.
247. Martis macula \&juba quid fint.248:VorajoMartis.ibud. o 249 Martis globus ex quatuor element is compolitus. ibid. Es 2 so.Centrŭ globi Martis.2sI.Vis influxivaillius. ib. Martius globus tam perniciofics cur incalo conftitutus: 252.53253 . Cur circa proprium centrum volvatur. 253. Martisutilitates. 254. Mars ampbicyrtosaliquando apparet.254. Partim à Sole, partim à proprialuce illuminatur.ibid. E2 257. Phafium: Martialium caufe. 256: Marsfanguineocolore cur appareat2s7 Martis. diffantia à terra, Ef planet is.25g.

Mafculi Jubterranei Cacodremones: funt.608 Eorum finis $\sigma^{2}$. tentamina.

668

Materia coeleftis non differt efSentialiter à terreftri. I SI. Materia folidaisolis non aduriturigne Solis. 206. Materia caleftis \& fublunaris non differunt:pecie. $374.376 .60^{2} 445$ Materia prima quid fit. 375 . Non patiturmutationem. ibid. Eternum durat:443: 'Materiainitio creata adhucexiftit. 583. Omnibus ineft.ib.

Maximum abfolutum quid fit. 379. Maximum contract um. $380 . \%$ fegq.

Mercuriilocus, motus, figura.1s4 Phafes. I5s. Obfervationes circaipfum. ibid. Difficulter \& raroobfervatur.156. Structura or naturaipfins ibid.60157. Macule.s58. Vertigo. 


\section{จุต 10$) 54$}

rigo.ibid. \& 160 . Mercurialis globi compofitio. 15g. Mercserius quomodo vimingenie conferat. 160. Vis ejus influxiva quomodo aliquando augetur, aut impeditur. 161 . Ea quomodo agat in inferiora. 163 . Mercuriiglobus cur non babeat incolas.I's

Mercurii proprietates.666. Mefcurivis of calidum innatum femper mobulis. ibid. Metallorum productionis cauja. 663 Meteorologica impreffiones an fint in Luna. $\quad 94 . \xi^{3}$ Seqq. Methodus procedendi in boc $O$ pinculo. ris.

Minere metallorum Cupri

Mineralium productio. 545 . Mineralium crafsa E' faculenta pars est efca ignis.6sr. Mineralia ob vaporofam feminis univerfalis fubftantiam non in imo terra, fedpenes fuperficiem reperiuntur. 667 Monftrorum marinorum mirus in medicina ufus.

625

Montes Chilenfes mira altitudines.

Montes, valles, \&unbreluniarium montium.106. Montesignivomi Solis. 200. Montes, fylve, छु fimiliafub aqua reperiuntur.6 27. Montium tractus jub mari quid fignent. 633 Montium catena à polo ad po-
Ium. itr. Mons nullus celebris bydrophylacio caret.

654 Motor univerfic est Deus of Intelligentive. 427 Motus ftellar um primus 83 consmunis. 26. isecundus E proprius.27 Motus retardationis ftellarum. $i b$. Motusftellarum varii.

355

Motus Solis triplex.21 s.e Motus Solaris velocitas.

237

Mundi divifio.1g. Ejus partium dipofitio go ordo 20. Ejus figurapherica.21.Centrim.ibid. Diameter, axis,poli,typus. 22. Nundi confenfus. 287. Fabrica mirabilis. 360.Vafit as mirabilis.36.3.e Mundi productio. 36 s. Ejus partium difcretio. 368 . Tlundus contract um maximum. 379.440. MCurdus cur in finitus effe non potuerit. 381 . Ejus mira dipojitio. 384 . Symsnetria corporummindanorum. 391.53 Seqq. Mundus an fit immenfus.412. Cur unus tantum. ibid. छ Seqq. MCundus corporeus dependet neceffario à Deo.4Ig. Conditus propter hominem.442.452.672. Mundus an propter folwon hominem conditus. 452

453 Muricis origo ou usus. $\quad 63 I$ fans.

Mufica mirificos affectus pro$7^{2}$

N.

Natura non incufanda, wbi inTtte $z$ term 
tervenit defect us hominum: 564 Nibili definitio.434. Nibilfub duplicifenfu concipipotest.437. Nihilum Deo cosvum.

439

Nomina Solisigneum effe not ant.

207

Novem fublunarinm entium gradus.

Nova caelipbanomena.

Novi Mundi detectio.

422

12

ta

Noxinglobo. Mercurit qualis. 167 Nubes cur non compareant in Luma.Q5. cur non fint circa Lunam.103. ${ }_{13} 3$. Nubes terram pervaganter. $1 I_{2} 2$ Nubes Fovis.

O.

Obfervationes calefes Aftronomorum ope tubo/picillorum.47. ObServationes circa Venerent.

obfervatio E experientia multadocet.

Occulta Dei judicia. $462.463 .46 \mathrm{~s}$

Oceanus Atblanticus canalibus abundat.633. Oceani Auftralis cum Atblantico commutatio. $\quad 634$

Oceani lunaris mirabilias. 100.106

Omnia ex: quatuor elementis compofita.140. Omnia corporaterreo-bumido canftant. Is 8. Omnia in ammibus funt. 204.397. \& feqq. Oo

opinio cujusdam de natatu afrorum in caelo liquido.

opweculi hujus scribendi occasio.
14. Opufculum boc corr admodum Dialogifcriptum.

is.

Ordines rerum creatarum novem, comparaticum novem Intellect ual is mundi Ordinibus. $\quad 420$

ofcillatio Lune quid.preftet. I2a Ovorum conftitutio, figura, bc. 600.0 vum utrum priw, an volucris. ibid. Virtutem in iis Latentem excitat calor externus.603. Ova pifcium non exctuduntur volucrum mado.

6IS

P.

Parabola de bonis at ernis.674. Seqq.Parabole compofitio. $\quad 67 a$ Paradifusterreftris. $8 \%$ An adbucextet.

88

Penna volucrum unde generentur.603. Earundem colorum caufa. 604

Phafes Lune varie quo fine fiant, 124. Earum ratio ou finis exponitur. I2s, Phafium Martialium sauSa.

Picesm pelagses in globo Martis. $25 s$ Piper quomodo ag at intro affum. ptum.

Pifces fine aqua cur nequeant vivere. S5I. Pifcium origo.607. Pifces hominisfiguram referentes. $\quad 624$ Planet quanam ftella.23. 2uomodo àfixisftellis, E' à fe invicem diffing wantur, ibid. Eormm compa- 


\section{$35(0) 5$}

rutio cun feptem principalibus. membris corporis bumani.1Ig. Planeta idem cur varios effectus in. mundo producat.286. Planetarum, diftantia à terracx Rbeite fententia. 328 . Eorum mira harmania. 394 dofeqg:

Plante ex quo fact a. 577 . 2u0modogenerentur. 588 . Earum $p^{i-}$ ritus.

Plumbum ejusque differontia aे Sarno.

Pluvia igneain Sole.

Polarisftella. $351.6^{2} / \mathrm{eqq}$.

Polus realis non est in mundo. 353

Primum mobile utrum fit. 426

Prof unditas maris cur tenebricofifima.

628

Proteftatio Auctoris circa hajus opufculifententias.

is

- Pyrophylaciaintra Terram. 540 ofeqq. Pyrophylacia America. 660

Q.

2 uadrupedum ortus exterra. 593. Differentiam corm conftituit forma.

594

- 2ualitates fecunde aftris inJunt. 164 . 2ualitates elementares. prima of fecunde infunt Veneri.t. I I

2uantitas fuperficiei Ppherice terra,ex diverfis altitudinibus pectate.

82

Quatuor in Itinerario Kirche. rianos upponustur.

40. 2uercus patrida noct u liccent.

Q29 Quintam effentiam cali nugas vocat S. Bafilius. $\quad 4.4$

R.

Rebelliones populorum unde oriantur.

Regianer \& maria terreniglobi quáfigurâpectentur exalto. $\quad 84$ Rheit doctrina circa vertiginemplanetarum. $\quad 144$ Ruentiun aquarum ingensftrepitus.

a 45

S.

salfedinem quomodo mare in. montibus deperdat. $\quad 634$ Salvandorum paucitas cur tanta:

Saturnus: 300 Comitum ejus

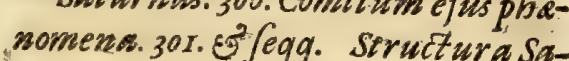

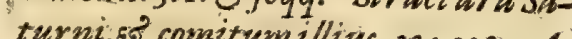
peritas comitum illives. 305.308. ABeritas Saturni. 307. Sat urnus tricorpor. 308. Finis Saturni. 30g. Epithet a, effect us, malignit as Saturni. 312. S. Seqq. Structura Saturni.3I 4 Vtilitates in inferioribas. 31 s. Saturni comites. 316. Eorum phanomena.ibid. \& feqq. Saturnus, ejusque comites, non illuminanturfufficienter à Sole. 3Ig. Saturnus cur circa. axem funsm gyretur: 320. Saturni connites quomodo illuminent Saturnum ibid. Saturni magnitudo, o Itte 3 diftard

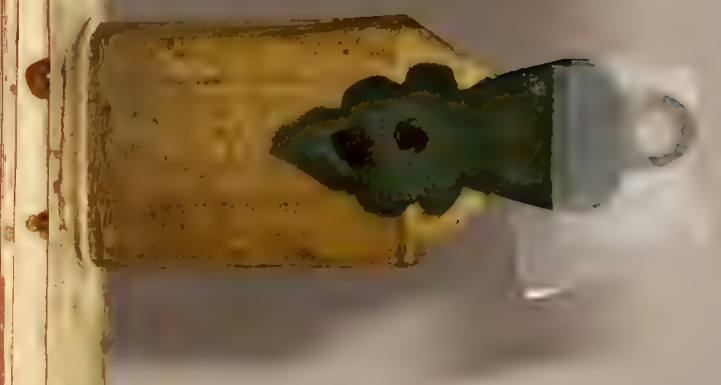




\section{की}

diftantianiterra. 321. o a sole. 322

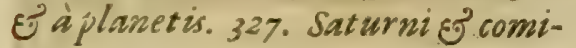
turn ejus vertigo 0.323 . Saturnus an etiain à Sole illuminetur.ibid. Saturnianfuld. 324. Saturni comitum fructura, \& magnitudo. 330. Habent fua propria centra.

Semen Mundi in omnibus 33 I

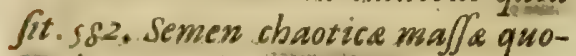
moácommiftum.

584

Seminalis virtutis vis. sog. Seminis duogenera in volucribus. 600 Semite aqua explicantur. - S3I Senfitive nature quadruplex genus.

Senfus in iis, que non attingit nos decipit.

Sivenes, earumque defcriptio. 623 Viresfeuvirtutesearum. $\quad 024$ Solis eft us, \& ebullitio. 49. Solis apparentra ex Luna. II6. Solisepitheta. 16 g. Sol est ignea fubftantice. 170. E' Jeqq. Aapparet fimilis eri.liquefacto in fornacibus fuf oriis. 173 Est formaliter calidus. 175. Solis ignis pabulo indiget. I77. Ejus asperitas Seuinequalitas.178. Ejus ignis an pyramidalis.ibid. जo $x>9$. Sol cur non exurat Univerfum. ibid. Ejus calor cur prope terram major. 180 Solcur reflectione ionem producat, ignis veronon. ibid. Ejus macule E facula. IgI. 2uomodoobferventur. 182. Solis vertigo.185. Structura o natura. 186.193. 196. \& $/$ eqq. Con- ftat exliquido of folido. 186. Solis Oceanus igneus cum infulis. ibid. Solis canales fubterranei.187. 20I. Solaresexbalationes. 188. Solares. macula quid fint. ibid. Solis facies. 19I. magnitudo. 193 . \& Seqq. Solaris centrinatura. 197 . Solnon potuit ex meroliquore igneo componi. 200. Solis ignivomi montes.ibid. Solis corpus beterogeneum.20r. Pan/permiá. conftat. ibid. \& 202. Varies facult otisbuse st praditus. 203. Sol cur circa proprium centrumi noveatur. ihid. Aneminenter tantium calorem habeat.207. Solmaximis alterationibus.obnaxius. 212. Solis praftantia. ibid. Ejus radii \& lumen nature $i$ gnea. 214. Solis motus triplex. 215 Macula of facula ejus quomodo nafantur.215.216. Solare corpus inter omniapraftantifimum. 217. Solis motus diurnus, ejusque effect us ibid. item annuns, ejusque effectus. 2Ig item vertiginis mot us, ejusque effect us. 2I g. Sol certis temperibus totus impalluit.222. Ejusevaporationes in terra quide efficiant. ibid. Solcorpusheterogeneum. 223. Ejustolores quidnotent. ibid. Solis atmo/phara. 224. Sol morbos fuos chronicos patitur. 226. Cur non deficiat exhalandotantam copiam. 235. 2uomodo moveatur, $\xi^{3}$ a quo.ibid. Movetur ab Intelligentiis. 237. Velocitas motusillius.ibid. Diffantia ejus media. ì Ter- 


\section{ตร $6(0) 5$}

ì Terra. 238. Solnon illuminat fovemintegrè.280. Solis effectus. 374 Spatiumimaginarium. " 436 . \& Stannum quid fit. fegq: spectra fubterranea. 668. Invo sato Deo evane curt. ibed.

Stelliarum dua Junt clafJes, fixe, $\Xi^{2}$ planeti: 23. Stellarum fixarumnumerus: 24: \& 25. \& 333: Stell e prims magnitudinis. 2s. Stellenovavaria. 26. Siellarum motus primus $5^{2}$ cornmunis. ibid. Secundus Ejproprius.27: Siellas ex elementis conn: pofitas docet $S$. Chryfoftomus: 44 Stella innsmierabiles. s2: Stellarum fixarum apectus: 113: Stellarum noviter ortarum genefis. 220. Stel: le nove circa Govem wija quid font. 2.90. Stella mult a telejcopio detecta. 335. Stella videntur efje innwinera. biles. 336. 348. Stellarum diftantia: à terra. 337. Motu's earum velocitas. 339. Stella fixenon diftant omnes equaliter à terra.342. Stella folares or lunares.343. E' legq. Non illuminantur à Sole: 344 . Diftantia ftellarum fixarum à planetis. 348 . Stellefixa in firmamentomoventur in peculzaribus circulis inftar planetarum. 349. \& feqq: Stellarum: motusvarii.35s. Stella fingule ha. bent Intelligentias:ibid. \&o Jua centra or atmopheras. 357. Earum motus ab Oriente in Occidentem quomodofiat.ibid. Stellenoveunde fiant.358: Cur femper fixe ineodem locoappareant.ibid. Earum genefis probat corruptibilitatem coeli.35g. Stella novain Caffiopeia quomodo orta. 360. Stellarum dipofitio mirabilis. 36x. Stelle fixe cur femper eandem diftantiam inter fe tenere videantur:

410

Subterranei meatus fructura E'defcriptio. 634. Subterraneaidfuaria:

662

subilitas atheris repirandifacultatem tollit:

sulphur,bitumen, \& naphta unde.ersing 644 Suppolarium regionum confitutio.

syftema Mundi quidfit. sos sos Atemata varia Mundi. ibid. \& 37 ac 38

T.

Tempeftatumpectacula. $\quad 667$ Terraest vere in medio Univerfi. ss. Cur in medio fit collocata is Deo.s6. Nonfertur circa proprium axem: "Is. Terrafaciesexalto pectat qualis foret. 78. Quanta ejus pars videatur ex varies altitudinibus: 82. Terrephafes è Luna pectate. IIs. Ejusdem apectus ex Venere. 146 . Terraquoad totam fub. fantiamincorruptibilis. 359. Terra inans \& vacua quid/at. Gen. J. 367.

Ter-

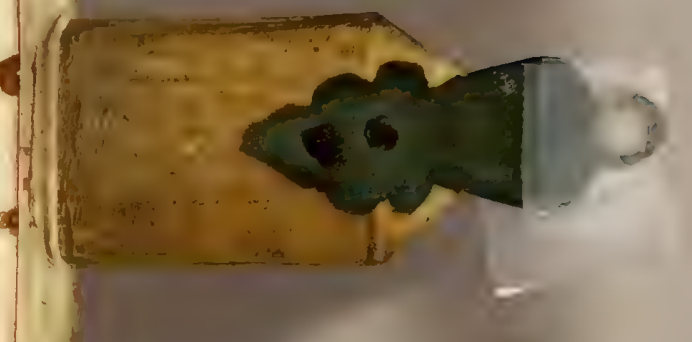




\section{母.}

-..... Terra univerfa nat ure centrum. 388. Cur immobilis. 389. Qualisfutura poft jeculi confunnnationem. 447. Terracreat ante omnia. 579 Terramotusorizo. 633. Terreincoguite deforiptio. 36 . Terraigne dejtituta.periret.648. Terre interna dipofitio.655.Terra innismeris meatibus perfoffacur confiftat.6 57 . Terremotuum fubterraneorum caufa.

Terraqueus globus non eft penitusintus folidus.

557

Terreuw elementum in globo Martis.

Teftace animalia unde fint. Oro Thermarum variarum ratio of origo.

$66 I$

Trias priwa increata. AIg. Secunda creata ibid. Trias tertia. 416 Triadis Sacrofanit a Verbiincarnaticlaraintuitio.

677

\section{V.}

Ventitumef aciunt mare.

Ventorum vehementifimorum Jub terraorigo $\sigma^{\circ}$ caula. 640 . Ventorum Junt plurima receptacula.

OSI

Venus planet: ejusque nomina. 24.129. Venus of Mercurius è Lunat quales compareant.113. Veneris $\sqrt{2}-$ dus.129. Ejus phanomena antiqua. 130.Venus nuncprait, nuncfequitur Solem.ibid Alias major, aliàs minor apparet. ibid. Veneris ortus du occafus beliacus: 30 . Venes aliquaredo velocior, aliquando tardior sole. 131. Ejus pha/es Lanaribus fimiles. ibid. Venus circa Solem movetur. ibid. Mutat magnitudinem apparentem.133.- Mutuatur lumen a Sole. ibid. Interdiu con/picua.137 Eodem die veppertina \&? matutixa. ibid. Unabraw efficit object usorporum. ibid. Ejus diftantiad Terra, in à Sole.138. Eius diameter apparens, magnitudo, revolusio integra. ibid. Structuradonaturm. 13.9 140.UPperitas illius. I4I. Veneris magnitudo. 145. Vertizo. 143 Effect ius 140. Venus quomodo gratiame decorem influat. ibid.

Vermes marini, feu Dactyli, in. montium fiffuris.

629

Vertigo Lune. 102. Vertigo Veneris. 43 . Vertigo solis, ejusque effectus. 21 . Vertiginis mot us fingulorum planetarum ex opinione Rheitie.

265

Virtus Lund appropriata quenam fit. $\quad{ }_{123}$

Vis influxiva Venerisglobi. 148

Vmbra lunaris corporis longitudo.

Unionis bypoftatice modus bumano intellectu impercepitibilis.

455

Univer fum quomodo fat in onsnibus, or ommia in ipfo.

399 
$-5(0) 9 t^{\circ}$

- Unsm calman ponit S.Bonaven Vortices immenfe quorfune tura.

4 quanderivient.

633

Volucres cur exaquaproduct a i Utilitates aque of ignisfubterDeo. 578 . Volucrum dotes \& natu rales proprietates. ranei.

Voragoinglobo Martis. $\quad 248$ Vortices jolares, \& Sliorum caleftium corporion. 2.3i. Non inifeenturinter fe. 232. Rapiuntur à fuis globis. 233. Vortices Solis 32 Martis non mifcentur.

$$
2.34
$$$$
542
$$$$
\text { Z. }
$$

Zodiaxiduoincalo.

27 Zone torride res cur tantums differant abiis, qua fub zonistemperatis proveniunt.

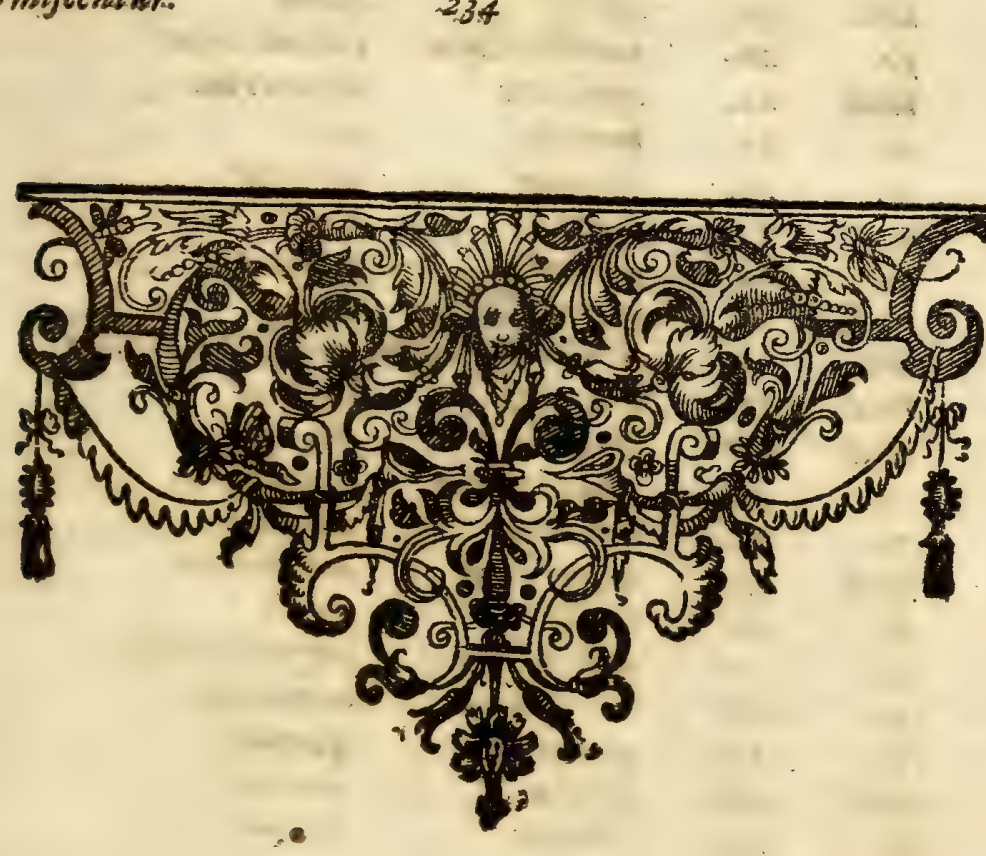

Uuu

Erra: 


\section{asco) 50}

\section{Errata Typographica.}

Propter Auctoris abfentiam irreprerunt fphalmata quædam typographica, ut fieri plerumque folet; quorum præcipua, \& qux Lectorem morari pofient, correctahic appofuimus. Reliqua Lector corriget.

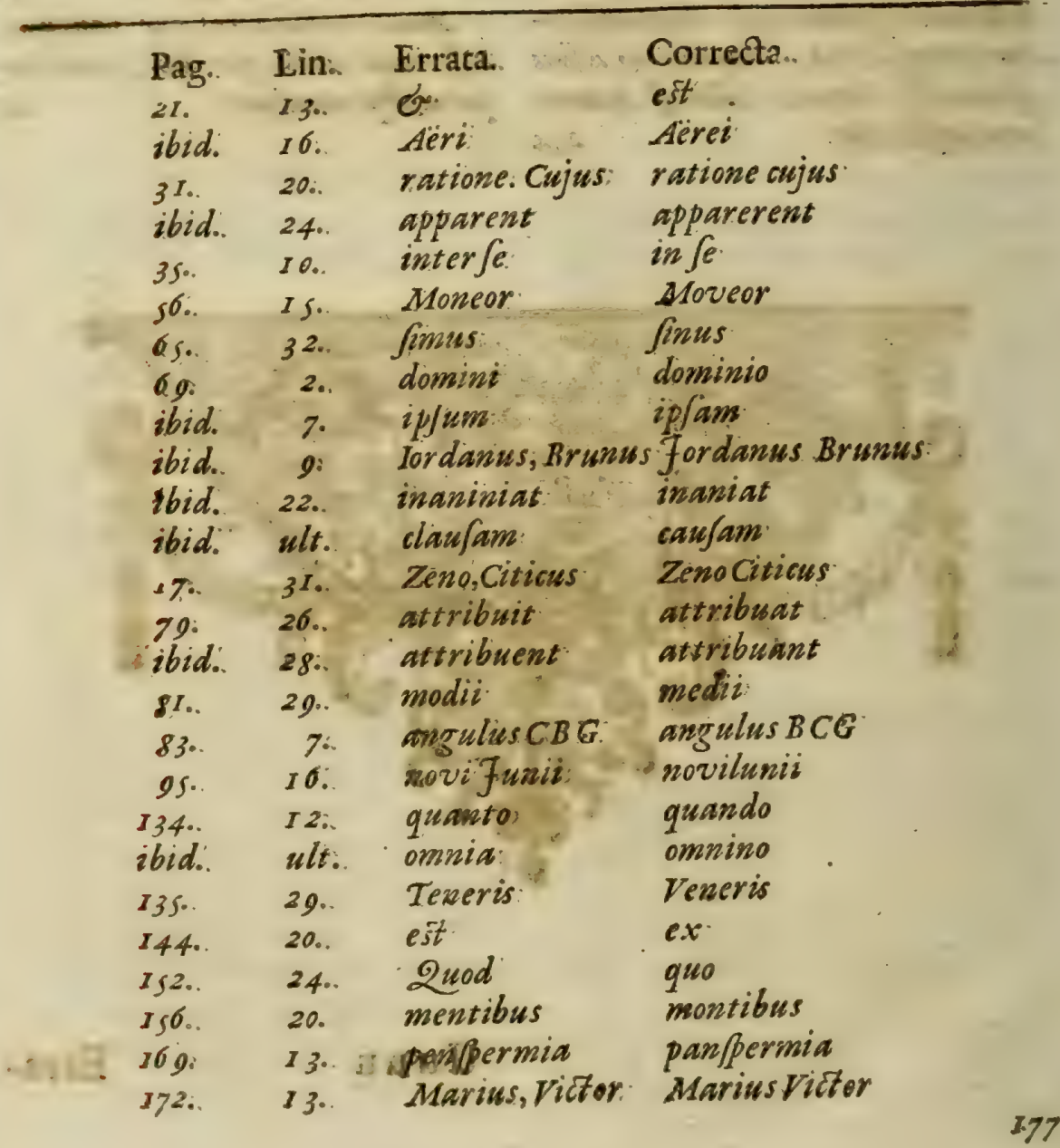




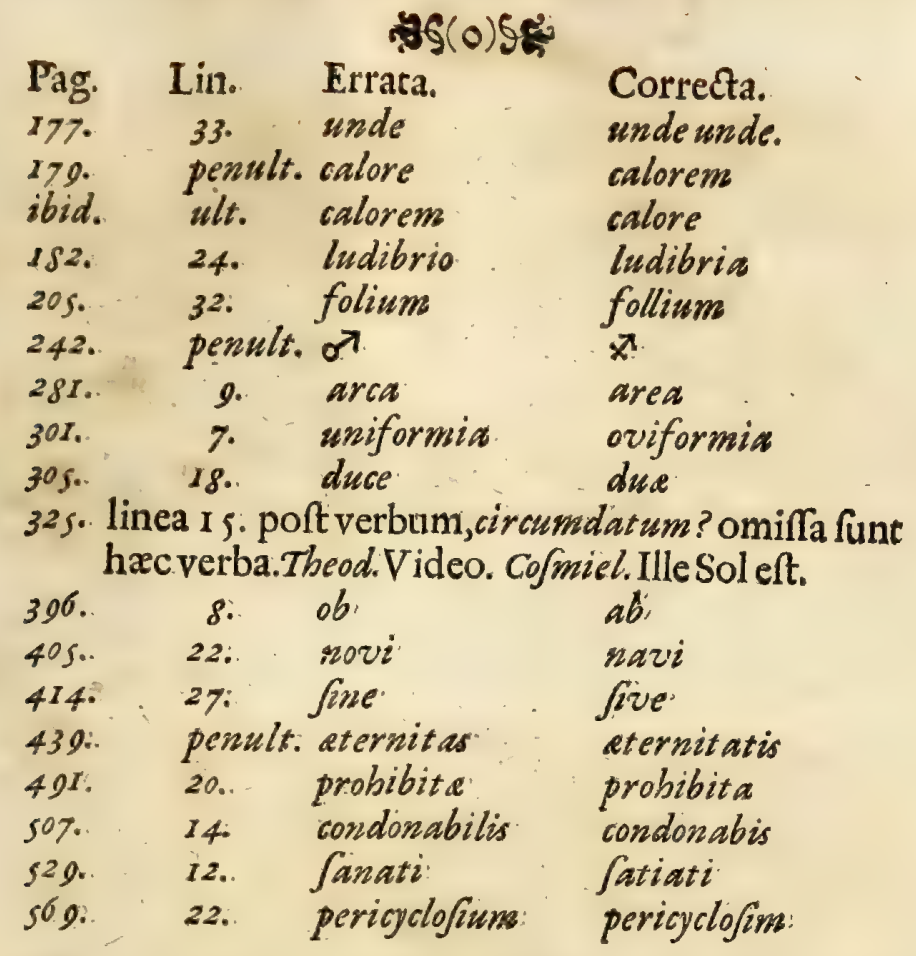

LEC'TORI MEO:

$S$ Udat nunc, Lector Benevole, füb prælo Curfus nofter $\mathcal{N}$ Mathematicus, hoc elt, omnium Mathematicarum, Difciplina rum Encyclopædia , unico volumine non adeo magno comprehenfa ; lucemq; publica m videbit; Deo favente, proximè futuris mundinis Pafchalibus a nni 166 I. Interim elaboramus, vel potiüs ja $m$ pæenè confecta $m$ pr $x$ lo paramus Phyficam Curiolam, five Mirabilia Naturæ; qua m deinde, fi coelum annuet, excipiet Technica Curio$f æ$, five Mirabilia Artis. Complectetur utraq; , quidquid in Natura \& Arte rarum atque a rca num eft, neq; in Magia, noftra pertractatum. Vale, \& fave. 

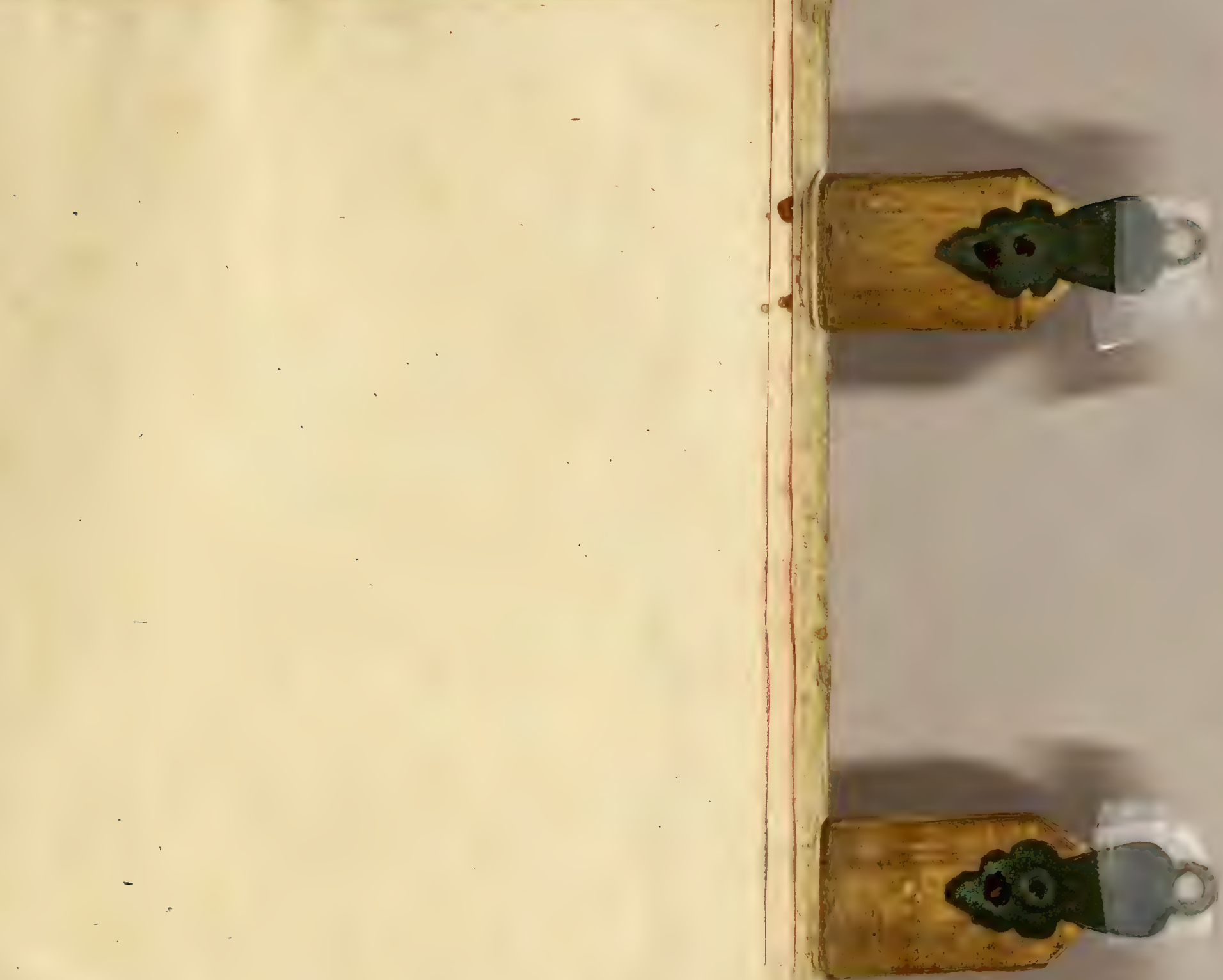


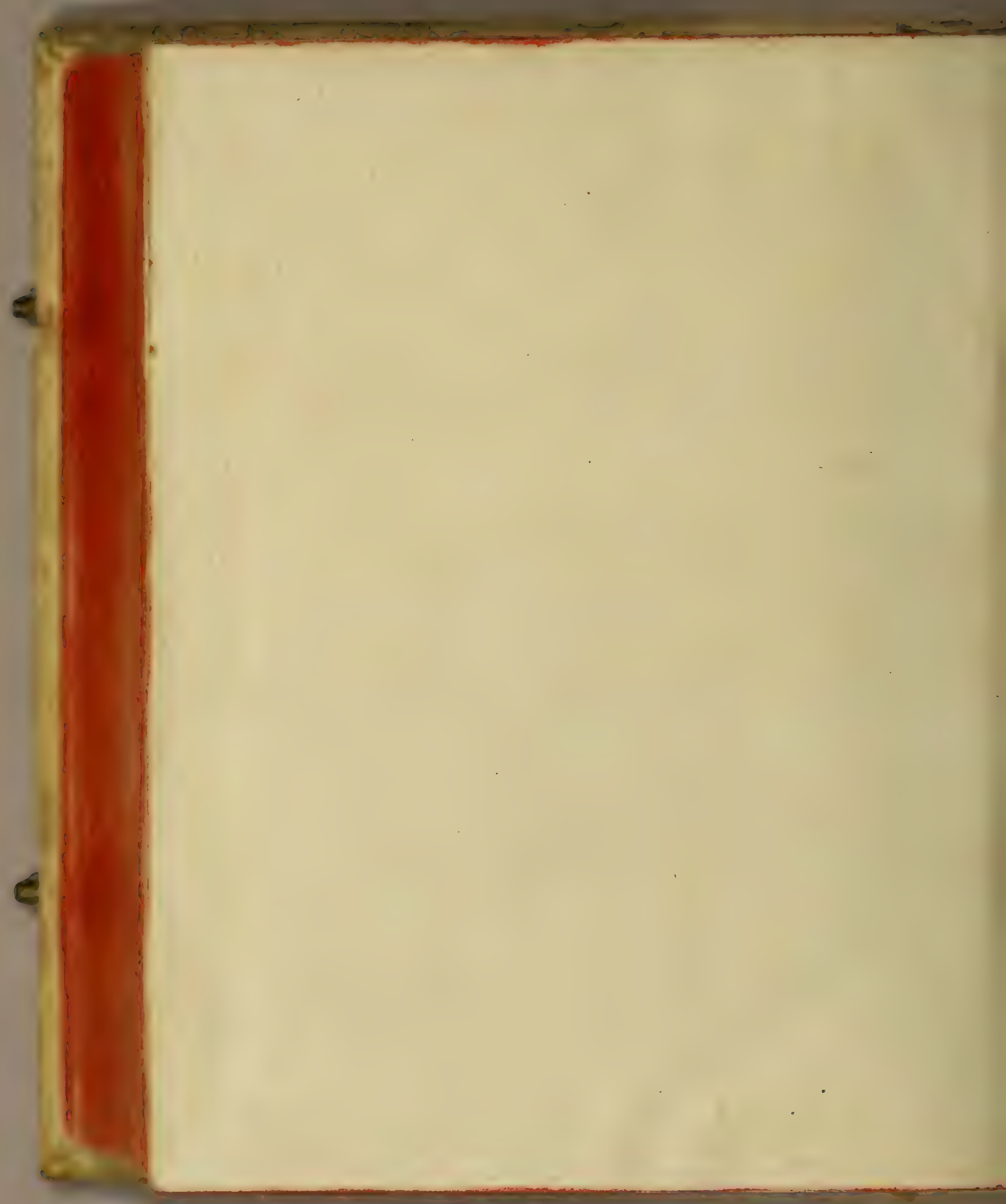




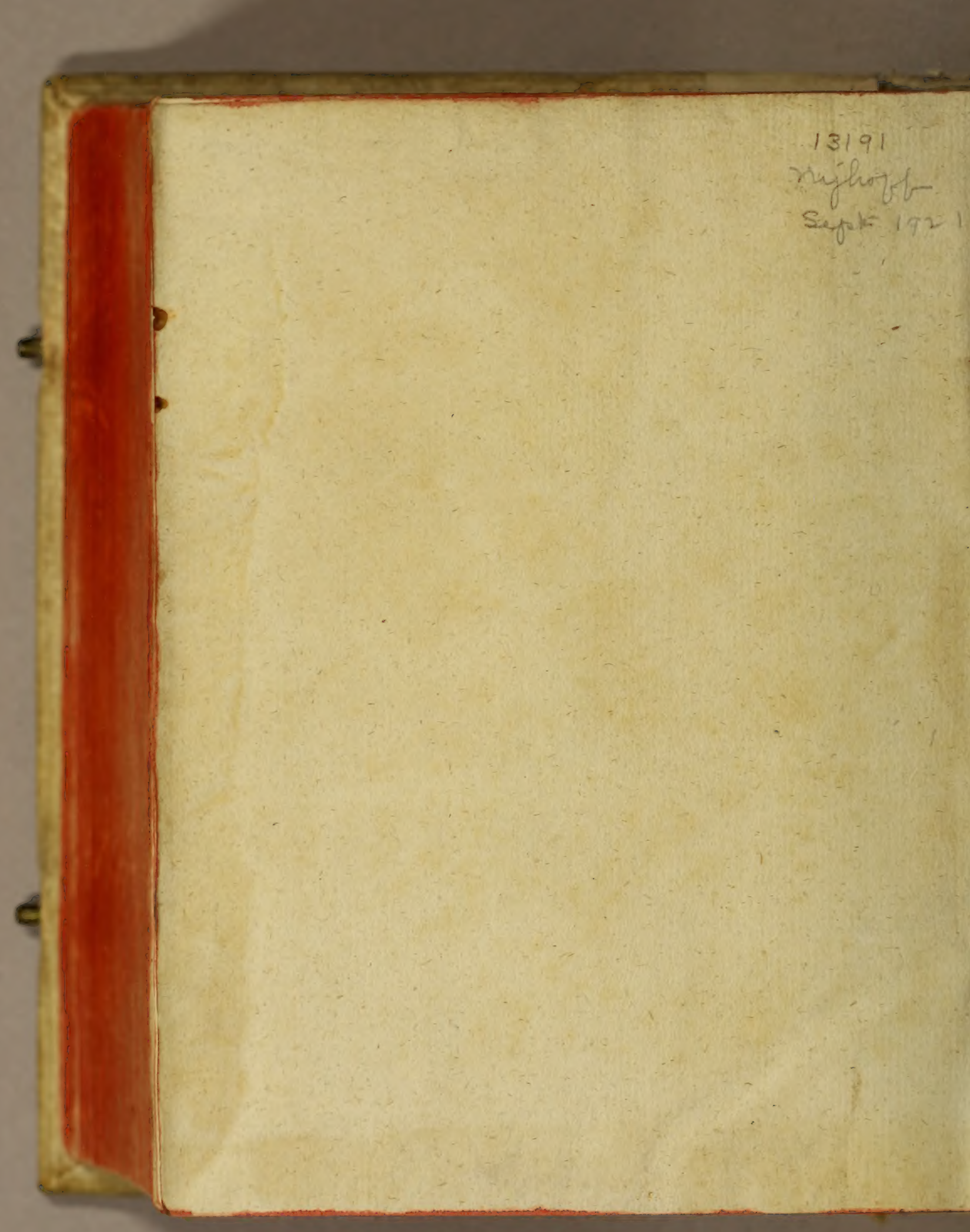


Kiroher, $A_{0}$. Iter extatiour cooleste, quo mundi opifioium, i.e. coelestis expansi...exponitur. 22 ed.

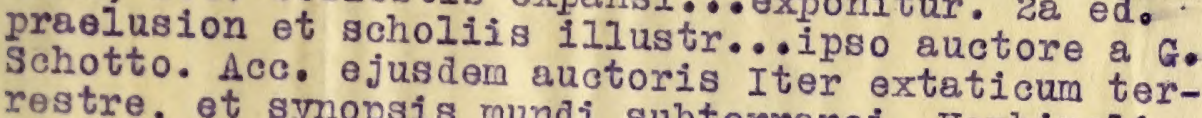
1660. With engrev. pigskin with glasps. Contains $a_{0.0}$ : Liber neteorol Gld.24.loscopus; liber phyto-zoographug; liber magicus; liber mechanicus; eto chimicus; It treats as, Iter mechanicus; etc.

reperiuntu.o.: Americis montibus majores nulli le isthnus t Australis terrae portio; Mare Austratudinis; llovi lrundi detectio; Terram et seqq. pyrophylacia Americae, etc. 


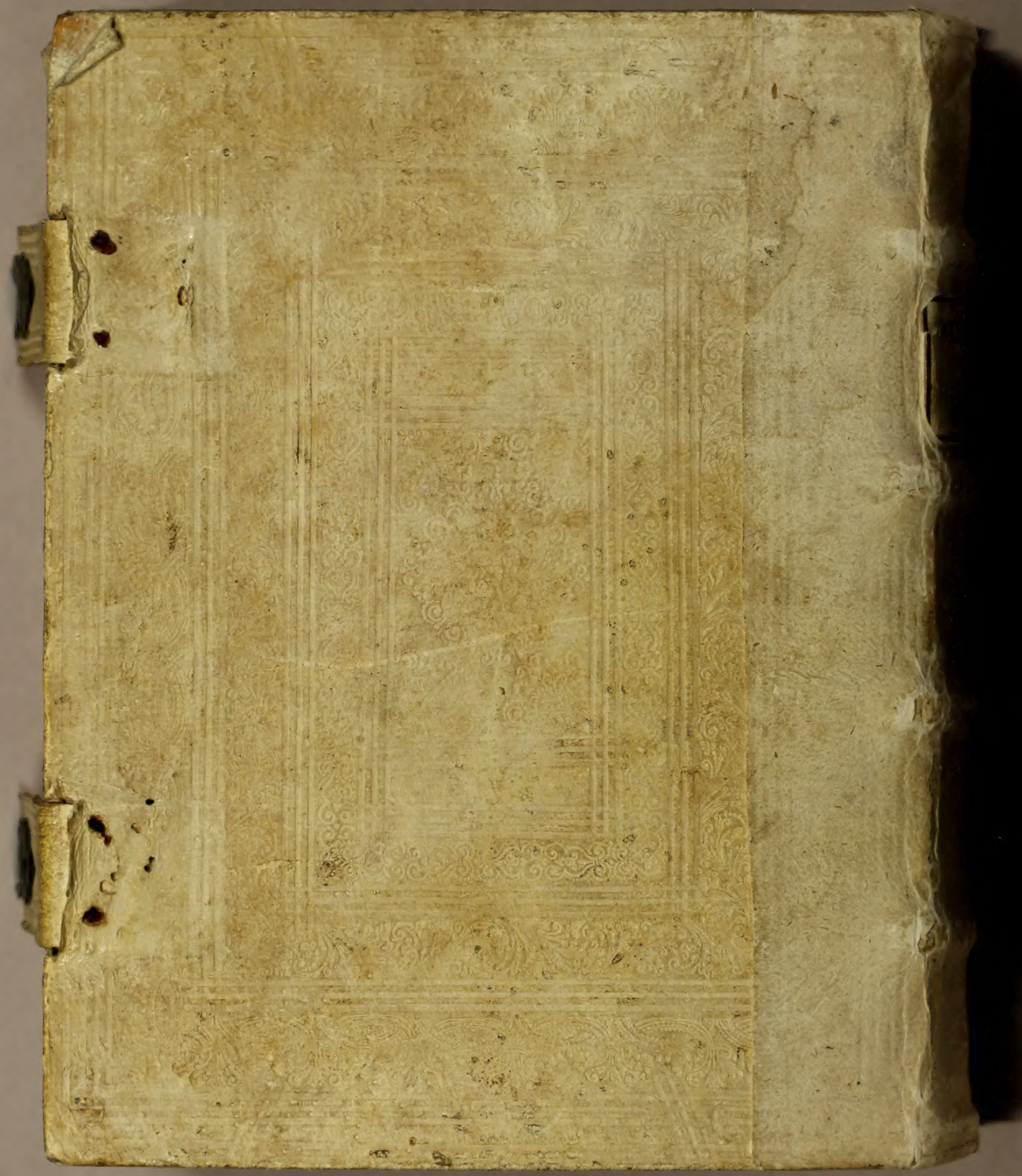

